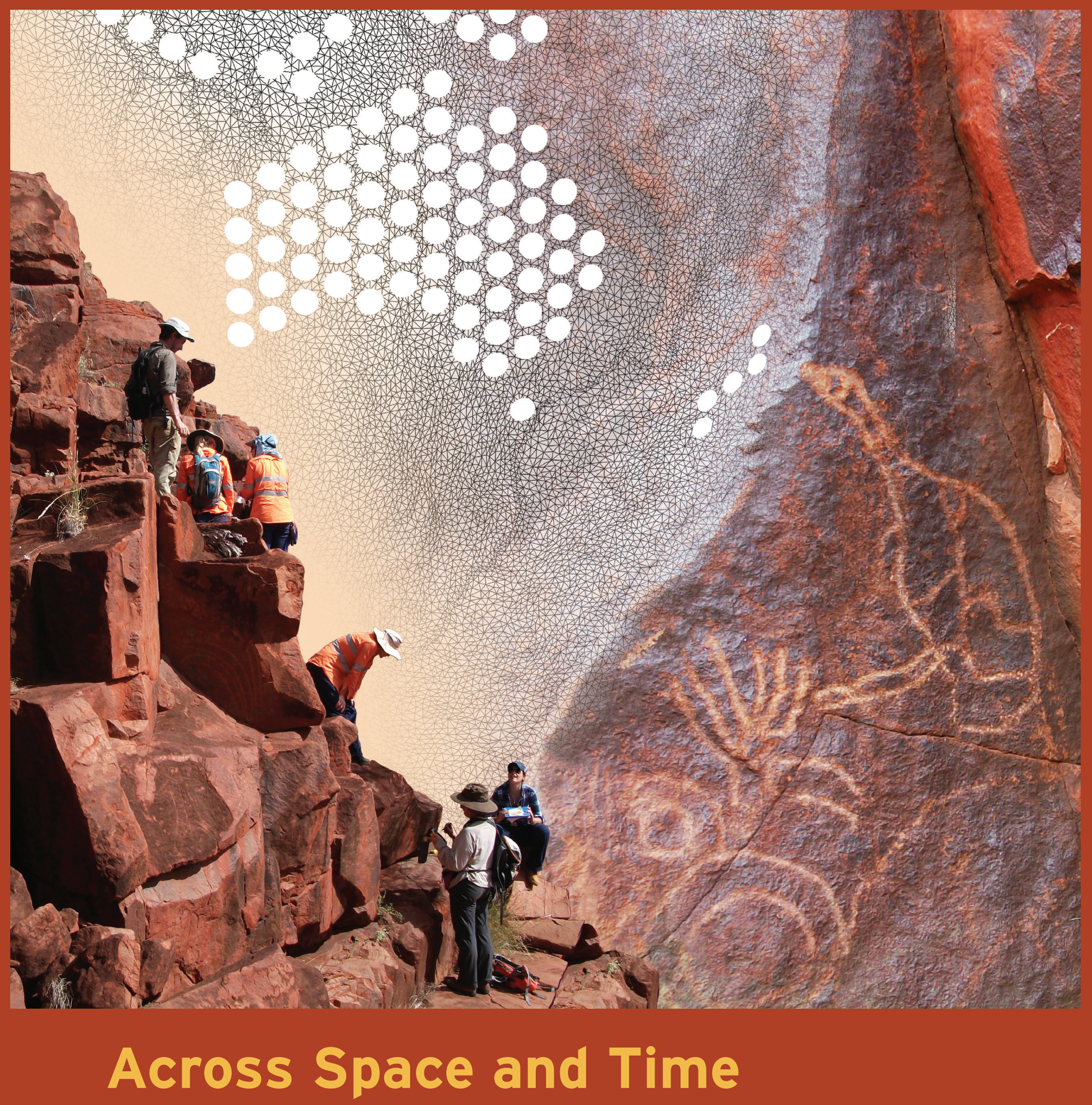

Papers from the 41st Conference

Edited by Arianna Traviglia

on Computer Applications and

Quantitative Methods in Archaeology

Perth, 25-28 March 2013

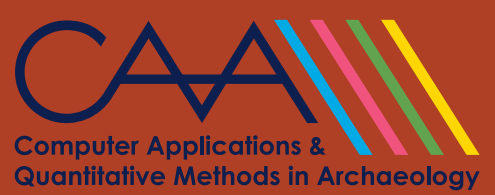




\section{Across Space and Time}





\section{Across Space and Time}

\section{Papers from the $41^{\text {st }}$ Conference on Computer Applications and Quantitative \\ Methods in Archaeology}

Perth, 25-28 March 2013

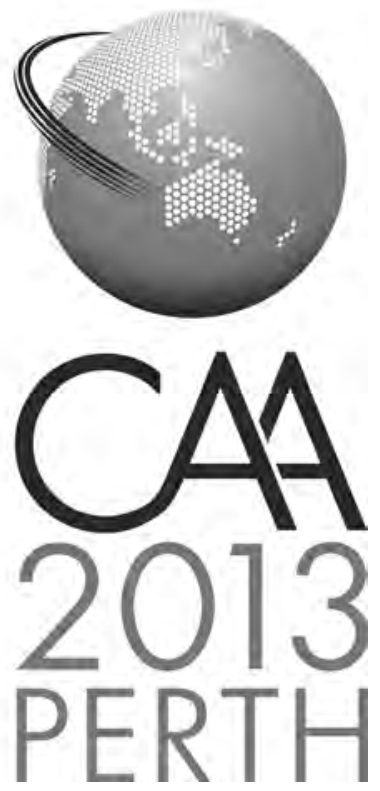

Edited by

Arianna Traviglia 
This book is published in the CAA series Computer Applications and Quantitative Methods in Archaeology.

Cover design: Ian Kirkpatrick

Cover image: Wanmanna archaeological site and computer renderings of reconstructed 3D surfaces and rock art. Original images copyright: CRAR+M (Centre for Rock Art Research + Management: The University of Western Australia). Images courtesy of Paul Bourke, iVEC@ UWA (The University of Western Australia). Images reproduced with permission from Niyarpirli traditional custodians, Newman.

Lay-out: IzaRomanowska

Amsterdam University Press English-language titles are distributed in the US and Canada by the University of Chicago Press.

ISBN 9789089647153 (hardback)

e-ISBN 9789048524433 (pdf)

NUR 682

(C) Computer Applications and Quantitative Methods in Archaeology (CAA) / Amsterdam University Press, Amsterdam 2015

All rights reserved. Without limiting the rights under copyright reserved above, no part of this book may be reproduced, stored in or introduced into a retrieval system, or transmitted, in any form or by any means (electronic, mechanical, photocopying, recording or otherwise) without the written permission of both the copyright owner and the author of the book.

Every effort has been made to obtain permission to use all copyrighted illustrations reproduced in this book. Nonetheless, whosoever believes to have rights to this material is advised to contact the publisher. 


\section{Table of Contents}

$9 \quad$ Preface

15 Across Space and Time

Arianna Traviglia

\section{DATA ACQUISITION}

25 Remote Sensing in Maritime Archaeology, from the Slide Rule to the Supercomputer* Jeremy N. Green

36 Remote Sensing (Short and Long Range)

36 The Story Beneath the Canopy: an Airborne Lidar Survey Over Angkor, Phnom Kulen and Koh Ker, Northwestern Cambodia

Damian Evans, Kasper Hanus, Roland Fletcher

45 GeOBIA Approaches to Remote Sensing of Fossil Landscapes: Two Case Studies from Northern Italy

Armando De Guio, Luigi Magnini and Cinzia Bettineschi

54 Palmyra Revisited from Space - High-Resolution Satellite Prospection of a UNESCO World Heritage Site

Roland Linck, J örg W. E. Fassbinder, Stefan Buckreuss

64 Classification of Geophysical Data of Angkor, Cambodia and its Potential as an Online Source

Till F. Sonnemann

\section{$70 \quad$ Field and Laboratory Data Recording}

70 The Accuracy of the Field Survey Results and its Implications in the Correct Understanding of Past and Present Practices

Luis Antonio Sevillano Perea and Victorino Mayoral Herrera

80 Arbitrary Offline Data Capture on All of Your Androids: The FAIMS Mobile Platform Adela Sobotkova, Brian Ballsun-Stanton, Shawn Ross, Penny Crook

89 Creating a Paperless Recording System for Pilbara Rock Art

Stafford Smith, Jo McDonald, Jane Balme, Glen MacLaren, Alistair Paterson

97 Beyond Tablet Computers as a Tool for Data Collection: Three Seasons of Processing and Curating Digital Data in a Paperless World

J ohn Wallrodt, Kevin Dicus, Leigh Lieberman, Gregory Tucker

104 Applying Low Budget Equipment and Open Source Software for High Resolution Documentation of Archaeological Stratigraphy and Features

Undine Lieberwirth, Bernhard Fritsch, Markus Metz, Markus Neteler, Kerstin Kühnle

120 Old Problems and New Challenges in Archaeological Sites Data Management. The REVEAL Experience at Ammaia (Portugal)

Cristina Corsi, Eben Gay, Eleftheria Paliou, Donald Sanders 
129 The Parnassus Project: Archaeology and Engineering Collaboration for 3D Data Collection and Analysis

Dina D’Ayala, Penny Copeland, Yasemin Didem Aktas, Graeme Earl, Aykut Erkal, James Miles, Elizabeth Richley, Victoria Stephenson, Kris Strutt

144 Photogrammetry and RTI Survey of Hoa Hakananai'a Easter Island Statue James Miles, Mike Pitts, Hembo Pagi, Graeme Earl

156 Some Methodological Considerations and Suggestions for Good Practice in Diagnosticsand Visualizations of Complex Archaeological Sites: the Experience of the Radio-Past Project

Frank Vermeulen, Cristina Corsi

167 DATA ANALYSIS AND MANAGEMENT

169 Reflections Upon 3o+ Years of Computing and Field Archaeology in the Valey of Pickering, North Yorkshire UK. *

Dominic Powlesland

192 Computational Modelling and GIS

192 Competition and Culture Change in Prehistoric Socio-Environmental Systems

Carolin Vegvari, Robert A. Foley

203 Agent-based Modelling and Archaeological Hypothesis Testing: the Case Study of the European Lower Palaeolithic

Iza Romanowska

215 Sailing the Simulated Seas: a New Simulation for Evaluating Prehistoric Seafaring $\otimes$ Benjamin Davies, Simon H. Bickler

224 Agricultural Territories and GIS Modelling: the Long-Term Case Study of Menorca Monica De Cet, Rainer Duttmann, Vicente Lull, Rafael Micó, J ohannes Müller, Cristina Rihuete Herrada, Roberto Risch, Philip Verhagen

239 Systemic Approach and Spatial Organization: from the City to Networks of Cities Xavier Rodier, Lahouari Kaddouri, Pierre Garmy

249 Detection of Spatio-Morphological Structures On the Basis of Archaeological Data with Mathematical Morphology and Variogaphy. Application to Syrian Archaeological Sites

Johanna Fusco

261 Least Cost Path Analysis for Predicting Glacial Archaeological Site Potential in Central Europe

Stephanie R. Rogers, Claude Collet, Ralph Lugon

276 Spatial Statistic Analysis of Dating Using Pottery: an Aid to the Characterization of Cultural Areas in West Central France

Lise Bellanger, Philippe Husi, Yassine Laghzali

283 Scale Dependent Patterns in South-Eastern Norway

Mieko Matsumoto, Espen Uleberg 
289 Estimation of Archaeological Potential with a Page Rank Based Predictive Model: the Urban Area of Pisa

Nevio Dubbini, Gabriele Gattiglia

298 Kolmogorov-Smirnov Statistics in the Context of Centuriation

J ohn William Michael Peterson

303 Data Management and Analysis

303 Integration of CIDOC CRM with OGC Standards to Model Spatial Information Gerald Hiebel, Martin Doerr, Øyvind Eide

311 Reality Bites: Reviewing a Decade of Online Collaboration

Susan Hamilton, Peter McKeague

319 An Empirical Approach to the Analysis of Archaeological Discourse Patricia Martín-Rodilla

326 Expressing Temporal and Subjective Information about Archaeological Entities Cesar Gonzalez-Perez, Patricia Martín-Rodilla, Rebeca Blanco-Rotea

336 From dBase III+ to the Semantic Web: Twenty-Five Years of the Coin Hoards of the Roman Republic Database

Ethan Gruber, Kris Lockyear

347 Higeomes: Distributed Geodatabases in an Archaeological J oint Research Project Frank Boochs, Kai-Christian Bruhn, Christophe Cruz, Ashish Karmacharya, Tobias Kohr

358 The Archaeological Resource Cataloging System (ARCS): A Better Way of Working with Digital Archives

J on M. Frey, Timothy E. Gregory, Lita Tzortzopoulou-Gregory

\section{DATA DISSEMINATION}

367 Reimagining Archaeological Publication for the 21st Century*

Eric C. Kansa

$3793 D$ Modelling and Visualisation

379 Playing Angkor: Exploring the Historical and Archaeological Themes of the Khmer Empire through Game Engine Technologies

Tom Chandler

386 The Virtual Archaeology Project- Towards an Interactive Multi-scalar 3D Visualisation in Computer Game Engines

Arian Goren, Kay Kohlmeyer, Thomas Bremer, Arie Kai-Browne, Wiebke Bebermeier, Dennis Öztürk, Stefan Öztürk, Tobias Müller

401 A Roman Street at the Time of Constantine: Interactive Visit with Access to Ancient Source Materials

Philippe Fleury, Sophie Madeleine, Nicolas Lefèvre 
408 Fortress City Saarlouis: Development of an Interactive 3D City Model Using Web Technologies

Kristian Sons, Georg Demme, Wolfgang Herget, Philipp Slusallek

415 An Interactive Virtual Roaming System for Beijing Hutong

Guoguang Du, Zhongke Wu, Mingquan Zhou, Kang Wang, Chongbin Xu, Ziyang Li, Pengfei Xu, Dongcan Jiang and Xingce Wang

423 A Documentation System for Digital Reconstructions with References to the Mausoleum of the Tang-Dynasty at Zhaoling, in Shaanxi Province, China

Mieke Pfarr-Harfst

430 3D Modelling Technologies in Humanities. A Literature-Based Survey about Reconstruction and Visualisation of Historic Objects

Sander Münster, Thomas Köhler, Stephan Hoppe

442 A 3D Assessment Tool for Precise Recording of Ceramic Fragments Using Image Processing and Computational Geometry Tools

Fernando Zvietcovich, Benjamin Castaneda, Luis J aime Castillo, J ulio Saldana

453 Eigen Paicas: A 3D Reconstruction of Entire Vessels Using Information of a Single Fragment and a Database

Fernando Zvietcovich, Benjamin Castaneda, Luis J aime Castillo, J ulio Saldana

463 Towards the Automatic Classification of Pottery Sherds: Two Complementary Approaches

Chiara Piccoli, Prashant Aparajeya, Georgios Th. Papadopoulos, John Bintliff, Frederic Fol Leymarie, Philip Bes, Mark van der Enden, J eroen Poblome, Petros Daras

475 Shape and Technological Organisation of Lithic Solutrean Points from Iberia: a Computational Approach for Exploring the Diversity of Shapes

Isabell Schmidt, Vincent Mom

482 Cultural Heritage Management and Interpretation

482 Is the use of GIS in Cultural Heritage Outdated?

Claire Reeler

488 The End Game: As Scotland's Historic Land-Use Assessment Project Reaches Completion What Have We Learned?

Kirsty Millican and Mike Middleton

494 A 21st Century Record: Maintaining a Modern Monuments Record

Susan Hamilton

501 Preserving Lost Industrial Heritage: Newcastle Australia

Tessa Morrison, Helen Giggins, Nicholas Foulcher

508 Uncovering the Missing Routes: an Algorithmic Study on the Illicit Antiquities Trade Network

Christos Tsirogiannis, Constantinos Tsirogiannis

*: KeynoteAddress

$\otimes:$ Nick Ryan Award 


\section{Preface}

The present volume includes 50 selected peer-reviewed papers presented at the 41st Computer Applications and Quantitative Methods in Archaeology Across Spaceand Time (CAA2013) conference held in Perth (Western Australia) in March 2013 at the University Club of Western Australia and hosted by the recently established CAA Australia National Chapter. It also hosts a paper presented at the 40th Computer Applications and Quantitative Methods in Archaeology (CAA2012) conference held in Southampton.

An extended overview of the conferenceand the proceedings preparation is supplied in the opening paper of this volumeand authored by the Conference Chair and Proceedings Editor. This preface will serve instead to acknowledge and thank all the people involved in different roles in the conference organisation and the editorial work behind this volume. The Chair acknowledges the impossibility of mentioning all that havegiven a contribution, nonetheless shewould like to express her sincere gratitude to everyone that participated in making CAA 2013 a thriving event. In the following paragraphs those whose contributions were most essential and most welcomed are recognised and thanked.

\section{Conference organisation}

Listing in chronological order, first to be thanked are the members of the CAA Executive Steering Committee and the extended Steering Committee for their precious advises, suggestions and guidance throughout the conference and post-conference process. Among these, special mentions go to Guus Lange for his continuous encouragement and for undertaking a number of reviews larger than anybody else; to the CAA Chair Gary Lock for guidance and direction as well as promptly assisting with last-minute reviews; and to Philip Verhagen for assistance in all the phases of abstract and paper reviewing and editorial process. Likewise, organisers and supporters of previous CAA conferences (such as Graeme Earl, Javier Melero, Jeffrey Clark, Lisa Fischer, Leif Isaksen) should be acknowledged for the helpful insights and suggestions they provided before the event and for sharing their conference organisation experience. J ohn Pouncett and Axel Posluschny should also be recognised for their precious contribution in managing the student bursary program and dealing with financial aspects of it. A special thank goes to Hembo Pagi for the invaluable computer programming service and consultancy that he swiftly provided for the CAA conference management software system (OCS) as well as his positive attitude at hard times.

Among members of the CAA2013 organising committee, a huge debt of gratitude goes to Stephen White for his continuous support, assistance and work in many aspects of the conference organisation that he (almost willingly) undertook since the day in which the CAA 2013 conference was assigned to Australia. In particular, he provided much needed help in dealing with the (many) website layout issues, the final program print layout and hundreds of other tasks, too many to mention or even remember. Enormous appreciation has to be given to Gail Higginbottom, treasurer of the CAA Australia National Chapter, for her invaluable help with assembling the program and creating the layout of the conference schedule as well as a number of other tasks (of which the pinnacle was the organisation of a wine tasting stall at the Venue location) both before and during the conference. Thanks also to Ian Johnson, Chair of the CAA Australia National Chapter, for the first draft of the program booklet and schedule. Huge gratitude goes to J ane Fyfe (University of Western Australia) for the precious local' logistic support: her understanding of the working of the UWA facilities and infrastructure was fundamental to have quick response to all the problems that had to be faced and access to all theneeded services. J ennifer Rodriguez (Western Australian Museum) must be acknowledged for her valuable assistance during the conference and for running the Student-to-student accommodation initiative with the help of Wendy Van Duivenvoorde (Flinders University). The important role of Felicity Morel-Ednie Brown (Western Australia Government) should be recognised for the bid acquisition and fund-raising, this last a task which was crucial to the operation 
of the conference. Together with the organising committee members, Martin King (University of Sydney) should be mentioned for all his input before the conference and dealing with accounting, financial and administrative aspects during the months preceding it.

CAA 2013 was also the occasion to forge or reinforce links with colleagues from University of Western Australia. Above all gratitude goes to Thomas Whitley, a long-standing member of CAA North America providentially moved to Australia just shortly before the conference, for all his support in situ, and Toby Burrows for precious assistance with many administration tasks; together with them, the other colleagues of the discipline of Archaeology J o McDonald, Alistair Paterson and J oe Dortch. To this last, CAA2013 is indebted for taking time from his busy schedule to lead pre and post-conference tours that were highly appreciated. We extend the CAA Australia gratitude to the Vice-Chancellor of the University of Western Australia Professor Paul J ohnson and to the Dean of the Faculty of Arts Professor Krishna Sen for the speeches at the Opening ceremony and the Welcome reception.

Volunteers always play a very important role during a conference event. Particular mention must be made of Megan Berry (University of Western Australia) who coordinated the superb cohort of volunteers that ensured the smooth running of the conference at the venue and Sam Harper (University of Western Australia) that enthusiastically helped her in this taxing mission. Thanks also to all the student volunteers that actively gave their time to support the conference, before, during and after, and who are too many to list here. Although unnamed, they were crucial to the operation of the conference. In particular, thanks to Rebecca Foote (University of Western Australia) for her passionate help, for her support in creating maps and signage to ease the CAA delegates moving across the UWA campus and even for swift medical response at a time of need; to Nick Wiggins for taking on many IT and web-based tasks and taking over the management of the social media communication before and during the conference: his assistance was extremely beneficial for the whole conference process; to Elizabeth Smith (Macquarie University) that managed the student volunteers based in Sydney and provided content for the website and assistance with delegate accommodations; to Mary Jane Cuyler for her support in acquiring patronage and endorsement. Charlie Dortch, retired curator of archaeology from the WA Museum, must be acknowledged for generously offering to guide the post-conference tour to Rottnest Island.

The Conference keynotes (in order of appearance) Eric Kansa (Open Context and UC Berkeley), Jeremy Green (Western Australian Museum) and Dominic Powlesland (Landscape Research Centre and University of Cambridge, UK) should be mentioned for delivering three excellent keynote addresses that have entertained the CAA audience, made it reflect on important issues facing the future of our discipline and disclosed new horizons of computer applications in archaeology. Many session organisers helped to select appropriate presentations and papers and ran their sessions with dedication, for which we are grateful.

The Conference Chair wishes also to express her sincere gratitude to Len Collard (University of Western Australia) for performing, as part of the opening ceremony, an emotional 'Welcome to country', the way local Indigenous land custodians welcome delegates to their country. Based on the Aboriginal dreaming, 'Welcome to Country' recognises the ancestral spirits who created the boundaries and lands, and allow safe passage to visitors. The chair would likealso to mention Thomas Hillard and Lea Beness for their warm encouragement throughout the difficult and very chaotic period that preceded - and followed - the CAA 2013 conference, and especially Thomas who, in an extremely busy academic teaching period, travelled a total of $6000+\mathrm{km}$ in less than 3 days only to show his support to this event by attending it for at least one day.

Last but not least, the Chair and the CAA Australia National chapter wish to thank all those who participated, especially the colleagues that have travelled a long distance to be in Perth arriving from Europe, USA, or East Asia, providing exciting contributions that ensured the success of the conference. 


\section{Contributing institutions, partners, sponsors and exhibitors}

TheConferenceChair on behalf of CAAAustralia National Chapter would like to extend her deepest appreciation to the corporate sponsors whose financial and in-kind contributions were essential for CAA 2013 to take place. Particular mention must be made of our main contributors, the University of Western Australia and the Perth Convention Bureau together with Tourism Western Australia.

The University of Western Australia provided generous funding for setting up the conference. The University, and in particular the discipline of Archaeology, should be acknowledged also for welcoming the CAA2O13 Conference in the UWA Campus and offering their infrastructures, facilities and personnel for a smooth running of the event. The Perth Convention Bureau together with Tourism Western Australia provided financial support for marketing the event, ensuring a wide international participation.

Other organisations and businesses have also contributed to the conference either as sponsors, partners or supporters and to them goes the gratitude of CAA Australia. Archae-aus, our Bronze Sponsor, contributed liberally to the general support fund for the conference. The University of Sydney provided accounting and administrative support as well as IT support with the online payment system. The CAA Australia is also grateful to Macquarie University Ancient Cultures Research Centre, whose sponsorship supported the costs of the venue; to Federated Archaeological Information Management Systems (FAIMS) project for helping to sponsor the opening reception at the University Club; to the Australasian Association for Digital Humanities, which generously funded the Best Poster awards; to Society for the Study of Early Christianity (SSEC) established at Macquarie University and MAHA (Macquarie Ancient History Association) for their kind financial contributions; to Eureka Archaeological Research and Consulting for their sponsorship and the time of their staff members; and to Squire Sanders, which provided legal service as part of an in-kind sponsorship. Conference Partners ArcLand and EARSeL should be mentioned for putting together and chairing sessions related to their areas of expertise. The UWA Maritime Museum (Western Australia Museum) has made an important contribution to CAA2013 and its delegates by extending free entry to conference attendees, for which we are sincerely grateful. The patronage of the Government of Western Australia, City of Perth, Icomos Australia, and CHASS should also be acknowledged.

\section{Publication process}

The preparation of a proceeding volume is a huge and time-consuming task and it requires the support of many. First and foremost, Iza Romanowska is deeply appreciated for her undertaking the production of the volume layout and typesetting. Her experience with the editing of CAA proceedings was providential to the efficiency of the overall publication process and her assistance much appreciated; moreover, her infinite patience in dealing with the Editor's (sometimes excessive) attention to detail should be certainly recognised. The CAA Editorial Board should also be mentioned for continuous assistance and guidance.

All the anonymous members of the CAA Review Panel, who by painstakingly undertaking the assigned reviews supported the selection of presentations - first - and papers to be published - later should not beforgotten: the production of a quality peer-reviewed volume relies essentially on them.

Thanks should also be addressed to Paul Bourke (University of Western Australia) and the CRAR+M at the University of Western Australia for the wonderful images that have been used for the creation of the volume cover, representing the Wanmanna archaeological site and computer renderings of reconstructed 3D surfaces and rock art, and of course thanks should be directed to Ian Kirkpatrick for the brilliant design work he produced assembling them together. 


\section{Acknowledgement of Country}

Finally, on behalf of the CAA2013 conference organisers and CAA Australia the Chair would like to tribute an acknowledgement to the Whadjuck Nyungar who are the Traditional Owners of the Perth metropolitan area and surrounding districts. We would like to acknowledge these traditional owners of the land on which we have held the CAA2013 conference and pay our respects to the Nyungar Elders past, present, and future for they are custodians of the history, the cultural practice, traditions, lands, seas, fresh water and swamps of their people. We thank them for allowing us to meet on their land.

Arianna Traviglia

Chair, CAA2013 Organising Committee 
Main contributors
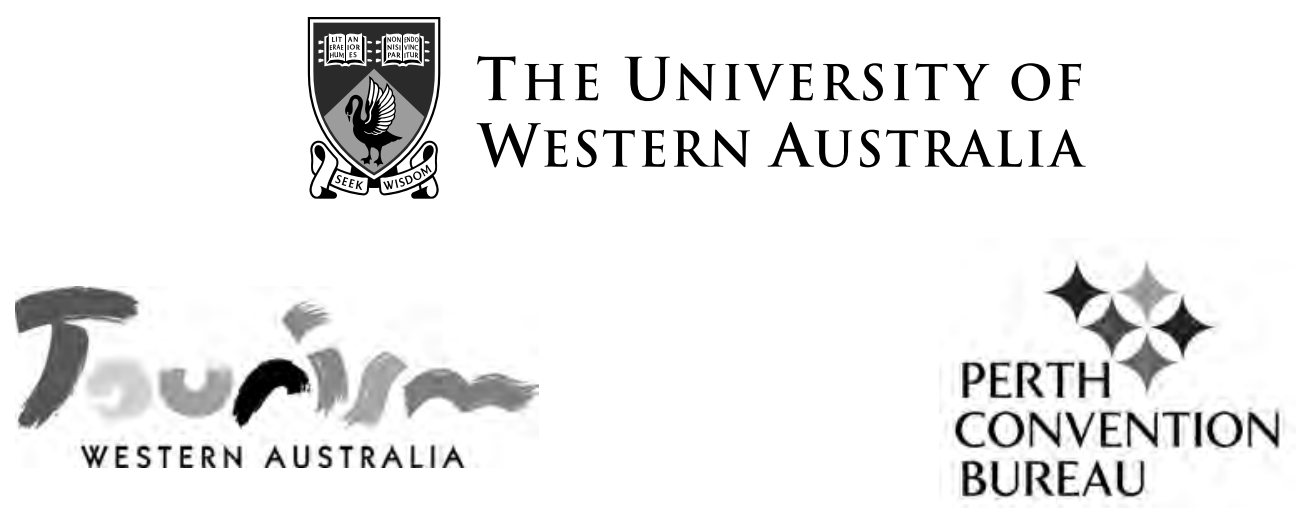

Bronze Sponsor

\section{archae-aus}

Other sponsors and contributors

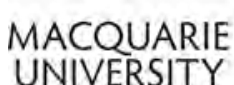

UNIVERSITY

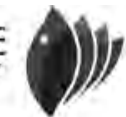

ANCIENT CULTURES

RESEARCH CENTRE
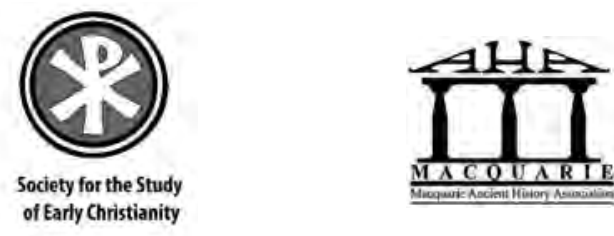
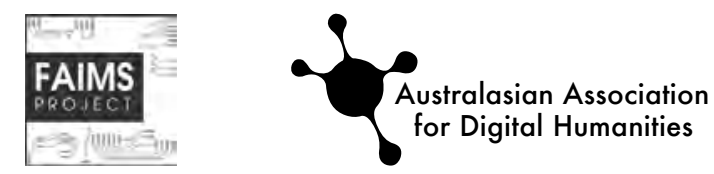

SQUIRE : SANDERS

\section{Exhibitors}

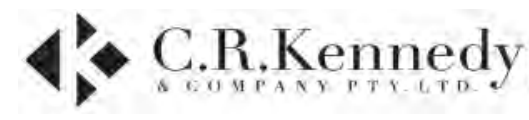

Partners
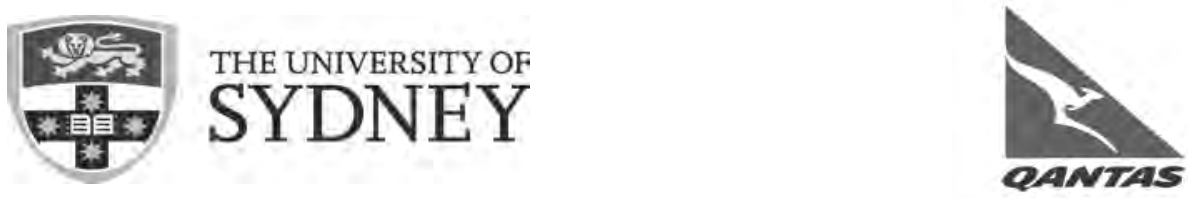

\section{Supporters}
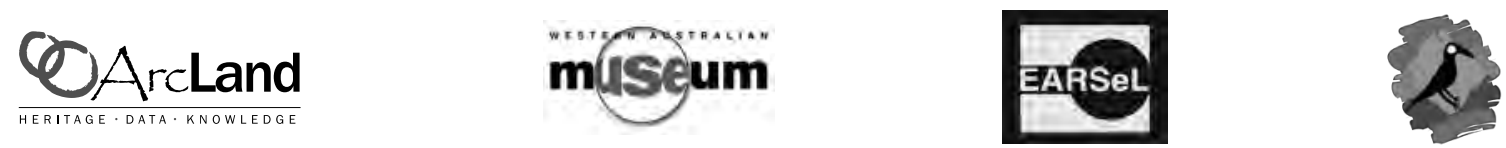



\title{
Across Space and Time
}

\author{
Arianna Traviglia \\ CAA Australia National Chapter
}

The 41st Computer Applications and Quantitative Methods in Archaeology Across Space and Time (CAA2013) conference was held in the city of Perth (Western Australia) from 25th to 28th March 2013. The theme of the conference was 'Across Space and Time' which alluded to both the paths that archaeological research moves across and to the space and time that delegates would have to travel to reach the 2013 CAA destination. The conference was hosted by CAA Australia National Chapter, which was purposely created in the months just after the successful bid presented in 2010. Two academic institutions, The University of Western Australia and The University of Sydney, supported the conference in different ways, using their physical and organisational infrastructures. The specific entities involved in the event organisation were the Discipline of Archaeology, School of Social Sciences at the University of Western Australia, and Arts eResearch and the Faculty of Arts (providing accounting support) at the University of Sydney.

The primary venue of CAA 2013 was the University Club of Western Australia, a modern building located in the campus of The University of Western Australia, on the banks of the Swan River facing Matilda Bay and the Perth city skyline. The University Club proved to be an excellent and much appreciated choice for its beautiful location and surroundings, the first-rate conference facilities and the superb management that ensured the smooth running of the conference. Several locations across the University of Western Australia, where conference workshops took place on the first and second day, served as secondary venues.

The CAA 2013 Perth conference organisers strove to produce a conference experience that, beside serving the traditional functions of CAA conferences of providing a venue for showcasing, disseminating and discussing advancements in computational and digital methods applied to archaeology, could also promote the wider adoption of such methods and start collaborative networks within the Australasian region, while extending the membership of CAA in the region.

\section{Before the Conference}

The candidature to host conference was presented in Granada, Spain, in 2010 during the Fusion of Cultures CAA 2010 conference by the writer and Felicity Morel-Ednie Brown. As indicated in the brief speech preceding the vote at the 2010 CAA AGM, our goal in hosting the conference in Australia was to makeCAA fully global and to expand the CAA membership beyond the last frontier'. The following year, 2011, CAA was going to be held in Asia for the first time (Revive the Past CAA 2011, Beijing, China), acting to engage Asian scholars, bring fresh perspectives and build newrelationships. Continuing this globalisation pathway, we proposed to hold the CAA conference for 2013 in Australia (the first time that CAA would be conducted in the Southern hemisphere, a milestone in the CAA history), allowing colleagues from Oceania to attend it. The project soon found interest and support by a number of Australian academic institutions, research centres and government bodies that provided assistance for the conference to succeed.

The time leading up to the conference was full of strife. The financial crisis that had hit the global markets in 2008 (and, with them, the economies of many countries worldwide) had not receded during the years and months preceding the CAA 2013 Perth event, and it had indeed worsened the financial situations of European and American countries (and academic institutions). At about the sametime, Australia, which had been only marginally shattered by the economic downturn, was starting to enjoy a very strong dollar over most national currencies. That gap kept steadily growing during the year preceding the conference (Fig. 1, left). Perth itself, a thriving city back then at the centre of the Australian mining boom, already boasted what would be

Corresponding author: chair@caa2013.org 


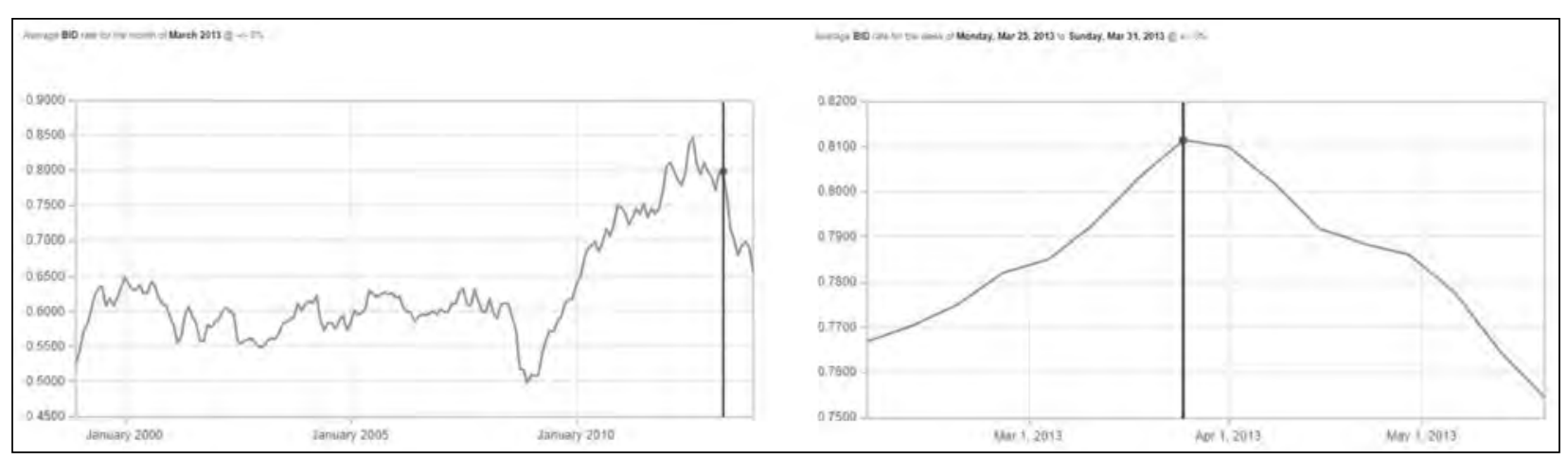

Figure 1. Australian Dollar-Euro exchange rate. On March 25th 2013, the week of the conference, the exchange rate reached the fourth highest peak in the history of the exchange rate between the two currencies.

considered - from a European perspective - high costs for accommodations and meals.

Months before the conference it was clear that these two factors combined together could have represented an explosive situation for typical CAA delegates, making it financially very difficult for many to join the event, especially considering the great distances that one has to cover to reach Perth (even for those simply coming from a different shore of Australia) and the costs related to that. It is to be faced, indeed: the Australian continent is far from pretty much everywhere. The Conference organisers watched with growing preoccupation the increasingly rising exchange rates in the months preceding the conference. Sardonically enough, the week of the conference the exchange rate reached the fourth highest peak in almost 15 years; after that the exchange rate started its slow but unstoppable descent (Fig 1, right).

With these difficulties very clear in mind and faced with the prospect of a very low attendance (and all the financial issues it would create), the organisation team had to devote a considerable amount of energy to fund raising in order to offset the high costs so that they would not have to pass on the real cost of the conference in the way of high registration fees. At the end, thanks to a number of generous contributors, we were able to maintain the fees at the average level of previous conference fees, while offering full board meals and lavish refreshments in the registration package.

In an attempt to support students, low incomers and ECRs with facing the costs of the travel, other programs were initiated, such as the student-to-student initiative, created to encourage Perth-based student delegates to host students from around Australia or overseas while the visiting student was attending CAA Perth 2013. While providing an opportunity for a cheap accommodation, the purpose of this initiative was to promote national and international links between students and provide a great opportunity to form friendships and professional contacts that may last throughout their careers. In addition, CAA provided, as every year, a set of bursary awards to financially support students, low incomers and ECRs to attend the conference: of the ones eligible to receive financial support, 31 students accepted.

In June 2012, the CAA 2013 organisers issued an open call for sessions proposals. 39 session proposals were received and 35+ accepted (although not all, in the end, were convened) after merging some proposals that focused on similar subjects. Next to the usual session formats, such as roundtables, workshops, short and long sessions, we trialled (in the best tradition of freedom that CAA bestows over local organisers) the Focus session format, consisting of thematically-related five minutes key-point presentations timed by a discussant pulling the theme together, followed by a room-based breakout organised around posters or demos presenting additional information to maximise networking.

In the month of August 2012 a call for papers and posters wasissued with a deadlinefor submission set on October 2012. 226 proposals (including both posters and papers) were received and reviewed with the support of the CAA Review panel, with 2 to 3 reviewers assigned to each abstract. The final 
number of papers accepted for presentation or that were actually presented was lower: 19 proposals were rejected and several others were withdrawn in the months preceding the conference.

\section{During the Conference}

The conference was privileged to host about 250 participants from 24 countries, which we considered an exceptionally good number when looking at the global financial situation and the distance conveners had to travel (and the associated costs). Of those, 87 were registered as students.

About 115 participants were from Australasian region (this a remarkable success for a conference previously unfamiliar to the Australasian landscape) and the remaining split across nations worldwide, with representative from almost all the European countries as well as several parts the United States and, for the first time - to the best of our knowledge a representative from Saudi Arabia. The five nations with the broadest representation at CAA 2013 (after Australia) were UK, USA, Germany, Czech Republic and the Netherlands.

The conference was composed of 29 parallel sessions, within which the 157 accepted papers were presented (delivered as short, long or focus papers), together with 25 posters. The total number of contributions required running four or, at times, five parallel sessions held over three full days. Ten workshops were separately offered in parallel sessions on the first conference day and one during the second conference day, proposed by some of the most active CAA long-standing members and 'new entries'; each workshop dealt with different topics spanning from complex systems and agentbased modelling to archaeological interpretation and airborne laser scanning, passing through archaeological conceptual modelling.

Although started on the 25th of March with the Workshop day, the conference was formally commenced on the second day with an Official Conference Opening during which welcoming remarks were provided by the University of Western Australia Vice Chancellor Professor Paul Johnson. The speech was followed by a 'Welcome to country', the customary ceremony performed by Aboriginal elders to welcome visitors to their traditional land - a protocol that has been a part of Aboriginal cultures for thousands of years - which was performed by Len Collard, ARCResearch Fellowat that University. During the performance, the delegates were welcomed by Len in his position as representative of the Whadjuck Nyungar, the Traditional Owners of the Perth metropolitan area and surrounding districts, and had the possibility to hear a brief piece performed by didgeridoo, the traditional wind instrument used by Indigenous Australians.

At the end of the ceremony, Dr E. Kansa, Program Director of Open Context - a data publishing venue for archaeology - provided a much appreciated keynote speech that enlightened the attendees on theissues and thegreat challenges faced by scholarly communications and, more specifically, by archaeological scientific communication. We heard also howinnovations in many areas, including Linked Open Data, Web services, and services for data citation and preservation, are enriching the archaeology information ecosystem and promise to make archaeological knowledge contributions more broadly accessible and relevant to other disciplines and public communities

In the following days, the other two keynotes had the arduous task to drag our conveners out of their comfortable hotel rooms before $8.30 \mathrm{am}$ in order to attend their speeches.

On the third conference day morning, the brilliant presentation of Dr J eremy Green, Head of the Department of Maritime Archaeology at the Western Australian Museum, Fremantle (Western Australia), introduced attendees to the history of application of computer technologies to maritime archaeology and how computers revolutionised maritime archaeology over the past 40 years. He himself a pioneer of computer application in underwater archaeological exploration, Dr Green went through the rapid evolution of technological aided underwater exploration and provided an overview of the progresses in the fields of remote sensing, GIS and photogrammetry applied to maritime archaeology.

The inspirational keynote speech offered on the last day by Prof. Dominic Powlesland, Director of the Landscape Research Centre, North Yorkshire (UK), an internationally recognised front 
runner in the application of computing to field archaeology, delighted the early-bird delegates with the entertainingly narrated tale of his over three decades long research in the Vale of Pickering. Along the way, the paper reflected also on different aspects of past, current and future archaeological research, and the role of applied computing to improve and enhance - rather than replace - "the observational, recording and delivery infrastructure which has for so long been the subject of site-hut and bar-room discussion" (D. Powlesland).

Each of the keynote speeches opened a session related to the topic explored in them. Overall, the other sessions of the conference spanned across the topics that are typical of CAA and included data modelling, management and integration; field and laboratory data recording; linked data and the semantic web; data analysis and visualisation; 3D modelling, visualisation and simulations; spatiotemporal modelling, GIS and remote sensing. Some of the session were specific to the Australasian region and included, for example, the application of $3 \mathrm{D}$ visualisation to rock art and cultural heritage management and the implementation of a recently developed Australian archaeological information management systems (the Federated Archaeological Information Management Systems FAIMS).

The sessions were brilliantly presided over by a number of chairs (some of which had to be enlisted just in the weeks before the conference due unforeseen events that made it impossible for the original chairs to be at the conference) that ensured the fluid operation of the proceedings.

To promote networking and socialising in an informal environment, we had decide, as mentioned, to include in the conference package the provision of lunches that were served in the beautiful Alfresco Terrace of the University Club, a partially covered balcony on the first floor of the Club, which provided guests with a uniquespace overlooking the university campus to hold get-togethers. We have been pleased to hear, later on, that many collaboration links have been created during these pleasant interludes.

\section{Social Events}

The CAA conference was also the occasion (and, maybe, especially so) for many long-time friends to meet and spend time together, and for new friendships to be established. This was certainly facilitated by a number of social events that flanked the conference proceedings.

On March 24th, CAA conveners already in Perth were invited to enjoy an evening out in the beautiful sea-side town of Freemantle, south of Perth, before the start of the conference. The informal event was held at a local renowned microbrewery, Little Creatures, sitting right on the bay with beautiful views across the water.

On the first conference day, at the conclusion of the workshops, all the Conference delegates were invited to participate to the Welcome Reception that was held at University Club. Guests were supposed to be welcomed in the Alfresco Terrace, but an unexpected and sudden storm made it more appealing and safer to use the Club's covered space. Canapés and excellent Western Australian wines offered to the CAA delegates made up for the change of scene. At the reception, the delegates were welcomed by remarks from Dean of the Faculty of Arts, Professor Krishna Sen.

On March 27th, with the official opening of the Poster Session, at the same time the CAA 2013 Poster Panel was judging the posters, the McHenry Hohnen Vintners presented across the foyer space their wines for tasting and purchase. That same evening, the Conference Dinner was held in the Thomas Hardwick Function Room of The Old Brewery, the name of the room paying tribute to the original Brew master. The Old Brewery provided a stunning riverside feature venue.

The day after, following the official closing of the conference, a large part of the conveners slowly congregated to a popular nearby establishment called the Captain Stirling Hotel, few minutes walk from the University, an attractive and pleasant place popular among UWA students and staff. Conveners indulged there for several hours before a number of them moved downtown to the Hula Bula Bar, chosen as their menu mentions archaeologists being responsible for the resurrection of their Rum Cocktail. There, the bar's elaborate drinks formally closed the conference, although someCAA members would re-enact the closing ritual the following day, when a smaller number of delegates that participated 
to the post conference tour gathered once more for further toasts.

\section{The Post Conference Tour}

The post conference tour was just another of those things that had been planned one way and had to undergo several changes of plan.

Indeed, it is likely that all the conference organisers will have at the end of the day a long list of disrupted plans, but the story of the planning (and re-planning) of this post conference tour is so peculiar and full of negative coincidences that it is felt necessary to give a short outline of it.

About a month before the conference, the site that we had originally planned to visit, the Walyunga National Park, was first flooded and the archaeological site we had planned to visit wiped out; against the odds, we still maintained the plan, as the beauty of the National Park by itself would have been worth a visit. Then, two weeks before the conference, the entire area was involved in a vast fire that destroyed part of the National Park. Moreover, only at that time, more or less the day after the beginning of the fire, we also found out that the even the second part of the tour, including wine tasting in the Swan Valley vineyards, would have had to be cancelled as local legislation prevented serving alcohol on Good Friday (which was the day of the tour) unless flanked by a full meal served at the premises (and all the vineyards with a restaurant at the premises were closed that day). The post conference tour was therefore hurriedly rearranged and moved to another location. The choice fell on Rottnest Island, a stunning island just 18 kilometres off Perth's coastline. We therefore put together a tour combining sightseeing local environmental attractions and archaeological/ historical highlights. We were able to enlist Charlie Dortch, father of UWA colleague J oe Dortch, as an expert guide that could lead us to explore the island. Charlie Dortch worked for many years as curator of archaeology at the WA Museum and has gained through the years a deep knowledge of the history of Rottnest Island. The tour included about 45 minutes ferry ride to the island, where delegates were welcomed with a brief Welcome to country ceremony performed by Reg Yarran before being picked up by a bus touring the isle. During the bus tour the delegates had the time to stop in some iconic spots of Rottnest Island and had the opportunity of a close encounter of the marsupial species that have given the name to the island, the 'quokka'. Dutch sailors in the 17th century named the island 'rottnest', which translates to 'ratsnest' island in Dutch: the name was bestowed on the wrong assumption that the Quokkas on the island were large rats. The bus tour ended in the proximity of one of the few food stations on the island, where delegates enjoyed lunch, which was followed by a brief hike to one of the island beaches, where a group of courageous delegates bathed in the crystalline (yet cold) waters of the bay. Upon return on mainland, the CAA members still fit, after the long day, for some extra hiking embarked on a short visit of the city of Fremantle and closed the day tour at the tables of one of the few pubs of Fremantle open on Good Friday.

\section{After the Conference}

Shortly after the end of the conference authors were invited to submit their manuscripts for those to be considered, after peer review, for publication within the CAA series. In conformity with previous editors, we decided to provide all the presenters with the same opportunity to submit a paper of 3000 or 5000 words irrespective of their presentation type (long, short, poster) at CAA 2013. Generally, the 3000 words limit was adopted for papers that were more preliminary in nature and displayed research at early stages. About 60 papers were originally submitted and only the best 50 were ultimately selected for publication; these were published both in printed and online form. We also took the decision to host a paper accepted for the CAA2012 Proceedings and that accidentally had not been included in that volume. The decision of limiting the number of papers that could be included in a CAA volume and admitting to the printed form only a selection of the very best submitted papers chosen through a scholarly peer review process had been adopted in the past years from CAA on the base of a number of considerations. These include: the high costs of publishing large volumes as the number of contributions to CAA conferences have grown larger; the ineffectiveness of publishing everything that was submitted especially where it did not meet the academic standards envisaged by CAA; the necessity of providing sufficient space for thorough discussion to papers deserving publication; the 
recognition of the importance of peer-review system to guarantee academic credit; the incentive that a selection process provides to authors to submit a mature contribution for publication in the proceedings rather than a simple project report. With these considerations in mind, the selection process was organised along the lines of a rigorous peer review approach and a scrupulous editing of the selected papers.

The peer review process (a single blind peer review undertaken in double round) was performed with thesupport of theCAAReviewPanel.Each paper was vetted by a minimum of 3 referees ( or even more in case of papers requiring multiple expertise or the review of which had been particularly controversial) and underwent through two rounds of reviews: first at the time of submission of manuscripts and then following the revision undertaken by the authors upon receiving the comments of reviewers (it is to be noted that no paper has been accepted without a request of changes, minor changes at a minimum). After the second review, reviewers were asked to provide their final decision, either accepting or rejecting the paper. The amended manuscripts that had passed the second review round were then edited for English and consistency, following the style established for the publication; at the end of this procedure they were submitted to authors as proofs and authors were given the chance to review and correct them once more (in this case, only for minor issues such as referencing systems and missing information), a procedure that in some cases had to be repeated twice.

The papers in this volume were arranged following a specific grouping approach. Firstly, the papers were clustered within broader domains (corresponding to chapters in the Proceeding volume) that would include two or more of the topics covered in what, during the conference, were separate sessions. The different domain sections were then clustered in three macro-groups (data acquisition, data analysis and management, data dissemination) and arranged in the Proceeding volume following the sequential criteria followed in the archaeological process of collecting data, storing and processing them and finally sharing and disseminating them. It is worth mentioning that these clusterings were intended to provide a logic structure to the reader looking for specific types of papers, but that several of the papers included in a section could have been incorporated within different ones as they were describing multiple methods or approaches. Within each domain/ chapter, the papers were organised following a logic sequence, with papers holding similar content grouped together. As a solution - adopted also in the past years - to cut on costs, figures and tables were printed in greyscale as manuscripts are available onlinein their original colour version. When caption of images make reference to colour codes, therefore, the reader should refer to the online version.

In their preface to the CAA 2007 Proceedings (Layers of Perception), the Editors had most rightfully suggested to future CAA editors to take a morestructured approached to thereviewprocedure. We hope that we have taken up their precious advice by enforcing deadlines with reviewers in each review round and, most of all, by introducing a well structured evaluation form, specifically requesting the opinion of the reviewers on a number of explicit aspects of the submitted papers, ranging from the quality of English to the clarity of style and quality of images, and by asking them later on to check if the requested changes had been convincingly implemented by the authors. This might have not completely removed the dissimilarity in the quality and elaborateness of the reviews, but certainly had a beneficial effect in providing most of the time the editor with timely and complete reviews to base paper acceptance decisions on.

While working at the publication of the proceedings, we have been guided by two principles. First, to produce a high quality volume, that could match the scientificity criteria required to proceedings with high academic credit. Secondly, we strove to produce it within the timeframe indicated by the general CAA guidelines (i.e. before the following CAA conference) and, indeed, we had been able to match the April 2014 deadline in terms of production of the draft. However, unforeseen printing issues have since then gotten in the way and the printing schedule has been moved by the publisher initially to J une 2014 and, later, at the end of the same year, following a lengthy renegotiation of the original contract. We had similar situations happening in the past for other CAA proceedings, with printing schedules shifted forward by publishers despite all the attempts of the 
editors to match the agreed deadlines: the issue of uncertainty of the publication schedule appears to be the challenge that future CAA proceeding editors will have to make their own and they will need to find effective ways to avoid unwanted delays.

Looking at how we have addressed the CAA 2007 proceedings editors' suggestion, we can certainly say that, although the overall publication process is now more structured, the editorial process can still be ameliorated. The introduction and implementation of a yearly updated CAA Review panel in the past years have significantly increased the availability of reviewers and, as consequence, the speed of the review process, an aspect highly appreciated by CAA authors. Likewise, the management of the entire procedure has been streamlined by the adoption of Open Conference Systems (OCS). However, 'human factor' keeps having a prominent role in defining the speed at which editors can work, and apparently harmless situations like late notification of reviewing unavailability or late submittal of reviews have certainly complicated a process that is complex already. Notwithstanding the shortcomings, the excellent work of the reviewers allowed for the process to run all in all smoothly and the bulk of the double-round review process was completed within 5 to 6 months from the submission of papers.

\section{Final Considerations}

Organising the CAA 2013 conference has proved to be a challenging task, well beyond what was expected (regardless of the countless warnings from previous organisers), with many unforeseen and unfavourable events and circumstances to face, issues to solve, situations to turn around. With thebid accepted in early 2010 and the publication process completed near the end of 2014, the conference process has occupied a large portion of the Chair's time for almost four years. It is with a certain degree of relief therefore that she can see now that time is finally come to put CAA 2013 behind her. It will be indeed a strange sensation not to have to deal with planning, managing, budgeting, accounting, making choices, solving issues, editing, and completing any more actions related to the CAA 2013 event.

Notwithstanding the impact that organising a conference can have on one's own life, this writing will not end without encouraging - as previous CAA Editors have done in their prefaces to the Proceedings - a new generation of CAA members, especially the ones from less represented countries within the CAA landscape, to undertake the taxing but rewarding task of organising a CAA conference. 



\section{DATA ACQUISITION}

Remote Sensing (Short and Long Range)

Field and Laboratory Data Recording 



\title{
Remote Sensing in Maritime Archaeology, from the Slide Rule to the Supercomputer
}

\author{
J eremy N. Green \\ Western Australian Museum, Australia
}

\begin{abstract}
:
Since the 1950s there has been a steadily increasing use of computing in the field of underwater archaeology. This has been driven by the need to utilise time underwater as efficiently as possible. The development of applications originally created for the offshore gas and oil industry has provided devices and computing applications that can be utilised in the archaeological domain. This paper deals with some of the advancements in computing application for underwater surveying and underwater cultural heritage management.
\end{abstract}

Keywords:

Maritime Archaeology, Remote Sensing, Photogrammetry, Underwater Surveying

\section{Introduction}

Maritime archaeology, like computing science, is a relatively new discipline that, likewise, evolved dramatically throughout the 20th century, a time when hard-hat divers, under the direction of archaeologists on the surface, investigated ancient wreck sites. The Antikythera site, off the island of Antikythera, Greece, is probably the most famous example of this 'primordial' underwater archaeological research: there, a large number of bronze and marble statues dating from the first century BCE were recovered with such arrangements in place. Oddly, a devicenowrecognised as an ancient analogue computer, the Antikythera Mechanism, was recovered at that site (Freeth and J ones 2012).

It was only with the invention of the aqua-lung and the development of diving sports that working underwater became feasible for archaeologists. From the onset, the problem of working underwater was that time is of the essence: the air in the tank is finite, and the deeper one operates, the quicker the air is used up. In addition, the effects of breathing air under pressure have two limiting side effects: nitrogen narcosis, which affects the diver's ability to operate at depth, and decompression sickness, which is the problem of dissolved gasses in the body. This requires lengthy decompression in shallow water to allow them to be flushed from the system. Working underwater has also limitations caused by

Corresponding author:

jeremy.green@museum.wa.gov.au cold water, currents and the lack of ability to talk to others working with you. All this has resulted in the archaeologists having to find ways of being as efficient as possible underwater (Bass and Katzev 1968).

Archaeologists involved in the underwater world do not have the same advantages as their terrestrial counterparts. Searching for archaeological sites underwater is often difficult and complex for the obvious reason that one cannot spend an indefinite time there. Visual searches are feasible in very shallow water. In deeper water a submersible can be used. However, these methods are either time consuming or expensive. As a result, there is a reliance on remote sensing as a cost-effective alternative. Such technique, widely used in the minerals and oil exploration field, can be operated 24 hours a day and - under certain conditions - is extremely effective in locating underwater archaeological sites. This paper outlines the developments in the field and point to the way the field is developing.

\section{Position Fixing}

In the past, position fixing at sea has been extremely complex. Close to shore it was possible to use land transits or horizontal sextant angles (Green 2004, 34). Further out to sea, out of sight of land, it became more difficult, even using a variety of radio and radar based systems, which in any case were either very expensive to operate or gave poor 


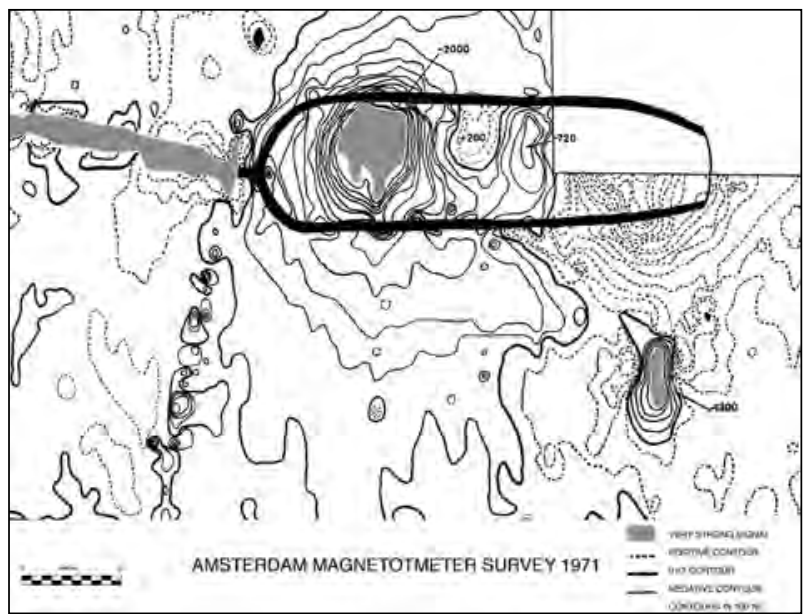

Figure 1. Close plot magnetometer survey of the VOC ship Amsterdam wrecked on Hastings Beach, UK, in 1749 and surveyed in 1971. The ship outline is in black; the linear feature (grey) represents a buried steel air pipe used to excavate site. The linear anomaly running from bow downwards is possibly a mast. The -1300 NT anomaly (lower right) is possibly an anchor.

accuracy. With the advent of the Global Positioning System(GPS), sitepositioninghas changed radically. It is now possible to locate one's position anywhere on the surface of the Earth to about $\pm 2.5 \mathrm{~m}$ using a small hand-held instrument; with more complex systems this can be reduced to sub-centimetre accuracy. For an archaeologist, on the surface of the sea, a precision of $+2.5 \mathrm{~m}$ is generally more than adequate as the sites are often tens of meters below the surface, so even the ability to easily return to a site is an enormous bonus. What has not yet been satisfactorily solved is how to connect the seabed to the sea surface, so that the underwater position can be accurately recorded via the GPS. The GPS is also vital when operating remote sensing equipment because it provides a constant stream of position data necessary to georeference the remotely sensed data.

\section{Magnetometers}

Magnetometers were first used in an underwater archaeological context to search for shipwrecks in the sixties (Hall 1966).

This author was involved in magnetometer surveys of two shipwreck sites, the Amsterdam, a VOC (Verenigde Oostindische Compagnie or Dutch

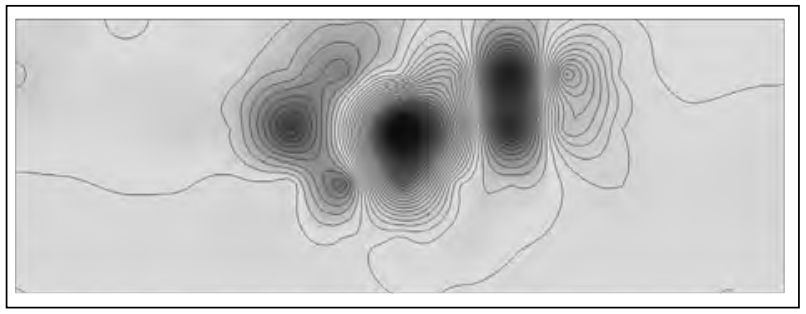

Figure 2. Magnetometer close plot of the 4th century BC Kyrenia shipwreck, Cyprus, showing the anomaly caused by the amphora. Area is $15 \mathrm{~m}$ long by $5 \mathrm{~m}$ wide.

east India Company) vessel wrecked in Hastings (UK) in 1749 (Marsden 1985) (Fig 1) and the Greek 4th century BCE Kyrenia shipwreck in Cyprus (Green, Hall and Katzev 1967) (Fig 2). In these sites, the magnetometer was used to plot the extent of the wreck sites.

In the case of the Kyrenia shipwreck - a merchant ship with a cargo of amphorae and other goods - the magnetometer survey was complicated by the fact that the amphorae retain a thermoremnant magnetic field since the ferrous material in the clay - when fired above the Curie Point (between 858 and $\left.1043^{\circ} \mathrm{C}\right)$ - aligns with the Earth's magnetic field. However, this signal is quite small within a cargo of amphorae since the random stacking will tend to cancel out.

While close-plot magnetometer survey can have specific applications in a variety of situations, its main use in maritime archaeology is in the location of sites. Obviously, large iron shipwrecks are easy to find, as their magnetic signature will be very large. Recently, airborne magnetometers have been used to locate wreck sites and the application of this technique has some interesting implications as described below.

\subsection{General marine magnetometers}

The first marine magnetometers were based on the proton precession system. They suffered from noise problems in the towing cable and low sampling rate that required a slow survey speed. The advent of high precision marine magnetometers, particularly the overhauser and caesium vapour instruments, has resulted in a great improvement in the efficiency of survey work. These magnetometers have a high sampling rate and a signal to noise ratio 


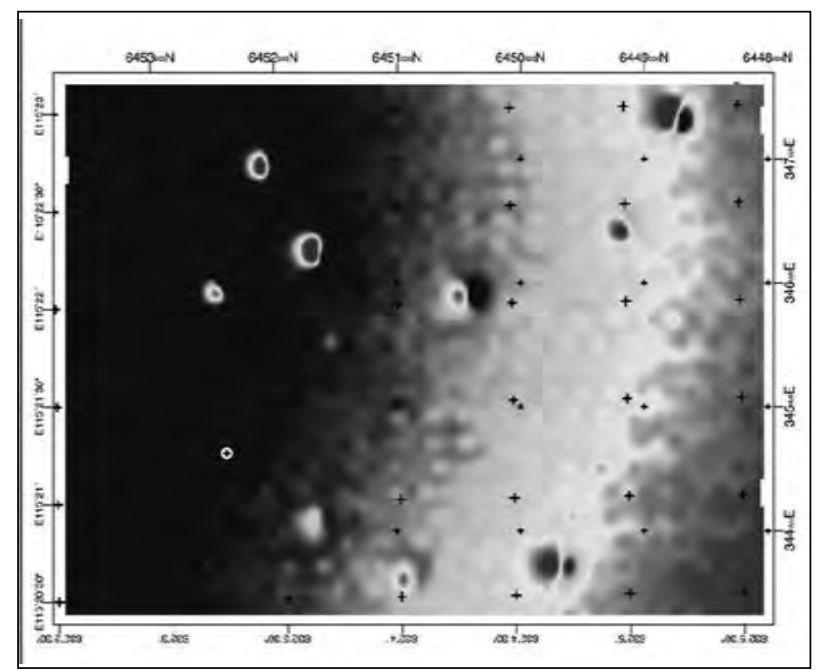

Figure 3. Aerial magnetometer survey of the Deepwater Graveyard off Fremantle Western Australia. Nine magnetic targets correspond with iron ships that were scuttled in waters between 80-100 m depth.

up to 100 times better that the proton instruments. Additionally, the processing software is now very sophisticated, and can integrate GPS information with the magnetic field intensity and real time plotting of anomalies. Where once the readout was on a paper trace, and the results had to be manually transferred from the plotter, now the entire procedure is digital, with the additional bonus that the position of the vessel - and thus the detector head - can be recorded together with the signal to enable an XY plot to be produced.

\subsection{Deep-water location using aerial magnetometer}

The Deep Water Graveyard off Fremantle (Western Australia) is the site where ships are scuttled after they are of no further use. The sites lie in 80-100 $\mathrm{m}$ of water beyond conventional SCUBA (Self Contained Underwater Breathing Apparatus) operations, and initially the position of the wreck sites were uncertain. An experiment was set up in order to test if an aerial magnetometer might be able to detect sites in the graveyard and a local aerial survey company was contracted to fly two areas: one centred on the Deep Water Graveyard (24 sq. km); the second, further out to sea, centred on the approximate position of HMAS Derwent, a 2100 tonne river class frigate, scuttled in 1994 in $200 \mathrm{~m}$ of water $(8 \mathrm{sq} . \mathrm{km})$. A team of the University of Technology of Sydney (UTS) flew the area and

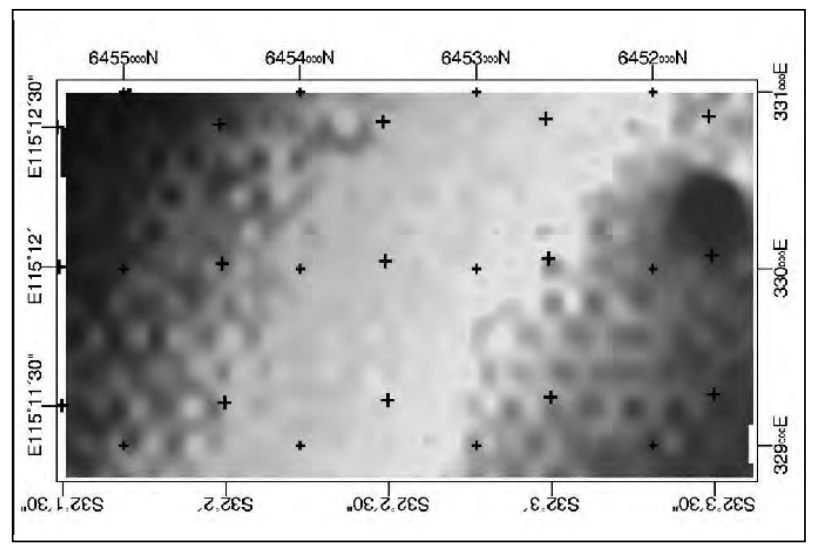

Figure 4. Aerial magnetometer survey showing the site of HMAS Derwent (lower centre) scuttled in $200 \mathrm{~m}$ of water in the Deepwater Graveyard.

undertook the survey at $50 \mathrm{~m}$ above the surface of the sea, taking $1 \mathrm{hr} 20$ mins to survey the first area and about 30 minutes to survey the second (not counting the time to and from the survey areas). The results were surprising. The Graveyard survey showed 10 sites (Fig. 3) and HMAS Derwent showed up quite clearly (Fig 4) in the expected position.

Calculations of the Derwent anomaly (Green 2002) show that the $14 \mathrm{nT}$ anomaly was consistent with the Hall Equation (Hall 1966), which predicted a $16 \mathrm{nT}$ anomaly for thevessel taking into account the length/breadth magnifying effect in the equation:

$$
\Delta M=\frac{A}{B} 10^{4} \frac{W}{D^{3}}
$$

where $\Delta \mathrm{M}$ is the anomaly in nanotesla, $\mathrm{W}$ is mass in tonnes, $\mathrm{D}$ is distance from centre of object and $\mathrm{A} / \mathrm{B}$ is the length $(\mathrm{A})$ to breadth (B) ratio.

\subsection{Shallow water location with aerial magnetometers}

The Correio da Azia was a Portuguese vessel wrecked in 1816 near Point Cloates in the northwest of Australia. It had been the subject of numerous searches, all of which proved unsuccessful. There were two contemporary documents that described the site where the ship was lost, somewhere in close proximity to the Ningaloo Reef system. However, the Ningaloo Reef system is a complex of coral outcrops and reefs that makes conventional searches very difficult, as one has to avoid the shallows. Following the success of the Deep Water 


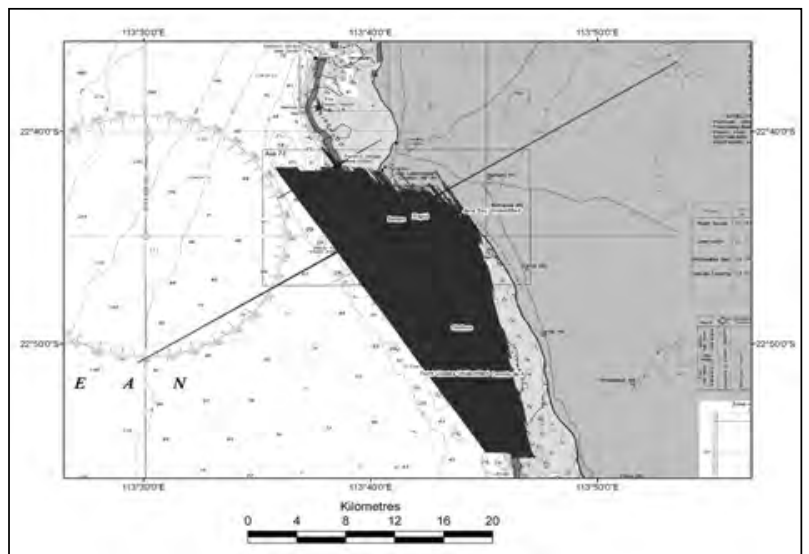

Figure 5. Plot showing the area covered in an aerial magnetometer survey searching for the Correio da Azia lost in 1816.

Graveyard aerial survey, at the request of the Western Australian Maritime Museum (Fremantle), a Western Australian survey company, Fugro Airborne Services, flew an aerial magnetic survey over the approximate area where the wreck was thought to lay. The survey successfully identified a number of known sites (Fig. 5), but revealed two magnetic anomalies, close together, indicating that they might be associated with the Correio da Azia (Fig. 6).

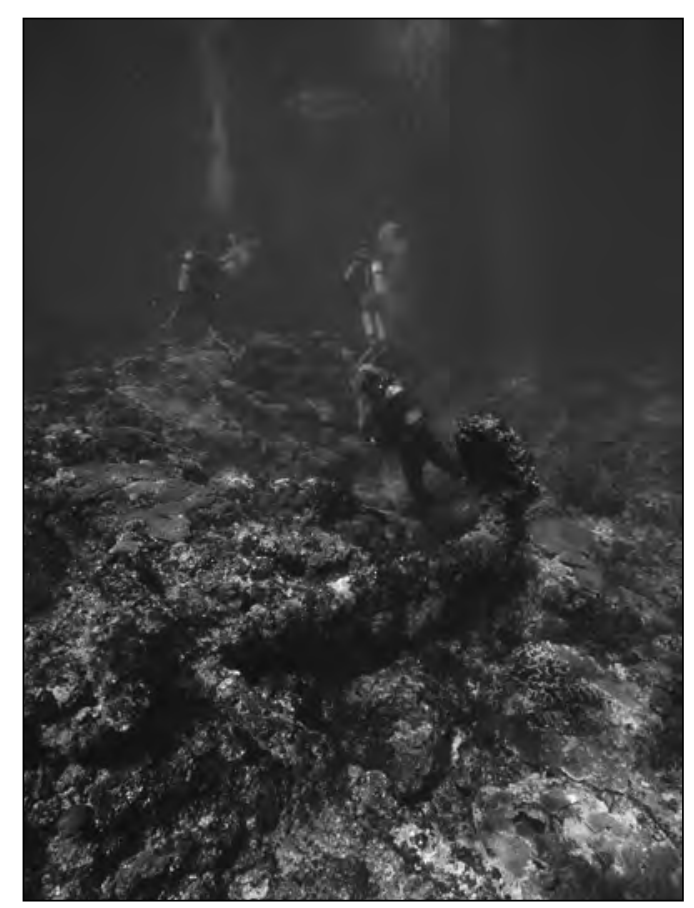

Figure 7. Correio da Azia site with large iron anchor.

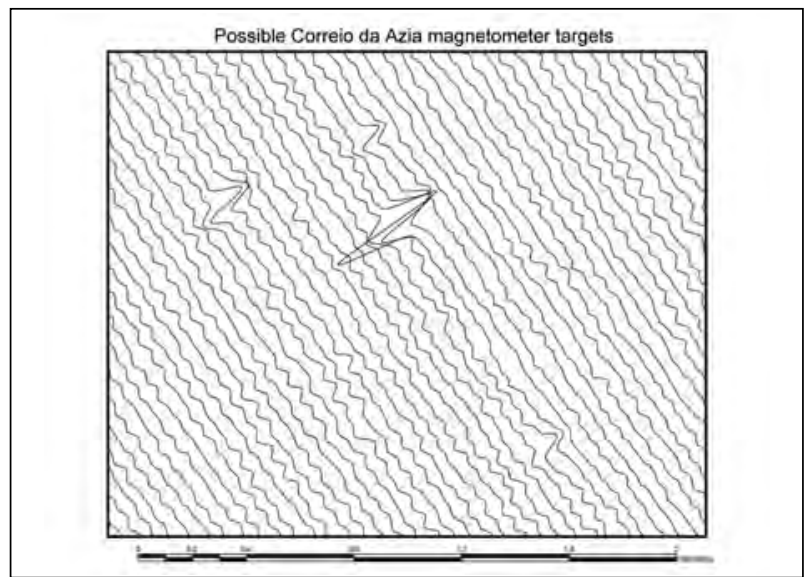

Figure 6. Plot showing the magnetic targets found in the search for the Correio da Azia. The large central target has been identified as the Correio da Azia; the smaller target to left is an unidentified late 19th century site; the two other targets are yet to be located.

Upon inspection of the two magnetic targets, two separate wreck sites were identified. One had coins dating no later than 1816 , confirming that the wreck was the Correio da Azia. The other wreck is still unidentified, dating from the third quarter of the 19th century. The Correio da Azia had iron ballasts and two small guns and an anchor (Fig. 7). Similarly, the unidentified site had several large anchors providing a similar sort of anomaly. This project clearly demonstrated that a small site with just approximately a tonne of iron could easily be detected with a low-flying aerial magnetometer, opening the way to further employment of the technique.

\section{Metal Detectors}

Metal detectors have a limited application in searching for sites underwater because the detection range is relatively small. They are more useful for finding small to medium sized buried objects and for defining the extent of a located site. The most recent underwater metal detectors even have the ability to discriminate between ferrous and nonferrous material. The metal detector can also be used in conjunction with a magnetometer survey on a wreck site; this combined use of metal detectors and magnetometers was undertaken on both the Kyrenia (Fig. 8) and the Amsterdam wrecks (see above). 


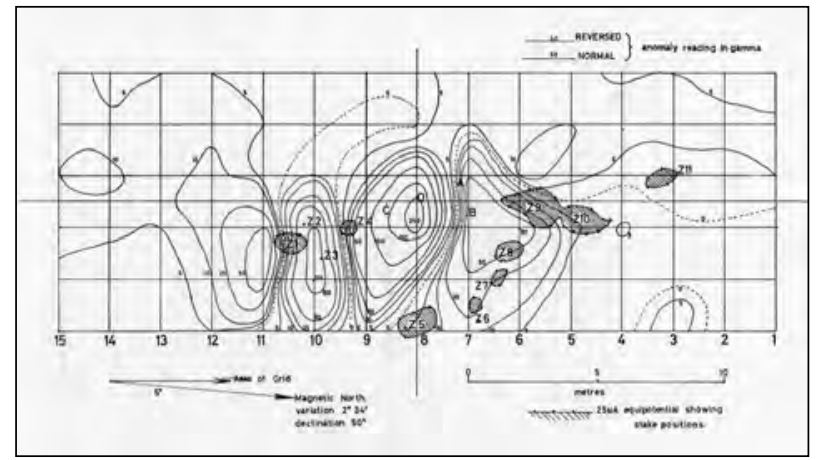

Figure 8. Kyrenia shipwreck showing the combined magnetometer and metal detector surveys allowing discrimination of non-ferrous material (lead sheeting). $\mathrm{Z1}$ and $\mathrm{Z4}$ are ferrous targets, the rest are non-ferrous.

\section{Side Scan Sonar}

The side scan transducer emits a fan-shaped pulse of sound that has a narrow beam width in the fore and aft directions and a wide beam width laterally. The fan shaped beam lies in a plane at right angles to the track of the tow-fish and the centre of the beam is directed slightly downward from the horizontal toward the maximum anticipated range. Nonlinear time-variable amplification enhances the signals coming from distant objects and compensates for strong near-field signals. The unit records the intensity of the return of the timevariable signal.

In the case of a towed fish, the trace displays three elements: the seabed, the water surface and a shadow picture of the seabed. Interpretation of the record is often quite complex and the side scan is best operated over a smooth sandy seabed in flat calm conditions. The system is generally interfaced with a GPS, so that the image trace is created to scale usually on an underlying map. As the sonar image is to scale, the trace of the target can be measured and its dimensions determined without having to dive on it (Figs 9-10).

Where there are rocks, the signal from cultural remains - even quite large iron wrecks - are difficult to detect. Additionally, if there are any swell or windblown waves, this can cause the fish to yaw and create surface return noise that obscures the bottom trace. Thus, at times, even very large sites can be

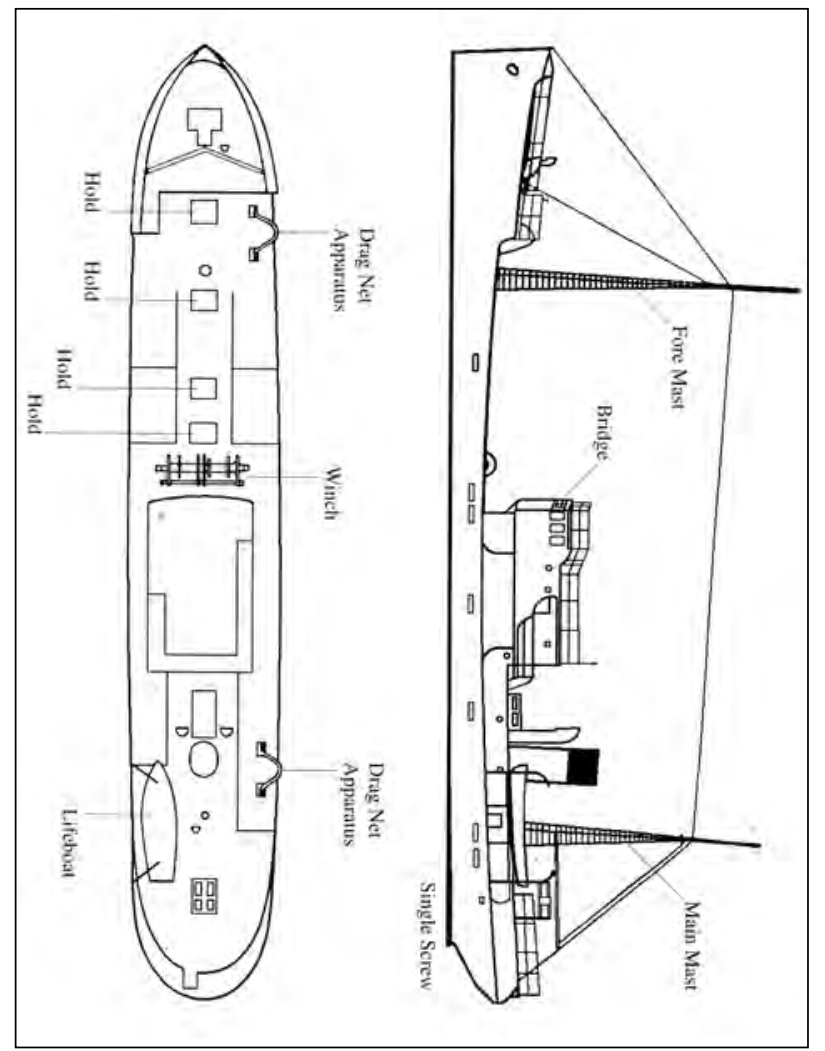

Figure 9. Side scan sonar trace of the Sapporo Maru, Truck Lagoon. This vessel was one of the few vessels that had not been found and this sonar trace was the first indication of the vessel since its loss in 1944.

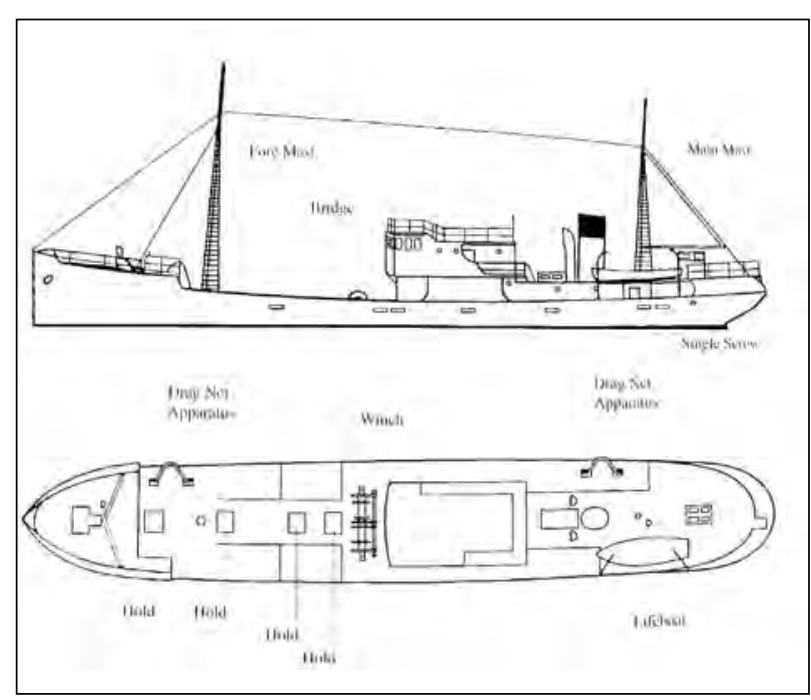

Figure 10. Plan of the Sapporo Maru from Bailey 2000:440. 


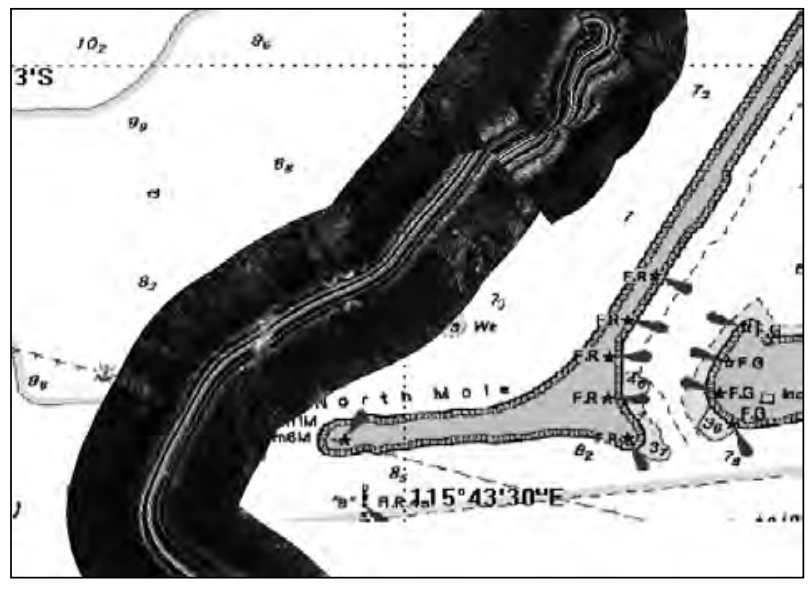

Figure 11. Sonar mosaic superimposed on a GIS showing the North Mole Barge, off Fremantle, Western Australia.

missed due to these effects. Most side scan sonar systems that can be deployed from a small boat by hand have ranges up to about $500 \mathrm{~m}$ on either side of the fish. The range is related to the frequency that the transducer operates: the higher the frequency, the shorter the range, but the higher the resolution. Thus a $150 \mathrm{KHz}$ system usually has a maximum range of about $750 \mathrm{~m}$ and is able to detect objects about $0.5 \mathrm{~m}$ in size. A $900 \mathrm{KHz}$ system would have a range of about $50 \mathrm{~m}$ and a resolution of about 1 $\mathrm{cm}$. The side scan sonar can be highly sophisticated deep-water systems that are extremely expensive, weigh hundreds of kilograms and require deck winches.

One of the most interesting developments with side scan sonar is the ability to georeference the sonar images. This means that - as the side scan sonar is constantly monitoring position - the location of the source of the sonar image is known for each sonar "ping", given that the beam extends outwards, but is extremely narrow in longitudinal direction. As the course is known, the azimuth or direction of each narrow beam sonar ping is known. Since the range is also known, it is possible to track the path of the sonar sweep (Fig. 11). For each point on the graphic image of the seabed that is output from the side scan sonar, a precise location can be given. With additional processing it is then possible to take the graphic image (usually a tiff or jpeg file) and georeference it. Thus, when the image is displayed, it is shown in its correct orientation.

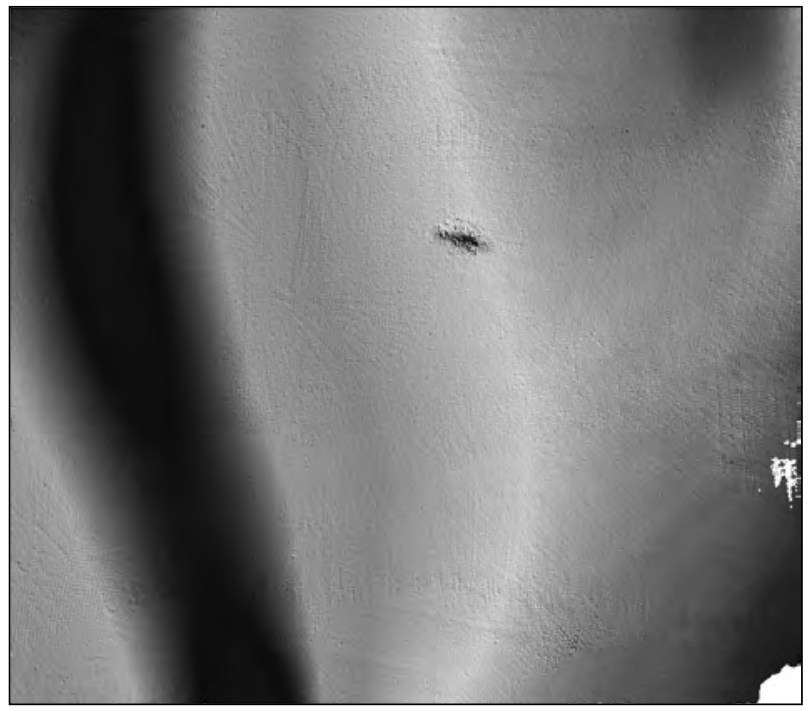

Figure 12. A multibeam image of HMAS Derwent in 200 $m$ of water (Courtesy of RAN Hydrographic Department).

\section{Multibeam}

A recently developed system for surveying the seabed is the multibeam sonar. This system is widely used in hydrographic survey work but, although excellent for logging the depth of large areas of seabed, its underwater archaeological applications are limited (Fig. 12). Multibeam sonar systems transmit a fan-shaped acoustic signal similar to that of the side scan sonar. Instead of continuously recording the strength of the return echo, the multibeam system measures and records the time for the acoustic signal to travel from the transmitter (transducer) to the seabed (or object) and back to the receiver. The system has a large number of receivers that record the angle of arrival of the signal; the system then calculates the depth at seabed from the timeand the angle of return of the signal. Multibeam sonar systems are generally attached to a vessel rather than being towed like a side scan, so it is also necessary to be able to precisely measure the motion of the sensor relative to the surface of the earth. The coverage area on the seafloor is dependent on the depth of water. Typically the greater is the depth, the less is the resolution; for example, in $200 \mathrm{~m}$ of water it is just possible to determine the outline of a large ship. The multibeam can be used to generate a three dimensional image of the seabed features and create depth contour plots or alternatively an image of a wreck site. 
Remote Sensing in Maritime Archaeology, from the Slide Rule to the Supercomputer J eremy N. Green

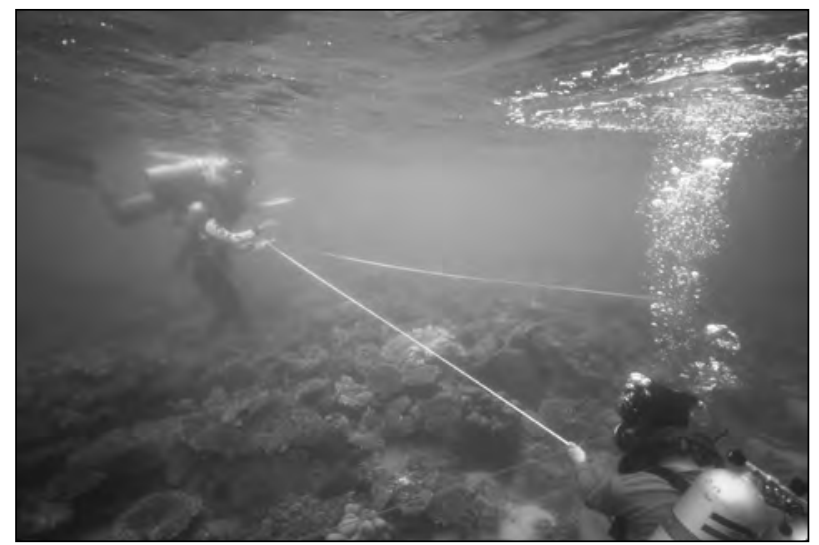

Figure 13. Simple trilateration on a wreck site using tape measures.

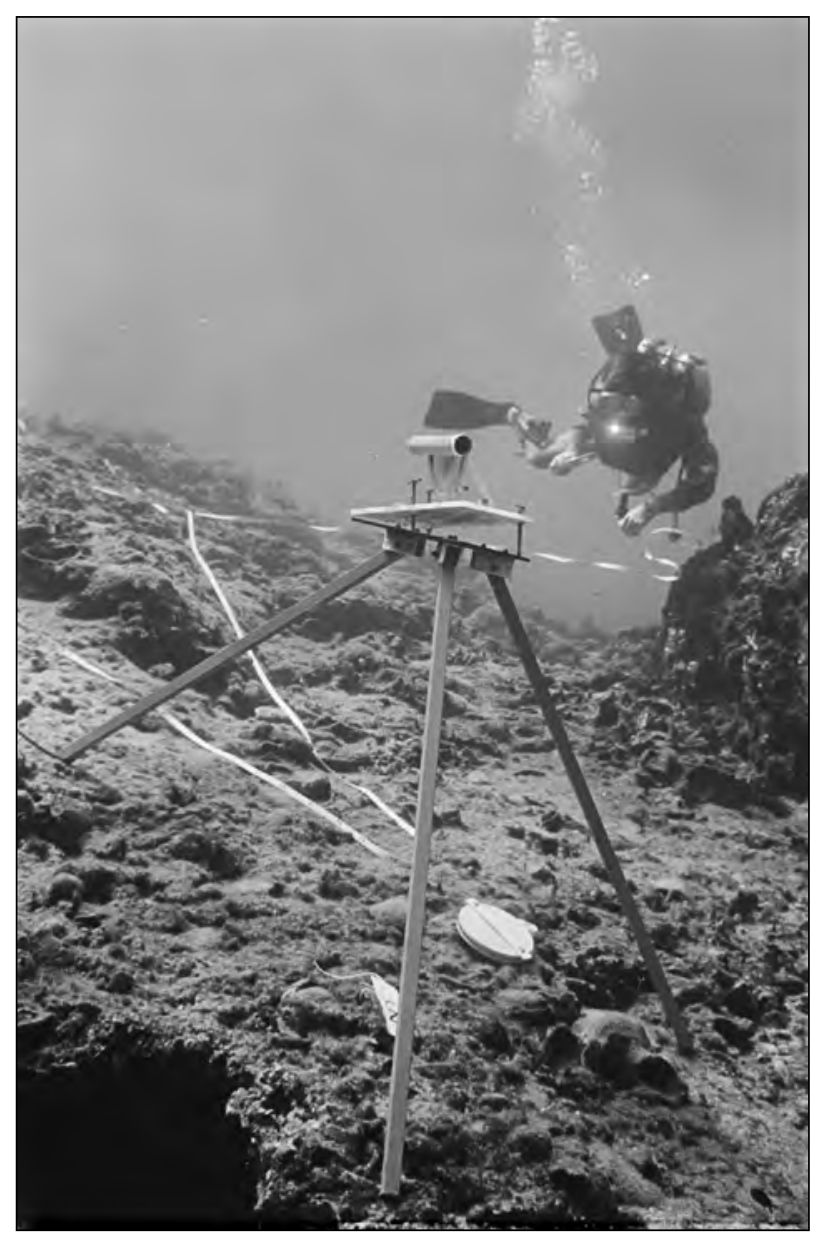

Figure 15. A simple underwater theodolite being used to record a site.

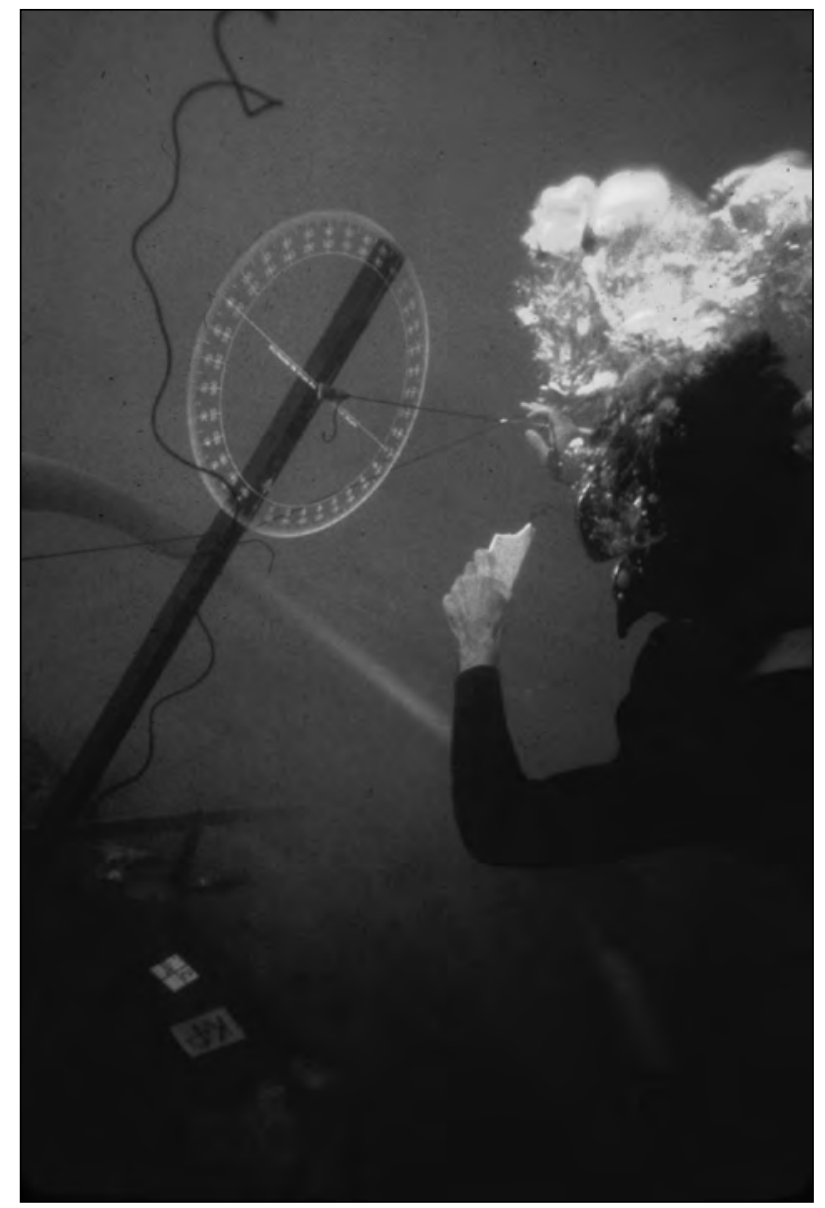

Figure 14. A simple angle measuring device being used to record the hull of a shipwreck.

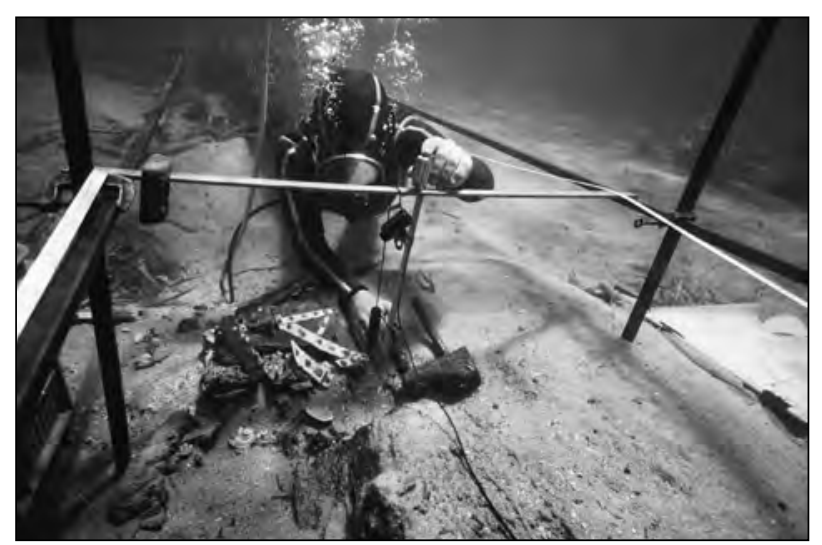

Figure 16. A three-dimensional recording system. 


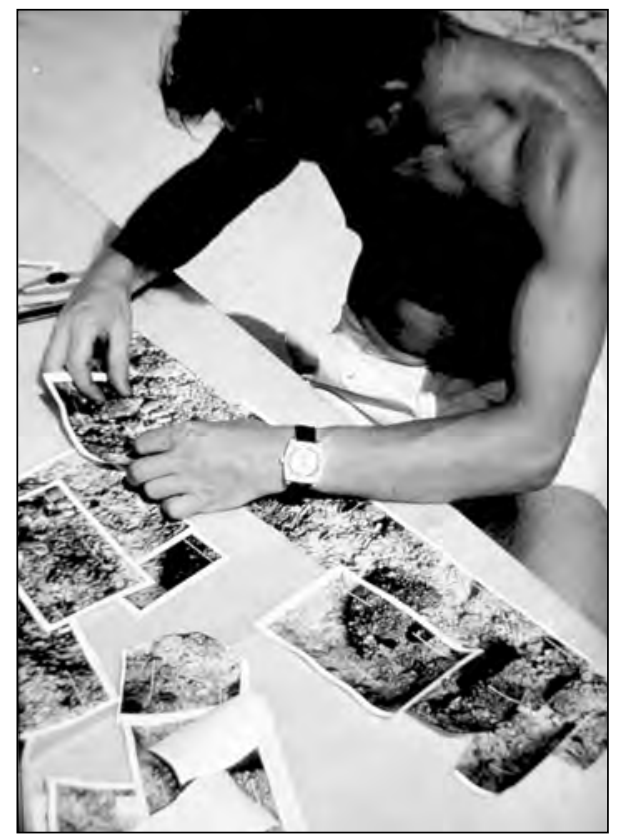

Figure 17. Above. Laying up a photomosaic in the old way.

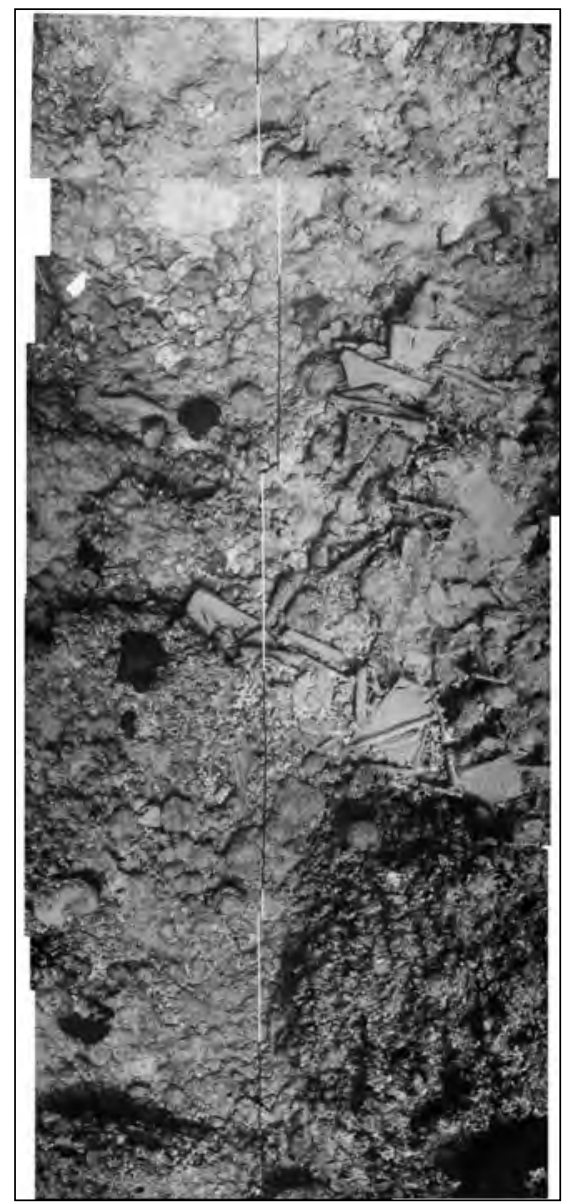

\section{Recording Sites Manually}

From the onset of archaeologists working underwater the tape measure has been the primary measuring tool. Surveying using tape measures is usually carried out as trilateration, from a number of fixed points (Fig. 13). Angle measuring devices can also be used and these range from the simple (Fig. 14 ) to the complex. In some cases preliminary site plans are often made using distance-offset, where the offset from a base line records the location of objects. Various options can also be utilised with varying degrees of accuracy including distanceangle, underwater non-optical theodolites (Fig. 15) and profiling devices using spirit levels (Leonard and Scheifele 1972). More sophisticated surveying methods, particularly for hull structures, included rigid grid frames (Fig. 16) to obtain Cartesian X Y $Z$ coordinates (Henderson 1976). In the early days, three-dimensional trilateration was extremely difficult: often five tapes were used to obtain redundancy in the measurements, an approach that was cumbersome and time consuming. In addition tapes were affected by currents and are difficult to use in poor visibility conditions. More recently, a number of software packages have been developed to improve the accuracy of the recording system, particularly by enabling large numbers of measurements to be processed to provide information on potential bad measurements (Holt 2003).

Alternative methods of recording sites have been investigated and used; these include sonar position fixing systems (Atkinson, Duncan and Green 1988) and photographic measuring (see 8).

\section{Recording Sites Photographically}

With the advent of good underwater cameras, recording sites has become more feasible and photomosaicing easier to perform. Initially, photomosaics were produced by taking vertical or near-vertical photographs of - say - a wreck site and then printing the images and pasting them onto a baseboard to form a mosaic (Fig. 17). The process was tedious and time consuming, but at least did

Figure 18. Right. A photomosaic of a wreck site at Cape Andreas, Cyprus, recorded in 1970 and created using modern computer software mosaicing program. 


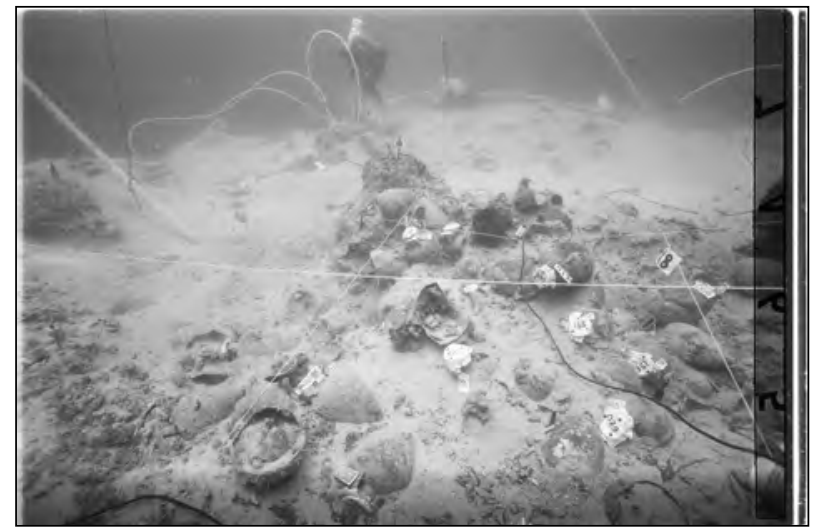

Figure 19. Photograph used in the PhotoModeller program to produce three-dimensional plans of a wreck site.

produce a good visual representation of a site, provided there was not a lot of vertical elevation. Because of perspective distortion it was only possible to produce a photomosaic of something that has a small amount of elevation in it, so the technique had limitations. Initially, photogrammetry was used largely in the aerial mapping field, but simple photogrammetric methods started soon to be used to record archaeological sites underwater. With the advent of the digital imagery, a number of lowcost programs became available to speed up the mosaicing process, presenting new opportunities for the archaeologist working underwater (Martin and Martin 2002). In addition, digital cameras

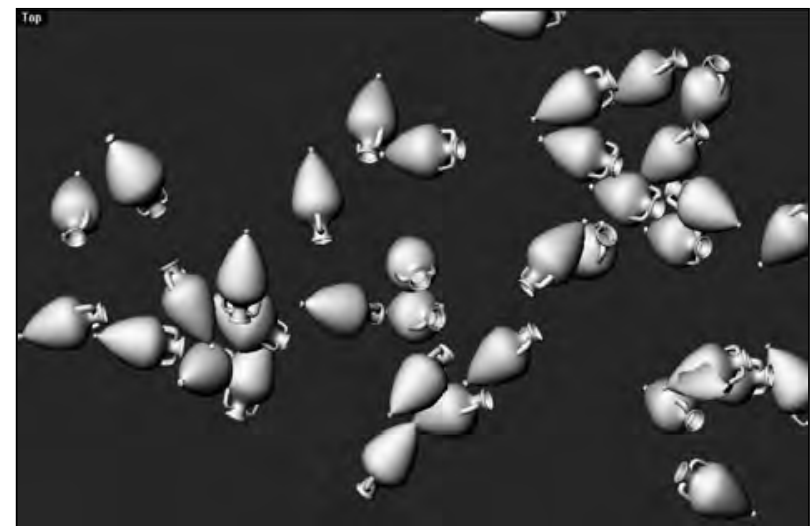

Figure 20. A three-dimensional plan of an amphora wreck in Turkey.

speeded up the imagery management process, making images almost instantly available. Today, an array of programs make the process of producing a photomosaic almost automatic, so that few minutes after the image recording a photomosaic can be obtained (Figs 17- 18).

Various photogrammetric programs (such as PhotoModeler - see PhotoModeler 2014) are available that enable a series of photographs to be used to create a three dimensional model. This technique can be used in a number of different ways: it can, for example, speed up the procedure of recording amphorae on a wreck site. This

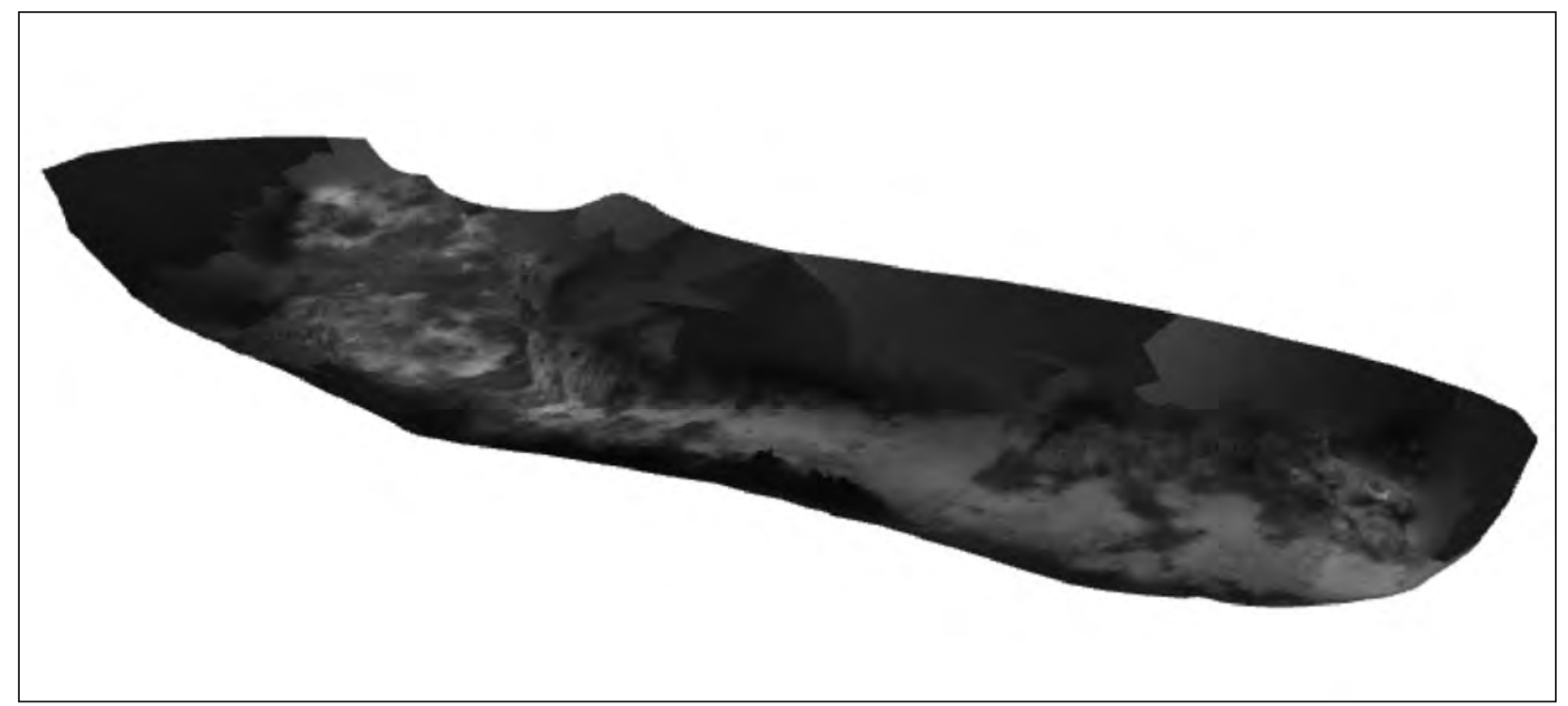

Figure 21. A active three-dimensional plan of a wreck site in Malta taken with 120 photographs and processed using the software Agisoft Photoscan (Agisoft 2014). 
Across Space and Time. Papers from the 41st Conference on

Computer Applications and Quantitative Methods in Archaeology. Perth, 25-28 March 2013

\begin{tabular}{|c|c|c|c|c|c|}
\hline Survey type & $\begin{array}{c}\text { Approximate } \\
\text { RMS accuracy } \\
\text { (mm) }\end{array}$ & $\begin{array}{c}\text { Survey time } \\
\text { (minutes) }\end{array}$ & $\begin{array}{c}\text { Set up } \\
\text { survey } \\
\text { (minutes) }\end{array}$ & $\begin{array}{c}\text { Processing } \\
\text { (minutes) }\end{array}$ & $\begin{array}{c}\text { Total } \\
\text { (minutes) }\end{array}$ \\
\hline Inter-point hand-measurement land & 0 & 96 & 0 & 30 & 126 \\
\hline Inter-point hand-measurement UW & 20 & 86 & 0 & 30 & 116 \\
\hline Control point hand-measurement UW & 37 & 100 & 10 & 30 & 118 \\
\hline PhotoModeler Land & 14 & 10 & 0 & 25 & 35 \\
\hline PhotoModeler UW & 18 & 10 & 0 & 25 & 35 \\
\hline
\end{tabular}

Table 1. Tabulation of five different survey methods on a three-dimensional rigid tower: two methods were used on land and three underwater. Inter-point hand measurements were taken on land (taking measurements between all the points on the tower and then running through SiteSurveyor program to calculate positions and errors). This was taken as the reference and the survey techniques were compared for accuracy against this information; additionally, the time taken to complete the different surveys was noted.

apparently simple operation, if manually operated, would require over 15 measurements with a tape measure in order to record the location of a single amphora and take up over 30 minutes of a diver to be accomplished; using photogrammetric software instead the whole process can be completed in a few minutes and quickly applied to record any number of amphorae (Green, Matthews and Turanli 2002) (Figs 19-20).

An investigation of the relative efficiency of traditional survey methods using tapes compared with photographic techniques using Photomodeler showed that there was a considerable advantage in using the photographic method, both in time and accuracy (Green and Gainsford 2003). The results are tabulated in Table 1 (below) and indicate that - provided environmental conditions, such as visibility, are sufficiently good - , photogrammetric software such as Photomodeler ensure a better accuracy than manual recording and a considerable reduction of time spent underwater.

Digital programs continue to evolve rapidly and there is currently a number of programs that create three-dimensional images of sites (such as PhotoScan - Agisoft 2014). A series of photographs taken of a site can be processed and such images can be manipulated and measurements taken from them (Fig. 21).

To some extent, such techniques have made the more traditional photogrammetric techniques obsolete. Where once photogrammetry involved huge analogue machines, that with the advent of sophisticate computing became obsolete, so too today the development of image recognition technology - whereby the program recognises similar features on multiple images - has created a range of new technologies.

\section{Collating Information with GIS}

For the archaeologist, technology is simply a tool that makes one's life easier. Interpretation of archaeological information is still required and, to date, no computer program can do that. However, the ability to visualise sites and excavation information in a presentation different from a twodimensional layered form - as supplied by GIS - is a huge advantage. GIS enables multiple layers of geographical information to be displayed so that it can be easily analysed and managed. The GIS is particularly useful for underwater cultural heritage managers who need to have a clear idea of the extent of cultural features and the impacts that are likely to affect them. For the archaeologists, likewise, the merging of geographical information such as maps and aerial photographs - with other spatial information - such as site plans and survey information - allows data to be better visualised. The growing availability of public domain data including historical maps and aerial photography, bathymetry, charts and maps allows new opportunities for the realisation of GIS. The GIS is also helping to bridge gaps between different types of archaeology, and is particularly relevant in the rapidly developing field of underwater cultural landscapes, where the previous division between terrestrial and marine no longer exists. 


\section{References}

Agisoft. 2014. “ Agisoft PhotoScan.” Accessed March 15. http:// www.agisoft.ru/products/ photoscan/ standard/ .

Atkinson, K., A. Duncan, and J. N. Green. 1988. “The application of a least squares adjustment program to underwater survey." International J ournal of Nautical Archaeology 17:113- 118.

Bailey, D. E. 2000. World War II Wrecks of the Truck lagoon. Redding: North Valley Diver Publications.

Bass, G. F., and M. L. Katzev. 1968. "New tools for underwater archaeology." Archaeology 21:164- 173.

Freeth, T., and A. Jones. 2012. "The Cosmos in the Antikythera Mechanism." Institute for the Study of the Ancient World Papers 4. Accessed March 15, 2014. http:// dlib.nyu.edu/awdl/isaw/ isaw-papers/4/ .

Green, J. N. 1990. Maritime archaeology: a technical handbook. London: Academic Press.

Green, J . N. 2002. "Side scan sonar and magnetometer for locating archaeological sites." Bulletin of the Australasian Institute for Maritime Archaeology 26:119- 131.

Green, J. N. 2004. Maritime archaeology: a technical handbook. London: Elsevier.

Green, J. N., and M. Gainsford. 2003. "Evaluation of underwater surveying techniques." International J ournal of Nautical Archaeology 32:252- 261.

Green, J. N., E. T. Hall, and M. L. Katzev. 1967. "Survey of a Greek shipwreck off Kyrenia, Cyprus." Archaeometry 10:47- 56 .

Green, J. N., S. Matthews, and T. Turanli. 2002. "Technical communication: underwater archaeological surveying using PhotoModeler, VirtualMapper: different applications for different problems." International J ournal of Nautical Archaeology 31:283- 292.

Hall, E. T. 1966. "Use of Proton Magnetometer in Underwater Archaeology.” Archaeometry 9 (1):32- 44.

Henderson, G. 1976. "James Matthews excavation, summer 1974. An interim report." International J ournal of Nautical Archaeology 5:245- 51.
Holt, P. 2003. "An assessment of quality in underwater archaeological surveys using tape measurements." International Journal of Nautical Archaeology 32 (2):246- 251.

Leonard, P., and S. Scheifele. 1972. "An underwater measuring device." International Journal of Nautical Archaeology 1:165- 169.

Marsden, P. 1985. The wreck of the Amsterdam. London: Hutchinson.

Martin, C. J . M., and E. A. Martin. 2002. “An underwater photomosaic technique using Photoshop." International J ournal of Nautical Archaeology 3:137- 147.

PhotoModeler. 2014. " PhotoModeler.” Accessed March 15. http:// www.photomodeler.com/ products/modeler/ default.html. 


\title{
The Story Beneath the Canopy: an Airborne Lidar Survey Over Angkor, Phnom Kulen and Koh Ker, Northwestern Cambodia
}

\author{
Damian Evans \\ The University of Sydney, Australia \\ Kasper Hanus \\ The University of Sydney, Australia and J agiellonian University, Poland \\ Roland Fletcher \\ The University of Sydney, Australia
}

\begin{abstract}
:
In the last hundred and fifty years several projects of archaeological mapping have been undertaken at the site of Angkor, in northwestern Cambodia. The most recent studies, conducted by the Greater Angkor Project, haverevealed thatAngkor is a vast low-density urban complex, perhaps thelargest of itskind in the entire pre-industrial world. And yet, until now, crucial areas of the archaeological complex haveremained unmapped because vegetation has obscured the surface traces of the civilisation from conventional remote sensing instruments. With a view to overcoming this limitation, we completed a large-scale airborne laser scanning (lidar) mission over Angkor in 2012. In this paper we describe the technical parameters of the mission and outline the processing routines and algorithms we used to develop our results. We present a range of preliminary outcomes of the research program, which have implications not only for understanding Angkor but also for future comparative studies of low-density urbanism in tropical forest environments.
\end{abstract}

\section{Keywords}

Remote Sensing, Urbanism, Lidar, Angkor, Cambodia

\section{Introduction and Background}

Recent projects of archaeological mapping in and around the World Heritage Site of Angkor, in Cambodia, have uncovered what is perhaps the most extensive urban complex of the pre-industrial world (Evans et al. 2007). Located on the northern shores of Cambodia's great lake, the Tonle Sap, the city of Angkor was the political, geographic and spiritual heart of the Khmer Empire from the 9th to 15 th centuries $\mathrm{AD}$. The Empire reached its apogee in the 12th to 13th centuries, at which point the sphere of influence of Khmer civilisation stretched across most of mainland Southeast Asia (Coe 2003).

Angkor has been the focus of scholarly research since the second half of the nineteenth century, but this work has often been interrupted by the turbulent political situation of Southeast

Corresponding author: kasper.hanus@gmail.com
Asia. As violence finally waned in Cambodia in the 1990 s following decades of civil unrest, field archaeologists once again turned their attention to sites such as Angkor. One of the projects established during that period was the Greater Angkor Project (GAP), a multinational collaboration between the University of Sydney (Australia), the École française d'Extrême-Orient (France) and the APSARA National Authority (Cambodia). Now in its fifteenth year, GAP has produced a large body of work dealing with human-environment interactions and the trajectory of urban growth and decline in medieval Cambodia. GAP is one component of a broader, global collaboration seeking to understand the nature of low density urbanism in tropical forest environments (Fletcher et al. 2006).

GAP research activities include excavations, surface surveys and a suite of remote sensing techniques encompassing numerous sensors and 


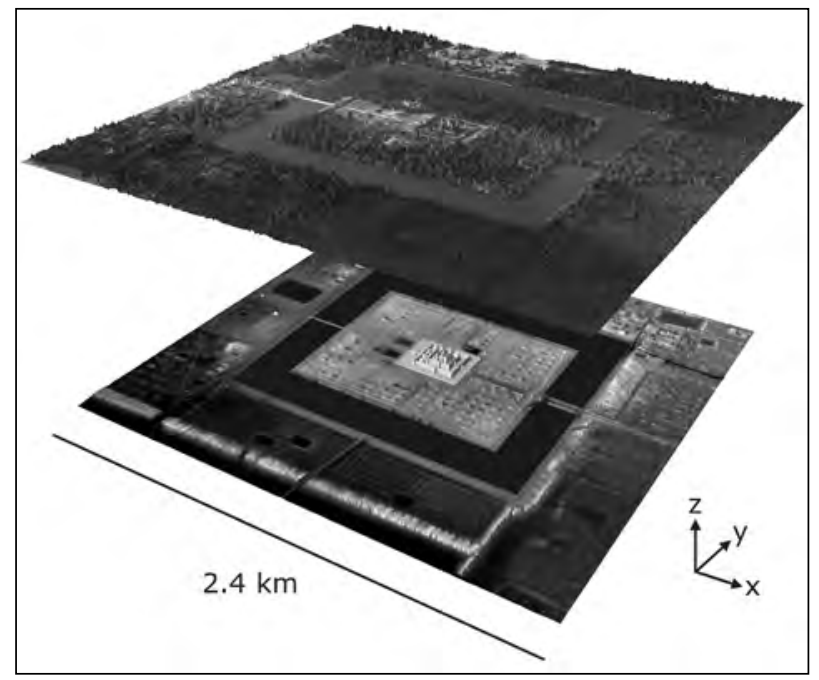

Figure 1. An oblique view of Angkor Wat and its immediate environs. Top layer: Digital orthophoto mosaic, with elevation derived from the lidar digital surface model at $1 \mathrm{~m}$ resolution. Bottom layer: extruded lidar digital terrain model, with $0.5 \mathrm{~m}$ resolution and $2 x$ vertical exaggeration. Red lines indicate modern linear features including roads and canals.

platforms (Evans et al. 2007; Evans and Traviglia 2012; Evans and Moylan 2013). Applications of remote sensing at Angkor have conventionally revolved around mapping and analysing the spatial patterning of surface topographic variations, or 'archaeological topography'. These analyses reveal the fabric and structure of long-disappeared urban networks; even if the built environment of Angkor was comprised of non-durable materials such as wood and thatch, it is possible to discern the remnant traces of occupation mounds, ponds, roadways, canals and other features on the surface of the landscape even centuries later.

One of key limitations of this program, however, has been the inability to 'see through' the vegetation that covers a significant percentage of the Angkor area, in particular the dense dipterocarp forest that blankets the central monumental zone. Large areas of white space have remained on archaeological maps, and thus, characterisations of Angkor's urban morphology have always remained qualified and partial (Evans et al. 2013). In 2011 and 2012, in an effort to solve this longstanding problem, researchers from GAP launched an initiative to take advantage of the unique vegetationpenetrating capabilities of airborne laser scanning

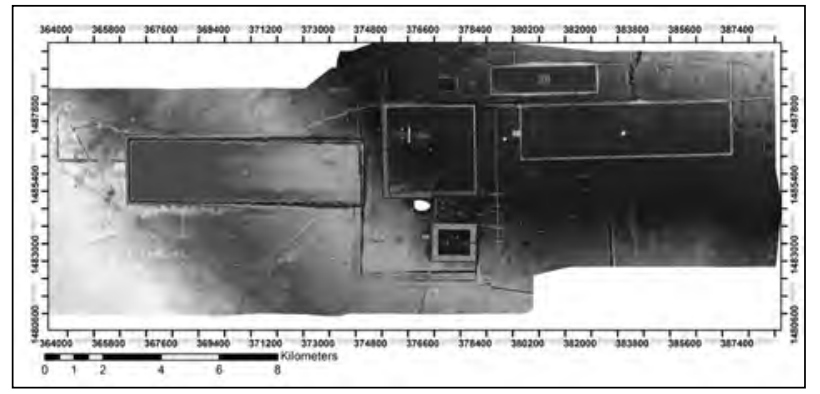

Figure 2. Lidar acquisition block at Angkor covering the main cluster of monumental architecture: Angkor Wat (in the south), the walled city of Angkor Thom (central part of image), Preah Khan (in the north), assorted state temples and vast artificial water reservoirs (or "baray"). The length of the runway of Siem Reap International Airport, lying just south of the West Baray, gives a clear sense of the tremendous scale of engineering works at Angkor. Coordinates are UTM/WGS84.

(lidar). A research partnership was developed with international partners within the framework of the Khmer LiDAR Archaeology Consortium (KALC), consisting of the APSARA National Authority (Lead GovernmentPartner), the University of Sydney (Lead Technical Partner), the École française d'ExtrêmeOrient (Lead Administrative Partner), the Société Concessionaired'Aéroport, theHungarian Indochina Corporation, J apan-APSARA Safeguarding Angkor, the Archaeology and Development Foundation, and the World Monuments Fund. In April of 2012, KALC successfully completed an extensive, highresolution lidar survey covering $370 \mathrm{~km}^{2}$ of Angkor and areas in the extended region around Angkor, notably the 8th-9th century capital of Phnom Kulen (or "Mahendraparvata") and the ephemeral 10th century capital of Koh Ker (Evans et al. 2013).

\section{Methods}

The KALC acquisition of April 2012 was, to our knowledge, the first bespoke archaeological lidar project ever undertaken in Asia (Opitz and Cowley 2013), and was at the time the most extensive archaeological lidar acquisition ever completed. The survey zone covers not only the well-known central monuments of Angkor such as Angkor Wat (Fig. 1), Angkor Thom and Ta Prohm but also medieval urban and agricultural landscapes, some of which are now covered by dense vegetation (Fig. 2). The survey was carefully timed to coincide with the transition from the dry season to the wet season, in 
order to mitigate the potential for various factors to degrade the quality of the final dataset. In April, early rains have extinguished most of the fires lit by farmers for the annual dry-season burn-off. The rains also helped to settle much of the haze that is created both by that burn-off and also by the wind-blown dust from the arid Cambodian landscape. On the other hand, in the month of April these early rains have not yet produced substantial regrowth of understory or of leaf cover in deciduous forests, and thus April presents a unique window of opportunity for archaeological lidar missions in this part of Southeast Asia. Twenty hours of flight time were undertaken between the 16th and the 22nd of April, with the Leica ALS60 lidar instrument mounted to a Eurocopter AS350B2 and collecting in full waveform mode. The waveform data were not used for the purposes of this analysis and will be the focus of further investigation. The waveform data were pre-discretised into several billion individual measurements, and further classified into 'ground' and 'non-ground' returns in a Terrascan environment (Axelsson 2000). The ground returns were the most significant from an archaeological point of view; these averaged two points per meter squared across the entire acquisition area, with a vertical and horizontal accuracy of $15 \mathrm{~cm}$ or better.

The lidar survey was complemented by the acquisition around 5000 high-resolution vertical aerial photographs using a conventional camera, with a resolution of approximately $10 \mathrm{~cm}$ per pixel. These were roughly georeferenced using Global Positioning System (GPS) data from the aircraft and camera parameters, to allowassessment of local land use/land cover conditions and adjust classification parameters during the point classification process in Terrascan. Resources were not devoted to precisely georeferencing or orthorectifying these images; the lidar acquisition was concentrated in forested areas, so the aerial photographs usually provide little more than an overview of canopy and were considered to be of minimal archaeological value. Exceptions were made for photographs acquired directly over the major temple sites (Fig. 1); these were handgeoreferenced against lidar data in an ArcGIS environment.

The classified point data was processed into ASCII, LAS and Terrascan BIN formats. A geodatabase was created in ESRI ArcGIS 10.1 software to provide a working space for further interpretation and visualisation. For convenience the geodatabase was divided into eight blocks (Angkor, Phnom Kulen, Koh Ker, Lovea, the North Channel, Roluos, the East Road and Beng Mealea), with each block containing three basic data products processed from the ground points: a "terrain" dataset (ESRI 2012) including a triangulated irregular network (TIN); a $1 \mathrm{~m}$ resolution raster digital terrain model (DTM) derived from the TIN using the linear interpolation method; and a $1 \mathrm{~m}$ resolution hillshade model derived from the DTM, with light coming from the NW and an angle for the light source of $45^{\circ}$ up from the horizon. The terrain dataset has proven particularly useful both as a visualisation method and as a tool for analysis: it represents TIN data with varied levels of detail in different scales, so working on large areas is still possible on less powerful computers. In our opinion, working directly on the TIN (rather than processed raster data products) offers the end-user a superior understanding of the structure of the topographic relief. Thevertices of the TINarecapableof providing better information about specific points of reflected laser light (Crutchley and Crow 2009, 10), allowing one to interpret topographic anomalies with greater certainty. The $270^{\circ}$ (NW) light azimuth used for most analyses was determined by the structure of Angkor's urban and religious landscape, in which most features are rectilinear and orientated to the cardinal directions. However, some feature types are less likely to be strictly cardinally-oriented (in particular highways and canals, which often conform less to the dictates of sacred geography), and thus additional hillshade models were required using different angles of illumination (Fig. 3). Using these analytical techniques, traces of Angkor-period human activity could still be clearly discerned as topographic features including platforms, ponds, embankments and channels.

The programs of airborne scanning and deskbasedanalysiswerefollowedbyaprogram ofintensive ground verification of newly-identified features, using methods such as ground survey, coring and test trenching ( $1 \mathrm{x} 1 \mathrm{~m}$ or $1 \mathrm{x} 2 \mathrm{~m}$ units). In addition to confirming the antiquity of topographical anomalies, these ground-based methods also provided critically important information on the ability of lidar to penetrate different kinds of tropical vegetation. Presently, most of the central monumental zone 


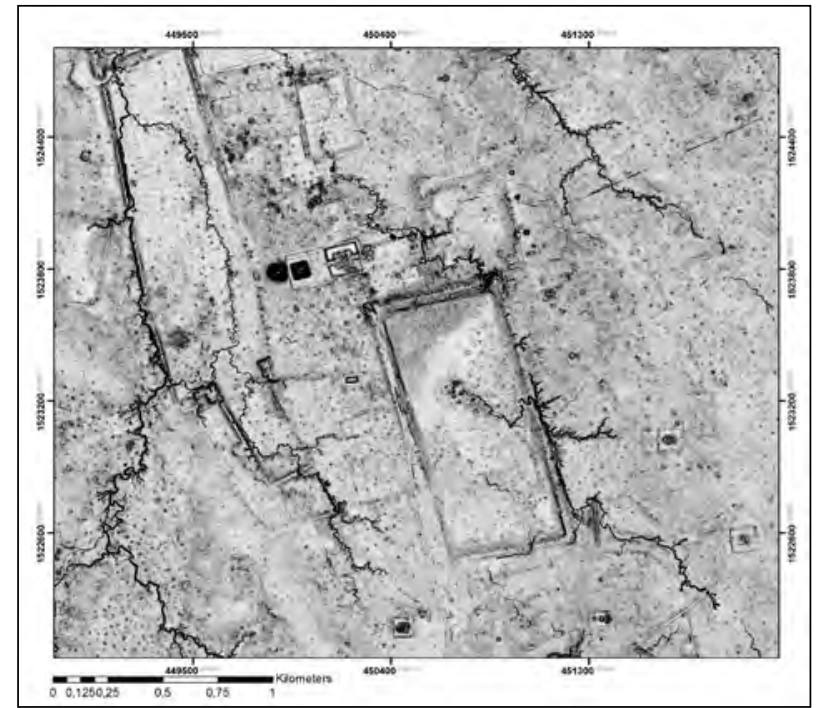

Figure 3. The naturally-undulating topography of Koh Ker, $80 \mathrm{~km}$ northeast of Angkor, demanded additional elaboration of lidar visualisations. Sky-view factor (Kokalj, Zakšek, and Oštir 2011) was applied to exaggerate discrete features such as rice field boundaries or water management infrastructure. Such features illustrate the extensive economic hinterland for this 10th century capital of the Khmer Empire. Coordinates are UTM/WGS84.

of Angkor is covered with secondary rainforest, where dense canopy inhibits the development of a dense understory; in these areas, our classification routines provided a relatively unproblematic distinction between ground and non-ground points, and micro-topographic relief of archaeological interest was clearly visible. However, our survey area encompassed a wide range of vegetation types (Fig. 4), some of which proved to be far more problematic for laser penetration than dense forest canopy. In the Phnom Kulen area, for example, the forest is heavily disturbed due to selective logging and clearance for swidden agriculture. Succession in these areas is characterised by the growth of a dense layer of shrubs and ferns at low height (typically less than $2 \mathrm{~m}$ ), and this frequently remains as 'noise' within the classified ground dataset. Another area with a particularly dense understory was the treed southern embankment of Angkor's largest reservoir, the West Baray, where low-lying bushes (up to 2-3 m) provided an almost impenetrable barrier against laser pulses reaching the ground. Similarly, areas of open fields are occasionally dotted with bushes and low-lying trees with dense foliage, and these too

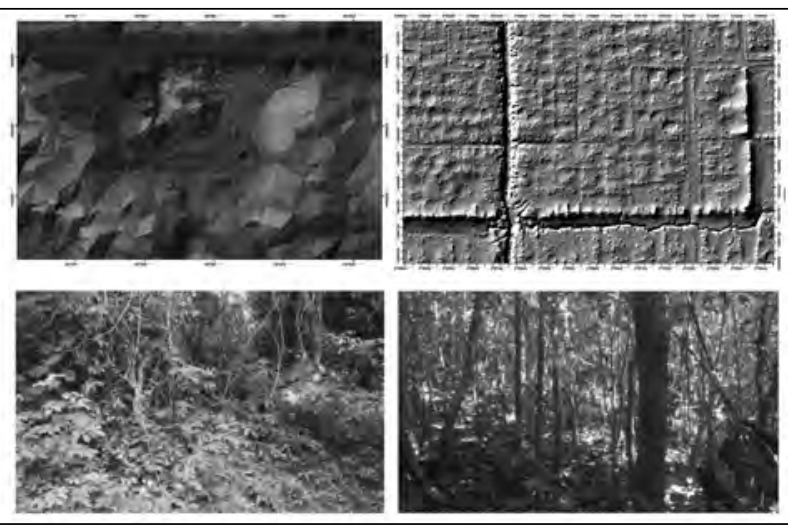

Figure 4. Tropical vegetation cover demonstrates a high degree of spatial variability depending on soil moisture, angle of slope, or soil type. Thus vegetation cover is characterised by variable density which in turn affects the ability of the laser pulses to penetrate to the ground. This figure illustrates how different types of shrubs and trees influence lidar ground returns. Bottom left: dense shrubs of few meters height at the temple of Ak Yum, which is partially buried under the embankment of the West Baray. Top left: a TIN of the area around Ak Yum shows how patches of low-lying vegetation can result in poor-quality data products. Bottom right: Secondary forest in the vicinity of Ta Prohm temple. Top right: a hillshade model of terrain covered by secondary forest in the vicinity of Ta Prohm temple, showing the ground with exceptional clarity. Coordinates are UTM/WGS84.

often confused the ground-classification algorithm and manifested as noise within the DTM product. Preliminary work in 2013 suggests that these issues may be resolved in the future though continued processing of the full waveform data (Lasaponara, Coluzzi and Masini 2011).

\section{Results and Discussion}

The principal objective of the lidar survey was to further illuminate the structure of the denselypopulated and heavily-vegetated urban core of Angkor, and also the dispersed, low density urban complex that stretched for hundreds of square kilometres beyond it. This specific type of spatial patterning is increasingly recognised as a defining characteristic of tropical urbanism in regions such as Mesoamerica, Southeast Asia and possibly also Sri Lanka (Fletcher 2012, 289). The morphology of dispersed, low-density settlement complexes is distinctly different from the preindustrial norm: 
agricultural areas are interspersed with residential areas to form an extended agro-urban settlement complex, the boundary of which is very problematic to define. Gaining an understanding of the structure of urban space over the widest possible area is therefore a crucial requirement of studies of such cities, which in turn creates a series of logistical and financial hurdles to mapping archaeological topography in an area of such size. The application of an airborne laser scanner helped to overcome these issues at Angkor, and has provided entirely new perspectives on the archaeological landscape. Preliminary results of the data analysis have revealed a vast array of archaeological features that had remained undocumented even after a century and a half of archaeological mapping projects at Angkor. Some of these features have clearly hydraulic functions, while others may be defensive. Some are clearly integral components of Angkor's residential and agricultural spaces, while others are highly atypical and have functions that cannot, for now, be conclusively determined.

The airborne laser scanning mission completed by KALC has greatly contributed to our understanding of the structure of urban form at Angkor. Previous surveys undertaken by Gaucher (2004) within the 12th century 'walled city' of Angkor Thom, combined with surveys undertaken by GAP on the agro-urban landscape of Greater Angkor (Evans et al. 2007) had clearly revealed the site as low-density urban complex with an extensive water management system and a central cluster of monumental architecture. The new lidar data confirm various elements of that interpretation: within Angkor Thom, for example, one can clearly see a formalised urban landscape covering $9 \mathrm{~km}^{2}$. It includes not only the well-known royal palace precinct and the surrounding religious architecture, but also an orthogonal network of roadways that divides the space into rectilinear 'city blocks', each of which contains a number of residential platforms and ponds. Our analysis therefore entirely affirms the previous work completed by Gaucher.

On the other hand, a major revelation from the lidar data is that this formal cityscape extended far beyond the $9 \mathrm{~km}^{2}$ enclosed city walls and 'spilled out' into extramural areas, for a total areal extent of approximately $35 \mathrm{~km}^{2}$ (Evans et al. 2013). That $35 \mathrm{~km}^{2}$ encompasses much of the area

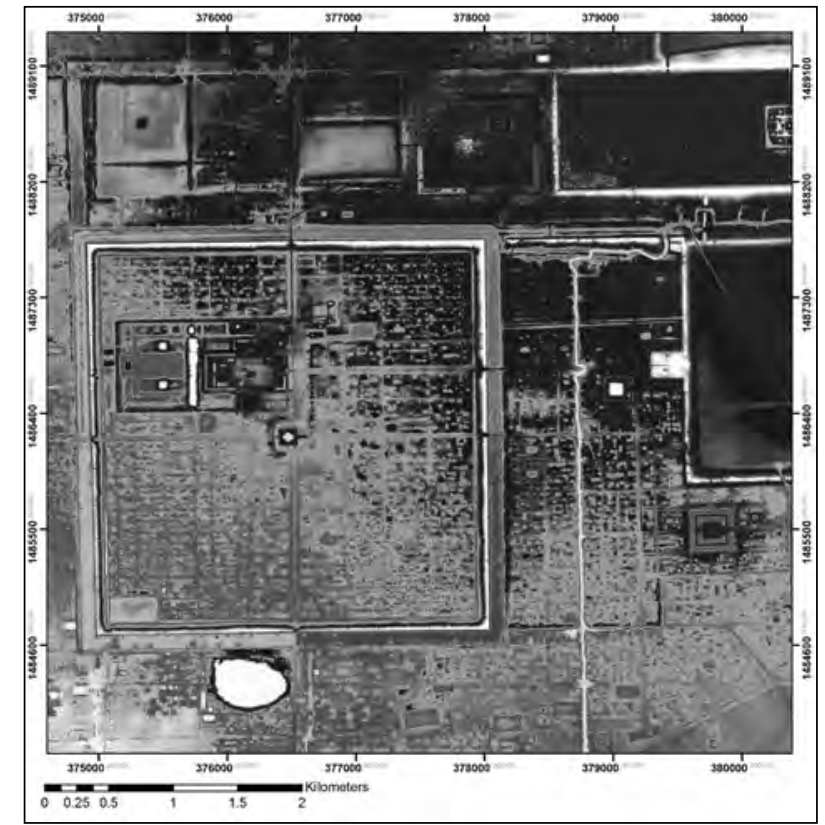

Figure 5. The urban core of Angkor, showing evidence of a much greater population density than the rest of Greater Angkor. Significantly, the lidar shows that the denselyinhabited, formally-planned urban network extended far beyond the $3 \times 3 \mathrm{~km}$ 'enclosing wall' of Angkor Thom. In fact, this central urban grid covered approximately $35 \mathrm{~km}^{2}$ and encompassed most of the major temples in the ceremonial center of Angkor. Coordinates are UTM/ WGS84.

between Angkor Thom and the East Baray (Fig. 5). In most cases the extramural urban grid does not align particularly well with the intramural grid of Angkor Thom, but in some cases one can clearly see a spatial and functional (and likely therefore chronological) relationship between features on the inside and outside of Angkor Thom's city walls. Beyond the well-planned urban core, the lidar data also confirm previous interpretations of Greater Angkor's dispersed agro-urban landscape. According to Evans et al. (2013) : “Greater Angkor was a polynuclear urban landscape, with a dense urban core and an extended agro-urban periphery containing numerous secondary, highly urbanized centres." Dating the various elements of urban form remains a major challenge at this point, considering that Angkor developed over the course of many centuries. A further elaboration of the spatial and chronological relationships between surface features will be a major focus of ongoing research at Angkor, and should help to clarify various issues 


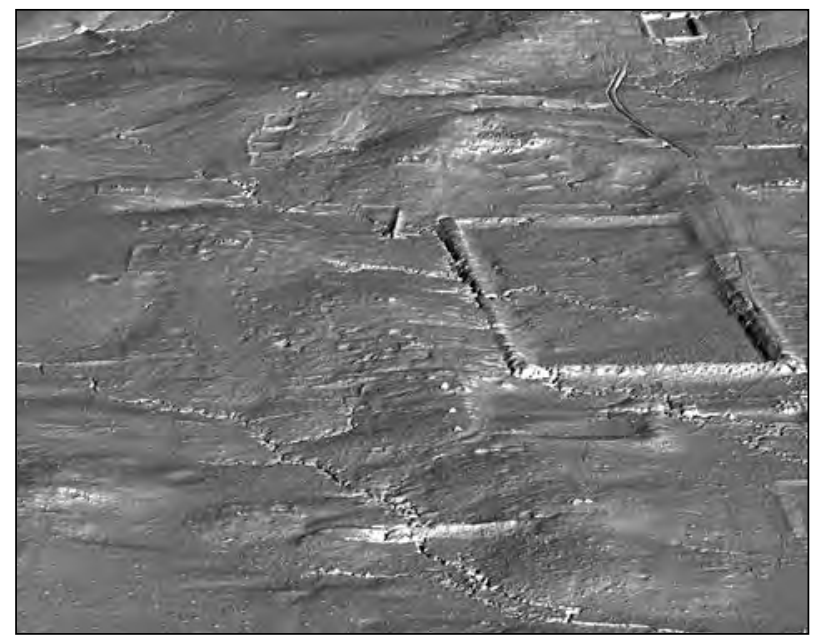

Figure 6. Three dimensional visualisation of the cityscape of Koh Ker. Hydraulic engineering revealed by lidar includes earthen dams across valleys and a substantial array of ponds and reservoirs. Prior to the Lidar program, the only major water management feature documented in the area shown here was the Rahal, which is the large $(650 \times 1300 \mathrm{~m})$ reservoir on the right side of the image.

surrounding the development of urban form over time and space.

Insights from the lidar data have not been limited to the Angkor region. In the Phnom Kulen acquisition block, the lidar reveals an entire urban landscape that almost certainly corresponds with a 8th-9th century capital called "Mahendraparvata", previously known primarily from inscriptions and temples. Our view of Mahendraparvata has been transformed from a scatter of relatively isolated points on the map, to a view of the urban fabric - occupation mounds, highways, canals, entire neighbourhoods - that stretch between and far beyond those temples (Evans et al. 2013). Similarly, a reappraisal of Koh Ker based in part on the lidar data has revealed an extensive urban landscape around main temples, surrounded by a vast network of rice fields (Evans 2010-2011). At Koh Ker, we can also see previously undocumented water management features, including numerous small reservoirs and massive dams (Fig. 6).

Some of the most valuable new perspectives from the lidar data have been in the domain of water management. Reconstruction and modelling of medieval hydrology has always been a core part of the research agenda of GAP, and this work is critical for understanding human-environment interactions and for shedding light on various issues to do with the demise of Angkor. One of the key challenges to the sustainability of civilisations in monsoon Southeast Asia is the sharp seasonality of the monsoon climate, which results in water scarcity for half of the year and an abundance of water for the other half of the year. Furthermore, annual rainfall is highly variable, and studies have shown the existence of 'megadroughts' of decades in duration in the Angkor period, with obvious implications for the sustainability of an economy based on rice agriculture (Buckley et al. 2010; Coe 2003). It is likely that the key to the success of the civilisation of Angkor - and perhaps also the key to its demise- lay in their ability or inability to develop and implement technological solutions to this core problem of water supply (Groslier 1979). Coming to terms with the structure of the water management system, and the agricultural field system that it serviced, is therefore a key component of the archaeological research agenda.

Previous studies of water management at Angkor presented schematic overviews of the development of the hydraulic network over time and space (Fletcher et al. 2008). It became clear from this work that Angkor consisted of three distinct water management zones for capture, storage and distribution. As with the structure of urbanism, however, the precise structure of the water management system was least clear precisely at the most important point - the critical juncture of those three different zones in the forested area of central Angkor. Not only are we now able to see that hydraulic structure with near-perfect clarity, but the high-resolution elevation data permits complex hydrological modelling, and we expect to refine our models of medieval water management at Angkor in the near future.

What has become clear already is that very small ponds (perhaps shared by a few households) were a ubiquitous feature within the denselypopulated urban core of Angkor. To assist with pond identification a special algorithm was developed. Thealgorithm, based on the ESRI AroGIS Hydrology Toolbox, identifies if negative relief features are able to contain water by examining if all pixels around depression have higher elevation value. This algorithm revealed several thousand ponds beneath 


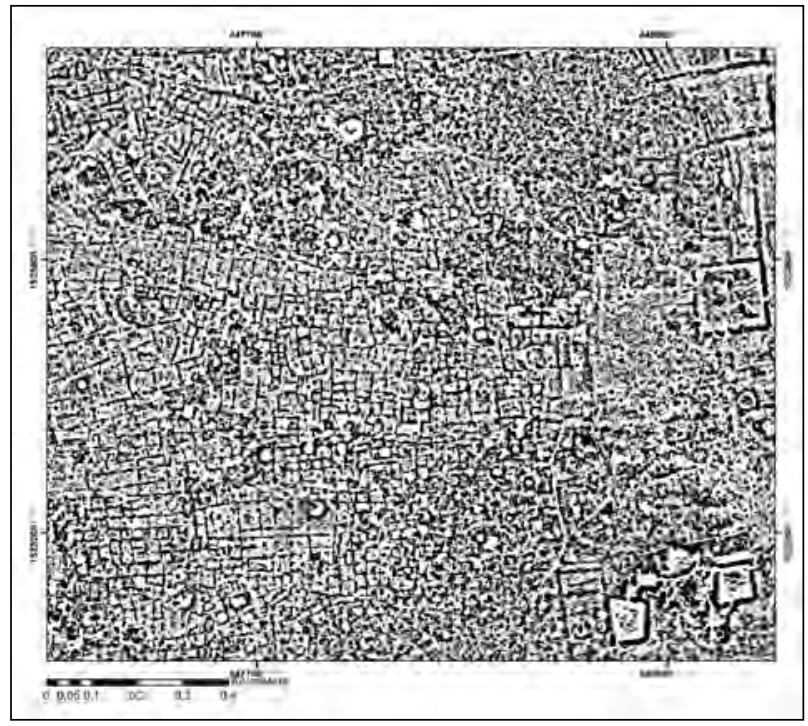

Figure 7. Local Relief Modelling (LRM) served as an effective tool for examining the extent of medieval agriculture at Koh Ker. Rice fields with $20-30 \mathrm{~cm}$ high field walls can clearly be seen in the LRM data, even though these agricultural areas have been long abandoned to the forest. The rugged terrain of Koh Ker initially obscured the field walls on the general topographic visualisation, so LRM is essential tool for visualisation and analysis. Coordinates are UTM/WGS84.

vegetation in the $35 \mathrm{~km}^{2}$ urban core of Angkor. Because the land surface in this area is a naturallyflat alluvial plain, the algorithm was highly effective in identifying pond features of archaeological interest, as there are essentially no natural basins in the area. The existence of these ponds was verified through ground investigation, and also by comparison with the ponds previously mapped using ground-based methods in the $9 \mathrm{~km}^{2}$ area of Angkor Thom previously surveyed by Gaucher (2004). If the number of households supported by an individual pond could be determined through archaeological excavation, the way would be paved for palaeodemographic studies that would provide the first accurate population figures for Angkor. A similar approach was applied for the Maya lowland, where archaeologists were able to arrive at estimates of maximum population by quantifying cisterns (McAnany 1990).

As noted above, the Angkorian economy revolved principally around rice cultivation. Scott Hawken (2011) and Christophe Pottier (2000) have proven that research on remnant rice field patterns can provide a great deal of useful information about the ancient and medieval past of northwest Cambodia, and the structure and extent of rice field networks has long been a focus of study at Angkor. At Koh Ker, similar traces of rice fields had been noted (Evans 2010-2011) but these had never been fully mapped due to forest cover. In our standard lidar data products for Koh Ker (TIN, hillshade and DTM), the highly variable topography of the area rendered these traces difficult to see: the dynamic range of the imagery as displayed on-screen was not enough to reveal traces of field walls at decimetre scale in the context of Koh Ker's rolling hills. In this case, we solved the problem by using the Local Relief Modelling (LRM) technique described by Hesse (2010), which demonstrated its ability to highlight the pattern of rice boundaries. LRM enabled the marginalisation of terrain hilliness and exaggeration of discrete relief of the field boundaries (Fig. 7). For the first time the complete image of this ephemeral capital of the king J ayavarman IV, who ruled the Khmer Empire between $\sim 928$ and $\sim 941$ $\mathrm{AD}$, has been revealed (Evans 2010-2011; Evans et al. 2013). Although much of the area around the great monuments of Koh Ker is still inaccessible due to minefields, we can now see that those monuments formed the urban core of Koh Ker, at the centre of a dispersed agro-urban landscape dominated by paddies, occupation zones and water management infrastructure. Thus, the lidar results have transformed our understanding of the medieval urban complex by providing crucial context to the temples, such as knowledge of their hinterland and the economic base of the city.

\section{Conclusions}

Research on low-density urbanism, both in Asia and in the Americas, was in urgent need of a tool for efficient surveying of vast areas, usually covered with dense, tropical vegetation. Over twenty years ago Don Rice and Patrick Culbert (1990) lamented the lack of adequate technologies to obtain a comprehensive view of Maya cities. However, now the introduction of airborne laser scanning for archaeological purposes has made it possible. Surveys in Belize (Chase et al. 2011) and Cambodia have shown that lidar should be routinely applied as a method of understanding tropical urbanism. It also finally paves the way for a comparative archaeology of early urban centres in 
tropical environments, which prima facie exhibit many similarities, for example a dense cluster of central monumental architecture encircled by agrourban landscapes and extensive water management systems (Coe 1961; Fletcher 2012). Using the results of the KALC airborne laser scanning mission in Cambodia, we have applied a suite of algorithms and methods that are specifically suited for this purpose, and that have already delivered results of some considerable archaeological significance. The ArcGIS Terrain Dataset allowed us to create an extensive visualisation on the whole surveyed area - on an enormous scale of $370 \mathrm{~km}^{2}$ - without losing any information from any individual lidar pulse. These kinds of techniques will prove extremely useful as work on low-density urbanism progresses. This research agenda requires us to look for details of structures at the very smallest scale - mere centimetres in some instances - while simultaneously considering how those microtopographic elements articulate with landscapescale features such as massive water management infrastructure. Lidar is uniquely equipped to do so in forested environments, and by arriving at a more detailed understanding of how tropical vegetation affects the reflections, we are now able to further refine algorithms for better ground/non-ground point segregation. We hope that an increased awareness of the techniques employed at Angkor, as outlined in this paper, will make a contribution to better understanding how lidar interacts with vegetation covering archaeological features in tropical forests, and will assist in the planning of future campaigns of archaeological lidar in these challenging environments.

\section{Bibliography}

Axelsson, P. 2000. "DEM generation from laser scanner data using adaptive TIN models." International Archives of Photogrammetry and Remote Sensing 33 (4):111- 118.

Buckley, B. M., K. J. Anchukaitis, D. Penny, R. Fletcher, E. R. Cook, M. Sano, L. C. Nam, A. Wichienkeeo, T. T. Minh, and T. M. Hong. 2010. "Climate as a contributing factor in the demise of Angkor, Cambodia." Proceedings of the National Academy of Sciences of the United States of America 107 (15):6748- 6752.

Chase, A. F., D. Z. Chase, J . F. Weishampel, J . B. Drake, R. L. Shrestha, K. C. Slatton, J J . Awe, and W. E. Carter. 2011.
"Airborne LiDAR, archaeology, and the ancient Maya landscape at Caracol, Belize." J ournal of Archaeological Science 38 (2):387- 398.

Coe, M. 1961. "Social Typology and the Tropical Forest Civilisations." Comparative Studies in Society and History 4:65- 85.

Coe, M. 2003. Angkor and the Khmer civilization. New York: Thames \& Hudson.

Crutchley, S., and P. Crow. 2009. The Light Fantastic: Using airborne laser scanning in archaeological survey. Swindon: English Heritage.

ESRI. 2012. "What is a terrain dataset?" Accessed 11 November 2013. http://resources.arcgis.com/en/help/ main/ 10.1/index.html\#/ / 005v00000002000000.

Evans, D. 2010-2011. "The Landscape Archaeology of Koh Ker, Northwest Cambodia.” Bulletin de l'École française d'Extrême-Orient 97-98:91- 150.

Evans, D., and E. Moylan. 2013. "Pixels, Ponds and People: Mapping Cultural and Archaeological Landscapes in Cambodia Using Historical Aerial Imagery." In Archaeology from Historical Aerial and Satellite Archives, edited by W. Hanson and I. Oltean, 291- 313. New York: Springer.

Evans, D. H., R. J. Fletcher, C. Pottier, J .-B. Chevance, D. Soutif, B. S. Tan, S. Im, D. Ea, T. Tin, S. Kim, C. Cromarty, S. De Greef, K. Hanus, P. Bâty, R. Kuszinger, I. Shimoda, and G. Boornazian. 2013. "Uncovering archaeological landscapes at Angkor using lidar." Proceedings of the National Academy of Sciences of the United States of America 110 (31):12595- 12600.

Evans, D., C. Pottier, R. Fletcher, S. Hensley, I. Tapley, A. Milne, and M. Barbetti. 2007. "A comprehensive archaeological map of the world's largest preindustrial settlement complex at Angkor, Cambodia." Proceedings of the National Academy of Sciences of the United States of America 104 (36):14277- 14282.

Evans, D., and A. Traviglia. 2012. “Uncovering Angkor: Integrated Remote Sensing Applications in the Archaeology of Early Cambodia." In Satellite Remote Sensing: A New Tool for Archaeology, edited by R. Lasaponara and N. Masini, 197-230. New York: Springer.

Fletcher, R. 2012. “Low-density, agrarian-based 
Across Space and Time. Papers from the 41st Conference on

Computer Applications and Quantitative Methods in Archaeology. Perth, 25-28 March 2013

urbanism: Scale, power and ecology." In The Archaeology of Complex Societies, edited by M.E. Smith, 285- 320. New York: Cambridge University Press.

Fletcher, R. J., D. Penny, M. Barbetti, C. Pottier, T. Heng, C. Khieu, and S. Tous. 2006. "The Greater Angkor Project 2005- 2009: Issues and Program." In Uncovering Southeast Asia's Past: selected papers from the 10th International Conference of the European Association of Southeast Asian Archaeologists, edited by E. A. Bacus, I. Glover, and V. Pigott, 347- 354. Singapore: NUS Press.

Fletcher, R., C. Pottier, D. Evans, and M. Kummu. 2008. "The development of the water management system at Angkor: A provisional model." Bulletin of the Indo-Pacific Prehistory Association 28:57- 66.

Gaucher, J. 2004. “Angkor Thom, une utopie réalisée? Structuration de l'espace et modèle indien d'urbanisme dans le Cambodge ancien." Arts Asiatiques 59:58- 86.

Groslier, B.-P. 1979. “La cité hydraulique angkorienne: exploitation ou surexploitation du sol?” Bulletin del'École française d'Extrême-Orient 66:161- 202.

Hawken, S. 2011. "Metropolis of Ricefields: A Topographical Classification of a Dispersed Urban Complex." PhD diss., University of Sydney.

Hesse, R. 2010. “LiDAR-derived Local Relief Models-a new tool for archaeological prospection." Archaeological Prospection 17 (2):67- 72.

Kokalj, Z., K. Zakšek, and K. Oštir. 2011. "Application of sky-view factor for the visualisation of historic landscape features in lidar-derived relief models." Antiquity 85 (327):263- 273.

Lasaponara, R., R. Coluzzi, and N. Masini. 2011. "Flights into the past: full-waveform airborne laser scanning data for archaeological investigation." Journal of Archaeological Science 38 (9):2061- 2070.

McAnany, P. A. 1990. "Water storage in the Puuc region of the northern Maya lowlands: A key to population estimates and architectural variability." In Precolumbian Population History in the Maya Lowlands edited by T. P. Culbert and D. S. Rice, 263- 284. Albuquerque: University of New Mexico Press.

Opitz, R. S., and D. C. Cowley. 2013. “Interpreting archaeological topography: lasers, 3D data, observation, visualisation and applications." In Interpreting archaeological topography: 3D data, visualisation and observation, edited by R. S. Opitz and D. C. Cowley, 1- 12. Oxford: Oxbow Books.

Pottier, C. 2000. "Some Evidence of an Inter-relationship between Hydraulic Features and Rice Field Patterns at Angkor during Ancient Times." J ournal of Sophia Asian Studies 18:99- 120.

Rice, D. S., and T. P. Culbert. 1990. "Historical contexts for population reconstruction in the Maya lowlands." In Precolumbian population history in the Maya lowlands, edited by T. P. Culbert and D. S. Rice, 1- 36. Albuquerque: University of New Mexico Press. 


\title{
GeOBIA Approaches to Remote Sensing of Fossil Landscapes: Two Case Studies from Northern Italy
}

\author{
Armando De Guio, Luigi Magnini and Cinzia Bettineschi \\ University of Padova, Italy
}

\begin{abstract}
:
This paper presents the preliminary results of an object-based imageanalysis aimed at theimplementation of a package of procedures of remotely sensed object/pattern/scenery recognition specifically designed for thesemi-automaticand automaticrecognition of a batch of critical archaeological and ethnoarchaeological features. The research focuses on theguided recognition of mountain and plain features with elliptic, linear and polygonal shape on high resolution aerial photographs and near-infrared imagery. Case studies from Northern Italy are investigated, stating the image processing steps and highlighting the pros and cons of using an artificial intelligence for the analysis in the domain of Remote Sensing.
\end{abstract}

\section{Keywords:}

Remote Sensing, Geobia, Automatic And Semi-Automatic Recognition, Prehistoric Rural Landscape, Landscape Archaeology

\section{Introduction}

One of the major problems of remote sensing is the complex and palimpsestic origin of most archaeological contexts. The long-term human/ environment interactions have often cumulatively produced what has been defined as a fossil landscape (Balista et al. 1998): an intricate overlapping of diachronic signatures and traces, each one characterised by a different degree of residuality. The distinction and differentiation of these various features is, therefore, a matter of central concern for the understanding of the historical, cultural and archaeological development of a given territory. It should be emphasised, moreover, the significant ambiguity/equifinality (Skyttner 2005; von Bertalanffy 1956) that some of these features present in the final state of their morphogenetic paths.

Photo-interpretation of the archaeological site and off-site features is usually carried out case-by-case, resulting in a highly time consuming and economically expensive task. In order to avoid errors and bias (e.g. pareidolia) that may, in some circumstances, affect the human mind and to improve the comparability of analytical data, we decided to use a specific software designed for semi-manual, semi-automatic and automatic spatial analysis. This procedure simultaneously examines a widerangeof data - dimensional, butalso chromatic, formal, textural, structural, spatial-relational - with a sound methodological consistency allowing to critically reduce the range of random variability of the output data.

Hay and Castilla (2008) defined Geographic Object-Based Image Analysis (i.e. GeOBIA; also generically OBIA) as: "a sub-discipline of Geographic Information Science (GIScience) devoted to developing automated methods to partition remote sensing imagery into meaningful image-objects, and assessing their characteristics through spatial, spectral and temporal scales, so as to generate new geographic information in GIS-ready format". This means that the conceptual unit of the process is no more represented by single pixels (or voxels, in a three-dimensional coordinate system), but by homogeneous image objects and their relationships. For a systematic overview of the researches on the topic the reader is referred to the recent synthesis of Blaschke (2010) and to the related bibliography.

The OBIA approach has been applied in archaeology for the development of predictive maps using high-resolution DEMs by Verhagen and Drăguț (2012), but until now only a few attempts were made in order to classify fossil or buried archaeological structures via their residual traces on the ground - like for example soil-marks, grassmarks etc. (Magnini 2011).

Corresponding author: luigi.magnini@gmail.com 


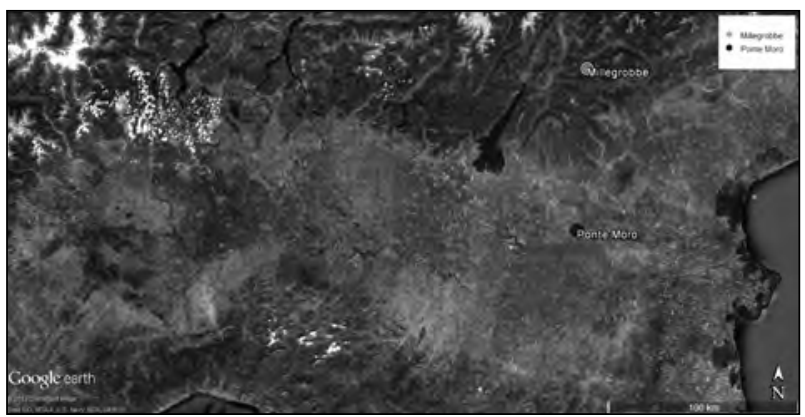

Figure 1. The location of Millegrobbe (Lavarone, TN) and Ponte Moro (Cerea, VR) in the context of Northern Italy.

\section{Know Why to Know How: Methodology and Preliminary Steps of the Research}

Object-based image analysis can be divided in two main steps: segmentation and classification, that can be repeated in sequence as many times as needed (Benz et al. 2004). Segmentation uses a series of mathematical and logical operations on the image-data in order to obtain meaningful groups of pixels. To simplify, segmentation cuts the image into multiple crude objects, which can therefore be further edited, hierarchised and then classified.

We found that multi-resolution segmentation with varying scale, shape and compactness parameters was the optimal option to analyse our multilayered archaeological landscapes. In fact, the multi-resolution algorithm (Baatz and Shäpe 2000) divides the image into polygons, maximising at the same time the mutual heterogeneity and theinternal homogeneity. It is essentially a bottom-up technique which merges single pixels to create larger image objects. The following step, called classification, involves the systematic grouping of image objects into categories on the basis of colour, shape, texture and/ or structural and spatial relationships.

Definiens/eCognition, although proprietary, is the most common software for GeOBIA applications (see Anders, Seijmonsbergen and Bouten 2011; Dronova, Gong and Wang 2011; Peña-Barragàn et al. 2011; Vieira et al. 2012); this is the reason why we decided to use it as well.

At the beginning of our research we chose to test in our study areas (Fig. 1) four different kinds of classification in order to understand the pros

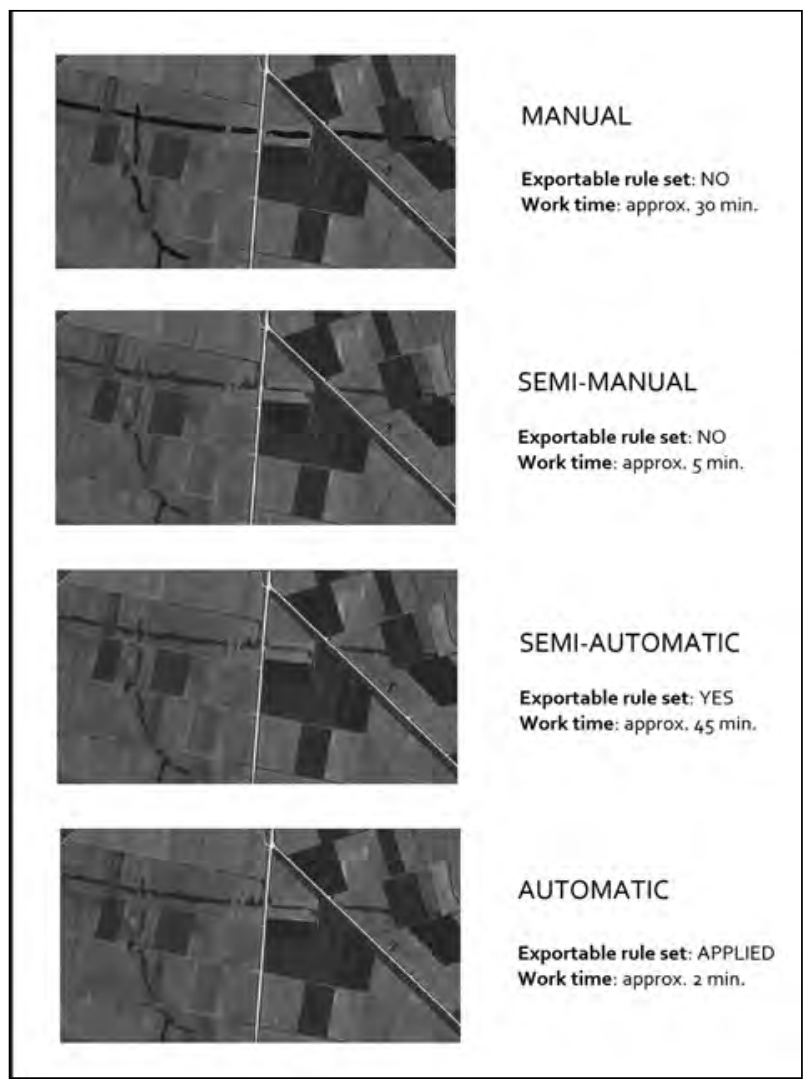

Figure 2. Comparison of outcomes and timing to classify the roadway in Ponte Moro through: a) manual recognition (Quantum Gis); b) semi-manual recognition (eCognition); c) semi-automatic recognition (eCognition); d) automatic recognition (eCognition).

and cons of one compared to the others. Thus, as showed in Figs 2-3, we used: 1) a classic visual/ manual approach (Quantum GIS); 2) a semimanual approach (eCognition); 3) a semi-automatic approach (eCognition); 4) an automatic approach (eCognition).

The visual-manual classification with a GISbased software (in this case we used Quantum GIS, but many other options are also available) is primarily based on the operator's experience, while the degree of detail is linked to the work time/ quality ratio that best suits the specific project. This is what archaeologists usually do for the purpose of photo interpretation.

For the semi-manual approach to classification as shown in Figs 2-3, we started from the raw segmentation data and manually selected the image 


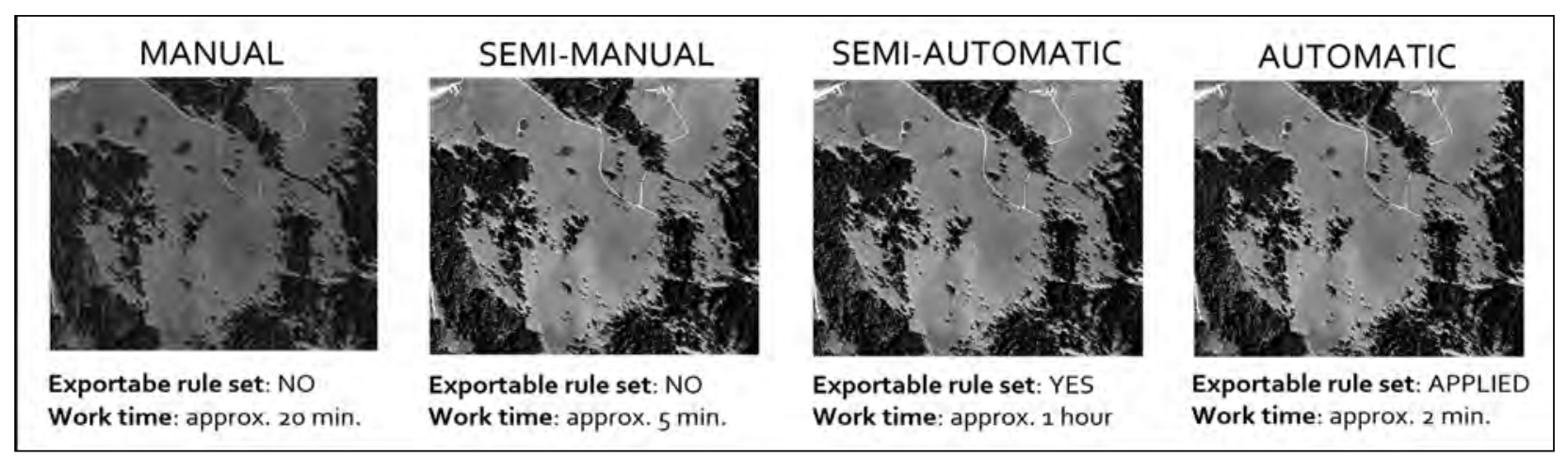

Figure 3. Comparison of outcomes and timing to classify the mountain pools in Millegrobbe through: a) manual recognition (Quantum Gis); b) semi-manual recognition (eCognition); c) semi-automatic recognition (eCognition); d) automatic recognition (eCognition).

objects to classify. This methodology, though still largely depending on the operator's expertise and his cognitive maps, provides a somewhat objective basis (because the shape of the polygons/image objects is generated by the software according to the properties of the image) to direct all the subsequent processing. It also makes possible to obtain a good level of detail in a relatively short work time; but, of course, reusable rule-sets cannot be created using a semi-manual procedure.

In order to successfully classify in an automatic or semi-automatic way the intended landscape features, it is essential to understand their characteristics and recognise their peculiarities with respect to the context where they can be found in. This means that the operator must have a mental model of the expected results to identify the specific parameters of the features to be selected for analysis; in other words, during the selection of the classification parameters and the creation of a ruleset the artificial intelligence has to be instructed and guided by the human mind. In the next paragraphs (3.1 and 3.2) we will present a semi-automatic procedure for the creation of a rule-set aimed at the classification of a series of ancient man-made and natural features. As for the automatic classification shown in Figs 2-3, we run the rule-sets derived from the semi-automatic classification over the same image-data: as proved by Drăguț and Blaschke (2006) this procedure gave identical results, ensuring the reproducibility of the outcomes. The software can - in a following stage - repeat the same procedure for an unlimited number of times, applying an identical rule-set to different images which possess the same or comparable geographic, anthropogenic and/or physical features: it is the crucial shift from a semi-automatic to an automatic photo interpretation and it will be in fact the main focus of our future research. Needless to say, this latter approach can involve a number of risks whose impact needs to be assessed according to the cost/ benefit ratio and the complexity of the project.

\section{Case Studies}

This section will present two case studies in mountain and plain environments that will involve distinctive mental models implemented by selecting the appropriate, locally sensitive object features and by considering them in a logical succession. These steps allowed us to achieve a semi-automatic photo interpretation with a quite higher heuristic impact in comparison to the manual procedure.

The preliminary study which will also be summarised below is also an essential phase of the work. In fact it highlighted the basic information on the features of interest (shape, average area, dimensions etc.) which were subsequently used as classification parameters.

The detailed explanation of each object feature which will be mentioned in the following paragraphs and the related formulae can be found in eCognition's Reference Book (Trimble Germany $\mathrm{GmbH}$ 2011).

\subsection{Ponte Moro (Cerea - VR, Italy)}

Ponte Moro is a rural, off-site area located in the low Po Plain near the terramara settlement of 
Across Space and Time. Papers from the 41st Conference on

Computer Applications and Quantitative Methods in Archaeology. Perth, 25-28 March 2013
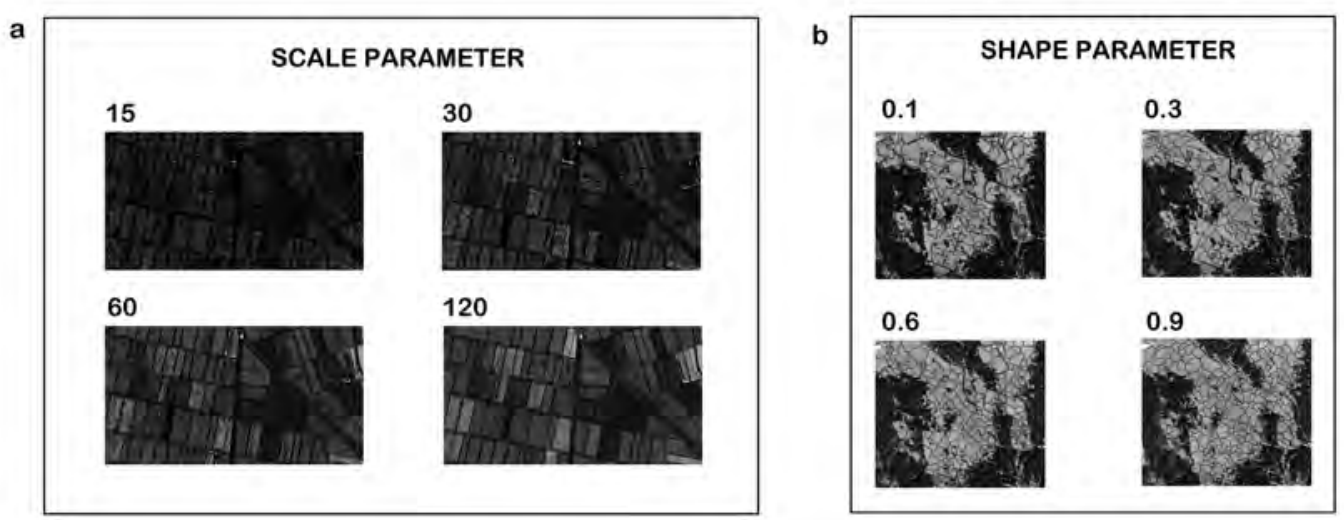

Figure 4. a) Ponte Moro: comparison of the outcomes of a segmentation with scale parameter of 15, 30, 60 and 120; b) Millegrobbe: comparison of the outcomes of a segmentation with shape parameter of 0.1, 0.3, 0.6 and 0.9.

Castello del Tartaro, occupied between the Middle Bronze Age (MBA) and the Late Bronze Age (LBA). The area is currently under investigation by the AMPBV (Alto Medio Polesine Basso Veronese) project (Balista et al. 1986; De Guio, Betto and Balista 2011 and related bibliography), codirected by the Department of Cultural Heritage: Archaeology and History of Art, Cinema and Music (University of Padua) and the Institute of University College (London), in collaboration with the Archaeological Superintendence of Veneto, Boston University, Clarke University (USA-MASS), Accordia Research Centre (London), Center for Remote Sensing (Boston), Nanotechnology Lab (Boston). The aim is to examine the extremely well-preserved fossil landscape of the Valli Grandi Veronesi, a true landscape of power' arisen during the MBA and characterised by a massive occupation of the wider middle to low Po plain. In particular, Ponte Moro shows the buried remains of a roadway and a palaeochannel both related to the prehistoric occupation. Geoarcheological studies and C14 results carried out in the area confirm the hypothesis proposed on the basis of the Remote Sensinganalysis and support the dating of the road to the Bronze Age (Betto, De Angeli and Sartor 2006).

In order to classify the subsurface archaeological features and the related surface patterns, we first applied a multi-resolution segmentation (parameters: scale 30, shape 0.1, compactness 0.5 ) to an aerial orthophoto (copyright CGR - Compagnia Generale Ripreseaeree Parma, 2008) overlaid with a near-infrared digital

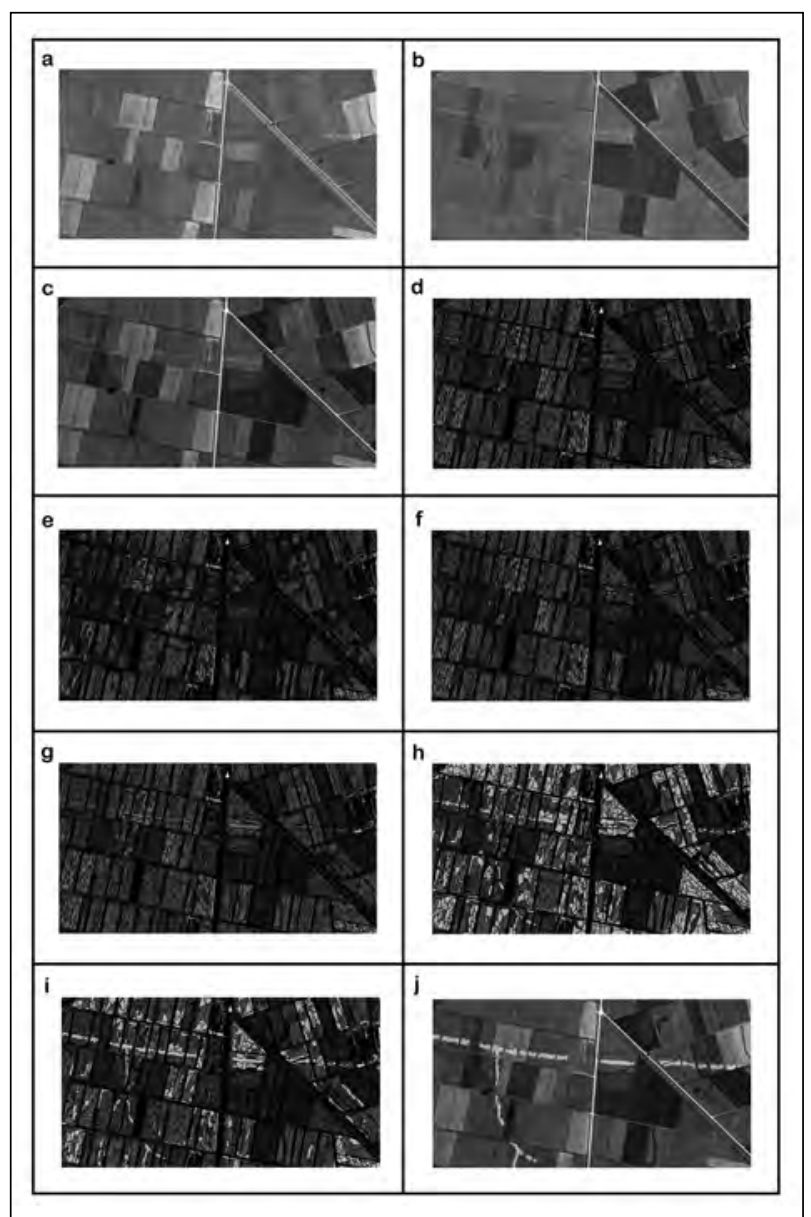

Figure 5. Creation of a rule set (through semi-automatic recognition) for the classification of a paleochannel (blue) and a buried roadway (yellow) in Ponte Moro. Step of the project and final results. 


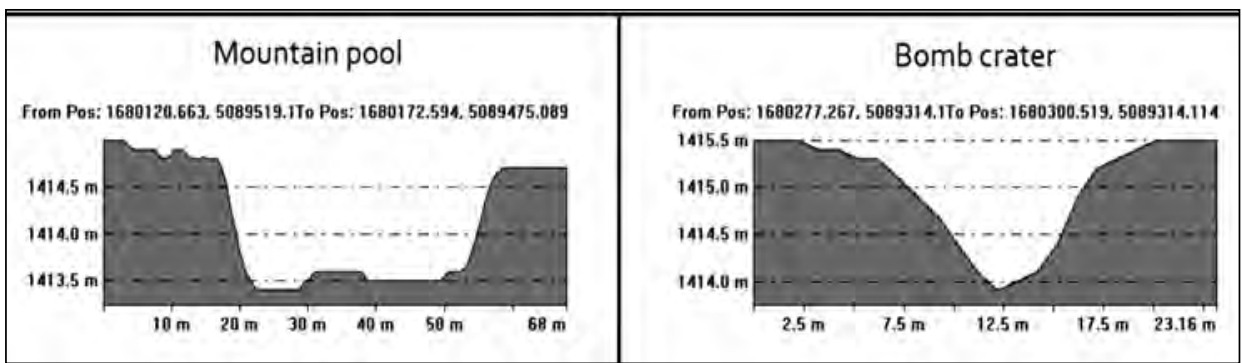

Figure 6. Comparison between the sections of a mountain pool (left) and a bomb crater (right) from Millegrobbe. Global Mapper reworking of lidar data.

orthophoto (copyright CGR Parma, 2008) at the same spatial resolution of $0.5 \mathrm{~m}$. The reason for this choice is that the two images offered significantly different data: the palaeochannel was well recognisable only from the near-infrared image, while the roadway was clearer on the simple aerial orthophoto. The selection of the scale parameter was obtained by comparing the results achieved using values of 15, 30, 60 and 120 . The higher the values, the larger the image objects. As shown in Fig. 4a, an apparent over-segmentation was thus necessary to distinguish image objects pertaining to the buried archaeological structures from those related to agrarian features of adjacent fields. The homogeneity criterion is based on the ratio between colour and shape: higher values of 'shape' (max 0.9) involve a lower weight of the spectral characteristics in the overall homogeneity parameter (for technical details and algorithms, see Benz et al. 2004). Since the chromatic level was the most important factor for our analysis, we chose to use a low shape value.

We started the project with the classification of the palaeochannel (blue in Fig. 5) by considering the 'mean' feature of the near-infrared layer (layer 4). The palaeochannel, in fact, can be recognised basically due to the different vegetation growth (grass-marks and crop-marks) and considering that the vegetation has a high reflection in the near infrared channel, this was the first characteristic we used to select the image objects of interest. Segmentation, due to the presence of modern roads and canals, split the palaeochannel into many very small image objects, so we used the object feature 'area' to unclassify the biggest image objects, related to fields and recent infrastructures. Then we considered the 'max diff' and the 'standard deviation' (on the near infrared layer) features, because the image objects of the palaeochannel are relatively inhomogeneous in terms of texture and colour, being the final outcome of anthropogenic and post-depositional processes. We also used the 'merge region' algorithm, to combine the adjacent image objects belonging to the palaeochannel class so that we could obtain a shape more and more similar to the profile of the prehistoric watercourse as seen on the near infrared image. The software also identified a further structure on the eastern side of the image which had never been recognised before by traditional photo interpretation. The area presents all the spectral and textural characteristics of fossil riverbeds: upcoming field checks will allow to clarify its detailed nature (ground truth).

The recognition of the roadway was then implemented as a new class, starting from the same segmentation data. At this point, it was clear that the continuity of the roadway alignment was interrupted by a series of modern roads and irrigation canals. In order to remove such sources of noise, we classified all of the image objects that had middle to low values of the length/ width' feature. Then, by elimination, we considered the 'mean' feature of the green layer, so that we could choose only the light-coloured image objects, mainly related to the ancient roadway. Subsequently, we selected the image objects with small to medium 'area' and to improve the image reading we used the 'merge region' algorithm that joins neighbouring image objects of the same class. In the end we eliminated the remaining background noise thanks to the 'brightness', 'area' and 'rectangular fit' features.

\subsection{Millegrobbe (Lavarone - TN, Italy)}

The mountainous area of Millegrobbe (Fig. 1) is a cumulative landscape, massively occupied since Late Bronze Age for metalworking. Later on, it was centre of a complex mountain economy (woodland exploitation, pastoralism, stone quarrying etc.) and finally it became a well-known bloody theatre of the First World War. History has left impressive signature of marks on the ground, which are currently under investigation in a series of projects 
promoted by the University of Padua (De Guio and Zammatteo 2005; De Guio et al. 2013 and related bibliography; Magnini 2011; Pearce and De Guio 1999).

The current research is mainly focusing on: 1) project Ad metalla, centered on palaeometallurgy (Bronze-Age roasting and smelting); 2) Archaeology of War, linked to the impact of the Great War on the Vezzena-Luserna-Lavarone plateaux (thousands of kilometres of military roads and trenches and millions of bomb craters); 3) ethnoarchaeology and 'Archaeology of Us' (actualistic studies), all connected to a wide spectrum of mountain economy as well as to a softer archaeology of the mind (from pasture pools to stone piles, deforestation holes, charcoal pits, lime kilns, toponyms, local traditions, legends and fairy-tales etc.).

In order to differentiate all these traces from a remote point of view, it is necessary to recognise their differences in shape, section, dimensions, colour, and - even more importantly - their reciprocal and contextual relationships on all kinds of available imagery of the area, such as aerial photos, near-infrared digital orthophoto, NDVI, lidar, and RADAR data.

In particular, we decided to refer to the following three types of features that, although very different from each other, share a high degree of ambiguity with other structures present in the same reference area (De Guio et al. 2013):

a. Trenches (linear equifinality with roads, trails, muleteers, cross trampling traces, land divisions and boundaries): long, narrow and zigzagging ditches in the ground dug by soldiers during the First World War as a defence against enemy fire. They were of variable size: about two meters deep, equally wide, stretched from a few meters to several kilometres in length. The historical maps (copyright IGM - Istituto Geografico Militare, 1969) allowed the identification in the Millegrobbe surroundings of an area called 'extrenches' in which we will attempt to remotely identify the remains of any possible ground structure associated with the Great War.

b. Mountain pools (circular/ elliptic equifinality with cairns, treethrows, charcoal pits, lime

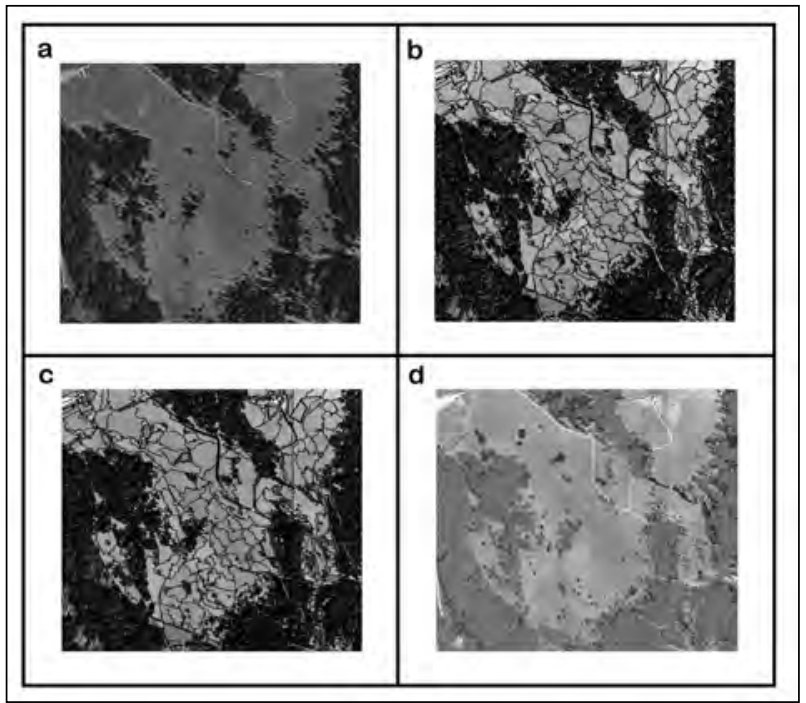

Figure 7. Creation of a rule set (through semi-automatic recognition) for the classification of mountain pools (red), malgas (yellow), woodland (green) and war trenches (blue) in Millegrobbe. Step of the project and final results.

kilns, smelting platforms, ice storage pits, bomb craters, sinkholes): typical alpine and pre-alpine seasonal pools, occasionally derived from natural depressions but usually man-made, especially in karst regions. The diameter varies between five and sixty meters, but frequently it ranges from ten to thirty meters, while the approximate depth is between half a meter and a meter and a half (Fig. 6). The Late Bronze Age roasting/ smelting furnaces and slags of Millegrobbe are strictly linked with some of these structures, as they are the only basins (often trapped by local morphology and quite recognisable even at the post-abandonment stage) that can provide the water reserverequired for metallurgical activities. The correct identification of mountain pools (both active and fossil, normally in clustered distributions across different pastures) plays therefore a considerable role not only from the ethnographic, but also from the archaeological and paleometallurgical point of view.

c. 'Malga' (i.e. shepherd's huts, poligonal/ rectangular equifinality with military warehouses, barracks, outposts, artillery emplacements, stockyards): traditional residential-productive unit of the mountain landscape, centre of the pastoral economy (breeding, dairy production etc.). Characterised by widely varying shapes 
and sizes, they can sometimes consist of several compartments connected one to each other (stable, poultry, piggery, cistern, cheese storage room, living spaces and so on).

The semi-automatic multi-class recognition of the target features was set on an aerial orthophoto (CGR Parma 2000) overlaid with a near-infrared digital orthophoto (CGR Parma 2008). The first step of the analysis was to perform a multi-resolution segmentation with the following parameters: scale 100 , shape 0.1 , compactness 0.5 . The selection of the values of the segmentation parameters is subject to the samelogic already discussed for the case study of Ponte Moro; to evaluate the resulting segmentation in relation to the variation of the 'shape' parameter, see Fig. 4b. This comparison shows quite clearly that reducing the colour significance, proportionally reduces the recognition of the structures of interest.

The second level concerns the creation of a new class, here called 'trenches' and identified with the colour blue (Fig. 7). The obvious attributes of the trenches in both the selected images are linear shape and colour, which differ significantly from that of the surroundings. We began the creation of our rule set by selecting all image-objects with a middle-to-high length and width ratio, through the use of the length/ width' feature. However, we chose to exclude those image objects with the highest ratio, which corresponded to the modern roadways. Also, we unclassified image objects with the largest and smallest areas, that were not related to the structures of interest. Subsequently we considered the 'mean' feature of the green layer (to remove part of the vegetation) and of the near-infrared layer, where the profile of the trench was better delineated. Once the objects belonging to the trench were identified, we used the 'merge region' algorithm to join the adjacent image objects. In this way we could identify the trench as a limited number of image objects, which are easier to work with. Finally the features 'brightness' and 'standard deviation' were used in sequence on the near-infrared layer, in order to eliminate the remaining background noise not related to our analysis.

In addition to the recognition of different types of individual classes, the software simultaneously classifies different types of evidences starting from the same raw segmentation data. Therefore we decided to set up a multi-class project, taking into consideration, beyond the trenches, also mountain pools (red), malga (yellow) and woodland (green).

Pools were classified mainly thanks to their circular shape, their peculiar colour and the absence or presence of water inside. The features considered are in order: 'roundness', 'area' (in relation to the average size of the alpine pools as outlined by the related bibliography), 'mean' on the red layer and 'brightness', to take advantage of their colour and reflectance characteristics.

The malga, being man-made structures rather regular and quadrangular-shaped, have been classified with the 'rectangular fit' feature. Then the smaller image objects, related to shadow within the trees, were eliminated by taking into consideration their 'area'. Ultimately 'brightness' allowed us to remove those image objects with high contrast values, which corresponded to modern buildings.

Classifying the forest coverage, although it may seem difficult because of its irregular shape, is extremely fast, as demonstrated by numerous casestudies (e.g. Dorren, Maier and Seijmonsbergen 2003; Heyman et al. 2003). In our case the 'mean' feature on the green band made it possible to obtain highly accurate results and also to identify individual trees in open field.

\section{Conclusion and Perspectives}

These study cases confirm the applicability of object based image analysis to archaeological photo interpretation and strengthen its role to identify features evident at ground level as well as remains exclusively detectable from aerial or near-infrared view. However, implementing a geospatial analysis on surface structures or landscape-related features (our original purpose) is very different from the identification of buried archaeological remains, whose peculiar characteristics have been informed by the succession or interaction of a variety of depositional and post-depositional formation processes: these involve specific actors (physiogenetic, bio-genetic and anthropo-genetic) and related behavioural scripts. Such a complexity in the epigenetic path outlines the difficulties to formalise an unambiguous heuristic model. 
Across Space and Time. Papers from the 41st Conference on

Computer Applications and Quantitative Methods in Archaeology. Perth, 25-28 March 2013

The software also ensures some kind of 'controlled automation' of the photo interpretation process and the exportability of the supporting rule sets in a way that seems particularly useful when workingonlargescaleprojectsto speed up theobject/ pattern/ scenery recognition task. It should however be considered, given the high internal variability of the outcomes on the ground of the archaeological surface and subsurface structures, that in the case of a fully automatic approach the operator's control on the obtained results is still essential in order to finetune or recalibrate the parameters according to the specific research targets, locally sensitive info/noise ratio and and/ or ground-truth feedback.

OBIA methodology provides innovative hints, pointing to interesting archaeological developments in the near future. The research here presented is a work in progress, which is now focusing on the use of different types of data (NDVI, lidar, RADAR, etc.) and trying to explore both their specific potential as well as their possible cross-validating redundancy. This will, ultimately, help to develop more and deeper rule/ knowledge based approaches to landscape archaeology.

\section{Bibliography}

Anders, N. S., A. C. Seijmonsbergen, and W. Bouten. 2011. "Segmentation optimization and stratified object-based analysis for semi-automated geomorphological mapping." Remote Sensing of Environment 115:2976- 2985.

Baatz, M., and A. Shäpe 2000. "Multiresulution segmentation - an optimization approach for high quality multi-scale image segmentation." In Angewandte Geographishe Informationsverarbeitung Vol. XII, edited by J. Strobl, T. Blaschke, and G. Griesebner, 12-23. Heidelberg: Wichmann.

Balista, C., M. Bagolan, F. Cafiero, A. De Guio, S. Levi, R.D. Whitehouse, and J. Wilkins. 1998. "Bronze-Age «Fossil Landscapes» in the Po Plain." In Mensch und Umwelt in der Bronzezeit Europas, edited by B. Hänsel, 493-499. Kiel: Oetker-Voges Verlag.

Balista, C., H. Blake, A. De Guio, C. Howard Davis, P. Howard, R. D. Whitehouse, andJ. Wilkins. 1986. "Progetto Alto Polesine. Marzo-Aprile 1986. Relazione preliminare.” Quaderni di Archeologia del Veneto II:21- 25.
Benz, U.C., P. Hofmann, G. Willhauck, I. Lingenfelder, and M. Heynen. 2004. "Multi-resolution, object-oriented fuzzy analysis of remote sensing data for GIS-ready information." ISPRS Journal of Photogrammetry and Remote Sensing 58:239- 258.

Betto, A., G. De Angeli, and F. Sartor. 2006. “«Embanked roads» of the Southern Valli Grandi Veronesi. Between air photointerpretation and ground evaluation of buried stratigraphy: a positive feedback." In From Space to Place: 2nd International Conference on Remote Sensing in Archaeology. Proceedings of the 2nd International Workshop, CNR, Rome, Italy, December 4-7, 2006, edited by S. Campana and M. Forte, 487-490. Oxford: Archaeopress.

Blaschke, T. 2010. "Object based image analysis for remote sensing." ISPRS J ournal of Photogrammetry and Remote Sensing 65 (1):2- 16.

De Guio, A., A. Betto, and C. Balista. 2011. "Per la tutela e la valorizzazione di un patrimonio paesaggisticoculturale unico nel suo genere: le tracce degli antichi campi, dei canali e delle strade su terrapieno di età preistorica e romana conservate nel sottosuolo delle Valli Grandi e Medio Veronese." In Pianificazione territoriale, urbanistica e archeologia: una sintesi possibile, edited by M. Saracino, 79- 124. Verona: Comune di Verona.

De Guio, A., A. Betto, M. Migliavacca, and L. Magnini. 2013. "Mountain fossil landscapes and the "archaeology of us": an object/ pattern/ scenery recognition experiment." In Proceedings of the 5th International Congress of Ethnoarchaeology, Roma, ISAO, May 13-14 2010, edited by F. Lugli, A. A. Stoppiello, and S. Biagetti, 241-247. Oxford: Archaeopress.

De Guio, A., and P. Zammatteo (eds). 2005. “Luserna - La storia di un paesaggio Alpino." Atti del Convegno "SUL CONFINE... Percorsi tra archeologia, etnoarcheologia e storia lungo i passi della montagna di Luserna" Luserna, 28 dicembre 2002. Padova: S.A.R.G.O.N. Editrice.

Dorren, L. K., B. Maier, and A. C. Seijmonsbergen. 2003. "Improved Landsat-based forest mapping in steep mountainous terrain using object-based classification." Forest Ecology and Management 183:31- 46.

Drăguţ, L., and T. Blaschke. 2006. "Automated classification of landform elements using object-based image analysis." Geomorphology 81:330- 344. 
Dronova, I., P. Gong, and L. Wang. 2011. "Object-based analysis and change detection of major wetland cover types and their classification uncertainty during the low water period at Poyang Lake, China." Remote Sensing of Environment 115:3220- 3236.

Hay, G. J., and G. Castilla. 2008. "Geographic object based image analysis (GEOBIA): a new name for a new discipline." In Object Based Image Analysis, edited by T. Blaschke, S. Lang, and G. Hay, 93-112. Heidelberg: Springer.

Heyman, O., G. G. Gaston, A. J. Kimerling, and J. T. Campbell. 2003. "A persegment approach to improving aspen mapping from high-resolution remote sensing imagery." J ournal of Forestry 101(4):29- 33.

Magnini, L. 2011. "OPSR: object, pattern, scenery recognition in archeologia. L'approccio eCognition al caso di studio di Millegrobbe (TN)." BA Thesis, University of Padua.

Pearce, M., and A. De Guio. 1999. "Between the mountains and the plain: an integrated metal production and circulation system in later Bronze Age north-eastern Italy." In Prehistoric Environment, society, and economy - Papers of the international colloquium PAESE '97 in Zurich, edited by P. Della Casa, 289- 293. Bonn: Habelt.

Peña-Barragàn, J. M., M. K. Ngugi, R. E. Plant, J. Six. 2011. "Object-based crop identification using multiple vegetation indices, textural features and crop phenology." Remote Sensing of Environment 115:1301- 1316.

Skyttner, L. 2005. General System Theory. Singapore: World Scientific Publishing.

Trimble Germany GmbH. 2011. eCognition Developer 8.7 Reference Book. Document Version 8.7. Munich: Trimble.

Verhagen, P., and Drăguț L., 2012. "Object-based landform delineation and classification from DEMs for archaeological predictive mapping." Journal of Archaeological Science 39:698- 703.

Vieira, M. A., A. R. Formaggio, C. D. Rennó, C. Atzberger, D. A. Aguiar, M. P. Mello. 2012. "Object Based Image Analysis and Data Mining applied to a remotely sensed Landsat time-series to map sugarcane over large areas." Remote Sensing of Environment 123:553- 562. von Bertalanffy, L. 1956. "General System Theory." In General Systems (Yearbook of the Society for the Advancement of General Systems Theory), vol. 1, edited by L. Von Bertalanffy and A. Rapoport, 1-10. Ann Arbor: Society for General Systems Research. 


\title{
Palmyra Revisited from Space - High-Resolution Satellite Prospection of a UNESCO World Heritage Site
}

\author{
Roland Linck, J örg W. E. Fassbinder \\ Bavarian State Dept. for Monuments and Sites and Ludwig-Maximilians-University, Germany.
}

Stefan Buckreuss

German Aerospace Centre, Germany.

\begin{abstract}
:
The launch of TerraSAR-X widened the application of Synthetic Aperture Radar (SAR) in the archaeological prospection tremendously. SAR now can be used effectively for the integrated geophysical prospection of huge ancient settlements and cities such as Palmyra. On the one hand, ground-based methods like magnetometry and resistivity can provide detailed insights into the buried archaeological remains. On the other hand, it is possible to get a fast overview of a site and its cultural landscape by space-borne survey methods, e.g. optical satellite photos or satellite radar. This paper will show the results of an integrated geophysical prospection by magnetometry, resistivity, satellite photos and radar in the area of the ancient Palmyra. While the first two methods could prove the existence of a Hellenistic town south of the Wadi el Kubur and map its layout in detail, the space-borne results provide an overview over the upstanding remains, as well as several new structures of the buried archaeology of this famous caravan city in the Syrian Desert.
\end{abstract}

\section{Keywords:}

Synthetic Aperture Radar, TerraSAR-X, Remote Sensing, Magnetometry, Syria

\section{Introduction}

In the last decades, integrated geophysical prospection has become a very important tool in archaeology (Fassbinder 2007; Gaffney and Gater 2003; Neubauer et al. 2002; Scollar et al. 1990). Modern excavations often need prior geophysical prospection, as large-scale excavations cannot be carried out anymore today because of cost reasons and thesurvey results givestronghints for promising areas. Furthermore geophysical prospection is a non-destructive tool for the understanding of an archaeological site in its context. Therefore, in 1997/98 a cooperation between the Bavarian State Department of Monuments and Sites (BLfD) in Munich and the Institute of Classical Archaeology of the University Vienna was established for geophysical surveys by magnetometry and resistivity prospection in the proposed area of the Hellenistic

Corresponding author: roland.linck@blfd.bayern.de part of Palmyra. Since 2011, another cooperation of the BLfD and the German Aerospace Centre (DLR) in Oberpfaffenhofen has the goal to investigate the whole town by remote sensing with optical and radar satellites. The advantage of satellite-based archaeological prospection is theaccessibility of even very remote archaeological sites, which often cannot be surveyed by ground-based methods because of political or other reasons. To understand the development and structure of historic settlements, it is often important to survey the entire settled area.

The ancient ruins of Palmyra provide an excellent test site for geophysical methods and remote sensing because huge parts of the city remain unexcavated and nearly the whole settlement had never been overbuilt in post-ancient times. Another important factor is that the archaeological findings are covered by only a thin layer of sand and provide good contrast to the surrounding material. 


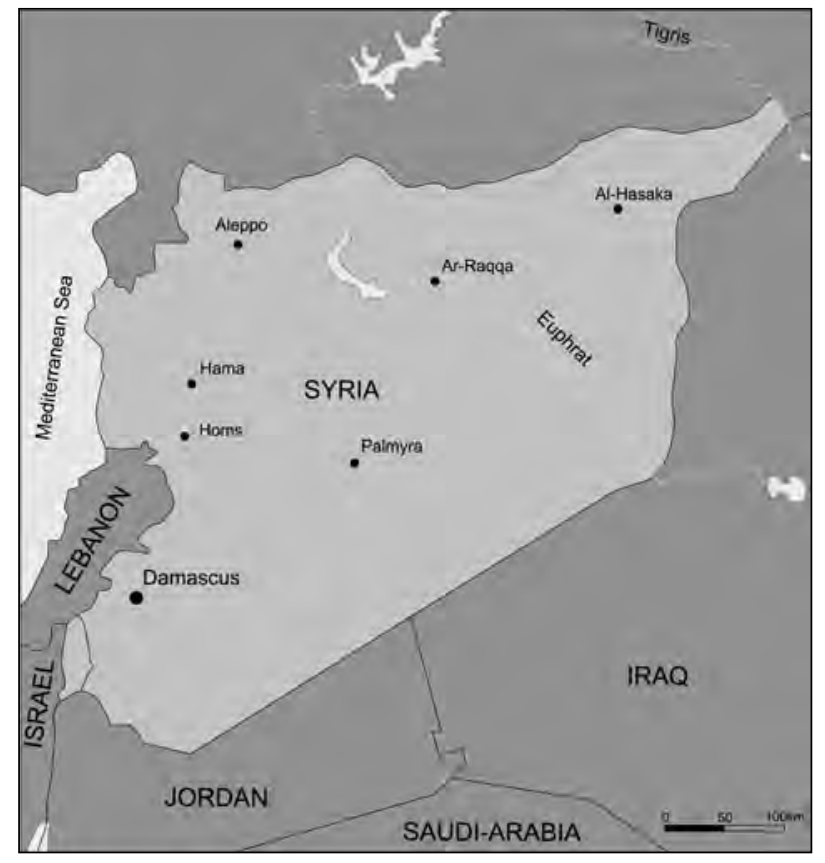

Figure 1. Map of Syria showing the location of Palmyra in central Syria, 230 km northeast of the capital Damascus.

\section{Archaeological Background}

Palmyra is situated $230 \mathrm{~km}$ northeast of Damascus in a fertile oasis in the Syrian Desert (Fig. 1). Hence, the area was settled since Palaeolithic times (75,000 BP) (Bounni and al-As'ad 1990; Browning 1979). The first written evidence can be dated to the 2nd millennium BCE, when Palmyra is mentionedin theAssyrian and Babylonian cuneiform plates of Kültepe (Cappadocia) and Mari (Syria) (alAs'ad and Schmidt-Colinet 2005b; Degeorge 2002; Michalowski 1968). Further evidence can be found for Hellenistic period occupation in the area south of the Wadi el Kubur that runs through the ancient city. When Palmyra got part of the Diadochian Empire of Seleukos in the 3rd century BCE, there was an increase in prosperity, as the Palmyrenes managed to set up the only safe caravan route in the region. In the 1st century CE Palmyra became part of the Roman province Syria (Hartmann 2001). In the following centuries, Palmyra was step by step Romanised. The most prosperous time of Palmyra came in the 2nd century CE, when the Nabatean Empire, which was the biggest enemy in caravan trade, was conquered by the Roman emperor Trajan (Degeorge 2002). This can be proved by the monumental architecture of this century, when the well known monuments like e.g. the Bel-sanctuary, the Great Column Road and the tower tombs were erected. In this time, the Palmyrene trade network reached from Spain in the west to China in the east, but already at the end of the same century the decline began as a consequence of the Parthian wars and the associated shift of the trading route towards the north (Degeorge 2002). After the famous usurpation of Queen Zenobia in $262 \mathrm{CE}$, Palmyra was conquered by the Roman emperor Aurelian and afterwards it only served as a military post at the Roman Limes Arabicus. In 300 CE Diocletian built a new city wall and a huge fortress in the western part of the city (al-As'ad and SchmidtColinet 2005b; Degeorge 2002; Gawlikowski 2005; Hartmann 2001). In $634 \mathrm{CE}$ it was conquered by the Arabs under their general Khalid ibn al-Walid (al-As'ad and Schmidt-Colinet 2005a; Degeorge 2002). But after the Abbasids moved their capital from Damascus to Bagdad, Palmyra totally lost its importance and it declined to a small village (alAs'ad 1987; 1993; al-As'ad, al-As'ad and SchmidtColinet 2005; al-As'ad and Schmidt-Colinet 2005b). In Ottoman times (16th-19th century) Palmyra was a negligible settlement, left open for the raid of the Bedouins (al-As'ad 1993).

As Palmyra today is the most important ruin site of the Hellenistic-Roman times in Syria, it was declared as a UNESCO World Heritage Site in 1980. The first systematic excavations started already at the beginning of the 20th century by Russian and German archaeological missions (Michalowski 1968). Since this time there had been excavations by archaeologists from all over the world until 2011, when the political situation made it impossible to work in Syria. However, there is still a huge amount of the ancient city that has not been documented until now. The main building material of the excavated buildings in Palmyra has been limestone, which provides a good visibility of the remains in the geophysical results.

\section{Geological Background}

The region of Palmyra is characterised by two different geological units. In the north and west, the mountains of the Palmyra chains which belong to the Antilebanon tower up to $1000 \mathrm{~m}$ ASL. For comparison: Palmyra lies at only 395 m ASL (J ux and Omara 1960; Schachinger 1987). The Palmyra 
chains consist mainly of dolomites, which were used to construct the ancient buildings. They continue further towards the Euphrates River in a southwestnortheast direction. South and east of Palmyra, the Syrian Desert is situated, which is characterised by loose sand dunes. In the direct southern neighbourhood of the city, a huge sebkha, a salt plain of $330 \mathrm{~km}^{2}$, can be found. This salt plain was already used in ancient times and provided one of the reasons of the wealthiness of Palmyra (Sanlaville and Traboulsi 1996).

\section{Methods}

\subsection{Magnetometry}

For the geophysical survey of archaeological sites, several ground-based methods were applied. These are mainly magnetometry, resistivity prospection and ground-penetrating-radar. Magnetometry is a successful and cost-effective tool for the detailed mapping of large areas in a reasonable time (English Heritage 2008). Total field magnetometers like the used Scintrex Smartmag SM4G Special provide the best results for archaeological prospection. The reason is that all components of the Earth's magnetic field are recorded; the resulting anomaly therefore is much stronger than the one recorded by fluxgate magnetometers, which record only one vector component. For our purpose and in order to reach the highest possible sensitivity combined with a maximum speed of prospection, the so-called "duosensor" configuration (Fassbinder 2010) was chosen. The sensors are therefore mounted on a wooden frame and carried in a zigzag-mode $30 \mathrm{~cm}$ above the ground. The profiles are oriented approximately east-west in order to minimise technical disturbances of the magnetometer probes. The Scintrex Smartmag SM4G Special magnetometer provides a measurement of the geomagnetic field with sensitivity of $\pm 10 \mathrm{pT}$; for comparison: the value of the geomagnetic field in Palmyra in March 1997 has been $45,440 \pm 30 \mathrm{nT}$.

During 1997 and 1998 the solar activity and diurnal variation induced by the solar wind were very low. These linear changes in the daily variation of the geomagnetic field were reduced to the mean value of the $40 \mathrm{~m}$ sampling profile or alternatively to the mean value of all data of a $40 \times 40 \mathrm{~m}$ grid
(Fassbinder and Gorka 2009). Here it is assumed that the variation of the Earth's magnetic field during one profile length of $40 \mathrm{~m}$ follows a linear increase or decrease in intensity. If so, it is possible to eliminate this variation for each traverse line by a reduction to the mean line value. This filters apparent linear structures parallel to the profile. Alternatively, in magnetically quiet areas it is also useful to calculate the mean value of the whole $40 \times 40 \mathrm{~m}$ grid and use this value as described above. Additionally, by using this procedure the difference between the measurement of both magnetometer probes and the - theoretically calculated - mean value of the Earth's magnetic field was obtained. This intensity difference gave the apparent magnetic anomaly, which was caused by the magnetic properties of the archaeological structure, the soil magnetism and the geology. To cancel the natural micro-pulsations of the Earth's magnetic field, a band pass filter in the hardware of the magnetometer processor was used. The processing of the magnetometer data was achieved by some self-written resampling software and Geoscan Geoplot. Afterwards, the results were displayed by Golden Software Surfer.

Usually more than $90 \%$ of the magnetometer data in a $40 \mathrm{~m}$ grid on archaeological sites vary in the range of $\pm 10 \mathrm{nT}$ from the corrected mean value of the geomagnetic field. Stronger anomalies can be ascribed to burned structures or to pieces of iron containing slag or modern iron debris. In-situ burning, pieces of iron and the traces of hypocausts are easily distinguishable by their different direction of magnetic dipole anomalies, but also by their high intensities (> $\pm 50 \mathrm{nT})$.

\subsection{Resistivity prospection}

Almost all of the Hellenistic and Roman buildings are stone constructions which have a strong contrast against the surrounding soil in electric conductivity. For this reason, the stone buildings are mapped very clearly through resistivity prospection, which is based on the apparent differences in the conductivity of the soil. Clays and marls, for example, have specific resistivity values of $3-100 \mathrm{Ohm} \mathrm{m}$. On the contrary, sand, limestone and sandstone provide resistivity values of 100 $5000 \mathrm{Ohm} \mathrm{m}$. In conductive wet soil the resistivity of stone constructions is several degrees higher than in the surrounding soil. 


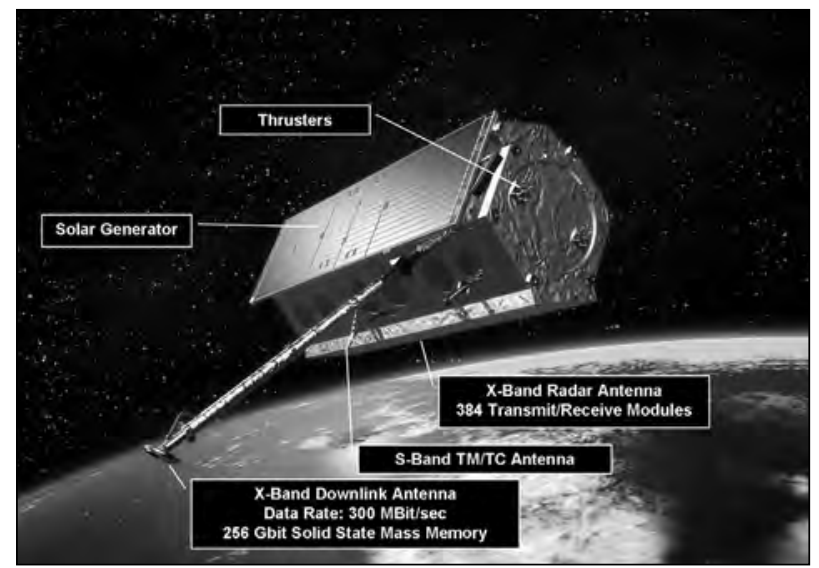

Figure 2. Artist view of the TerraSAR-X satellite. Note the solar generator (upper left), the boom with the $X$-Band downlink antenna (lower left) and the $X$-band radar antenna (lower right).

The commercial Geoscan RM15 instrument in a so called dual-pole configuration was used to collect electrical resistivity data. In this configuration, the two current probes are positioned in "infinity" (i.e. in a distance of around $50 \mathrm{~m}$ away from the measurement grid). The survey was conducted with two potential electrodes mounted at a frame in a fixed distance of $50 \mathrm{~cm}$.

The data processing was done with Geoscan Geoplot and Golden Software Surfer again. To eliminate the natural variations of soil moisture and to enhance the visible archaeological remains, a high-pass filter was applied to the data.

\subsection{Satellite radar}

While the spatial resolution of the groundbased methods is tremendously high, the resolution of satellite sensors was enhanced in the last few years. Therefore, the new satellites likeWorldView-2 offer a point spacing of $0.6 \mathrm{~m}$ in optical images. The improvement is even more dramatic in images created through Synthetic Aperture Radar. Before the launch of the German radar satellite TerraSAR-X in 2007 only a resolution of $5-25 \mathrm{~m}$ could be achieved. Now a resolution of SAR images of 1 - 2 $\mathrm{m}$ is available.

Synthetic Aperture Radar (SAR) provides a powerful tool for archaeological prospection from space. Thismethod is based on a satellitesensorin the microwave frequency range, which is illuminating the Earth's surface with short electromagnetic impulses. Therefore, SAR is an active survey method and measurements are possible independently of daylight and weather conditions (Lee and Pottier 2009). Because of the specific reflection conditions in the microwave spectrum, the SAR image can show even structures which are smaller than the actual resolution of the sensor (Albertz 2009). This is a very important fact for the satellite-based prospection of archaeological sites like Palmyra that mainly consist of faint archaeological remains.

To get the highest possible resolution from space, a technical expedient, the so-called aperture synthesis, has to be applied. All targets are illuminated several times in one measurement cycle and the returned signals are correlated by their amplitude and phase. Afterwards, the data points are treated as if they were gathered by one long antenna (Albertz 2009; Bamler 1999; Lee and Pottier 2009). This is called the aperture synthesis and the method is named Synthetic Aperture Radar. SAR is the only possibility to get high-resolution radar data from space. Because of the huge distance between sensor and targets, a $15 \mathrm{~km}$ length physical antenna would be needed for a resolution of $1 \mathrm{~m}$; by SAR this length is reduced to $5 \mathrm{~m}$.

The first high-resolution German SARmission started in 2007 by the launch of the radar satellite TerraSAR-X. The project is a Public Private Partnership between the "Bundesministerium für Bildung und Forschung"(BMBF), the DLR and the Astrium $\mathrm{GmbH}$ and will last approximately until 2018. TerraSAR-X is a very compact satellite with a length of $5 \mathrm{~m}$ and a diameter of $2.4 \mathrm{~m}$ (Fig. 2). Nevertheless, it carries 384 transmitter/receiver antennae with an X-band radar frequency of 9.65 GHz. For further details on the mission, the interested reader is referred to e.g. Krieger et al. (2010) and Werninghaus and Buckreuss (2010).

TerraSAR-X data can be ordered directly at the DLR by a scientific proposal. As all of the standard processing steps applied to SAR data (especially the speckle reduction by a multi-look approach) lower the resolution, we used the original data of the satellite.

The advantage of using SAR instead of optical satellite images as a main space-borne method 


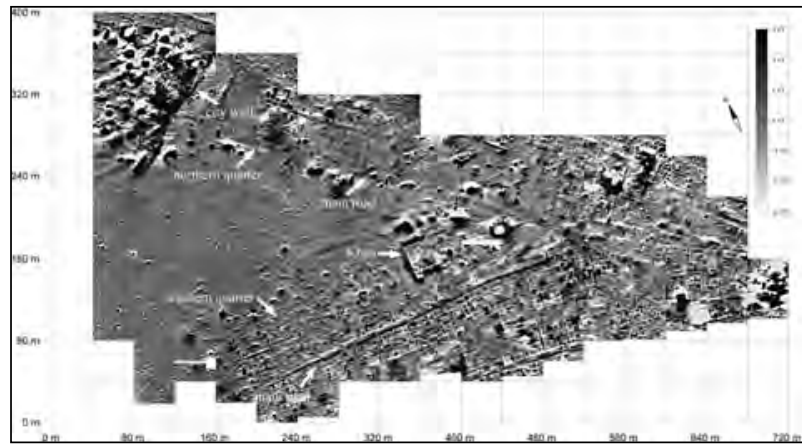

Figure 3. Magnetogram of the Hellenistic town of Palmyra. Overlay with the high-pass filter to visualize the stone walls in more detail. Caesium magnetometer Scintrex Smartmag SM4G-Special, Duo-Sensor-configuration, Dynamics: $\pm 3 n T$ in 256 greyscales, Sensitivity: \pm 10 pT, Point density: $50 \times 25 \mathrm{~cm}$, interpolated to $25 \times 25 \mathrm{~cm}$, 40-m-grids (Becker and Fassbinder 1999).

is that by radar it is possible to detect buried archaeology as the active signal can penetrate the soil. Furthermore the method is independent on the daylight and weather conditions.

\section{Results}

\subsection{Ground-based prospection}

The magnetometry and resistivity prospection was carried out in March 1997 and 1998. Whereas the magnetometer prospecting covered ca. 20 ha in thearea of the supposed Hellenistic town (Fig. 3 and 5 rectangle), the resistivity prospecting concentrated on two grids (60 x $40 \mathrm{~m}$ and $160 \times 120 \mathrm{~m}$ ) (Fig. 4 showing a high density of stone constructions). The results prove that the Hellenistic Palmyra was subdivided by three main streets oriented to the east and meeting in a V-shaped conjunction (Fig. 3). This conjunction astonishingly appears nearly empty and is only flanked by some kilns and grave monuments (Becker and Fassbinder 1999; Fassbinder and Linck 2012; Linck, Fassbinder and Buckreuss 2012). The northern one was underlain by a water pipeline, which can be identified by a higher magnetisation in the magnetogram and which has been proved by subsequent excavations (Plattner 2012).

The "Northern Quarter" was located north of this road (Fig. 3). It was characterised by a loose arrangement of large palaces with inner courtyards. One of the most striking buildings, the so-called

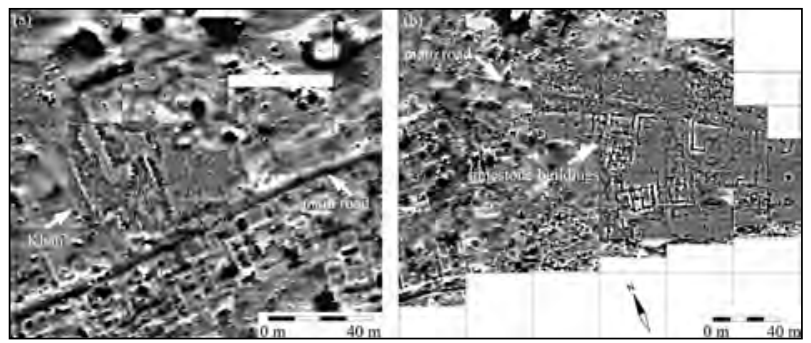

Figure 4. High-pass filter of the resistogram of (a) one of the palaces of the Palmyrene elite, (b) an area with dense irregular houses in the east of the town. Plotted over the corresponding part of the magnetogram. Geoscan RM15, Dualpol-configuration, Dynamics: $\pm 10 \Delta \mathrm{Ohm} \mathrm{m}$, Point density: $50 \times 50 \mathrm{~cm}$, interpolated to $25 \times 25 \mathrm{~cm}$, 20-m-grids (resistogram), 40-m-grids (magnetogram) (Becker and Fassbinder 1999).

"Khan", has been subsequently surveyed by resistivity prospection (Fig. 4a) and archaeological excavations. In the geophysical results it displays a high electric resistivity. Therefore, it can be inferred that it was constructed of limestone. The Khan consisted of several distinct rooms and apparently was erected in a building pit filled with burnt debris showing up as a positive magnetic anomaly (Schmidt-Colinetand al-As'ad 2000). Near the wadi, the magnetogram shows comparatively obscured, but nevertheless monumental floor plans. This could probably be explained by an extensive destruction of the buildings through periodic flooding and sedimentation by the wadi. This might expalin why the Hellenistic town has been abandoned in Roman times and a new one has been constructed north of Wadi el Kubur (Fassbinder and Linck 2012; Linck, Fassbinder and Buckreuss 2012).

The "Southern Quarter", on the contrary, was built with densely arranged small-scale houses (Fig. 3 and 4b). They were not limited to the main roads and extended to the minor roads. Therefore, this quarter had a nearly radial structure (Becker and Fassbinder 1999; Fassbinder and Linck 2012; Linck, Fassbinder and Buckreuss 2012). Small-scale excavations in selected parts of the magnetogram confirmed this interpretation and showed that the majority of the houses was constructed of weak magnetised limestone. On the contrary, some of the foundations show up as positive anomalies, which might signify that they were built with burnt mud bricks that have a higher magnetisation than 


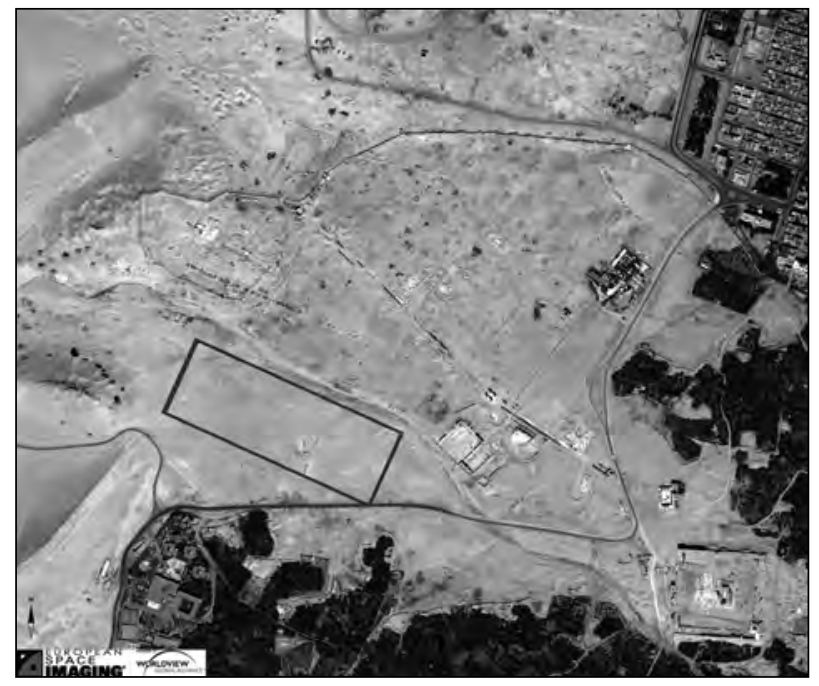

Figure 5. Optical image of the U.S. remote sensing satellite WorldView-2 in the area of ancient Palmyra. Clearly visible are the upstanding remains, but because of small sand accumulations at shallow buried walls even subsurface structures can be identified. Data take: 11. April 2011, Resolution: $0.6 \mathrm{~m}$. The rectangle indicates the location of the magnetometry grid.

the surrounding soil. Unfortunately, geophysical surveys could not be undertaken in the southern limit of the quarter because of a nearby highly frequented modern road.

West of the Khan, a nearly empty area is visible in the magnetogram (Fig. 3). SchmidtColinet and al-As'ad (2000) supposed that this place could have been used as temporary storage yard for camel caravans or a place for nomad tents that did not leave many traces in the soil. This assumption cannot be verified by presented geophysical data, but it is obvious if one compares the results with those intensively used parts in the rest of the magnetogram.

In the westernmost part of the survey area, a city wall can be identified in the elongation of a hill ridge that served as a natural barrier and limited the town to the west. Outside of the wall a dense layout of extensively burnt structures can beseen that reach until the wall and are evidence of an extreme fire. Archaeological structures cannot be distinguished in this area.

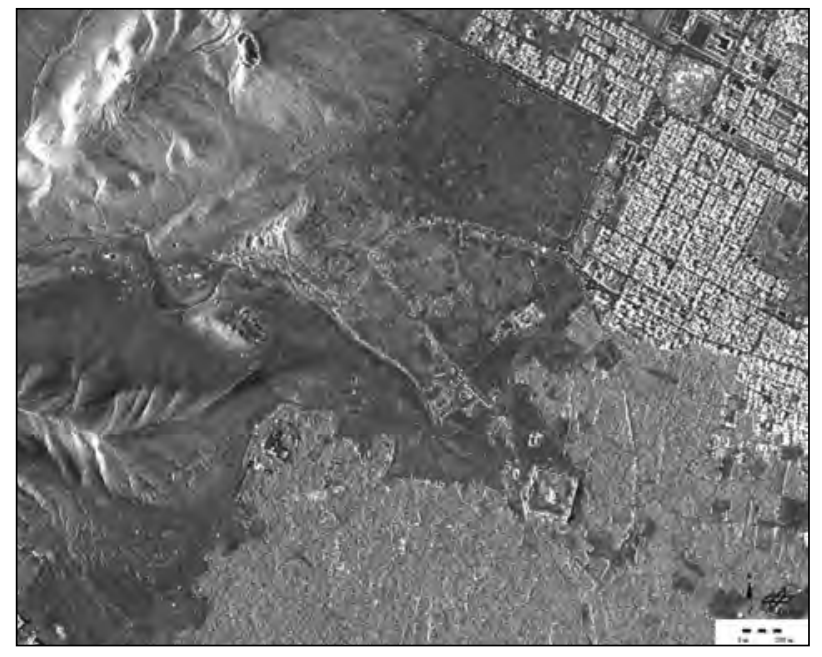

Figure 6. Radargram of TerraSAR- $X$ in the area of the ancient Palmyra. Especially upstanding structures can be distinguished very well, but even parts of the buried archaeology are detectable. Data take: 28. February 2011, Horizontal polarisation, Spatially enhanced mode, Resolution: 1 - 2 m.

\subsection{Space-borne prospection}

Whereas the ground-based surveys concentrated on the Hellenistic part of Palmyra, the space-borne images covered the whole archaeological site, including the Roman part and the surrounding graveyards.

For the analysis of optical satellite data, a WorldView-2 image recorded on April 11th 2011 is used. It has a resolution of $0.6 \mathrm{~m}$ and therefore even faint and small-scale anomalies at the surface can be identified.

The area of the ancient city is disturbed by several modern tracks and a row of regularly arranged holes of a quanat. Nevertheless, a perfect view on the upstanding ancient Palmyra can be achieved (Fig. 5). Several monuments are well preserved, especially in the Roman town. First of all, the Diocletian city wall surrounding the settlement can be clearly identified and several watchtowers and bastions are visible. In the interior part of the city, the good state of preservation of the official buildings is remarkable. In the eastern corner, the huge Bel-sanctuary can be seen. Even today, the $200 \times 200 \mathrm{~m}$ court with the surrounding wall and the temple are impressive buildings. Further to the west 
the Nabu-sanctuary, the agora and the theatre are flanking the famous Great Column Road that runs through Palmyra from southeast to northwest. The westernmost part of the city is occupied by the late Roman military camp, whose layout is still visible today. In the living quarters, some of the roads and the adjacent buildings appear because of small sand accumulations at these shallow buried structures. It is remarkable that only the southwest to northeast running roads can be detected. The sand accumulation by the wind operates in this direction, and therefore the orthogonal linking roads remain unseen by optical images in the subsurface (Linck, Fassbinder and Buckreuss 2012). The same effect is reported by GORS (2002) in theanalysis of IKONOS images. South of the wadi, the earlier Hellenistic town detected by magnetometry is visible. Only the Khan, excavated by a German-Austrian-Syrian mission, is visible at first glance. Nevertheless, a detailed analysis of this area offers several other buried structures. Some of the palaces in the "North Quarter" and the main roads, detected by magnetic prospecting, appear as slight sand accumulations in the satellite image (Linck, Fassbinder and Buckreuss 2012). Some of these walls were already reported as soil marks in aerial photos of the 1930s (Dentzer and Saupin 1996). In the west, the Hellenistic Palmyra is limited by a city wall already identified in the magnetogram, an elongation of the natural boundary of a nearby hill. The whole ancient settlement of Palmyra is surrounded by numerous burials. Remains of the graves that were sometimes constructed as tower tombs are aligned along the roads towards the city.

Even with a resolution of $0.6 \mathrm{~m}$ only structures preserved on surface can be identified. Buried structures can only be visualised by satellite radar. Therefore a radargram of the German satellite TerraSAR-X from February 28th 2011 was used (Fig. $6)$. The resolution of 1-2m ensures that at least the larger archaeological structures can be detected.

The rectangular corners of the upstanding ancient remains provide good reflectors for the radar waves: these structures are highly visible: the important monuments, known also from the optical images, like the Diocletian city wall, the Bel-sanctuary, the Column Road, the agora and the theatre, all appear very clearly (Linck and Fassbinder 2011; 2012; Linck, Fassbinder and Buckreuss 2012;
Linck, Fassbinder and Papathanassiou 2011) (Fig. 6 ). The city wall with its bastions and watchtowers depicts a very strong reflector, as it is $2.8 \mathrm{~m}$ thick (Wiegand 1932). The Nabu-sanctuary west of the huge Bel-sanctuary appears more detailed in the radar image than in the optical one because the preserved columns depict good corner reflectors for radar waves. Therefore, also the Column Road with its partitioning gates is visible very clearly. The Belsanctuary itself acts as one of the strongest reflectors, as it is one of the best preserved monuments. The buried archaeological structures appear mainly on the sub-pixel level and a time-consuming, detailed analysis was necessary to be able to map them. In the Roman town the layout of the entire rectangular grid of theroads can be drawn (Linckand Fassbinder 2011; 2012; Linck, Fassbinder and Buckreuss 2012: Linck, Fassbinder and Papathanasiou 2011) (Fig. 6). Because of the special reflection characteristics of radar waves, even some of the buried ancient buildingsaredetectable. Among thesearchaeological features, there is a considerable amount of so far unknown structures that are not mapped in the most recent map of the site by Schnädelbach (2010). The results hence prove that it is possible to map buried archaeological remains by satellite radar and it can be added to the promising and successful prospection methods.

The most striking object in the Hellenistic part is the excavated Khan (Fig. 6). Here the radargram shows several structures already known from the magnetic survey, e.g. the main roads that are very clearly visible because of their size, some minor roads, the city wall in the west and some walls of buildings. However, it is not possible to get all buildings in detail like in the magnetogram, since the resolution is limited to $1 \mathrm{~m}$. Again, like in the Roman part, several so far unknown archaeological objects become visible, especially in parts that were not covered by the magnetometer prospection.

\section{Conclusions}

The geophysical prospection of intensively used ancient archaeological sites like Palmyra is very promising. This is proved by a huge amount of successful measurements (Benech 2007; Erkul, Stümpel and Wunderlich 2011; Fassbinder 2011). While the majority of such sites show magnetic anomalies of more than $\pm 30 \mathrm{nT}$, in Palmyra 
Palmyra Revisited from Space - High-Resolution Satellite Prospection of a UNESCO World Heritage Site Roland Linck, Jörg W.E. Fassbinder and Stefan Buckreuss

comparatively weak anomalies of $\pm 3 \mathrm{nT}$ occur. The relative weak magnetic anomalies in huge parts of the measured area do not prove the hypothesis that the Hellenistic part was abandoned after extensive destruction by fire. In fact, it is much more probable that the city was moved to the north of the wadi after several catastrophic flooding. The results enable furthermore the location of the Hellenistic part and make it possible to draw a detailed map of its radial layout.

The remote sensing approach by optical satellite images and Synthetic Aperture Radar provides the verification of already known parts of the city map of Palmyra. However, several new features can also be identified too. As TerraSAR-X can detect both upstanding monuments as well as buried archaeological features, it is evident that the $\mathrm{X}$-band radar waves can penetrate into the ground. This fact has rarely been observed before and offers a totally new horizon for the use of high-resolution satellite radar in the archaeological prospection. Although remote sensing cannot substitute ground-based geophysical measurements, it can provide a good overview of the expected features. This helps to select suitable areas for more time consuming geophysical surveys, which can now be then undertaken only in pre-selected areas. The use of space-borne techniques is especially of high interest in the case of quite large archaeological sites that cannot be totally surveyed by excavations and ground-based methods. Moreover, it often provides the sole possibility of archaeological prospection in regions with a difficult political situation like Syria at the moment.

The opportunity to obtain SAR data with an outstanding resolution of $25 \mathrm{~cm}$ from TerraSAR-X through a proposed scientific project in autumn 2013 will enormously widen the usability of this method. This project will make available high-resolution data with only a slight difference in resolution between SAR and ground-based methods, making the comparison of the two data sets more effective.

\section{Bibliography}

al-As'ad, K. 1987. "NeueEntdeckungen islamischer Bauten in Palmyra." In Palmyra. Geschichte, Kunstund Kultur der syrischen Oasenstadt, edited by E. M. Ruprechtsberger, 254- 257. Linz: Druck- und Verlagsanstalt Gutenberg.
al-As'ad, K. 1993. "Palmyra in islamischer Zeit." In Syrien. Von den Aposteln zu den Kalifen, edited by E. M. Ruprechtsberger, 360-364. Mainz: Verlag Philip von Zabern.

al-As'ad, K., W. al-As'ad, and A. Schmidt-Colinet. 2005. "Ausblick." In Palmyra - Kulturbegegnung im Grenzbereich, edited by A. Schmidt-Colinet, 83-91. Mainz: Verlag Philipp von Zabern.

al-As'ad, K., and A. Schmidt-Colinet. 2005a. "Kulturbegegnung im Grenzbereich." In Palmyra Kulturbegegnung im Grenzbereich, edited by A. SchmidtColinet, 36- 63. Mainz: Verlag Philipp von Zabern.

al-As'ad, K., and A. Schmidt-Colinet. 2005b. "Zur Einführung." In Palmyra - Kulturbegegnung im Grenzbereich, edited by A. Schmidt-Colinet, 2- 12. Mainz: Verlag Philipp von Zabern.

Albertz, J. 2009. Einführung in die Fernerkundung. Grundlagen der Interpretation von Luft und Satellitenbildern. Darmstadt: Wissenschaftliche Buchgesellschaft.

Bamler, R. 1999. "The SRTM Mission: A World-Wide 30 m Resolution DEM from SAR Interferometry in 11 Days." In Photogrammetric Week'99, edited by D. Fritsch and R. Spiller, 145- 154. Heidelberg: Wichmann Verlag.

Becker, H., and J. W. E. Fassbinder. 1999. "Combined Caesium Magnetometry and Resitivity Survey in Palmyra (Syria) 1997 and 1998." In Archaeological Prospection: Third International Conference on archaeological prospection, Munich, 9-11 September 1999, edited by J. W. E. Fassbinder and W. Irlinger, 156-160. München: Karl M. Lipp Verlag.

Benech, C. 2007. "New approach to the study of city planning and domestic dwellings in the ancient Near East." Archaeological Prospection 14:87- 103.

Bounni, A., and K. al-As'ad. 1990. Palmyra. Geschichte, Denkmäler, Museum. Damaskus.

Browning, I. 1979. Palmyra. London: Chatto \& Windus Ltd.

Degeorge, G. 2002. Palmyra. München: Hirmer Verlag.

Dentzer, J. M., and R. Saupin. 1996. “L'espace urbain à 
Across Space and Time. Papers from the 41st Conference on

Computer Applications and Quantitative Methods in Archaeology. Perth, 25-28 March 2013

Palmyre remarques sur des photographies aériennes anciennes." Les Annales Archéologiques Arabes Syriennes 52:297- 318.

English Heritage. 2008. Geophysical Survey in Archaeological Field Evaluation. Swindon: English Heritage Publications.

Erkul, E., H. Stümpel, and T. Wunderlich. 2011. "Geophysical investigation of the Hittite city of Sarissa." In Archaeological Prospection. Proceedings of the 9th International Conference on Archaeological Prospection. Izmir-Turkey, 19-24.09.2011, edited by M. G. Drahor and M. A. Berge, 40-44. Istanbul: Archaeology and Art Publications.

Fassbinder, J. W. E. 2007. “Unter Acker und Wadi: Magnetometerprospektion in der Archäologie." In Einführung in die Archäometrie, edited by G. A. Wagner, 51- 73. Berlin: Springer Verlag.

Fassbinder, J. W. E. 2010. "Geophysikalische Prospektionsmethoden - Chancen für das archäologische Erbe." In Toccare - Non Toccare, edited by E. Emmerling, 10- 32. München: Siegl Verlag.

Fassbinder, J . W. E. 2011. "Geophysikalische Prospektion in Pompeiopolis. " In Pompeiopolis. Eine Zwischenbilanz aus der Metropole Paphlagoniens nach fünf Kampagnen (2006-2010), edited by L. Summerer, 17- 27. Langenweißbach: Verlag Beier \& Beran.

Fassbinder, J. W. E., and T. Gorka. 2009. "Beneath the desert soil - archaeological prospecting with caesium magnetometer." In New technologies for archaeology. Multidisciplinary investigations in Palpa and Nasca, Peru, edited by M. Reindel and G. A. Wagner, 49-69. Berlin: Springer Verlag.

Fassbinder,J . W. E., and R. Linck. 2012. "Geophysikalische Prospektion." In Palmyras Reichtum durch weltweiten Handel. Archäologische Untersuchungen im Bereich der hellenistischen Stadt, Bd.1: Architektur und Ausstattung, edited by A. Schmidt-Colinet and W. Al-As'ad, 79-88. Wien: Verlag Holzhausen.

Gaffney, C., and J. Gater. 2003. Revealing the Buried Past: Geophysics for Archaeologists. The Mill: Tempus Publishing Ltd.

Gawlikowski, M. 2005. “Tempel, Gräber und Kasernen.
Die polnischen Ausgrabungen im Diokletianslager." In Palmyra - Kulturbegegnung im Grenzbereich, edited by A. Schmidt-Colinet, 22-28. Mainz: Verlag Philipp von Zabern.

GORS. 2002. Syria - Archaeology from Space. Damaskus: General Organization of Remote Sensing.

Hartmann, U. 2001. Das palmyrenische Teilreich. Stuttgart: Franz Steiner Verlag.

Jux, U., and S. M. Omara. 1960. "Der geologische Aufbau der Umgebung von Palmyra in Syrien." Geologische Rundschau 49 (2):467- 486.

Krieger, G., I. Hajnsek, K. Papathanassiou, M. Younis, and A. Moreira. 2010. "Interferometric Synthetic Aperture Radar (SAR) Missions Employing Formation Flying. A German Earth satellite system is designed to produce data on forest structure, biomass, tectonic shifts and glacier movements, and to advance understanding of Earth dynamics." Proceedings of the IEEE 98 (5):816- 843.

Lee, J. S., and E. Pottier. 2009. Polarimetric Radar Imaging. From Basics to Applications. Boca Raton: CRC Press.

Linck, R., and J. W. E. Fassbinder. 2011. "Im Reich der Königin Zenobia: Satellitenradar und Magnetometerprospektion in Palmyra, Syrien." Denkmalpflege Informationen 149:74- 77.

Linck, R., J. W. E. Fassbinder, and S. Buckreuss. 2012. "Integrated geophysical prospection by high-resolution optical satellite images, Synthetic Aperture Radar and magnetometry at the example of the UNESCO World Heritage Site of Palmyra (Syria)." Archaeology and Geoinformatics 7: CD-ROM.

Linck, R., J. W. E. Fassbinder, and K. Papathanassiou. 2011. "Multipol-SAR-Survey of the UNESCO World Heritage Site Palmyra (Syria)." In Archaeological Prospection. Proceedings of the 9th International Conference on Archaeological Prospection. IzmirTurkey, 19-24.09.2011, edited by M. G. Drahor and M. A. Berge, 21-24. Istanbul: Archaeology and Art Publications.

Michalowski, K. 1968. Palmyra. Wien: Anton Schroll \& Co.

Neubauer, W., A. Eder-Hinterleitner, S. Seren, and 
Palmyra Revisited from Space - High-Resolution Satellite Prospection of a UNESCO World Heritage Site Roland Linck, Jörg W.E. Fassbinder and Stefan Buckreuss

M. Peter. 2002. "Georadar in the Roman Civil Town Carnuntum, Austria: An Approach for Archaeological Interpretation of GPR Data." Archaeological Prospection 9 (3):135- 156.

Plattner, G. 2012. “Sondage I: Eine hellenistisch-römische Straßenkreuzung und angrenzende Wohnbebauung. Baubefund, Architektur, Chronologie." In Palmyras Reichtum durch weltweiten Handel. Archäologische Untersuchungen im Bereich der hellenistischen Stadt, Bd.1: Architektur und Ausstattung, edited by A. SchmidtColinet and W. Al-As'ad, 89- 117. Wien: Holzhausen.

Sanlaville, P., and M. Traboulsi. 1996. "Palmyre et la Steppe Syrienne." Les Annales Archéologiques Arabes Syriennes 52:29-40.

Schachinger, S. 1987. "Palmyra im Landschaftsbild." In Palmyra. Geschichte, Kunst und Kultur der syrischen Oasenstadt, edited by E. M. Ruprechtsberger, 12-15. Linz: Druck und Verlagsanstalt Gutenberg.

Schmidt-Colinet,A., andK.Al-As'ad. 2000. "ZurUrbanistik des hellenistischen Palmyra. Ein Vorbericht."Damaszener Mitteilungen 12:61-93.

Schnädelbach, K. 2010. Topographia Palmyrena, Vol. 1: Topography. Bonn: Rudolf Habelt Verlag.

Scollar, I., A. Tabbagh, A. Hesse, and I. Herzog. 1990. Archaeological Prospecting and Remote Sensing. Cambridge: Cambridge University Press.

Werninghaus, R., and S. Buckreuss. 2010. "The TerraSAR-X Mission and System Design." IEEE Transactions on Geoscience and Remote Sensing 48 (2):606- 614 .

Wiegand, T. 1932. Palmyra. Ergebnisse der Expeditionen von 1902 und 1917. Berlin: Heinrich Keller Verlag. 


\title{
Classification of Geophysical Data of Angkor, Cambodia and its Potential as an Online Source
}

\author{
Till F. Sonnemann \\ Leiden University, The Netherlands
}

\begin{abstract}
:
This paper introduces a classification of archaeological finds from extensive geophysical surveys at the UNESCO World Heritage Site of Angkor, Cambodia, and addresses the challenges to create an online database that serves the research community. The existing offline database was created as part of an interdisciplinary archaeology team investigating the medieval Khmer capital. A combination of close range and remote sensing techniques was deployed on diverse archaeological sites, such as production and habitation areas, temples, their enclosures, and the vast water management system. The various locations were investigated by GPR, and a small number further identified by excavation. All subsurface features were geo-referenced, categorised, and the information stored in a GIS. The results, particularly the ones related to small surveys and surveys of not previously investigated sites, are seldom published, but they still need to be described and made accessible for future research and heritage conservation. Using previously unpublished analysis of the small Angkorian temple site at Doun Kaev as an example, this paper discusses examples of existing databases and the issues regarding a proposed online database for geophysical surveys for Angkor and comparable historic sites.
\end{abstract}

\section{Keywords:}

GPR, Angkor, Database, Geophysics, Archaeology

\section{Introduction}

Angkor was a major centre in medieval Southeast Asia and today has significant historic value for Cambodia. Structures and settlements of the medieval Khmer centre of Angkor ( 7th to 16th century CE) spread over an immense area. Multiple international teams are working within the precinct of the UNESCO world heritage site, a number of them using geophysical methods as part of their research. Their work will need to be recorded for the growing number of local researchers and subsequent international teams.

A great number of those surveys produce data which, by themselves, would have little chance to be acknowledged as sufficiently significant for publication. This includes equipment suitability studies, investigation on a particular soil type, the search for potential archaeological features which may not be detected, or a new technique that turns out to be ineffective. However, providing information about techniques used on a particular site and where the data can be found would help future research significantly.

Corresponding author: tillsonnemann@hotmail.com
Taking into consideration the fast pace of development around Siem Reap, gateway to the UNESCO world heritage site, smaller archaeological sites may be destroyed before they can be investigated. An easily accessible and updatable geophysical database on features of archaeological importance would save information on the buried, and often unknown, heritage and serve as a guide to plan and direct future research.

\section{GPR Surveys at Angkor and the Example of Doun Kaev}

As part of the international and multidisciplinary Greater Angkor Project, extensive GPR surveys have produced hundreds of kilometres of data files (Sonnemann 2011) of detailed subsurface information, a characteristic that only geophysical techniques offer. The scale of each survey, often conducted in collaboration with other research groups, was dependent on the particular focus of archaeological research. Following investigations on the water management system by Groslier (1979), Pottier (2000), Kummu (2009), Fletcher et al. (2008), part of it - including the original floodplain and its modifications, earthen canals and 
large reservoirs - was investigated through long 2D GPR transects crossing the landscape. Areas with possible masonry subsurface structures inside and close to the large temple enclosures as well as potential habitation and construction sites were mapped and processed using 3D GPR. The data sets were analysed in combination with other remote sensing techniques (including aerial, visual and SAR satellite), and a number of finds were further investigated in excavations and, where possible, dated.

As part of this project, the GPR survey conducted at Doun Kaev (number xyz in Fig. 1) is an example of a situation described above: an insignificant site with minor geophysical findings. A result that possibly would not be published: the information therefore may not be accessible to other parties. The area consists of two small temple sites near the village of Doun Kaev, located northwest of the West Baray, which were investigated in collaboration with L. Benbow of the University of Sydney. The objective was to improve the understanding of settlement patterns, identify remaining underground structural features such as foundations, and to ascertain their orientation and depth, as well as to identify any archaeological featuresaround thetemplesite(Sonnemann2011,88, 126- 127, 308). The resulting data are a combination of $2 \mathrm{D}$ profiles and $3 \mathrm{D}$ grids, representing both types of data collected and analysed.

The aerial image interpretation comprises two small temple sites close to each other (Evans 2007). An unnamed temple mound (CP96) lies $150 \mathrm{~m}$ south of one known as Kok Song (LL600). Their configuration is similar to numerous examples of small temple sites mapped by remote sensing (Pottier 1999). Both sites are roughly oriented east-west, with three sides enclosed by a moat, now empty, and an earthen causeway crossing the moat to the central platform from the east (see area overview in Fig. 4). The moat of small temples was originally filled by ground and rain water, providing a simple year-round water supply (Kummu 2009, 1416). There is a small pond to the north, a trapeang, which was used as a supplementary water and fishing source. The layout of the earthworks and limited scatter of ceramic sherds are the only visible remains indicating a temple site. There is no evidence of a superstructure: the shrines were either

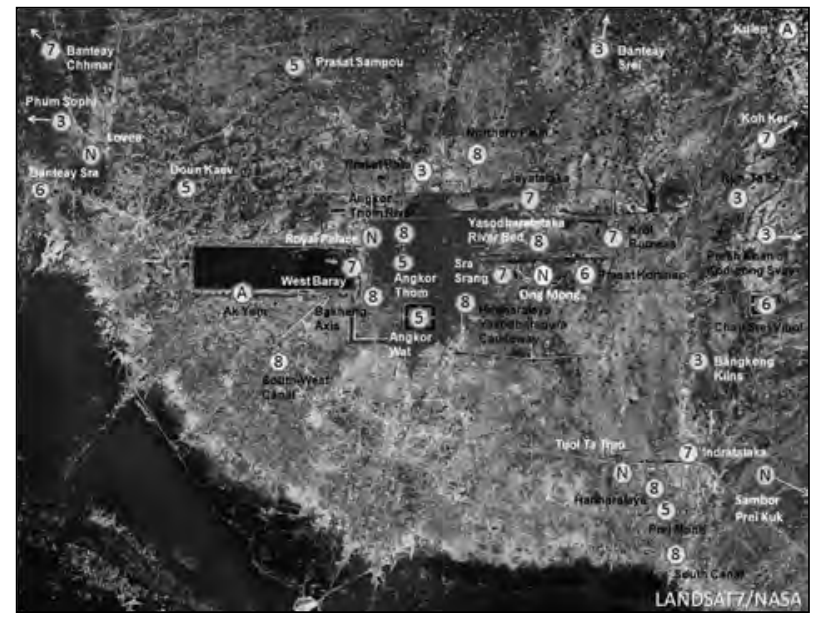

Figure 1. Overview of GPR data collection at Angkor. The numbers shown correspond to the chapter where the site is described in Sonnemann (2011). The letter A indicates entries in the appendix; $N$ marks surveys conducted after 2010. (Background Image: Landsat7/NASA).

constructed of perishable material, such as wood, or made of bricks, which may have been reused elsewhere. The central earthen mound of CP96 is void of vegetation, with a smooth and flat earthen surface flanked by palm trees and scrubs.

The GPR results of a $30 \mathrm{~m}$ by $30 \mathrm{~m}$ grid at CP96 (Fig. 2) display two rectangular and, without doubt, masonry features which are positioned at a 90 degree angle. The main and roughly squared feature, of a dimension of $9 \mathrm{~m}$ by $9 \mathrm{~m}$, is in alignment with the entrance causeway on the western side. A second feature of a dimension of $6.5 \mathrm{~m}$ by $6 \mathrm{~m}$ lies to the north. A third, less obvious feature of $7 \mathrm{~m} \times 3.5 \mathrm{~m}$ matches the smaller one on the southern side. A thin linear feature that connects the corners of the three features might be the connection to an additional platform to the east. The data provide evidence of the rectangular foundation of two masonry towers and a less clear signal of a third one. The larger and deeper feature could represent the central temple tower which faced the entrance to the east; the smaller northern shrine could have matched another small shrine to the south, the foundations of which were removed. The whole ensemble displays a symmetrical outline between the three features which might have been connected by a small wall.

In the centre of Kok Song, however, dry clay walls enclose a large ditch, evidence of looting. The 


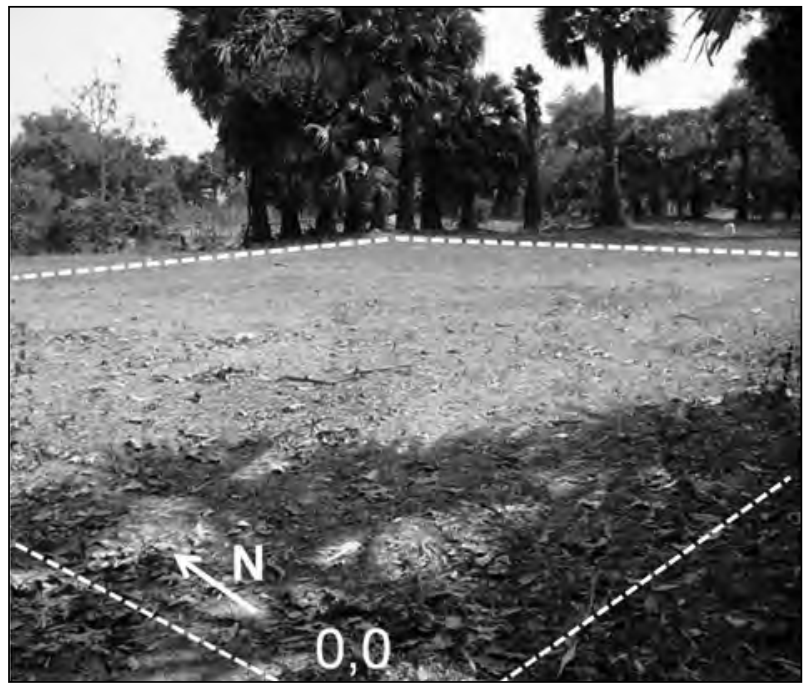

Figure 2. Top: a) Image of CP96 with the area of Grid DK_G1. Right: b) 3D-iso-surface of tower remains.

GPR survey of $21 \mathrm{~m}$ by $14 \mathrm{~m}$ was strongly affected by the topography, and did not reveal evidence of remaining subsurface masonry features.

For each temple site, two additional long profiles were collected through the moat and over the platform to the other side (Fig. 3), showing the depth of each moat and the extent of the platforms at CP96.

\section{Classification of the Database}

As with every GPR survey completed at Angkor as part of this campaign, the results from Doun Kaev were recorded and plotted in a GIS database. Many sites that were surveyed by GPR by the author until 2010, and which were not covered in the $\mathrm{PhD}$ thesis itself, were made available in the appendix (Sonnemann 2011, 295-352). To guide data entry and to provide a search option, the sites and detected features were classified. In addition, the findings of the surveys were summarised, with images displaying the location, the area covered and transects produced, as well as the main results. So was Doun Kaev (Fig. 4), on the basis of the classification described below.

The following discussion gives an idea of how the subsurface information was primarily arranged, leaving the option to extend this list particularly for archaeological finds at Angkor. Primary entries concern basic and objective information as in every

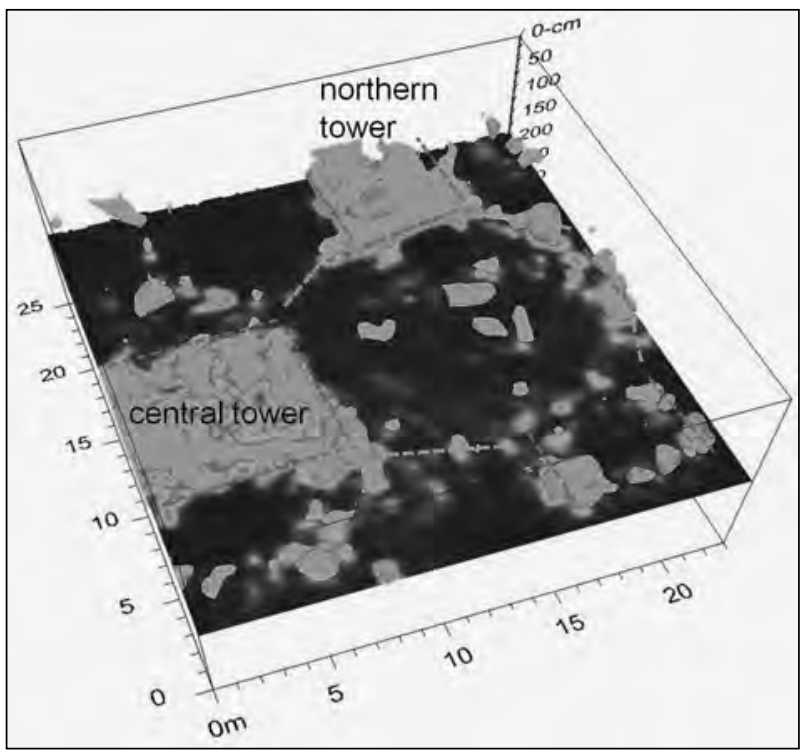

other database. The archaeological site investigated is either named after a data entry (CP96) or after a location close to the survey site (Doun Kaev). 'Who' directed the survey provides contact information; the 'collaboration' with someone who may have initiated the survey not only covers data rights but often leads to information on subsequent research. 'When' the survey was conducted is particularly important in a subtropical environment where strong monsoons floods can change the soil properties considerably one part of the year, and in a region where development occurs. Other information include what 'technique' was used, the 'size' and spacing of thearea covered and the length' of collected profile data.

Secondary entries concern the (historical) functional context of the site. Divided into different 'research categories', the identified

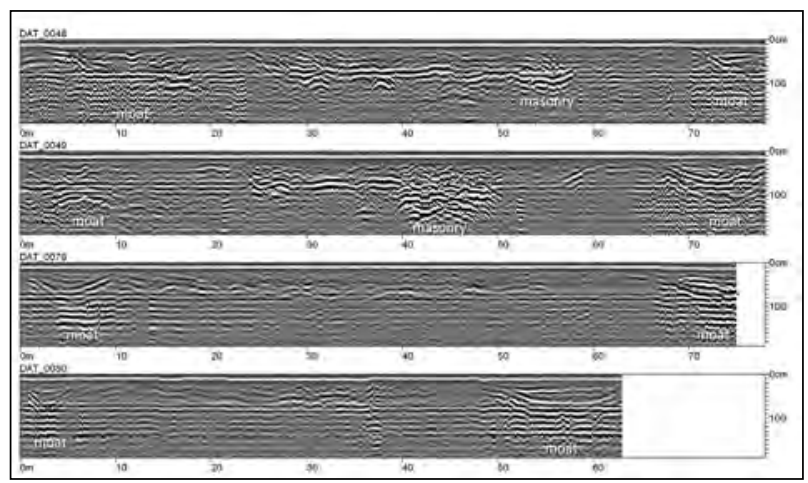

Figure 3. 2D-Profiles from temple mounds (CP96, upper 2, Kok Song, lower 2), and adjacent moats. 


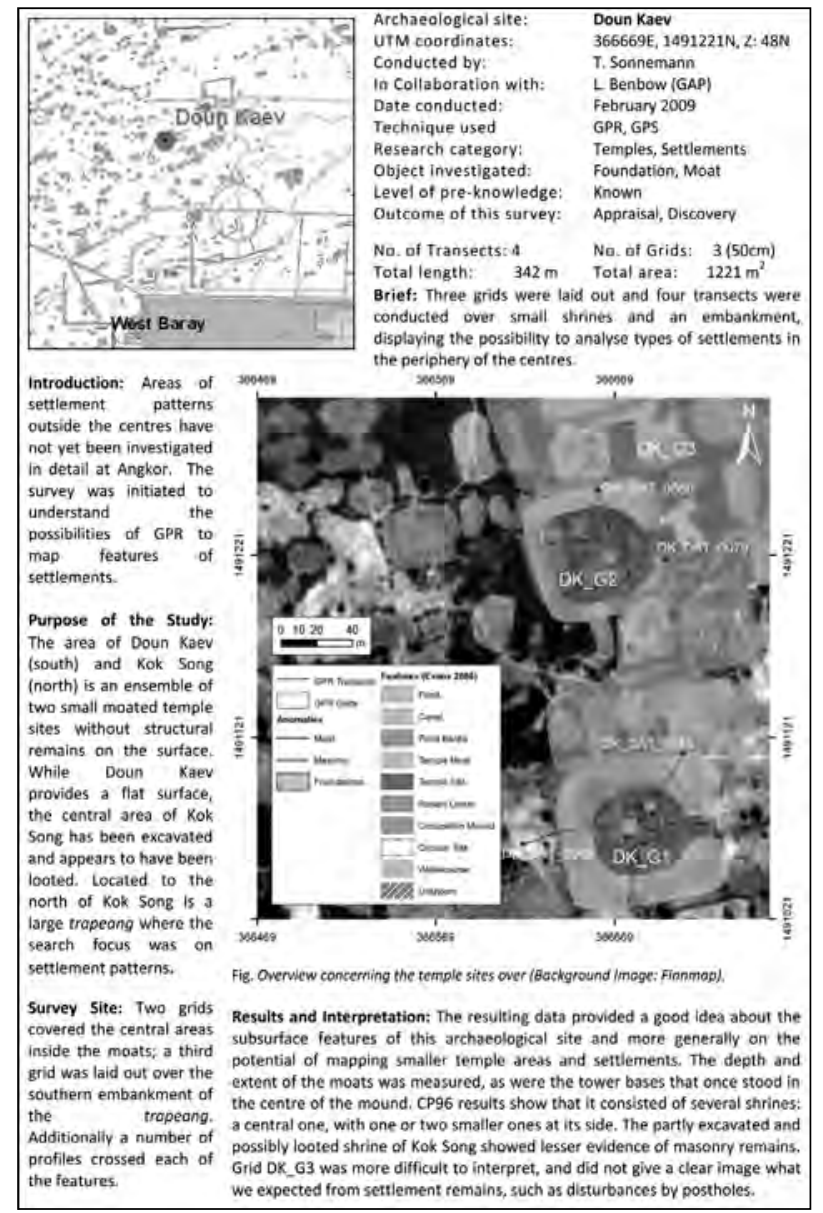

Figure 4. Idea design to display survey goal and some results, based on the example of Doun Kaev.

archaeological features were generally classified in accordance to Pottier (1999). The broadest scale concerns the 'network' of the water management and transportation system. Natural features are predominantly sedimentary remains of former natural streams, while artificial features are human made canals, and their earthen embankments that are used as roads. Also part of this network, and of particular importance, are the great reservoirs, particularly their inlets and outlets. Considerably smaller are the 'temple' areas in the vicinity of masonry monuments and enclosures, where investigated features concern foundations, moats and ponds. The most detailed category of investigation are 'settlement' features on raised earthen mounds, which potentially provided living space (house mounds), production sites for ceramic (kilns) and metal (furnaces), and burials.
The last entries concern the notional contents of the research. Based on existing literature, e.g. (Bruguier and Nady 1998), the level of knowledge' prior to the investigation is defined. Of a site known by location, its dimension, underground extent or form may not be clear. In contrast, Angkorian structures often have geometric symmetries. 'Geometry' therefore refers to a missing element in an assumed geometric pattern or configuration that is to be found. 'Topography' refers to a conspicuous landscape element indicating an archaeological site. A survey classified as 'methodology' focuses predominantly on the adoption of a technique to a specific environment.

The degree to which the knowledge of the area is influenced by the 'outcome of the survey' is classified by the last category. 'Appraisal' extended our knowledge of a known feature using a different technique. 'Identification' added size and depth to a reported feature. 'Discovery' revealed an assumed or previously unknown feature.

\section{Accessibility of the Data and Protection from Misuse}

An immense number of international teams are working all over the UNESCO world cultural heritage site, which may even increase in the future. Coordination of the various research teams lies with the APSARA Authority, and collaboration with this local heritage organisation is particularly important.

Numerous databases related to Angkor exist. Some of the archaeological data is presented as part of larger geographic information systems that include modern infrastructure and environmental issues, as established by J ICA (2005-2009); most of these however are offline. Others concern landscape archaeology (by EFEO and GAP), archaeological finds and ceramics inventories (numerous) and historical photo archives (by EFEO). Some information on published literature is available online (Persee 2014). Others concern the published literature on particular cultural sites, as published by Bruguier and Nady (1998). In those accessible databases, only published and reviewed articles are stored online, and publishing rights are clear. A different type is the currently planned database on Angkorian inscriptions (pers. com. J. Estève, D. Soutif). There, different levels of information - 
from the simple photos to scans or rubbings of the Khmer or Sanskrit epigraphs, to their transcriptions and translations into another language, and finally to their interpretation - produce a complex issue on data rights.

An openly accessible geophysical database could address similar problems. To make the information available to other researchers and heritage organisations in a digital environment, an online geophysical database would need to be easily accessible, updatable, and provide the opportunity to add new sites and information.

The issue of use and data rights by a third party has to be clearly defined, particularly when unpublished data are available. Consequently, the type and amount of information made available has to be considered. "Raw" data would need a large amount of storage space. If the data are processed, what processing steps were used? Geophysical data interpretation often depends on a highly subjective analysis; different processing, or the software in use, can significantly change the data potential. And additional data from other methods could lead to a new interpretation of the finds. Too much information, however, could raise another problem: depending on what is displayed predominantly on sites less known and unprotected, public access to location data could possibly lead to looting. It would be advantageous if the database was not fully available to the public, but hosted and updated instead by an organisation with a long-lasting interest in Angkor, possibly UNESCO and APSARA Authority, who could give permission to access, add and change information. A point open for discussion would be to make the entries voluntary, or, similar to research proposals and final reports, a requirement.

The issue of geophysical data archival is of course not new. A. Schmidt and E. Ernenwein provide in Guides to Good Practise: Geophysical Data in Archaeology an overview on how archiving of geophysical data could be achieved (Schmidt and Ernenwein 2014). There are a number of publicly accessible online databases that provide information on archaeological or geophysical surveys. The website of the International Association of Classical Archaeology (AIAC), FASTIONLINE (FastiOnLine 2014), hosts a database that documents archaeological surveys in Southern and Eastern Europe. An outstanding example for geophysical databases is the English Heritage Geophysical Survey Database (ADS 2014a) which gives information about 2700 surveys (as of 2011) conducted in England since the late 1960s. Incorporated into the Archaeological Data Service (ADS 2014b), the websites are publicly accessible and searchable, and provide basic information and contacts. The user statistics show a relatively low, but constant access, 1-3 website visitors/day in 2013, and download rates with 3-10 users/month in 2013 (as accessed on 4-102013: ADS 2013). A similar project regarding Dutch archaeology, E-depot voor de Nederlandse archeologie (EDNA 2014), completed between 2004 and 2006, provides information about a number of geophysical prospection surveys in the Netherlands and discusses quality standards in the country's archaeological surveys. Social media websites with particular interest in academic research such as the fast growing Academia (Academia 2014), where researchers provide access to published articles and reports, show that in the research community there is interest in data sharing.

\section{Conclusions}

Geophysical datasets by themselves are often seen as non-conclusive, particularly in archaeology. New discoveries therefore request confirmation by excavation. Angkor is certainly not the only archaeological site where data sharing could advance archaeological research. It would be particularly helpful, however, for large archaeological sites, where many different research teams are working. In Cambodia, many international teams come into the country only for their field season, which reduces the possibility for cross-communication. Newly gained information is stored away in survey reports, written in languages other than English, and not easily accessible to other research teams. The classification of geophysical data from Angkor in Sonnemann (2011), as shown in the survey at Doun Kaev, is only a first step to organise and make this valuable information available to a broader research community. This data set would have to be made readily availableand, more importantly, easily expandable. By having categorised the information, data entry by dropdown menu should easily be arranged in an online database. The categories introduced should be open for expansion and could 
as well host other scientific methods. A platform similar to the English Heritage Geophysical Survey Database, run by an organisation that has contact to, and to some extent also control of, all research teams, to upload and access geophysical and archaeological information under clear rules would prevent misuse. By providing basic survey and contact information, data rights should be kept with the person responsible for data entry. The information on what has been done at a particular site may support future research and collaboration between different international research teams.

\section{Bibliography}

Academia. 2014. "Academia.edu is a place to share and follow research." Accessed March 15. http: //www. academia.edu.

ADS. 2013. "The Geophysical Survey Database. English Heritage, 2012." Accessed October 4, 2013. http:// archaeologydataservice.ac.uk/ archives/view/ ehgsdb eh_2011/stats.cfm.

ADS. 2014a. "The Geophysical Survey Database English Heritage, 2012." Accessed March 15. http://sdb2.eng-h. gov.uk/.

ADS. 2014b. "Archaeology Data Service." Accessed March 15, 2014. http:// archaeologydataservice.ac.uk/ .

ADS. 2014b. "Archaeology Data Service." Accessed March 15. http:// archaeologydataservice.ac.uk/ .

Bruguier, B., and P. Nady. 1998. Bibliographie du Cambodge ancien. Paris: École Française d'ExtrêmeOrient.

EDNA. 2014. "E-depot voor de Nederlandse archeologie." Accessed March 15. http:// www.edna.nl/ .

Evans, D. 2007. "Putting Angkor on the Map: A New Survey of a Khmer 'Hydraulic City' in Historical and Theoretical Contest." PhD diss., University of Sydney.

FastiOnLine. 2014. "A database of archaeological excavations since the year 2000." Accessed March 15, 2014. http:// www.fastionline.org/ .

Fletcher, R., C. Pottier, D. Evans, and M. Kummu. 2008. "The development of the water management system of
Angkor: a provisional model." Bulletin of the Indo-Pacific Prehistory Association 28:57-66.

Groslier, B. P. 1979. “La cité hydraulique angkorienne: exploitation ou surexploration du sol?" Bulletin de l'École Française d'Extrême Orient 66:161- 206.

Japan International Cooperation Agency (JICA). 19992005. Cambodia Reconnaissance Survey Digital Data. Phnom Penh: Ministry of Public Works and Transportation (MPWT) and Kingdom of Cambodia and J apan International Cooperation Agency (J ICA).

Kummu, M. 2009. “Watermanagementin Angkor: Human impacts on hydrology and sediment transportation." Journal of Environmental Management 90 (3):14131421.

Persee. 2014. " Bulletin de l'École française d'ExtrêmeOrient." Accessed March 15 2014. http:// www.persee.fr/ web/revues/home/ prescript/ revue/ befeo.

Pottier, C. 1999. "Carte archéologique de la Région d'Angkor. Zone sud." PhD diss., Université Paris III -Sorbonne Nouvelle.

Pottier, C. 2000. "Some evidence of an inter-relationship between hydraulic features and rice field patterns at Angkor during ancient times." The Journal of Sophia Asian Studies 18:99- 119.

Schmidt, A., and E. Ernenwein. 2014. "Guide to Good Practice: Geophysical Data in Archaeology." Accessed March 15, 2014. http://guides.archaeologydataservice. ac.uk/g2gp/Geophysics_Toc.

Sonnemann, T. 2011. "Angkor Underground - Applying GPR to analyse the diachronic structure of a great urban complex." PhD diss., University of Sydney. 


\title{
The Accuracy of the Field Survey Results and its Implications in the Correct Understanding of Past and Present Practices
}

\author{
Luis Antonio Sevillano Perea and Victorino Mayoral Herrera \\ Instituto de Arqueología - Mérida, Spain
}

\begin{abstract}
:
The archaeological pedestrian surveys have become one of the main tools of the landscape archaeology research. A materiality approach to the surface archaeological record must take into account the physical properties of the entities of interest and the environment which contains them. Both are essential aspects to understand the way the archaeological entities were created and their post-depositional evolution. Nevertheless, there have been few discussions about the character of the archaeological surface compound or the accuracy of the methods to document it. These topics have a significant role to give an interpretation of the past and present practices material reflection. In this essay, the potentialities of the spatial analyst tools are used to examine the consistency of the surface survey data. Thus, a map that quantifies the frequency of the findings is used to analyse and visualize one of the main biasing factors within the surface surveys: the inter-observer variation.
\end{abstract}

\section{Keywords:}

Landscape Archaeology, Surface Survey, Archaeological Record, Findings Frequency Map

\section{Archaeological Landscape. Physical and Non-physical Aspects}

Our point of departure is the conception of the current landscape as a result of diverse agents interaction. Particularly, the agrarian landscape is a complex reality where many factors have acted to create the compounded system which we currently study. Consequently, the main interest is to understand how past societiesand their environment interacted in order to create the present landscape.

Recent theoretical approaches in archaeology maintain different perceptions of these processes and the importance devoted to the diverse nature of the "actors" involved. However, there exists a general trend which revalorizes the physical aspects of the archaeological record with independence of the theoretical perspective. Thus, terms such as "Processual-Plus" (Hegmon 2003) or "Symmetrical Archaeology" (Witmore 2007) or even the latest works of "Behaviour Archaeology" are good examples of this renewed approach to the material aspect of the archaeological record.

Following this tendency, some scholars attempt to draw our attention to materiality over

Corresponding author: Isevillano@iam.csic.es meaning. To keep this in mind means to "shift our conception of minerals from "raw" materials forming the background of human activities, to constructed, signifying elements within individual and community epistemological projects" (Owoc 2004, 119). In other words, stressing "the experiential rather than therepresentativequalities of the material culture" (Boivin 2005, 175), because the essence of these tangible elements "is at least partly determined by its material qualities" (J ones 2004, 328).

The experience, the processes of "perceiving, thinking, remembering and learning" need to be considered "within the ecological context of people's interrelations with their environments" (Ingold 2000, 171). And "instead of reducing the world to a regime of two opposing ontological realms, culture - nature, this approach claims that nearly everything happens between the two extremes, happens by way of mediation and translation". A network of agents that "links human and non humans in intimate relationship" (Olsen 2003, 98). The properties of the mind are fashioned through the involvement and the relationship with other agents. Thus, the activities included within the dwelling experience are equally necessary to form and reform the social relationships. 
In such a wide frame, the techniques used to analyse our target cannot be homogeneous. Instead, they have to include ways to take into account the natural and biological features of the landscape as cultural ones. It is obvious that each collectivity is constrained by the physical features of the environment in which they live. Some of their properties, identified in the current landscape, can be measured and quantified, matching with the positive sciences position. It is a necessary requisite to simultaneously consider how the landscape is socially and culturally generated, while also paying attention to its physical properties.

The mechanical features of the things will enable or constrain specific uses of them. To understand whether the material features of the different entities have an effect on the way the landscape is shaped, we have to explore and examine them. One of the main objectives of this kind of work is to delineate the temporal and spatial networks that link these tangible entities with the social behaviour of past cultures. Nevertheless, the point is not to examine whether the predominant process which shaped the landscape as object was a functional or symbolic one, but to explore "the interaction between the properties of materials and the way in which they are socialized" (J ones 2004, 335).

In addition, natural and biological features and processes are important not only in the creation of a specific society and culture, but also in our capability to detect their material remains. An interesting connection between the Return to things approach and the importance of the physical features of the archaeological record was investigated by M. B. Schiffer. To capture this connection he used the term "formation processes" (Schiffer 1976; 1983) and later the "behavioral chain", which "begins with the procurement of materials for manufacture but continues after use, through deposition until recovery by a researcher" (Skibo and Schiffer 2008, 22). It has to be clear that a physical entity does not have an inherent meaning that can be easily inferred; rather, things provoke and acquire meanings while losing some others throughout their life history. We can identify many implications of this perspective within thelandscape archaeology. Then, the landscape has several facets, from the dwelling perspective of past cultures to our contemporary experience with a definite space. Following already exposed methodological strategies (Chapa et al. 2003, 14; Vicent 1991, 3637 , we do not try to reconstruct the landscape or the environmental context which existed previously, but we use the present features to infer and analyse the social, economic and symbolic systems of past cultures. Within those features, the detection and interpretation of the agrarian practices is the main goal of our research work. Several actions that took placein a concretespacehaveresulted in aplethora of material remains that are distributed non-randomly over the space. Then, our survey scheme must allow us to record as precisely as possible those artefacts distributions, either on-site or off-site compounds. To achieve this objective, the strategy adopted is based on the non-site perspective (Thomas 1975); with a noteworthy influence of the Mediterranean tradition off-site surveys (Bintliff and Snodgrass 1988; Wilkinson 1992). Consequently, the features of the archaeological document are strongly related to the research project methodological approach.

\section{A Noteworthy Entity Within the Landscape, the Surface Archaeological Record}

The surface archaeological record has certain properties and qualities; therefore it is necessary to differentiate it from the general archaeological compound. We conceive the surface archaeological record as a discontinuous, heterogeneous and diachronic assemblage of elements that are the outcome of a number of processes within a concrete space. It is present in the most superficial layer of the earth and its chronology is contemporary. By recording its distribution, abundance, frequency and composition, it can be examined giving us a significant amount of archaeological information.

Thus, therecord of theseattributes must bethe main objective of the surface surveys. Nevertheless, the field-walkers meet diverse problems and biasing factors when performing this task. Accordingly, there exists a solid bibliographical corpus analysing thereliability of the archaeological surface document (Banning, Hawkins and Stewart 2006; Bintliff et al. 1999; Fanning and Holdaway 2004; Hirth 1978; Leusen 2002; Shennan 1985; Shott 1995; Schon 2002; Wandsnider and Camilli 1992). 


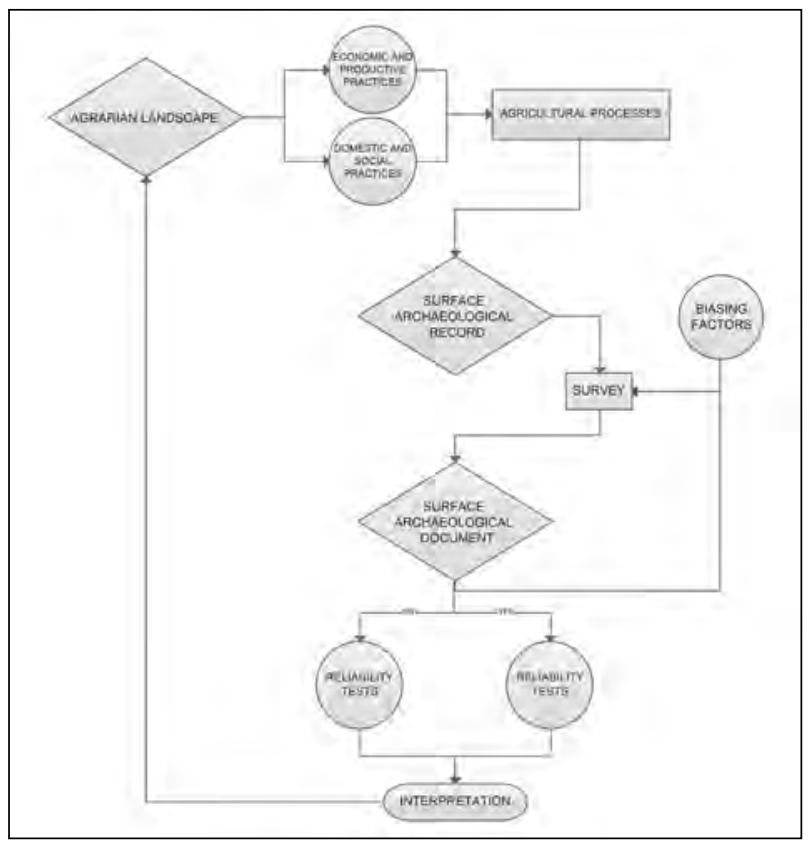

Figure 1. Survey project methodology.

Two different kinds of works have been performed to check the reliability of the survey results. On the one hand, some researchers have based their studies on unknown archaeological populations. They have used the archaeological data obtained during the fieldwork connected to other information (e.g., vegetation presence...). On the other hand, various archaeologist have based their analysis on artificial and then known artefact populations (seeding experiments). In any case, both kind of analysis show the existence of an important uncertainty in the archaeological document.

Within these studies, the classification of the physical conditions of the survey units and the explanation of the survey strategy are main topics which help us understand how the vegetation, the ground conditions, the inter-observervariability, the properties of thearchaeological targets, among other things, affect the surface record documentation. Therefore, the interpretation of the surface record must contain an analysis of the possible biases present in the archaeological data which we gathered (Figure 1 shows the methodological approach adopted).

Following this line of thinking, we have been performing a number of projects devoted to test the quality of the data gathered within a variety of surface surveys campaigns in the middle Guadiana basin and the Medellín's territory. The main ideais to use the important amount of information generated by the chosen survey strategy in order to test how close is the archaeological document generated to the actual archaeological surface aggregate.

\subsection{Archaeological surface record. Two main} aspects to examine: its material character and its spatial location

As stated above, the surface archaeological distributions are a heterogeneous assemblage. Therefore, we cannot expect the same behaviour in different archaeological compounds. In addition, we have to remember that these collections are mostly detected on ploughed plots ofland, wherearepetitive practice dislocates some objects from their original position. Thus, not only the material properties but their spatial location can give us important information. Our main objective is to get some evidence about the societies that produced them. Meanwhile, we also collect information about how later societies interacted with the same environment and the outcome of previous occupation of that space. By attempting to detect the activities carried out there, we can infer the possiblepost-depositional processes of the archaeological record.

From our viewpoint the materiality of the landscape has an explanatory value for cultural processes. The environment and its dwellers generate a specific system, a body of rules and traditions that can be reached in the archaeological record. It is one of our tools to test "the embodied ancient lives whose domestic, ritual, public and commercial waste has been imprinted into such abundant human debris on the disturbed surface (...)" (Bintliff 2009, 184).

When we think about the analysis of agronomic practices, we have to take into account not only the potentialities of the soil type, but also the repetition of some of these experiences through the time and the effects of the economic and social efficiency of these practices. Thus, the heterogeneity of an artefact distribution map is directly linked with the variety of processes that have taken place within a particular space. The diachronic repetition of some of them would have ended up in the establishment of a specific pattern. Then, the use of 
different strategies must be needed to understand the spatial structure of the artefact distributions in some contexts.

2.2 The spatial analysis techniques and the archaeological surface record

Thespatial techniquesnot only havemultiplied the possible analysis which can be performed, but they have also magnified the precision of our recording ability and have improved efficiency in the field work. They can help us to set up the patterns of the material aspect of the landscape and to link these tangible entities with the social behaviour that generated them. Spatial analysis is a useful tool to conjoin both aims especially considering their potential for the statistical and cartographical representation of this mixed statement.

Nevertheless, until recent years, the GIScience (as in the case with many other disciplines) has failed to recreate all the worries and concerns of either the Natural or Social Sciences. However, there have been some efforts to address this gap (e.g. Representing GIS edited by Fisher and Unwin 2005).

The frame of reference of the Euclidean notion of space (continuum invariable) is still the most prominent within the GIScience. In any case, it is becoming easier to find new approximations where the representation of the space is constructed on a time-scale basis or even trough qualitative or perceived perspectives, leading us to a "humancentered archaeology of space" (Wheatley 2004).

When we talk about time it seems obvious that the main approach to this variable is just to ignore the real time in favour of the artificial notion of a sequence of states. In considering the qualitative analysis in the spatial technologies within an archaeological perspective, the question that arises is whether these techniques are just a descriptive and representational tool or an analytical one. And if we adopt the last option, how useful are the qualitative methods to understand the landscape?

To some extent, the experimental work we present here is related to these strategies which are under development. Particularly, we want so see how the frequency of the findings during surface surveys behaves. As we will see below, this kind of quantifications is obviously linked with the abundance of archaeological entities, but we use a temporal frame to compute it instead a spatial frame of reference (squared meter for instance). Consequently, this shows how many artefacts the surveyors recorded per minute.

\section{An Experiment From the Surface Surveys: the Findings Frequency Map as an Alternative Analytical Tool to Understand the Surface Document}

\subsection{Research project background}

The agrarian landscapes of Peninsular South West offer an excellent opportunity to test our ideas about the meaning of archaeological surface record. Since 2009 we are developing a research project in this area focused in the long-term sequence of historical change at a territorial scale.

Our aim was to open "windows" of intensive archaeological record, with the surface survey as one of the cornerstone sources of evidence. The area around the historical site of Medellín was one of these windows for research (Fig. 2). This settlement has played an important rolein the middle Guadiana basin from the Bronze Age until the Early Modern times.

It was assumed that surface evidence goes much beyond the identification of "sites". This premise determined a project design oriented to use artefacts as the most elemental unit and to analyse their distribution in the whole study area. Such a time-consuming strategy obliged us to establish a hierarchical sampling design. First, a natural boundary sector of the basin was selected in an attempt to explore different landscape units of the valley. Second, seven longitudinal transects across this area were outlined and within them a systematic inspection of every land plot was performed. The specific procedure for survey was organised in three stages. First, 10 meter-spaced field-walkers covered the terrain, using GPS receivers to map the distribution of finds across their tracks. Every team member kept thesamereceiver duringthecampaign, so we can link the results discussed below to specific individuals. Second, this geo-referenced count was used to map the global distribution of finds in the field; and thirdly, the analysis of its varying density 


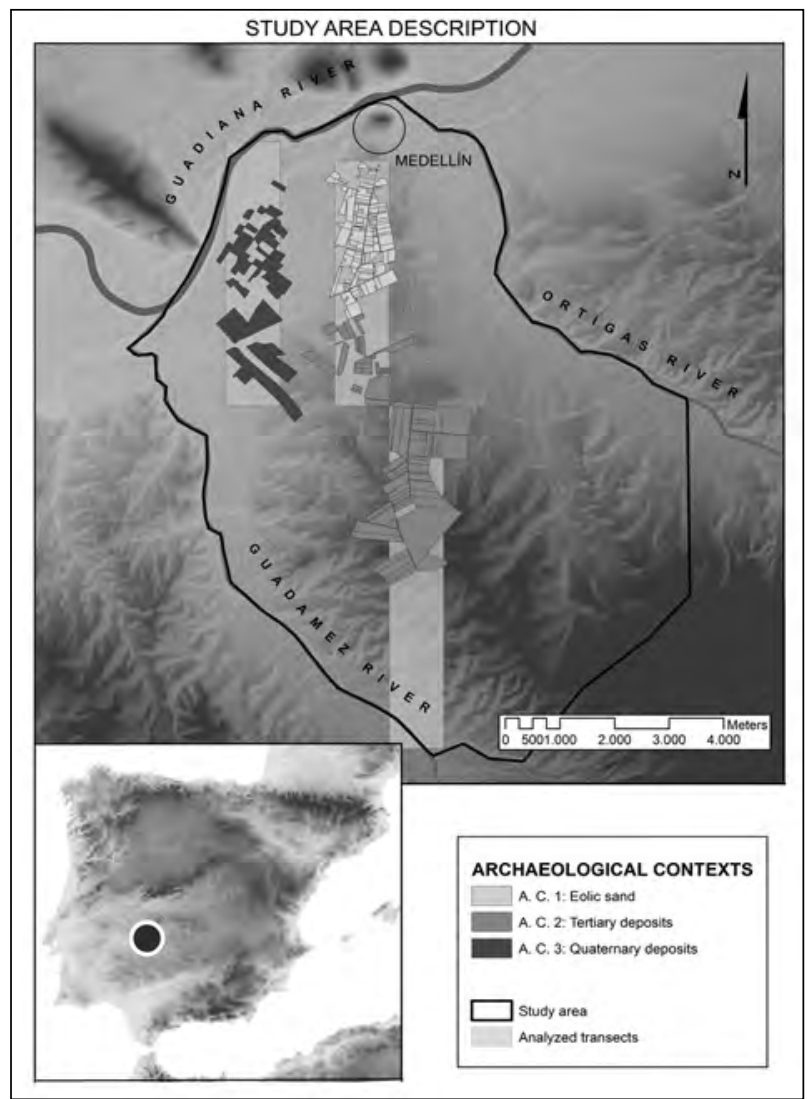

Figure 2. Study area description.

was used to determine where to focus our attention and how to structure a more qualitative treatment through systematic sherd collection (Mayoral, Cerrillo and Celestino 2009).

The analysis of the Medellín's survey results led us to differentiate three areas or archaeological contexts (Fig. 2). The surface archaeological record shows particular properties at each archaeological context. These three contexts mainly coincide with unequal soil units, which present different structure and composition and have encountered dissimilar geomorphological processes. The background density and composition of the surface document is essentially homogeneous within each archaeological context. This reason led us to examine the quantification of the data separately. Actually, it is possible to detect different behavior of the targets examined at every archaeological context. This fact alerts us about the efficiency of possible experiments. They will be indicative of specific biases behaviour, but it is feasible that we will find a different pattern in other areas. Therefore, the use and examination

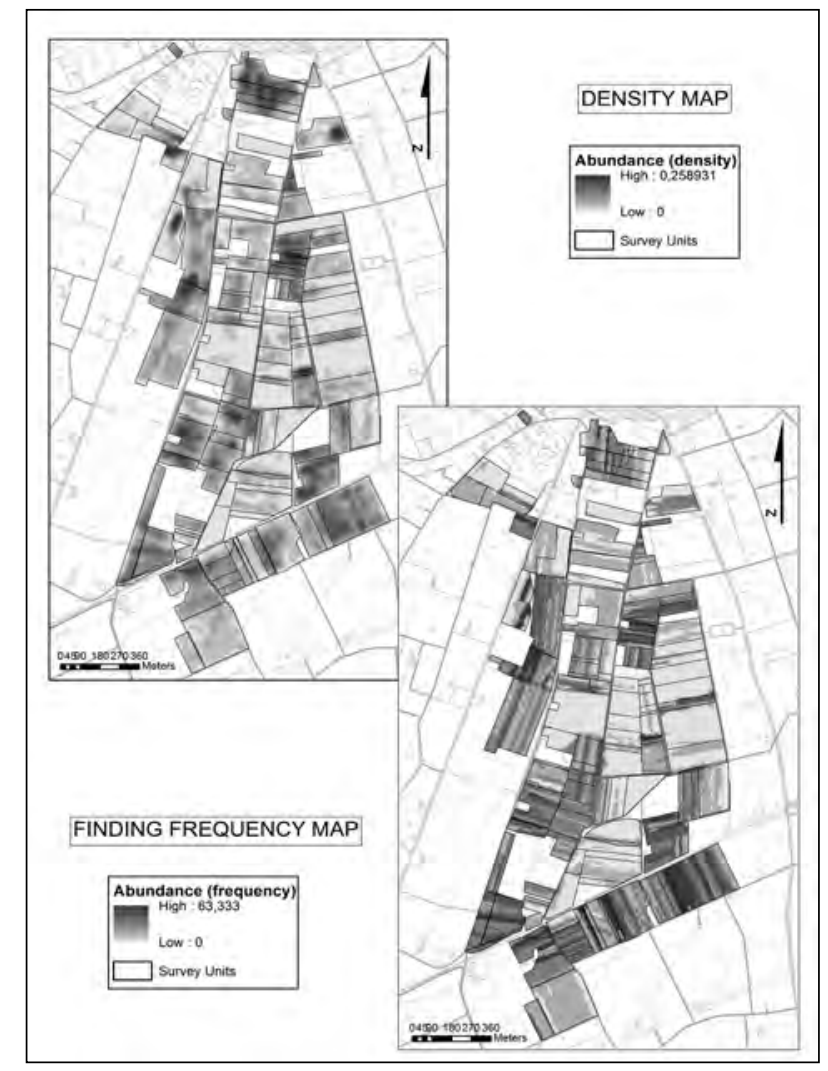

Figure 3. Findings frequency and density maps comparison. Archaeological Context 1.

of the actual data gathered during the surveys seem to be a suitable way to explore the biasing factors, specially taking into account the great level of precision reached.

\subsection{The findings frequency map: a definition}

When we talk about the frequency map, we refer to the computation of points (artefacts) recorded per minute by each surveyor during the performance of surface surveys. The realisation of these measurements has been possible due to the survey method employed. The adopted non-site survey strategy gives the geographical position of the identified artefacts. But also next to the geographic location data, other information is recorded, such as the time the artefact was identified. These two items are the basis for the kind of quantifications we will discuss here: the findings frequency map and the density map (Fig. 3).

Nevertheless, the source of both maps is the same. Thus, the exploration of these two different 
values of each artefact leads us to alternative readings of the archaeological document. To build the findings frequency map we have individualised the points recorded each minute. Since artefacts were not found every minute, especially in those areas that present less abundance of archaeological entities, we have employed a generalisation of the data. The chosen procedure has been to classify the artefacts recorded every fifteen minutes. The use of this temporal span was considered appropriate given the size of the survey units and the distributional accuracy expected. It was also a way to ease the classification method in order to exclude the possibility of over representing the temporal precision. We have to conceive this map as an alternative exploration of the surface archaeological document. In addition, it is also a tool to control the survey techniques.

\subsection{The properties and limitations of the findings frequency map}

In this section, it will be described the main features of the findings frequency map. This record is an attribute linked to a point. Thus, the creation of a continuous map has some risks. It is supposed that each surveyor performs the survey using their unequal aptitudes to identify entities in the space. Furthermore, the data are also generated by different team members following a track. These two properties of the survey strategy makes us conscious that the output frequency map will not completely reflect the spatial variation, since the two facts already mentioned limit the primary geostatistic assumption that places that are close together tend to have similar characteristics. However, it is noteworthy to recall that the two limitations stated before can also be present in the density maps, since both are based in a sampling strategy.

The frequency map is built from a set of different group of points. The distribution of these groups, with diverse points per minute values, shows how the findings frequency changed through the surveyed space, while it retains the information related to the surveyor that identified each artefact. Thus, the frequency map must not be envisaged as a source to precisely identify cultural anomalies in the space. That must be expected on a map which is computed using the geographical information of the artefacts or survey units.

\section{The Applications of the Findings Frequency Map}

Our map does not illustrate temporal changes, but shows the time needed to perform a specific task. Besides we can see that the answer of the attribute quantified (points per minute) is not always following the same trend as the density map does. Then, using both maps and their comparison appear to us as an innovative and helpful tool to understand the answer of the archaeological document to particular biases in definite spaces that presented certain physical and environmental conditions.

We find some benefits in using this kind of quantification of the surface archaeological document. As some researchers have highlighted, there are many distorting factors that affect the archaeological record identification. This map allows us to check one of them: the differences between surveyors and their diverse answer to external distorting factors, particularly the vegetation presence. Within our work we have devoted special attention to examine the strong positive correlation between theartefactdensityand thesurfacevisibility. The findings frequency rates contain a slightly different structure, but also follow the same trend. The findings frequency map shows the differences among surveyors spatially, as they go through the survey units. We see the findings frequency map as a useful instrument to understand how to construct the archaeological document and to test how the possible biasing factors influence our work. Thus, the frequency quantifications allow examining these two distorting elements: the difference among surveyors and the field-walker individual answer to the variable vegetation presence.

\subsection{Findings frequency quantification and inter- observer variations}

There have been some studies which have attempted to analyse the inter-observer variability. It is assumed that there are important differences among the surveyors' identification rates and that these differences are influenced by some factors such as the lack of concentration or the experience.

The main objective of this kind of quantifications is to measure the homogeneity of the data collected. Moreover, it is assumed that the 


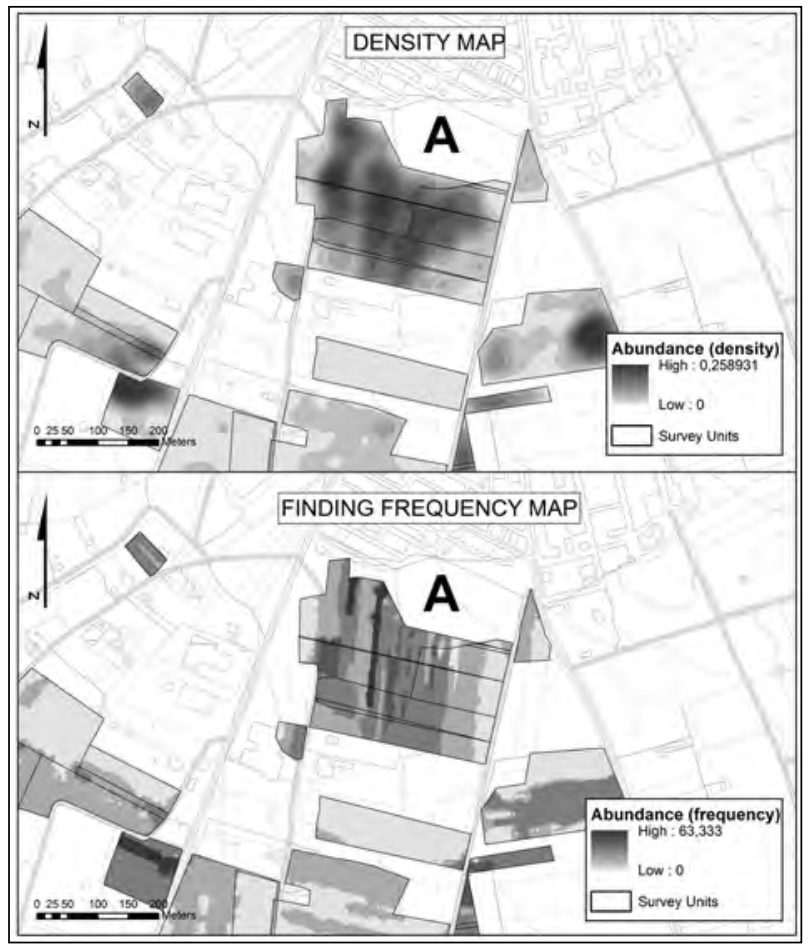

Figure 4. Site A. Findings frequency and density maps comparison.

distorting factors include an unknown amount of noise in the data which results in a heterogeneous dataset. The differences among surveyors are a consequence of the crew composition. Thus, these differences can vary from survey to survey. In our case, the team was composed mainly by students of archaeology and it was led by experienced crew members. Using the results of the two campaigns examined here (2009-2010) we have a total of 18 surveyors which we have been classified as experienced and inexpert members.

The results show that the average points per meter of the inexperienced team are the $76,5 \%$ of the mean points per meter of the general results. Meanwhile, the experienced team recorded the $121,7 \%$. Then, it is obvious that the previous experience is an important cause of the interobserver rates variations. Nevertheless, there also exist variations within the two different groups.

It is because of these sharp differences that it seems important to locate the artefacts identified by the surveyors spatially. Accordingly, the findings frequency map can be a way to explain specific offsite distributions or to help to describe the shapeand items distribution of some special interest artefact concentrations or sites. As we can see in figure 4 (Archaeological context 1) the differences among field-walkers are also present in the artefact density map and can have a strong influence in the shape of the artefact concentrations. In the density map, the site named A has an area with a lower density in the centre. When we examine this distribution next to the findings frequency map we can determine that the lower density in this particular space may be the result of the inter-observer differences. Other offsite distributions anomalies can be attached to the same problem.

We have used two parallel quantifications of the data to check the inter-observer differences. On the one hand we have calculated the total amount of artefacts identified by each surveyor per meter walked. We adopted this system because, as already pointed out, the density data cannot giveinformation about the individual performance of the survey of each field-walker. Nevertheless, this numbers refers to a very general scale. On the other hand we have the findings frequency data of each individual crew member, where it is possible to reach a higher level of precision. It is important to notice that the kind of quantification that better reflect the biases analysed is expressed in a spatial basis: the density. Still, it excludes an important amount of details, basically those related to the individuals. Consequently, it does not allow testing the surveyors' identification rate variability. Notably, the findings frequency map may be an appropriate alternative to explore this feature of the archaeological document.

\subsection{The influence of the archaeological compound features on the surveyors differences}

We assert the importance of this analysis since the inter-observer differences are one of the stronger biases. The distorting factors do not appear at random and then the field work result is a heterogeneous assemblage, which needs to be examined before assuming that our data contain a reliable sample of the surface archaeological record.

After the analysis of our survey data we can detect that when the artefacts abundance (and consequentlytheclusteringindex) ismedium orhigh, the distorting factor biases follow a specific pattern. Nevertheless, when the abundance of artefacts is 
low, such pattern is more difficult to ascertain. We see that scheme when we analyse the results of the unequal surface visibility conditions (mainly vegetation cover), but it is also possible to see the same behaviour when we examine the differences among surveyors. This last factor seems to have a strong influence everywhere. The points per meter and points per minute coefficient of variation for the contexts 1 and 2 is not far from the $50 \%$, while the coefficient of the context 3 approximately duplicates this amount (Table 1). Therefore, as a general conclusion, we can assert that the differences among field-walkers are stronger when the clustering index is low in the survey analysed. On the contrary, we obtain more coherent results when the survey units show a higher abundance of artefacts.

Contexts number 1 and 2 (where we find higher densities) show a smaller coefficient of variation. Regardless of their archaeological potential, this leads us to think that the differences among surveyors are less distorting in this area than in Context number 3. The obtained proportions support the idea presented by Wandsnider and Camilli (Wandsnider and Camilli 1992, 180-182). They consider the artefacts clustering as a key factor to assuring the reliability of the field survey data. The coefficient of variation has been used, because it is considered a suitable tool to measure the dispersion of data sets with different units.

\subsection{Surface vegetation and field-walkers differences}

The analysis of the Medellín's survey results also suggests that the differences among surveyors have several implications. We assume that the quality of the data collected improves or decreases depending on the visibility conditions and that the surveyors' differences rates can vary. Due to this assumption, it can be interesting to compare the data obtained by the field-walkers with different surface conditions. "Average" columns of the Table number 2 show the points per meter and points per minute results. It is clear that the amount of

\begin{tabular}{|c|c|c|c|c|c|c|}
\hline \multirow{2}{*}{} & \multicolumn{3}{|c|}{ POINTS PER METIER } & \multicolumn{3}{c|}{ POINTS PER MINUTE } \\
\cline { 2 - 7 } & AVERAGE & $\begin{array}{c}\text { STANDARD } \\
\text { OEVIATION }\end{array}$ & $\begin{array}{c}\text { COEF, OF } \\
\text { VARIATION }\end{array}$ & AVERAGE & $\begin{array}{c}\text { STANDARD } \\
\text { DEVIATION }\end{array}$ & $\begin{array}{c}\text { COEF. OF } \\
\text { VARIATION }\end{array}$ \\
\hline CONTEXT1 & 0,2705 & 0,1303 & 48,0 & 15,15 & 8,36 & 56,6 \\
\hline CONTEXT2 & 0,0585 & 0,0249 & 42,5 & 3,90 & 2,53 & 65,7 \\
\hline CONTEXT 3 & 0,0154 & 0,0164 & 106,0 & 3,71 & 3,43 & 92,5 \\
\hline
\end{tabular}

Table 1. Points per meter and points per minute general results.

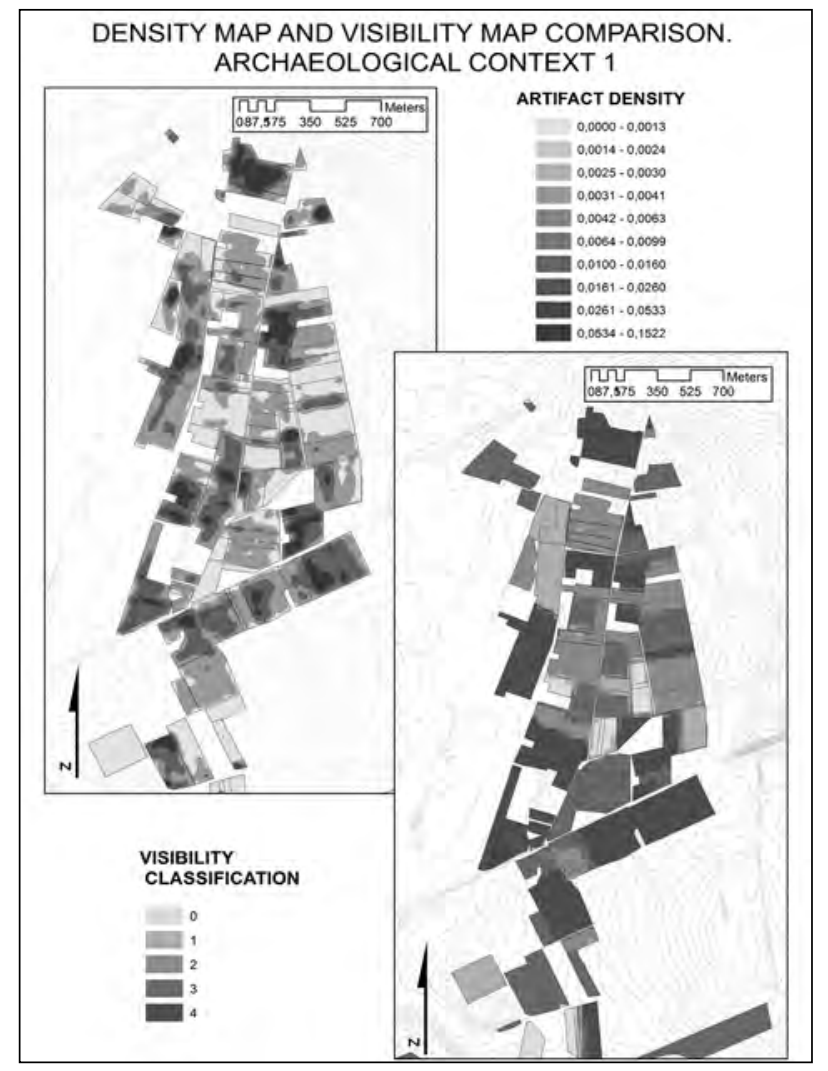

Figure 5. Artefact density map and visibility classification map. Archaeological Context 1.

artefacts detected increases when the visibility conditions are better in both quantifications, as we can visualise spatially in figure 5 . In addition, the quantification of the average points per minute and their coefficient of variation of specific areas suggest that the differences among surveyors tend to be sharper when we find poor visibility conditions. It is possible to detect it especially in Context 1 . The conclusions of some of our parallel works show that factors such as earth compaction or the artefact clustering influence are less distorting in this space than in the other contexts. Only the vegetation cover seems to have a statistically significant influence in the Context 1 and the homogeneity of the interobserver difference supports this hypothesis.

Highlighted in the Table 2, we can see how the coefficient of variation decreases while the visibility conditions are better. It means that the differences among surveyors are less noteworthy when they face survey units with good visibility. Nevertheless, it is not always easy to detect the affection of this bias in our data. It is largely linked to the character 
Across Space and Time. Papers from the 41st Conference on

Computer Applications and Quantitative Methods in Archaeology. Perth, 25-28 March 2013

\begin{tabular}{|c|c|c|c|c|c|c|c|c|c|c|}
\hline \multicolumn{9}{|c|}{ POINTS PER METER } & \multicolumn{2}{|c|}{ POINTS PER MINUTE } \\
\hline $\begin{array}{l}\text { SURFACE } \\
\text { VISIBIUTY }\end{array}$ & $\begin{array}{l}\text { AVERAGE } \\
2009\end{array}$ & $\begin{array}{c}\text { STNDRD. } \\
\text { DEVIATION } \\
2009\end{array}$ & $\begin{array}{c}\text { COEF. } \\
\text { VARIATION } \\
2009\end{array}$ & $\begin{array}{c}\text { AVERAGE } \\
2010\end{array}$ & \begin{tabular}{|c|} 
STNDRD. \\
DEVIATION \\
2010
\end{tabular} & \begin{tabular}{|c|} 
COEF. \\
VARIATION \\
2010 \\
\end{tabular} & $\begin{array}{l}\text { AVERAGE } \\
09-10\end{array}$ & $\begin{array}{c}\text { COEF. } \\
\text { VARIATION } \\
09.10\end{array}$ & $\begin{array}{c}\text { AVERAGE } \\
09-10\end{array}$ & $\begin{array}{c}\text { COEF. } \\
\text { VARIATION } \\
\text { O9-10 }\end{array}$ \\
\hline \multicolumn{11}{|l|}{ CONTEXT 1} \\
\hline SVIS. 1 & 0.0586 & 0,0554 & 94,5 & 0.1665 & 0,0628 & 37,7 & 0,0910 & 66,1 & 9,74 & 55,3 \\
\hline SVIS. 2 & 0,1063 & 0,0601 & 56,5 & 0,3676 & 0,2655 & 72,2 & 0,2269 & 64,4 & 15,36 & 58,7 \\
\hline S VIS. 3 & 0.2517 & 0,0825 & 32,8 & 0,4037 & 0,1678 & 41.6 & 0,3169 & 37.2 & 16,36 & 63,56 \\
\hline 5 VIS. 4 & 0,2226 & 0,1065 & 47,9 & 0,5870 & 0,2414 & 41,1 & 0,4352 & 44,5 & 19,13 & 49,5 \\
\hline \multicolumn{11}{|l|}{ CONIEXT2 } \\
\hline SVIS. 1 & 0,0317 & 0,0149 & 47,1 & & & & 0,0318 & 47,1 & 4,23 & 57,2 \\
\hline SVIS. 2 & 0,0291 & 0.0101 & 34,9 & 0,0494 & 0,0216 & 43,7 & 0.0986 & 39,3 & 3,19 & 77,3 \\
\hline S VIS. 3 & 0,0688 & 0,0209 & 30,4 & 0,0606 & 0,0347 & 57,3 & 0,0647 & 43,9 & 4.45 & 69,2 \\
\hline SVIS. 4 & 0,1034 & 0,0399 & 38,6 & 0,0660 & 0,0285 & 43,2 & 0,0836 & 40,9 & 3,73 & 49,5 \\
\hline \multicolumn{11}{|l|}{ CONTEXT 3} \\
\hline SVIS. 1 & 0,0083 & 0,0078 & 94,2 & & & & 0,0083 & 94,2 & 2,30 & 141 \\
\hline SVIS. 2 & 0,0167 & 0.0199 & 119,5 & & & & 0,0167 & 119.5 & 5,93 & 85,8 \\
\hline SVIS. 3 & 0,0158 & 0,0118 & 74,4 & & & & 0,0158 & 74,4 & 4,02 & 78,6 \\
\hline SVIS. 4 & 0,0209 & 0,0259 & 124,2 & & & & 0,0209 & 124,2 & 2,60 & 86,2 \\
\hline
\end{tabular}

Table 2. Relationship between the points per meter/points per minute results and the surface visibility cover).

of the archaeological record as it is to the physical properties of the soil or the specific conditions of the environment in the time of the survey.

In the Context 2 we do not find important differences among the visibility conditions coefficient of variation percentage. The results of other analysis already performed lead us to think that the earth compaction and the orientation of the light, next to the vegetation cover play an important role in the construction of the archaeological document in this space. Meanwhile, there is no specific pattern in Context 3 and it seems that the coefficient of variation rates are randomised or strongly influenced by other biasing factors.

\section{Concluding Remarks}

This work adds new discussion topics to the papers devoted to the reliability of the surface archaeological record documentation. By using a new kind of quantification - the findings frequency map - it is possible to identify the differences among surveyors spatially. From our viewpoint it is important to examine this distorting factor, since it is considered to be one of the biases that more strongly affect the homogeneity of the data. The conclusions reached here, as could be expected, support the hypothesis that asserts: "the better the conditions of a survey, the higher the quality of the data recorded". Then, there is not only an increase of the abundance of the artefacts recorded, but the consistence of our survey strategy is strengthened.

The information presented here has been constructed using real surface survey data. Consequently, the application of the statements presented is limited, since not all the surveyors have followed the same track. But in any case it can be seen as an indicator of theimportance of this biasing factor and the existence of a specific pattern.

These results stress the importance of the unequal field-walker rates as a factor that adds heterogeneity in our data. Therefore, the examination of the surveyors' difference rates should guide us to improve our knowledge about the way the archaeological document was built, which at the end can influence our interpretations. This information also can be used to plan new surveys in order to assert as much homogeneity as possible in the data collected.

\section{Acknowledgements}

This contribution shows some results of the research project "The evolution of an agrarian landscape: the territory of Medellin from the Iron Age to Roman times" (2008-2011), funded by the Autonomous Government of Extremadura (Ref:PRI08B050).

\section{Bibliography}

Banning, E. B., A. L. Hawkins, and S. T. Stewart. 2006. "Detection Functions for Archaeological Survey." American Antiquity 71 (4):723- 742.

Bintliff, J. L. 2009. "Is the essence of innovative archaeology a technology for the unconcious?" In Metals and Societies: Studies in honour of Barbara S. Ottaway, edited by T. L. Kienlin and B. W Roberts, 181-190. Bonn: UPA.

Bintliff, J. L., and A. Snodgrass. 1988. "Off-Site Pottery Distributions: A Regional and Interregional Perspective." Current Antropology 29 (3):506- 513. 
The Accuracy of the Field Survey Results and its Implications in the Correct Understanding Luis Antonio Sevillano Perea and Victorino Mayoral Herrera

Bintliff, J. L., P. Howard, and A. Snodgrass. 1999. "The Hidden Landscape of Prehistoric Greece." Journal of Mediterranean Archaeology 12 (2):139-168.

Boivin, N. 2005. "Post-textual archaeology and archaeological science." Archaeometry 47 (1):175- 179.

Chapa, T., A. Uriarte, J . M. Vicent, V. Mayoral, J . Pereira. 2003. "Propuesta metodológica para una prospección arqueológica sistemática: el caso del Guadiana Menor (J aén, España).” Trabajos de Prehistoria 60 (1):11- 34.

Fanning, P. C., and S. J. Holdaway. 2004. "Artefact Visibility at Open Sites in Western New South Wales, Australia." J ournal of Field Archaeology 29 (3/4):255271

Fisher, P., and D. J. Unwin. 2005. Re-presenting GIS. West Sussex: J ohn Willey \& Sons, Ltd.

Hegmon, M. 2003. "Setting Theoretical Egos Aside: Issues and Theory in North American Archaeology." American Antiquity 68 (2):213- 243.

Hirth, K. G. 1978. "Problems in data recovery and Measurement in Settlement Archaeology." Journal of Field Archaeology 5 (2):125- 131.

Ingold, T. 2000. The Perception of the Environment. Essays on livehood, dwelling and skill. London: Routledge.

J ones, A. 2004. "Archaeometry and materiality: material based analysis in theory and practice." Archaeometry 46 (3):327- 338.

Mayoral Herrera, V., E. Cerrillo Cuenca, and S. Celestino Pérez. 2009. "Métodos de prospección arqueológica intensiva en el marco de un proyecto regional: el caso dela comarca de La Serena (Badajoz).” Trabajos de Prehistoria 66 (1):7- 25 .

Olsen, B. 2003. "Material Culture after text: Re Membering Things." Norwegian Archaeological Review 36 (2):87- 104.

Owoc, M. A. 2004. "A phenomenology of the buried landscape. Soil as material culture in the Bronze Age of South-West Britain." In Soils, Stones and Symbols. Cultural Perceptions of the Mineral World., edited by N. Boivin and M. A. Owoc, 107-122. London: UCL Press.
Schiffer, M. B. 1976. Behavioral Archaeology. New York: Acedemic Press.

Schiffer, M. B. 1983. "Toward the Identification of Formation Processes.” American Antiquity 48 (4):675706.

Schon, R. 2002. "Seeding the Landscape: Experimental Contributions to Regional Survey Methodology." Ph.D. diss., Bryn Mawr College.

Shennan, S. 1985. Experiments in the Collection and Analysis of Archaeological Surface Data: The East Hampshire Survey. Sheffield: Sheffield University Press.

Shott, M. J. 1995. "Reliability of Archaeological Records on Cultivated Surfaces: A Michigan Case Study." J ournal of Field Archaeology 22 (4):475- 490.

Skibo, J. M., and M. B. Shchiffer. 2008. People and Things. A Behavioral Approach to Material Culture. New York: Springer.

Thomas, D. H. 1975. "Nonsite Sampling in Archaeology: Up the Creek without a Site?" In Sampling in Archaeology, edited by J. W. Mueller, 45-60 Tucson: University of Arizona Press.

Van Leusen, P. M. 2002. "Pattern to process: methodological investigations into formation and interpretation of spatial patterns in archaeological landscapes.” Ph.D. diss., University of Groningen.

Vicent García, J. 1991. "Fundamentos teóricometodológicos para un programa de investigación arqueogeográfica." In El cambio cultural del IV al II milenios a. C. en la comarca del noroeste de Murcia, edited by P. López García, 29-119. Madrid: CSIC.

Wandsnider, L., and E. Camilli. 1992. "The Character of surface archaeological deposits and its influence on survey accuracy." J ournal of Field Archaeology 19:169- 187.

Wheatley, D. 2004. "Making space for an archaeology of place." Internet Archaeology 15. doi:10.11141/ia.15.10.

Wilkinson, T. J. 1992. "Off-site archaeology." National Geographic Research and Exploration 8:196- 207.

Witmore, C. L. 2007. "Symmetrical archaeology: excerpts of a manifesto." World Archaeology 39 (4):546- 562. 


\title{
Arbitrary Offline Data Capture on All of Your Androids: The FAIMS Mobile Platform
}

\author{
Adela Sobotkova, Brian Ballsun-Stanton, Shawn Ross \\ University of New South Wales, Australia \\ Penny Crook \\ La Trobe University, Australia
}

\begin{abstract}
:
This paper presents three key problems addressed by the Federated Archaeological Information Management Systems (FAIMS) project and presented during a Round Table session at the 2013 CAA. FAIMS is a major Australian digital infrastructure project established in 2012 to develop open source eResearch tools to improve archaeological data management. We first review existing Android GIS applications and discuss their performance and suitability for archaeological fieldwork in remote locations, before presenting the lessons of this review for FAIMS mobile application development. We then discuss the variety of Australian archaeological practice, suggesting how semantically compatible datasets may be produced from diverse sources at the time of data creation. Finally, we introduce the data structure underlying our mobile application, which accommodates a wide range of practices and data models while promoting syntactic and semantic dataset compatibility.
\end{abstract}

\section{Keywords:}

Field Recording, Mobile, GIS, Android, Dataset Compatibility

\section{Introduction}

The Federated Archaeological Information Management Systems (FAIMS) project is a major eResearch project established to build new tools to collect and share archaeological data. It is funded by the National eResearch Collaboration Tools and Resources (NeCTAR) program, an Australian Government initiative to develop digital infrastructure for Australian researchers. The project is led by the University of New South Wales, Sydney, in collaboration with participants from 40 organisations, including universities, archaeological consultancies and heritage agencies in Australia and overseas. FAIMS was launched on 5J une 2012, with an ambitious schedule to deliver a full production release of three open-source tools by December 2013:

- A mobile platform for offline, spatially-aware data collection, using native Android code, to deliver highly customisable workflow design;

- A web application for processing data exported from the mobile platform, utilising Heurist (Arts

Corresponding author:a.sobotkova@unsw.edu.au
eResearch 2014), a product of the University of Sydney's Arts eResearch laboratory; and

- An online repository for archiving, disseminating and comparing data exported from the mobile platform, or Heurist, using a local instance of the Digital Archaeological Record - tDAR (Digital Antiquity 2014), created by Digital Antiquity in Arizona.

These requirements, amongst others, arose from the FAIMS Stocktaking Workshop held at the University of New South Wales, Sydney, in August 2012. This workshop brought together archaeologists, practitioners and developers from Australia and overseas for an intensive four-day discussion of archaeological information systems (for an overview of the workshop see Ross et al. 2013, 111-114).

A hands-on workshop held on 25 March 2013 at the CAA conference provided the first opportunity to demonstrate prototypes of the mobile application and the online repository. The fortuitous location of the CAA in Perth offered us a rare opportunity to learn more about overseas digital projects alongside the 


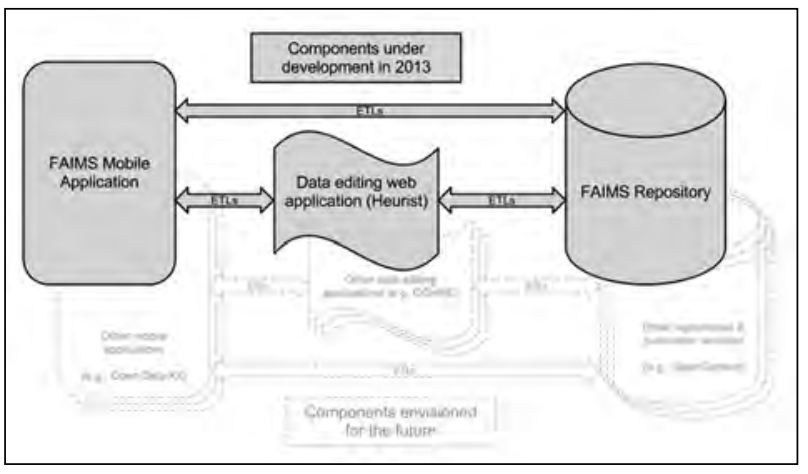

Figure 1. Current and planned federation components of the FAIMS infrastructure.

challenges faced by local archaeologists undertaking fieldwork in Western Australia. Unsurprisingly, this CAA workshop produced valuable feedback.

For a broader overview of the FAIMS project and the rationale behind its development agenda, please see Ross et al. (2013, 107-110).

This paper is distilled from a CAA Round Table and focuses on three specific challenges faced by the FAIMS project:

- The lack of robust, mobile GIS and mapping tools for handheld devices catering to the needs of archaeologists;

- The semantic incompatibility of archaeological datasets;

- The difficulty of accommodating the diverse data models used by archaeologists;

We discuss the solutions FAIMS has chosen to implement in light of these challenges, namely:

- The development of an open source, archaeologyspecific, offline-capable, mobile GIS for Android;

- A system using proven approaches from IT localisation to facilitate the creation of semantically compatible datasets;

- A highly normalised relational database that can accommodate a wide range of data models, meeting the varied needs of archaeologists.

We appreciate this opportunity to present background research and technical detail that has not been appropriate for other publication venues.

\section{When Theory Meets Reality: A Story of Archaeological Survey and Mobile GIS}

The FAIMS project decided at an early stage to work within the Android ecosystem for the mobile components of the project. A wide range of Android devices exist in a variety of form factors, with many features like digitisers, a variety of sensors (e.g., electronic compasses and barometers), and expandable storage. These devices are complemented by a rapidly growing number of free or inexpensive apps of interest to archaeologists (e.g., vector drawing, accurate altimeters, CAD rendering, etc.). Moreover, the FAIMS project is committed to open source development, for which the Android ecosystem is better suited than its competitors.

Despite the growth and potential of the Android ecosystem, however, some tools have developed slowly. Offline, mobile GIS, which was identified as essential at the FAIMS Stocktaking Workshop, is amongst these missing applications.

In September 2012, two of our authors (Shawn Ross and Adela Sobotkova) were invited to Greece to undertake a surface survey feasibility study around the ancient city of Troizen. We had been conducting a pedestrian survey and remote sensing project in Bulgaria between 2008 and 2011 (Ross et al. 2010; 2012), and had developed a workflow for raw data collection in the field using a combination of digital and paper recording. Our equipment comprised handheld PDAs (HP iPaq 200 series) equipped with Trimble GPS receivers (Bluetooth or SD card). These devices ran ArcPAD, the only software available at the initiation of the project (2008) that could:

- Display georeferenced data or base maps (rasters and vectors),

- Create and edit vector data,

- Display current position overlaid on spatial data,

- Connect to internal or external sensors,

- Be sufficiently customisable,

- Work offline. 
These requirements were not exclusive to our workflow, but appear to be shared by other projects (Tripcevich 2004a; 2004b; Tripcevich and Wernke 2010; Wagtendonk and DeJ eu 2007).

Having previously undertaken feasibility assessments with a digital workflow, the Troizen assignment appeared straightforward. We reviewed our legacy geodatabases, adapted one for the study of Troizen, packed our PDAs (Windows Mobile devices) and set out for Greece. Fate intervened, however, and our luggage with the PDAs was delayed in transit, remaining unavailable until our window for fieldwork was over. We had, however, brought along two brand-new Android phones (Nexus 4) and a tablet (Nexus 7) in our carry-on luggage for entertainment on the long flight and, making a virtue of necessity, began to explore the utility of Android devices in the field.

After two days of testing various mobile GIS applications (see 'Overview' in Sobotkova 2013) we were forced to admit that it was impossible to display our position on a georeferenced raster and to produce and edit vector shapes using an Android device without internet connectivity.

Apps with the richest features such as raster rendering and vector creation and editing worked only online (GeoMobile for ArcGIS), or at best after an extended online setup and caching process, including the use of a web map service. Other applications could display certain publicly available base layers (e.g., OpenStreetMaps or Google Maps), but they would not render our own raster data (a commercial high-resolution satellite image in geotiff or ECW format). Some of the applications could not create or edit some vector shapes like lines or polygons. As an example, when offline gvSIG Mini displayedmapsbycachingviews of OpenStreetMaps, it retained basic navigation functionality but it could not create or edit vector data. MapsDataCollection provided similar cached map display and allowed for simple waypoint collection, but it could not load a legacy raster image or create and edit lines or polygons. Similarly, LocusFree and Oruxmaps supplied wonderful mapping and navigation tools using cached online maps, but did not allow for the display of our legacy raster or the collection of data beyond waypoints.
qGIS for Android, a mobile version of qGIS desktop software developed by the OSGEO community, seemed like the only tool that would providetherangefeatures weneeded. Unfortunately, a bug in one component had inadvertently disabled all the menus in the app and the developer, Marco Bernasocchi, spent most of the fall of 2012 fixing this problem (perhaps revealing a weakness of distributed, open-source software development). In the meantime, qGIS for Android was unusable.

Inspired (and chastened) by our experience, we further reviewed available mobile GIS applications for our CAA presentation (Sobotkova 2013). While most of the apps did not work for us, they may still be helpful to other projects. Their feature sets may also have significantly improved since fall 2012, as the development of mobile applications often advances quickly. These applications, moreover, served as models (and cautionary examples) for our own mobile GIS application development.

With our PDAs unavailable at Troizen and having found no acceptable substitute for ArcPAD, we reverted to paper, using printouts of our satellite image and a longhand journal to record surface conditions. The landscape around Troizen was overgrown with Mediterranean scrub, or covered by citrus or olive orchards. Without the GPS position clearly displayed over the satellite image, our navigation through this dense vegetation was hampered. All the handwritten notes on the map or in our journals had to be digitised. While we completed our feasibility study in the time allotted (with the help of additional personnel), it was frustrating to resort to paper despite having three Android devices and years of experience in digital fieldwork.

Our experience in Greece demonstrated the continuing lack of mobile GIS applications suitable for archaeological fieldwork in areas lacking internet connectivity. Most of the applications we tried were turn-key solutions, designed for outdoors sporting activities, geocaching, navigation or other purposes. They were not designed to meet the needs of field research, which often entails not only the display and creation of geospatial data, but also the management of structured data and multimedia - all offline, and preferably with some capacity for customisation. 


\subsection{The FAIMS Mobile Application: A platform for} demanding field data collection

The lack of robust, data-centred mobile GIS applications for offline use presented a major opportunity for the FAIMS project, especially considering that the most innovative aspect of our project involves the development of mobile device applications for the collection and management of archaeological data.

The FAIMS mobile application is datadriven but geospatially enabled. It uses the SpatiaLite extension for the SQLite relational database management system to deliver GIS features alongside the ability to collect and manage structured data. Visualisation of data is done using the Nutiteq geospatial library (Nutiteq 2014), for which the FAIMS project has purchased a license that allows its unlimited distribution as part of our open source package. The underlying SQLite database is highly normalised and customisable (see section 4 below), allowing it to accommodate diverse datasets. The SpatiaLite extension allows vector shapes (with their projections and other necessary metadata) to be stored in the database itself, allowing greater flexibility than is the case with software (like ArcGIS) that associates data with a single shape. Multiple shapes, for example, can be associated with any given record. It is also easier to build and render multi-table relational data, with all of its advantages over the 'flat' single-table data more commonly seen in AroGIS deployments.

This combination of SQLite, SpatiaLite, and Nutiteq supports a core GIS functionality that includes:

- Ingest and rendering of legacy raster and vector data in common GIS formats (geotiff, shapefile);

- Simple and advanced vector editing (manual creation and editing of points, lines, and polygons; generation of buffers and mathematically constrained shapes);

- Layer management;

- Collection of spatially-aware structured data and multimedia;
- Connectivity to internal or external (Bluetooth) GPS;

- Basic navigation (direction and distance from current location to any vector shape).

Besides the lightweight GIS functionality, it also offers the following features:

- Customisable data schemata and user interfaces;

- File management for images, drawings, and other multimedia files;

- Versioning and backup;

- Automatic synchronisation across multiple mobile devices;

- Export to other FAIMS components (data editing web application; online repository);

- Export in widely-useable formats (XML; third normal form relational database);

- Tools for the creation of semantically compatible datasets;

- Offline functionality.

In light of our stocktaking activities, we believe that these features meet the needs of archaeologists and other researchers engaged in fieldwork better than existing Android (or iOS) mapping and GIS applications. Considering the enhanced ability to manage structured data and multimedia, as well as automated synchronisation, versioning, and backup, we also believe the FAIMS mobile application offers meaningful advantages over ArcPAD and other proprietary mobile GIS products.

\section{Syntactic and Semantic Compatibility of Archaeological Datasets}

The ability to create and manage structured data and export it in common formats (syntactic or technical interoperability) does not ensure that the data produced will have unambiguous, shared meaning (semantic interoperability). If the production of compatible data for synthetic and comparative study represents an important 
goal of archaeological information systems, then a means of reconciling datasets is necessary. Previous approaches to this problem have included the use of shared standardsand vocabularies for theproduction of data, reconciliation through ontology mapping at the time of data archiving in a repository (cf. tDAR: Spielmann and Kintigh 2011), or loose coupling', the ability to export syntactically interoperable data in machine-reusable form for manual reconciliation using tools like custom databases or Google Refine (cf. Open Context: Kansa and Bissel 2010, 44). Each of these approaches has drawbacks. Archaeologists have yet to agree on shared standards that they are willing to deploy widely across projects. Ontology mapping at the time of ingest is time-consuming and costly, representing a tax that discourages submission to repositories that require it. Loose coupling does not completely eliminate the need to clean and rectify data at the time of ingest into repositories that support it, and requires further effort on the part of the researcher who must manually reconcile 'data slices' from various sources.

Informed by our Stocktaking Workshop, FAIMS has sought to improve the semantic compatibility of data from the moment of its creation, without requiring explicit adherence to an explicit, shared data standard. The FAIMS mobile application provides for background mapping of terms and concepts, using an approach borrowed from IT practices of localisation. This approach involves mapping local terms to core concepts, displaying the local terms during data collection, but associating the data collected with the core concept (see Section 4.2 below). The mapping is done as part of the mobile platform customisation process (and can easily be inherited from other projects), so all data is mapped to core concepts as it is created. This process accommodates the diversity of archaeological practice, while still producing datasets that are largely, if not entirely, semantically compatible.

\subsection{Diversity in standards for archaeological data capture in Australia}

The vast majority of archaeological work in Australia is carried out by consultant archaeologists assisting developers and site owners to comply with heritage planning and environmental protection legislation (Ulm et al. 2005). This work is guided not only by principles enshrined in the acts themselves, butalso thepolicies, manuals, supportingdocuments and, in some cases, prescriptive templates and recording sheets. Australian archaeological practice is, however, governed by many separatejurisdictions spanning federal, state and local governments. At the state level, for example, indigenous, historical, and maritime archaeological resources are subject to different legislation and often managed by different departments and agencies in each state (Burke and Smith 2004; see also Australian Government. Department of the Environment 2011). It is essential that we accommodate these diverse standards and guidelines in order to cultivate a user base large enough to sustain the project. During stocktaking, we conducted a preliminary review of available documentation governing excavation, survey and artefact analysis from each state. We compiled statutes, guidelines, recording sheets and glossaries relevant to archaeological recording, as well as examples of actual recording sheets used by archaeologists in the field.

A group of five excavation recording sheets can serve as a preliminary example. Each sheet used between 22 and 62 concepts. Approximately 120 different terms were used, but by collating all of the concepts, we were able to map them to 106 unique concepts for excavation, some 80 per cent of which were used on more than one recording sheet. Only five, however, were common to all sheets: Site, Area, Context, Recorded By and Recorded When.

Seeing that some 80 per cent of concepts were shared across more than one recording sheet, it is clearlypossibletoreconcilemucharchaeological data by mappingit to a core ontology. Initially, the FAIMS project intended to use an existing ontology, such as the CIDOC-CRM, for this purpose (ICOM 2013), but none of the existing ontologies were optimised for field recording (most had been developed for cultural heritage management). The FAIMS project has reluctantly chosen to develop a new ontology. It is doing so in as descriptive a manner as possible, using the review of documentation described above, supplemented by analysis of archaeological publications (including a computer-assisted text analysis project conducted by two honours students at UNSW). We will collate and publish this ontology online as linked data, with mapped links to other thesauri and published standards, including the 


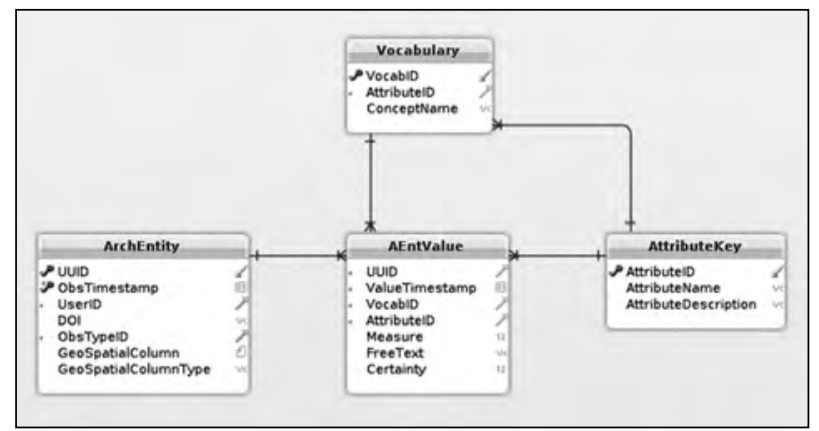

Figure 2. The essential four tables of the DKNF appendonly database demonstrating an ArchEnt implementation.

CIDOC-CRM and thesauri such as those produced by the Getty Conservation Institute and English Heritage. Once this ontology is produced, it will be embedded in the FAIMS mobile application, which has the capacity to map the terminology of any given project against it. Users will see their own local terms and concepts in the application's user interface, but the corresponding core concept from the FAIMS ontology will also be embedded in the data (see Section 4.2 below). In this manner, ontology mapping is done in the background at the time of data creation, obviating the need for manual mapping or reconciliation later in the lifecycle of the data. If an 80 per cent correspondence of concepts in the resulting datasets can be achieved, it will mark a substantial improvement in archaeological dataset compatibility.

\section{Relational and Nonrelational Program Independent Schemas: Supporting Arbitrary Archaeological Data Models}

Another facet of archaeological practice that hinders the production of compatible datasets is that archaeologists employ a wide range of research strategies, each of which requires a customised data structure. Currently, projects that want to go digital typically develop a bespoke relational database or geodatabase (using, e.g., MS Access or ArcGIS plus SQL Server), a situation that is neither optimal nor sustainable (Ross et al. 2013). Instead, the FAIMS project has developed a robust yet generalised database schema that mimics 'NoSQL' key-value stores using a Domain-Key Normal Form (DKNF) relational schema (Fagin 1981). True NoSQL data stores were either not well supported on Android or were incompatible with GIS software, which generally expects tabular or relational data. As

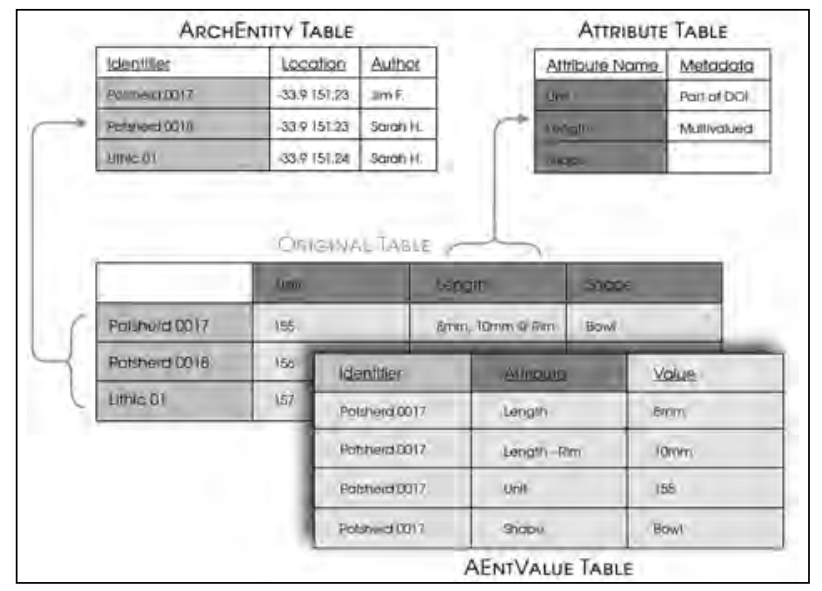

Figure 3. A tabular data transformation into DKNF.

noted above, the DKNF database was implemented in SQLite with SpatiaLite extension.

The arbitrary structure of the incoming data - with every user requiring a custom schema based on his or her own knowledge representation presented a challenging problem in database design. We employ the SQL database as a key-value store, associating a series of 'attributes' (as keys) with a specific ArchEntity ('Archaeological Entity', the atomic unit of archaeological practice). In order to implement a key-value store, we have normalised our data schema to Domain-Key (Sixth) Normal form. Furthermore, we provide version control and multiple client updates of the same data without data loss through an append-only store-no record is ever deleted, it is merely superseded by newer entries that can be reviewed and 'rolled back' if needed.

\subsection{DKNF Implementation: The FAIMS Data Structure}

Our central data structure is comprised of four tables: ArchEntity, AEntValue, AttributeKey, and Vocabulary. It is best thought of, however, as a single, virtual table. Imagine a spreadsheet with the top row and the first column locked:

- The 'ArchEntity' table acts as the first 'column' in our spreadsheet, providing a unique identifier (along with relevant metadata) representing each archaeological entity. This identifier designates a 'row' that will contain all of the information about that entity. 
- The 'AttributeKey' table can be thought of as the frozen 'row' at the top of the spreadsheet with 'column' names representing the things you want to record about all of the Archaeological Entities, providing a constrained set of attributes concerning each entity.

- The 'AEntValue' table represents the data held in the body of the table (each 'cell' being an intersection of an ArchEntity 'row' and the AttributeKey 'column'). The boundaries of the multi-valued 'cell' (i.e., a unique record) are identified by the triple determinant of Universally Unique Identifier, Timestamp, and Attribute ID.

- This DKNF implementation provides a flexible data schema that can be used in a wide range of scenarios; only the values contained in the ArchEntity and AttributeKey tables need to be specified at project startup in order to define the types of Archaeological Entities being recorded and the range of Attribute Keys applied to them. Significant customisation can be achieved with limited investment of developer time.

\subsection{Localisation}

The final supporting table, 'Vocabulary' provides for the controlled vocabularies used by the localisation process. The Vocabulary table interacts with the localisation definition document, which maps local vocabularies used by individual projects against common archaeological concepts. The program uses localisation techniques by looking for and replacing keyed strings. For example it finds '\{StratigraphicUnitID\}' and shows it as 'Context Number' in the user interface. By replacing strings on display, we maintain a shared vocabulary independent of, but supporting, different terminologies.

\subsection{Append-only Datastore}

We intend to never lose data. To achieve that goal, we have instituted an append-only data store, a method modelled on Google's Protobuffs (Chang et al. 2008, 7). Only writes are allowed to the database; updates and deletions are simulated through inserts. The current records are merely the set of all values with the latest timestamp for a given Universally Unique Identifier and attribute pair.

\begin{tabular}{|c|c|}
\hline DOI & $10.1007 / 510761-011-0158-6$ \\
\hline Name & Stratigraphic Unit ID \\
\hline Definition & $\begin{array}{l}\text { The reference number or code allocated to the primary } \\
\text { unit of the stratigraphic sequence: the physical result of } \\
\text { a single physical action, whether it leaves a positive or } \\
\text { negative record within the sequence (Museum of } \\
\text { London } 1994: 1 \text { ). This number may be unique to the } \\
\text { Site or an Anea of the site. Contexts maybe grouped into } \\
\text { Features or partitioned into arbitrary syjes or Grids. }\end{array}$ \\
\hline Aliases & $\begin{array}{l}\text { 'Stratigraphic Context ID', 'Context ID', 'Context } \\
\text { Number', 'Context No', 'Unit', 'Unit Number', 'Locus' }\end{array}$ \\
\hline See also & Sori, feature, Gind \\
\hline Equivalent to & EH Components Thesaurus: 1 ver \\
\hline
\end{tabular}

Figure 4. Wireframe of an example concept in the proposed FAIMS online ontology.

The queries we have designed for normal access to the database will simply disregard all records with an old timestamp or a deleted Boolean set to 'true', but the deleted or modified records will remain in the database. This approach makes it trivial to review changes and recover data, as no data is ever deleted or changed.

\section{Conclusions}

It has been a tradition that archaeologists adapt tools and methodologies developed for other disciplines. While this has worked in the past, at this juncture robust tools for data management are taking a long time to arrive. The FAIMS project has had the opportunity to build a data collection application tailored to the idiosyncratic needs of archaeologists. It is one of the first attempts to develop a generic, highly customisable, geospatially capable data collection tool for Android. We believe it is flexible enough to accommodate the highly variable workflows and diverse research agendas of individual archaeological projects, yetrobust enough to record complex data types and data structures, all while facilitating dataset compatibility. In building for the particular needs of archaeologists we have developed a tool that is attracting interest from a range of scientists collecting complex, idiosyncratic data, offline and in remote locations. Archaeology may have the opportunity to lead instead of follow IT development for a change.

At the CAA meeting in March 2013, we demonstrated our earliest public prototype. By the time this paper appears in print, our production release will be freely available on Google Play. While 
much fine-tuning and some feature development remains, we are confident that the feature set summarised in Ross et al. (2013) and discussed in more depth here is viable, and will be ready for use. At this moment, Sobotkova has again returned from a two-week project in Greece, having done remote sensing on the island of Andros. Needless to say, the Android tablets were in the carry-on luggage, but not for entertainment this time. Only a year after our disappointing experience, they served as a data capture platform for field research using a beta version of the FAIMS mobile platform.

\section{Acknowledgements}

The FAIMS project is funded by NeCTAR and led by the University of New South Wales. Organisations involved in development include La Trobe University, University of Sydney Arts eResearch, Intersect, and the Victorian eResearch Strategic Initiative (VeRSI). We are supported by 35 other organisations and a large community of archaeologists, programmers and digital humanists across Australia and overseas. We acknowledge their ongoing efforts to aid us in the successful development and long term sustainability of FAIMS. We would like to thank the CAA organisers, particularly Arianna Traviglia, for organising such a wonderful conference and giving us the opportunity to showcase FAIMS. Above all else, we wish to thank the conference participants who took the time to attend our sessions and gave us encouragement and honest feedback. Many thanks to Geoff Matheson for the $6 \mathrm{NF} / \mathrm{DKNF}$ diagram.

\section{Bibliography}

Arts eResearch. 2014. "Heurist Academic Knowledge Management System Version 3." Accessed January 15. http:// heur-db-pro-1.ucc.usyd.edu.au/HEURIST/index. html.

Burke, H., and C. Smith. 2004. The Archaeologist's Field Handbook. Sydney: Allen \& Unwin.

Chang, F., J. Dean, S. Ghemawat, W. Hsieh, D. Wallach, M. Burrows, T. Chandra, A. Fikes, and R. Gruber. 2008. "Bigtable: A Distributed Storage System for Structured Data." ACM Transactions on Computer Systems 26 (2):1- 26. doi:10.1145/ 1365815.1365816.
Digital Antiquity. 2014. “What can you dig up?” Accessed J anuary 15. http:// www.tdar.org/ .

Fagin, R. 1981. "A Normal Form for Relational Databases That Is Based on Domains and Keys." ACM Transactions on Computer Systems 6 (3):387-415. doi:10.1145/319587.319592.

Kansa, E. C., and A. Bissell. 2010. "Web Syndication Approaches for Sharing Primary Data in 'Small Science' Domains." Data Science J ournal 9:42-53. doi:10.2481/ dsj.009-012.

ICOM. 2013. "The CIDOC Conceptual Reference Model." Last modified January 18. http://www.cidoc-crm.org/ index.html.

Nutiteq. 2014. "Better maps SDK for Android." Accessed J anuary 15. http:// www.nutiteq.com.

Ross, S., A. Sobotkova, B. Ballsun-Stanton, and P. Crook. 2013. "Creating eResearch Tools for Archaeologists: The Federated Archaeological Information Management Systems Project." Australian Archaeology 77:107- 119.

Ross, S., A. Sobotkova, S. Connor, and I. Iliev. 2010. “An Interdisciplinary Pilot Project in the Environs of Kabyle, Bulgaria." Archaeologia Bulgarica 14 (2):69- 85.

Ross, S., A. Sobotkova, I. Iliev, S. Connor, and S. Bakardzhiev. 2012. The Tundzha Regional Archaeological Project: Elhovo 2009 Preliminary Report. Yambol: Historical Museum Yambol.

Sobotkova, A. 2013. "GIS on Android: Not Ready for the Prime Time? Mobile Applications and Spatial Recording During Fieldwork." Poster presented at the Across Space and Time 41st Computer Applications and Quantitative Methods in Archaeology Conference, Perth, Western Australia, March 25-28. http://hdl.handle. net/ 102.100.100/ 12207.

Spielmann, K. A., and K.W. Kintigh. 2011. "The Digital Archaeological Record: The Potentials of Archaeozoological Data Integration Through tDAR." The SAA Archaeological Record 11 (1):22- 25.

Australian Government Department of the Environment. 2011. State of the Environment 2011: Independent Report to theAustralian Government Minister for Sustainability, Environment, Water, Population and Communities. 
Across Space and Time. Papers from the 41st Conference on

Computer Applications and Quantitative Methods in Archaeology. Perth, 25-28 March 2013

Canberra: Commonwealth of Australia. http://www. environment.gov.au/ node/ 22909.

Tripcevich, N. 2004a. "Interfaces: Mobile GIS in Archaeological Survey." The SAA Archaeological Record 4 (3):17- 22.

Tripcevich, N. 2004b. "Flexibility by Design: How Mobile GIS Meets the Needs of Archaeological Survey." Cartography and Geographic Information Science 31 (3):137- 151.

Tripcevich, N., and S. Wernke. 2010. "On-Site Recording of Excavation Data Using Mobile GIS." J ournal of Field Archaeology 35 (4):380- 397.

Ulm, S., S. Nichols, and C. Dalley. 2005. "Mapping the Shape of Contemporary Australian Archaeology: Implications for Archaeology Teaching and Learning." Australian Archaeology 61:11- 23.

Wagtendonk, A. J., and R. A. M. De J eu. 2007. "Sensible Field Computing: Evaluating the Use of Mobile GIS Methods in Scientific Fieldwork." Photogrammetric Engineering \& Remote Sensing 73 (6):651- 662. 


\title{
Creating a Paperless Recording System for Pilbara Rock Art
}

\author{
Stafford Smith \\ University of Western Australia and Smith Field and Spatial, Australia \\ J o McDonald, J ane Balme \\ University of Western Australia, Australia \\ Glen MacLaren \\ Environmental Systems Solutions, Australia \\ Alistair Paterson \\ University of Western Australia, Australia
}

\begin{abstract}
:
The Centre for Rock Art Research at the University of Western Australia is directing much work into the Pilbara region. In collaboration with Environmental Systems Solutions, the Centre has developed a paperless field recording system and database to manage the high volume of work in this area. Digital forms on mobile devices, direct incorporation of DSLR photos, and a simple download procedure into the field database over Wi-Fi, present a solution that standardises recording methods, saves time on data entry, and reduces the opportunity for human error. The central database hosted at UWA provides a platform for powerful analyses of the rock art and provides a pathway for repatriating information about the art to Indigenous groups.
\end{abstract}

Keywords:

Digital Field Recording, Smartphone, Eye-Fi, Rock Art, Database

\section{Introduction}

In early 2012, the Centre for RockArt Research + Management at UWA (hereafter, CRARM) embarked on a project to develop a database to assist in the responsible management of data being collected by its researchers in the Pilbara region of Western Australia. Funded by a grant from the Pilbara Development Corporation (PDC), CRARM appointed ESSolutions to assist in this development. Building on a structure developed by McDonald and MacLaren for a similar web-enabled database and mobile field recording procedure for all site types on the CSR Project (Veth 2012), the Pilbara Rock Art Database was born. This database and mobile data collection system was developed with research and management goals, and has been field tested at the 2012 Happy Valley Field School - a jointly run Rio Tinto /CRARM rock art recording field school held on Murujuga (the Dampier Archipelago). The paperless recording system synchronises descriptive

Corresponding author: smithfieldandspatial@gmail.com data collection, GPS location data and photographic records, and the database has been established to accommodate both newly collected material and legacy data from four decades of consultancy work in the region. The system has been designed with cultural protocols to allow information to be shared with collaborating Aboriginal communities. These protocols will ensure that language groups, native title boundaries and gender restrictions can be accommodated in this data sharing arrangement in the future.

Most of the CRARM work using the system has so far be focussed on Murujuga (the Dampier Archipelago) on the north coast of Western Australia, a land and seascape containing an extraordinarily abundant and diverse rock art assemblage in the form of petroglyphs (engraved art). The area is an iconic region for Australian Indigenous heritage and it is widely recognised as one of the world's most culturally and scientifically significant rock-art provinces (McDonald and Veth 2009). Mining and 
related development of the area since the 1960s has resulted in numerous surveys of the region's rock art (e.g. J o McDonald CHM 2006; 2009; Mulvaney 2011; Veth et al 1993; Vinnicombe 1987; 2002). Continuing economic growth in the region means that there is increasing pressure to further record, evaluate, and interpret this art. With the listing of this rock art province on the National heritage List in 2007, there is a requirement for a heritage inventory of this land; and with the designation of the Murujuga National Park (co-managed by Murujuga Aboriginal Corporation and the Department of Environment and Conservation) there are immediate and medium- term management needs for such a database.

In designing a database for rock art research in thePilbara, it was necessary to consider the nature of existing datasets generated from previous research. The results of previous work in the region exist as a variety of datasets that have been collected using different methods, usually involving paper records and associated digital data such as photographs. The datasets differ in their structure and content and have been entered into disparate database systems specific to the aims of individual research projects or management programs. This situation has made it difficult for Traditional Owners, researchers and other groups to obtain access to the complete sets of information for research and management purposes.

We aimed to create a database into which all previous work could be drawn and the results of future work could be added. The database also had to also have the ability to handlea wide range of data types as well as allow manual entry of legacy data. We designed the database to be web-based so that is was easily accessible from multiple locations, thus avoiding the problems of siloed data (Jeffrey et al. 2011). Scalable access and editing permission levels, including access for community and Traditional Owner groups were identified as particularly important for the system.

For current recording projects we wanted to develop a mobile system of digital field recording. This would be tailored to integrate directly with the database system, and also serve to standardise recording methods to enhance the comparability of datasets. The recording system would avoid paper forms and the associated long hours of manual data entry with potential for associated transcription errors, instead allowing data to be uploaded directly into the database system from mobile recording devices. The system would also remove the complex process of relating photographic records to textbased records, which was found to be a source of error in previous approaches. In this paper we briefly describe the Pilbara Rock Art Database and discuss the successes and problems of the paperless mobile recording system. The system devised is still in the testing phase of development and here we discuss the system by referring to a particular example in which it was developed and tested - the Happy Valley Field School.

\section{The Pilbara Rock Art Database}

Much research is currently focussed on webenabled databases for archaeological data and rock art in particular, and a number of database tools already exist that met some of our needs. Perhaps the best example to date is The Digital Archaeological Record (Digital Antiquity 2014), but many projects are emerging simultaneously, such as the Federated Archaeological Information Management Systems Project (FAIMS 2014), the Canning Stock Route Database (Veth 2012), and Mukurtu (Mukurtu CMS 2014). The specific needs of CRARM required the implementation of a database that could be synchronised with a mobile digital recording system, and that balanced standardisation with flexibility. CRARM engaged Environmental Systems Solutions (ESS Pty Ltd) - a Melbourne-based software design organisation to implement a web based database and field recording system, building on the Canning Stock Route Database that was developed by ESS for the Canning Stock Route Project (Veth 2012).

The database comprises (i) a relational database that provides an organised structure for storing rock art data and (ii) a user interface that allows users of the system to interact with the data and to navigate through the database content. A range of open source tools and components have been utilised in the development of the user interface including 'OpenLayers'. This technology is used to present users with an interactive web map interface that can be used to record and display the geographic location and extent of rock art sites. A reporting or querying module presented in the user interface 


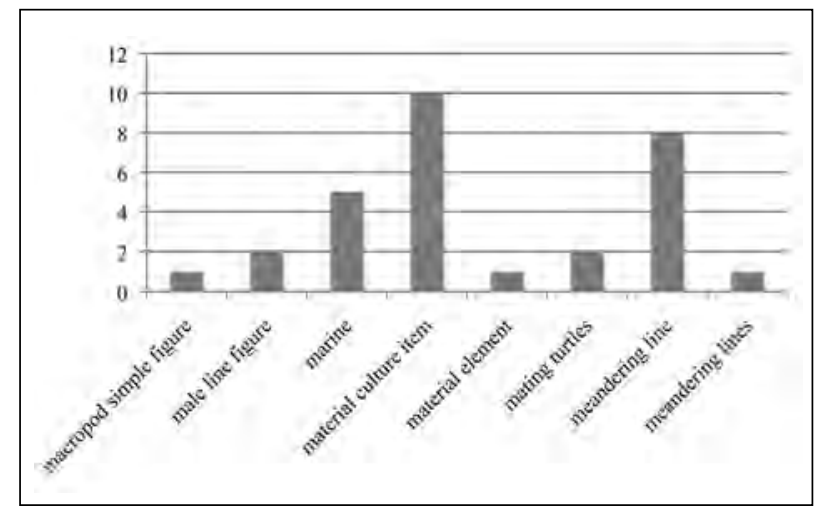

Figure 1. An example chart that summarises some of the recorded motif classes.

allows users to generate meaningful summaries of the system content. These outputs can then be used to generate various types of data summaries in the form of charts and tables. The list of available data summaries that can be executed includes the spatial density of motifs of various types and the numbers of sites, panels and motifs within particular regions. Fig. 1 provides an example of a chart that has been generated from the reporting module.

The system provides the means to record, store, search and summarise a diverse range of data forms including, documents, spatial information, photographs, and videos that depict various rock art site characteristics. Data can be downloaded in a variety of formats, including GIS formats for more complex spatial analyses. Permission levels can also be used to limit which registered users can view and or modify the datasets. This has been used to align with cultural protocols on the restriction of sensitive knowledge and simultaneously allow information to be shared with collaborating Aboriginal communities. Similar web based cultural heritage information management systems are used by various Aboriginal groups and government organisations throughout Australia.

\section{The Paperless Field Recording System and the Happy Valley Field School}

Happy Valley is an area of granophyre ridges on Rio Tinto leasehold land in the Dampier Archipelago (including Burrup Peninsular) National Heritage Listed Place ('NHL Place'). Petroglyphs occur across this area in very high densities. Each year, for the last four years, as part of its Net Benefit arrangement with SEWPAC (The Department of Sustainability, Environment, Water, Population and Communities), Rio Tinto has supported a rock art recording field school with CRARM with the purpose of documenting the rock art in the NHL Place. Students are taught the principles of rock art classification and recording, and document the art supervised by UWA and Rio Tinto staff. With as many as eight recording teams operating simultaneously, a large amount of data is gathered each year.

Up until 2012, the field workflow for this field school has consisted of manual recording of each panel and motif on paper forms. In addition to these forms, numerous photographs were taken of both the panels and motifs, and each panel was surveyed using a differential GPS. The main problems identified with this method were:

- A lack of standardisation in attribute recording and data structure and concomitant problems for inter-project comparison;

- The time consuming and error-inducing data entry phase;

- The time consuming and error-inducing process of manually relating the disparate data types (photos, GPS, paper form records etc.); and

- Thelack of a centralised facility to house the data.

In view of these problems, the requirements for the field recording system were to:

- Reduce the need for manual data entry to the greatest extent possible;

- Providea way to relateGPS data and photographs directly to their targets at the time of recording;

- Provide a balance between standardisation of recorded attributes and customisability for different areas/research questions;

- Ensure that the system is useable by nontechnicians; and

- Ensure a simple and coherent workflow. 


\section{The Approach}

Much funding and research has focussed on field based recording systems, but experience shows that existing solutions are often quickly out-dated by the rapid pace of technological development. Initially we considered using a modified version of a data collection application using ArcPAD running on Trimble devices as used by the Canning Stock Route team (between 2008 and 2010). Early on in the development process, it became evident that for our purposes this platform had been overtaken by new developments in smartphone technology, which now provide a cost-effective, and more functional and easily accessible platform for data collection.

The field recording system implemented is based on the software package called Mobile Data Studio (MDS). This package allows custom digital recording forms to be developed and deployed to mobile devices running iOS, Android, or Windows Mobile operating systems. Data recording forms designed in MDS were trialled in the field using various devices including iPhones, iPads, Android phones and tablet devices. Of these the Samsung Galaxy Notes smartphone seems to provide the best all round performance and usability. These devices are somewhere between the size of an iPhone and an iPad, are portable, have a large enough screen for most tasks, have usable cameras and one of the most accurate inbuilt GPS units in any smartphone on the market. However, the wide range of supported devices means that, when necessary, researchers' and students' personal smartphones can be used as additional recording devices in the field. In some situations (e.g. where the recorder is stationary recording larger sites, and where sitting down is an option), the larger screen of a tablet may be useful,

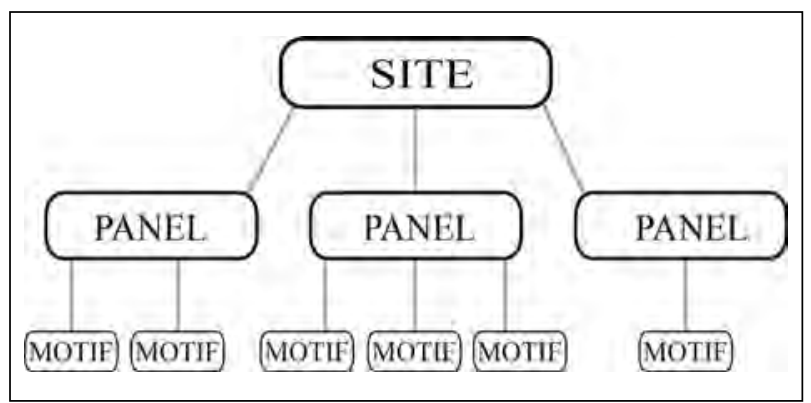

Figure 2. Hierarchy of field recording forms for the Pilbara Rock Art paperless recording system. and the forms can be deployed to iPads or similar devices. In more mobile recording field situations, where balancing the tablet in rocky terrain becomes logistical and a repetitive strain risk, the smaller devices havebeen found to be more useful. The setup time for an additional device is minimal and requires only basic technical skills. This easy scalability of the system was seen as a distinct advantage of the Mobile Data Studio software.

\section{Field Recording Methods - Site Recording Forms}

The field method consists of three components: site recording, data download and auditing. Site recording takes place using three separate digital data entry forms on the mobile device. One form describes the archaeological site or place where the art is located; the second form describes the panel i.e. the surface on which the art is located, and the third form provides the layout for the information describing each art motif. This hierarchy of recording forms is illustrated in Fig. 2.

Each form contains specific fields that are filled in, either manually using the devices keypad or from drop down lists containing pre-set values. The forms are comprehensive. In summary, the site form includes location information for the site, location of art within the site, environmental variables, ethnographiccomments and sitephotographs. There is also a 'site condition' section, where disturbance, damage and suggested management actions can be specified. The panel form compiles information about the art surface. Attributes include type of panel (on a boulder or in a rock shelter), its location and size, aspect and dip, surface attributes, geology, condition, weathering and photographs. The motif form is used to record individual art motifs. On this form measurements and orientations are routinely described and art technique information is recorded. Up to five photographs and a digital image of a field sketch can be inserted into the form itself as thumbnails and visualised in context.

Themost critical part of themotifform is where motifs are classified according to a class and subject. The main classes used are Anthropomorphic, Zoomorphic, Geometric and Spooromorphic (which relates to animal tracks). Once a class has been determined for a particular motif, the user is 
prompted to select from a subset of predefined subject classifications. For example, Fig. 3 shows screen grabs of the recording form, showing how the motif class and subject terminologies are standardised for each field project with predetermined drop down selectable lists (such as that shown in part in Fig. 3). This has obvious benefits within a project for analysis, but the dropdown lists used may not transferable across diverse project areas. To this end the lists are customisable and can be modified before the beginning of a project, or even during the project.

On each form there are fields to insert photographs that can be either populated from the devices' inbuilt camera, or from photos sent to the mobile device over a Wi-Fi connection, using a WiFi enabled camera (see Eye-Fi below). Each form has a field for GPS coordinates that can be populated by direct connection to the mobile devices' inbuilt GPS, or manually entered from a more accurate surveying instrument.

At the conclusion of each day, the second component of the field method takes place. Data is downloaded by wireless connection to the Mobile Data Studio database that is housed on the field laptop. As data is sent to the Mobile Data Studio server, it is automatically appended to tables within a Microsoft Access database on the field laptop. The SQL querying functions in this application are used to audit the data. At the conclusion of fieldwork this data is uploaded to the main repository database. This is then accessible through any web browser by an authorised user (usually CRARM researchers or designated Aboriginal community members).

In practise the wireless data transfer works well, and in over 1000 iterations no errors were encountered. This part of the workflow is a great improvement on data entry, and works especially well if both photographs and GPS data are captured using the device itself.

\section{Eye-Fi Technology}

In most rock art recording situations high quality photographs are necessary for archival and analytical purposes, and the inbuilt cameras in mobile devices cannot suffice for all photographic requirements. Many researchers prefer to take

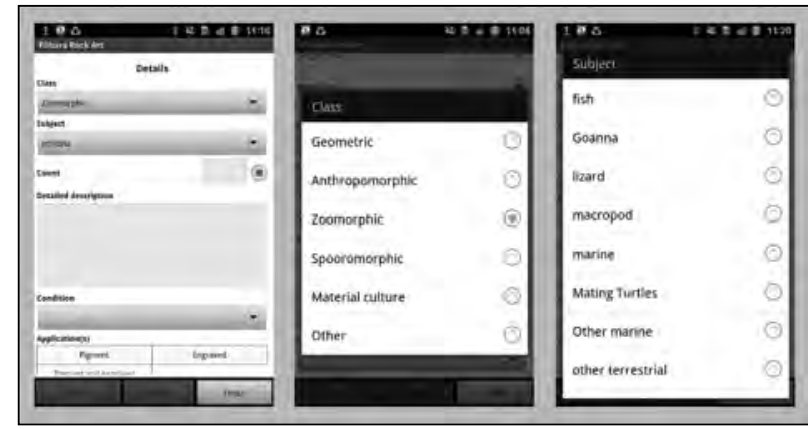

Figure 3. Screen grabs of the mobile device showing motif class and subject selection choices.

photographs, especially of theindividual motifs, with full frame dSLRs such as Canon 5Ds and Nikon D3s. This of course results in an additional dataset (the digital photo files) that must be related to the digital recording form for the pictured motif or panel, etc. In previous workflows, the linking of photographs to database records (usually through transcription of manually written photo logs) had been very time consuming and often introduced errors.

A solution was trialled using wireless photo transfer direct from the cameras to the mobile devices in the field. The hardware used for this is the Eye-Fi card, manufactured by Eye-Fi Inc. The hardware consists of a Wi-Fi antenna on an SD card, which can broadcast its own wireless network over which the photographs can be transferred to the mobile device. The cards are inserted into cameras and double as the storage media. While the Eye-Fi technology is only available on SD cards, we have successfully used specific SD-Compact Flash adapters to Wi-Fi enable cameras that use the Compact Flash format for storage.

In our field-testing, each recording team has a mobile device, and an Eye-Fi card that is specifically associated with that device. Recorders can begin photographing a target (i.e. a Site, Panel, or Motif) at any stage, and a thumbnail of the relevant photo will be sent to the paired mobile device as soon as it is within range $(\sim 10 \mathrm{~m})$. Thumbnails of these photos can then beinserted into the recording forms and visualised within the form itself. Critically, the original filename of the photo is preserved and stored in a hidden data field. This means that the original photo filenames are present in the database record for each form, which is a significant improvement in minimising the errors of association that had 


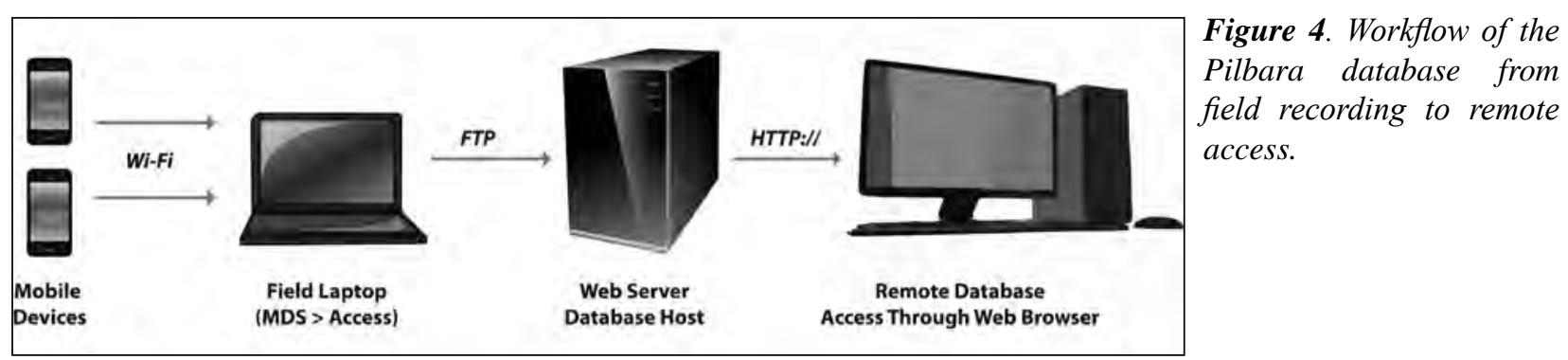

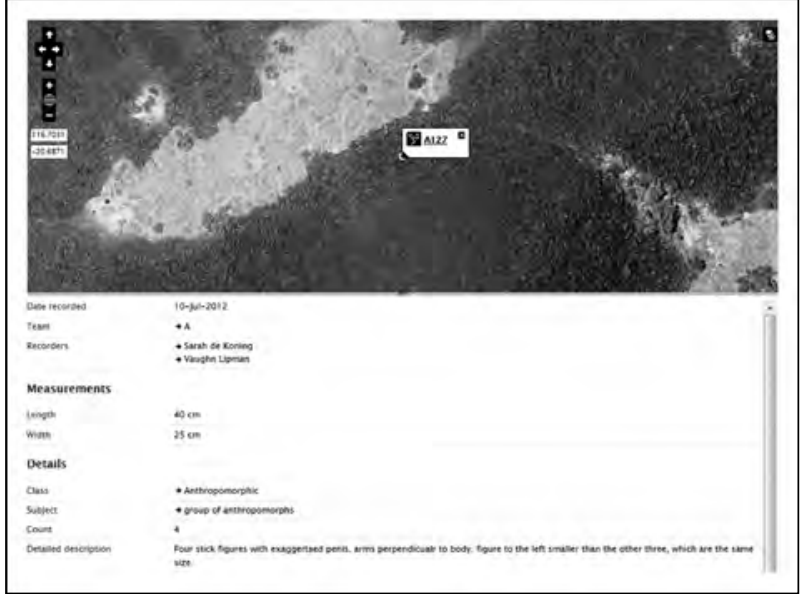

Figure 5. screen grab showing motif form on background of Google Earth ${ }^{T M}$ image.

previously been identified as a problem in the manual production of photo logs.

At the end of each field recording session, the wireless data download of the recording forms now includes photo thumbnails and original filenames that are automatically related to the correct motif or panel etc. If required, a traditional photo log can be easily generated from the database using an SQL query in a matter of seconds. The full versions (often RAW files) must still be archived directly from the camera, but as the original filenames are stored in the database, they are also referenced. We are still testing the Eye-Fi system, but it appears to work well at this stage.

\section{Connecting to the Database}

Once data has been audited and relationships checked with a series of SQL queries, the data is uploaded to the server via an FTP connection that can then be accessed though a web browser (Fig. 4).

The database also contains a series of forms detailing sites, rock art panels, and motifs, and these contain the same fields as are present on the mobile recording forms. Data transferred from mobile data collection devices populates these same photo, site, panel and motif forms. Once data has been transferred, the database system can beimmediately interrogated using a range of methods, including a series of search tools or a map containing a range of satellite images, aerial photographs and topographic map layers. Users of the system are able to obtain more information about any entry by selecting from the map (Fig. 5) or from a search result list. This takes the user to a detailed page about the selected entry with a map showing its location and a summary of all other information that has been previously related to it.

In addition to accepting data from the mobile devices, the database can also be used as a portal for data entry. Forms that contain identical fields to the mobile devices can be completed and submitted, and a database entry is created. The database is structured hierarchically so that one or more rock art motif(s) entries may be recorded on any given panel and one or more panel(s) may be recorded for any given site entry. The database also has the capacity to accept an extensive range of multimedia and document formats, all of which may be added as entries and related to previously recorded sites, panels or motifs.

The database system can be used to generate summarised datasets that can be used in other specialised systems such as a GIS or a statistical analysis package. Other outputs include tables of categories and list options (the contents of the dropdown lists) that are presented on forms. These lists are used to update the selection list items that are also presented on the mobile data collection forms. This ensures that any selections made on data collection forms in the field correspond exactly to those contained in the system when it is transferred. 


\section{How Well Did We Meet the Objectives?}

Whilst the system is still in the testing phase, we are well on the way to meeting the objectives of a standardised mobile recording system that allows flexibility for different projects. The need for manual data entry from paper forms has effectively been removed. This is a clear advantage and means that evenings in the field can be spent doing some basic analysis of results and planning the next day's approach in an informed manner. However, it should be noted that the time taken to audit data remains significant. In the future we hope to partly automate the data auditing process, by designing database queries to target and report on inconsistencies, anomalies and common data entry errors.

The balance between standardisation and customisability has been difficult to address, but we have had some success. Drop-down lists have encouraged standardised nomenclature and provided alevel of comparability not seen in previous datasets. However, an inherent limitation of drop down lists (e.g. Fig. 3) is that they do not cover all possible archaeological scenarios. Fields can be filled as 'Other' and described, but this is not an elegant solution. Ideally, it would be possible to add terms to the drop down lists while in the field, which are then made available to the other mobile devices in the team wirelessly. When crossing cultural, geological and geographical boundaries, the set of descriptive terms used will also vary. This situation has been handled thus far by enabling customisation of the drop down lists. Subsets of terms for different areas are available in the online database, and these can be downloaded and imported into Mobile Data Studio at the commencement of each job. It is expected that the refinement of these lists of dropdown options is likely to be an ongoing process as CRARM begins research in other style provinces. It is difficult to develop a recording system that satisfies different researchers accustomed to their own recording methods. Whilst the sets of terms used to record attributes can be easily modified, the actual structure of our recording methodology is relatively inflexible, and cannot be infinitely expanded. In an effort to accommodate different methods, we have included the option to record a wide range of attributes. Researchers can then choose which attributes they would like to mobilise in the recording of their different field areas. The data will then still be comparable across commonly recorded fields. No attempt at standardisation will completely satisfy all stakeholders.

The workflow is relatively simple to follow once people are trained in the system. Most significantly, the lab workflow has been greatly simplified, with all data relationships occurring in the field as a result of the system's architecture. For example - all photographs and GPS data pertaining to a panel are digitally related to the textual information pertaining that panel at the time of recording.

In evaluating whether the system is faster or better than previous methods of recording on paper forms we must also consider accuracy, usability and flexibility. Once recorders are familiar with the system it is generally faster than using paper forms, and significantly faster in regions where there is stylistic homogeneity. However, the primary advantages of this system do not lie in reducing the time taken to record art in the field. Instead, the advantages are that it encourages standardisation, it reduces the time taken for data entry, it promotes ease and reliability of relating the different data types, and the most important advantage of all is that it produces greater coherence in the resulting data.

\section{The Future}

Once the testing phase is complete, our immediate goals are to train other potential users of the system. We have a number of staff, post-graduate researchers and undergraduates in CRARM who wish to mobilise this technology in a range of field areas. We are also working on developing collaborative research and management projects with a number of Aboriginal communities in the Pilbara, Western Desert and Kimberley (e.g., the Murujuga Rangers and the Birriliburu IPA Rangers in the Western Desert), and these groups require training in the field use, management potential and development of access protocols in their various rock art sites. Tools to automate the data auditing process are also a priority, as is data entry of legacy data directly into the database. The feasibility of incorporating 3rd party apps into the recording system for tasks such as sketching will also be investigated. We also aim to develop integration and connectivity to external high precision GPS devices 
using the NMEA protocol. However, as mobile devices begin to incorporate higher quality cameras and GPS chips, we hope to further simplify our field recording workflow by having a single device for recording all characteristics of rock art sites and motifs.

\section{Acknowledgements}

We would like to thank the Pilbara Development Commission who generously provided a grant for the development of the Pilbara rock art database.

\section{Bibliography}

Digital Antiquity. 2014. "tDAR/ About." Accessed March 15. http:// www.tdar.org/ about.

FAIMS. 2014. "FAIMS.” Accessed March 15. http:// www. fedarch.org/ wordpress/mission.

Jeffrey, S., L. Xia, J. Richards, J. Bateman, K. Kintigh, F. Pierce-McManamon, and A. Brin. 2011. "TheTransatlantic Archaeology Gateway: Bridging the Digital Ocean." In Revive the Past. Computer Applications and Quantitative Methods in Archaeology (CAA). Proceedings of the 39th International Conference, Beijing, April 12-16, edited by M. Zhou, I. Romanowska, Z. Wu, P. Xu, and P. Verhagen 198- 208. Amsterdam: Pallas Publications.

McDonald, J. 2006. "A study of the distribution of rock art and stone structures on the Dampier Archipelago." Internal Report. Canberra: Heritage Division of the Department of Environment and Heritage.

McDonald, J. 2009. “Archaeological survey of Deep Gorge on the Burrup Peninsula (Murujuga) Dampier Archipelago WA." Internal Report. Perth: Department of Indigenous Affairs.

McDonald, J., and P. Veth. 2009. “Dampier Archipelago petroglyphs: scientific values and National Heritage listing." Archaeology in Oceania 44 (S1):49- 69.

Mukurtu. 2014. "Mukurtu CMS." Accessed March 15. http:// www.mukurtu.org.

Mulvaney, K. J . 2011. “About Time: Toward a sequencing of the Dampier Archipelago Petroglyphs of the Pilbara region, Western Australia." In Fire and Hearth' Thirty
Years On: Essays in Honour of Sylvia Hallam, edited by C. Bird and R. E. Webb, 30-49. Perth: Records of the Western Australian Museum.

Veth, P.M. 2012. "From Discovery to Commoditization Rock Art Management in Remote Australia." In A Companion to Rock Art, edited by J . J . McDonald and P. M. Veth, 546- 560. Malden: Wiley Publishing.

Veth, P., E. Bradshaw, T. Gara, N. Hall, P. Haydock, and P. Kendrick. 1993. "Burrup Peninsula Aboriginal Heritage Project." Internal report. Perth: Department of Conservation and Land Management.

Vinnicombe, P. 1987. Dampier Archaeological Project: Resource Document, Survey and Salvage of Aboriginal Sites, Burrup Peninsula, Western Australia. Perth: Western Australian Museum.

Vinnicombe, P. 2002. "Petroglyphs of the Dampier Archipelago: background to development and descriptive analysis." Rock Art Research 19(1):3- 27. 


\title{
Beyond Tablet Computers as a Tool for Data Collection: Three Seasons of Processing and Curating Digital Data in a Paperless World
}

\author{
John Wallrodt \\ University of Cincinnati, USA \\ Kevin Dicus \\ Case Western University, USA \\ Leigh Lieberman \\ Princeton University, USA \\ Gregory Tucker \\ University of Michigan, USA
}

\begin{abstract}
:
During the 2010-2012 campaigns of the Pompeii Archaeological Research Project: Porta Stabia we implemented an increasingly robust program of digital data collection through the first application of tablet computers in all aspects of fieldwork. In addition to their positive impact, we have also encountered unique challenges to the processing and curation of this data. These include an increase in the amount of interpretation necessary by those managing the collected data, the production of non-standard records, and the steep learning curve that results from the employment of new technologies. This paper sheds light on our experiences and reactions to this digital revolution.
\end{abstract}

\section{Keywords:}

Tablet Computing, Digital Curation, Communication, Post-Excavation Processing, Data Collection

The Pompeii Archaeological Research Project: Porta Stabia, or PARP:PS, has excavated for eight consecutive seasons in the southern portion of Pompeii, in a corner of the city partially bounded by the Quadriporticus, the theatres, and the city wall. From 2005-2009, mostof the project documentation and data management was undertaken with standard practices, such as drawing on mylar (or semi-opaque tracing paper) and maintaining paper records. While the creation of born-digital data has been commonplace in many archaeological field projects over the years (including PARP:PS) they have been restricted to limited data types (such as point location data) or have used an array of taskspecific devices to complete their documentation (Powlesland and May 2009). While some projects have created digital workflows for database work or for site location data with GPS, the authors know of none that have created an entirely digital workflow for trench-side data collection (Fee et al. 2013). In

Corresponding author: john.wallrodt@uc.edu
2010, the newly released Apple iPad allowed for technological advances in project documentation and data security, leading PARP:PS to develop the first completely paperless documentation and data-management system. Since then, it has been a goal of the PARP:PS team to develop an efficient, fully digital workflow. The digital workflow itself is described in much greater detail in theblogPaperless Archaeology (Paperless Archaeology 2014). There you can find templates of the database that we use as well as samples of other document types in their native formats.

Adopting a paperless recording system has streamlined data entry and increased access to digital project data (Pompeii Archaeological Research Project: Porta Stabia 2011; Ellis and Wallrodt 2012). These changes brought some unexpected challenges as the members of our team, including excavators, trench supervisors, spatial data technicians, small finds specialists, 


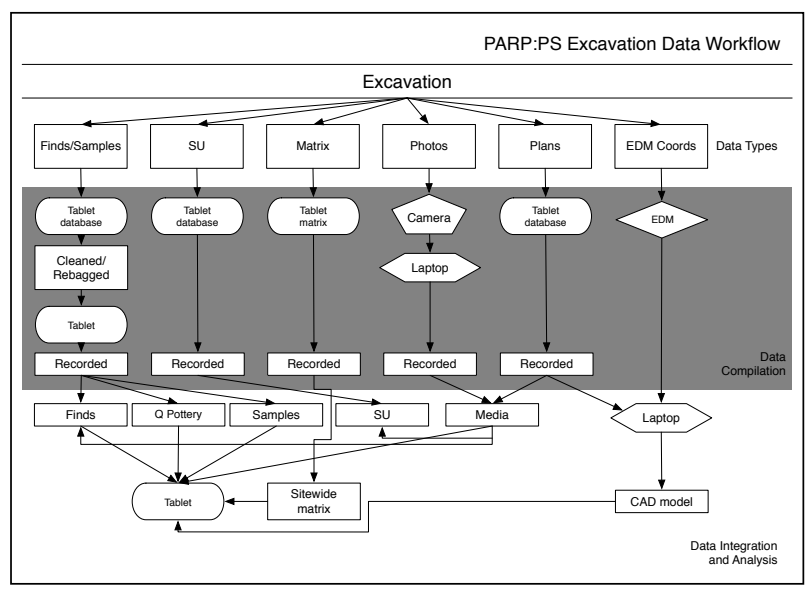

Figure 1. Workflow for trenchside recording for PARP:PS.

and environmental archaeologists, adapted to the new workflow. This paper will not focus on data collection with tablet computers, but rather on how a paperless workflow affects the intermediate stages of the archaeological process, the steps immediately following excavation and initial documentation. Here we discuss three main challenges: an increase in the amount of interpretation necessary by postexcavation specialists for some types of data, the production of distorted records, and the steep learning curve that necessarily results from the employment of new technologies. Our primary data collection methods have been described elsewhere (Wallrodt 2011a). By focusing our discussions on the needs of the first immediate data consumers rather than data collection and capture, we aim to explore solutions for enhancing the utility of data across the levels of collection, analysis, and dissemination.

\section{Transitions and Increased Interpretation}

\subsection{Finds}

Prior to the adoption of tablet computers in the field in 2010, each supervisor's paper binder held detailed descriptions of a given trench's stratigraphic units (SUs), related small finds, and environmental material; matrices were often informal sketches drawn intermittently. Access to this data required consultation of the physical binders, and communication of this information to specialists was ad hoc at best. Similarly, information that might be useful in guiding excavation, such as the latest datable pottery sherds or the significance of particular coins in an SU was communicated only

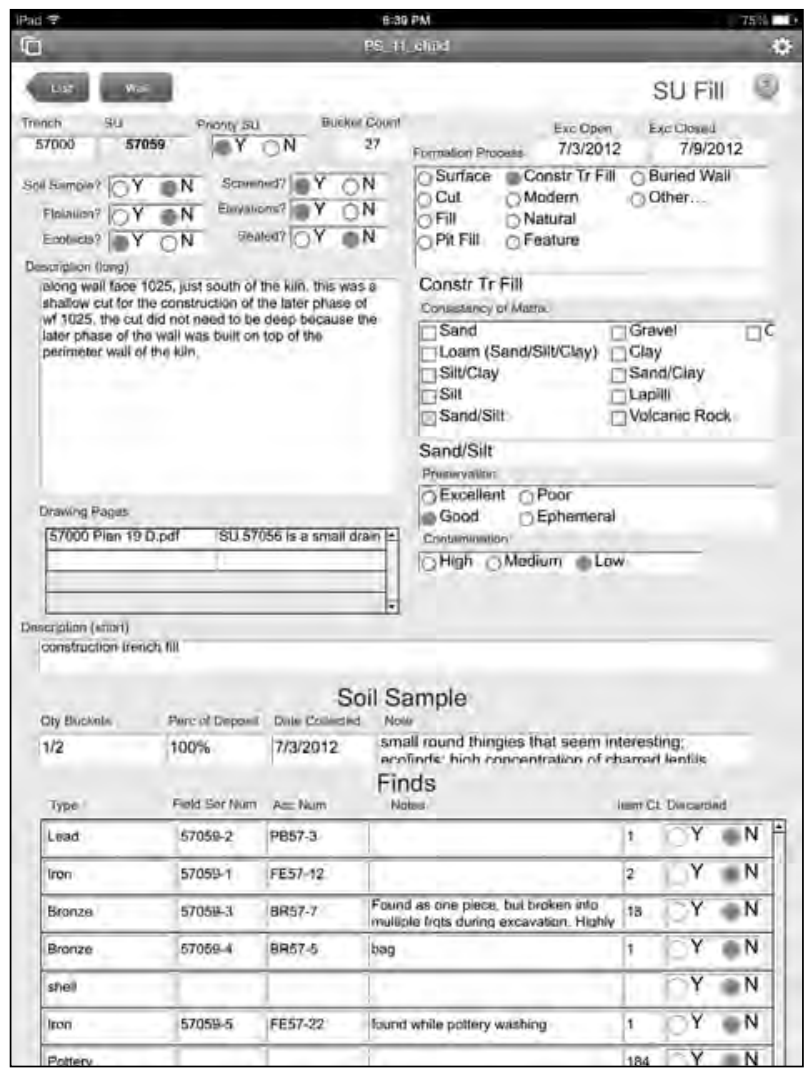

Figure 2. Tablet interface for field recording. Finds are given Field Serial Numbers by the excavator upon discovery. They are given Accession Numbers by the finds specialist upon proper inventory.

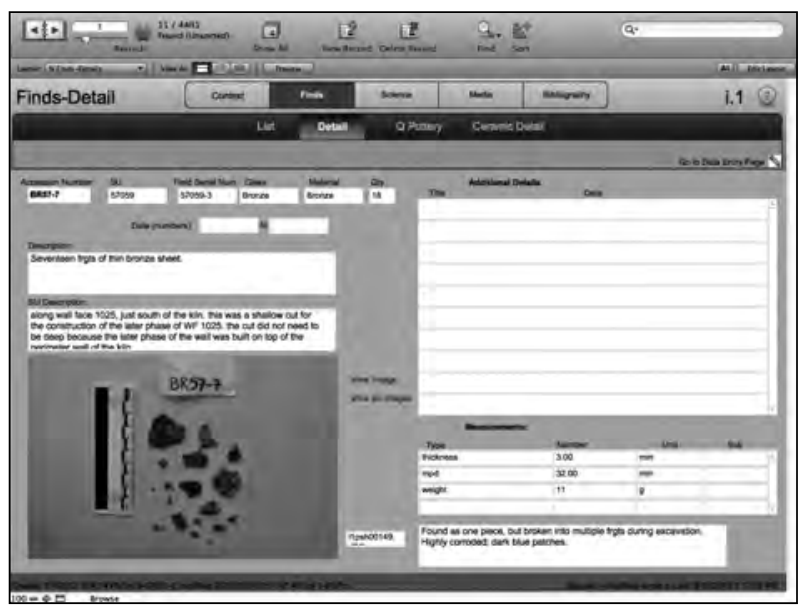

Figure 3. Desktop interface for small finds recording. The small finds specialist has access to the field notes and within a few hours the small finds details will be available to the excavator. 


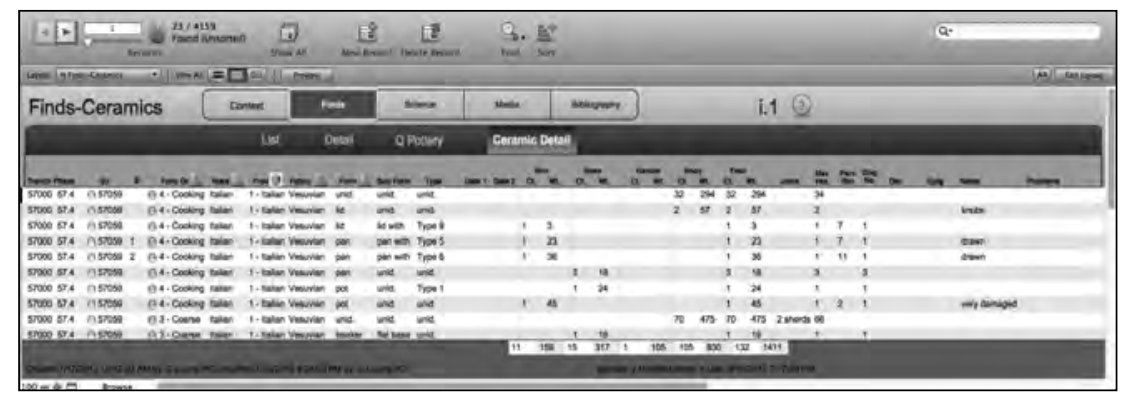

Figure 4. A sample of detailed ceramic information directly entered into the database as they are identified.

through casual conversation between specialists and excavators, and not delivered in any kind of pro forma fashion.

In our paperless system, all of the information about SUs, ceramics, coins, small finds, and environmental samples is entered onto the tablets in the field. The tablets are synced with our main database at midday and in the evening, allowing all contextual information to be distributed on a consistent basis. For example, the ceramicists, usually working on laptops in the storerooms, have complete access to a current database that describes each SU. Similarly, the numismatist, using his own laptop, has access to regularly updated stratigraphic matrices that are created on the trench tablets. Trench supervisors using those tablets are easily able to flag an SU as a priority in the database while in the field, which encourages specialists to process that context first. Likewise, trench supervisors can easily see in the database when the materials from their priority SUs have been processed.
The various finds specialists can also see each other's data quite easily and in a format that they find the most useful for their own work, whether working on a tablet or computer. For example, the numismatist has access to information regarding pottery that has already been processed by the members of the ceramics team, and similarly, the pottery specialists are able to consider any data already recorded by the numismatist. Overall, the members of the excavation team who work with various classes of excavated materials have immediate access to much more information than ever before primarily because there is no need to wait for paper records to be digitised.

\subsection{Spatial}

Digital data collection has long been a core component of the spatial data segment of PARP:PS, with a total station recording $3 \mathrm{D}$ data. The plans and sections drawn by the team were documented using mylar until the introduction of tablet computers in

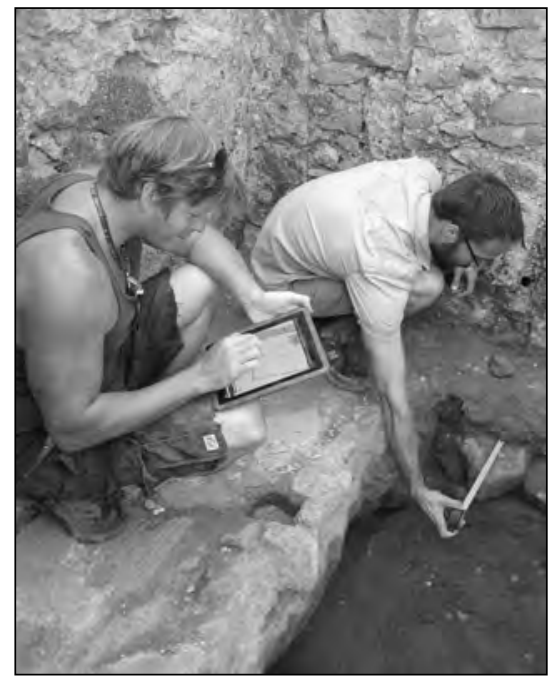

Figure 5. Field drawing for PARP:PS on the tablet.

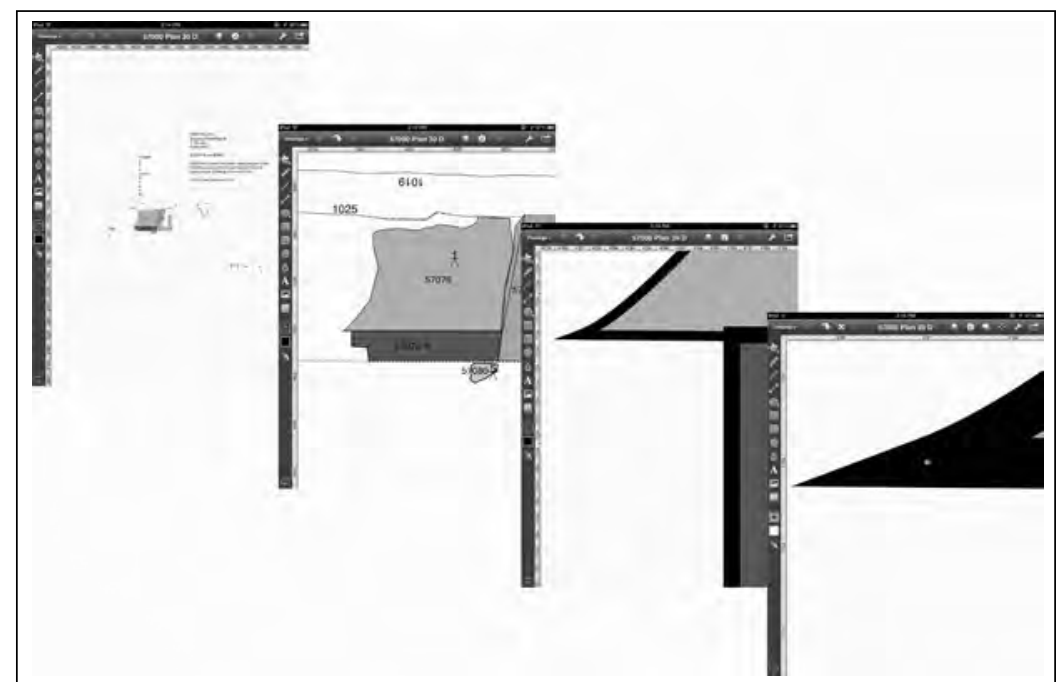

Figure 6. The zooming interface of TouchDraw ( ${ }^{\mathrm{TM}}$ ) on the tablet that allows drawings to be submitted in 1:1 scale. 


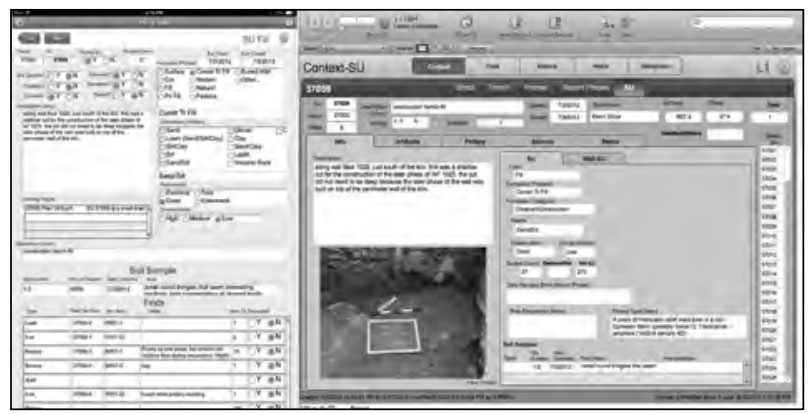

Figure 7. SU57059 data in both tablet view (left) and desktop view (right) from the same database. Note the tabbed interface that allows the desktop view to access additional categories of information. This desktop view is also available on the tablet, but not by default.

2010. We now draw directly on the tablets in the field using TouchDraw, a vector drawing app that requires no limits on canvas size, thus allowing us to produce drawings without resorting to traditional 1:10 or 1:20 scales as different views can be produced simply by zooming in or out on the digital canvas.

Perhaps the most unforeseen change in the responsibilities of processing and managing these spatial data is the increased precision introduced by a scale-less drawing technique. There is a changing interpretive burden on the CAD specialist with the introduction of these plans to the CAD model. Overlapping lines and open shapes are just some examples of situations that require modification to the primary data by the specialist, forcing interpretation to be made in the CAD environment, rather than in the field. Some of these issues can be corrected by changes in the drawing techniques or additional training, while some require immediate communication between the CAD specialist and the trench artist. In a paper workflow, where items are drawn and scanned later, these things would have been adjusted during the tracing or scanning steps. But now specialists must identify these immediately, lest errors make their way into the final model.

The speed with which drawings are identified as complete, processed into the CAD model, and then made available in the field on the trench tablets allows for a two directional verification system. Not only is the dialogue discussed above able to take place quickly and efficiently, while the contexts are still fresh in the excavators minds, but also the field team can recognise computing errors or misinterpretations and alert the spatial data team much more quickly than before. In the past, they would not have had access to the digital files for weeks or may not have viewed them at all, but now they may have features modelled and returned to their plans within a day. This active verification of each context leads to a greater dialogue with the excavation team as errors are identified, and to a more complete understanding of what is being modelled by the specialists.

\subsection{Field}

The project's trench supervisors engage with the data in various ways. They are responsible for their teams' entry of immediate observations into the database using the FileMakerGo app on the tablets in the field. This includes full descriptions of each SU encountered, quantification of all material culture, photographs, and drawings. Supervisors are furthermore the first consumers of data from specialists which they use to create a phased narrative of the site's occupational history.

Because the phased narrative requires the interpretation of multiple types of data, the trench supervisor's greatest benefit is the collation of all classes of information into a single database. Previously, when PARP:PS relied on paper documents, each trench generated many hundreds of pages of records. These ranged in form from SU sheets and finds sheets to large rolls of drawings on mylar. Thus, in order to write the final excavation report, reams of paper documents were consulted, a task that quickly became unwieldy. Today, all of these documents are found in a single source, stored electronically, and accessible by means of the tablets in the trenches or laptops back at the dig house. The increase in data accessibility and portability makes data interpretation much more clean and organised.

The switch to tablets has fundamentally aided the supervisors' dual roles. In the trench, digital data entry not only accommodates the stringent methodology of excavation, but furthermore guides and reinforces that methodology. Throughout the transition from paper to paperless, excavation methodology has remained consistent: all information about a context, including the SU sheet, small finds and environmental information, photos, plans, and elevations, must be recorded before 
that context may be closed and removed. When this information is recorded digitally, the speed at which it makes it to our specialists for analysis and interpretation is profoundly faster than it was with paper records. The open access to the data by any excavator or specialist and the quick processing of those data give a certain transparency to the project.

\section{Distorted Records}

Since the paperless workflow provides increased access to in-progress work, we must necessarily protect ourselves from the distortion of records that may result from the immediate availability of incomplete data. To a certain extent the production of distorted records is an inherent consequence of the archaeological process; however, the greater confidence that members of the excavation team place in digital records can exacerbate this problem.

\subsection{Finds}

Distorted records can most conspicuously result from the work of the specialists who process small finds and ceramics. Although in both the old and new systems, pottery from a particular context is not examined by specialists until that specific SU is completely excavated, the data produced by the ceramicists are returned to the trench supervisors and members of the excavation team in almost realtime as the pottery is processed. For very large SUs, or for complex ceramic assemblages that require multiple ceramic specialists for interpretation, this can produce partial analyses which could influence interpretation in the field. The ceramicist and numismatist might also process finds from the same $\mathrm{SU}$ at different times, leading to some question about the final dating of the SU.

These issues are best overcome by continued personal communication among various members of the excavation team. We aid this personal communication by an audit trail that records all edits in all of the fields in the database with a description of the user and machine that recorded the data. In this way, important details are no longer only transmitted orally, and changes can all be tracked and highlighted in the database.

\subsection{Spatial}

We are able to minimise data distortion in the field drawings by training the drawing teams in short sessions to show them how to apply standard drawing conventions through a new user interface, the tablet (Tucker and Wallrodt 2013). Since the drawings are reviewed and added to the $\mathrm{CAD}$ model within hours of being completed in the trench, the two-way verification discussed earlier can ensure that the model is an accurate representation of the site. This process is made even more efficient through the presence of the spatial technician on site with the field team, reducing the space and time needed to further ground-truth the plans. Plans at the middle or end of the season require very little touch-up as they have grown organically, with constant data verification, both from the spatial and the excavation sides of the team.

\subsection{Field}

The increased intermediate use of collected data has furthermore helped to refine the methodology of the trench teams. Implementing tablets has encouraged more consistent dialogue between various specialists and members of the excavation team. Supervisors now communicate many times daily with spatial, small finds, ceramic, and environmental specialists about new details they have accessed in the database. Supervisors must focus on, then, not just the trench itself and the stages of excavation, but also how the information about the excavation is conveyed to the entire team. There is a greater accountability to the rest of the team: drawings must be accurate, small finds and pottery must be listed and quantified, SU sheets must be complete to consider a context closed; any variations quickly impact the productivity of rest of the team. There are also, however, better safeguards: if it happens that there is an anomaly or inaccuracy, it is found and corrected before the end of the field season.

\section{Learning Curve}

This project has worked for years under the idea that team members first using the new technology would accept it after recognising its ease of use and usefulness (Davis 1989; Hinds and Kiesler 1995; Venkatesh et al. 2003) and that 


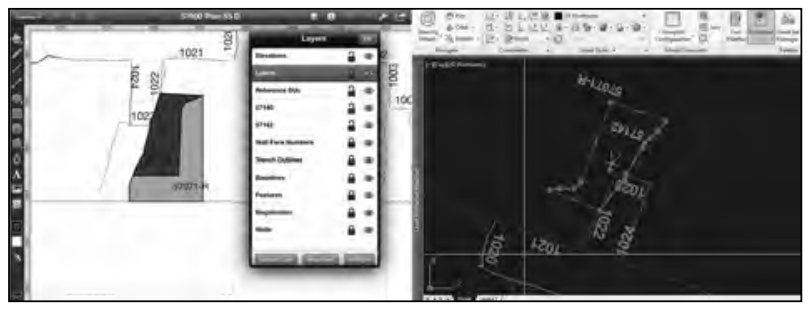

Figure 8. SU 57142 in both the TouchDraw ( $\left.{ }^{\mathrm{TM}}\right)$ interface on the tablet (left) and AutoCAD ( ${ }^{\mathrm{TM}}$ ) interface on the desktop (right).

the technology would become second nature in its second year. While the most significant instances of this digital learning curve have revolved around the entry of primary data into the tablets, development and growth are also evident in the intermediate phases of processing.

\subsection{Finds}

The introduction of a robust series of checks and balances for finds processing was greatly enhanced by the transition from paper to paperless. Before 2009 members of the field team were responsible for documenting the various materials excavated only by noting their presence or absence on the SU forms. This process changed slightly in 2009 when the field team recorded quantities of objects that were kept and objects that were discarded. Small finds and non-bulk ceramics were assigned a serial number, which was listed at the bottom of the SU sheet and included on the tags that accompanied each find. The intention behind this rather informal process was to provide some sort of inventory control.

This process of assigning serial numbers was formalised during the 2010 season with the ability to have digital access to the database in the trenches. Each object was and still is assigned a unique Field Number by means of an automatic script in the database. This also creates a record in the database Small Finds table, which can beused by the Registrar for inventory control and further description. The database assigns a separate Accession Number to each object to avoid duplicates, and the Registrar serves as the intermediary between the field and the various specialists.

The learning curve for the specialists themselves is not incredibly great. Most of the specialists bring their own schemata to the project, and we have made every effort to develop a database that can accommodate their particular templates and interfaces, whether on tablets or computers, within our own comprehensive data structure.

\subsection{Spatial}

Learning how best to use the field plans was one of the biggest challenges of the conversion to paperless data collection. For the field team, the growing pains mostly revolved around learning how to draw in layers with vector software. For the $\mathrm{CAD}$ specialist, it involved learning new software and file conversion options, a topic which we have discussed elsewhere (Wallrodt 2011b). Any tweaks to the workflow have since been made to make data documentation by the excavation team as easy as possible and, when combined with faster data exchange between the field and the lab, the data were more accurate and more quickly finalised than when we employed standard collection techniques.

\subsection{Field}

As the database grows to incorporate new analytical techniques, it is necessary also to increase the amount of training provided to the trench supervisors to harness those new features. For example, the assemblages of two separate contexts can be compared and quantified directly by the database, allowing the supervisor to quickly determine if there is a statistical significance to seemingly comparable contexts. Searches on specific artefact types are possible: for instance, one can gather with a simple search a list of contexts in which a specific pottery class appears. All drawings are digitised and particular contexts can be found by means of a query; all of these digital relationships have been maintained and verified throughout the season, thus the software is able quite easily to produce rather straightforward but sophisticated collations of all data.

\section{Conclusions}

PARP:PS has benefited greatly from having a diverse group of scholars to act as immediate first consumers of the data produced in a paperless fashion. We have learned that there are some difficulties creating and digesting digitally produced 
data, but we have maintained that these problems are not insurmountable. We are learning about the additional training necessary for the team and how to best use the immediate access that we have to our data. We have also seen that the benefits of consistent data validation and increased project communication far outweigh the problems that we have encountered. Methodology does not have to be changed to a great degree; in fact, we are attempting to keep things as similar as possible to standard techniques so that any learning curve, as discussed above, comes from using a different user interface rather than a different method.

We are also constantly evaluating the processing of our data and its consumption. We can make minor changes through the season and introduce more major changes during the off-season. Our next step is to evaluate how the data is further consumed during periods of intense research as we transition into study seasons in preparation for our final reports. We expect this paperless approach to serve us best in the archival stage after the full publication of our excavation.

\section{Bibliography}

Davis, F. 1989. "Perceived Usefulness, Perceived Ease of Use, and User Acceptance of Information Technology." MIS Quarterly 13 (3):319- 340.

Ellis, S., and J. Wallrodt. 2011. "The 'Paper-less' Project: the use of iPads in the Excavations at Pompeii." Paper presented at the annual meeting for the Computer Applications and Quantitative Methods in Archaeology, Beijing, China, April 13, 2011.

Ellis, S., and J. Wallrodt. 2012. "Pompeii and the iPad: an update." Paper presented at the annual meeting for the Computer Applications and Quantitative Methods in Archaeology, Southampton, United Kingdom, March 28, 2012.

Fee, S. B., D. K. Pettegrew, and W. R. Caraher. 2013. "Taking Mobile Computing to the Field." Near Eastern Archaeology 76 (1):50- 55.

Hinds, P., and S. Kiesler. 1995. "Communication across Boundaries: Work, Structure, and Use of Communication Technologies in a Large Organization." Organizational Science 6 (4):373- 393.
Hopkins, C. 2010. "iPad at Pompeii: Does Tech Really RevolutionizeHowWeSeekthePast?[Update]."ReadWrite October 11. Accessed October 27, 2013. http:// readwrite. com/2010/10/11/ipad_at_pompeii_does_tech_really revolutionize_how\#awesm= olrTzkyXzzvgsv.

Paperless Archaeology 2014. "About." Accessed Oct 27, 2013. http:// paperlessarchaeology.com/about/ .

Pompeii Archaeological Research Project: Porta Stabia 2011. "iPads at Pompeii." Last modified April 12. http:// classics.uc.edu/pompeii/index.php/news/ 1- latest/142ipads2010.html .

Powlesland, D., and K. May. 2009. “DigIT: Archaeological Summary Report and Experiments in Digital Recording in the Field." Internet Archaeology 27 (11). Accessed October 24, 2013. http:// dx.doi.org/ 10.11141/ia.27.2.

Tucker, G., and J. Wallrodt. 2013. “Rethinking CAD Data Structures - Pompeii Archaeological Research Project: Porta Stabia." The CSA Newsletter XXVI (1). Accessed October 27, 2013. http:// csanet.org/ newsletter/ spring13/ nls1302.html.

Venkatesh, V., M. G. Morris, G. B. Davis, and F. D. Davis. 2003. "User Acceptance of Information Technology: Toward a Unified View." MIS Quarterly 27 (3):425- 478.

Wallrodt, J. 2011a. "1:1 Drawings Workflow." Paperless Archaeology J uly 10, 2011. Accessed Oct 27, 2013. http:// paperlessarchaeology.com/ 2011/ 07/ 10/ 11-drawingsworkflow/.

Wallrodt, J. 2011b. "Syncing Sample." Paperless Archaeology May 27, 2011. Accessed October 27, 2013. http:// paperlessarchaeology.com/ 2011/ 05/27/ syncingsample/. 


\title{
Applying Low Budget Equipment and Open Source Software for High Resolution Documentation of Archaeological Stratigraphy and Features
}

\author{
Undine Lieberwirth, \\ Free University Berlin, Germany \\ Bernhard Fritsch \\ Humboldt-University of Berlin, Germany \\ Markus Metz, Markus Neteler \\ Fondazione Edmund Mach, San Michele all'Adige, Italy \\ Kerstin Kühnle \\ Dresden University of Applied Sciences, Germany
}

\begin{abstract}
:
Available technology and measurement methods currently exceed the requirements of archaeological documentation at excavation in terms of precision, accuracy and resolution. Hence, archaeologists face the challenge of deciding not only what and how to document in archaeological terms, but also what degree of precision, accuracy and resolution are necessary and which tools are the most suitable for their purposes. This paper discusses controversial opinions and methods to face this challenge. On one hand, if we are not concerned with price, there is a wide variety of software and hardware technology to meet requirements far beyond archaeological limits. On the other hand, a growing community supports low cost developments in this field, and advances have now reached a point where Open Source (OS) results can compete with those from proprietary devices. As stated above, results and purposes are strongly related to aims and means. Documenting archaeological stratigraphy requires different levels of precision and resolution than documenting architecture, objects or finds. The challenge here is to consider purpose, possibilities, costs and managing accruing amounts of data. This paper aims to act as a kind of guide for archaeologists and historians to find the most suitable documentation equipment out of a wide range of possibilities.
\end{abstract}

\section{Keywords:}

Structure-from-motion, Laser scan, FOSS, Computation, Documentation

\section{Introduction}

Technological developments in the field of archaeological documentation and historical building research have increased in recent years at a rapid pace. Survey results will not only result in higher resolutions and more precise measurements, but these high-quality documentation procedures are normally also cost-intensive. Because of the latter fact, these methods are often beyond the budget of an archaeological project. Since these unfortunate constraints often set boundaries to

Corresponding author: undine.lieberwirth@fu-berlin.de scientific research, alternative methods are generally very welcome.

An option, which has already been widely accepted in archaeology, is the application of Open Source Software under the General Public License GPL (GNU 2014a). The ideology also meets the general aims of scientific work by applying the most transparent, independent research in terms of methodology and processing.

In this paper we aim to show and prove that these boundaries can be dissolved by alternative 
low-budget applications which can compete, in terms of quality, with established methods.

Thelow-cost equipment of this study consisted of a digital camera and two different software solutions for processing (one Open Source software, one proprietary software). The applied method for documentation was the so-called "structure-frommotion" (SfM), which was first successfully used in archaeological contexts two years ago (Ducke, Score and Reeves 2011).

The results of the SfM method used in this study were compared with those terrestrial 3D laser scanner (TLS) and its proprietary control and processing software, the use of which has already been established in archaeology. The first applications of a 3D laser scanner in archaeological research and monument management can be traced back one decade (Doneus, Neubauer and Studnicka 2003; Sachsen.de 2012). Since then, it has proven its quality beyond any doubt. For this reason, in this study the results of the TLS method were used as a reference for estimating the quality of the SfM outcome.

Both the photogrammetric SfM method and the TLS produce georeferenced 3D point clouds. Since these are in the same co-ordinate system they can be compared precisely in a 3D space.

Thetest took placein avariety of archaeological contexts in order to gain experience in practical use in different conditions and environments.

In this paper we give an overview of the results of this methodological comparison in terms of precision, quality, handling and costs from a user's perspective. We also discuss the advantages and disadvantages of the chosen low-budget methods BundlerTools (BT, Open Source) and VisualSFM (VSFM, proprietary), and in this context the newly developed software tools (GRASS GIS modules) (GRASS Development Team 2012) so that future users are able to choose the optimal way of documentation relative to their questions and needs.

\subsection{The archaeological research question}

Archaeological digital documentation is now widely understood to result in a digital 3D ground plan including all features, stratigraphical surface information, architecture, finds, objects etc., expressed as vectors mainly in CAD-based systems.

Approximately 10 years ago colleagues in Europe (Doneus and Neubauer 2004; Doneus and Neubauer 2005; Doneus, Neubauer and Studnicka 2003) started to document archaeological surfaces using 3D laser scanners, thereby producing 3D point clouds which recreate archaeological 2.5 D surfaces. This precise documentation of continuous surfaces represents a great step in archaeology. It completes the former vector models with a precise and nearly gapless surface description.

Until then, point clouds generated by lidar (acronym of Light Detection And Ranging) or total stations were normally the basis for creating digital elevation models (DEMs) in Geographic Information Systems (GIS) in archaeology. With the introduction of 3D laser scanners, archaeologists got the chance to model much smaller areas precisely (i.e. the top and bottom surfaces of archaeological stratigraphy).

However, since 3D laser scanners are expensive and require proprietary analysis software, applications of this kind will be restricted to a few exceptional projects. Therefore, the aim of this study was to look for alternative methods to document archaeological, stratigraphic surfaces, architecture, features, etc., for further processing and/ or analysis in a GIS or other software environment.

For testing the strength of the methodology in archaeological terms, we used three different archaeological environments.

\section{Case Study 1}

The first case study took place at the Western Porticus of the Main Forum in Ostia Antica, Italy. The stratigraphical surfaces we targeted contained material from the Late Roman Antiquity (100 $200 \mathrm{CE}$ ), and consisted of ceramic objects, stones and marble slabs, bricks, floor pavement and floor filling, screed material and sediments. Since some of the stratigraphical layers were very thin and could hardly be recognised, precise measurement of the top surfaces covering the whole area was of great importance. 
The study trench had an expanse of $2 \times 3 \mathrm{~m}$ and at its deepest spot approximately $1.3 \mathrm{~m}$. The documentation of one archaeological layer (SE201) was performed using by a terrestrial 3D laser scanner (Leica ScanStation 2) and a digital camera (Canon EOS D60). According to the on-site situation, the adjusted point cloud resolution for the laser scanner was $1 \mathrm{x} 1 \mathrm{~cm}$. Due to the depth and accessibility of the trench the scanner's position had to be changed twice.

In order to execute the SfM methods BT and VSFM, overlapping pictures of about 20-25 images/ layer were taken with different digital cameras. The calibration of the cameras in the process of creating the 3D point cloud is included into the SfM software. The resulting point count and resolution is dependent on the quality of the pictures (see 2 and Strecha et al. 2008). Thus, no extra step is necessary to prepare the data.

\section{Case Study 2}

For the second case study, a very different environment was chosen: a medieval cellar made of cobble stones in the Archaeological Park at Freyenstein, Germany. Again, the aim was to document the architecture of the preserved cellar walls in 3D quickly, economically and precisely. The documentation should be suitable for creating a construction drawing and generating several post-excavation analyses, e.g. measuring of details, creation of vertical and horizontal sections. We used the same equipment for the TLS, BT and VSFM methods as in case study 1 . In order to execute the SfM methods BT and VSFM, overlapping pictures of about 20 images/ wall were taken with the digital camera by a size of $3 \times 5 \mathrm{~m}$.

\section{Case Study 3}

Thethird studygenerateda3D pointcloud of an object. The aim was to find a suitable solution for $3 \mathrm{D}$ objects and features we encounter in archaeological environments. In this example, we chose a full-size portrait of an Antique Roman emperor with an uncertain identity (probably Antigonus II). The idea was to compare the digital 3D model of the sculpture with digital 3D models from other portraits in terms of physiognomic similarities in order to verify its identity.
For a third time, we used the same equipment for the TLS, BT and VSFM methods as in case study 1 and 2. In order to execute the SfM methods BT and VSFM, overlapping pictures of about 30 images of the complete portrait were taken with the digital camera.

\subsection{The methodological research question}

In this contest we were looking not only for the best digital reconstruction result but also for other parameters which effect archaeologists' decisions by choosing the most suitable method for their special needs according to the aims of the documentation. The two alternative SfM methods we compared with the established 3D TLS method should therefore fulfil the following methodological requirements.

The methods should be able to compete in terms of:

- Precision and quality with 3D laser scanner documentation (Precision \&Accuracy);

- Price, which should be affordable within a budget typical for an archaeological project (Costs);

- Method, which should use Open Source Software because of its ideology to reveal its source code;

- Algorithms used, which are vital for serious scientific research (Open Source \& Open Access, Learning Curve Hardware \& Software);

- Easy to transport equipment since archaeological sites are often off-road (Equipment Size \& Weight);

- Few working steps for saving time since excavations, whether for rescue or research, are always time limited (Working Steps);

- Processing time of the models, which should be appropriate to execute them on-site for verification (Processing Time);

- Being appropriate for a wide range of features, not only restricted to detailed architecture and not restricted by price to well-funded projects. 
Given that applications in science should fulfil the requirements of being comprehensible, verifiable, and repeatable, access to the algorithms used in software tools as well as their free access for research meant we were biased in favour of the SfM method (Rocchini and Neteler 2012).

\section{The Documentation Processes}

During the tests on different archaeological sites, the laser scanning results acted as a reference model sinceweassumed this well established method is widely recognised and hence not controversial.

\subsection{Method 1. Photogrammetry: BundlerTools (BT)}

A couple of years after the introduction of terrestrial laser scanners in archaeology, the method of image-based modelling, using a photogrammetric method to generate 3D point clouds of objects and architectural features and later called Structurefrom-Motion (SfM), has started to become more common in the same subjects (e.g. El-Hakim et al. 2008). Research in this field (e.g. Debrevec, Taylor and Malik 1996; Pollyfeys et al. 2000; Snavely, Seitz and Szeliski 2006; 2007) over the past decade has led to the development of different software packages and web services. The choice of tools is still growing and new developments are announced almost monthly.

After the release of Bundler (Snavely, Seitz and Szeliski 2006; 2007) under the GNU General Public License and CMVS/ PMVS2 (Furukawa and Ponce 2010; Furukawa et al. 2010) to create dense point clouds, usability and/ or velocity are constantly being improved in such programs as VisualSFM (Wu 2007; Wu et al. 2011; Wu 2014), RunSFM (Ho 2014), SFMToolkit (Visual Experiment 2014), APERO-MICMAC (MICMAC 2014) or Phython Photogrammetry Toolbox (Arc-Team 2014) free available for academic use.

At the same time, such proprietary software solutions as Agisoft PhotoScan (Agisoft 2014) or aSPECT3D (ArcTron 3D 2012) have been developed. The unusual fact that software has been developed specifically for archaeological purposes shows the great attraction of this method in the field of archaeological data acquisition.

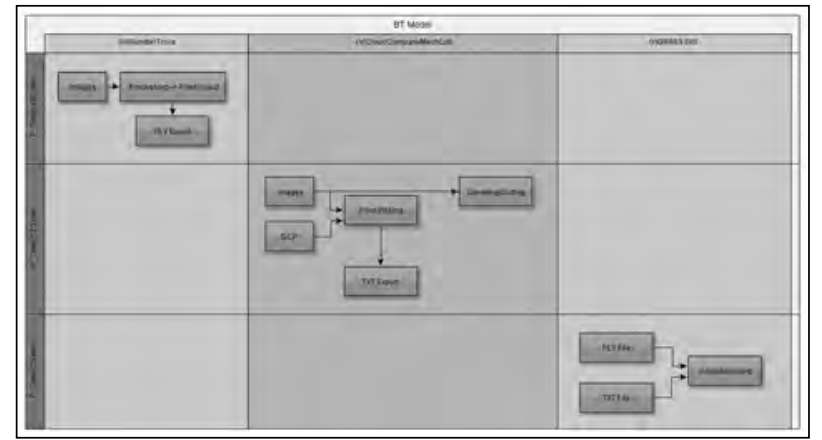

Figure 1. Workflow Method 1, BundlerTools, with Processing Time (P_Time) and Working Steps within the different software packages.

Additionally, there are several alternative web services like ARC3D (ARC3D 2013) and Autodesk ReCap (2014), which require an internet connection which is not available on every excavation.

Disregarding the chosen processing software, the method of Structure-from-Motion requires a set of unsorted digital images, marked and measured control points and software to calculate and create the 3D point cloud model. The process of work contains five steps (Fig. 1):

- First, taking pictures of the object or archaeological layer (surface). This requires nothing more than taking care to shoot a good image (sharpness, light conditions etc.) with a minimum overlap of $60 \%$. Control points also have to be placed in such a way that they are visible in as many pictures as possible.

- The second step is to measure the ground control points (GCP). They are vital for the georeferencing process and to align single layers and objects.

- The third step is the computation of the 3D point cloud. As mentioned above, there are a number of ways to do this. In this study, we used BundlerTools (BundlerTools 2014), a script which combines several FOSS modules like Bundler, CMVS and PMVS2 to create dense 3D point clouds in just one step on a UBUNTU/ FEDORA operating system.

- The post-processing in this study was done in MeshLab V1.3.0a (MeshLab 2011) and 
CloudCompare 1.0 (Cloud Compare 2011). These programs offer various and manageable tools for cleaning the point cloud (MeshLab) and point picking (CloudCompare) of the control points.

- Finally, the georeferencing was done by a new, especially developed module of Grass GIS 7.

The Structure-from-Motion approach first produces first of all a $3 \mathrm{D}$ point cloud in an arbitrary coordinate system which needs to be georeferenced. The purpose of georeferencing is to convert the arbitrary coordinates into real-world coordinates, which in turn allows combining the 3D point cloud with other spatial data fur further analysis. Georeferencing is commonly performed by using Ground Control Points (GCPs) with known coordinates in the arbitrary coordinate system and the real-world coordinate system. In our case, GCPs were markers on the excavated structures which could easily be identified in the $3 \mathrm{D}$ point cloud and on the real structure. The arbitrary coordinates of the markers could be determined by querying digital point coordinates. The real-world coordinates of the markers on the real structure were measured using a total station. This set of GCPs could then be used to calculate 3D transformation equations.

The part of the georeferencing was done by the OS GIS software GRASS GIS 7. Unless you want to keep the point cloud in a GIS environment (see 3.2), GRASS GIS needs three modules for importing, transforming and exporting the georeferenced point cloud.

The application BT and GRASS GIS was tested on a Linux-based system (x64), CloudCompare and Meshlab on a MSWindows-based system (x64).

\subsection{Method 2. Photogrammetry: Visual SfM}

Much has happened in the FOSS community working in this field since we started documenting the case studies in 2011. One and a half year can be enough time to develop the free software which combines all the steps we had to undertake in the BT method in just one software product.

Commonly, after creating overlapping pictures of the structure (we used the same images we created for the BT method), the free - but 'closed

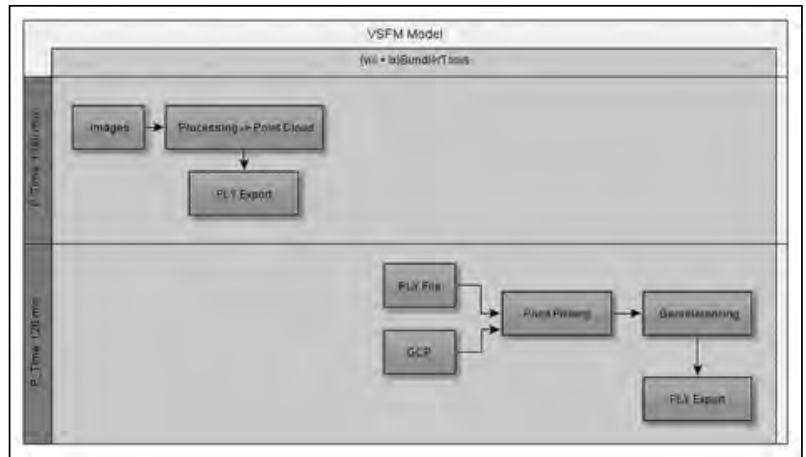

Figure 2. Workflow Method 2, VisualSFM, with Processing Time (P_Time) and Working Steps within the different software packages.

and proprietary' - software VisualSFM (VSFM) calculates the 3D point cloud and includes an option to georeference the result. The latter can be modified in the OS software MeshLab and Cloud Compare.

Step 1 and Step 2 are the same as in the BundlerTools method.

The third step is the computation of the 3D point cloud. Although VSFM uses a slightly different algorithm for camera calibration (Wu 2007) and can even work without the EXIF-data (metadata) of the images, the computing steps are very similar to BT: Matching images -> reconstructing a sparse point cloud - > reconstructing a dense point cloud.

The georeferencing function is included into the same software. For the georeferencing, the GCP values can be attached to the images in a separate VSFM function. Their values are finally used for the transformation of the 3D point cloud into a real-world coordinate system (Fig. 2). The whole application was tested on an MSWindows-based system (x64) and runs furthermore on Linux and Mac OSX.

\section{Results}

\subsection{Model comparison}

\section{Case study 1 - Ostia Antica}

In summary, three studies of different layers in one archaeological trench were executed. As an example to present in this paper, we choose one part with a size of $50 \times 100 \mathrm{~cm}$ of the archaeological layer 


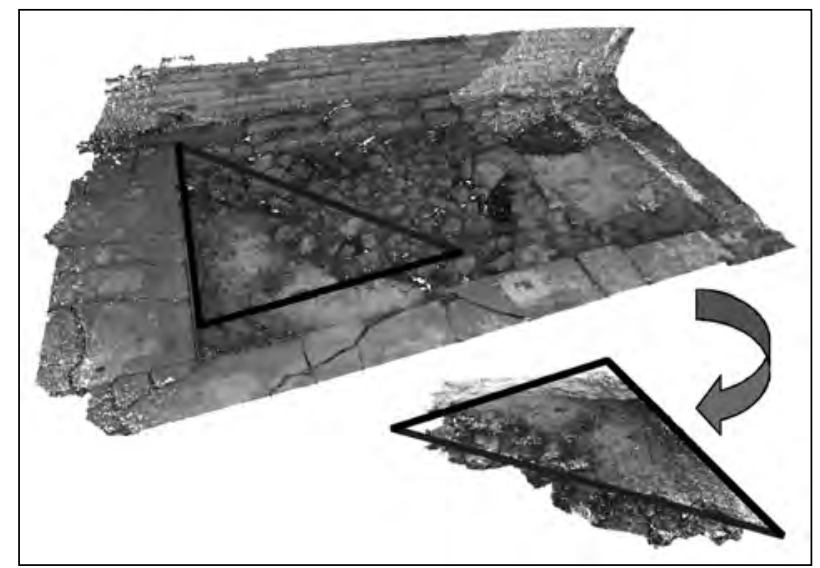

Figure 3. Excavation Trench 2, 3D point cloud generated by BT method, top surface of SE201 and example part, Ostia Antica/Italy.

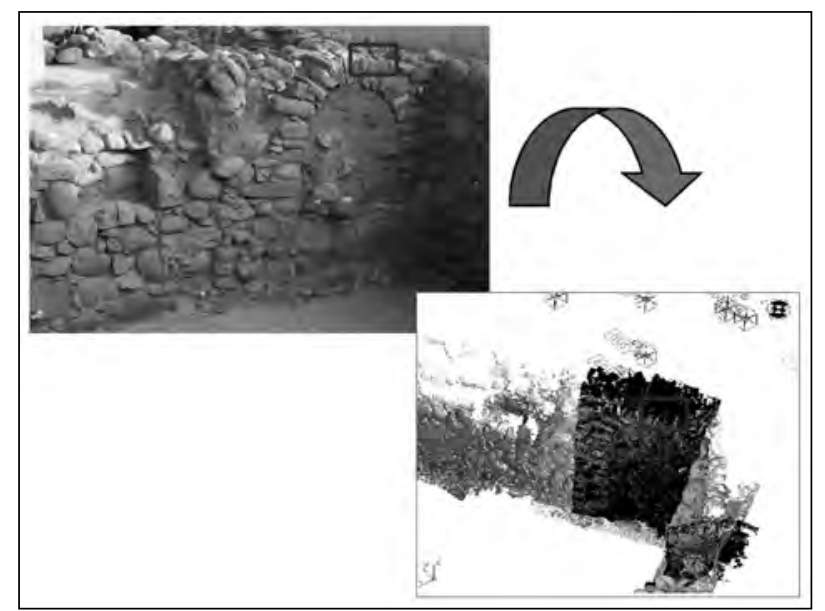

Figure 4. 3D point cloud generated by BT method, south wall of Middle Age cellar No. 2-1 Freyenstein/Germany and example part.

SE201. It consisted mainly of antique floor filling with screed material and hence had a highly jointed topography (Fig. 3).

\section{Case study 2 - Freyenstein}

The example in case study 2 was a $50 \times 50 \mathrm{~cm}$ part of the upper south wall of the medieval cellar No. 2-1 in Freyenstein/Germany. The surface we documented was made of cobble stones of different sizes with a sedimentological filling in between (Fig. 4). This resulted again in a highly jointed topography of different $3 \mathrm{D}$ shapes. The result is representative for four case studies we calculated in Freyenstein.

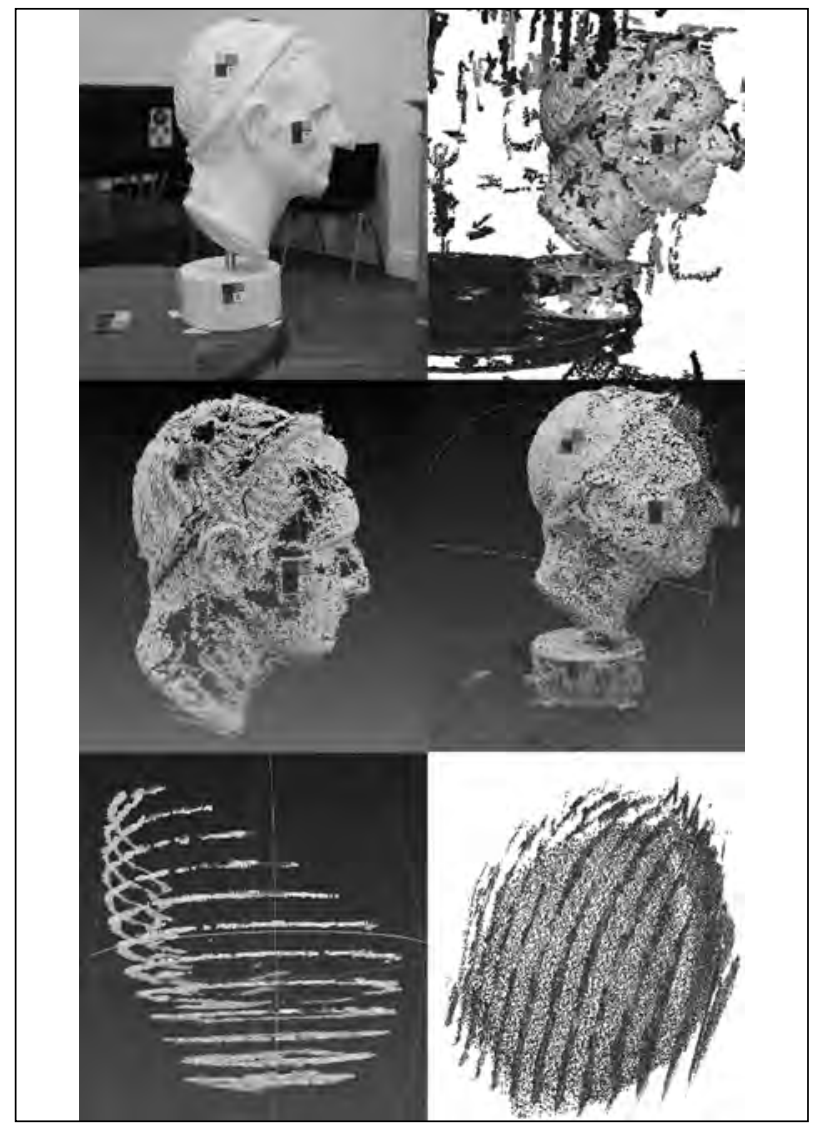

Figure 5. Portrait head of an Antique emperor, top right: 3D point cloud generated by VSFM, middle left: $3 D$ point cloud generated by VSFM and cleaned in MeshLab, middle right: $3 D$ point cloud generated by $B T$, bottom left: $3 D$ point cloud generated by BT after $90^{\circ}$ rotation, bottom right: $3 D$ point cloud generated by BT after $90^{\circ}$ rotation in blue in comparison with the TLS point cloud in red and the VSFM point cloud in green.

\section{Case study 3 - Sculpture}

The copy of a full-size portrait head of an Antique emperor made of gypsum was chosen for the third case study (Fig. 5). The different material and the filigree surface were very different from case studies 1 and 2, but represent - in archaeological terms - a very common object and material.

\section{Comparison}

In order to compare the resulting 3D point clouds of the two SfM methods with the reference model of the 3D laser scanner in terms of precision, we investigated the behaviour of the 3D Point clouds 
Across Space and Time. Papers from the 41st Conference on

Computer Applications and Quantitative Methods in Archaeology. Perth, 25-28 March 2013

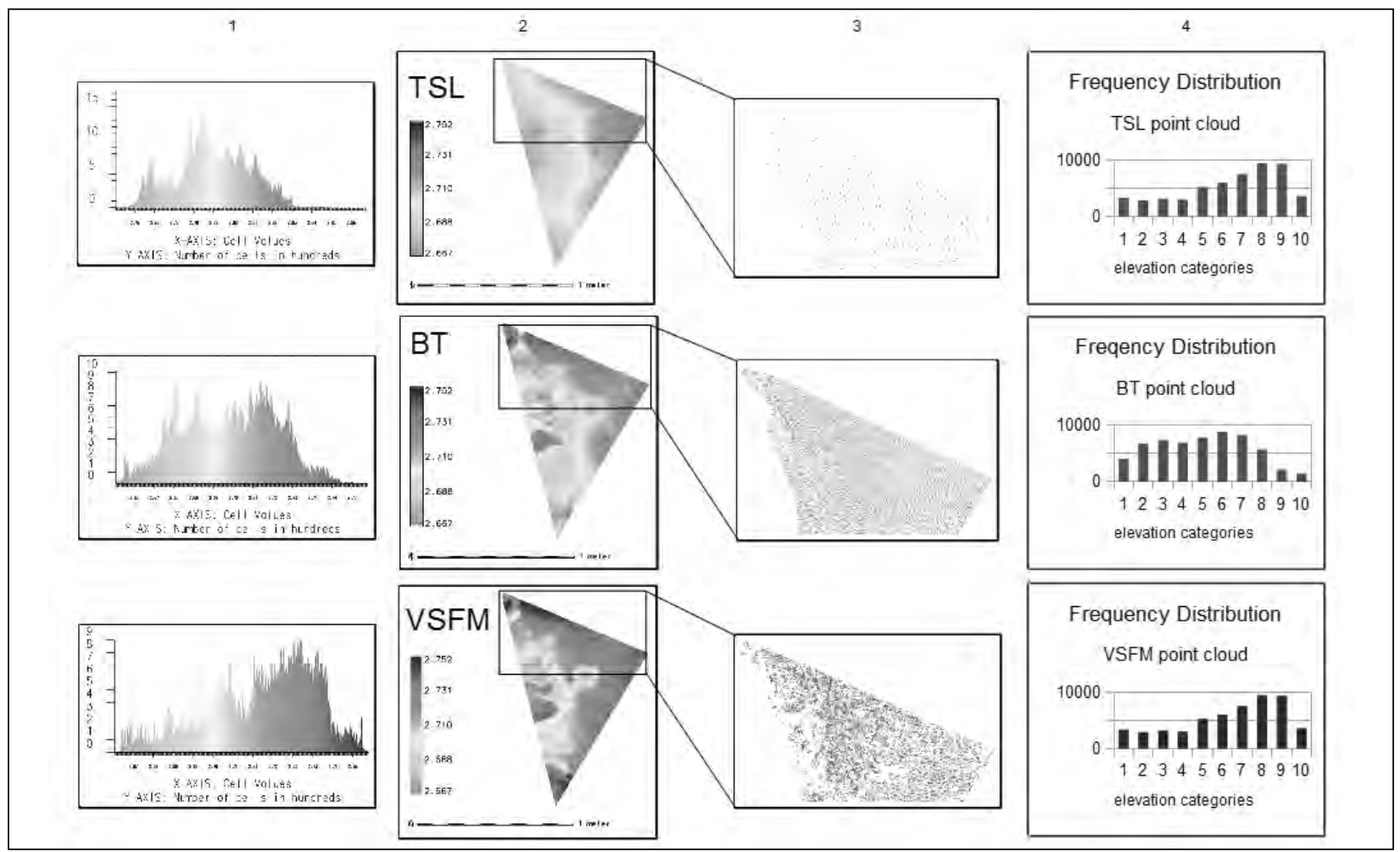

Figure 6. Case Study 1, sample part of SE201, column 1: Histograms of DEMs, column 2: DEMs, column 3: 3D point clouds (enlarged section of sample part), column 4: frequency distribution of 3D point clouds.

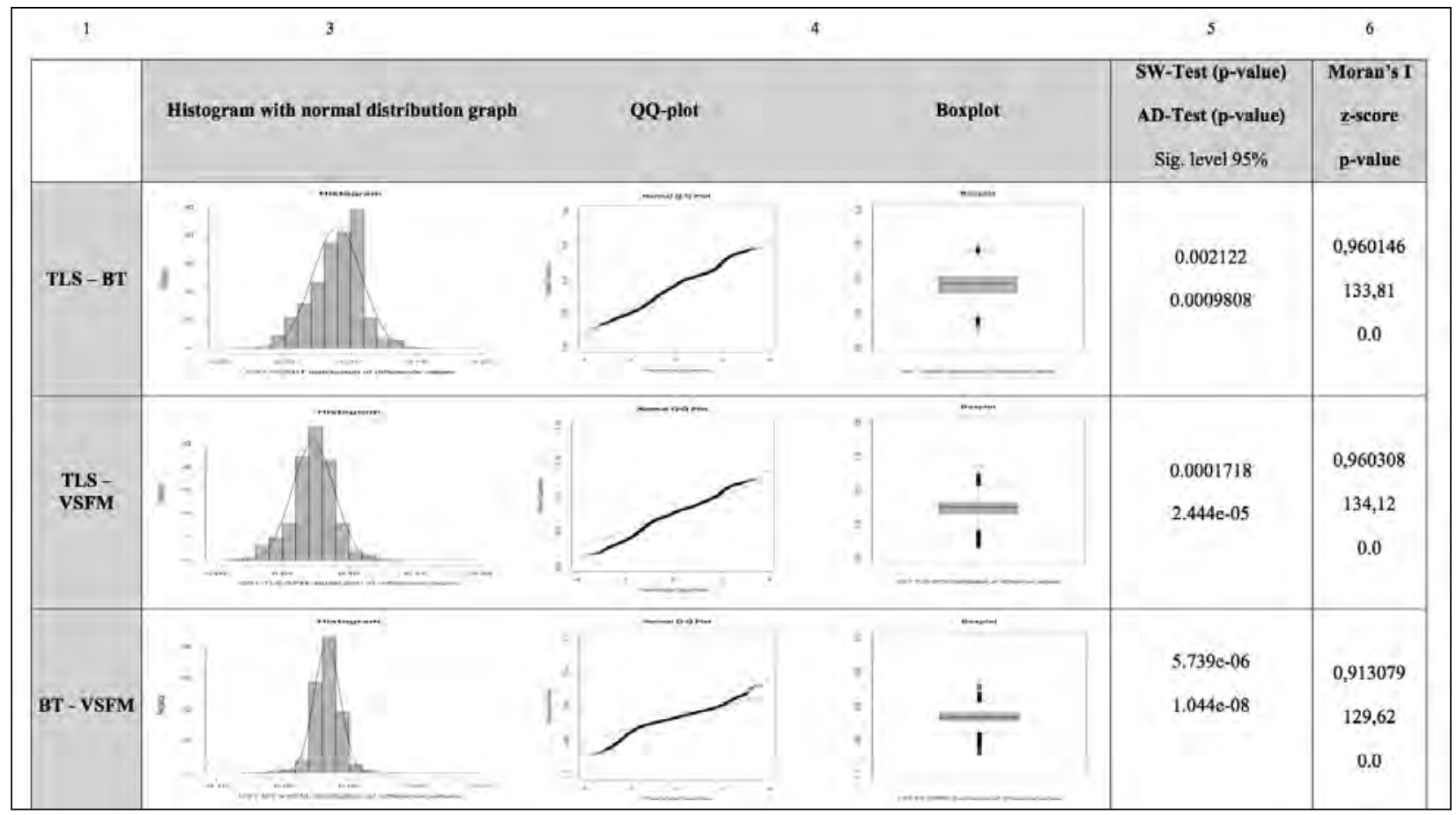

Table 2. (iii) Case Study 1- significance tests for difference maps; Legend: $S W$-Test $=$ Shapiro-Wilk test, AD-Test $=$ Anderson-Darling test. 


\begin{tabular}{|c|c|c|c|}
\hline & $\begin{array}{c}\text { Point } \\
\text { Count }\end{array}$ & $\begin{array}{c}\text { Point } \\
\text { Resolution } \\
\text { (inter-point } \\
\text { distance) }\end{array}$ & Mean / STD \\
\hline TLS & 5856 & 0.01294 & $\varnothing 2.79 \pm 0.015$ \\
\hline BT & 59162 & 0.00425 & $\varnothing 2.71 \pm 0.018$ \\
\hline VSFM & 54709 & 0.004454 & $\varnothing 2.72 \pm 0.012$ \\
\hline
\end{tabular}

Table 1. Case Study 1 - Statistics for 3D point clouds; The inter-point distance was obtained by GRASS GIS 7.0 module v.surf.bspline.

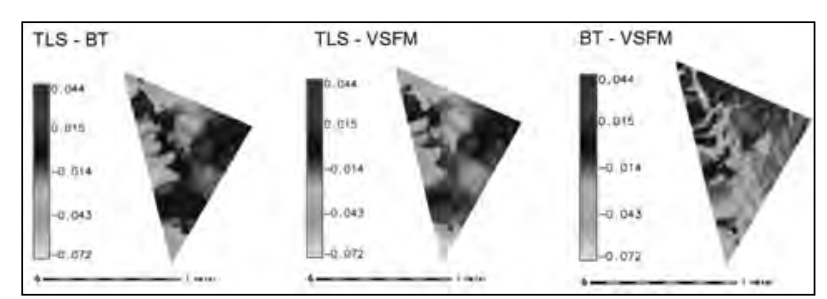

Figure 7. Case Study 1, difference maps displaying the deviation from each other below and above 0.

(Fig. 6, column 3, 4, and Table 1). Using them as a basis, we interpolated raster surfaces (digital elevation models, DEMs (Conolly and Lake 2006, 90-111); Fig. 6, column 1, 2, via the GRASS GIS 7.0 module v.surf.bspline; Table 2.1).

As a third step, we calculated the overlapping parts between the DEMs (via GRASS GIS 7.0, module r.mapcalc) in order to measure differences between the SfM DEMs and the reference model at certain places.

The resulting raster surfaces (difference maps Fig. 7), their histograms and plots (Table 2, column 3 , 4) show the difference from o between the reference, the laser scan DEM (TLS DEM), and the SfM DEMs as well as the difference between both SfM DEMs (BT-VSFM). This is expressed in the difference from o (the overlapping parts) in the negative and positive direction with a tolerance range of -0.08 and $0.05 \mathrm{~m}$. If we accept a difference tolerance to the reference of $\pm 0.01 \mathrm{~m}$, which might be sufficient in certain circumstances, we get the results of Table 3 , column 3.

The results, even in a wider tolerance range of $\pm 0.05 \mathrm{~m}$ (Table 3 , column 2), show clear similarities of the two SfM methods Bundlertools (BT) and VisualSfM (VSFM) with an overlap of $99 \%$ in the

\begin{tabular}{|c|c|c|}
\hline & $\begin{array}{c}\text { Overlapping } \\
\text { area } \mathbf{\pm 0 . 0 5} \mathbf{m}\end{array}$ & $\begin{array}{c}\text { Overlapping } \\
\text { area } \pm \mathbf{0 . 0 1 m}\end{array}$ \\
\hline TLS - BT & $3 \%$ & $0 \%$ \\
\hline TLS - VSFM & $9 \%$ & $0 \%$ \\
\hline BT - VSFM & $99 \%$ & $22 \%$ \\
\hline
\end{tabular}

Table 3. Case Study 1 - difference maps and their congruent areas according to the given tolerance of $\pm 0.05 \mathrm{~m}$ and $\pm 0.01 \mathrm{~m}$.

\begin{tabular}{|c|c|c|c|}
\hline & $\begin{array}{c}\text { Cell } \\
\text { Count }\end{array}$ & $\begin{array}{c}\text { Cell } \\
\text { Resolution }\end{array}$ & Mean / STD \\
\hline TLS - BT & 9850 & 0.007 & $0,0897 / 0,0185$ \\
\hline TLS - VSFM & 9891 & 0.007 & $0,0729 / 0,0157$ \\
\hline BT - VSFM & 10218 & 0.007 & $-0,0165 / 0,0097$ \\
\hline
\end{tabular}

Table 4. Case Study 1 - Statistics for difference maps; Cell Count $=$ amount of the non-null cells, Cell Resolution $=$ cell size, Mean $=$ mean of absolute values, STD = standard deviation.

$\pm 0.05 \mathrm{~m}$ tolerance range and of still $22 \%$ with $\pm 0.01 \mathrm{~m}$. Themodel created by the laser scanner does not share any overlapping areas in the acceptable range.

Considering this result, we looked at the quality of the DEMs by measuring the root mean square error (RMSE) of ground control points (GCPs, see 3.2) for getting an '... accurate assessment how well each cell in the DEM represents the true elevation.' (Wechsler 2007, 1483) and furthermore by studying the distribution and behaviour of the legacy data and their derivatives.

The point count in Table 1 shows a great difference in the total amount between the TLS and SfM methods of approx. 50 ooo. This difference can be explained by the TLS resolution adjustments which were chosen according to the topography of the archaeological surface by $0.01 \mathrm{~m} \times 0.01 \mathrm{~m}$ with a devise distance of approx. $3 \mathrm{~m}$. The SfM methods, on the other hand, used approx. 20 photographs for the automatic generation of the 3D point clouds. As mentioned later in this paper (see 4), the number of pictures is responsible for the point cloud resolution with a strong correlation to the inter-point distance (Table 1, column 2). A second indicator for differences is the mean value of the TLS point cloud which has a difference of max. $0.08 \mathrm{~m}$ from 
the SfM mean values. This indicates, as a consistent appearance, that the mean value is located at higher elevations than for the SfM results. The low spatial resolution of the TLS point cloud (Table 1, column 2) could therefore not take into account the strong relief of the surface from case study 1 . The low variance of the STD values supports this fact.

The post-processing TLS-result is a smoothed surface which explains the differences at certain places in the deviation calculations (Fig. 7 and Table 4). We hence decided that the TLS measurements could no longer act as reference in this study, but were still used as a comparison sample set.

Since a clustered pattern of elevation values of an artificial surface is evident, one cannot expect a random distribution of the measurement points. We therefore dismissed an investigation of statistical significance of the sample set.

However, the behaviour and distribution of the difference values in the difference maps was investigated by statistics to get information about similarities in the methodologies. For this, three different graphical plots (Table 2, column 3, 4) and two non-parametric one-sample tests, the ShapiroWilk-test (SW)

$$
W=\frac{\left(\sum_{i=1}^{n} a_{i} x_{(i)}\right)^{2}}{\sum_{i=1}^{n}\left(x_{i}-x\right)^{2}}
$$

and the Anderson-Darling-test (AD),

$$
\begin{gathered}
A^{2}=-n-S, \text { with } \\
S=\sum_{k=1}^{n} \frac{2 k-1}{n}\left[\ln F\left(Y_{k}\right)+\ln \left(1-F\left(Y_{n+1-k}\right)\right)\right]
\end{gathered}
$$

which are powerful mathematical procedures for statistical hypothesis testing against the Nullhypothesis $\left(\mathrm{H}_{0}\right)$ for large sample sizes (Razali 2011; Shapiro and Wilk 1965) were applied.

The difference maps results in Table 2 show clear clustered results in the graphical plots with SW and AD p-values < 0.05 (Table 2, column 5 ). This result is supported by the high Global Moran's Indices very close to +1 for clustered patterns (Conolly and Lake 2006, 158-160; Moran 1950),

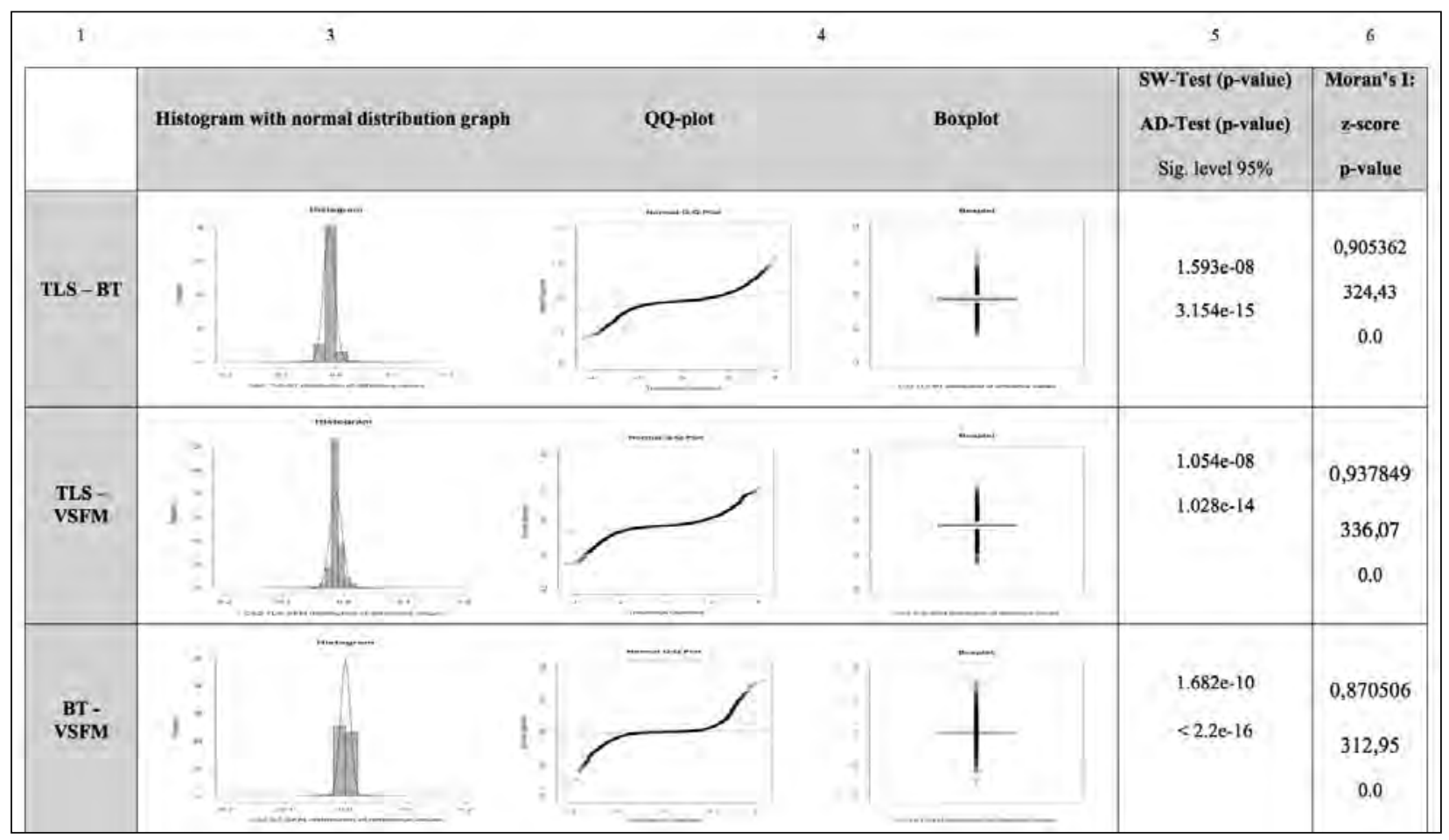

Table 5. (iii) Case Study 2 - significance tests for difference maps; Legend: SW-Test $=$ Shapiro-Wilk test, AD-Test $=$ Anderson-Darling test. 


$$
I=\frac{n}{S_{0}} \frac{\sum_{i=1}^{n} \sum_{j=1}^{n} w_{i, j z i} z_{j}}{\sum_{i=1}^{n} z_{i}{ }^{2}}
$$

an indicator for spatial auto-correlation between the value and the topography of the modelled surface. The high z-scores in combination with very low $p$-values (Table 2 , column 6 ) indicate high significance of the sample sets. Finally, the result of Table 3 supports the aforesaid assumption that the greatest differences occur between the laser scanner and SfM results.

\section{Case study 2}

The same procedures described above have been executed for case study 2 (Table 5) for obtaining statements about surface similarity of different measurement methods. Comparing the results of case study 1 and case study 2 the results are very similar from a proportional perspective (Tables 3 and 6).

Table 6 shows nearly no difference between the two SfM DEMs in the tolerance range of $\pm 0.01 \mathrm{~m}$ and still $1 / 4$ conformity between the TLS and SfM maps. This is proportionally similar to the case study 1 outcome. However, in contrast to the wider tolerance range $( \pm 0.05 \mathrm{~m})$ there is nearly complete conformity between all maps which was not the case in case study 1.

Considering the behaviour and distribution of the point clouds and their corresponding DEMs, except for the point count and its corresponding spatial resolution, there is no great difference between all three point clouds at all. This initial similarity runs through all subsequent calculations (Table 7 and 8) and explains the results in Table 6. We suppose that the reason for this might lie in the smooth topography of the surface in case study 2 . Such topographies have a greater chance for more realistic modelling for laser scan measurements with the same device adjustments as in case study 1. The amount of photographs for the SfM methods was as well the same.

Finally, the test of normality and autocorrelation in case study 2 (Table 5) revealed, like in case study 1 , a significant clustered distribution of

\begin{tabular}{|c|c|c|}
\hline & $\begin{array}{c}\text { Overlapping } \\
\text { area } \pm \mathbf{0 . 0 5}\end{array}$ & $\begin{array}{c}\text { Overlapping } \\
\text { area } \pm \mathbf{0 . 0 1}\end{array}$ \\
\hline TLS - BT & $99 \%$ & $25 \%$ \\
\hline TLS - VSFM & $99 \%$ & $24 \%$ \\
\hline BT - VSFM & $99 \%$ & $93 \%$ \\
\hline
\end{tabular}

Table 6. Case Study 2 - difference maps and their congruent areas according to the given tolerance.

\begin{tabular}{|c|c|c|c|}
\hline & $\begin{array}{c}\text { Point } \\
\text { Count }\end{array}$ & $\begin{array}{c}\text { Point } \\
\text { Resolution } \\
\text { (inter-point } \\
\text { distance) }\end{array}$ & Mean / STD \\
\hline TLS & 2289 & 0.004229 & $\varnothing 93.66 \pm 0.0072$ \\
\hline BT & 19424 & 0.001431 & $\varnothing 93.67 \pm 0.0069$ \\
\hline VSFM & 18391 & 0.001456 & $\varnothing 93.67 \pm 0.0085$ \\
\hline
\end{tabular}

Table 7. Case Study 2 - Statistics for 3D point clouds; The inter-point distance was obtained by GRASS GIS 7.0 module v.surf.bspline.

\begin{tabular}{|c|c|c|c|}
\hline & Cell Count & $\begin{array}{c}\text { Cell } \\
\text { Resolution }\end{array}$ & Mean / STD \\
\hline TLS - BT & 64460 & 0.0007 & $\begin{array}{c}-0,0128 / \\
0,0099\end{array}$ \\
\hline TLS - VSFM & 64460 & 0.0007 & $\begin{array}{c}-0,0129 / \\
0,0099\end{array}$ \\
\hline BT - VSFM & 64826 & 0.0007 & $-0,0007 /$ \\
& & & 0,0081 \\
\hline
\end{tabular}

Table 8. Case Study 2 - Statistics for difference maps; Cell Count $=$ amount of the non-null cells, Cell Resolution $=$ cell size, Mean = mean of absolute values, STD = standard deviation.

the difference maps. This result suits to the mean and STD with very low STD values and the result for the BT-VSFM difference map with $\pm 0.01 \mathrm{~m}$ tolerance. Both difference maps in case study 1 and case study 2 of BT minus VSFM show a slight bias towards a normal distribution whereas the difference maps involving the TLS results are in both case studies very similar.

\subsection{Georeferencing}

The comparative calculation described above was only possible because we were able to georeference all models. Since 3D point clouds in archaeological contexts have to be located in a 
Across Space and Time. Papers from the 41st Conference on

Computer Applications and Quantitative Methods in Archaeology. Perth, 25-28 March 2013

\begin{tabular}{|c|c|c|c|c|c|c|}
\hline GCP No. & \multicolumn{2}{|c|}{ TLS } & \multicolumn{2}{c|}{ BT } & \multicolumn{2}{c|}{ VSFM } \\
\hline & Horz & Vert & Horz & Vert & Horz & Vert \\
\hline 1 & 0.010 & 0.015 & 0.0008 & 0.0010 & 0.0005 & 0.0005 \\
\hline 2 & 0.011 & 0.012 & 0.0040 & 0.0045 & 0.0087 & 0.0083 \\
\hline 3 & 0.002 & 0.001 & 0.0075 & 0.0083 & 0.0063 & 0.0059 \\
\hline 4 & 0.001 & 0.001 & 0.0114 & 0.0126 & 0.0091 & 0.0009 \\
\hline 5 & 0.002 & 0.001 & 0.0071 & 0.0077 & 0.0150 & 0.0132 \\
\hline 6 & 0.001 & 0.001 & 0.0071 & 0.0079 & 0.0098 & 0.0088 \\
\hline
\end{tabular}

Table 9. Selection of RMS values occurring during registration (TLS) and georeferencing (BT and VSFM). The TSL RMSE measurement provided only three digits after comma.

georeferenced environment - otherwise they do not fit to other documentation - we were interested to improve the BT software result in this way. This part in the working steps and function within the different software is hence very important and is therefore included in most proprietary and non-proprietary SfM software packages, like VSFM. However, BT still lacked this function at the time of the study. Therefore, for the Open Source GRASS GIS software package (GRASS Development Team 2012; Neteler et al. 2012) a new software module 'v.ply.rectify' has been developed, sponsored by Topoi, the Berlin Excellence Cluster at Humboldt-University of Berlin and Free University Berlin about The Formation and Transformation of Space and Knowledge in Ancient Civilisations' (Topoi 2014). The new GRASS GIS module performs 3D georectification based on GCPs and offers different transformation methods. The 3D transformation method most appropriate for 3D point clouds produced with the Structurefrom-Motion approach is a Helmert transformation that preserves angles and proportions. This kind of transformation is also known as orthogonal transformation. Commonly used algorithms for Helmerttransformationarefound in thereprojection of spatial 3D data from one real-world coordinate system into another real-world coordinate system where the rotation angles are always very small, in the range of a few arc seconds. These algorithms are not suitable for georeferencing a 3D point cloud from an arbitrary coordinate system to a real-world coordinate system because the rotation angles can be as large as 180 degrees. Therefore a generalised version of the Helmert transformation was implemented, supporting large rotation angles. In addition, the polynomial 3D transformation equations of have been estimated. A first-order polynomial 3D transformation is also known as affine transformation with shift, scale, and rotation separately for each dimension. The new module tests whether the GCPs fulfil the requirements needed to perform the requested 3D transformation and provides diagnostics in terms of Root Mean Square Errors (RMSE) for the GCPs which help to identify outliers in the GCPs and quantify the accuracy of the coordinate transformation.

An extraction of the results generated in the case studies by the new GRASS GIS modules in comparison to the transformation results by the proprietary TLS software and VSFM are listed in the table below. Additional modules were developed for GRASS GIS to import and export 3D point clouds in the PLY format commonly used in archaeological SfM projects. The complete workflow in GRASS GIS thus consists of:

1. importing a 3D point cloud;

2. identifying and removing potential outliers in the GCPs based on the RMSE of the selected transformation method;

3. georeferencing the 3D point cloud with the selected GCPs and method; and

\begin{tabular}{|c|c|c|c|c|c|c|}
\hline Method & Costs & $\begin{array}{c}\text { Open Source \& } \\
\text { Open Access }\end{array}$ & $\begin{array}{c}\text { Equipment Size \& } \\
\text { Weight }\end{array}$ & Steps & Time & Curve \\
\hline BT & $\begin{array}{c}\text { camera, notebook, external drive } \\
€ 800-2500\end{array}$ & OS \& OA & $\begin{array}{c}\text { hand luggage size, } \\
\text { ca. } 1.5 \mathrm{~kg}\end{array}$ & 5 & 620 min & low \\
\hline VSFM & $\begin{array}{c}\text { camera, notebook, external drive } \\
€ 800-2500\end{array}$ & $\begin{array}{c}\text { Proprietary \&OA, } \\
\text { Free download }\end{array}$ & $\begin{array}{c}\text { hand luggage size, } \\
\text { ca. } 1.5 \mathrm{~kg}\end{array}$ & 4 & 1500 min & low \\
\hline
\end{tabular}

Table 10. Parameter comparison of SfM methods. 
4. optionally exporting the georeferenced 3D point cloud for further analysis in other software.

The precision of the results have been evaluated by both the deviation from measured real-world coordinates of the markers and visual inspection of the georeferenced objects (preserving angles and proportions). An additional module, to perform these parts in one step (v.ply.rectify), only runs in the Linux operating system at the time of this publication. The case studies were executed at FEDORA 18, a Unix-based operating system and GRASS GIS 7. The separate modules v.in.ply, v.out. ply, v.rectify are also available in the current GRASS GIS Windows version 7.

\subsection{Processing time, effort and resources}

According to the methodological research question, we compared not only the models but also the parameters (Table 10).

\section{Model precision and quality}

The precision of a measurement system (also called reproducibility or repeatability) is the degree to which repeated measurements under unchanged conditions show the same results (Taylor 1999, 128129). In the fields of science, engineering, industry, and statistics, the accuracy (J CGM 200 2012, 21) of a measurement system is the degree of closeness of measurements of a quantity to that quantity's actual (true) value.

In this study, we dismissed the working hypothesis in order to refer to the 3D point cloud generated by the terrestrial laser scanner for accuracy. However, bycomparingthetransformation results of the RMS errors, we could still use TLS as a reference since the GCP's acquisition and their use for the transformation is decoupled from the generation of the 3D point cloud. Hence, in both case studies we got very accurate results.

\section{Costs}

Even if some archaeological projects are very well funded, costs are an important factor in all projects. Saving costs for technical equipment releases resources for other important needs (e.g. professional staff, laboratory examinations etc.).
Costs in the case studies were very low or do not even occur since the SfM equipment which is needed belongs on every archaeological project as well as a total station for measuring the GCPs. However, since not every archaeologist is able to get low cost educational licences, we think it is important having an Open source alternative at hand.

\section{Open source and open access}

Processing software in science can be seen as a breadboard assembly where legacy data are processed via algorithms in order to transform them to a new result. Since scientists need to understand how these processes transform their raw data, knowledge of the internal procedures (the breadboard assembly) is vital.

Open Source software which follows the Open Source Definition (Open Source Initiative 2014) and is developed under the GPL license (GNU 2014b) and other related licenses fulfils these requirements. Since the BT application was tested on a Unix-based system, this application fulfils these requirements. The VSFM method was tested in an MSWindowsbased system but its documentation also mentions a Unix version for Ubuntu. Open Access guaranties the free access to scientific literature which also means software documentation through theinternet what we realised for both SfM methods.

\section{Equipment size and weight}

Transport and handling of equipment is a further important factor for archaeological excavations, which are often off-road. Hence, the size and weight of the additional equipment was also of great interest and therefore one study parameter. Finally, as was the case with the 'Cost' parameter, both SfM methods required no additional equipment.

\section{Working steps}

The detailed working steps of the two methods are depicted in the two diagrams (Figs 1 and 2). The BT method required just one step more than VSFM due to the software change for applying the georeferencing. 


\section{Processing time}

We defined "processing time" in this study in terms of the time required from starting the processing of the images until the final georeferenced 3D point cloud since the documentation time - taking pictures - was the same for both SfM methods. In the example in Figure 2 we display an average time for both methods. The VSFM method in the case studies needed about 10 times more than the BT method using comparable hardware.

\section{Learning curve}

This parameter investigated the effort to learn the handling of the hardware and working with the associated software (control software and/or processing software). Since both methods are very well documented (see the Project Website), even untrained users could follow their descriptions without further reading or workshop attendance.

\section{Discussion and Conclusions}

\subsection{Analysis}

The aim of this paper was to examine the results and the procedure of low budget equipment and Open Source or free available software for high resolution documentation of archaeological stratigraphy and features as alternative to high cost equipment. The three case studies provide just small glimpses of archaeological structures which were chosen in order to generate comparable sample sets. Although the study cannot give general advice, we hope that the analysis of the results of three very different archaeological examples can help support decisions regarding future applications in this field.

\section{Case Study 1 and 2}

During the first and second case study, it turned out that the reference we chose was not appropriate for the purposes of this study. Undoubtedly, the TLS method produces accurate and precise results. However, in our workinghypothesis weassumed that both SfM methods cannot compete with its results. With the background knowledge of being also the excavators of the sample structures we finally had to conclude that both SfM methods created much more realistic models than the laser scanner. The reasons for this result have been already described in detail above. One could hence argue that the laser scanner was not used to its full extent. This is true at one hand. On the other hand, the comparison tried to act within a realistic environment where a higher resolution adjustment for the laser scanner would have been too meticulously for the structures we measured. The precision of the SfM models could be supported by the RMSE results described in 3.2.

\section{Case Study 3}

As a contrast to the sample sets we used in case study 1 and 2, we applied the three methods to the challenging material gypsum. The TSL method produced reasonable results (Fig. 5, bottom right red point cloud). However, in order to generate a 3D point cloud, VSFM and BT referred more to the environment (Fig. 5, top right) than to the object itself. In Fig. 5 (left middle row) the cleaned point cloud has still many gaps on the object's surface. However, by changing the point of view one can recognise a strip-like order to the points (Fig. 5, left and bottom right) which do not represent the object's surface. In summary, the material seemed very problematic for the two SfM methods (Fig. 5, top left and bottom right).

Since SfM is based on feature extraction from the overlapping images, the colour, shape, material and roughness of an archaeological surface is vital for getting excellent results (Ducke, Score and Reeves 2011, 377-380). Objects without texture and a reflective surface are, according to our experiments, not suitable for the SfM method.

\subsection{Advantages and disadvantages}

Since the keywords Open Access and Open Source policies are nearly already established in many scientific fields, archaeologists and cultural scientists are becoming more and more aware of their potential and sustainability. Hence, this paper gives an inside in the usefulness of alternative documentation methods at sufficient precision and accuracy.

However, answering the question of which method is more suitable for certain purposes strongly depends on the scientific objective, research aims, circumstances, environment, time, 
budget and available hardware. The ideal method can only be determined on-site and is defined by the site's specific conditions since the find spectrum at archaeological excavations cannot be predicted precisely. Hence, the challenge of archaeological documentation is to provide a flexible system. In consideration of effective data acquisition and storage possibilities, the methods should follow an objective data documentation system and take long-term file storage into account. With the BT method such a system is now at hand. It is a threedimensional documentation method which is easy to handle, universal in scale and of low cost. Its advantages are:

- reliable results,

- fast post-processing,

- the 3D point cloud is already in a GIS system, if needed.

The downsides of this application are:

- manual GCP picking,

- many working steps/ software packages,

- the BT software itself runs only on a Unix-based system.

The negative results in the third case study showthelimits of theSfMmethod, which had nothing to do with the different processing algorithms we applied with both methods. The reason lies within the methodology of the generation of the 3D point cloud itself.

Returning to the 'Archaeological Research Question' we had in mind, neither SfM application is restricted to detailed architecture or highly funded projects. It is, on the contrary, open to a wide user community in archaeology and related disciplines.

\section{Acknowledgements}

The Topoi Summer School 2011 acted as part of the 'KBO Excavations' (Kent-Berlin Ostia Excavations 2011) which investigated inter alia the Main Forum of Ostia Antica under the direction of PD Dr. Axel Gering (Humboldt-University of
Berlin) under the auspices of the Soprintendenza Archeologica di Ostia directed by Prof. A. Pellegrino.

\section{Bibliography}

Agisoft. 2014. "Image based 3D modelling." Accessed March 30. http:// www.agisoft.ru/ .

ARC3D. 2013. "Automatic Reconstruction Cloud. Convert your images into 3D." Accessed March 30. http:// www. arc3d.be/ .

Arc-Team. 2014. "Download/Python Photogrammetry Toolbox." Accessed March 30. http:// 184.106.205.13/ arcteam/ppt.php.

ArcTron 3D. 2012. "Vereinen Sie Ihre Daten mit: aSPECT 3D. Innovative 3D-Information Management." Accessed March 30. http://www.arctron.de/fileadmin/ Dateiliste/01_Home/aSPECT3D_Neu_2012.pdf.

Arc-Team. 2014. "ATOR."Accessed March 30. http:// arcteam-open-research.blogspot.de/ .

Autodesk ReCap. 2014. "Autodesk ReCap." Accessed March 30. http:// www.autodesk.com/products/recap/ overview.

BundlerTools. 2014. "BundlerTools." Accessed 30 March, https:// github.com/ qwesda/ BundlerTools.

Cloud Compare. 2011. "3D point cloud and mesh processing software Open Source Project." Accessed March 30, 2014. http:// www.danielgm.net/ cc/ .

Conolly, J ., and M. Lake. 2006. Geographical Information Systems in Archaeology. Cambridge: Cambridge University Press

Debevec, P. E., C. J. Taylor, and J . Malik. 1996. “Modeling and rendering architecture from photographs: a hybrid geometry- and image-based approach." In SIGGRAPH '96, Proceedings of the 23rd Annual Conference on Computer Graphics, August 4-9, 1996, New Orleans, LA, USA, 11- 20. New York: ACM.

Doneus, M., and W. Neubauer. 2004. "Digital Recording of Stratigraphic Excavations." In Enter the Past. The E-way into the four Dimensions of Cultural Heritage. CAA 2003, Computer Applications and Quantitative Methods in Archaeology, edited by K. F Ausserer, W. 
Across Space and Time. Papers from the 41st Conference on

Computer Applications and Quantitative Methods in Archaeology. Perth, 25-28 March 2013

Börner, M. Goriany, and L. Karlhuber-Vöckl, 113-116. Oxford: Archaeopress.

Doneus, M., and W. Neubauer. 2005. "Laser scanners for 3D documentation of stratigraphic excavations." In International Workshop on Recording, Modeling and Visualization of Cultural Heritage, Ascona, May 22-27, 2005, edited by M. Baltsavias, A. Gruen, L. van Gool, and M. Pateraki. 193- 203. London: Taylor and Francis.

Doneus, M., W. Neubauer, and N. Studnicka. 2003. "Digital Recording of Stratigraphic Excavations." In Proceedings of the XIXth International Symposium, CIPA 2003: New Perspectives to Save Cultural Heritage. Antalya (Turkey), 30 September-04 October 2003, edited by M. O. Altan, 451- 456. Istanbul: CIPA

Ducke, B., D. Score, and J . Reeves. 2011."Cultural Heritage: Multiview 3D reconstruction of the archaeological site at Weymouth from image series." Computers and Graphics 35 (2):375- 382

El-Hakim, S., F. Remondino, F. Voltolini, and F. Gonzo. 2008. "Effective high resolution $3 \mathrm{D}$ geometric reconstruction of heritage and archaeological sites from images." In Layers of Perception. Proceedings of the 35th International Conference on Computer Applications and Quantitative Methods in Archaeology (CAA), Berlin, 2-6 April 2007, edited by A. Posluschny, K. Lambers, and I. Herzog, 43- 50. Bonn: Dr. Rudof Habelt GmbH.

Free Software Foundation. 2014a. "GNU General Public License." Accessed January 15, 2012. http:// www.gnu. org/ licenses/ gpl-3.0.html.

Free Software Foundation. 2014b. "What is GNU?" Accessed March 15. http:// www.gnu.org/ .

Furukawa, Y., B. Curless, S. M. Seitz, and R. Szeliski. 2010. "Towards Internet-scale Multi-view Stereo." In Proceedings of IEEE Conference on Computer Vision and Pattern Recognition (CVPR), 13-18 June, San Francisco, 1434- 1441. Los Alamitos: IEEE.

Furukawa, Y., and J. Ponce. 2010. "Accurate, dense, and robust multi-view stereopsis." IEEE Transactions on Pattern Analysis and Machine Intelligence 32 (8):13621376.

GRASS Development Team. 2012. "Geographic Resources Analysis Support System (GRASS) Software, Version 7.0.”
Accessed March 30, 2014. http:// grass.osgeo.org.

Ho, N. 2014. "RunSFM.” Accessed March 30, http:// nghiaho.com/ ?page_id=253.

J CGM 200. 2012. “International Vocabulary of Metrology - Basic and General Concepts and Associated Terms (VIM)." Accessed on March 30, 2014. http:// www.bipm. org/ utils/common/documents/jcgm/J CGM_200_2012. pdf.

Kent-Berlin Ostia Excavations. 2014. "Ostia. Harbour city of ancient Rome." Accessed March 30. http:// lateantiqueostia.wordpress.com/about/.

MeshLab. 2011. "MeshLab.” Accessed March 30, 2014. http:// meshlab.sourceforge.net/ .

MICMAC. 2014. "APERO-MICMAC." Accessed March 30. http:// www.tapenade.gamsau.archi.fr/TAPEnADe/ Tools.html.

Moran, P. 1950. "Notes on Continuous Stochastic Phenomena." Biometrika 37 (1-2): 17- 23.

Neteler, M., M. H. Bowman, M. Landa, and M. Metz. 2012. "GRASS GIS: a multi-purpose Open Source GIS." Environmental Modelling \& Software 31:124- 130.

Open SourceInitiative. 2014. "TheOpen SourceInitiative." Accessed March 15. http:// opensource.org/ .

Pollyfeys, M., R. Koch, M. Vergauwen, and L. Van Gool. 2000. "Automated reconstruction of 3D scenes from sequences of images." ISPRSJ ournal of Photogrammetry and Remote Sensing 55 (4):251- 267.

Razali, N., and Y. B. Wah. 2011. "Power comparison of Shapiro-Wilk, Kolmogorov-Smirnov, Lilliefors and Anderson-Darling test." J ournal of Statistical Modeling and Analytics 2 (1):21- 33.

Rocchini, D., and M. Neteler. 2012. "Let the four freedoms paradigm apply to ecology." Trends in Ecology \& Evolution 27 (6):310- 311.

Sachsen.de. 2012. '3d Laserscanning." Accessed March 30. http:// www.sachsen.de/ en/ 1842.htm.

Shapiro, S. S., and M. B. Wilk. 1965. "An Analysis of Variance Test for Normality (Complete Samples)." 
Biometrika 52 (3/4):591-611.

Snavely, N., S. M. Seitz, and R. Szeliski. 2006. "Photo tourism: exploring photo collections in 3D." In ACM Transactions on Graphics (TOG) - Proceedings of ACM SIGGRAPH 200625 (3):835- 846.

Snavely, N., S. M. Seitz, and R. Szeliski. 2007. "Modeling the World from Internet Photo Collections." International J ournal of Computer Vision 80 (2):189- 210.

Strecha, C., W. von Hansen, L. van Gool, P. Fua, and U. Thoennessen. 2008. "On benchmarking camera calibration and multi-view stereo for high resolution imagery." In Proceedings of IEEE Conference on Computer Vision and Pattern Recognition (CVPR), 23-28 J une, Great Boston, 1- 8. Los Alamitos: IEEE.

Taylor, J. R. 1999. An Introduction to Error Analysis: The Study of Uncertainties in Physical Measurements. Sausalito: University Science Books.

Topoi. 2014. "Welcome to the excellence cluster TOPOI!" Accessed March 15. http:// www.topoi.org/ .

Visual Experiment. 2014. "SFMToolkit." Accessed March 30. http:// www.visual-experiments.com/demos/ sfmtoolkit/.

Wechsler, S. P. 2007. “Uncertainties associated with digital elevation models for hydrologic applications: a review." Hydrology and Earth System Sciences 11:14811500.

Wu, C. 2007. "SiftGPU: A GPU implementation of Scale Invaraint Feature Transform (SIFT)." Accessed March 30. http:// cs.unc.edu/ ccwu/ siftgpu.

Wu, C. 2014. "VisualSFM: A Visual Structure from Motion System." Accessed March 30. http:// ccwu.me/vsfm/ .

Wu, C., S. Agarwal, B. Curless, and S. M. Seitz. 2011. "Multicore Bundle Adjustment." In Proceedings of IEEE Conference on Computer Vision and Pattern Recognition (CVPR), 20-25J une, Orlando, 3057- 3064. Los Alamitos: IEEE. 


\title{
Old Problems and New Challenges in Archaeological Sites Data Management. The REVEAL Experience at Ammaia (Portugal)
}

\author{
Cristina Corsi \\ University of Cassino, Italy and Universidade de Évora, Portugal \\ Eben Gay \\ Brown University, USA \\ Eleftheria Paliou \\ Ruprecht-Karls-Universität-Heidelberg, Germany and Universidade de Évora - CIDEHUS, Portugal \\ Donald Sanders \\ The Institute for the Visualization of History, Inc., USA
}

\begin{abstract}
:
REVEAL is a free software solution that can ensure that excavations are fully documented and that the record is accurate. Cooperatively developed by Brown University, the University of North Carolina and the Institute for the Visualization of History (USA), REVEAL has been tested in many archaeological sites all over the world. Among them, the deserted Roman town of Ammaia (Portugal) has been chosen because of the peculiarities of the datasets and because the site is the main "open-lab" of the EU funded project Radio-Past and other projects. This paper aims to present our current experience with REVEAL, discuss its potential and review possible use of features that have not yet been accessed.
\end{abstract}

\section{Keywords:}

REVEAL Package Software, Data Management in Complex Archaeological Sites, Computer-Vision and Pattern-Recognition, Roman Townsite of Ammaia

\section{The REVEAL Software Package}

REVEAL (Reconstruction and Exploratory Visualization: Engineering meets ArchaeoLogy) is the product of an on-going four-year US National Science Foundation-funded project named "IIICXT-Core Computer Vision Research: Promoting Paradigm Shifts in Archaeology" (Grant \#0808718: NSF 2014; Galor et al. 2010; Gay et al. 2010; Vizin 2014).

REVEAL is being developed by a consortium of innovators among the Laboratory for Man/ Machine Systems, Brown University's Division of Engineering (Providence, Rhode Island, USA), the Department of Electrical and Computer Engineering, the University of North Carolina at Charlotte (North Carolina; USA) and the Institute for the Visualization of History (Williamstown, Massachusetts, USA).

Corresponding author: c.corsi@unicas.it
This project is working toward important accomplishments in computer-vision and patternrecognition (CVPR) research, as well as in digital archaeology. Its endeavours will offer significant contributions to core CVPR research and to archaeological data-collection and visualization systems. In fact, the project combines computervision, pattern-recognition, and machine-learning research to augment applications for cultural heritage and the humanities in general (additional online resources: Computer Vision @ LEMS 2014; Sourceforge 2014; Vizin 2014; YouTube 2014).

REVEAL runs on Windows XP 32 bit, Windows Vista 32 or 64 bit, Windows 732 or 64 bit, and Windows 8. A stand-alone REVEAL system is recommended to havean i7 processor, 4 gigabytes of memory, and at least 40 gigabytes of free disk space. If processing complex objects from photos to 3D models, then more memory will speed the process 


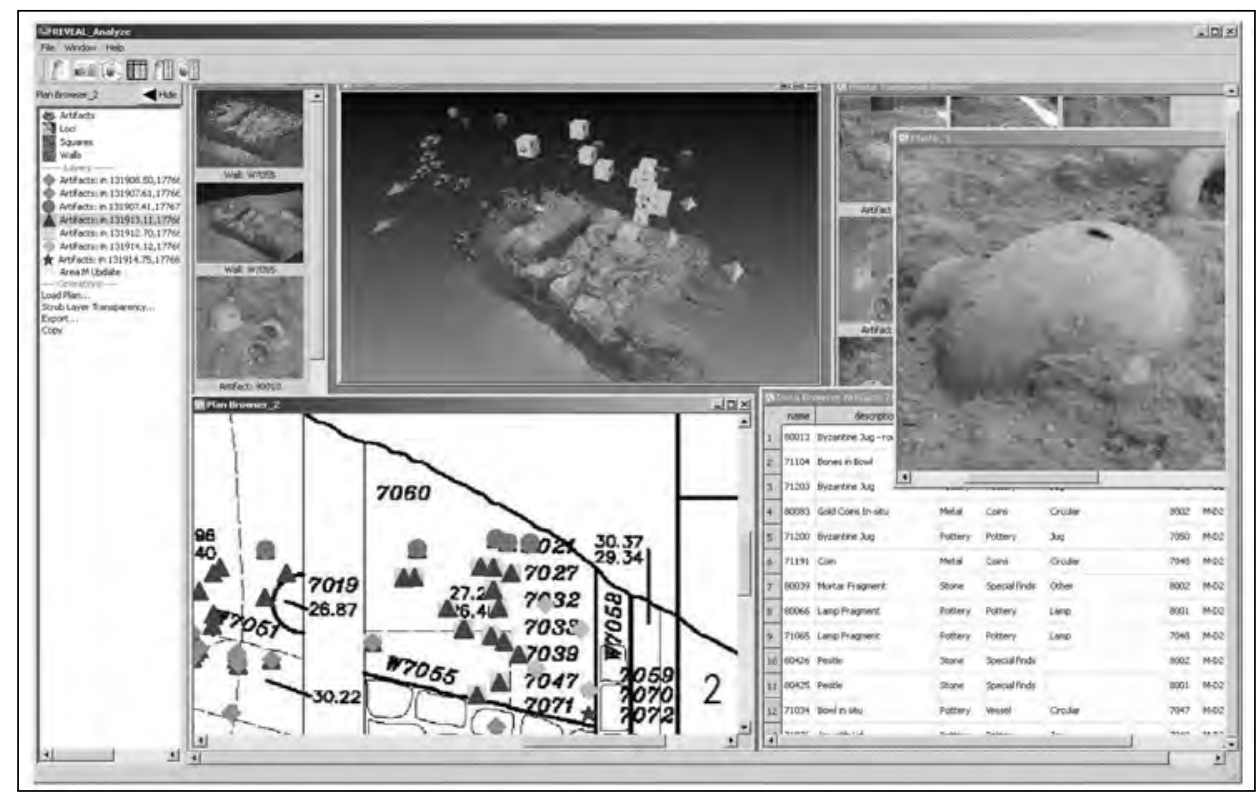

Figure 1. REVEAL software package. Screenshot of Analyzer module, which integrates geo-aligned satellite photos, geo-aligned plans, geo-aligned $3 D$ models, photographs, and tabular data (elaboration D. Sanders).

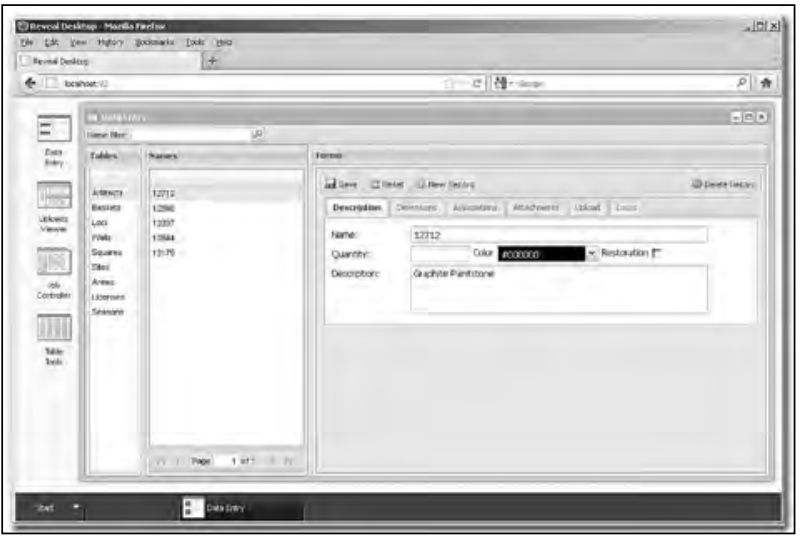

Figure 2. REVEAL software package. Screenshot of the Web browser-based forms for texts and tables data entry (elaboration D. Sanders).

significantly. For instance, an object with 100 photos will run best on 16 gigabytes of memory and an object with 150 photos will run best on a system with 32 gigabytes. REVEAL can be configured for distributed systems with separate database server, web server, multiple data entry systems, multiple photo-to-3D servers, and multiple analyser workstations. For more information about this sort of configuration, see the REVEAL installation guide.

The consortium of developers devised a single, all-digital toolkit for acquiring, coordinating, studying, and presenting archaeological data that streamlines the excavation documentation and analysis processes. REVEAL uses: computer automation tools to speed up data entry tasks via an open-source Web interface; computer vision algorithms to replace manual imaging tasks; and integrated tabular, 2D, and 3D media resources to enhance querying, comprehension, and dissemination. Although we began with archaeological excavations as our focus, the resulting software can be used for any heritage documentation project. The REVEAL database is completely customisable, so any project comprised of data, photographs, 2D plans, and 3D models can be supported by a user-configured database.

The initial goals were to enable realtime hypothesis testing during excavation by improving data acquisition through automation, including geolocated position recording, advanced photomodelling, and full integration of all user data. REVEAL thus becomes a single repository for everything about an excavation, or any other heritage site, with integrated multimedia analysis functions (including immediate access to tabular, photo, video, and 3D data) and integrated display of that data on plans or in spatially geolocated 3D models of trenches, architecture, or small finds (Fig. 1). This means that from any single data type there is direct access to and display of all other related datasets. REVEAL thus combines multiple modes of input and data browsing, a database, and a sophisticated user interface. 


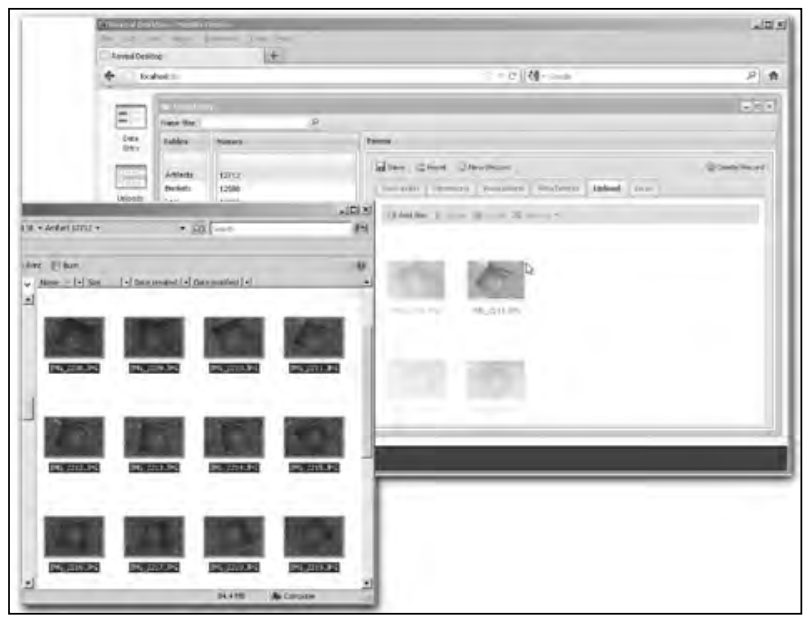

Figure 3. REVEAL software package. Screenshot of the interface to drag and drop photos from the device into REVEAL (elaboration D. Sanders).

In the field, the REVEAL data entry process is made up of two parts. Text is entered onto Web browser-based (customisable) forms and can happen via laptops, tablets or smartphones (Fig. 2). Photographs of all work and contexts (and thus all information about the site, all records of fieldwork activity, and even some information that teams may not realise were captured) can be dragged and dropped from the device to the REVEAL screen and can be taken with regular consumer digital cameras (or handheld device cameras) (Fig. 3). No special lighting, no camera calibration, and no special equipment of any kind are needed.

As soon as the photos have been dropped into and associated with the objects in view, the REVEAL Sentinel photomodelling process can begin. The REVEAL photomodelling process moves through the following steps: (1) find common points in the photos (called SIFT - Scale Invariant Feature Transform - ); (2) calculate the camera positions (called bundling - a structure-from-motion system for unordered image collections -); (3) shoot rays through each pixel to find, intersect, and define common points across all images; and (4) create the 3D models from the common points. Photographs can also be used to geolocate the 3D models. Overlapping features or specific markers placed in the scenes are shot at the site level, the building or trench level, and the artefact level so that a continuous set of models can be built and the results geolocated accurately within each succeedinglarger-

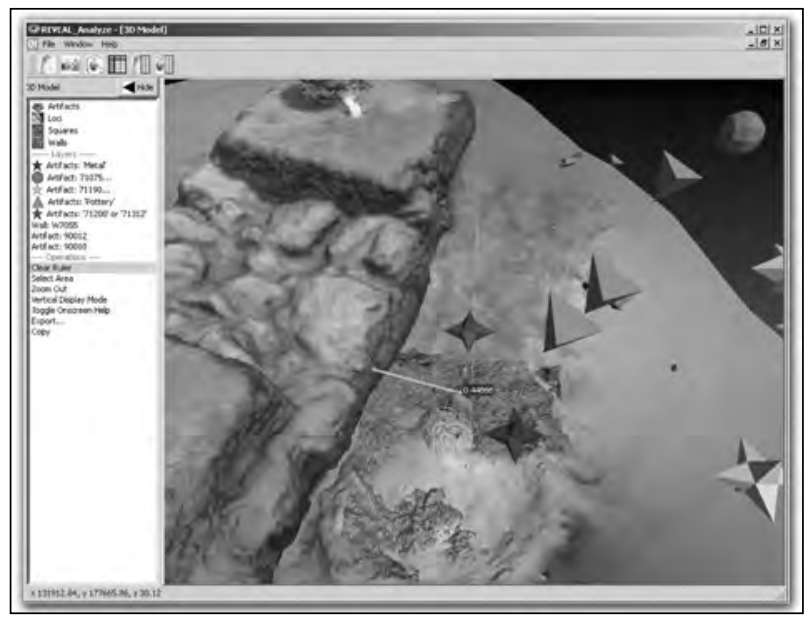

Figure 4. REVEAL software package. Screenshot of the created $3 D$ model of excavated structures and related geolocated distribution of artefacts viewed in REVEAL Analyzer (elaboration D. Sanders).

scale model. The models can be viewed in REVEAL Analyzer (Fig. 4). Analyzer is the REVEAL data analysis module, which has been designed for nontechnical users. Analyzer's user interface provides a simple select-and-filter access to the user's data, allowing the user to make sophisticated queries to the database without requiring database skills.

REVEAL Analyzer integrates geo-aligned satellite photos, geo-aligned plans, geo-aligned 3D models, photographs, and tabular data in a single program. The main screen has a persistent and context-sensitive master information panel and index at the left edge of the windowand, at the right, space for several individual browser windows that each display photographs, plans, satellite images, tabular data, or 3D models. Any object in the database that is displayed in one of the windows will automatically link to other data types for that same object, which can be viewed singly or in conjunction with contextual information (Fig. 1).

Data analysis, visualisation, and querying can happen across plans (to view 2D contexts and assemblages), across data tables (to compare objects or select custom sets of fields for specific data retrieval), across sets of photographs (to view thumbnail sets or high-resolution images), and interactive models showing (to view 3D contexts of artefacts, features, and structures). Data are integrated from any REVEAL browser window to 
any other within the software; all data are internally linked, and all screens, views, and tools have context-sensitive help. The package is presented in a simple interface that allows sophisticated analysis, hypothesis testing, and visualisation.

REVEAL allows researchers and field teams to ask new questions of the data, and the visualisations and data analysis results from REVEAL permit immediate field-level decision support. During excavation, archaeologists are, in fact, asked first to identify the stratigraphic units and then remove them in the reverse order to that one in which they formed. For this reason, it is essential to rely upon an instrument which can help in reconstructing the "matrix" in real time, meaning the sequence of what was formed first and what later, making use of the possibility to visualise stratigraphic units in 3D and not only in plan or section drawings. Furthermore, the visualisation of spatial distribution of artefacts with related database can help in understanding the function of determined areas in the course of the excavation. In this way, archaeologists can predict some results and sketch interpretative models on the basis of comparative research and experience, and can therefore limit "destructive" operations like excavation itself. Anyone using the system at one site or comparing data across many sites can understand 3D spatial relationships from data collected today, yesterday, or last month with equal ease, whether the evidence has been removed or not. Contexts can be viewed and compared in colour, interactively, and in 3D simulations of their original contexts of assemblages and features. These types of inquiries are simply not possible using traditional methods or even using most of the current digital methods individually.

Other packages for recordingand management of archaeological data like Integrated Archaeological Database (IADB 2011) or comparable systems like Archaeological Recording Kit (ARK 2014) have not been tested in any of our "open laboratories", so it is impossible for us to give an opinion on it. However, one comparative example can be found in the use we made of other multi-view 3D reconstruction software for image-based 3D modelling. Before introducing REVEAL, in fact, several teams of the project used the standard edition of Agisoft Photoscan (Agisoft 2014), chosen most of all on the basis of the affordable price for the non- professional version (around 180 \$). By taking photos from several sides of an object (we worked mainly on structures and walls), we performed the aerial and close-range triangulation, the point cloud generation, the 3D model generation and the texture mapping. These operations of digitalisation and photogrammetric geometrisation are possible without applying markers or circumstantial measurements. This procedure can be utilised in case of original artefacts of any size as well as of aerial vistas and it is in the field of high resolution aerial photography that the most recent applications have been done (Verhoeven et al. 2013). Still, this software covers only the needs for 3D modelling and does not offer integration with the database. Furthermore, the image processing is very slow and requires machines with high performances.

Users of REVEAL can export single or sets of photos, plans, or $3 \mathrm{D}$ models and can filter and arrange data in a variety of file formats. Thus, REVEAL supports post-excavation research, teaching, and publication preparation. For example, the software allows for 3D contextual visualisations, viewing artefact distributions over time, drawing cultural inferences across large sites, and filtering, organising, and exporting tables, plans and other images. Further, REVEAL can be loaded in to a variety of hardware configurations, from standalone systems using a single computer and camera, to centralised distributed systems via local wi-fi connections from laptops and handheld devices and multiple cameras.

In summary, datacan beinputinto REVEALvia laptops, smartphones, and tablets; photomodelling can happen using images taken with consumergrade cameras without special equipment. REVEAL has a flexible data configuration system, flexible system configuration, integrated media and database explorer windows, and can export to the popular file formats. The key points can be summarised as follows:

- REVEAL allows real-time hypothesis testing as excavations unfold.

- It allows archaeologists to digitally record, visualise, and query all aspects of excavation progress, and it is very useful for creating publication-ready output. The benefits of a 
three-dimensional view are immediate: the operation of "dismantling" and removing the stratigraphic units is easier, and the benefits are even more evident in the phase of "replacement" of the dug and removed volumes. Interpretation is facilitated and therefore it is simpler to disseminate it in publication, for specialists and wider public. The software is free and opensource (Sourceforge 2014).

\section{A Test-Site: the Roman Town of Ammaia in Lusitania (Portugal)}

REVEAL has been field tested in many sites around the world for all sorts of documentation and recording projects (e.g., Catalhöyuk, Turkey; Chavin de Huantar, Peru; Tel Eton, Tel es-Safi, and Apollonia-Arsuf, Israel; Middleborough, USA; Surtshellir, Iceland; and for recording and photomodelling cuneiform objects at Cornell University). Among them, the site of Ammaia, an Early Imperial Roman town in central Lusitania (Portugal), has been chosen because of the peculiarities of the datasets and because the site is the main "open-lab" of several international and national projects. Among them, we can mention:

- The project entitled 'Geo-archaeological research of Roman Landscapes in Alentejo' (Uevora CIDEHUS, in collaboration with the Belgian Ghent University and the Italian University of Cassino);

- 'Radio-Past', a European FP7MarieCurie/ People Action IAPP project, entitled 'Radiography of the past. Integrated non-destructive approaches to understand and valorise complex archaeological sites'. In this project, four academic partners (Universities of Évora, Ghent and Ljubljana and the British School at Rome) and three SMEs (7Reasons - Austria, Past2Present - the Netherlands and Eastern Atlas - Germany) have pooled their resources in order to develop integrated approaches to studying different urban sites (mostly Roman) and searching for effective ways in which to present their results to a wider public (van Roode et al. 2012);

- The Ammaia project. A concerted action of archaeology, natural sciences and applied technologies to place a Roman town in context' is financed by the Portuguese National Fund for Research (FCT). In this project, UEvora's (here represented by the research centres CIDEHUS and HERCULES) main partners are the Department of Electrical Engineering and the Institute for Systems and Robotics (ISR) of the Instituto Superior Técnico (IST) in Lisbon. The foremost objective of this project is the creation of opportunities to transfer knowledge and to validate developments and innovation in the methodology of archaeological surveys. One of the priorities of this project is the development of a new low budget' system for high-resolution low altitude lidar scanning. Another priority is to investigate further possibilities in the automation of certain types of field survey (such as geophysics). This project, which will last for three years, was launched in 2011.

In Ammaia the focus is on the integration of approaches for understanding and visualising complex archaeological sites, and excavation is only a limited part of the research agenda. For this reason, we were interested in testing the possibilities of REVEAL to integrate data of different nature.

Starting in 2008, the scientific direction of the site has been undertaken by Frank Vermeulen and Cristina Corsi. Recent campaigns (2008-2011) have encompassed:

- Geoarchaeological survey and geomorphologic study (Vermeulen et al. 2005; Corsi and Vermeulen 2009; Vermeulen et al. 2012);

- Production ofaDTMwith DGPS (in collaboration with the Instituto de Arquelogia de Mérida: Corsi and Vermeulen 2012a, 31-36);

- Geological and pedological analysis, including coring (Corsi and Vermeulen 2012a, 23-30);

- Systematic artefact collection (Corsi and Vermeulen 2012a, 127-135);

- Aerial photography and remote sensing operations including study of historical aerial photos (Corsi and Vermeulen 2008; Verhoeven, Taelman and Vermeulen 2012);

- Architectural survey and photogrammetry of 


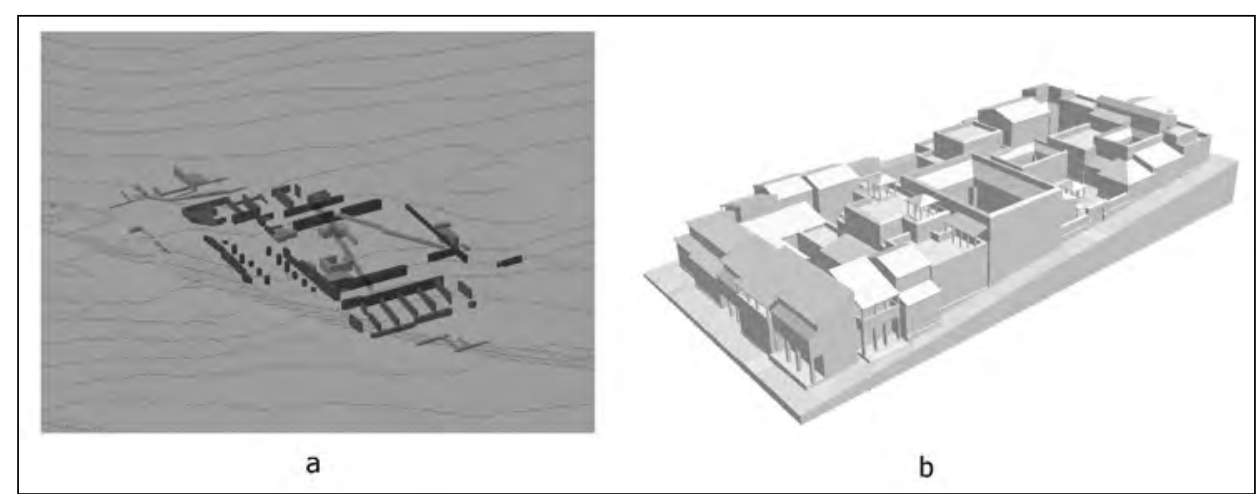

Figure 5. a) $3 D G P R$ data visualisation in ArcGIS, b) $3 D$ building reconstruction in ArcScene (elaboration E. Paliou).

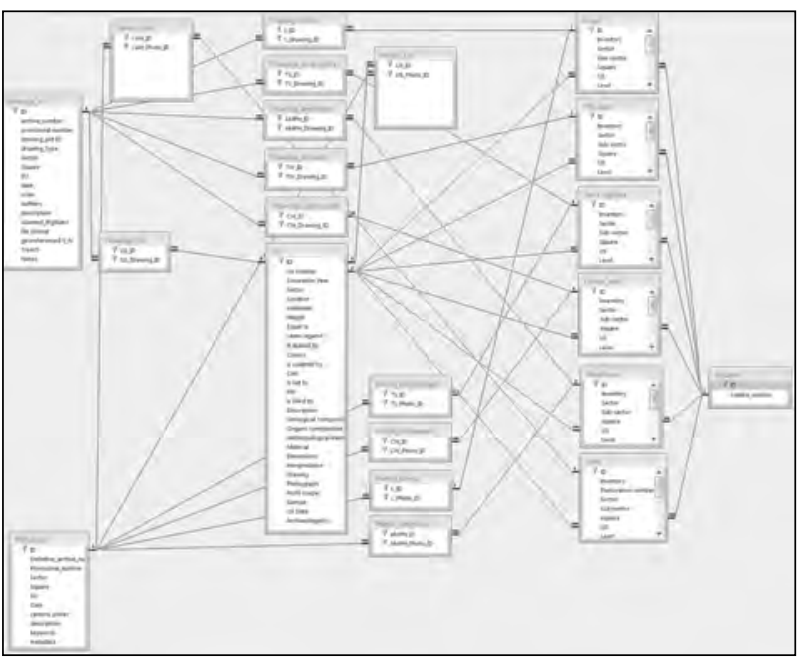

Figure 6. Relational database schema in MS Access (elaboration E. Paliou).

surviving walls structures (in collaboration with the Italian University of Tuscia);

- Terrestrial laser scanning (TLS, in collaboration with The Discovery Programme - Ireland) and documentation of above ground monuments;

- Extensive geophysical survey with different techniques and diverse strategies and methodologies of data capture (Corsi and Vermeulen 2012a, 47-114);

- Stratigraphic and ground-truthing excavations (Corsi, J ohnson and Vermeulen 2012; Corsi and Vermeulen 2012a, 47-49, 146-148; Corsi and Vermeulen 2012b);

- Archaeological materials study and associated laboratory activities for the analysis and restoration of finds, and archaeometric analysis.

\section{The Data Management}

Thereis noneed to stress that the data collected over 18 years of fieldwork range enormously both qualitatively and quantitatively.

Given the diversity of the archaeological datasets collected atAmmaia, two different database management systems were used: a spatial database implemented with ArcGIS and a relational database managed with MS Access. The development of the GIS database had two main objectives. Firstly, to produce spatial representations that sufficiently describe the nature and complexity of the multidimensional archaeological record of the Roman site. Secondly, to permit the integration, exploration and formal analysis of the collected data in ways that enhance interpretations. Within the GIS environment both 2D and 3D data integration was possible. Two-dimensional overlays of geophysical, topographical and geoarchaeological datasets proved valuable for the interpretation and cross-validation of survey results (Paliou 2012). 3D data integration was also possible using the more recent 3D visualisation functionalities of ArcGIS. For example, GPR interpretations and building reconstructions, were imported as AutoCAD three-dimensional geometry (3D faces) and were converted to ArcGIS multipatch objects that were used for the evaluation of archaeological information in three dimensions (Fig. 5). Furthermore, data on excavation units and archaeological artefacts as well as their photographic documentation were organised in a relational database which was implemented using MS Access (Fig. 6). Database tables were later related to GIS polygon shapefiles representing excavation units, a process which permitted the performance of queries on the spatial associations of archaeological artefacts. 
The above solutions, which are commonly employed for the management of archaeological data, were sufficient for meeting many of the needs of the project. Nonetheless, the use of a single data management system which can effectively integrate all the datasets collected at Ammaia over the years (geophysical, geoarchaeological, topographical, excavation data, graphic and photographic documentation), while at the same time offering new possibilities for data recording and $3 \mathrm{D}$ visualisation, would have many advantages in the context of RadioRast. Like most projects of the 7th Framework of the European Commission, this project is intended to develop innovative approaches to research in different fields. Particularly interesting is this context of integration between research in humanities and ICTS. Furthermore, archaeological excavation is intended in the framework of the Radio-Past project only as "ground-truthing", therefore excavation campaigns are short and include limited areas, with specific objectives which include the field-check of what detected via remote sensing and geophysical survey. In this sense, the test is immediate and covers aspects of data integration.

\section{Conclusions}

One of strategic objectives in the development of REVEAL is undoubtedly the possibility to capture data in real-time. This approach not only saves time but also avoids mistakes in recording. REVALS also aims to obtain a better integration of the different types of documentation required in an archaeological excavation. This crucial point was missed in our project, as when REVEAL was fully operative, our fieldwork was completed. In any case, we could not have performed the data input via webinterface, as in Ammaia we are not connected to wi$\mathrm{fi}$ and the extension of the archaeological park is too large to allow the implant of a local network, which instead is active inside the museum. Furthermore, while we are equipped with good digital cameras, we do not have tablets or portable devices. So, we have to undertake data capture procedures using "traditional" systems, like paper recording sheets, and only in a second phase digitise the data. Unfortunately, this is the "standard" equipment of an archaeological project, mostly in remote areas of Southern Europe, where the data entry and the data processing are activities usually carried out in the laboratory.
In this sense, the most important "test" for the use of REVEAL performed in Ammaia, was about the possibility to process data from old excavations. The customisation in this case is more demanding, and the integration between CPVR and documentation is less efficient. To summarise, we can say that integration of "old documentation" with REVEAL is possible and efficient, but best results are obtained when additional photographic documentation can be obtained.

Undoubtedly, the "winning" and dominating aspect of REVEAL is the computer vision related one. REVEAL offers significant contributions to the integration of archaeological data-collection and visualisation systems. Compared to commercial software which perform photogrammetric volumetric geometrisation and 3D reconstruction on the base of a series of images taken from several sides of an object or a structure, without applying markers or circumstantial measurements, REVEAL appears much faster in the data processing and much more accurate in the final product, when compared to the experience achieved in the course of the last 10 years with other systems and software for documentation, asabovedescribed. As we sawabove, a large amount of data in Ammaia is constituted by georeferenced plotted two-dimensional results of the geophysical survey. When investigating how these datasets can be best incorporated and perhaps analysed in the REVEAL system, we had to conclude that for this purpose commercial software, even if not specifically developed for archaeological site analysis, still proved to be more efficient for spatial analysis. In our experience, we can therefore say that REVEAL presents a major paradigm shift in how archaeologists collect information, but not in the way they analyse spatial relationships, visualise artifactual interrelationships, study contexts, and disseminate research conclusions.

When discussing how REVEAL can make a difference for presenting and analysing new digitally recorded datasets and smoothly integrate old types of documentation and whether any new insight into artefact distributions resulted, we can stress how the integration of different datasets was facilitated and most of all, how the visualisation of results in 3D made the decision-making and interpretation processes easier and more efficient. Essentially, how our understanding was enhanced. In fact, when 
"rebuilding" the sequence of events which affected the area we are excavating, it is very beneficial to be able to visualise the stratigraphic units, whether earth layers or structures, in 3D. Dynamics and events, functions and zooning are better understood when it is possible to view simultaneously phenomena connected to space and time.

\section{Bibliography}

Agisoft. 2014. "Image-based 3D modeling." Accessed J anuary 15. http:// www.agisoft.ru/ .

ARK. 2014. "An open source solution to project recording." Accessed J anuary 15. http:// ark.lparchaeology.com/ .

Computer Vision @ LEMS. 2014. "Reveal". Accessed February 20. http://vision.lems.brown.edu/ project desc/Reveal/.

Corsi, C., P. S. Johnson, and F. Vermeulen. 2012. "A Geomagnetic Survey of Ammaia: a contribution to understanding Roman Urbanism in Lusitania." J ournal of Roman Archaeology 25:121- 145.

Corsi, C., and F. Vermeulen. 2008. "Elementi per la ricostruzione del paesaggio urbano e suburbano della città romana di Ammaia in Lusitania." Archeologia Aerea 3:177- 194.

Corsi, C., and F. Vermeulen. 2009. "Archaeology of a Roman landscape in Central Portugal." Egyptian J ournal of Environmental Change I (1):1- 5. Accessed J anuary 15, 2014. http:/ / www.envegypt.com/ EJ EC/ uploads/ 26.pdf/ .

Corsi, C., and F. Vermeulen (eds.). 2012a. Ammaia I: the survey. A Romano-Lusitanian townscape revealed. Ghent: Academia Press.

Corsi, C., and F. Vermeulen. 2012b. "Water in Ammaia. Infrastructures and Leisure in a Roman Town of Lusitania." In SPA. Sanitas Per Aquam. Tagungsband des Internationalen Frontinus-Symposiums zur Technik und Kulturgeschichte der antiken Thermen, Aachen, 18- 22. März 2009, edited by R. Kreiner and W. Letzner, 183- 190. Leuven: Peeters Publisher.

Galor, K., D. Sanders, and A. Willis. 2010. "Semiautomated data capture and image processing: new routes to interactive 3D models." In Space, Time, Place Third International Conference on Remote Sensing in
Archaeology, 17th-21st August 2009, Tiruchirappalli, Tamil Nadu, India, edited by S. Campana, M. Forte, and C. Liuzza, 179- 188. Oxford: Archaeopress.

Gay, E., K. Galor, D. B. Cooper, A. Willis, B. B. Kimia, S. Karumuri, G. Taubin, W. Doutre, D. Sanders, and S. Liu. 2010. "REVEAL Intermediate Report." In Proceedings of CVPR Workshop on Applications of Computer Vision in Archaeology (ACVA'10), 1-6. Piscataway: IEEE.

IADB. 2011. “Integrated Archaeological Database." Last modified May 20. http://www.iadb.org.uk/.

NSF. 2014. "III-CXT-Core Large: Computer Vision Research: Promoting Paradigm Shifts in Archaeology." Accessed February 20. http:/ / www.nsf.gov/ awardsearch/ showAward.do?AwardNumber $=0808718$.

Paliou, E. 2012. "Digital data management and integration at Ammaia". In Ammaia I: the survey. A RomanoLusitanian townscape revealed, edited by C. Corsi and F. Vermeulen, 122- 126. Ghent: Academia Press.

Radio-Past. 2014. “Radio Past.” Accessed February 2014. http:// www2.radiopast.eu/ ?page_id=144/ .

Sourceforge. 2014. “REVEAL_Analyze.” AccessedJ anuary 15. http:// sourceforge.net/ projects/ revealanalyze/ .

van Roode, S., C. Corsi, M. Klein, F. Vermeulen, and G. Weinlinger. 2012. "Radiography of the Past: a total project for digital prospection and modeling of complex sites." In Landscape Archaeology Between Art and Science: From a Multi- to an Interdisciplinary Approach (Landscape \& Heritage Proceedings), Proceedings of the 1st Landscape Archaeology Conference: LAC2010 (Amsterdam 26th - 28th January 2010), edited by S. J. Kluiving and E. Guttmann-Bond, 429-441. Amsterdam: Amsterdam University Press.

Verhoeven, G., Ch. Sevara, W. Karel, C. Ressl, M. Doneus, and Ch. Briese. 2013. "Undistorting the Past: New 3 Techniques for Orthorectification of Archaeological Aerial Frame Imagery." In Good practice in archaeological diagnostics. Non-invasive survey of complex archaeological sites, edited by C. Corsi, B. Slapsak, and F. Vermeulen, 31-61. Berlin: Springer.

Verhoeven, G., D. Taelman, and F. Vermeulen. 2012. "Computer vision-based orthophoto mapping of complex archaeological sites: the ancient quarry of Pitaranha 
Across Space and Time. Papers from the 41st Conference on

Computer Applications and Quantitative Methods in Archaeology. Perth, 25-28 March 2013

(Portugal-Spain)." Archaeometry 54 (6):1114- 1129.

Vermeulen, F., C. Corsi, and M. De Dapper. 2012.

"Surveying the townscape of Roman Ammaia (Alentejo, Portugal): a geoarchaeological approach of the forum area." Geoarchaeology 27 (2):105- 187.

Vermeulen, F., M. De Dapper, C. Corsi, and S. Deprez. 2005. "Geoarchaeological observations on the Roman town of Ammaia." Internet Archaeology 19. http:// intarch.ac.uk/journal/issue19/corsi_index.html/.

Vizin. 2014. "REVEAL (Reconstruction and Exploratory Visualization: Engineering meets)." Accessed February 20. http:// www.vizin.org/ projects/ reveal/project.html/ .

YouTube. 2014. "REVEAL Overview.” Accessed February 20. http:// www.youtube.com/ watch?v=10J kiEMiMSg/ . 


\title{
The Parnassus Project: Archaeology and Engineering Collaboration for 3D Data Collection and Analysis
}

\author{
Dina D'Ayala \\ University College London, UK \\ Penny Copeland \\ University of Southampton, UK \\ Yasemin Didem Aktas \\ University College London, UK \\ Graeme Earl \\ University of Southampton, UK \\ Aykut Erkal \\ Istanbul Kemerburgaz Universitesi, Turkey \\ J ames Miles and Elizabeth Richley \\ University of Southampton, UK \\ Victoria Stephenson \\ University College London, UK \\ Kris Strutt \\ University of Southampton, UK
}

\begin{abstract}
:
The Parnassus Project was set up in 2010 as a multidisciplinary approach to the effects of extreme weather on cultural heritage involving the Engineering, Hydrography and Archaeology departments at the British Universities of Bath (now moved to UCL), Bristol and Southampton respectively. As the project nears completion, this paper is an investigation into the collaboration dedicated to preserving cultural heritage in the future. The project members from engineering and archaeology have worked closely together, collecting data, using and developing a range of technologies from each discipline to analyse buildings. Buildings are three dimensional environments and assessing the effects of climate change has to reflect this. The pooling of knowledge and equipment has led to the use of a wider range of technologies than would be in use by either discipline alone. Those technologies includes total station survey on buildings using AutoCAD and TheoLt to consider stability and proximity to water and 3D AutoCAD models in AutoDesk's Algor structural analysis software to model structural integrity during increased flood risks, remote climate monitoring on/in the walls of chosen buildings together with electrical resistance tomography (ERT) on the walls to look at difference of structure, water and temperature on the outside and inside of walls for the impact of driving rain and freeze-thaw action and finally laboratory based weathering tests analysed using laser scanning and photogrammetry to quantify damage. This paper assesses the results of the collaboration from the perspective of each task and gives an overview of the results to demonstrate the possibilities and benefits of the interdisciplinary mixing of ideas, the aims of the project and technologies involved.
\end{abstract}

\section{Keywords:}

Buildings, ERT, Photogrammetry, Structural Analysis, Climate Monitoring, the Parnassus Project

Corresponding author: James.Miles@soton.ac.uk 


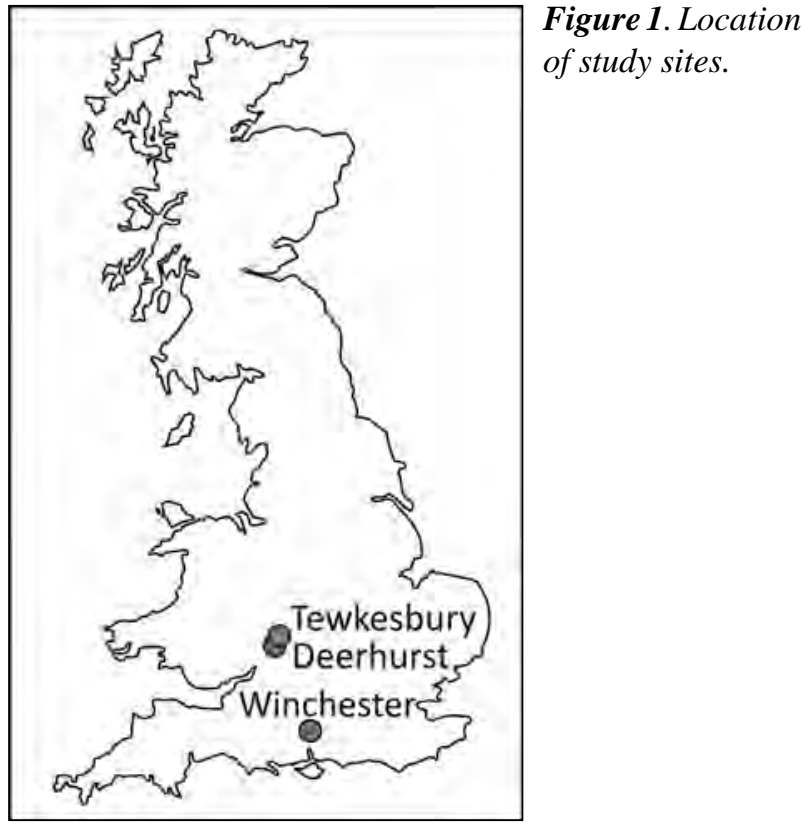

TheParnassusProjectwassetupin2010 aspart of the Science and Heritage Programme in Britain, funded to encourage the collaboration of Science and Humanities researchers and to call on a range of disciplinary expertise and resources to broaden the ways in which changes to cultural heritage and its conservation are understood. The overall aim of the Parnassus Project was to understand the effect of climate change on historic buildings and archaeological sites, primarily the impact of flooding and driving rain on structural integrity and material properties, and evaluate resilience and adaptation measures able to counteract and prevent adverse effects. Each member of the project had a separate area of study taking advantage of their specialisms: UCL: driving rain and climate monitoring; Southampton: archaeological evidence for early adaptation during the Little Ice Age; Bristol Engineering: Freeze-thaw action on materials; Bristol Hydrography: Predictive modelling of flooding. A number of key sites were chosen as worthy of study on the basis of their propensity to flooding or damp. As the project progressed it became clear that Engineering at UCL and Archaeology at Southampton shared many common goals and that each used methodologies that could benefit the other partner. This paper discusses the fruitful collaboration that developed between UCL Engineering and Southampton Archaeology and can only give an overview of the results to show the potential of such interdisciplinary working.

\section{History of Sites in the Study}

The Parnassus Project had identified a number of sites as having problems with climate at its commencement. Of these, the collaborative team considered Mill Bank in Tewkesbury, Odda's Chapel in Deerhurstand Winchester Cathedral crypt (Fig. 1). These sites have historically suffered from extreme weather and flooding problems and have had various solutions attempted. These sites have great heritage value and their continued vulnerability to natural forces makes each site unique and worth studying.

\subsection{Tewkesbury Mill and Mill Bank}

The town of Tewkesbury was chosen because it has had a regular history of flooding with frequent major events (Bennett 1830), and recently suffered very extensive floods in 2007 and 2012 cutting off the town. Tewkesbury is sited at the confluences of the Severn and the Avon, both major British rivers. In addition, a small river, the Swilgate runs to the east of the town. An artificial cut was made to create the Mill Avon, a slower flowing wide channel, probably by Tewkesbury Abbey, around the time of its creation in the 12th century although it may have been based on a smaller artificial channel (Heighway 2003 , 1). The economic importance of Tewkesbury, through most of the town's history, has resulted mainly from its proximity to rivers (Elrington 1968). In addition to the collaboration work, Bristol Hydrography has also concentrated on Tewkesbury for their flood modelling.

There appears to have been a mill on the Mill Avon from the 12th century (Heighway 2003, 1), forming part of a group of buildings servicing and profiting the Abbey (Elrington 1968), including a large watermill. The present mill was built in with a later extension (Fig. 2). In 2004 when the Mill was converted into flats, the ground floor was converted into a garage despite usually flooding every winter (N. Purchase pers. comm.).

No.1 Mill Bank sits opposite the mill. English Heritage dates the building as late 15th or early 16th century and it was built originally as two or three houses and part of a terrace. It is likely to have been owned with the mill by the Abbey, as they stayed in ownership together until the 20th century. The current owners believe that the cottages were built 


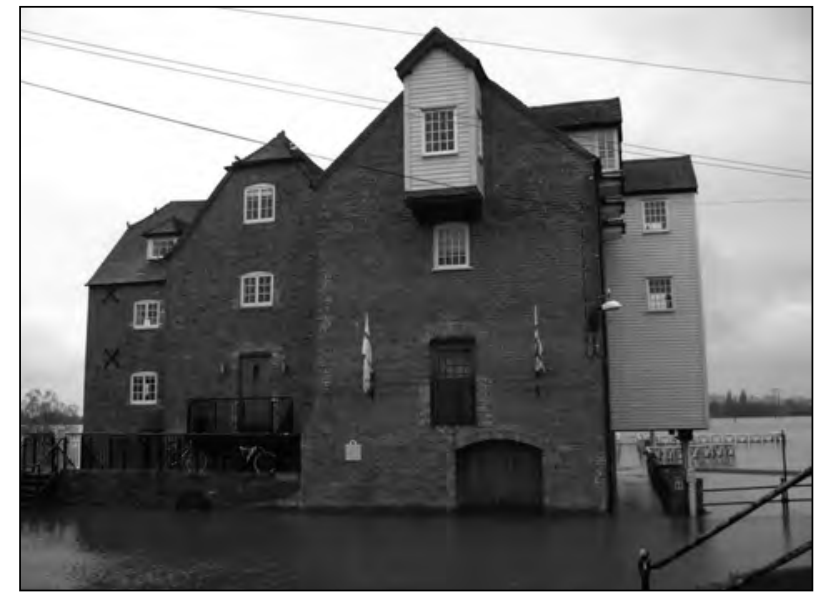

Figure 2. Tewkesbury Abbey Mill in Flood, May 2012. Mill Bank itself has a raised walkway along the east side of the Mill Avon, on which a range of timber framed houses sit. The walkway has historic origins but was refaced in the 19th century in blue engineering bricks, retaining the original stone steps on Mill Street.

for a corn merchant who was employed by the Abbey to sell their surplus (P. Purkiss pers. comm.). The building is timber framed with brick nogging, and wattle and daub panels. It has a jettied first floor along Mill Bank and tension bracing (Verey and Brooks 2002, 734). There are traces of carved columns on the posts of the ground floor front elevation. The frame is raised on low foundations of rough stone, with two high sandstone steps to a raised floor reducing the flood risk further.

\subsection{Odda's Chapel, Deerhurst}

Three miles downstream of Tewkesbury is the village of Deerhurst, lying on the edge of the Severn flood plain. There is evidence of Roman habitation in the village and Deerhurst has both a surviving Anglo-Saxon parish church dating from c. 8th century (Verey and Brooks 2002, 42, 44), and Odda's Chapel, a late Anglo-Saxon chapel (Verey and Brooks 2002, 45) (Fig. 3).

Odda's chapel was not discovered until 1885 when it was "disentangled" from Abbot's Court farmhouse. The nave was found being used as the kitchen with a bedroom above (Taylor and Taylor 1965, 210). It can be dated to 1056 thanks to a stone discovered nearby around 1675 commemorating in Latin the chapel's foundation (Verey and Brooks 2002, 45): "Earl Odda had this royal hall built and

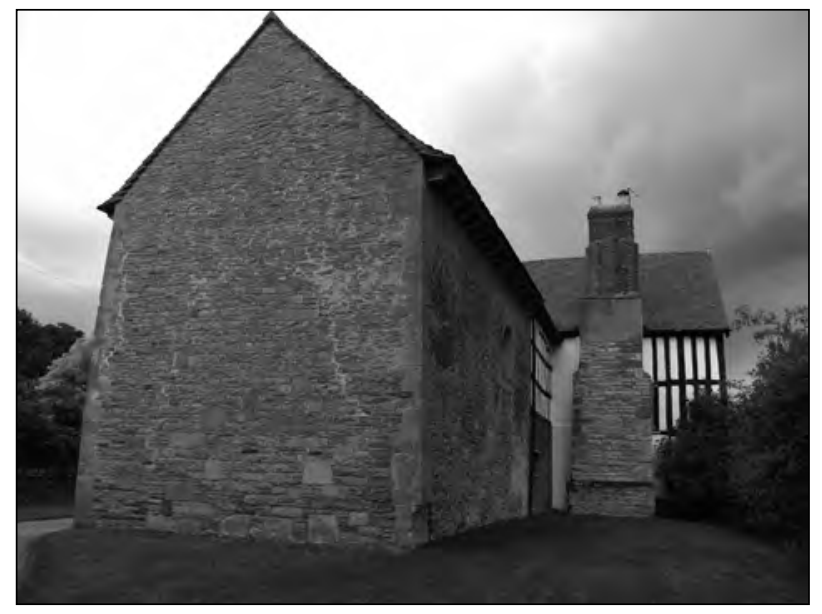

Figure 3. Odda's Chapel, Deerhurst.

dedicated in honour of the Holy Trinity for the soul of his brother Aelfric which left the body in this place". Odda's chapel was out of use by 1540 (Currie 1983, 60).

The chapel was a simple nave and chancel building of two rectangular rooms with a moulded chancel arch between (Taylor and Taylor 1965, 210), and two opposing windows and doorways in the nave (Verey and Brooks 2002, 334). The building is constructed in a rubble bond of Blue Lias stone (Elrington 1968), with dressed oolitic stone used for the arches, imposts and jambs (Butterworth 1887, 106). Abbot's Court that adjoins the chapel is a part jettied timber frame building, with timbers dating from 1591 and 1593/ 4 (Bridge 2001, 2).

The village has a long history of flooding. J ohn Leland wrote in the early sixteenth century: "So that when the Severne much risith the Water cummith almoste aboute the Towne" (Latimer 1890, 266). The village now has a substantial flood barrier, raised in 2009 following the inundation of the village in 2007 . The chapel however lies outside the barrier lying on a slight rise, very rarely flooding (except in 2007). The building is currently roofed but open and unheated.

\subsection{Winchester Cathedral crypt}

Winchester lies in the flood plain of the River Itchen which cuts through the chalk hills of the South Downs. The cathedral lies on chalky marl concealing a layer of peat up to $1 \mathrm{~m}$ thick, which in turn overlies a deep layer of waterlogged gravel which slopes 
to the south east of the cathedral (Henderson and Crook 1984, 14, 21). This caused subsidence problems during the building of the south transept and the later retrochoir at the east end (Henderson and Crook 1984, 22).

The cathedral is around $250 \mathrm{~m}$ from the river and was built within a town quarter dedicated to power and religion, surrounded by the New Minster, St. Mary's Abbey (Nunnaminster) and the Bishop's Palace of Wolvesey (Henderson and Crook 1984, 14). Water management is a theme throughout Winchester. When the Romans settled in the river valley, they culverted parts of the braided streams (Zant 1991, 13) and possibly moved the rest of the river east (Zant and Scobie 1991, 13). There are a substantial number of water channels within close range of the cathedral and these help to carry water away.

Much of the crypt is original to the building of the cathedral in the 11th century, but much of the cathedral above has been rebuilt. The Lady Chapel, at the extreme east end of the cathedral was built in

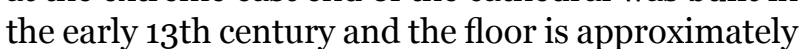
$30 \mathrm{~cm}$ above that of the main crypt (Crook 1989, 19), suggesting there was not a major problem with flooding when it was built. However, the floor of the crypt was infilled by more than a metre in the 14th century, presumably to take the floor level above the regular winter floods, possibly brought on by the worsening weather of the Little Ice Age from c.1300. Most of this infill was dug out in 1886, with the resultant reoccurrence of flooding (Crook 1989, 5). Currently the crypt floods each year up to a depth of $60 \mathrm{~cm}$ (Crook 1989, 5).

Source of the stone for the cathedral is well documented with land on the Isle of Wight granted by a charter of King William Rufus for the building of his church. The quarried stone is Quarr stone, a very shelly limestone, often called "featherbed stone" (Tatton-Brown 1993, 37). In the crypt all the visible Romanesque masonry is Quarr stone except for the cushion capitals and the drum blocks of oolite (Tatton-Brown 1993, 38).

The cathedral was built on beech log and loose stone foundations laid in trenches cut in the water logged soil and peat (Henderson and Crook 1984, 21). In 1905 wide cracks were observed in the

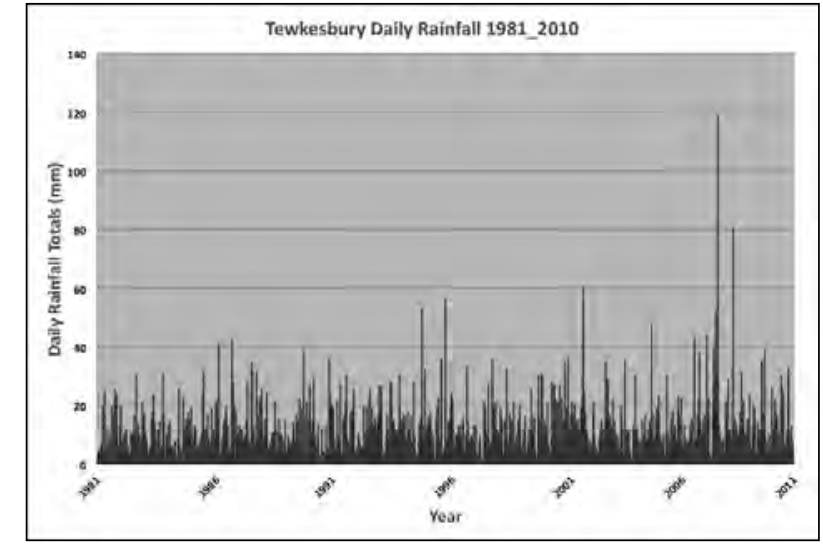

Figure 4. 30 year profile of daily rainfall relating to Tewkesbury and Odda's Chapel, Gloucestershire.

crypt, south aisle of retrochoir and the north and south transepts (Henderson and Crook 1984, 38). The stonework was stabilised by injecting concrete before progressing to the underpinning (using divers) (Henderson and Crook 1984, 51-53, 67).

\section{Laboratory Analysis}

The history and character of the study sites led into the programme of laboratory analysis at UCL within the Parnassus Project. The purpose was to investigate the effect of extreme environmental conditions on the mechanical properties and behaviour of traditional UK building materials, using the study sites as examples. The study of these materials in controlled situations allows for detailed characterisation of the relationship between exposure and response, information which, when applied to the study of heritage and archaeological sites, better informs our ability to protect and prevent decay.

The derivation of climate simulations used in the laboratory, and the sourcing of materials for testing have been carried out using information obtained from the case study sites. Climate data have been used to profile the typical rainfall conditions at the sites, which is translated into test conditions. An example of the long term rainfall data collection is shown in Fig. 4, applicable to Tewkesbury and Odda's Chapel. This shows the total daily rainfall observed during the last 30 years, which provides for calibration against average and boundary conditions. 


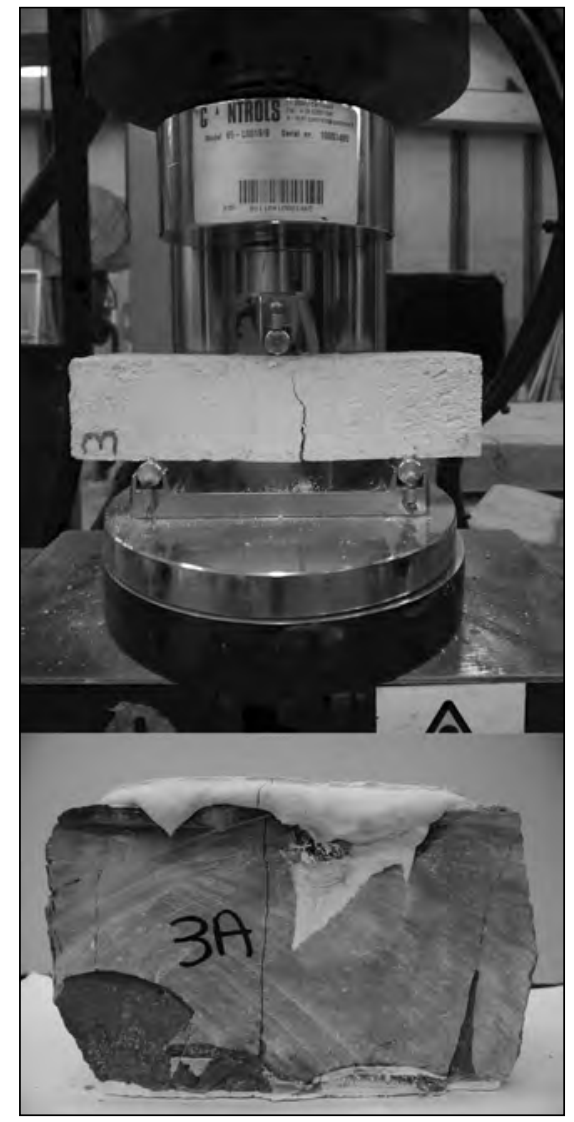

Figure 5.

Hydraulic

lime prism

sample during

flex test (top),

Reclaimed

Blue Lias Stone

Block (bottom).

Survey of the case study sites included considering the prevalence of differing materials and systems. The choice of construction type and materials in the laboratory programme reflects individual conditions at the study sites so that the results contribute most efficiently to the study of risk.

Reclaimed historical Blue Lias stone, similar to that used at Odda's Chapel, was sourced for use in constructing one of the specimen walls in the laboratory. The lime mortar used was typical of those used in conservation repair work, and representative of historical lime mortar mixes. Fig. 5 shows the two material samples. Laboratory analysis has characterised the porosity of the materials, and analysed the effect of moisture content on the mechanical characteristics of the materials. The work has looked at both materials individually, and in construction as stone masonry samples.

Fig. 6 shows the absorption profile of the reclaimed Blue Lias stone and hydraulic lime mortar used to represent walls at Odda's Chapel. This is

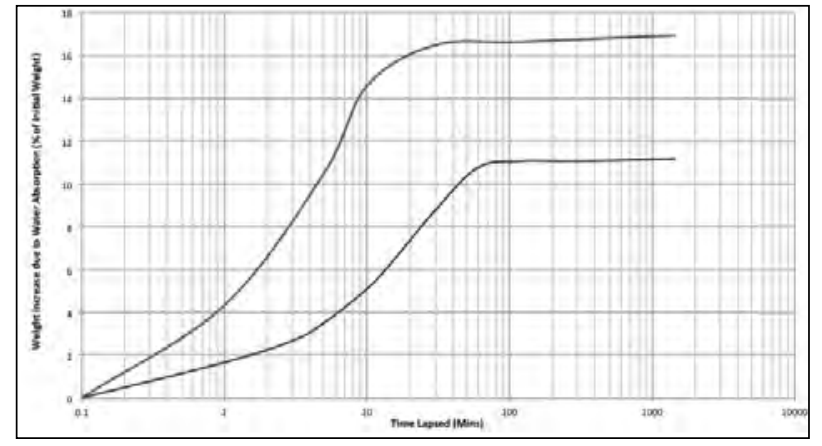

Figure 6. Absorption profiles of Blue Lias stone sample (top line) and reproduction hydraulic lime mortar sample (bottom line).

measured in accordance with BS EN 1015-18:2002, which provides an absorption coefficient for mortars for comparison purposes. The test subjects a material sample to submersion in water up to $1 \mathrm{~cm}$ in depth for a period of 24 hours. The graph is shown logarithmically with respect to time to better show the profile of absorption, as in reality the initial rate of absorption far exceeds that of the latter portion of the test.

The test showed the mortar to have a total absorption of $17 \%$. The absorption of the Blue Lias in comparison is lower, approximately $14 \%$. This would suggest that when exposed to moisture either through wind driven rain or flood, the mortar will absorb more of the moisture than the stone, which supports the large amount of repair work visible on the mortar at Odda's Chapel.

The compressive strength of the Blue Lias was found to be $5 \mathrm{MPa}$, and this remained unchanged when the material was subjected to wetting. This is not a surprising discovery, considering the high strength and stability of the stone. The mortar does however exhibit a mechanical response to the wetting, and the effect on strength of the material is profiled in Table 1. A loss of up to $30 \%$ of the compressive strength of the material is exhibited in a short time period, which is significant considering the multi-day nature of many UK flood events.

\section{Electrical Resistivity Tomography}

As UCL were studying the mechanical effects from absorption of moisture in structures, Electrical Resistivity Tomography (ERT) was put forward as a potential technique to compare laboratory 


\begin{tabular}{|c|c|c|}
\hline $\begin{array}{c}\text { Length of Time } \\
\text { Wetted }\end{array}$ & $\begin{array}{c}\text { Compressive } \\
\text { Strength (MPa) }\end{array}$ & $\begin{array}{c}\text { Percentage Loss } \\
\text { in Strength }\end{array}$ \\
\hline Not Wetted & 2.0 & $0 \%$ \\
\hline 4 hours & 1.6 & $20 \%$ \\
\hline 24 hours & 1.4 & $30 \%$ \\
\hline
\end{tabular}

Table 1. Hydraulic Lime Mortar Mechanical Properties.

results with on-site measurements ERT is used for archaeological prospection to identify changes in the flow of electricity underground that result from the presence of buried objects. In this study, it seemed appropriate to apply this technology to identify and measure the change in water content in the building materials that generate change in the flow of the electrical current.

Conductivity is controlled by certain natural or spontaneous potentials occurring in the subsurface that are caused by electrochemical or mechanical activity (Telford, Geldart and Sheriff 1996, 283). The controlling factor in all cases is water content. The porous nature of most stone and brick enables a certain degree of conductivity (and hence resistivity) as these pores can become saturated with water, and become electrolytic conductors. However water conductivity varies considerably depending upon the amount and conductivity of dissolved chlorides and other minerals (Telford, Geldart and Sheriff 1996, 286). The strength of these potentials is associated with various factors, the weathering of mineral bodies, variation in rock properties (mineral content), bioelectric activity of organic material, corrosion, thermal and pressure gradients in fluids, and other phenomena of similar nature (Telford, Geldart and Sheriff 1996, 283).

The sensitivity of electrical measurements to water content is well known however their application has been limited in the field of civil engineering (Kruschwitz 2007, 2-3). The traditional form of ERT is to use spike probes inserted into the ground at set intervals to establish galvanic contact (Tsourlos and Tsokas 2011, 174). Measurements on historic monuments must be non-destructive so surface contact electrodes were considered. Studies of different materials including copper flatbase electrodes (Cosentino and Martorana 2001) to conductive gel or bentonite electrodes (Athanasiou et al 2007, 263-72) have shown that these types of electrodes can be used successfully in place of traditional spike electrodes. In recent years several non-destructive studies have been conducted using the ERT technique to assess the moisture content of historic walls (Colla and Maierhofer 2000, 89398; Mol and Preston 2010,1079-1095; Sass 2005, 359- 74; Sass and Viles 2006, 257- 63; Tsourlos and Tsokas 2011, 173-186), and the effects of ionised/ saline water (Kruschwitz 2007) as well as driving rain demonstrating the validity of this technique. Consequently it was decided to employ nondestructive surface contract electrodes, consisting of a 10mm diameter plate with a raised "cup" which held Ten20 Conductive gel, a neuro-diagnostic electrode paste which enables a galvanic contact and aids in the adhesion of the electrodes to the wall. The size of these electrodes also allows them to be placed very close together to allow for a detailed survey.

A series of measurements were taken throughout 2012 on historic masonry at Odda's Chapel and Winchester Cathedral crypt, together with test walls in laboratory conditions at UCL to measure moisture levels through changing resistivity. The ERT survey was undertaken using a Tigre Ohmega Resistivity meter with t probes arranged vertically on the walls at an interval of $5 \mathrm{~cm}$. Measurements were taken on both interior and exterior segments of the walls. The survey parameters were set in ImagerPro 2006 and an expanding Wenner Array (Loke 1999, 11-12) was chosen for its strong signal strength and ability to reduce background noise, however the horizontal coverage is relatively poor. The data were processed using Res2Dinv.

\subsection{Winchester Cathedral Crypt ERT}

Results from the exterior and interior of the crypt (Fig. 7) show that moisture content varies significantly between the readings taken on 22/06/2012, 19/07/2012, 05/09/2012 and 18/10/2012. When the interior ERT profiles at Winchester are compared to the internal flooding data (Fig. 8) it appears that the moisture content in the walls does not correlate with it. This is explored further in the work at Odda's Chapel.

\subsection{Odda's Chapel ERT}

ERT was undertaken on two dates alongside environmental monitoring being carried out on 


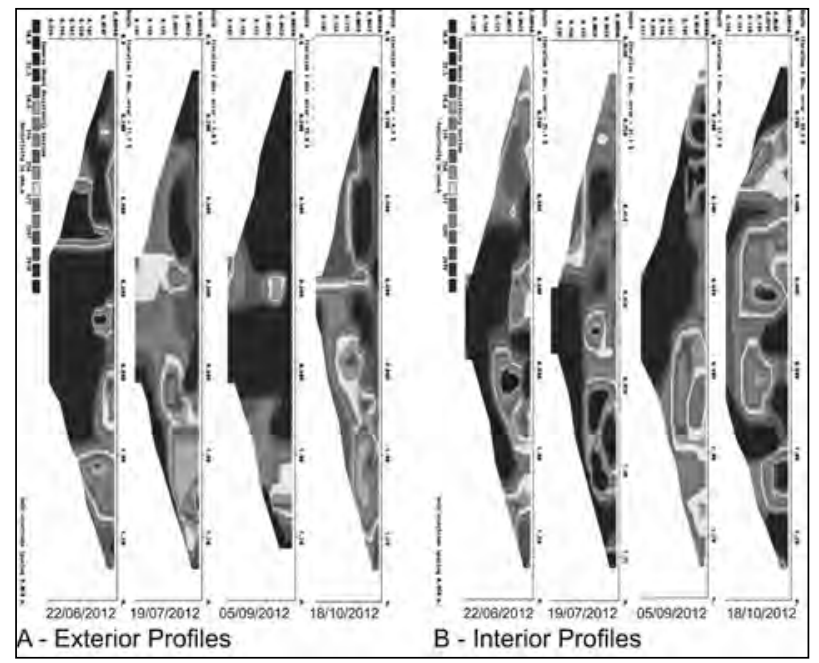

Figure 7. ERT results from Winchester Cathedral - Exterior (A), Interior (B) for dates 22/06/2012, 19/07/2012, 05/09/2012 and 18/10/2012. See the online version of the proceedings for a colour version.

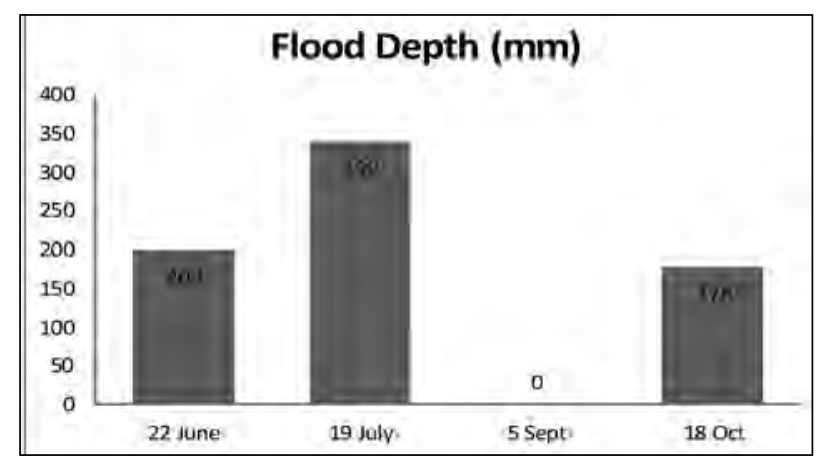

Figure 8. Height of flooding in the main body of Winchester crypt during ERT surveys.

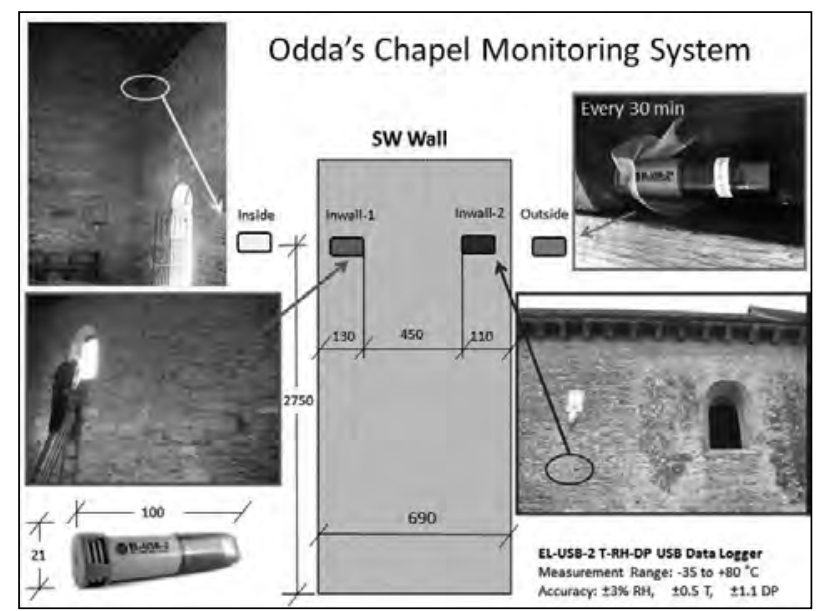

Figure 9. Location and examples of monitoring sensors and equipment at Odda's Chapel. the same wall by UCL. The combination of these two data sets gives a valuable insight into how the historical walls absorb atmospheric moisture. The monitoring included a number of sensors and recorders on and in the wall of the building (Fig. 9). There is an observablelag showing in the monitoring data (Fig. 10) between the rise in humidity outside to the corresponding rise in the humidity shown in the in-wall sensor (no. 2) closest to the exterior. This sensor also shows a clear inverse relationship where humidity lowers substantially with higher temperatures. The interior humidity sensor (no. 1) also appears to respond to the general temperature trend rather than the spikes of humidity.

The four ERT profiles demonstrate interesting comparisons with the monitoring data (Fig. 10). The first ERT data set was recorded on the 31st July 2012 (Fig. 11) and shows the surface of interior wall (a) being damp closer to the ground drying out as the height increased. Within the wall to a "depth" of $10 \mathrm{~cm}$ the wall is damp but becomes dryer and more resistant as the current goes deeper (approximately $13 \mathrm{~cm}$ into the wall). In contrast to this, the exterior profile (b) shows more uniformity with the spread of readings generally demonstrating a high resistivity and consequently a dryer wall.

The monitoring data for the week including the 31st July (Fig. 10) show the relative humidity ranges from 39 to $88 \%$ with the ground having been saturated the week before testing, with humidity between 50 and $80 \%$ during the week before. Despite rain on the day (team observations), external in-wall humidity was lower than all the other humidity readings. The temperature was also cooler but the range during the week before shows variation from $16-33^{\circ} \mathrm{C}$. The effect of solar gain raises the temperature within the wall in contrast to the external air.

The ERT profiles recorded on the 8th November (Fig. 12) show considerable contrast to those of the 31st July. The interior profile (a) is wetter than previously with a damper core, though still maintaining a dry, high resistance patch further up the wall. The exterior profile (b) shows a much dryer core but is considerably wetter from the surface to a depth of $8 \mathrm{~cm}$. Monitoring data from the week around the 8th November (Fig. 10) shows that the internal relative humidity in November had 
Across Space and Time. Papers from the 41st Conference on

Computer Applications and Quantitative Methods in Archaeology. Perth, 25-28 March 2013

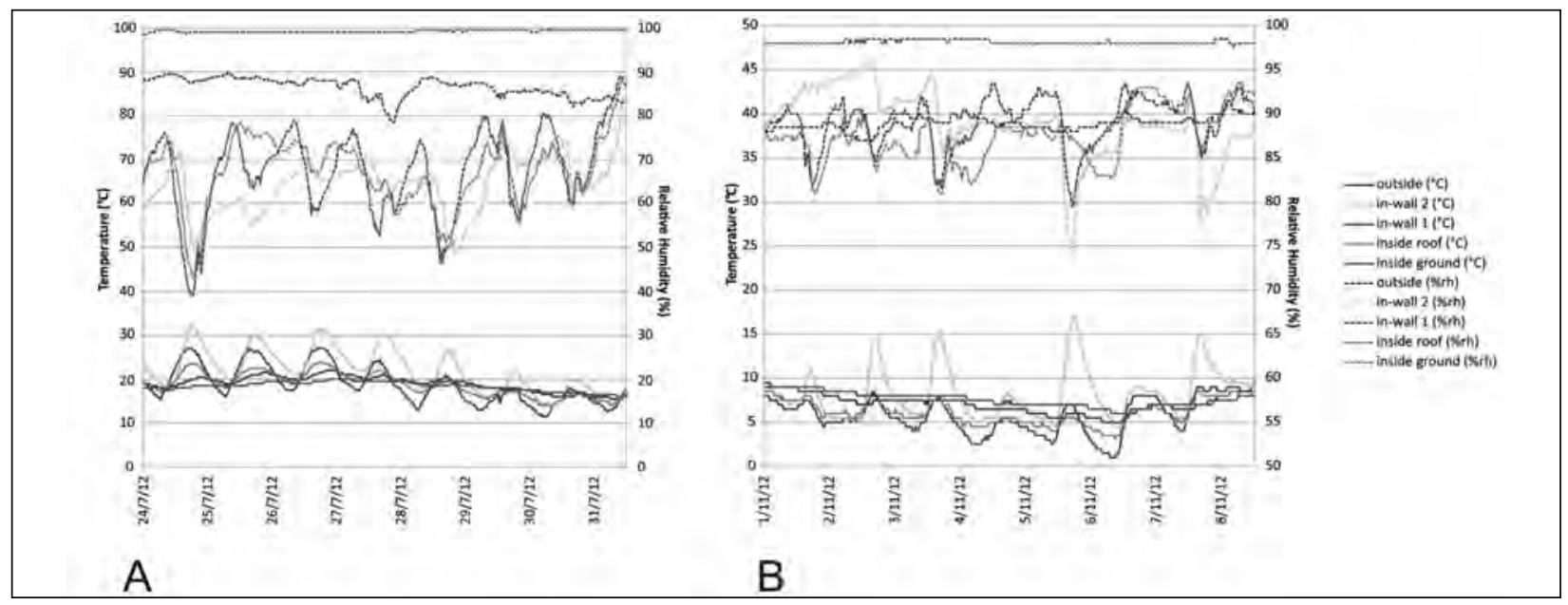

Figure 10. Environmental monitoring data at Odda's Chapel for the weeks ending 31/07/2012 and 8/11/2012. See the online version of the proceedings for a colour version.

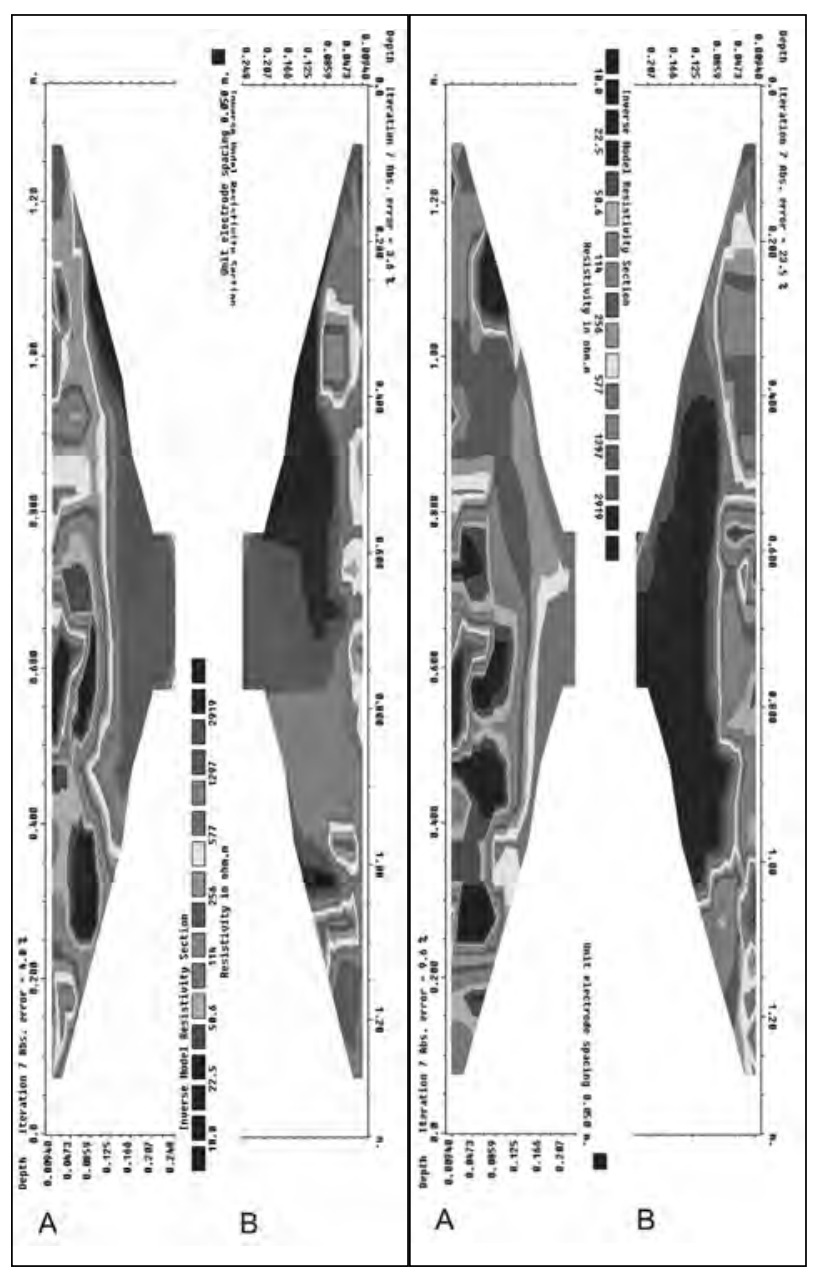

Figure 11 and 12. Left. Interior (A) and exterior (B) ERT at Odda's Chapel on 31/07/2012. Right. on 8/11/2012. See the online version of the proceedings for a colour version. a much smaller, yet higher range from 74 to $96 \%$ but the ground was less than saturated. In general however the external humidity had been c.82-93\% for most of the week before. Temperatures were only moderate during the week with a range of 1 to $17^{\circ} \mathrm{C}$, the majority of that being observed in the external wall sensors.

It is observable therefore that longer term environmental processes are more likely to affect the historic masonry than short term bursts. Although it was raining on July 31st, the results from the exterior of Odda's chapel show high resistivity close to the exterior wall surface, as opposed to the data from November where it was dry on the day but the results indicate wetter walls both internal and

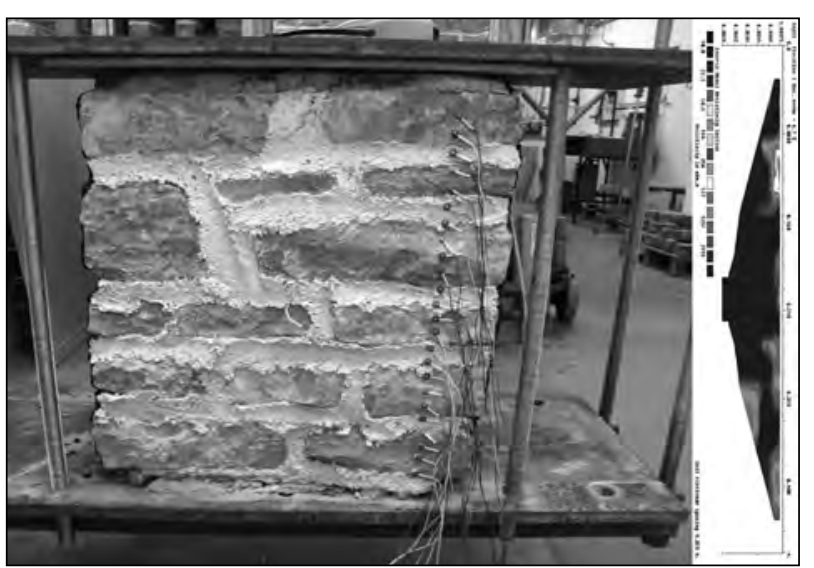

Figure 13. Test wall of Blue Lias constructed at UCL with probes attached (left), ERT result (right). 


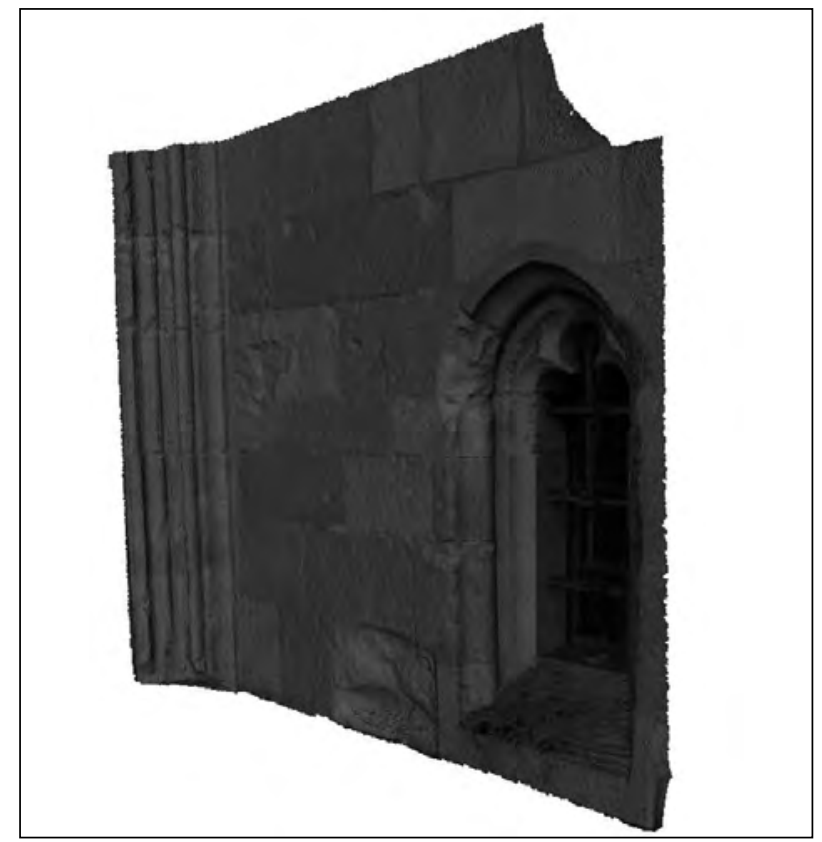

Figure 14. Photogrammetry of the exterior of Winchester Cathedral, the ERT study area.

external. Theincreased moisture in the environment over the preceding weeks in November is likely to account for this. The drying effect of wind on the exterior is noticeable, whereas the interior retains moisture constantly, despite being open.

The ERT was repeated on the small specimen wall of weathered Blue Lias constructed at UCL. The ERT results, with probes set $2.5 \mathrm{~mm}$ apart, are very different to the field tests but represent a fully dry environment with variations apparently being caused by the conductivity of the materials themselves (Fig. 13).

The work done so far has indicated that ERT can be used to monitor the water saturation of historic masonryand it is hoped that this will become a useful tool for conservation of historic buildings. Kruschwitz (2007) has shown in her doctoral thesis that salt weathering is a potent cause of rock decay and therefore the changing salinisation needs to be taken in to account. Intensively monitoring resistivity together with analysis of the physical structure, mineral and chemical content of the materials, as well as monitoring weather conditions, will allow for a fine-grained analysis into the movement of ions and saturation of the walls.

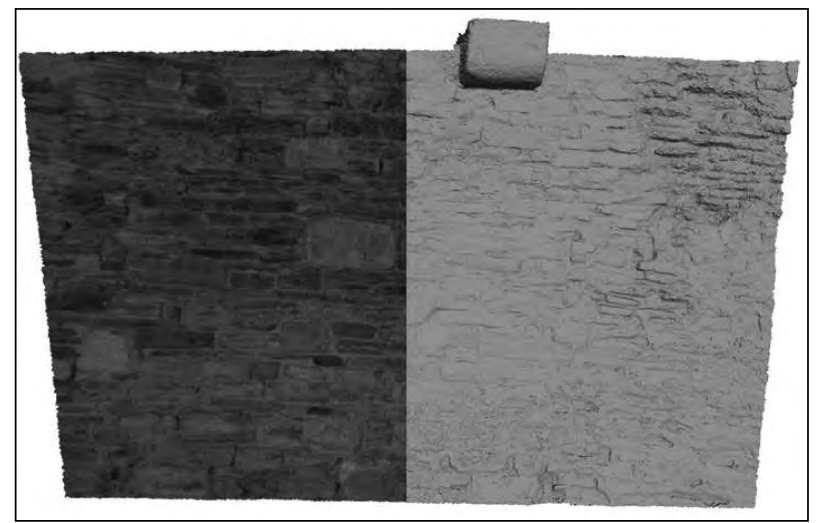

Figure 15. Photogrammetry of the exterior of Odda's Chapel showing textured and non-textured results alongside.

\section{Photogrammetry}

To complement ERT and to study the surfaces to which it was applied, the use of photogrammetry was included in the project. Increasingly within archaeology photogrammetry is being used to record buildings and produce three dimensional models. It involves a number of photographs being taken from a series of different angles, capturing overlapping features of a given subject from which a series of depth maps are produced. It is from these depth maps and overlapping features that the model is generated, first through a series of points and subsequently a meshed model. Photogrammetry was completed during investigations at Winchester Cathedral and Odda's Chapel, and on the specimen walls constructed at UCL's laboratory. The work completed by Kersten, Acevedo Pardo and Lindstaedt (2004), Pomaska (1996) and Yilmaz et al. (2007) provide an insight into the capturing of photogrammetry data within the study of buildings and their workflow system has been adopted but slightly altered within this study.

Photogrammetry was used in this study as a means of recording the high resolution surface detail of the areas where the ERT probes were placed. At both sites a series of models were completed over time of the interior and exterior areas allowing for a detailed recording of the surface features, which could then be used in conjunction with the ERT and weather monitoring systems. The use of photogrammetry was a pragmatic decision: there is no access to power for a laser scanner at Odda's chapel. However, photogrammetry has in recent 


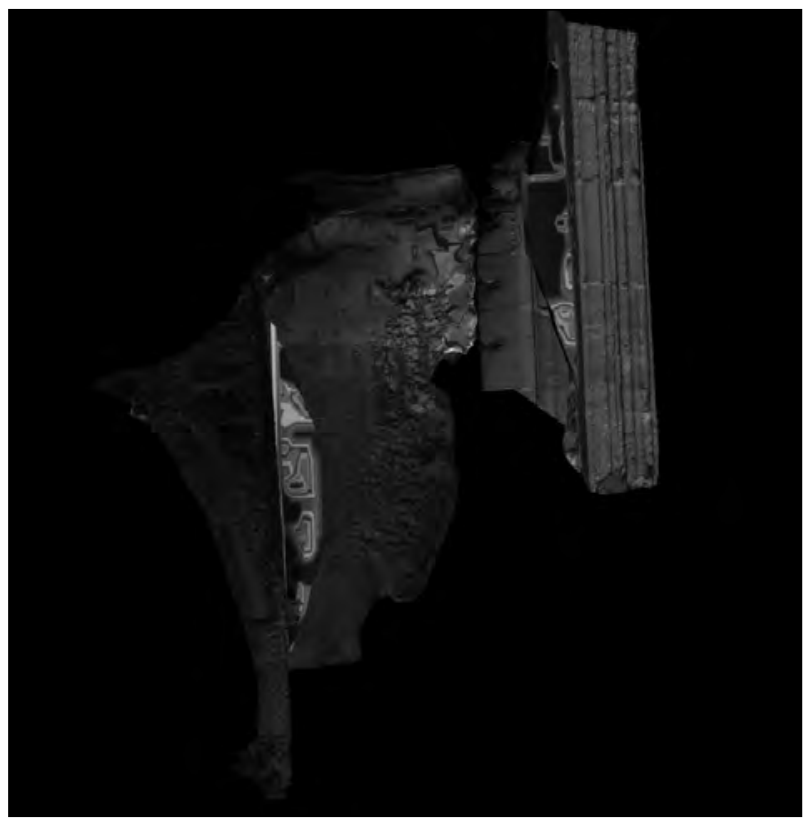

Figure 16. Photogrammetry of the Winchester Cathedral study area with representation of the ERT results located on the vertical sections of the wall to show the difference in internal and external results for a single section of wall.

years developed greatly and the resolution it now offers is comparable to that of laser scanning and in some cases it offers greater resolution.

The number of photographs taken at the sites ranged from 90 to 130 , depending on the size of the area needed to be recorded. A fixed aperture and focal range with single focus point was used in order to create a series of photographs that matched and that had very little error in colour as this would affect the end result. The images once captured were imported into Agisoft Photoscan and processed, first by drawing masks around the areas needed in each photograph, and then aligning them to create a point cloud. The point clouds were cleaned to remove any erroneous data and were then meshed with a face count of 800,000 . These models were then scaled

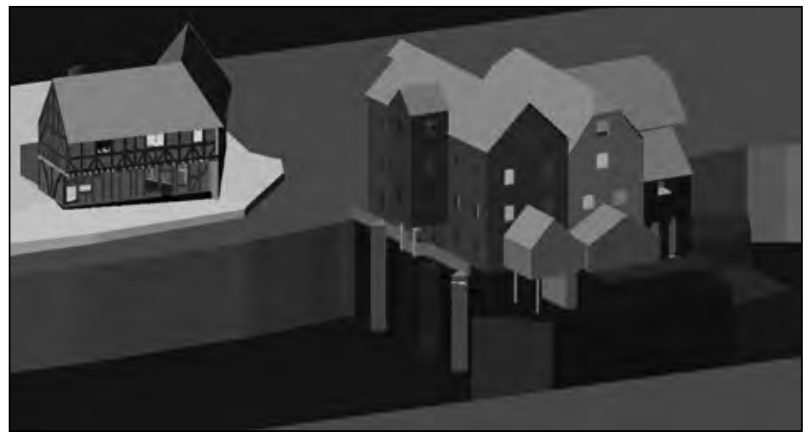

Figure 17. 3D model of the Mill Avon at Tewkesbury.

by selecting relevant known measurements with a texture added from the original photographs and were then exported into a .obj file format. Figs 14 and 15 provide an example of the final results.

As the ERT data have accurate measurements, images were created and attached to the scaled photogrammetry model in their correct position as a way to represent the moisture content within the walls, allowing for a comparison that bridges their relative thickness. Fig. 16 represents this with the placement of the ERT data at Winchester Cathedral. It highlights the wall thickness and gives an idea of the possibilities for further work on site with wider probe spacing to create an overlap of the two data sets, visualising the core of the wall. Furthermore having a complete virtual record of these walls over time would allow for the analysis of the surface deterioration

\section{Finite Element Modelling}

Drawing together all the information on materials provides structural information that can be both observed and measured. Finite Element Modelling (FEM) is used in the project to model large scale structural failure of study buildings. Mill Bank, Tewkesbury was selected as a study case. Southampton archaeology carried out a survey of the river area of Tewkesbury, the Abbey Mill and

\begin{tabular}{|c|c|c|c|}
\hline \multicolumn{2}{|c|}{ Timber (grade D40) } & \multicolumn{2}{c|}{ Brick masonry } \\
\hline Mass density (kg/m3) & 800 & Mass density (kg/m3) & 1700 \\
\hline Modulus of elasticity (MPa) & 10800 & Modulus of elasticity (MPa) & 2400 \\
\hline Poisson's ratio & 0.2 & Poisson's ratio & 0.2 \\
\hline Yield strength (MPa) & 7.5 & Cohesion (MPa) & 0.5 \\
\hline & & Angle of friction (rad) & 0.7 \\
\hline & & Tension cut-off coefficient (MPa) & 0.1 \\
\hline
\end{tabular}

Table 2. Material properties used in the finite element model. 


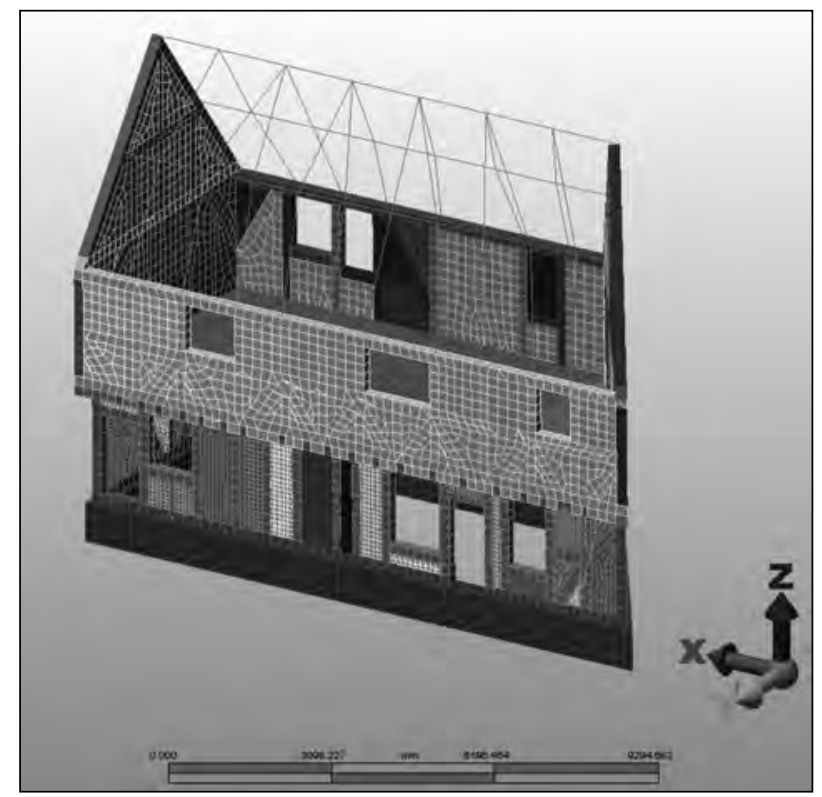

Figure 18. Finite Element model of Mill bank showing the division of the model into adjoining cells.

1 Mill Bank using a Leica TCR 805 connected to TheoLt which allows the visualisation of the data in AutoCAD during the survey. A 3D model of the study buildings and the surrounding context was created, with the water level recorded both up and down stream of the mill.

Separate models of each building were made in AutoCAD, together with an overall model of the riverbank area (Fig. 17). The CAD drawing of 1 Mill Bank was converted by UCL into a FEM model (Fig. 18) in Autodesk Simulation, which is one of the most commonly used commercially available software for the structural analysis of historical constructions (e.g. Croci et al. 2010, 779; Paganoni and D'Ayala 2010, 834; Sepe, Speranza and Viskovic 2008, 411; Tsai and D'Ayala 2011, 711). The purpose of the FEM model was to consider the strength of the structure of the building, and how it would respond to any weakness caused by flooding and worsening weather in the future. The software divides the model into cells which can act against each other and deflect according to the modelled pressures applied. In addition to the geometrical features, the nonlinearity of material properties were also attempted to be reflected as closely as possible. To this end, the timber frame skeleton was modelled by using Von Mises plasticity option with isotropic hardening, while Drucker Prager yield criterion

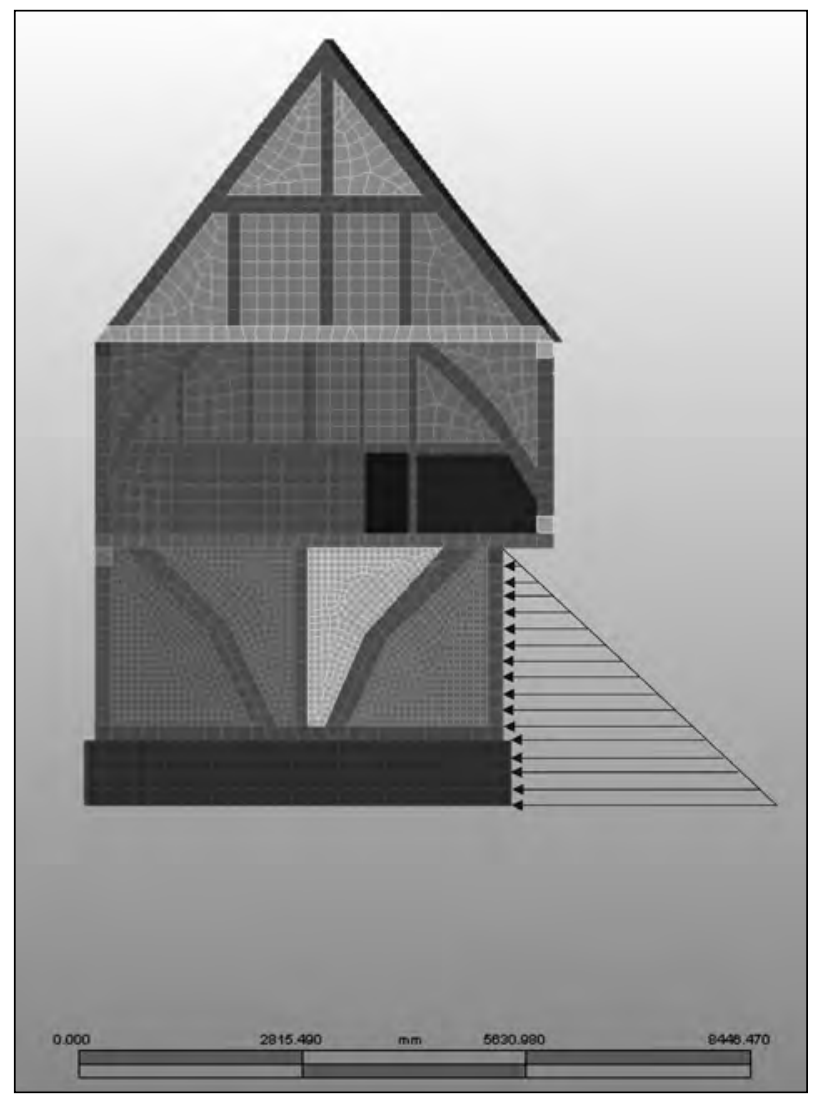

Figure 19. Illustration of hydrostatic Loading diminishing with height against the front elevation.

was used for the brick masonry infill. The input parameters used for material properties are shown in Table 2.

The compressive strength values of brick and mortar were determined by laboratory tests as 19.5 and $0.6 \mathrm{MPa}$, respectively. The tensile strength value used for the evaluation of the results was derived based as follows:

$$
f_{k}=K_{b}{ }^{0.7} f_{m}^{0.3} \text {, where }
$$

$\mathrm{f}_{\mathrm{k}}$ : compressive strength of masonry (MPa)

$\mathrm{f}_{\mathrm{b}}$ : compressive strength of brick (MPa)

$\mathrm{f}_{\mathrm{m}}$ : compressive strength of mortar (MPa)

K: constant (assumed to be 0.35 - an average of the values given by Eurocode 6) (Eurocode 6 2012, 32) 
Across Space and Time. Papers from the 41st Conference on

Computer Applications and Quantitative Methods in Archaeology. Perth, 25-28 March 2013
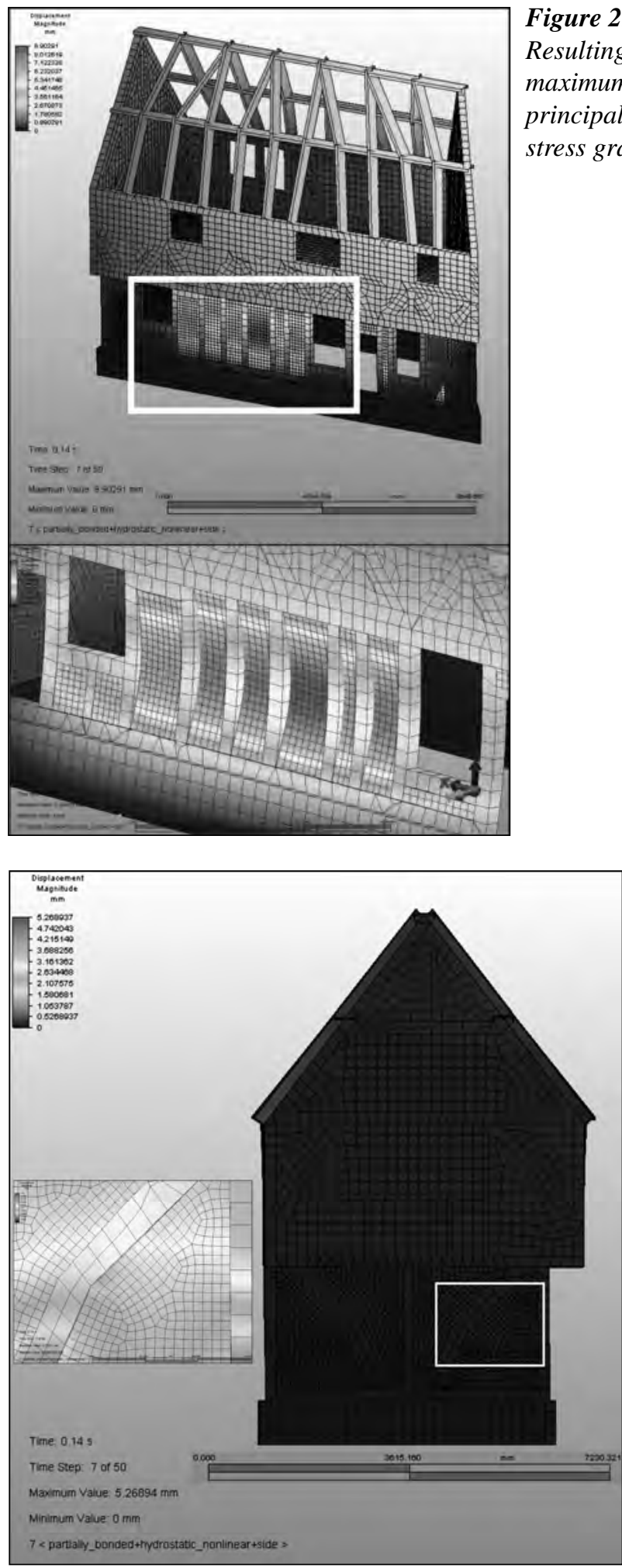

Figure 22. Gap formation between timber elements on the side facades. See the online version of the proceedings for a colour version.

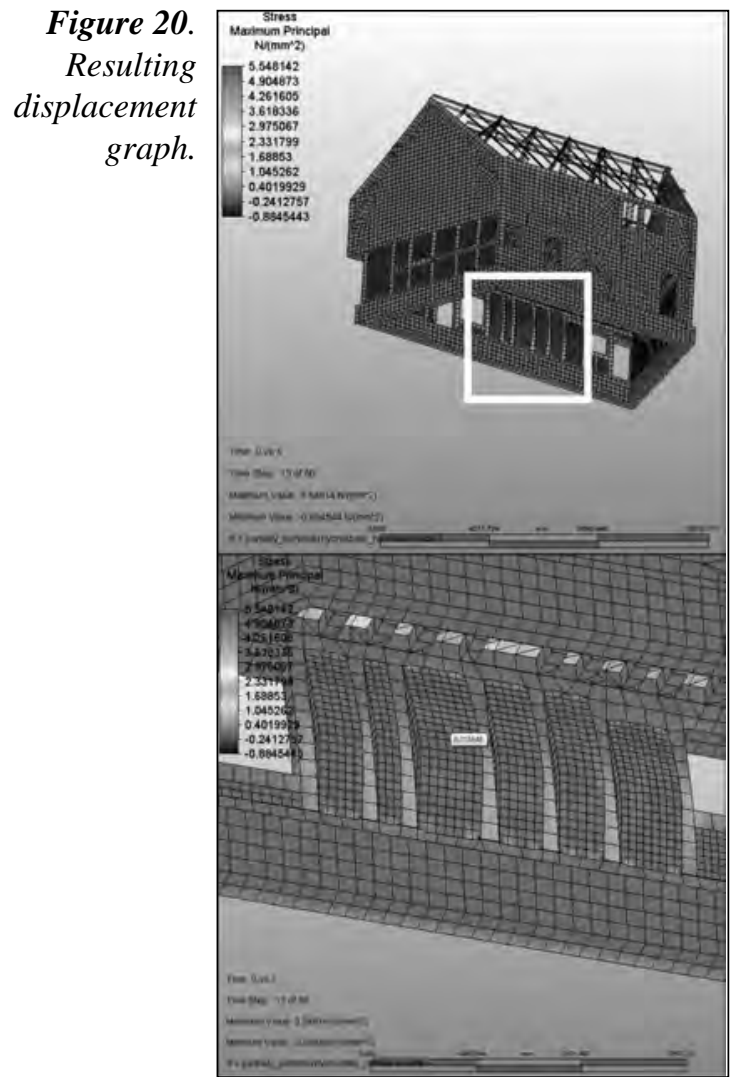

Therefore, the compressive strength of the masonry (fk) is 2.4 MPa, and the tensile strength can be assumed to be 1/ 10 of the compressive strength (i.e. Hayen, Van Balen and Van Gemert 2004, 396), which is equal to $0.24 \mathrm{MPa}$.

The preliminary analyses were carried out by using 'Mechanical Event Simulation' analysis type. In addition to first floor live load and roof load equal to $1.5 \mathrm{kN} / \mathrm{m}^{2}$ and $2.0 \mathrm{kN} / \mathrm{m}$, respectively, the model was also hydrostatically loaded to simulate flooding for the full height of the ground floor (approximately 3.3m) at the front façade (Fig. 19). In order to identify the damage mechanisms, the contact surfaces between timber frame and masonry infill were defined as partially bonded on the front and side facades of the ground floor, while the other contact surfaces were accepted to be bonded to decrease computation time.

The results show the brick infill on the frames which are loaded in the out-of-plane direction tends to bend under hydrostatic loading (Fig. 20) and 
cracks due to excessive tensile stress formations (Fig. 21). In addition to this, gap formation between timber framing and brick infill was also successfully simulated (Fig. 22). Although these gaps are very thin (in the range of $1 / 50$ of a millimetre) the cumulative effect of these openings should be further investigated.

These preliminary analyses clearly show that the separation between timber framing and masonry infill can be simulated by using such an approach, and that this can be used to understand the structural problems of heritage buildings in the future. For a more robust and reliable quantification future modelling work will include:

- More realistic contact definitions: The contact definition should reflect weak mortar bonding between timber frame and brick masonry infill, and the static and dynamic friction between these surfaces when the mortar fails.

- Effect of windows and doors: Although windows and doors are not load-bearing elements, they should still contribute to a more homogeneous distribution of hydrostatic loading at the facade.

- Actual boundary conditions: The Mill Bank building is part of a terrace, i.e. is adjacent to other structures at both sides.

- Worst case flooding scenarios: The future projections indicate the highest water height would be around 4 metres (Smith et al. 2013).

\section{Conclusions}

The Parnassus Project has achieved the goals of the Science and Heritage Project in the successful collaboration of the participants from separate disciplines. UCL and Southampton have worked together in four different areas: laboratory work specimens, ERT, Photogrammetry and FEM, each supported by the more traditional historical or archaeological background of the study buildings. Datasets were gathered by mixed teams with analysis being divided by specialisms and work is continuing with further collaboration on thin sectioning brick, mortar samples and coring work at Bodiam Castle.
The strength of the Parnassus Project has been in its interdisciplinary nature. Engineers have used archaeological knowledge and techniques in studying the preservation of the fabric of heritage buildings and to look to their long term future survival. Archaeology, in counterpart, has used engineering techniques for analysing the original construction of these heritage buildings. Together, valuable information has been acquired on the mechanisms that lead to past, present and future damage of historic buildings and archaeological sites. Beyond the collaboration lies the improved future of heritage buildings, particularly with an enhanced understanding of the behaviour of humidity both in the cores of walls, and on the more vulnerable external faces. While this paper only gives an overview of work carried out by the team, it does demonstrate the potential for further future partnerships.

\section{Acknowledgements}

We would like to thank all the residents of Mill Bank, Tewkesbury, English Heritage, and the staff at Winchester Cathedral for their help in giving us access, and their patience.

\section{Bibliography}

Athanasiou, E. N., P. I. Tsourlos, G. N. Vargemezis, C. B.Papazachos, and G. N. Tsokas. 2007. "Non-Destructive Dc Resistivity Surveying Using Flat-Base Electrodes." Near Surface Geophysics 5 (4):263- 72.

Bennett, J. 1830. A History of Tewkesbury. Tewkesbury: Bennett.

Bridge, M. 2001. Tree-Ring Analysis of Timbers from Odda's Chapel, Deerhurst, Gloucestershire. London: English Heritage.

Butterworth, G. 1887. "The Saxon Chapel at Deerhurst." Transactions of the Bristol and Gloucestershire Archaeological Society 11:105- 116.

Colla, C., and C. Maierhofer. 2000. "Investigation of Historic Masonry Via Radar Reflection and Tomography." In Proceedings of the Eighth International Conference on Ground Penetrating Radar (GPR 2000). Vol. 4084, 
Across Space and Time. Papers from the 41st Conference on

Computer Applications and Quantitative Methods in Archaeology. Perth, 25-28 March 2013

edited by D. A. Noon, G. F. Stickley, and D. Longstaff, 893- 98. San Diego: SPIE

Cosentino, P., and R. Martorana. 2001. "The Resistivity Grid Applied to Wall Structures: First Results." Paper presented at the 7th Meeting of the Environemental and Engineering Geophysical society, European Section, Brimingham, UK, September 2-6.

Croci, G., A. Viskovic, A. Herzalla, M. Erdik, M. Akdoğan, G. De Canio, and L. Antonelli. 2010. "Seismic Assessment by Numerical Analyses and Shaking Table Tests for Complex Masonry Structures: The Hagia Irene Case Study." Advanced Materials Research 133-134:777- 782.

Crook, J. 1989. "The Romanesque East Arm and Crypt of Winchester Cathedral." J ournal of the British Archaeological Association 142:1- 36.

Currie, C. R. J. 1983. “A Romanesque Roof at Odda's Chapel, Deerhurst, Gloucestershire." Antiquaries J ournal 63:58- 63.

Elrington, C. R., ed. 1968. "The Borough of Tewkesbury: Economic History." In A History of the County of Gloucester: volume 8, 137-146. Accessed June 14, 2011. http:// www.british-history.ac.uk/ report. aspx?compid $=66392$.

Eurocode 6. 2012. Design of Masonry Structures BS EN 1996-1-1:2005+A1:2012. Brussels: European Comittee for Standardization. http:// www.eurocodes.co.uk/ EurocodeDetail.aspx?Eurocode $=6$.

Hayen, R., K. Van Balen, and D. Van Gemert. 2004. "The Mechanical Behaviour of Mortars in Triaxial Compression." In Arch Bridges ARCH'04 Advances in Assessment, Structural Design and Construction, edited by P. Roca and C. Molins, 395- 404. Barcelona: CIMNE.

Heighway, C. 2003. "Tewkesbury before the Normans." In Tewkesbury Abbey: History, Art and Architecture, edited by R. K. Morris and R. Shoesmith, 1- 11. Logaston: Logaston Press.

Henderson, I. T., and J. Crook. 1984. The Winchester Diver: the saving of a Great Cathedral. Winchester: Henderson and Stirk.

Kersten, T., C. Acevedo Pardo, and M. Lindstaedt. 2004. “3D Acquisition, Modelling and Visualization of North
German Castles by Digital Architectural Photogrammetry.” The International Archives of Photogrammetry, Remote Sensing and Spatial Information Sciences 35 (B2):126132.

Kruschwitz, S.F. 2007. Assessment of the Complex Resistivity Behaviour or Salt Affected Building Materials. $\mathrm{PhD}$ diss., Technischen Universitaet Berlin.

Latimer, J. 1890. "Leland in Gloucestershire." Transactions of the Bristol and Gloucestershire Archaeological Society 14:221- 284.

Loke, M. H. 1999. "Electrical imaging surveys for environmental and engineering studies - a practical guide to 2-D and 3-D surveys." Accessed J une 2013. http:// www.georentals.co.uk/ Lokenote.pdf.

Mol, L., and P. R. Preston. 2010. 'The Writing's in the Wall: A Review of New Preliminary Applications of Electrical Resistivity Tomography within Archaeology." Archaeometry 52 (6):1079- 1095.

Paganoni, S., and S. D’Ayala. 2010. “Experimental and Computational Validation of Dissipative Prototype for the Seismic Protection of Heritage Buildings." In International Conference on Structural Analysis of Historical Constructions. Shanghai, People's Republic of China, edited by X. Gu and X. Song, 831- 836. Dürnten: Trans Tech Publications Inc.

Pomaska, G. 1996. "Implementation of Digital 3D-Models in Building Surveys Based on Multi Image Photogrammetry." International Archives of Photogrammetry and Remote Sensing 31:487- 492.

Sass, O. 2005. "Rock Moisture Measurements: Techniques, Results, and Implications for Weathering." Earth Surface Processes and Landforms 30 (3):359- 74.

Sass, O., and H. A. Viles. 2006. "How Wet Are These Walls? Testing A Novel Technique For Measuring Moisture In Ruined Walls." J ournal of Cultural Heritage $7(4): 257-63$.

Sepe, V., E. Speranza, and A. Viskovic. 2008. "A Method for Large-Scale Vulnerability Assessment of Historic Towers." Structural Control and Health Monitoring 15(3):389-415.

Smith, A., P. Bates, J. Freer, and F. Wetterhall. 2013. 
"Investigating the application of climate models in flood projection across the U.K." Hydrological Processes 28: 2810- 2823.

Tatton-Brown, T. 1993. "Building Stones of Winchester Cathedral." In Winchester Cathedral: Nine Hundred Years, edited by J . Crook, 37-46. Chichester: Phillimore and Co.

Taylor, H. M., and J. Taylor. 1965. Anglo-Saxon Architecture. Vol.1. Cambridge: C.U.P

Telford, W. M., L. P Geldart, and R. E. Sheriff. 1996. Applied Geophysics. Cambridge: Press Syndicate of the University of Cambridge.

Tsai, P-H., and D. D’Ayala. 2011. "Performance-Based Seismic Assessment Method for Taiwanese Historic DiehDou Timber Structures." Earthquake Engineering and Structural Dynamics 40:709- 729.

Tsourlos, P. I., and G. N. Tsokas. 2011. "Non-Destructive Electrical Resistivity Tomography Survey at the South Walls of the Acropolis of Athens." Archaeological Prospection 18(3):173- 186.

Verey, D., and A. Brooks. 2002. Gloucestershire 2: The Vale and the Forest of Dean. Buildings of England Series. London:Yale University Press.

Yilmaz, H., M. Yakar, S. Gulec, and O. M. Dulgerler. 2007. "Importance of Digital Close-Range Photogrammetry in Documentation of Cultural Heritage." J ournal of Cultural Heritage 8 (4):428- 433.

Zant, J. M. 1991. "Early Roman Winchester." In The Brooks, Winchester: A Preliminary Report on the Excavations, 1987-88, edited by G. D. Scobie, J. M. Zant, and R. Whinney, 9-17. Winchester: Winchester Museum Service.

Zant, J. M., and G. D. Scobie. 1991. "Early Roman Topography." In The Brooks, Winchester: A Preliminary Report on the Excavations, 1987-88, edited by G. D. Scobie, J. M. Zant, and R. Whinney, 7-8. Winchester: Winchester Museum Service. 


\title{
Photogrammetry and RTI Survey of Hoa Hakananai'a Easter Island Statue
}

\author{
J ames Miles \\ University of Southampton, UK \\ Mike Pitts \\ British Archaeology Magazine, UK \\ Hembo Pagi and Graeme Earl \\ University of Southampton, UK
}

\begin{abstract}
:
The paper will examine the use of RTI and photogrammetry of the British Museum's Hoa Hakananai'a Easter Island statue. The paper will focus on the acquisition and processing of the data and highlight their potential within the study of petroglyphs found on the statue. It will discuss the dissemination of the data and the potential of the two techniques in identifying and disproving academically accepted interpretations of the engraved markings.
\end{abstract}

\section{Keywords:}

Photogrammetry, RTI, Easter Island, Petroglyphs

\section{Introduction}

Hoa Hakananai'a, in the care of the British Museum in London since it was delivered there in 1869, is one of the best known and most admired individual Easter Island statues. Throughout the 19th and 20th centuries, apart from brief periods when it was taken into safety during the Second World War, it was on public display with its back against a wall, first partially outdoors under the front atrium of the British Museum, and later inside the museum's former ethnology galleries at the Museum of Mankind in Burlington Gardens.

With the opening of the British Museum's Great Court development in 2000, Hoa Hakananai'a returned to Bloomsbury, raised on a high display base. For the first time it was possible for the public to walk around the statue and view its entirety in good light, initially in the Great Court itself and then at its present site close by in the Wellcome Gallery.

A surprisingly large number of lectures, reports, logs and albums were made at the time by members of HMS Topaze's crew about their experiences on Easter Island and their discovery and removal of Hoa Hakananai'a. Several of these were published, such as Palmer (1870), and manuscript

Corresponding author: James.Miles@soton.ac.uk material survives around the world in various archives. The statue has been well represented in popular culture, inspiring poets and artists, featuring on a British postage stamp in 2003 and appearing in museum Director Neil MacGregor's list of the 100 objects with which he told the history of the world on BBC radio (MacGregor 2011, 449- 55). It is popular with visitors, who pose in front of it to be photographed.

Yet, until recently such public interest faced near indifference from the academic community. The first published study devoted to the statue since the 19th century of which we are aware, was conducted barely 20 years ago by Jo Anne Van Tilburg (1992). Since then she has revised and expanded this report (2006), written a guidebook (2004) and commissioned a laser scan of the carving (2007; Van Tilburg and Pakarati 2012).

Van Tilburg's work provides a useful record of the statue's historical associations and its journey from Rapa Nui to England. She is less concerned with Hoa Hakananai'a's archaeology; at the time of writing, her laser study remains unavailable (see below). Most recently, Horley and Lee (2008) and Davletshin (2012) have published interesting analyses of the statue's petroglyphs based on study of the carvings and photographs. We felt 
that examination using modern digital technology would reveal new insights into Hoa Hakananai'a. Importantly, it would also allow the creation of imagery that would expand opportunities for others around the world to study and appreciate the statue's details.

\section{History of the Statue}

Hoa Hakananai'a's overall form is considered typical when compared to other Easter Island statues (Flenley and Bahn 2003, 178; Van Tilburg 2004, 45- 7). Its features - heavy brow, blocky face, prominent nipples, arms down the sides with hands reaching towards the stomach, long stylised ears and a 'girdle' across the lower back - all fall within the range of details seen across Easter Island.

Considered among the thousand statues recorded on the island, however, Hoa Hakananai'a is otherwise unusual. In 1868 it was found not at the common locations, standing at and around the main statue quarry at Rano Raraku, or fallen from coastal platforms where they once stood in groups, but on its own, high above a sea cliff, half-buried inside a stone-roofed houseand - unlike any other recorded, identifiable large statue beyond the Rano Raraku quarries standing upright without restoration (Van Tilburg 2006).

The statue itself is also distinctive. It is one of only fifteen or so known to have been carved from grey flow lava; most are of softer, yellow-brown Rano Raraku tuff. For a fully formed, traditional large statue, at around $2.5 \mathrm{~m}$ high it is relatively small. While no full analysis of the island's statues has been published, observers agree that typical examples found away from the quarries (where some specimens are significantly larger still) are around 3.5- $6 \mathrm{~m}$ high (Flenley and Bahn 2003, 104- 6; Van Tilburg 1994, 22-23).

Of particular interest are the petroglyphs on Hoa Hakananai'a's back, unmatched on any other statue. There is general agreement that these were added at a later date to a finished figure (Van Tilburg 2006). They clearly relate to an extraordinary complex of petroglyphs carved on the native rock at the location where the statue stood before its removal, around a group of stone houses' known as 'Orongo village' (Lee 1992; Horley and Lee 2009).
Notably featuring symbols of female genitalia and bird designs with human attributes, these have been linked, like the stone houses, to the island's unique, historically recorded 'birdman cult', traditionally assumed to have succeeded a cult linked to the statues (Horley and Lee 2009; Lee 1992). There has been no scientific excavation at the house that enclosed the statue, the best description being that of Katherine Routledge (1920, 435-438).

While highly visible, the carvings on Hoa Hakananai'a are not easy to study in its gallery setting. Current lighting, as is to be expected, is fixed, and determined by a desire to convey atmosphere as much as clarity. Wear and damage appear to have eroded parts, though it is sometimes difficult to distinguish damage from original carving, perhaps accounting for some of the recent disagreements about how the petroglyphs should be read as seen in the papers completed by Davletshin (2012) and Van Tilburg and Pakarati (2012). Most observers have seen two large birdmen on the back (Van Tilburg 1992), but Horley and Lee (2008, 112-14) suggest a complex reading, with at least two phases, including as many as four possible birdmen. Near the top of the head, above the birdmen, Horley and Lee (2008) have no doubts that female genitalia are represented, while Van Tilburg $(2006,38)$ sees a range of possible interpretations. Some areas of the carvings seemed to defy analysis completely. Such issues, impossible to resolve with evidence available when we began this study, hindered interpretation of the meanings of the carvings and Hoa Hakananai'a.

\section{Methods Used}

The statue as it stands is currently in one of the busiest atria of the British museum and access to it is restricted by the sheer number of tourists that visit. It was necessary then to gain access to the museum after it had closed to enable us to investigate and record the statue in detail. With access being limited and the problems associated with viewing lower resolution photographs, it was agreed that a virtual model, at a high resolution, needed to be created in order to analyse the statue and create a record that could be viewed in detail away from the museum. Many discussions took place as to how this would be completed with laser scanning, photogrammetry, structured light and Reflectance Transformation Imaging all being suggested. Each of these methods 


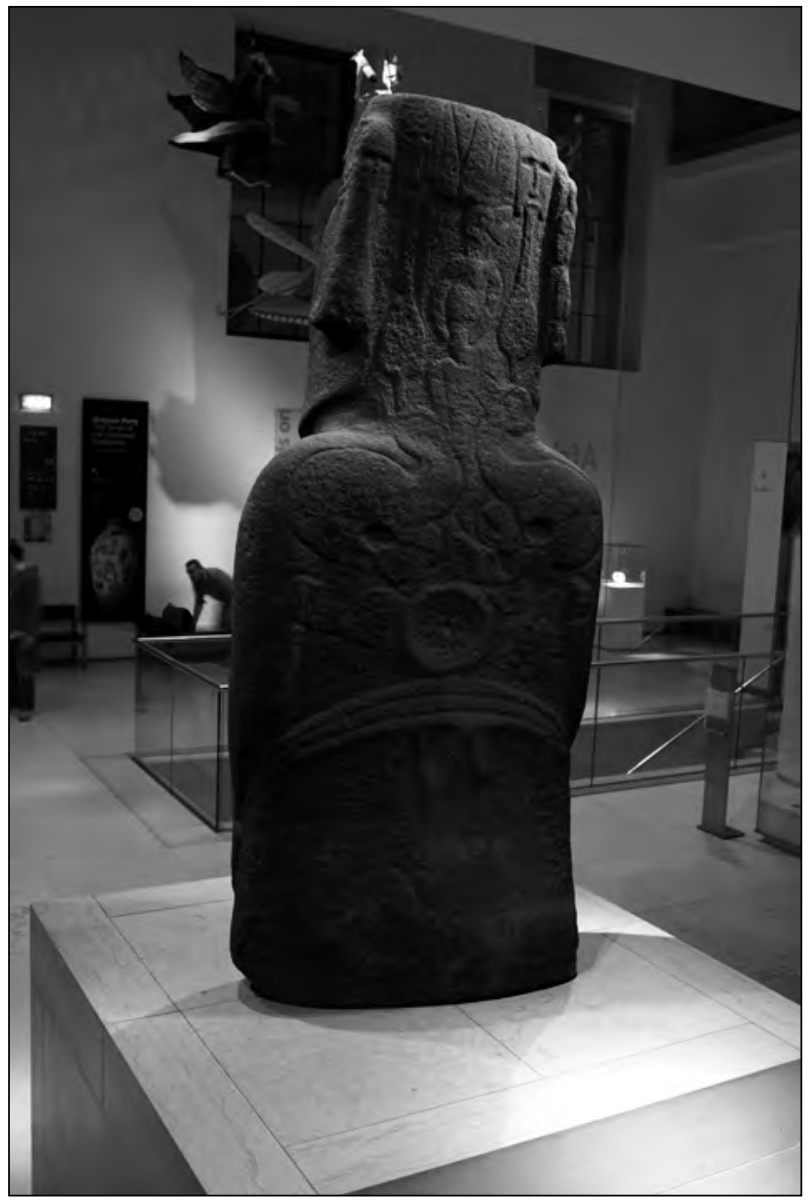

Figure 1. Hoa Hakananai'a in its current position in the Wellcome Gallery (Photo: Hembo Pagi).

allows for the statue to be recorded in a specific way with all having limitations and benefits within the capturing and resolution of the final model. Importantly, Van Tilburg (2007) recorded the statue using a Z+F UK laser scanner in 2007. The work is not currently publicly available and in order not to replicate existing data capture, albeit with a higher resolution than the $\mathrm{Z}+\mathrm{F}$ UK offers, it was decided that it would be inappropriate to use a laser scanner for this current study.

In addition to Van Tilburg's prior use laser scanning was also considered impractical given the time and access constraints. This impractically is in part due to the area surrounding the statue, as it limits the space available with which a laser scanner can be used. The statue (Fig. 1) currently sits on a platform which is about a meter in height and thus a scaffolding unit would be needed to accurately record the statue fully. This in itself provides a logistical problem in terms of capturing due to the positioning that the scanner would have to take. It could have been placed on a scaffolding unit and moved around, but generally scaffolding units, through their stability, would be hard to move and would in many cases cause gaps in the data due to the field of view. This impractically is also related to the positioning of the necessary targets with which the scan data would be stitched by. The targets would have to be placed in a position away from the statue, as the surface was not to be touched, thus creating larger scan areas which would in turn increase the file and point size of the model. This too would increase the time taken to record the statue, as the scanner would have to be set up to record the same resolution throughout a 360 degree view, rather than the specific angle with which the statue would be in in relation to the scan position. This field of view is also important in terms of the differing heights at which the scanner would have to be placed, as most scanners offer a limited vertical angle from which they can scan.

Structured light scanning was also considered. Papers by Stumpfel et al. (2003) and Akca et al. (2006) suggest that this method could be employed on objects of similar size to Hoa Hakananai'ain order to produce a high resolution model comparable to laser scanning. However, this method suffers from the same problems in terms of positioning and movement around the statue. Structured light works by the recording of a patterned sequence over the object and depending on the system used, offers a resolution of microns. To get this level of detail the statue would have to be recorded several times at very small increments, in the same way that a triangulation laser scanner works, through the stitching of multiple scans through overlapping features. Again the time available on site made this impossible. This left two options, photogrammetry and Reflectance Transformation Imaging. It was decided that these two methods would be used in conjunction with one another to record the statue.

Photogrammetry is the process by which a series of photographs are taken from differing positions which are then used to create a virtual model. The process works by creating a series of photographs that overlap themselves, these overlapping features are then matched, stitching the 
photographs together; depth mapsarethen produced from these photographs which are then transformed into a point cloud which is then processed to createa meshed model which is explained in detail in White's (2013) work. The necessary number of photographic captures and range of locations is dependent on the object. Crucially, there is a need to capture enough overlapping features, from a suitable angle, to enable the software to produce a sufficiently high resolution model.

Photogrammetric capture, even for complex objects, is a quick process. It also makes use of portable equipment and as such allowed capturing of areas via a scaffolding tower that would have been difficult to produce by other means. The photographs were taken from one angle and the scaffolding could then be moved to another position within the space of a few minutes, rather than the time associated with other methods, creating a complete capture in less than five hours. The use of photogrammetry in this case was also supported by the work by Heinz (2002), Ioannidis and Tsakiri (2003) and J azayeri et al. (2010), who deal with artefacts of comparable size and detail.

The second method used was Reflectance Transformation Imaging (RTI), a simple technique that offers the analysis of subtle changes of surface morphology. The technology behind it has been discussed at length in a number of papers such as Malzbender etal. (2001) and Mudgeetal. (2006), but essentially the technique works under the principle that any sampled pixel on a surface illuminated at varying angles has different luminance values. By capturing a series of photographs from a fixed position with changing incident light direction RTI algorithms such as Polynomial Texture Maps (PTM) are able to represent the view from an arbitrary position. The technique has the ability to be used on any sized object from a microscopic level (Earl et al. 2011) to objects that are larger in size (Dellepiane et al. 2006). The short RTI capture time, similar equipment and capture requirements, and the subtle nature of many of the surface details made this method appropriate for the study of Hoa Hakananai'a. The combination of photogrammetry and Reflectance Transformation Imaging was seen to provide a sufficient breadth of data to address the study's key questions.

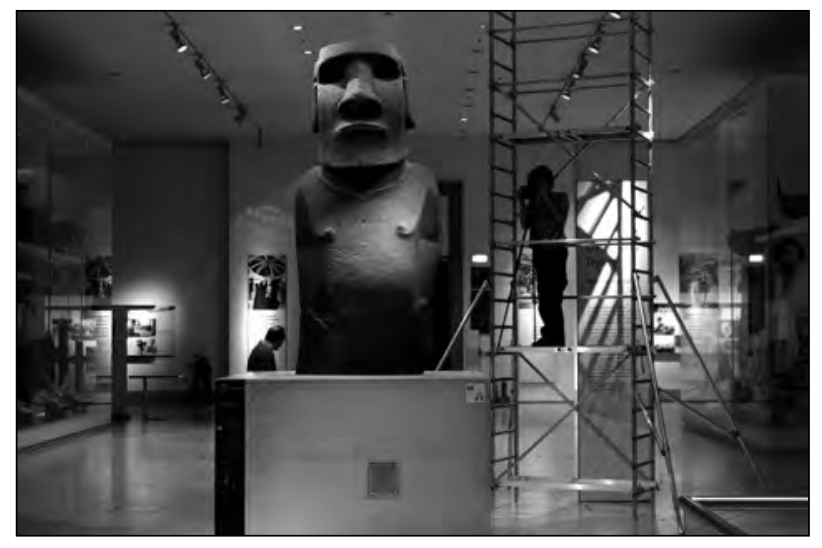

Figure 2. Photogrammetry capture using scaffolding (Photo: Mike Pitts).

\section{Capturing and Processing}

Having discussed the reasoning why photogrammetry and Reflectance Transformation Imaging were used within this investigation, the following section describes the workflow associated with each method.

\subsection{Photogrammetry}

The photogrammetry survey was completed using a Nikon D3X (Nikon 2013a) and a Nikon D7000 (Nikon 2013b). A series of photographs was taken by both sets of cameras creating enough data that could then be used to produce a virtual model. In total over five hundred photographs were taken throughout the recording of the statue. The large sample was in part a consequence of the limited time available with sufficient access, and designed to minimise the chance of significant gaps in the coverage. The D7000 was used at ground level to capture enough overall photographs of the statue and was further employed to capture close up detail of the petroglyphs, again from the ground. The D3X was used in conjunction with the scaffolding unit provided by the British Museum and a series of photographs were taken at three specific height levels to create a number of different views (Fig. 2). After each series of photographs were taken, the scaffolding unit was then moved and the process was repeated. Each camera was set at the same focal length and aperture and a single focus point was used on the cameras to create an even spread of similar focused images. 


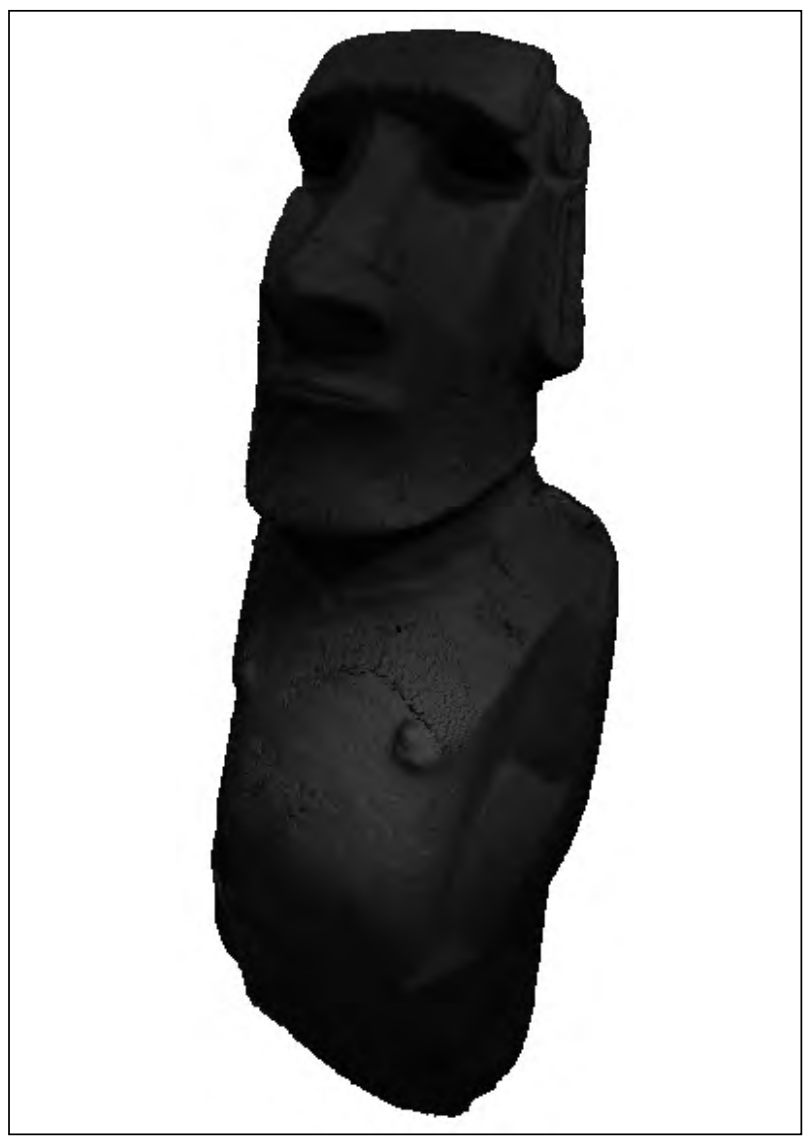

Figure 3. Photogrammetry model highlighting poor mesh results (Photo: James Miles).

With over five hundred images recorded the next stage within the production of the model was to select relevant images that would then be used. In the initial test processing, the majority of theimages were used, using up four hundred and fifty hours of processing time. The resulting model produced was poor with a number of errors in the mesh (Fig. 3), largely as a consequence of the varying surface illumination as fixed spotlights were used by the museum to illuminate the statue, introducing significant shadowing of some areas and highlights in others. In the second stage a subset of the capture datasets was defined that contained one hundred and fifty images with little or no self-shadowing and with manually defined masks (Fig. 4). This masking capability offered by Agisoft PhotoScan (2013) enables the software to specifically focus on certain sections of the photographs used, reducing the time spent on computing the point and mesh data and on generating erroneous points. The masked photographs were then processed and

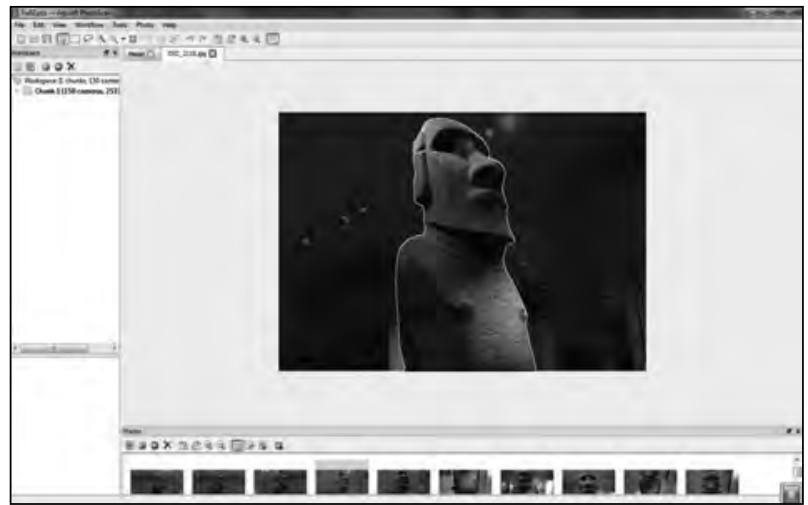

Figure 4. Photogrammetry masking within AgiSoft Photoscan (Photo: James Miles).

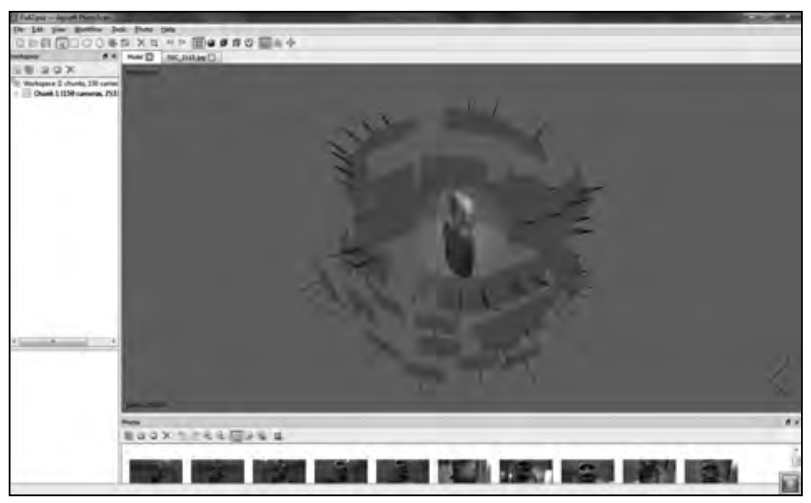

Figure 5. Photogrammetry camera position and points within AgiSoft Photoscan (Photo: James Miles).

aligned at a high accuracy setting in order to create the necessary point cloud, which can be seen in Fig. 5. The processed point cloud within the software can also be used to identify the varying camera positions, which in turn highlights the possible need to use more images if a certain angle was not covered enough through the initial alignment of photographs.

Once the point cloud was successfully produced it was then tidied to remove any remaining outliers. The model was then meshed, again using a high accuracy setting, to produce the specified six hundred thousand faces. Following further cleaning the model was then textured using the images used within the processing.

The time taken to produce this model was less than two days and was produced using two different resolution images (24.4mpx and $16.2 \mathrm{mpx}$ ) through the combination of the two different cameras needed 


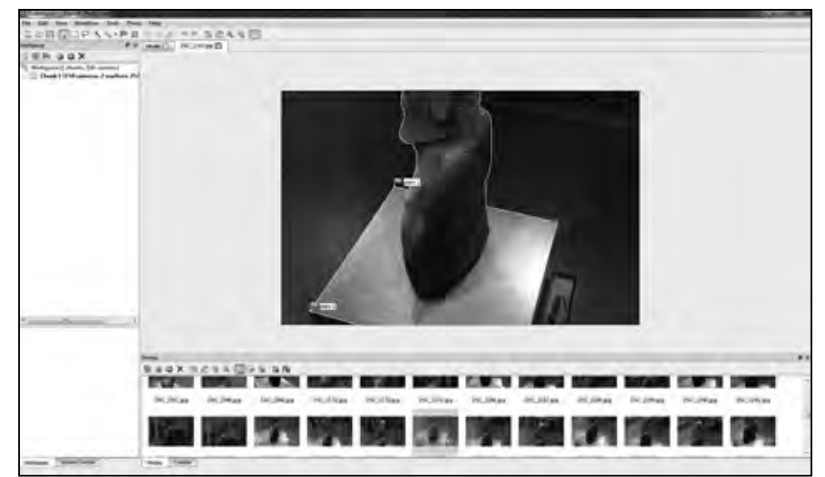

Figure 6. Photogrammetry scaling tool within AgiSoft Photoscan (Photo: James Miles).

within the capturing due to the time constrains discussed previously. It was initially thought that the combination of two different resolution images would affect the end model through the variation of pixel resolution in the overlapping images and create errors in the data, as the software relies on the features at a pixel level being similar and with multiple resolution images this may not have been the case. Nonetheless it has been proved that this, through the correct selection of images, can be result in a model that is accurate and desirable. The model was then scaled using measurements taken from the statue's platform, by selecting relevant points in the images (Fig. 6) and defining the length between them (Fig. 7). With the model being scaled and textured correctly it was then exported as a .obj file which could then be used in MeshLab (2013) for analysis.

\subsection{Reflectance Transformation Imaging (RTI)}

The capturing of the Reflectance Transformation Imaging data was completed using the Nikon D3x (2013a) used within the photogrammetry survey. One capture was produced on the front of the stomach area and four on the back of Hoa Hakananai'a. The front RTI was stimulated by Davletshin's (2012) research which proposed a birdman on the front, nowinvisible to thenaked eye. The complex back surface of Hoa Hakananai'a has been interpreted in a number of different ways. In order to provide sufficiently detailed light direction and pixels coverage the back was split into four overlapping regions. The capturing was completed by using the scaffolding unit provided, allowing for precise positioning of the camera in line with areas of interest. Images were taken via a wireless trigger

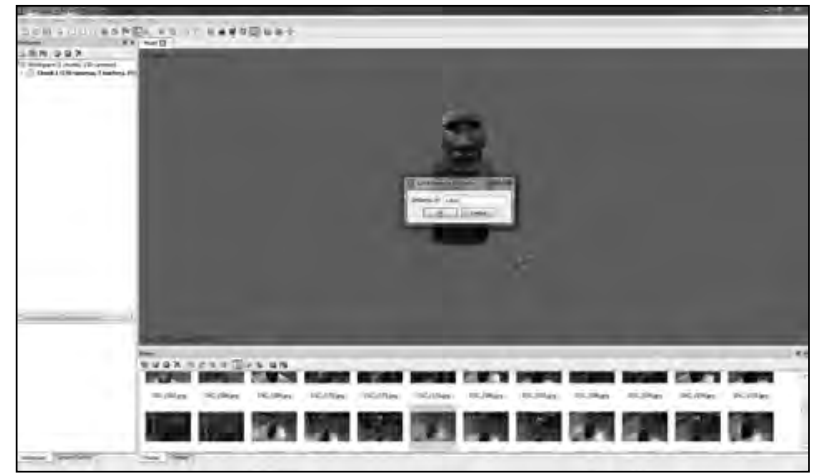

Figure 7. Defining measurement between two selected points to scale the photogrammetry model in AgiSoft Photoscan (Photo: James Miles).

that connected the camera and the light source, in this case a Nikon SB- 910 speedlight (Nikon 2013c) as seen in Fig. 8. Using a wireless trigger minimised the risk of camera movement. Each dataset varied in the number of photographs taken but in general ranged from 57 to 87 images. These were then processed using the RTI builder open source software (2013). This uses the highlight visible on a spherical black shiny ball included in each image to

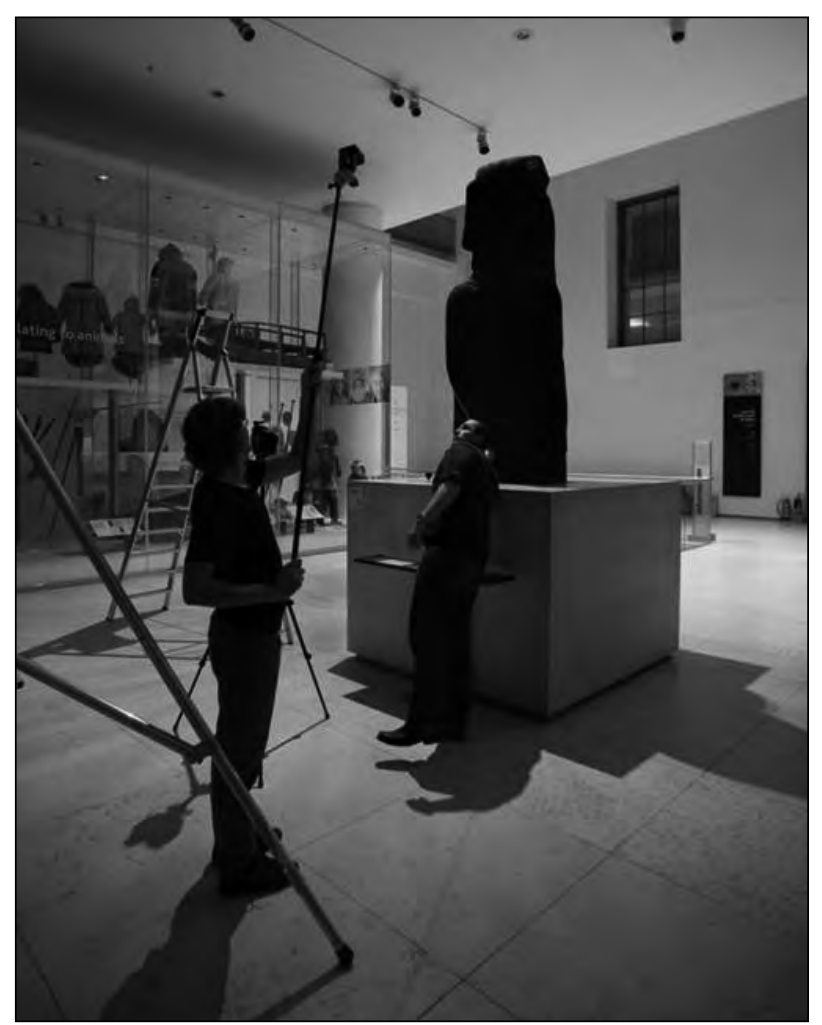

Figure 8. RTI capture of the Hoa Hakananai'a statue (Photo: Mike Pitts). 


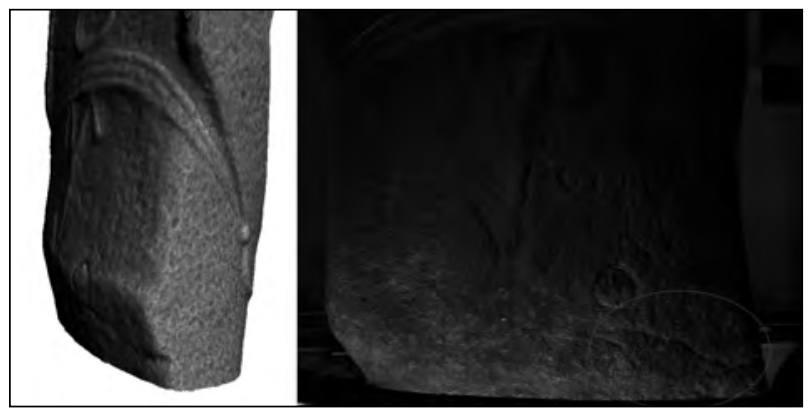

Figure 9. Photogrammetry model on the left and RTI dataset on the right highlighting the tapering base of the statue (Photo: James Miles).

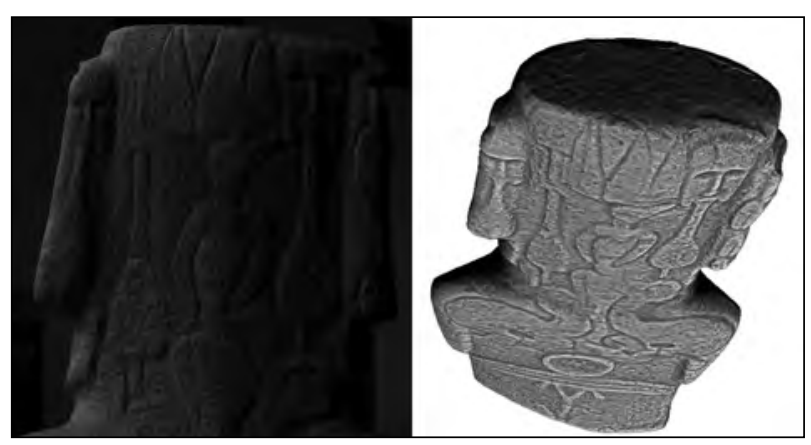

Figure 10. Photogrammetry model on the left and RTI dataset on the right highlighting the two komari on the top of the statue's head (Photo: James Miles).

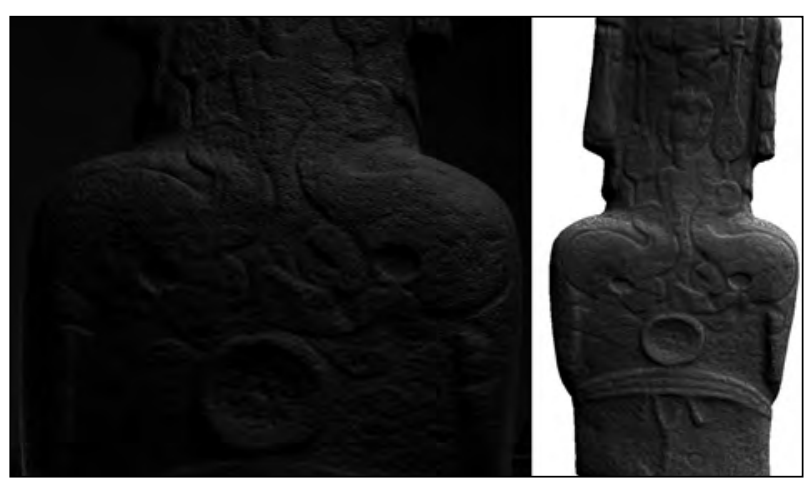

Figure 11. Photogrammetry model on the left and RTI dataset on the right highlighting the rounded beak of the right birdman (Photo: James Miles).

define incident light direction. This in turn is used to process the images via PTM, with the outputs then displayed in the RTI viewer.

\section{Results}

Through the combination of photogrammetry and RTI, we were able to throw new light on a

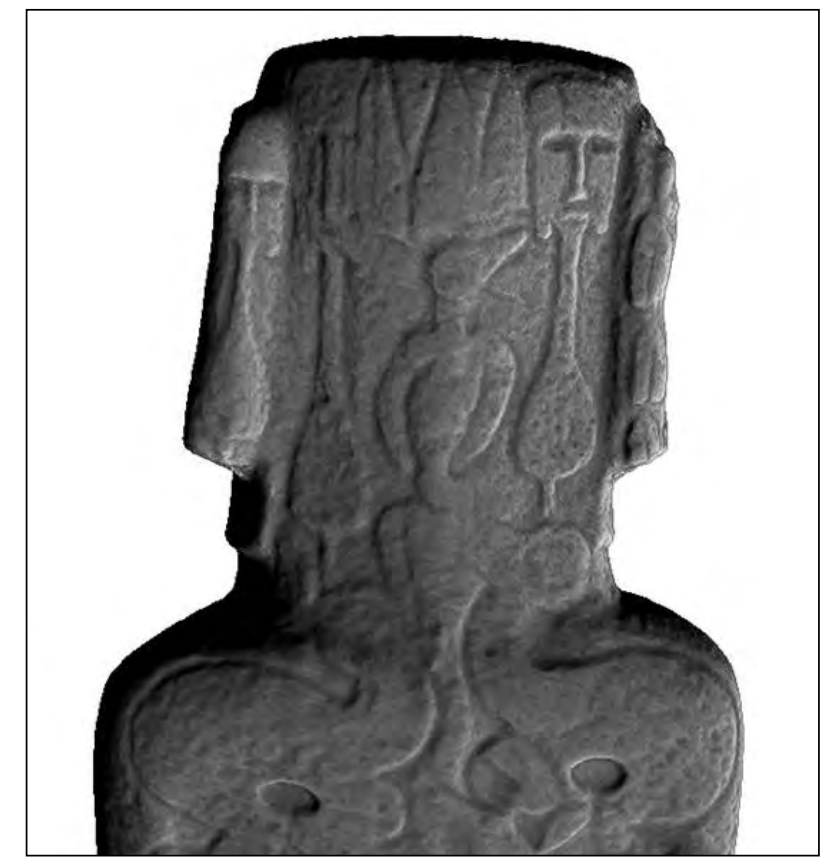

Figure 12. Photogrammetry model of the hatchling above the two birdmen (Photo: James Miles).

number of features. Our research continues, and will be described in detail in appropriate archaeological journals. Significant insights include the likelihood that the statue was not made to stand on a platform before being moved to the site where it was found in 1868, as has often been suggested. Instead it appears to have an original tapering base (Fig. 9).

A further insight from our work is that the carvings on the back at the top of the head resolve clearly into two komari, the schematic island designs for female genitalia, carved before the other petroglyphs (Fig. 10). The later engravings all appear to be contemporary. We propose that they constitute a single composition that narrates the island's unique birdman ceremony as recorded in the 19th and early 20th centuries, an interpretation unexpectedly supported by an overlooked photograph of the statue taken in Chile in 1868 (Pitts in press). Our new imagery shows a rounded beak on the right birdman, in contrast to all previous modern depictions as pointed (Fig. 11). This can be read as a sign of female gender (Horley and Lee 2012, 9), with the corollary that the other birdman is male; the male figure on the left and the female on the right are matched on either side by traditional male and female island symbols. The small bird between and above the two large figures 


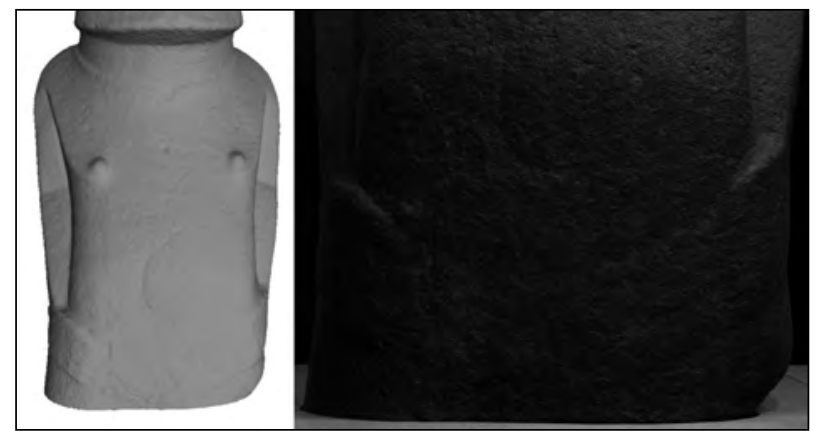

Figure 13. Photogrammetry model on the left and RTI dataset on the right highlighting the front of the statue showing damage and evidence of fingers (Photo: James Miles).

can then be interpreted as a hatchling (Pitts et al. in press) (Fig. 12).

On thefront of the statue, wefound no evidence to support the recent interpretation of elusive grooves as an overlooked birdman (Davletshin 2012). Instead the imaging results suggest that they are recent damage (Fig. 13). Also on the front we can see faint indications of fingers around the navel, which may have formerly been more prominent, but were later removed (Fig. 13). Hard to see by visual inspection in the museum, the statue's buttocks emerge prominently within the data (Fig. 14).

Another key part of this investigation was the combination of these two methods and how the datasets could be used in conjunction with one another. The results gained provided a fuller understanding of the statue and the meaning behind the petroglyphs, but it was decided that more could be done within the analysis of the statue. Photogrammetry produces a virtual model from which a texture is added based on the images taken and RTI produces a dataset where images can be saved based on the identification of surface detail. As the texture for the virtual model is an image it was logical to add the RTI datasets to the model directly to strengthen our analysis, in order to create a direct comparison within the model to detect surfaces details that were at first ambiguous. This was completed through the use of 3DReshaper (2013), as it allowed the RTI images to be digitally placed onto the photogrammetry model (Fig. 15). This provided an amalgamation of the raw data that could be altered depending on the area required for closer examination. Multiple images of different

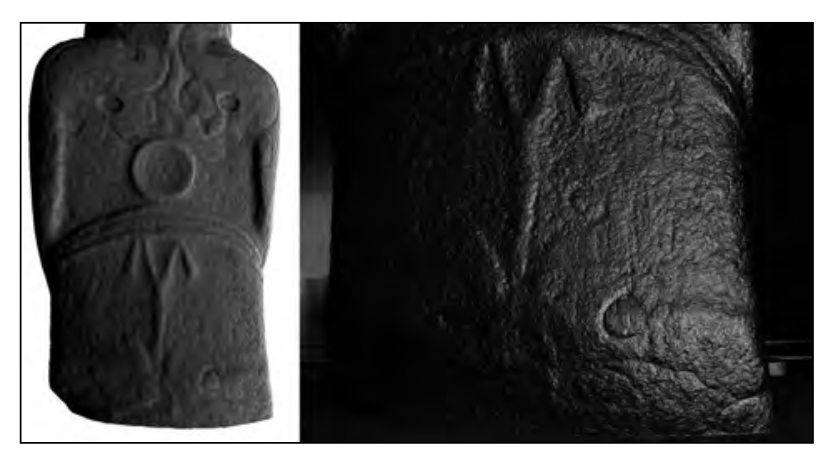

Figure 14. Photogrammetry model on the left and RTI dataset on the right highlighting the statue's buttocks (Photo: James Miles).

angled light positions were used within this process to allow for multiple textures, thus creating a system for analysis without having to compare the datasets separately. Further to this, the combination of this data allows the public, who may not understand the necessary software, to view the data as a complete representation rather than as separate parts. Additionally it allows future researchers, who may not have access to the statue, to have available better images from which they can base their own understanding. Likewise colour was added to the statue (Fig. 16) to depict the areas that were found

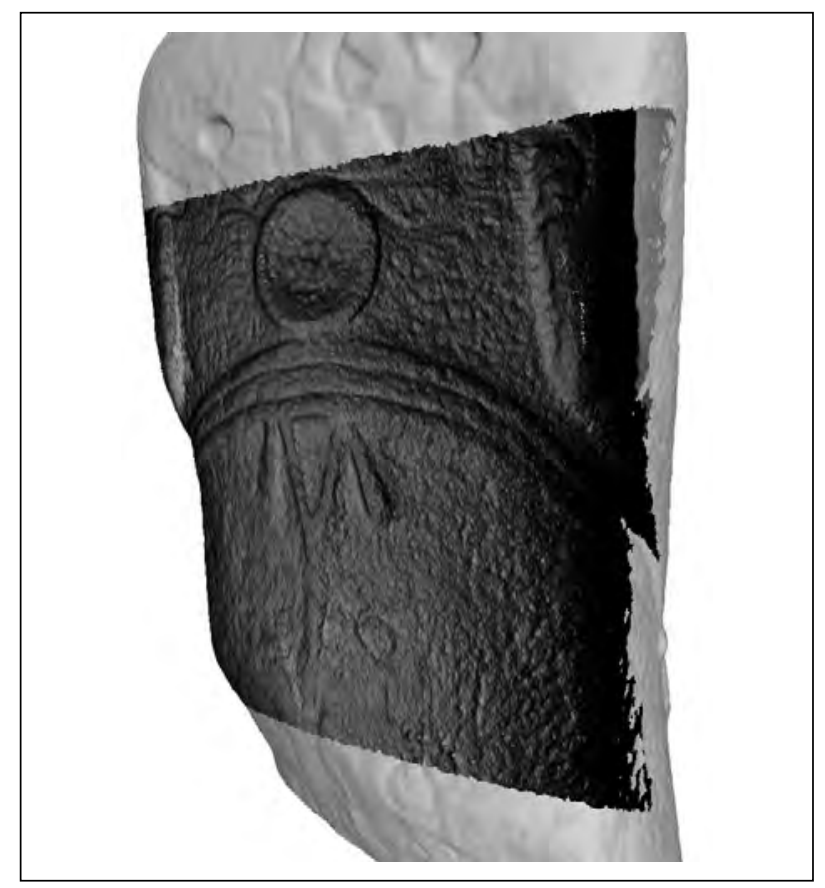

Figure 15. Combination of a RTI dataset on the photogrammetry model of the statue (Photo: James Miles). 


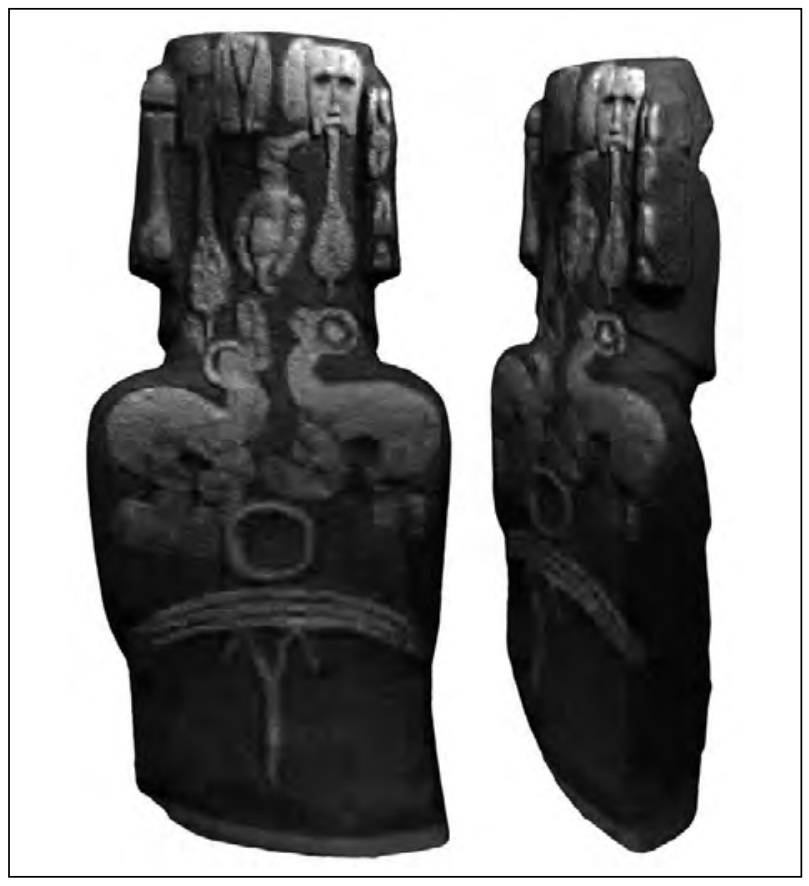

Figure 16. Colour added to the photogrammetry model identifying the areas discussed (Photo: James Miles).

to be of importance and again can be used by future researchers and public to understand the reasoning behind the found results.

\section{Public Dissemination}

Public dissemination was a significant component of the research. As the work completed was purely digital it meant that the photogrammetry model and the RTI datasets could be placed online and viewed in the same or similar ways to those employed within the analysis. The photogrammetry model was uploaded to a website called Grabcad (2013) in a heavily decimated format. This allows users the ability to move and control the model in a virtual environment. Through this viewer the model can be embedded within any website, including that of the British Museum, which in turn allows for the public to view the statue from more angles and more closely than they are allowed to in the gallery. Measurements and sections can also be drawn within the viewer.

Virtual access to the RTI datasets is currently less well supported, although a wordpress plugin, created by author Hembo Pagi (2012) and based on the Material Objects (2013) viewer was used.
This plugin again allows for the embedding of these datasets within any website, but is restricted by the java content enabled on the computers which are used to view them. As a consequence certain screenshot images have also been included online (Miles 2013) where users have the ability to go from a normal photograph to that of an RTI (more RTI examples presented this way are available at University of Southampton 2014). This technique then allows for a more limited view of the data but at a high resolution and with varying lighting and filters. In work currently underway funded by the AHRC we are producing a new open source viewer that will resolve all current issues around web distribution of RTI data, bringing Hoa Hakananai'a not only more fully to desktop computers but also to laptops and smartphones, and in a form that will enable sharing of interpretations.

Since we started to make the project datasets public, along with an article published in British Archaeology magazine (Pitts et al. 2013), a number of questions regarding the work and the meaning of the petroglyphs have been received. The online distribution has led to future collaborations focused on the data and on Hoa Hakananai'a in general. We also hope to undertake future work on other Easter Island statues as a development of our trial methodology.

Despite the digital outputs of this work the need to see and touch the statue in person remains powerful. However, access will continue to be difficult. The proliferation of affordable, high quality 3D printing equipment is thus increasingly relevant. Work completed by Allard et al. (2005) provides an insightinto theproduction of a 3D print of a museum object that is too fragile to be touched, offering a realistic representation that can be reproduced many times over. Likewise the work completed by Celani et al. (2009) highlights the potential that 3D printing has within museum sculptures following a similar method of data collection as used within this study. There are no technological impediments to sharing the Hoa Hakananai'a in its digital form online in order that it could be 3D printed by those who wish to study the object without the digital mediation of the computer. The high resolution three dimensional model that is available would support high quality, textured and coloured 3D prints. The sharing of these data and the production of replicas 
remains a complex issue however and one that we and our partners will continue to evaluate.

\section{Conclusions}

The work completed highlights the benefits of combining photogrammetry and RTI within one research project. The points outlined above provide new insights into Hoa Hakananai'a and to modes of capturing and representing such artefacts. The work completed has demonstrated that multi-resolution images can be used to produce a highly accurate photogrammetric model. It likewise demonstrated the ability to combine two different datasets within one. The paper has focussed on the technological impact that the study has had within the understanding of Hoa Hakananai'a and it provides a basis from which further work can be continued, both in the British Museum and elsewhere.

\section{Acknowledgements}

We are grateful to the British Museum for allowing us to study the statue outside public opening hours, and assisting us in this work. The photogrammetry model was created with Agisoft PhotoScan software and analysed in MeshLab; the RTIs were made and viewed with open source software produced by Universidade do Minho, Cultural Heritage Imaging and HP Labs, using equipment funded by the Arts and Humanities Research Council as part of the AHRC RTISAD project. Our continuing work on RTI is funded by the AHRC RTI FoF project.

\section{Bibliography}

3DReshaper. 2013. “3DReshaper.” Accessed March 13. http:// www.3dreshaper.com.

Agisoft. 2013. "Agisoft PhotoScan." Accessed March 8. http:// www.agisoft.ru/products/photoscan.

Akca, D., A. Gruen, Z. Alkis, N. Demir, B. Breuckmann, I. Erduyan, and E. Nadir. 2006."3D modeling of the Weary Herakles statue with a coded structured light system." International Archives of the Photogrammetry, Remote Sensing and Spatial Information Sciences 36 (5):14- 19.

Allard, T., M. Sitchon, R. Sawatzky, and R. D. Hoppa. 2005. "Use of hand-held laser scanning and 3d printing for creation of a museum exhibit." In Proceedings of 6th International Symposium on Virtual Reality, Archaeology and Cultural Heritage VAST 2005: Short and Project Papers, edited by M. Mudge, N. Ryan, and R. Scopigno, 97- 101. http:// public-repository.epoch-net. org/publications/VAST2005/ shortpapers/ short3006. pdf.

Celani, G., L. Cancherini, A. Jardini, M. Oliveira, J. V. Lopes da Silva, and V. Piccoli. 2009. "3D digitation of museum sculptures for model-making purposes: difficulties and possible solutions." In Innovative Developments in Design and Manufacturing: Advanced Research in Virtual and Rapid Prototyping - Proceedings of VR@P4, Oct. 2009, Leiria, Portugal edited by P. J. Bártolo, 157- 160. Boca Raton: CRC Press.

Davletshin, A 2012. "An overlooked image on the Hoahaka-nana'ia stone statue from Easter Island in the British Museum.” Rapa Nui J ournal 26:57- 85.

Dellepiane, M., M. Corsini, M. Callieri, and R. Scopigno. 2006. "High Quality PTM Acquisition: Reflection Transformation Imaging for Large Objects." In VAST 2006: The 7th International Symposium on Virtual Reality, Archaeology and Intelligent Cultural Heritage, Nicosia, Cyprus, 2006. Proceedings edited by M. Ioannides, D. B. Arnold, F. Niccolucci, and K. Mania, 179186. Aire-la-Ville: The Eurographics Association.

Earl, G., P. J. Basford, A. S. Bischoff, A. Bowman, C. Crowther, J. Dahl, M. Hodgson, K. Martinez, L. Isaksen, H. Pagi, K. E. Piquette, and E. Kotoula. 2011. "Reflectance transformation imaging systems for ancient documentary artefacts." In EVA London 2011: Electronic Visualisation and the Arts edited by J. P. Bowen, S. Dunn, and K. Ng, 147- 154. London: BCS.

Flenley, J., and P. Bahn. 2003. "The Enigmas of Easter Island." Oxford: Oxford University Press.

GrabCAD, 2013. "GrabCAD.” Accessed April 10. http:// grabcad.com/library/ hoa-hakananai-a.

Heinz, G. 2002. "Pharaoh Pepi, I.: documentation of the oldest known life-size metal sculpture using laser scanning and photogrammetry." In Proceedings of the CIPA WG 6 International Workshop on Scanning for Cultural Heritage Recording edited by W. Boehler, 127131. Corfu: ISPRS. 
Horley, P., and G. Lee. 2008. "Painted and carved house embellishments at 'Orongo village, Easter Island.” Rapa Nui J ournal 23:106- 24.

Horley, P., and G. Lee. 2012. “Easter Island's birdman stones in the collection of the Peabody Museum of Archaeology and Ethnology, Cambridge, Massachusetts." Rapa Nui J ournal 26:5- 20.

Lee, G. 1992. Rock Art of Easter Island: Symbols of Power, Prayers to the Gods. Los Angeles: University of California.

Ioannidis, C., and M. Tsakiri. 2003. "Laser scanning and photogrammetry for the documentation of a large statueexperiences in the combined use." In Proceedings of the XIXth International Symposium, CIPA 2003: new perspectives to save cultural heritage: Antalya (Turkey), 30 September-04 October 2003, edited by O. Altan, 517523. Istanbul: CIPA 2003.

Jazayeri, I., C. S. Fraser, and S. Cronk. 2010 "Automated 3D object reconstruction via multi-image closerange photogrammetry." In Proceedings of the ISPRS Commission V Mid-Term Symposium 'Close Range Image Measurement Techniques', edited by J. P. Mills, D. M. Barber, P. E. Miller, and I. Newton, 305-310. Newcastle: ISPRS.

Meshlab. 2013. “MeshLab.” Accessed March 8. http:// meshlab.sourceforge.net.

MacGregor, N. 2011. "A History of the World in 100 Objects." London: Penguin.

Malzbender, T., D. Gelb, and H. Wolters. 2001. "Polynomial texture maps." In Proceedings of the 28th annual conference on Computer graphics and interactive techniques, edited by L. Pocock, 519-528. New York: ACM Press.

Material Objects. 2013. "Material Objects.” Accessed J une 13. http:// materialobjects.com/ ptm.

Miles, J . 2013. "The Voice of Easter Island in the British Museum." The ACRG blog, April 10. http://acrg.soton. ac.uk/ blog/ 3169.

Miles, J., M. Pitts, H. Pagi, and G. Earl. in press. “New applications of photogrammetry and reflectance transformation imaging to an Easter Island statue."
Antiquity.

Mudge, M., T. Malzbender, C. Schroer, and M. Lum. 2006. "New reflection transformation imaging methods for rock art and multiple-viewpoint display." In VAST 2006: Proceedings of the 7th International Symposium on Virtual Reality, Archaeology and Intelligent Cultural Heritage, Nicosia, Cyprus, 2006, edited by M. Ioannides, D. B. Arnold, F. Niccolucci, and K. Mania, 195-202. The Eurographics Association.

Nikon. 2013a. "Nikon D3X.” Accessed March 8. http:// imaging.nikon.com/lineup/dslr/d3x.

Nikon 2013b. “Nikon D7000.” Accessed March 8. http:// imaging.nikon.com/lineup/dslr/d7000.

Nikon 2013c. “Nikon SB- 910.” Accessed March 8. http:// imaging.nikon.com/lineup/speedlights/sb-910.

Pagi, H. 2012. "RTI viewer for Wordpress." Arheovision blog, April 20. http:// www.arheovisioon.ee/ en/blog/ technologies/2012/03/rti-viewer-for-wordpress.

Pitts, M. in press. 'Hoa Hakananai'a, an Easter Island statue now in the British Museum, photographed in 1868." Rapa Nui J ournal.

Pitts, M., J . Miles, H. Pagi, and G. Earl, G. in press. "Hoa Hakananai'a: a new study of an Easter Island statue in the British Museum." Antiquaries J ournal.

Pitts, M., J. Miles, H. Pagi, and G. Earl. 2013. "Taking flight: the story of Hoa Hakananai'a." British Archaeology 130:24- 31.

Palmer, J . L. 1870. "A visit to Easter Island, or Rapa Nui, in 1868." J ournal of the Royal Geographical Society of London 40:167- 81.

RTI builder. 2013. "Cultural Heritage Imaging.” Accessed March 8. http:// culturalheritageimaging.org/What_We Offer/Downloads.

Routledge, K. 1920. "Survey of the village and carved rocks of Orongo, Easter Island, by the Mana Expedition." Journal of the Royal Anthropological Institute 50:42545.

Stumpfel, J., C. Tchou, T. Hawkins, P. Martinez, B. Emerson, M. Brownlow, A. Jones, N. Yun, and P. 
Debevec. 2003. "Digital Reunification of the Parthenon and its Sculptures." In VAST 2003: The 4th International Symposium on Virtual Reality, Archaeology and Intelligent Cultural Heritage, Brighton, United Kingdom, 2003, edited by D. B. Arnold, A. Chalmers, and F. Niccolucci, 41-50. Aire-la-Ville: Eurographics Association.

University of Southampton. 2014. "Archaeological Computing Research Group." Accessed March 15. http:// acrg.soton.ac.uk/tag/rti-example.

Van Tilburg, J. 1992. HMS Topaze on Easter Island. London: British Museum.

Van Tilburg, J. 2004. Hoa Hakananai'a. London: British Museum.

Van Tilburg, J. 2006. Remote Possibilities: Hoa Hakananai'a and HMS Topaze on Rapa Nui. London: British Museum.

Van Tilburg, J. 2007. Hoa Hakananai'a laser scan project. Accessed February 14. http:// www.eisp.org/ 10.

Van Tilburg,J ., andC. A. Pakarati. 2012. “HoaHakananai'a in detail: comment on A Davletshin's unconvincing assertion of an "overlooked image" on the ventral side of the 'Orongo statue now in the British Museum." Rapa Nui J ournal 26:64-66.

White, D. A. 2013 "LIDAR, Point Clouds, and Their Archaeological Applications." In Mapping Archaeological Landscapes from Space edited by D. Comer and M. J. Harrower, 175- 186. New York: Springer. 


\title{
Some Methodological Considerations and Suggestions for Good Practice in Diagnostics and Visualizations of Complex Archaeological Sites: the Experience of the Radio-Past Project
}

\author{
Frank Vermeulen \\ Ghent University, Belgium \\ Cristina Corsi \\ University of Cassino, Italy
}

\begin{abstract}
:
Thepaper presents somemethodological considerations collected in theframework of theEU-funded project "Radio-Past" (2009 - 2013). The core aim of this project was to develop well integrated non-destructive approaches for understanding, interpreting and visualising new and old research results on large and complex abandoned archaeological sites. As coordinators of this successful collaboration we address here issues of integration between remote sensing operations, geophysical and geo-archaeological survey, surface collection and "ground truthing". This is illustrated with some results from case studies within the project, where approaches have been tuned according to diverse ecological and cultural scenarios. These sites, considered as "open labs" for the experimentation and development of new strategies, allowed also the creation of innovative VR (Virtual Reality) reconstructions whose potential and limits can now be probed. The methodological suggestions presented here can be considered as good practice and will be of use in future archaeological projects integrating wide-scale survey and digital reconstructions.
\end{abstract}

\section{Keywords:}

Archaeological Survey, Geophysical Prospection, Methodological Guidelines, VR Reconstruction

\section{Introduction}

In this paper we present the research experience gained within the framework of the EUfunded project "Radiography of the Past" (RadioPast) whosemain objective was to developintegrated non-destructive approaches for understanding complex and large archaeological sites, which today are located in agricultural territories. This project (Corsi and Vermeulen 2012, 3; van Roodeetal. 2012) has in the course of the last four years (2009 - 2013) seen thecollaboration of seven European teams from the academic and the commercial world. They are the archaeological departments of the universities of Evora (P), Ghent (B) and Ljubljana (Sl), the British school at Rome (UK) and the small enterprises 7Reasons (A), Eastern Atlas (D) and Past2Present (NL). In the framework of this and some other national and international associated projects, researchers coming from very different fields (archaeology, geophysics, geology, geomorphology,

Corresponding author: frank.vermeulen@ugent.be
ICT, virtual reality imaging, cultural heritage management, chemistry, archaeometry, etc.) have collaborated in producing a "radiography" of what is still buried under ground on a number of large and complex archaeological sites. Beside completing new and exciting archaeological fieldwork in several European countries, the project has created also a good forum for reflection on methodologies for data integration, interpretation, visualisation and valorisation of large sets of archaeological records from complex sites. The main activity carried out by this consortium of researchers with different backgrounds was the setting up of several "open laboratories". They are a series of complex and large archaeological sites spread over continental and especially Mediterranean Europe. Although situated in the most diverse landscapes they are all deserted multi-period classical towns where old and new fieldwork could be integrated and used for advancing methodological approaches. They include the abandoned Roman towns sites of Ammaia (P) and Mariana (F), a series of classical town sites in 
the middle Adriatic Potenza valley (I) and central Boeotia (G), the complex Roman imperial urban port site at Ostia-Portus (I) and the Roman town of Carnuntum on the Danube (A).

In most of these large sites, with an ancient urban character and a long settlement history, the Radio-Past team integrated different types of research methodologies such as remote sensing, geophysical survey, geomatics, geo-archaeological survey, surface artefact collection and "ground truthing". Combining available old survey data with results from new and (often) total coverage prospections allowed the research team to establish a scheme for "good practice in archaeological diagnostics", which promotes the application of all these different approaches as much and as fully as possible. Consequently, it is of essence to create workflows when one starts to tackle large sites with such a battery of non-invasive operations. A single and unique workflow for fieldwork, to be applied to all types of sites, is not an option nor a goal, as each site offers its own unique possibilities for fieldwork. Yet, it is good to have a specific sequence of possible operations in mind when a large scale project is being developed.

Among the objectives of the project RadioPast is the definition of guidelines for good practice in archaeological diagnostics. We achieved this ambitious goal by including not only the researchers of the project but also internationally renowned experts who substantially contributed to the success of the project. They participated in all the events and training initiatives organised in the last four years (Corsi, Slapšak and Vermeulen 2013).

We will illustrate most of the methodological insights presented here by way of the very recent results from fieldwork on these sites. Especially the common field operations by the whole RadioPast team on the abandoned Roman town site of Ammaia in Portugal served as real field laboratories (Corsi and Vermeulen 2012). One important aspect needs however to be stressed: all archaeological sites studied in the project were known to different degrees before we started our research program and all had seen some fieldwork before. In most cases, however, these were poorly documented traditional excavations giving insight in only a few "windows" of the whole site. In other cases, such as at Carnuntum, in Ostia/ Portus and on some deserted town sites in Boeotia (Tanagra, Thespiae, etc.), there was already a long tradition of intensive survey approaches before the start of Radio-Past, as we can see in most projects of so-called "urban survey" in action today (J ohnson and Millett 2012; Vermeulen et al. 2012).

\section{Desktop Research}

This availability of existing research data, often called legacy data, requires us to stress one point in particular. The need for taking good care of all existing documentation, in whichever language and form it has been produced, is quintessential for any archaeological project involving new fieldwork and surveys. This means including an obvious intensive phase of "desktop"-research, preferably at the very beginning of data collection. However, as nowadays we are too often confronted with socalled "exceptional" discoveries through ever more sophisticated geophysics or remote sensing, the urge to see what is already available from earlier observations, pieced together long before by former, more traditional research achieved with much less expensive investments of time and resources, and the need for such screening and insertion of legacy data, must not be taken lightly.

Contemporary remote sensing and geophysical surveys demonstrate increasingly refined technological approaches and more reliable results, and the speed of data acquisition and analysis is achieving unprecedented quality and unparalleled resolution. Yet, it is also true that research methodologies cannot be inspired only by the objectives of "maximisation of data collection across as broad an area as possible" (Millett 2012, 26), and that historical criticism and the distinction between data acquisition and the elaboration of new knowledge have to always be kept in mind.

We believe that historical cartography is a distinct field where huge amounts of data can now be collected and well integrated with new survey approaches by means of GIS processing. Several examples of this kind were well tested recently. One comes from the lower Potenza Valley in Italy (Corsi, De Dapper and Vermeulen 2009). Here, the integrated elaboration of the mid-nineteenth century cadastre and historical aerial photography has made it possible to reconstruct several phases 


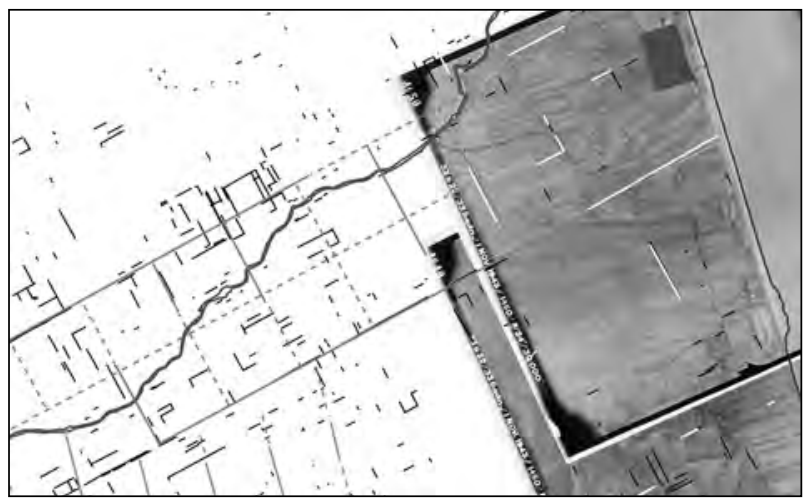

Figure 1. The use within GIS of digitised cartographic data from 19th century cadastral maps and historical aerial photography (RAF, 1945) allowed the partial reconstruction of systems of Roman land division near the colony of Potentia in central-Adriatic Italy (elaboration C. Corsi).

of Roman land division, only partially known from earlier research (Fig. 1).

On-going intensive surveys carried out here by a team from Ghent University, especially in and around the Roman colony of Potentia, at the mouth of the river, gives some insights into the complexity of the archaeological landscape between circa 200 B.C. and A.D. 600 . The interdisciplinary approaches used here includes low altitude aerial photography, systematic archaeological field walking, artefact studies, re-examination of excavated evidence, detailed geomorphologic field mapping, geophysical surveys and detailed topographic mapping. Thanks especially to oblique and vertical aerial photography, geomorphologic fieldwork and coring it is now possible to reconstruct a complete sequence of the important changes that have affected the river bed during the last two millennia, including its impact on the Roman town during and after its lifespan. Newly found archival documents of the 18th and 19th centuries can now shed light on the exact chronology of the river bed's shifts, providing detail on the events of the last centuries when human interference was much more consistent, as several artificial channels were dug to divert the river bed north of the old settlement. The georeferencing of thesecadastremapsin the Geographical Information System (GIS) of the survey-project now offers the possibility of dating several palaeo-channels detected in the aerial imagery, along with the help of intensive and integrated geomorphologic surveys.

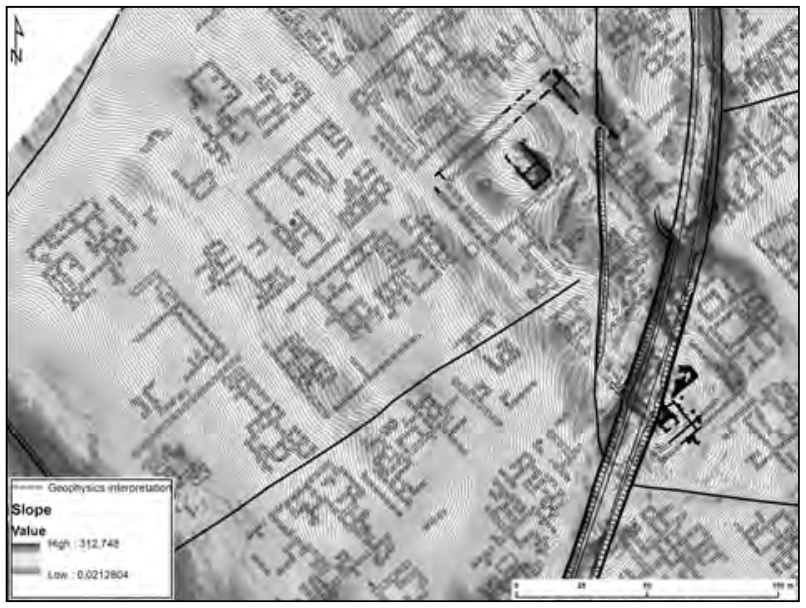

Figure 2. A high resolution DTM obtained by way of DGPS measurements on the Roman town-site of Ammaia (Portugal) was crucial for the mapping and interpretation of geophysics data (elaboration E. Paliou and V. Mayoral).

Comparable work was done recently on another Radio-Past test site, in Mariana in Corsica (Corsi, Roblin-J ouve and Vermeulen 2009). Both examples underscore that intensive use of historical aerial photography and cartography in addition to such contemporary methods as large scale geophysics can show the unexpected complexity of sites and their wider landscape background.

\section{Geomatics and Geo-archaeology}

Special attention must be given to a series of geomatic surveys from the onset of most projects on abandoned sites. They are among the field operations wejudge to be crucial in almostall projects with large scale non-invasive field operations. The importance of a high-resolution Digital Terrain Model (DTM) of the investigated area cannot be overemphasised. One is needed to not only contextualise better the underground features detected by geophysical surveys, but also to better understand the "phenomenology" of complex sites and landscapes. The DTM is needed to support volumetric and 3D reconstructions, and to allow spatial analysis with a full understanding of post-depositional processes. DTMs can also play a role when studying the effects of processes affecting the representativeness and conservation of the archaeological record. A powerful way to explore the temporal dimension can be the evaluation of different models derived from photogrammetric restitutions of historical flights. 
Certain mathematical procedures can be used to estimate topographical changes quantitatively. These results may be very useful to assess the reliability of the results of surface surveys and the preservation of archaeological deposits (Martínez del Pozo and Mayoral Herrera 2013, 5-6).

In our project we experimented with traditional topographic surveys using total stations, as well as with higher resolution differential global positioning systems (DGPS) to build terrain models (Fig. 2).

We also found that when historical vertical aerial photographs and the know-how to use them are available, the production of photogrammetric DTM's is even of higher value. Of course, the latest developments in lidar technologies offer new potential for refined DTMs, but these data are not yet available in many European countries (especially in Southern Europe) and commercial high resolution lidar is still a costly enterprise (Doneus et al. 2007). Experiments with low altitude and flexible data collection of surface relief at high resolution using lasers and aerial photography may be the future, as some of our teamwork in Portugal and Italy has proven (Verhoeven et al. 2009; 2012).Of the same order of importance, but still somewhat undervalued in many field projects, is the insertion of a series of geo-archaeological field operations. Coring, landscape evaluations, erosion modelling of certain sites and their landscape background, and other techniques can all be of use and need most of all to be inserted well in the whole program and strategy of field operations, enabling a constant dialogue between the geo-scientists and archaeologists in the field. The need for geo-archaeological approaches is relevant if we want to deal with the sometimes high stratigraphic complexity of the surveyed sites and the dynamic landscapes they are part of. Insite geo-archaeological analysis first and foremost focuses on the genesis of the archaeological sites, that is the formation processes on the scale of the sites themselves, and on the factors leading to the fossilisation, preservation or reworking of the archaeological remains (Rapp and Hill 1998). Such approaches are thus complementary to the purely archaeological, traditional stratigraphic approach. They allow to establish the origin of the archaeological sediments and their evolution by highlighting linkages with anthropogenic and

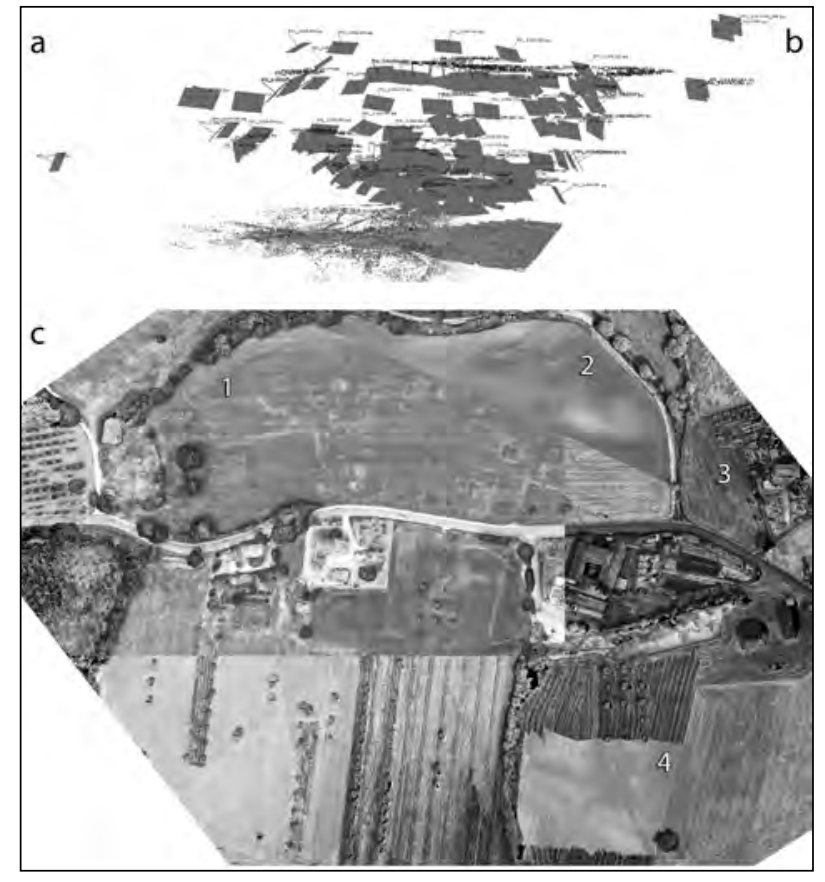

Figure 3. Ortho-rectification procedures on new oblique aerial photographs allowed the mapping of most of the Roman street and building infrastructure of the abandoned Italian urban site of Trea (elaboration $G$. Verhoeven and F. Vermeulen).

bio-pedological processes as well as geological depositional (sedimentary) and/ or post-depositional factors (Vermeulen and De Dapper 2000).

\section{Remote Sensing and Geophysics}

Today, the major developments in noninvasive survey projects on large greenfield sites (meaning deserted settlements with no or almost no-continuity of occupation) with a complex history are centred on intensive remote sensing and geophysical prospections. When the methodological framework of large scale and systematic surveys on abandoned ancient urban sites was formulated during the late 1980 os (Bintliff and Snodgrass 1988) the systematic collection of artefacts at the surface was stressed as the main approach. A series of developments, especially in the fields of geophysics, active aerial photography, multispectral remote sensing and GIS-analysis, has generated an upsurge in non-destructive surveys of such sites (J ohnson and Millett 2012; Vermeulen et al. 2012). Recently, the role of geophysical surveys has been emphasised, but aerial surveys also may claim their 


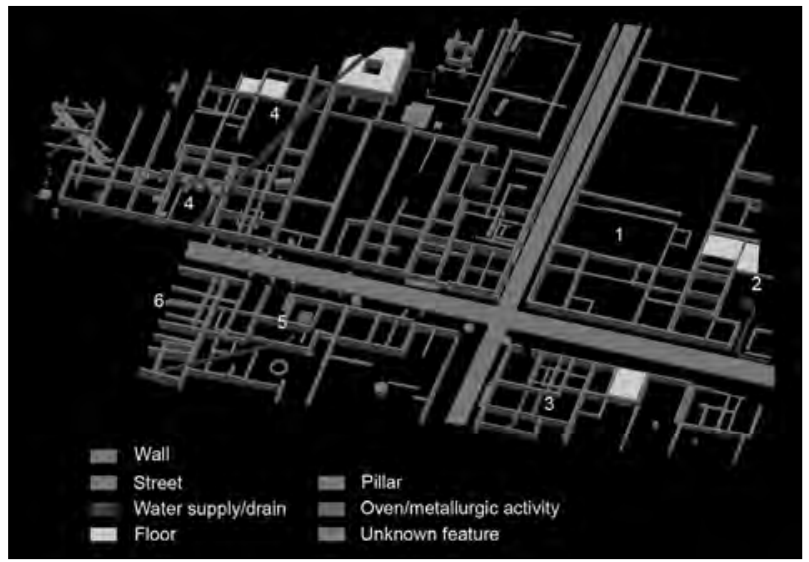

Figure 4. High resolution GPR survey of an intra-mural area in the abandoned Roman town-site of Mariana, Corsica allowed exceptionally detailed $3 D$-interpretations of the buried evidence (elaboration L. Verdonck).

crucial role today (Ceraudo 2013). It is impressive how non-invasive surveys using aerial photography and large-scale geophysics exponentially explode the data record, and thereby change our views of the past. Sometimes they also make us aware that we need to move from the comfort zone of the site-scale to the much more daring landscape scale (Fig. 3).

Yet, the experience carried out in Portugal showed how "flexible" the fieldwork methodology and data capture strategies have to be in order to overcome the difficulties that inevitably arise when dealing with different geographical and historical contexts. At the site of Ammaia, for instance, the available historical, vertical aerial photography is poor, because of the remoteness and isolation of the region, which lacks strategic, economic and communications interest. There, our trials to obtain additional high resolution imagery with devices which elsewhere proved to be very efficient for remote sensing (the helikite developed at Ghent University and the zeppelin in use at the Instituto de Arquelogia de Mérida) were frustrated by the meteorological (too windy) or ecological (tree canopy) conditions.

At the same time, experimental research carried out in collaboration with the Instituto Superior Tecnico of the Politecnico - University of Lisbon, to develop a "low-cost" device for lidar data capture has not given, after two years of tests, good results. Therefore the data integration did not encompass all the possibilities which are nowadays available in the field of archaeological diagnostics. This resulted in a certain stress on geophysical survey, which gave in Ammaia excellent results (Fig. 4).

Yet, we wish to underline how essential is the deployment of all possible approaches and techniques. In other "reference sites" of the project Radio-Past, in fact, the integration between remote sensingand geophysical surveyled to theobservation of how different is the information that can be obtained with the two different systems, especially when discussing the issue of the scale (Vermeulen, Slapšak and D. Mlekuž 2012; Corsi in press).

Whatever the case, indeed, when planning data capture procedures, especially with geophysics, scale is of the essence (in general, for guidelines in geophysical survey in archaeology see: Schmidt and Ernenwein 2013). Correct choices need to be made and surveys of too small areas have often resulted in completely incomprehensible results or false interpretations. Wise advice is to plan an extensive prospection as the "patterning in geophysical anomalies only becomes fully evident once a large area has been surveyed" (Millett 2012, 28).

A debate on what is more useful, "geophysics" or "aerial photography", is meaningless. Both have their merits and complement each other. Additionally, within both domains we need to use all relevant material and approaches as much as possible. It makes no sense to discuss whether "vertical" or "oblique" photographs are better, or to choose only geomagnetic surveys when earth resistance or georadar surveys are available. Most researchers increasingly agree that applying different survey techniques to the same site increases substantially the completeness of the picture that can be reconstructed. And we should focus more on how different subsoil features appear according to the type of survey we are applying. As surveys in the future will be increasingly multi-method, we will have to integrate our data as best as possible while maintaining detail. Although they are the subject of improvingsophisticated technological developments and yield more reliable results, remote sensing and geophysical surveys in archaeology have for a long time followed separate paths. It is only recently that the infinite possibilities for meaningful integration have been tested and more varied combinations 


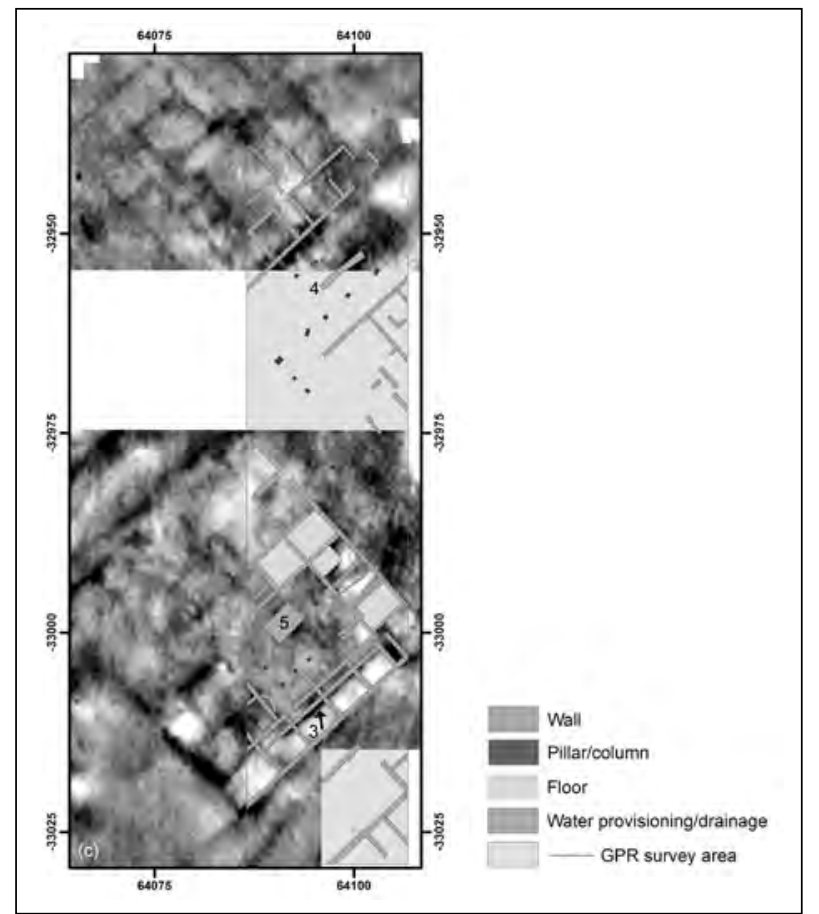

Figure 5. Data-fusion and archaeological interpretation of GPR data overlying earth resistance data from a large domus surveyed in the Roman town-site of Ammaia (elaboration L. Verdonck).

with other survey methods have been introduced (J ohnson and Millett 2012; Vermeulen et al. 2012).

The integration of these datasets to achieve a real fusion of raw data is to be preferred over the simple integration of interpreted data. This can be more objective and often allows for new and more transparent approaches to the evidence. The example of the abandoned Roman town of Trea in the Italian Potenza valley (Vermeulen, Slapšak and D. Mlekuž 2012), where we fused earth resistance imagery with magnetic data, helped considerably in deciphering the structures of the monumental town centre. From several other examples within RadioPast, such as in the Roman town centres of Mariana (Verdonck 2012) and Ammaia (Verdonck and Taelman 2012; Vermeulen, Corsi and De Dapper 2012), we learned that it is sometimes imperative to go to higher resolutions with certain surveys. To appreciate the details of a Roman house and not just understand the size and position of a housing block, means that high resolution GPR and earth resistance need to join efforts in a well-chosen and smaller survey area. Subsequently, this can produce interpretations with the power of extrapolation to other areas of the site where only lower resolution was possible (Fig. 5).

In some cases, the speed of the process of data acquisition and analysis has yielded unprecedented quality and unparalleled resolution. This has led researchers to automatic interpretations and perhaps even too hasty reconstructions where methodological frameworks and historical criticisms have not been elaborated. In the application of intensive geophysical surveys should we just use "the technique of firstly mapping the geophysical anomalies by physically tracing around them in a software package and then discussing their interpretation"? (Millett 2012, 29). In this way, by keeping only information about their shapes, do not we lose information about their qualities (such as their magnitudes)? Here, the power of high resolution georadar survey and its capacity to reveal depth and depth relationships has taken us beyond conventional boundaries on several occasions. When soils, time and land use permit the application of high resolution radar, this technique needs to get the priority it rightfully deserves.

\section{Not to be Forgotten: Archiving and Ground Truthing}

All of the foregoing brings about much more data to archive, and even if most of us do not like to archive - it is just too much work and not immediately rewarding - we absolutely need to do this carefully (Schmiedt 2013). A good plan and a correct use of GIS technology is essential here and well-organised data need to constantly be the subject of control and if needed adaptation to new digital realities. Distribution via the Internet and open access can also play a role in this. One of the advantages of good archiving is that it allows us to better monitor changes within sites, especially when our sources and field data are collected at different moments in time. This is not important to better grasp the meaning of many features that are photographed or scanned over longer time periods, and it is also of essence for the cultural resource management of sites and their monitoring to halt possible degradations.

The application of a strategy to check seriously the data obtained via large scale non-invasive 


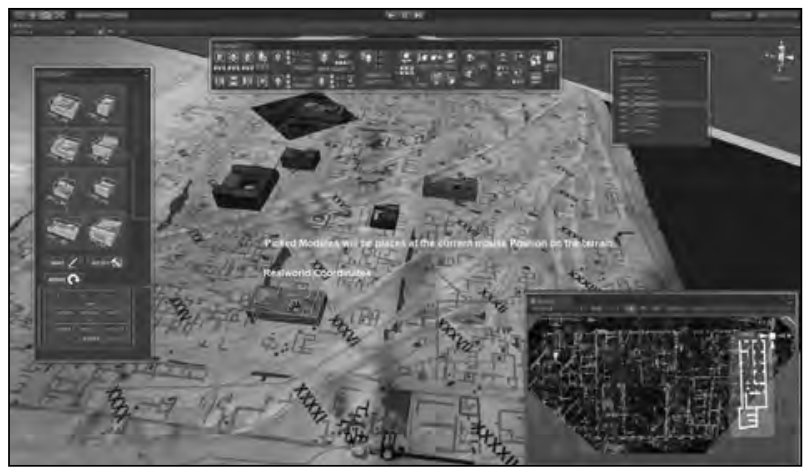

Figure 6. The process of 3D-based virtual archaeology model building (with Unity-software) as applied to the full coverage geophysics survey data in Ammaia (elaboration M. Klein).

operations is equallyimportant. Apartfrom checking our geophysical survey data by cross-referencing them with different subsurface techniques or through aerial photography, so-called groundtruthing can also be obtained by small interventions into the soil. In certain projects researchers have combined survey with intensive trial excavation, such as in recent years at Ostia and Amiternum (Bauer et al. 1999; Heinzelmann et al. 2010). Yet, some researchers are very "sceptical about putting too much weight on the evidence of very small trial trenches when investigating very large features or very complex urban stratigraphy" (Millett 2012, 31). It can indeed be questioned how representative these trenches are of the complexity of urban stratigraphy and how significant these sequences are of different sectors, between public and private buildings, or between areas of the most diverse social classes in an urban settlement. If well-chosen, these trenches, and sometimes the full excavation of a particular window into the site, can be of great value in solving certain interpretative problems. For example, they might aid in the identification of particular architectural structures or help in the understanding of ill-defined results from particular geophysical prospections. Their most important contribution of course lies in establishing a relative or absolute chronology of certain building phases in the complex settlement history. If we stick to a noninvasive philosophy such field checks or a better appreciation of the chronological sequences can also be obtained by certain well controlled artefact collections or by well-designed and well-executed coring operations.

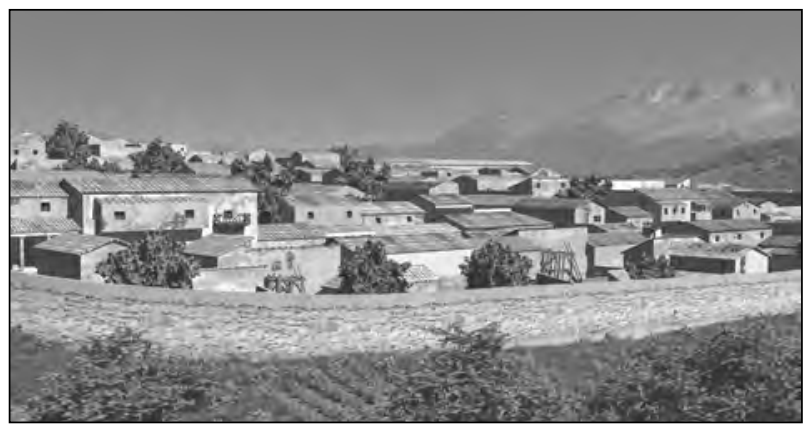

Figure 7. Screenshot of the virtual archaeology film based on the integrated survey and reconstruction of the Roman town of Ammaia (elaboration M. Klein).

\section{Data Visualisation and Reconstructions}

The Radio-Past project made the effort to reach not only a scientific public but also a wider audience by way of 3D reconstructions of our archaeological interpretations. In these contexts it is imperative that we seek ways to show our different views and hypotheses and to create a clear link between the interpreted data and the obtained reconstructions or imaginative visualisations. Let us illustrate these points with the main topic of the Radio-Past field operations: deserted classical towns. During the past decade much progress has been achieved in integrated non-invasive surveys of Roman towns in the Mediterranean. This has first of all promoted Roman urbanism studies in a dramatic way, by inserting thewidevarietyof nowalmost fullymapped towns into the debate. Secondly this evolution has made us think about new ways of representing and virtually reconstructing these Roman towns in view of further discussion among scholars, but most of all to inform and involve the wider public. It represents a shift from past research with a significant impact on how the material culture relating to such cityscapes is documented and understood. No more do we make extrapolations based on too little information about one or two windows looking into the site via (often old) excavations. Reconstructions are now based on intensive total site surveys integrated with all available evidence from excavations, geoapproaches, legacy finds and comparative research.

We realised that the time for nice, but very static, artists' impressions of Roman towns should be over when they are not upgraded from knowledge 
of old excavations to a more holistic view of the ancient city that permits analysing its space and the movement of its inhabitants,. This is especially true in the case study of the Romano-Lusitanian town Ammaia (Fig. 6 and 7), but also in our on-going work at Portus and the Potenza valley towns in Italy. In these places trials have been completed to probe the limits of VR.

We can observe that the preliminary results are well worth viewing and that the obtained VR reconstructions of these Roman settlements are the result of much interactive work and discussion among team specialists of different fields, using a wide array of local, regional and supra-regional data. Yet, we must be aware that these reconstructions are tentative and experimental. It is even more important to understand that the spatial perception and analysis of the new maps, the reconstructed spaces, and the architecture requires caution. Much of the data remains non-stratigraphic in nature and some of the interpretations cannot disentangle the complexity of many centuries of settlement development.

We also stress here that the mostly twodimensional mapping output from a GIS, based essentially on non-invasive survey data, is often not enough to represent landscape complexity and dynamics. The reconstruction of ancient cityscapes is a challenging research activity implying the management of a high level of uncertainty. Furthermore, as the archaeological landscape that we can observe today is the result of a long process of transformation, it is very important to store diachronic relationships describing how the site and its environment changed over time and to propose a reliable interpretation of the whole ecological context. We should, therefore, design digital models that convey uncertainty and propose different hypotheses of how buildings were constructed, decorated or used. "Since the level of uncertainty is a challenge, transparency is essential to understand and build research hypotheses and conclusions, particularly in areas where data is questionable, incomplete or conflicting" (Cerato and Pescarin 2013). This transparency here means that digital reconstructions should offer the possibility to check the basic data and the whole reconstruction process, with possibilities of constant evaluation. A full presentation of metadata is now accepted as a practical way to follow this approach. This can be added to the creation of a (web-based) tool that allows interactive visualisation and queries of multi-resolution 3D models (Humer et al. 2011). Important for educational aspects and the wider public are the presence of links from each digital model, or relevant parts thereof, to the body of archaeological and documentary evidence (Cerato and Pescarin 2013).

\section{Conclusions}

Partly as a result of increasing sophistication in the technology of remote sensing and geophysical survey, but also to cope with the fast development of our landscape environment under human pressure, teams of archaeologists in Europe and beyond are more and more inclined to uses sets of non-invasive survey in their field strategies. The extraordinary nature of results from wide survey applications on large and complex sites urges us to clearly state the principles behind the new approaches and to design carefully methodological frameworks based on good practice. It is of utmost importance to take into account not only successful experience, but also failures, as it is also from the "worst of times in survey" that we are able to learn (Millett 2012, 26-27). We cannot emphasise enough that there is a need for very smart strategies for the processing, interpretation and archiving of the many types and quantities of field data and some of the examples from the Radio Past project might well be of help to others in the future. While designing strategies we need also to keep an eye on the many matters of scale and resolution that we have to deal with when surveying large and multi-period sites. Real understanding of the complexity of such sites, like gradually abandoned ancient towns, demands constant confrontation with the results, identification of visibility or interpretation problems and most of all a lively debate based on bringing together experiences from different environments and landscapes. Sometimes, also, we must be fully aware that we do not always need the latest or most expensive technology, but that we just have to ask the right questions.

\section{Bibliography}

Bauer, F. A., M. Heinzelmann, A. Martin, and A. Schaub. 1999. "Untersuchungen im Bereich der 
Across Space and Time. Papers from the 41st Conference on

Computer Applications and Quantitative Methods in Archaeology. Perth, 25-28 March 2013

kostantinischen Bischofskirche Ostias. Vorbericht zur ersten Grabungskampagne." Mitteilungen des Deutschen Archäeologischen Instituts, Römische Abteilung 106:289- 341.

Bintliff, J. L., and A. M. Snodgrass. 1988. "Mediterranean survey and the city.” Antiquity 62:57- 71.

Cerato, I., and S. Pescarin. 2013. "Reconstructing past landscapes for virtual museums." In Good practice in archaeological diagnostics. Non-invasive survey of complex archaeological sites, edited by C. Corsi, B. Slapšak, and F. Vermeulen, 285- 296. Berlin: Springer.

Ceraudo, G. 2013. "Aerial Photography in Archaeology." In Good practice in archaeological diagnostics. Noninvasive survey of complex archaeological sites, edited by C. Corsi, B. Slapšak, and F. Vermeulen, 11- 30. Berlin: Springer,

Corsi, C. in press. "Il cielo sopra Mariana. Aviatori e archeologi alla scoperta di una colonia romana in Corsica." Archeologia Aerea. Studi di Aerotopografia Archeologica 10.

Corsi, C., M. De Dapper, and F. Vermeulen. 2009. "River bed changing in the Lower Potenza Valley (Mid-Adriatic Italy). A geo-archaeological approach to historical documents." Zeitschrift für Geomorphologie 53 (1):8398.

Corsi, C., A. Roblin-J ouve, and F. Vermeulen. 2009. "Géoarchéologie autour de la ville romaine de Mariana et de la basse vallée du Golo." In Ol'Man River. Geoarchaeological aspects of rivers and river plains, edited by M. De Dapper, F. Vermeulen, S. Deprez, and D. Taelman, 257- 272. Gent: Academia Press.

Corsi, C., B. Slapšak, and F. Vermeulen. 2013. Good practice in archaeological diagnostics. Non-invasive survey of complex archaeological sites. Berlin: Springer.

Corsi, C., and F. Vermeulen. 2012. Ammaia I: The survey. A Romano-Lusitanian Townscape Revealed. Gent: Academia Press.

Doneus, M., C. Briese, M. Fera, U. Fornwagner, M. Griebl, M.J anner, and M.-C. Zingerle. 2007. "Documentation and analysis of archaeological sites using aerial reconnaissance and airborne laser scanning." In AnticIPAting the Future of the Cultural Past. Proceedings of the XXI
International Symposium CIPA. Athens 2007, edited by A. Georgopoulos, 275- 80. Athens: ICOMOS.

Heinzelmann M., D. Jordan, and C. Murer. 2010. "Amiternum and the upper Aterno valley: a Sabine-Roman town and its territory." J ournal of Roman Archaeology 23:55- 83

Humer, F., C. Gugl, M. Pregesbauer, F. Vermeulen, C. Corsi, and M. Klein. 2011. "Current Productions Carnuntum, German Limes and Radiopast." Virtual Archaeology Review 4:131- 137.

J ohnson, P. S., and M. Millett, eds. 2012. Archaeological Survey and the City. Oxford: Oxbow.

Martínez del Pozo, J. A., and V. Mayoral Herrera. 2013. "Creating and analysing digital terrain models for archaeological research." In Good practice in archaeological diagnostics. Non-invasive survey of complex archaeological sites, edited by C. Corsi, B. Slapšak, and F. Vermeulen, 227- 243. Berlin: Springer,.

Millett, M. 2012. "Understanding Roman Towns in Italy: Reflections on the role of Geophysical Survey." In Archaeological Survey and the City, edited by P. S. J ohnson and M. Millett, 24-44. Oxford: Oxbow.

Rapp, G., and C. Hill. 1998. Geoarchaeology: the earth science approach to archaeological interpretation. New Haven: Yale University Press.

Schmidt, A. 2013. Geophysical Data in Archaeology: A Guide to Good Practice. Oxford: Oxbow Books.

Schmidt, A., and E. Ernenwein. 2013. Guide to Good Practice: Geophysical Data in Archaeology. York: Archaeology Data Service, University of York. Accessed January 15, 2014. http://guides.archaeologydataservice. ac.uk/g2gp/Geophysics_Toc.

van Roode, S., F. Vermeulen, C. Corsi, M. Klein, and G. Weinlinger. 2012. "Radiography of a townscape. Understanding, visualising and managing a Roman townsite." In Landscape Archaeology Between Art and Science: From a Multi- to an Interdisciplinary Approach (Landscape \& Heritage Proceedings), Proceedings of the 1st Landscape Archaeology Conference: LAC2010 (Amsterdam 26th - 28th J anuary 2010), edited by S. J . Kluiving and E. Guttmann-Bond, 429-441. Amsterdam: Amsterdam University Press. 
Verdonck, L. 2012. "Fluxgate gradiometer and GPR survey to locate and characterize the perimeter, Early Imperial centre and street network of the Roman town Mariana (Corsica)." In Archaeological Survey and the City, edited by P. S. J ohnson and M. Millett, 241-260. Oxford: Oxbow.

Verdonck, L., and D. Taelman, 2012. "Ground-penetrating radar survey at Ammaia." In Ammaia I: The survey. A Romano-Lusitanian Townscape Revealed, edited by C. Corsi and F. Vermeulen, 69- 81. Gent: Academia Press.

Verhoeven, G., M. Doneus, Ch. Briese, and F. Vermeulen. 2012. "Mapping by matching - A computer visionbased approach to fast and accurate georeferencing of archaeological aerial photographs." Journal of Archaeological Science 39:2060- 2070.

Verhoeven, G., J. Loenders, F. Vermeulen, and R. Docter. 2009. "Helikite aerial photography - a versatile means of unmanned, radio controlled, low-altitude aerial archaeology." Archaeological Prospection 16:125- 138.

Vermeulen, F., G. J. Burgers, S. Keay, and C. Corsi, eds. 2012. Urban Landscape Survey in Italy and the Mediterranean. Oxford: Oxbow.

Vermeulen, F., C. Corsi, and M. De Dapper. 2012. "Surveying the townscape of Roman Ammaia (Alentejo, Portugal): a geoarchaeological approach of the forum area." Geoarchaeology, 27 (2):105- 187.

Vermeulen, F., and M. De Dapper, eds. 2000. Geoarchaeology of the Landscapes of Classical Antiquity, International Colloquium Ghent 23-24 October 1998. Leuven:Peeters Babesch.

Vermeulen, F., B. Slapšak, and D. Mlekuž. 2012. "Surveying the Townscape of Roman Trea (Picenum)." In Archaeological Survey and the City, edited by P. S. J ohnson and M. Millett, 261-282. Oxford: Oxbow. 



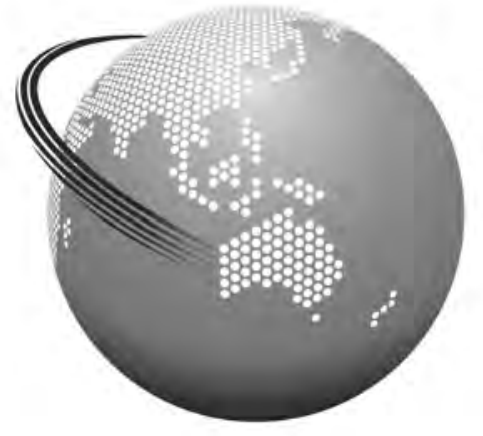

DATA ANALYSIS AND

MANAGEMENT

Computational Modelling and GIS

Data Management and Analysis 



\title{
Reflections Upon 3o+ Years of Computing and Field Archaeology in the Vale of Pickering, North Yorkshire UK \\ My mind Boggles as I Goggle at my Google or 10,000 years beneath the arable landscape of the Vale of Pickering, North Yorkshire, UK
}

\author{
Dominic Powlesland \\ Landscape Research Centre and University of Cambridge, UK
}

\begin{abstract}
:
When called to conduct a short rescue excavation ahead of sand extraction at a small quarry in Eastern Yorkshire in 1977 I had no idea that I would ultimately undertake a barely-funded project (in what at first glance was one of the bleakest places I had ever visited) or that I would still be working there 35 years later. I certainly had no idea that less than 5 years later a large van would pull up outside the 12th Century house (hovel) that I lived in and deliver the many boxes that made up a Wang 2000 computer with 8K of in-box memory. That computer, which like so many of its successors joined the techno-scrapheap in an annoyingly small time, was the instrument that I first learned to program and which triggered the idea that this 'new' technology might have something to offer field archaeology. During the early years of applied computing in archaeology our work as archaeologists was constrained by the limitations and need to make it 'fit' the available technology. However, in the last few years this situation has become completely reversed and now we have the freedom to bend the technology to our will'. In my case that has been the search for the 'real archaeology', how much stuff is out there, and when is enough, enough? What do we actually need to know before we can even think of asking or better answering difficult questions, and how do we secure the knowledge infrastructure required to process the archaeological theory' that now seemingly 'dominates' our much maligned field discipline? This paper will examine not so much the toys and software but the process of discovery and delivery of landscape-scale data from the individual grave to a complete landscape in 3D and 4D, and the urgency with which we must work if it is not all to be a waste of time. Along the way it will reflect upon aspects of past, current and future research and the role of applied computing in improving and enhancing rather than simply replacing the observational, recording and delivery infrastructure which has for so long been the subject of site-hut and bar-room discussion.
\end{abstract}

\section{Keywords:}

Landscape Archaeology, Digital Data Recording, Hand-held Devices, Remote Sensing, Geophysics, Vale of Pickering

\section{In the Beginning}

Archaeological excavations begun at Cook's Quarry, West Heslerton in the Vale of Pickering, North Yorkshire, during 1978, following the chance discovery of Early Anglo-Saxon burials during mineral extraction. These excavations, still continuing today on a bi-annual basis, provided the

Corresponding author: d.powlesland@btinternet.com setting for the development of one of the longest programs of archaeological landscape research in Britain (Powlesland, Haughton and Hanson 1986).

By 1980 it was realised that the ad-hock arrangements for short summer season rescue excavations managed remotely from Manchester were inappropriate for what was clearly a project that would need to cover many hectares of 
excavation over a number of years. In 1980 the Landscape Research Centre (LRC) was founded as an educational research Trust and a research design prepared in order to define a valid research context for the on-going excavations at Cook's Quarry and forward looking objectives for the Trust (Powlesland 1980). At the same time, it quickly became clear that the recording needs of potentially many hectares of excavation could generate a life-challenging and chaotic mountain of disorganised paperwork that would hinder rather than help us to understand the Mesolithic to Medieval archaeology that would subsequently be destroyed by sand quarrying. For much of the previous decade discussions regarding excavation and recording methodologies were a major focus of the end of day pub/campsite discussions that were a feature of the new world of Rescue Archaeology. The increasing size and limited timescales associated with rescue excavation projects in general required an increasingly formalised approach to recording. In response, a whole raft of different pro-forma recording forms were generated by field archaeologists throughout Britain. In contrast with diaries, daybooks and the backs of cigarette packets which may have served as repositories of measurements and descriptions in the past, the pro- forma sheets with clearly labelled boxes in which to record information offered the potential to generate a fairly standardised and structured record. The pro-forma sheets provided a structured framework for the record intended to prompt the recorder to ensure that no required information was omitted. At this time there was a somewhat illusory - or even delusional - obsession with the search for greater objectivity in the record and that somehow a structured record would help this.

At around this time what remains the most significant contribution of computing to archaeology- that of the word-processor emerged to change the face of both writing and publishing forever. Over a period of 18 months word processors were used to design recording forms that had been the subject of months of discussion regarding the list and nature of the data fields to be recorded. These discussions, involving both the field excavation team and the developing local authority archaeological service at North Yorkshire County Council, formed the basis of what was to emerge as one of the first computerised Sites and Monuments
Records in Britain. Our recording system for these early excavations was designed to form a component of this emerging database and was intended to be generic rather than site-specific and capable of recording in a standard format archaeological sites of any period and material of any type.

The transition from pro-forma records to computerised database was both inevitable and essential. The long phase of debate and discussion regarding the content of the record, undertakencritically - without direct interaction with a computer, was designed not so much in terms of what to include in the form but what we might wish to get out of the record; this is elementary, but it has meant that the structure as originally developed has continued to serve well for nearly 35 years with only minimal changes.

The design process was not constrained by any awareness of the limitations inherent in the primitive computers of the early 1980s. It was ambitiously targeted towards transforming our ability to use the information - both physical and documentary - generated by excavation to ask and identify increasingly complex questions rather than simply hope that by collecting vast amounts of unstructured data the past would conveniently offer up the answers to questions never asked or identified. At the time the ambitious questions posed and the desire to see the results output in elaborate and detailed graphical form were beyond the capabilities of the technology available. The reality was that we had a single text-only data entry screen linked through a somewhat fragile connection to a mainframe computer more than 50 miles away and with no local printing facility. Forms completed on site were later dispatched to the post-dissolution farm house attached to the ruins of a former nunnery, which served as the somewhat cold and damp home-office. The data was then typed into the terminal, which was prone to line failures, regular power-cuts and system crashes of the mainframe computer; the upshot meant that large numbers of records had to be re-entered multiple times. With excavations always oversized and undermanned, the opportunity to enter records whilst the excavation was progressing were limited so that the majority of the records had to be entered after the excavation was complete, and therefore too late to rectify - by observation on site - any inconsistencies identified 
at this late stage that could compromise later analysis.

The advantages in having an offsite computerised archive stored on the County Council mainframe were somewhat offset by the fact that we had no local printer and a monochrome text- only monitor. Whilst it was easy, if frustrating, to enter the data, we had to travel 50 miles each way to get anything back out, or wait several days for the postman to deliver a primitive dot-matrix print-out. Our very limited programming skills meant that on one highly embarrassing occasion, when we had intended to generate a relatively simple list of a few thousand finds, a programming error resulted in the data search effectively locking up the mainframe for several hours, in addition to setting all the printers in county hall printing in unison - not the best way to gain friends in the County Council computing services department. Remarkable as it seems today, even given the 'huge' capacity of the mainframe computer, which by today's standards was tiny, most of the fields of information gathered were of necessity entered using alphanumeric codes to facilitate storage if not ease of comprehension. The creation of an acceptable data structure utilising the most rudimentary computing skills may have been significant as the objectives were determined not so much by what was possible at the time as by what we might wish to ultimately retrieve from the database regardless of computing limitations.

It seems somewhat absurd to look back and realise the degree to which the donation at about the same time of an IBM golf-ball typewriter, albeit one with the keyboard attached to a Wang 2000 computer, revolutionised our work. This computer, that a fewyears before had cost rather more than one seasons excavation budget, had 8K of memory and used an intelligent cassette drive to store programs and data. Eight-inch floppy disks had a capacity of no more than $128 \mathrm{~K}$, and programming was achieved using a hardcoded version of the BASIC programming language. The printer produced far better and faster output than an existing electric typewriter but, far more importantly, could be used as a plotter. Besides taking up more than two cubic metres of my home, the computer that was required just to type on the keyboardless golf-ball printer offered the potential to develop a simple database designed to help organise the several thousand lecture slides that were regularly trawled through on the basis that the same set should never be used twice, thereby avoiding rote performances. A fortune was spent on phone calls to a surprisingly patient father and skilled programmer who dictated lines of code down the phone - some ten years or so later this position was reversed. After many hours of filling the rudimentary database it was suddenly realised that the relevant information could be quickly retrieved in response to a simple query. That Eureka moment marked the end of the lecture slide database project with the realisation that far more useful and interesting tasks could now be attempted, particularly with the printer serving as a plotter. Shortly afterwards, this trusty pioneer of a computer reached the end of its life - it began to lose its memory, something demonstrated most dramatically and terminally when it was turned on one morning and, instead of displaying the expected $\gg$ READY on the screen, it simply stated $>$ VEED.

\section{A Computer in the Hand...}

The steep learning curve associated with the development of the coded and detailed structures of the archaeological record and with learning to program in BASIC on the 8K Wang mini-computer was to be of great benefit. It soon became apparent that in order to gain a serious advantage over the paper record by utilising the data management and search-ability provided by a computer-based recording system then this should be implemented on site while the excavation was in progress. Today, when people carry mobile phones that are many times more powerful and with vast capacity compared with the Wang mini-computer, it is difficult for many to appreciate how much things have progressed. I remain unsure as to whether it was 1982 or 1983 when we got hold of our first Sharp PC-1500 hand-held computer. With the same 8K capacity as the Wang minicomputer and a version of the BASIC programming language incorporated in a package smaller than most paperback books, this robust little device had peripherals including a four pen colour printer-plotter which used small till rolls. Its greatest limitation was the single-line screen; this was seen as a critical problem by many other archaeologists, commented on particularly by those yet to contemplate the transition from recording via a site diary and related note books to a structured and computerised record. 
The absurdity of this criticism is highlighted today by the fashionable use of Twitter, reflected in a recent Web crawl that showed that universities are now offering courses in 'Social Media for Archaeologists' - surely an opportunity for an alternative, but arguably less productive, distraction to the accumulated pleasure of scanning the landscape for days on end using Google Earth. The coded recording system originally developed for use with the mainframe was adapted and programmed into the tiny handhelds which employed very reliable CMOS memory. By 1984 all textual recording on site was undertaken in the field using the Sharp handhelds; this was made possible when Sharp Electronics accepted our request for support through the donation of the necessary hardware. The keyboards survived the harsh sandy environment of the excavations and, even after one of the handhelds was dropped in a bucket of water, we discovered that after a thorough drying out the programs and data remained uncorrupted. We continued to use the PC1500's and upgraded versions for more than ten years, the only significant problem being that after many tens of thousands of finds had been recorded the letters wore off the keys and had to be re-applied every few weeks with an indelible marker.

At the 2013 Perth CAA conference I was privileged to hear a number of papers extolling the value of using mobile phones for recording, with an emphasis on the fact that this 'speeded up the recording process.' Speed archaeology has been wonderfully characterised by the British comedian Eddie Izzard in a video clip which can be viewed on YouTube (YouTube 2014). After more than 30 years using hand-held recording devices in the field I remain unconvinced that the approach necessarily speeds up the recording process, although it is abundantly clear that direct digital recording in the field can increase the uniformity of the record and, more importantly, radically enhance datamanagement and data analysis during the postexcavation stage.

The first attempts to transfer the original pro-forma/mainframe recording system onto a handheld device set out to assist the user with a sequence of prompts which in turn responded to the data as entered. The result, whilst a potentially powerful teaching aid, was in reality unusable since it required the recording process to be conducted in a linear fashion with each field completed in a fixed sequence. This approach failed to take into account the flexibility necessary to support the complexity of the excavation and recording process as encountered in a large rescue project with vast numbers of contexts being excavated simultaneously, in some cases over a considerable period of time. The small capacity and power of early handhelds, and for that matter the first PCs, was such that if they were to be of any use at all then approaches to recording had to be adapted - without compromising the basic structure - to fit the computer; extensive use of both numericand alphanumericcodesnotonlyminimised the memory required for record storage but also improved search and sort times for data retrieval purposes. The use of coded data fields, implemented a few years later using pull-down menus of key terms, was not only computationally efficient but also introduced a high degree of standardisation in the record. Printed Reference Code lists, sealed in plastic against the dirt and weather were found to be flexible, with new terms being added to the lists as necessary.

However data is recorded, whether on paper or computer, the resulting records are of limited use if incomplete. A singular advantage of computerised data collection procedures is the facility for automated record checking to determine whether the necessary fields in each record are correctly filled in. The practicalities of excavation are such that a simple software scan of the fields in a record cannot serve as a valid check of completeness in the face of the realities of excavation in which some data may simply not be available or, in the case of features, which for good reason may only have been partially excavated. Rather than use software simply to validate whether the fields in any record were 'filled', and therefore theoretically complete, a single Yes/No field was introduced in which the recorder logged when they considered the record to be complete. This approach encouraged the users to check their records for completeness and to be aware of the importance of making sure the records were as complete as the situation would allow. A feature of the download software written to transfer records from the handheld computers to the PC was that, while all the records were saved to the PC, those flagged as 'incomplete' were also sent back to the handheld device. When the storage capacity of the handheld was reached no new records could 
be created until space was made available through the download of 'completed' records; this approach encouraged users both to limit the number of contexts being excavated at any one time and to take responsibility for managing their own recording process.

The record was divided between those fields that were seen as entirely descriptive such as dimensions, location, form, deposit makeup and stratigraphy, and those that were interpretive such as the feature type and description. There was widespread debate throughout the late 1970s and 1980s regarding the degree to which recording was objective rather than subjective, the reality being that the whole process of excavation is highly subjective and to split hairs about interpretation of features created by theintervention of the trowel was taking things too far. The idea that excavation can be totally objective without any interpretation in the field seems to me to diminish what we as excavators do. It is easy for someone remote from the day to day task of trying to understand evidence in the ground, which not only dictates how the process of discovery develops, but also provides the underlying interpretive framework, to argue that to interpret a context is not objective but many would disagree. The interpretive process engages the excavator in a questioning process without which bigger questions pertaining to the nature of collective features - such as post-hole structures - can be addressed in the field rather than assembled from the archive during the post-excavation process. Post-hole based structures in difficult excavation environments can be far from obvious, with the subtle remains of small post-holes difficult to see or feel, and thus extra effort can be required to isolate them. The separation between the purely empirical and the interpretative provided a structure that facilitated computer based analysis to compare the factual records relating to particular interpretations.

The accumulated context records provided a remarkable environment for retrospective analysis of the content of the record; the recording of soil colour, for example, is notoriously susceptible to problems of differing perception and description, and yet the 'objective' approach based on the use of a Munsell Colour Chart is seen by many as complex or confusing and also susceptible to different interpretations. A significant feature of the Cook's
Quarry excavations at West Heslerton is that the site has been buried by a deposit of aeolian sands which have been mobile since at least the Early Mesolithic period. Those aeolian sands, which appear to have originated as a type of loess blowing off the glaciers that formerly surrounded the Vale of Pickering on three sides, are iron enriched and ochre in colour. This material, which remains mobile today, has in some areas accumulated over time affording a high degree of physical protection to the buried archaeological deposits. Excavation has shown that buried Neolithic old ground surfaces here are almost black in colour and that over time the addition of the blown sands has changed the colour of the soil by the increasing inclusion of the reddish sands. An analysis of the recorded Munsell colours when compared with the site chronology revealed what in our experience is a unique degree of correlation between soil colour and date spanning the chronological range from the later Neolithic to Early Medieval periods. Similarly, an analysis of the recorded features comparing form and size with recorded interpretation correlated directly with the interpretations by the excavators of post-holes or pits. The limitation imposed by the allocation of only 128 characters for additional notes was less restrictive than first appearance since the scale, location, form, soils and basic interpretation wereall defined in the coded fields. The primary objectives in developing a computerised recording system, applied in the field during the excavation process, was not to expedite the process but to improve uniformity, reliability and analytical potential of the record during the post excavation phase, which needed to be set against the realities of conducting rescue excavations with a volunteer workforce in which those recording in the field were unlikely to be in easy contact following the excavation season.

Having worked for many years in urban archaeology, the large, open and relatively unstratified rural excavations at Cook's Quarry seemed, in abstract, to offer the potential for much more 'simple' archaeology, a concept that was of course as far from the truth as possible. The deeply stratified urban deposits with highly differentiated layers, clear cut-lines and structures with hard building materials and mortared joints was in stark contrast to the subtlety of the rural deposits where texture was so often the defining characteristic in deposits which appeared otherwise identical, and 
frequently were exceptionally difficult to define. The shallow ditches, gullies, truncated post-holes and graves were far from easy to define; often, the backfilled graves were almost impossible to define and whole surfaces had to be reduced to ensure that burials had not been missed.

At the same time as the computerised context record was being developed the linked artefact record was designed. This employed similar techniques, with many coded fields to facilitate recording of material as processed on site, and was very much focussed upon the individual recording of each artefact. By treating all artefacts and indeed ecofacts as individual items, recorded in detail, extensive analysis could be undertaken by computer without overemphasis on some aspects of the record. The distributions of material, particularly in the buried soils, could be studied in detail through plots generated during the excavation process.

\section{Integrating the Record Contexts, Objects and Space}

By the mid 1980's the introduction of the Electronic Distance Meter (EDM), the forerunner of the total-stations so familiar on excavations today, enabled all finds to be easily and individually plotted with simple software and working strategies designed to combine the 3D locational data with the detailed object records. The combination of on-site recording of context and finds data allowed us to change what were unnecessarily complex excavation strategies that unnecessarily expanded the record. Linear features, such as ditches, which extended over several hundred metres, had by convention been divided up into uniform segments of defined length, each of which was allocated its own context numbers, substantially because this allowed the rough location of bulk collected finds to be isolated. With individual 3D recording of each object this approach was unnecessary and long linear features, which frequently appeared to have the 'same' filling characteristics and deposits extending for very long distances, could be allocated contexts only on the basis of the deposits themselves without irrelevant subdivision. True distributions could be plotted and variability of material distribution within very long features could be examined without the compromise introduced by segment based recording. The field recording system at a relatively early stages is presented in Philip Barker's 'Understanding Archaeological Excavation' (1986, 113-117, Figs 47a-47i) and a little later in the third edition of his 'Techniques of Archaeological Excavation' (1995, 187- 192, Figs 57-61); a more recent assessment can be read in Internet Archaeology 27 (Powlesland and May 2010).

In contrast with the rapid adoption of Electronic Distance Meters, followed by Total Stations (TSt) with built in data loggers for on-site survey, hand-held datalogging of excavation data has been conspicuous by its absence on archaeological excavations almost everywhere, although now, after more than 30 years, the concept of recording using mobile phones or tablet computers is just beginning to see widespread adoption. In Britain, the work of Dr. Nick Ryan and associates from the computing department of the University of Kent also pioneered a number of applications using a variety of different instruments; similarly, this work had too little effect upon mainstream fieldwork (Morse, Ryan and Pascoe 1998; Pascoe, Morse and Ryan 1998).

Theadoption of the TSt for use on site provided the basis for improved accuracy in field survey and may well have increased the speed of survey; at the same time, it provided an opportunity to develop practices that, for all the speed and 'accuracy', actually compromised the record. I remember with horror, having introduced the potential for the use of the TSt for finds recording and survey during excavation to a team in Scandinavia during the mid 1980's, I returned to visit a year later to find that the principle use of the TSt was to record the centre points of post holes which were mapped only by plotting a circle around the logged centre-point; any evidence about the form or shape of the post-hole that might give an insight into understanding the structural elements beyond a simple plan were thus excluded from the record.

The use of the TSt for pre-excavation planning of large features during and after the removal of top-soil on large open-area excavations can be very useful; however, if one is to use the TSt to plan features during or after excavation, one has to be aware of the impact of taking occasional points around a feature or deposit and then joining the dots', which does not equate with a carefully observed and drawn large scale plan. The primary 


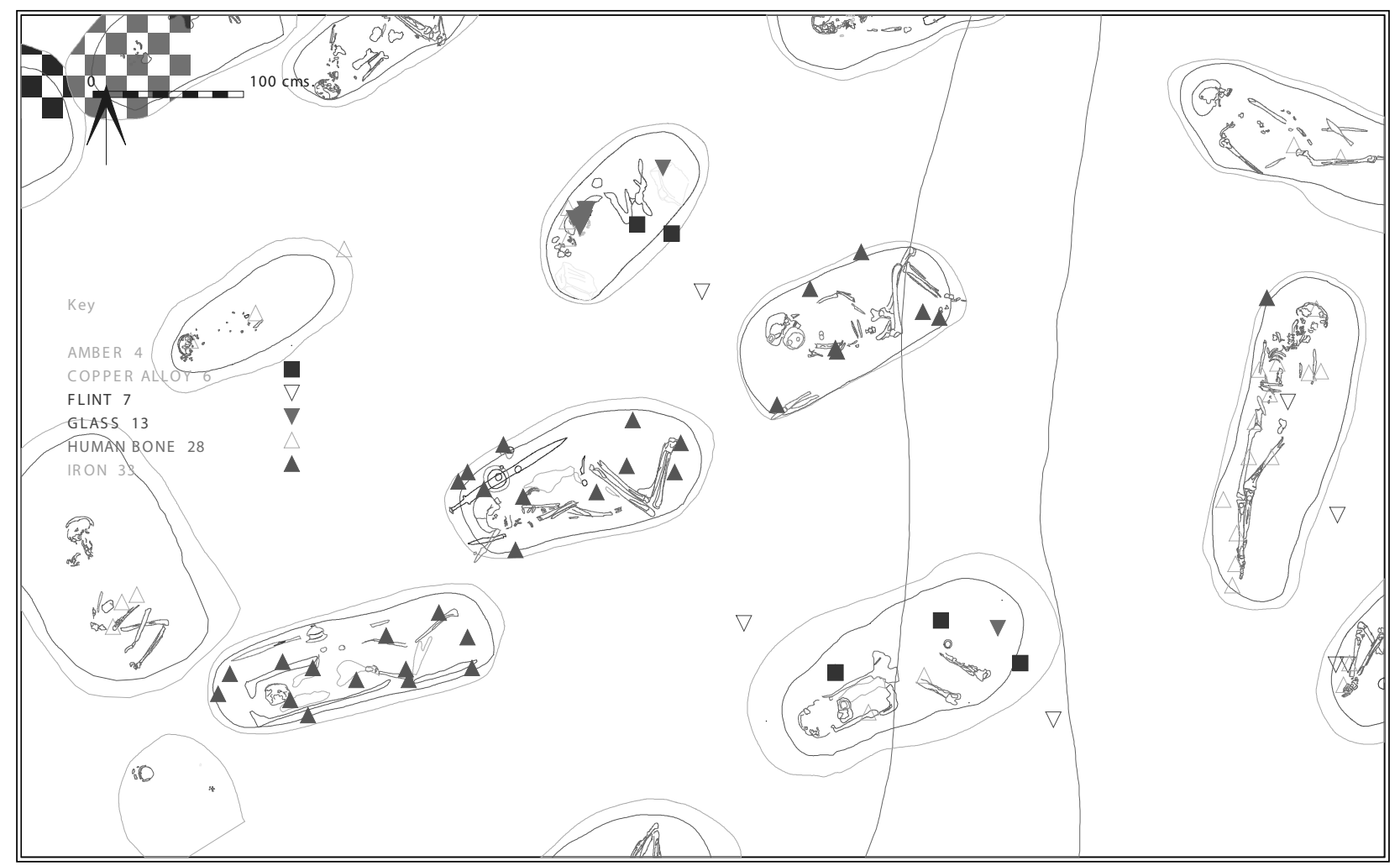

Figure 1. Plan showing a number of Early Anglo-Saxon graves and their contents generated directly from the digitised site plan and object database. Only minimal additional work is needed to re-position the key of plotted objects for publication purposes.

concern in recording is to observe and document and to engage with the subtleties that result from the site formation, de-formation and excavation processes, whilst remembering that excavation is a one-off experiment and that one cannot return to re-examine contexts once they have been destroyed. Our objectives with regard to digital recording in the field were never focussed upon the speed of recording but on the recorders' engagement with the excavation and recording process in response to the questions raised by having to complete each field in the structured context record.

As someone who had spent a number of years drawing highly detailed, full-colour, multi-context site plans of excavations in Winchester, and funding my way through university through the creation of publication drawings for other people's excavation reports or books, the computerised record was of only limited interest without some sort of plotting and digital mapping facility. Having developed software to handle the recording of the contexts and objects using handheld computers in the field, it was realised that there was no suitable or affordable software for visually managing and plotting the data being collected. At this stage, for instance, AutoCAD was just one of many CAD programmes and ArcInfo, besides being totally unaffordable to independent rescue archaeologists like ourselves, required computing resources far beyond those available and was exceptionally difficult to use even to produce simple distribution maps. From the point of the writer's personal sanity, the decision to write the software necessary for plotting and mapping the excavations in progress may not have been the best choice, but it was more a case of one thing leading to another and so, as soon as one problem was resolved or a solution found, another was identified and things went on for more than three decades.

Thousands of evening hours were invested in the development of tailor-made software, G-Sys, that remains the primary data management and integration tool used by the LRC in all its fieldwork. Although classed as a GIS, the software's focus is upon integration, management, supporting 


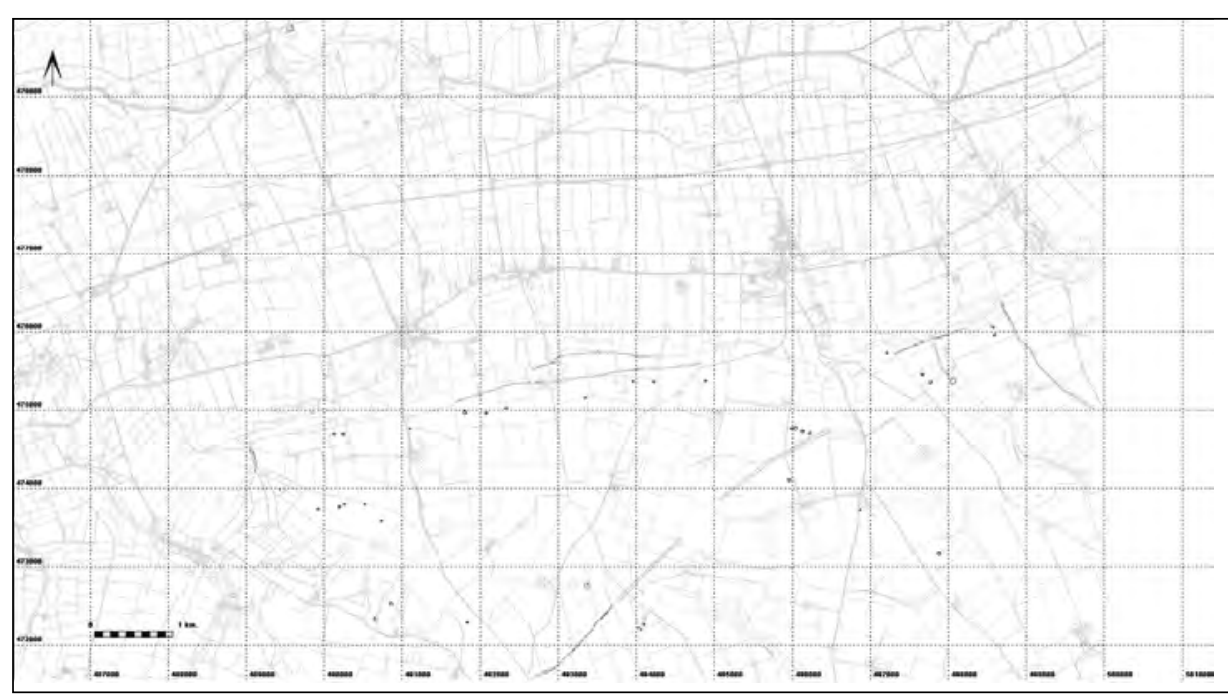

Figure 2. Plot of recorded archaeological evidence in the vicinity of West Heslerton in the mid-1970s. A picture reflecting apparent emptiness rather than intensive human activity.

publication and providing 3D and 4D functions not found in other software (Fig. 1). The strategic engagement with computerised recording that has characterised the work of the LRC owes much to the simple fact that, as director of the Trust, I was able to make the application of computing a key part of the archaeological process.

At the sametime, as our attention was focussed upon the increasing integration of computing within the excavation and recording strategy, we also reviewed other 'standard techniques' used in publication and started to use pencil for all our pottery drawings and in the case of glass beads, watercolours which in both cases were far more subtle mediums than the conventional inked line drawings (for examples see Powlesland, Haughton and Hanson 1986, and Haughton and Powlesland 1999).

The primary drive to identify ways in which we could adapt our work practices to fit with the computing resources available was directed towards the excavation process; the computing hardware and software was merely another tool used to develop consistent and integrated approaches to data gathering and resource management.

As the excavations progressed at increasing scales it became very clear that we needed not to stand on the edge and look in, but to stand in the middle and look out in order to understand the complex archaeology and context of our tiny excavations which, even when they covered as much as $4 \mathrm{Ha}$ in a single excavation season, were, in landscape terms, microscopic.

\section{Looking into the Landscape}

The multi-period and multitude of different activities, including domestic settlement, burial, agriculture and ritual, represented in the archaeological record encountered during excavation demanded a more comprehensive approach to the landscape as a whole than could be achieved through excavation alone. As early as 1980 a regular programme of air photography was begun to examine the hinterland of the primary excavation area centred around the Cook's Quarry site in West Heslerton. When work began here, the 'site' was situated in a distributional blank like a barely started canvas, with one or two known 'sites' that had been recorded in the 1950s and 1960s. The Vale of Pickering had been considered a large wetland area not suitable for later prehistoric to early medieval settlement and other activity. A number of exceptions apply including Star Carr, Staple Howe, the Roman fort and associated settlements at Malton and its immediate hinterland, and a number of early church, monastic and castle sites situated around the periphery of the Vale. Formerly the Vale had been the setting for the largest inland body of open water in Britain, which may have encouraged the acceptance of the desperately small level of known archaeological evidence compared to the wealth of evidence known about, for example, the Yorkshire Wolds, a landscape which during the 19th century was dominated by a vast collection of upstanding 


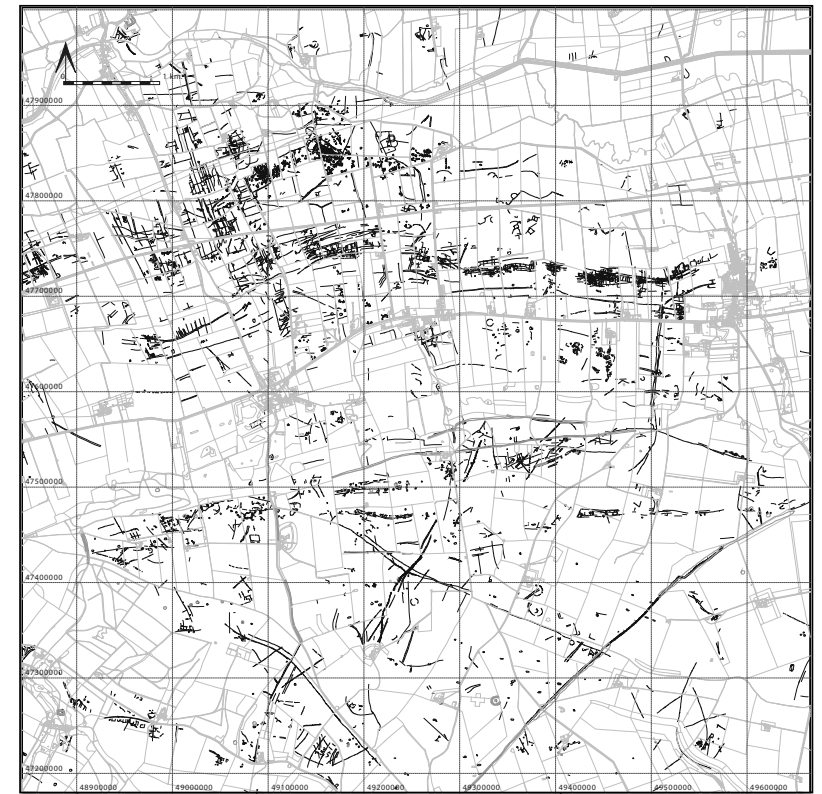

Figure 3. Plot of crop-mark features and earthwork features (in green) around West Heslerton as mapped in the 1990s. The vast number of features identified reflects the returns of more than 25 years of airborne observation and should be compared with the plot in Fig. 2.

earthen monuments in the form of Barrows and Linear Earthworks (Fig. 2). The status of the Wolds in the tradition of British Archaeology, as second only to Wessex in the literature pertaining to the Neolithic and Bronze Age, was established through the work of great antiquarians including Canon Greenwell, with whom 'the General', Augustus LaneFox Pitt- Rivers worked, and, most importantly, J . R. Mortimer, who between them not only emptied the contents of hundreds of burial mounds but also began to excavate scientifically and to record the excavation process (Greenwell and Rolleston 1877; Mortimer 1905).

Air photographic research by the LRC was principally targeted towards a primary research area of $8 \times 10 \mathrm{~km}$, centred upon West Heslerton and later expanded to $20 \mathrm{x} 10 \mathrm{~km}$. This was the focus of regular and repeated low level air-photography undertaken through many short flights in a Cessna light aircraft made possiblethrough the generosity of a local farmer and pilot. This work transformed our impression of theisolated evidenceat Cook's Quarry and indicated that the extraordinary archaeology being excavated had lain substantially unobserved because of the presence of the blown sand which had buried the earthen monuments so visible on the Wolds, and which had for the most part such poor agricultural value that it was rarely used for intensive cereal crops, which generate the most prolific crop- marks (Fig. 3). At the time the land to the east and west of the Cook's Quarry site was described by a land agent as 'virtually worthless'; it is with great regret that we did not consider buying land at that point in order to secure the future of the buried archaeology, but the evidence of archaeological presence and the realisation that the next three decades would see developments in industrialised agriculture that would threaten the fragile but exceptionally well preserved deposits, could not have been anticipated.

A fundamental component of the air photography programme was the fact that the results of each flight could easily be integrated within the mapping and documentation system developed for the excavation data in a seamless environment that combined point, plan and image data in a single user environment. It is difficult to determine the degree to which the research into the wider landscape carried out through conventional oblique air-photography, and later using airborne multi-spectral imaging systems, was made possible on account of the extant data management systems, but it is unlikely that this strand of research would have developed in the direction it did without it.

\section{Revisiting Old Landscapes to Increase the View}

We had dabbled in geophysical survey during the very early 1980s, but the response had been poor and the technique was not revisited until nearly a decade had passed and we experimented with the use of geophysical survey to assist excavation strategy development by integrating survey within the excavation programme.

Surveys undertaken on our behalf by English Heritage as part of the massive research excavation programme on an Early Anglo-Saxon or Anglian settlement site at West Heslerton, sponsored by English Heritage, indicated that, in contrast with our earlier tests at Cook's Quarry, exceptional results could be secured on the sandy and chalky soils occupied by the settlement. New experiments were conducted in which high resolution survey on a 


\begin{abstract}
$.25 \times .25 \mathrm{~m}$ grid were conducted over the excavation area after the ploughsoil, which acts as a magnetic filter, had been removed (Powlesland 2009). The returns were both detailed and very clear, revealing even small features in areas where visibility on the stripped surface was poor on account of the difficult to read soils. The benefit of being able to survey the excavation areas as work continued, and to overlay finds plots and plans on a daily basis, meant that we were alerted to the presence of features that could not easily be seen on the ground, as well as identifying the best positions to place sections or open transects on features which, though poorly defined at the surface, could be clearly delimited in the geophysical surveys. This careful comparison with the distribution of the individual finds and the geophysical surveys revealed that in areas of the excavation linear features had clearly been cut through the buried soils at a position many centimetres above the point at which the features become visible enough to excavate; this had a tremendous bearing on the interpretation of the site stratigraphy. It is certain that this situation is not unique to West Heslerton and we need to be very aware that often during excavation we are unable to see the boundaries of features clearly until we have ourselves truncated them.
\end{abstract}

The exceptional results gained from the gradiometer surveys undertaken during the excavation coincided with a fall-off in the return from the air photographic programme. It appeared that we had reached saturation point in the returns from airborne remote sensing, an impression that once again was far from the truth, but reflected ground conditions in a way that was not to become obvious for a number of years. Although the impression that had emerged from many years of air photography indicated a landscape with a considerable resource of prehistoric and later archaeology, it was equally interspersed with gaps, gapsthatseemedillogical and potentially a reflection of conditions for crop- or soilmark formation rather than of human behaviour in thelandscape. As thelarge excavations on the AngloSaxon settlement drew to a close in the 1996/ 7, new experiments were conducted using gradiometers to investigate both the areas of recorded crop-marks and the 'empty' gaps in the overall picture. The settlement excavation, the first of its kind and scale in the North of England, was based on the principle that $100 \%$ of the site should be observed and then an appropriate sampling strategy, involving excavation of no less than $50 \%$ of any recognised feature or deposit, should be adopted. In developing a landscape-scale approach to geophysical survey it was considered that $100 \%$ of the area of interest should be investigated even if this included fields, paddocks and, on occasion, garden areas. Theresults of the airborne surveys transformed our view of a previously 'empty' landscape into one dominated by barrows, hengiform monuments and linear, albeit interrupted, ladder settlements'- described as such on account of linear arrangements of rectangular enclosures following trackways for many miles with the appearance of ladders laid out across the landscape, a characteristic settlement form of the Late Iron Age and continuing in this area through the Roman period (Derych 2012). In contrast with geomagnetic survey, which either returns a result or does not, determined by a limited range of variables which exclude climatic conditions, air-borne remote sensing is sensitive to the varied response over time to a wealth of different environmental conditions coupled with the nature of the subsoils, ground conditions, the crops being grown and the climatic conditions throughout the growing season, as well as the position of the viewer or recorder in the air.

The geophysical survey results, derived from single surveys rather than years of repeat observations, further transformed the picture that had emerged through the airborne remote sensing programme in a completely unanticipated fashion, returning results that challenged almost all our preconceptions whether concerned with the scale of the population from the Neolithic onwards, the distribution, density and extent of cemeteries or domestic activity from later prehistory to the late Anglo-Saxon period (3500 BCE to $950 \mathrm{CE}$ ) (Lyall and Powlesland 1986). Once again it can legitimately be claimed that the vast scale of the fieldwork conducted in the Vale of Pickering, whether the $30+\mathrm{Ha}$ of open area excavations, $1250 \mathrm{Ha}$ of high resolution geomagnetic survey and 200 sq km of repeat air photography, could not have been implemented without the underpinning provided by a computer based infrastructure in which the variety of data could be integrated, viewed and managed (Powlesland 2009; 2011).

The research strategy that evolved with the constantly changing results from these 
collective data collection sessions was triggered by an overwhelming dissatisfaction with so-called 'theoretical archaeology', which had emerged as a major 'research field' in academic institutions firstly in America and then in Britain and other parts of Europe. A blissful ignorance of what the so called 'new archaeology' was meant that for some years we were under the totally false impression that this was about scientific excavation coupled with better and more durable recording systems. If we are to develop or at least test archaeological theories then we need an appropriate data resource, and what we hopelessly lack in most locations is a resource that could be used for intelligent query. Even more problematic is the fact that in most environments we have absolutely no idea of how much archaeology thereis; in theoretical terms if we are to base theories on no data at all then some of us would argue that the theory is entirely worthless faced with an absence of evidence or proof testing. How can we hope to start building pictures of the past if they are based only upon the chance discovery of objects, landscape features or crop-marks and, at best, represent only a sample of unknown size from a population of evidence that is, similarly, of unknown size.

The research objectives of the LRC developed not so much out of any interest in any particular period or aspect of archaeology in the landscape but out of desire to find out how much archaeology exists in a particular piece of landscape and how this contrasts with other landscape areas within and beyond the vicinity. One of the by-products of the increase in the scale of 'commercially supported or developer funded excavations' has been a perceived need to adopt standardised and easily costed sampling programmes; however, how can you sensibly sample a completely unknown population.

\section{Changing the Past}

Having started in a landscape with apparently no archaeological evidence, the results of manyyears of research had demonstrated a landscape that was effectively full of activity, a landscape that revealed the characteristics of settlement patterns that not only gave new insights into the late prehistoric to medieval occupation and use of the landscape, but also contrasted with established views to a degree which implied the need for reassessment of almost every chronological period. This is not a situation entirely unique to the Vale of Pickering and is increasingly reflected in the results secured through excavations associated with very large scale infrastructure developments.

Being able to assemble and manage a vast chronological and spatial dataset using computing networks and software enables the users to ask questions that could not affordably be addressed using manual records and mapping systems. It is debatable, however, that the application of GIS has generated many 'new' discoveries resulting from automated analysis as some would argue. Too often we have heard enthusiastic papers delivered at meetings which refer to the creation of nearnessto-water buffers following rivers, which may or may not reveal previously unidentified settlement foci; how often would the same have been immediately obvious when examined by eye using a paper map? The most powerful analytical tools we are able to use are our eyes and our brains and we must accept that what we get out of our computing systems is as much defined by how and what we put into them as the questions that curiosity impels us to ask.

Developments in computing and internet platforms have led us to a position where we no longer have to shoe-horn our data collection, management and display strategies around the available computing power as we did 30 years ago. Advances in computing, particularly game computing, have supported the development of new applications that offer the potential to radically enhance the archaeological record, whilst the development of internet delivery systems means that we are able to deliver high density and quality data in a way that is scale independent anywhere in the world. The fact that we can now approach archaeological computing without the constraints that dictated how we worked in the past means that we can concentrate our efforts upon collecting richer data, asking better informed and more responsive questions and delivering better or more complete stories, the computers and software taking their proper place as everyday parts of the archaeological toolkit.

\section{The Publication Challenge}

The publication programme for the excavated Anglian Settlement Excavation at West Heslerton 


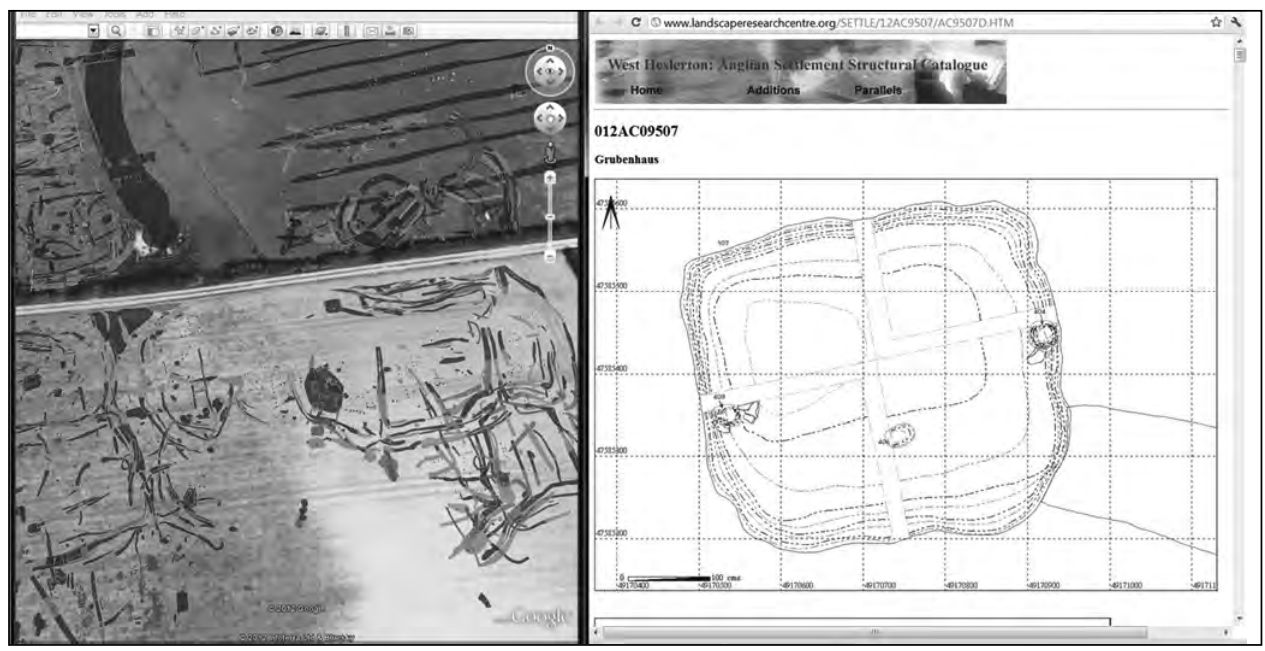

Figure 4. West Heslerton Anglian Settlement excavation archive viewed using the Google Earth plug-in with linked pages visible.

has, for many good reasons often beyond our control, taken far longer than it should have. However, the work devoted to designing record structures and identifying the sort of queries we should wish to ask, and in creating a Web-CD based archive means that the archive for this excavation is, to quote a number of colleagues, more accessible than for any other excavation of this scale in the world. The Web-CD, a concept designed for the distribution of archive data on CD Rom, employed simple web pages to manage the archived information and a full list of all the contexts that could be simply searched using a web browser.

Duringthepost-excavation stageitwasrealised that many of the specialists were less familiar with the use of conventional databases than we might have assumed and, in order to support external specialists, the primary archive was exported in Web-CD format, designed to provide the bulk of the primary data in a form that could be examined merely by typing in the key-id of any context. The structure is explained in a paper published in the fifth edition of Internet Archaeology during 1998, at atime when thearchivewas incomplete(Powlesland, Clemence and Lyall 1998). Subsequently the WebCD archive was completed and placed within the LRC webspace as an online archive. The archive comprises more than 25,000 contexts and includes the field drawings, digitised plans and sections, and finds lists covering more than 150,000 objects.

The Web-CD archiving process evolved over time such that later entries include not only URL links from the plans to the sections, but also active stratigraphic diagrams which allow you to travel through the record following the stratigraphic relationships. The searchability of this archive is based entirely upon the key-id structure adopted at the very beginning of the computerisation process; by employing a key-id that combines the site code, area code, and context number, any full context number may be searched for and found using Google (for an example, try typing 012AC09507 into Google and it should take you to the archive page for a single Grubenhaus). Interestingly, when the format was designed and defined the Google search engine did not exist. Clearly the potential of cloud based archives employing search engines to search through structured data has the potential to further transform our archiving and dissemination approaches employing off-site and open access storage facilities. The same data-set can also be examined through the visual interface provided by Google Earth, the volume of data in this case may challenge older computers with limited memory (LRC 2014a) (Fig. 4).

If online storage of archives in hyperlinked html files provides a powerful mechanism for the dissemination of the excavation data, coupled, of course, with the free distribution of the primary and complete databases in simple formats for those that wish to undertake their own searches and further research and analysis, the distribution and open management of the landscape data is both different and more problematic.

In contrast with excavation data, which is generated through the disassembly of the 
archaeological deposits under study, remote sensing - whether from the air or the ground - is primarily non-destructive, providing a method of observation without contact, with the acknowledged limitation of lack of verification. Certain types of intervention such as plough soil sieving or surface collection, which do not impact the buried and undisturbed stratigraphy, might be similarly classed as the primary resource is left intact. The combined excavations undertaken around West Heslerton have included the examination and recording of some 30,000 contexts; the remote sensing programmecombining airborne imaging and ground based geophysical surveys - have revealed a further 30,000 landscape features. In contrast with the excavations, the remote sensing programme lacks the interpretative precision possible in excavation or the supporting material culture evidence that can provide a precise chronological record.

More than anything else, the landscape based research shows that the term 'site', which is inward looking and tinged with myopia, is for the most part inappropriate and that much of the terminology that has developed based upon a site-centric view of landscapes is similarly inappropriate. We have used a number of different paradigms to encapsulate our views of landscape which have tended to rely upon a concept of multiple 'sites' swimming in a landscape of emptiness in which there is no control sample to give any idea of what happens between the 'sites'.

We have also tended to use the term 'Palimpsest' with regard to the evolution of the settled landscape, indicating - it would seema belief in discontinuity in the landscape - to take palimpsest literally, it refers to the re-use of vellum after earlier texts have been erased. With the exception of the introduction of Rig \& Furrow field systems, when large tracts of landscape are re-written excluding the major boundaries, the evidence points to the settled landscape reflecting a continuum with each evolution building upon and incorporating preceding facets of the human landscape rather than their complete removal and over-writing. Re-organisation of aspects of the later Prehistoric and Roman landscapes in part of Britain may have changed the overall view of the landscape but primarily absorbed or even embraced what was already in place rather than completely removing it.
Arguably the most significant feature of the research in the Vale of Pickering has been the proactiveapproach to seek or discover thearchaeological resource in a landscape otherwise seemingly empty. In this search for the past of a landscape we have had to address issues that do not necessarily arise in reactive research. Taking the evidence as documented in the mid 1970s we could have undertaken analysis of the distribution of Late Neolithic and Bronze Age burial complexes in the area, in which the Vale of Pickering was a total distributional blank situated between the active burial and indeed ritual environments of the Yorkshire Wolds and North York Moors. Our interpretations and any theory building derived from our analysis would have been fundamentally flawed on the basis of absence of evidence rather than the evidence of absence.

\section{Questions of Scale and Time}

The large-scale landscape survey in the Vale was triggered by the desire to identify the context for the exceptional archaeology that emerged through the excavations at Cook's Quarry, the Anglian Cemetery and then the associated settlement. Each of these excavations raised questions that countered our perceptions, whether it be the presence of an extensive group of Late Neolithic and Bronze Age burial mounds or Barrows in the base of the Vale - where such monuments, to quote a visitor to the excavations in 1980, 'should not exist'or the extensive open settlement and associated burial complex from the Late Bronze to Early Iron Age contemporary with the excavated palisaded enclosures at Staple Howe and Devil's Hill, both situated on the scarp slope of the Yorkshire Wolds immediately to the south. In the case of the Anglian cemetery, and perhaps more so in the case of the Anglian settlement, they pointed to higher populations and more structured settlements at a much greater scale than had previously been considered possible.

In trying to identify the context of the archaeology under excavation the landscape surveys have returned far more than was anticipated. Why this should be the case more than anything reflects upon our very limited understanding of rural space and the 'site' based paradigms that underpin most archaeological interpretation of landscape. What the landscape level surveys reveal is that the 


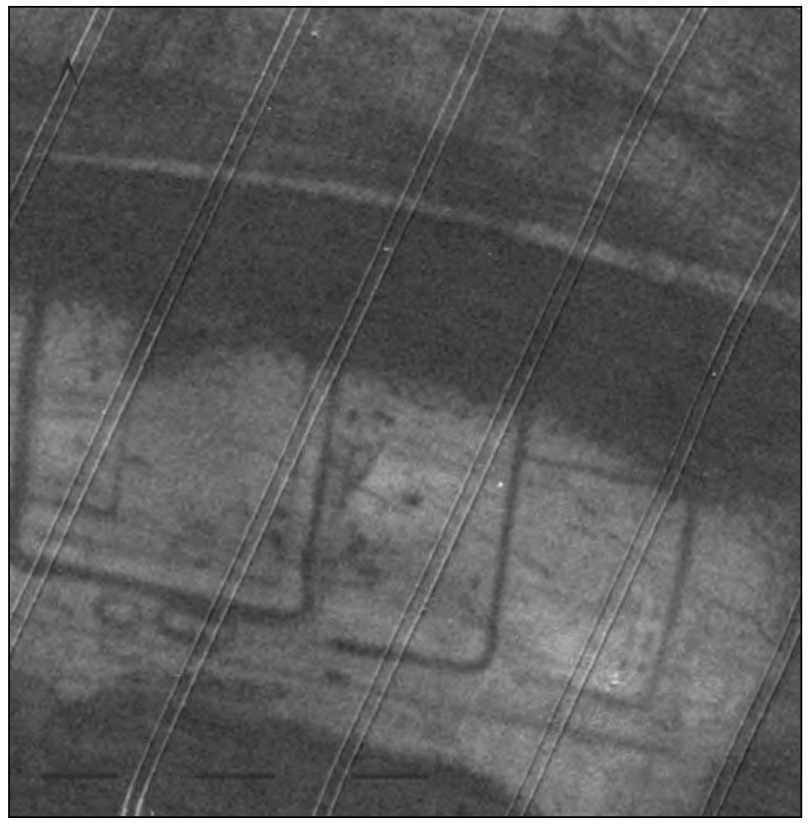

Figure 5. $8 \mathrm{~cm}$ resolution air photograph showing cropmarks of Iron Age/Roman enclosures in ripening barley.

unanticipated nature, density and chronological depth exposed in the excavations at West Heslerton are in no way exceptional. More significantly, they do truly represent a small sample of a general picture, a picture in which almost every square metre of the 'useable' landscape is utilised from a very early period, with the remarkable and arguably deliberate exclusion of some 'empty' areas. It should, of course, surprise us if this is not the case.

The challenges of investigating landscapes are quite different from those encountered during excavation and expose the weaknesses in which we, as archaeologists, have expressed time, the more so since we started using computers which allow us to unthinkingly generate snapshot images of space at any particular time, phase or period. We can perceive time as a collection of static points or as a continuum, but in reality the landscape of today and indeed at any time in the past - is a product of natural events and agencies overlain by human interference, all of which are linked to multiple time spaces, each changing at different and often variable rates. Since one of our tasks in research is to secure the preservation of potential data for future researchers and, to some degree, to defend the past from casual threats of development and industrialised agriculture, then it is critical that we

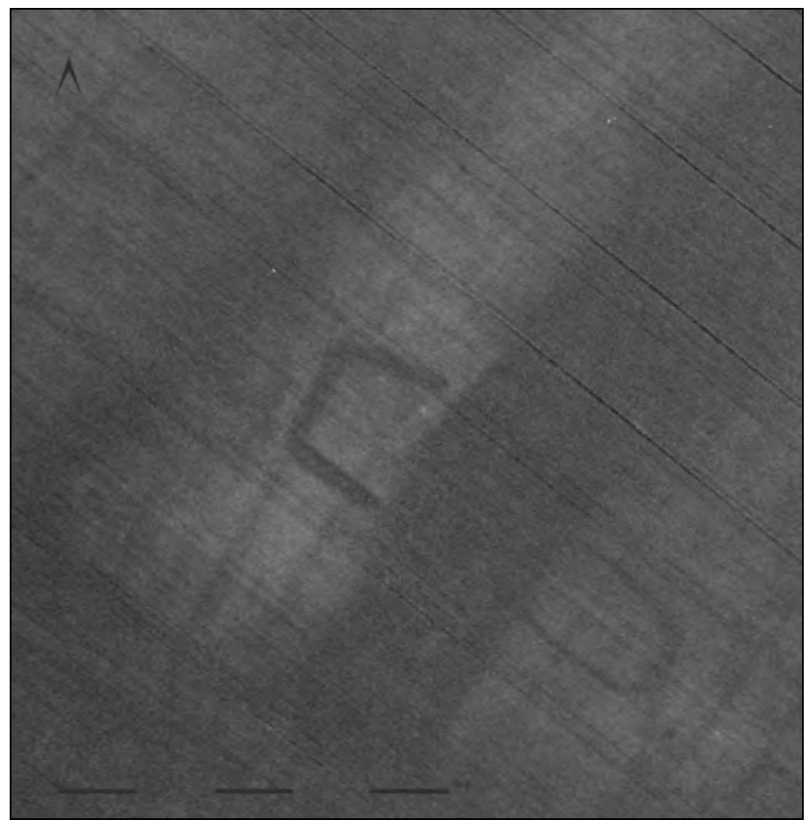

Figure 6. $8 \mathrm{~cm}$ resolution air photograph showing cropmarks in linseed of an enclosure crossing a dry valley (date unknown).

develop mechanisms that articulate the combined parameters of time and space in ways that inform the heritage management process.

In the past, GIS applications, which might be used to manage and display landscape scale data, were constrained by the extraordinarily high licensing fees charged for digital map data. In the work in the Vale of Pickering a working relationship with the local authority, North Yorkshire County Council, whose heritage management infrastructure has been greatly enhanced as a product of the research undertaken, provided the LRC with access to digital map data for shared projects. High resolution air-photographic and land surface modelling data from airborne radar survey was affordable when purchased from GetMapping and NextMAP under the LRCs charitable and academic research status. For our purposes these resources provided a better basemap for data integration than could be achieved using Ordnance Survey digital map data.

Much higher resolution $(8 \mathrm{~cm})$ vertical photography and Lidar data covering the core research area was secured through two research grants from the Natural Environment Research 


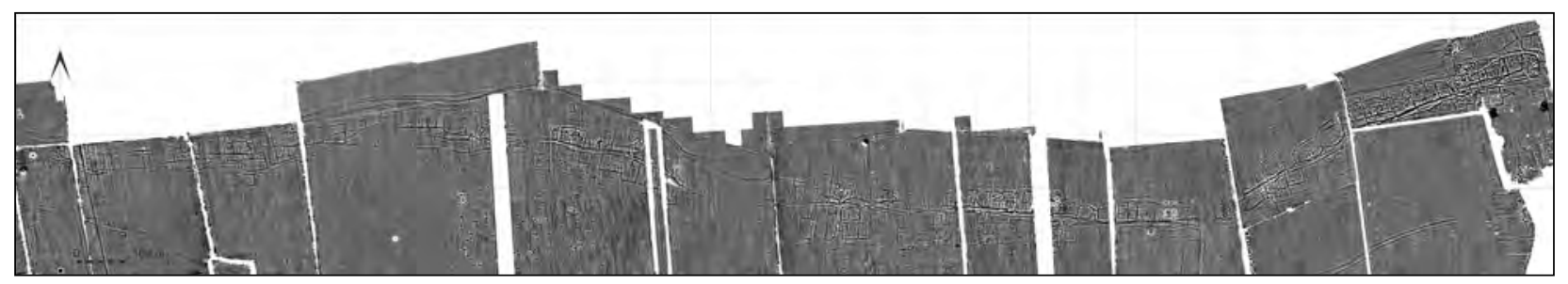

Figure 7. Detailed view showing c.3 $\mathrm{km}$ of contiguous geophysical survey to the east of West Heslerton showing sections of 'ladder settlement'following the edge of former wetlands with evidence of Roman flood defences comprising massive drainage ditches marking the northern boundary of the linear settlement complex.

Council in 1992 and 2005 as part of data grants for research on theapplication of multi-spectral imaging in particular (Powlesland, Lyall and Donoghue 1997) (see Figs 5 and 6). The returns from these two imaging projects exposed the limits of single flight air survey, with the first survey returning visible crop-marks covering more than $50 \%$ of all the cropmarks recorded in the area over the previous 15 years. The second flight did secure Lidar coverage but only a handful of crop-mark sites were visible. The multi-spectral projects were constrained by the relatively low resolution (1.5- $2 \mathrm{~m})$ of the multiand hyper-spectral instruments used and the target size of the archaeological features we were hoping to map. Serious enthusiasm for the method after the first flight resulted from the flight being undertaken at effectively exactly the right time in a year with high crop-mark visibility. Whilst the second project tempered some of that enthusiasm, it did confirm that, once we have multi-spectral sensors with recording resolutions in the range of $10-25 \mathrm{~cm}$, conventional air photography could arguably become redundant for some aspects of aerial research. Whilst technically this may become possible, in reality the eyes in the plane have a huge role in securing an understanding of the nature and interpretation of crop-marks which could otherwise easily be overlooked or hopelessly misunderstood. As with the field recording process it is critical once again with regard to multi-spectral surveys to appreciate that, no matter how exceptional is the available software, it is the eyes and brains of the operator that are able to identify and comprehend the archaeological content of these resources.

As mentioned above, the decision to undertake large area geophysics was made in response to the reduction in returns from airborne survey and the need to determine the degree to which the picture that had emerged from many years of airborne survey were a complete or incomplete reflection of the archaeological picture. It was critical to determine whether apparent gaps in the record were genuine gaps or simply locations where no evidence had been identified because of differing ground, crop or environmental conditions that had precluded the formation of crop or even soil marks.

The approach to mapping the results of the airborne and ground based surveys closely matched that developed for generating the digital archive for the excavations, with each individual feature digitised using a digitising tablet tracing over high resolution prints of the geo-referenced data-sets. The generation of digitised drawings by tracing the unedited field drawings produced high quality drawings that could be used for publication without any re-working. This approach is perhaps more time consuming than to use on-screen digitising, but the results are preferable in multi-scalar data sets that are viewed and output at any scale (see Fig. 10 below). The digitised vector results and supporting database support interrogation and plotting on the basis of a variety of criteria, but the scale of the dataset proved particularly challenging.

For daily use the geophysical imagery overlaid upon rectified air-photographs, with facilities to vary the transparency and order of the various image data sources, could happily be managed on a reasonably powerful desktop computer. Panning along the full $11 \mathrm{~km}$ by $2 \mathrm{~km}$ area that forms the primary geophysical survey zone is easy and a little mind blowing on a computer but difficult to output at any useful scale. That said, for more than a decade the LRC 'wallpaper', or rather a number of copies, have been viewed at conferences and meetings around the world, printed at scales of 1:2,000 or 1:1000, for smaller parts, on paper rolls measuring 4-6m in length (see Figs 7 and 8 ). 


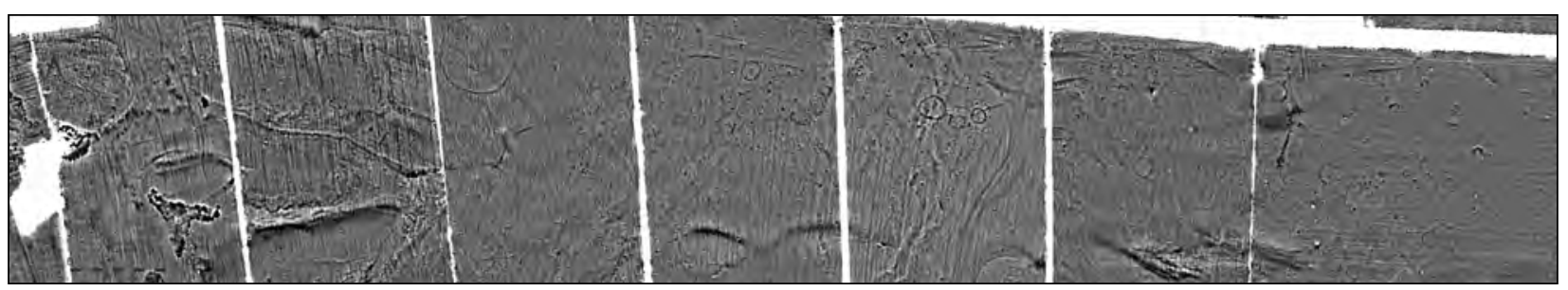

Figure 8. A view of part of the 'wallpaper' showing many kilometres of contiguous geomagnetic survey, in this case showing a vast spread of Late Neolithic and Bronze Age monuments including a small hengiform monument and a large number of round and other barrows in what excavations indicate must have been a maintained monumental landscape.

Clearly this approach is impractical as a publication strategy and, although a synthetic discussion of the results of this work is in process on paper, it is simply not possible to 'read' a sufficiently large area of ground at any time. The fact that all the data has been generated within a GIS environment made it ideal for distribution over the internet; this may seem simple to achieve, but there are inherent problems in publishing on the Web which are less critical with regard to publication on paper. The publication of complex multi-faceted datasets on the Web can be impacted by copyright issues covering underlying map or image data, whilst for very large and detailed surveys, such as that undertaken in the Vale of Pickering, onehas to beaware of thepotential impact upon landowners, who have generously given permission for survey to take place, and from treasure hunters searching for material in the fields over cemeteries or even domestic areas.

\section{Goggling at Google}

The Landscape Research Centre Digital Atlas of the Archaeology of the Vale of Pickering (LRC 2014b) was created to provide a mechanism for the general and academicpublic to access theinterpreted results of the air and ground based surveys (LRC 2014c). The choice of the Google Earth plugin as the development platform was both logical and free. It provides the underlying air-photographic mapping and 3D model free of charge and an interface that is easy for anyone to use to observe the data at any scale in $2 \mathrm{D}$ or $3 \mathrm{D}$, an interface that the majority of the computer using public can use. The delivery of large volumes of image and vector data at any scale on slow internet connections is difficult, but is at the core of the Google Earth toolkit. Perhaps the most significant feature is the facility to support 4D data, i.e. 3D data with a time component, which is one of the more significant challenges for the archaeologist. Dr. Ian J ohnson (University of Sydney) was a pioneer in developing dedicated software that addressed methods of articulating time in archaeological datasets through his TimeMap project (J ohnson 2004; J ohnson and Wilson 2003). The Google Earth plugin supports the use of time based information with reference both to imagery and to vector coverages. This function is most easily demonstrated by using Google Earth, zooming to a preferred location, and clicking on the small clock icon on the icon bar; where the Google image coverage has been updated, the user can use a small slider at the top left hand part of the screen to view a sequence of different images taken at different times over the same area. It is worth noting that the dates reported for the imagery in the lower centre of the screen seem not to be particularly accurate.

In the LRC Digital Atlas the digitised polygons outlining features identified in airborne and geophysical images are linked database records that include three time fields, one to indicate an assumed start date for the feature, a second to indicate when the feature ceases to be actively in use, and a third to indicate when the feature ceases to be a component of the landscape (Fig. 9). For example, a late Neolithic Barrow may have been constructed at 2200BC, continued to serve as a burial monument until 1800BC, but continue to be visible as a landscape feature until $\mathrm{AD} 1740$. By using the clock function in animation mode, the atlas presents feature data colour-coded according to the start date, and then shows features in grey until they are considered no longer to be a part of the visible landscape. The dates used are, of course, estimates based on interpretations, which may in some cases be best guesses, but if at any time in the future the precisionisincreased thedata-setcan beregenerated 


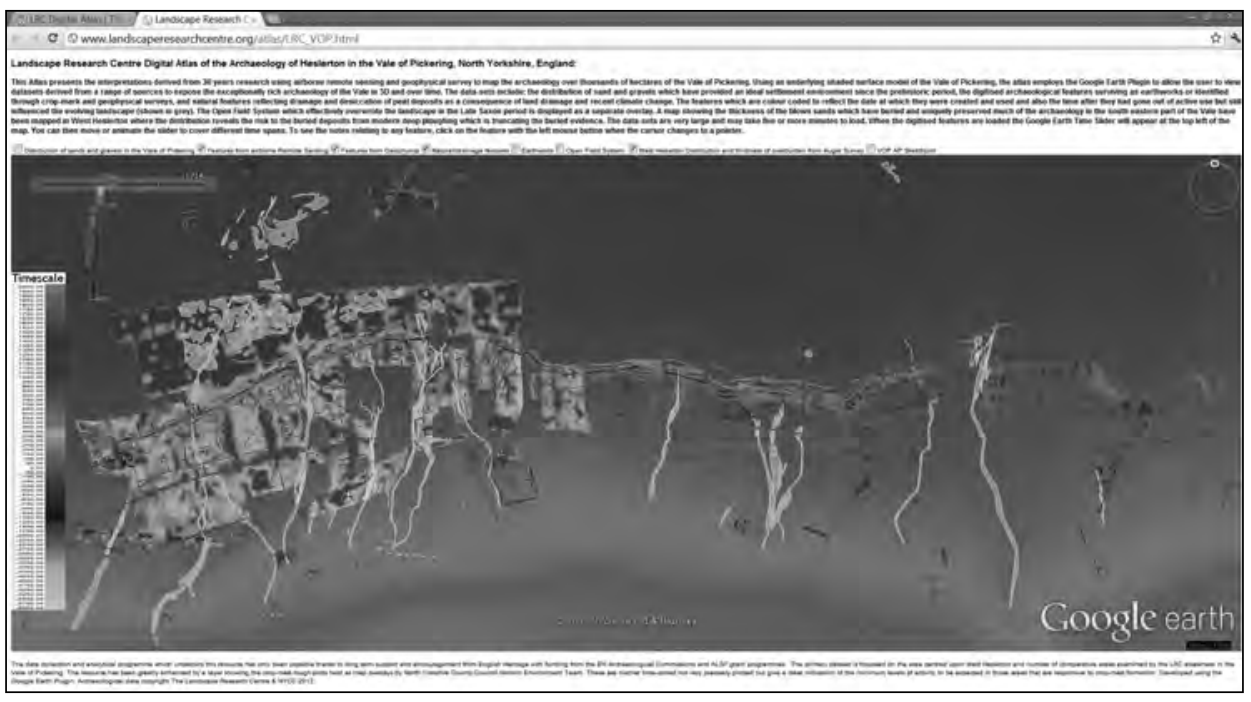

Figure 9. Screen dump of The Landscape Research Centre Digital Atlas of the archaeology of the Vale of Pickering: this view incorporates an underlying digital terrain model, a map covering part of the area showing the depth of protective layers of blown sands and the archaeological features reflecting the time-span from the later Prehistoric to Late-Medieval periods.

to reflect the updated database. The flexibility and simplicity provided by the Google Earth interface is ideally suited for presenting 4D spatial data, data that of course can also be interrogated by clicking on any feature with the mouse to report the basic feature details.

By using a freely available and easily used interface to the landscape survey data rather than a complex GIS platform, users from school children to the interested retired, heritage managers to developers, have access to a huge resource which should drive efforts to secure the future sustainability of an internationally significant archaeological resource. The digital Atlas has been compiled in two versions; the public access version incorporates a solid-model of the underlying topography beneath the feature plots, while a second research version excludes the underlying model which reveals the air-photographic map imagery as well as including the individual geophysical survey images and $8 \mathrm{~cm}$ resolution air photography.

The funding secured from English Heritage to enable us to carry out the large scale surveys during the last fifteen years was granted in the context of heritage sustainability and the risk from mineral extraction, and in order to secure a representative picture of the scale, density and range of the buried resource and determine how large an individual but comparable landscape chunk needs to be in order to develop appropriate assessment strategies. The collated data precisely satisfies the research designs under which it was collected but, more significantly, completely transforms our comprehension of the evolving landscape. Smaller pieces of work have provided a degree of environmental background to a landscape that now appears, on the basis of density and scale of activity, to be unique, but of course is not. Two features are perhaps unique - the scale, intensity and duration within which the same chunk of landscape has been under investigation, and the presence over a large part of the area of a late and post-glacial body of Aeolian sand, which has buried archaeological deposits in a way very rarely found in Britain, at depths between a few centimetres and, in places, morethan two metres, preservingoccupation surfaces and completely burying monuments, such as round barrows, in a landscape that at the surface is effectively featureless.

\section{Bringing it All Together}

A single representative example brings together the results of the excavations and landscape survey work where it concerns the archaeology of the Early Medieval or Early to Middle Saxon period. The discovery of the Anglian Cemetery during sand extraction in 1977 was followed by a small excavation which, at the time, was thought to have completely uncovered a small cemetery considered to be of only 35 graves (Powlesland, Haughton and Hanson 1986). Had it not been for the decision to investigate other areas which were due to be quarried, and a misunderstanding by English Heritage, the grantawarding body, that the cemetery was actually another site in Cambridgeshire (thought to be highly worthy of funding from central government), 


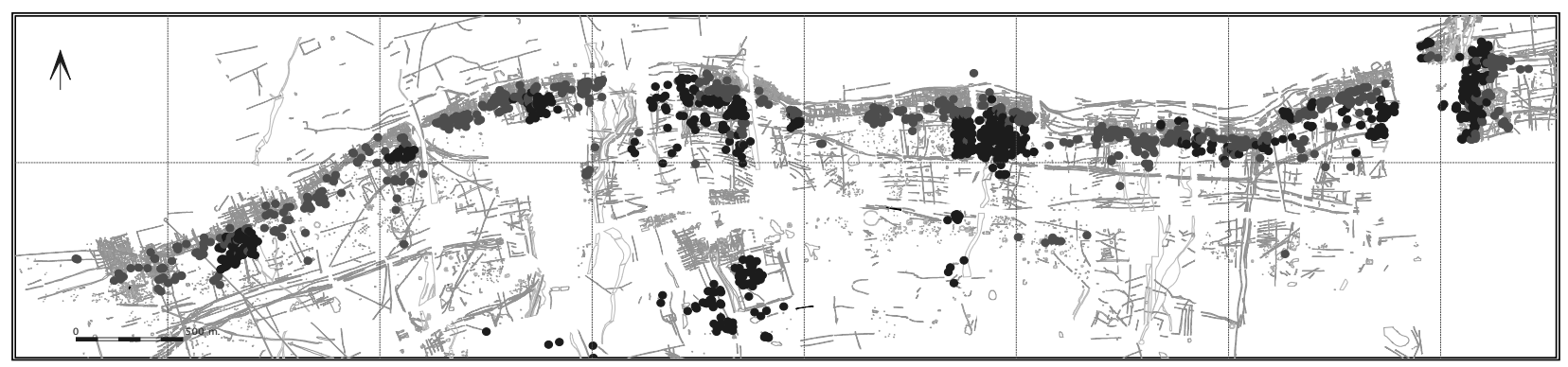

Figure 10. The combined results of recorded crop-marks and geophysical anomalies over an $7.5 \times 1.5 \mathrm{~km}$ area showing the distribution of late Iron Age and Roman 'barrowlets'- Red dots, thought to be cremation burial sites and EarlyMiddle Saxon Grubenhäuser (cavity floor Buildings - Blue dots) indicating high population densities within land-use patterns that arguably reflect high degrees of continuity from the Late Iron Age to Early Medieval periods.

nothing more might have happened and it is likely that the South Eastern quadrant of the Vale of Pickering may have remained substantially a distributional blank. Whilst excavation to the north of the Cemetery revealed an exceptional area of later prehistoric activity, including domestic, burial and monumental activity, the discovery of more burials in the cemetery led to further excavation which revealed a total cemetery size estimated to contain more that 350 burials in addition to the excavation of nearly $10 \mathrm{Ha}$ of other prehistoric activity (Haughton and Powlesland 1999). The rapid adoption of field based computerised recording was driven by the combined complexities of the scale and multi-period nature of the archaeology, and the fact that investigation was on a seasonal basis with a substantially volunteer workforce, without the sort of infrastructure present in the large urban rescue excavation units such as that of the Museum of London.

The discovery of the Anglian settlement at West Heslerton in 1984 during the later phases of the excavation of the cemetery resulted from a search in a logical location for which there was no convincing crop mark evidence; a proactive rather than chance discovery. In keeping with the academic view of the time and to some extent supported by the distribution of the trial trenches, it was estimated that the settlement might cover about $10 \mathrm{Ha}$. As subsequent excavation was to prove, thefull extent of theAnglian settlement was nearly $25 \mathrm{Ha}$ (Powlesland 1997; Powlesland et al. 1998). More significantly, its layout and development appeared not to conform to the received wisdom of the time, developed with reference to the settlements at Mucking, Essex and West Stow, Suffolk, where a model of development was based upon gradually shifting and short lived farmsteads rather than a substantial proto-village as in the case of West Heslerton (J ones 1973; 1974; 1979; 1980; West 1985). The suggestion that Early to Middle Saxon West Heslerton is an anomaly has been argued by some, and without the landscape survey this view could perhaps have been sustained (Wickham 2005).

Early Anglo-Saxon settlements incorporate two primary structural forms: highly uniform rectangular timber framed structures based on small post-settings, and Grubenhäuser, cavity floor buildings incorporating a large sub-floor pit that is generally filled with refuse after the buildings are dismantled and abandoned (Tipper 2004). These large pits, which can be over a metre deep and up to $8 \times 6 \mathrm{~m}$ in plan, generate a highly distinctive response when surveyed using magnetometers or gradiometers and, as long as the resolution of the survey is high enough, are easily interpreted in contrast with the post holes, which are only visible in magnetic surveys undertaken after removal of the plough-soil and even then infrequently (Fig. 10). The geophysical surveys to the East and West of West Heslerton have demonstrated the presence of more than 1,300 Grubenhäuser in 13 different clusters, two of which, at the present day villages of East Heslerton and Sherburn, indicate larger settlements than that at West Heslerton, thelatter example being twice the size. Smaller clusters of these structures at $c .800 \mathrm{~m}$ intervals indicate a hierarchy in these settlements as a whole but, most of all, rather than a landscape with widely distributed small farmsteads with a small population eking out a living, we have a fully active landscape supporting a large population utilising all available space, a situation that other 
evidence indicates was already the case from the Bronze Age onwards.

It is critically important that we should not be complacent about the results of this research and realise that this is the result of more than 30 years of continuous focus upon a single landscape applying every technique that was available to us. It indicates, however, not that the Vale of Pickering is unique, but that we should assume that it is representative of river valley settings throughout lowland eastern England. Sadly, the scale of discovery is such that there is no mechanism within current legislation that would allow for long-term preservation or funded sustainability of this resource.

\section{Crisis Point and the Future of the Past}

Although at the outset of this paper it was argued that the need for speed should not drive archaeological research, and particularly the choice of recording and data collection approach, 35 years is far too long. While there are very good arguments with regard to the major landscape survey that nearly 35 years of repeat air photography or over a decade of large scale geophysical survey has produced a stunning return, we cannot afford to use the same approach if we are to secure a future for the undiscovered resources of our past. At the same time as this research was taking place, the very resource being studied was being compromised; the blown sand that had protected exceptional deposits from damage for thousands of years continues to move, particularly when deeper ploughing brings it to the surface. Industrialised agriculture, the extensive use of chemical fertilisers and irrigation systems, have transformed the least productive sandy soils to make them ideal for the production of root crops, which are grown using increasingly massive tractors, and other plant, ploughing to depths that cut through the blown sands to the softer archaeological deposits beneath. Industrial farming has also had a devastating effect on the chalk Wolds, which contain the eastern end of the Vale of Pickering on the southern side; the ploughed landscape has turned white, owing to the very high quantities of broken chalk bedrock incorporated in the very thin 'ploughsoil'. The top-soils have migrated into the dry valleys leaving most of the land in conditions that were last present at the end of the last glaciation.
If the research in the Vale is not to have been a waste of time we need to apply the lessons learned, mostly from anecdotal observation, and approach other landscapes using greater efficiency. We have learned that changes in the nature of the crops grown, together with climate change, and combined with the truncation of buried features, means that we see crop-marks forming at different times than 35 years ago and that they are increasingly visible using vertical photography rather than the oblique approach that has dominated air photographic reconnaissance over the last 50 years. The use of multi-rotor photographic platforms or small drones offers the potential for repeatable GPS-controlled fly-overs of large areas and for generating images which modern hardware and software can rectify in 3D space, in a way not possible a few years ago. Ground based geophysical surveys need no longer be undertaken by walking backwards and forwards, covering hundreds of kilometres at metre intervals. Cart-based systems employing multiple closely based sensors and pulled behind quad bikes can generate high density accurate data logged under GPS control at ten times the rate possible on foot, so that $500 \mathrm{Ha}$ could be surveyed in couple of months rather than over a whole year (Gaffney et al. 2012; Trinks et al. 2010). In both of the above cases the quality and potential of the data returned is in no way diminished and, although collected and processed at rates we could not have imagined a decade ago, still require the same degree of attention with regard to interpretation, but even this is enhanced by having large areas of data to interpret at the same time.

\section{Back to the Drawing Board - Digital Photography Comes of Age}

During the last six years the LRC has been reengaging in looking at the field recording process which, regardless of any views of what is the right way to do anything', has been impacted by the economics of developer funded excavation. Pressures on time, in particular, have had a tremendous effect on the drawn record both for plans and sections. The huge improvements in digital cameras and computer hardware, particularly computer games technology, coupled with new instruments such as 3D scanners or software employing Structure From Motion, have provided new ways to enhance the documentation both of landscapes and excavations (Powlesland in press; Verhoeven 2011). Critically, 


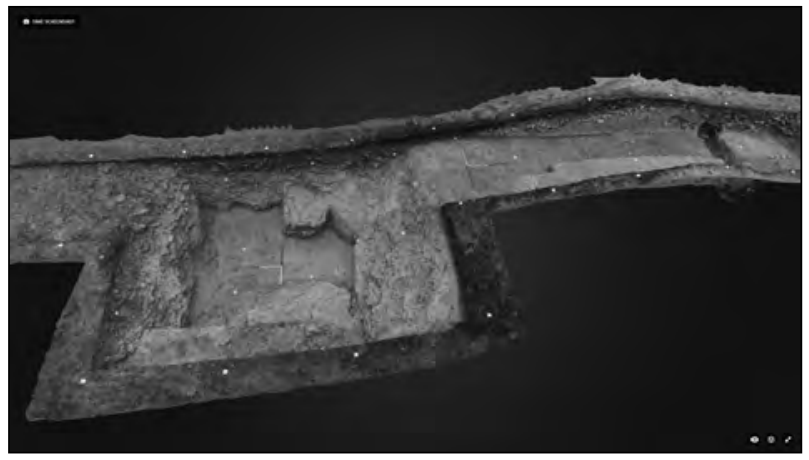

Figure 11. 3Di model of an excavated section through the ditch and surviving rampart of the Late Bronze Age Hillfort at Roulston Scar, North Yorkshire: the precision and viewing options of the model compare favourably with conventional 2D drawings, but should be accompanied by drawings indicating the excavators' interpretation.

these techniques neither 'preserve the site' nor replace the conventional approaches to recording as some would argue. Both approaches generate vast quantities of data, and there is increasingly a strong argument that 3D Scanning can far more cheaply be replaced by 3D Imaging (3Di) from photography in the majority of excavation contexts (Figs 11 and 12).

We should be concerned about the volumes of data that we gather and its long term preservation. The advent of effective resolution digital photography will almost certainly lead to a vast amount of record loss in the future, and it is likely that high resolution archival prints, which need not be very large, might provide the best secure medium for long term preservation of the digital imagery.

In the case of 3D point-clouds and 3Di we may have to contemplate storing only the primary data and metafiles, which document the sequence of steps that transformed that data to models which may be used for publication and published online at a reduced scale, on the basis that the metafiles can be used to automatically re-produce the finished results at any time without the need to store all the resulting data. What is very certain is that photographic textured 3D images can greatly enhance the black and white line drawings that are conventionally drawn in the field in a way that is far greater than single photographs which cannot record texture in the same way as a 3D Image. As such, the use of 3Di will transform our records and

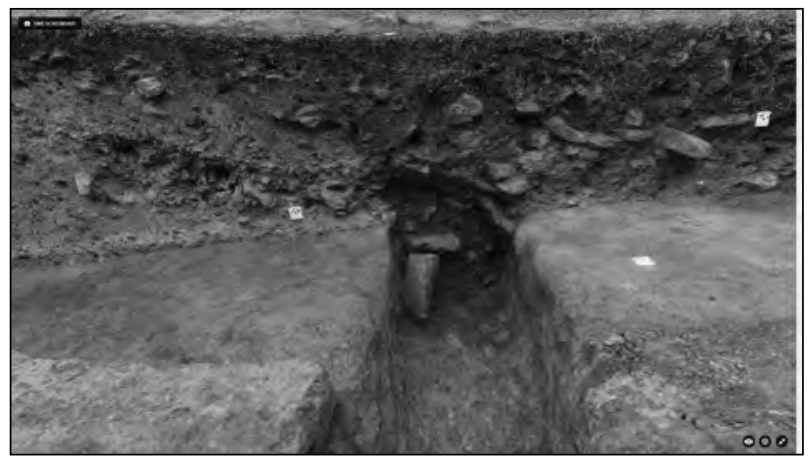

Figure 12. Detail view of the section seen in Fig. 11, showing how the 3Di model excels in being able to show the textural as well as colour variations in the stratigraphy. The texture recorded in this way, which can be enhanced through virtual lighting, is difficult if not impossible to document in conventional monochrome section drawings.

hopefully will give the field archaeologist more time to touch, feel and engage with the 'sites' that we destroy through excavation.

\section{Conclusions}

It would be entirely wrong to conclude on a negative point, and if one of the by-products of running a 35 year research project on the same small block of land in the rural North of Englanddescribed recently by a conservative Peer, Lord Howell, as 'the desolate north' with reference to its suitability for fracking for gas - is the realisation that had we known in the beginning what we know now, then we would either not have started the research at all or done something entirely different. The fact is that this research has 'changed the past', or at least our knowledge of it.

It is also a fact that the work could not have been done without the computing infrastructureand software that has supported the scaleand diversity of the work. The information gathered, combined and distributed on the web through the West Heslerton Settlement Excavation Archive and the Digital Atlas combines detailed and precise evidence from more than 35Ha of excavation and thousands of hectares of geophysical and airborne evidence.

However, the rapid destruction of the wellpreserved buried resource, sadly unnoticed for the first 30 years, highlights the need for strategic 
thinking if we are to identify and curate in a sustainable fashion other equivalent landscape samples, notjust in Britain butall over the globe. The research raises important issues about the term 'site' on the one hand, and the fences that 'contain', for instance, World Heritage Sites - or at least the bits of them that we know about. The research highlights the need for proactive investigation to identify the capacity of any portion of landscape for the many archaeologies that it may contain and to develop an intellectual resource that could underpin real theory building and testing. It also highlights the need for long term strategies; it must be appreciated that whilst there are numerous long running projects around the globe, a regular summer digging season undertaken for a few weeks every year is not the same as ongoing projects that run for years for 52 weeks a year.

There is clearly a need to develop entirely new approaches to securing the future of landscape archaeology, which are not based on the 'sites' discovered by chance, by the casual recovery of material culture evidence, or chance observation of a crop-mark. We need to remain alert to the fact that there has been a rapid increase in the number and clarity of crop-mark sites, not because they have goneunnoticed by the many keen air-photographers, but because truncation of the subsoil has increased the contrast between the archaeological features and the natural subsoil within which they were set. It is not always easy when we see a 'stunning' cropmark to appreciate that its quality more than likely reflects the degree of recent plough damage, and we should focus our attention on the fields next door where at present nothing is visible.

We also need to acknowledge the joy that can be had from undertaking fieldwork, and from sharing the results with thenew generations to whom will be bequeathed our torn and damaged landscapes - not by giving the odd lecture about 'the fun stuff', or a couple of weeks spent digging with a few moments of shovelling, trowelling, digitising etc., but by the regular challenge of on-landscape engagement.

Wemustalso beawarethateverynowand then, when we think the buried soils and floor deposits that will rewrite the lives of our predecessors have been completely stuffed, we not only discover a fragment still intact but also a farmer or landowner who is willing to change their landscape by converting arable land to grazing land, thus limiting the plough damage which is having such a devastating and invisible effect on our rural archaeology. This has recently become a reality thanks to European Union Agricultural Subsidies covering about $100 \mathrm{Ha}$ of the most intensive areas of identified but unexamined archaeology in West and East Heslerton.

Finally, we must remember also to engage with emptiness - those places within a landscape full of past peoples in which we can seenothing. J ust because we cannot see any sign of past activity it does not mean that nothing happened there; it may simply besomewhere that something very important happened without leaving the sort of archaeological grammar in the form of cut or built features that we seek to find through remote sensing, and this will require yet another approach to discover the secret of why a perfectly useful piece of land appears to us to have not been used - one of the most difficult things to explain to heritage managers in local authority development control.

Dominic Powlesland

From the middle of the Vale of Pickering, just past midsummer.

\section{Bibliography}

Barker, P. A. 1986. Understanding Archaeological Excavation. London: Batsford.

Barker, P. A. 1995. Techniques of Archaeological Excavation. London: Batsford.

Derych, A. 2012. "The Roman Paradox: Linear Enclosure Complexes in the Yorkshire Wolds." The Yorkshire Archaeological Forum 1:33-42.

Gaffney, C., V. Gaffney, W. Neubauer, E. Baldwin, H. Chapman, P. Garwood, H. Moulden, T. Sparrow, R. Bates, K. Löcker, A. Hinterleitner, I. Trinks, E. Nau, T. Zitz, S. Floery, G. Verhoeven, and M. Doneus. 2012. "The Stonehenge Hidden Landscapes Project." Archaeological Prospection 19 (2):147- 155.

Greenwell, W., and G. Rolleston. 1877. British barrows, a record of the examination of sepulchral mounds in 
Across Space and Time. Papers from the 41st Conference on

Computer Applications and Quantitative Methods in Archaeology. Perth, 25-28 March 2013

various parts of England. Oxford: Clarendon Press.

Haughton, C. A., and D. J. Powlesland. 1999. West Heslerton. TheAnglian Cemetery. Yedingham: Landscape Research Centre.

Johnson, I. 2004. "Putting time on the map: using TimeMap for map animation and web delivery." GeoInformatics 7 (5):26- 29.

J ohnson, I., and A. Wilson 2003. "The TimeMap Project: Developing Time-Based GIS Display for Cultural Data." J ournal of GIS in Archaeology 1:123- 135.

Jones, M. 1973. "An ancient landscape palimpsest at Mucking." Essex Archaeology and History 5:6- 12.

J ones, M. 1974. “The Mucking excavations 1974.”J ournal of the Thurrock Local History Society 18:32- 41.

Jones, M. 1979. "Saxon sunken huts: problems of interpretation." Archaeological J ournal 136:53-9.

Jones, M. 1980. "Mucking and the Early Saxon rural settlements in Essex." In Archaeology in Essex to $\mathrm{AD}$ 1500, edited by D. Buckley, 82- 89. London: Council for British Archaeology.

LRC 2014a. "West Heslerton Anglo-Saxon Settlement Archive in Google Earth." Accessed J une 15. http:// thelrc. wordpress.com/ 2012/ 01/ 26/ west-heslerton-anglosaxon-settlement-archive-in-google-earth/ .

LRC 2014b. “LRCDigital Atlas.” Accessed J une 15. http:// thelrc.wordpress.com/lrc-digital-atlas/ .

LRC 2014c. "Landscape Research Centre Digital Atlas of the Archaeology of Heslerton in the Vale of Pickering, North Yorkshire, England." Accessed J une 15. http:// www.landscaperesearchcentre.org/atlas/LRC_VOP.html.

Lyall, J., and D. J. Powlesland. 1996. "The application of high resolution fluxgate gradiometery as an aid to excavation planning and strategy formulation." Internet Archaeology 1. Last modified September 11, 1996. doi:10.11141/ia.1.3.

Morse, D. R., N. Ryan and J. Pascoe. 1998. "Enhanced reality fieldwork using hand-held computers in the field." Life Sciences Educational Computing 9 (1):18- 20.
Mortimer, J. R. 1905. Forty years' researches in British and Saxon burial mounds of East Yorkshire. London: A. Brown and sons.

Pascoe, J., D. R. Morse, and N. Ryan. 1998. “Developing Personal Technology for the Field. "Personal Technologies 2 (1):28- 36.

Powlesland, D. J . 1980. The Heslerton Parish Project. 20 years of archaeological research in the Vale of Pickering (LRC 2000). Yedingham: Landscape Research Centre. Accessed J une 15. http:// www.landscaperesearchcentre. org/ html/hpp.htm.

Powlesland, D. J . 1997. "Early Anglo-Saxon Settlements, Structures form and layout." In The Anglo-Saxons from the Migration Period to the8th Century: An Ethnographic Perspective, edited by J. Hines. Woodbridge: Boydell Press.

Powlesland, D. J. 2009. "Why Bother? Large scale geomagnetic survey and the quest for Real Archaeology." In Seeing the Unseen, Geophysics and Landscape Archaeology, edited by S. Campana and S. Piro, 167- 182. Leiden: CRC Press/ Balkema.

Powlesland, D. J. 2011. "Identifying the Unimaginable Managing the Unmanageable." In Remote Sensing for Archaeological Heritage Management: Proceedings of the 11th EAC Heritage Management Symposium, Reykjavík, Iceland, 25-27 March 2010, edited by D. Cowley, 17- 32. Budapest: Archaeolingua.

Powlesland, D. J . in press. Enhancing the Archaeological Record - 3D Imaging from Free Range Photography: A guide for Field Archaeologists.

Powlesland, D. J., et al. 1998. "The West Heslerton Assessment." Internet Archaeology 5. Last modified March 23, 1999. doi:10.11141/ia.5.4.

Powlesland D. J ., H. Clemence, and J . Lyall. 1998. “West Heslerton: WEB-CD. The application of HTML and WEB Tools for creating a distibuted excavation archive in the form of a WEB-CD." Internet Archaeology 5. Last modified October 5, 1998. doi:10.11141/ia.5.2.

Powlesland, D. J., C. A. Haughton, and J. H. Hanson. 1986. "Excavations at Heslerton, North Yorkshire 197882." Archaeological J ournal 143:53- 173. 
Powlesland, D. J., J. Lyall, and D. Donoghue. 1997. "Enhancing the record through remote sensing: the application and integration of multi-sensor, non-invasive remote sensing techniques for the enhancement of the Sites and Monuments Record, Heslerton Parish Project, N. Yorkshire, England." Internet Archaeology 2. Last modified April 18, 1997. http://intarch.ac.uk/journal/ issue2/pld/index.html.

Powlesland, D.J ., and K. May. 2010. “DigIT: Archaeological Summary Report and Experiments in Digital Recording in the Field." Internet Archaeology 27. Last modified February 2, 2010. doi:10.11141/ia.27.2.

Tipper, J. 2004. The Grubenhaus in Anglo-Saxon England: an analysis and interpretation of the evidence from a most distinctive building type. Yedingham: Landscape Research Centre.

Trinks, I., B. Johansson, J. Gustafsson, J. Emilsson, J. Friborg, C. Gustafsson, J. Nissen, and A. Hinterleitner. 2010. "Efficient, large-scale archaeological prospection using a true three-dimensional ground-penetrating Radar Array system." Archaeological Prospection 17 (3):175186.

Verhoeven, G. 2011. "Taking computer vision aloft Archaeological three-dimensional reconstructions from aerial photographs with PhotoScan." Archaeological Prospection 18 (1):67- 73.

YouTube 2014. "Eddie Izzard - Speed Archaeology." Accessed June 15. https://www.youtube.com/ watch?v=YdqlrOrQr6o.

West, S. E. 1985. West Stow, the Anglo-Saxon Village, Suffolk. Ipswich: Suffolk County Planning Department.

Wickham, C. 2005. Framing the Early Middle Ages: Europe and the Mediterranean, 40o-80o. Oxford: Oxford University Press. 


\title{
Competition and Culture Change in Prehistoric Socio-Environmental Systems
}

\author{
Carolin Vegvari and Robert A. Foley \\ University of Cambridge, UK
}

\begin{abstract}
:
Competition for resources can be considered a major driving force for social and cultural change in human societies. Here, we suggest two directly observable measures of competition at the individual and group levels: 1) the percentage of individuals within a group that do not meet their resource requirements and 2) the percentage of groups within a population in which at least one individual does not meet his/ her resource requirements. We use these measures within an agent-based simulation framework to investigate the potential influence of patterns of resource distribution and social rules on the intensity of competition among human individuals and among social groups. We then relate competition intensity to cultural developments in prehistoric populations and make suggestions how measures of competition can be incorporated into archaeological and anthropological research.
\end{abstract}

\section{Keywords:}

Competition, Culture Change, Complex Systems Simulation

\section{Introduction}

Culture is one of the most important means by which humans adapt to their environment and create their own ecological niche (Odling-Smee et al. 2003). As such cultural traits and entire cultural systems are subject to natural selection. In this paper we investigate how competition can drive the natural selection of cultural adaptations. We ask how competition among individuals and groups affects the levels of cultural complexity in different human populations under different environmental circumstances. For this purpose, we design a spatially explicit agent-based simulation model that allows us to test a number of hypotheses on environmental attributes, the social characteristics of a population, the ensuing intensity of competition and its effect on cultural complexity. We use agentbased modelling because it is an intuitive way of analysing human populations and their behaviour in a specified environmental context. Moreover, evolutionary outcomes are always the product of adaptive as well as historical factors. Both of these can be easily incorporated into agent-based models as individuals are modelled independently and can store information of past events.

Corresponding author:cv275@cam.ac.uk

\subsection{Culture and selection}

According to Darwin's theory of natural selection, there are four conditions for evolution by natural selection: reproduction, variance, inheritance and competition (Darwin 1859). We can find all these conditions in the context of human culture. While culture may have many meanings, from an information-theoretical perspective culture can be defined as socially acquired information that governs behaviour. Individual items of information or cultural traits are passed on from one individual to another more or less faithfully (reproduction and inheritance), and different individuals may express different variants of a cultural trait (variation).

Consequently, we can hypothesise that competition and selection may also play a role in cultural evolution. However, when we talk about culture we have to distinguish between two different - if not entirely separate - modes of selection: cultural selection and natural selection. The differential survival of cultural traits in human populations is called cultural selection (Boyd and Richerson 1985; Cavalli-Sforza and Feldman 1981). The mechanisms of cultural selection and evolution have been comprehensively discussed elsewhere (e.g. Mesoudi 2011). Here we are interested in how human-environment interactions can give rise to competition among human individuals and groups. 


\subsection{Competition}

Competition for resources occurs when the amount of resources is restricted and there are more individuals than resources. Theoretically we can distinguish between two types of competition, scramble and contest competition. Scramble competition occurs when all individuals have equal access to resources. Individuals lose access to resources if others find and use them first. In contrast, contest competition occurs when individuals or groups of individuals can exclude others from access to resources (Boone 2002; Sterck etal. 1997). In practice these types of competition are not mutually exclusive and occur along a continuum. Which type of competition predominates depends on the "defendability" and hence the nature and distribution of resources. The resources of huntingand-gathering societies are typically less defendable than those of agricultural societies. Therefore, we can assume that scramble competition may have been relatively more important in pre-agricultural than in agricultural societies (Bowles and Choi 2013).

Competition is difficult to measure in nature and can only be assessed indirectly by the effect it has on individuals or groups. Most competition models in the biological sciences do not measure competition directly but refer to its consequences, for example population extinction or stable coexistence. A popular technique of modelling competition in biology is the Gause-Lotka-Volterra equation system which has also been applied to language competition (e.g. Kandler and Steele 2008; May and Leonard 1975; Rozdilsky and Stone 2001). In this model system, the negative effect of competition by one population on the growth rate of another is proportional to the sizes of both populations. The proportionality constant indicates the strength of competition.

For the purpose of our analysis, we want to measure competition directly. We define two measures of competition among individuals and groups that can be directly observed in our simulation framework. Thus, we define withingroup competition as the percentage of individuals within a group that do not meet their resource requirements. Similarly, we define between-group competition as the percentage of groups within a population in which at least one individual does not meet his/her resource requirements. We also measure the total competition as the percentage of all individuals within the total population that cannot meet their resource requirements.

\subsection{Hypotheses}

Based on these definitions, we investigate the effect of environmental resource distribution, social interaction and resource pressure on cultural complexity. We formulate the following hypotheses. 1) Competition levels within and among groups will be higher in patchy environments than in environments with a continuous resource distribution. The reason is that individuals will aggregate inside resource patches and cannot easily mitigate increasing competition by moving to nearby patches. 2) Greater distances between resource patches will result in higher between-group and within-group competition levels, as greater distances prove a bigger obstacle to migration. 3) Bigger patch sizes will decrease competition both within and among groups, because groups can distribute freely within patches. 4) Social contacts among groups will increase competition within and among groups. In our model social contacts among groups include finding mating partners in other groups and learning cultural traits from members of other groups. Consequently, intergroup contacts may increase the number of potential mating partners and therefore the reproductive rate. Note that here we do not consider resource sharing which has the potential of decreasing competition among individuals and groups (e.g. Premo 2005). 5) Higher resource pressure will increase competition within and among groups. 6) If fertility and thus the population grouth rate are linked to resource availability, higher resource availability will increase withinand between-group competition. 7) According to our definition between-group competition will rise faster than within-group competition, but will be less sensitive to small changes in environmental conditions.

\section{Methods}

(For full model descriptions according to the standard protocol for agent-based models following Grimm et al. 2006, see Appendix B. Please email the corresponding author to obtain the source code.) 


\subsection{Model 1: Resource distribution and intergroup contact}

We propose an agent-based simulation model in which the behaviour of low-level entities, agents as representations of human individuals, gives rise to properties on higher organisational levels. We consider three organisational levels: individuals, groups of individuals, and the total population. Each individual is a member of a group, and all groups together constitute the total population. Individuals can be male or female and reproduce sexually. For simplicity groups are not internally structured in this set of analyses.

The model environment consists of a grid of 50 x 50 squares. Squares within resource patches contain the same amount of one generalised resource. Squares outside of resource patches contain zero resource units. One group can occupy one square. As individuals consume resources within their group's square at a fixed rate, group size is limited by resource availability. If individuals fail to meet their minimum resource requirements they can migrate to a neighbouring square (see Appendix $\mathrm{B}$ for details). To keep environmental conditions constant, all resources are replenished at the beginning of each new time step. Individuals need to have a minimum age of fifteen time steps and a minimum energy value of six resource units before they can reproduce. Partners are chosen at random.

We analysed within-group and betweengroup competition levels in patchy environments for different sizes of resource patches $(1,2 \times 2,3 \times$ 3 squares) and distances between resource patches (1, 2, 3, 4 squares), and in the absence or presence of contact between groups (see Appendix B, Fig. 1 for example figures of patch configurations). We changed the amount of resource per square to 50 , 100 , or 500 resource units. Additionally, we ran the same simulations for a uniform distribution of resources. Each run starts with a group of fifty individuals. The simulation runs for 1000 time steps. For this analysis we measured within-group competition and between-group competition at the end of each simulation run. We compare the results of ten independent simulation runs for each scenario using Wilcoxon-rank-sum tests (Wilcoxon 1945). We did not consider cultural traits or varying resource pressures in this set of analyses.

\subsection{Model 2: Resource pressure}

Model 2 is an extension of model 1 in which we consider the effect of resource pressure on competition among groups and individuals and on cultural complexity. There is no one definition of cultural complexity that would fit all purposes. Cultural complexity may be represented by the number of different cultural traits in a population, for example, a population's tool-kit size or the number of different techno-units (Oswalt 1976). Cultural complexity may be evident in the number of layers of stratification or social heterogeneity of a population (McGuire 1983). Additionally, complexity can be identified in the number of different relationships among different cultural traits (Enquist et al. 2011). For the purpose of our study, we define cultural complexity operationally as the number of different cultural traits per individual in a population. This means we measure cultural complexity by the size of a trait list (represented by a vector in our simulation model).

Model 2 differs from model 1 as follows. The environment consists of a grid of $10 \times 10$ squares. Each group occupies one square. Each square contains equal amounts of ten different resources. We start each simulation with a group of fifty individuals. Individuals store their cultural traits in a vector. All individuals first have the same basic proficiency at the same cultural trait that enables them to exploit one specified environmental resource. Cultural traits correspond to a specified position in the cultural trait vector. The position of a trait in the vector determines which resource it can be applied to. The variants of each cultural trait are represented by integer values in the range of one to ten. The numerical value of each variant can be converted into the efficiency at extracting a particular resource by the following equation:

consumption rate $=$ basic rate $+($ trait value -1$) \times$ selection differential

The consumption rate corresponds to the resource extraction efficiency. The basic rate is the consumption rate if the cultural trait variant has a value of one. The selection differential is a key model parameter that determines the level of competition for resources and thereby the strength of selection. It can be interpreted, according to Lande and Arnold's (1983) original definition, as an estimate of the 
total selection on a trait, including both direct and indirect selection via selection on other correlated traits. Note, however, that for the sake of simplicity all traits in our model are uncorrelated.

If an individual does not meet the minimum resource requirements, he/ she randomly chooses another individual as a model and copies the cultural traits of the model. This means that individuals only invest in the acquisition of new or improved cultural skills if they are under resource stress. With a probability of five per cent the learner gets the trait wrong (copy error rate), so that the copied trait is either one unit higher or lower than the original trait variant of the cultural model (see Appendix B for details).

Once an individual has reached the highest possible value that a variant of a cultural trait can reach in our simulation, he/ she is able to invent an independent new cultural trait that will enable him/ her to exploit a new resource. This trait fills the next position in the trait vector. Thus, we assume that a sufficient proficiency and experience at previously existing technology is necessary to invent new technology. Inventing a new trait comes at a cost that is subtracted from the individual's energy score. If individuals do not have enough stored energy, they cannot invent new traits (see Appendix B ).

Immediately after invention, a new trait is always present with a value of one. By modification during learning more efficient variants can be invented. A trait can belost again, if it is reset to zero. Duringeach timestep, eachindividual onlyconsumes one resource, unless one resource is not enough to meet the minimum resource requirements. In this case, the individual tries to complement the missing resource units by consuming other resources. Resource energy is added to the individual's energy score. The energy scorecannot exceed 50 units. Since resources are always consumed in the same order they are effectively ranked according to preference.

Simulations run for 1000 timesteps. At the end of the simulation we measure the average number of cultural traits per individual, and within-group, between-group and total competition as defined in the introduction. We compare the results of ten independent simulation runs for each scenario using Wilcoxon-rank-sum tests (Wilcoxon 1945).

\section{Results}

All descriptivestatements of theresults section refer to the model results and not automatically to reality. We will discuss the results as they refer to our hypotheses stated in theintroduction. Please see Appendix A for tabulated values and statistics. One of our central findings is that no factor influencing competition (e.g. patch size, resource density, resource pressure, etc.) acts independently of other factors. This means that the impact and sometimes even the direction of one of these factors on competition are modulated by other factors. As we will argue in the discussion, therefore, considering individual factors in a complex system in isolation from other factors may lead to a distorted and incomplete assessment of their actual effects.

\subsection{Competition levels within and among groups} will be higher in patchy environments than in environments with a continuous resource distribution

As predicted, within-group competition is higher in environments with a patchy resource distribution than in environments with a continuous resource distribution. The difference is especially marked if the resource density within patches is high (Figs 1 and 2). Consequently, we may expect that social rules which mitigate within-group competition are most likely to arise in patchy environments. Examples for competition-mitigating behaviours are food-sharing, culturally mediated choices on birth spacing, and territoriality (Premo 2005; Read and LeBlanc 2003).

Between-group competition is not always higher in patchy than in continuous resource distributions. In fact, the highest levels of between-group competition occur in continuous resource distributions with high resource densities (Appendix A, Table 1). As proposed in hypothesis 7 , between-group competition tends to be generally high regardless of resource distribution. Therefore, we can hypothesise that differences in selection pressure between continuous and patchy resource distributions are mainly due to differences in withingroup competition levels. 


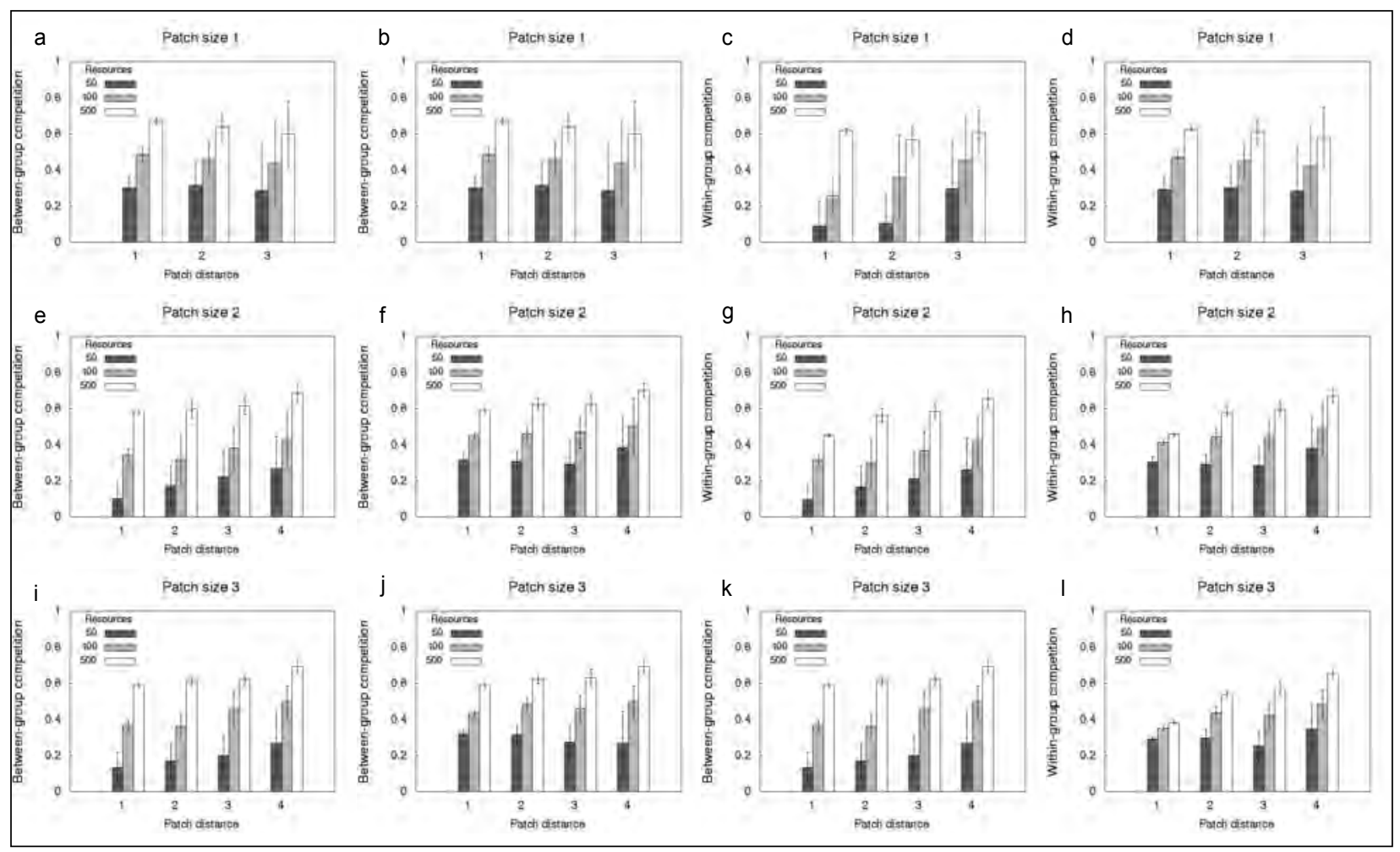

Figure 1. Between- and within-group competition levels in different resource distributions and in the absence or presence of contact among groups. $a$-d: patch size $1 \times 1$; e-h: patch size 2x2; i-l: patch size 3x3; a, e, i: between-group competition, no contact between different groups; $b$, $f$, $j$ : between-group competition, contact between different groups; $c, g, k$ : within-group competition, no contact between different groups; $d, h$, l: within-group competition, contact between different groups; $y$-axis: competition levels; $x$-axis: patch distance; the number of resource units per square in resource patches is indicated in grey scales (legend).

\subsection{Greater distances between resource patches will result in higher competition levels}

We find that both between-group and withingroup competition levels grow stronger as the distance between patches increases. However, this statement needs to be qualified. The effect of distance - as we pointed out earlier - is modulated by other variables. Thus, the effect of distance on competition levels becomes stronger as patches grow larger, more resource-dense, and in the absence of contact among groups (Appendix A, Tables 3 and 7). At lower resource densities and for smaller patches only big differences in distance significantly increase competition among or within groups. This is intuitive if we consider that populations in large patches with abundant resources can maintain higher reproductive rates. Therefore, these populations will be affected more severely by distance as an obstacle to migration once they have reached their habitat's resource limit. While both between-group and within-group competition grow larger with increasing distance between patches, within-group competition is more sensitive to distance at low resource-densities.

\subsection{Bigger patch sizes will decrease competition within and among groups}

The prediction holds for both betweenand within-group competition, but only under certain circumstances. The effect of patch size is much weaker than that of patch distance, and is modulated by other variables (Appendix A, Tables 4 and 8). Patch size has the strongest influence on competition levels if the distance between patches is small and the resource density within patches high. Therefore, we would expect patch size only to be important in habitats that are relatively resourceabundant and not too fragmented in the first place. 


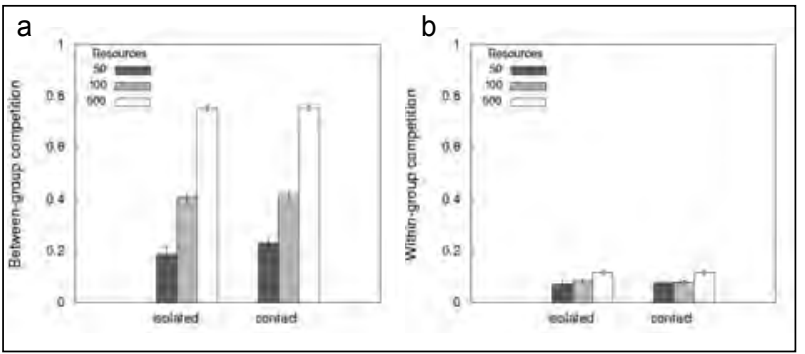

Figure 2. Between- and within-groups competition levels in environment with uniform resource distribution. a: between-group competition levels in isolated groups and groups in contact with other groups. b: within-group competition levels in isolated groups and groups in contact with other groups; the number of resource units per square in resource patches is indicated in grey scales (legend).

3.4 Social contacts among groups will increase between- and within-group competition

Social contacts among groups, which in model 1 correspond to mating contacts, indeed increase competition with similar strength among and within groups (Appendix A, Tables 5 and 9). However, social contacts do not increase competition in high-resource-density patches, because under these conditions groups are already so large that further contacts outside one's own group become insignificant. Unsurprisingly, if great distances between patches prevent contact among patches, social rules that allow contact among groups become negligible.

3.5 Higher resource pressure will increase competition within and among groups

When we consider the results of model 2 , we have to distinguish between two different cases. When there is no contact among groups (neither for mating nor for cultural transmission) between- and within-group competition and total competition increase linearly with resource pressure (Fig. 3; Appendix A, Tables 12, 13, 17, 20, 23). However, when there is contact among groups, within-group competition and total competition have a non-linear relationship with resource pressure. They increase up to a point, but further increases in resource pressure lead to a decrease in within-group and total competition. This effect is mediated by the interaction of resource pressure and population size. Very high resource pressure can reduce the population size which in turn reduces competition within the population and within groups.

At the same time, almost all groups are in competition with each other. So between-group competition is always near its maximum, and increasing resource pressure has little effect on between-group competition. Only differences at the very low end or the very high end of the resource pressure range cause significant differences in between-group competition. Consequently, the possibility for technological intensification and extensification in combination with resource pressure leads to a high intensity of competition among human groups.

Concerning the number of cultural traits per individual, our measure for cultural complexity, we find that increasing resource pressure is associated with higher cultural complexity of a population (Fig. 3; Appendix A, Tables 11 and 14). Resource pressure may act on populations via its effect on total and within-group competition. In addition, cultural complexity is also influenced by population size (see 3.6.).

3.6 If population growth is linked to resource availability, higher resource availability will increase between- and within-group competition

Our results for model 1 indicate that resource availability has the strongest and most consistent effect on competition of all factors examined (Appendix A, Tables 6 and 10). The explanation is that in the absence of innovation and the possibility to increase one's efficiency at a subsistence-related trait, higher resource availability is the only way to increase an individual's fertility. A higher birth rate increases within- and between-group competition.

If in addition innovation and intensification are considered (model 2), higher resource availability can increase the competition among groups (Appendix A, Table 21). Contrarily, higher resource availability tends to decrease the competition within groups and within the population as a whole (Appendix A, Tables 18 and 24). Thismeans that even though higher resource abundance can decrease the number of starving individuals within each 


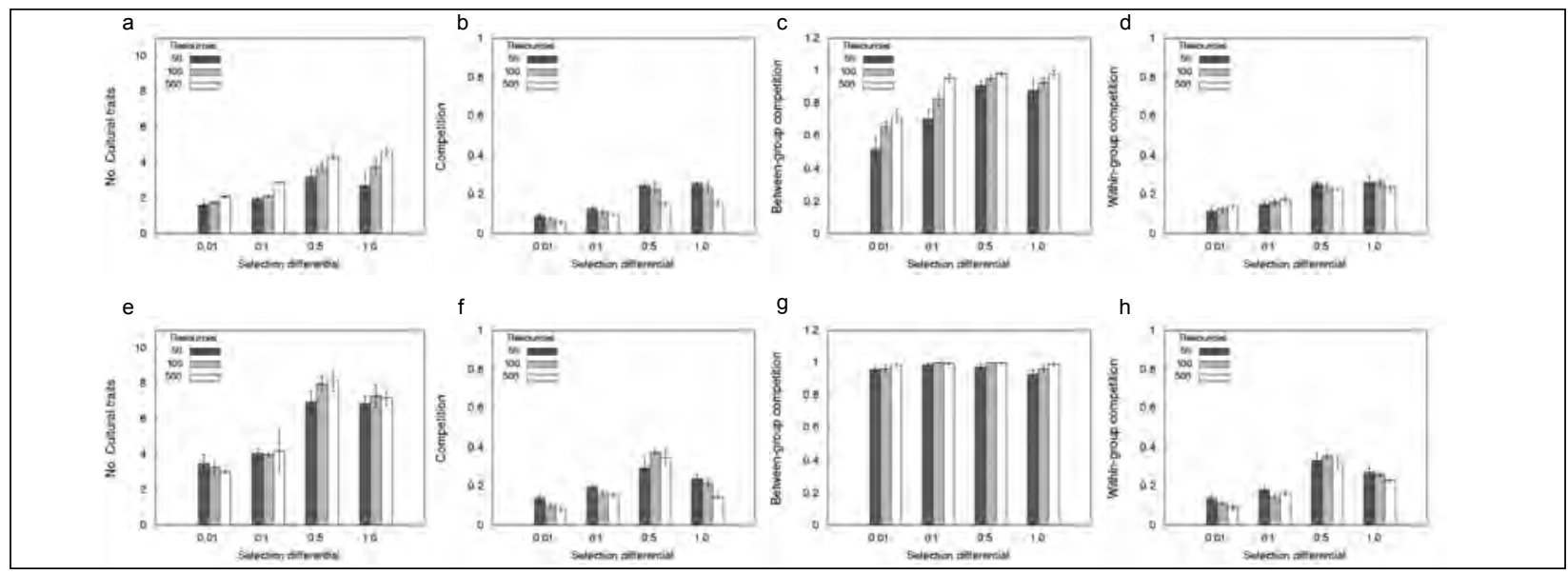

Figure 3. Mean number of cultural traits and competition intensity in populations under different levels of resource pressure and in the absence or presence of contact among groups. $a$, e: Mean number of cultural traits per individual; $b$, f: total competition; $c, g$ : between-group competition; $d$, h: within-group competition; a-d: no contact between different groups; $e$ - $h$ : contact between different groups; $x$-axis: selection differential; the number of resource units per square is indicated in grey scales (legend).

group, the number of groups in which at least one individual suffers resource shortfalls increases. The reason is that in our model individuals and groups exhibit almost perfect scramble competition. Others cannot be excluded from resources, unless one uses them first. The results resemble the equilibrium expected under perfect competition in an economic market (Vickers 1995).

Under certain circumstances higher resource abundance correlates with higher cultural complexity (Appendix A, Table 15). This may be explained by the resulting higher demographic growth rate and the consequent higher number of learners and cultural models (Henrich 2004; Powell et al. 2009). Population size itself, however, is a consequence of resource pressure and the ability of a population to utilise environmental resources, this means its adaptive cultural traits.

3.7 According to our definition, between-group competition will rise faster than within-group competition, but will be less sensitive to small changes in environmental conditions

From the results discussed above, we see that between-group competition is higher than within-group competition in environments with a continuous resource distribution and when we consider innovation and intensification in our model (Figs 2, 3). For patchy resource distributions, within- group competition is somewhat more sensitive to small changes in variables, but overall follows the same pattern as between-group competition. This does not mean that group selection would outweigh individual selection. In fact, as between-group competition seems to be less sensitive to changes in environmental conditions, it may be less relevant for driving behavioural adaptations. However, constantly high levels of between-group competition could explain the evolution of parochial altruism in human groups and may be a driving force of cultural diversification (Bowles 2006; Bowles 2009; Foley 2004).

\section{Discussion}

In our simulation model we consider human populations in their environment as complex adaptive systems. This means that human cultural behaviour is not only governed by social rules and demographic structure, but is also an adaptive response to environmental challenges. Conventional models of biological or cultural competition primarily aim to find conditions under which competing populations go extinct or coexist. In contrast, we use our model as an experimental test box to directly measure competition under various environmental and social circumstances, and to assess the effect of competition on the cultural attributes of human populations. Starting from the simulation results we can make a number 
of predictions about the archaeological record and past human cultural behaviour.

Our results suggest that competition among individuals and groups may be a non-negligible force in human cultural evolution. Competition can occur among individuals within groups and among groups within a population. In our model, competition mainly corresponds to scramble competition as found in egalitarian hunter-gatherer societies (Boone 2002). The resource density within patches and the distance between patches have the biggest effects on both within-group and betweengroup competition in patchy environments.

Increased competition within human populations in our model provides a potential driving force for cultural change, for example, if climate change leads to habitat fragmentation and patchy environmental resource distributions. In the context of archaeological cultures our results suggest that a moderate degree of resource patchiness or habitat fragmentation, as measured by the ratio of patch size to patch distance, may be associated with high levels of competition both within and among groups (Fahrig 2003). In addition, high resource abundance within patches markedly increases both within- and between-group competition.

One important resource for which human groups compete is water (Birdsell 1953; Bretzke et al. 2012). If we accept that resource competition may be a potent driver of culture change, this could explain why the earliest complex cultures developed in the Afro-Asiatic monsoon belt during a period of increased aridity following global environmental deterioration (Brooks 2006). Similar environmental conditions may be associated with more complex material culture in the South African Middle Stone Age (McCall 2007) and the European Upper Palaeolithic (Bocquet-Appel and Demars 2000).

However, the simulation results do not imply that environmental deterioration in itself would lead to more complex culture, or that competition is the main factor influencing cultural evolution. Rather, competition levels depend on relative resource availability and distribution, and on demographic developments. As such competition can actually be higher in environments in which resources are more abundant, but their distribution is clustered. The explanation is that the importance of competition relative to other limiting factors may be more important in abundant environments (Dhondt 2010).

In our second simulation model cultural complexity was influenced by both resource pressure (pressure to innovate new traits mediated by competition for resources) and population size (higher number of potential innovators). This means that there may not be one pre-defined set of social and environmental circumstances that allows for or drives the evolution of cultural complexity. The innovation of new traits to avoid competition due to resource pressure is known as extensification. The improvement by modification of existing resource-extraction technologies to gain a relative competitive advantage is called intensification (Boserup 1964). Both are implemented in our model. The simultaneous occurrence of intensification and extensification has been observed and studied in detail in Californian forager populations (Beaton 1991).

Interestingly, extensification at the population level has also been observed in biological experiments with stickleback populations. Svanbäck and Bolnik (2007) showed that intraspecific competition can drive diversity in resource use in natural populations. In sticklebacks, however, diversification at the population level is accompanied by increased specialisation and disruptive selection at the individual level (Bolnik 2004; Svanbäck and Bolnik 2005). This is what we can also observe in complex human societies (Henrich and Boyd 2008; Wahl 2002). Our model does not address the question of individual specialisation but could easily be extended. The empirical data suggest that social and economic "complexification" is mainly driven by within-group competition, but also by competitive interactions with other groups (Bolnik et al. 2010). Therefore, a better understanding of the causes and consequences of competition at the individual and group levels is necessary to understand the diverse evolutionary trajectories of different human cultures.

According to our definitions of within- and between-group competition, the latter is usually higher. We repeat that this does not mean that group selection would be stronger than selection 
at the individual level. It shows, however, that competition does not have to be equally distributed among individuals and groups. In our simulation model, we observe that in most circumstances many groups will have a few individuals who cannot meet their resource requirements. Conversely, we never observed that there were only a few groups in which most individuals could not meet their resource requirements at any given time. Presumably such groups would go extinct quickly if they cannot find a solution to counteract resource shortage (migration, exploitation of new resources etc.). The extinction of Neanderthals in Europe following the arrival of modern humans might be a possible example (Banks et al. 2006).

In terms of practical research, our definitions of within- and between-group competition can be more easily applied to living populations, for example by assessing the nutritional status or income of individuals. Quantifying competition in the archaeological record may be more difficult. Skeletal material can be studied to reconstruct the demographic development and health status of prehistoric human populations, as has been done for a comparison of pre-agricultural and early agricultural societies (Eshed et al. 2004; Lambert 2009). The prevalence of interpersonal violence and warfare between groups may also be inferred from skeletal records (Bowles 2009). However, the degree to which direct evidence for interpersonal violence reflects competition levels is contentious (Jurmain et al. 2009). In the absence of an extensive skeletal record, the intensity of competition can usually only be estimated indirectly. For instance, the study of faunal assemblages may provide indirect estimates for the type, intensity and causes of competition (Marín Arroyo 2009; Phoca-Cosmetatou 2009; Stiner et al. 1999). Further, environmental reconstructions and estimates of past population sizes could be used to estimate competition and how it may have been distributed among individuals and groups.

For this purpose we need to understand how individuals and groups adapt socially and culturally to specific sets of environmental conditions. As we have seen in the results section, environmental factors do not act in isolation. Their effect on human behaviour depends markedly on the state of other environmental factors and the existing social and cultural organisation of a human population. Consequently, a thorough understanding of human cultural systems in their environmental context requires an analytical approach that can integrate the multiplicity of environmental and social factors that influence human behaviour and may in turn be affected by human actions. Agent-based simulation modelling is a useful experimental toolbox to test hypotheses on human-environment interactions in the past. As such it can help us to elucidate the cultural and behavioural processes that have given rise to patterns in the archaeological record.

\section{Acknowledgements}

Carolin Vegvari is supported by a scholarship from the Studienstiftung des deutschen Volkes and holds a CHESS award from the University of Cambridge. We made use of the CamGrid HTPCfacilities provided by the University of Cambridge Computing Service.

\section{Bibliography}

Banks, W.E., F. d'Errico, A. Townsend Peterson, M. Kageyama, A. Sima, and M.-F. Sanchez-Goñi. 2008. "Neanderthal extinction by competitive exclusion." PLoS ONE 3 (12):e3972.

Beaton, J. M. 1991. "Extensification and intensification in central California prehistory.” Antiquity 65:946- 952.

Birdsell, J. B. 1953. “Some environmental and cultural factors influencing the structuring of Australian Aboriginal populations." The American Naturalist 87 (834, Supplement):171- 207.

Bocquet-Appel, J.-P., and P.-Y. Demars. 2000. "Population Kinetics in the Upper Palaeolithic in western Europe." J ournal of Archaeological Science 27:551- 570.

Bolnik, D. I. 2004. "Can intraspecific competition drive disruptive selection? An experimental test in natural populations of sticklebacks." Evolution 58 (3):608-618.

Bolnik, D. I., T. Ingram, W. E. Stutz, L. K. Snowberg, O. L. Lau, and J. S. Paull. 2010. "Ecological release from interspecific competition leads to decoupled changes in population and individual niche width." Proceedings of the Royal Society of London B 277:1789- 1797. 
Boone, J. L. 2002. "Subsistence strategies and early human population history: an evolutionary ecological perspective." World Archaeology 34 (1):6- 25.

Boserup, E. 1964. The Conditions of Agricultural Growth. Chicago: Aldine.

Bowles, S. 2006. "Group competition, reproductive leveling, and the evolution of human altruism." Science 314:1569- 1572.

Bowles, S. 2009. "Did warfare among ancestral huntergatherers affect the evolution of human social behaviors?" Science 324:1293- 1298.

Bowles, S., and J-K. Choi. 2013. "Coevolution of farming and private property during the early Holocene." Proceedings of the National Academy of the United States of America 110 (22):8830- 8835.

Boyd, R., and P. J. Richerson. 1985. Culture and the Evolutionary Process. Chicago: The University of Chicago Press.

Bretzke, K., P. Drechsler, and N. J. Conard. 2012. "Water availability and land use during the Upper and Epipalaeolithic in southwestern Syria." Journal of Archaeological Science 39:2272- 2279.

Brooks, N. 2006. "Cultural responses to aridity in the Middle Holocene and increased social complexity." Quaternary International 151:29- 49.

Cavalli-Sforza, L. L., and M. W. Feldman. 1981. Cultural Transmission and Evolution. Princeton: Princeton University Press.

Darwin, C. R. 1859. On the Origin of Species by Means of Natural Selection. London: J ohn Murray.

Dhondt, A. A. 2010. "Effects of competition on great and blue tit reproduction." J ournal of Animal Ecology 79:257- 265 .

Enquist, M., S. Ghirlanda, and K. Eriksson. 2011. "Modelling the Evolution and Diversity of Cumulative Culture." Philosophical Transactions of the Royal Society B 366:412- 423 .

Eshed, V., A. Gopher, T. B. Gage, and I. Hershkovitz 2004. "Has the transition to agriculture reshaped the demographic structure of prehistoric populations?" American J ournal of Physical Anthropology 12:315- 329.

Fahrig, L. 2003. "Effects of habitat fragmentation on biodiversity." Annual Review of Ecology, Evolution and Systematics 34:487- 515.

Foley, R. A. 2004. "The evolutionary ecology of linguistic diversity in human populations." In Traces of Ancestry: Studies in Honour of Colin Renfrew, edited by M. J ones, 61- 71. Cambridge: McDonald Institute for Archaeological Research.

Grimm, V., U. Berger, F. Bastiansen, S. Eliassen, V. Ginot, J. Giske, J. Goss-Custard, T. Grand, S. K. Heinz, G. Huse, A. Huth, J. U. Jepsen, C. J ørgensen, W. M. Mooij, B. Müller, Guy Pe'er, C. Piou, S. F. Railsback, A. M. Robbins, M. M. Robbins, E. Rossmanith, N. Rüger, E. Strand, S. Souissi, R. A. Stillman, R. Vabø, U. Visser, and D. L. DeAngelis. 2006. "A Standard Protocol for Describing Individual-Based and Agent-Based Models." Ecological Modelling 198:115- 126.

Henrich, J. 2004. “Demography and cultural evolution: how adaptive cultural processes can produce maladaptive losses: the Tasmanian case." American Antiquity 69 (2):197- 214 .

Henrich, J., and R. Boyd. 2008. "Division of labor, economic specialization, and the evolution of social stratification." Current Anthropology 49 (4):715- 724.

J urmain, R., E. J. Bartelink, A. Leventhal, V. Bellifemine, I. Nechayev, M. Atwood, and D. DiGiuseppe. 2009. "Paleoepidemiological patterns of interpersonal aggression in a prehistoric central California population from CA-ALA-329." American Journal of Physical Anthropology 139:462- 473.

Kandler, A. and J. Steele. 2008. "Ecological models of language competition." Biological Theory 3 (2):164- 173.

Lambert, P. M. 2009. "Health versus fitness: competing themes in the origins and spread of agriculture?" Current Anthropology 50 (5):603-608.

Lande, R. and S. J. Arnold. 1983. "The measurement of selection on correlated characters." Evolution 37 (6):1210- 1226 .

Marín Arroyo, A. B. 2009. “Economic adaptations during 
the LateGlacial in northern Spain: a simulation approach." Before Farming: the archaeology and anthropology of hunter-gatherers 2 (article 3):1- 18.

May, R. M. and W. J. Leonard. 1975. "Nonlinear aspects of competition between three species." SIAM J ournal of Applied Mathematics 29 (2):243- 253.

McCall, G. S. 2007. "Behavioral Ecological Models of Lithic Technology Change During the Later Middle Stone Age of South Africa." J ournal of Archaeological Science 34:1738- 1751.

McGuire, R. H. 1983. "Breaking Down Cultural Complexity: Inequality and Heterogeneity." Advances in Archaeological Method and Theory 6:91- 142.

Mesoudi, A. 2011. Cultural Evolution: How Darwinian Theory Can Explain Human Culture and Synthesize the Social Sciences. Chicago: The University of Chicago Press.

Odling-Smee, F. J., K. N. Laland, and M. W. Feldman. 2003. Niche Construction: The Neglected Process in Evolution. Princeton: Princeton University Press.

Oswalt, W. H. 1976. An Anthropological Analysis of FoodGetting Technology. New York: Wiley.

Phoca-Cosmetatou, N. 2009. "Specialisation and diversification: a tale of two subsistence strategies from Late Glacial Italy." Before Farming: the archaeology and anthropology of hunter-gatherers 3 (2):1- 29.

Powell, A., S. Shennan, and M. G. Thomas. 2009 “Late Pleistocene demography and the appearance of modern human behavior." Science 324:1298- 1301.

Premo, L. S. 2005. "Patchiness and prosociality: an agentbased model of Plio/ Pleistocene hominid food sharing." In Multi-Agent and Multi-Agent-Based Simulation: Lecture Notes in Computer Science Volume 3415, edited by P. Davidsson, B. Logan, and K. Takadama, 210-224. New York: Springer.

Read, D. W., and S. A. LeBlanc. 2003. "Population growth, carrying capacity, and conflict." Current Anthropology 44 (1):59- 76 .

Rozdilsky, I. D. and L. Stone. 2001. "Complexity can enhance stability in competitive systems." Ecology Letters 4:397- 400 .
Sterck, E. H. M., D. P. Watts, and C. P. van Schaik. 1997. "The evolution of female social relationships in nonhuman primates." Behavioral Ecology and Sociobiology 41:201309.

Stiner, M. C., N.D. Munro, T.A. Surovell, E. Tchernov, and O. Bar-Yosef. 1999. "Paleolithic population growth pulses evidenced by small animal exploitation." Science 283:190- 194.

Svanbäck, R., and D. I. Bolnik. 2005. "Intraspecific competition affects the strength of individual specialization: an optimal diet theory method." Evolutionary Ecology Research 7:993- 1012.

Svanbäck, R., and D. I. Bolnik. 2007. "Intraspecific competition drives increased resource use diversity within a natural population." Proceedings of the Royal Society of London B 274:839- 844.

Vickers, J. 1995. "Concepts of competition." Oxford Economic Papers 47:1- 23.

Wahl, L. M. 2002. "Evolving the division of labour: generalists, specialists and task allocation." Journal of Theoretical Biology 219:371- 388.

Wilcoxon, F. 1945. "Individual comparisons by ranking methods." Biometrics Bulletin 1(6):80- 83. 


\title{
Agent-based Modelling and Archaeological Hypothesis Testing: the Case Study of the European Lower Palaeolithic
}

\author{
Iza Romanowska \\ University of Southampton, UK
}

\begin{abstract}
:
SHEEP (Simulating Hominin Expansion in the Early Pleistocene) is an Agent-based model (ABM) of the first Out of Africa hominin dispersal, designed to explore the spatial pattern of Lower Palaeolithic site distribution in Europe. The SHEEP model uses a deterministic environmental approach to evaluate potential routes into Europe and their impact on the pattern of site distribution in the eastern and western parts of the continent. The model consists of three main simulated elements: 1) population growth, 2) a spatial spreading process and 3) the friction map, which includes both environmental and topographic information. The impact of different geographical projections on the outcome of the model has been evaluated. The results show that we are unable to reproduce the null hypothesis and observed spatial pattern of European sites is not a result of differences in dispersal routes. This case study showcases the use of $A B M$ as a simple and efficient tool for hypotheses testing with a high potential for archaeological applications.
\end{abstract}

Keywords:

Agent-based Modelling, Lower Palaeolithic, ‘Out of Africa’ Dispersal

\section{Introduction}

SHEEP (Simulating Hominin Expansion in the Early Pleistocene) is an Agent-based Model $(\mathrm{ABM})$ designed to test the hypothesis that the low density of Early and Middle Pleistocene (1.8-0.3 Ma) sites in Central and Eastern Europe results from a specific dispersal pattern into the continent. Dispersal routes into new regions have the potential to shape the pattern of population density on the meso- and macro- scales. However, apart from conceptual models no quantitative research method has ever been used to investigate their potential impact on population density and its archaeological manifestation - the distribution of archaeological sites. ABM constitutes an alternative approach to one of the challenges that conventional archaeological methods are confronted with: the static nature of what is often referred to as the 'dotson-a-map' method where site distribution maps are used to infer the causal relationship between certain processes (such as land use, settlement patterns, or environmental conditioning) and site locations (see for example Grove 2012; Alcock and Rempel 2006 for other takes on the problem). The main strength of ABM comes from its ability to test hypotheses

Corresponding author: I.Romanowska@soton.ac.uk using a dynamic process rather than a static 'snap shot' approach of spatial statistics followed by interpretational conceptual modelling.

The research questions will be introduced in the first section of this paper, followed by a review of the ABM methodology, its strengths and limitations. The subsequent sections will give the model description in an adapted ODD (Overview, Design Concepts, Details) format (Grimm et al. 2006; 2010; for an archaeological application see: Scherjon 2013). Finally, the results of the experiment and a few general conclusions are given.

1.1 The pattern: spatial dichotomy between east and west

The dichotomy between the density of Early and Middle Pleistocene sites east and west of the Rhine constitutes a robust spatio-temporal pattern. The Lower Palaeolithic sites in Central Europe are few and far between compared to the record in Western Europe (Fig. 1). Over 130 stratified Lower Palaeolithic sites are known from Western Europe (estimate based on literature reviewin Romanowska 2009), not including surface finds which can be counted in the thousands (see for example Wymer 


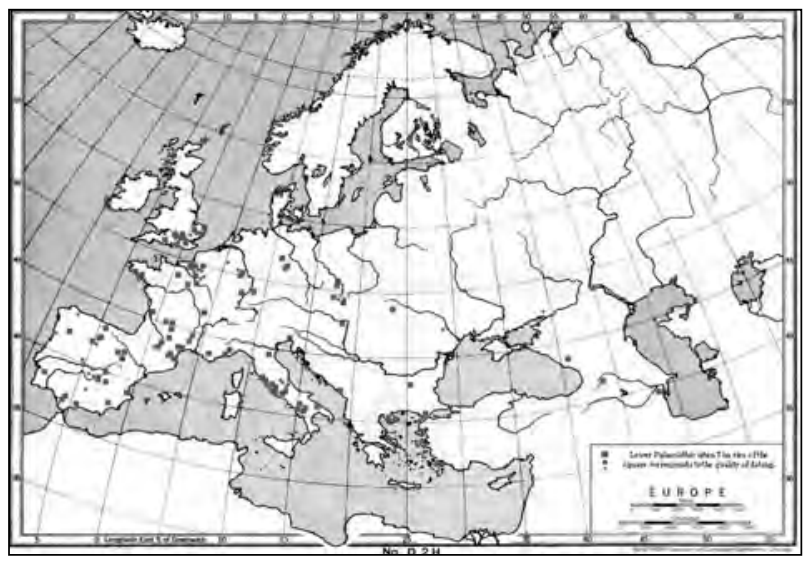

Figure 1. The distribution of Lower Palaeolithic sites in Europe.

1999 or Roe 1981 for the English record). In Central and Eastern Europe even a very generous count including surface finds, possible geofacts or very small assemblages such as Stránská Skála, Gajtan, Kończyce, Kudaro or Garasimovka (Doronichev and Golovanova 2010; Roebroeks and Kolfschoten 1995; Runnels 1995) brings the total number of sites to no more than 40 .

Considering that Central and Eastern Europe constitute about two thirds of the continent this represents a robust pattern that has not incited much research so far. It has been mentioned in passing by various authors (Bosinski 2006; Darlas 1995; Dennell and Roebroeks 1996; Gamble 1999; Hopkinson 2007) but little academic effort has been invested into understanding this phenomenon. Therefore, it is not clear if it represents a real past pattern, i.e. demographic disparity between different parts of the continent as suggested by Doronichev and Golovanova (2010), or a modern research bias.

So far only three scenarios have been put forward in order to explain this dichotomy:

- State of the research (Doronichev 2011; Moncel 2010);

- Climate (Hopkinson 2007; Martos 1994; Moncel 2010);

- Dispersal routes and demography (Bar-Yosef and Belfer-Cohen 2011; Rolland 1995; Tourloukis 2010; Villa 2001).

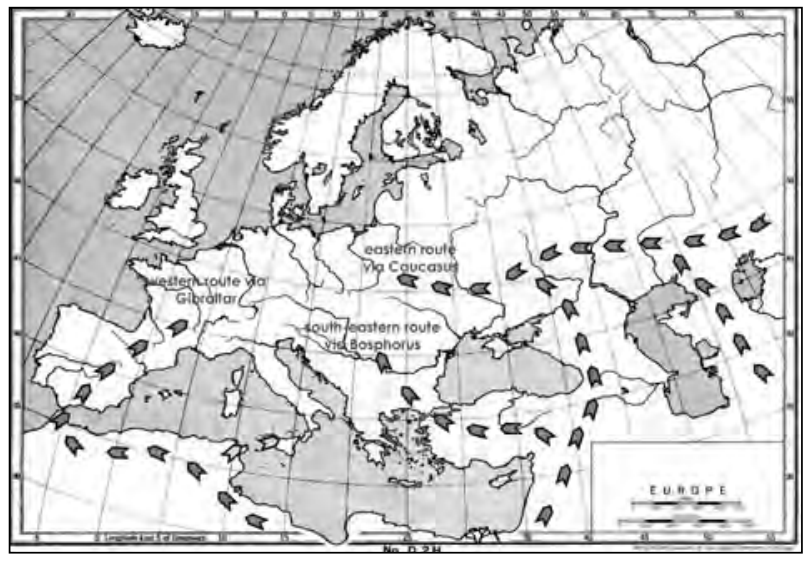

Figure 2. Potential dispersal routes into Europe.

This paper is concerned with testing the last hypothesis.

\subsection{Dispersal routes}

Geographically, Europe is surrounded by substantial water bodies from the west and the south which, to the best of our knowledge regarding Palaeolithic seafaring (Bednarik 1999), would constitute significant barriers for the Early and Middle Pleistocene hominin dispersal events. Therefore, only four to five possible routes into Europe can be seriously considered, via land bridges or minor bodies of water such as straits (Fig. 2) (Harvati et al. 2008; Rolland 1995; Sánchez 2006; Tourloukis 2010; Villa 2001).

The eastern (via Ukraine) and south-eastern (via the Balkans) routes are generally accepted as plausible dispersal corridors into Europe. The western routes (via Giblartar and via Sicily) involve crossing a significant stretch of water and therefore it has been intensely debated (Bednarik 1999; de los Terreros 2000; Derricourt 2005). The current consensus seems to be that the Gibraltar route is plausible while the Sicily route is not (Villa 2001). However, some authors (Carbonell and Rodriguez 2006) pointed out the lack of animal migration via Gibraltar at that time, which may be a good indicator of the relative difficulty of the crossing. In the SHEEP both sea (Giblartar) and land routes (Balkan, Ukraine) were tested in the same way. 
Agent-based Modelling and Archaeological Hypothesis Testing: the Case Study of the European Lower Palaeolithic Iza Romanowska

\section{Why Modelling?}

The conventional methodology in archaeology for the study of the first dispersal is largely based on qualitative considerations, where arguments are being debated without quantitative validation or explicitly stating the assumptions (for example BarYosef and Belfer-Cohen 2001; Carabonell et al. 2010; Derricourt 2006; Moncel 2010; Palombo 2013 to name just a few). I believe that the discussion could benefit from a tool which allows for quantitatively assessing of the proposed scenarios.

Simulation and geographical analysis are probably the only two quantitative approaches that have already been applied to this issue (Field et al. 2007; Holmes 2007a, b; Mithen and Reed 2002; Nikita and Nikitas 2005; Steele 2009). However, geographical analysis has limitations for the study of a dynamic process such as dispersal. I would argue that a combination of geographical and simulation approaches would be more fruitful as it allows for an integration and confrontation of the actual archaeological data with potential processes which led to the creation of the archaeological record in a tightly controlled manner.

\subsection{Agent-based Modelling (ABM) - modelling as a controlled environment lab}

Agent-based Modelling ( $\mathrm{ABM})$ is a computational technique used in a number of disciplinesincludingecology, planning and thesocial sciences (for a full overview see Niazi and Hussain 2011). Contrary to equation-based modelling (EBM) where the modelled individuals are assumed to be homogenous and well mixed, it uses individual software entities (called agents) which can interact with the environment and with each other (Kowarik et al. 2008; Nguyen 2010; Parunak et al. 1998). $\mathrm{ABM}$ has been used in archaeology for over a decade. One of the first applications of ABM - the iconic model of the rise and collapse of Anasazi (Axtell et al. 2002; Dean et al. 2000, but see J anssen 2009) - established the technique more strongly in social sciences and humanities and soon a number of applications followed (including Bentley et al. 2005; Graham 2006; Graham and Steiner 2008; Griffin and Stanish 2007; contributions in Kohler and Gumerman 2000; Kowarik et al. 2008; Mesoudi and O'Brien 2008; Premo 2006 among others.
For an overwiev of the history of simulations in archaeology see Costopoulos and Lake 2010; Kohler 2012; Lake 2001; 2014).

ABM provides a unique platform for testing hypotheses (Axtell et al. 2002; Epstein 2007; 2008; Macal and North 2010; Premo 2006; 2010) and highlightinginconsistencies in theinitial hypothesis; it allows researchers to build models independent from the data, thus creating a virtual benchmark of how the data would be expected to look given the initial set of assumptions and processes modelled. It therefore helps "to eliminate plausible scenarios that are nevertheless unlikely to have occurred" (Premo 2006, 108). This technique has been repeatedly used to model movement patterns on different scales, be it human expansion into new lands, traffic modelling or animal migration (Castle and Crooks 2006; O'Sullivan 2008; O'Sullivan and Haklay 2000).

\section{Model Description}

\subsection{Purpose}

The strengths of $A B M$ introduced in the previous section make this method highly suitable for addressing the issue this paper is concerned with, namely evaluating the impact of dispersal routes on site distribution in Europe during the Lower Palaeolithic. Previous attempts to use modelling for human dispersal studies - the 'Stepping out' model (Hughes et al. 2007; Mithen and Reeds 2002) and the unnamed model of Nikita and Nikitas (2005) - were focused largely on determining the likely arrival date of hominins at a given location (see also Steele 2009 for an overview of EBM case studies). The SHEEP model has been developed to answer more general research questions:

- Could the expansion into Central and Eastern Europe be delayed because one of the routes into Europe was unavailable to hominins?

- Are there any parameter sets that would hinder or prevent dispersal through Central and Eastern Europe?

- Under what configuration of the dispersal routes could the peopling of Central and Eastern Europe be delayed compared to Western Europe? 


\subsection{Model entities and scales}

The model consists of two entities: the agents representing the hominin population and the friction map in the form of a square grid ('patches') representing the environment over which the agents are dispersing.

The agents

Each agent represents a Boolean value (yes/ no) of 'human presence' rather than individuals or human groups. In that sense the model is similar to cellular automata models used before for modelling the general patterns of Pleistocene dispersals (for example Mithen and Reeds 2002). The reasons for the spatial expansion of hominin groups were not modelled explicitly (apart from population growth) as it falls outside of the research aims of the simulation.

\section{The environment}

Climate, relief and vegetation distribution are often quoted as crucial factors influencing large-scale human movement (King and Bailey 2006; Rolland 1995; van der Made 2011; van der Made and Mateos 2010). This notion is particularly relevant for the first 'Out of Africa' dispersal (ca. $1.8 \mathrm{Ma}$ ) and it has been argued that this dispersal should be regarded as a home-range expansion of a large land mammalian species rather than a socially-driven human invasion of new territories (Holmes 2007a and references therein). The SHEEP model therefore uses a deterministic climate/ relief approach to evaluate the impact of dispersal routes on the pattern of site distribution.

\section{The scale}

The SHEEP model uses a relative time scale, i.e. it does not generate exact arrival dates (such as in Mithen and Reed 2002 or Nikita and Nikitas 2005), but explores the process, i.e. the rates of dispersal into different parts of Europe.

\subsection{Submodels}

The model consists of three standard elements used for dispersal simulations (Steele 2009): 1) population growth, 2) a spatial spreading process

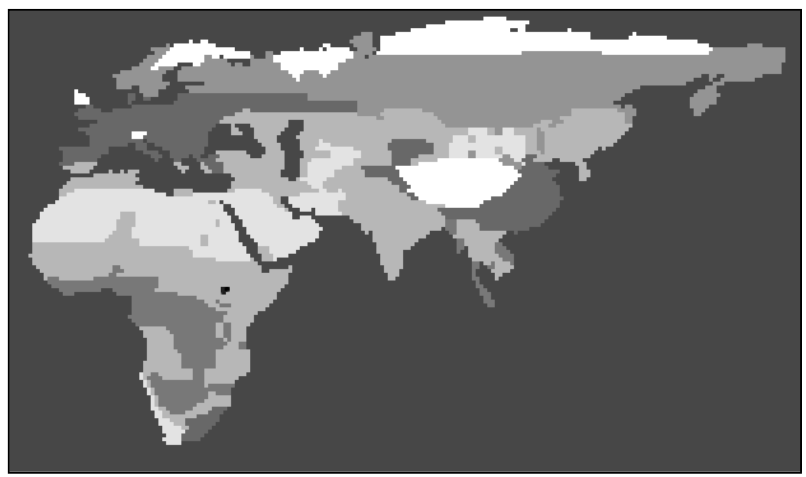

Figure 3. The friction map.

and 3) the terrain. The model was created and run using the ABM software platform NetLogo and its GIS extension (Railsback and Grimm 2011; Wilensky 1999); the terrain maps were prepared using ArcMap 10.1.

\section{Population growth}

The agents in this model reproduce according to two variables: 'Fertility' and 'Mortality'. Their values were generated from averaged fertility rates of modern hunter gatherers (Pennington 2001) recalculated to show 'chance of producing a child in a given year' (rather than the real fertility rate which describes an average number of children per female) and doubled to speed up the simulation.

\section{Terrain}

The friction map (Fig. 3) was generated as a raster map ( $\mathrm{x}, \mathrm{y}$ and vegetation values) based on the data of the Pliocene Research Interpretation and Synoptic Mapping project (PRISM 3) (Holmes 2007a, b; Hughes et al. 2007; van der Made and Mateos 2010; Salzmann et al. 2008a, b). NetCDF files with the vegetation and topography rasters were obtained from the project's website (USGS 2010) . ThePRISMdatais currently the most comprehensive global reconstruction for any warm period prior to the current conditions (Salzmann et al. 2008a). It is also a dataset that is the closest chronologically to the modelled system and is publicly available. Nevertheless, the PRISM dataset is a simulation in itself and therefore cannot be regarded as 'empirical data'. It is also a reconstruction of a Pliocene not Pleistocene environment. More global circulation models of higher resolution tested against the available paleoenvironmental data are needed if 
Agent-based Modelling and Archaeological Hypothesis Testing: the Case Study of the European Lower Palaeolithic Iza Romanowska

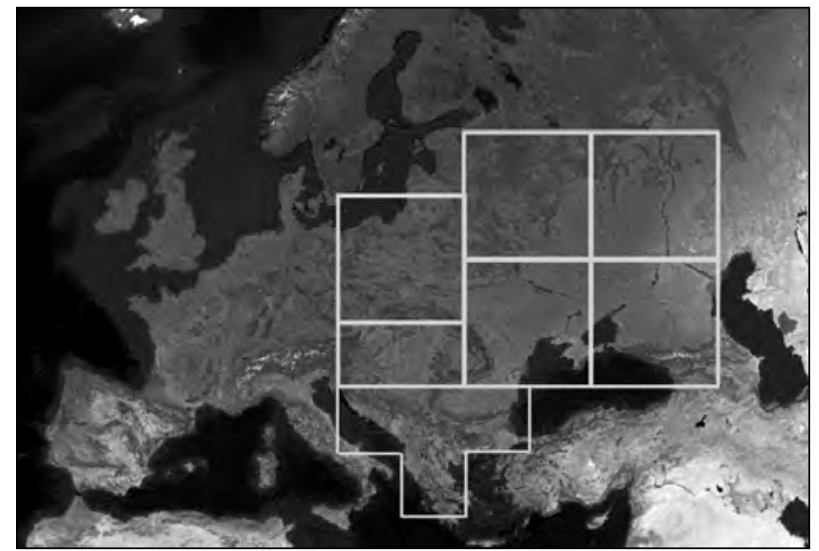

Figure 4. The template used to compare the results of the runs.

we aim to develop finer dispersal models. However, given the continental rather than regional scale of the research questions of this model the PRISM dataset was deemed sufficient.

Four projections have been tested to check if they impact the results: Robinson, Mercator, Azimuthal-Equidistant and PlateCarréeProjections. The simulation was run 10 times for each projection. Each 10 runs used the same seeds therefore limiting the influence of the model's stochasticity. The results were analised in the same way as the general model output (see section 3.4). A one-way analysis of variance showed an overall highly significant effect of the projection type on the results of the simulation $\left(\mathrm{F}_{3,76}=6.103, \mathrm{p}<0.00089\right)$. However, multiple comparisons (Tukey's HSD, overall alpha level 0.05) indicated that the only significant twoway contrast was between the Plate Carrée (which is the default setting between ArcGIS and NetLogo) and the remaining projections. This means that the differences in the simulation results for the Azimuthal Equidistant, Mercator and Robinson projections were negligible whilst the Plate Carrée projection produced results significantly dissimilar to the other three.

\section{Spatial spreading process}

With each discrete time step the agents can disperse to new cells on the terrain map within the radius specified by the dispersal rate of the raster cells. Dispersal rates for each type of vegetation cover are informed by our current understanding of hominin adaptations to the environment (Dennell 2004). The vegetation raster file was reclassified and each class was attributed thefollowing values for thevegetation parameter (meaning: "the difficulty of crossing"):

- $\quad$ water $=200$,

- ice $=100$,

- boreal forest $=50$,

- desert =10,

- tropical, temperate forest $=5$,

- $\quad$ savannah and grassland =1.

The vegetation parameter describes the difficulty of crossing an area by hominins. These numbers are chosen arbitrarily but they closely mirror our current understanding of hominin adaptations. For example the grassland environments were given a very low parameter value because hominin preference for grasslands and mosaic environments have been noted many times (see Dennel and Roebroeks 2005 for the discussion in the context of dispersal). The very high value of the vegetation parameter attributed to cold boreal forest is supported by the virtual lack of sites in the cold zones of Europe and Asia probably related to only sporadic use of fire (if any) at that time (de Lumley 2006; Roebroeks and Villa 2011). For the temperate and tropical forests the issue is not so clear cut, as both environments are not favourable for the preservation of bones and perhaps sometimes overlooked by archaeologists. However, a small number of fairly late sites were located in forested environments, such as Beeches Pit, UK and Vértesszölös, Hungary (Kretzoi and Dobosi 1990; Preece et al. 2006). Therefore it has been given the benefit of the doubt, i.e. a relatively low value for its vegetation parameter. Finally, the value of the vegetation parameter for deserts was double that of temperate/tropical forest but much lower than the cold, boreal zone. The main reason for this is our poor understanding of the extent and conditions in the Sahara at that time (Holmes 2007a). Numerous researchers postulated the so-called 'green Sahara' (Claussen et al. 1998; Drake et al. 2011; Foley et

\begin{tabular}{|c|c|}
\hline Start Location & East Africa \\
\hline Starting Population & 20 \\
\hline Fertility Rate & 0.1 \\
\hline Mortality Rate & 0.42 \\
\hline
\end{tabular}

Table 1. Parameter values used in the model initialisation. 
Across Space and Time. Papers from the 41st Conference on

Computer Applications and Quantitative Methods in Archaeology. Perth, 25-28 March 2013

\begin{tabular}{|l|c|c|c|c|c|c|c|c|}
\hline & \multicolumn{2}{|c|}{ All Routes } & \multicolumn{2}{c|}{ No Bosphorus } & \multicolumn{2}{c|}{ No Caucasus } & \multicolumn{2}{c|}{ No Gibraltar } \\
\hline Balkans & 48 & $96 \%$ & 13 & $26 \%$ & 50 & $100 \%$ & 50 & $100 \%$ \\
\hline South East & 50 & $100 \%$ & 50 & $100 \%$ & 10 & $20 \%$ & 50 & $100 \%$ \\
\hline Ukraine & 50 & $100 \%$ & 50 & $100 \%$ & 30 & $60 \%$ & 50 & $100 \%$ \\
\hline South Central & 33 & $66 \%$ & 20 & $40 \%$ & 35 & $70 \%$ & 50 & $100 \%$ \\
\hline North Central & 9 & $18 \%$ & 2 & $4 \%$ & 0 & $0 \%$ & 50 & $100 \%$ \\
\hline West East & 23 & $46 \%$ & 38 & $76 \%$ & 2 & $4 \%$ & 50 & $100 \%$ \\
\hline East East & 43 & $86 \%$ & 46 & $92 \%$ & 2 & $4 \%$ & 50 & $100 \%$ \\
\hline
\end{tabular}

Table 2. Results of the simulation. The first column of each tested scenario indicates in how many of the runs the agents reached that particular area (see Fig. 4), the second gives the same number as a percentage.

al. 2003) and more controversially 'green Arabia' hypotheses - short humid phases during which green corridors would allow for hominin dispersal even if the general conditions were inhospitable.

\subsection{Initialisation, process overview and observation}

Table 1 gives an overview of the parameter values used for the initialisation of the model. The starting point for all agents is located on a single raster cell in Eastern Africa.

With each turn of the model all the agents have a chance to reproduce or die according to the birth and death rates (see section 3.3 Population Growth). Every newly created agent is placed on an empty cell located in a radius determined by the vegetation parameter (see section 3.3 Spatial Spreading Process). This produces a regular wave of advance spreading in a concentric pattern from the starting point, slowing down and speeding up in different environmental zones.

The model stops when an agent appears on one of the two 'stopping raster cells' - the Western Europe cell located on the border between Spain and Southern France or the Central European cell located in Northern Germany.

In order to test the hypothesis the model was

Figure 5. The final visualisations of the most typical results of the simulation runs: a) all routes available; $b$ ) no Balkan route; c) no Caucasus route; d) no Gibraltar route. Light colour indicates human presence and the front of dispersal can be seen as black band. Please see the colour version of the proceedings for clearer figures.
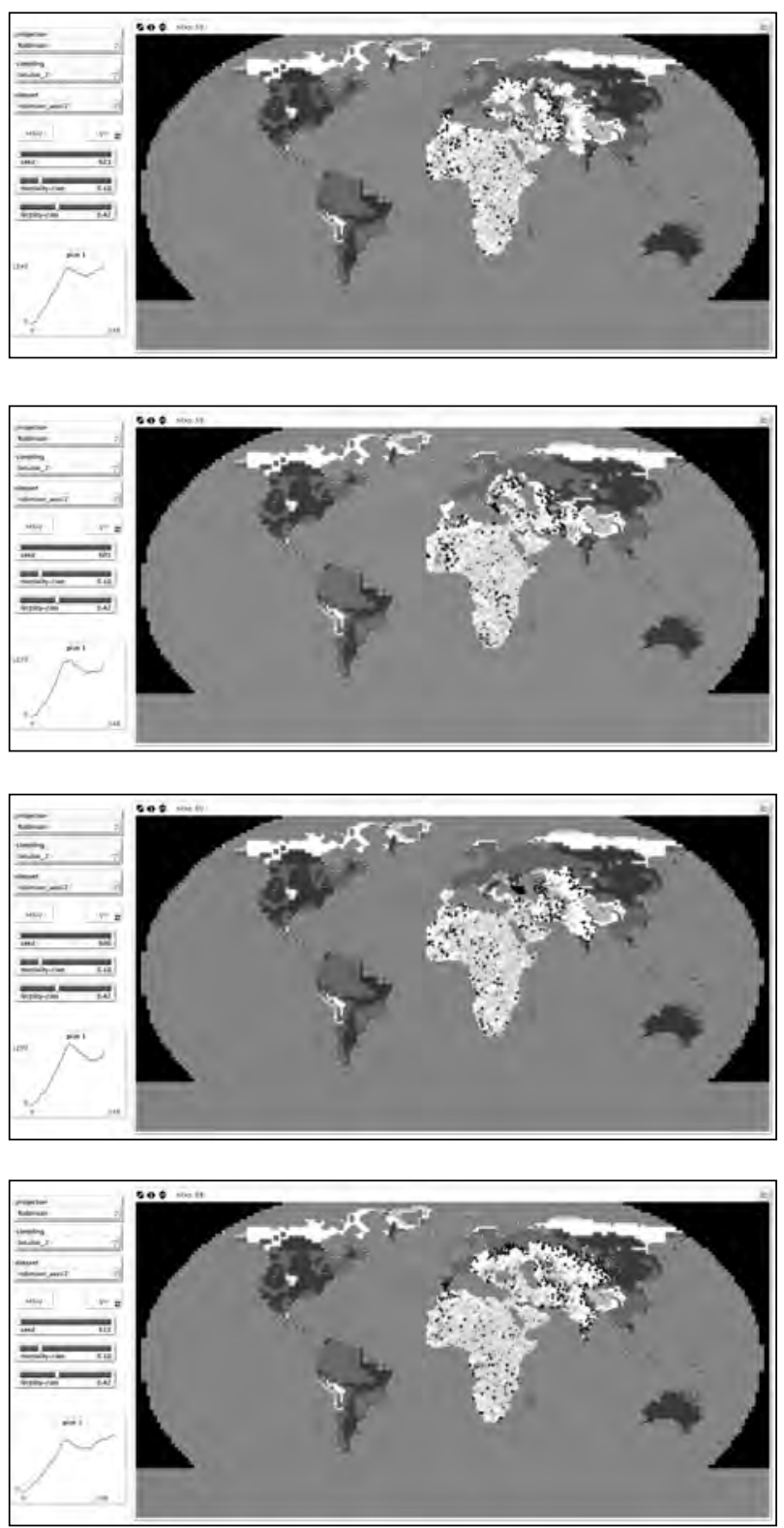
Agent-based Modelling and Archaeological Hypothesis Testing: the Case Study of the European Lower Palaeolithic Iza Romanowska

iterated 50 times for each of the following alternative scenarios: a) all dispersal routes into Europe are available for hominins (Fig. 5a); b) the Balkan route is blocked (Fig. 5b); c) the Eastern route via the Caucasus is blocked (Fig. 5c); d) the Gibraltar route is blocked (Fig. 5d); After each run, the view of the final result was exported and visually compared with the template (Fig. 4) to assess how far the dispersal reached in each case.

\section{Results}

As discussed in detail in section 3.1, the null hypothesis states that the availability of certain dispersal routes could have impacted the pattern of hominin dispersal into Europe, which is, in turn, reflected in the observed pattern of Lower Palaeolithic sitedistribution. If, under the conditions imposed by the parameter values, no tested scenario produced such a pattern (hominin arrival in Central and Eastern Europe significantly delayed in respect to Western Europe) then the null hypothesis will be conditionally rejected.

This model shows that under the conditions described above the dispersal into Central and Eastern Europe could not be affected by the dispersal routes to such an extent that no occupation at all occurred during the Lower Palaeolithic (Table 2 and visualisations of the most typical runs: Fig. 5). If all the possible routes were passable, hominin expansion should reach the Balkans and Ukraine at a similar time as Spain and southern France (Fig. 5a). A similar pattern occurs if one of the eastern routes is blocked out - the agents reach modern day Ukraine or the Balkans at the same time as they reach Spain and Southern France (Figs 5b and 5c). Thus, the null hypothesis (i.e. that the spatial distribution of known Early and Middle Pleistocene sites in Europe is a result of a particular configuration of dispersal routes) can be rejected under the conditions imposed by the processes and parameter values used in the simulation.

In almost all cases, Eastern Europe (and especially the Ukrainian steppes) is peopled before the Balkans. Also, even if the route via Turkey and the Balkans is the only eastern route available, the expansion very often reaches modern day Ukraine before hominins arrive in Spain and Southern France (Fig. 5c). This indicates that the Ukrainian steppes hold a very high potential for early sites, only a fraction of which have been found so far (Stepanchuk et al. 2010).

If the Gibraltar route was not available for dispersal, the final pattern closely resembles the archaeological record, showing a quick spread of hominins into the southern and south-eastern part of Asia (Dennell 2004; Swisher et al. 1994) and a substantial delay in the appearance of hominins in Europe (Fig. 5d). This is a strong indication that the environmental structure of the Early Pleistocene world alone may explain the fast spread through South Asia making other, more complicated scenarios redundant.

\section{Conclusions}

As mentioned before ABM is often used for testing hypotheses and highlighting inconsistencies in the initial hypothesis. This study used that strength to provide a quantitative evaluation of the hypothesis that the pattern of European Lower Palaeolithic site distribution is caused by dispersal routes. The results show that it is highly unlikely that dispersal routes caused the observed spatiotemporal pattern of site distribution and we should therefore turn our attention to other possible explanations (for an overview of other hypotheses, see Romanowska 2012; 2013).

However, it has to be noted that the observed patterns are very sensitive to small changes in the underlying friction map. This highlights theneed for more fine-grained palaeoenvironmental mapping if more detailed results are required. 'Prism 3' is currently the most accurate paleoenvironmental mapping of that time period (Salzman et al. 2008a; 2008b) and hopes are high that better quality environmental data can be collated in the near future given the rapid development of sophisticated global circulation models. This would allow for more detailed simulations, perhaps looking at smaller scale, regional case studies and producing exact arrival dates which can then be compared to the archaeological record to validate the simulations. Such models would require even more clever treatment of the spatial component, with the topographic data matching the resolution of the vegetation data and a better handling of the spatial spreading process. However, until then only very 
coarse grained research questions such as the one asked at the beginning of the paper can be reliably modelled using agent-based simulations.

\section{Acknowledgements}

The author would like to thank Tom Brughmans, Graeme Earl, David Wheatley and Jason Noble as well as three anonymous reviewers for their comments on the earlier drafts of this paper.

\section{Bibliography}

Alcock, S., and J. Rempel. 2006. "The More Unusual Dots on the Map: "Special- Purpose" Sites and the Texture of Landscape." In Surveying the Greek Chora. The Black Sea Region in a Comparative Perspective, edited by P. G. Bildeand V. F. Stolba, 27- 46. Aarthus: Aarthus University Press.

Axtell, R. L., J . M. Epstein, J . S. Dean, G. J . Gumerman, A. C. Swedlund, J. Harburger, S. Chakravarty, R. Hammond, J. Parker, M. Parker. 2002. "Population growth and collapse in a multiagent model of the Kayenta Anasazi in Long House Valley." Proceedings of the National Academy of Sciences of the United States of America 99 (3):7275- 7279.

Bar-Yosef, O., and A. Belfer-Cohen. 2011. "Following Pleistocene road signs of human dispersals across Eurasia." Quaternary International 285:30- 43.

Bednarik, R. G. 1999. "Maritime navigation in the Lower and Middle Palaeolithic." Comptes Rendus de l'Académie des Sciences-Series IIA-Earth and Planetary Science 328 (8):559- 563.

Bentley, A. R., M. Lake, and S. Shennan. 2005. "Specialisation and wealth inequality in a model of a clustered economic network." J ournal of Archaeological Science 32 (9):1346- 1356.

Bosinski, G. 2006. 'Les premiers peuplements del'Europe centrale et del'Est." Comptes Rendus Palevol 5(1-2):311317.

Carbonell, E., and X. P. Rodriguez. 2006. "The first human settlement of Mediterranean Europe." Comptes Rendus Palevol 5 (1-2):291- 298.
Carbonell, E., R. Sala Ramos, X. Pedro Rodríguez, M. Mosquera, A. Ollé, J. María Vergès, B. Martínez- Navarro, and J. M. Bermúdez de Castro. 2010. "Early hominid dispersals: A technological hypothesis for 'out of Africa'." Quaternary International 223- 224:36- 44.

Castle, C. J. E., and A. T. Crooks. 2006. Principles and Concepts of Agent-Based Modelling for Developing Geospatial Simulations. London: UCL.

Claussen, M., V. Brovkin, A. Ganopolski, C. Kubatzki, and V. Petoukhov. 1998. "Modelling Global Terrestrial Vegetation- climate Interaction." Philosophical Transactions of the Royal Society B: Biological Sciences 353 (1365):53- 63.

Costopoulos, A., and M. W. Lake (eds.) 2010. Simulating Change. Archaeology Into the Twenty-first Century. Salt Lake City: University of Utah Press.

Darlas, A. 1995. "The Earliest Occupation of Europe: The Balkans." In The earliest occupation of Europe; proceedings of the European Science Foundation Workshop at Tautavel (France) 1993, edited by W. Roebroeks and T. Kolfschoten, 51-60. Leiden: Leiden University Press.

Dean J. S., G. J.Gumerman, J. M. Epstein, R. L. Axtell, A. C. Swedlund, M. T. Parker, and S. MoCarroll. 2000. "Understanding Anasazi Culture Change Through Agent Based Modeling." In Dynamics in Human and Primate Societies: Agent Based Modeling of Social and Spatial Processes, edited by T. Kohler and G. Gumerman. New York/ London: Oxford University Press.

de los Terreros, Y. S. 2000. "Los orígenes del poblamiento Paleolítico en Europa: una visión bioestratégica.” Espacio, tiempo y forma. Serie I, Prehistoria y arqueología 13:3360.

DeLumley, H. 2006. "Ilya400 000 Ans: LaDomestication Du Feu, Un Formidable Moteur D'hominisation." Comptes Rendus Palevol 5 (1-2):149- 154.

Dennell, R. W. 2004. "Hominid Dispersals and Asian Biogeography during the Lower and Early Middle Pleistocene, c. 2.0-0.5 Mya." Asian Perspectives 43 (2):205- 226.

Dennell, R. W., and W. Roebroeks. 1996. "The Earliest Colonization of Europe: The Short Chronology Revisited" 
Agent-based Modelling and Archaeological Hypothesis Testing: the Case Study of the European Lower Palaeolithic Iza Romanowska

Antiquity 70:535- 542 .

Derricourt, R. 2006. “Getting 'Out of Africa': Sea Crossings, Land Crossings and Culture in the Hominin Migrations." J ournal of World Prehistory 19 (2):119- 132.

Dennell, R. W., and W. Roebroeks. 2005. "An Asian perspective on early human dispersal from Africa." Nature 438 (7071):1099- 1104.

Doronichev, V. 2011. “LePaléolithiqueAncien Del’Europe Orientale Et Du Caucase.” L'Anthropologie 115:197- 24.

Doronichev, V., and L. Golovanova. 2010. "Beyond the Acheulean: A view on the Lower Paleolithic occupation of Western Eurasia." Quaternary International 223224:327- 344 .

Drake, N. A., Roger M. Blench, S. J. Armitage, C. S. Bristow, and K. H. White. 2011. "Ancient Watercourses and Biogeography of the Sahara Explain the Peopling of the Desert." Proceedings of the National Academy of Sciences of the United States of America 108 (2):458- 62.

Epstein, J. M. 2007. "Agent-Based Computational Models and Generative Social Science." In Generative Social Science: Studies in Agent-Based Computational Modeling, edited by J oshua M. Epstein, 1-43. Princeton: Princeton University Press.

Epstein, J. M. 2008. “Why Model?” Journal of Artificial Societies and Social Simulation 11(4).

Field, J. S., M. D. Petraglia, and M. Mirazón Lahr. 2007. "The southern dispersal hypothesis and the South Asian archaeological record: Examination of dispersal routes through GIS analysis." Journal of Anthropological Archaeology 26 (1):88- 108.

Foley, J. A., M. T. Coe, M. Scheffer, and G. Wang. 2003. "Regime Shifts in the Sahara and Sahel: Interactions Between Ecological and Climatic Systems in Northern Africa." Ecosystems 6 (6):524- 532.

Gamble, C. 1999. The Palaeolithic Societies of Europe. Cambridge: Cambridge University Press.

Graham, S. 2006. "Networks, Agent-Based Models and the Antonine Itineraries: Implications for Roman Archaeology." J ournal of Mediterranean Archaeology 19 (1):45- 64 .
Graham, S., and J . Steiner. 2008. "Travellersim: Growing Settlement Structures and Territories with AgentBased Modelling." In Digital Discovery. Exploring New Frontiers in Human Heritage. CAA2006. Computer Applications and Quantitative Methods in Archaeology. Proceedings of the 34th Conference, Fargo, United States, April 2006, edited by J. T. Clark and E. M. Hagemeister. Budapest: Archaeolingua.

Griffin, A. F., and C. Stanish. 2007. "An Agent-based Model of Prehistoric Settlement Patterns and Political Consolidation in the Lake Titicaca Basin of Peru and Bolivia." Structure and Dynamics 2 (2):1-46.

Grimm, V., U. Berger, F. Bastiansen, S. Eliassen, V. Ginot, J. Giske, J. Goss- Custard, T. Grand, S. K. Heinz, G. Huse, A. Huth, J. U. Jepsen, C. Jørgensen, W. M. Mooij, B. Müller, G. Pe'er, C. Piou, S. F. Railsback, A. M. Robbins, M. M. Robbins, E. Rossmanith, N. Rüger, E. Strand, S. Souissi, R. A. Stillman, R. Vabø, U. Visser, D. L. DeAngelis. 2006. "A Standard Protocol for Describing Individual- based and Agent- based Models." Ecological Modelling 198 (1- 2):115- 126.

Grimm, V., U. Berger, D. L. De Angelis, J. G. Polhill, J. Giske, and S. F. Railsback. 2010. "The ODD Protocol: A Review and First Update." Ecological Modelling 221 (23):2760- 2768.

Grove, M. 2012. "Scatters, patches, and palimpsests: Solving the contemporaneity problem." In Unravelling the Palaeolithic, edited by K. Ruebens, I. Romanowska, and R. Bynoe, 14- 29. Oxford: Archaeopress.

Harvati, K., E. Panagopoulou, P. Karkanas, A. Athanassiou, and S. Frost. 2008. "Preliminary Results of the Aliakmon Palaeolithic/ Palaeoanthropological Survey, Greece, 2004-2005." In The Paleolithic of the Balkans, edited by A. Darlas and D. Mihailović, 1819:15-20. Oxford: Archaeopress.

Holmes, K. 2007a. GISSimulation of the Earliest Hominid Colonisation of Eurasia. Oxford: Archaeopress.

Holmes, K. 2007b. "Using Pliocene Palaeoclimatic Data to Postulate Dispersal Pathways of Early Hominins." Palaeogeography, Palaeoclimatology, Palaeoecology 248 (1- 2):96- 108.

Hopkinson, T. 2007. "The transition from the Lower to the Middle Palaeolithic in Europe and the incorporation 
Across Space and Time. Papers from the 41st Conference on

Computer Applications and Quantitative Methods in Archaeology. Perth, 25-28 March 2013

of difference." Antiquity 81:294- 307.

Hughes, J. K, A. Haywood, S. J. Mithen, B. W. Sellwood, and P. J. Valdes. 2007. "Investigating early hominin dispersal patterns: developing a framework for climate data integration." J ournal of Human Evolution 53:465474.

Janssen, M. A. 2009. "Understanding Artificial Anasazi." Journal of Artificial Societies and Social Simulation 12 (4).

King, G., and G. Bailey. 2006. "Tectonics and human evolution." Antiquity 80:265-286.

Kohler, T. A. 2012. "Complex Systems and Archaeology.” In Archaeological Theory Today, edited by I. Hodder, 93- 123. Cambridge: Polity Press.

Kohler, T. A., and G. J. Gumerman. 2000. Dynamics in Human and Primate Societies: Agent-based models of social and spatial processes. NewYork: Oxford University Press.

Kowarik, K., H. Reschreiter, G. Wurzer, R. Totschnig, and A. Rausch. 2008. "Mining with Agents Agent-based Modeling for the Bronze Age Salt Mine of Hallstatt (Upper Austria)." In 13th International Congress Cultural Heritage and New Technologies, Vienna, 2008, 1- 19. Stadt Wien, Stadtarchäologie: Vienna.

Kretzoi, M., and V. Dobosi. 1990. Vértesszölös. Site, man and culture. Budapest: Akadémiai Kiadó.

Lake, M. 2001. "The use of pedestrian modelling in archaeology, with an example from the study of cultural learning." Environment and Planning B: Planning and Design 28 (3):385- 403.

Lake, M. 2014. "Trends in Archaeological Simulation." Journal of Archaeological Method and Theory 21:258287.

Macal, C. M., and M. J . North. 2010. "Tutorial on agentbased modelling and simulation." J ournal of Simulation 4 (3):151- 162.

Martos, A. J. 1994. "Algunas cuestiones de interés sobre el poblamiento del continente europeo durante el Pleistoceno Medio." Espacio, tiempo y forma. Serie I, Prehistoria y arqueología (7): 13-42.
Mesoudi, A., and M. J. O’Brien. 2008. 'The Cultural Transmission of Great Basin Projectile- Point Technology II : An Agent- Based Computer Simulation." American Antiquity 73 (4):627- 644.

Mithen, S., and M. Reed. 2002. "Stepping out: a computer simulation of hominid dispersal from Africa." J ournal of Human Evolution 43 (4):433- 462.

Moncel, M.-H. 2010. "Oldest human expansions in Eurasia: Favouring and limiting factors." Quaternary International 223-224:1-9.

Nguyen, N., P. Taillandier, A. Drogoul, and P. Auger. 2012. "Inferring Equation-Based Models from AgentBased Models: A Case Study in Competition Dynamics." In Principles and Practice of Multi-Agent Systems 13th International Conference, PRIMA 2010 Kolkata, India, November 12-15, 2010 Revised Selected Papers, edited by N. Desai, A. Liu, and M. Winikoff, 413-427. Kolkata: Springer.

Niazi, M., and A. Hussain. 2011. "Agent- based Computing from Multi-agent Systems to Agent-based Models: a Visual Survey." Scientometrics 89 (2):479- 499.

Nikitas, P., and E. Nikita. 2005. "A study of hominin dispersal out of Africa using computer simulations." J ournal of Human Evolution 49 (5):602- 17.

O’Sullivan, D. 2008. “Geographical Information Science: Agent- based Models." Progress in Human Geography $32(4): 541-50$.

O'Sullivan, D., and M. Haklay. 2000. "Agent-based Models and Individualism: Is the World Agent- based?" Environment and Planning A 32 (8):1409- 25.

Palombo, M. R. 2013. “What About Causal Mechanisms Promoting Early Hominin Dispersal in Eurasia? A Research Agenda for Answering a Hotly Debated Question.” Quaternary International 295:13- 27.

Parunak, H., R. Van Dyke, R. Savit, L. Riolo. 1998. "Agent- Based Modeling vs. Equation- Based Modeling: A Case Study and Users' Guide." In Multi-Agent Systems and Agent-Based Simulation. Proceedings of the First International Workshop, MABS '98, Paris, France, July 4-6, 1998, edited by J. S. Sichman, R. Conte, and N. Gilbert, 10- 25. Berlin: Springer. 
Agent-based Modelling and Archaeological Hypothesis Testing: the Case Study of the European Lower Palaeolithic Iza Romanowska

Pennington, R. 2001. "Hunter-gatherer demography." In Hunter-gatherers: an interdisciplinary perspective, edited by C. Panter-Brick, 170-204. Cambridge: Cambridge University Press.

Preece, R. C., J. A. J. Gowlett, S. A. Parfitt, D. R. Bridgland, and S. G. Lewis. 2006. "Humans in the Hoxnian: Habitat, Context and Fire Use at Beeches Pit, West Stow, Suffolk, UK." J ournal of Quaternary Science 21 (5):485- 496.

Premo, L. S. 2006. "Agent- based models as behavioral laboratories for evolutionary anthropological research." Arizona Anthropologist 17:91- 113.

Premo, L. 2010. "Equifinality and Explanation: The Role of Agent- Based Modeling in Postpositivist Archaeology." In Simulating Change. Archaeology into the TwentyFirst Century, edited by A. Costopoulos and M. Lake, 28- 37. Salt Lake City: University of Utah Press.

Railsback, S. F., and V. Grimm. 2011. Agent-Based and Individual-Based Modeling: A Practical Introduction. Princeton: Princeton University Press.

Roe, D. A. 1981. The Lower and Middle Palaeolithic Periods in Britain. London: Routledge and Kegan Paul.

Roebroeks, W., and P. Villa. 2011. "On the Earliest Evidence for Habitual Use of Fire in Europe." Proceedings of the National Academy of Sciences of the United States of America 108 (13):5209- 5214.

Roebroeks, W., and T. van Kolfschoten. 1995. The earliest occupation of Europe. Proceed-ings of the European Science Foundation workshop at Tautavel (France), 1993. Leiden: Leiden University Press.

Romanowska, I. 2009. "Spatial and Temporal Variability in the European Lower Palaeolithic." MA Thesis, Jagiellonian University.

Romanowska, I. 2012. “Ex Oriente Lux: a Re- Evaluation of the Lower Palaeolithic of Central and Eastern Europe. In Unravelling the Palaeolithic, edited by K. Ruebens, I. Romanowska, and R. Bynoe, 1- 13. Oxford: ArchaeoPress.

Romanowska, I. 2013. "Playing Hide and Seek with the European Lower Palaeolithic. A Critical Re-evaluation of the Spatial Distribution of Sites in Central and Eastern Europe." MPhil Thesis, University of Southampton.
Rolland, N. 1995. "Biogéographie et préhistoire: le cas du peuplement paléolithique inférieur de l'Europe." In Nature et Culture, actes du colloque international de Liège (13-17 décembre 1993), edited by M. Otte, 11-61. 68. Liège: Université de Liège.

Runnels, C. 1995. "Review of Aegean Prehistory IV: The Stone Age of Greece from the Palaeolithic to the Advent of the Neolithic." American Journal of Archaeology, 99(4):699- 728 .

Salzmann, U., A. M. Haywood, and D. J. Lunt. 2008a. "The Past is a Guide to the Future? Comparing Middle Pliocene Vegetation With Predicted Biome Distributions for the 21st Century." Philosophical Transactions of the Royal Society A 367 (1886):189- 204.

Salzmann, U., A. M. Haywood, D. J . Lunt, P. J . Valdes, and D. J. Hill. 2008b. "A new Global Biome Reconstruction and Data-Model Comparison for the middle Pliocene." Global Ecology and Biogeography 17(3):432- 447.

Sánchez, G. 2006. “El Poblamiento De Europa En Torno Al Límite Matuyama/Brunhes: Su Origen y Su Significado En La Evolución Humana.” Trabajos De Prehistoria 63 (1):47-68.

Scherjon, F. 2013. "SteppingIn - Modern Humans Moving into Europe - Implementation." In Archaeology in the Digital Era. Papers from the 40th Annual Conference of Computer Applications and Quantitative Methods in Archaeology (CAA), Southampton, 26-29 March 2012, edited by G. Earl, T. Sly, A. Chrysanthi, P. Murrieta- Flores, C. Papadopoulos, I. Romanowska, and D. Wheatley, 105117. Amsterdam: Amsterdam University Press.

Steele, J. 2009. "Human Dispersals: Mathematical Models and the Archaeological Record." Human Biology 81(2-3):121- 140.

Stepanchuk, V., S. Ryzhov, L. Rekovets, and Z. Matviishina. 2010. "The Lower Palaeolithic of Ukraine: Current Evidence." Quaternary International 223- 224:131- 142.

Swisher, C. C., G. H. Curtis, T. J acob, A. G. Getty, and A. Suprijo. 1994. "Age of the Earliest Known Hominids in J ava, Indonesia." Science 263:1118- 1121.

Tourloukis, V. 2010. The early and middle Pleistocene archaeological record of Greece: current status and future prospects. Leiden: Leiden University Press. 
Across Space and Time. Papers from the 41st Conference on

Computer Applications and Quantitative Methods in Archaeology. Perth, 25-28 March 2013

van der Made, J . 2011. “Biogeography and climatic change as a context to human dispersal out of Africa and within Eurasia." Quaternary Science Reviews 30 (11- 12):13531367.

USGS. 2010. "PRISM Pliocene Research Interpretation and Synoptic Mapping. Data Product." Last modified October 21. http:// geology.er.usgs.gov/ eespteam/ prism/ prism_data.html.

van der Made, J., and A. Mateos. 2010. “Longstanding biogeographic patterns and the dispersal of early Homo out of Africa and into Europe." Quaternary International 223- 224:195- 200.

Villa, P. 2001. "Early Italy and the Colonization of Western Europe." Quaternary International 75:113- 130.

Wilensky, U. 1999. “NetLogo.” Accessed J anuary 15, 2014. http:// ccl.northwestern.edu/ netlogo.

Wymer, J. 1999. The Lower Palaeolithic Occupation of Britain. Salisbury: Wessex Archaeology. 


\title{
Sailing the Simulated Seas: a New Simulation for Evaluating Prehistoric Seafaring
}

\author{
Benjamin Davies \\ The University of Auckland, New Zealand \\ Simon H. Bickler \\ Bickler Consultants Ltd., New Zealand
}

\begin{abstract}
:
Humans have been traversing the world's oceans for at least 50,000 years. For archaeologists interested in prehistoric seafaring, computer simulation has proven a useful method for investigating the challenges and strategies used in the past. However, a number of barriers have inhibited wider adoption of the simulation approach. We present a prototype for a flexible voyaging simulation to model prehistoric seafaring. Combining freeware technologies in GIS, statistics, and agent-based modelling with open source datasets, our simulation is capable of testing hypotheses ranging from drift to directed voyaging across the globe, at comparable or higher resolution than previous studies. A case study from the Pacific is offered which demonstrates some of the capabilities of the system. In time, we hope to introduce this as a tool for researchers worldwide to explore questions of prehistoric oceanic voyaging.
\end{abstract}

\section{Keywords:}

Seafaring, Voyaging, Simulation, Agent-based Modelling, Maritime Archaeology

\section{Background}

Humans have been traversing the worlds' oceans for at least the last 50,000 years (Hiscock 2008); according to some, this behaviour may even extend to other members of the genus Homo(Ruxton and Wilkinson 2012). Many hypotheses pertaining to the human diaspora rest on an understanding of the capabilities of prehistoric seafarers and the conditions they may have encountered (Allen and O'Connell 2011; Birdsell 1977; Kirch 2010; Surovell 2003; Westley and Dix 2008). However, archaeological traces of seafaring technology are few and most of the events which led people to take to the seas are beyond the scope of written accounts or oral traditions.

Since the ground breaking work of Levinson, Ward, and Webb (1973), there have been numerous applications of computer simulation to prehistoric oceanic voyaging (e.g. Callaghan 2001; Fitzpatrick and Callaghan 2011; Irwin, Bickler and Quirke.1990; Montenegro et al. 2006). Almost all of these are structurally similar to that original study: virtual "boats" are sent out from one terrestrial location, interacting with the winds and/or currents based

Corresponding author: b.davies@auckland.ac.nz on performance characteristics of the modelled vessel and/or strategy employed by the modelled navigator, until the boat comes into contact with a different parcel of land or exceeds a time or area limit (presumably meeting a grisly fate).

A comparison of some of the published simulations is shown in Table 1. Despite having very similar goals, they exhibit a number of differences in terms of structure and exhibit some or all of the following limitations:

- Restricted spatial extent;

- Limited to contemporary shorelines;

- Dependence on licensed or otherwise difficult to access software and datasets;

- Probabilistic or deterministic environmental inputs;

- Limited to drift or directed voyages;

- Restricted range of vessel and navigational options.

Most early simulations were built to deal with 
Across Space and Time. Papers from the 41st Conference on

Computer Applications and Quantitative Methods in Archaeology. Perth, 25-28 March 2013

\begin{tabular}{|c|c|c|c|c|c|c|c|c|c|c|}
\hline 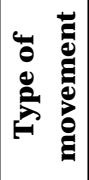 & 亗 & 营 & 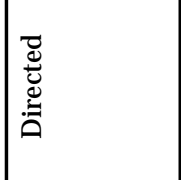 & 营 & 䓌 & 壳 & 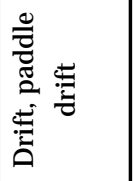 & 营 & 尝 & 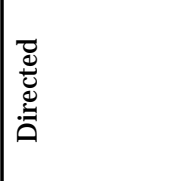 \\
\hline 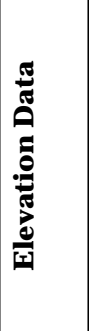 & 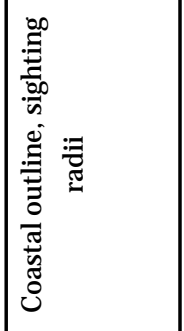 & & 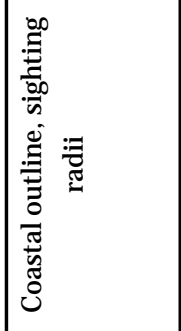 & 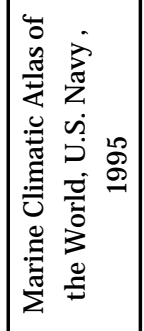 & 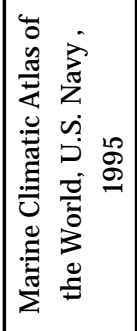 & 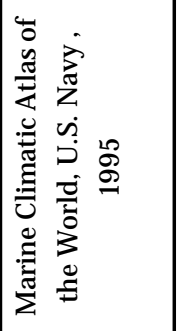 & & 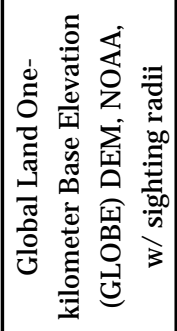 & 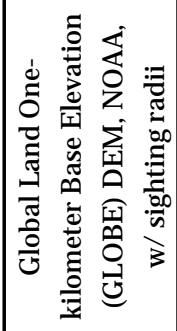 & 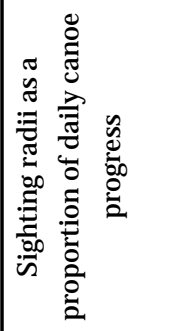 \\
\hline 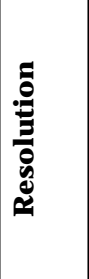 & 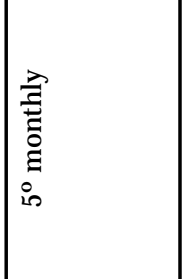 & 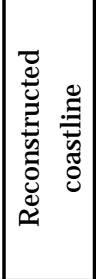 & $\frac{\pi}{2}$ & 익 & 의 & 익 & 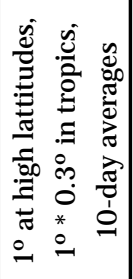 & 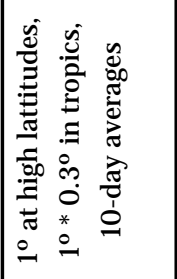 & 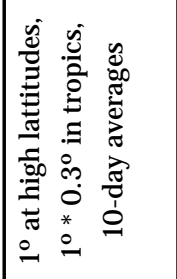 & $\stackrel{\pi}{a}$ \\
\hline 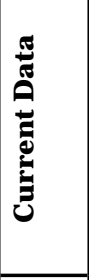 & 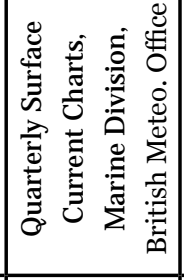 & & $\frac{\pi}{2}$ & 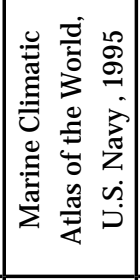 & 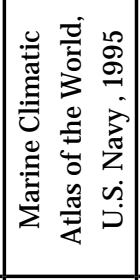 & 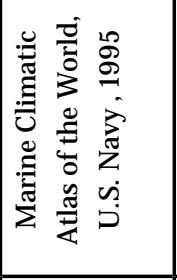 & 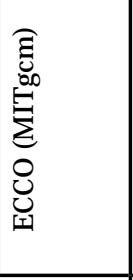 & 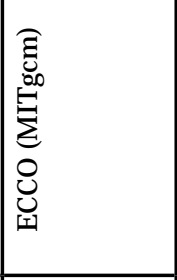 & 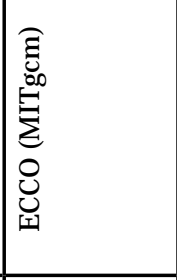 & $\frac{\pi}{a}$ \\
\hline 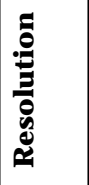 & 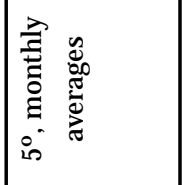 & $\frac{\pi}{\pi}$ & 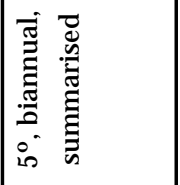 & 익 & 의 & 의 & 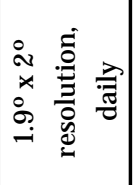 & 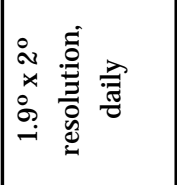 & 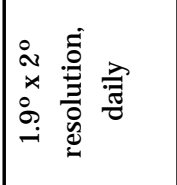 & 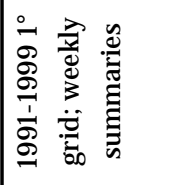 \\
\hline $\begin{array}{l}\frac{5}{\pi} \\
0 \\
0 \\
3 \\
3\end{array}$ & 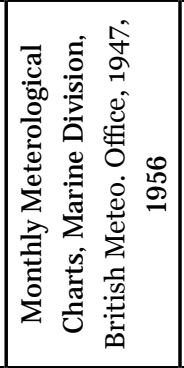 & $\frac{\pi}{a}$ & 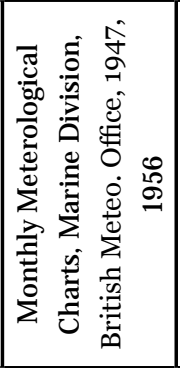 & 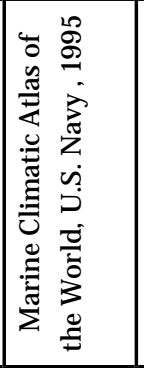 & 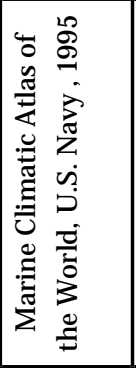 & 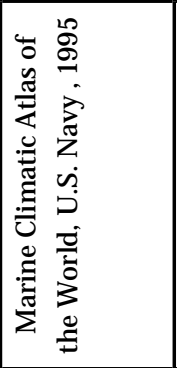 & 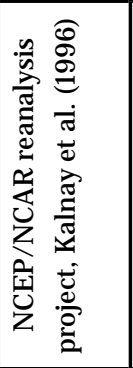 & 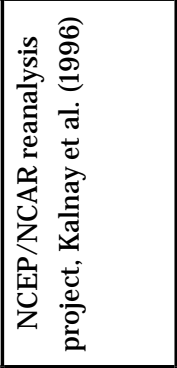 & 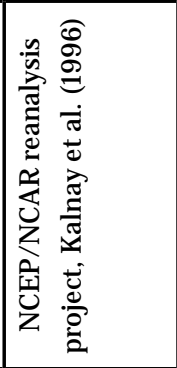 & 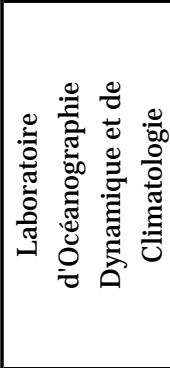 \\
\hline 氖 & 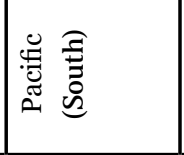 & 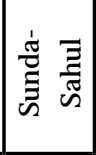 & 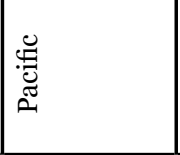 & $\begin{array}{l}\text { वี } \\
\text { हृ: } \\
\text { đ্ }\end{array}$ & 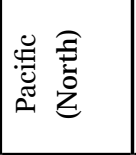 & 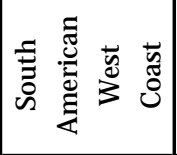 & 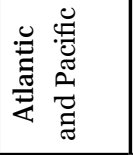 & 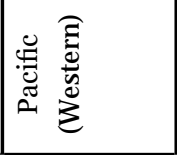 & 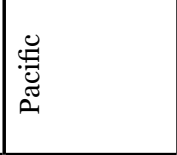 & 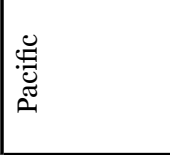 \\
\hline 量 & 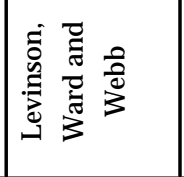 & $\begin{array}{l}0 \\
0 \\
0 \\
3 \\
3\end{array}$ & 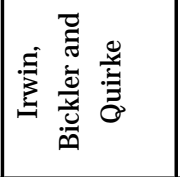 & 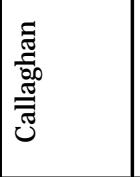 & 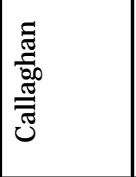 & 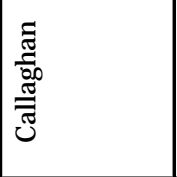 & 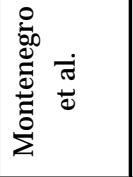 & 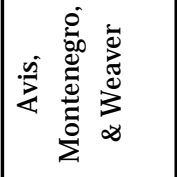 & 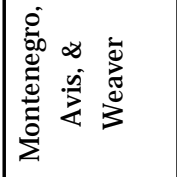 & 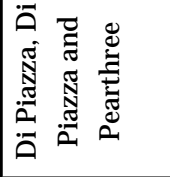 \\
\hline 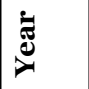 & $\stackrel{\Re}{\Omega}$ & $\begin{array}{l}1 \\
\stackrel{0}{9} \\
9\end{array}$ & ळ్ & ఫ్రి & 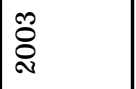 & ڤ్ণి & ஜ̊̀ & & ڤे̀े & 商 \\
\hline
\end{tabular}


Sailing the Simulated Seas: a New Simulation for Evaluating Prehistoric Seafaring Benjamin Davies and Simon H. Bickler

\begin{tabular}{|c|c|c|c|c|c|c|c|c|}
\hline Year & Authors & Region & Wind Data & Res. & $\begin{array}{c}\text { Current } \\
\text { Data }\end{array}$ & Res. & $\begin{array}{c}\text { Elevation } \\
\text { Data }\end{array}$ & $\begin{array}{c}\text { Type of } \\
\text { movement }\end{array}$ \\
\hline 2008 & Evans & Pacific & $\begin{array}{c}\text { SSM/ I with } \\
\text { ECMWF blended } \\
\text { by NASA (DAO) }\end{array}$ & $\begin{array}{c}2.5^{\circ} \times 2^{\circ}, 6 \\
\text { hourly }\end{array}$ & $\mathrm{n} / \mathrm{a}$ & $\mathrm{n} / \mathrm{a}$ & $\begin{array}{l}\text { Coastal outline, } \\
\text { sighting radii }\end{array}$ & Directed \\
\hline 2008 & $\begin{array}{c}\text { Fitzpatrick } \\
\& \\
\text { Callaghan }\end{array}$ & $\begin{array}{l}\text { Indian } \\
\text { Ocean }\end{array}$ & $\begin{array}{c}\text { Marine Climatic } \\
\text { Atlas of the } \\
\text { World, U.S. } \\
\text { Navy, } 1995\end{array}$ & 10 & $\begin{array}{c}\text { Marine } \\
\text { Climatic Atlas } \\
\text { of the World, } \\
\text { U.S. Navy, } \\
1995\end{array}$ & $1^{0}$ & $\begin{array}{l}\text { Marine Climatic } \\
\text { Atlas of the } \\
\text { World, U.S. } \\
\text { Navy , } 1995\end{array}$ & Drift \\
\hline 2013 & $\begin{array}{c}\text { Fitzpatrick } \\
\& \& \\
\text { Callaghan }\end{array}$ & $\begin{array}{c}\text { Pacific } \\
\text { (Western) }\end{array}$ & $\begin{array}{c}\text { Marine Climatic } \\
\text { Atlas of the } \\
\text { World, U.S. } \\
\text { Navy, } 1995\end{array}$ & $1^{0}$ & $\begin{array}{c}\text { Marine } \\
\text { Climatic Atlas } \\
\text { of the World, } \\
\text { U.S. Navy, } \\
1995\end{array}$ & $1^{0}$ & $\begin{array}{l}\text { Marine Climatic } \\
\text { Atlas of the } \\
\text { World, U.S. } \\
\text { Navy , } 1995\end{array}$ & Directed \\
\hline 2013 & $\begin{array}{c}\text { Davies \& } \\
\text { Bickler }\end{array}$ & Global & $\begin{array}{l}\text { NOAA Blended } \\
\text { Sea Winds } \\
\text { (Zhang et al } \\
\text { 2006) }\end{array}$ & $0.25^{\mathrm{o}}$ & $\begin{array}{l}\text { NOAA Ocean } \\
\text { Surface } \\
\text { Currents } \\
\text { Analyses - } \\
\text { Real time } \\
\text { (OSCAR) }\end{array}$ & $0.33^{\circ}$ & $\begin{array}{c}\text { General } \\
\text { Bathymetric } \\
\text { Chart of the } \\
\text { Oceans, British } \\
\text { Oceanographic } \\
\text { Data Centre }\end{array}$ & $\begin{array}{l}\text { Directed, } \\
\text { Drift }\end{array}$ \\
\hline
\end{tabular}

Table 1. Comparison of existing voyaging simulations used in archaeological literature (cont. from previous page).

a specific problem which constrained the extent to a particular sea or quadrant of an ocean. This often reflected technical limitations of available computing rather than strictly project definition; however, this restricted the applicability of the results outside the geographic area for which the simulation was originally developed.

These constraints extended to the input data relating to landforms, winds, and currents. Very few simulations explicitly account for changes in shorelines (see Wild 1986), but advances in the available bathymetric data greatly increase the possibilities and potential for refinement. Additionally, many of the original climatological datasets were obtained through cooperation with meteorological or astronomical agencies. While much of the data used in these simulations came at no financial cost, some of it is difficult to obtain or comes in an obsolete digital format.

The wind and current data used in the earlier simulations relied on probabilistic models that average speed and direction, selecting conditions randomly from the regionalised distributions (e.g. Irwin, Bickler and Quirke. 1990; Levinson, Ward and Webb 1973). While this creates the right frequency of conditions, it ignores the spatial and temporal autocorrelation of winds and currents. Some simulations therefore used deterministic methods, which sampled real time series data to generate winds and currents (e.g. Evans 2008; Montenegro 2006). While managing the autocorrelation problem, the ability of this method to capture the potential variability in conditions outside of the measured (modern) period has not been tested.

Vessel performance has also been relatively limited with a focus on either pure drift voyages relating to accidental colonisation or those which are directed under sail. Some questions might involve combinations of drifting and sailing, while others might warrant comparisons between the two. Modelling the range of vessels capable of different levels of drifting and sailing, and the strategies employed by and purposes of the sailors using them is what drives the archaeological research.

Despite these limitations, many of which represent technical constraints rather than conceptual ones, the success of the previous simulations listed in Table 1 has been in providing systematic testing of important archaeological questions. In the Pacific, for example, the work of 


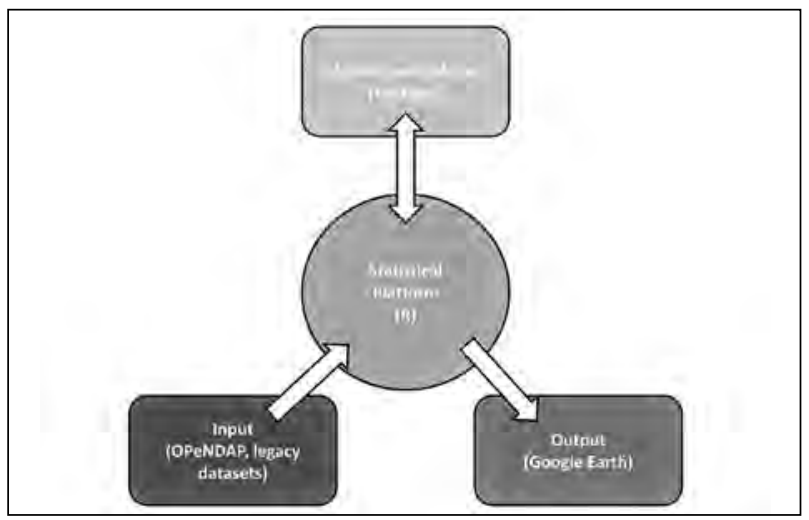

Figure 1. Simulation structure.

simulators is foundational to prevailing hypotheses of Polynesian migration and origins (Irwin et al. 1990; Levinson, Ward and Webb 1973), but also provide relevant challenges to prevailing models (e.g. Montenegro et al. 2008; Wyatt 2004).

We want to provoke a change in thinking about the role of simulation in archaeological research. With the advent of object-oriented programming (Kohler and van der Leeuw 2007), easy to learn programming platforms (Robertson 2005), and the rise of "Big Data" (Boyd and Crawford 2012), simulations and datasets are more accessible and more flexible than they have been in the past. Simulations no longer have to be constructed painstakingly as part of a limited research programme; instead, they can be used as tools to think with (Epstein 2008; O'Sullivan and Perry 2013), helping archaeologists develop more comprehensive hypotheses and explore ideas to inform future field work and analyses.

To this end, our task was to design a simulation system flexible enough to be used to answer questions pertaining to seafaring at relating to different time periods and different places, using freely available software and freely available, high resolution sources of data.

\section{System Structure and Input Data}

The simulation is comprised of four main software components (Fig. 1): NetLogo, R, OPeNDAP, and Google Earth. Simulations are controlled using NetLogo, an agent-based modelling platform made available through Northwestern University (Wilensky 1999). Data manipulation and some statistical functions are conducted in $\mathrm{R}$ via Thiele and Grimm's (2010) NetLogo-R extension. Some data (elevation, legacy datasets) are kept local, while open source data is obtained and subset in NetCDF format via an OPeNDAP server, processed in $\mathrm{R}$ using the netcdf library, and fed into the NetLogo GIS extension as an ASCII file. Spatial data from the simulation is sent to $\mathrm{R}$ to be parsed and converted into Keyhole Markup Language (KML) using the sp and rgdal libraries, and output as a file readable by Google Earth.

Global rasterdatasetsforbathymetry, windand currents are subset, re-projected, and re-sampled for the area around the vessel as it moves in order to reduce the amount of data being utilised at one time. The use of other relevant climatalogical data can also be added as required. Vessel performance characteristics have been derived from a number of different sources including ethnographic and ethnohistoric research (e.g. Evans 2008; Lauer 1976), experimental voyaging and reconstructions e.g. Doran 1981; Englert 2012; Finney 1977; Horvath and Finney 1976), as well as modern engineering analysis (e.g. J acobs 2003; Marchaj 1979).

\section{1 Bathymetry}

Coastlines used in the experiments described here were determined using 30-arc second digital elevation data, specifically the General Bathymetric Chart of the Oceans (GEBCO) dataset available from the British Oceanographic Data Centre (GEBCO 2013). Like previous work, this simulation utilises the notion of 'sighting radii' which determines the visibility of islands (e.g., Irwin, Bickler and Quirke 1990). Some studies have used incremental radii dependent on the relative size or elevation of a given landmass. The present study makes use of the equation for visibility for objects above the horizon (Eq. 1) to determine the visibility of any point on the map from sea:

$$
\mathrm{D} \approx 3.57\left(\sqrt{ } \mathrm{h}_{\mathrm{i}}+\sqrt{ } \mathrm{h}_{\mathrm{k}}\right)
$$

Where is the height of the observer and is the height of the observed object or landmass, both in metres above sea level. This provides islands with visibility buffers which more accurately reflect the shape of the landform. Since the GEBCO dataset is bathymetric, the simulated sea level can be tuned 
parametrically relative to modern levels. The difference between modern sea level and sea levels during the Last Glacial Maximum in Southeast Asia, for example, is displayed in Fig. 2.

\subsection{Winds and currents}

While previous simulations used either stochastic or deterministic environmental data for wind data, either can be chosen in the current model. For the stochastic version, the data used are effectively the same as that used by Levinson, Ward, and Webb (1973): compass roses of average wind directions expressed across the entire Pacific Ocean at 5 intervals. These roses provide the relative frequency and average speed of wind for all points of the compass. Where 16-point data was available it was used, otherwise wind directions were cardinal and ordinal points only. In these models, wind speeds can either be generated using a local random distribution, or set to a fixed speed related to craft performance. Additional compass rose data is available from the Marine Atlas of the World (U.S. Navy 1995) was acquired, although manipulation of this dataset is required for modern operating systems.

The default setting for the simulation is based on deterministic data, using gridded, multicomponent wind and current data obtained from the National Oceanic and Atmospheric Administration (NOAA). Winds are part of the Blended Sea Winds dataset (Zhang et al. 2006). Global current data comes from the NOAA Ocean Surface Current Analyses - Real time (OSCAR) dataset (National Oceanic and Atmospheric Administration 2013). Each cell within a grid contains both a U and V numerical component, from which direction and speed $(\mathrm{m} / \mathrm{s})$ can be extracted. Wind data is available at 6-hourly readings at a resolution of $0.25^{\circ}$ for years 1987 to present; surface current data is available as 5-day averages at a resolution of $0.33^{\circ}$ for years 1992 to present. Grids are cycled through at a rate consistent with the resolution of the dataset.

\subsection{Performance characteristics}

Performance combines here two different dimensions: the capabilities of the vessels being studied and those of the navigators that sailed them. Vessel capability encapsulates the available

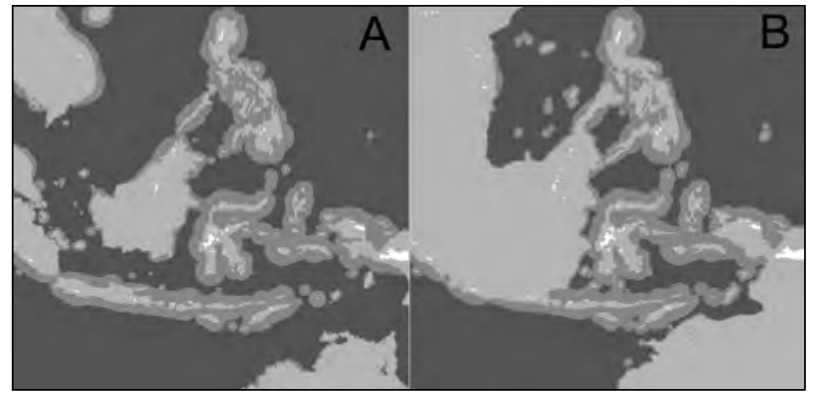

Figure 2. Output from simulation user interface, showing coastlines at present $(A)$ and coastlines during the last glacial maximum (B). Light blue shading indicates sighting radii.

technology including rafting, sailing and potentially even powered cruising. The crucial elements relating to vessel performance are associated with movement as affected by surface sea currents and surface winds (Marchaj 1979). For sailed vessels, performance is derived primarily from polar diagrams, which are often used to represent vessel speed as a proportion of the wind speed relative to the angle of the vessel's course. The progress of drifting vessels is determined by the USCG Leeward Drift Equation (United States Coast Guard 2013; see also Montenegro et al. 2006), which calculates the combined effects of currents and leeward wind propulsion on drifting vessels relative to the size and shape of the vessel. Although only rarely modelled, vessel capacity and durability is another area of research that can be important for answering archaeological research questions.

Navigation performance relates more specifically to the choices made by navigators in response to the different environmental conditions. This is usually encapsulated simply by the choice of direction a vessel tries to sail in, but factors such as position estimation, target choice and available knowledge and technology greater influence that choice. We allow navigators access to different concepts such as rhumb line sailing, latitude sailing, dead reckoning, tacking, and so on. Drifting vessels may or may not have the capacity to paddle, deploy a sea anchor, or set up a rudimentary sail for downwind movement.

\section{Model Case Study}

The current simulation is still in its early stages but it is possible to test out its performance using a literature-derived case study. The scenario 


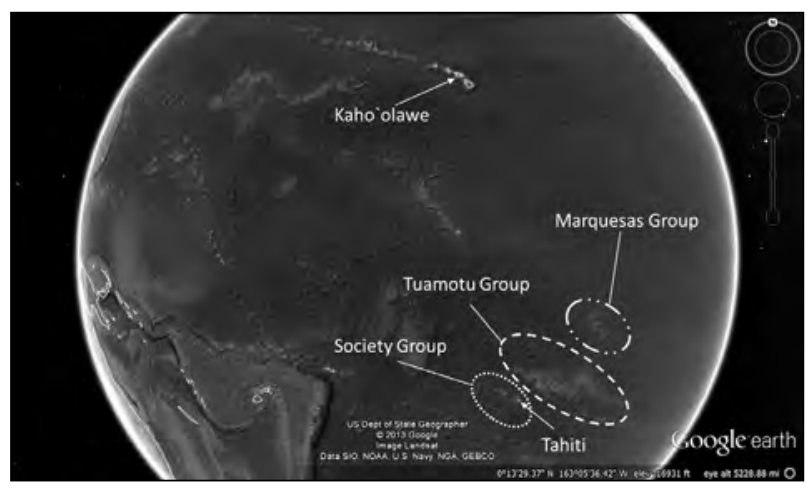

Figure 3. East Polynesia, with areas discussed in the text highlighted.

discussed below focuses on the Pacific region where the authors have greater familiarity. For more information on the settings used in these models, please see the ODD in Appendix A.

\section{1 "The Road to Tahiti"}

The case study is drawn from Hawaiian ethnographic literature pertaining to pre-European voyages between the Hawaiian archipelago and Tahiti (Kirch, Ruggles and Sharp 2013). The waters off the western coast of Kaho'olawe are known as Ke Ala I Kahiki (literally, "The Way to Foreign Lands", but often translated as "The Road to Tahiti"). According to tradition, a bearing taken off a promontory on Kaho'olawe (Ka Lae O Ke Ala I Kahiki) from within those waters will lead to Tahiti (Pukui et al. 1974). These toponyms, combined with oral traditions and archaeological evidence in the

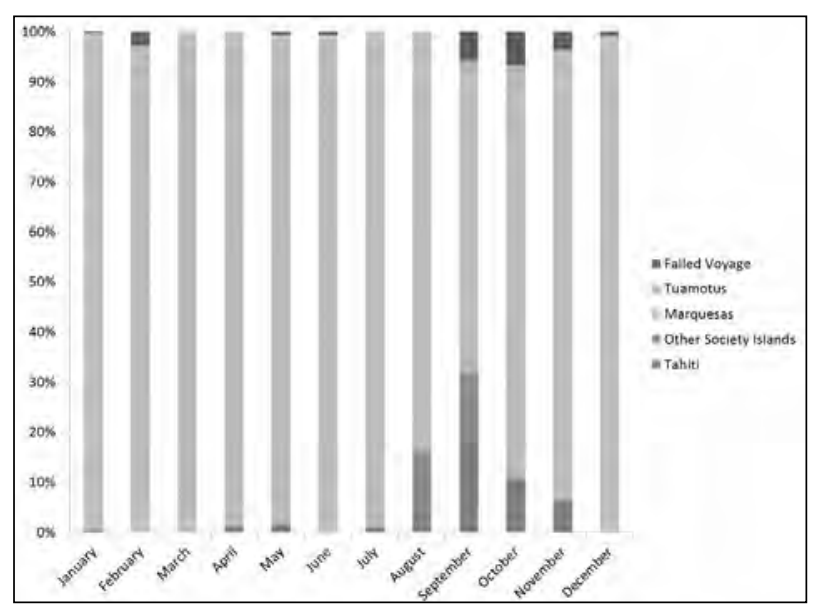

Figure 4. Frequency of successful landings from Ke Ala I Kahiki Point by month. form of stone artefact provenance (Collerson and Weisler 2007), suggest that contact between these island groups in opposing hemispheres may have taken place with some frequency. The question we sought to address was whether voyages taken from Ke Ala I Kahiki reliably made landfall at Tahiti or nearby islands (Fig. 3).

In the simulation, navigators were given the ability to follow a rhumb along a given bearing, to tack in the face of adverse winds, and awareness of latitude; abilities often attributed to Pacific Island navigators (Irwin 1992; Lewis 1964). Boats were positioned just off the west coast of Kaho'olawe, bearings were taken from the point, and ten boats were set off each day of the year 2000 (chosen because it did not exhibit strong ENSO characteristics). If a boat travelled within sighting range of a given landmass, it turned toward that location and proceeded until landfall was made. If a boat travelled beyond $22^{\circ} \mathrm{S}$, it picks a random heading within $90^{\circ}$ either side of true north. Voyages longer than 45 days were considered lost and the simulation was halted. The frequencies of landfalls at locations reached were tabulated.

The results of this experiment, illustrated in Figs 4 and 5, show a wide variety of resultant paths for voyages departing from a single point in Ke Ala I Kahiki channel. However, landfall rates were very high. While a few did land at Tahiti, most fell to the east, arriving at atolls in the Tuamotu chain. This "screen of islands" has been cited as presenting a large target for traditional navigators,

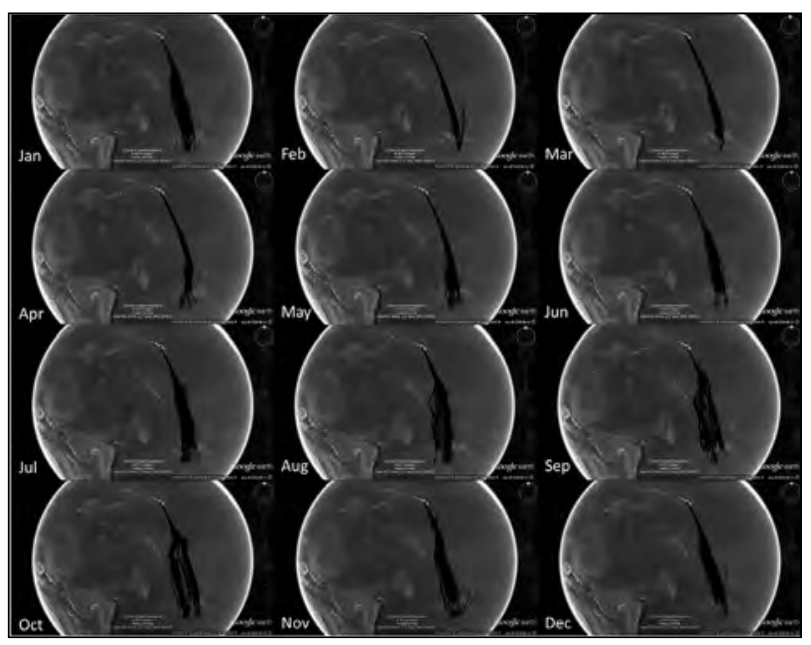

Figure 5. Spatial distribution of monthly simulations. 
so the number of landings there should come as little surprise, and groups landing there could use local "island-hopping" voyages to transit to Tahiti (Lewis 1964). For the year under study, the likelihood of landing to the west at Tahiti or other islands in the Society group increased particularly in the southern hemisphere spring. Failed voyages, determined by sailing beyond a limit of 45 days, were few. Failure rates on real voyages were likely to be higher as changing visibility and storm conditions are factored in, let alone issues of crew sustenance. A more thorough treatment on this particular topic is clearly warranted. However, despite being limited in scope, the performance of the simulation to model directed sailing voyages was successful.

\section{Discussion}

Thecurrentsimulation is still in its early testing stages, but has already been shown to incorporate the abilities of many of the previous simulations as well as being capable of using multiple sources of climatological data. A number of areas, some identified earlier in the text, provide opportunities for improvement.

The simulation currently uses only stochastic and deterministic environmental datasets for input, but using real time series data to generate artificial time series data by means of stochastic weather generation algorithms (Wilks and Wilby 1999) is being investigated as an alternative. Producing geospatial coverages that are autocorrelated would be computationally intensive, and such a caveat speaks to one of the core tenets of modelling, which is to simplify processes in order to emphasise core processes (Epstein 2008). However, this method (or something like it) would add a good deal of realism to models which might require it, and circumvent the issues of determinism and autocorrelation.

Incorporating modelled data is a priority for the next phase of development. Palaeoclimate data, for instance the CLIMAP dataset or its PMIP replacements (Braconnot et al. 2007), would allow for more informed interpretations of prehistoric winds and currents, especially in fine scale experiments in areas such as Wallacea where they may have played a crucial role in the colonisation of Australia. Likewise, tidal forcing models like the Princeton Ocean Model (Blumberg and Mellor 1987) would permit more detailed investigations of nearshore activity and shorter crossings between island gaps. Integrating coastal models which respect changes to landforms and glaciers would also provide opportunities to examine hypotheses where coastal geomorphology is paramount (Westley and Dix 2008; Wyatt 2004).

Finally, the influence of the navigator in voyaging choices is another area requiring further investigation. Currently, the simulation allows for knowledge of some basic tenets of sailing. Historical and ethnohistorical data can be used to augment decision-making rules for simulated navigators under various conditions. In terms of input data, we have yet to include knowledge of marine and shore ecosystems for guiding boats to shore (Lewis 1964). However, simulations focused on testing out different objectives of the sailors, from voyages of exploration, colonisation, resource extraction or warfare may be useful in understanding the presence or absence of archaeological remains in different places at different times. By emphasising navigators as problem-solvers, simulations can be used to evaluate the role of individual agency in human maritime migration and mobility.

\section{Bibliography}

Allen, J., and J. F. O'Connell. 2009. "Getting from Sunda to Sahul." In Islands of Inquiry, edited by G. Clark, F. Leach, and S. O'Connor, 31- 46. Canberra: ANU Press.

Avis, C., Á. Montenegro, and A. Weaver. 2008. "Simulating Island Discovery During the Lapita Expansion." In Canoes of the Grand Ocean, edited by A. Di Piazza and E. Pearthree, 121- 142. Oxford: Archaeopress.

Birdsell, J. B. 1977. "The Recalibration of a Paradigm for the First Peopling of Greater Australia." In Sunda and Sahul: Prehistoric Studies in Southeast Asia, Melanesia, and Australia, edited by J . Allen, J . Golson, and R. J ones, 113- 168. London: Academic Press.

Blumberg, A., and G. Mellor. 1987. "A Description of a Three-dimensional Coastal Ocean Circulation Model." In Three-Dimensional Coastal Ocean Models, edited by N. Heaps, 1- 16. Washington: American Geophysical Union.

Boyd, D., and K. Crawford. 2012. "Critical Questions for Big Data." Information, Communication \& Society 15 
Across Space and Time. Papers from the 41st Conference on

Computer Applications and Quantitative Methods in Archaeology. Perth, 25-28 March 2013

(5):662- 679 .

Braconnot, P., B. Otto-Bliesner, S. Harrison, S. Joussaume, J.-Y. Peterchmitt, A. Abe-Ouchi, M. Crucifix, E. Driesschaert, Th. Fichefet, and C. D. Hewitt. 2007. "Results of PMIP2 Coupled Simulations of the MidHolocene and Last Glacial Maximum-Part 1: Experiments and Large-scale Features." Climate of the Past 3 (2):261277.

Callaghan, R. T. 2001. "Ceramic Age Seafaring and Interaction Potential in the Antilles: a Computer Simulation." Current Anthropology 42:308- 313.

Callaghan, R. T. 2003a. "Prehistoric Trade Between Ecuador and West Mexico: A Computer Simulation of Coastal Voyages." Antiquity 77 (298): 796- 804.

Callaghan, R. T. 2003b. "The Use of Simulation Models to Estimate Frequency and Location of J apanese Edo Period Wrecks Along the Canadian Pacific Coast." Canadian J ournal of Archaeology/J ournal Canadien d'Archéologie 27:74-94.

Callaghan, R. T., and S. M. Fitzpatrick. 2008. “Examining Prehistoric Migration Patterns in the Palauan Archipelago: a Computer Simulated Analysis of Drift Voyaging." Asian Perspectives 47 (1):28- 44.

Collerson, K. D., and M. I. Weisler. 2007. "Stone Adze Compositions and the Extent of Ancient Polynesian Voyaging and Trade." Science 317:1907- 1911.

Di Piazza, A., P. Di Piazza, and E. Pearthree. 2007. "Sailing Virtual Canoes Across Oceania: Revisiting Island Accessibility." J ournal of Archaeological Science 34:1219- 1225.

Doran, E. B. 1981. Wangka: Austronesian Canoe Origins. College Station: Texas A\&M University Press.

Englert, A. 2012. "Travel Speedin theVikingAge: Results of Trial Voyages with Reconstructed Ship Finds." In Between Continents. Proceedings of the Twelth Symposium on Boat and Ship Archaeology Istanbul 2009, edited by N. Günsenin, 269-278. Istanbul: University of Istanbul/ ZeroBooks.

Epstein, J. M. 2008. “Why Model?” Journal of Artificial Societies and Social Simulation 11(4):1- 5.
Evans, B. 2008. "Simulating Polynesian Double-hulled Canoe Voyaging: Combining Digital and Experimental Data to Prepare for a Voyage to Rapa Nui (Easter Island)." In Canoes of the Grand Ocean, edited by A. Di Piazza and E. Pearthree, 143- 154. Oxford: Archaeopress.

Finney, B. R. 1977. 'Voyaging Canoes and the Settlement of Polynesia." Science 196 (4296): 1277- 1285.

Fitzpatrick, S. T., and R. T. Callaghan. 2013. "Estimating trajectories of colonisation to the Mariana Islands, western Pacific." Antiquity 87:840-853.

Garcia, R. R., H. F. Díaz, R. G. Herrera, J. Eischeid, M. R. Prieto, E. Hernández, L. Gimeno, F. R. Durán, and A. M. Bascary. 2001. "Atmospheric Circulation Changes in the Tropical Pacific Inferred from the Voyages of the Manila Galleons in the Sixteenth-eighteenth Centuries." Bulletin of the American Meteorological Society 82 (11):24352455 .

GEBCO. 2013. "General Bathymetric Chart of the Oceans." Accessed J une 18. http:/ / www.gebco.net.

Grimm, V., U. Berger, D. L. DeAngelis, J. G. Polhill, J. Giske, and S. F. Railsback. 2010. "The ODD protocol: a review and first update." Ecological Modelling 221 (23):2760- 2768 .

Hiscock, P. 2008. Archaeology of Ancient Australia. London: Routledge.

Horvath, S. M., and B. R. Finney. 1969. "Paddling Experiments and the Question of Polynesian Voyaging." American Anthropologist 71 (2):271- 276.

Irwin, G. 1992. Prehistoric Exploration and Colonisation of the Pacific. Cambridge, Melbourne: Cambridge University Press.

Irwin, G., S. Bickler, and P. Quirke. 1990. 'Voyaging by Canoe and Computer: Experiments in the Settlement of the Pacific Ocean.” Antiquity 64:34- 50.

Jacobs, B. A. 2003. "Mathematical Modelling of Oceanic Canoe Performance." MA Thesis, University of Auckland.

Kalnay, E., M. Kanamitsu, R. Kistler, W. Collins, D. Deaven, L. Gandin, M. Iredell, S. Saha, G. White, J. Woollen, Y. Zhu, M. Chelliah, W. Ebisuzaki, W. Higgins, J . Janowiak, K. C. Mo, C. Ropelewski, J. Wang, A. Leetmaa, 
Sailing the Simulated Seas: a New Simulation for Evaluating Prehistoric Seafaring Benjamin Davies and Simon H. Bickler

R. Reynolds, R. J enne, and D. J oseph, 1996. "The NMC/ NCAR 40-Year Reanalysis Project." Bulletin of the American Meteorological Society 77:437-471.

Kirch, P. V. 2010. "Peopling of the Pacific: a Holistic Anthropological Perspective." Annual Review of Anthropology 39:131- 148.

Kirch, P. V., C. Ruggles, and W. D. Sharp. 2013. "The Pānānā or 'Sighting Wall'at Hanamauloa, Kahikinui, Maui: Archaeological Investigation of a Possible Navigational Monument." Journal of the Polynesian Society 122 (1):45- 68.

Kohler, T. A., and S. E. van der Leeuw. 2007. "Introduction: Historical Socionatural Systems and Models." In The Model-Based Archaeology of Socionatual Systems, edited by T. A. Kohler and S. E. van der Leeuw, 1- 12. Santa Fe: School for Advanced Research Press.

Lauer, P. K. 1970. "Sailing with the Amphlett Islanders." The J ournal of the Polynesian Society 79 (4):381- 398.

Levinson, M., R. G. Ward, and J. W. Webb. 1973. The Settlement of Polynesia: a Computer Simulation. Minneapolis: University of Minnesota Press.

Lewis, D. 1964. "Polynesian Navigational Methods.” The J ournal of the Polynesian Society 73 (4):364- 374.

Marchaj, C. A. 1979. Aero-hydrodynamics of Sailing. London: Granada Publishing.

Montenegro, Á., R. Hetherington, M. Eby, and Andrew J. Weaver. 2006. "Modelling Pre-historic Transoceanic Crossings into the Americas." Quaternary Science Reviews 25 (11):1323- 1338.

National Oceanic and Atmospheric Administration. 2013. "Near-realtime global ocean surface currents derived from satellite altimeter and scatterometer data." Accessed J une 18. http:/ / www.oscar.noaa.gov.

O'Sullivan, D., and G. L. W. Perry. 2013. Spatial Simulation: Exploring Pattern and Process. Hoboken: Wiley.

Pukui, M. K., S. H. Elbert, and E. T. Mookini. 1974. Place Names of Hawaii. Honolulu: University of Hawaii Press.

Robertson, D. A. 2005. “Agent-based modeling toolkits
Netlogo, RePast, and Swarm." Academy of Management Learning and Education 4 (4):525- 527.

Ruxton, G. D., and D. M. Wilkinson. 2012. "Population Trajectories for Accidental Versus Planned Colonisation of Islands.”J ournal of Human Evolution 63 (3):507- 511.

Surovell, T. A. 2003. "Simulating Coastal Migration in New World Colonization." Current Anthropology 44 (4):580- 591.

Thiele, J. C., and V. Grimm. 2010. "NetLogo Meets R: Linking Agent-based Models with a Toolbox for Their Analysis." Environmental Modelling \& Software 25 (8):972-974.

United States Coast Guard. 2013. U.S. Coast Guard Addendum to the United States National Search and Rescue Supplement (NSS) to the International Aeronautical and Maritime Search and Rescue Manual (IAMSAR). COMDTINST M16130.2F. Washington, DC: U.S. Coast Guard.

Westley, K., and J. Dix. 2008. "The Solutrean Atlantic Hypothesis: a View from the Ocean." J ournal of the North Atlantic 1(1):85- 98.

Wild, S. 1986. "Voyaging to Australia: 30,000 Years Ago." Computers \& Graphics 10 (3):207-212.

Wilensky, U. 1999. NetLogo 5.0.3. Accessed J anuary 15, 2014. http:// ccl.northwestern.edu/netlogo.

Wilks, D. S., and R. L. Wilby. 1999. "The Weather Generation Game: a Review of Stochastic Weather Models." Progress in Physical Geography 23 (3):329357.

Wyatt, S. 2004. "Ancient Transpacific Voyaging to the New World via Pleistocene South Pacific Islands." Geoarchaeology 19 (6):511- 529.

Zhang, H.-M., R.W. Reynolds, and J. J. Bates. 2006. "Blended and gridded high resolution global sea surface wind speed and climatology from multiple satellites: 1987 present." Paper presented at the American Meteorological Society 2006 Annual Meeting, Atlanta, GA, J anuary 29 February 2. 


\title{
Agricultural Territories and GIS Modelling: the Long-Term Case Study of Menorca
}

\author{
Monica De Cet, Rainer Duttmann \\ Kiel University, Germany \\ Vicente Lull, Rafael Micó \\ Autonomous University of Barcelona, Spain \\ Johannes Müller \\ Kiel University, Germany \\ Cristina Rihuete Herrada, Roberto Risch \\ Autonomous University of Barcelona, Spain \\ Philip Verhagen \\ VU University Amsterdam, The Netherlands
}

\begin{abstract}
:
This paper explores the heuristic value of a palaeo-agrarian methodology and GIS modelling through the use of a well-studied archaeological landscape located in the western Mediterranean region. Taking the theoretical framework of the Aguas Project as a reference, a research design is developed for this specific case study. In particular, we apply the new modelling procedure to the settlement site data of the island of Menorca (Balearic Islands, Spain), in combination with a substantial volume of palaeo-economic studies and historical information. The results of this study are presented in the form of territorial maps showing the hypothetical areas of dry land cultivation over a long-term chronology and across the entire island. This investigation aims to contribute to the discussion on the relevance of archaeological and palaeoecological data for our understanding of the present day landscapes and their sustainable development in the future.
\end{abstract}

\section{Keywords:}

Palaeo-Agrarian Analysis, GIS Modelling, Prehistory, Menorca, Sustainability

\section{Introduction}

GIS modelling is a powerful tool to explore the socio-economic sphere of past societies. Recent interdisciplinary approaches coupled with GIS analyses have demonstrated that the investigation of socio-economic aspects of past Mediterranean communities can provide specific historical knowledge. Until now, the Aguas, Archaeomedes and Archaedyn projects (Castro et al. 1998; 2002; Gandini, Favory and Nuninger 2012; van der Leeuw 1998) represent important studies that have offered a complete reference framework for modelling Mediterranean socio-natural systems. Reconstructions of human dynamics, settlement and production patterns, practices of land use as

Corresponding author: mdecet@gshdl.uni-kiel.de well as palaeo-agrarian analysis are some of the main methodological issues highlighted by these projects that revealed complex long-term territorial dynamics for Mediterranean landscapes over the last millennia.

In this paper, weshowthepotential of a palaeoagrarian analysis in GIS modelling using the case study of the Mediterranean island of Menorca. In particular, we focus our attention on reconstructing agricultural territories of dry land cultivation from Naviform times (ca. $1600 \mathrm{cal}$ BCE) until the Andalusian period (ca. $1200 \mathrm{CE}$ ). The research design of this study has been developed on the basis of the theoretical framework of the above mentioned Aguas Project, carried out in the southeast of Spain during the late 1990s. In particular, we have 
followed the palaeo-agrarian analysis used in the Aguas valley in order to determine the long term effect of local agricultural strategies on Menorca's environment and socio-economic situation. In view of the exceptionally dense archaeological settlement record and high population numbers documented for certain historical timeframes, one important question which emerges is whether the island had sufficient resources to allow such a development, or if it became dependent on supplies from overseas beyond a certain ecological, social or political threshold (e.g. from Mallorca or the continent). By answering this question, we approach the underlining structure of socio-natural interactions on a rather limited territory, its resilience in light of different social and political situations, and we attach a specific meaning to the concept of "sustainability" which is relevant to the future development of the island. The obtained results, expressed in the form of maps illustrating the hypothetical agricultural territories through time, provide insights into particular short-term situations as well as into the long-lasting strategies of dry land cultivation in Menorca. The results confirm the potential of such palaeo-agrarian approaches in archaeology, and demonstrate how similar GIS modelling techniques can be efficiently re-implemented in different archaeological contexts (Müller 2003; El-Kassem and Müller 2003)). Finally, the present paper illustrates the development and socioecological behaviour of one of the most important features of human subsistence - agricultural production - over ca. 2800 years on the island of Menorca by means of GIS modelling. This investigation represents the first attempt to apply a palaeo-agrarian analysis on Menorca based on archaeological spatial data and GIS modelling.

\section{Study Area}

The island of Menorca is located at the easternmost point of the Balearic Island archipelago, in the centre of the western Mediterranean Basin. With a relatively limited surface of ca. $700 \mathrm{~km}^{2}$ and a $216 \mathrm{~km}$ coastline, Menorca represents the most remote island from the Iberian Peninsula. Often defined as an "invisible" island due to its overall flat topography and a maximum elevation of only $357 \mathrm{~m}$ ASL (El Toro), Menorca presents a variety of landscapes. Its two main geographical settings are related togeology: thenorthern region, Tramuntana,

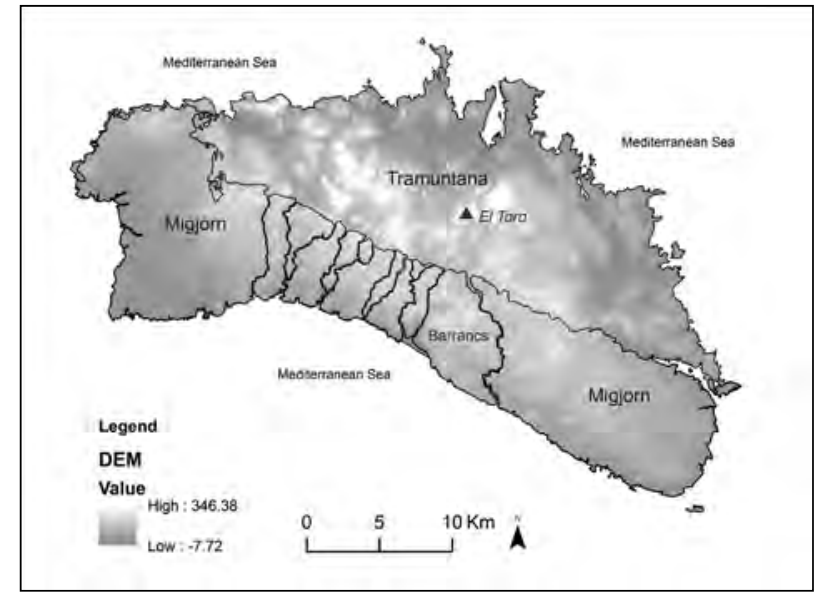

Figure 1. The island of Menorca (Balearic Islands, Spain). Digital Elevation Model, courtesy of Ordenació de Territori Department- CIM Menorca, Spain.

with a rugged topography and geological material from the Paleozoic and Mesozoic, and the southern region, Migjorn, which mainly forms a flat terrain with calcarenitic materials from the Miocene. Furthermore, the central area of the Migjorn, known as the Barrancs (ravines), is associated to temporal streams entrenched in small gorges, which follow an $\mathrm{N}$-S orientation running towards the southern coast (Cardona, J uaneda and de Pablo 1999; Didac 1997; Fornós, Obrador and Rosselló 2004) (Fig. 1).

Human occupation in Menorca commenced at the end of the 3rd millennium BCE, documented by funerary sites. From 1600-1500 cal BCE onwards, the first firm evidence of domestic features appeared in the form of boat-shaped stone buildings, the socalled naviformes. In the 9th century cal BCE, a settlement pattern organised around monumental towers, known as talaiots, was established across the entire island. During the final years of the 6th century BCE at the outset of the Post-talaiotic period, the termination of the previous Talaiotic settlements occurs (Micó 2005; 2006). In 123 BCE, Menorca became part of the Roman Empire. After the fall of the Roman Empire, Vandals, Byzantines and Andalusians successively dominated the political fate of the island (Casasnovas 2007, 165195).

In 1993 Menorca was declared a reserve biosphere by the UNESCO (Vidal-Hernández and Comas 2010). The overall equilibrium between demography, economy, and territory over the 
last centuries has guaranteed the extraordinary conservation of the natural environment together with the preservation of the historical countryside across the island (Vidal-Bendito 1989, 31). Signs of rural architecture are still visible, such as typical agrarian household structures from the 19th century, for example, the Llocs (J ordi and Taltavull 1979, 255).

The economy of Menorca has retained an agriculturalemphasisuntilrecenttimes. Thepresence of dry land farming and cereals as an agricultural strategy is also documented from Prehistory until Andalusian times through carbonised seeds and historical sources. Cereals, mainly wheat and barley, were the principal products of Menorcan fields until the 1960s (Casasnovas 2006, 283). Moreover, the mechanisation of Menorcan agriculture only commenced around the 1970s (Bisson 2007, 3), whereas traditional practices of cultivation were maintained on the island for centuries. Thus, dry land farming has always been perceived by the local population as being of primary importance (Marí i Pons, Florit and Pons 1991, 129), with first written accounts dating back to 1293 (Casasnovas 2000, 26). Abundant records on agricultural practices, crop harvesting, and yield productivity are available (e.g. Bonet 1988).

An exceptional array of data is also provided for the demography of Menorca. Early knowledge about the population living on the Insulae Baliares was already noted by Greek and Latin authors (Zucca 1998; Casasnovas 2006). Medieval chronicles and vassalage acts provide us with information regarding the human aspects of Andalusian influence on Menorca (Rosselló 1980; Serra et al. 1977; Vidal-Bendito 1969, 12- 15). Furthermore, the demographic development from the 14th until the 19th century is well-known thanks to accountant and fiscal reports, sacramental books, land registries, and census data (Vidal-Bendito, Dubon and Gomila 1979).

\section{Methodological Framework}

\subsection{Research design}

The theoretical and methodological background of the palaeo-agrarian analysis of the Aguas Project was the initial starting point from which we developed our methodology (Castro et al. 1998, 20-30, 68-84). In particular, this investigation allowed the researchers to model prehistoric and historic land use strategies and their environmental impact during the last 6000 years based on an assessment of the agricultural potential and the palaeo-demographic trajectory of the Aguas Valley.

A specific research layout was developed for the present case study, while all the necessary data available for Menorca were compiled, including its precise archaeological, historical, and socioeconomic background. For our investigation, we adopted a chronological scale similar to the Aguas Project, ranging from prehistory (ca. $1600 \mathrm{cal} \mathrm{BCE}$ ) to the Andalusian period (ca. 903-1287 CE), and we essentially aimed to achieve an analogous result in the form of interpretative maps, which illustrate the long-term palaeo-agrarian trajectory of the island. But, in contrast to the Aguas Project, which considered several forms of land use, we based our research on a distinct eco-agrarian focus by exclusively modelling the hypothetical areas of dry land cultivation, which has always been theeconomic base of the island's population, as previously noted.

The preliminary stage of this research included a discussion on the specific variables to be implemented in the agricultural modelling. The second stage of our investigation was dedicated to data collection and organisation. As usual, the accuracy of the final results relies on the relevance of the initially selected variables deployed in the model, as well as on the quality of the available data. As highlighted for the case of the Aguas Valley, researchers had to take several variables into account in order to obtain an accurate output of past agrarian patterns. Land use types, geology, topography, and the dietary needs of a given population were the main variables included in the modelling procedure (Castro et al. 1998, 28-30; 2002; Verhagen et al. 2007, 173). For the case of Menorca, ethnographic studies on modern rural settlements (Llocs) have highlighted a clear connection between topography, soil quality, and the degree of rural occupation (VidalBendito 1973, 54). In fact, the agrarian structure of the Llocs mainly seems to have developed in areas that guaranteed maximum advantages in terms of economy and salubriousness. Moreover, recent studies have also highlighted that the prehistoric 


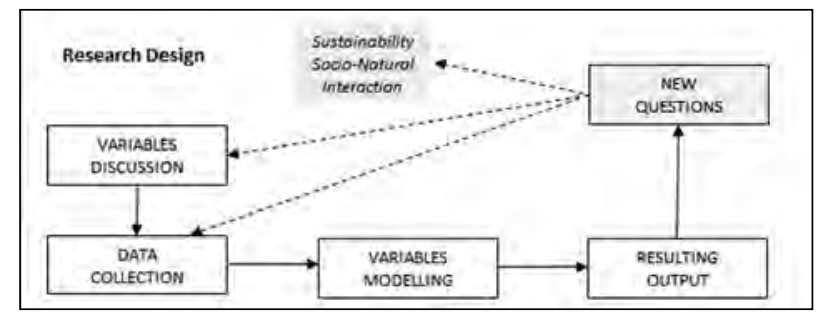

Figure 2. Outline illustrating the research design followed in this paper.

occupations on the island were close neighbours of the Llocs, suggesting that similar criteria in deciding where to settle prevailed through time (De Cet et al. in press). Considering the importance of the variables of the Aguas project together with the specific condition of the Menorcan Llocs, we decided to record settlement site data, the estimated amount of dry land farmingneeded per time period, available dry farming areas, and topographical accessibility as the most likely factors that could have intervened in the determination of the locations of agricultural territories on Menorca. We did not initially consider the geological base, as today both the pre-Neogene northern area and the southern Miocene plateau present a high agricultural potential. By means of the mentioned factors, we aimed to achieve a comprehensive integration of archaeological, demographical, natural landscape, and agricultural factors in order to reach the highest possible degree of accuracy for the modelled territories.

Finally, these variables were geographically modelled, creating maps representing the most probable agricultural territories of each established socio-historical context. The final output raised further, new questions that dialectically led us back to re-think the applied research design structure and the initial historical questions concerning the meaning of the concept of "sustainability" and socionatural interaction in the context of a Mediterranean island (Fig. 2).

\subsection{Description of the variables and modelling procedures}

\section{Settlement sites (Variable 1)}

The settlement site data involved in our investigation has been obtained from a broader research database (De Cet 2014). This database categorised each site according to its degree of chronological resolution, architectural evidence, as well as pottery, lithic, and other recorded artefacts. We imported the data and successively organised the settlement record into separate text files per time period, in which site codes and geographic coordinates have been specified. The total number of settlement sites (702 domestic records) involved in this paper cover a broad chronological span from Prehistory to Andalusian times, specifically for the following time periods: Naviform (ca. 1600-1100/ 1000 cal BCE), Talaiotic (ca. 850- 550 cal BCE), Post-talaiotic (ca. 550- 123 cal BCE), Roman-Republican (ca. 123 cal BCE- 27 BCE), Early Roman Empire (ca. 27 BCE- 284 CE), Late Antiquity and the "Dark-Ages" (ca. 425-903 CE), and Andalusian times (ca. 903-1287 CE). The remarkable number of radiocarbon dates (ca. 800) enabled the establishment of this solid chronology for the prehistory of Menorca (for a recent overview Lull et al. 2008: 12-36), which we have adopted as the chronological framework of this paper.

Required dry land farming per time period (Variable 2)

As previously noted, dry farming has been of primary economic importance in Menorca from prehistoric until recent times. All societies seem to have based their subsistence on this activity, as verified by archaeological and historical evidence. In fact, the presence of cereals since the Naviform period is attested by analyses of macro-remains that indicate the existence of species related to the family of Triticum wheat, mainly as $T$. monococcum Einkorn wheat, T. dicoccum Emmer wheat, and Hordeum Vulgare barley in the burial deposit of Es Càrritx (Stika 1999, 527, table 1), in Hipogeo 3 of S'Alblegall (Arnau, Gornés and Stika 2003, 122, table 1), and in a storage vessel from Torralba d'en Salord (Fernández 1991, 40; Moffet 1992, 89, table 1). Moreover, the trace element analysis in human bones from Es Càrritx (Peréz-Peréz, Fernández and Turbón 1999, 559) and later studies on stable isotopes on human collagen (Van Strydonck, Boudin and Ervynck 2002, 189) seem to indicate that the island population had a mixed diet based on subsistence farming and husbandry.

The significant consumption of cereals among prehistoric communities is also attested in the following Talaiotic and Post-talaiotic periods, 
from which vegetal inclusions in building materials (Arnau, Gornés and Stika 2003, 128) and macroremains from House 2 (Casa 2) of Torre d'en Gaumes (Pérez-Juez et al. 2007, 64) indicate the presence of cereal species belonging to the Triticum and Hordeum families. Cereal farming is also confirmed in Balearic communities during Roman times by the author Pliny the Elder (II BCE) in Naturalis Historia, which narrates the devastation of cereal crops by hares (PLIN. Nat. III, 11, 78) and refers to the presence of good quality wheat and the production of military bread for the Balearic slingers (PLIN. Nat. XVIII 13, 67; PLIN. Nat. XIV 71). Moreover, in Bibliotheca Historica (DIOD. V, 16) by Diodorus Siculus (ca. 90-27 BCE) and in Geographica (STR. III, 5, 1) by Strabo (ca. 63- 64 BCE- ca. $24 \mathrm{CE}$ ) the agricultural soils of Menorca are described as fertile and very productive (Zucca 1998, 174, 24; Casasnovas 2006, 18, 25). Later, records about vassal taxes point out that Andalusian authorities had to donate a notable quantity of wheat to King Jaime I (Vidal-Bendito 1969, 15). In addition, the Muslim historian Al-Zuhri (AH 124/741-2) refers in his manuscripts to the fertility and copious products that could be obtained from Menorcan fields during Roman times (Casasnovas 2006, 35).

Demography is the prime determinant of the extension of the agricultural territories, if the population lived on local resources. Therefore, in order to approach agricultural land as a variable in our model, it was necessary to hypothesise the dietary needs for each time period considered in the investigation. In particular, we decided to calculate the approximate required amount of resources, combining specific demographic and subsistence parameters.

First, we estimated the demographic development in terms of population numbers for each time-period of the investigation. The earliest direct information on the demography of Menorca is provided by Diodorus Siculus (ca. 90-27 BCE) in his Bibliotheca Historica (DIOD. $\mathrm{V}$, 17), which mentions 30.000 inhabitants on Menorca for the Post-talaiotic time period before the Roman conquest (Zucca 1998, 37). According to the archaeological database, 449 Post-talaiotic settlements can be identified on the island. Given the excellent preservation of the archaeological heritage of Menorca, including the current total of 1806 sites or ca. 2.5 sites per $\mathrm{km}^{2}$ (Gornés and Gual 2012a), the monumentality of its prehistoric architecture, and the radiocarbon dating research carried out during the last decades that indicates 1 dated site every 12.3 $\mathrm{km}^{2}$ (Micó 2005, 11), this number probably comes close to the real number of habitation sites existing before the Roman conquest. The exceptional archaeological record is partly due to the merit of Mascarò- Pasarius, who exhaustively catalogued settlement and funerary structures during the last century (Mascarò- Pasarius 1958; Mascarò-Pasarius and de Nicolás 1982) and carried out enquiries with locals. Moreover, from the late 1990s the archaeological service CIM Heritage Department has given primary importance to an update of this archaeological cartography by a special team in charge of supervising building activities and monitoring the archaeological sites (Gornés 2008; Gornés and Gual 2002; 2012b). By combining both values, we would reach an average number of ca. 66.7 inhabitants per settlement during the Posttalaiotic time period. Notably, if we undertake palaeo-demographic calculations based on the archaeological evidence concerning Post-talaiotic settlement size, a very similar figure is obtained: applying the parameters proposed by Renfrew (1972) and Schreiber and Kintigh (1996) the average population per settlement would be pinpointed within a range of ca. 86- 50 inhabitants. Overall, the real demographic development on Menorca from the 14th to the 16th century CE (Vidal-Bendito, Dubon and Gomila 1979, 15) and from the 17th19th century (Salvator 1982; Casasnovas 2011; INE 2013; Murillo 2008; Riudavets i Tuduri 1885; Vidal 1989), including growths and fluctuations, never exceeded 40.000 inhabitants, which corresponds to ca. 57 inhabitants $/ \mathrm{km}^{2}$. By this correspondence between census data and archaeological records, together with the geo-ecological uniformity that this island represents (see section 2), and with the aim to obtain a rough estimation of the total number of inhabitants for each time period, we propose to take the average number of 66.7 inhabitants per site as a constant value for all the periods of this research investigation (variable 1). As most of the 702 archaeological sites of our database are multiperiod settlements, it was impossible to establish their individual sizes during each of the different moments of occupation. However, given that the maximum extension of settlement remains 
generally corresponds to the Post-talaiotic/ Roman Republican period, this value would correspond to the average, maximum number of inhabitants per site. This decision also takes into account that urbanism only experienced a limited development during the Roman Imperial and the Andalusian periods, while a more or less dispersed rural population always formed the dominant settlement pattern.

Second, we assessed a referenceamount of dry farmingland per person on the basis of ethnographic records. Asmentioned above, a considerable number of documents on cereal productivity and historical land use practices are available for Menorca. These sources help us to identify the value that could have possibly been associated to the dietary needs of past communities on the island. If, for example, the diverse records from the year $1818 \mathrm{CE}$ are used as a reference that considered a wheat productivity of $357 \mathrm{~kg} /$ hectares, a total population of 37.114 inhabitants, and a total extension of dry farming on the island measuring 35.021 hectares, we reach the approximate value of 0.94 hectares as the quantity of required dry farming land to sustain each person at that particular time on the island (Casasnovas 2006, 208, 308; Méndez 2007, 396). Taking into account the non-industrial nature of these agricultural records as well as the general economic uniformity, commonly based on cereal cultivation over centuries (see section 2), we considered this value to be transferable to the conditions of past societies on Menorca.

As a last step, we combined the hypothetical demographic trajectory with the reference value of 0.94 needed hectares of land per person. This provides us with an outline of the total hectares of agricultural land needed to satisfy the communities of each time period of this investigation (variable 2 ). The total amount has been equally distributed among all sites, as it is impossible to establish the size or population of 702 recorded settlements in each of its occupation phases. As a starting premise, we also assume that all the sites had equal access to agricultural resources.

Available dry land farming area (Variable 3)

After having estimated the amount of required hectares of dry land farming per each time period of this investigation (variable 2), we assessed the scope of geographical space where this specific estimated amount of hectares could have been located. In particular, we needed to define the expansion of required hectares where past Menorcan communities could have found available areas for dry land cultivation. As we have already mentioned, traditional agriculture was preserved in Menorca until recent times. Moreover, the late mechanisation of fields, especially for cereal cultivation, has allowed the retention of sustainable agricultural practices until the 1970s.

Therefore, the dry farming area in the land use map of 1956 (courtesy of the Department of Territory, Consell Insular de Menorca) represents a reasonable starting point, since it illustrates the most probable areas of land use taking conditions of non-industrialisation into account. The total area of available dry land farming in 1956 amounted to 43.540 hectares, and it is mainly associated with Miocene geology and low erodible materials (Martínez and Espinal 2005, 32- 33). Moreover, it is composed almost completely of cambisol soils, a type of soil that is extremely fertile and suitable for cereal cultivation (IUSS Working Group WRB 2007, 75). Finally, the dry land farming area in the land use map of 1956 was exported to ArcGIS and GRASS GIS in polygon shapefiles as the actual mask where our hypothetical territories could be pinpointed.

\section{Accessibility of terrain (Variable 4)}

Following the definition of needed dry farming hectares for each time period (variables 1-2) and the potential agricultural space of the island (variable 3), we needed to consider the actual accessibility of terrains from the point of view of settlement locations (variable 4). In particular, the basic assumption we wanted to consider in our model was related to the fact that past communities could have sought potential land at minimum distances from their settlements.

The accessibility of terrain was therefore assessed by the creation of a single cost-distancemap for each settlement involved in this paper. Each costdistance map has been clipped with the actual extent of the availablemask for dry land farming cultivation (variable 3). Ultimately, we gained a total of 702 cost-distance maps that quantify the accessibility of 


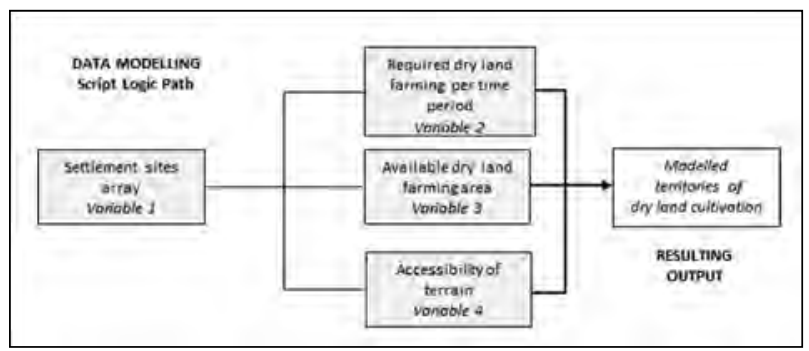

Figure 3. Outline showing the logic path followed by the script in the modelling procedure.

terrain within the available dry land farming area for each particular site. The cost-distance maps were obtained from the digital elevation model (5x5 m spatial resolution DEM courtesy of the Department of Territory, Consell Insular de Menorca) and slope maps through standardised tools in ArcGIS and Grass GIS. The use of least-cost path (LCP) analysis in the reconstruction of prehistoric routes through case studies (e.g. Ejstrud 2005; Gietl et al. 2008; Herzog 2013; Llobera 2000; Llobera and Sluckin 2007; Verhagen 2013; Zakšek et al. 2008) is still very much debated. However, experimentation with different LCP algorithms is beyond the scope of this study. The cost-distance maps were constructed on the basis of the popular Tobler's hiking equation

$$
\mathrm{v}=6 \exp \left\{-3.5^{*} \operatorname{abs}(\mathrm{S}+0.05)\right\}
$$

(Tobler 1993) that specifies the velocity of traversing each grid cell on foot, depending on the steepness of slope and the direction of movement (uphill or downhill). The equation can easily be converted to provide an output that assigns to each pixel a cost value of the time needed to cross it. The resolution of the DEM is not sufficient to correctly identify steep ravines (barrancs). They were therefore manually digitised and received a special cost-distance value, amounting to 10 minutes crossing time.

\subsection{The modelling procedure}

Subsequent to the processing steps for the variables, we designed the script for the modelling procedure. At the moment, there are no available tools in common GIS software that can entirely compute the model we wanted to run for the aims we intended to achieve in our investigation. Therefore, on the basis of the Aguas modelling procedure (see Castro et al. 1998, 29; Verhagen et al. 2007, 173), we designed a script for the particular case study of Menorca that involves the selected variables (supra, variables 1-2-3-4) that we wanted to employ in our model.

Technically, the script has been realised in the Python language and was implemented in a Grass GIS interface. Fig. 33 illustrates the logic path that the script follows to determine the location of the agricultural territories of dry land farming of each time period. First, the script imports the settlement site array of a specific time period in the format of text files (variable 1). In particular, each time period has been put to run separately, in order to produce a separate output. Afterwards, the script runs through the site array to determine the agricultural territories of every particular site. In the process of determining the territories, the script considers that it has to look for the locations of the total amount of needed dry land farming per time period (variable 2 ) in the dry land farming mask (variable 3), and by occupying before the pixels around the sites with minimum cost-distance values (variable 4), therefore fulfilling the assumption of potential land at minimum cost-distances.

Each settlement has its own territory. These respective pixels will no longer be available for the construction of the other contemporaneous territories. Finally, the script produces maps in the form of single raster maps on which the hypothetical territories of dry land cultivation are visible for each time period. Afterwards, the output can be easily exported to a different GIS interface for its elaboration or for further processing, for example, to create a cumulative map of territories that combines all the obtained maps (see next section).

\section{Results and Discussion}

The resulting output of obtained modelled territories represents a significant extent of the geographical regions, in terms of temporal and spatial characteristics. In fact, the maps provide for a deep time span - the dry farming trajectory of the entire island of Menorca. Moreover, thanks to the well-defined settlement site data used in this research, we reached a considerable accuracy for the modelled territories. The territories are concretised in the form of single maps and one cumulative map as described below. 


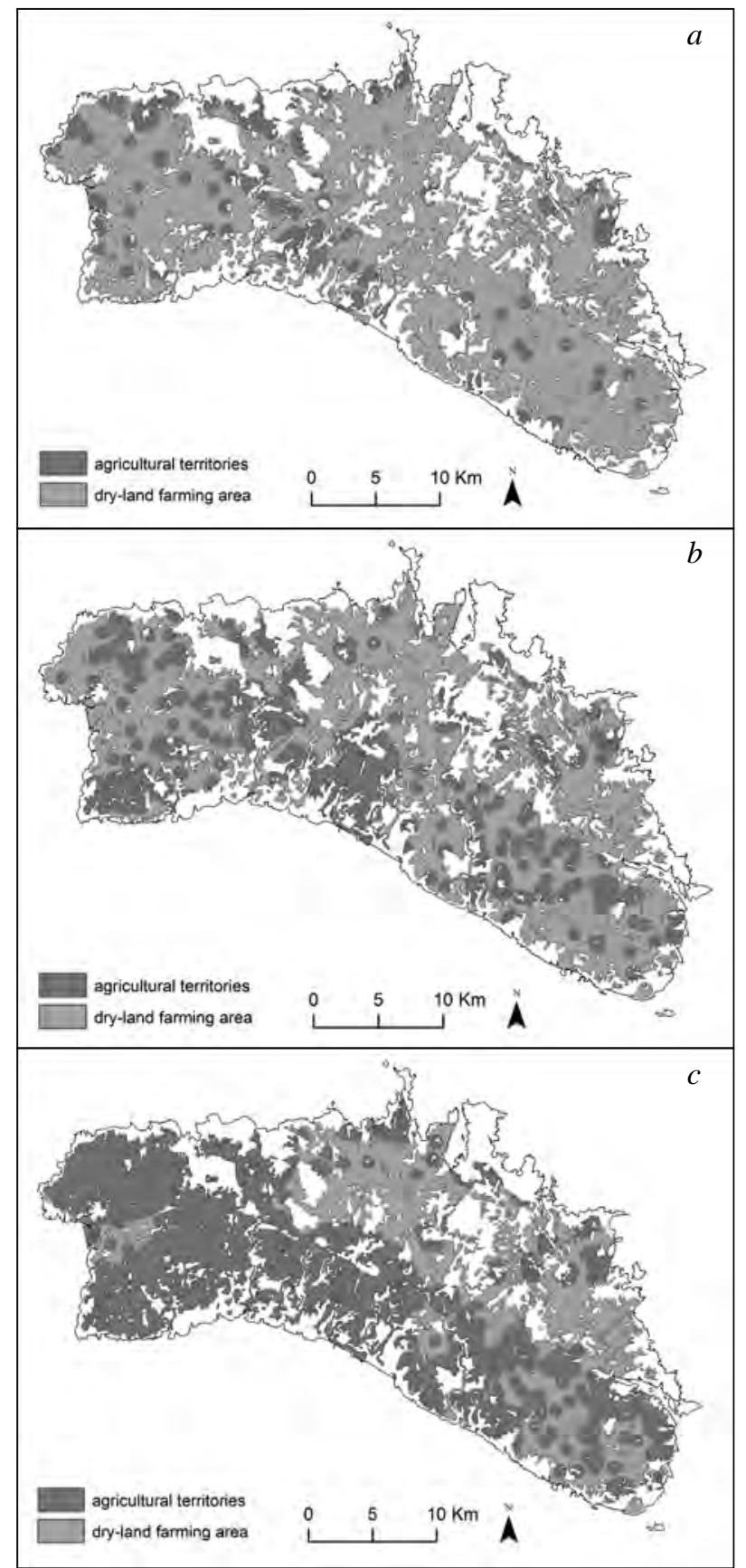

\subsection{Single maps of modelled territories}

The single maps of the modelled territories show the hypothetical dry land cultivation areas for each time period of this investigation. Based on a constant value of demography per settlement and dietary needs, the seven obtained maps cover the prehistoric timeframe of the Naviform, the Talaiotic and Post-talaiotic periods, as well as the historical

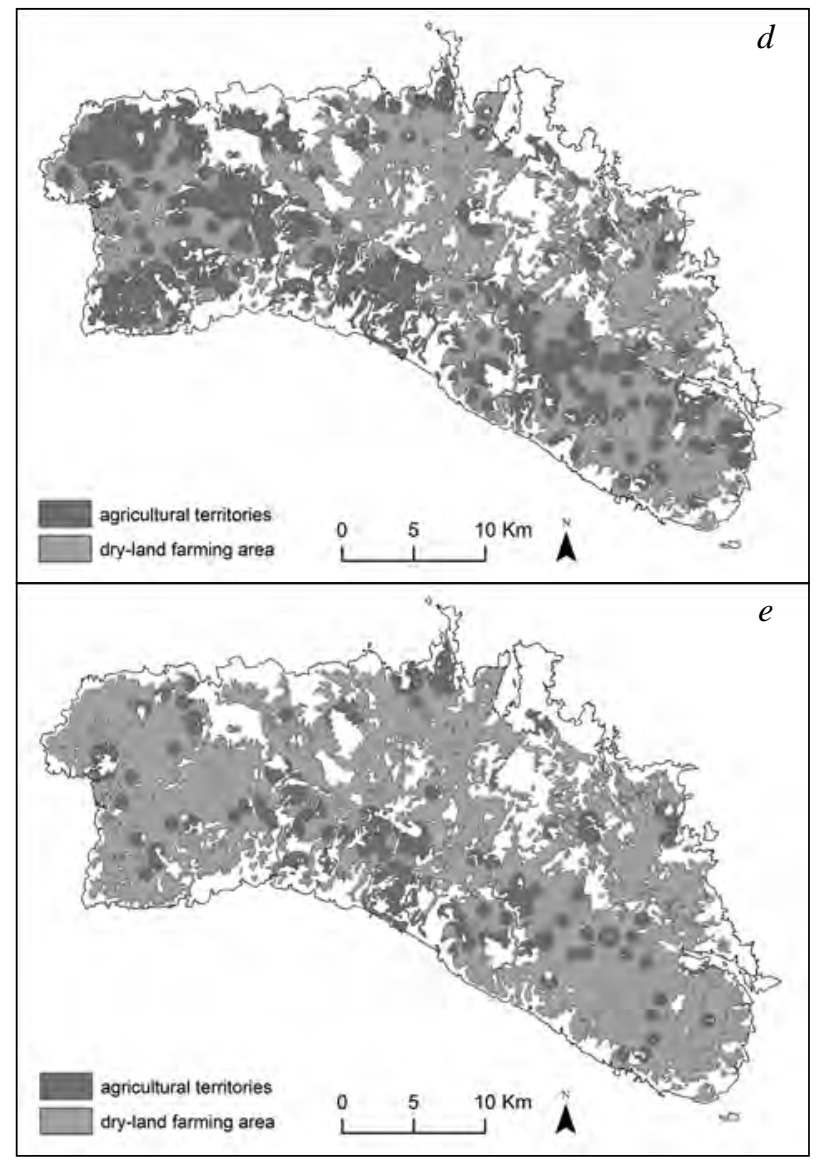

Figure 4. Modelled agricultural territories of dry land farming based on a constant demographic value of inhabitants per site and dietary needs. a) Naviform period (ca. 1600-1100/1000 cal BCE); b) Talaiotic period (ca. 850-550/500 cal BCE); c) Post-talaiotic period (ca. 550/500 -123 cal BCE); d) Roman-Republican period (123 cal BCE- 27 BCE); e) Andalusian times (c. 9031287 CE).

time periods of the Roman-Republic, the Early Roman Empire, Late Antiquity and the Dark Ages up to the Andalusian period.

Our maps show a fluctuation in the extension of the territories, together with a change in the geographical focus over time. As visible in Fig. 4, the Naviform territories present a disperse pattern and are mostly located on the western part of the island. In the following Talaiotic period, although a preference for the western area is still visible, we observe an increase of the agricultural territories over the southern-central area. The subsequent 
Post-talaiotic period illustrates an expansion of the cultivated areas: the western and southerncentral areas across the dry farming mask are completely filled. The modelled territories during Roman-Republican times still maintain a dense orientation across the northwest and southerncentral areas. In addition, a decrease of agricultural territories with respect to the previous periods begins and lasts through the Early-Roman Empire and Late Antiquity until Andalusian times. The Andalusian regions appear rather sparse on the territory, although a denser concentration of such territories on the central area of the island, known as the Barrancs, can be observed. Obviously, in this period we also need to take into account the presence of a peasant population in the urban centres of Maó (Magun) in the eastern area of the island and Ciutadella (Medina- Menurka) in the western area. The population surely cultivated the rich agricultural areas around these towns, which we cannot grasp with the present model focused on rural occupations.

Overall, the territorial development shown in our resulting maps finds comparisons with previous studies based on spatial analysis that highlighted changes in site density. Recent investigations have in fact indicated a considerable increase in the number and density of settlements from the Naviform to the Post-talaiotic period, together with a significant break in population development from Roman-Republican times onwards. Moreover, in terms of the geographical focus researchers suggested a denser occupation of the western and southern-central areas of the island from prehistory until Andalusian times (De Cet et al. in press, 397399). The complex location pattern of cultivation areas revealed by our modelled territories can be associated with the archaeological record and additional analyses. For instance, the modelled territories of the Post-talaiotic period show a notable expansion of their cultivation extent across the island. The same expansion coincides with pollen diagrams and charcoal analyses from the Balearic Iron Age, during which an increase of herbaceous communities seems to indicate the intensification of cereal production (Mariscal 1996, 204; Piqué and Noguera 2002, 296; Yll et al. 1997, 346). Moreover, a considerable presence of mill tools, amolons, across the island (Risch 2003, 308), with phytolith remains referring to the grass family Poaceae,

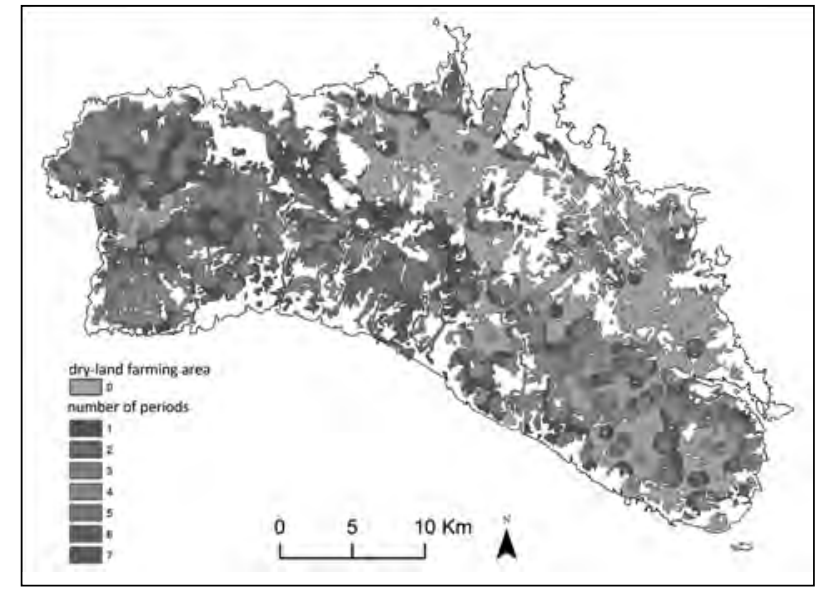

Figure 5. Cumulative map of modelled agricultural territories of dry land farming from Naviform (ca. 1600 1100/1000 cal BCE) to Andalusian times (ca. 903-1287 CE).

mainly Festucoideae (Pérez-J uez et al. 2007, 64), is also observed for this particular period.

\subsection{Cumulative map of territories}

The cumulative map of the territories illustrates the sum of all modelled territories from Naviform to Andalusian times. The result is a map (Fig. 5) that shows the most recurrent areas of hypothetical dry farming cultivation over a long time span. The legend symbolises the different territorial weight counts; in fact, the numbers from 1 to 7 refer to the number of periods that a specific area recurs in our modelled territories of cultivation. Therefore, areas with value 1 correspond to locations that are exclusively presentin onetimeperiod, whereas areas with values higher than 1 and up to 7 represent areas that are displayed in more than one period until the

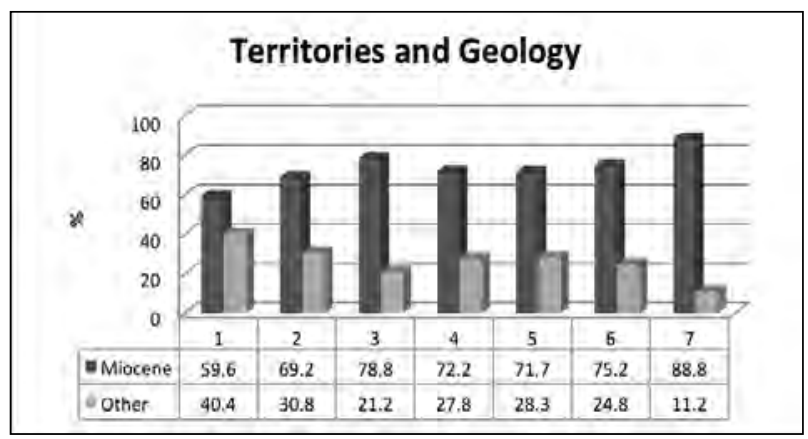

Figure 6. Histogram with percentages of association between the cumulative territories (weight counts) and geology. 


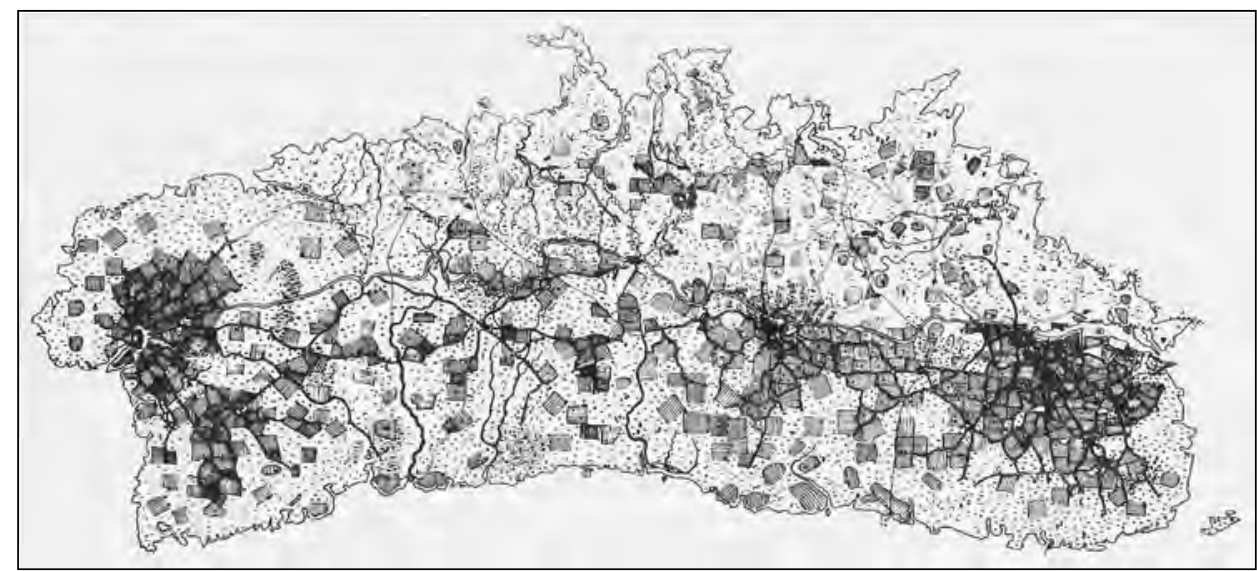

Figure 7. Cultivated fields (ruled lines) in Menorca during the year 1770 (Museum of Mahón, Menorca). Fountain pen reproduction by $D$. Bisson 2007, 12.

maximum of seven periods as the total number of periods of this investigation.

Overall, the cumulative territories, which are intensively spread over the western and southerncentral areas, are mainly associated with Miocene geology. In fact, as indicated in the previous section, the same dry farming mask (variable 3) that represented the optimum extent for the location of our modelled territories, presented a significant correlation with Miocene materials. Fig. 6 shows the histogram with the percentages of association between the different territorial weight counts, from 1 to 7, and the geology. An interesting observation is the gradual increase, up to $30 \%$, of the territorial weights 1 to 7 on Miocene geology. These figures indicate that the most recurrent areas of hypothetical cultivation of dry land farming reveal a large preference for the Miocene. In fact, areas with a territorial weight of 7 are almost totally (88.9\%) displayed on Miocene materials. The Miocene platform, representing the most apt area for cultivation, seems to have been important for agricultural purposes over time. In fact, in contrast to the northern-eastern area of Tramuntana, this area features the most-suitable soil for cereal production (Vidal-Bendito, Dubon and Gomila 1979, 8) in terms of fertility, water drainage, and topographical accessibility (Florit, Pons and Mari 1990, 17-18). Further confirmation of a continual preference for the Miocene platform also exists from historic times, for example, a map from 1770 shows how cultivated fields are preferentially located along the Miocene platform (Fig. 7). In contrast, the distribution of the 19th century farm houses - the Llocs - also covers the Pre-Neogene Tramuntana district, indicating a clear difference between contemporary agricultural landscape and settlement patterns and the situation modelled for prehistoric, ancient, medieval and even modern times.

Moreover, we can interestingly see in our cumulative map that the most recurrent areas of hypothetical cultivation (in Fig. 5, legend values 6-7) correspond to areas of the lowland Barranc-ravines. In particular, the ecological literature defines the Barrancs as one of the most favourable areas on the island in terms of abundance and availability of resources. The lowland Barrancs represent areas rich in biotypes, flora, and fauna (Cardona Florit 1980, 35), including high-quality fields for cereal and other crop harvesting, a favourable eco-climate, and abundant water (Martínez 2005, 15; Orfila 1985, 21). The continued preference for this area visible in our modelled territories together with the significant occupation during Andalusian times, leads us to assume that the Barrancs were probably recognised over time for the benefits they provided. These territories could have represented one of the areas, where cultivation practices were continuously carried out in the course of time.

The results of the spatial modelling have further socio-historical and environmental implications, which cannot be addressed in this methodological paper. The combination of our modelling with other archaeological variables, such as the botanical, faunal and macro-lithic records, imported commodities (such as Punic and Roman amphorae) or architectonic data, allow us to obtain a more detailed view of the economic and social context in which these agricultural territories were generated. 


\section{Conclusions}

Menorca has proven to be an ideal framework in order to test a research design that allows the reconstruction of hypothetical agricultural territories of dry farming cultivation on a long-term perspective. The significant results obtained through the modelling procedure enable us to reconsider the old-fashioned concept of an island as a "laboratory (J. Evans)" (Patton 1996, 2). According to the author, an island represents- due to its geographical borders - an ideal framework for archaeologists to study the manner in which communities have adapted to their natural environments. In fact, our resulting maps of the modelled territories show us how the communities on Menorca may have possibly adapted to the agrarian resources on the island, where the agrarian areas could have been located over time, and the hypothetical geographical extent of these areas.

Beyond the general socio-economic interpretation of these territorial maps, it is of primary importance to highlight that we have demonstrated the efficiency of palaeo-agrarian analysis in archaeology through this investigation. The research design structure of this paper suggests that such a modelling procedure can be re-implemented in other contexts, exclusively if two a priori conditions are satisfied. First, the archaeological sites implied in the model should exhibit a good degree of chronological resolution in order to be classified into specific time periods. Second, the selected case study should have access to a variety of sources about agriculture, demography, history, and environment to create a valid interpretative framework. Once satisfied, both conditions enable an investigation of the longterm effects of an agricultural trajectory, and also facilitate the accuracy in the modelled maps.

As highlighted for the Aguas Project, the maps with the agricultural territories set up different scenarios, possibly comparable to the archaeological reality. Moreover, the resulting output represents the starting point for long-term interpretations, for example, for the examination of long-term carrying capacities. Researchers often have described Menorca as an island with a limited range of available resources, and highlighted that from the first occupation of the island onwards communities probably made use of the fields with the best qualities in order to obtain major profits from the landscape (Benjamí 2000, 42-43). In fact, in our territorial maps we observe a recurrence of hypothetical agricultural occupation in the area of the Barrancs, not surprisingly considered as one of the best ecological niches of the island. This evidence leads us to consider that perhaps particular "preferenced" agricultural areas were used continuously over time. The spatial modelling has shown that an agricultural production restricted only to the Miocene Migjorn region enabled a demographic trajectory and the rise of diverse socio-political systems since the first occupation of Menorca until the 18th century $\mathrm{CE}$, reaching up to 30.000 inhabitants at certain times, without the need to import basic subsistence resources from outside sources. Even the extension of agricultural land into the Tramuntana area did not allow the support of significantly larger population numbers in the 19th or 20 th centuries. Instead, in all previous times the northern part of the island seems to have represented a true economic and ecological "reservoir", where alternative resources could be obtained, for examplein times of agricultural failure.

In conclusion, we confirm the potential of the palaeo-agrarian methodology of this paper as a promising tool of socio-archaeological and palaeoenvironmental research. Landscape development and environmental policy making would profit from the implementation of such interdisciplinary research projects in many regions, as they provide a deeper insight into the structure of long-term social dynamics, environmental response, and the existence of critical resources or degradation strategies.

\section{Acknowledgements}

We wish to thank the Consell Insular de Menorca, Departments of "Cultura, Patrimoni i Educació" and "Ordenació del territori", Spain for environmental and heritage data access, and in particular our thanks go to Simón Gornés, Joana Gual, Ricard Cots Torrelles, and Josep Florit Gomila for their availability and assistance on Menorca. The authors are extremely grateful to Eileen Kücükkaraca (Graduate School Human Development in Landscapes, Kiel) for her assistance in editing the manuscript and our conference 
presentation. Special thanks are furthermore due to Nicole Taylor (Graduate School Human Development in Landscapes, Kiel) for her help in editing the abstract submission and Florian Bauer (Graduate School Human Development in Landscapes, Kiel) for his technical support in Kiel. This investigation forms part of the Binational Cooperation Agreement between the Graduate School Human Development in Landscapes (Kiel University) and the Department of Prehistory (Autonomous University of Barcelona)(AIB2010DE-00200), and of the research on socio-economic and environmental change in the Mediterranean, supported by the Research Board of the Generalitat de Catalunya (2009SGR778).

\section{Bibliography}

Arnau, P., J. S. Gornés, and H.-P. Stika. 2003. “Los Hipogeos de S'Albegall (Ferreries) y la Agricultura Cerealística a mediados del Segundo Milenio cal ANE en Menorca." Trabajos de Prehistoria 60:117- 130.

Benjamí, C. 2000. "Plantejaments per a l'analisi del procés d'establiment humà en petits medis insulars. El cas de l'arxipèlag Balear." In Colonització humana en ambients insulars. Interació amb el medi i adaptació cultural, edited by V. M. Guerrero and S. Gornés, 11- 71. Palma de Mallorca: UIB.

Bisson, J. 2007. La tierra y el hombre en Menorca. 1966 Facsimile edition. Maó: Institut Menorquí d'Estudis.

Bonet, A. 1988. Menorca Pagesa. Menorca: Maó Consell Insular de Menorca.

Cardona, L., F. J uaneda, and F. de Pablo. 1999. Guia dels Espais Naturals de Menorca. Maó: Editorial Institut Menorquí d'Estudis.

Cardona Florit, M. A. 1980. Estudi de les zones d'interès botànic i ecològic de Menorca. Maó: Consell Insular de Menorca.

Casasnovas, M. A, ed. 2000. “De Manurqa a Menorca." In Enciclopèdia de Menorca 10, 3-29. Maó: Obra Cultural de Menorca.

Casasnovas, M. A. 2006. Recursos i materials per a l'estudi dela història de Menorca. Ciutadella de Menorca: IES J osep M. Quadrado.
Casasnovas, M. A. 2007. Història de les Illes Balears. Palma de Mallorca: Editorial Moll Mallorca.

Casasnovas, M. A, ed. 2011. Historia III. De la Menorca britanica a la consolidació de l'estat liberal (1712-1854). Enciclopèdia de Menorca 11. Maó: Obra Cultural de Menorca.

Castro, P., R. Chapman, S. Gili, V. Lull, R. Micó, C. Rihuete, R. Risch, and M. E. Sanahuja, eds. 1998. Aguas Project - Palaeoclimatic reconstruction and the dynamics of human settlement and land-use in the area of the middle Aguas (Almería) of the south-east of the Iberian Peninsula. Luxemburg: Publications of the European Commission: Science, Research and Development.

Castro, P., R. Chapman, S. Gili, V. Lull, R. Micó, C. Rihuete, R. Risch, M. E. Sanahuja, and P. Verhagen. 2002. "Archaeology in the south east of the Iberian Peninsula: a bridge between past and future social spaces." In Europe's Cultural Landscape: archaeologists and themanagement of change, edited by G. Fairclough, S. Rippon, and D. Bull, 133- 145. Exeter: Exeter University Press.

DeCet, M. 2014. "ThePrehistory of Menorca: Environment and Demography." PhD diss., University of Kiel.

De Cet, M., R. Duttmann, J. Gual, S. Gornés, J. Müller, R. Risch, E. Sintes, and B. Willié. 2013. "Changing settlement patterns in the Mediterranean Context: A Case Study of Menorca (Balearic Islands) from Prehistory to the 19th century AD." In Archaeology in the Digital Era. Papers from the 40th Annual Conference of Computer Applications and Quantitative Methods in Archaeology (CAA), Southampton, 26-29 March 2012, edited by G. Earl, T. Sly, A. Chrysanthi, P. Murrieta-Flores, C. Papadopoulos, I. Romanowska, and D. Wheatley, 389399. Amsterdam: Amsterdam University Press.

Didac, F. 1997. Geografía de les Illes Balears. Palma de Mallorca: Editorial Lleonard Muntaner.

El-Kassem M, and J. Müller. 2003. "Predictions for Iron Age Landscapes of Bornholm." In Archäoprognose I Symposium Landschaftsarchäologie und geographische Informationssysteme, edited by J. Kunow and J. Müller, 135- 140. Wünsdorf: Brandenburgische Landesamt für Denkmalpflege.

Ejstrub, B. 2005. "Cost surface analysis and ancient roads: a comparison." In Temps et espaces de l'homme 
en société, analyses et modèles spatiaux en archéologie. Actes des XXVe rencontres internationales d'archéologie et d'histoire d'Antibes - 2004, edited by J. F. Berger, F. Bertoncello, F. Braemer, G. Davtian, and M. Gazenbeek, 135- 139. Antibes: Éditions APDCA.

Fernández, M. 1991. "La transición hacia la cultura talayótica en Menorca.” Trabajos de Prehistoria 48:3750 .

Florit, S., P. Pons, and S. Mari. 1990. Estudi marc pel desenvolupament agrari de l'illa de Menorca. Maó: Consell Insular de Menorca.

Fornós, J . J ., A. Obrador, and V. M. Rosselló, eds. 2004. Historia Natural del Migjorn de Menorca: el medi físic i l 'influx humà. Palma de Mallorca: Societat d'Història natural de les Balears - Institut Menorquí d'Estudis Fundació Sa Nostra.

Gandini, C., F. Favory, and L. Nuninger, eds. 2012. Settlement Patterns, Production and Trades from Neolithic to Middle Ages. Final Conference Dijon, 23-25 June 2008. ARCHAEDYN: 7 Millennia of Territorial Dynamics. Oxford: Archaeopress.

Gietl, R., M. Doneus, and M. Fera. 2008. "Cost Distance Analysis in an Alpine Environment: Comparison of Different Cost Surface Modules." In Layers of Perception. Proceedings of the 35th International Conference on Computer Applications and Quantitative Methods in Archaeology (CAA), Berlin, Germany, April 2-6, 2007, edited by A. Posluschny, K. Lambers, and I. Herzog, 336341. Bonn: Dr. Rudolf Habelt GmbH.

Gornés, S., and J. Gual. 2002. "Reflexions sobre la revalorització i rendibilització social del Patrimoni arqueològic de les Illes Balears.” Mayurqa 28:195- 206.

Gornés, S. 2008. “La repercusión del Decreto 2563/ 1966, de 10 de Septiembre, en la protección del Patrimonio Arqueológico de Menorca." Revista Patrimonio Cultural y Derecho 12: 105- 122.

Gornés, S., and J. Gual. 2002. "Reflexions sobre la revalorització i rendibilització social del Patrimoni arqueològic de les Illes Balears." Mayurqa 28:195- 206.

Gornés, S., and J. Gual. 2012a. "La protección del Patrimonio Arqueológico en el Planeamiento Urbanístico de Menorca: modelos de gestión mirando al futuro."
Paper presented at First International Conference on Best Practices in World Heritage: Archaeology, Minorca, Spain, 9- 13 April.

Gornés, S., and J. Gual. 2012b. "The Protection of Archaeological Heritage in Menorca Urban Planning: models of management looking ahead." In Proceedings of the First International Conference on Best Practices in World Heritage: Archaeology, 9-13 April 2012, edited by A. Castillo Mahon, 1072-1074. Madrid: Universidad Complutense de Madrid.

Herzog, I. 2013. "Theory and Practice of Cost Functions." In Fusion of Cultures. Proceedings of the 38th Annual Conference on Computer Applications and Quantitative Methods in Archaeology, Granada, Spain, April 2010, edited by F. Contreras, M. Farjas, and F. J . Melero, 375382. Oxford: Archaeopress.

INE. 2013. "INEbase / Demografía y población / Cifras de población y Censos demográficos.” Accessed June 17. http:// www.ine.es/inebmenu/mnu_cifraspob.htm.

IUSS Working Group WRB. 2007. 'World reference base for soil resources 2006, first update 2007. World Soil Resources Reports No. 103.” Accessed June 17, 2013. http:/ / www.fao.org/ fileadmin/ templates/ nr/ images/ resources/pdf_documents/wrb2007_red.pdf.

J ordi, V., and E. Taltavull, eds. 1979. Arquitectura Rural (I) - Enciclopèdia de Menorca 16. Maó: Obra Cultural de Menorca.

Llobera, M. 2000. "Understanding movement: a pilot model towards the sociology of movement." In Beyond the Map. Archaeology and Spatial Technologies, edited by G. Lock, 65- 84. Amsterdam: IOS Press/ Ohmsha.

Llobera, M., and T. M. Sluckin. 2007. "Zigzagging: Theoretical insights on climbing strategies." J ournal of Theoretical Biology 249:206- 217.

Lull, V., R. Micó, B. Palomar, C. Rihuete, and R. Risch, eds. 2008. Cerámica talayótica. La producción alfarera mallorquina entre ca. 900 y 550 a.n.e. Barcelona: Edicions Bellaterra.

Marí i Pons, S., S. Florit, and P. Pons. 1991. "Agricultura de Menorca." In Enciclopèdia de Menorca 12, edited by G. López, S. Marí i Pons, T. Serra, S. Florit, P. Pons, and B. Okiñena, 129- 193. Maó: Obra Cultural de Menorca. 
Mariscal, B. 1996. "Variación de la vegetación de Menorca en los últimos 4000 años.” Revista de Menorca 1:197- 217.

Martínez, A. 2005. Sínies i vinyes, horts i molins. Una Mirada al desaparegut entorn rural de Maó. Maó: Amics del Museu de Menorca.

Martínez, J . A., and S. Espinal. 2005. “Avaluació del Risc d’Erosió Hídrica del Parc Natural de s'Albufera des Grau (Menorca). Informe tècnic relatiu al contracte menor 1648/2005 de 19 de maig de 2005 de la Conselleria de Medi Ambient (Direcció General de Biodiversitat) del Govern de les Illes Balears i la Universitat de Lleida (conveni C0705)." Technical report courtesy of the S'Albufera National Park, Menorca.

Mascaró Pasarius, J ., ed. 1958. Els monuments megalítics a l'illa de Menorca. Institut d'Estudis Catalans. Barcelona: Institut d'Estudis Catalans.

Mascaró Pasarius, J., and J. C. de Nicolás. 1982. “Carta Arqueológica de Menorca." In Geografía e Historia de Menorca. Vol. II, edited by J. Mascaró Pasarius, 2- 186. Ciutadella de Menorca: Impremta Allès.

Méndez, A. 2007. "De la vinya a la ramaderia: el canvi en el model agrari menorquí (1708-2006).” PhD diss., Universitat de les Illes Balears.

Micó, R. 2005. Cronología absoluta y periodización de la Prehistória de las Islas Baleares. Oxford: Archaeopress.

Micó, R. 2006. "Radiocarbon dating and Balearic prehistory: Reviewing the Periodization of the Prehistoric Sequence." Radiocarbon 48 (3):421- 434.

Moffett, L. 1992. "Cereals from a Bronze Age Storage Vessel at Torralba D'En Salort, Menorca, Spain." Vegetation History and Archaeobotany 1:87- 91.

Müller, J. 2003. "Settlement Areas, Landscape Archaeology and Predictive Mapping." In Archäoprognose I Symposium Landschaftsarchäologieund geographische Informationssysteme, edited by J . Kunow and J . Müller, 27-34. Wünsdorf: Brandenburgische Landesamt für Denkmalpflege.

Murillo, A. 2008. El terme del Mercadal a l'època del barocc. Maó: Institut Menorquí d’Estudis.

Orfila, G. 1985. L'estudi integrat dels barrancs menorquin: cap a una aproximació didàctica. Palma de Mallorca: ICE.

Patton, M. 1996. Islands in time. Island Sociogeography and Mediterranean Prehistory. London and New York: Routledge.

Pérez-Pérez, A., E. Fernández, and D. Turbón. 1999. "Análisis de los oligoelementos sobre restos humanos de la Cova de Es Càrritx." In La cova de Es Càrritx y La cova de Es Mussol. Ideología y sociedad en la prehistoria de Menorca, edited by V. Lull, S. Gili, R. Micó, C. Rihuete, and R. Risch, 557-566. Barcelona: Consell Insular de Menorca.

Pérez-J uez, A., J. Wiseman, P. Goldberg, J . Hansen, K. Mullen, M. Ostovich, C. Payne, S. Gornés, D. Cabanes, I. Euba, J . V. Morales, J . Morín, and F. López. 2007. “El uso del espacio doméstico de una estructura del Talayótica Final: excavación de la Casa 2 del yacimiento de Torre d'en Galmés, Alayor 2003-2006." In L'arqueologia a Menorca: eina per el coneixement del passat, edited by Consell Insular de Menorca, 53- 73. Maó: Consell Insular de Menorca.

Piqué, R., and M. Noguera. 2002. "Landscape and Management of forest resources in the Balearic Islands during the I- II millennium BC." In World Islands in Prehistory. International Insular Investigations Series, edited by W. Waldren and J. A. Ensenyat, 293-300. Oxford: Archaeopress.

Renfrew, C. 1972. The Emergence of Civilisation. The Cyclades and the Aegean in the third millennium BC. London: Taylor \&Francis.

Risch, R. 2003. “Los artefactos macrolíticos del yacimiento talayótico y postalayótico de Son Ferragut (Sineu, Mallorca)." In Mujeresy hombres en espacios domésticos: trabajo y vida social en la Prehistoria de Mallorca (c. 700-50o cal ANE), edited by P. Castro, T. Escoriza, and M. E. Sanahuja, 306- 319. Oxford: Archeopress.

Riudavets i Tudurí, P. 1885. Historia de la isla de Menorca. Maó: Imprenta de Bernardo Fabregues.

Rosselló, V. R. 1980. Aportacions a la historia medieval de Menorca. El segleXIII. Maó: Consell Insular de Menorca.

Salvator, L. (Erzherzog von Österreich). 1982. La Isla de Menorca: en texto eimágenes. 1, partegeneral. Translated 
Across Space and Time. Papers from the 41st Conference on

Computer Applications and Quantitative Methods in Archaeology. Perth, 25-28 March 2013

by C. Sánchez Rodrigo, and B. Sánchez Rodrigo. Palma de Mallorca: Caja de Ahorros “Sa Nostra” Woerl.

Serra, M. L., G. Roselló, J. A. Orfila, and J. C. de Nicolas. 1977. Historia de Menorca. De los orígenes al final de la Edad Media. Maó: Rafael Timoner Sintes.

Schreiber, K., and K. Kintigh. 1996. "A test of the relationship between site size and population." American Antiquity 61 (2):573- 579.

Stika, H.-P. 1999. “Los macrorestos botánicos de la Cova des Càrritx." In La cova de Es Càrritx y La cova de Es Mussol. Ideología y sociedad en la prehistoria de Menorca, edited by V. Lull, S. Gili, R. Micó, C. Rihuete, and R. Risch, 521-531. Barcelona: Consell Insular de Menorca.

Tobler, W. 1993. "Non-isotropic geographical modelling”. In Three presentations on geographical analysis and modeling 1) non-isotropic modeling 2) speculations on the geometry of geography 3) global spatial analysis. National Center for Geographic Information and Analysis Technical report 93-1. Accessed March 15, 2014. http:// www.ncgia.ucsb.edu/Publications/Tech Reports/93/93-1.PDF.

Van der Leeuw, S., ed. 1998. The Archaeomedes Project - Understanding the natural and anthropogenic causes of land degradation and desertification in the Mediterranean. Luxemburg: Office for Official Publications of the European Union.

Van Strydonck, M., M. Boudin, and A. Ervynck. 2002. "Stable Isotopes $\left({ }^{13} \mathrm{C}\right.$ and $\left.{ }^{15} \mathrm{~N}\right)$ and Diet: Animal and Human Bone Collagen from Prehistoric Sites on Mallorca and Menorca (Balearic Islands, Spain)." In World Islands in Prehistory. International Insular Investigations Series, edited by W. Waldren and J . A. Ensenyat, 189197. Oxford: Archaeopress.

Verhagen, P. 2013. "On the Road to Nowhere? Least Cost Paths, Accessibility and the Predictive Modelling Perspective." In Fusion of Cultures. Proceedings of the 38th Annual Conference on Computer Applications and Quantitative Methods in Archaeology, Granada, Spain, April 2010, edited by F. Contreras, M. Farjas, and F. J. Melero, 383- 389. Oxford: Archaeopress.

Verhagen, P., S. Gili, R. Micó, and R. Risch. 2007. "Modelling Prehistoric Land Use Distribution in the Rio Aguas Vally (S.E. Spain)." In Case Studies in
Archaeological Predictive Modelling, edited by $\mathrm{P}$. Verhagen, 171- 191. Leiden: Leiden University Press.

Vidal-Bendito, T. 1969. "Evolución de la agricultura y de la propiedad rural en la isla de Menorca." Revista de Menorca 21(2):21- 46.

Vidal-Bendito, T. 1973. La casa rural y la arquitectura tradicional menorquinas: estudio geográfico. Barcelona: Departamento de Geografía, Universidad de Barcelona.

Vidal-Bendito, T. 1989. "La población de Menorca: present i futur." In Jornadas sobre conservación y desarrollo en Menorca: celebrado en Llatzeret de Maó-Menorca, Baleares, España, (29-3O-IX-1989), edited by J . M. Vidal and J . Rita, 31-46. Menorca: Unesco.

Vidal-Hernández, J. M., and E. Comas, eds. 2010. J ornades sobre els 15 anys de la reserva de la biosfera de Menorca (2008: Maó). Maó: Institut Menorquí d’Estudis.

Vidal-Bendito, T., M.L. Dubon, and J. Gomila. 1979. “La població menorquina (I) i (II)." In Enciclopèdia de Menorca IX:3- 21. Maó: Obra Cultural de Menorca.

Vidal, J. J. 1989. El cens de Floridablanca a les Illes Baleares 1786-1787. Palma de Mallorca: Miquel Font Editor.

Yll, E., R. Pérez, J. Pantaleon, and J. M Roure. 1997. "Palynological Evidence for Climatic Change and Human Activity during the Holocene on Minorca (Balearic Islands)." Quaternary Research 48:339- 347.

Zakšek, K., E. Fovet, L. Nuninger, and T. Pobodnikar. 2008. "Path Modelling and Settlement Pattern." In Layers of Perception. Proceedings of the 35th International Conference on Computer Applications and Quantitative Methods in Archaeology (CAA), Berlin, Germany, April 2-6, 2007, edited by A. Posluschny, K. Lambers, and I. Herzog, 309- 315. Bonn: Habelt.

Zucca, R. 1998. Insulae Baliares. Le isole sotto il dominio romano. Roma: Carocci Editore. 


\title{
Systemic Approach and Spatial Organization: from the City to Networks of Cities
}

\author{
Xavier Rodier \\ Université François-Rabelais, France \\ Lahouari Kaddouri \\ Université d'Avignon, France \\ Pierre Garmy \\ Université Paul-Valéry - CNRS, France
}

\begin{abstract}
:
On-going collaboration between archaeologists and geographers has given rise to notable advances in the study of cities at intra- and inter-urban levels. This work is based on the transfer of methods and models from geographical sciences to historical sciences, with specific emphasis on the systemic approach. From this theoretical approach, we argue that cities at different times and on different spatial scales resemble systems. Case studies of the city of Tours and of the territories of the ancient city of Nimes and of the Languedoc (southern France) are used to describe and visualise the spatial organisation of these territories.
\end{abstract}

\section{Keywords:}

Urban Hierarchy, Spatial Proximity, Scale, Urban Functions, System, Spatial Interaction

\section{Introduction}

The systemic approach has proven fruitful for studying objects at different scales, in both archaeology and geography. Indeed, a city can be considered as a system in itself or as part of a system of cities. However, this systemic approach of intraand inter-urban space is understood differently in geography and archaeology: different temporalities involve different perspectives on sustainability and transitions from one system to another. Geographic and archaeological approaches and models are used separately and jointly to study the dynamics of urban space. In geography, this involves adapting concepts of spatial analysis to take into account large time spans, during which semantic changes may operate in the entities under study. The historical sciences take a modelling approach to the appropriation of space in order to shift from recording elements of the historical topography in space and time as simple supports to studying transformations in space and over time.

Collaboration between archaeologists and geographers has led to notable advances in the analysis of local networks of ancient settlements, at

Corresponding author: xavier.rodier@univ-tours.fr both the intra- and inter-urban levels. At the intraurban level, this concerns the way the city system is understood, notably by observing long-term urban transformations. At the inter-urban level, the analysis focuses on spatial patterns of settlements and the relationships between ancient cities (Durand-Dastès et al. 1998; Garmy et al. 2005a).

This work is based on the transfer of methods and models from geographical sciences to historical sciences. Whatever the temporality (ancient or modern city) and scale (city or local networks), the approach is systemic, even if not always explicitly so (Galinié, Rodier and Saligny 2004; Garmy 2012; Kaddouri 2004; Rodier, Galinié and Brunet 2010). This approach is essential for understanding organisations and spatial structures from the city to systems of cities (Berry 1964; Durand-Dastès et al. 1998; Garmy 2012; Garmy et al. 2005a; 2005b; Garmy and Kaddouri 2013; Nuninger and Sanders 2006). Although not specific to geographical studies, the central concept of spatial interaction, which was developed and formalised in the 1960s in the Systems of Cities theory (Berry 1964; Nystuen and Dacey 1961; Pred 1973), was transferred to archaeology within a diachronic perspective of characterisation and transformation of settlement 
networks to highlight population dynamics (Durand-Dastès et al. 1998; Gandini, Favory and Nuninger 2012; Garmy et al. 2005b; Nuninger and Sanders 2006).

In the first section, we describe the principles and concepts linked to this approach, and the transfer of this approach to archaeology using three examples, one intra-urban and the other two interurban. In the second section, we aim to show the possible studies related to these three cases, which open up encouraging perspectives for understanding the spatial dynamics of these urban systems.

\section{City Systems and Systems of Cities}

The systemic approach was adopted in geography in the 1970s, but its application in archaeology occurred later. This timing difference can partly be explained by the difficulty of transferring models due to a significant difference between historical objects and geographic objects. In this section, we describe first the systemic approach and then the similarities and differences between geographic and historical objects. Finally, we show how the transfer was made possible in our case studies in the ancient city of Tours, and in the network of settlements in the territories of the city of Nîmes and Languedoc.

\subsection{The systemic approach}

The systemic approach was developed essentially in the USA in the 1940s, although some earlier references to it can be found. The aim is to develop a scientific framework to understand and model the world taking into account its complexity. L. von Bertalanffy (1976) was the first to formalise this approach in his reference book General Theory of Systems. In France, two books in particular popularised the approach: Limits to growth (Halte à la croissance) by the Club of Rome (Meadows et al. 1972) and Le Macroscope (de Rosnay 1975). Since then, many developments have occurred, leading to a large number of definitions of the concept of system. Different schools have emerged, each one developing specific points taken from the general approach (Durand-Dastès 1992; Pumain, Sanders and Saint-J ulien 1989).
As observed by Roger Brunet (1979), all geographers consciously or unconsciously use a systemic approach when seeking to understand how human societies planned and organised space, and the effects and constraints of space and organisation on these human societies (Brunet and Dollfus 1990). It is on account of these actions and interactions between space and society that geography relies explicitly on the systemic approach (Baudelle and Pinchemel 1986), defined below.

\section{General principles}

Unlike the analytical approach, which is based on the principles of evidence, reductionism, causality, and exhaustiveness, the systemic approach relies on principles of relevance, holism and purpose. With regard to systems of cities, the aim is to produce a model explaining their survival and resilience and how their different components combine to form an interrelated whole.

\section{Concepts}

The systemic approach is based on five main concepts. First, interaction or interdependence, resulting from the reciprocal influence of two elements. This is a dual action, and not a simple matter of cause and effect. One specific form of this interaction is the feedback loop. The second concept is holism. In contrast to the Cartesian approach which views phenomena as the sum of their parts, the systemic approach looks at phenomena as a whole in order to grasp their complexity. In the words of the French philosopher Pascal "It is impossible to know the parts without knowing the whole, nor to know the whole without knowing the parts". Holism involves looking not only at the internal order of systems but also at the conditions outside the system that impact on it. The third concept is system organisation, formed by the state and process of the system. This involves not just the action but the result of that action. The fourth concept involves the notion of the goal or purpose of the system. The fifth concept, system complexity, concerns first the number of elements making up the system and their interrelationships, secondly, uncertainty and contingency factors, and thirdly the relationship between chance and determinism. 
This approach requires taking a stance from both a theoretical perspective, by complying with the principles and concepts described above, and, empirically, by adopting the method of systemic triangulation which involves looking at structural, functional and historical aspects. With regard to structural aspects, these include first the boundaries of the system. Systems that have relationships with the external environment are called open systems and form part of a meta-system - a system of systems. Within the boundaries of a system, the internal environment and its interactions give rise to sub-systems. By contrast, closed systems are only theoretical or experimental. Another structural aspect concerns items or entities that can be counted, identified and classified. In geography, this includes people, buildings, and amenities. A third aspect concerns networks; for example, transport and communication networks that distribute liquid, solids, energy, information, etc. Finally, structural aspects include facilities for storing the energy of the system.

The functional aspect includes flows of various kinds, decision centres that receive information and turn them into action, feedback loops, and response times. The historical aspect (genetic or dynamic) is related to the evolutionary nature of the system, with a memory and a project capable of self-organisation. Frequently, it is only the history of the system that can account for some aspects of its operation. For social systems, it is appropriate to start the observation with this aspect.

\subsection{Geographical vs historical objects}

A system is a construct. Objects, whether they are historical or geographic, can be modelled using this approach provided the concept of systemic triangulation is respected. In many archaeological studies, settlements (historical objects) are likened to towns (geographical objects) and networks of settlements to systems of towns (Garmy et al. 2005a; 2005b). However, the objects differ in nature, leading to certain difficulties in validating the transfer of the approach or of systemic models, particularly with regard to their temporal dimension.

When investigating spatial dynamics, we try to explain how objects are different or similar depending on whether they are geographical or

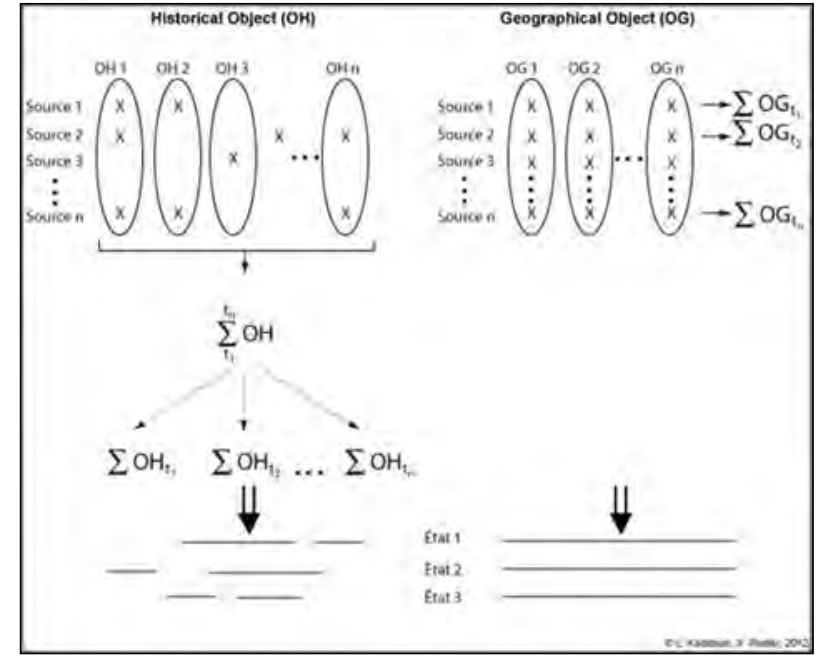

Figure 1. Geographical object vs historical object.

historical (Rodier and Kaddouri 2012). Differences may arise from the variety of archaeological sources used to construct a historical object or from different views of the life and genealogy of objects in different disciplines. Similarities between objects concern dimensional aspects - thematic, spatial and temporal - , or relate to the fact that they are or can be localised, while differing in nature and temporality.

In geography (Fig. 1, right), information about objects is generally considered to come from the same source, so that comparable sets of objects can be produced over time. By contrast, in archaeology (Fig. 1, left), the sources are heterogeneous (written, material, iconographic, etc.), so sets of historical objects can be constructed that are more or less incompletebecause their dates may notall beknown. The former provides homogeneous successive snapshots, while in the latter, the snapshots are discontinuous and thus less comparable. Transfer can occur when there is sufficient information.

\subsection{The preindustrial city and network of cities: transferring approaches and methods}

In our three case studies, one intra-urban and the other two inter-urban, we demonstrate how the historical objects of the ancient city of Tours and the territories of Nîmes and Languedoc can be likened to systems, making it possible to carry out systemic modelling and related analysis methods. 


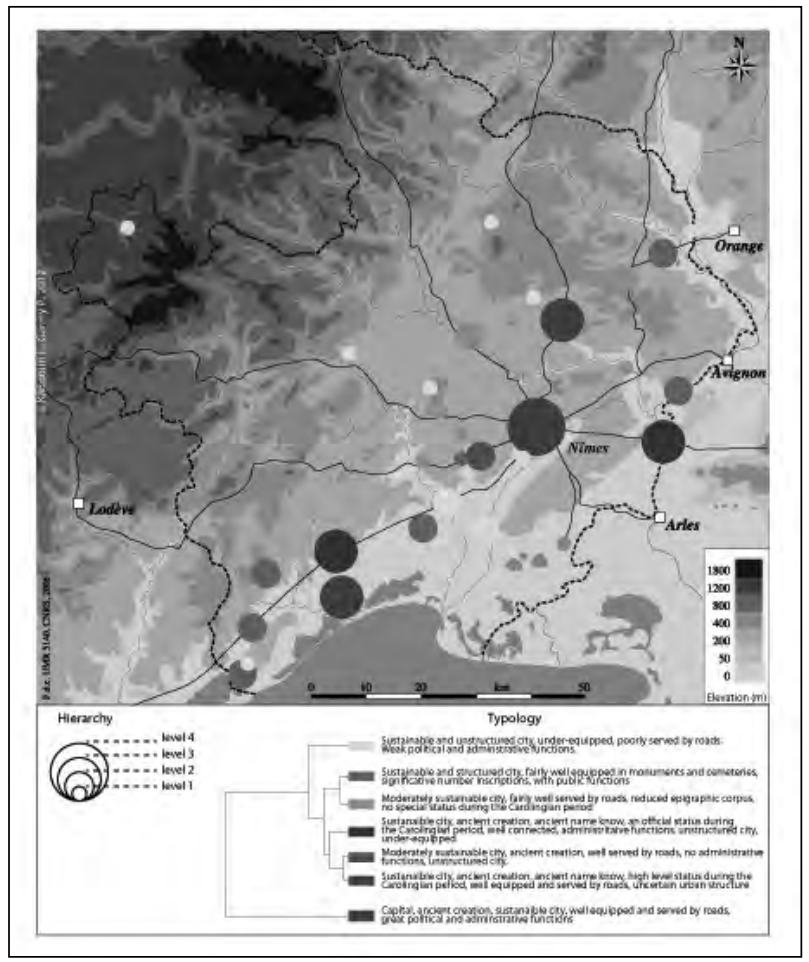

Figure 2. Hierarchy and typology in the territory of the city of Nîmes.

Territories of the city of Nîmes and of Languedoc: from a network of towns to a system of towns

The systemic approach has proved successful for both geography and archaeology. At the intraurban scale it introduces and describes the various relationships between objects in the urban space, yielding a better understanding of thecity's fabric. At theinter-urban scale, it shows the structuring role of interactions between settlements, cities and towns in the formation and transformation of networks of settlements and systems of towns (e.g. Fig. 2).

Even though our information about ancient sites differs from that of current city systems, about which we have vast amounts of information, studies carried out in the Rhône valley by Durand-Dastès and colleagues (Durand-Dastès et al. 1998) and by Pierre Garmy (2002) showhowknowledge about the functioning of hierarchical systems of cities today can be transferred to the analysis of hierarchical operations in an ancient city. The administrative organisation ofancienttownsandvillages, therelative impermeability of administrative boundaries, and

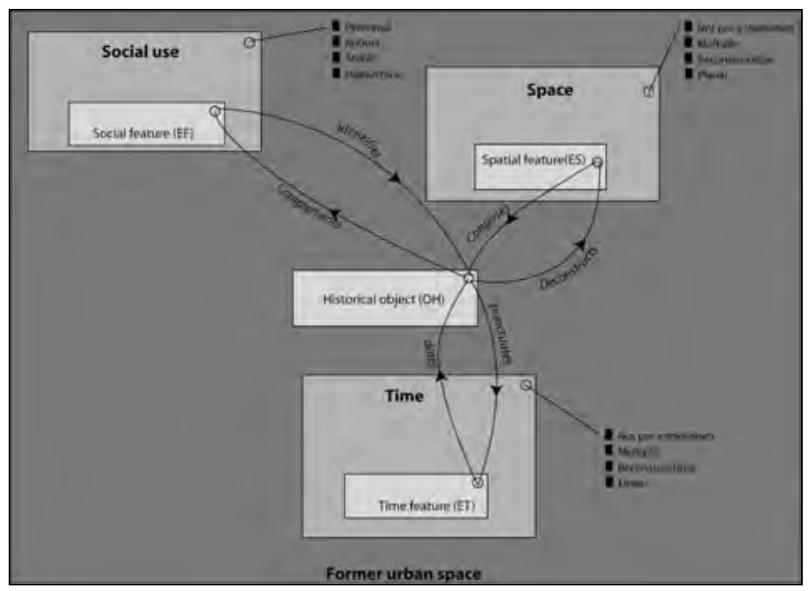

Figure 3. Systemic model of former urban space.

the difficulties of travel produced networks of towns and villages at different hierarchical levels. A set of sites can be likened to a network, but at the same time, the strong interrelationships, interactions and interdependencies of sites within a single administrative province suggest that this network of sites resembles a system. Thus, archaeologists' knowledge of the territory and time, associated with conceptual and methodological knowledge about the functioning of urban systems, have yielded new information about spatial organisation within the territories of Nîmes and the city networks of Languedoc, making it possible to put forward hypothetical views.

The city of Tours: from intra-urban network to city system

It is easy to assume that objects and actors and their inter-relationships are all elements of the urban system. From a historical perspective, the system is characterised by its functions - political, military, economic, religious, and so on. The study of the urban fabric (Galinié 2000) aims to identify the relationships between all the elements of the system so that what we call the "city" is more than the sum of the objects that make up the urban space.

The principle used to understand the urban space involves a systemic approach whereby the town is seen as a set of complex objects (Galinié, Rodier and Saligny 2004; Rodier and Saligny 2010). The town system used to study the urban fabric over long time spans is composed of three sub-systems relating to the historical objects from the level 
of excavation to that of the former urban space: function (social use), space (location, surface area and morphology), and time (dating and chronology) (e.g. Fig. 3).

This systemic approach can be used to identify a Historical Object, each sub-system providing a possible key. Within this framework, the process of interaction between each sub-system and the Historical Object modifies and/or enhances the definition of the Historical Object itself.

Within each sub-system there is a process of reiteration, each with its own logic, linked to the process of both inductive and hypotheticodeductive interpretation of the archaeological data. This results in feedback about social features (functional specialisation), spatial features (spatial interaction), and time features (path dependency). In addition, each historical object provides feedback both for each dimension, identifying new functions and deconstructing space and time, and also for the "former urban space" system through its placein the urban fabric.

\section{Spatial Dynamics and Analysis of a Preindustrial Urban System}

Systems are essentially dynamic. However, systemic studies have two different objectives depending on whether they seek to compare urban systems at time $\mathrm{t}$ (synchronic approach) or to compare a single urban system at different times (diachronic approach). The spatial analysis methods applied to systems differ in these two approaches. We describe below these two approaches and their related analysis methods, applied to our three urban systems - the city of Tours and the ancient territories of Nîmes and Languedoc.

\subsection{Synchronic analysis of urban systems}

\section{The city}

Foralongtimethestudy of citieshas beenbased on a model established during the 1960s, the early days of urban archaeology. This model was based on the establishment of a series of topographic maps, and sometimes of a database. The first example of the reconstruction of archaeological knowledge of urban space on historical topographic maps is The
Future of London Past published by Martin Biddle (1973). Based on the historical development of the topography of the city from all available sources, the aim of this work was to understand the urban space. Following that model, urban archaeological work in the city of Tours has been conducted at the intraurban level, based on a collection of archaeological heritage documents, Les archives du sol à Tours, published by Henri Galinié and Bernard Randoin in 1979 (Galinié and Randoin 1979).

The study of cities from a long-term perspective is based on sets of topographic maps at different times (city map of the 4th, 9th, 14th centuries etc.). This type of representation, using sets of snapshots, poses two major problems for the archaeologist working on the urban fabric. First, the chronological break-down is always decided a priori, based on historical knowledge of the city that does not always refer to a relevant material reality. Secondly, these maps are only snapshots and rarely show the duration of phenomena.

Establishing a snapshot of each period of the urban space is the essential preliminary step for comparing different towns at the same period. However, on the whole, this work is used only to observe the diachronic changes of a single town by empirical comparison of the series of maps. The rare collections in which towns are treated homogeneously (such as the 22 assessment documents of the archaeological heritage of the cities of France, published by the National Centre for Urban Archaeology between 1983 and 2013) have never in fact given rise to the synchronic studies that they make possible. However, this is one of the objectives of the chrono-chorematic approach (see 2.2.1), which is itself based on historical topography.

\section{Systems of cities}

The case presented here, applied to systems of cities, is based on the principles of the gravity model (e.g. Figs 4 and 5). This is a classic model of spatial analysis used to formalise the interactions between human settlements in ancient times, when little information is available about links and exchanges between sites. The goal is to identify networks of settlements that can be linked to a certain time by relationships involving complementarities, dependencies and trade. The assumption is that 


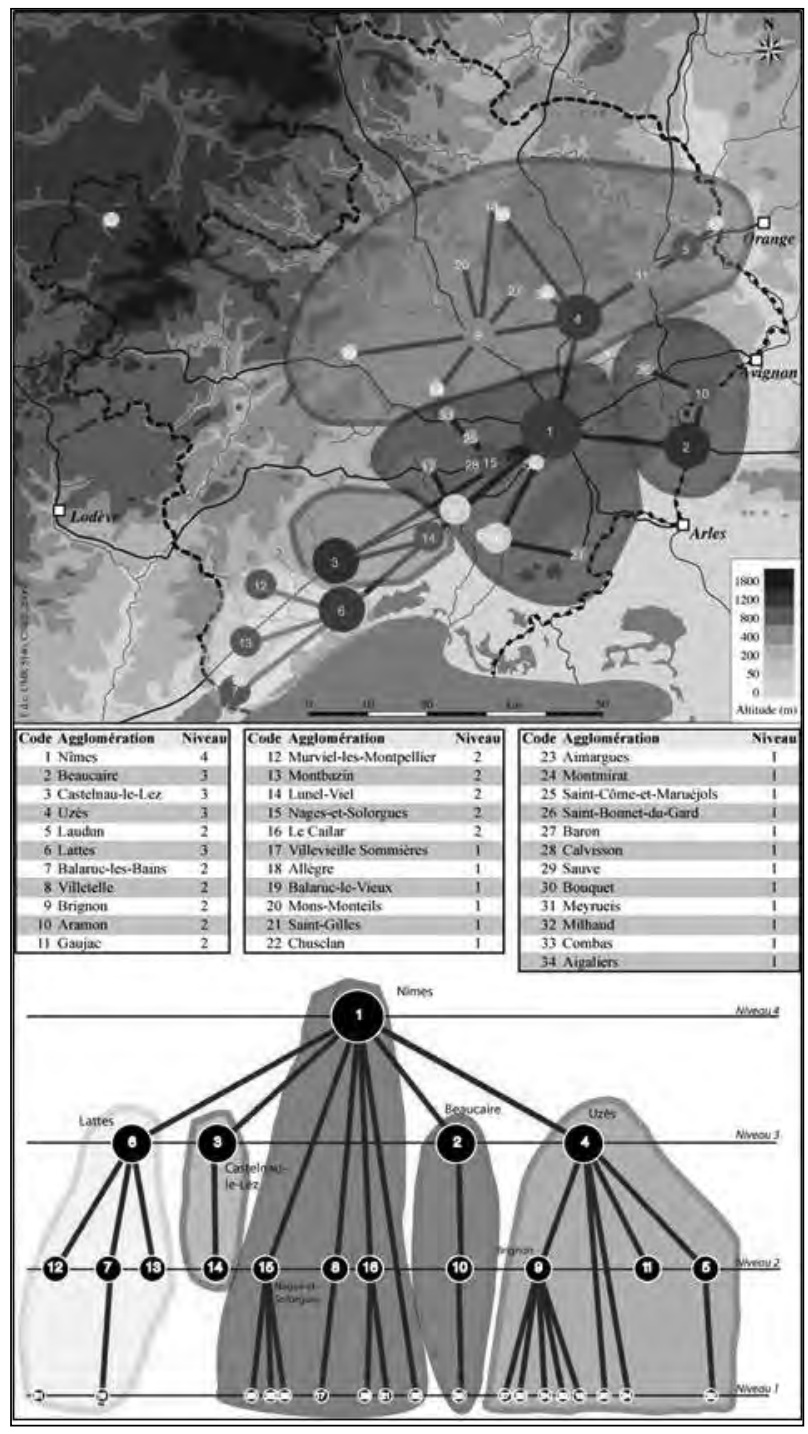

Figure 4. Synchronic analysis of cities in the territory of Nimes with the first gravity model.

these groups of settlements somehow "worked" together, without necessarily having any specific legal, economic and / or political system.

The challenge is both to identify the settlement that acted as the focal point, attracting other institutions in one way or another and, at the same time, to identify associated local networks, comprising groups of settlements dominated by the centre, only from archaeological information about earlier periods of these settlements and knowledge of their geographical position. The main issue is the hierarchical ranking of sites based on analysis of archaeological, environmental and spatial criteria.

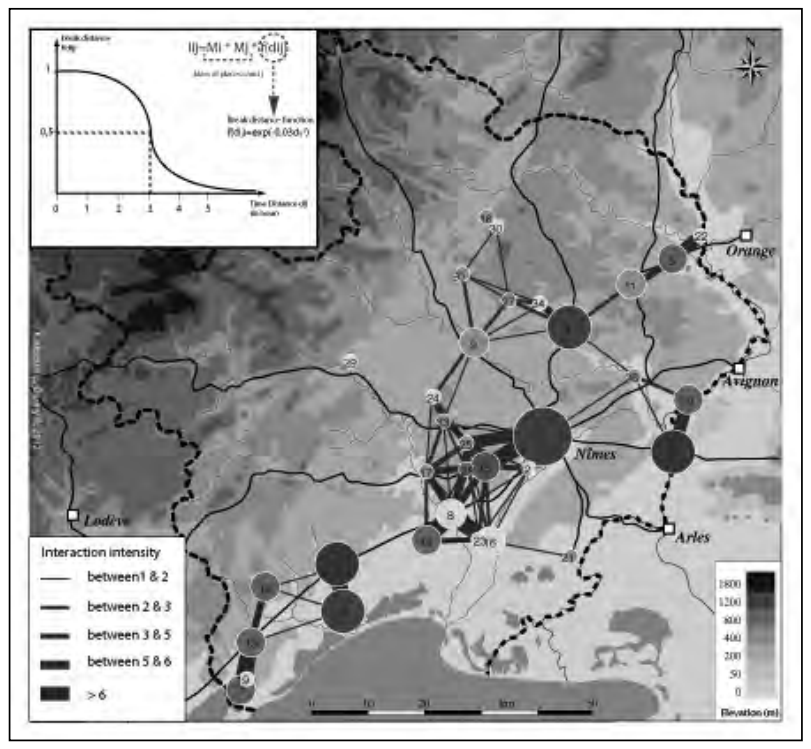

Figure 5. Synchronic analysis of cities in the territory of Nîmes with the second gravity model.

Similarly, the following application of the gravity model shows the interaction between settlements, together with a quantification of trade (based on distance between cities and the importance of the cities).

\subsection{Diachronic analysis of urban systems}

\section{City system}

The diachronic approach is more complicated, and other methods are required, such as chronochorematics. The chorematic approach involves identifying thecombination of elementary structures in a given city that best accounts for its spatial organisation. These basic structures, which Roger Brunet $(1980$; 1986) named choremes, provide a language for "writing the world". The map model of a city highlights how different elements and generic forces combine to produce a particular space. Chrono-chorematics adds the temporal dimension, with the dual aim of providing an account of the specific history of a particular city, and of comparing cities according to typological and chronological criteria (Rodier, Grataloup and Guilloteau 2010). In practice, this approach is both inductive, based on knowledge of the city from historical data, and hypothetico-deductive, whereby the specific position can be deduced from the assumed position of the city within a theoretical time-frame. 
In the chorem matrix by Roger Brunet (1986), each spatial configuration is on a line (mesh, grid, gravitation, contact, tropism, territorial dynamic, hierarchy) and describes a point, line, area, or network in the column. The model is built by combining elements. It can be specific, for example, the city of Tours at around $150 \mathrm{CE}$, or theoretical, for example, the open town.

We used the chrono-chorematic approach to create eight theoretical models to describe eight time periods for the cities of north-western Europe from the beginning of urbanisation to the present day. They provide a graphical overview of knowledge of the periodisation of urban history in north-western Europe. At the same time, multiple case studies offer a dual reading of the cities under study, on the one hand inductive, from specific to general, and on the other deductive, from the model to local reality. These case studies combine elements of the urban system from its origins in order to highlight and understand the path dependency of the city.

Chrono-chorematics is a heuristic tool to identify common points and differences, to identify differences between the theoretical temporal model and specific periodisation, to compare time sequences, and ultimately to characterise path dependency.

Another way to explore theintra-urban system has emerged from the work of urban archaeology and historical topography. The OH_FET model was developed to contribute to the understanding of former urban space (Rodier and Saligny 2010). This model has been used in several programs at the scale of the city, a district, and an excavation site, always based on a systemic approach. Each level corresponds to a specific object, which involves changing the descriptors in the three dimensions of the model: semantic (here social use), spatial, and temporal. At each level of analysis there is a specific implementation of the model in a GIS. The definition of the historical object being manipulated is reexamined at each level. The relationships between these objects constitute the elements of a multi-level and dynamic system.

The OH_FET model, developed for the city scale, was used to study the city of Tours and implemented in the Topography of Pre-industrial

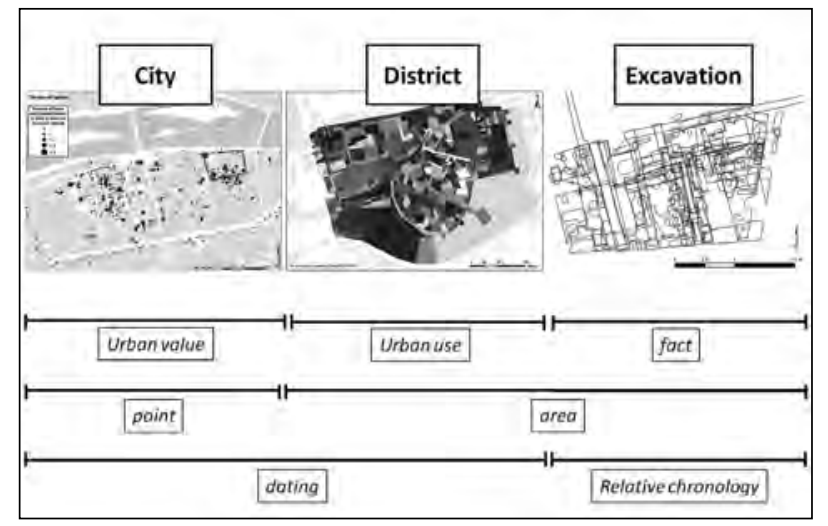

Figure 6. Analysis of the city system of Tours on three scales using the OH_FET model.

Tours GIS (ToToPI) (Rodier et al. 2010). It has been used to study changes in a district of the city and it has also been tested on data from a previously studied excavation site (e.g. Fig.5).

The model is based on three dimensions and provides outputs for each dimension or pair of dimensions. The historical object is at the heart of the model. We observe the distribution of spatial and temporal features, and the distribution of social uses. The intersection of paired dimensions highlights aspects such as continuity of use of space, the spatial distribution of social uses, and the distribution and change of social uses over time.

\section{Systems of cities}

The next example is taken from a work in progress on changes in settlement systems and the transitions between different states of these systems. Using a systemic approach and different modelling forms, the aim is to understand the processes that led to these major changes in spatial organisation, going through different modelling stages (from a discursive to an agent-based model) in order to achieve a continuous spatio-temporal simulation of the processes leading to a change in the population system.

One of the most widely used forms of representation for systemic modelling is the sagittal diagram. Often using mathematical language or discourse, sagittal diagrams are particularly useful for geographers as a way of formalising systems due to their relatively low degree of abstraction and complexity compared to other forms of 


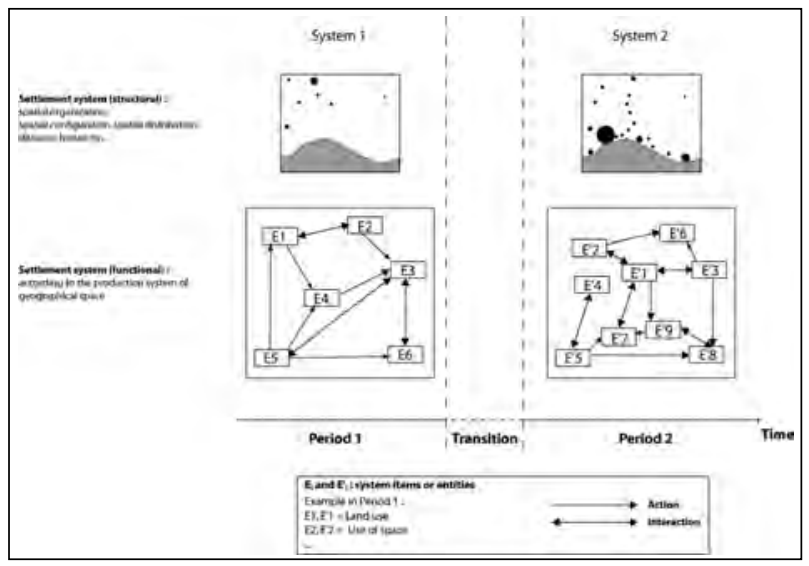

Figure 7. Diachronic approach to understanding a system of cities using a sagittal diagram.

representation. They can model the urban system in all its aspects - structural, functional and historical. Therelationshipsbetween theelements of thesystem enable simulation of the system, helping understand the processes leading to the change. Figure 7 shows a theoretical territory where a settlement system in period 1 changes into another system in period 2 . Information about the transition between these two periods is often lacking.

The first step was to describe the settlement systems at different periods (periods 1 and 2). This description of the system's structure and operation was made only by archaeologist experts. The model was further developed by increasing the abstraction level by changing its shape, and this was fitted on the analysis grid representing the production system of geographical space that was proposed by Pinchemel, Pinchemel and Brunet in the 1970s (e.g. Fig. 8). This systemic model can describe all spaces and changes of and in space of the five basic practices of the various spatial actors: appropriating, exploiting, exchanging, dwelling, and managing.

For the archaeologists, geographers and modellers of the team, the first step was to construct a formalised discursive model based on the uses of space mentioned above, and using a common grid. Hence, system 1 before transition and system 2 after transition are described using the same criteria.

The next step again involved changing the shape by converting the formalised discursive model into a sagittal diagram. The following example shows the transition of a settlement system in Languedoc (south of France) between the end of the Bronze Age and the 4th- 3rd century BCE. Each use is described by period and by the various factors that may have played a role in the observed changes (in this instance, inhabiting and type of power). Figure 9 shows the sagittal diagrams of the two periods mentioned above. Elements of the system are more or less calibrated on the elements of the production system of space. This work is still in progress. All links, actions / interactions between elements of the system are explained elsewhere. The aim here is not only to simplify the model but also to bring us closer to the final stage which involves a further change in the shape of these systemic models, i.e. modelling and transition to an agent- based model, in order to simulate the whole of the process and the changes.

\section{Conclusions}

All these examples follow a systemic approach, even if it is more or less explicit and formalised. In geography today, the formation and results of corpora and models are more robust and allow better explanatory interpretations. In archaeology, the data models are better able to integrate heterogeneous data, but the results are always subject to interpretation by the specialist discipline, at the intersection of inductive and hypotheticodeductive processes. However, these differences in interpretation processes are gradually decreasing, because the objects studied by geographers are becoming more complex with multiple sources, requiring robust models of data integration, while

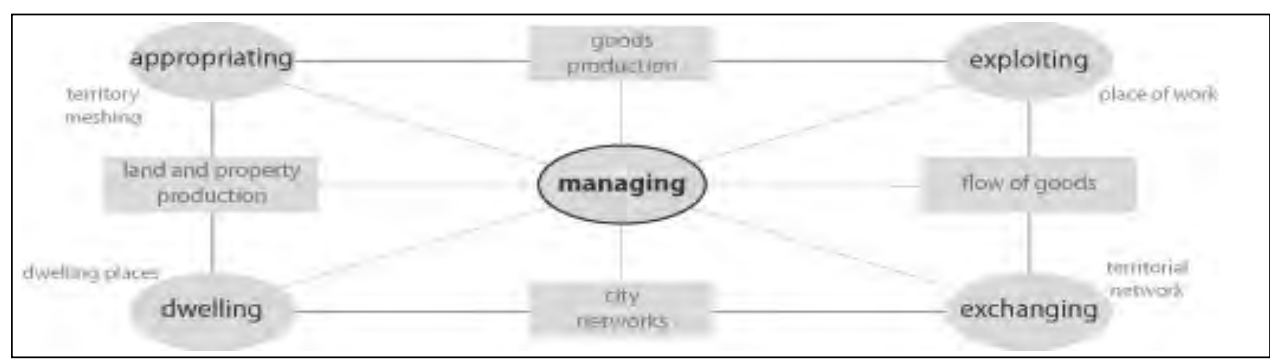

Figure 8. The production system of geographical space. 


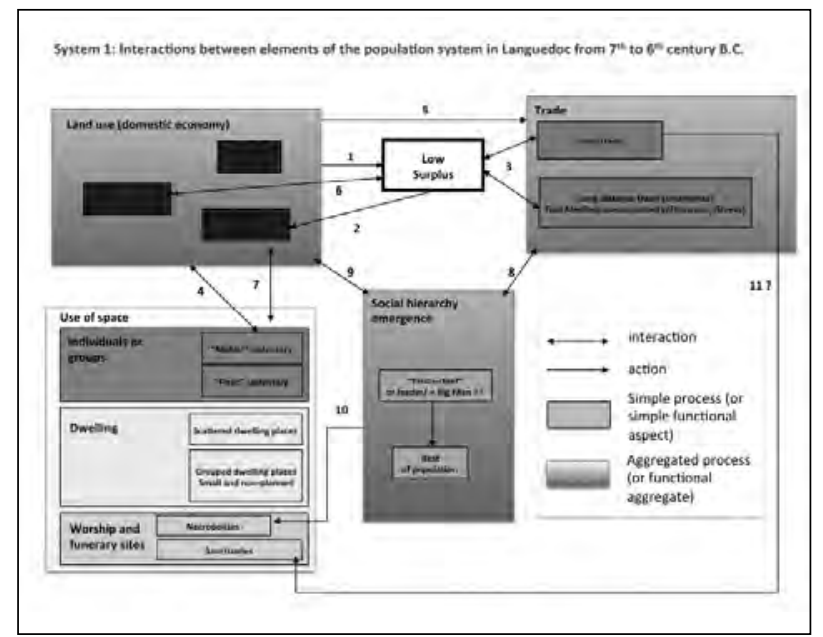

Figure 9. Sagittal diagrams of period 1 of the population system in Languedoc.

archaeologists are becoming more tolerant of higher levels of abstraction, with greater acceptance of quantitative modelling.

In all cases, the results provide an initial formalisation of objects. The whole process tends towards multi-scale modelling with the ultimate aim of understanding the interactions between intra- and inter-urban phenomena. This requires designing multi-scale models that take into account the influence of the transformation of the urban space on the settlement networks, and conversely the impact of the position of a city within a network on its spatial organisation.

By combining these approaches, the TransMonDyn program aims to model transitions at extremely varied scales of time and space between systems consisting of stylised facts.

\section{Acknowledgements}

This paper was written with the collaboration of Hélène Mathian and Lena Sanders (UMR 8504 Géographie Cités, Paris). We work together in two network of interdisciplinary research on modelling in human sciences. We wish to thank the CNRS (French National Centre for Scientific Research) research group, "Modélisation des dynamique spatial (GdR 3359 MoDyS: CNRS 2013), and the TransMonDyn program (ANR-10-BLAN-1805 TransMonDyn: ANRTransmondyn 2014) funded by the ANR (French National Research Agency).

\section{Bibliography}

ANRTransmondyn. 2014. "Accueil.” Accessed March 15. https:// sites.google.com/site/transmondyn/ .

Baudelle, G., and P. Pinchemel. 1986. "De l'analyse systémique de l'espace au système spatial en géographie." In Espaces, jeux et enjeux, edited by F. Auriac and R. Brunet, 83- 94 Paris: Fayard-Fondation Diderot.

Berry, B. J. L. 1964. "Cities as systems within systems of cities." Papers in Regional Science 13 (1):147- 163.

Biddle, M., D. Hudson, and C. Heighway. 1973. The future of London's past, a survey of the archaeological implications of planning and development in the nation's capital. Worcester: Rescue: A trust for British Archaeology.

Brunet, R. 1979. "Systèmes et approche systémique en géographie." Bulletin de l'Association des Géographes Français 465:399- 407.

Brunet, R. 1980. "La composition des modèles dans l'analyse spatiale." L'Espace géographique. 4:253- 265.

Brunet, R. 1986. "La carte-modèle et les chorèmes." Mappemonde 86 (4):2- 6.

Brunet, R., and O. Dollfus. 1990. Mondes nouveaux. Paris: Hachette/ Reclus.

CNRS. 2013. " GdR 3359 Modélisation des Dynamiques Spatiales." Last modified March 4. http://modys.univtours.fr.

de Rosnay, J. 1975. Le Macroscope: vers une vision globale. Paris: Editions du Seuil.

Durand-Dastes, F. 1992. "Les modèles en géographie." In Encyclopédie de géographie, edited by A. Bailly, R. Ferras, and D. Pumian, 311- 325. Paris: Economica.

Durand-Dastès, F., F. Favory, J .-L. Fiches, H. Mathian, D. Pumain, C. Raynaud, L. Sanders, and S. Van der Leeuw. 1998. ARCHAEOMEDES. Des oppida aux métropoles. Archéologues et géographes en vallée du Rhône. Paris: Anthropos.

Galinié, H. 2000. Ville, espace urbain et archéologie. Tours: PUFR. 
Across Space and Time. Papers from the 41st Conference on

Computer Applications and Quantitative Methods in Archaeology. Perth, 25-28 March 2013

Galinié, H., B. Randoin, R. Kemp, and M. Holtz. 1979. Les archives du sol à Tours, survie et avenir de l'archéologie de la ville. Tours: La Simarre.

Galinié, H., X. Rodier, and L. Saligny. 2004. “Entité fonctionnelles, entités spatiale et dynamique urbaine dans la longue durée." Histoire \& Mesure XIX (3/4):223- 242.

Gandini, C., F. Favory, and L. Nuninger. 2012. Settlement patterns, production and trades from the Neolithic to the Middle Ages. Oxford: Archaeopress.

Garmy, P. 2002. 'Villa-vicus: une question d'espace?” Revue Archéologique de Narbonaise 35:27- 37.

Garmy, P. 2012. Villes, Réseaux et systèmes de villes. Paris: Errance

Garmy, P., and L. Kaddouri. 2013. "Modélisation spatiale d'un réseau urbain antique: à propos des villes de la cité de Nîmes." In Archéologie de l'espace urbain, edited by E. Lorans and X. Rodier, 479-493. Tours: PUFR/CTHS.

Garmy, P., L. Kaddouri, C. Rozenblat, and L. Schneider. 2005a. 'Logiques spatiales et 'systèmes de villes' en Lodévois de l'Antiquité à la période moderne." In Temps et Espaces de l'Homme en société, Analyses et modèles spatiaux en Archéologie. XXV rencontres internationales d'archéologie et d'histoire d'Antibes, edited by J.-F. Berger, F. Bertoncello, F. Braemer, G. Davtian, and M. Gazenbeek, 335- 346. Antibes: Éditions APDCA.

Garmy, P., L. Kaddouri, C. Rozenblat, and L. Schneider. 2005b. "Structures spatiales du peuplement antique dans la cité de Luteva." In Mélanges offerts à Philippe Leveau, edited by A. Bouet and F. Verdin, 95-111. Bordeaux: Ausonius éditions.

Kaddouri, L. 2004. "Structures spatiales et mises en réseaux de villes pour la régionalisation des territoires." PhD diss., Université de Montpellier 3.

Meadows, D., D. Meadows, J. Randers, and W. Behrens. 1972. The Limits to Growth. New York: Universe Books.

Nuninger, L., and L. Sanders. 2006. "La modélisation des réseaux d'habitat en archéologie: trois expériences.” M@ ppemonde 83 (3). Accessed February 21, 2014. http:// mappemonde.mgm.fr/ num11/ articles/ art06302.html.

Nystuen, J. D., M. F. Dacey. 1961. “A graph theory interpretation of nodal regions." Papers in Regional Science 7 (1):29- 42.

Pred, A. R. 1973. Urban growth and the circulation of information: The United States system of cities, 17901840. Cambridge: Harvard University Press.

Pumain, D., L. Sanders, and T. Saint-J ulien. 1989. Villes et Auto-organisation. Paris: Economica.

Rodier, X., H. Galinié, and R. Brunet. 2010. “Tours: étude chrono-chorématique.” M@ppemonde 100 (4). Accessed February 21, 2014. http:// mappemonde.mgm.fr/ num28/ articles/ art10406.html.

Rodier, X., C. Grataloup, and C. Guilloteau (eds). 2010. “Chrono-chorématique urbaine.” M@ppemonde 100 (4). Accessed February 21, 2014. http://mappemonde.mgm. fr/dos_chrono.html.

Rodier, X., and L. Kaddouri. 2012 "Modéliser les dynamiques spatiales en sciences humaines." In Variabilités environnementales, mutations sociales. Nature, intensités, échelles et temporalités des changements, XXXIIe rencontres internationales d'archéologie et d'histoire d'Antibes, edited by $F$. Bertoncello and F. Braemer, 115- 126. Antibes: Éditions APDCA.

Rodier, X., and L. Saligny. 2010 “Modélisation des objets historiques selon la fonction, l'espace et le temps pour l'étude des dynamiques urbaines dans la longue durée." Cybergeo: European J ournal of Geography, Systèmes, Modélisation, Géostatistiques 502:2-23. Accessed February 21, 2014. doi: 10.4000/ cybergeo.23175.

Rodier, X., L. Saligny, B. Lefebvre, and J Pouliot. 2010. “ToToPI (Topographie de Tours Pré-Industriel), a GIS for understanding urban dynamics based on the $\mathrm{OH}$ FET model (Social Use, Space and Time)." In Making History Interactive, Computer Application and Quantitative Methods in Archaeology, edited by B. Fricher, J. Webb Crawford, and D. Koller, 337- 349. Oxford: Archeopress.

von Bertalanffy, L. 1976. General System theory: Foundations, Development, Applications. New York: George Braziller. 


\title{
Detection of Spatio-Morphological Structures 0n the Basis of Archaeological Data with Mathematical Morphology and Variogaphy. Application to Syrian Archaeological Sites
}

\author{
Johanna Fusco \\ University of Nice-Sophia Antipolis, France
}

\begin{abstract}
:
Spatial analysis methods and concepts are now often used to solve archaeological problematics, thus fuelling the development of new methodological perspectives. This paper presents a set of original spatial analysis tools and methods, which could shed new light on the study of past settlement systems in spatial archaeology. These methods - in particular variography and mathematical morphology - allow to describe the deployment of a phenomenon throughout space and time within the irregularities of a spatial and temporal structure, to identify invisible structures from visible shapes, and to link these shapes to the processes which produced them. This paper introduces an application of these methods, consisting in the detection of spatial configurations in the arrangement of archaeological sites in the Leja Plateau (Southern Syria).
\end{abstract}

\section{Keywords:}

Spatial Analysis, Mathematical Morphology, Variography, Spatial Archaeology, Southern Syria

\section{Introduction}

Since the 1990s several research programs, bringing together geographers, historians, archaeologists and natural scientists, have been fuelling a renewed interest in the study and perception of spatial dynamics. The development and use of spatial analysis tools in archaeology draw on spatial theory and question how one or several phenomena are set in space. Space is thereby considered as a complex entity formed by visible components (places, infrastructures, spatial patterns) and by invisible elements (the relationships between them) which constitute its structure and dynamics (Voiron 1995). This paper suggests considering this epistemological line of thoughts from a new methodological perspective: we attempt to develop an original approach in order to describe and understand the spatial organisations of past settlement systems, which is developed through several theoretical and methodological aspects.

Firstly, we shall consider spatial structures (defined as invisible relationships between visible spatial elements) created by the location of geographical and archaeological objects through the concept of shape. This process of positioning

Corresponding author: johanna.fusco@unice.fr. has been developed for several years in Spatial Analysis, and has been applied mostly to the study of contemporaneous urban and territorial forms (Liziard and Voiron 2012; Voiron 1995, 127-171). It suggests that structure is an arrangement of observable and analysable shapes, which is consequently related to the spatial configuration (organisation of theshapes). Furthermore, webelieve that research into spatial shapes and structures should beconducted in an exploratory way. Byletting the data speak for itself we should stay open to the emergent spatial patterns. This implies the use of particular methods and tools, which combine at the same time a powerful ability to detect shapes and their organisations, and a high flexibility and room for manoeuvre. This compromise may be found in the creation of a protocol of analysis associating geostatistics and image analysis by Mathematical Morphology (see chapter 2).

These analyses will permit to highlight the importance of integrating uncertainty in Spatial archaeology studies. Indeed, archaeological information is subject to several forms of imperfection. If the flaws of spatio-temporal data are not taken into account and defined precisely, the validity of the results might be questioned. Scholars have adopted several behaviours to cope with these 


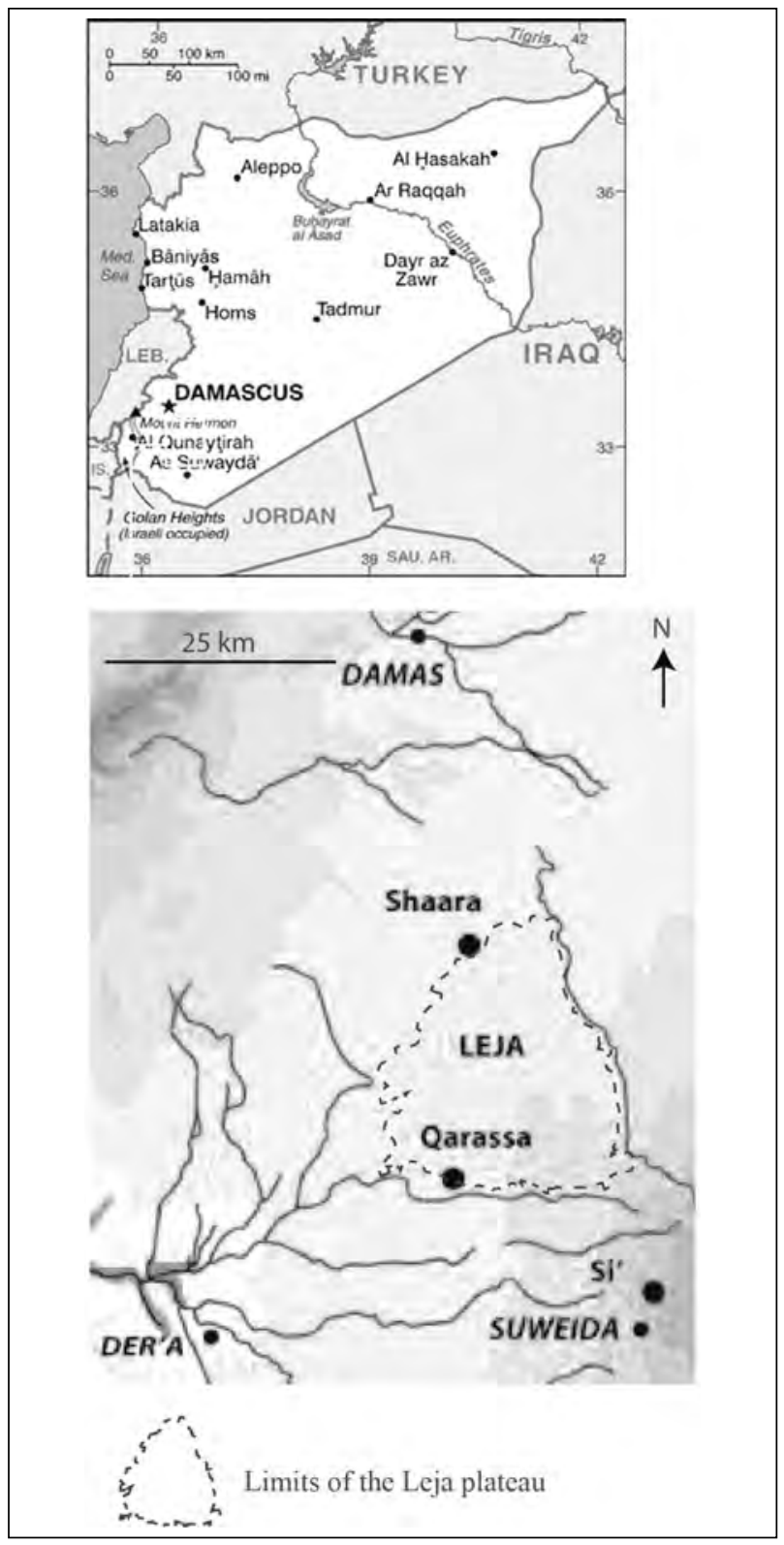

Figure 1. Location of the studied area (CEPAM CNR 2014).

imperfections; some of them attempt to eliminate them as far as possible by improving acquisition modes, whilst others produce robust algorithms and programs capable to tolerate imprecision (Bloch and Maître 2004, 12). Our approach is however to reason with imperfection, which becomes a whole form of knowledge and information. Such an approach implies to develop approximate modes of reasoning and to consider meta-knowledge, that is to say knowledge of these imperfections.
A methodological protocol has been elaborated on the basis of these epistemological and theoretical lines, and then applied to an archaeological problematic, whose purpose is to describe the spatial organisation of archaeological sites on the Leja Plateau (South of Syria). It should be noted that this study, which forms a small part of a doctoral research in Geography, provides a first experiment of this "spatio-morphological" approach (Voiron 2009) applied to past settlement systems. At this stage of reflexion, our purpose is then more to investigate its potentials in methodological and theoretical dimensions than producing usable results.

\section{Studied Area and Data}

The studied area is the Leja (Fig. 1), a semiarid basaltic plateau which forms a $30 \mathrm{~km}$ triangle, surrounded by the agricultural plains of Hawran (South of Syria), about $50 \mathrm{~km}$ south of Damascus. This plateau results from Holocene lava flows, which have never been decomposed, towering 5 to $15 \mathrm{~m}$ above the plain (Rohmer and Criaud 2010, 43). Since 2003, this microregion has been surveyed by archaeologists of theFranco-Syrian mission "Atlas of pre- and protohistorical sites of the South of Syria", directed by Frank Braemer and Michel al-Maqdissi. These researches provided a vast wealth of data from the Neolithic to the Ottoman period including monuments, circulation and defence networks, antique agglomerations and their agricultural fitting out (Rohmer and Criaud 2010, 43-45). In this context, archaeologists attempt to understand the changing land use systems through time, including aspects of rural-pastoral and/or agricultural economy and urban settlements, landscapes and communications organisations, water management, and analysis of the past environment (Mission Syrie du Sud 2012).

The dataset used in this study comes from of the PaléoSYR ANR 's database (National Agency for Research - Holocene palaeoenvironments and settlements patterns in Western Syria; coPI: F. Braemer, CEPAM, Nice; B. Geyer, MOM, Lyon), and consists in three elements: the location of archaeological sites on the Leja plateau (Fig. 2a), the basaltic coverage levels of the area (Fig. 2b), and the intensity and kind of archaeological survey campaigns on the different parts of the area (Fig. 2c). 

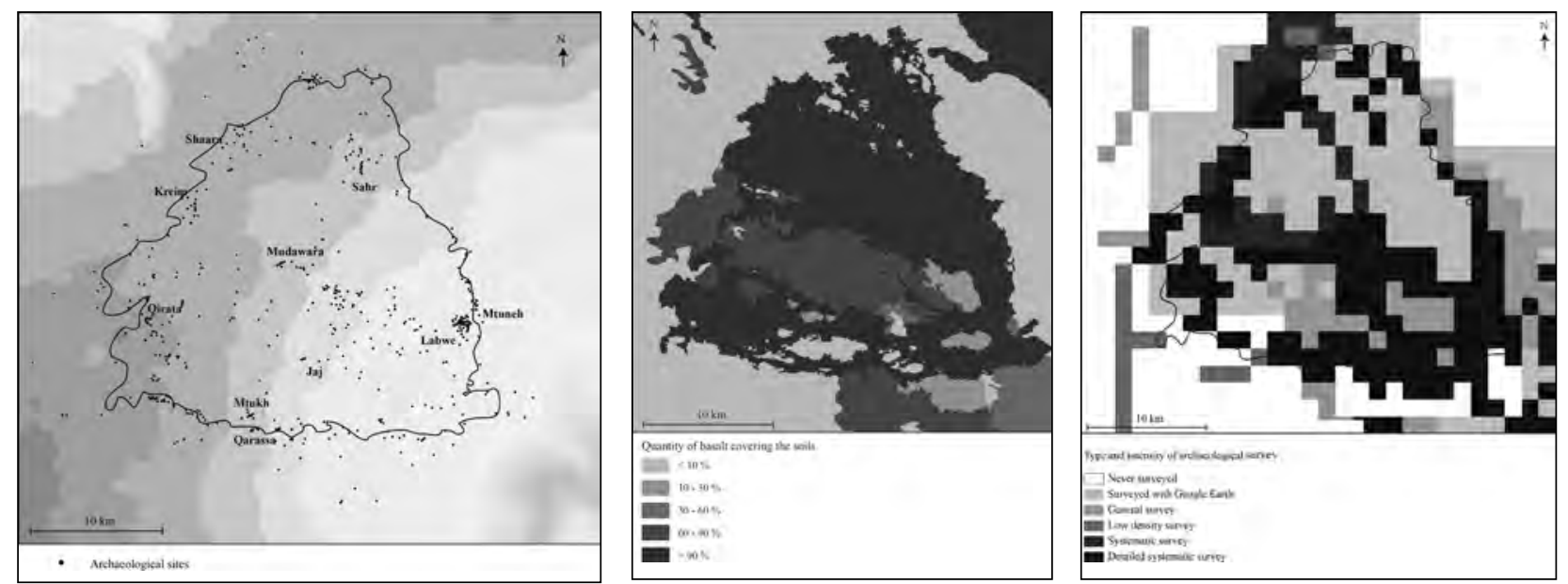

Figure 2. The dataset used in this study: location of archaeological sites (a), basaltic coverage levels (b) and survey intensity (c) - GIS and database G. Davtian, F. Braemer.

This map attests that whilst some parts of the field have been precisely probed, some others have been less intensively or even never investigated, and thus materialises the flaws of our data, its imprecision and incompleteness. This means that all the data cannot have the same weight in the analysis, and thus the same explicatory dimension.

We shall emphasise that the purpose of our analyses is only to illustrate concretely how the presented methodological procedure could be applied to archaeological problematic and data. Tackling settlement systems in all their complexity requires indeed taking varied information and data into account. It is obvious that several elements relative to the nature of archaeological sites and to the environment should be introduced or improved in order to reach an explicative dimension. In our particular case, we gathered in one point grid or one image all the archaeological sites, without taking into account their characteristics. This attitude is indeed essential at the first steps of the exploratory study, as it constitutes a first approach of the problematic and of the spatial structures, and gives us the possibility to estimate the overall footprint of men in the landscape.

\section{The Spatio-Morphological Approach: Methods and Tools}

Whilst data analysis seems not going without statistics, this approach is not relevant to detect spatial structures as it postulates the independence of factorial axes (Voiron and Dauphiné 1988, 7- 11). Therefore, in order to consider spatially varying properties of past phenomena materialised by archaeological data, we shall use a set of tools which takes into account the spatio-temporal nonindependence of geographical - and by extension, archaeological - data, such as geostatistics and mathematical morphology.

\subsection{Variography and geostatistics}

Lloyd and Atkinson (Lloyd and Atkinson 2004 , 152) provided a broad review of the few existing published applications of geostatistics in archaeological contexts, which mostly deal with the geostatistical spatial prediction method of kriging. They illustrate the wide range of archaeological problems which geostatistics may help to solve, and provide an introduction on the subject. Markofsky and Devan (Markofsky and Devan 2011, 432433) provided useful explanation on the method too, and apply it to investigate directional spatial autocorrelation in surface artefact distributions. Geographers have exploited geostatistics' potential as well, for example to characterise spatial dependence in the field of mineral exploration (Samal et al. 2011) or in order to define and predict urban spread phenomena (Voiron and Dauphiné 1988; Lajoie and Mathian 1989).

This study will focus only on the variogram, the core tool in geostatistical analysis, which is a curve representing the degree of spatial continuity 
of phenomena (Matheron 1963, 1250). It permits to know to what extent what happens in one point looks like or not, in average, to what happens in its surroundings distant of $h$. The more or less rapid increase of the variogram represents the more or less rapid deterioration of the influence of a point over more and more remote zones of the phenomena (Matheron 1963, 1250). Thus, the variogram $2 \gamma(\mathrm{h})$ is defined by the relation:

$$
2 \gamma(h)=\frac{1}{n-h} \sum_{i=1}^{n-h}\left(f_{i+h}-f_{i}\right)^{2}
$$

where $n$ is the total number of points, and $i$ the location of these points. The variogram reveals the spatial distribution of phenomena and describes its average structure and dependence effects.

This paper attempts to show that variography may be highly useful and relevant in an exploratory context. It brings indeed a first approach of the deployment of phenomena on space, highlights their spatial behaviours, and so gives us several research leads on their spatial organisation.

\subsection{Image analysis through mathematical morphology}

Mathematical morphology (MM) was created in the mid-'60s in France at the Ecole des Mines de Paris in Fontainebleau by G. Matheron (Matheron 1967) and J. Serra (Serra 1982). It is an efficient image processing method that is "both a theory and a toolbox" (Voiron 2009, 3), where the objects of the digitalised image are considered as a set of points on a grid. The purpose of MM is to organise the information contained in each pixel, to design their arrangement and to provide quantitative and qualitative descriptions of geometrical structures of images. The relationships between pixels are analysed through the use of geometric shapes (circle, hexagon, vector) called structuring elements, whose size determines the extent of the neighbourhood. The chosen structuring element will then guide the series of transformations we will operate on the image, in order to perceive the geographical information that lies in the most significant shapes and structures of the image (Voiron 1995, 25). The purpose is to smooth data, while conserving its essential shape characteristics and eliminating irrelevancies in order to reveal one structural aspect of the image, and to highlight invisible structures (Haralick et al. 1987, 532).

MM provides several advantages over other techniques, as "it preserves edge information, it uses shape-based processing and it is computationally efficient" (Voiron 2009, 4). It differs from most of image processing methods which are based on linear mathematical operations, as it essentially relies on min-max operators (Werman 1985), and as the pixel value itself has here less importance than the relationships with its neighbourhood (Voiron 2009, 4). Thus this method is suited to all questions about spread problems (Serra 2007; Voiron 2009) and spatial propagation simulations, and has already been applied to simulating spatial risks, flooding, epidemics and fires (Serra 2007). Finally, one of the main contributions of MM is most obvious when we consider the acquisition process of data that usually require a vector-based representation. Indeed, as the objects shown on the digitalised image are only points on a resolution grid, they lose for a moment their integrity, unlike in vector-based GIS. The distinction between vector and raster data, and the difficulties we often encounter in most of the GIS when we want to analyse jointly these two kinds of image, do not exist anymore (Voiron 1995).

Among the hundreds of transformations that MM algorithms offer, we selected a few simple ones for the purposes of this paper, in order to introduce this methodology and to suggest the possibilities they provide in an archaeological context. For the needs of this study, dilation and erosion (Fig. 3), closing and opening algorithms (Fig. 3) and the perceptual graph algorithm (Fig. 4) and their use in our particular context are presented on the figures below. For further information about classical and more modern morphological techniques, see the paper of J . Breen, R. J ones and H. Talbot (2000).

To conclude this methodological section, we shall emphasise that their powerful aptitude to detect spatial structures is not the only advantage of variography and $\mathrm{MM}$ : in a practical dimension, these methods open the nature of data and their entry procedures: they permit to analyse any phenomena represented on spatialised data grids, which can be built from a qualitative or quantitative database or even from a map (Voiron 1995, 17-25). They permit to simplify and to organise a rich and 


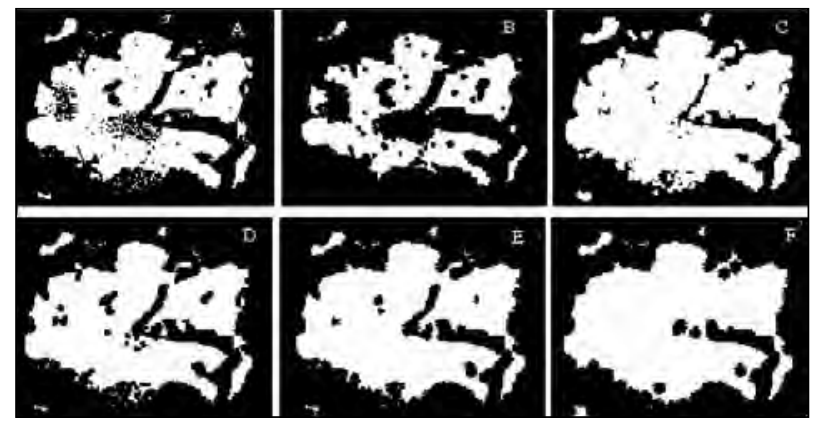

Figure 3. Examples of image transformations using erosion, dilation and closing. Dilation and erosion are the basis of MM treatments: we add or remove a certain number of pixels from the outlines of the image. Combining these two transformations is called a "closing" (a dilation followed by an erosion of the same size), or an "opening”, which is the opposite. That way, we operate a sieving or a granulometry of the elements of the image: the opening permits to describe their size distribution, whilst the closing sieves the space situated between the components of the image, and gives us structural information about the distance separating the components. A: initial set; $B$ : an erosion of A; $C$ : $a$ dilation of A, D: a closing size 1 of A; E: a closing size 2 of A; F: a closing size 3 of A (Voiron 2009).

complex dataset, and to take into account both qualitative and quantitative information - which is often the case in archaeology (De Runz et al. 2007, 114) - from an image or a point grid, without losing any information in this process.

\section{Elaboration of a Spatio-Morphological Analysis Procedure from Archaeological Data}

On the previous sections of this paper, we attempted to demonstrate theoretically the relevance and the complementarity of variography and MM. Indeed, the first tool permits to obtain an average and synthetic representation of a phenomena, and to orient the treatments operated with the second one, which gives us information on the shape of structures through space and on their spatial organisation.

In order to illustrate this position and to show concretely how a spatio-morphological procedure can be led and adapted to archaeological problematics and data, we applied it to the dataset presented on the first section.

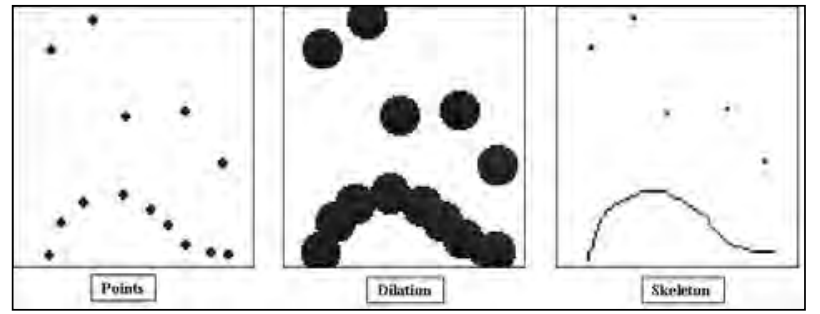

Figure 4. Detection of alignments with the perceptual graph algorithm. This operation consists in linking each point to its closest neighbours. The purpose is to obtain the skeleton of this structure in order to detect or rebuild alignments by drawing a network, whose main directions might then be identified (Voiron 1995).

4.1 First step: obtain an average representation of spatial behaviour of phenomena and research leads with variography

- One-dimensional variography calculations and results: highlight the average repartition of archaeological sites on the studied area

For the purposes of variography treatments, we converted our images into two data grids. Whilst the first one only materialises the number of archaeological sites contained in each cell (Fig. 5), the second one introduces survey intensity levels (Fig. 6). Indeed, the zones which have not been surveyed (see Fig. 2c) have been removed from the grid, and by extension from the analysis, as their explicative dimension is considered as too low and uncertain.

We calculated then four variograms on the basis of these data grids, and distinguished them according to their directions (North-South and East-West) in figure 7 , in order to compare the results we obtain depending on whether we take survey intensity levels into account or not. This comparison aims to question the relevance of an approach introducing data uncertainty within the analyses.

Whilst the two variograms calculated in the North-South direction seem to materialise the same spatial repartition phenomena, we can notice that the variogram 1 is smoother than the variogram 2 , which displays marked contrasts. The first curve is then probably smoothed by the high number of zeros of the grid, corresponding to the non-surveyed 


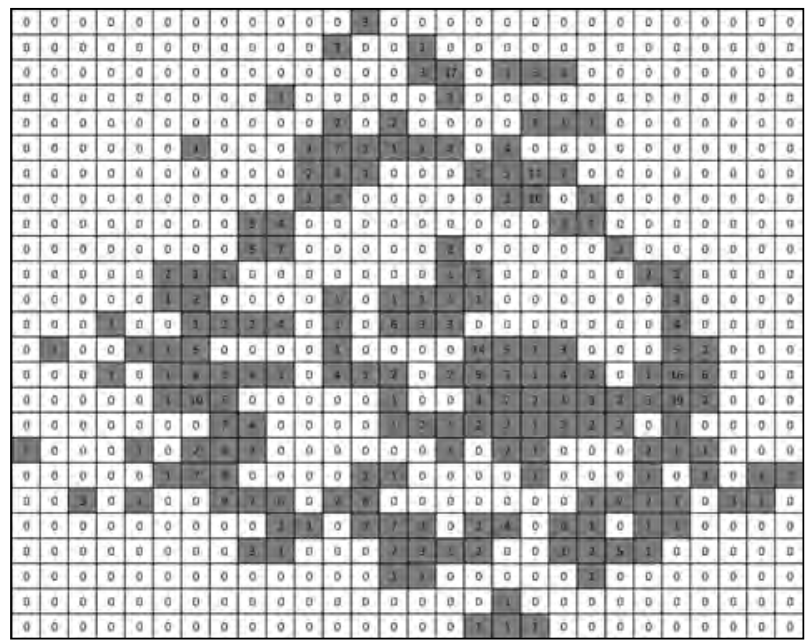

Figure 5. From the location of archaeological sites to a data grid. Each cell of the grid represents $4 \mathrm{~km}^{2}$ in reality, and the numbers inform about the number of archaeological sites included in each cell.

zones, which havebeen removed from the calculation of the variogram 2 . Therefore, taking into account levels of uncertainty does not fundamentally change the shape of the results in this context, but highlights in a more perceptible way the spatial structures and relations between the archaeological objects.

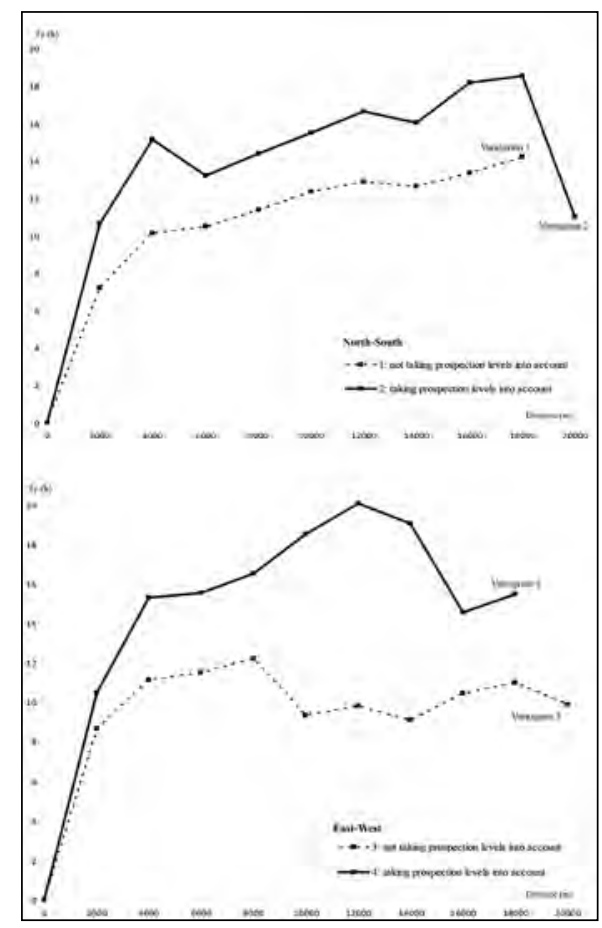

Figure 7. Variograms calculated on the two data grids, in two directions.

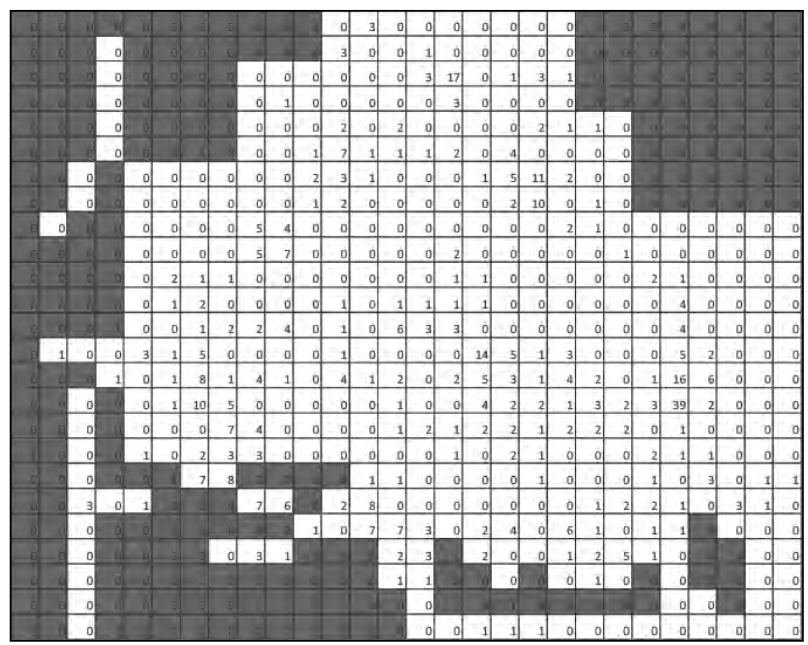

Figure 6. Elimination of the non-surveyed zones from the data grid (grey cells).

Moreover, the curves 1 and 2 increase very fast from the origin, until the step 2 ( $4 \mathrm{~km}$ in reality). It indicates that close cells materialise very different repartition phenomena. The repartition of the sites varies with distance, as we shift from high values (in other words, concentration zones) to low values (empty zones, or with a little number of sites). The first scale of structures opposes thus empty zones to zones with concentrations of archaeological sites, distant of $4 \mathrm{~km}$.

Then two levels of nested structures appear at the steps 6 and 8, showing the existence of regionalisation phenomena in the distribution of archaeological sites, every 12 and $18 \mathrm{~km}$.

The East-West variograms display the same aspect until the step 4, and we can notice the same smoothing effect as on the variogram 1 . The first two steps depict the same concentration phenomena as in the North-South direction: if we connect these two observations, we can deduce that these concentrations might have an areolar shape, as they have the same structure in both directions.

But the curves 3 and 4 become radically different starting from step 5: the variogram 3 presents a "hole effect", which points out the linking of two zones with similar values and makes the variogram drop suddenly. Thus, whilst the number of sites decreases progressively the further you move away from the concentration zones, other concentration phenomena appear since $10 \mathrm{~km}$. 


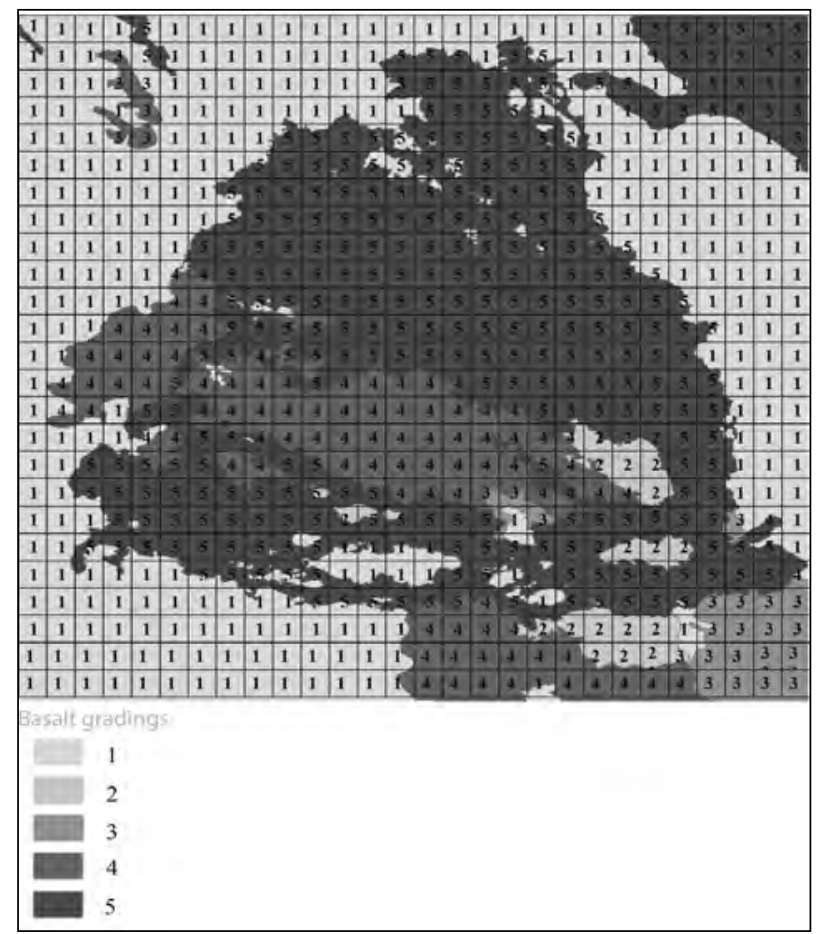

Figure 8. From the image of the basaltic coverage of the Leja to a data grid.

Thevariogram 4 showstwo scales of structures, corresponding to the concentration levels of two sites, meeting every $4 \mathrm{~km}$ for the first one and every $12 \mathrm{~km}$ for the second one. The hole effect we notice beyond step 6 shows that zones having similar values, and distant of $14 \mathrm{~km}$ have been linked. But another interesting fact is that the hole effect we detected on the first curve is not visible anymore: the concentration effects we noticed on the basis of this particular behaviour of the variogram was then probably only caused by the high concentrations of zeros, that we removed afterwards on the second analysis.

Therefore, this compared analysis shows the major importance of taking the degree of survey intensity into account. Indeed, the second scale of structures $(12 \mathrm{~km})$ cannot be detected if this information is not integrated in the calculation, and the hole effect on the first curve could have led us to huge interpretation errors.

- Crossed variography calculations and results: highlight the average relation between the quantity of basalt on the soils and the location of archaeological sites on the studied area.
Until this point, we attempted to describe the evolution of one variable (the archaeological sites) through space. However, variography also gives us the possibility to reveal a link between two variables, to describe how they co-vary through space, while measuring their spatial dependence. This extension of the variogram is called a crossed variogram: as each point of the grid is now characterised by two variables $f$ and $g$, the crossed variogram is given by the formula

$$
\not f g(h)=\frac{1}{n-h} \sum_{i=i}^{N-h}\left(f_{i}-f_{i+h}\right)\left(g_{i}-g_{i+h}\right)
$$

$\gamma$ fg gives information on how the two variables evolve through space. The obtained values can be positive or negative, depending on the nature of the relation: if they are positive, the two variables co-vary in the same way; if they are negative, the variables co-vary in an opposite way. The more the values exceed zero, the higher the spatial relation between the two variables. The presence of troughs or ridges on the curve materialise spatial dissociation phenomena.

Thus we chose to calculate the crossed variogram between the basaltic coverage and the location of the archaeological sites, in order to investigate the relationship between these two variables. The question is then to know if the number of sites in each cell of the grid, and the basaltic coverage level are correlated; in other words if the quantity of basalt on the soils and its variation through space could eventually have been one of the factors of the settlement of populations on the concentration zones we revealed on the first variography treatments. To achieve this aim, we created a data grid where the five graphic levels of basaltic coverage shown on the map have been expressed into values from 1 (the lesser percentage of basalt on the soils) to 5 (Fig.8).

We finally crossed this new data grid with the grid containing the number of archaeological sites and calculated the variogram of the co-variation of these two variables, in North-South and East-West directions (Fig. 9). Each curve describes in itself the co-variation between the two variables that we relate. 


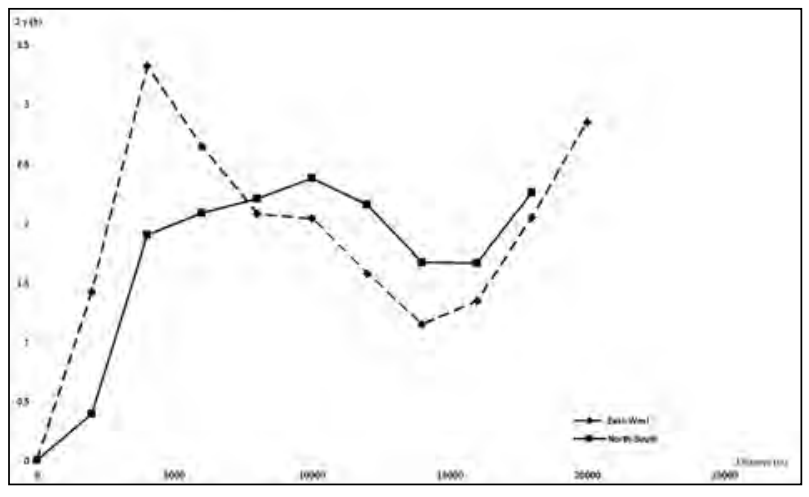

Figure 9. Crossed variogram between the location of archaeological sites and the basaltic coverage of the soils.

The crossed variogram is positive, which means that the two variables evolve together in an identical way: thus, when one increases with distance, the other one increases too. We also notice that a strong correlation exists between these two variables: the higher the percentage of basalt on the soils, the higher the number of archaeological sites.

Variography treatments have thus brought some hints about spatial structures on the Leja plateau. We detected several major forms of repartition of archaeological sites, as a phenomenon of clustering of archaeological sites on average $4 \mathrm{~km}$ perimeters across the area, and a high correlation between the percentage of basalt in the soils and the number of archaeological sites.

We will now try to point out where and how these phenomena inscribe into space, in a more precise and local way, with the help of image processing by MM.

\subsection{Second step: locate and visualise the detected spatial configurations, with MM.}

We first converted the images we wanted to analyse in a binary format, materialising the presence (white colour) or absence (black colour) of the phenomena (Fig. 10). All the following treatments have been carried out with the MM software Micromorph, developed at the Centre of MM of Mines Paristech (France).

Wefirst operated a closing on the archaeological sites image, in order to sieve the distance between the components of the image and let appear the

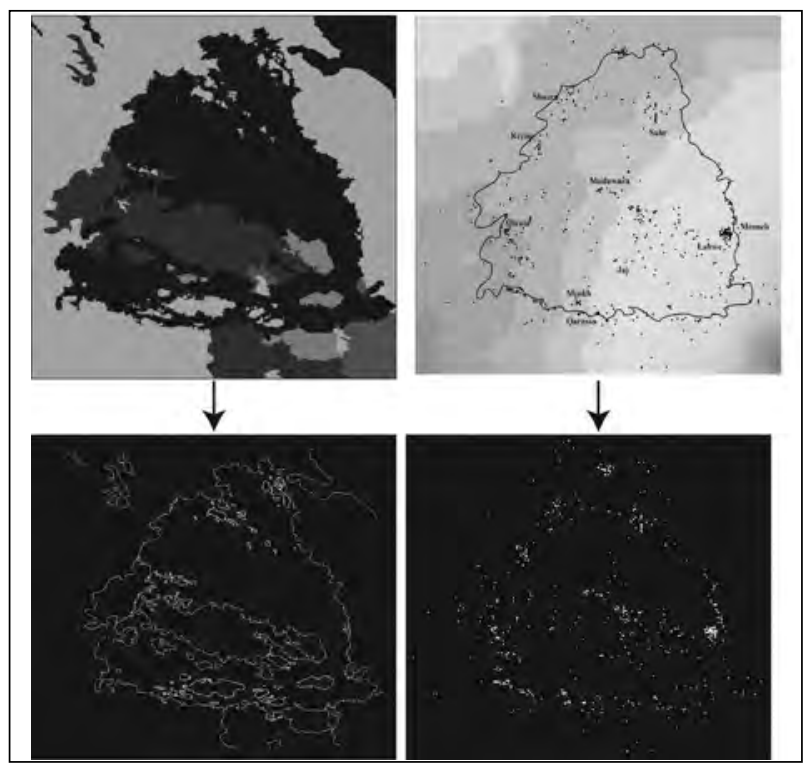

Figure 10. Conversion of archaeological sites and basaltic coverage images in a binary format.

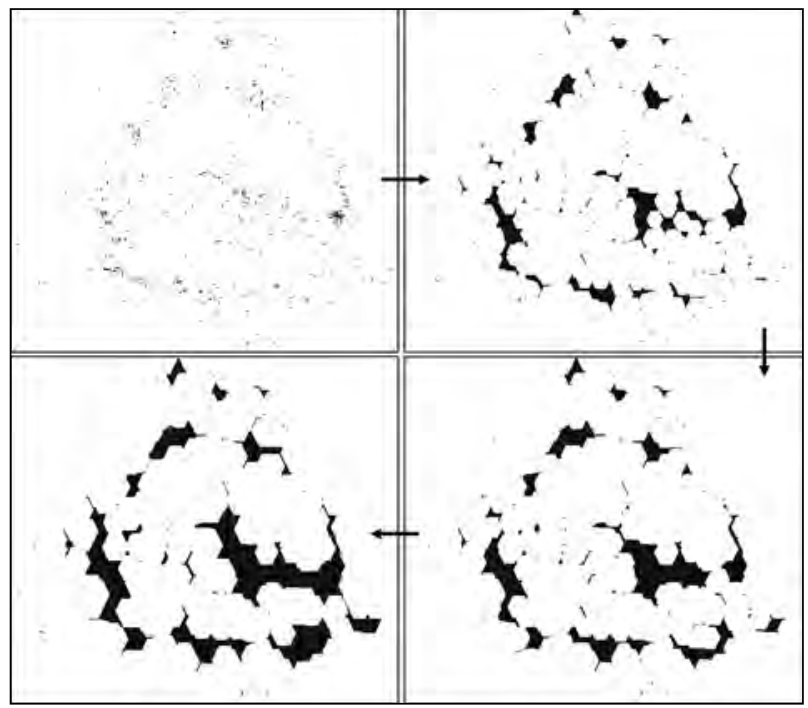

Figure 11. Results of the closing algorithm at three successive sizes.

concentrations of points. The higher the closing step, the more spaced sites are connected to each other. It is thus interesting - or even necessary to test several closing sizes, in order to compare the spatial shapes which emerge whether we consider distant or closest sites. The figure 11 displays the results of this closing algorithm at three successive closing sizes.

We applied then the perceptual graph algorithm on the obtained shapes in order to reduce 


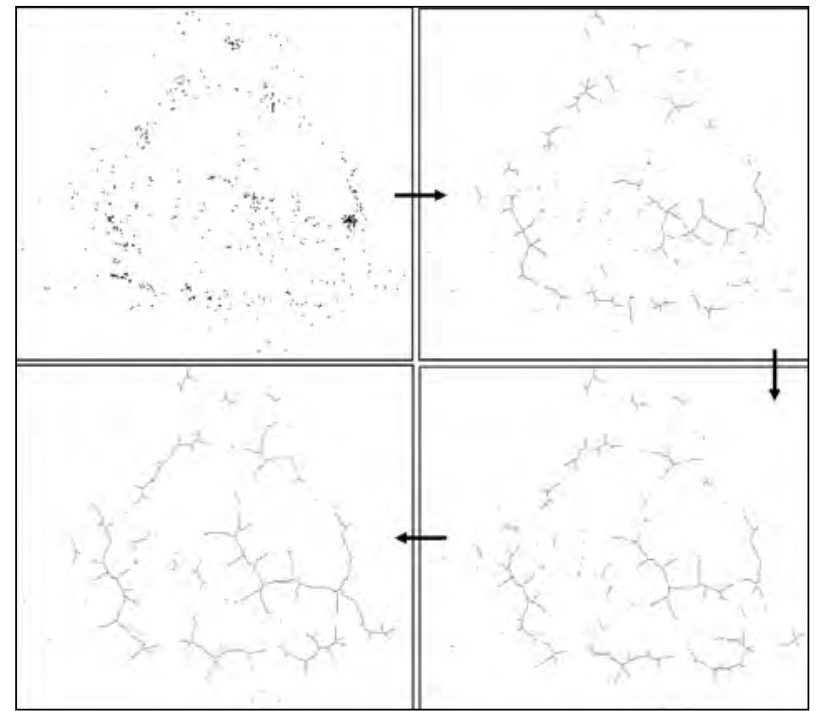

Figure 12. Results of the perceptual algorithm calculated on the closings (Fig. 11).

them to their skeleton and to reveal their elementary structure and alignments.

The information detected on the figures 11 and 12 can be now synthesised. The first closing step on the image b clearly shows the concentration of the closest sites, that we detected with the first variography treatments. It is interesting to notice that even if we increased the closing size in the images $c$ and $d$, the general structure we observe on the image $b$ strengthens but doesn't change, with a very particular circular shape intersected by a central "branch". This structure is then not relative to the distance between the sites, but is generalised to the disposition of all the archaeological sites.

But in order to not only describe but try to explain this phenomenon, we will to try to find a connexion between this one and some other variable. As the variography treatments revealed us a strong correlation between the location of archaeological sites and the basaltic coverage in the area, we decided to follow this lead and to introduce the basaltic coverage in MM treatments.

In order to visualise a co-variation between archaeological sites and the nature of the soils, we dilated successively the limits of the different zones of basaltic coverage. At each dilation size, we counted the number of archaeological sites which were included into the buffer. This process ends

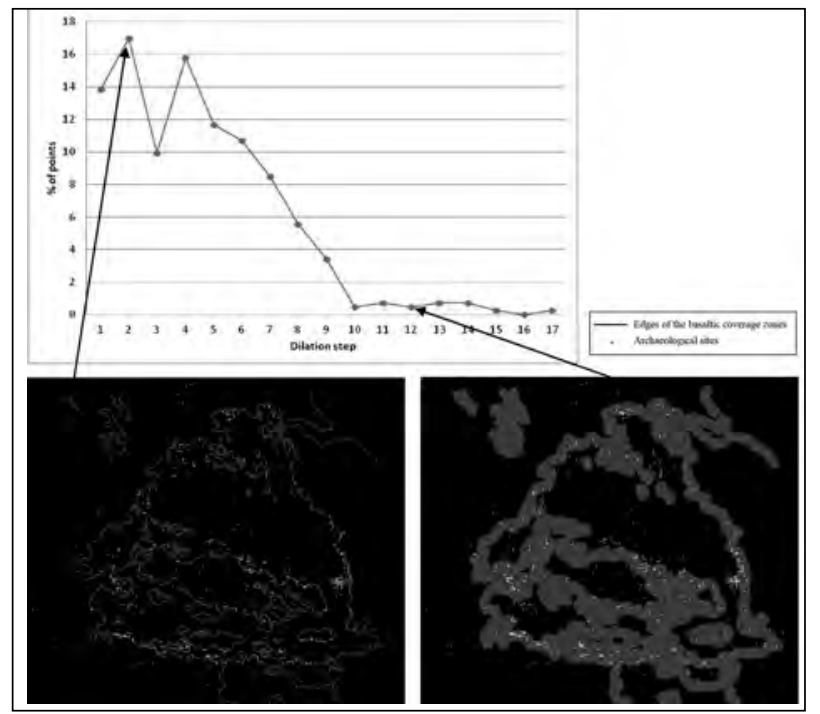

Figure 13. Percentage of points contained in the buffer zone of the basaltic coverage zones.

when all the sites are included in the buffer. The graphic on the figure 13 shows the percentage of points included at each dilation size.

We can notice that most of the archaeological sites are contained in the first four dilation steps: the more we move away from the limits of the basaltic coverage zones, the less we find concentrations of sites. It shows that most of the archaeological sites are located on the edges of the area: this could mean that the concentration phenomena we detected with the variogram and located with the previous MM treatments are not eventually only dependent on the quantity of basalt we find on the soils, but on the interface between two basaltic coverage levels.

\section{Discussion and Conclusions}

The spatio-morphological exploratory approach combines two complementary methods, variography and mathematical morphology. This process allows first to obtain some leads of research thanks to a synthesis of the relationships between the variables, an average representation of phenomena. Then, these results are re-mobilised in order to seek the spatial repartition of structures through space.

As mentioned previously, the purpose of our analyses was only to illustrate concretely how the presented methodological procedure could be applied to archaeological problematic and data. 
It is indeed obvious that several elements should be introduced or improved in order to go beyond the purely descriptive dimension and reach an explicative dimension. Tackling settlement systems in all their complexity and researching the links of causality between their components requires indeed taking varied information and data into account in the analysis. In our particular case, the main drawback comes from the gathering in one point grid or oneimage all thearchaeological sites, without taking into account their inner characteristics. This attitude is however essential at the first steps of the study, as it constitutes a first approach to the problematic and to the spatial structures, but should be then left behind.

Two methodological means might allow us to break down our gathered data: the first one consists in creating several images or point grids, each one representing one dimension or attribute of the studied phenomena or variable. That way, we could introduce a difference between habitat and funerary archaeological sites; for example, as they do not pertain to the same functional dimension, their location could result from different purposes and causalities, which cannot be mixed in our research of spatial structures. Splitting the archaeological sites into several images and point grids according to their period and comparing the variography and $\mathrm{MM}$ results could also permit us to introduce the idea of change into the analysis and to see how the spatial structures evolved through space and time. Separating settlement and funerary sites in two point grids might, in the first times, permit to analyse their co-variation through space. We carried out this first treatment in order to illustrate more concretely the future perspectives of this study (Fig. 14).

These two variograms show a positive covariation between habitat and funerary sites, but we can notice an interesting difference between the variograms in the two directions: the East-West curve shows indeed higher values than the NorthSouth one, which tends to zero. The variogram calculated in the East-West direction shows that the number of habitat and funerary sites increases with distance, until we reach the step 4 of the analysis, that is to say $8000 \mathrm{~m}$, which materialises the point of maximum spatial dependence between the two variables. An archaeological interpretation of these

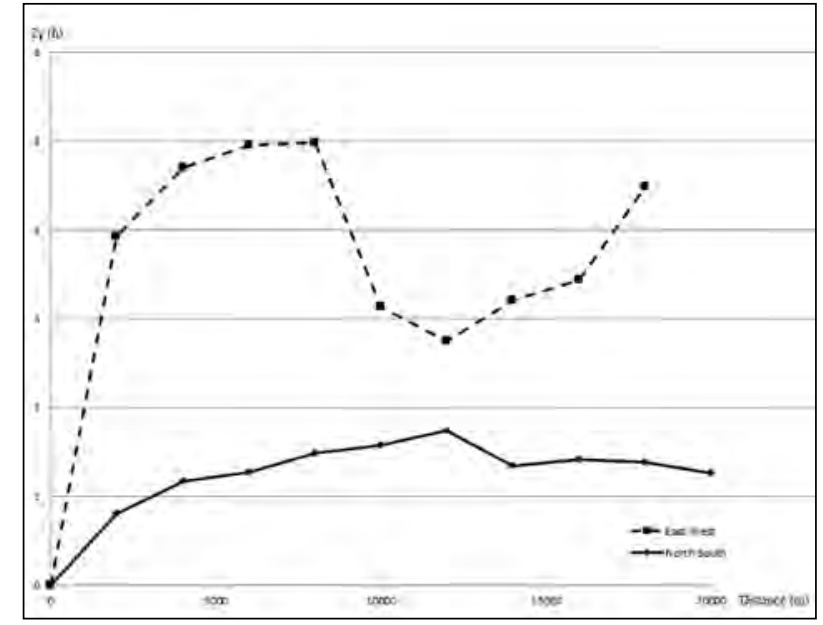

Figure 14. Crossed variogram between the location of dwellings and funerary sites.

results will be presented after having introduced several contextual and temporal elements in the analysis. Thus, contrary to what one may think, we are here far from considering that all the variables of a phenomenon are independent and should be separated radically in the analysis: on the contrary, detaching them is a mean to discover the links they share, their mutual causalities, and to compare their evolutions in time and space. In other words, our aim is to deconstruct to better rebuild...

Another way to discretise one phenomenon according to its different aspects is brought by MM. It is indeed possible to overtake the binary approach (presence/absence of a phenomenon) by building grey-level images. Each pixel of the image, representing one aspect of the phenomena, will be then described by a grey level, which opens the treatment possibilities and the complexity degree of phenomena. This approach could be useful here in order to take into account the different survey levels in the analyses and not only to oppose the surveyed and not surveyed zones.

Finally, we shall call attention to thereader that there is obviously always a result when analyses are carried out. However, the relevance of these results can always be questioned, as well as the data used to investigate correlation between different variables. These spatial analysis methods and the whole protocol of study have been indeed disconnected from their research context for the purposes of this paper, whose aim was only to focus on the presented 
particular tools and methods. But they will be soon applied, tested and interpreted more carefully, in the framework of a thesis attempting to grasp the complexity of past settlement systems and their changes over time.

\section{Acknowledgements}

This study was carried out as part of the programme of the UMR Etude des Structures, des Processus d'Adaptation et des Changements de l'Espace (ESPACE) and the UMR Cultures et Environnements, Préhistoire, Antiquité, MoyenÂge (CEPAM). I thank Christine Voiron, for having introduced me to the methods and tools I used in this paper, and for having helped mein theinterpretation of the results. Frank Braemer, who has given me access to the PaléoSyr database, and who provided me his information and advice on the studied area and problematic, is gratefully acknowledged.

\section{Bibliography}

Bloch, I., and H. Maitre. 2004. Les méthodes de raisonnement dans les images. Ecole Nationale Supérieure des Télécommunications. Paris: ENST. Accessed January 15, 2014. http://perso.telecomparistech. fr/ bloch/VOIR/ poly_voir.pdf.

Breen, E. J., R.J ones, and H. Talbot. 2000. "Mathematical Morphology: A useful set of tools for image analysis." Statistics and Computing 10:105- 120.

CEPAM CNRS. 2014. "Mission Syrie du Sud.” Accessed January $15 . \quad$ http://www.cepam.cnrs.fr/ projet/ missionsyriedusud/.

De Runz, C., and Desjardin, E. 2010. "Imperfect Spatiotemporal Information Analysisin a GIS: Application to Archæological Information Completion Hypothesis." In Methods for Handling Imperfect Spatial Information, edited by R. Jeansoulin, O. Papini, H. Prade, and S. Schockaert, 341- 356. Berlin: Springer.

De Runz, C., E. Desjardin, F. Piantoni, and M. Herbin. 2007. "Using fuzzy logic to manage uncertain multimodal data in an archaeological GIS." In 5th International Symposium on Spatial Data Quality, 114- 119. Enschede. http:// crestic.univ-reims.fr/ publication/1013/pdf.

Haralick, R.M., S.R. Sternberg, and X. Zhuang. 1987.
"Image Analysis Using Mathematical Morphology." IEEE Transactions on Pattern Analysis and Machine Intelligence 9 (4):532-550. doi: 10.1109/ TPAMI.1987.4767941.

Lajoie, G., and H. Mathian. 1989. "Application of variograms in urban geography." In Spatial Analysis and Population Dynamics, Proceedings of the 6th European Colloquium of Theoretical and Quantitative Geography, Chantilly, edited by D. Pumain, 295-310. Paris: John Libbey-Eurotext/ INED.

Liziard, S., and C. Voiron. 2012. "The Contribution of Mathematical Morphology in Spatial Analysis of Aggregated Data: Home Building Evolution in the French Riviera during the Twentieth Century." In Proceedings of the AGILE 2012 International Conference on Geographic Information Science, Avignon, April, 24-27, edited by J. Gensel, D. Josselin, and D. Vandenbroucke, 249- 254. New York: Springer.

Lloyd, C. D., and P. M. Atkinson. 2004. "Archaeology and geostatistics." J ournal of Archaeological Science 31 (2):151- 165.

Markofsky, S., and A. Bevan. 2011. "Directional analysis of surface artifact distributions. A case study from the Murghab Delta, Turkmenistan." Journal of Archaeological Science 39:428- 439.

Matheron, G. 1963. “Principles of Geostatistics.” Economic Geology 58:1246- 1266.

Matheron, G. 1967. Elements pour une théorie des milieux poreux. Paris: Masson.

Matheron, G. 1971. The theory of regionalised variables and its applications. Paris: Ecole Nationale Superieure des Mines de Paris.

Rohmer, J., and H. Criaud. 2010. "Schémas d'occupation d'une enclave semi-aride. Le Leja (Syrie du Sud), de l'âge du Bronze à la veille de l'annexion à Rome (3600 av. J.-C.-fin du 1er s. apr. J.-C.)." In Regards croisés sur l'étude archéologique des paysages anciens. Nouvelles recherches dans lebassin méditerranéen, en Asiecentrale et au Proche et au Moyen-Orient (TMO 56), edited by H. Alarashi, 43-63. Lyon: TMO 56, Maison de l'Orient méditerranéen.

Samal, A.R., R. Sengupta, and R. Fifarek. 2011. “Modeling 
Across Space and Time. Papers from the 41st Conference on

Computer Applications and Quantitative Methods in Archaeology. Perth, 25-28 March 2013

spatial anisotropy of gold concentration data using GIS-based interpolated maps and variogram analysis: implications for structural control of mineralization." J ournal of Earth System Science 120 (4):583- 59.

Serra, J. 1982. Image Analysis and Mathematical Morphology. London: Academic Press.

Serra, J. 1988. Image Analysis and Mathematical Morphology. Vol.2: Theoretical Advance. London: Academic Press.

Serra,J . 2007. “Therandom spreadmodel.”In Proceedings of the 8th International Symposium on Mathematical Morphology, vol.1, edited by G. J. F. Banon, J . Barrera, U. D. M. Braga-Neto, and N. S. T. Hirata, 87-98. Sao J ose dos Campos: INPE.

Voiron, C. 1995. Analyse spatiale et analyse d'images. Montpellier: GIP RECLUS.

Voiron, C., and A. Dauphiné. 1988. Variogrammes et structures spatiales. Montpellier: GIP Reclus.

Voiron, C. 2009. "Predicting the Urban Spread Using Spatio-Morphological Models." In Geocomputation and urban planning, edited by B. Murgante, G. Borruso and A. Lapucci, 223-236. Berlin: Springer.

Werman, M., and S. Peleg, 1985. "Min-max operators in texture analysis." IEEE Transactions on Pattern Analysis and Machine Intelligence 7:730- 733. 


\title{
Least Cost Path Analysis for Predicting Glacial Archaeological Site Potential in Central Europe
}

\author{
Stephanie R. Rogers, Claude Collet \\ University of Fribourg, Switzerland \\ Ralph Lugon \\ University of Applied Sciences and Arts, Western Switzerland
}

\begin{abstract}
:
Recent changes in climate have led to an increased exposure of glacial archaeological artefacts due to the melting of glaciers and ice patches. Here we calculated Least Cost Paths (LCPs) between archaeologically significant locations in Switzerland and Italy using a Least Cost Path Analysis (LCPA) method in which cost rasters were first calibrated at a study site near Haut-Val de Réchy, Switzerland to develop a prehistoric cost raster. Tools were used to calculate the LCPs based on DEM-derived slope using Tobler's anisotropic hiking function and landcover. Our results have since provided a focus for prehistoric glacial archaeological prospection in the Pennine Alps of central Europe, as well as led to the discovery of an artefact from the Bronze Age ( 2,800 years BP). This methodology could be used as an example for identifying additional sites of prehistoric glacial archaeological remains around the world.
\end{abstract}

\section{Keywords:}

Glacial Archaeology, GIS, Least Cost Path Analysis

\section{Introduction}

The current warming period is leading to a rise in the exposure of archaeological artefacts due to increased melting in the cryosphere (Dixon, Manley and Lee 2005; Molyneaux and Reay 2010). As a result, prehistoric and historic archaeological remains have been discovered near the margins of melting glaciers, ice patches, and permafrost in various places around the world (Krajick 2002). The frozen setting in which these artefacts have been found provides a unique preservation environment that withstands decomposition and allows organic biological and cultural materials to remain intact, enabling the collection and scientific analysis of rare and irreplaceable objects (Andrews and MacKay 2012; Molyneaux and Reay 2010). For example, one of the most complete prehistoric finds, Ötzi the Tyrolean Iceman, was found protruding from a high-altitude ice patch near the border of Austria and Italy in 1991 (Prinoth-Fornwagner and Niklaus 1994; Seidler et al. 1992). Because the corpse was so well-preserved for the last $\sim 5,300$ years, the study of this specimen has provided unique information about the place of origin, ancestry, genetics, diet, and diseases that inflicted prehistoric people from this region (Janko, Stark and Zink 2012; Keller et

Corresponding author: stephrogers5@gmail.com al. 2012; Shouse 2001). The accidental discovery of Ötzi led to the stark realisation that similar finds could be expected as temperatures continue to rise. As a result, archaeologists in North America (Andrews et al. 2012; Andrews and MacKay 2012; Dixon, Manley and Lee 2005; Farnell et al. 2004; Hare et al. 2004; Lee 2012; VanderHoek, Tedor and McMahan 2007), Asia (Goossens et al. 2007), and Europe, specifically Norway (Callanan 2012; Farbregd 1972;) and Switzerland (Hafner 2012) have increased efforts to investigate high altitudes with the aspirations of intercepting materials which have been, or will soon be, exposed in order to protect and conserve cultural heritage before it decomposes or becomes destroyed by the current environment or anthropogenic causes. Some interesting finds include prehistoric hunting materials in Alaska and northern Canada (c.f. Dixon, Manley and Lee 2005; Hare et al. 2012; VanderHoek, Tedor and McMahan 2007;) and a 6,000 year record of archaeological remains from an ice patch in the Bernese Alps in Switzerland (Hafner 2012), which attests to the use of high mountain passes by humans in the Swiss Alps for thousands of years.

The Pennine Alps (sometimes referred to as the Valais Alps) located along the Swiss-Italian border, are an area of glacial archaeological interest 
due to their topographic location, rich cultural past, and prominent glaciated territory. The PennineAlps are characterised by their high peaks; the highest being the Dufour peak (4,634 $\mathrm{m}$ above sea level) and the most well-known, the Matterhorn (4,478 $\mathrm{m}$ asl). High mountain passes connect Switzerland's canton of Valais to northern Italy's provinces of Aosta and Piedmont. Archaeological finds have demonstrated that mountain passes between Switzerland and Italy have been used as trade and travel routes for thousands of years (Coolidge 1912; Curdy 2007; Harriss 1970; 1971), with the earliest indication of human usage originating from the Mesolithic period (Curdy, Leuzinger-Piccand and Leuzinger 2003). Numerous written documents from medieval times attest to the existence of close ties between the Swiss and Italian sides of the Pennine Alps through small alpine passes. For example the exchange of wine and sheep between the Aosta and Zermatt valleys was important for the commercial development in those areas (Ammann 1992). However, navigating through mountainous terrain is often a difficult task, especially when travelling with goods for trade or commerce, or a large number of people for migration. For this reason, many archaeologists have assumed that these remote, high altitude regions were marginal and not used excessively by humans (Walsh, Richer and de Beaulieu 2006). Due to recent accidental finds in high altitude locations around the world, there is increased interest in the archaeology of glaciated and frozen regions, especially in the Pennine Alps, whose geographical and cultural attributes make them a region of great archaeological interest.

In the Pennine Alps, numerous glaciated mountain passes exist which allow the passage between Switzerland and Italy. However, the vast glaciated surface area and high altitudes pose problems for archaeological investigation. Due to the size of the study area and the inaccessibility of some passes, it is impossible to visit all of the potential sites of interest due to time and cost constraints. Therefore, Least Cost Path Analysis (LCPA), a Geographic Information Systems (GIS) method, was used to aid in glacial archaeological investigations by narrowing down potential site locations based on the principle that people want to take the least physically demanding route possible to get from one location to another. LCPA is one of a variety of predictive methodologies developed in GIS that has

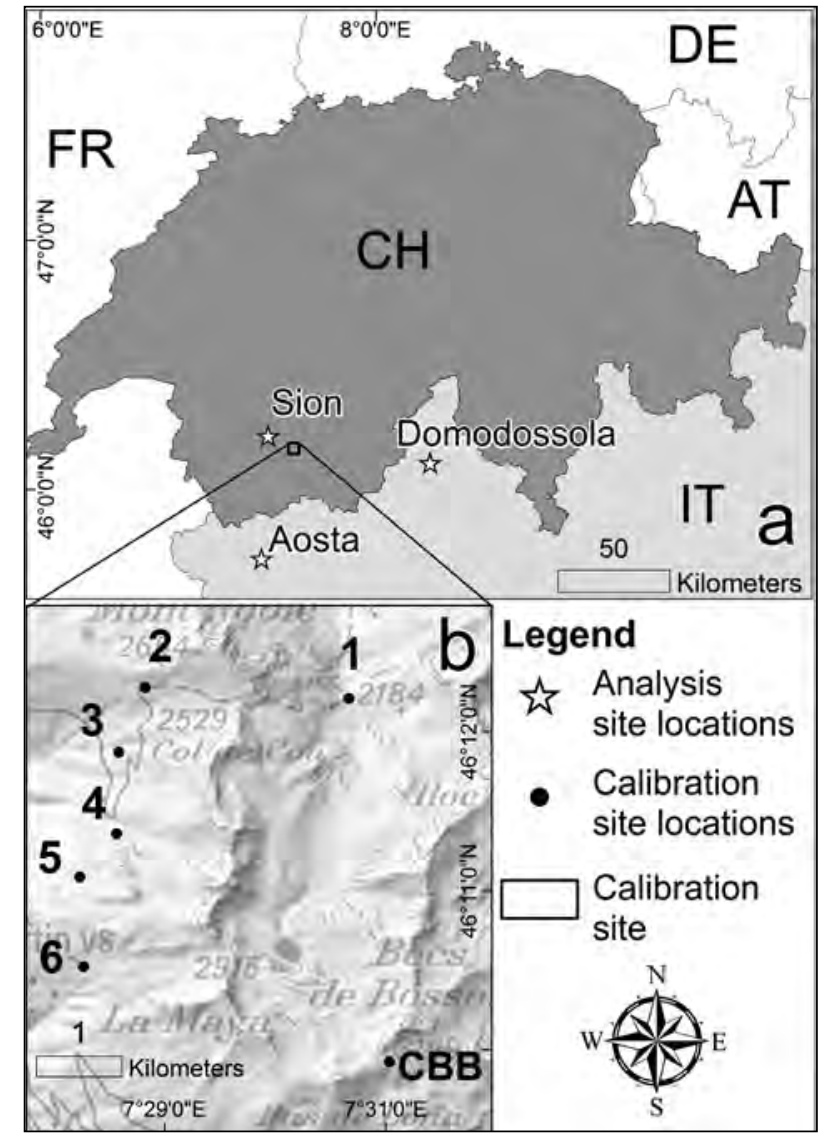

Figure 1. Overview of study areas. Reproduced with permission of Swisstopo (BA14037).

been adapted for archaeological investigations and has been increasingly applied in research along with the expansion and ease of access to GIS data, tools and software (Anderson and Gillam 2000; Bell and Lock 2000; Egeland, Nicholson and Gasparian 2010; Gaffney and Stančič 1991; Gorenflo and Gale 1990; Herzog and Posluschny 2011; Howey 2007; Kondo and Seino 2011; Madry and Rakos 1996; Verhagen and J eneson 2012). It has been used to link together archaeological site locations (Bell, Wilson and Wickham 2002; Gorenflo and Gale 1990; Tripcevich 2008), to track prehistoric migration patterns (Egeland, Nicholson and Gasparian 2010; Krist and Brown 1994), and also as a first step in research to predict potential travel routes (c.f. Anderson and Gillam 2000; Verhagen and J eneson 2012). Here, we followed the latter approach and used LCPA as a decision support tool and a stepping stone for further archaeological investigation in remote high altitude regions of the Pennine Alps. 
Using LCPAs, we attempted to predict which high mountain passes were most-likely travelled in prehistoric times based on topographic properties and landcover characteristics. Our main objective was to aid in understanding the effects of the slope of the terrain and differing landcover types on travel routes through mountainous terrain using a calibration site and later applying those results to two analysis sites in order to aid archaeologists in high altitude investigations. By first implementing a seriesofLCPAsona calibration sitein theHaut-Val de Réchy (HVR), Switzerland, a prehistoric cost raster weighting scheme was established and later applied to two analysis sites between Sion, Switzerland and both Aosta and Domodossola, Italy (Fig. 1a). The region around Sion has an archaeological record dating back to the Mesolithic (Curdy 2007) while northern Italy has a record dating back to the Epipaleolithic, although the Ossola and Aosta Valleys have provided few artefacts (Crotti, Pignat and Rachoud-Schneider 2002; Di Maio 2007). From these archaeologically significant locations, we determined potential travel routes between sites and discovered a previously unstudied mountain pass from which an archaeological artefact was retrieved, thus showing the possibility to use LCPA as a first step in glacial archaeological investigations by narrowing down potential travel routes across mountainous terrain in order to ultimately find, protect, and conserve archaeological remains.

\section{Methods}

In ArcGIS 10.1, the process of creating Least Cost Paths (LCPs) requires two steps: 1) the creation of the accumulative cost distance raster (ACDR) using the Path Distance tool and 2) the calculation of the LCP with the aforementioned ACDR as an input into the Cost Path tool. The ACDR defines the cost value for each cell in the raster initiating from the point of interest. The cost grows as the distance from the source location increases, thus each cell in the resulting ACDR represents the cost of travel back to the source location (ESRI 2013; Whitley and Hicks 2003). Along with the surface distance, landcover and slope were also included in the Path Distance calculation in order to account for the impeding costs of differing landcovers and slope values when traversing terrains. Landcover can be modelled isotropically as the direction of travel does not affect the cost of crossing a certain landcover type (van Leusen 1999; Wheatley and Gillings 2002). However, when incorporating slope into travel calculations, anisotropic modelling should be implemented to account for the changes in cost incurred when travelling up, down, or perpendicular to the slope (Bell and Lock 2000; Eastman 2003; van Leusen 2002). For this reason, Tobler's hiking function for undulating terrain (Tobler 1993), which was elaborated from Imhof (1968), was used to calculate walking times based on DEM-derived slope value calculations. Tobler's original equation:

$$
\mathrm{v}=6 \exp (-3.5 * \operatorname{abs}(\mathrm{s}+0.05)) \text {, where: }
$$

$\mathrm{v}$, the walking velocity in $\mathrm{km} / \mathrm{h}$,

$\mathrm{s}$, the $\mathrm{dh} / \mathrm{dx}=$ slope $=\tan$ (theta).

calculates walking on flat terrain at approximately $5 \mathrm{~km} / \mathrm{h}$. The walking speed is greatest when travelling downslope at a slight decline, with speeds progressively declining as slopes decrease and increase (Gorenflo and Gale 1990). To facilitate the integration of the algorithm into the Path Distance tool in ArcGIS, the reciprocal of the equation was used as suggested by Tripcevich (2008; 2009) in order to directly calculate walking times:

Time $(\mathrm{hrs}) / \mathrm{m}=0.000166666 *(\exp (3.5 * \operatorname{abs}(\mathrm{s}+0.05)))$

Thus thetimein hours/ $\mathrm{m}$ was calculated as the vertical factor for each slope value and multiplied by the surface distance and isotropic friction values to obtain the ACDRs. The Cost Path tool was then used to calculate the LCPs from the ACDRs and the cost backlink rasters. The backlink raster, which is also an output of the Path Distance tool, defines the neighbouring raster cell which is the next on the least accumulative cost path back to the source, while also accounting for the surface distance and the vertical factor (ESRI 2013).

\subsection{Calibration site}

The Haut-Val de Réchy (HVR), Switzerland was used as the calibration site for this study and is located at the southern end of the Val de Réchy (46⿳亠口冋 11' N, 7o 30` E - World Geodetic System 1984 (WGS84)) (Fig. 1b). This relatively small $\left(\sim 40 \mathrm{~km}^{2}\right)$ calibration site was used as a control site to create a prehistoric cost raster which was 
later integrated into the LCPA between the larger study area $\left(\sim 4,500 \mathrm{~km}^{2}\right)$ between Switzerland and Italy. This calibration site was chosen based on its topographic features, including various mountain passes, its altitude range $(\sim 1,000 \mathrm{~m})$, its differing landcovers, its geomorphologic familiarity (Gardaz 1998; Lugon and Delaloye 2001; Tenthorey 1993), and its accessibility for future ground-truthing purposes. The HVR is distinguished by its flat bottomed U-shaped valley and steep surrounding ridge formed by glacial activity (Tenthorey 1993). Six starting locations were strategically chosen from which walking times to and from the Cabin de Becs de Bosson (CBB) were calculated (Fig. 1b). The CBB is located at an elevation of 2,988 $\mathrm{m}$ asl on the southern side of the ridge that surrounds the HVR, and is adjacent to the Becs de Bosson mountain $(3,129 \mathrm{~m}$ asl). The starting locations for the LCPs were selected based on their geographic locations (i.e. near mountain passes or swamps) to investigate how different landcovers and slopes affected the correspondingLCPs. Five of the six startinglocations were situated on the western side of the ridge to test the effects of varying topography on paths, while one starting location (number 1, Fig. 1b) was situated to the north of the valley directly behind a swamp to test the effects of varying landcover characteristics.

For the calibration site, the inputs to the Path Distance tool included the following (Table 1): point locations for each site, four reclassified landcover layers, the $25 \mathrm{~m}$ DEM from Swisstopo, and Tobler's value table. The original landcover layer was the Swisstopo Vector25 Primary Surfaces shapefile (Federal Office of Topography 2014) which, in this specific study region, had 12 different landcover classes of which some could be amalgamated for the purposes of this analysis (e.g. the four differing types of scree were grouped into the same category). Subsequently, four different weighting schemes were used to represent four different scenarios: current landcover, prehistoric landcover (with two different weighting schemes), and the topographic landcover (Table 2). Weights were established and assigned after a consensus between the authors and other research group members was reached regarding the ease or difficulty to traverse respective landcover classes. For example, for the current landcover raster, the "Other" category, which incorporates open spaces and grassy areas, was assumed to be the easiest to traverse and was therefore assigned a weight of 1 . The "Forest, Bushes" category was decided to be three times more difficult to traverse and was therefore assigned a weight of 3 . The "Scree" category was given a weight of 4 as it was deemed more difficult to cross than forest, although less difficult to cross than "Residential/Rock", which was given a weight of 5. The "Swamp" category was given a weight of 10 as it was assumed that people would avoid these, however they were not deemed impossible to cross. The "Water" category was given a weight of 999 assuming that people would not be willing to swim across a water body, but instead go around it. For both prehistoric landcover weighting schemes a treeline of $2,000 \mathrm{~m}$ was assumed (Colombaroli et al. 2010), therefore everything below that level was covered with trees. The first prehistoric landcover weighting scheme was similar to the current landcover, except that the treeline was a determining factor for forest cover. The "Other" and "Forest, Bush" categories were given values of 3 or 4 depending on whether they were located above or below thetreeline, respectively. The weights of the remaining categories stayed the same as the current landcover weighting scheme. After somepreliminary testing, it was decided that travel times were highly exaggerated when these weights were applied so a second prehistoric landcover weighting scheme was created which divided each weight in half. The final weighting scheme, representing the topographic landcover, was used to test the effects of the slope of the terrain on LCPs. Thus, each class was given a weight of 1, except "Water" which remained at 999. The respective landcover layers were used as the cost raster input to the Path Distance tool to model isotropic friction across the surface. The resulting LCPs were analysed and visually compared with current hiking trails on the 1:25,000 topographic map and their respective travel times. The control travel times were calculated using the Switzerland Mobility Wanderland website (Switzerland Mobility 2013a) which computes walking times based on the calculation used by the Swiss Hiking trail network, Suisse Rando (Switzerland Mobility 2013b). Suisse Rando calculates path travel times based on the horizontal distance, height difference, and slope between start and end locations (Switzerland Mobility 2013b). Henceforth, these paths will be referred to as the Wanderland Paths (WPs). 
Least Cost Path Analysis for Predicting Glacial Archaeological Site Potential in Central Europe Stephanie R. Rogers et al.

\begin{tabular}{|c|c|c|c|}
\hline $\begin{array}{l}\text { Input to Path } \\
\text { Distance tool }\end{array}$ & Function & Layers used: calibration site & $\begin{array}{l}\text { Layers used: analysis } \\
\text { sites }\end{array}$ \\
\hline Feature source data & $\begin{array}{l}\text { Start point; cost distance } \\
\text { raster will be created based } \\
\text { on this point }\end{array}$ & $\begin{array}{l}\text { Sites } 1 \text { to } 6 \text {, Cabin de Becs de Bosson } \\
\text { (CBB) }\end{array}$ & Sion, Aosta, Domodossola \\
\hline $\begin{array}{l}\text { Input cost raster } \\
\text { (Isotropic friction } \\
\text { layer) }\end{array}$ & $\begin{array}{l}\text { Landcover raster which } \\
\text { denotes the weight of each } \\
\text { landcover type }\end{array}$ & $\begin{array}{c}\text { Swisstopo's Vector } 25 \mathrm{~m} \text { Primary } \\
\text { Surfaces layer reclassified as: Current } \\
\text { LC, Prehistoric LC (first and second } \\
\text { weightings), Topographic LC (see Table } 2 \\
\text { for reclassification schemes) }\end{array}$ & $\begin{array}{l}\text { Corine } 2006100 \text { m landcover } \\
\text { layer reclassified (Table 3) } \\
\text { using the Prehistoric LC } \\
\text { second weighting scheme and } \\
\text { resampled to } 25 \mathrm{~m} \\
\end{array}$ \\
\hline Input surface raster & $\begin{array}{l}\text { The raster from which the } \\
\text { true distance is calculated }\end{array}$ & $25 \mathrm{~m}$ DEM from Swisstopo & $\begin{array}{c}30 \mathrm{~m} \text { ASTER DEM resampled } \\
\text { to } 25 \mathrm{~m} \\
\end{array}$ \\
\hline Input vertical raster & $\begin{array}{l}\text { The layer used to calculate } \\
\text { the slope. The slope value } \\
\text { is then multiplied by the } \\
\text { vertical factor }\end{array}$ & $25 \mathrm{~m}$ DEM from Swisstopo & $\begin{array}{c}30 \mathrm{~m} \text { ASTER DEM resampled } \\
\text { to } 25 \mathrm{~m}\end{array}$ \\
\hline $\begin{array}{c}\text { Vertical factor } \\
\text { (Anisotropic friction } \\
\text { table) }\end{array}$ & $\begin{array}{c}\text { The input table which defines } \\
\text { the walking speeds required } \\
\text { to traverse each degree of } \\
\text { slope }\end{array}$ & $\begin{array}{l}\text { Values calculated from Tobler's walking } \\
\text { function in table format }\end{array}$ & $\begin{array}{c}\text { Values calculated from } \\
\text { Tobler's hiking function in } \\
\text { table format }\end{array}$ \\
\hline
\end{tabular}

Table 1. Inputs into the Path Distance tool.

\begin{tabular}{|c|c|c|c|c|c|c|c|c|}
\hline $\begin{array}{l}\text { Original LC } \\
\text { class }\end{array}$ & Current LC & Weight & \multicolumn{2}{|c|}{ Prehistoric LC } & $\begin{array}{c}\text { Weight } \\
1\end{array}$ & $\begin{array}{c}\text { Weight } \\
2\end{array}$ & $\begin{array}{l}\text { Topo } \\
\text { LC }\end{array}$ & Weight \\
\hline \multirow[t]{2}{*}{ Other } & \multirow[t]{2}{*}{ Other } & 1 & Other, Forest & Above $2000 \mathrm{~m}$ & 3 & 1.5 & \multirow[t]{13}{*}{ Other } & 1 \\
\hline & & & $\begin{array}{l}\text { Other, Forest, Bush, } \\
\text { Residential, All Scree }\end{array}$ & Below $2000 \mathrm{~m}$ & 4 & 2 & & \\
\hline \multirow[t]{2}{*}{ Forest } & \multirow{4}{*}{$\begin{array}{l}\text { Forest, } \\
\text { Bushes }\end{array}$} & 3 & Other, Forest & Above $2000 \mathrm{~m}$ & 3 & 1.5 & & 1 \\
\hline & & & $\begin{array}{l}\text { Other, Forest, Bush, } \\
\text { Residential, All Scree }\end{array}$ & Below $2000 \mathrm{~m}$ & 4 & 2 & & \\
\hline Sparse forest & & 3 & Other, Forest & Above $2000 \mathrm{~m}$ & 3 & 1.5 & & 1 \\
\hline Bush & & 3 & $\begin{array}{l}\text { Other, Forest, Bush, } \\
\text { Residential, All Scree }\end{array}$ & Below $2000 \mathrm{~m}$ & 4 & 2 & & 1 \\
\hline Scree & \multirow[t]{4}{*}{ Scree } & 4 & \multirow{4}{*}{$\begin{array}{l}\text { Other, Forest, Bush, } \\
\text { Residential, All Scree }\end{array}$} & & 4 & 2 & & 1 \\
\hline Scree in forest & & 4 & & & 4 & 2 & & 1 \\
\hline $\begin{array}{l}\text { Scree with } \\
\text { bushes }\end{array}$ & & 4 & & & 4 & 2 & & 1 \\
\hline $\begin{array}{l}\text { Scree in sparse } \\
\text { forest }\end{array}$ & & 4 & & & 4 & 2 & & 1 \\
\hline $\begin{array}{l}\text { Residential } \\
\text { Zone }\end{array}$ & \multirow[t]{2}{*}{$\begin{array}{l}\text { Residential, } \\
\text { Rock }\end{array}$} & 5 & $\begin{array}{l}\text { Other, Forest, Bush, } \\
\text { Residential, All Scree }\end{array}$ & & 4 & 2 & & 1 \\
\hline Rock & & 5 & Rock & & 5 & 2.5 & & 1 \\
\hline Swamp & Swamp & 10 & Swamp & & 10 & 5 & & 1 \\
\hline Lake & Water & 999 & Water & & 999 & 499.5 & Water & 999 \\
\hline $\begin{array}{l}\text { Resulting path } \\
\text { name }\end{array}$ & \multicolumn{2}{|c|}{ Current LC Path (CLP) } & \multicolumn{4}{|c|}{ Prehistoric LC Path (PLP)* } & \multicolumn{2}{|c|}{$\begin{array}{l}\text { Topographic LC } \\
\text { Path (TLP) }\end{array}$} \\
\hline
\end{tabular}

Table 2. Calibration site reclassification table. 
Across Space and Time. Papers from the 41st Conference on

Computer Applications and Quantitative Methods in Archaeology. Perth, 25-28 March 2013

\begin{tabular}{|c|c|c|}
\hline Original CORINE Landcover class & Reclassification categories & Prehistoric LC 2nd weight \\
\hline Pastures (above $2000 \mathrm{~m}$ ) & \multirow[t]{6}{*}{ Open space above $2000 \mathrm{~m}$} & 1.5 \\
\hline Coniferous forest (above $2000 \mathrm{~m}$ ) & & 1.5 \\
\hline Natural grasslands (above $2000 \mathrm{~m}$ ) & & 1.5 \\
\hline Moors and heathland (above $2000 \mathrm{~m}$ ) & & 1.5 \\
\hline Sparsely vegetated areas (above $2000 \mathrm{~m}$ ) & & 1.5 \\
\hline Glaciers and perpetual snow & & 1.5 \\
\hline Continuous urban fabric & \multirow[t]{26}{*}{ Everything below $2000 \mathrm{~m}$} & 2 \\
\hline Discontinuous urban fabric & & 2 \\
\hline Industrial or commercial units & & 2 \\
\hline Road and rail networks and associated land & & 2 \\
\hline Port areas & & 2 \\
\hline Airports & & 2 \\
\hline Mineral extraction sites & & 2 \\
\hline Construction sites & & 2 \\
\hline Green urban areas & & 2 \\
\hline Sport and leisure facilities & & 2 \\
\hline Non-irrigated arable land & & 2 \\
\hline Rice fields & & 2 \\
\hline Vineyards & & 2 \\
\hline Fruit trees and berry plantations & & 2 \\
\hline Pastures (below 2000 m) & & 2 \\
\hline Complex cultivation patterns & & 2 \\
\hline Land principally occupied by agriculture & & 2 \\
\hline Broad-leaved forest & & 2 \\
\hline Coniferous forest (below $2000 \mathrm{~m}$ ) & & 2 \\
\hline Mixed forest (below 2000 m) & & 2 \\
\hline Natural grasslands (below $2000 \mathrm{~m}$ ) & & 2 \\
\hline Moors and heathland (below $2000 \mathrm{~m}$ ) & & 2 \\
\hline Transitional woodland-shrub & & 2 \\
\hline Beaches, dunes, sands & & 2 \\
\hline Sparsely vegetated areas (below $2000 \mathrm{~m}$ ) & & 2 \\
\hline Burnt areas & & 2 \\
\hline Bare rocks & Rock & 2.5 \\
\hline Inland marshes & \multirow[t]{3}{*}{ Swamp, watercourse } & 5 \\
\hline Peat bogs & & 5 \\
\hline Water courses & & 5 \\
\hline Water bodies & Water body & 499.5 \\
\hline
\end{tabular}

Table 3. Analysis site reclassification table.

\subsection{Analysis sites}

Based on the results from the calibration site (section 3.1), the second weighting of the prehistoric landcover cost raster was used as the isotropic input to calculate the LCPs between the analysis sites. The inputs to the Path Distance tool varied slightly due to the lack of availability of data layers for this cross-border study. The landcover layer and DEM were downloaded from free sources online; the 


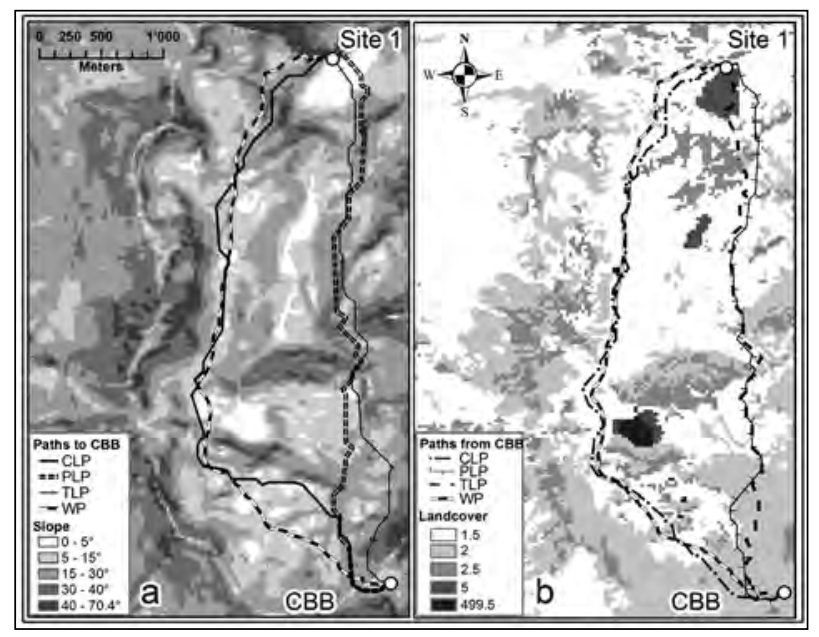

Figure 2. Results of LCPA for Site 1 at calibration site. Reproduced with permission of Swisstopo (BA14037).

2006 version of the Coordination of Information on the Environment (European Environment Agency 2012) $100 \mathrm{~m}$ resolution landcover layer (European Environment Agency 2012) and the research grade Advanced Spaceborne Thermal Emission Radiometer Global DEM(ASTER GDEMV2) (NASA J et Propulsion Laboratory 2004) of 30 m resolution, respectively. Each layer was re-sampled to $25 \mathrm{~m}$ for analysis. The landcover layer was reclassified into five categories and weighted based on the results from the calibration site: open space above $2,000 \mathrm{~m}$ (assuming a treeline of $2,000 \mathrm{~m}$ ), everything below 2,000 m (except rock, swamp, and water), rock, swamp/ watercourse, and water body (Table 3 ).

\section{Sion/Domodossola}

The first analysis site was located between Sion (46 $14^{\prime}$ N, 7o $22^{\prime}$ E, 500 m asl), situated in the canton of Valais in the southwest corner of

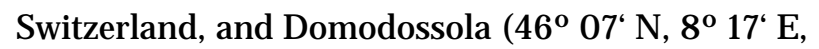
$272 \mathrm{~m}$ asl), located in the northwest of the province of Piedmont, Italy (Fig. 1a). The straightlinedistance between these two locations is approximately $74 \mathrm{~km}$.

\section{Sion/Aosta}

The second analysis site was between Sion and Aosta (45 $44^{\prime} \mathrm{N}$, 70 19` E, $583 \mathrm{~m}$ asl), which is the name of the town, but also the province, in the northwestern part of Italy (Fig. 1a). The straight-line distance between the two locations is approximately $55 \mathrm{~km}$.

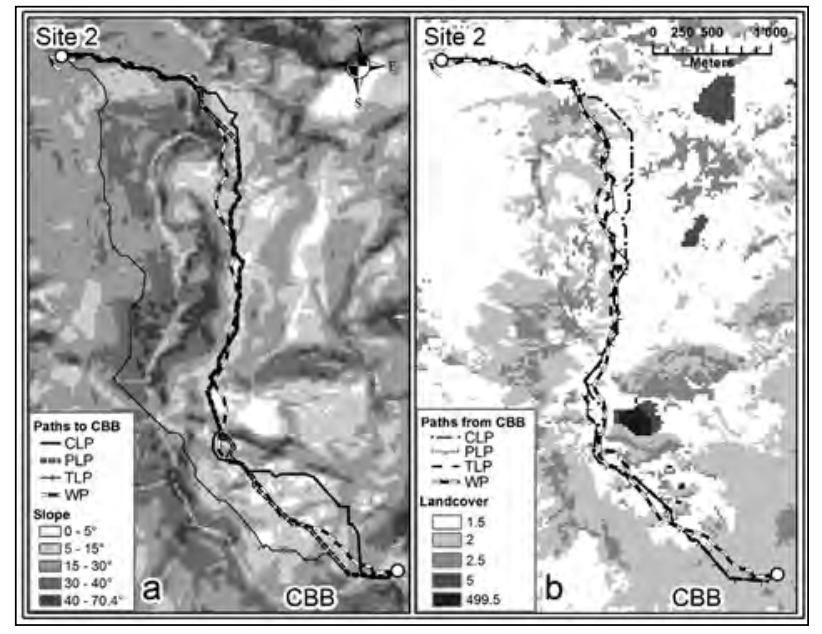

Figure 3. Results of LCPA for Site 2 at calibration site. Reproduced with permission of Swisstopo (BA14037).

\section{Archaeological prospection}

After the LCPs for the analysis sites were analysed and discussed with archaeologists and historians familiar with the area, various passes were selected for archaeological prospection. From the Sion/Domodossola LCP, archaeological prospection was undertaken at the Forca d'Aurona on September 20th, 2012. From the Sion/Aosta site, the region surrounding the $\mathrm{Col}$ de Cleuson and the Grand Désert glacier were investigated on J uly 30th, 2012 from the north side of the Col de Cleuson and September 11th, 2012 from the south side. A handheld Garmin GPS receiver was used to mark the location of finds.

\section{Results}

\subsection{Calibration site}

At each site, paths created using the topographic landcover raster resulted in the shortest walking times. At Site 1 (Fig. 2), the topographic landcover path (TLP) was the only path which went through the swamp located directly south of the starting location (Fig. 2b). At Site 2 (Fig. 3), all paths followed similar routes by travelling along the valley bottom, except the TLP stayed outside of the valley until the Pas de Lovégno, avoiding the multiple slope changes (Fig. 3a). The majority of the other paths followed the lowest landcover weightings (Fig. 3b) while the TLP was unaffected by those values. Consequently, in comparison to the times 
Across Space and Time. Papers from the 41st Conference on

Computer Applications and Quantitative Methods in Archaeology. Perth, 25-28 March 2013

\begin{tabular}{|c|c|c|c|c|c|c|c|c|c|}
\hline \multirow[b]{2}{*}{ Site } & \multirow[b]{2}{*}{ Lat } & \multirow[b]{2}{*}{ Lon } & \multirow[b]{2}{*}{ Alt(m) } & \multicolumn{2}{|c|}{ CLP } & \multicolumn{2}{|c|}{ PLP (1st) } & \multicolumn{2}{|c|}{ PLP (2nd) } \\
\hline & & & & Away & Return & Away & Return & Away & Return \\
\hline 1 & $46^{\circ} 12^{\prime} 12^{\prime \prime} \mathrm{N}$ & $7030 ‘ 40^{\prime \prime} \mathrm{E}$ & 2,184 & 03:06:40 & 02:13:06 & 06:27:00 & 04:38:36 & 03:13:30 & 02:19:18 \\
\hline 2 & $46^{\circ} 12^{\prime} 17^{\prime \prime} \mathrm{N}$ & 70 28'49" E & 2,326 & 03:12:21 & 02:26:56 & 06:39:29 & 05:14:49 & 03:19:44 & 02:37:24 \\
\hline 3 & $46^{\mathrm{o}} 11^{\prime} 52^{\prime \prime} \mathrm{N}$ & 70 28‘35" E & 2,126 & 03:27:33 & 02:33:32 & 07:08:15 & 05:17:09 & 03:34:08 & 02:38:34 \\
\hline 4 & $46^{\circ} 11^{\prime 2} 22^{\prime \prime} \mathrm{N}$ & 70 28“34" E & 2,190 & 03:12:35 & 02:21:46 & 06:29:32 & 04:48:59 & 03:14:46 & $02: 24: 30$ \\
\hline 5 & $46^{\circ} 11^{\prime \prime} 5^{\prime \prime} \mathrm{N}$ & 70 28‘14" E & 2,240 & 03:02:40 & 02:16:06 & 06:05:50 & 04:32:46 & 03:02:55 & 02:16:22 \\
\hline 6 & $46^{\text {o }} 10^{\prime 3} 31^{\prime \prime} \mathrm{N}$ & 70 28‘16" E & 2,171 & 02:52:11 & 02:12:46 & 05:56:32 & 04:17:20 & 02:58:23 & 02:08:40 \\
\hline
\end{tabular}

\begin{tabular}{|c|c|c|c|c|c|c|c|}
\hline \multirow[b]{2}{*}{ Site } & \multirow[b]{2}{*}{ Lat } & \multirow[b]{2}{*}{ Lon } & \multirow[b]{2}{*}{$\operatorname{Alt}(\mathrm{m})$} & \multicolumn{2}{|c|}{ TLP } & \multicolumn{2}{|c|}{ WP } \\
\hline & & & & Away & Return & Away & Return \\
\hline 1 & $46^{\circ} 12^{\prime} 12^{\prime \prime} \mathrm{N}$ & $7030^{\prime} 40^{\prime \prime} \mathrm{E}$ & 2,184 & 01:54:11 & 01:19:58 & 02:38:00 & 01:47:00 \\
\hline 2 & $46^{\circ} 12^{\prime} 17^{\prime \prime} \mathrm{N}$ & $77^{\circ} 28^{\prime} 49^{\prime \prime} \mathrm{E}$ & 2,326 & 02:02:16 & 01:36:11 & 02:41:00 & 01:54:00 \\
\hline 3 & $46^{\circ} 11^{\prime} 52^{\prime \prime} \mathrm{N}$ & 70 28“35" E & 2,126 & 02:08:56 & 01:34:38 & 02:48:00 & 01:53:00 \\
\hline 4 & $46^{\circ} 11^{\prime 2} 22^{\prime \prime} \mathrm{N}$ & 70 28'34" E & 2,190 & 01:56:53 & $01: 25: 48$ & 03:10:00 & 02:16:00 \\
\hline 5 & $46^{\circ} 11^{\prime \prime} 5^{\prime \prime} \mathrm{N}$ & 70 28’14" E & 2,240 & 01:49:42 & $01: 20: 50$ & 02:40:00 & 01:52:00 \\
\hline 6 & $46^{\circ} 10^{\prime 3} 31^{\prime \prime} \mathrm{N}$ & $7028^{\prime} 16^{\prime \prime} \mathrm{E}$ & 2,171 & 01:49:14 & 01:18:44 & 02:28:00 & 01:34:00 \\
\hline
\end{tabular}

Table 4. Calibration site calculated walking times.

calculated by the Wanderland Paths (WPs), the TLPs underestimated the walking times required.

The paths created using the current landcover cost raster (CLPs) took into account the reclassified landcover types both above and below the treeline. At the majority of sites, the CLPs followed a similar path as the WPs (Fig. 2 and Fig. 3). In general, CLP walking times were on average about 20 minutes more than the walking times calculated by the WPs (Table 4), therefore slightly overestimating the walking times required.

The paths created using the Prehistoric landcover cost raster were identical for both the first and second weighting schemes. Visually, the prehistoric landcover paths (PLPs) were similar to the majority of other calculated paths. In terms of time, the first weighting for the prehistoric landcover produced very long walking times, often three times longer than the rest. The paths created using the second weighting scheme better estimated the walking times compared to the WPs but still slightly overestimated walking times by about 30 minutes on average.

Based on these results, paths created with the prehistoric landcover cost raster using the second weighting scheme were most similar to both the hiking trails on the 1:25,000 topographic map and the walking times calculated by Suisse Rando.
Therefore, the prehistoric landcover cost raster with the second weighting scheme was used as the input to the Path Distance tool for the analysis site between Sion and Aosta.

\subsection{Analysis sites}

\section{Sion/ Domodossola}

From Sion to Domodossola (Fig. 4), the LCP travelled firstly through the Rhône valley in a northeast direction and continued through the valley on low-weighted landcover values (Fig. 4b) and flat terrain (Fig. 4c) for approximately $50 \mathrm{~km}$ before reaching the town of Brig. From Brig, the path ascended to the Forca d'Aurona (2,686 $\mathrm{m}$ asl) which is a currently unglaciated mountain pass south of the Punta d'Aurona (2,985 $\mathrm{m}$ asl). From the pass, the LCP descended into Italy in a southeast direction toward Varzo and then continued following the Val Divedro until reaching Domodossola in 48:54:39. The return path from Domodossola to Sion was visually similar but was calculated to take 48:34:00 in total.

\section{Sion/ Aosta}

The LCPs from Sion to Aosta and Aosta to Sion also followed similar routes in both directions. From Sion, the LCP moved in a southerly direction through the Val de Nendaz, continuing on flat 


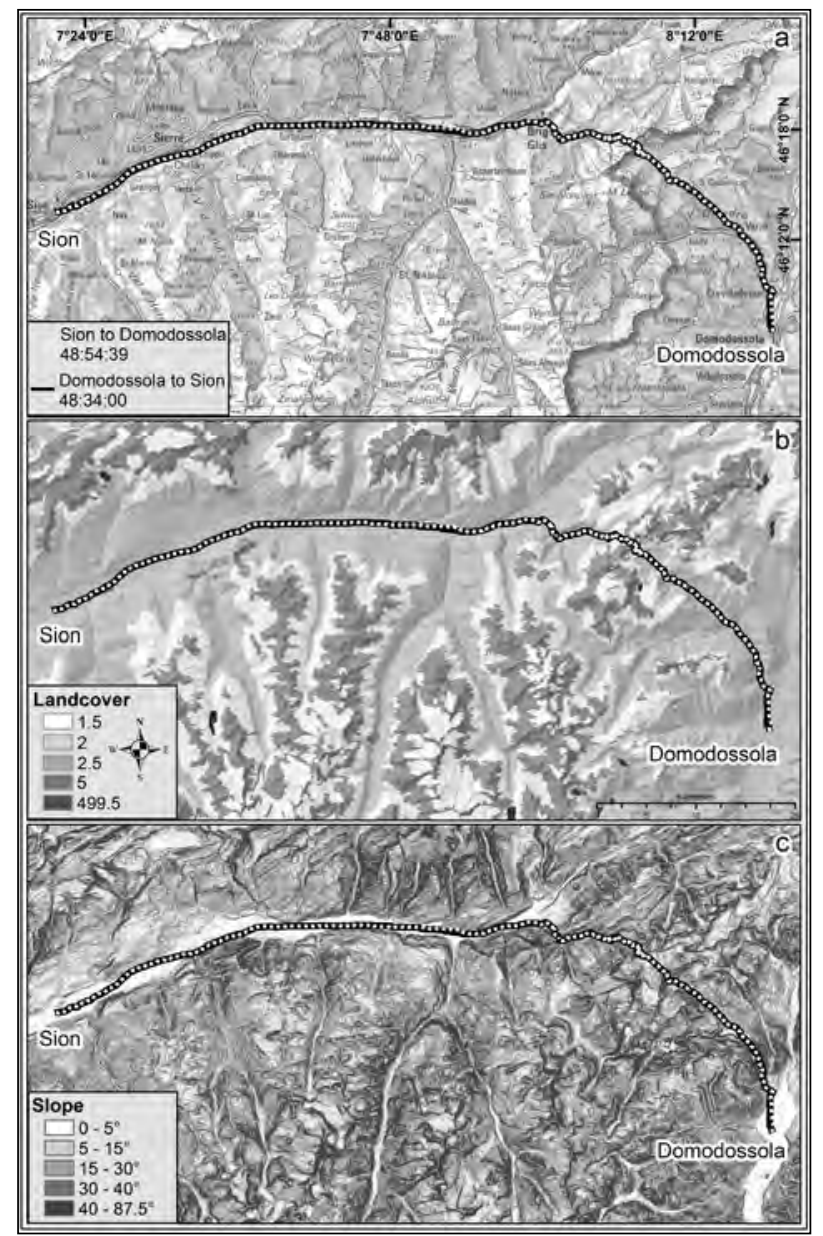

Figure 4. Results of LCPA for analysis site between Sion and Domodossola. Reproduced with permission of Swisstopo (BA14037).

terrain below 2,000 $\mathrm{m}$ asl, depicted by thelandcover value change, until it made an ascent to the west of the Rosablanche mountain (3,336 m asl) (Fig. 5a). To cross this mountain pass, the LCP passed over the Grand Désert glacier and through the Col de Cleuson (3,018 $\mathrm{m}$ asl) (Figs. 5 and 6). After passing the col, the path descended into the Val de Bagnes and continued on a southeast route perpendicular to the slope, across an area of low landcover values, past the Lac de Mauvoisin (Fig. 5b, c). After the lake, the path remained along the flat slopes and lowlyweighted landcover values until turning southwest near the Grand Charmotane and began the ascent to the Fenêtre de Durand (2,805 m asl) along the northwest side of the Glacier de Fenêtre. After crossing the Fenêtre de Durand mountain pass, the LCP descended into Italy's Valle d'Aosta in a southwest direction. The path moved southwest

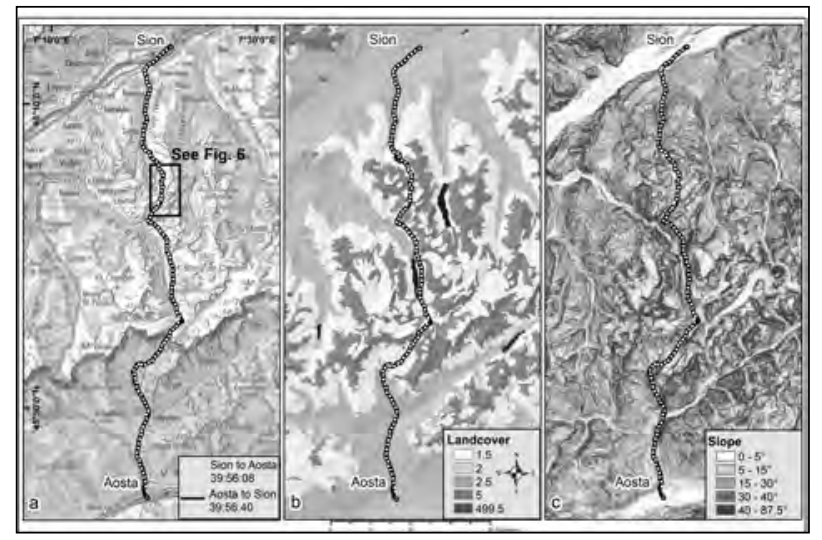

Figure 5. Results of LCPA for analysis site between Sion and Aosta. Reproduced with permission of Swisstopo (BA14037).

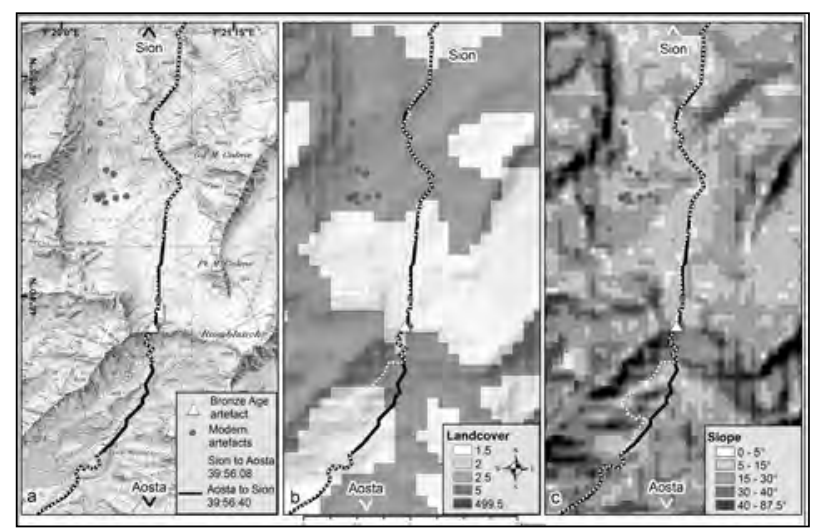

Figure 6. Zoomed in section of the results of LCPA between Sion and Aosta at Col de Cleuson. Reproduced with permission of Swisstopo (BA14037).

around an area of steep slopes before heading directly south, continuing on the low slopes and low-valued landcover regions, until reaching Aosta. The journey in the southern direction took a total of 39:56:08. The path from Aosta to Sion differed only significantly in a few places, namely just south of the Col de Cleuson (Fig. 5) and near the Grand Charmotane. The path from Aosta to Sion took a total of 39:56:40.

\section{Archaeological prospection}

As a result of the Sion/Domodossola LCPA, the mountain pass of Forca d'Aurona (Fig. 4) which separates Switzerland and Italy, was archaeologically investigated. The recent construction of a cabin on this currently non-glaciated pass made the retrieval of archaeological remains impossible as the original 
landcover had been destroyed. Only modern artefacts were found at the remaining ice patches.

The LCP from Sion/Aosta led to two days of prospection at the Col de Cleuson (Fig. 6). A total of 16 items, all pieces of wood, were discovered at the margin of the Grand Désert glacier, on the pass of the Col de Cleuson, or directly on the glacier (Fig. 6). Five of the six dated items were modern ( 180 - $125 \mathrm{BP})$, but one piece of wood, which was found directly on the Col de Cleuson (3,018 m asl), partially concealed under rocks, was dated to $2,795 \pm 35$ BP (Poz-52269). This piece of wood was approximately $40 \mathrm{~cm}$ long and $3 \mathrm{~cm}$ in diameter. The presence of this artefact attests to the use of this pass in prehistoric times.

\section{Discussion}

In this study we found a Bronze Age piece of wood on top of a previously unstudied mountain pass by using least cost path analyses in conjunction with Tobler's hiking function and by testing the effects of differing landcover weights on paths at a calibration site. In doing so, certain assumptions and estimations had to be made in order to gain a better general understanding of movement through mountainous terrain. Tobler's hiking function, which was calibrated from empirical data of soldiers walking through varying topography, assumes that topography affects the walking speeds of people travelling through it (Gorenflo and Gale 1990; Imhof 1968; Tobler 1993). Although it has been criticised for not being based on scientific experiments (Herzog 2012), it is still the most used algorithm for LCPA in archaeological studies (Bell and Lock 2000; Gorenflo and Gale 1990; Verhagen and Jeneson 2012; Whitley and Hicks 2003). The integration of this algorithm into GIS and LCPA is useful for the estimation of time required and potential paths taken when traversing undulating terrains. Another algorithm which calculates walking times is the r.walk function from GRASS (GRASS Development Team 2013; Neteler and Mitasova 2008). Research using this function has also shown interesting results (Madry and Rakos 1996; Ullah and Bergin 2012). However, a greater body of literature supports the use of Tobler's hiking function, therefore it was deemed most suitable for this study (e.g. Bell and Lock 2000; Gorenflo and Gale 1990; Verhagen and Jeneson 2012; Whitley and Hicks 2003). Furthermore, instead of using time as the measure, it has been stated that perhaps energy is a better indicator of human travel as time can be perceived differently in different cultures and time-periods (Herzog and Posluschny 2011; Kondo and Seino 2011; Llobera and Sluckin 2007; van Leusen 2002;). Some researchers have developed and implemented energy based algorithms into their calculations (Kondo and Seino 2011; van Leusen 2002), which would be interesting to adapt and implement in this study area.

When conducting any type of prehistoric analysis in GIS, it is important to take into account the paleoenvironment, or past environmental characteristics (Wheatley and Gillings 2002). In this study, a prehistoric landcover raster was created by experimenting at the calibration site. The landcover reclassification schemes used at the calibration site were based on discussions between archaeologists, historians, and geographers to obtain a consensus about friction levels for each type of terrain. The $2,000 \mathrm{~m}$ asl treeline level was an estimation of the upper limit of the forest influenced by the first important prehistoric human impact (Colombaroli et al. 2010). Although this method was relatively crude, it was important to acknowledge that landcover is constantly evolving due to natural and anthropogenic reasons and this should be taken into account when conducting GIS analysis (Wheatley and Gillings 2000).

The analysis of the results from the calibration site indicated that the walking times and routes taken by the LCP varied depending on the inputs to the LCPA model. For example, the paths calculated using the topographic landcover cost raster were the shortest in terms of time, because they were influenced only by the slope of the terrain and did not take into effect the landcover weights. The use of the topographic landcover cost raster allowed visualisation of the effects of both the isotropic and anisotropic inputs into the model. The majority of past archaeological studies using LCPA have relied solely on the slope of the terrain, thus anisotropic friction, in LCPA models (Bell and Lock 2000; Egeland, Nicholson and Gasparian 2010; Gaffney and Stančič 1991; Gorenflo and Gale 1990; Herzog and Posluschny 2011; Kondo and Seino 2011; Tripcevich 2008; Verhagen and Jeneson 2012), therefore neglected the isotropic aspect. The incorporation of 
both isotropic and anisotropic frictions integrates both the magnitude and force of frictions across the cost surface (Bell and Lock 2000) and thus results in a more representative model of the terrain (van Leusen 2002). Similar to Howey (2007), in this study land cover was integrated as the isotropic friction along with slope as the anisotropic friction. However, it was not assumed that landcover and slope of the terrain were the only factors affecting the travel patterns of prehistoric people. In fact, it has been suggested that numerous social and cultural factors affected their travel decisions (Llobera 2000; Lock and Pouncett 2010; Murrieta-Flores 2010; 2012). Times calculated by the first weighting scheme of the prehistoric landcover cost raster were highly exaggerated, and took approximately three times longer than the paths calculated by the WPs. However, visually they seemed to be most consistent with the trails on the current topographic map. When each weight was divided in half to create the second prehistoric weighting scheme, the resulting paths were visually the same but had more accurate walking times compared to the WPs calculated by Suisse Rando. Thus, the prehistoric landcover with the second weighting scheme was adopted for the analysis between Sion and Aosta. The comparison of the LCP with present day walking trails was based on the assumption that the walking trails that exist today are based upon the same principle that people desire to take the easiest route possible when walking over mountainous terrain. The model could be further strengthened through groundtruth validation of walking times at the calibration site and it should be reiterated that the concept of time was not necessarily the same in the past as it is today.

The LCPA at the analysis sites narrowed down vast, mountainous study regions to aid glacial archaeological prospection and proved to be beneficial for discovering a previously unknown archaeological site with the detection of a prehistoric artefact at the Sion/Aosta site. Because of high elevations and low-accessibility in mountainous regions, it was physically impossible to visit every site of interest within the Pennine Alps. Thus, LCPA enabled a focused study area to be more thoroughly investigated with field reconnisance and site visitation. With the aid of archaeologists and historians, the Forca d'Aurona and Col de Cleuson were chosen for further investigation based on the outcomes of the LCPA. The Forca d'Aurona was once a glaciated pass, but with the current climate situation, there was no ice or snow on the pass in the late summer of 2012 when archaeological prospection was conducted. From a glacial archaeological perspective, sites free of ice and snow yield fewer archaeological remains because the majority have decomposed or been destroyed by anthropogenic causes, as was the case at this site. Conversely, the region surrounding the Col de Cleuson is currently glaciated and had not been previously studied, archaeologically nor historically. Thus a new location of interest was discovered. The 16 pieces of wood retrieved from the Col de Cleuson and near the margin of the Grand Désert glacier attest to the fact that people have used this pass for thousands of years and could be of future interest to archaeologists. It should be noted that any piece of wood found at such high elevation (almost 1,000 $\mathrm{m}$ above the current treeline) was not a natural phenomenon, but had to be transported there by someone or something. According to Verhagen and J eneson (2012), despite being a popular research technique LCPA does not usually result in predictive success. The Forca d'Aurona showed thelimit to this method, and perhaps for the future, more emphasis should be placed on passes which are still glaciated or surrounded by snow and ice. On the other hand, the results at the Col de Cleuson showed that in a region rich in cultural occurrences and terrain which often determines travel routes, that this method was effective as a decision support tool for the purposes of finding new sites for glacial archaeological investigation.

\section{Acknowledgements}

This research has been supported by the Swiss National Science Foundation (grant CR2112 130279), by the Service des bâtiments, monuments et archéologie, (Canton du Valais, Switzerland) and by the History Museum of Valais (Switzerland). Thanks to Philippe Curdy, curator at the History Museum of Valais, for all of his inputs and assistance with the model and fieldwork and also thanks to the project group for their inputs, including historians Muriel Eschmann-Richon and Pierre Dubuis, and geomorphologist Reynald Delaloye. Also, thank you to the three anonymous reviewers who helped strengthen this paper. 
Across Space and Time. Papers from the 41st Conference on

Computer Applications and Quantitative Methods in Archaeology. Perth, 25-28 March 2013

\section{Bibliography}

Ammann, H.-R. 1992. “Quelques aspects de l'importation du vin valdôtain en Valais au XVIe siècle.” In Vigne e vini nel Piemonte moderno, edited by R. Comba, 461-480. Alba-Cuneo: L'Arcière.

Anderson, D. G., and J. C. Gillam. 2000. "Paleoindian Colonization of the Americas: Implications from an Examination of Physiography, Demography, and Artifact Distribution." American Antiquity 65:43- 66.

Andrews, T. D., and G. MacKay. 2012. "The Archaeology and Paleoecology of Alpine Ice Patches: A Global Perspective." Arctic 65:iii- vi.

Andrews, T. D., G. MacKay, L. Andrew, W. Stephenson, A. Barker, C. Alix, and the Shútagot'ine Elders of Tulita. 2012. "Alpine Ice Patches and Shúhtagot'ine Land Use in the Mackenzie and Selwyn Mountains, Northwest Territories, Canada." Arctic 65:22- 42.

Bell, T., and G. R. Lock. 2000. "Topographic and Cultural Influences on Walking the Ridgeway in Later Prehistoric Times." In Beyond the Map: Archaeology and Spatial Technologies, edited by G. R. Lock, 85- 100. Oxford: IOS Press.

Bell, T., A. Wilson, and A. Wickham. 2002. "Tracking the Samnites: Landscape and Communications Routes in the Sangro Valley, Italy." American J ournal of Archaeology 106:169- 186.

Callanan, M. 2012. "Central Norwegian Snow Patch Archaeology: Patterns Past and Present." Arctic 65:178188.

Colombaroli, D., P. D. Henne, P. Kaltenrieder, E. Gobet, and W. Tinner. 2010."Species Responses to Fire, Climate and Human Impact at Tree Line in the Alps as Evidenced by Palaeo-environmental Records and a Dynamic Simulation Model."J ournal of Ecology 98:1346- 1357.

Coolidge, W. A. B. 1912. Alpine Studies. London: Longmans, Green and co.

Crotti, P., G. Pignat, and A.-M. Rachoud-Schneider, eds. 2002. Premiers Hommes Dans Les Alpes de 50000 à 5 000 Avant Jésus-Christ. Lausanne: Éditions Payot/Sion, Musées cantonaux du Valais.
Curdy, P. 2007. "Prehistoric Settlement in Middle and High Altitudes in the Upper Rhone Valley (Valais-Vaud, Switzerland): A Summary of Twenty Years of Research." Preistoria Alpina 42:99- 108.

Curdy, P, C. Leuzinger-Piccand, and U. Leuzinger. 2003. "Zermatt Alp Hermettji et les cols secondaires du Valais." In ConstellaSion. Hommage à Alain Gallay, edited by M. Besse, L.-I. Stahl Gretsch, and P. Curdy, 73- 88. Lausanne: Cahiers d'ardhéologie romande.

Di Maio, P. 2007. Prime Impronte Dell'uomo Nella Regione Sempione-Arbola. Torino: Celid.

Dixon, E. J., W. F. Manley, and C. M. Lee. 2005. "The Emerging Archaeology of Glaciers and Ice Patches: Examples from Alaska's Wrangell-St. Elias National Park and Preserve." American Antiquity 70:129- 143.

Eastman, J . R. 2003. IDRISI Kilimanjaro: Guide to GIS and Image Processing. Worcester: Clark Labs, Clark University.

Egeland, C. P., C. M. Nicholson, and B. Gasparian. 2010. “Using GIS and Ecological Variables to Identify High Potential Areas for Paleoanthropological Survey: An Example from Northern Armenia." J ournal of Ecological Anthropology 14:89- 98.

ESRI. 2013. "Environmental System Research Institute." ArcGIS Online. Accessed May 16. http://www.arcgis. $\mathrm{com} /$ home/ .

European Environment Agency. 2012. "Corine Land Cover 2006." Last modified 29 November. http://www. eea.europa.eu/ data-and-maps/ data/ corine-land-cover2006-clc2006-100-m-version-12-2009.

Farbregd, O. 1972. "Pilefunn fra Oppdalsfjella (arrow finds from the Oppdal mountains)." Det Kgl. Norske Videnskabers Selskab, Muskeet, Miscellanea 5:105- 117.

Farnell, R., P. G. Hare, E. Blake, V. Bowyer, C. Schweger, S. Greer, and R. Gotthardt. 2004. "Multidisciplinary Investigations of Alpine Ice Patches in Southwest Yukon, Canada: Paleoenvironmental and Paleobiological Investigations." Arctic 57:247- 259.

Federal Office of Topography Swisstopo. 2014. "VECTOR25." Accessed January 15. http://www. swisstopo.admin.ch/internet/ swisstopo/ en/ home/ 
products/ landscape/ vector25.html.

Gaffney, V. L., and Z. Stančič. 1991. Gis Approaches to Regional Analysis: A Case Study of the Island of Hvar. Ljubljana: Znanstveni inštitut.

Gardaz, J .-M. 1998. Permafrost Prospecting, Periglacial and Rock Glacier Hydrology in Mountain Areas. Case Studies in the Valais Alps, Switzerland. Fribourg: University of Fribourg.

Goossens, R., A. De Wulf, J. Bourgeois, W. Gheyle, B.Van Bever, M. Vanommeslaeghe, D. Dossche, and D. Devriendt. 2007. "The Frozen Tombs of the Altai Mountains Inventarisation and Conservation." In AntiCIPAting theFuture of the Cultural Past. Proceedings of the 21st International CIPA Symposium, October 1-6, 2007, Athens, Greece, edited by A. Georgopoulos. Accessed March 15, 2014. http:// cipa.icomos.org/index. php?id=63.

Gorenflo, L. J., and N. Gale. 1990. "Mapping Regional Settlement in Information Space." Journal of Anthropological Archaeology 9:240- 274.

GRASS Development Team. 2013. "GRASS GIS Reference Manual." Accessed October 2. http://grass.osgeo.org/ grass70/manuals/index.html.

Hafner, A. 2012. "Archaeological Discoveries on Schnidejoch and at Other Ice Sites in the European Alps." Arctic 65:189- 202.

Hare, P. G., S. Greer, R. Gotthardt, R. Farnell, V.Bowyer, C. Schweger, and D. Strand. 2004. "Ethnographic and Archaeological Investigations of Alpine Ice Patches in Southwest Yukon, Canada." Arctic 57:260- 272.

Hare, P. G, C. D. Thomas, T. N. Topper, and R. M. Gotthardt. 2012. "The Archaeology of Yukon Ice Patches: New Artifacts, Observations, and Insights." Arctic 65:118135.

Harriss, B. 1970. "The Theodulpass: a History." Alpine J ournal 75:87-94.

Harriss, B. 1971. "The Monte Moro Pass and the Col D’Herens." Alpine J ournal 76:127- 132.

Herzog, I. 2012. "The Potential and Limits of Optimal Path Analysis." In Computational Approaches to
Archaeological Spaces, edited by A. Bevan and M. Lake, 1-26. London: Left Coast Press.

Herzog, I., and A. Posluschny. 2011. "Tilt - Slopedependent Least Cost Path Calculations Revisited." In On the Road to Reconstructing the Past, Computer Applications and Quantitative Methods in Archaeology (CAA). Proceedings of the 36th International Conference, Budapest, April 2008, edited by J. Erzsébet, F. Redő, and V. Szeverényi, 236- 242. Budapest: Archaeolingua

Howey, M. C. L. 2007. "Using Multi-criteria Cost Surface Analysis to Explore Past Regional Landscapes: a Case Study of Ritual Activity and Social Interaction in Michigan, AD 1200-1600." J ournal of Archaeological Science 34:1830- 1846.

Imhof, E. 1968. Gelände und Karte. Erlenbach-Zürich: Eugen Rentsch Verlag.

Janko, M., R. W. Stark, and A. Zink. 2012. "Preservation of 5300 Year Old Red Blood Cells in the Iceman." J ournal of the Royal Society Interface 9:2581- 2590.

Keller, A., A. Graefen, M. Ball, M. Matzas, V. Boisguerin, F. Maixner, and P. Leidinger, Christina Backes, R. Khairat, M. Forster, B. Stade, A. Franke, J. Mayer, J. Spangler, S. McLaughlin, M. Shah, C. Lee, T. Harkins, A. Sartori, A. Moreno-Estrada, B. Henn, M. Sikora, O. Semino, J. Chiaroni, S. Rootsi, N. M. Myres, V. M. Cabrera, P. A. Underhill, C. D. Bustamante, E. Egarter Vigl, M. Samadelli, G. Cipollini, J. Haas, H. Katus, B. D. O'Connor, M. R.J. Carlson, B. Meder, N. Blin, E. Meese, C. M. Pusch, and A. Zink. 2012. "New Insights into the Tyrolean Iceman's Origin and Phenotype as Inferred by Whole-genome Sequencing." Nature Communications 3:698- 706 .

Kondo, Y., and Y. Seino. 2011. "GPS-aided Walking Experiments and Data-driven Travel Cost Modeling on the Historical Road of Nakasendō-Kisoji (Central Highland Japan)." In Making History Interactive, Computer Applications and Quantitative Methods in Archaeology. Proceedings of the 37th International Conference, Williamsburg, Virginia, United States of America, March 2009, edited by B. Frischer, J . W. Crawford, and D. Koller, 158- 165. Oxford: Archaeopress.

Krajick, K. 2002. "Melting Glaciers Release Ancient Relics." Science 296:454- 456. 
Across Space and Time. Papers from the 41st Conference on

Computer Applications and Quantitative Methods in Archaeology. Perth, 25-28 March 2013

Krist, F. J., and D. G. Brown. 1994. "GIS Modeling of Paleo-indian Period Caribou Migrations and Viewsheds in Northeastern Lower Michigan." Photogrammetric Engineering and Remote Sensing 60:1129- 1138.

Lee, C. M. 2012. "Withering Snow and Ice in the Midlatitudes: A New Archaeological and Paleobiological Record for the Rocky Mountain Region." Arctic 65:165177.

Llobera, M. P. 2000. “Understanding Movement: A Pilot Model Towards the Sociology of Movement." In Beyond the Map: Archaeology and Spatial Technologies, edited by G. R. Lock, 65- 84. Oxford: IOS Press.

Llobera, M., and T. J. Sluckin. 2007. "Zigzagging: Theoretical Insights on Climbing Strategies." J ournal of Theoretical Biology 249:206- 217.

Lock, G., and J. Pouncett. 2010. "Walking the Ridgeway Revisited: The Methodological and Theoretical Implications of Scale Dependency for the Derivation of Slope and Calculation of Least-cost Pathways." In Making History Interactive, Computer Applications and Quantitative Methods in Archaeology. Proceedings of the 37th International Conference, Williamsburg, Virginia, United States of America, March 2009, edited by B. Frischer, J . W. Crawford, and D. Koller, 191- 202. Oxford: Archaeopress.

Lugon, R., and R. Delaloye. 2001. "Modelling Alpine Permafrost Distribution, Val de Réchy, Valais Alps (Switzerland)." Norsk Geografisk Tidsskrift - Norwegian J ournal of Geography 55:224- 229.

Madry, S., and L. Rakos. 1996. "Line-of-sight and Costsurface Techniques for Regional Research in the Arroux RiverValley." In New Methods, Old Problems. Geographic Information Systems in Modern Archaeological Research, edited by H. Maschner, 104- 126. Carbondale: Southern Illinois University.

Molyneaux, K., and D. S. Reay. 2010. "Frozen Archaeology Meltdown.” Nature Geoscience 4:2- 2.

Murrieta-Flores, P. A. 2010. "Travelling in a Prehistoric Landscape: Exploring the Influences That Shaped Human Movement." In Making History Interactive, Computer Applications and Quantitative Methods in Archaeology. Proceedings of the 37th International Conference, Williamsburg, Virginia, United States of America, March
2009, edited by B. Frischer, J . W. Crawford, and D. Koller, 249- 267. Oxford: Archaeopress.

Murrieta-Flores, P. A. 2012. “Understanding Human Movement through Spatial Technologies. The Role of Natural Areas of Transit in the Late Prehistory of Southwestern Iberia." Trabajos de Prehistoria 69:103- 122.

NASA J et Propulsion Laboratory. 2004. "ASTER Global Digital Elevation Map Announcement.” Last modified September 7. http:/ / asterweb.jpl.nasa.gov/ gdem.asp.

Neteler, M., and H. Mitasova. 2008. Open Source GIS: A Grass GIS Approach. London: Springer.

Prinoth-Fornwagner, R., and T. R. Niklaus. 1994. "The Man in the Ice: Results from Radiocarbon Dating." Nuclear Instruments and Methods in Physics Research Section B: Beam Interactions with Materials and Atoms 92:282- 290 .

Seidler, H., W. Bernhard, M. Teschler-Nicola, W. Platzer, D. zur Nedden, R. Henn, A. Oberhauser, and T. Sjøvold. 1992. "Some Anthropological Aspects of the Prehistoric Tyrolean Ice Man." Science 258:455- 457.

Shouse, B. 2001. "For Ice Man, the Band Plays On." Science 293:2373- 2373.

Switzerland Mobility. 2013a. "SwitzerlandMobility Hiking in Switzerland." Accessed May 31. http://www. wanderland.ch.

Switzerland Mobility. 2013b. "Suisse Rando." Accessed May 31. http:// www.wandern.ch.

Tenthorey, G. 1993. Paysage géomorphologique du Haut-Val de Réchy (Valais, Suisse) et hydrologie liée aux glaciers rocheux. Fribourg: Université de Fribourg.

Tobler, W. 1993. "Non-isotropic geographical modelling”. In Three presentations on geographical analysis and modeling 1) non-isotropic modeling 2) speculations on the geometry of geography 3) global spatial analysis. National Center for Geographic Information and Analysis Technical report 93-1. Accessed March 15, 2014. http:// www.ncgia. ucsb.edu/ Publications/Tech_Reports/ 93/93-1.PDF.

Tripcevich, N. 2008. "Estimating Llama Caravan Travel Speeds." Poster presented at the UC Santa Barbara Department of Geography, California, April 2008. 
Accessed May 14, 2013. http://works.bepress.com/ tripcevich/23.

Tripcevich, N. 2009. “Workshop 2009, No. 1 - Viewshed and Cost Distance." Accessed May 13, 2013. http:// mapaspects.org/ courses/gis-and-anthropology/ workshop-2009-viewshed-and-cost-distance.

Ullah, I. I., and S. M. Bergin. 2012. "Modeling the Consequences of Village Site Location." In Least Cost Analysis of Social Landscapes: Archaeological Case Studies, edited by D. A. White and S. L. Surface-Evans, 155- 173. Salt Lake City: University of Utah Press.

van Leusen, M. 1999. “Viewshed and Cost Surface Analysis Using GIS (Cartographic Modelling in a Cell-Based GIS II)." In New Techniques for Old Times. CAA98. Computer Applications and Quantitative Methods in Archaeology. Proceedings of the26th Conference, edited byJ .A. Barceló, I. Briz, and A. Vila, 215-224. Oxford: Archaeopress.

van Leusen, M. 2002. "Pattern to Process: Methodological Investigations Into the Formation and Interpretation of Spatial Patterns in Archaeological Landscapes." $\mathrm{PhD}$ diss., University of Groningen.

VanderHoek, R., R. M. Tedor, and J . D. McMahan. 2007. "Cultural Materials Recovered From Ice Patches In The Denali Highway Region, Central Alaska, 2003-2005." Alaska J ournal of Anthropology 5:185- 200.

Verhagen, P., and K. Jeneson. 2012. "A Roman Puzzle. Trying to Find the Via Belgica with GIS." In Thinking Beyond the Tool. Archaeological Computing and the Interpretive Process, edited by A. Chrysanthi, P. Murrieta-Flores, and C. Papadopoulus, 123-130. Oxford: Archaeopress.

Walsh, K., S. Richer, and J.-L. de Beaulieu. 2006. "Attitudes to Altitude: Changing Meanings and Perceptions Within a 'marginal' Alpine Landscape - the Integration of Palaeoecological and Archaeological Data in a High-altitude Landscape in the French Alps." World Archaeology 38:436-454.

Wheatley, D., and M. Gillings. 2000. 'Vision, Perception and GIS: Developing Enriched Approaches to the Study of Archaeological Visibility." In Beyond the Map: Archaeology and Spatial Technologies, edited by G. R. Lock, 1-26. Oxford: IOS Press.
Wheatley, D., and M. Gillings. 2002. Spatial Technology and Archaeology: The Archaeological Applications of GIS. London: Taylor \& Francis Group.

Whitley, T. G., and L. M. Hicks. 2003. "A Geographic Information Systems approach to understanding potential prehistoric and historic travel corridors." Southeastern Archaeology 22:77-91. 


\title{
Spatial Statistic Analysis of Dating Using Pottery: an Aid to the Characterization of Cultural Areas in West Central France
}

\author{
Lise Bellanger \\ Université de Nantes, France \\ Philippe Husi \\ Université de Tours, France \\ Yassine Laghzali \\ IFREMER, France
}

\begin{abstract}
:
Obtaining accurate and precise estimated dates is an important objective in archaeology. But characterising cultural areas and making socio-economic interpretations of archaeological contexts is equally important. In this paper, we briefly present two original statistical models developed to estimate context dates using pottery. Then we compare, for each context, their two possible estimated dates, using tools for spatial point patterns applied to the difference, and provide answers to archaeological issues in the socio-economic domain. The proposed approach represents an innovative way to study and better understand economic and even cultural areas. It is applied to the analysis of archaeological contexts in West Central France, based on a large collection of medieval pottery finds.
\end{abstract}

\section{Keywords:}

Medieval Period, Pottery Analysis, Chronology, Archaeological Contexts, Regression Model, Spatial Point Pattern Analysis

\section{Introduction}

Analysing chronological patterns is one of the major issues in archaeology. How can the date of a specific context be estimated? What does this date represent? Dating an archaeological context is always delicate. It is important to keep in mind what is to be dated, either a one-off event occurring at a specific moment, or a process built up over time. Numerous statistical methodological approaches have been developed and implemented to produce estimated dates for each studied archaeological context. While obtaining precise estimated dates of archaeological contexts is an important objective, characterising socio-economic or cultural spaces is another one. Since the middle of the 80s, attention has been paid to the development of methods for the analysis of archaeological site distributions patterns (Butzer 1982; Evans, Knappett and Rivers 2012; Orton 1982; Robertson et al. 2006; Rodier et al. 2011). Our main objective is to propose a novel

Corresponding author: lise.bellanger@univ-nantes.fr statistical approach to clarify and interpret such cultural areas using one of the most commonly used archaeological artefact: pottery.

This paper is organised as follows. In section 2 , we present the archaeological objectives and the study area. In section 3, we describe the proposed methodology, based on a combination of two different approaches: statistical models developed to date contexts using pottery (Bellanger and Husi 2012) and spatial statistical analysis. We show how the comparison of results of two dating models could be used to analyse the archaeological material of several geographically separated sites and also to provide answers to archaeological issues in socio-economic domain. In section 4 , our method is applied to the analysis of contexts in the centre-west of France, based on a large collection of medieval pottery finds. We form the archaeological assumption that the further the archaeological contexts are from the reference point (Tours), the more the estimated dates by the two models diverge, and we check it statistically. 
Through this study, we aim to illustrate the simplicity and effectiveness of our approach to highlight specific economic and even cultural pottery areas in West Central France.

\section{Archaeological Objectives and Study Area}

\subsection{Archaeological objectives}

In this work, we seek to identify or to clarify socio-economic or cultural areas using pottery. Pottery is one of the major archaeological sources for understanding long-term changes of such areas and has many advantages that make it an artefact of choice for attempting to answer the raised issues. The main advantage of pottery comes from its excellent preservation in the ground, which results in large amounts of pottery being unearthed within archaeological contexts. In addition, ceramic has often a rapid typological evolution, a characteristic that makes it significantly effective for dating contexts, even in situations where pottery cannot be intrinsically dated. Thereby, in a previous work, we developed two models for dating stratigraphic contexts based on pottery (Bellanger and Husi 2012). The dates obtained through the use of these two models do not always coincide, even if the models are generally good. We can therefore make the assumption that the different chronological horizons are related - to a certain extent - to the occurrence of areas with dissimilar pottery trade relations. Our current study on the characterisation of areas with pottery stands therefore in direct continuity with our previous work, as discussed in more detail in Section 3.

\subsection{Archaeological study area and corpus}

To achieve the characterisation goal, it is necessary first of all to choose an archaeological study area belonging to an homogeneous material culture area. We use here the area of West Central France (with the city of Tours as reference point), which has been well studied - and continues to be through various research projects (Husi 2013).

Why Tours? Because this city has been for 40 years the subject of numerous excavations (Galinié 2007) and pottery has been (and still is!) systematically studied. Indeed, it has one of the most

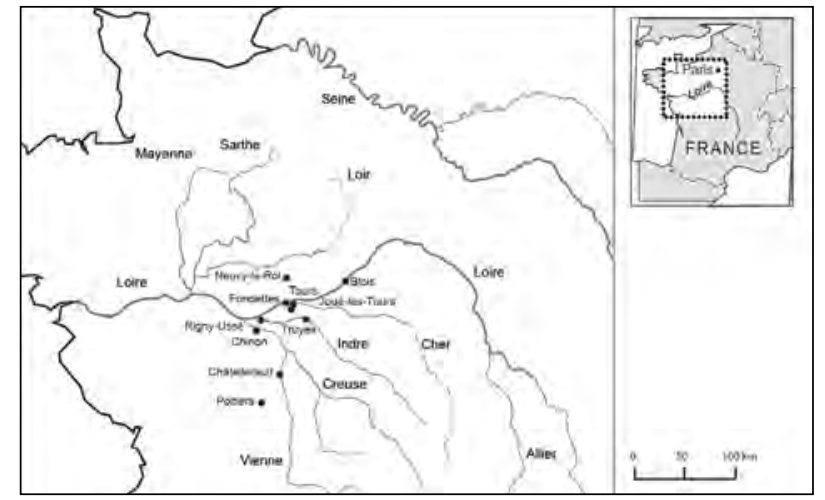

Figure 1. Map of the 10 places selected for study in West Central France.

important pottery data corpus studied and validated in France. The data is stored in a database system named Arsol (Archives du Sol: Soil Archives) which has been used by the "Archéologie et Territoires" Laboratory (CNRS - Tours University) since 1990 for processing archaeological data. The BaDoC module, a pottery database in ArSol, can process the data according to different quantitative techniques regardless of the diversity of the typological assemblages and the scale of archaeological contexts (Husi and Rodier 2011).

In the present study, the general corpus is composed of 147 stratigraphic sets located at 25 archaeological sites corresponding to 10 different places (towns and rural sites) presented on a map at Fig. 1. For each studied stratigraphic set, values for 185 fabrics (pottery products) are measured. In this way, we define the particular pottery profile of each set. The pottery corpus is composed of 8000 Minimum Vessel Count (MVC).

Datingmodels are generated by a largenumber of pottery assemblages coming from excavations of the city of Tours and are then applied to other sites to obtained estimated dates.

The spatial analysis, further developed in this paper, is based on the idea that the further archaeological contexts (dated from the same tradition of pottery) are from the reference point (Tours), the more dates - estimated by the models - differ from those of the reference point itself. This time lag, explained by the circulation time of pottery itself, or of techniques and know-how, from one area to another, is the way - chosen here - to better 
identify different socio-economic or cultural areas through pottery.

\section{Methodology}

As we previously presented, for a fixed stratigraphic set, the mismatch of possible available estimated dates using pottery is a way to detect and understand pottery exchanges. Firstly, we briefly describe two previously statistical models developed to date stratigraphic sets using pottery (Bellanger and Husi 2012). Secondly, we present spatial statistical analysis carried out with spatial indicators.

\subsection{Statistical models for dating using pottery}

How do we date in calendar time stratigraphic archaeological contexts coming from one or several excavations? A way to do that is to compare pottery assemblages of dated sets including coins or other dating artefacts (named 'active sets') with sets without absolute chronological information (named 'supplementary sets'). All studied sets are closed contexts or occupation levels in which pottery is present, but not always include coins. In our case, we use pottery assemblages quantified in MVC to obtain simultaneously the dating and the position of supplementary sets in the stratigraphy and in the chronology.

However, dating in archaeology can cover various concepts and thus can lead to different statistical models. In Bellanger and Husi (2012) we develop two statistical models formalising the widely-used intuitive procedures for dating archaeological contexts using pottery and the infrequent artefacts that can be dated in calendar time: coins. Two possible dates are obtained as result:

- The time event corresponds to a moment (a date) in successive actions. The first statistical model (Mod1) estimates for a given stratigraphic set the date of coins using a linear regression model on components of results CA (Correspondence Analysis) on pottery assemblages (MVC per fabrics). (Mod1) predicts a mean date in calendar time for undated stratigraphic sets (for example without coins).
- The accumulation time is interpreted as a formation process reflecting the duration or succession of events recorded in the soil. The second statistical model (Mod2) is a Gaussian mixture based on results of (Mod1). It estimates the chronological profile of each set based on proportion of each fabrics dated by (Mod1).

The statistical methodology, combining different statistical methods (linear model, correspondence analysis, gaussian mixture), illustrated by curves, is an original archaeological dating tool. Consistency of results between the two models highlights the robustness of the obtained dating. It is very important to test it and also to interpret potential divergences; principally for supplementary stratigraphic sets for which we have no absolute chronological information. Indeed, in this work, we compare Mod1 and Mod2 via the absolute difference between Mod1 and Mod2 (noted in the following abs(Mod1 - Mod2)) to characterise the spatial pattern of archaeological sets linked to economic/ cultural areas.

\subsection{Spatial indicators}

Heterogeneity and incompleteness are the most often encountered problems in spatial archaeological data: data are not measured anywhere, but at a limited number of locations! As a consequence, for our spatial problem, it is not possible to used geostatistics. We therefore choose to work from simple spatial indicators that allow us, without additional assumptions, to obtain readable results. The selected indicators are statistics intended to describe and visualise spatial distributions. They have been described and their properties studied for fish populations in Woillez, Rivoirard and Petitgas (2009).

They do not depend on the perimeter of the spatial domain and whether or not zero density values are included. Consequently, these statistics do not depend on the area in terms of size and geometry on which measures are done.

They can be grouped into two main categories:

- Location indicators (centre of gravity and spatial patches); 


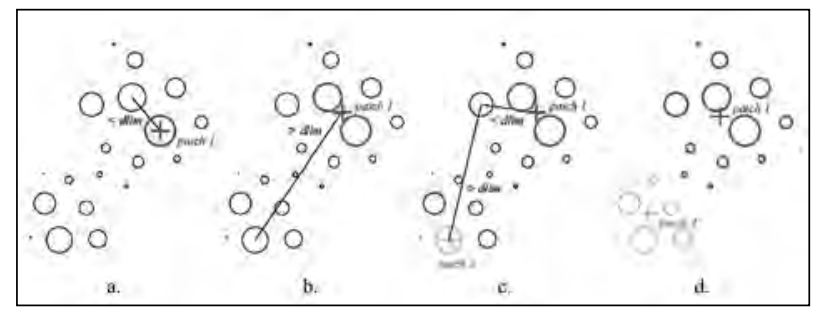

Figure 2. Algorithm for the selection of spatial patches, taken from Woillez, Rivoirard and Petitgas (2009).

- Occupation of space indicators (inertia and isotropy).

We use it to detect changes in the spatial distribution of the regionalised variable $\mathrm{z}$ equal to abs(Mod1 - Mod2) defined above.

\subsubsection{Centre of gravity (CG) and inertia (I)}

The centre of gravity (CG) is defined as the mean location of the studied phenomenon in space: it can be seen as the average position of an observation point (here a stratigraphic set) taken at random from in the area of study. The inertia (I) indicates the spatial dispersion of the regionalised variable around CG, that is the mean square distance between an individual (here a stratigraphic set) and CG.

In the case of irregular sampling, areas of influence around observation points can be used as weighting factors. It can be evaluated by overlaying a very fine regular grid and counting the grid points closer to the observation point (s). In practice, for $\mathrm{N}$ observation points $\mathrm{S}_{\mathrm{i}}=\left(\mathrm{x}_{\mathrm{i}}, \mathrm{y}_{\mathrm{i}}\right)$, areas of influence $\alpha_{\mathrm{i}}$ and $\mathrm{z}\left(\mathrm{s}_{\mathrm{i}}\right)$ the value of the regionalised variable $\mathrm{z}$ at $\mathrm{s}_{\mathrm{i}}$, we have:

$$
G C=\frac{\sum_{i=1}^{N} \alpha_{i} s_{i} z\left(s_{i}\right)}{\sum_{i=1}^{N} \alpha_{i} z\left(s_{i}\right)} \text { and } l=\frac{\sum_{i=1}^{N}\left(s_{i}-G C\right)^{2} \alpha_{i} z\left(s_{i}\right)}{\sum_{i=1}^{N} \alpha_{i} z\left(s_{i}\right)}
$$

Measurability and sensitivity of CG and I is explored in details by Woillez (2007).

\subsubsection{Isotropy (Iso) and anisotropy (Aniso)}

A spatial distribution is said to be isotropic if thereis the samedispersion of the population around CG in every direction. In general, it is not true, and the spatial distribution is said to be anisotropic. To obtain a measure of isotropy and also anisotropy, the inertia I is decomposed on inertia on its two principal axes orthogonal each other. Principal axes and their corresponding inertia $\left(\left(\mathrm{I}_{\max }\right)\right.$ and $\left.\left(\mathrm{I}_{\min }\right)\right)$ are obtained as the eigen vectors and values of a Principal Component Analysis (PCA) of the coordinates of archaeological sets weighted by the values of regionalised variable (Bez et al. 1997). We have the two following index:

$$
\begin{gathered}
I s o=\sqrt{\frac{I_{\min }}{I_{\max }}} \in[0 ; 1] \text { and Aniso }=I s o^{-1}=\sqrt{\frac{I_{\max }}{I_{\min }}} \geq 1 \\
\text { where } I=I_{\max }+I_{\min }
\end{gathered}
$$

In case of isotropy, the values of Iso and Aniso approach 1. More details on these indicators can be found in Woillez (2007). In our work, we will see in section 4 that the direction of the principal axis would help to detect a preferential direction in pottery socio-economic exchange.

\subsubsection{Number of spatial patches}

When the spatial distribution of the phenomenon presents heterogeneous local aggregations called "patches", it may be interesting to identify and then characterise them. An algorithm proposed by Petitgas (Woillez, Rivoirard and Petitgas 2009) has been used. An observation point $s_{i}$ is assigned to a patch according to its value of density $\mathrm{z}\left(\mathrm{s}_{\mathrm{i}}\right)$ and its distance from the other existing patches, with respect to a maximal threshold distance dlim to its CG. The algorithm starts by ordering the observation points, and by decreasing order of their density value. The first point corresponding to the highest density value $\max _{(\mathrm{i}=1, \ldots, \mathrm{N})} \mathrm{z}\left(\mathrm{s}_{\mathrm{i}}\right)$ is regarded as the first patch (Fig. 2a). Then, another point is attributed to the nearest patch, if the distance to its CG is smaller than the threshold distance dlim (Fig. 2b). Otherwise, it defines a new patch (Fig. 2c). The summary index calculated is the number of patches (NP) (Fig. 2d). The results on spatial patches are very influenced by the choice of the threshold dlim and the location of the highest density values. NP indicates the level of patchiness of sets at a large scale. All statistical analyses are performed using the free software R ( $R$ development core team 2011).

\section{Results}

\subsection{Data corpus for spatial analysis}

In this study, as we focus on the characterisation of spatial patterns, our data corpus is composed of 
240 values of abs(Mod1 - Mod2)) (defined in 3.1), corresponding to stratigraphic sets located at 25 archaeological sites corresponding to 10 different places (see 2.2). An extract from the available data is presented in Table 1 below.

We make the assumption that the further the archaeological contexts are from the reference location of Tours, the more the estimated dates by the two models could diverge. Indeed, a small difference indicates that both estimated dates are close and the models fit well (Tours and Blois) even if the true date is unknown. At the opposite, a high difference is interpreted as a misestimation of date, reflecting the fact that the models are not adapted (Châtellerault and Poitiers).

\subsection{Preliminary results}

To better understand the impact of variations of the regionalised variable on spatial indicators, we present in Fig. 3 some results of a constant spatially distributed data set (Cte) and results for our data corpus abs(Mod1-Mod2) on the right. The X- and Y-axes correspond to latitude and longitude. The black cross is positioned on the centre of gravity (CG), from which it represents the square root of inertia (I) along each of its two principal axes. For

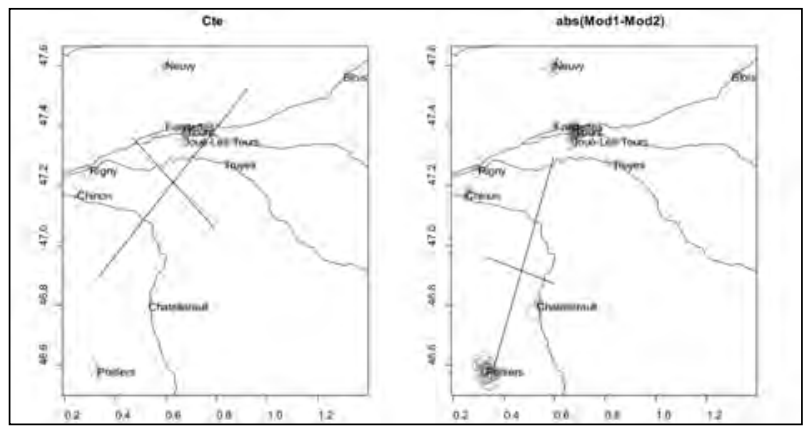

Figure 3. Examples of spatially distributed data sets, (cte) showing the impact of a constant regionalised variable on studied indicators values.

the same spatial area, we clearly observe here that all spatial indicators have changed: CG, but also the principal axes that characterise the elongation of the spatial distribution. Results on our data corpus (Fig. 3 right) highlight a CG sensitive to high values of abs(Mod1 - Mod2) measuring for Poitiers and Châtellerault and a marked anisotropy in the preferential direction northeast-southwest. This direction corresponds to a strong heterogeneity on the axis southwest (Poitiers, Châtellerault) to northeast (Tours) where pottery material is the most different throughout the ages, or is similar but shifted in time. It also reveals the potential existence of different pottery areas.

\begin{tabular}{|c|c|c|c|c|c|}
\hline Towns and sites & Sets & Coins (dates AD) & Mod1 & Mod2 & abs(Mod1-Mod2) \\
\hline \multicolumn{6}{|c|}{ Tours : example of reference (active) sets with coins used for the construction of the 2 models } \\
\hline Tours & AA000034 & 354 & 355 & 370 & 15 \\
\hline Tours & AA00016e & 814 & 846 & 813 & 33 \\
\hline Tours & AA000020 & 1100 & 1092 & 1107 & 15 \\
\hline Tours & D1 & 1341 & 1357 & 1360 & 3 \\
\hline Tours & $\mathrm{J} 2$ & 1476 & 1475 & 1486 & 11 \\
\hline Tours & G1b & 1488 & 1489 & 1489 & 0 \\
\hline Tours & $\mathrm{R}$ & 1631 & 1635 & 1611 & 24 \\
\hline \multicolumn{6}{|c|}{ Example of others Towns : example of supplementary sets without coins dating by estimation of the models } \\
\hline Blois (65 km of Tours) & Z001 & $?$ & 859 & 853 & 6 \\
\hline Blois & Z003 & $?$ & 849 & 852 & 3 \\
\hline Chatellerault & Z021 & ? & 1104 & 1208 & 104 \\
\hline Chatellerault & Z022 & $?$ & 957 & 808 & 149 \\
\hline Poitiers (100 km of Tours) & Z094 & $?$ & 1062 & 1203 & 141 \\
\hline Poitiers & Z096 & $?$ & 994 & 1203 & 209 \\
\hline Poitiers & Z097a & $?$ & 1037 & 1205 & 168 \\
\hline
\end{tabular}

Table 1. Extract from the available data corpus: 1) reference active sets of Tours with dates of coins used for the construction of the models; 2) supplementary sets coming from others towns. 
Spatial Statistic Analysis of Dating Using Pottery: an Aid to the Characterization of Cultural Areas Lise Bellanger, Philippe Husi and Yassine Laghzali

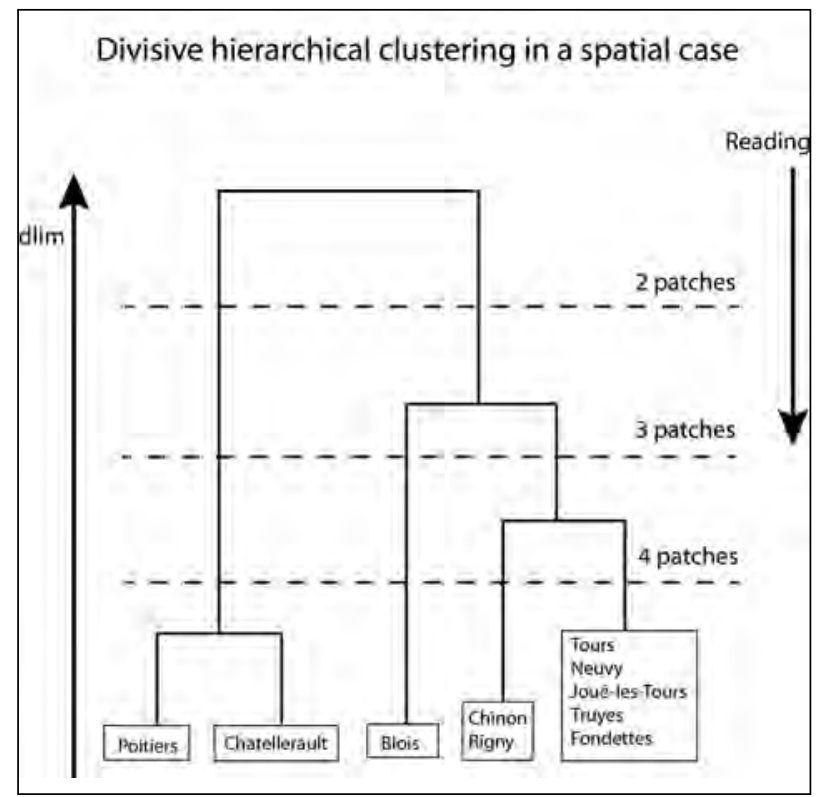

Figure 4. The numbers of spatial patches.

\subsection{Results for the studied data corpus}

To better detect and understand the presence of pottery areas, we try to identify patches by attributing each set to the nearest patches using the algorithm described in section 3. Fig. 4 presents the numbers of spatial patches when the threshold distance (dlim) varies. This approach is similar to divisive hierarchical clustering (see for example Everitt, Landau and Leese 2001 for more details), which consists of a series of partitions that separates in our cases the archaeological sets successively into finer groups or patches.

We are not interested in the complete hierarchy, but only in one or two partitions obtained from it. As in hierarchical clustering, there is no consensus about which rule to apply to choose the partition and the number of present groups. We use the expertise of the archaeologist and retain the partitions into two and three spatial patches. The partition into two spatial patches confirms the existence of two large pottery areas, the Loire valley and the Vienne valley, with probably less exchange of pottery between them (Fig. 5).

The partition into three spatial patches (Fig. 6) allows us to detect three socio-economic and cultural areas based on pottery trade within a radius of $30 \mathrm{~km}$ around a major consumption centres (Tours,

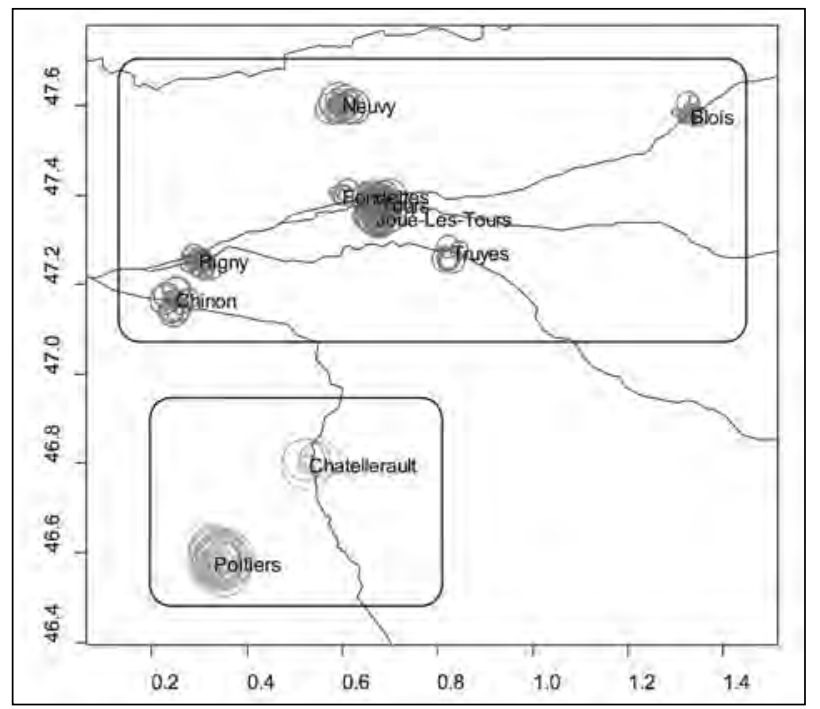

Figure 5. Partition into two spatial patches of abs(Mod1$\operatorname{Mod} 2)$.

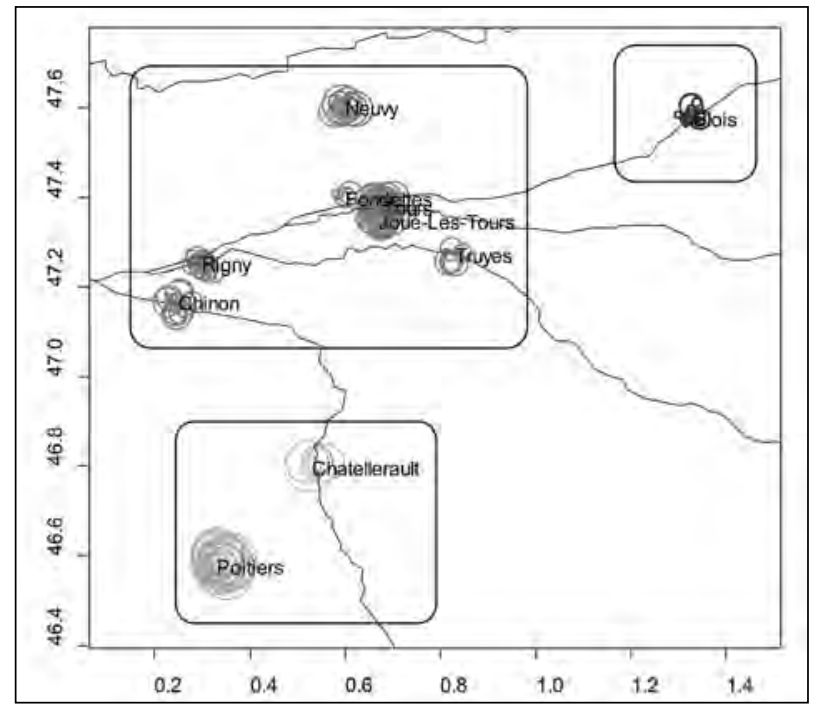

Figure 6. Partition into three spatial patches of abs(Mod1-Mod2).

Blois and Poitiers). This interpretation, based on the statistical results, is confirmed by the archaeological analysis of pottery, for example the distribution of red painting and glazed pottery between the 8th and 11th century. A first area with a pottery facies presents red-painted and glazed ware around Tours dating to the middle of 8th to 11th century. A second area with a same pottery facies is located around Poitiers, but observed later, between the 10th and 11th century. A third area exists around Blois, with a pottery facies presenting only red-painted ware, but also observed later than at Tours. These few 
exceptional pottery productions are presented here only to illustrate our results. But in fact, these three areas were also confirmed by the analysis of a bigger corpus of productions.

\section{Conclusions and Perspectives}

In this paper, we propose a spatial statistical procedure to provide answers to archaeological issues in the socio-economic domain. Our modelbased approach uses classical and less classical tools, like spatial indicators, as useful statistics to describe, capture and interpret spatial patterns. Our spatial statistical procedure is applied to the analysis of archaeological contexts in West Central France, based on a large collection of medieval pottery finds. Spatial indicators corresponding to the studied data allow us to relate spatial distribution properties of archaeological variables to their dynamics and contribute to understand the socio-economic exchanges.

Different archaeological points could be made to conclude this paper. Firstly, spatial analysis of chronological information is an important help to build cultural areas. Secondly, the presence of the same pottery at different places and/or at different times reflects the rapidity of exchanges of product, know-how, modes and competition. Thirdly, the organisation of these economic and cultural areas in West Central France depends mainly on the river network and the location of the main centres of consumption or diffusion.

In the coming years, it will be essential to integrate several new sites in our model-based approach to understand the organisation of the products' distributions and to clarify the cultural facies. We also plan to create an $\mathrm{R}$ tool that would provide archaeologists a simple way to apply our model-based approach to other archaeological data.

\section{Bibliography}

Bellanger, L., and P. Husi. 2012. "Statistical tool for dating and interpreting archaeological contexts using pottery." J ournal of Archaeological Science 39:777- 790.

Bez, N., J. Rivoirard, P. Guiblin, and M. Walsh. 1997. "Covariogram and related tools for structural analysis of fish survey data." In Geostatistics Wollongong'96, Volume
2, edited by E. Y. Baafi and N. A. Schofield, 1316-1327. Dordrecht: Kluwer.

Butzer, K. W. 1982. Archaeology as Human Ecology. New York: Cambridge University Press.

Evans, T., C. Knappett, and R. Rivers. 2012. "Interactions in Space For Archaeological Models." Advances in Complex Systems 15 (1):150009-1-1150009-17.

Everitt, B. S., S. Landau, and M. Leese. 2001. Cluster Analysis. London: Arnold.

Galinié, H. 2007. Tours antique et médiéval. Lieux de vie, temps de la ville. Tours: FERAC.

Husi, P. 2013. La céramique du haut Moyen Age (6e $10^{\mathrm{e}} \mathrm{s}$.) dans le Centre-Ouest de la France: de la chronotypologie aux aires culturelles. Tours: FERAC-ARCHEA.

Husi, P., and X. Rodier 2011. "ArSol: An archaeological data processing system." In On the road to reconstruct the past, Computer Application and Quantitative Methods in Archaeology (CAA), Proceedings of the 36th International Conference, Budapest, April 2-6 2008, edited by E. Jerem, F. Redö, and V. Szeverényi, 86-92. Budapest: Archaeolingua.

Orton, C. 1982. "Stochastic process and archaeological mechanism in spatial analysis."J ournal of Archaeological Sciences 9:1- 7 .

R Development Core Team. 2011. R: A Language and Environment for Statistical Computing. Last modified J anuary 1. http:// www.r-project.org/ .

Robertson, E. C., J. D. Seibert, D. C. Fernandez, and M. U. Zender. 2006. Spaceand Spatial Analysisin Archaeology. Canada: University of Calgary Press.

Rodier, X., O. Barge, L. Saligny, L. Nuninger, and F. Bertoncello. 2011. Information spatiale et archéologie. Paris: Errance Archéologiques.

Woillez, M., J. Rivoirard, and P. Petitgas. 2009. “Notes on survey-based spatial indicators for monitoring fish populations." Aquatic Living Resources 22:155- 164.

Woillez, M. 2007. "Contributions géostatistiques à la biologie halieutique." $\mathrm{PhD}$ diss., École Nationale Supérieure des Mines de Paris. 


\title{
Scale Dependent Patterns in South-Eastern Norway
}

\author{
Mieko Matsumoto and Espen Uleberg \\ Museum of Cultural History, University of Oslo
}

\begin{abstract}
:
The paper presents an analysis of Neolithic settlement patterns over the landscape regions in the three counties of Akershus, Oslo, and Buskerud in South-Eastern Norway. Over several years the data set has been integrated in a large database with free access at the University of Oslo. Each find is recorded with coordinates with different accuracy levels. This analysis includes finds with a provenance accuracy of cadastral unit and better. Possible interpretations at two different scale levels are discussed. The broad scale level presents a settlement pattern in relation to different landscape regions. A tentative result suggests a gradually more intensive use of the inland areas and more activity in the higher valleys throughout the Neolithic. At the same time a shift within the regions is implied. Moreover, at a more detailed level, the site analysis reveals mobility and settlement change within the landscape regions.
\end{abstract}

\section{Keywords:}

Large Databases, Accuracy, Scale Levels, Neolithic Settlement Patterns, Norwegian Landscape Regions

\section{Introduction}

Museum collections can be characterised by archaeological material with a great diversity of provenances: stray finds, artefacts collected during surveys at open air sites and material from excavations. Some artefacts are meticulously documented, while others have only limited information about the location and find circumstances. Furthermore, dating offers the additional time dimension. The aim of this paper is an analysis of Neolithic settlement patterns in different landscape types through artefact representation at different scales of time and space.

\section{Categorisations}

We always categorise the world around us in certain ways. Archaeologists tend to organise and analyse their material according to a very few of the potentially infinite number of unit sizes, ranging from artefact, feature over culture to country and continent (Wobst 2006). The units influence or even determine our understanding of past cultures.

Theseunits existin the space- timecontinuum that we live and move in. Space can be categorised as a variety of entities; landscapes, seascapes, and river systems, but also taskscapes (Ingold 1993). The notion of a taskscape makes us focus on how

Corresponding author: mieko.matsumoto@khm.uio.no the perceived landscape is filled with meaning and created and re-created by those living and acting in it. Ingold demonstrates how the dimension of time is added as the taskscape integrates time, space, and experience. Places are filled with meaning through present events, through the memory of events in the past, and the expectation of events in the future: the annual cycle between different ecological zones and daily activities like hunting, fishing, eating, toolmaking and -repair. They all combine to form the actively made taskscape.

Some of our actions leave traces in the three dimensional space. The events become visible through debris and lost, discarded or deposited artefacts, all of which are subsequently recorded as archaeological sites. Some of the sites indicate a very brief moment: a loss, or a short stop when tools were mended or discarded. Some are occupational sites where people returned several times over the years, and some are places for offerings or burials. These places were deliberately chosen because they had or were given a certain meaning. The depositions of material culture filled the landscape with meaning for the people inhabiting it. Such places contributed to the lived history, the taskscape, that surrounded the people living there.

All these activities took place in a space - time continuum at a larger or smaller site, and during a longer or shorter time interval. The artefact density 
and diversity can reflect the number of events at a site. Places that have attracted activities many times over long time spans can be described as attractors or centre points. What is now a point on a two-dimensional map was an event that had not only a spatial extension (Uleberg 2004), but also a duration.

The geographic area that is represented by such a point can have different shapes and forms. The unit it represents can be a geographically larger area, and then more events will fall within it than when the area is small. Similarly, when the time unit is a longer time span, it will contain many more events than when the time unit is shorter. In this way, the number of finds within a space-time unit is correlating with the choice of scale and analytical units. There is a wide range of possible spatial units that can be used, like squares of a certain size, administrative units or landscape types. Examples of different time units are centuries, archaeological or geological periods, and paleoclimatic zones. The choice of unit will inevitably influence the results of the analyses, a challenge known by geographers as the Modifiable Area Unit Problem (MAUP) (Harris 2006, 48-50). The area unit in this paper will be landscape regions. A parallel to MAUP that includes time is addressed as the Modifiable Temporal Unit Problem (MTUP). MTUP consists of duration, temporal resolution, and point in time (Çöltekin et al. 2011).

The time-slices that are chosen for analyses are often given by how the material can be dated. At sites with few or no deposits, like open air Stone Age sites in Norway, events through long time spans can befound together, and it is often not possibleto order them in a time sequence. Typology and C14-dating can reconstruct some of the distribution in time, but often within rather wide limits. It can be possible to say that a site has been visited several times, and it can be argued for a time of deposition for certain artefacts. For instance, at a site that contains both an Early Mesolithic axe and a Late Neolithic dagger, these two artefacts can bear witness to events at the two separate points in time. It is, however, not really possible to know anything for sure about the duration of the events that created this deposition or loss.
Archaeological temporal scale can mean the structure of the archaeological deposit and also the scale of measurement and interpretation. Patterns of landscape use can be perceptible only if the time scale is large enough for this pattern to emerge in the archaeological record. The scale of explanation must therefore relate to the scale of observation (Holdaway and Wandsnider 2006). The range of the scale of observation is limited by how precisely the artefacts can be dated. In the archaeological collection of the Museum of Cultural History in Oslo, accumulated over more than 200 years, this limitation becomes even morepronounced, sincethe context and provenance of the museum acquisitions from the 19th century are inevitably far less detailed than for finds from recent excavations. The next section will discuss the diversified information in the database at the museum.

\section{The Database}

The database at the Museum of Cultural History in Oslo is the product of an on-going national cooperation among the six university museums in Norway to create common database solutions. In this way, the databases can give us an overview of archaeological material all over Norway. Lists of artefacts with metadata and coordinates can today be downloaded freely from the internet (Universitetsmuseenes Samlingsportaler 2014) so that everyone can create their own maps.

The geographical position of a site is described by a set of metadata. The precision of a point is in general a quantitative measure, given with a range depending on how the coordinates were recorded. In this database the metadata does not refer to the precision but to the accuracy of the point, and the categories are qualitative rather than quantitative. The main categories are site, cadastral unit, municipality, and county, but they also include place name types like island, lake, and mountain.

The chosen categories are an adjusted version of the name categories used in the Norwegian standard for exchange of geographical information (Kartverket 2014a). These qualitative categories of accuracy are chosen because they may well reflect the provenance. Very often the information refers only the farm where the artefact was found. Such a cadastral unit can be a rather large area and cover 
different environments like river banks, agricultural fields, woods, and mountain areas. The coordinates chosen to represent the cadastral unit are in the farmyard. Similarly, the parish church is chosen as the representation point for a parish, and the town hall for a municipality. These points are preferred over a polygon centre point for two reasons. Firstly, there is a greater chance that the find was made close to the farmhouses than in the woods. Secondly, the user may more intuitively understand a point at the farmyard or the town hall as a representative point. Coordinates for other geographical name types, like island or lake, are taken from the web pages of the Norwegian Mapping Authority (Kartverket 2014b).

The different categories of accuracy make it possible to include various sets of the total material in different types of analyses. It is important to choose accuracy according to the purpose of the study. Accuracy is connected to scale, and consequently finds with different accuracies can be used at different scales. A map of finds from all of Norway on one page can include finds from a municipality or other larger areas. On a map at a larger scale, of a smaller area of land, it would be very misleading to show any lower accuracy than the cadastral unit. Analyses of sites in relation to water, soil types, and prehistoric shorelines, should only include sites where the precise location is known. Most of the finds in the collection are registered with coordinates for the cadastral unit, and can be included in landscape analyses which also have a rather coarse resolution.

\section{Landscapes Reference System}

The landscape reference system applied in this paper has been developed by the Norwegian Institute for Forest and Landscape (Puschmann 2005). It encompasses six landscape components: Major landform, Minor terrain form, Water and watercourses, Vegetation, Agricultural land, and Built-up areas/technical installations. The method focuses on the spatial content of the landscape and the interplay between naturally given and culturally created factors. It describes the landscape at three scale levels. The most overarching level has six regions: Coast, Fjord, Lower valleys, Woodlands, Valley and Mountain settlements, and Mountain areas. The scale level for this map is 1:2 million.
The next intermediate scale level is 1:500 000 and divides the country into 45 regions determined by the dominating landscape components. One region can have several separate areas where a common element is repeated. The limit will be where this repetitive pattern stops, often at dominating heights. The third scale level is at 1:250 000, and divides Norway into 444 sub-regions. When choosing between the different scale levels, it is important to bear in mind the generalisations that have been made to construct the maps. This landscape reference system gives an opportunity to aggregate artefacts independently of modern administrative borders.

The classes used in the landscape reference system are not always in accordance with an archaeological division of regions, but they are a good starting point for landscape descriptions. Early Neolithic finds from Eastern Norway has been grouped within three zones based on an aggregation of regions at the intermediate scale (Solheim 2012, 52- 55). The ten regions in Buskerud, Akershus, and Oslo have been aggregated into seven in this paper. Three regions are joined into one mountain region, and two types of valley regions have been combined into one valley region.

\section{The Archaeological Material}

The Stone Age in South-Eastern Norway is a period with dramatic landscape changes. The land was pressed down by the heavy ice sheet until thelast Ice Ageended at around $10000 \mathrm{BP}$. Theeustaticland rise has brought up the coast line around the Oslo Fjord to as much as $220 \mathrm{~m}$ asl. J ust after the Ice Age, the land rise was quite rapid (Sørensen 1979), and people might have experienced landscape changes within their life time - islands becoming part of the mainland, fjords becoming dry land or lakes. In the Mesolithic, parts of today's inland landscape regions were coast or fjord zones and the coastal regions were submerged. However, at the onset of the Neolithic, the sea level was only around $30 \mathrm{~m}$ higher than today. At the scale level chosen here, it is possible to correlate the landscape regions and Neolithic sites. The three counties Akershus, Oslo and Buskerud are chosen because they represent a diversity of landscapes, a cross section from the Oslo Fjord to the High Mountains. 


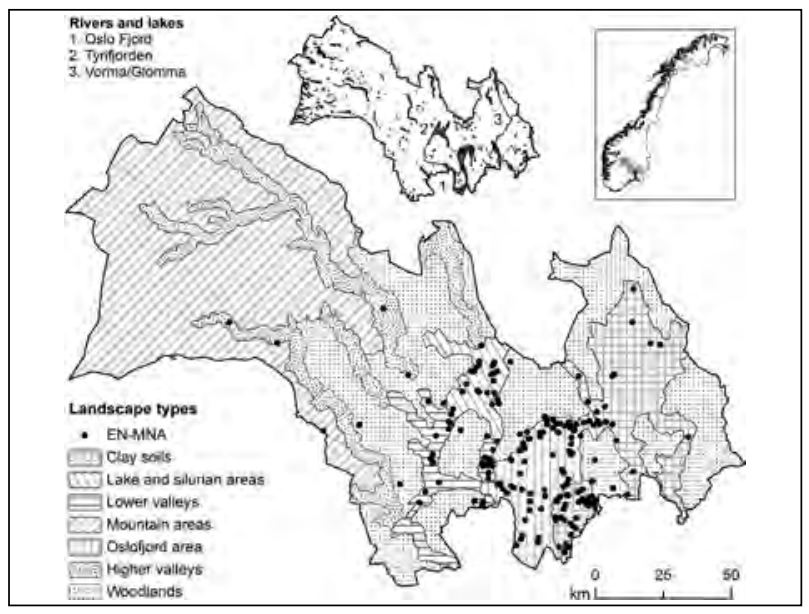

Figure 1. Sites from the Early Neolithic (EN) and the Early Middle Neolithic (MNA).

The material types chosen for this paper are axes, sickles, and daggers. Theseimpressiveartefacts are elaborately made, either of imported flint or of local stone of high quality. Such prestige objects reflect the taskscape of deliberate depositions for burials and offerings, and not debris and loss. They are mainly stray finds that have been sent to the museum over a long period of time. Since they are often found in connection with agricultural activity like ploughing, it is difficult to place them in a reliable context. Only eleven Neolithic burials could, with any certainty, be identified in the material from Buskerud (Reitan 2005).

There could be a higher chance of finding axes in cultivated fields, and this could influence an analysis of finds in relation to landscapes. However, an analysis of the relation between cultivated fields and the number of Mesolithic axes per municipality West of the Oslo Fjord shows no such correlation. It has therefore been concluded that the distribution of Mesolithic axes is representative of the Mesolithic settlements in this area (Glørstad 2002, 20-21). It can be assumed that the same should be valid for axes, sickles, and daggers from the Neolithic.

The problems described as MAUP are addressed by letting the single find be the area unit. The question is whether the accuracy of the location allows the point to be used in a detailed or a broader scale level analysis. Only objects with an accuracy of cadastral unit or better are included. In this way modern administrative units, which in this connection are arbitrary, will not influence the

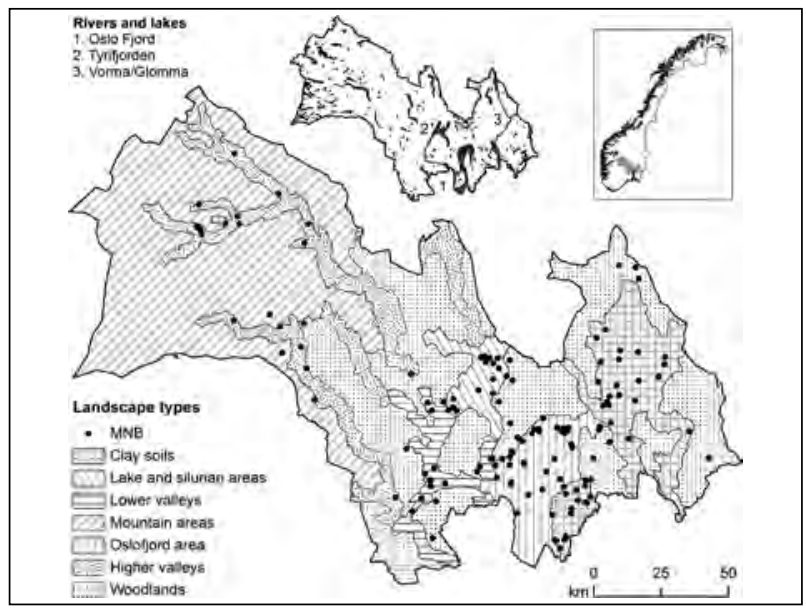

Figure 2. Sites from the Late Middle Neolithic (MNB).

results. Concerning the time scale, the dating will mainly rely on typology, and the time units will be determined by the dating of the chosen artefact types.

The categorisation of time, expressed through different names for different periods, carries with it an expectation of change. Thisisnot least thecasefor the transition from the Mesolithic to the Neolithic. Changes in subsistence patterns should be reflected in different settlement distributions. The Norwegian archaeological material, however, indicates that there was not a radical shift at the Early Neolithic, but that substantial changes occurred from the onset of the Late Neolithic (Prescott 1995).

\section{Interpretation}

There are several archaeological studies focusing on a single county (e.g. Amundsen 2011; Mikkelsen 1989; Reitan 2005; Østmo 1988), and some cross-county works that present larger regions of Norway. Late Mesolithic societies around the Oslo Fjord (Glørstad 2010) and Early Neolithic in Eastern Norway (Solheim 2012) have been described more independently of administrative borders.

Recent finds of Funnelbeaker sites shows Early Neolithic agriculture also in areas retracted from the coast (Østmo and Skogstrand 2006), and there are several indications of grazing in the inland clay soil area, the earliest at 4850 BP (Høeg 1997, 127). There is, however, also a continuation of subsistence and settlement patterns, mainly on sandy soils in 


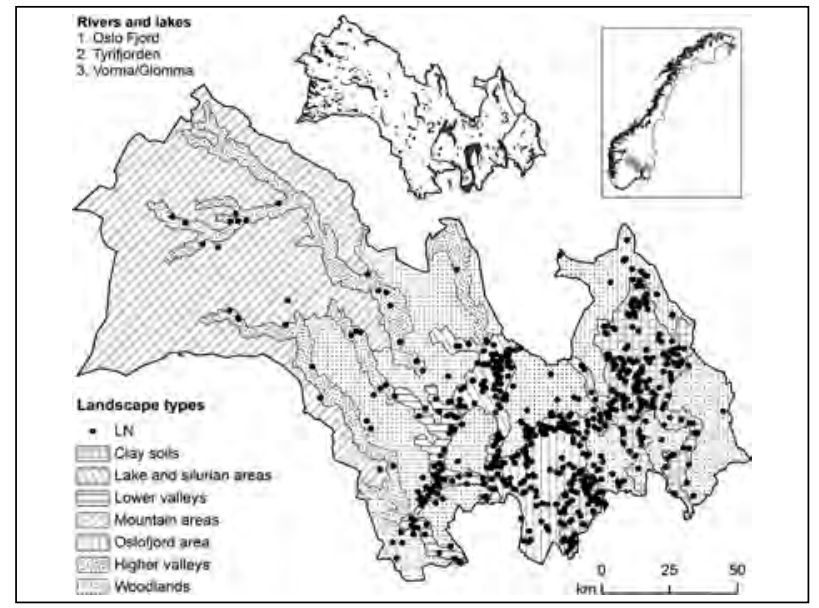

Figure 3. Sites from the Late Neolithic (LN).

the coastal zone, from the Late Mesolithic through the first parts of the Neolithic in Norway. This implies that hunting and fishing are still important for the subsistence (Amundsen et al. 2006; Reitan 2005, 90-92). This pattern can be seen in Fig. 1, where it is evident that the majority of finds from the Early Neolithic (EN) and the early Middle Neolithic (MNA) (5 000-4 200 BP) occurs mainly in areas close to the coast.

In the late Middle Neolithic (MNB) (4 2003900 BP) (Fig. 2), there is an increased use of the higher valleys in the West, with a more extensive pastoralism in combination with inland hunting. There is a shift away from the areas close to the coast, but not to the woodlands. The clay soils are more used, both relatively and in absolute numbers. The increased use of the clay soil in the interior Northeast could also imply pastoralism rather than agriculture (Reitan 2005). However, the first signs of cultivating barley are found on the clay soils as early as 4150 BP (Høeg 1997, 132).

The impression at this scale level may be described as intensification, i.e. more use of the interior areas, but also a shift of areas within the landscape regions, especially in the Lake and Silurian areas. At a more detailed scale level this becomes clearer, as only a few of the sites, around $10 \%$, have finds from both EN/MNA and MNB. This may demonstrate a shift of the preferred location in the landscape.

The following Late Neolithic period shows a strong intensification of land use (Fig. 3). In many parts of Norway, there is a shift to a new settlement pattern that continues throughout the Bronze and Iron Ages (Prescott 1995). The same kind of shift is not possible to observe in this material. The finds continue to cluster in the areas best suited for agriculture and pastoralism. There are more finds in the valleys leading up to the High Mountains, but it is generally a pattern of more intensive and extensive use of the same landscapes as in the preceding periods. Looking at a more detailed scale, and including all artefacts dated to EN and MN, $30 \%$ of the sites from any of the two earlier periods have been used also in the Late Neolithic, and slightly more than $20 \%$ of the Late Neolithic sites have finds from the earlier Neolithic periods. In this way a change of the settlement pattern is reflected at a detailed scale level.

\section{Concluding Remarks}

This paper has suggested some patterns at different scale levels. The landscape regions can be aggregated into categories that reflect the distribution of the archaeological material. There are practically no sites in the areas characterised as woodlands. The few exceptions are related to the rivers Glomma and Vorma. At this scale level it is also clear that both the Oslo Fjord and the lake Tyrifjorden attract settlements throughout the period, but that the areas further away from the Oslo Fjord become more important. There is a gradual intensification with wider use of the interior and higher valleys. Movement and change within the landscape regions can be found in a comparison of single sites. There is only a small number of sites that are used both in the earlier and later part of the Neolithic. The results obtained through this study encourage further work. We may expect that the geographical area can be extended; first to include the rest of Eastern Norway. In addition, analyses at intermediate scale levels over larger areas could also demonstrate new tendencies and patterns in the archaeological material that have not yet been discovered.

\section{Bibliography}

Amundsen, H. R. 2011. "Mot de store kulturtradisjonene. Endringsprosesser fra tidligneolitikum til førromersk jernalder mellom Mjøsa og Femunden." PhD diss., Universitetet i Oslo. 
Across Space and Time. Papers from the 41st Conference on

Computer Applications and Quantitative Methods in Archaeology. Perth, 25-28 March 2013

Amundsen, Ø. M., S. Knutsen, A. Mjærum, and G. Reitan. 2006. "Nøkleby i Ski, Akershus - en tidligneolittisk jordbruksboplass?" Primitive tider 9:85- 96.

Çöltekin, A., S. De Sabbata, C. Willi, I. Vontobel, S. Pfister, M. Kuhn, and M. Lacayo. 2011. "Modifiable Temporal Unit Problem." Paper presented at ISPRS/ ICA workshop "Persistent problems in geographic visualization." (ICC2011), Paris, France, 2. J uly.

Glørstad, H. 2002. “Østnorske skafthullhakker fra mesolitikum. Arkeologisk og forhistorisk betydning - illustrert med et eksempelstudium fra vestsiden av Oslofjorden." Viking 65:7-47.

Glørstad, H. 2010 The structure and history of the Late Mesolithic societies in the Oslo fjord area $6300-3800$ BC. Mölndal: Bricoleur press.

Harris, T. 2006. "Scale as Artifact: GIS, Ecological Fallacy, and Archaeological Analysis." In Confronting Scale in Archaeology. Issues of Theory and Practice, edited by G. Lock and B. L. Molyneaux, 39- 53. New York: Springer.

Holdaway, S. J., and L. Wandsnider. 2006. "Temporal Scales and Archaeological Landscapes from the Eastern Desert of Australia and Intermontane North America." In Confronting Scale in Archaeology. Issues of Theory and Practice, edited by G. Lock and B. L. Molyneaux, 183202. New York: Springer.

Høeg, H. I. 1997. Pollenanalytiske undersøkelser på Øvre Romerike: Ullensaker og Nannestad, Akershus fylke: Gardermoprosjektet. Varia 46. Oslo: Universitetets Oldsaksamling.

Kartverket. 2014a. "SOSI." Accessed February 15. http:// www.statkart.no/ Standarder/ SOSI/.

Kartverket. 2014b. "Kartverket.” Accessed February 15. http:// www.norgeskart.no/ .

Ingold, T. 1993. "The temporality of landscape." World Archaeology 25 (2):152- 174.

Mikkelsen, E. 1989. Fra jeger til bonde. Utviklingen av jordbrukssamfunn i Telemark i steinalder og bronsealder. Universitetets Oldsaksamlings Skrifter Ny rekke, Nr 11. Oslo: Universitetets Oldsaksamling.

Prescott, C. 1995. From Stone Age to Iron Age. A study from Sogn, western Norway. Oxford: Tempus Reparatum.

Puschmann, O. 2005. Najonalt referansesystem for landskap. Beskrivelse av Norges 45 landskapsregioner. NIJ OS rapporter 10. Oslo: Norsk institutt for jord- og skogkartlegging.

Reitan, G. 2005. “Neolitikum i Buskerud - skikk, bruk og erverv i et langtidsperspektiv." MA thesis, Universitetet i Oslo.

Solheim, S. 2012. "Lokal praksis og fremmed opphav. Arbeidsdeling, sosiale relasjoner og differensiering i østnorsk tidligneolitikum.” Ph.D. diss., Universitetet i Oslo.

Sørensen, R. 1979. "Late Weichselian deglaciation in the Oslofjord area.” Boreas 8:241- 246.

Uleberg, E. 2004. "Settlement patterns and landscape perception in Norwegian mountains in the Stone Age." In The Humanized Mineral World: Towards social and symbolic evaluation of prehistoric technologies in South Eastern Europe. Proceedings of the ESF workshop, Sofia, 3-6 September 2003, edited by T. Tsonev and E. M. Kokelj, 83- 87. Liège: Universitè de Liège.

Universitetsmuseenes Samlingsportaler. 2014. "Kulturhistorie." Accessed February 20. http://www. unimus.no/ .

Wobst, H. M. 2006. "Artifacts as Social Interference: The Politics of Spatial Scale." In Confronting Scale in Archaeology. Issues of Theory and Practice, edited by G. Lock and B. L. Molyneaux, 55- 64. New York: Springer.

Østmo, E. 1988. Etableringen avjordbrukskulturi Østfold i steinalderen. Oslo: Universitetets Oldsaksamling.

Østmo, E., and L. Skogstrand. 2006. "Nye funn av traktbegerkeramikk ved Oslofjorden. Børsebakke og Vøyenenga." Viking 69:69-90. 


\title{
Estimation of Archaeological Potential with a Page Rank Based Predictive Model: the Urban Area of Pisa
}

\author{
Nevio Dubbini and Gabriele Gattiglia \\ University of Pisa, Italy
}

\begin{abstract}
:
We present an analysis of multi-faceted, GIS managed data for determining the archaeological potential of the urban area of Pisa (MAPPA 2014a). The identification of relations among finds is a key issue for the data mining in the archaeological interpretation process: spatial and functional organisation levels allow only particular configurations of parameters defining the potential. A PageRank based model is applied, since the criteria for assigning importance to web pages by search engines are also based on relations. The procedure includes the categorisation of finds; the assignment of initial absolute values of potential to the available data, through an automatic procedure; the definition of functional areas (urban, suburban, rural); and the application of a PageRank based algorithm. The results, including the map of archaeological potential, are to be considered as the first steps towards an automatic, formally definable, and repeatable approach to the computation of archaeological potential.
\end{abstract}

\section{Keywords:}

Predictive Modelling, Archaeological Potential, PageRank, Archaeological GIS, Geomorphology

\section{Introduction}

The MAPPA project is a research project in which archaeologists, geologistsand mathematicians have studied predictive modelling tools applied to the archaeological potential of an urban area. The map of archaeological potential is a technical but above all conceptual development of common archaeological maps. All the information taken from excavations, written sources, archive documents, and aerial and satellite photographs is included in a map of archaeological potential. Moreover, this is a predictivemap: theestimation of the probability that certain areas may conceal unknown archaeological remains is achieved by projecting the knowledge regarding neighbouring areas onto them, with a degree of approximation that varies according to the quantity and quality of available data.

In this study we present results obtained by an analysis of multi-faceted, diachronic, GIS managed data for determining the archaeological potential of the urban area of Pisa. The need for dealing with the urban context implied the necessity to consider archaeological finds instead of archaeological sites, and to develop a new

Corresponding author: nevio.dubbini@gmail.com predictive model (Dubbini and Gattiglia 2012) that takes also into account the heterogeneity and the complexity of datasets. We considered a number of datasets, concerning different aspects of the problem: archaeological data, buildings archaeological data, historical data, toponymic data, geomorphological data. The archaeological GIS data model was developed to manage heterogeneous data, which represent the urban archaeological complexity. We worked with both topographic (e.g. geomorphologic, hydrographic, toponymic data) and urban data (e.g. archaeological stratifications, buildings, road network, hypotheses of historians and archaeologists). The archaeological data model combined raw data and interpreted data, and range from less synthetic data (i.e. the context level) to more synthetic data. The key unit of the data model was the archaeological intervention, but the model also included the filing of published data, archive data and data resulting from building archaeology, and georeferencing and vectorisation data in order to understand the urban fabric development and the level of architectural heritage preservation. In addition, we considered: (i) the collection of written and published documentary sources with the aim to locate no longer existing place names, production activities, infrastructures and topographic structures; (ii) the computerised acquisition of 
historical mapping to trace urban transformation throughout the modern and contemporary ages.

Preliminary to the implementation of the mathematical model and to the creation of the input files, available archaeological data had to be categorised assigning each find to a category, in order to effectively implement the algorithm, and to make the results general enough to beapplied also in different contexts (Fabiani and Gattiglia 2012). The archaeological potential represents the possibility that more or less significant archaeological stratification is preserved. The following parameters were identified to estimate the archaeological potential: type of settlement, density of settlement, multi-layering of deposits, removable or nonremovable nature of the archaeological deposit, degree of preservation of the deposit, and the depth of the deposit (Anichini et al. 2011).

The aim of this paper is to describe the mathematical model and the algorithm used to estimate archaeological potential, and to present some results about the case study area: the urban area of Pisa. First, we had the problem of properly defining the concept of archaeological potential. To this aim, it was necessary to distinguish between what we called absolute potential and archaeological potential. The absolute potential (i.e. initial conditions) is defined in order to assign a potential value to the available data, while the archaeological potential (i.e. the output of the algorithm) is an estimate of the informative value of the archaeological stratification. Both measure of potentiality were divided into 5 different levels, by partitioning uniformly the numerical value in 5 parts. The division into levels is particularly useful for large-scale urban and landscape planning, and for users to have an overview of the areas with greater or lesser potential. Level 1 refers to (especially extra-urban) areas containing mostly natural stratifications or stratifications reworked by man (e.g. floodplains involving agricultural work), with low information potential. Level 2 refers to contexts similar to the previous one; however, evidence from photointerpretation suggests more marked intervention by man: e.g. traces of agricultural partitioning or road connection networks. Rural structures may also be found, as well as necropolis areas and other deposits with high information potential, but limited diachrony.
Level 3 refers to areas characterised by variable information potential, usually restricted to certain historical periods. Level 4 refers to areas with complex stratigraphic deposits and high, averagely developed (in diachronic terms) information potential. Lastly, level 5 potential refers to an area featuring the highest information value and high diachrony of archaeological deposits.

As for the value of absolute potential of finds, it was obtained by summing two different components, concerning the type of archaeological information and the removable or non-removable nature of archaeological finds. The archaeological reasoning behind this rating is given by the necessity to formalise (in our approach, in a binary manner) the amount of archaeological information that each find can produce.

\section{- The type of archaeological information}

To compute the value of this parameter a list of 19 areas of interest were drawn up, corresponding to the main informative fields on which the finds can provide information. The identified areas of interest are: production, building techniques, trade, food, agriculture/ breeding, worship, waste management, political/institutional aspects, social and gender aspects, physical anthropology, fauna/flora, geomorphology, viability/transport, health and hygiene, warfare, land management, leisure, tradition, water system. After having defined those areas of interest, categories of finds were assigned a value of absolute potential by summing, for each area of interest, the value 1 if the category provided information on that informative field, and 0 otherwise. For example the category "domus" was given the value 12 since a domus can provide information about 12 areas of interests.

- The removable or non-removable nature of the archaeological finds

This parameter concerns the persistent/ transient nature of each archaeological trace. It is assumed that more structured archaeological remains (e.g. a stone building) have higher information potential, since there is a greater chance of identifying those remains in the archaeological deposit. The values assigned to 
this parameter are 1 for masonry-built items (e.g. 'insula', 'tower house', 'domus', 'palace', 'theatre', 'church', 'prison',' forum', 'church'); 0.5, for items envisaging masonry but which can be less structured (e.g. an adobe building, 'river bank', 'enclosure', henhouse', 'pigsty', 'stable', 'hearth'); 0 , in the case of items without masonry work (e.g., 'canal', 'reclamation', 'trench', 'agricultural land', 'clearing', 'camp', 'waste dump') (Anichini et al. 2013).

In this way the value of absolute potential can range from 1 to 20 . Once the value of absolute potential has been defined, we had a way of transforming the available archaeological data into numerical values, suitable to serve as an input for the mathematical model. The other main ingredient of the model is a way of representing relations among finds. The identification of relations among finds is a key issue for the data mining during the archaeological interpretation process. In urban areas the spatial and the functional organisation provide meaningful information for the automatic extraction of possible configurations of the parameters defining the potential. In other words, depending also on the archaeological period we are considering, it is possible to distinguish parts in which only particular configuration of parameters that define the archaeological potential are feasible, or most probable. So the relations among finds can strengthen or weaken the archaeological potential of the area itself. The authors showed how a PageRank based model (Bini, Dubbini and Steffè 2011; 2012) can be used to assign the archaeological potential: the criteria used for attributing archaeological potential and those used for assigning importance to web pages by search engines are both based on relations. The method, moreover, has revealed to be relevant in the urban context, where, to the knowledge of the authors, no existing predictive model has been applied.

\section{Problem Definition: Estimation of the Archaeological Potential}

All the data listed in this section were managed as different GIS layers. The mathematical analyses were carried on in a matrix ambient (Matlab ${ }^{\circledR}$ ), and the matrix produced by the algorithm was converted in an output raster, so readable by a GIS application.
Thesubsurface was divided into3-dimensional cells forming layers, each one covering the whole study area. The number of layers is equal to the number of archaeological periods, because this is a straightforward way to distinguish between the relations acting inside the same archaeological period and the relations acting through periods. The 7 periods the archaeological team defined were: Protohistory, Etruscan Period, Roman Period, Late Roman Period, Early Medieval Period, Late Medieval Period, Modern Age, Contemporary Age. We therefore divided the subsurface of the work area in $n=n 1 \times n 2$ cells for every one of the 7 layers. For each of the $7 \mathrm{n}$ cells the absolute potential value was given on the basis of available data, as described before. So at the initial stage, the value of each cell is equal to the archaeological absolute potential of that cell. The problem is that of estimating the archaeological potential in every cell. On the basis of the information of different kind resumed from available data, the following input data were created, to be processed by the algorithm. The files on the list below were created for every archaeological period.

- Certain geolocation data: certain geolocation data were defined here as the data with known spatial coordinates. Notice that data was considered as certain geolocation data even where the dating was uncertain, that is, what defines the category of certain geolocation data is the quality of the knowledge of the spatial 2-d coordinates. For instance, we considered as certain geolocation data from excavations with known spatial 2-d coordinates, as well as data relating to aerial photography anomalies. Certain geolocation data were organised in a $\mathrm{n} 1$ $\mathrm{x}$ n2 matrix, whose element $i, j$ represents the absolute potential of that cell given by the certain geolocation data inside the cell.

- Uncertain geolocation data: uncertain geolocation data were defined here as the data with unknown spatial coordinates, i.e. data for which we only knew that they are located in a certain spatial region. For instance, we considered as uncertain geolocation data, data from excavations with uncertain spatial 2-d coordinates, as well as data from medieval written sources. The values of absolute potential of uncertain geolocation data are computed by dividing the absolute potential of the category 
of find by the number of cells included in the probable geolocation of the find. Uncertain geolocation data were organised in a $\mathrm{n} 1 \mathrm{x} \mathrm{n} 2$ matrix, whose element $i, j$ represents the absolute potential of that cell given by the uncertain geolocation data inside the cell.

- Shapes: from certain geolocation data, the archaeological team tried to give a shape to finds, e.g. to draw a house from a wall or a floor, or the continuation of a street from a piece of it. Each shape was given an empirical accuracy value varying from 1 to 6 ( 1 is the value of maximum precision), expressing how much the size and the orientation of the shape can be deduced with precision, on the basis of finds close by and of the geomorphologic datum (Anichini et al. 2013). The values of absolute potential of shapes were computed by dividing the absolute potential of the category of find the shape belongs to, by the precision value of the shape. Shapes data were organised in a n1 x n2 matrix, whose element $i, j$ represents the absolute potential of that cell given by the shapes.

- Geomorphologic data: these data were deduced from geological survey, in order to identify, for each archaeological period, the diverse geomorphologic features, which were distinguished in river, floodplain, wetland, marshy area, morphological high. Also the geomorphologic datum was given an absolute potential value, by summing for each geomorphologic feature the absolute potential of all the categories of finds that can be present in that geomorphologic feature. Geomorphologic data were organised in a n1 $\mathrm{x} \mathrm{n2} \mathrm{matrix,} \mathrm{whose}$ element $i, j$ represents the absolute potential of that cell given by the geomorphology.

The input files defined above, and their values of absolute potential, were used in different ways, as will be shown later in the section describing the algorithm. In addition, the algorithm makes use of functional areas, i.e. levels of spatial and functional organisation in which the urban space is organised (e.g. urban, suburban, rural areas). Each urban centre, in each archaeological period, is surrounded by a suburban area, and, more externally, by a rural area. Apart from the different names and functions that those three functional areas assumed in each

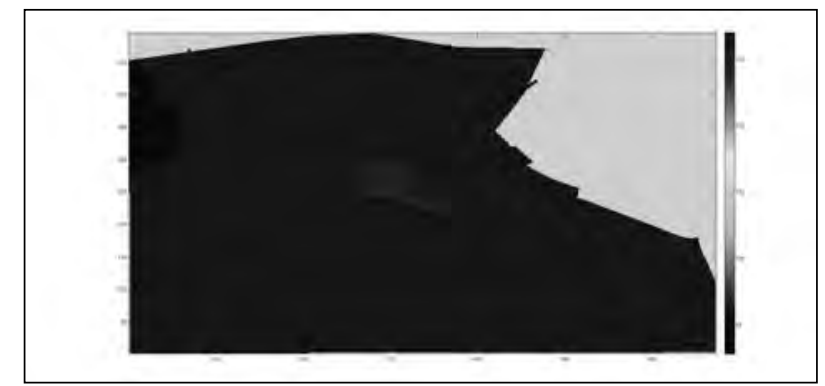

Figure 1. The geomorphological datum, as obtained for the Late Medieval Period: the floodplain is in dark red, the morphological high is in red, the river, the wetlands, and the marshy areas are in (different shades of) blue.

archaeological period, it was useful to define them in a rather general way. The identification of the functional areas is based on many elements, since it depends on the different settlement types, the relationships among them and the environmental context. To limit the subjectivity in defining the functional areas for each archaeological period, we used an automatic procedure to define them. We describe the basic procedure below, disregardingany minor variations due to the particular characteristics of some archaeological period.

- First, each category of finds has been associated with the functional areas it can belong to, and with the functional areas it cannot belong to. On the basis of that two different types of finds were defined: those characterising a functional area (characterising finds), and those not characterising any particular functional area (non-characterising finds).

- For each find characterising a functional area, a $200 \mathrm{~m}$ (300 m for the Etruscan period) circular buffer is defined. All the non-characterising finds in that buffer are absorbed in that functional area.

- In a following step, non-characterising elements already included in the buffers in the previous step, generate new buffer of $50 \%$ of the length of the original radius, enlarging in this way the functional area.

- All the non-characterising finds define a $100 \mathrm{~m}$ radius circular buffer. If at least 5 finds are inside that buffer, and each one of them is less than $100 \mathrm{~m}$ far from a find characterising the urban 


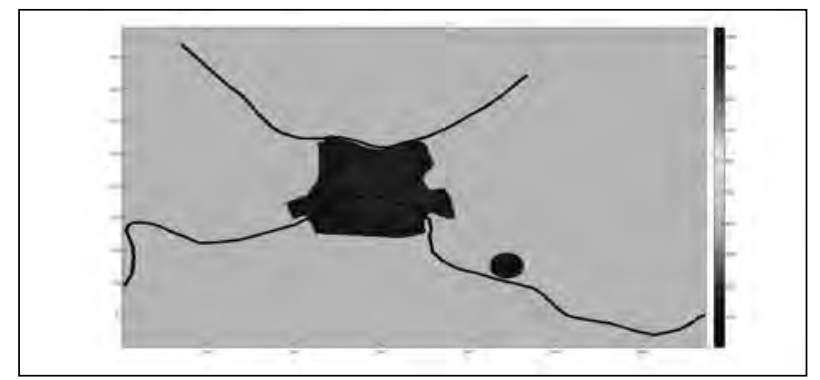

Figure 2. The functional areas, as obtained by the described procedure for the Late Medieval Period: the urban area is in red, the suburban area in dark red, the rural area in sky blue.

functional area, then the 5 finds and their buffer are included in the urban functional area.

- The expansion of each functional area continues until some buffer of a functional area meet a buffer of another functional area, determining in this way a boundary between the two functional areas.
- After all functional areas have been defined, the cells not belonging to any functional area are assigned to the rural functional area, except for those cells in the geomorphologic values of "river", "wetland", "marshy area".

- In order to use functional areas in the algorithm (see 3) , an absolute potential value was defined. In a similar way to what was done with the geomorphologic input, for every functional area the categories of finds that can be inside the area were listed, and their absolute potential values were summed to give the value of the functional area (Anichini et al. 2013).

After the definition of the functional areas, another two input files were created, expressing synchronic and diachronic associations among finds. Those associations were used in the algorithm to enhance the spread of archaeological potential on the basis of the probable presence of "valuable" finds in the surroundings of particular (categories of) finds.

\begin{tabular}{|c|c|c|}
\hline INPUT & DESCRIPTION & ABSOLUTE POTENTIAL COMPUTATION \\
\hline $\begin{array}{l}\text { Certain geolocation } \\
\text { data }\end{array}$ & $\begin{array}{l}\text { Data with known spatial (but not } \\
\text { necessarily temporal) coordinates }\end{array}$ & $\begin{array}{l}\text { The absolute potential value is given by the sum of } \\
\text { potentials of certain geolocation finds inside each cell }\end{array}$ \\
\hline $\begin{array}{l}\text { Uncertain geolocation } \\
\text { data }\end{array}$ & Data with unknown spatial coordinates & $\begin{array}{l}\text { First divide the absolute potential of the find by the } \\
\text { number of cells included in the probable geolocation of the } \\
\text { find.The absolute potential value is then given by the sum } \\
\text { of potentials of uncertain geolocation finds inside each cell }\end{array}$ \\
\hline Shapes & $\begin{array}{l}\text { Probable shape of certain geolocation } \\
\text { finds. An empirical precision value is } \\
\text { assigned (from } 1 \text { to } 6 \text { ) }\end{array}$ & $\begin{array}{l}\text { First divide the absolute potential of the find the shape } \\
\text { belongs to, by the precision value of the shape. The } \\
\text { absolute potential value is then given by the sum of } \\
\text { potentials of shapes inside each cell }\end{array}$ \\
\hline Geomorphological data & $\begin{array}{l}\text { Deduced from geological survey, to } \\
\text { identify geomorphological features }\end{array}$ & $\begin{array}{l}\text { The absolute potential value is assigned by summing the } \\
\text { absolute potential of all the finds that can be present in } \\
\text { each geomorphological feature }\end{array}$ \\
\hline Functional areas & $\begin{array}{l}\text { Levels of spatial and functional } \\
\text { organization, i.e. urban, suburban, rural } \\
\text { areas }\end{array}$ & The computation procedure is described in the paper \\
\hline Synchronic associations & $\begin{array}{l}\text { Each category is associated to the most } \\
\text { probable categories founded at a distance } \\
<50 \mathrm{~m} \text {, in the same archaeological period }\end{array}$ & $\begin{array}{c}\text { The values of potential are computed by summing the } \\
\text { potential values of the categories associated to the finds } \\
\text { located in that cell }\end{array}$ \\
\hline Diachronic associations & $\begin{array}{l}\text { Each category is associated to the most } \\
\text { probable categories founded at a distance } \\
<50 \mathrm{~m} \text {, in the chronologically previous or } \\
\text { following archaeological period }\end{array}$ & $\begin{array}{c}\text { The values of potential are computed by summing the } \\
\text { potential values of the categories associated to the finds } \\
\text { located in that cell }\end{array}$ \\
\hline
\end{tabular}

Table 1. Inputs of the algorithm. 
- As for the synchronic associations, for all categories of finds, depending on the functional areas in which they are located, each category was associated to the most probable categories found at a distance $<50 \mathrm{~m}$. With the expression "most probable" we mean at least in $75 \%$ of the attestations. This input file, for each cell, contains the sum of the potential values of the categories associated to the finds located in that cell.

- As for the diachronic associations, for all categories of finds, depending on the functional areas in which they are located, each category was associated to the most probable categories found at a distance $<50 \mathrm{~m}$ (in the 2-dimensional spatial coordinates), in the chronologically previous or following archaeological period. This input file, for each cell, contains the sum of the potential values of the categories associated to the find located in that cell.

The size of (square) cells was chosen to be $10 \mathrm{x}$ $10 \mathrm{~m}$ : this size was the outcome of different factors taken into account. On one hand, the archaeological data could be located with precision, but the geomorphologic data could be given a precision no higher than $10 \times 10 \mathrm{~m}$, due to the number of elevation points available for the creation of each historical DEM; on the other hand there is a tradeoff between the size of the cells and the total number of cells covering the work area, so that the smaller the size of the cells, the higher the total number of cells covering the area. Therefore the smaller the size of the cells, the more cells there are for which the archaeological potential has to be estimated. For example, in the limiting case for which we would like to estimate the archaeological potential of each point of the study area with arbitrary precision, we would have a finite number of input data, but we should estimate the potential of an infinite number of points. To solve this problem we searched (numerically) the maximum of a function representing the difference between the amount of information given by the available data in the case that cells are considered as "pixels of an image", and the area of cells divided by the total number of cells. The amount of information given by the available data is computed as the Shannon entropy (Shannon 1948) of a binary matrix where each cell containing input data is given the value 1 , and the other cells are given a 0 value. So the resulting formula is $\max _{l \in N} w\left[-p_{1} \log \left(p_{1}\right)-p_{0} \log \left(p_{0}\right)\right]-(1-w)\left[\frac{l^{2}}{n}\right]$

where $\mathrm{p}_{1}$ and $\mathrm{p}_{0}$ are defined as the relative frequency of cells with data and with no data respectively in the study area, $l$ is the edge of the cells, and $\mathrm{w}$ is a parameter. The maximisation, for different values of $\mathrm{w}$ near $1 / 2$, yield the "optimal" size of cells between 10 and $14 \mathrm{~m}$. For this reason we chose the size of cells to be $10 \mathrm{~m}$. This decision was also taken for practical reasons: since the first trials, data were given for $10 \mathrm{~m}$, and so no other smoothing is needed to adapt data for cells of other sizes. In order to perform computations on values of archaeological potential "per unit of area", the value of absolute potentials of cells was divided by its area, so making computations as independent as possible of the cell size.

\section{The Mathematical Model}

Mathematically, we applied a PageRank based model. The model not only needs the vector of absolute potential, but also a matrix of weights. A general introduction to the PageRank model can be found in Langville and Meyer (2006), while the application of PageRank based techniques to the estimation of the archaeological potential can be found in Bini et al. (2011). It is important to note that the algorithm was applied to each period separately, so that we have a potential map for each archaeological period, which we can "sum" as a last step (Dubbini 2013) .

Before describing how the model works, we describe how the two inputs of the PageRank based model are constructed, the vector D representing available data, and the matrix of weights $\mathrm{S}$. The vector $\mathrm{D}$ is a matrix of dimensions $\mathrm{n} 1 \mathrm{x} \mathrm{n} 2$, reshaped to a column vector of length $n$, and is obtained by the sum of the matrices of absolute potential of certain geolocation data, uncertain geolocation data and shapes.

The matrix of weights Sis a $\mathrm{n} \mathrm{n}$ matrix whose element $i, j$ represents the weight (value) of the link between the cell $j$ and the cell $i$. We now describe how this matrix is computed:

- Each cell with a find distributes its importance to a square mask of cells centred on the cell itself. 


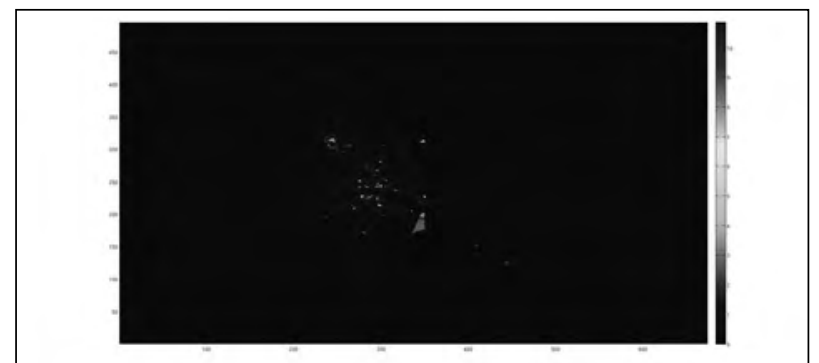

Figure 3. The vector $D$ for the Late Medieval Period, obtained by the sum of the matrices of absolute potential of certain data, uncertain data and shapes.

The edge of this square is set to be equal to the absolute potential value of the functional area the cell belongs to. We used the values of functional areas in this way since the absolute potential of functional areas was assigned on the basis of the finds that can be present in the functional areas: therefore, in higher valued functional areas, it is justified that the region in which the potential is spread is larger, and vice versa.

- When a mask as in the previous step is constructed, the total weight (i.e. the sum of weights distributed by a cell) inside the mask is given by the value of the functional area plus a value proportional to the sum of synchronic and diachronic associations. We used this value to address the total weight because the "quantity of potential" that a cell can spread is influenced as well by the probability of finding high or low valued finds in the nearby.

- The distribution of weights in the mask around each cell is given by the uniform distribution weighted by the geomorphologic values of the mask around the cell, and weighted by the functional areas values. This is because the geomorphologic datum constitutes a basic influence on the spread or archaeological potential, and because the functional areas values - since they are proportional to the total potential of the finds you can find in the area can be used to weight the diffusion of potential.

The model uses the data described above, to estimate the archaeological potential. The algorithm is made of a basic procedure, applied repeatedly, consisting in a modification of the standard PageRank, whose output is the vector of the estimated archaeological potential:

1. The vector $\mathrm{D}$ representing available data and the matrix of weights $\mathrm{S}$ are generated as described above;

2. The following iterations are performed:

$$
\begin{aligned}
& \text { for } i=1, \ldots, 1000 \\
& \begin{aligned}
A & =S \cdot x+\left[\begin{array}{ccc}
1 / n & \cdots & 1 / n \\
\vdots & \ddots & \vdots \\
1 / n & \cdots & 1 / n
\end{array}\right] \cdot x ; \\
A & =(1-\text { yield }) \cdot A+\text { yield } x ; \\
\underline{u} & =[11 \ldots 1] ; \\
y & =\text { rel } \cdot(A)+(1-r e l) \cdot\left[D \cdot\left(u^{T} \cdot x\right)\right] ; \\
y & =\frac{y}{\sum_{i=1}^{n} y_{i}} \\
x & =y ;
\end{aligned} \\
& \text { end } \\
& D=\text { speed_up } x+(1 \text {-speed_up }) \cdot D ;
\end{aligned}
$$

In these formulas $\mathrm{x}$ is a stochastic (i.e. the sum of its component equals 1) random column vector

\begin{tabular}{|c|c|}
\hline $\begin{array}{l}\text { Each cell distributes its importance to a } \\
\text { square mask of cells }\end{array}$ & $\begin{array}{l}\text { The edge of the square is given by the absolute potential value of the functional } \\
\text { area the cell belongs to }\end{array}$ \\
\hline The sum of weights distributed by a cell & $\begin{array}{l}\text { Given by the value of the functional area plus a value proportional to the sum of } \\
\text { synchronic and diachronic associations }\end{array}$ \\
\hline The distribution of weights & $\begin{array}{l}\text { Given by the uniform distribution weighted by the geomorphological values of the } \\
\text { mask around the cell, and weighted by the functional areas values }\end{array}$ \\
\hline
\end{tabular}
of dimension $\mathrm{n}$, used as an initial condition for the application of the iteration described in the "for" cycle (the result of these iterations are independent of the initial condition). algorithm:

The following parameters are used in the

- Maxit (natural number) is the number of times the steps 1. and 2. are executed. Each time we

Table 2. Computation of the matrix of weights. 
applied steps 1 . and 2. the algorithm makes a step in the prediction of archaeological potential, and after each step the result is taken as the new starting point for the next step. So, the greater maxit is, the more the predictions "turn from" the original data.

- Speed_up (belonging to $[0,1]$ ) is the weight expressing the part of the new absolute potential due to the results of the application of steps 1 . and 2., and the part due to the absolute potential of the previous step. So, the more speed up approaches 1 , the less the new computation is due to the data from the previous step.

- Rel (belonging to $[0,1]$ ) is the parameter determininghowmuch wetakeinto consideration the potential given by the weight matrix $\mathrm{S}$ (relations), with respect to how much we take in consideration the potential given by the values of absolute potential. So, the closer rel is to 1 , the less the absolute values of the potential are taken in consideration, and the more the matrix of weights $\mathrm{S}$ (i.e. the relations) is preeminent in determining the archaeological potential.

- Yield (belonging to $[0,1]$ ) is the amount of potential each cell keeps for itself, with respect to the rest, which is distributed on the basis of the weight matrix S. So the closer yield is to 1 , the more each cell keeps potential for itself.

\section{The Results}

The map of archaeological potential was created for each one of the 7 layers, one for each archaeological period under consideration: Protohistory, Etruscan Period, Roman Period, Late Roman Period, Early Medieval Period, LateMedieval Period, Modern Age, Contemporary Age. The final result was tested by means of the data of 14 new cores. Those data could not be included in a specific archaeological period, because of the nature itself of the method of investigation. Hence the validation of the results provided by thealgorithm was performed on the overall archaeological potential. The overall absolute potential was divided into 5 levels, in the same way as the estimated archaeological potential. The comparison was performed computing the difference between the level of the overall estimated archaeological potential and the level of the overall

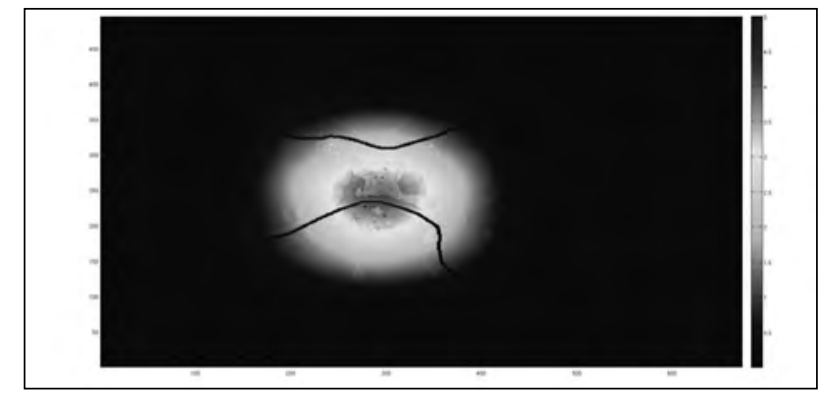

Figure 4. The result of the application of the algorithm to estimate the archaeological potential, for the Late Medieval Period.

absolute potential. The proportion of exactly estimated potential levels is $9 / 13=69,2 \%$, while the maximum error is 1 , with an average error of 0.3077 (Dubbini 2013).

The results presented, including the archaeological potential map, aretobeconsidered the first steps towards an automatic, formally definable, and repeatable approach to the computation of archaeological potential. Of course no completely automated procedure would be possible in this and any task involving social and human behaviour, so also in the proposed algorithm the procedure is controlled by the users (archaeologists), who can manage the whole process assigning values to parameters. For these reasons, the map of archaeological potential should be always evaluated in conjunction with the interpreted archaeological data published in MappaGIS (MAPPA 2014b), and with the raw data released as open data in MOD (MAPPA 2014c). In this way, the predictive map of archaeological potential is a useful and powerful tool both for land management and for archaeological research.

\section{Acknowledgements}

MAPPA project has been supported by Regione Toscana and is carried out by the Department of Archaeological Sciences, Department of Earth Sciences, and the Department of Mathematics of the University of Pisa, with external collaboration from the Regional Directorate for Cultural and Landscape Heritage of Tuscany, the Superintendency for Archaeological Heritage of Tuscany, the Superintendency for Architectural, Landscape and Ethno-anthropological Heritage for the Provinces of Pisa and Livorno, the Municipality 
of Pisa, the National Institute of Geophysics and Vulcanology, the National Aerial Photograph Archive, and the Digital Culture Laboratory CISIAU Interdepartmental Centre of Information Services for the Humanities.

\section{Bibliography}

Anichini, F., M. Bini, F. Fabiani, G. Gattiglia, S. Giacomelli, M. L. Gualandi, M. Pappalardo, and G. Sarti. 2011. "Definition of the parameters of the Archaeological Potential of an urban area." MapPapers 1:47- 49. Accessed October 26, 2013. doi: 10.4456/MAPPA.2011.04.

Anichini, F., F. Fabiani, G. Gattiglia, and F. Ghizzani Marcì. 2013. "Questione di pesi: valori, parametri, relazioni per il calcolo del potenziale archeologico." In MAPPA. Metodologie Applicate alla Predittività del Potenziale Archeologico. Volume II, edited by F. Anichini, N. Dubbini, F. Fabiani, G. Gattiglia, and M. L. Gualandi, 89- 100. Roma: Edizioni Nuova Cultura.

Bini, D., N. Dubbini, and S. Steffè. 2011. "Mathematical models for the determination of archaeological potential." MapPapers 1:77-85. Accessed October 26, 2013. doi: 10.4456/ MAPPA.2011.08.

Bini, D., N. Dubbini, and S. Steffè. 2012. "On the two main issues about the application of page rank for the determination of archaeological potential." MapPapers 2:45-50. Accessed October 26, 2013. doi: 10.4456/ MAPPA.2012.04.

Dubbini, N. 2013. "L'algoritmo MAPPA." In MAPPA. Metodologie Applicate alla Predittività del Potenziale Archeologico. Volume II, edited by F. Anichini, N. Dubbini, F. Fabiani, G. Gattiglia, and M. L. Gualandi, 101- 114. Roma: Edizioni Nuova Cultura.

Dubbini, N., and G. Gattiglia. 2012. "Mathematical Models for the Determination of Archaeological Potential." In Archaeology in the Digital Era. Volume II. e-Papers from the 40th Annual Conference of Computer Applications and Quantitative Methods in Archaeology (CAA), Southampton, 26-29 March 2012, edited by G. Earl, T. Sly, A. Chrysanthi, P. Murrieta-Flores, C. Papadopoulos, I. Romanowska, and D. Wheatley, 710-719. Amsterdam: Amsterdam University Press.

Fabiani, F., and G. Gattiglia. 2012. "The digital archiving structure." In MAPPA. Methodology Applied to
Archaeological Potential Predicitivity. Volume I, edited by F. Anichini, F. Fabiani, G. Gattiglia, and M. L. Gualandi, 4 - 73. Roma: Edizioni Nuova Cultura.

Langville, A. N., and C. D. Meyer. 2006. Google's PageRank and Beyond: The Science of Search Engine Rankings. Princeton: Princeton University Press.

MAPPA 2014a. “Mappa project.” Accessed January 15. http:// www.mappaproject.org/ .

MAPPA 2014b. “MappaGIS.” Accessed J anuary 15. http:// www.mappaproject.org/ webgis/ .

MAPPA 2014c. "MAPPAopenDATA." Accessed January 15. http:// www.mappaproject.org/ mod/ .

Shannon, C. E. 1948. "A Mathematical Theory of Communication." The Bell System Technical Journal 27:379- 423, 623- 656 . 


\title{
Kolmogorov-Smirnov Statistics in the Context of Centuriation
}

\author{
John William Michael Peterson \\ University of East Anglia, UK
}

\begin{abstract}
:
The Kolmogorov-Smirnov D statistic may be used to assess the relationship between archaeological sites and models of Roman centuriated cadastres. Interactive web pages allow exploration and learning about (i) the relationship of the $\mathrm{D}$ value to site frequency and spatial distribution and (ii) the sensitivity of $\mathrm{D}$, in a particular case, to variation in the parameters of a model. The latter investigation reveals that, within narrow limits, only parameter values of a published hypothetical centuriation give significant D values for medieval church sites in a neighbouring area. This suggests that the cadastre existed and extended there.
\end{abstract}

\section{Keywords:}

Kolmogorov-Smirnov, D-statistic, Centuriation

The South Norfolk "A" Roman cadastre was first presented at the CAA conference 25 years ago (Peterson 1988a) and a plan was also published elsewhere (Fig. 1). Hypothetically, the system was a centuriation extending (at that time) approximately 25km south of Norwich (UK) (Fig. 1).

The parameters of its model were (i) the Ordnance Survey (OS) grid reference of one intersection (indicated by a star in the figure), (ii) the assumed module (grid square size) of $709.5 \mathrm{~m}$ and (iii) the orientation of the system relative to OS grid north. This last parameter was calculated from the coordinates of two points lying on features corresponding to parallel grid lines (indicated in the figure by arrows).

The OS grid references of intersection points were then calculated by a Basic program (later replaced by a spreadsheet) and plotted on paper maps. Major topographic features (roads, paths and parish boundaries) were traced if they corresponded to hypothetical cadastral grid lines (limites) drawn on the maps, thus producing possible remnants of the system. This proposed Roman system did not find favour with British commentators, but gained some publication and acceptance in parts of continental Europe (Chouquer 2013; Chouquer and Favory 1992; Peterson 1998).

Apartfrom theperception of possiblesurviving linear traces, a hypothetical centuriated survey may be examined by measuring the association of sites

Corresponding author: j.peterson@uea.ac.uk with its limites, in the expectation that they will be closer than would be seen by chance. The South Norfolk "A" system, as originally proposed, was unsuitable for this test, because of limited data, but another independently proposed centuriated system, in Dutch Limburg, proved more rewarding. A spreadsheet was used to calculate the distances of various sets of Iron Age and Roman sites from the limites. The numbers observed and expected within a given distance were ordered cumulatively and, for each set of sites, the unlikelihood of the observed distributions was calculated using the KolmogorovSmirnov D statistic.

The statistically significant results were presented at the 1995 CAA conference (Peterson 1996), but this apparent confirmation of the proposed Limburg centuriation did not turn out to be convincing. According to Roymans and Derks (2011, 11), archaeologists have become increasingly sceptical of centuriation proposals in the northern Roman provinces, although they may admit the existence of centuriated cadastres as surveys without corresponding land division.

Nevertheless, further examination of a possible extension of South Norfolk "A" seems to reveal a result similar to that obtained in Limburg. Cartography shows that many of the existing boundaries in Lothingland, the eastern coastal area between Great Yarmouth and Lowestoft (Fig. 2), have its orientation. This similarity of orientation of linear features might be attributed to natural influences, particularly the orientation of 


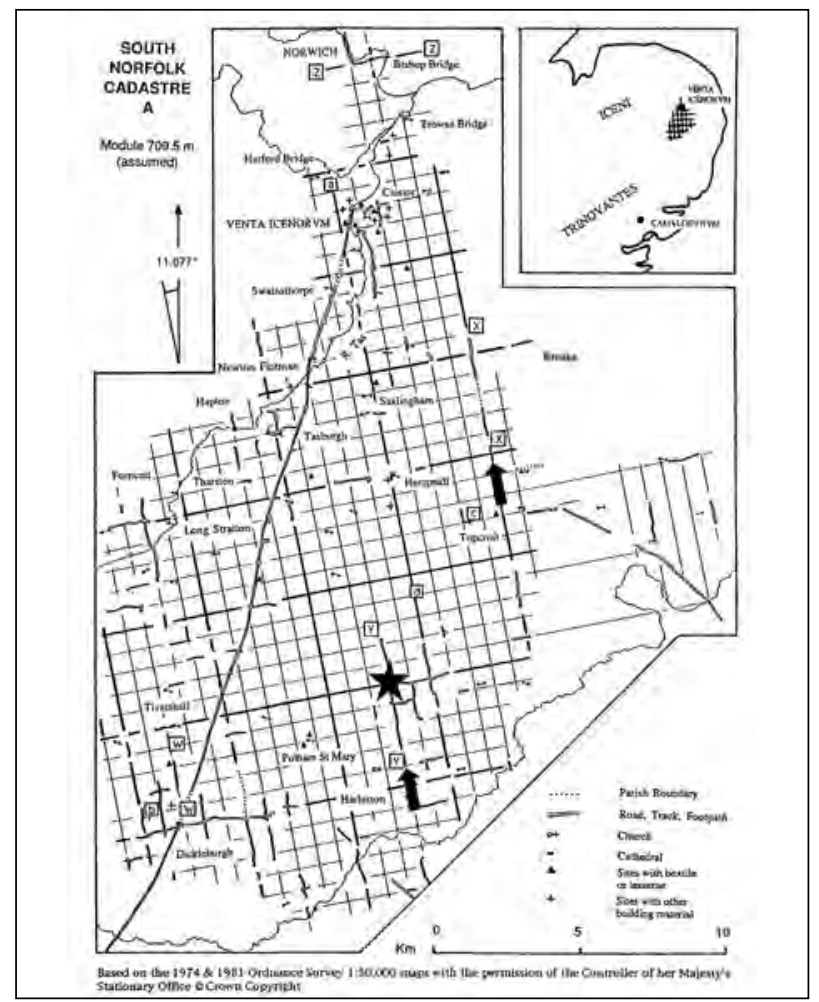

Figure 1. The South Norfolk A cadastre (Peterson 1988b: Fig. 8, with additions).

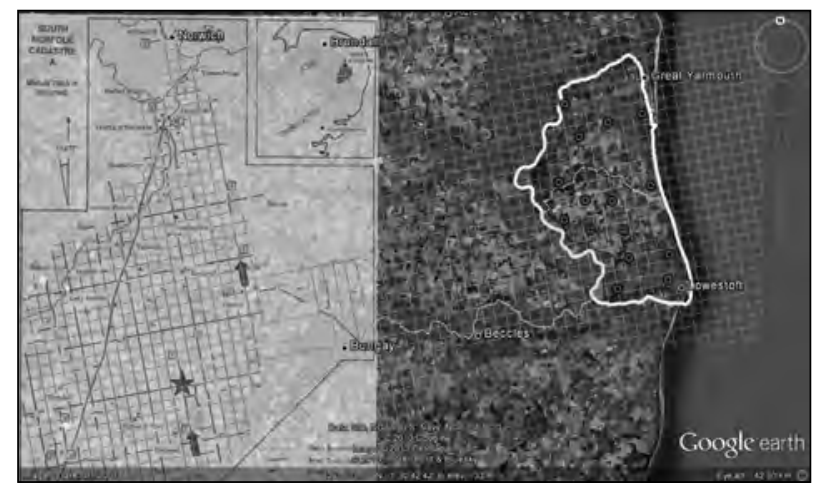

Figure 2. Google Earth image with (left) correctly positioned overlay of Figure 1 and (right) Lothingland outlined in white.

Lothingland's eastern coast, but it is also noticeable that medieval churches (Fig.2, the round symbols), which may be thought of as point features, are on or close to hypothetical limites or lines that divide centuries in half. The now-isolated church of Ashby (Fig. 3) is an example of the latter.

Since Lothingland is defined by natural water features, the medieval church sites within it are an

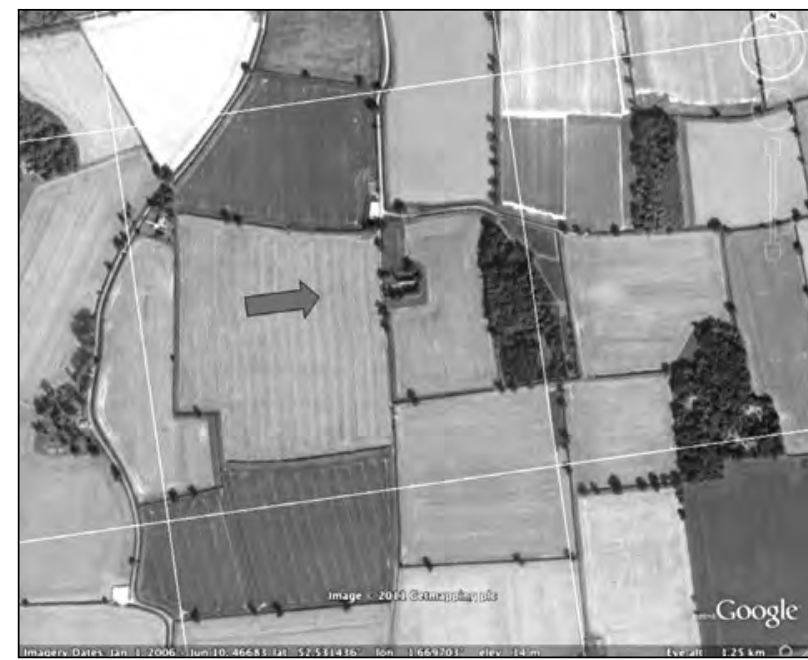

Figure 3. Landscape in central Lothingland with computer-generated grid of "South Norfolk " $A$ " (white lines) and postion of Ashby church (arrow).

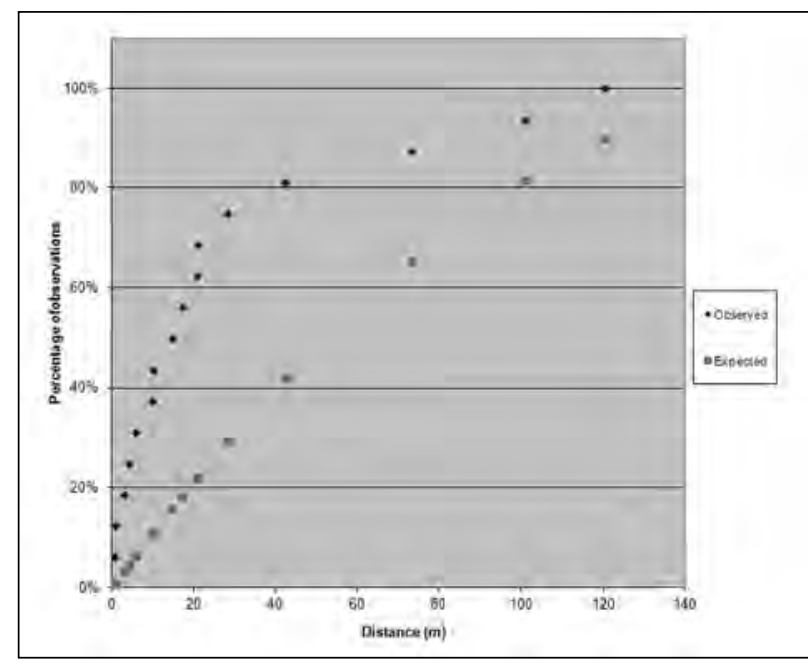

Figure 4. Kolmogorov-Smirnov graph for Lothingland medieval churches.

independently defined set of proxy data that may be used as to assess the plausibility of the original hypothesis. This area contains 16 church sites. The Kolmogorov-Smirnov D value for them, as compared to a random distribution of points in a half size grid (module $=354.75 \mathrm{~m}$ ), indicates a very low probability $(\mathrm{D}=0.4670, \mathrm{p}<0.0005)$ that the distribution of their distances from the grid lines would be observed if the sites were placed randomly with respect to the grid. It is probably a reasonable assumption that, although the distances of the church sites from each other will not be randomly distributed because (for example) there will 


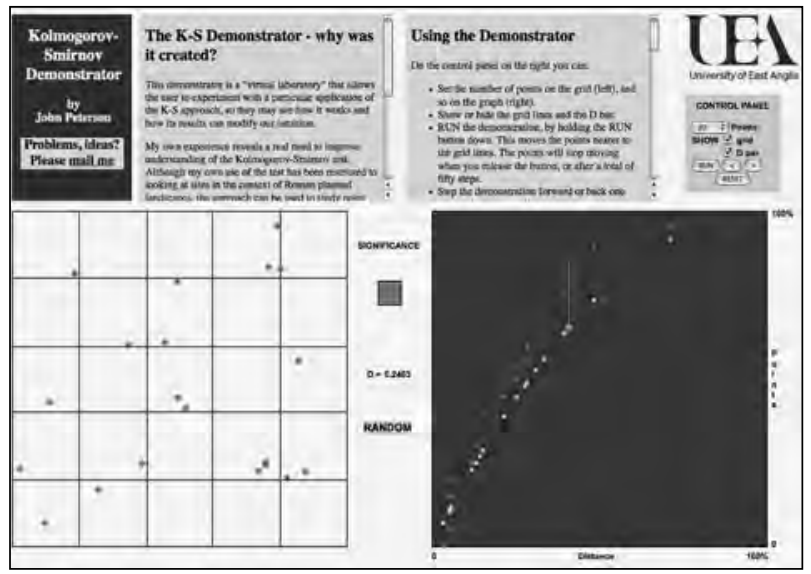

Figure 5. Output from Kolmogorov-Smirnov demonstator for a random 20 point distribution.

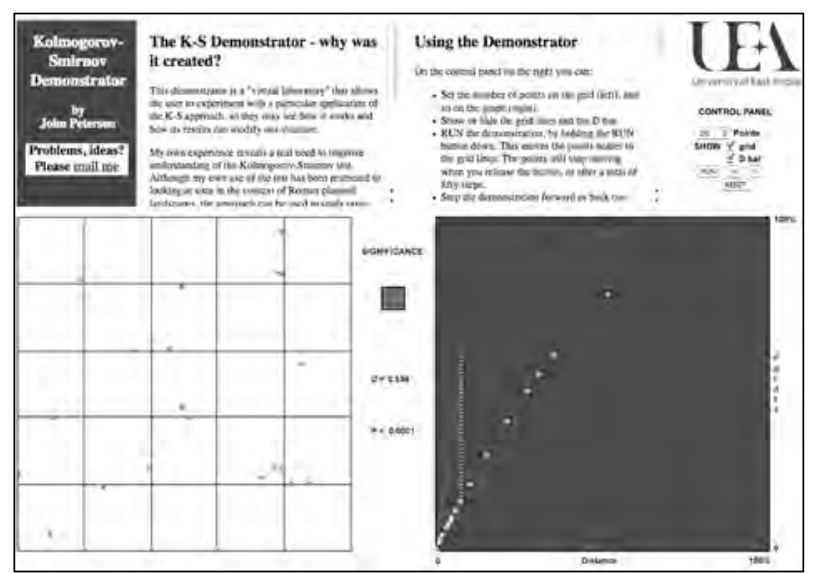

Figure 6. Increased $D$ value and significance level resulting from moving points closer to grid lines (cf. Fig. 5).

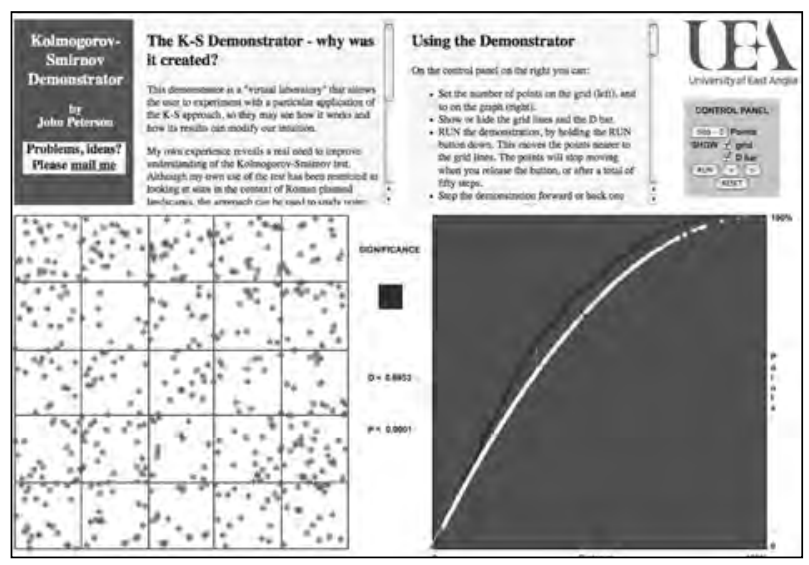

Figure 7. Output from Kolmogorov-Smirnov demonstator for a non-random 500 point distribution. probably be a minimum distance between churches, the distribution of their distances from an arbitrary set of grid lines will, on the null hypothesis, be a sample drawn from a uniform random distribution of points in the grid square.

Although this result is positive, those unaccustomed to using numerical approaches may find the Kolmogorov-Smirnov graph, including that for the Lothingland churches (Fig.4), hard to appreciate. In an attempt to overcome this difficulty, a dynamic web page, the Kolmogorov-Smirnov Demonstrator, has been developed in prototype. This displays (to the left) a set of points randomly distributed in a gridded space, and also (to the right) the corresponding Kolmogorov-Smirnov graph. The maximum $D$ value and its level of significance is also displayed (Fig. 5). A box in the centre of the screen represents the significance level by its colour, from green (not significant) to red (highly significant). The symbols representing the observations are coloured in the same way.

The user can command the software to move points towards grid lines and see how the $\mathrm{D}$ value, and the unlikelihood of the distribution, increases as the points approach the lines of the square grid (Fig. 6).

An important feature is that the number of points can be altered. This reveals that intuition is not very useful in assessing this sort of spatial relationship. A small number of randomly distributed points can seem to be closely associated with the grid lines when they are not (Fig. 5). Conversely, a display of 500 points in the square grid can resemble a random distribution when there is a less than 1:10,000 chance of it being so (Fig. 7).

The Kolmorov-Smirnov Demonstrator may allow better understanding of the meaning of the resulting statistic, and show that the use of this statistical method can provide results that are more reliable than unaided intuition but, even when the method is understood, the results may still not convince.

At the 1995CAA conferenceIrwin Scollar asked the author if it could be proved that the parameters for the Limburg cadastre were exceptional in producing such a high $\mathrm{D}$ value for some of the site 


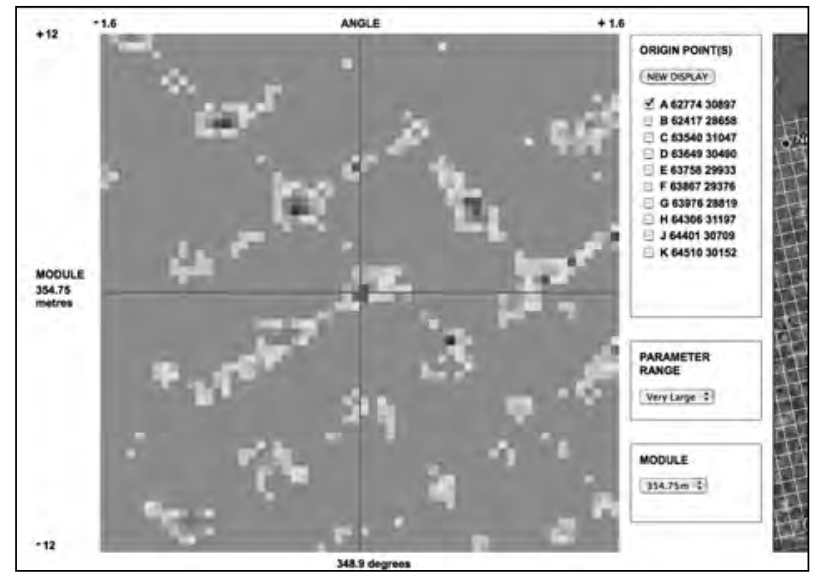

Figure 8. Right hand side of Kolmogorov-Smirnov Sensitivity Test screen. Point A (alone) selected as origin.

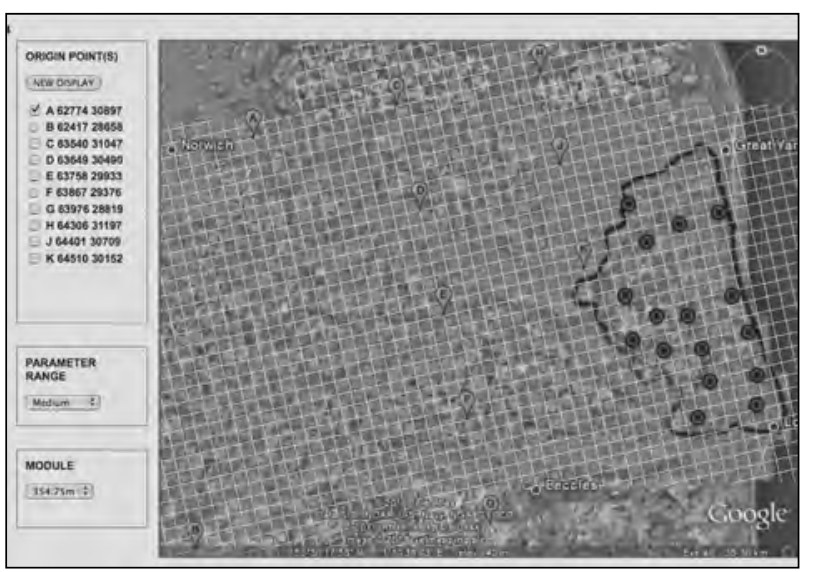

Figure 9. Left hand side of the above display (Fig. 8), showing $D$ values with medium parameter range.

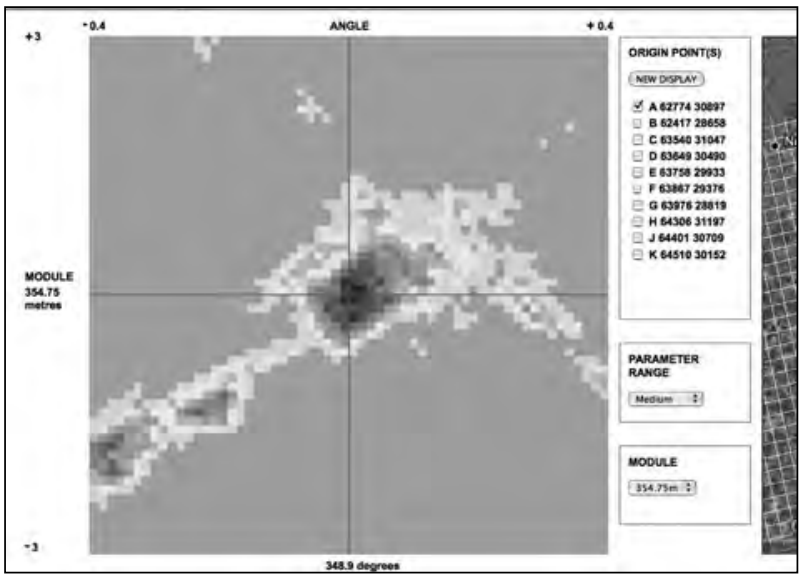

Figure 10. Display with point A selected as origin and very large parameter range. distributions. Might there not be other parameters that would produce an equally unlikely result? This was a difficult question to answer. The number of possible parameter sets is very large; much laborious work would be involved. Consequently, at that time the matter was left.

Now, increased computing power is available and, for the Lothingland church sites, there is a significantly different question. Given that the choice of parameters in this new area must be constrained by the need for the hypothetical grid not to differ significantly from the grid already postulated in the original area (Fig. 1), we may fix one of the original grid intersection points and allow the other parameters to vary, thus indicating the sensitivity of $\mathrm{D}$ to changes in them. Several points defined by the original model were chosen as possible fixed "origin" points and displayed on the right hand side of another dynamic web page (Fig. 8).

Initially a single origin point, A (Fig.8 top left) and a medium parameter range (Angle $=348.9 \pm$ 0.4 , module $=354.75 \pm 3$ ) were used.

For this origin, near Norwich, a plot of maximum $\mathrm{D}$ values, in the two dimensions of variation in angle and half-grid size (Fig. 9), showed an island of improbability around the original parameter values, indicated by increasingly red cell colour in a green sea of randomness. However, contrary to expectation, an outlying smaller island of improbability could also be seen. This was puzzling.

Even more puzzling was the result obtained by continuing to use the same single origin point, but increasing the parameter range (Fig. 10). Other much larger islands, arranged in a almost regular pattern, then appeared. However, it could be seen that the position of these other islands changed with the choice of origin point, whereas the island around the original parameter values changed very little in position and shape. This suggested that the other islands were "ghosts" that depended on the choice of origin.

Since the ghosts were in different positions for each origin point it was decided to generate a plot of mean $\mathrm{D}$ values produced using more than one origin point. When points E, G and J were used (Fig. 8), this eliminated nearly all the ghosts (Fig. 


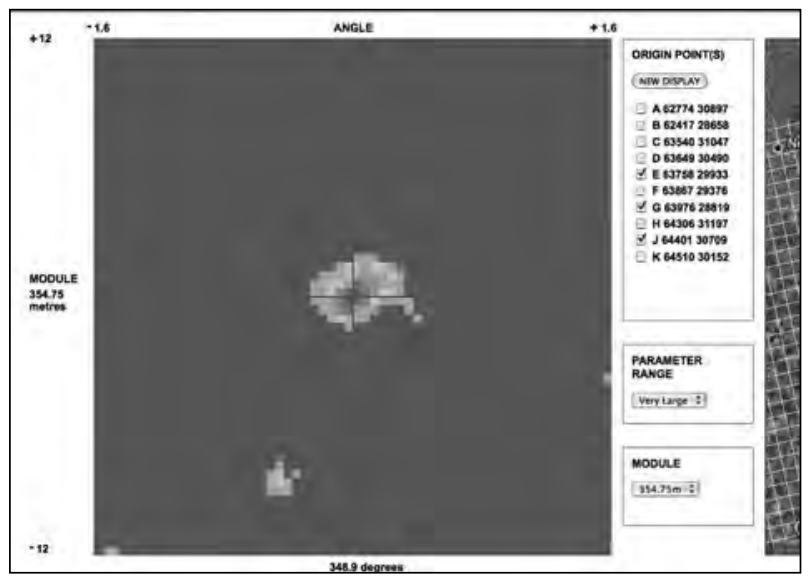

Figure 11. Display of mean $D$ values for three origin points, very large parameter range.

11). Closer inspection, using the same points but a small parameter range (Fig.12) then indicated that the association between church sites and the grid is sensitive to a small change in angle $\left( \pm 0.05^{\circ}\right)$ and module $( \pm 0.5 \mathrm{~m}$ in half the side of a century).

In consequence it seems that only parameter values very close to those originally proposed would explain the anomalous distribution of Lothingland churches with respect to its half-size grid. This piece of evidence seems to support the original hypothesis.

\section{Bibliography}

Chouquer, G. 2013. "Actualités de la centuriation: interrogations autour de la méthodologie." Accessed October 15. http:// www.archeogeographie.org/index. php?rub=presentation/infos/ centurs.

Chouquer, G., and F. Favory. 1992. Les arpenteurs romains: théorie et pratique. Paris: Errance.

Peterson, J. W. M. 1988a. "Information systems and the interpretation of Roman cadastres." In Computer and Quantitative Methods in Archaeology 1988: CAA 88. edited by S. P. Q. Rahtz, 133- 149. Oxford: B.A.R.

Peterson, J. W. M. 1988b. "Roman cadastres in Britain: I - South NorfolkA.” Dialogues d'histoire ancienne 14:167199.

Peterson, J. W. M. 1996. “A computer model of Roman landscape in South Limburg." In Interfacing the past: computer applications and quantitative methods in

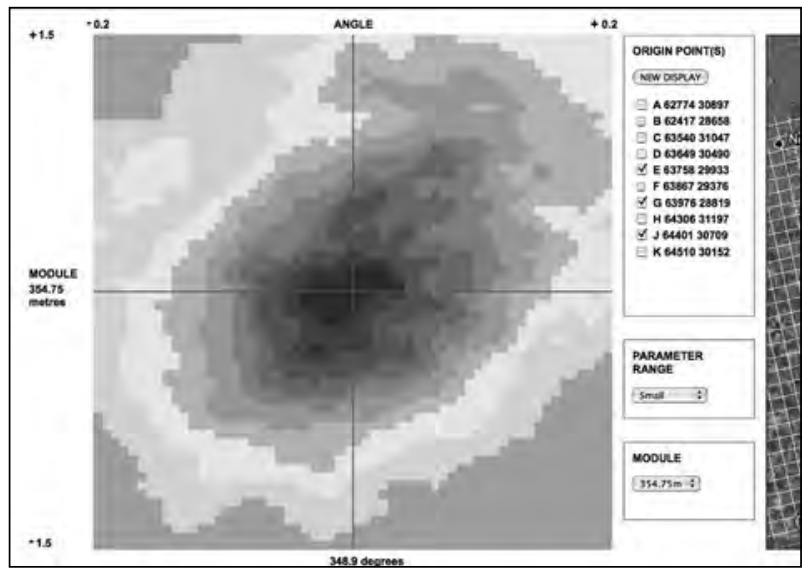

Figure 12. Display using the same points as in Figure 11, small parameter range.

archaeology 1995, edited by $\mathrm{H}$. Kamermans and $\mathrm{K}$. Fennema, 185- 194. Leiden: University of Leiden.

Peterson, J. W. M. 1998. "South Norfolk 'A'." In Atlas Historique des cadastres d'Europe 1, Dossier I - Royaume-Uni, edited by M. Clavel-Lévêque and A. Vignot, 1-11. Luxembourg: Office for Official Publications of the European Community.

Roymans, N., and T. Derks. 2011. "Studying Roman villa landscapes in the 21st century. A multi-dimensional approach." In Villa Landscapes in the Roman North: Economy, Culture and Lifestyles, edited by N. Roymans and T. Derks, 3-44. Amsterdam: Amsterdam University Press. 


\title{
Integration of CIDOC CRM with OGC Standards to Model Spatial Information
}

\author{
Gerald Hiebel \\ Foundation for Research and Technology, Greece and University of Innsbruck, Austria \\ Martin Doerr \\ Foundation for Research and Technology, Greece \\ Øyvind Eide \\ Universität Passau, Germany
}

\begin{abstract}
:
The ISO certified ontology of the CIDOC CRM provides the concepts to model archaeological data in their semantic context while the Open Geospatial Consortiums (OGC) defines standards for geographic information. In this paper we present the CRMgeo extension which integrates the CIDOC CRM the with the OGC standard of 'GeoSPARQL-A Geographic Query Language for RDF Data' which is based on concepts of the existing OGC standards. To bridge the gap between the two conceptual models CRMgeo differentiates two kinds of place concepts. Phenomenal places that derive their identity through real world objects and the spacetime volumes they occupy and declarative places that have been created through human definitions and may approximate phenomenal places. These place concepts are applied to the practice of referencing places with placenames available in gazetteers and related to the corresponding OGC standard. CRMgeo provides the ontological foundation to integrate CIDOC CRM datasets with GIS data.
\end{abstract}

Keywords:

Ontology, CIDOC CRM, GIS, OGC Standards, CRMgeo

\section{Introduction}

There is a growing interest to enrich cultural heritage data with precise and well identified descriptions of location and geometry of sites of historical events or remains, objects and natural features. On the one side there is already a tradition of more than two decades of using GIS systems for representing cultural-historical and archaeological data and reasoning on properties of spatial distribution, vicinity or accessibility. These systems tend to be closed and focus more on representing feature categories by visual symbols at different scales than integrating rich object descriptions. They have been very successful in all kinds of 'geosciences', resource management and public administration, whereas cultural heritage is only a marginal application area. On the other hand, archives, libraries and museums keep detailed historical records of things with very poor spatial determination. Often in thelanguage of the source or

Corresponding author: gerald.hiebel@uibk.ac.at local context, which was more or less unambiguous at the time of creation. In other cases, only wider geopolitical units, such as 'Parthenon in Athens,' are used. They rather focus on typologies, individual objects, people, kinds of events, precise dates and periods. This practice comes now in conflict when users want to integrate city plans, tourism guides, detailed excavation or restoration records, where the fact that 'people know quite well where the Parthenon lies' or 'you'll seeit when you go to Athens' is not helpful for advanced IT systems. Thus, the two traditions, the 'GIS community' and the 'cultural heritage community' have developed standards which precisely reflect the two different foci - the Open Geospatial Consortium (OGC) Standards for Geographic Information (OGC 2013) which are the building blocks of the recently published GeoSPARQL ontology (OGC 2012) and the ontology of the CIDOC CRM (Le Boeff et al. 2012) which is the ISO standard for representing cultural heritage information. To identify the formal language of each ontology in this paper we use subscript ${ }_{C}$ for CIDOC 
CRM and subscript ${ }_{g}$ for GeoSPARQL following the concepts and properties of the ontologies.

The integration of detailed geoinformation with CIDOC CRM is a research issue that has been addressed in various projects. The AnnoMAD System (Felicetti et al. 2010) already uses OGC standards to represent geoinformation within CRM structures when utilising Geography Markup Language (GML) in Information Objects that refer to Places of cultural objects. The CLAROS project (OeRC 2014) uses the 'Basic Geo Vocabulary' RDF representation (W3C 2014). English Heritage created the CRMEH (University of South Wales 2014), an extension to the CIDOC CRM for archaeological excavations with single context recording. The extension uses the concept of Spatial Coordinates within the CRM to relate to spatial $\mathrm{X}, \mathrm{Y}$ and $\mathrm{Z}$ coordinates through datatype properties. At the German National Museum the WissKI project (WissKI 2014) started an initiative to investigate the possibilities of integrating coordinate information within the CRM (Hiebel et al. 2012).

In this attempt to combine GeoSPARQL with CIDOC CRM, we experienced a surprise: the two standards shared no concepts. Even though the CRM was explicitly intended to interface with OGC Standards, neither of the standards allow for expressing objectively where something is in a way which is robust against changes of spatial scale and time. For instance, the CRM allows for specifying a property has former or current location ${ }$, without declaring if the location is or was the extent of the object, was within the extent of the object or included its extent. The statement Forum Romanum has former or current location ${ }_{c}$ Rome could mean that thebuiltstructures of the Forum Romanumareeither close to, within the boundaries or overlapping with (current?) Rome. GeoSPARQL, on the other side, allows for assigning one or more precise Geometries to a Feature ${ }_{\sigma^{\prime}}$ but does not say how the real matter of theFeature with its smaller irregularities relates to those. The Forum Romanum could be represented as a point, a rectangle containing the (currently known?) extent of the built structures, polygons representing the footprints of the ruins or even 3D models representing virtual reconstructions of the buildings. So, for any Feature there is a spatial scale at which a Geometry ${ }_{g}$ of a detail cannot be compared any more to the Geometry of the whole, nor is the temporal validity range explicitly modelled even though the OGC Standards provide mechanisms for assigning a temporal component. We need to link the two ontologies, modelling in detail the overlap. This allows for covering the underdetermined concepts and properties of each of the ontologies by shared specialisations rather than generalisations. Through this we reached a surprisingly detailed model which seems to give a complete account of all practical components necessary to verify such a question, in agreement with the laws of physics, the practice of geometric measurement and archaeological reasoning. This model called CRMgeo (identified by subscript ${ }_{o c}$ ), indeed appears to have the capability to link both ontologies and show the way to correctly reconcile data at any scale and time. Not by inventing precision or truth that cannot be acquired, but by quantifying or delimiting the indeterminacies introduced through interpretations or measurement methods, as is good practice in natural sciences. Through the following example of representing the Varus battle in our model we will introduce concepts that are neither available in CIDOC CRM nor in GeoSPARQL. Nevertheless we believe these concepts to be necessary in order to model observations of the remains from historical events and hypotheses about the events.

\section{Refining the Place ${ }_{c}$ Concept of the CIDOC CRM Ontology}

We want to illustrate our refinement of the Place $_{\mathbf{c}}$ concept with the historical event of the Varus battle to describe the epistemological process of defining Places $_{\mathbf{c}}$ based on historical sources and archaeological evidence. In $9 \mathrm{CE}$, three Roman legions under Varus were ambushed by allied German tribes under Arminius. A few years later Roman troops visited the battlefield and buried the Roman remains. This story was described in Roman sources like the Annals of Tacitus (The Latin Library 2014). The precise location of the battle place was not included in ancient texts and is unknown. The descriptions of the battle from Roman sources include indications of the place in relation to rivers and indications of the kind of terrain in which the battle was fought. Based on these sources, various hypothesis have been formulated about the real place of the battle. One of the hypotheses from the 18th century (Stüve 1789) was supported by archaeological finds in the late 1980 os (Harnecker 


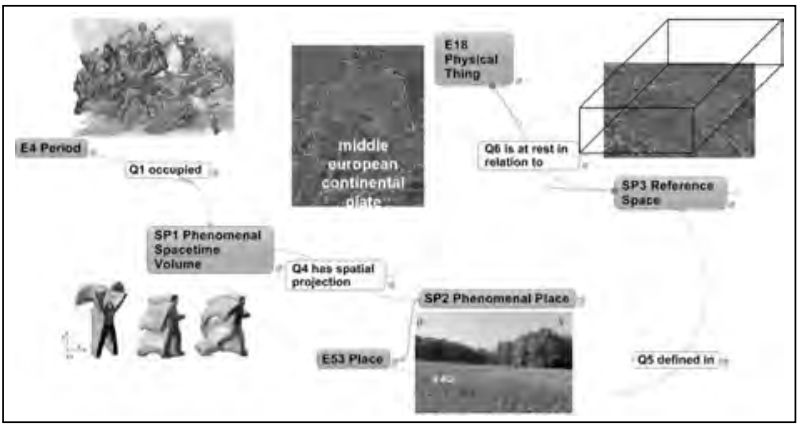

Figure 1. Introducing Phenomenal Space Time Volume ${ }_{c g}$, Phenomenal Place ${ }_{c g}$ and Reference Space ${ }_{c g}$.

1999). A key indication of the correct identification of the battle place is the recovery in situ of human bones that show clear traces of having been exposed to the elements for some time before being buried: this sequence matches the story proposed by the Roman sources.

\subsection{Phenomenal Places $_{\mathrm{cg}}$ based on Phenomenal Spacetime Volumes ${ }_{\mathrm{og}}$ and Reference Spaces $_{\mathrm{og}}$}

We want to introduce the concept of a Phenomenal Place $_{c y}$ to represent the real place where an event happened in history. A prerequisite for the use of the concept in our example is the belief that the Varus battle was a true event. As the battle is bound in time we need another concept that includes the real temporal extent of the battle in addition to the place.

We want to call this concept the Phenomenal (or true) Spacetime Volume $_{c g}$ which is a 4 dimensional point set (volume) that material phenomena like Events (moregenerally Periods $_{c}$ ) or Physical Things occupy in spacetime. It is regarded to be unique but unknown and unobservable in its exact extent. However, in general, there exist kinds of evidence of points in spacetime for which we can tell if they are in or out of a specific Phenomenal Spacetime Volume ${ }_{\text {cy. }}$ It is necessary to compare and relate Events ${ }_{\mathbf{c}}$ or Physical Things with each other. As Archaeology commits to one common reality regardless of the different opinions that exist of this reality the Phenomenal Spacetime Volume is a central concept representing this one reality. The Phenomenal Place $_{o g}$ is a spatial projection of the Phenomenal Spacetime Volume cr $_{\text {within a }}$ Reference Space ${ }_{\text {cg }}$ which is the (typically Euclidian) Space that is at rest in relation to an instance of a

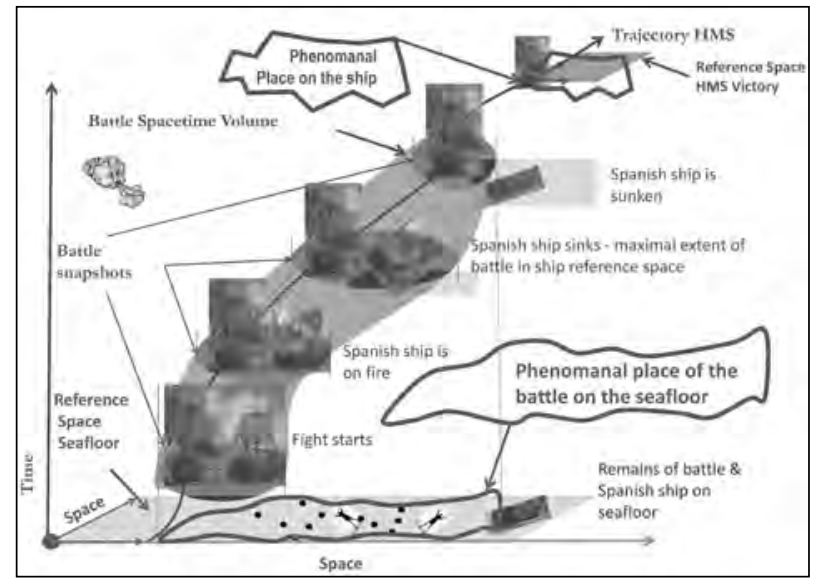

Figure 2. Creation of two Phenomenal Places $_{c g}$ from one Spacetime Volume . .

Physical Thing $\mathrm{c}_{\mathrm{c}}$ and extends infinitely beyond it. In the case of the Varus battle we assume the space is at rest in relation to today's middle European continental plate. Phenomenal Places ${ }_{\mathrm{cg}}$ derive their identity through Events ${ }_{\mathbf{c}}$ or Physical Things ${ }_{\mathbf{c}}$ over the Phenomenal Spacetime Volume ${ }_{\text {og }}$ that they occupy as illustrated in Figure 1.

We want now to illustrate the importance of the Reference Space concept for events taking place on moving objects using as example the Battle of Trafalgar between the English and allied FrenchSpanish fleet and Lord Nelson's death on the HMS Victory. For an historian interested in Lord Nelson's death the events on board of the HMS Victory are important. For an archaeologist interested in the remains of the Trafalgar battle on the seafloor it is important to formulate hypothesis in relation to the seafloor, where we would expect to find debris of the fight. Therefore, depending on the research question, the same event may be projected either on the ship as Reference Space $_{\text {og }}$ or on the seafloor as Reference Space ${ }_{\mathrm{cg}}$. Each projection creates one Phenomenal Place ${ }_{c g}$ resulting in two Phenomenal Places $_{\text {og }}$ of one unique Space Time Volume ${ }_{\text {og }}$. The Phenomenal Place ${ }_{c g}$ on the ship ceases to exist when the ship as base for the Reference Space $_{\mathrm{cg}}$ ceases to exist. The Phenomenal Place on the seafloor ceases to exist when the seafloor disappears under the continental plate (this is relevant for palaeontology). Figure 3 illustrates the projection of the one unique battle SpacetimeVolume $_{\mathrm{cg}}$ on two Reference Spaces $_{\mathrm{cg}}$ resulting in two Phenomenal Places $_{\text {og. }}$. 


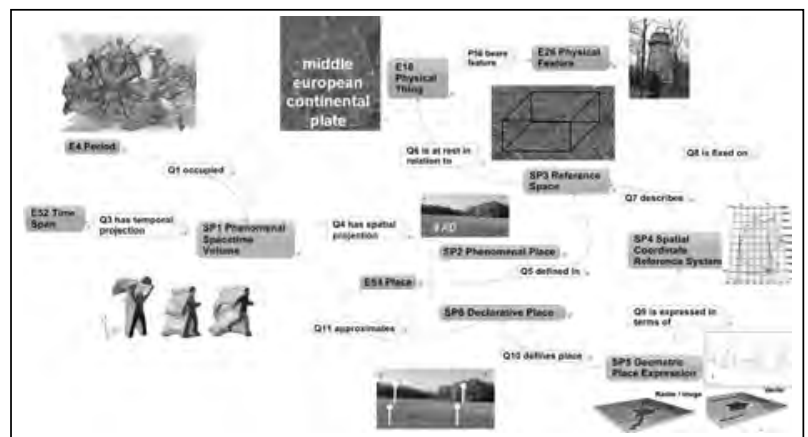

Figure 3. Introducing Geometric Place Expression ${ }_{c g}$ and Declarative Place $_{c g}$ as approximation of a Phenomenal Place $_{c g}$.

2.2 DeclarativePlaces based on Spatial Coordinate Reference Systems cg $_{\text {and Geometric Place }}$ Expressions $_{\mathrm{cg}}$

After introducing the Phenomenal Place ${ }_{\mathrm{cg}}$ as the real place of the Varus battle we want to provide the concepts to approximate its spatial position and extent with Declarative Places ${ }_{\text {cg }}$ that are defined by humans. Locations within the Reference Space ${ }_{c g}$ can be described using some kind of Spatial Coordinate

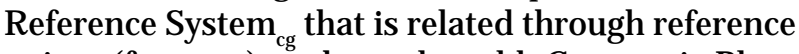
points (features) to the real world. Geometric Place Expressions ${ }_{c g}$ are expressed in a Spatial Coordinate Reference System ${ }_{c y}$. A Geometric Place Expression ${ }_{c g^{\prime}}$ which can be seen as a prescription to find the intended place in the real world, may be created from an observation with a measurement device or the simple drawing of a line on a map. Both actions create a Declarative Place ${ }_{c g}$ that can be visited in the corresponding Reference Space ${ }_{\text {og }}$ of the real world. A Declarative Place $_{\mathrm{cg}}$ derives its identity through the description in the Geometric Place Expression ${ }_{c g}$ and not through a Phenomenal Place that it may approximate. Figure 3 shows the relations between Phenomenal $_{c g}$ and Declarative Places $_{\mathrm{cg}}$ and their related concepts.

\section{Geoinformation Standards}

The standards in the ISO 19100 Series for Geographic Information (ISO 2013) provide the backbone for the development of Geodata Infrastructures like INSPIRE - Infrastructures for Spatial Information in the European Community (European Commission 2014). The development of these standards is realised by the Open Geospatial Consortiums (OGC) which is an international voluntary consensus standards organisation with more than 400 partners. OGC standards are submitted to the ISO process through the ISO/ technical committee 211. They can be grouped in Abstract Specifications defining conceptual models to represent geographic information and Implementation Specifications defining how to implement these conceptual models.

\subsection{Abstract specifications}

The Abstract Specifications use UML (Unified Modelling Language) to describe the classes with their attributes and relations. The fundamental unit of geospatial information within the geoinformation community is the 'Feature' which is defined in ISO 19101as an 'abstraction of a real world phenomenon'. It is a geographic feature if it is associated with a location relative to the Earth. Feature instances derive their semantics and valid use from the meaning of the corresponding real world entities. A layered model abstracts from the real world to a so called 'Project World' which is a world view for a specific task (e.g. cartography, cadastre or pavement management). The categories of features captured in a Project World are feature types. The model describes the relations between real world entities, features and their representations. There are three popular approaches for the modelling of geospatial features and each is specified in a separate abstract specification standard. The first is called 'Features with Geometry' and models the spatial extent of a feature with point, lines, polygons, and other geometric primitives that come from a list of wellknown types. The abstract specification standard is ISO 19107. The second approach is called 'Feature as Coverage' as specified in ISO 19123, including images as a special case. The third approach is 'Feature as Observation' as specified in ISO 19156, where an observation is an action with a result which has a value describing some phenomenon. An observation feature binds a result to the feature upon which the observation was made. The observed property is a property of the feature of interest. All these primary feature types areintimately related, yet have distinct concepts (OGC 2009).

ISO 19136 Geography Markup Language (GML) is one Implementation Specification that is based on the conceptualisations and classes defined in the Abstract Specifications. 


\subsection{GeoSPARQL}

SPARQL is a protocol and query language for the Semantic Web defined in terms of the $\mathrm{W}_{3} \mathrm{C}$ 's $\mathrm{RDF}$ data model in much the same way as SQL is a query language for relational databases. In 2012 the OGCadopted the 'OGCGeoSPARQL - A Geographic Query Language for RDF Data' standard. It defines spatial extensions to the W3C's SPARQL protocol and RDF query language. GeoSPARQL provides now a framework how to implement OGC Standards with semantic technologies through $\mathrm{RDF} / \mathrm{OWL}$ encoding. Its introduction allows the integration of RDF specified information models with the OGC/ ISO standards developed in the geoinformation community. The OGC GeoSPARQL standard supports representing and querying geospatial data on the Semantic Web. It provides the foundational geospatial vocabulary for linked data involving location and defines extensions to SPARQL for processing geospatial data. GeoSPARQL comprises five modules:

1. The Core Component defines top-level RDFS/ OWL classes for spatial objects.

2. The Geometry Component defines RDFS data types for serialising geometry data, RDFS/OWL classes for geometry object types, geometryrelated RDF properties, and non-topological spatial query functions for geometry objects.

3. The Geometry Topology Component defines topological query functions.

4. The Topological Vocabulary Component defines $\mathrm{RDF}$ properties for asserting topological relations between spatial objects.

5. The Query Rewrite Component defines rules for transforming a simple triple pattern that tests a topological relation between two features into an equivalent query involving concrete geometries and topological query functions (OGC 2012).

\subsection{Core component and geometry component}

The Core Component contains two main classes. The root class within the hierarchy of the GeoSPARQL ontology is SpatialObject representing everything that can have a spatial representation. Its

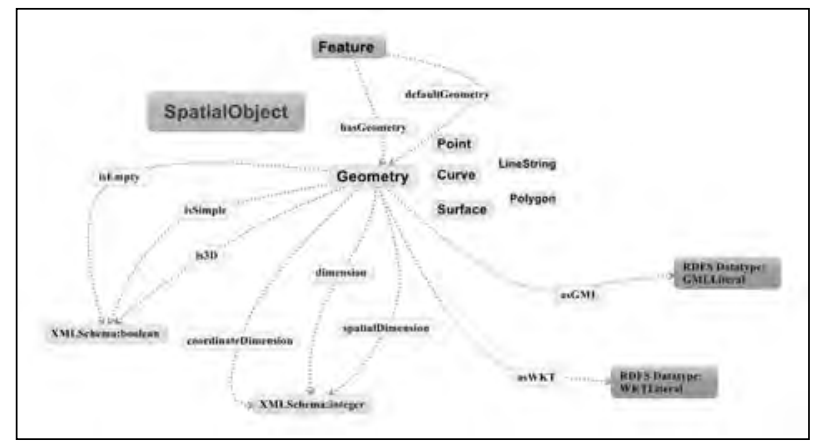

Figure 4. GeoSPARQL Core component classes (SpatialObject $_{g}$, Feature ) and the Geometry $_{g}$ class with their basic relating properties.

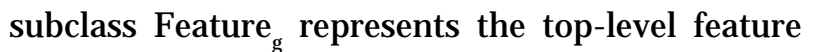
type and is equivalent to GFI_Feature as defined in ISO 19156-Observation and Measurement. In an implementation this abstract class shall be substituted by a concrete class representing a feature type from an application schema associated with a domain of discourse. The Geometry Component defines a vocabulary for asserting information about geometry data, and it defines query functions for operating on geometry data. A single root class Geometry $_{g}$ is defined as a subclass of the SpatialObject $\mathrm{g}_{\mathrm{g}}$ lass defined in the Core Component. As part of the vocabulary, an RDFS data type is defined for encoding detailed geometry information as a literal value. A literal representation of a Geometry is needed so that geometric values may be treated as a single unit. Such a representation allows geometries to be passed to external functions for computations and to be returned from a query. In addition, properties are defined for describing geometry data and for associating geometries with features. To represent the actual coordinates of a Geometry $_{g^{\prime}}$ a so called Serialisation is used. That means that the coordinates are stored in a format which defines the sequence of the characters. Two formats are specified. One is Well Known Text (WKT) Serialisation as defined in ISO 19125 Simple Feature Profile and the other is a GML Serialisation as defined in ISO 19136 Geography Markup Language. These specifications (ISO 19125; ISO 19136) are also the base for subclasses of the geometry class. An $\mathrm{RDF} / \mathrm{OWL}$ class hierarchy can be generated from the WKT or GML schema that implements GM Object from ISO 19107- Spatial Schema as illustrated in Figure 4 for a simplified GML schema. Coordinate reference system information is encoded in the WKT or GML Serialisation. In future there is 


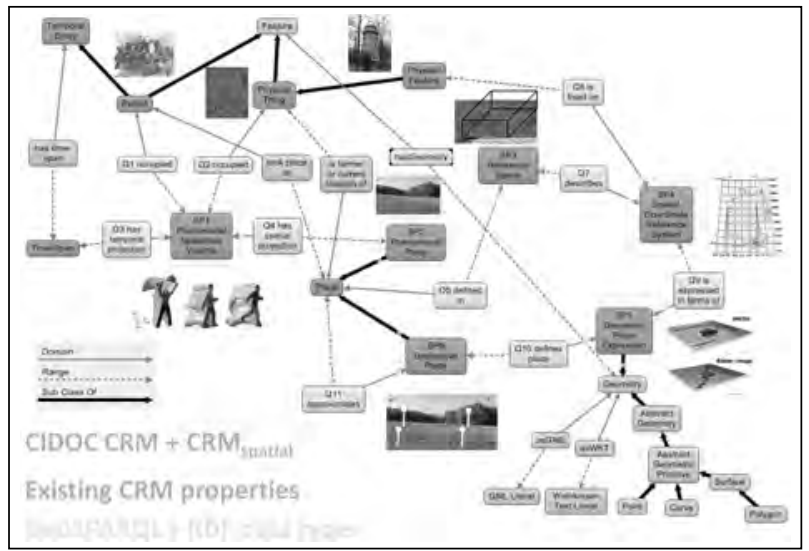

Figure 5. Integration of CIDOC CRM and GeOSPARQL through CRMgeo.

the perspective for further extensions covering $\mathrm{KML}$ or GeoJ SON Serialisations (OGC 2012).

\section{CRMgeo Extension}

The concepts and relations developed in the integration process have been explained and specified in the CRMgeo extension (Doerr, Hiebel and Eide 2013) and implemented in RDFS. Through the explicit modelling of different identities of Phenomenal ${ }_{\mathrm{cq}}$ and Declarative Places ${ }_{\mathrm{cq}}$ we can link CIDOC CRM conceptualisations which are targeted at thephenomenal world with GeoSPARQL concepts. Figure 5 provides a graphical view of CIDOC CRM, CRMgeo and GeoSPARQL classes. The link to the GeoSPARQL class Feature ${ }_{g}$ is realised through Period $_{c}$ (as superclass of Event) and Physical Thing ${ }_{c}$

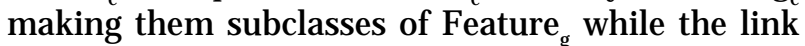
to GeoSPARQL Geometry is through the Geometric Place Expression $_{\text {og. A representation of spatial }}$ content with GML or WKT Literals within the CRM is possible through the GeoSPARQL properties asGML $_{\mathrm{g}}$ or asWKT . It shows that the existing CRM property of is former or current location ${ }_{c}$ relating Physical Things $_{c}$ to Places ${ }_{c}$ is a shortcut of the fully developed path from Physical Thing $\mathrm{g}_{\mathrm{c}}$ through occupied $_{\mathrm{cg}^{\prime}}$ Phenomenal Spacetime Volume ${ }_{\mathrm{og}}$, has spatial projection ${ }_{\text {og }}$ to Phenomenal Place ${ }_{\mathrm{og}}$. In case the destination of is former or current location is a Declarative Place $_{\text {og }}$ the fully developed path has to be extended from the Phenomenal Place through approximates ${ }_{\mathrm{og}}$ to the Declarative Place ${ }_{\mathrm{cg}}$. The same construct is true for Events (being a subclass of Period) and the property took place at $_{\mathrm{c}}$. In GeoSPARQL the property hasGeometry

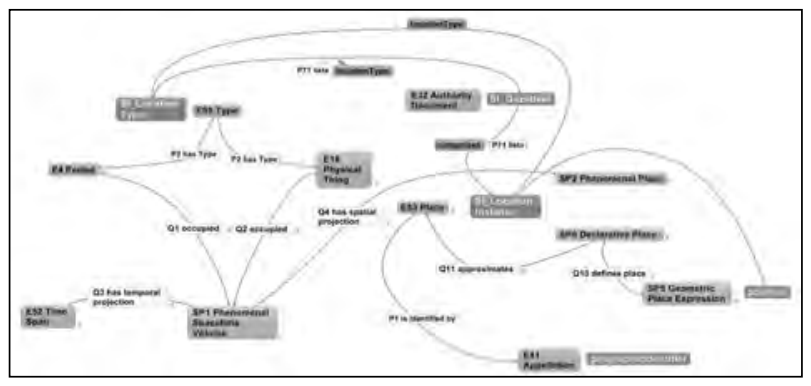

Figure 6. Representing concepts of ISO 19112, Spatial referencing by Geographic Identifiers with CIDOC CRM and CRMgeo.

which connects a Feature g directly to a Geometry $_{g}$ develops in our model to a path that passes through the concepts of Phenomenal Spacetime Volume ${ }_{\mathrm{cog}}$ Phenomenal Place ${ }_{\mathrm{og}}$ and Declarative Place ${ }_{\mathrm{og}}$ to the Geometric Place Expression ${ }_{c}$. These concepts are needed to make explicit that the proposition about the place of an object holds only for a specific time represented in the Spacetime Volume and the geometry is only an approximation of the real place (Phenomenal Place $e_{\text {og }}$ ) of the object.

\section{Representing Geographic Identifiers and Gazetteers}

References to places are often encountered in placenames that can be standardised and made available through gazetteers. Although GeoSPARQL does not include explicitly gazetteers they are defined in ISO 19112 - Spatial referencing by Geographic Identifiers.

The standard defines a model for geospatial references that relate the features and information represented in data or texts to positionsin geographic space. Geographic Identifiers are used to refer to geographic locations as an alternative to coordinates and may be names of towns or settlements or addresses with zip codes and street names. As ISO 19112 is in line with other ISO 19100 series standards, Geographic Identifiers can be expressed in GeoSPARQL. The Location Type (e.g. countries, cities, physiographic features, mountains) defines the nature or semantics of a Location Instance, which has a geographic identifier. Depending on the Location Type, placenames in Gazetteers identify places that are phenomenal, declarative or a mixture of both. The CRMgeo extension creates the link to 
the CIDOC CRM which provides the possibility to model sources and (implicit) assumptions that lead to the definition of a placename or geographic identifier. In ISO 19112 Gazetteers may contain coordinates of a representative point for the location instance within the 'position' field. In the CRMgeo extension positions in Gazetteers are Geometric Place Expressions ${ }_{\mathrm{cg}}$ that create Declarative Places $_{\mathrm{og}}{ }^{*}$ Figure 6 shows the relation of ISO 19112 concepts with CIDOC CRM and CRMgeo concepts

\section{Conclusions}

The proposed extension CRMgeo that links CIDOC CRM with GeoSPARQL provides the ontological foundation for an integration of CIDOC CRM encoded datasets with datasets represented in GIS. The introduction of new classes offers an explicit modelling of concepts that have been hidden until now within the Place class. Within the CIDOC CRM it would not have been possible to relate hypothesis (Declarative Places ${ }_{c y}$ ) of the Place $_{c}$ of the Varus battle to the real place of the battle (Phenomenal Place ${ }_{\mathrm{og}}$ ). Neither it would have been possible to define geometries for these hypothesis in spatial coordinatereference systems making explicit how they relate to Places through a Reference Space $_{\text {og }}$ that is fixed in relation to a Physical Thing . The OGC/ISO models are very sophisticated in dealing with geometric representations of real world phenomenon, but do not differentiate between the phenomenon and the spacetime volume that has been occupied by the phenomenon. It would not be possible to model the Varus Battle, the place of the Varus Battle and the return of Roman troops to this very place a few years later. The direct relation hasGeometry $_{\mathrm{g}}$ between Features ${ }_{\mathrm{g}}$ and Geometries $_{\mathrm{g}}$ again gives no possibility to differentiate between the real place of the battle and the hypothesis about this place. Through the linkage of CIDOC CRM and GeoSPARQL with the introduction of the presented classes it is now possible to model:

- real world phenomena,

- the spacetime volumes occupied by them,

- their spatial projections,

- the geometries created by humans to approximate these spatial projections.
The model makes explicit relations of different substance and identity between these four categories. This has not previously been done, neither in CIDOCCRMnor in GeoSPARQL. CRMgeo may be the basis for the use and development of different kinds of applications. Query engines for semantic networks that are able to process geometric and temporal information may now perform spatiotemporal queries on CRM encoded data, like finding spatiotemporal overlapping areas of battle remains, the spacetime volumes referred to by historical sources, and hypothesis for the true place of the Varus Battle. Geoinformation systems can be developed or used to analyse or visualise the complex relations that semantic networks of cultural data contain, including the provenance of data.

The visualisation of graph networks related to a geometry within a GIS is still a research issue. Future work will have to define different kinds of approximation (like includes or overlaps) relating Declarative Places $_{\text {og }}$ to Phenomenal Places ${ }_{\mathrm{og}}$. An elaboration of the property approximates ${ }_{\mathrm{og}}$ is necessary to develop sophisticated spatial reasoning and inferences based on geometric and topological relations.

\section{Acknowledgements}

This research project has been funded within the Marie Curie Actions-Intra-European Fellowships (IEF) Funding scheme under project number 299998. The views and opinions expressed in this paper are the sole responsibility of the authors and do not necessarily reflect the views of the European Commission.

\section{Bibliography}

Doerr, M., G. Hiebel, and Ø. Eide. 2013. "CRMgeo: Linking the CIDOC CRM to GeoSPARQL through a Spatiotemporal Refinement." Technical report: ICSFORTH/TR-435, April 2013. Accessed January 15, 2014. http://www.ics.forth.gr/tech-reports/2013/2013. TR435_CRMgeo_CIDOC_CRM_GeoSPARQL.pdf.

Felicetti, A., M. Samaes, K. Nys, and F. Niccolucci. 2010. "AnnoMAD: A Semantic Framework for the Management and the Integration of Full-text Excavation Data and Geographic Information." In VAST10: The 11th International Symposium on Virtual Reality, 
Across Space and Time. Papers from the 41st Conference on

Computer Applications and Quantitative Methods in Archaeology. Perth, 25-28 March 2013

Archaeology and Intelligent Cultural Heritage, edited by A. Artusi, M. J oly, G. Lucet, D. Pitzalis, and A. Ribes, 123130. Aire-la-Ville, Switzerland: Eurographics Association.

European Commission. 2014. "INSPIRE - Infrastructure for spatial information in the European Community." Accessed March 15. http:// inspire.jrc.ec.europa.eu/ .

Harnecker, J . 1999. Arminius, Varus und das Schlachtfeld von Kalkriese. Eine Einführung in die archäologischen Arbeiten und ihre Ergebnisse. Bramsche: Rasch.

Hiebel, G., Ø. Eide, M. Fichtner, K. Hanke, G. Hohmann, D. Lukas, and S. Krause 2012. "OGC GeoSparql and CIDOC CRM." Paper presented at the CRM-SIG Meeting, Heraklion, Greece, April 30 - May 03.

ISO. 2013. 'TSO/TC 211 - Geographic information/ Geomatic." Accessed Accessed April 23, 2014. http:// www.iso.org/iso/home/ store/ catalogue_tc/ catalogue tc_browse.htm?commid $=54904$.

Le Boeuf, P., M. Doerr, C.E. Ore, and S. Stead. 2012. "Definition of the CIDOC Conceptual Reference Model." Accessed June 6, 2013. http://www.cidoc-crm.org/ official_release_cidoc.html.

OeRC. 2014. "The world of art in the semantic web." Accessed January 15. http:// explore.clarosnet.org/XDB/ ASP/claroshome.

OGC. 2009. "The OpenGIS $\AA$ Abstract Specification: Topic 5: Features." Accessed 23 April 2014. http:// portal. opengeospatial.org/files/?artifact_id=29536.

OGC. 2012. “OGC GeoSPARQL - A Geographic Query Language for RDF Data." Accessed 20 J une 2013. http:// www.opengeospatial.org/standards/ geosparql.

OGC. 2013. "OGC® Standards and Supporting Documents." Accessed 23 April 2014. http://www. opengeospatial.org/ standards.

Stüve, J. E. 1789. Beschreibung und Geschichte des Hochstifts und Fürstenthums Osnabrück: mit einigen Urkunden. Osnabrück: Schmidt.

The Latin Library. 2014. "P. Corneli Taciti Annalivm Liber Primvs." Accessed March 15. http:// www.thelatinlibrary. com/tacitus/ tac.ann1.shtml.

University of South Wales. 2014. “CIDOC CRM
Implementation and the CRM-EH." Accessed J anuary 15. http:// hypermedia.research.glam.ac.uk/ resources/crm/ .

W3C. 2014. "W3C Semantic Web Interest Group." Accessed J anuary 15. http:/ / www.w3.org/ 2003/ 01/ geo/ .

WissKI. 2014. "The WissKI Project.” Accessed J anuary 15. http:// wiss-ki.eu/ . 


\title{
Reality Bites: Reviewing a Decade of Online Collaboration
}

\author{
Susan Hamilton and Peter McKeague \\ The Royal Commission on the Ancient and Historical Monuments of Scotland, UK
}

\begin{abstract}
:
The Royal Commission on the Ancient and Historical Monuments of Scotland maintains the national record of the archaeology, built and marine heritage of Scotland. Since 1998, information held on behalf of the public has been accessible online through the Canmore databaseand, from 2003, through PastMap, developed in partnership with Historic Scotland and several of Scotland's Historic Environment Records. Web portals provide the 'shop window' for RCAHMS, not only in terms of information curated but also increasingly through online sales. However, moving from the web as publication towards contributing to the web of data, or even more fundamentally simply sharing information with others, is constrained by a number of factors. This paper uses a number of case studies to share the experience of digital partnerships from our perspective as early adopters, data owners and data publishers, focusing particularly on the challenges of moving towards Open Data.
\end{abstract}

\section{Keywords:}

National Records, Licensing, Mapping, Open Data, Linked Data

\section{Introduction}

The Royal Commission on the Ancient and Historical Monuments of Scotland (RCAHMS) was founded in order to prepare an inventory of monuments which could subsequently be designated for some form of protection (Ferguson 2008, 4). This basic practice, collecting information on the historic environment, and making it available for others to use and base decisions upon, has continued for over a century and remains at the heart of what RCAHMS does, even as the role of the organisation has expanded considerably over the ensuing years (Dunbar 1992).

While opening up some datasets may prove relatively simple, the totality of information - and collections - held by RCAHMS is the product of many programmes and strands of data gathering that have created a complex, multi-layered and multi-authored whole with many 'owners' and stakeholders. Case studies are used in this paper to demonstrate the issues faced.

Of particular note is the case study (3.1) exploring the fundamental association between archaeological data and mapping. Mapping is much more than a tool to illustrate, explore and explain a

Corresponding author: susan.hamilton@rcahms.gov.uk site. The map presents an essential spatial attribute of the record about a site. Adapting business models from paper to a digital environment often raises complex issues around legacy, licensing and Intellectual Property Rights

\subsection{Definitions in use}

As described above and explored below, it is clear that RCAHMS makes data 'available', but is it 'open'? Terms such as 'Open Data' and 'open archaeology' have become common currency (Lake 2012) but it is important when using terms coined in the relatively recent past to be absolutely clear about what we mean by them. For the purposes of this paper, we have adopted the following definitions:

- Open (definition): "A piece of content or data is open if anyone is free to use, reuse, and redistribute it - subject only, at most, to the requirement to attribute and/or share-alike." (Open Knowledge Foundation 2013).

- Open Data: “...the notion of making data freely available online with minimal restrictions on reuse and redistribution. Data in this instance can be all the data resulting from research, rather than solely the research results." (Beale 2012, 614) 
- Open Archaeology: "Open Archaeology shares much of the philosophy of these open approaches and is predicated on promoting open redistribution and access to the data, processes and syntheses generated within the archaeological domain. This is aimed at both the production and consumption of archaeological knowledge with the associated aim of maximising transparency, reuse and engagement while maintaining professional probity." (Beck and Neylon 2012, 479).

During the course of the authors' research, it has become increasingly clear that there is a significant difference between open content and Open Data as defined by the Open Knowledge Foundation. Content represents the sum of the information available, including, for example, images and pdfs whereas data contains themetadata, facts and statistics. By ensuring these definitions are clearly understood, discussions about opening up data may be clarified. These terms and definitions have therefore been adopted for this paper.

\section{RCAHMS and Data Accessibility}

RCAHMSis well-placed to discuss accessibility and openness of information. It is an organisation which has moved from traditional methods of publishing via its inventory volumes, through publishing online via Canmore, to releasing Web Map Services. The latter are available via http// data.gov.uk or the INSPIRE Geoportal, under the INSPIRE Directive and as part of our contribution to Scotland's Spatial Data Infrastructure (McKeague et al. 2012). Under INSPIRE, a Web Feature Service for the Canmore point data will follow by the end of 2013.

The national record, Canmore (RCAHMS 2014a) was first published online in 1998. Putting RCAHMS records online was a significant step in the transition from a paper-based recording system. A map-based search was added in 2002, reflecting the organisation's early engagement with GIS - a natural step given the importance which spatial data and an understanding of the landscape has within the recording of monuments.

A collaborative mapping portal, PastMap, initially displaying just Historic Scotland designation data alongside RCAHMS Canmore locations, was launched in 2003 (Gillick et al. 2004) with several Historic Environment Records (HERs) joining subsequently. Re-launched in 2013, using the WFS where available, PastMap (RCAHMS 2014b) makes available 21 separate datasets from contributing organisations. Making these multiagency and multi-purpose datasets available, with the intention to add many more in future, is a key part of the emerging strategy for Scotland's Historic Environment Data (ALGAO 2013).

In 2004 further enhancements of Canmoresaw the addition of digital images to site records where available. Image sales and licensing were integrated into Canmore in 2009, delivering efficiencies through streamlining the public ordering system and providing a digital record of rights management, though also inevitably raising the issue of balancing revenue generation with providing access to data.

RCAHMS has a strong track record of being an experimental and willing early adopter of new digital technology. It is therefore well-placed to illustrate the challenges of making data available from its position as a national, governmental body. The case studies presented below explore our experiences of licensing, data gathering and dissemination.

\subsection{The operating context}

The context in which organisations operate is important. Nobody works in isolation, and there are often a range of drivers which can cause resistance to, or encourage, certain new directions.

All organisations are grappling with the rapid transitioning that is the hallmark of the digital age. This has enormous impacts on what work can be done, especially in a time of financial austerity when resources are under increasing pressure. In-house information technology departments, focused on day-to-day running of office systems and delivery of key projects, often lack time to invest in relevant training, for example training in Linked (Open) Data. This is not to say that the willingness is absent, but it does require that alternative solutions, such as working in partnership with university computer science departments, are found. 
As an organisation primarily funded by Scottish Government, RCAHMS must work towards the overarching National Performance Framework (Scottish Government 2013). This framework ensures the activities of Government are aligned with general themes such as 'healthier Scotland' and 'greener Scotland', which are broken down into a range of aims and objectives along with stated success measures. Within this sit more specific drivers resulting from policy, for example Scotland's Digital Future (Scottish Government 2012). At first glance, some of these initially seem to work against each other; for example the need to generate revenue as an organisation against the drive to open up data and content. However, these drivers are largely enabling rather than restrictive and can provide new opportunities and multiple benefits - for example encouraging volunteer groups to submit their research using an online form not only helps create a better understanding of the historic environment, but also works towards creating a population which has more confidence in engaging with the digital world.

Finally, at the most detailed level, there is the immediate context of the RCAHMS database. The data RCAHMS holds comes from a wide range of sources and has been built up for over a century. Within the national inventory, much of the content comes from reporting the work of others: fieldwork undertaken by commercial units, the work of academics, summaries of publications and references to other collections and repositories. This has created significant legacy issues: whilst Canmore presents a wealth of data from a variety of sources online, the heterogeneous character of the record is sometimes misunderstood as being both homogeneous and an Authorised Heritage Discourse (AHD: Otero-Pailos et al. 2010, 57), produced by specialists for a specialist purpose (Hamilton 2014) rather than a collaborative, contributory portal into Scotland's historic environment.

\section{Case Studies}

The following case studies highlight some of the external factors impacting on the desire to share information beyond web portals. These examples explore issues surrounding licensing, legacy data and ambitions for openness.
3.1 Case study one: ordnance survey and aerial photographic mapping; pan-government agreements

Most archaeological data has a spatial component, usually created, or referenced, against mapping published by a national mapping agency or another third party product. In Britain, the roles of the mappingagency - the OrdnanceSurvey - and the Royal Commissions on Ancient Monuments were long intertwined. The card index maintained by the Ordnance Survey Archaeology Division (OSAD) was the origin of the online resources of both RCAHMS and local authority historic environment records. Therole of the OSAD was formally transferred to the Royal Commissions in the early 1980s, and the card indexes were subsequently computerised.

There is an inherent relationship between the mapped object and the map base. Whilst the IPR of information referenced against maps was not overtly an issue for paper maps, it quickly became a dominant theme with the new business models emerging with the establishment of the OS as a trading fund and the release of vector-based mapping on an annual license. Legitimate concerns over direct copying of OS objects, or the creation by third parties of features or even attributes that directly reference the underlying OS map data, had the unintended effect of restricting the use and release of any information, an issue highlighted by the Free Our Data campaign as championed by The Guardian newspaper (Arthur and Cross 2006).

The emergence of OpenStreetMap (OpenStreetMap contributors 2014) and disruptive technologies such as Google Maps (Google 2014), Google Earth or Microsoft Bing (Microsoft 2014) providing competition, precipitated the release of some OS mapping under the generous terms of an OS Open Data license (Ordnance Survey 2013). This allows the licensee to create, copy, distribute and transmit the data, adapt the data, and exploit the data commercially, whether by sub-licensing it, combining it with other data, or including it in a product or application. Even so, in order for the organisation to generate the income it needs to exist, OS premium business products necessarily remain excluded from the OS Open Data license system. 


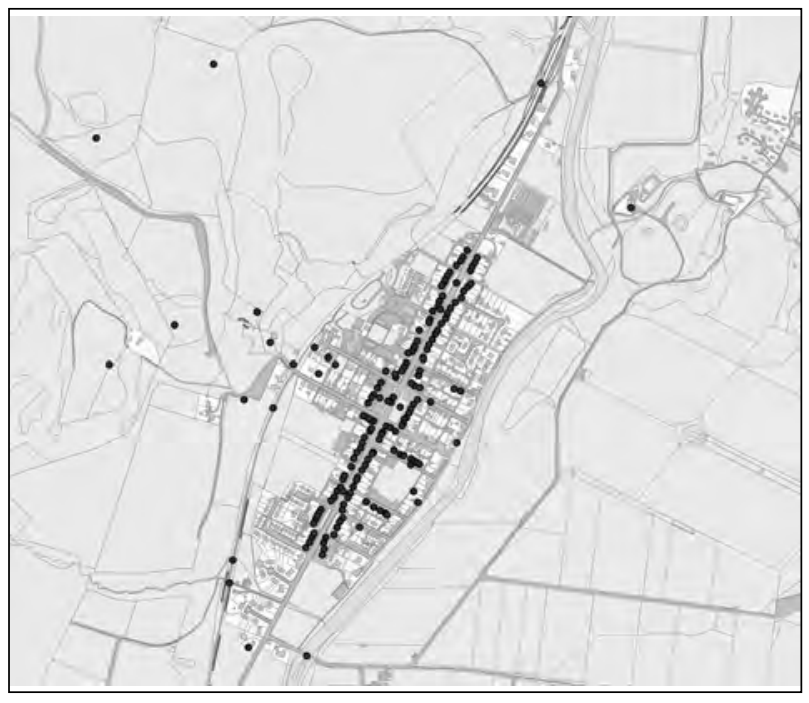

Figure 1. The planned village of Newcastleton, Scottish Borders. The point dataset representing individual records in Canmore is considered exempt by the OS. Background mapping (C) Crown Copyright and database right 2014. All rights reserved. Ordnance Survey Licence number 100020548.

The OS have also relaxed their conditions for some data created against their map background through the introduction of the Public Sector Derived Data Exemptions, providing terms equivalent to either the OS Open Data License or Free to Use Data terms. Exemptions are designed to enable public sector organisations to publish independently-sourced data to reduce costs, enable greater efficiency in government, fulfil statutory or legislative obligations and support government policies towards transparency and public data principles. However, candidate datasets must not set a precedent that might impact on OS commercial business, by damaging its reputation as a brand; compete with or act as a substitute for an existing or planned service from the OS or one of its business partners; or potentially infringe on third party IPR.

Whilst it is something of a departure to acknowledge shared IPR with the OS, the exemption removes a major hurdlein therelease of information. In recognition of the unique task of RCAHMS to promote the public use of information available in its database, the OS have confirmed that the national point dataset may be distributed on terms equivalent to those applicable to OS OpenData ${ }^{\mathrm{TM}}$ with acknowledgement of OS IPR. As a premium

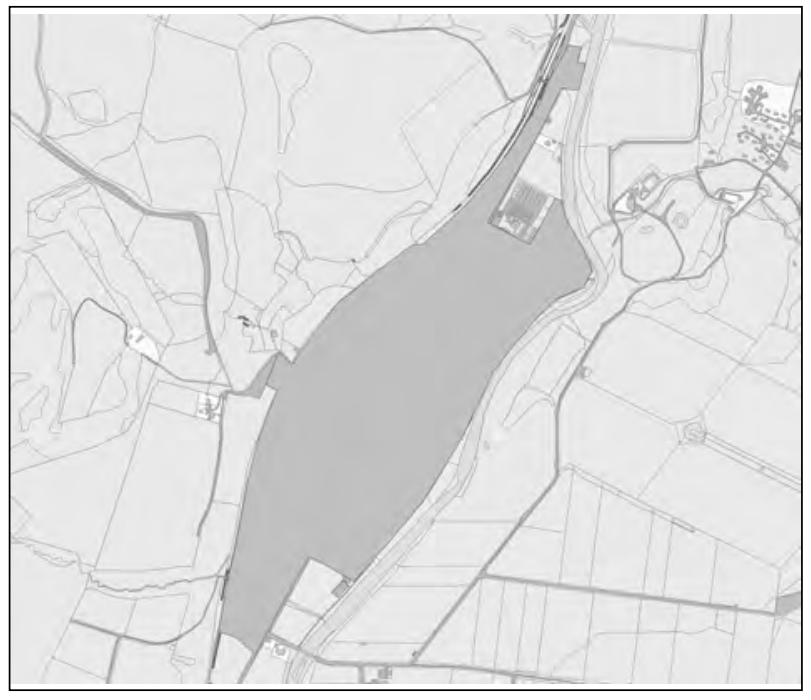

Figure 2. However, the area feature defining the extent of the planned village (derived from Historic Landuse Assessment mapping) does not qualify as it incorporates detail from the underlying base map. Background mapping (C) Crown Copyright and database right 2014. All rights reserved. Ordnance Survey Licence number 100020548.

product, OS Basic Scale mapping and imagery is outside the exemption process, and direct copying of base map features, for polygon or line data, could compromise exemption status. For example, defining the spatial extent of a building, or an urban excavation on a vacant building plot site, against the OS map base could be seen as directly replicating an OS product (Figs 1 and 2).

As noted above, the monopoly of background mapping is being steadily eroded and orthoimagery is increasingly available from a number of vendors. RCAHMS receives its orthoimagery as part of a Scottish Pan-Government agreement to provide mapping to the public sector and use of this imagery is increasingly important in projects such as Historic Landuse Assessment (Millican and Middleton 2014) and Defining Scotland's Places (Middleton 2011), ideally without any impediment of an asserted IPR from the licensor. New business models for born digital' products (products which do not have an analogue predecessor) may take a more pragmatic approach to the working practices of the digital age than long established businesses immersed in the world of paper records and copyright. 
3.2 Case study two: museum artefact geographical interface: the MAGI project

In much of the British Isles the maintenance of monument inventories, archival records and museum collections is fragmented. Scotland is fortunate with the integration of paper, photographic and digital archives as part of the national record through Canmore but museum collections have long remained separate and serve a separate primary purpose - management of the collection. The relationship and potential for joining between museum resources and Canmore was explored through a pilot study undertaken by National Museums Scotland (NMS) and RCAHMS in 2005 (Cowie and McKeague 2011). The handcrafted approach demonstrated potential but the proposition on a national scale remains daunting. The exact number of artefacts in museum collections is unknown, but NMS estimates it has well in excess of 2 million items in its archaeology collections alone (to $\mathrm{AD} 1000$ ). There will be many more artefacts catalogued in university museums, local authority museum services and private collections. These records have potential links to perhaps only 15,000 Canmore site records recording find spots or excavations (less than $10 \%$ of the archaeological records).

Neither Scottish museums nor RCAHMS have exposed their data as Linked Data. Reasons for this include: internal technical resource restrictions; uncertainty over the stability of the technology; concerns over the fitness for purpose of the data; and, of course, licensing. At present (September 2013) one small pilot project is underway to test how RCAHMS data could be made available in this way, but a wider 'rollout' of this has yet to be scheduled. However, the potential for adopting semantic web technologies to address this systemic challenge is immense. The potential benefits can all be tied to the National Performance Framework, making more information available on the historic environment by filling in significant gaps in the publicly available records (for instance records of chance finds), creating a better-informed record for curating Scotland's rich heritage.

This raises the potential to stimulate research not only within Scotland but across national boundaries, thus promoting Scotland's heritage, raising awareness of related resources through mash-ups of the museum and Canmore data in support of tourism as well as international research

\subsection{Case study three: social media and licensing}

Engagement with social media (Facebook 2014; Twitter 2014) is a way in which RCAHMS communicates and attracts new audiences. In advance of creating content for Facebook, an investigation of the web company's terms and conditions showed that any uploaded images could have been taken and used by Facebook for their own purposes. This represented a risk of the RCAHMS Crown Copyright imagery being used to generate revenue for others, but also a risk of breaching the agreements in place with those who had deposited material with us. Such IPR constraints explain why the RCAHMS Facebook page only contains links or pictures of pictures - e.g. a member of staff holding a favourite print.

In 2011, a Facebook page called 'Lost Edinburgh' harvested hundreds of images from Canmore. In light of the IPR restrictions explained above, RCAHMS requested that the images were removed. It was difficult to communicate to our audience that although increased public engagement with the RCAHMS collection was a positive development, the conditions under which the collection is held made that particular method of dissemination very problematic. However, the sheer volume of people for whom 'Facebook' is 'the Internet' means that finding ways of continuing to engage with social media is essential in order to continue engaging with the wider public.

\subsection{Case study four: SURE and future-proofing}

The Specialist User Recording Environment (Hamilton et al. 2013) is a programme of work which is aimed at enabling partners to make their data available to the public through Canmore, rather than through independent databases, thus reducing duplication of effort. Partners are drawn from local government (City of Dundee Council and Orkney Islands Archaeology Service), national government (The Treasure Trove unit [hosted by the NMS] and Scottish Canals) as well as the charity the National Trust for Scotland and a national society (the Garden History Society in Scotland). 
SURE is a digital-age undertaking only made possible by advances in technology. At the outset, the decision was made to avoid any issues arising about data ownership or legacy data by having clear lines of responsibility during the partnership and clarity in the event of a partnership ending. Although such preliminary legal or IPR discussions can be protracted, this investment is worthwhile in order to have future clarity and to have dealt with as many 'what ifs?' as possible. The benefits - increased quantity of data, from a range of sources, quickly and efficiently, being made available to the public far outweigh the time invested in concluding such negotiations. In terms of opening up data, the SURE Memorandum of Agreement also gives RCAHMS leeway in how it can make data available.

\section{Concluding Remarks}

If issues over background mapping IPR are steadily, if slowly, being resolved, RCAHMS and other public bodies, including local authorities, still face hurdles in releasing Open Data. Although RCAHMS has a good track record in adopting new technologies to promote Scotland's heritage, fully Open Data is proving hard to achieve comprehensively. There is a natural caution when faced by taking an irreversible step into the unknown, highlighted by concerns about how data is re-used - especially where IPR is concerned. As the case studies above demonstrate, Canmore is at heart a multi-authored and collaborative database, a status that adds further complexity to already thorny issues. Whilst there are drivers for Open Data from researchers, those engaged in the stewardship of the historic environment have legitimate concerns about the currency of information available online, requesting that professional advice should be sought at the earliest opportunity of proposed planning developments or in land management changes.

There is also a perceived clash between Open Data, and revenue generation, although Open Data should be viewed as metadata (or advertising) for related content to promote related saleable content. The need to preserve identity and promote the work of an organisation, particularly in an economic downturn, needs to be balanced by breaking down the barriers to sharing information between individual 'data silos'. As Gittings (2009, 88) observed the development of institutional websites to showcase work is invariably accompanied by a level of organisational branding promoting the proprietorial interests of the host organisation. This can accentuate existing barriers into sharing data by turning the 'data silos' into fortresses that may be breached individually but which fail to allow crosssearching. The concerns expressed by Gittings are addressed in the Scottish Government's Scotland's Digital Future- Delivery of Public Services (Scottish Government 2012) which sets out an ambitious vision for digital technology in a modern Scotland. Scotland's Digital Future challenges existingmodels of service delivery to drive improvement across public services by making online services accessible and easy to use. To do so requires the public sector to work collaboratively across Scotland, making best useof existinginfrastructure, crossingorganisational boundaries and adopting a 'digital first' approach under which the use of a digital channel is a positive choice (Scottish Government 2013, 6).

In particular, the value of Linked Open Data approaches has yet to be demonstrated to the uninitiated: solutions are not visual, the technology looks daunting and there is a perception by those outside the Linked Data community that it represents little gain for much investment. Hardpressed information technology departments lack the resources to invest training time in gaining new skills, and crucially there are not yet any demonstrable applications within the Scottish Government. Yet, in adopting a Linked Open Data approach, organisations can contribute their data to, and benefit from, the Web of Data, enabling those with the resources, skills and inclination to take existing information from multiple sources, transform it and realise its potential through novel solutions.

What is perhaps required is a new style of partnership; finding partners within computer science to work with RCAHMS and other bodies, and use cultural heritage data to produce the demonstrator application that will in turn encourage other Government departments. There is certainly potential for doing this with a subset of RCAHMS metadata - the grid references, site names and classifications - which is the most likely dataset to be made available as Open Data. The unavoidable requirement to drive revenue means that in the current climate of austerity, some control 
Reality Bites: Reviewing a Decade of Online Collaboration

Susan Hamilton and Peter McKeague

over content, such as digital images, needs to be maintained.

To date RCAHMS has published a wealth of data and digital content freely available online through Canmore and PastMap. There is a willingness to work towards the principles of Open Data. This may be achieved by finding the balance between releasing some of the key metadata as Open Data and reserving rights to certain content. The first steps in this direction have now been taken through the redeveloped PastMap portal, where users can freely download attribution data in csv format.

\section{Acknowledgements}

The authors are grateful to the Royal Society of Edinburgh for a generous travel grant to present this paper and to Kirsty Lingstadt and Robin Turner for comments on earlier drafts of this paper. Views expressed in this paper are personal opinions of the authors and do not necessarily reflect those of RCAHMS.

\section{Bibliography}

ALGAO. 2013. "Scotland's Historic Environment Data (SHED) Strategy - Consultation Draft." Accessed 11June. http:// www.algao.org.uk/ scotland.

Arthur, C., and M. Cross. 2006. "Give us back our crown jewels." The Guardian, March 9. Accessed March 15, 2014. http:// www.guardian.co.uk/ technology/ 2006/ mar/ 09/ education.epublic.

Beale, N. 2012. "How community archaeology can make use of Open Data to achieve further its objectives." World Archaeology 44 (4):612- 33.

Beck, A., and C. Neylon. 2012. "A vision for Open Archaeology." World Archaeology 44(4):479- 97.

Cowie, T., and P. McKeague. 2011. "Mapping material culture: exploring the interface between museum artefacts and their geographical context." Scottish Archaeological J ournal 32:73- 93.

Dunbar, J . 1992. "The Royal Commission on the Ancient and Historical Monuments of Scotland: the first eighty years." Transactions of the Ancient Monuments Society 36:13- 77.
Facebook. 2014. "AboutRoyal Commission on the Ancient and Historical Monuments of Scotland." Accessed March 15. https:// www.facebook.com/ RCAHMSand.

Ferguson, L. 2008. Treasured Places: A Centenary. Edinburgh: RCAHMS. Accessed J une 12, 2013. http:// www.rcahms.gov.uk/rcahms_media/files/publications/ treasured_places_rcahms.pdf.

Gillick, M., P. McKeague, and R. Strachan. 2004. “Online: web developments at the Royal Commission on the Ancient and Historical Monuments of Scotland and the development of a shared heritage portal with Historic Scotland." In Enter the Past. The E-way into the four Dimensions of Cultural Heritage. Proceedings of the 30th CAA conference held in Vienna, Austria, April 2003, edited by K. Fischer-Ausserer, W. Börner, M. Goriany, and L. Karlhuber-Vöckl, 374- 7. Oxford: Archaeopress.

Gittings, B. 2009. "Reflections on forty years of geographic information in Scotland: Standardisation, integration and representation." Scottish Geographical J ournal 125 (1):78-94.

Google. 2014. "Google Maps.” Accessed 15 January. https:// maps.google.com/ .

Hamilton, S. 2014. "A 21st Century Record: Maintaining a Modern Monuments Record." In Across Space and Time. Papers from the 41st Computer Applications and Quantitative Methods in Archaeology Conference (Perth, WA, 25-28 March 2013), edited by A. Traviglia, 494-500. Amsterdam: Amsterdam University Press.

Hamilton, S., R. Jones, and P. McKeague. 2013. “Old Places, New Ideas: New Routes into Canmore, the National Inventory of Scotland." In Archaeology in the Digital Era. Papers from the 40th Annual Conference of Computer Applications and Quantitative Methods in Archaeology (CAA), Southampton, 26-29 March 2012, edited by G. Earl, T. Sly, A. Chrysanthi, P. Murrieta-Flores, C. Papadopoulos, I. Romanowska, and D. Wheatley, 291298. Amsterdam: Pallas Publishing.

Lake, M. 2012. “Open Archaeology.” World Archaeology $44(4): 471-97$.

McKeague, P., A. Corns, and R. Shaw. 2012. “Developing a Spatial Data Infrastructure for Archaeological and Built Heritage." International J ournal of Spatial Data Infrastructures Research 7:38-65. Accessed June 12, 
Across Space and Time. Papers from the 41st Conference on

Computer Applications and Quantitative Methods in Archaeology. Perth, 25-28 March 2013

2013. doi: 10.2902/ 1725-0463.2012.07.art3.

Microsoft. 2014. "Bing." Accessed January 15. http:// www.bing.com/.

Middleton, M. 2011. "Mapping Scotland's Historic Environment: Guide to the Defining Scotland's Places (DSP) project methodologies." Last modified October 21. http:// tinyurl.com/ CanmoreMapping.

Millican, K., and M. Middleton 2014. "The end game: As Scotland's Historic Land-Use Assessment project reaches completion what have we learned?" In Across Space and Time. Papers from the 41st Computer Applications and Quantitative Methods in Archaeology Conference (Perth, WA, 25-28 March 2013), edited by A. Traviglia, 488- 493. Amsterdam: Amsterdam University Press.

Open Knowledge Foundation. 2013. "Open Definition." Accessed June 7. http://opendefinition.org/.

OpenStreetMap contributors. 2014. "OpenStreetMap". Accessed J anuary 15. http:/ / www.openstreetmap.org/ .

Ordnance Survey. 2013. "OSOpenData.” Accessed 11J une. http:/ www.ordnancesurvey.co.uk/ oswebsite/ business/ licenses/ using-and-creating-data-with-os-products/ osopendata/index.html.

Otero-Pailos, J . G., and S. West. 2010. "Heritage values.” In Understanding Heritage in Practice, edited by S.West, 47- 87. Manchester: Manchester University Press.

RCAHMS. 2014a. "Canmore." Accessed January 15. http:// canmore.rcahms.gov.uk.

RCAHMS. 2014b. “PastMap.” Accessed March 15. http:// pastmap.org.uk/.

Scottish Government. 2012. "Scotland's Digital Future - Delivery of Public Services." Last modified September $19 . \quad$ http://www.scotland.gov.uk/ Publications/ 2012/ 09/6272.

Scottish Government. 2013. "Scotland's Digital Future - Supporting the Transition to a World-leading Digital Economy." Last modified May 8. http://www.scotland. gov.uk/ Publications/ 2013/ 05/2347/ 0.

Scottish Government. 2014. "Scotland Performs." Last modified January 27. http://www.scotland.gov.uk/
About/ Performance/ scotPerforms.

Twitter. 2014. "RCAHMS.” Accessed March 15. https:// twitter.com/rcahms. 


\title{
An Empirical Approach to the Analysis of Archaeological Discourse
}

\author{
Patricia Martín-Rodilla \\ Spanish National Research Council (CSIC), Spain
}

\begin{abstract}
:
Archaeological data are the basis on which to generate information and knowledge about past events. Existing data are frequently limited to one project's scope or activity and are rarely used for other purposes. Software systems can help archaeologists to obtain relevant information from large amounts of data. To construct these systems, it is necessary to identify and understand the most common methods of inference that occur in archaeology, in order to include them as requirements of knowledge-assisted software systems. To achieve this, a set of archaeological case studies were selected and their discourses analysed, attempting to establish the characteristics of the inferences that were carried out in each case. The discourse analysis method, which has been successfully applied in other disciplines, has allowed us to find the different types of hypotheses that are usually managed in archaeology, and to analyse the potential uses of knowledge extraction techniques for archaeological data.
\end{abstract}

\section{Keywords:}

Discourse Analysis, Archaeological Discourse, Inference, Software-Assisted Knowledge Generation

\section{Introduction and Overview}

Archaeological practice produces a large amount of data, which are traditionally stored and managed in the context of individual projects or archaeological activities, and are often not used for other purposes. However, there have been new trends in archaeological information management in the last few years, as shown by several projects that aim to create data-sharing infrastructures for archaeology and other social sciences or humanities (ARIADNE2012; Bamboo 2014; DARIAH2014), that are intended to generate collaborative knowledge and re-use archaeological data. Therefore, it can be argued that the amounts of archaeological data shared are increasing day by day. But, what can we do with these data?

Knowledge generation processes are traditionally related to the DIKW (data-informationknowledge-wisdom) hierarchy (Ackoff 1988), a layered model for the classification of human understanding. Software components can be situated in one or several of these layers, or assist in the interfaces between two of them.

Corresponding author:

patricia.martin-rodilla@incipit.csic.es
Most of the knowledge generation processes that occur in the archaeology field involve complex mechanisms of abstraction, relation and interpretation of the data. Is it possible to assist the archaeologists in performing these processes? We think software systems have an important role in assisting archaeologists to perform these processes, because software has data-analysis features to carry out computational abstraction processes. However, a deep study of the reasoning modes in archaeology is necessary to achieve software assistance in this context. We have reviewed knowledge construction theories and studies about the reasoning processes in archaeology, which are discussed below. Comparative and empirical studies have been carried out to understand the characteristics of the practitioner, the domain and existing software solutions (Martín-Rodilla 2012). However, knowledge generation processes in archaeology are only partially supported by software, with existing ad hoc partial solutions in terms of data (GonzalezPérez and Parcero-Oubiña 2011). Therefore, integral studies of this topic are not found in the existing literature.

There are theoretical models about knowledge generation that define the corpus of this research. All existing models follow a hierarchical structure based on layers: Cleveland (1982) establishes a 
model in four layers: Fact \& ideas, Information, Knowledge and Wisdom. Cleveland's model lays the foundation to a human understanding theory. The intermediate processes between layers are not characterised in this work. Ackoff (1988) adds one step more, with five layers: Data, Information, Knowledge, Understanding and Wisdom. This model has been used for several years as a reference in psychology and cognitive studies. Carpenter and Cannady (2004), based on other characterisations of the intermediate process between layers (Bellinger 2004), incorporate feedback flow between layers. They propose a model with six layers: Environment, Data, Information, Knowledge, Wisdom and Vision. The intermediate steps are tagged with words that suggest cognitive processes between layers, such as rules, goals or values.

All the models studied share the common feature of modelling the transition from one level to the next as the application of cognitive processes. Thus, the characterisation of these cognitive processes in the archaeological domain is an initial point to solve the problems detected (Martín-Rodilla 2013), such as uncertainty inclusion, low level of collaborative knowledge generation management, etc. Gardin (2002), Stockinger (1990) or recently Doerr, Kritsotaki, and Boutsika (2011) note that a formalisation of these processes is possible, using approaches based on inferences that are applied to archaeological data. However, the level of formalisation of these studies is not high enough as to test the initial hypothesis of our work and obtain results that can be directly used in the requirements of knowledge-assisted software systems. It is necessary a formalisation that involves the most cases with a computer understandable approach, such as primitives approaches or formalisation by classification.

We have also reviewed what methods exist for software assisted knowledge generation in other disciplines or domains. The most significant one found is Chen etal. (2009), whichincludesacomplete model for assisted knowledge generation through software visualisation. It has been tested in the biomedical domain. The proposed model capturing the user's actions, establishing how the user is generating knowledge. In the next step, the system adapts its behaviour to the user and offers him/ her some help through specific tools. The authors reference DIKW as a framework for their model, without restrictions in terms of domain. We take the model of Chen et al. (2009) into consideration as a basis for our work in the archaeological domain, adapting the visualisation and the model proposed by the authors as necessary.

\section{Objectives and Approach}

In a typical knowledge-assisted software pipeline (Chen et al. 2009), the user is interacting with the data while carrying out tasks of different kinds (visualisation, statistical analysis, etc.). These tasks allow the user to generate either information or knowledge based on the data, going up to the next level in the DIKW hierarchy. In addition, the system captures information about the way of reasoning of the user and incorporates this information. In the following iterations of the pipeline, the system can adapt to the user and present the data in more adaptive formats. The goal of our work is to identify and characterise what ways of reasoning are usually employed in archaeology, so that a formal description of them can be used as requirements for knowledge-assisted software systems.

Most of the available information about inference in archaeology is in the form of narrative documents. Discourse analysis techniques, which attempt to discover the intention of the writer in function of the narrative elements presented in the text, are thus well suited. Discourse analysis is a vast field from linguistics that studies the organisation of thelanguage, above sentence or paragraph level, and identifies the elements that can provide information about the structure of the narrative element and the reasoning or objectives of the speaker or writer. The term "discourse analysis" was originally defined by Zelling Harris as the name for "a method for the analysis of the connected speech or writing for continuing descriptive linguistics beyond the limit of a single sentence at a time and for correlating culture and language" (Harris 1952). Currently, discourse analysis is successfully used by different fields in different contexts, with theoretical and implementation designs such as legal texts (Moens et al. 2007), biomedicine (Lacson, Barzilay and Long 2006) or information retrieval (Morato et al. 2003). In all cases the extraction and analysis of the discourse helps to understand the reasoning modes in the domain studied. 
Also, different approaches can be taken to analyse documents (or other kind of discourses) depending on the goals of the analysis, focusing on the structure of the clauses, the function of some elements in the discourse, the representations of texts, etc. (Graesser, McNamara and Louwerse 2011). We chose to follow the discourse analysis method of Hobbs (1985), because it allows the characterisation of argumentation relations between clauses. This method has been used on narrative texts in different languages (Knott and Sanders 1998), poems, algorithm descriptions and legal documents. Interestingly, it has also been used on an archaeological text, as described in Hobbs (1985).

This method describes ten types of coherence relations between clauses, including causal argumentations, contrastive argumentations, exemplifications, generalisation of arguments, etc. Hobbs identified concepts such as goal - the objective of the speaker in the paragraph analysed or elements - parts of the clauses with entity in the discourse - into each coherence relation defined. To analyse a text, each pair of clauses is tagged by one coherence relation, and then the elements of the relation chosen are characterised in the pair of clauses analysed. After a text has been analysed, it is necessary to validate the results. In our work, the original author of each document was contacted and asked to check the outcome of the analysis for consistency.

\section{Case Studies}

We have analysed archaeological documents from the Incipit digital repository (Digital-CSIC 2014), studying the structure of the argumentation narrative. In this paper we present a set of five cases studies. Each case study comprises a section of an archaeological document corresponding to inferences based on archaeological data. Below, and for each case study, the literal fragment of the text is first presented in quotation marks; next, it is characterised by one coherence relation and its details are described.

1. "In the Bronze Age, the Algar culture uses necropolis as funerary systems, while in the same period, neighbouring areas use individual burials" (Fernández Martín 2010).
The two clauses are separated by "while", signalling a parallel coherence relation. The structure of both "In the Bronze Age, the Algar culture uses necropolis as funerary systems" and "in the same period, neighbouring areas use individual burials" contains a time reference followed by a statement about some subject.

2. "The set of pots with the biggest size was probably used for seed storage" (Prieto-Martínez 1998).

This is an occasion coherence relation, which denotes a correlation relationship. In Hobbs method these correlation can be confused with a causal relationships, because there is not a specific relation type for it, very common in humanities. The second part of the sentence "was probably used for seed storage" correlates the first part "with the biggest size".

3. "The pots of better quality than the usual stereotypes as a result of selection of raw materials, symmetry, regularity, treatment and finishing were probably conceived as prestige items. It could also be inferred that these pots constituted works of craftsmanship due to a higher need of dedication and expertise" (Cobas Fernández and Parcero-Oubiña 2006).

This longer fragments needs to be tackled piecemeal, one sentence at a time. Then, the connection between sentences is tackled.

For the first sentence, the author claims that the original conception of the pots probably is correlated to their characteristics in terms of materials, finish, etc. It is thus an occasion coherence relation. For the second sentence, the author argues that the level of expertise and dedication is an indicator of the manufacturing process. As an explanation of the second part of the fragment, the archaeologist needs to state the first part. This kind of explanation, with small goals in the discourse to achieve more important goals can be described as an evaluation coherence relation. We can now characterise the relationship between the two sentences as an occasion coherence relation, because the second sentence is the final state of the first sentence in the argumentation chain. 
Across Space and Time. Papers from the 41st Conference on

Computer Applications and Quantitative Methods in Archaeology. Perth, 25-28 March 2013

4. "The combination of orientation, arrangement, distribution and decorative schema allow for the vertical reading of the pots; horizontal reading lets us intuitively imagine the remaining decoration without seeing it" (Cobas Fernández and Parcero-Oubiña 2006).

Thefragmentis dividedin two partsseparated bya semicolon. As in the first case study, the structure of the parts is similar: there is an attribute (the reading direction) and a statement about possible consequences; in one case, the consequence is the intuitive recognition of the pattern, while in another case it is the set of information that provides us. The characterisation is, as in the first case study, a parallel coherence relation.

5. "In the case of Units 100-110 sherdage, heavy surface abrasion led us to consider other criteria such as fabric to determine relative chronological position. The results of seriation in all three analytical categories (fabric, shape, surface treatment) demonstrate that these other areas are closely linked in time, that they ante-date B 200 and that they post-date the earlier pits (Units 1-34)" (Cobas Fernández and ParceroOubiña 2006; Prieto-Martínez 1998).

Again, each sentence is analysed in turn, and then their connection is worked out.

For the first sentence, one small goal in the discourse (following Hobbs terminology) - the heavy surface abrasion - leads to the main goal, the consideration of other criteria. This is an evaluation coherence relation.

For the second sentence, there is a causal relationship between the data-seriation results and the temporal hypotheses about the pits and the areas studied. It is thus an explanation coherence relation.

Finally, the relation between sentences is characterised as an occasion coherence relation, since the second sentence describes a state resulting of what is described in the first one.

The case studies shown here (summarised in Fig. 1 for convenience) comprise only very brief

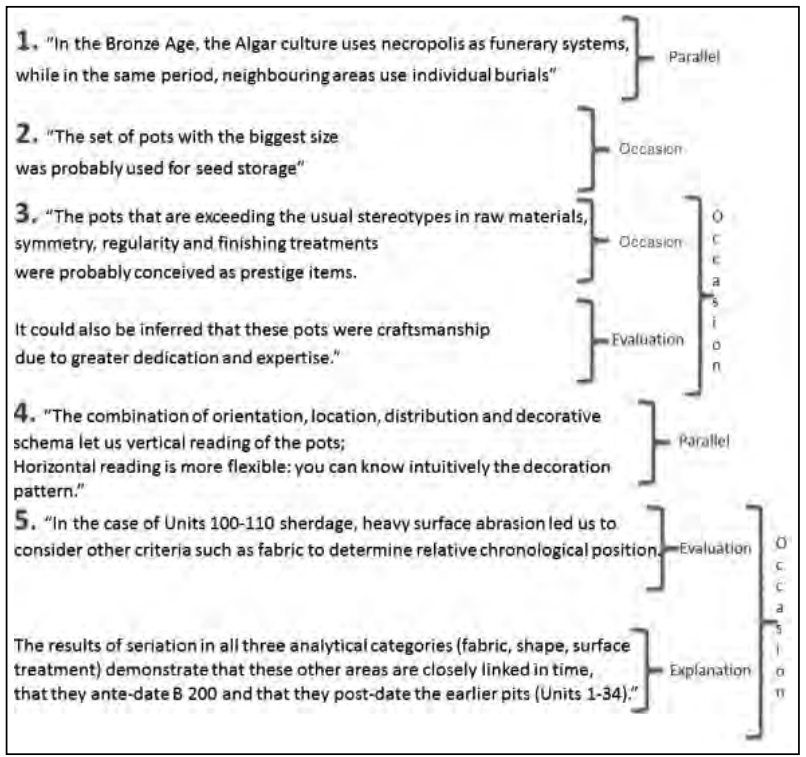

Figure 1. Selected case studies.

text fragments for the sake of simplicity. It should be noted, however, that the used method supports the much larger text units that are common in archaeological practice. The case studies presented here are only a small fraction of the analysed documents. Note that this research is an initial point to evaluate discourse analysis as extraction tool for archaeologist requirements and propose the inclusion of them in the knowledge assisted software pipeline. Thus, we have analysed 40 paragraphs from 6 different archaeological documents published in open repositories. All paragraphs are manually analysed, in order to maintain the original Hobbs approach and evaluate the method in the archaeological domain. In addition, we can check if the Hobbs's coherence relations are presented in the archaeological documentation.

\section{Reflections and Proposal}

All coherence relations described by Hobbs were identified in the analysed texts. However, not all coherence relations are equally common; for example, those related to the combination of values of several data items in order to build the argumentation are the most common ones. To assist with the study, coherence relationships were arranged into four groups, depending on the overall objective of the archaeologist writing the discourse, as shown in Table 1. 


\begin{tabular}{|c|c|}
\hline \multirow{2}{*}{ Building } & Parallel \\
\cline { 2 - 2 } & Elaboration \\
\cline { 2 - 2 } & Exemplification \\
\cline { 2 - 2 } & Generalization \\
\hline \multirow{2}{*}{ Clustering } & Contrast \\
\cline { 2 - 2 } & Violated expectation \\
\hline Situating & Background \\
\hline Combining & Occasion \\
\cline { 2 - 2 } & Explanation \\
\cline { 2 - 2 } & Elaboration \\
\cline { 2 - 2 } & Evaluation \\
\hline
\end{tabular}

Table 1. Proposed classification of Hobbs coherence relations.

- Building: inferences based on the structure, rather than particular values, of the data;

- Clustering: inferences based on grouping the data;

- Situating: inferences based on situating the data in a particular context or environment;

- Combining: inferences based on combining and/ or comparing values of different data items.

This scheme will be used as basis to formalise the cognitive processes carried out by practitioners in archaeology, in such a manner that the results can be used as requirements for knowledgeassisted software systems. The proposed method - as a complete pipeline mode - provides the methodological basisforstudiesonthepredominance of coherence relations in archaeological documents, as well as the generalisation of the proposal with analysis of large scale documentation. For this purposes will be necessary to adopt this proposal and develop similar experiments with greater volume of information.

\section{Conclusions and Vision}

As explained above, the knowledge-assisted pipeline is a framework that captures information about theuser's way of reasoning and uses it to adapt the system's operation. The proposed classification and analysis approach provides the underpinnings on which to base this.

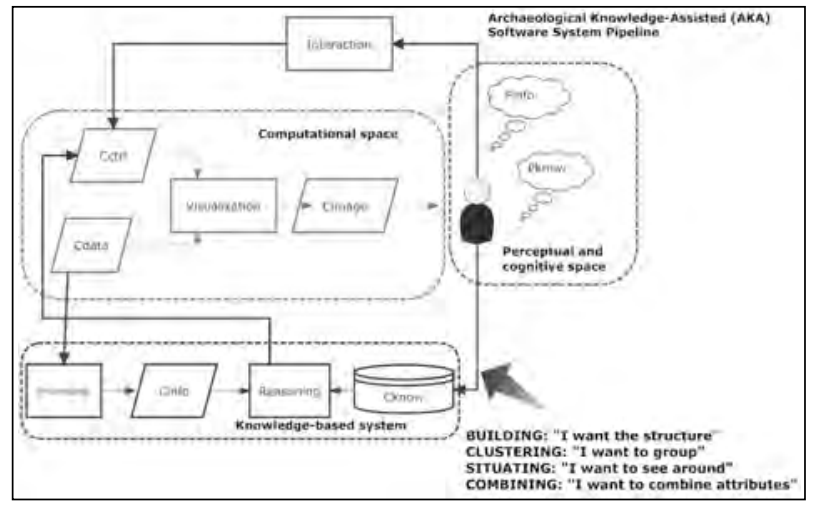

Figure 2. Incorporating inference classification to the Knowledge-Assisted software pipeline based on Chen et al. 2009.

Let us imagine that an archaeological dataset containing archaeological data about one excavation is available to a group of users. Users can interact with the dataset in many ways: comparing different attributes of the data, grouping data, establishing causal relations, searching for bibliography related to the data, etc. All the potential behavioural patterns of users would be captured into the system and described in terms of the different reasoning categories and coherence relations. Then, during a user's interactive session, this model is used so that the system can adapt as necessary; for example, if a user is trying to verify the correlation of two attributes, the system will identify this task as pertaining to the Combining category, and possibly to the Evaluation coherence relation. The system then adapts to the user by presenting the most appropriate user interface elements and visualisation options for this particular kind of task. We can see the complete pipeline in Fig. 2.

The assistance provided by these pipeline allow archaeologists to perform their data-analysis tasks based on computationally structured data - a trend that has grown in recent years - and become more aware of why and how they have come to a certain knowledge, what are the data they use as base or what kind of reasoning they have employed. This self-knowledge of modes of reasoning in the discipline and its application to groups is not possible with traditional methods. The inclusion of the inference classification in software systems can represent an interesting step forward in the discipline. 
In addition, our characterisation of the archaeological domain in terms of types of reasoning modes could be used, in the future, as the base to elaborate a set of guidelines for any researcher who tries to extract information based on archaeological record. For instance, we have an amount of data about an archaeological activity. We provide our objectives to the system with the data extracted through discourse analysis. If we know that the objective of the archaeologist is to establish causal relations, in the second iteration the software can offer several possibilities of correlation attributes values, in order to assist the archaeologist in the data-mining applications or correlation task. The same example can be applied to classification tasks or the other inferences activities detected.

The next step in our research is to use and test this characterisation of ways of reasoning in archaeology in an integral model of the system, using building, clustering, situating and combining as primitives to express the user requirements in each moment.

\section{Bibliography}

Ackoff, R. L. 1988. "From data to wisdom." J ournal of Applied Systems Analysis 16:3-9.

ARIADNE. 2012. "Advanced Research Infrastructure for Archaeological Dataset Networking in Europe 20132017." Accessed March 14, 2014. http://www.ariadneinfrastructure.eu/ .

Bamboo. 2014. “Bamboo Project 2008-2012.” Accessed March 14. http:// www.projectbamboo.org.

Bellinger, G. 2004. "Knowledge Management-Emerging Perspectives." Accessed March 10, 2014. http://www. systems-thinking.org/kmgmt/kmgmt.htm.

Carpenter, S. A., and J. Cannady. 2004. "Tool for Sharing and Assessing Models of Fusion-Based Space Transportation Systems." Proceedings of the 40th AIAA/ ASME/SAE/ASEE Joint Propulsion Conference and Exhibit. Accessed March 14, 2014. doi: 10.2514/6.20043535.

Chen, M., D. Ebert, H. Hagen, R. S. Laramee, R. van Liere, K.-L. Ma, W. Ribarsky, G. Scheuermann, and D. Silver. 2009. "Data, Information, and Knowledge in Visualization." IEEE Computer Graphics and Applications 29 (1):12- 19.

Cleveland, H. 1982. "Information as Resource." The Futurist 16:34- 39.

Cobas Fernández, I., and C. Parcero-Oubiña. 2006. Alto do Castro (Cuntis, Pontevedra). Síntesis de resultados y estudios de materiales, campaña 1993. Santiago de Compostela: Spanish National Research Council.

Digital-CSIC. 2014. "Document institutional repository. Spanish National Research Council." Accessed March 14. https:// digital.csic.es/ .

DARIAH. 2014. "DARIAH Digital Research Infrastructure for the Arts and Humanities." Accessed March 1. http:// www.dariah.eu/index.html.

Doerr, M., A. Kritsotaki, and K. Boutsika. 2011. "Factual argumentation - a core model for assertions making." J ournal on Computing and Cultural Heritage 3 (3):1- 34.

Fernández Martín, S. 2010.”Los complejos cerámicos del yacimiento arqueológico de La Motilla del Azuer (Daimiel, Ciudad Real)." PhD diss., University of Granada.

Gardin, J.-C. 2002. "Archaeological Discourse, Conceptual Modelling and Digitalisation: an Interim Report of the Logicist Program." In The Digital Heritage of Archaeology. CAA2002. Computer Applications and Quantitative Methods in Archaeology. Proceedings of the 30th CAA Conference, Heraklion, Crete, April 2002, edited by M. Doerr and A. Sarris, 5- 11. Athens: Hellenic Ministry of Culture.

Gonzalez-Pérez, C., and C. Parcero-Oubiña. 2011. "A Conceptual Model for Cultural Heritage Definition and Motivation." In Revive the Past. Computer Applications and Quantitative Methods in Archaeology (CAA). Proceedings of the 39th International Conference, Beijing, April 12-16 edited by M. Zhou, I. Romanowska, Z. Wu, P. Xu, and P. Verhagen, 234- 244. Amsterdam: Pallas Publications.

Graesser, A. C., D.S. McNamara, and M.M. Louwerse. 2011. "Methods of Automated Text Analysis." In Handbook of Reading Research Volume IV, edited by M. L. Kamil, P. David Pearson, E. Birr Moje, and P. P. Afflerbach, 34-53. New York: Routledge. 
Harris, Z. S. 1952. “Discourse analysis: A sample text.” Language 28 (4):474- 494.

Hobbs, J. R. 1985. On the Coherence and Structure of Discourse. Technical Report. Standford: Center for the Study of Language and Information (CSLI).

Knott, A., and T. Sanders 1998. "The classification of coherence relations and their linguistic markers: An exploration of two languages." J ournal of Pragmatics 30 (2):135- 175.

Lacson R. C., R. Barzilay, and W.J . Long. 2006. “Automatic analysis of medical dialogue in the home hemodialysis domain: structure induction and summarization." J ournal of Biomedical Informatics 39 (5):541- 555.

Martín-Rodilla, P. 2012. "The role of software in cultural heritage issues: Types, user needs and design guidelines based on principles of interaction." In Sixth International Conference on Research Challenges in Information Science (RCIS), edited by C. Rolland, J. Castro, and O. Pastor, 1-6. Valencia: IEEE.

Martín-Rodilla, P. 2013."Software-Assisted Knowledge Generation in the Archaeological Domain: A Conceptual Framework." In Proceedings of the Doctoral Consortium of the 25th International Conference on Advanced Information Systems Engineering (CAiSE 2013), Valencia, Spain, J une 21, 2013 edited by M. Indulska and B. Weber, 1001, paper 8:1-9. CEUR-WS.org. http:// ceurws.org/ Vol-1001/ paper8.pdf.

Moens, M.-F., E. Boiy, R. Mochales Palau, and C. Reed. 2007. "Automatic detection of arguments in legal texts." In Proceedings of the 11th international conference on Artificial intelligence and law, edited by ACM, 225- 230. Stanford: ACM.

Morato, J ., J . Llorens, G. Genova, and J . A. Moreiro. 2003. "Experiments in discourse analysis impact on information classification and retrieval algorithms." Information Processing \& Management 39 (6):825- 851.

Prieto-Martínez, M. P. 1998. “Forma, estilo y contexto en la cultura material de la Edad del Bronce gallega: cerámica campaniforme y cerámica no decorada." $\mathrm{PhD}$ diss., University of Santiago de Compostela.

Stockinger, P. 1990. “On Gardin's logicist analysis.” In Interpretation in the Humanities: Perspectives from
Artificial Intelligence edited by J. R. Ennals and J.-C. Gardin, 284- 304. London: British Library. 


\title{
Expressing Temporal and Subjective Information about Archaeological Entities
}

\author{
Cesar Gonzalez-Perez, Patricia Martín-Rodilla and Rebeca Blanco-Rotea \\ Institute of Heritage Sciences (Incipit), Spanish National Research Council (CSIC), Spain
}

\begin{abstract}
:
Information systems for archaeology are usually based on the description of discrete entities with wellknown attributes and associations. This has led to views of reality that are often artificially static, where stored information provides a temporal snapshot of what reality was like at a given moment, and also objectivised, corresponding to the judgment of reality by a particular set of authors. But reality is indeed diachronic and multivocal. Here we propose a mechanism to cope with such "soft issues" within the sphere of information modelling, based on the determination of which information features are of a temporal or subjective nature, and then using "object slices" to convey perdurant and multivocal semantics in software. The conceptual modelling language ConML has been provided with the necessary extensions so that the temporal and subjective aspects of archaeological entities can be described.
\end{abstract}

\section{Keywords:}

Conceptual Modelling, Temporality, Subjectivity, Multivocality, ConML

\section{Introduction}

Most information systems in archaeology work by storing information about the archaeological record, or any other reality that they describe, in terms of discrete entities with well-known attributes and associations. For example, a database for the management of heritage-protected buildings may establish that, for each building, the address, construction materials, current use, owner details and conservation status must be recorded. In a context like this, information tends to offer a stationary view of reality, in two senses. First of all, information in the system tends to get out of date, and thus portray a temporal snapshot of reality as it was at a given moment. Subsequent changes in reality mean that the information in the system is no longer valid; however this does not mean that the information in the system should be discarded or overwritten with new information, since the old one may have historical value. For example, a building may have been used as a hospital while it was owned by the Church, but now it belongs to the state government who has refurbished it as office space. Similarly, information in the system is created and entered by specific authors (either individuals or groups), which may not always share a common understanding of the archaeological record. For

Corresponding author:

cesar.gonzalez-perez@incipit.csic.es example, the local heritage office may judge that the building in our example is in good condition and does not need a restoration, but architects from a company hired to carry out an assessment may disagree. Under the assumptions of a traditional information system, the conservation status field in the database would show one of the two options, which would overrule the other. However, both judgements are interesting to keep.

In this regard, information systems are usually static and hegemonic; static because they show a "freeze-frame" depiction of what reality used to be at a certain point in the past, and hegemonic because they describe said reality according to the viewpoint of a given author. Other times and other voices are usually not represented. This situation is especially paradoxical in archaeology, given the central role that time has traditionally played in the field, and the increasing attention that is being paid to multivocality.

Some incipient solutions to these issues have been (and currently are being) explored in the realm of information systems and databases for archaeology, but none have been described at a theoretical level in a technology-agnostic manner. This means that, on the one hand, there is no way to re-implement the solutions devised by others in future systems; and, on the other hand, conveying 
Expressing Temporal and Subjective Information about Archaeological Entities

Cesar Gonzalez-Perez, Patricia Martín-Rodilla and Rebeca Blanco-Rotea

the essence of these solutions to archaeologists and other non-IT specialists is, to say the least, very difficult. In addition, the efforts have been much larger with regard to temporality than subjectivity management, probably due to the long tradition of research on temporal databases, e.g. Snodgrass and Ahn (1986) or, to a lesser extent, in the modelling of time, e.g. Svinterikou and Theodoulidis (1999), Price, Ramamohanarao and Srinivasan (1999). However, and despite these efforts, information systems in archaeology are still static and hegemonic. In this paper we propose a simple, affordable solution to capture time and subjectivity in conceptual models of the archaeological record. Rather than proposing a particular model of the archaeological record, we propose a collection of techniques to create timeand subjectivity-aware models of the archaeological record.Inparticular, section 2 describestheproposed solution, and Section 3 includes an example to illustrate it. Section 4 explains the formalisation that has been added to the ConML modelling language in order to support this solution. Section 5 discusses alternative and complementary approaches. Section 6 describes some applications and experiences that we have attained so far, and Section 7 presents the conclusions.

\section{Solution}

Any information system must be based on a conceptual model of the portion of reality that it aims to address (Evans 2003; Vernon 2013). For archaeology, this portion of reality most often includes the relevant archaeological record, which may be composed of artefacts, features, places and/ or other elements that are considered of importance, such as representations of the former (in the form of e.g. photographs, maps, drawings or reports). A conceptual model of all this is a precisely defined structured network of concepts that is expressed in a well-known language so that communication is facilitated. This is especially important, for example, if a team of archaeologists is to create a conceptual model of their relevant domain, and later a team of software developers is to create a database system based on said model. Different modelling languages exist, but ConML (Gonzalez-Perez 2012; Incipit 2013a) is especially suited for archaeology, since it was specifically designed to be affordable for nonIT specialists and with the humanities and social sciences in mind, and avoids the huge size, software-

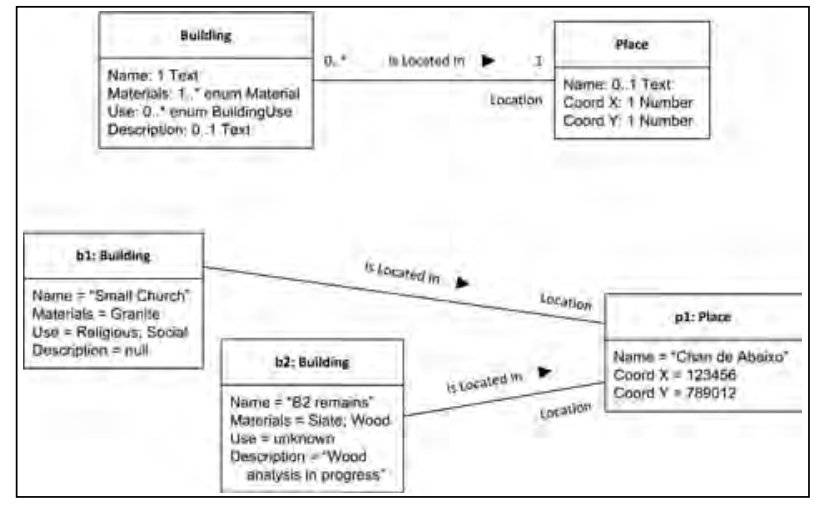

Figure 1. Diagram depicting a conceptual model containing two classes (top) and three objects (bottom). Each class represents a category of things in the observed reality, such as Building or Place, and contains a few attributes that describe that category. Each object, in turn, represents a particular entity about which information is kept; for example, b1 represents a building made of granite and used for religious and social purposes. Finally, objects can be linked together as specified by their classes; for example, both buildings b1 and b2 are located on the same place $\mathrm{p} 1$.

orientation and implementation noise of e.g. UML (ISO/IEC 2012). ConML is strongly object-oriented, meaning that entities in the observed reality are represented by objects in theconceptual model. Also, entities that share some common characteristics can be categorised together as belonging to a common class. Relevant characteristics of entities can be captured in the model through values, and values can be described from the point of view of the relevant class in the form of attributes. Fig. 1 depicts a sample conceptual model.

In addition, entities that are observed to be related to each other can be reflected in the model by adding links between the corresponding objects; and links can be described from the point of view of the relevant classes in the form of associations. This is also shown in Fig. 1. A model that focuses on the categories of things that exist, orareexpected to exist, in a given portion of the observed reality, is called a type model, and usually includes classes, attributes and associations. Correspondingly, a model that focuses on representing a set of actual things (that exist or may exist, or even may not) is called an instance model, and usually includes objects, values and links. The upper half of Fig. 1 is a type model, whereas the bottom half is an instance model. Type 
models, since they describe the categories of things, describe reality from an abstract viewpoint, and are usually employed to prescribe what instance models can be obtained, very much like the structure of a database prescribes the "shape" of the information that can be hosted in it.

This approach to modelling is often called class modelling or, from a more abstract point of view, structural modelling, since it focuses on the structure of reality. This contrasts with dynamic modelling, which focuses on how reality changes over time, but at the expense of hiding most of the information that is relevant, such as the values in the objects or the links between them (Rumbaugh et al. 1991). The solution proposed here is an extension of structural modelling that incorporates some elements of dynamic modelling while maintaining its full expressive power. Our solution is based on the following principles:

1. Some characteristics of an entity may change over time, and this change may be interesting to record. This is a case of ontic change of the entity, and is captured through temporal attributes or associations in the model.

2. Some characteristics of an entity may vary depending on who the observer is, and this change may be interesting to record. This is a case of epistemic change of theinformation about the entity, and is captured through subjective attributes or associations in the model.

3. Somecharacteristics of an entitymay changeover time and vary depending on who the observer is. This is a combined case.

An example of principle 1 is the Materials attribute of the Building class in Fig. 1; a building may have been made of stone and wood for most of its history, but some mortar may be added during a restoration process; later on, the mortar is removed and steel rods are inserted for better support. Although the material sequence of an archaeological buildingis rarely found in a straightforward manner, but deduced, we can safely assume that it is of archaeological interest to keep track of the different materials that were employed in a relevant building over time. Doing it in a diachronic, temporal way gives a richer picture of the building than using a presentist view that simply declares the materials currently employed.

An example of principle 2 is the Description attribute of the Building class in Fig. 1, especially if considered a highly interpretive attribute where archaeologists express their understanding of the associated material evidences. Strong interpretations such as "this was a storage area" or "these were the living quarters" are often contested and highly subjective. Keeping track of what each individual or group believes about a particular building, again, paints a much more vivid picture of the building than a single, hegemonic perspective that tries to reconcile everyone's views.

An example of principle 3 could be a Conservation Status attribute of the Building class. A building may be assessed as of being poorly preserved by some, but as relatively well preserved by others; this is a case of subjective variation. At the same time, ontic changes in the building over time are likely to trigger changes in the minds of said subjectivities, so that, for example, the author who assessed the building as relatively well preserved in the past changes her mind to think now that it is indeed poorly preserved.

It is important to emphasise the following. By recording the changes that an archaeological entity goes through over time, or the different perspectives that individuals have about it, no inconsistency or contradiction is being introduced. Precisely, our claim is that recording the fact that one individual believes that "this was a storage area" whereas someone else believes that "these were the living quarters" does not pose an inconsistency, but a completely consistent, complementary view of the archaeological entity under study.

Finally, it is important to remark that change over time or subjectivity may or may not be interesting to record, and this is a design decision that must be made for each information system or database depending on its goals and context. For example, a laboratory samples management system for archaeometric analysis would probably not need to record the past locations of an artefact since it was unearthed; however, the database of a research institute working on object histories would probably need to consider that. In other words, it is not that 


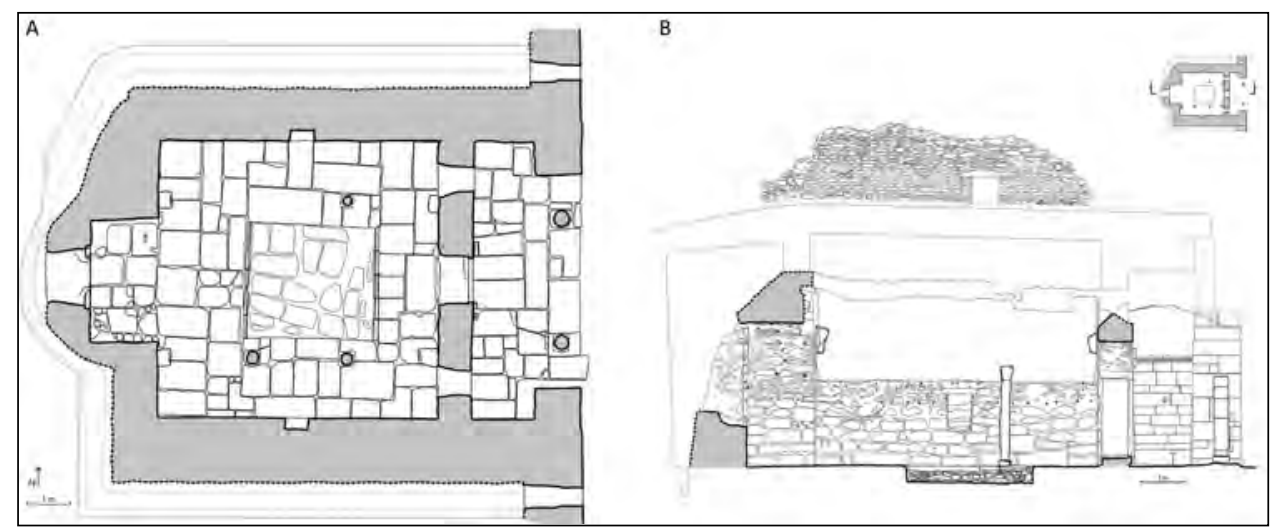

Figure 2. Plan and section of Santa Eulalia de Bóveda at present. A shows the plan of the hall and narthex; the pool structure can be seen in the centre. B shows a section showing underground and above ground structures. Drawings by Anxo Rodríguez-Paz

attributes (or associations) are inherently temporal or subjective; rather, we may decide to model them as such in order to keep track of their changes if such changes are considered relevant.

\section{Example}

This section uses an example based on an archaeological building to illustrate the solution proposed above. The fact that the chosen example is about the archaeology of architecture, however, does not mean that the proposed approach is limited to buildings or even material entities.

We introduce here the case of Santa Eulalia de Bóveda in Galicia, Spain. This is a building probably originating between the 5th and 6th centuries CE (Sanjurjo-Sánchez et al. 2010, as well as further references below) as a partially underground square hall plusnarthex, featuringasquarepool in thecentre (Fig. 2). The hall was divided by the construction of an arcade at some point, probably between the 10th and 13th centuries, and wall paintings were added at that time as well. An upper level was added between the 13th and 14th centuries, and a staircase to link both levels was constructed in the 18th century. The arcades, upper level and staircase were gone by the late 20th century, when archaeological and restoration works added some access elements so that the building could be opened to visitors. Please note that the dates we are using in this paper are still very tentative, and work is being done to obtain more precise knowledge through the dating of the mortar samples by optically-stimulated luminescence (OSL), as advanced in Sanjurjo-Sánchez et al. (2010). The major concern of this paper is not to show the exact dates of the monument, but to show that a building such as Santa Eulalia is the result of a long process that sequentially produces changes in its structure and function.

There are multiple hypotheses about what the original use of the building was. Castillo López (1927) has suggested that Santa Eulalia was a nymphaeum with a clearly symbolic use, and Schlunk (1935) has proposed a funerary use with symbolic but also social function. These authors place the original construction of the building slightly earlier than stated above, around the 4th century. Rodríguez Colmenero (1992) suggests a use related to Eastern religions, probably devoted to Isis or Serapis, and places construction between the 3rd and 4th centuries (Colmenero 2006). Finally, Blanco-Rotea et al. (2009) acknowledge that there are not enough evidences as to determine the original use and function of the building. Most authors, however, agree that Santa Eulalia was used for Christian cult after the 10th century (Montegro Rúa 2008, 26- 28), and there is no dispute that it was deconsecrated and used as a visitable monument from late 20th century.

The complex temporal and subjective information that we have on Santa Eulalia can be depicted by using an object slice matrix (Fig. 3). This diagram shows a collection of object slices, i.e. versions of the same object that pertain to different moments in time and/or authors. Being slices of the same object, all of them refer to the same entity in the observed reality; in our case, the building of Santa Eulalia. In the matrix, time is displayed horizontally from left to right, and subjective variation is displayed vertically. Object slices are arranged bidimensionally according to these two parameters. 


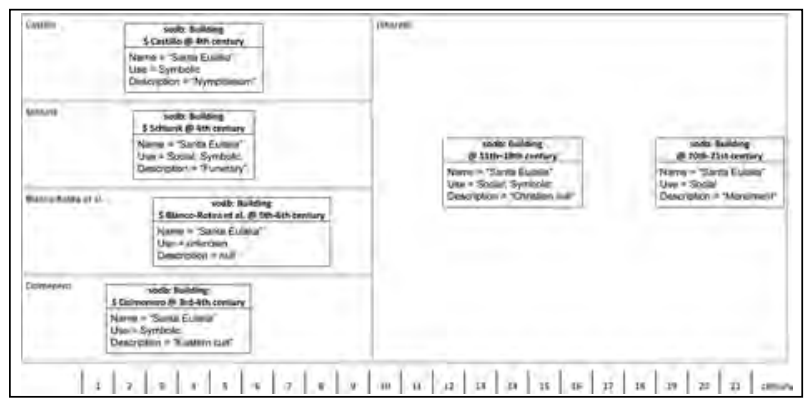

Figure 3. Object slice matrix for Santa Eulalia de Bóveda. Time is represented horizontally, from left to right. Subjectivities are represented vertically. Each box in the matrix depicts an object slice, i.e. a particular version of the sodb object for a given phase (marked through the “@” symbol) and perspective (marked by “\$”).

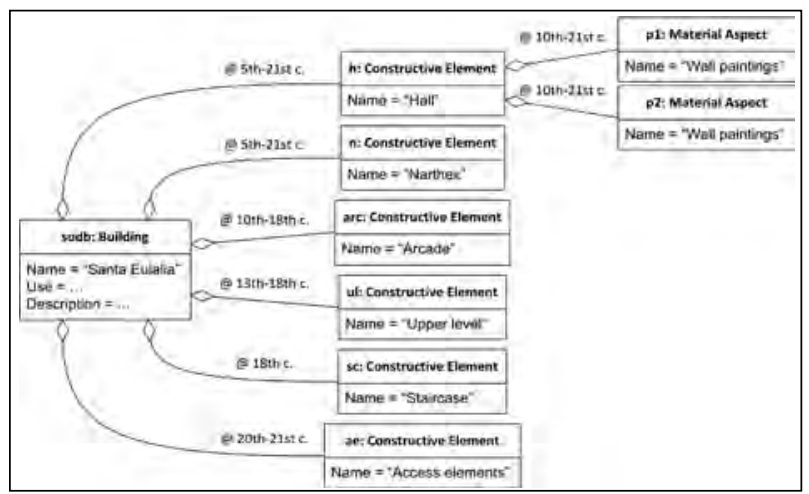

Figure 4. Diachronic composition diagram for Santa Eulalia de Bóveda. Each box represents an object, and each line linking two boxes represents a "is composed of" or "contains" link. Links are labelled with phase selectors.

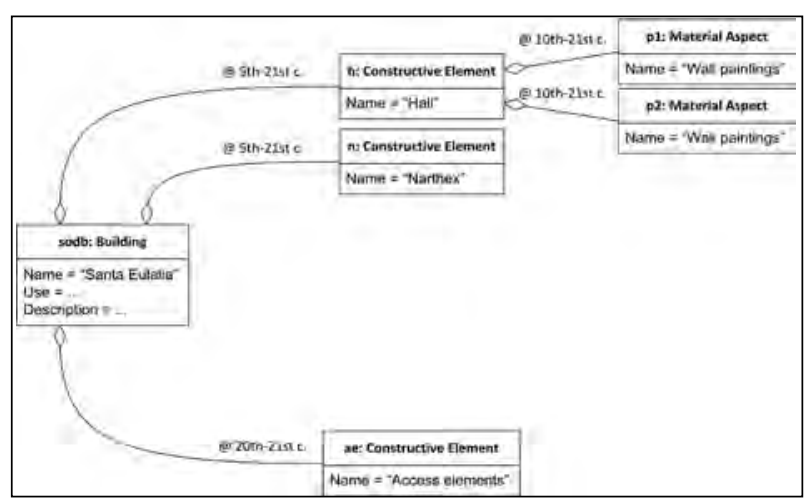

Figure 5. Instantaneous composition diagram for Santa Eulalia de Bóveda with target time of early 21st century, obtained from the previous diachronic diagram. Every object linked to sodb having phase selectors not including this target time has been removed. In other words, this is what Santa Eulalia looks like today.
In addition, object slices are labelled with phase and perspective selectors. A phase selector is a label that points to the particular time span to which the object slice applies, and is marked by a "@” symbol; for example, the right-most slice in Fig. 3 is labelled as "@ 20th-21st century", meaning that the description of Santa Eulalia as "Monument" only applies to that time range. Similarly, a perspective selector is a label that refers to the author to which the object slice applies, and is marked by a " $\$$ " symbol; for example, the slice at the very bottom of Fig. 3 is labelled as " $\$$ Colmenero", meaning that the description of Santa Eulalia as an "Eastern cult" is only shared by Rodríguez Colmenero. Note also that some slices are both temporal and subjective at the same time.

The object slice matrix is a good instrument to visualise how the values of an object change over time or subjectivities. However, links between objects are also subject to change. In the case of Santa Eulalia de Bóveda, a diachronic composition diagram can help to display these changes (Fig. 4). As its name suggests, a diachronic composition diagram shows what objects are or were the components of some given complex object over time, labelling each link between them with a phase selector. In Fig. 4, for example, it is stated that the sodb object, representing the Santa Eulalia building, was composed of the $h$ object, representing the hall, between the 5th and 21st centuries.

It is important to remark that this diagram is diachronic and, as such, does not depict reality at any point in time in particular; quite the opposite, it is often the case that reality never looked like what a diachronic composition diagram displays. Our interactions with observed reality are instantaneous, so that, in order to focus on a particular moment in relation with Santa Eulalia, we need to state a target point in time, and then remove every link whose phase selector does not include said target. For example, Fig. 5 shows a model of Santa Eulalia as of the early 21st century; every object linked to it with a phase selector that does not include this moment has been removed.

\section{Formalisation in ConML}

So far we have demonstrated how timeand subjectivity-varying values and links can be 
Expressing Temporal and Subjective Information about Archaeological Entities

Cesar Gonzalez-Perez, Patricia Martín-Rodilla and Rebeca Blanco-Rotea

\begin{tabular}{|c|c|c|c|c|c|c|}
\hline Building & & & & & & \\
\hline $\begin{array}{l}\text { Name: } 1 \text { Text } \\
\text { Use: } 0 . \text { enum Building Use }(\mathrm{S}, \mathrm{T})^{\text {Description: } 0.1 \text { Text }(\mathrm{S}, \mathrm{T})}\end{array}$ & & 0. & Name: 1 Text & 1 & $0.0^{\circ}$ & Name: 1 Text \\
\hline
\end{tabular}

Figure 6. Type model from which the Santa Eulalia de Bóveda examples have been generated. Attributes Use and Description of the Building class are marked as temporal and subjective. The composition associations between Building and Constructive Element, and between Constructive Element and Material Aspect, are marked as temporal.

recorded by using object slice matrices or diachronic composition diagrams. However, some additional observations about these lead to further questions. Specifically, it can be seen in Fig. 3 that the value for the Name attribute never changes, regardless of the time or the author; however, values for Use and Description attributes do change. As we explained in Section 2, a decision must be made when construction a model of the archaeological record about what attributes and associations are temporal and/ or subjective, depending on the interest that we may have on keeping track of the associated changes. In the example of Santa Eulalia de Bóveda, it is evident that the Use and Description attributes have been treated as both temporal and subjective, and the composition associations between the building and its parts have been treated as temporal (Fig. 4). The Name attribute has not been treated as temporal or subjective. This does not mean that it cannot change over time or depending on the observer; quite to the contrary, it can. However, changes to the Name attribute would not result in different object slices being generated, but to the new name overwriting the previous one on every object slice, thus giving a static, hegemonic view of the building as far as its name is concerned. Again, a model built for a different purpose may have chosen differently and treated the Name attribute as temporal and/ or subjective as well.

Which attributes and associations are treated as temporal, subjective or both must be clearly declared in a type model of thearchaeological record, so that this model can be successfully applied, either as a template for documenting evidence by creating the necessary instance models, or as an input for the development of an information system or database. The ConML language (Gonzalez-Perez 2012; Incipit 2013a) provides the following mechanisms to achieve this. First of all, attributes or associations that are intended to be treated temporally must be marked as "(T)" in the type model diagram and,

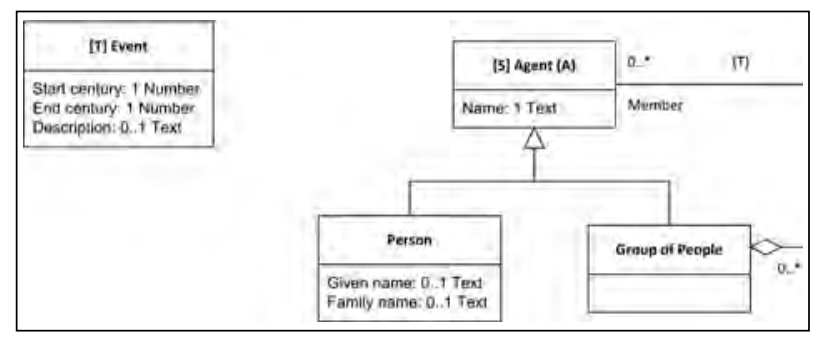

Figure 7. Classes with time and author semantics in our model, marked as "[T]" and "[S]", respectively. This diagram means that events will be used to specify phase markers in instance models, and agents (either individual persons or groups) will be used to specify perspective markers.

similarly, attributes or associations that are intended to be treated subjectively must be marked as "(S)". Attributes or associations with combined temporal and subjective semantics must be marked as both "(S, T)". Fig. 6 depicts a sample type model with the necessary classes, attributes and associations so that the instance models in Fig. 3, Fig. 4 and Fig. 5 can be generated.

Once the temporal and subjective attributes and associations are marked in the type model, object slices with temporally- and subjectivelyvarying values and links can be generated. These objects slices, however, need to be "placed" along the axes of time and/or subjectivity by using phase and perspective markers, as described in Section 3. As we explain above, a phase selector is a label consisting of a "@” symbol plus a time reference, and a perspective selector is a label consisting of a "\$" symbol plus an author reference. In ConML, references to time and authors need to be anchored to well-known elements in the model for the sake of clear semantics. This is achieved by making a time reference point to an object of a class that has been marked with time semantics; similarly, author references must point to objects of a class that has been marked with author semantics. "Time 
semantics" simply means that instances of that class represent time points or spans in the model, and "author semantics" means that instances of that class represent agents with the ability to issue interpretive statements about the observed reality. Fig. 7 depicts a fragment of a type model showing a class Event marked as "[T]", meaning time semantics; plus a class Agent marked as "[S]", meaning author semantics.

As a consequence, phase and perspective selectors appearing in instance models (such as those in Fig. 3, Fig. 4 and Fig. 5) must refer to objects of, respectively, the Event and Agent classes. For example, the phase selector in the right-most object slice in Fig. 3 “@ 20th-21st century” contains a reference to an instance of the Event class with values Start century $=20$ and End century $=21$. Similarly, the perspective selector of the bottom object slice in the same figure " $\$$ Colmenero" makes reference to an instance of the Person class with value Family name = "Rodríguez Colmenero".

The formal semantics and notation of ConML are larger and more complex than shown here, and a comprehensive description is out of scope of this paper. For additional information on ConML, please see (Incipit 2013b). For the details on the metamodel implementation of time and subjectivity management, please see (Gonzalez-Perez 2013).

\section{Alternative and Complementary Approaches}

Some alternative approaches to modelling temporality and subjectivity have been suggested, often in an informal manner and as part of technical implementations of databases or information systems, rather than technology-agnostic, reusable research outcomes. Here we examine a few.

A very pragmatic approach to dealing with temporality and subjectivity that sometimes can be seen in information systems and databases is that of highercardinalities: theattribute(orassociation) that is subject to change is artificially made multivalued in order to hold the multiple values that it may potentially go through over time or subjectivities. As an example of this approach, consider our previous example of the ConservationStatus attribute of the Building class (see Section 2). Most people would agree that any given building has a conservation status that changes over time, or which is different depending on who the observer is. However, this is still one conservation status rather than multiple. In other words, the building has a single conservation status (rather than multiple) at any given point in time, and from the perspective of any given observer. Therefore, the cardinality of this attribute is one, not many. The fact that its value may change must be dealt with as a separate fact, in order to differentiate this case from other cases where multiple values could genuinely be held at the same time and from the perspective of the same observer; for example, consider a Materials attribute, which captures the multiple materials of which any given building is simultaneously made of at any given time. In summary, using higher cardinalities to deal with temporality and subjectivity is prone to confusion and must be avoided.

Explicit historical traces or "logs" are also a common approach to dealing with the issue of temporality in database implementations. This involves maintaining a separate table (or similar construct) in the database for the sole purpose of keeping track of changes to a particular attribute. As an example of this approach, consider, again, the example of the ConservationStatus attribute of the Building class. Instead of storing the value of this attribute in the Buildings table, a database could have a separate table, named Buildings ConservationStatus, where every single value of this attribute is stored for every single building in the Buildings master table, usually together with a timestamp. This approach is perfectly valid, and constitutes a good implementation of the time semantics that we propose in this paper. However, the implementation alone, with no theory to support it, is not enough, since it lacks the necessary expressivity. In our previous example, the database table Building corresponds to a category in the archaeological record that is being modelled; however, the table Buildings_ConservationStatus does not. In the absence of a supporting theory, a database alone, or an information system working on top of it, cannot explain these differences. By seeing this approach under the light of the semantics proposed in this paper, the following benefits arise:

- It is very clear which tables correspond to relevant categories in the reality being modelled 
Expressing Temporal and Subjective Information about Archaeological Entities

Cesar Gonzalez-Perez, Patricia Martín-Rodilla and Rebeca Blanco-Rotea

and which do not; those tables that map to classes in the type model do, whereas those tables that map to an attribute (or association) marked as $\mathrm{S}$ and/ or T do not; rather, they correspond to the trace of values over subjectivities or time of said attribute.

- The timestamp values that often appear in "log" tables are mapped to phase selectors, and therefore they can become references to rows in some "time semantics" table if desired.

- Next to the mentioned timestamp column, a new author column can be added, the values of which would consist of references to some "author semantics" tableand map to perspectiveselectors. In this manner, subjectivity management can be easily added next to time management.

A few words must be said about the bitemporal approach, which is quite popular in the database community (Snodgrass and Ahn 1986; Svinterikou and Theodoulidis 1999). According to this approach, two timestamps are relevant for each fact: its valid time and its transaction time. Valid time states when the fact was valid, i.e. when observed reality conformed to what the fact states (for example, "Santa Eulalia had an upper level" has a valid time of 13th-18th c.); transaction time states when the fact was created and/ or entered into the database ("Santa Eulalia had an upper level" has a transaction time of 8 June 2013, since this is the date when I entered this fact into this document). Despite the attention that the bitemporal approach has enjoyed in the database literature, we argue that its applicability should not be taken beyond that and into conceptual modelling, especially in the realm of the humanities and social sciences, for the following reason. Valid times are about the entities themselves, whereas transaction times are about the facts that we state about said entities. In other words, transaction times are "meta" in relation to valid times. This means that transaction times constitute metainformation that describes the model rather than the entities being modelled and, as such, does not belong in the model (Gonzalez-Perez 2013). As with the case of historical traces or "logs", bitemporality can work at the database implementation level, but it should not be mixed with conceptual models of the archaeological record.
Finally, it is worth mentioning that the CIDOC Conceptual Reference Model (CRM) (ISO 2006), a widely known model of cultural heritage with a focus on the "curated knowledge of museums" (Crofts et al. 2011, i-ii), contains classes especially designed to represent time-related entities, such as E5 Event, and subject-related entities, such as E39 Actor. However, CIDOC CRM is a conceptual model of cultural heritage, rather than a general-purpose modelling language; and, similarly, constructs such as E5 Event and E39 Actor are categories of things that are expected to be found in reality, rather than cross-cutting mechanisms that can be used to express arbitrary temporality or subjectivity. From a formal modelling point of view, and following OMG's strict metamodelling paradigm (Atkinson 1998), CIDOC CRM is an M1 model, whereas ConML is an M2 language. For this reason, we conclude that the approach in CIDOC CRM is useful within CIDOC CRM models, but since CIDOC CRM is not a class-generating language, its mechanisms are more limited than those presented here.

\section{Applications}

The approach suggested here has been or is being applied in the context of two projects, which are briefly described.

The Cultural Heritage Abstract Reference Model (CHARM) (Gonzalez-Perez and Parcero Oubiña 2011; Incipit 2013d) is a wide and shallow conceptual model for cultural heritage, which includes over 160 classes representing very abstract concepts such as Place, Material Entity, Agent or Performative Entity. CHARM does not only represent the specific entities that might make up cultural heritage, but also other entities which, without doing so, are necessary in order to describe and understand the former, such as documents, representations or valorisations. CHARM has been designed to be used by a wide and diverse range of people and, rather than constituting an off-the-shelf, readily usable solution, it needs to be extended by each user to meet their particular needs. Although this entails some additional work, it also provides a mechanism to better adjust the resulting model to the task at hand, while still being based on the abstract reference model. An extensive description of the usage and extension mechanisms of CHARM can be found in Gonzalez-Perez et al. (2012). 
CHARM has been constructed using ConML, and special attention was payed to temporal and subjective semantics. As far as we know, CHARM is the only conceptual model covering the domain of archaeology that has considered these issues. Additional information on CHARM is available from Incipit (2013c).

A very different kind of project is Textura; this is an ongoing software development project aimed at the creation of a research-oriented infrastructure for cultural heritage information. Textura adopts CHARM as a foundational ontology for cultural heritage, and uses ConML as a modelling language to allow users to extend CHARM in order to define the details of their particular projects, such as what kinds of entities they are interested in, what attributes are relevant, and what temporal and subjective semantics are to be used. In this regard, Textura is an excellent proof of concept that the theoretical approach proposed here can be successfully be applied in practice.

\section{Conclusions}

In this paper we have argued that conceptual models in archaeology usually provide a temporally static and subjectively hegemonic view of the world. However, temporal change and multivocality must be captured in structural models in order to obtain richer, more expressive views of the archaeological record. We have used the example of Santa Eulalia de Bóveda to show how object slice matrices and diachronic composition diagrams can help to achieve this, and we have described the necessary formalisms in the ConML conceptual modelling language. Finally, we have discussed some alternative and complementary approaches, and briefly described some projects where our suggested solution has been or is being applied.

The proposed solution needs to be improved, though. One particular area that needs further research is that of the occurrence of subjective change over time. We have argued in Section 2 that subjective change is a case of epistemic change of the information about the entity; however, we might be making a category error here, as famously pointed out by Searle (1990) in his treatment of ontological subjectivity: if the focus of attention is displaced from the archaeological entity to the information about the entity, then what was epistemic turns to be ontic, and thus change should be better modelled as temporal change of the information rather than subjective change about the entity.

We look forward to reporting on the results of further research along these lines, as well as the application of the proposed approach to the Textura project, in future papers.

\section{Acknowledgements}

Part of the work described in this paper has been funded under grant 09SEC002606PR "Proxecto MIRFOL" of the INCITE Programme, Xunta de Galicia, Spain.

\section{Bibliography}

Atkinson, C. 1998. "Supporting and Applying the UML Conceptual Framework." In The Unified Modeling Language. «UML»'98: Beyond the Notation, edited by J . Bézivin and P.-A. Muller, 21- 36. Berlin: Springer.

Blanco-Rotea, R., R. Benavides García, J. Sanjurjo Sánchez, and D. Fernández Mosquera. 2009. "Evolución constructiva de Santa Eulalia de Bóveda (Lugo, Galicia)." Arqueología dela Arquitectura 6:149- 198.

Castillo López, Á.D. 1927. “Los descubrimientos de Santa Eulalia de Bóveda." Boletín de la Real Academia Gallega XVII (197):140- 142.

Crofts, N., M. Doerr, T. Gill, S. Stead, and M. Stiff, eds. 2011. "Definition of the CIDOC Conceptual Reference Model, version 5.0.3." Last modified May 2011. http:// www.cidoc-crm.org/docs/cidoc crm version 5.0.3.pdf.

Evans, E. 2003. Domain-Driven Design: Tackling Complexity in the Heart of Software. Upper Saddle River: Addison-Wesley Professional.

Gonzalez-Perez, C. 2012. "A Conceptual Modelling Language for the Humanities and Social Sciences." In Research Challenges in Information Science (RCIS), 2012 Sixth International Conference on, edited by C. Rolland, J. Castro, and O. Pastor, 1-6. Valencia: IEEE Computer Society.

Gonzalez-Perez, C. 2013. "Modelling Temporality and Subjectivity in ConML." In Research Challenges 
Expressing Temporal and Subjective Information about Archaeological Entities

Cesar Gonzalez-Perez, Patricia Martín-Rodilla and Rebeca Blanco-Rotea

in Information Science (RCIS), 2013 IEEE Seventh International Conference on, edited by R. Wieringa and S. Nurcan, 1- 6. Paris: IEEE Computer Society.

Gonzalez-Perez, C., P. Martín-Rodilla, C. ParceroOubiña, P. Fábrega-Álvarez, and A. Güimil-Fariña. 2012. "Extending an Abstract Reference Model for Transdisciplinary Work in Cultural Heritage." In Metadata and Semantics Research, edited by J. M. Dodero, M. Palomo-Duarte, and P. Karampiperis, 190201. Berlin: Springer.

Gonzalez-Perez, C., and C. Parcero Oubiña. 2011. "A Conceptual Model for Cultural Heritage Definition and Motivation." In Revive the Past: Proceeding of the 39th Conference on Computer Applications and Quantitative Methods in Archaeology, edited by M. Zhou, I. Romanowska, Z. Wu, P. Xu, and P. Verhagen, 234- 244. Amsterdam: Pallas Publications.

Incipit. 2013a. "ConML Technical Specification, version 1.3." Accessed March 17. http://www.conml.org/ Resources_TechSpec.aspx.

Incipit. 2013b. "ConML Conceptual modelling for the rest of us." Accessed March 17. http:// www.conml.org.

Incipit. 2013c. "CHARM Cultural Heritage Abstract Reference Model." Accessed March 17. http://www. charminfo.org.

Incipit. 2013d. "CHARM White Paper version 1.0.3." Last modified November 22. http://www.charminfo.org/ Documents/CHARM\%20White\%20Paper.pdf.

ISO. 2006. "Information and Documentation - A Reference Ontology for the Interchange of Cultural Heritage Information." ISO 21127:2006.

ISO/IEC. 2012. "Information technology - Unified Modeling Language (OMG UML) Part 1: Infrastructure." ISO/ IEC 19505-1:2012.

Montenegro Rúa, E. J. 2008. “O monumento de Santa Eulalia de Bóveda, síntese da súa historia coñecida." In Santa Eulalia de Bóveda, edited by E. J. Montenegro Rúa, R. Blanco-Rotea, and R. Benavides García, 11- 40. Santiago de Compostela: Xunta de Galicia.

Price, R., K. Ramamohanarao, and B. Srinivasan. 1999. "Spatiotemporal Extensions to Unified Modeling
Language." In Proceedings of the Tenth International Workshop on Databaseand Expert Systems Applications, edited by A. Cammelli, A. M. Tjoa, and R. R. Wagner, 460-461. Los Alamitos: IEEE Computer Society.

Rodríguez Colmenero, A. 1992. “Culto a las aguas y divinidades orientales en el Lugo romano: losmonumentos de Bóveda y San Roque." Espacio, Tiempo y Forma, Serie II, Historia Antigua V:309- 335.

Rodríguez Colmenero, A. 2006. “A aparición do cristianismo no ámbito do conveto xurídico lucense. Algúns testemuños." In San Froilán: Culto e Festa. Exposición en Lugo, edited by S. Lorenzo and F. Luis, 46- 69. Santiago de Compostela: Xunta de Galicia.

Rumbaugh, J ., M. Blaha, W. Premerlani, F. Eddy, and W. Lorensen. 1991. Object-Oriented Modeling and Design. Englewood Cliffs: Prentice-Hall.

Sanjurjo-Sánchez, J ., M. J . Trindade, R. Blanco-Rotea, R. Benavides Garcia, D. Fernández Mosquera, C. Burbidge, M. I. Prudêncio and M. I. Dias. 2010. "Chemical and mineralogical characterization of historic mortars from the Santa Eulalia de Bóveda temple, NW Spain." J ournal of Archaeological Science 37 (9):2346- 2351.

Schlunk, H. 1935. "Santa Eulalia de Bóveda.” Das Siebente Jahrzent. Festschrift für A. Glodschmidt:1- 13.

Searle, J. R. 1990. The Mystery of Consciousness. New York: The New York Review of Books.

Snodgrass, R. T., and I. Ahn. 1986. "Temporal Databases.” Computer 19 (9):35- 42.

Svinterikou, M., and B. Theodoulidis. 1999. "TUML: A Method for Modelling Temporal Information Systems." In Advanced Information Systems Engineering, edited by M. J arke and A. Oberweis, 456- 461. Berlin: Springer.

Vernon, V. 2013. Implementing Domain-Driven Design. Upper Saddle River: Addison-Wesley Professional. 


\title{
From dBase III+ to the Semantic Web: Twenty- Five Years of the Coin Hoards of the Roman Republic Database
}

\author{
Ethan Gruber \\ American Numismatic Society, USA \\ Kris Lockyear \\ University College London, UK
}

\begin{abstract}
:
The CHRR database began life in 1988 and has grown from 24 to over 700 hoards. It has been successfully moved between software packages and has been used as a teaching resource as well as for research. Over the last year the database has been incorporated into the online numismatic databases hosted by the American Numismatic Society. This paper addresses the issues raised in turning a long-term personal research database into a publicly available resource database built on the principles of linked open data. We will address both the technical challenges and the problem of the expectations of the target audience.
\end{abstract}

\section{Keywords:}

Numismatics, Hoards, Databases, Linked Data, Roman

\section{Background to the Project}

Coin hoards are an important source of information for numismatists. As sealed assemblages of coins they can be used in the relative dating of coin issues by seriation, a technique pioneered by numismatists prior to Petrie's famous study (Crawford 1990). The contents of hoards can be examined to show patterns of production and supply and the distribution of hoards indicate the regions and periods in which coins circulated. As such, numismatists regularly publish both detailed reports on individual hoards, as well as corpora of hoards of a particular period and issuer, for example Crawford's Roman Republican Coin Hoards (Crawford 1969).

The Coin Hoards of the Roman Republic (CHRR) database was started as part of an MSc dissertation by the second author (Lockyear 1989). At that time, the data it contained was solely that published in Roman Republican Coinage (RRC) by Crawford (1974). The principal, and at the time unrealised, aim was to test Crawford's estimates of the size of issues of coinage during the later Republic. The data, however, were also used to examine the factors that influence the structure of coin hoards via a computer simulation, a study that was published in the 1990 CAA proceedings

Corresponding author: noviodunum@hotmail.com
(Lockyear 1991). This initial research led to the second author to embark upon a doctorate which analysed a much larger set of coin hoards using a variety of statistical techniques including Dmax based cluster analysis (Lockyear 1995; 1996a) and Correspondence Analysis (Lockyear 1993; 2000; 2007a). Further simulation work also undertaken to examine the original question regarding the veracity of Crawford's die estimates (Lockyear 1999). The analytical part of the resultant thesis (Lockyear 1996b) was substantially revised ten years later (Lockyear 2007a).

The CHRR database was redesigned as part of the doctoral project, using a simplified version of Ryan's (1988) database schema (Fig. 1) and implemented in dBASE III+. This was necessary as data collection in the British Museum was undertaken using a double $5^{1 / 4}$ inch floppy "laptop". A suite of programs was written to ease data input, conversion, checking and manipulation (Lockyear 1996b, 120-127).

Following completion of the thesis, the database was used in teaching at the Institute of Archaeology, UCL, and for this it was imported into Microsoft Access. It was quickly found that the relation and attribute names were confusing to students and these were renamed (Lockyear 2007a, 12-19). No new data were added to the database 
From dBase III + to the Semantic Web: Twenty-Five Years of the Coin Hoards of the Roman Republic Database Ethan Gruber and Kris Lockyear

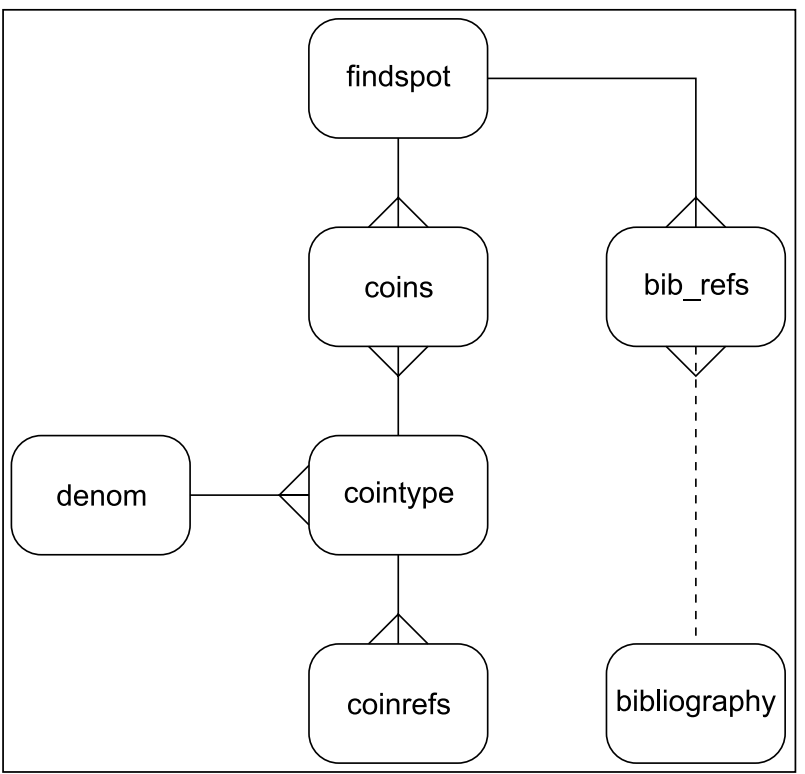

Figure 1. The entity relationship diagram for the CHRR database. The dashed line represents a conceptual link between the dBase/Access database and the bibliographic information stored in the second author's BibTeX files. Both sets of data have been included in CHRR Online.

until 2006 when a second phase of data collection was undertaken prior to a complete reworking of the analyses (Lockyear 2007a). Since 2007 new data have been added to the database in a piecemeal fashion, largely to enable specific pieces of research to be undertaken.

Following the publication of Patterns and Process the second author was approached by Rick Witschonke of the American Numismatic Society (ANS) with a view to creating an online version of the database which is the subject of this paper. CHRR Online is based on the principles of open linked data.

\section{Research v. Resource?}

Databases can be divided into three broad but overlapping types (Fig. 2). The first type consists of management databases which encompasses library catalogues or the ubiquitous sales databases beloved by writers of manuals. The second category consists of personal research databases. These are created by scholars for a particular project or interest with no intention, atleastinitially, of makingtheinformation publically available. The database application, if any, is basic and task orientated, the data included

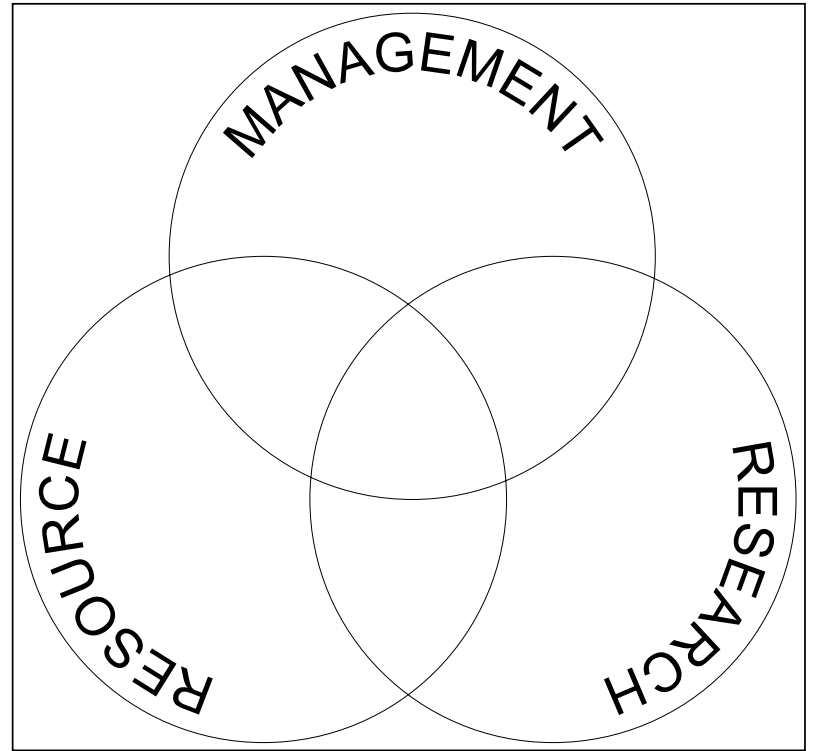

Figure 2. The relationship between database types.

are restricted to that immediately relevant to the project at hand and it is unlikely that any formal data definition document or manual exists. The creator and user of the database are the same person, and that person understands the limitations of the database, and how to use it. The last type, resource databases, are those created with the express intention of being a publically available resource for scholars, such as the Celtic Inscribed Stones Project database (UCL 2000). These databases suffer from having to try and predict what sort of data scholars will want, and in having to provide those data in a manner that academics not conversant with SQL and entity relationship diagrams can use.

The CHRR database was conceived and created solely for the purposes of the second author. As such there are gaps in the coverage. For example, few bronze hoards are included and early hoards are largely omitted. On the other hand, someareas, such as hoards from Romania, are very well represented. One major hurdle, therefore, was to create an online resource database from a personal research database in a way that the potential audience will appreciate its limitations and view the product as a glass half full, rather than a glass half empty. These challenges have been met by a process of informing, enhancing, and enabling.

The users of the database have a variety of sources to consult to inform them about the 
database. CHRR Online includes a FAQ section and help, a paper written for the American Journal of Numismatics (Lockyear in press) is also available from the site as well as links to the original $\mathrm{PhD}$ thesis and the relevant section of Patterns and Process (Lockyear 1996b; 2007a). The creator of the database is available to answer questions either via email or via various relevant online Bulletin boards.

The process of creating the online version of the database has already enhanced the content by the addition of more detailed information regarding coin types and by the provision of geographical data. In addition, new hoard data added to the CHRR database will be uploaded to the online version on a regular basis. It is planned to extend the coverage of the database as well as to add new hoards as the information becomes available.

Lastly, the web interface enables users to access the data via a variety of searches, to map the results, to plot graphs of the contents of the hoards and so on. Most importantly, it allows users to download the results of their searches to allow them to conduct more detailed analyses if they so wish.

The remainder of this paper examines the technical issues involved in converting a personal research database structured along relational lines into an open access resource database using linked data.

\section{NUDS for Hoards}

With no standard approach to encoding coin hoards electronically, the American Numismatic Society endeavoured to develop a draft XML schema in orderto addressinadequaciesin theprinted format of hoard catalogues and to serve as an interchange format between existing relational database systems designed for the recording of hoards and finds. To inform the data modelling process, a study of printed hoard publications was undertaken to create a flexible schema capable of representing relatively simple catalogues as well as those hoards published following modern archaeological excavations. To fulfil the former example, i.e., a simple hoard catalogue, An Inventory of Greek Coin Hoards (IGCH) (Thompson, Markhølm and Kraay 1973) was consulted. Listing more than 2,000 Greek coin hoards, a reference in IGCH rarely exceeds a few dozen lines, with the quantity of coins identified by merely mint or ruler. On the opposite end of the spectrum are the many hoards published in the last three decades, such as Bland and Burnett's The Normanby Hoard (Bland and Burnett 1988b). In this monograph, each coin is listed with its associated coin type in addition to physical attributes, such as weight and diameter.

CHRR lies somewhere in the middle of this spectrum, with the majority of coins defined by the type corpora, Roman Republican Coinage (RRC) (Crawford 1974) and Roman Imperial Coinage (RIC), but the records contain no specific physical characteristics. The heavy use of RRC and RIC to identify coins in CHRR makes it possible to extract data in the form of RDF directly from Nomisma.org, defined as a "collaborative effort to provide stable digital representations of numismatic concepts and entities" (Gruber et al. 2013; Nomisma 2014). The use of data from Nomisma is especially important in this case because the Access database contained a table for coin types, which on one hand was partially duplicated Nomisma's data, but was also incomplete for it lacked the mints, issuers, legends, and type descriptions that Nomisma's RDF contains. Other coins listed in Lockyear's database which were not identified by existing catalogue numbers are described by a general typology (e.g., "miscellaneous Republican denarius").

The schema for hoards is based largely on the Numismatic Description Standard (NUDS) XML schema, discussed in greater detail in "Linking Roman Coins: Current Work at the American Numismatic Society," presented at CAA 2012 (Gruber, Bransbourg and Meadows 2013). The basic structure of this NUDS-Hoard document is as follows:

- nudsHoard (root element),

$\diamond$ nudsHeader (header),

$\diamond$ descMeta (descriptive metadata),

- title (titles in multiple languages accepted),

- hoardDesc (hoard description):

- findspot,

- discovery,

- deposit, 
From dBase III + to the Semantic Web: Twenty-Five Years of the Coin Hoards of the Roman Republic Database Ethan Gruber and Kris Lockyear

- disposition,

- contentsDesc (contents description):

- contents (coins),

- containers,

- otherObjects (objects other than coinsingots, jewelry, etc.).

NUDS-Hoard includes a <nudsHeader> which contains metadata about the electronic record itself. The content and structure of this element areidentical to that of the $<$ nudsHeader $>$ in NUDS documents. Below the header is Descriptive Metadata which contains two subsections, in contrast to the same section in NUDS, which may contain six descriptive subsections in addition to several sets of descriptors.

The Hoard Description contains information about the find spot: the name and/or coordinates. The find spot can link to URIs defined by Nomisma or the Pleiades Gazetteer (Pleiades 2014) for ancient places, or Geonames (Geonames 2014) for modern ones. CHRR denotes the find spot by modern place name, and therefore Geonames URIs were adopted. The Geonames API allows programmatic extraction of geographic coordinates, facilitating the generation of KML for the mapping of hoards.

Linkingto URIs will likely bethemost common method of defining the find spot for a hoard, but geographic coordinates can also be explicitly input. These coordinates may be public or private (withheld from the public display of the record on the web). This is particularly advantageous when used in conjunction with URI-defined find spots. The public may see that a hoard was discovered near Lincoln, but specific and highly accurate GPS coordinates of the find spot may be recorded for the benefit of archaeologists and administrators, but blocked from appearance on the web to prevent looting of the site.

The Hoard Description contains information about the discovery of the hoard-the date, type of discovery (excavation, agricultural activity, metal detecting, etc.), the finder(s), or other notes about the circumstances of the discovery. After the discovery section is the deposit date. If this date is not explicitly expressed in the NUDS-Hoard record, the date can be derived programmatically by analysing the contents of the hoard. The date should be explicit when archaeology provides more accurate context than can be derived from the dates of the coinage, although this is unlikely for Republican hoards. Finally, the Hoard Description contains descriptors for the disposition of the hoard described generally as a whole. The disposition can also be defined on the coin level.

Below the Hoard Description section is the Contents Description, which comprises the bulk of the hoard record. The <contentsDesc $>$ contains three subsections: contents (for listing coinage), containers (for defining the materials, dates, and typologies of the containers in which the hoards were placed), and a listing of other objects found in the hoard. It is possible to internally link containers defined in the hoard record to coins and other objects listed in the Contents Description in order to maintain the relationship between the container and its contents, which may be useful in large hoards which consist of more than one container.

With the structure of the NUDS-Hoard document model generally described, attention must be focused more directly on the structure of the numismatic contents section of the record. Two XML elements may appear in the <contents $>$ : coin and coin group (<coinGrp $>$ ). The difference between these two elements is that the latter accommodates a "count" element to denote the quantity of coins which adhere to the descriptors listed within the group. Both elements allow any Descriptive Metadata elements found in NUDSPhysical Description, Typological Description, etc., defined by the NUDS XML namespace. A hoard very generally described by denomination may include one denarius and two quinarii in the structure outlined below in Code 1.

Although this structure is simple, statistical analyses can be supported because the data is machine-readable by processors capable of interpreting XML. Denominations are explicitly captured by XML tags which also link Nomisma URIs. The quantity of quinarii is captured in an XML “count” attribute.

One may expand the above XML fragment further by differentiating the two quinarii 


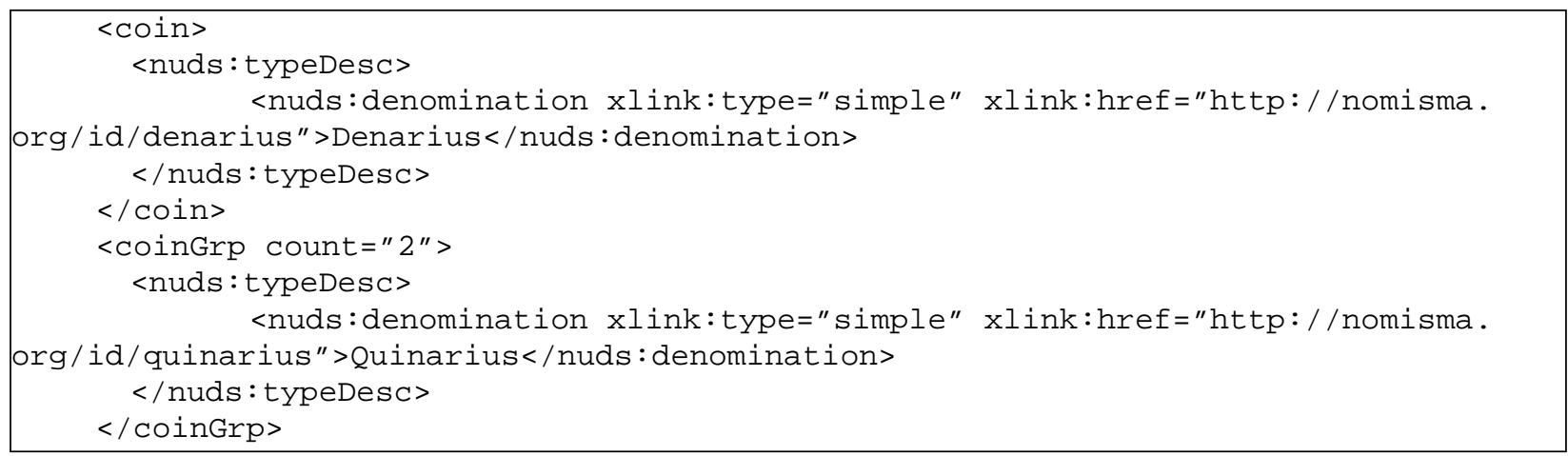

Code 1.

geographically by separating the $<$ coinGrp $>$ into two coins, each with a Typological Description including the denomination of quinarius, but one minted in Rome and the other Emerita, for example. Legends and type descriptions may also be inserted into the <typeDesc $>$. A < physDesc > element may be added for capturing the weight, diameter, and die axis of each coin. Thus, this approach to listing coins and coin groups within a hoard can accommodate the granular descriptive practices applied by Bland and Burnett in The Normanby Hoard (Bland and Burnett 1988a) and other similar publications.

The <typeDesc > within a coin or coin group can also utilise the xlink:href attribute to link to Nomisma URIs (Code 2 ).

Code 2 indicates that a hoard comprises of five instances of RRC 44/ 5 and one of RRC 88/2a. The majority of entries from the Access database were migrated into NUDS-Hoard XML records which contain little more than a reference to a Geonames URI for the find spot and a list of Nomisma URIs for Roman Republican Coinage numbers and their associated quantities. The data model is relatively simple, especially compared to the organisation of Lockyear's original database schema, but the analyses which may be conducted by users of the public interface are quite sophisticated. CHRR is built upon Numishare, an open-source application formanagingand publishingnumismaticdata, which was heavily modified to support the publication and dissemination of hoard data (Gruber et al. 2013).

\section{Numishare for Hoards}

From a presentational standpoint, CHRR does not differ significantly from Online Coins of the Roman Empire (OCRE 2014) or other Numisharebased digital numismatic collections. There is an HTML interface for searching and browsing the collection of hoards with keyword-based search and filtering by facets derived from typological attributes. Search results can be delivered in the form of Atom, KML, and CSV. It also contains a Solr facetbased mapping interface. CHRR's most significant departure from other Numishare collections for coins or coin types lies in the HTML representation of the NUDS-Hoard record. While the HTML resource for a hoard is not wholly dissimilar to a coin record in that it contains a textual description of the record (including a list of hoard contents), a mapping component, and a quantitative analysis component, the processes by which these aspects of the HTML view are generated differ substantially.

Before the transformation from XML into HTML can begin, the subject referenced by each unique xlink:href attribute associated with Typological Descriptions are imported into an XSLT

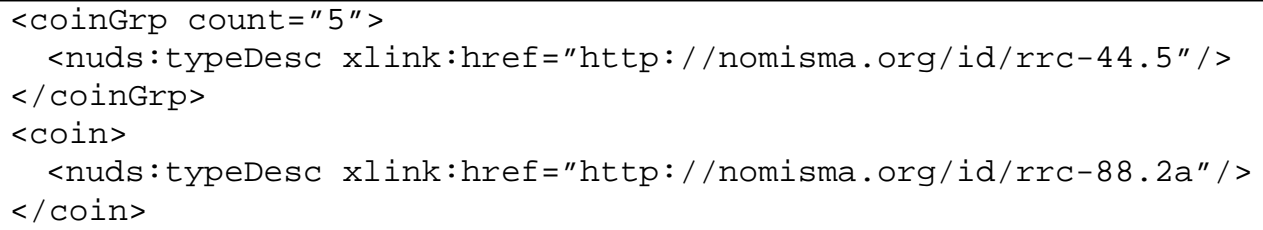

Code 2. 
From dBase III + to the Semantic Web: Twenty-Five Years of the Coin Hoards of the Roman Republic Database Ethan Gruber and Kris Lockyear

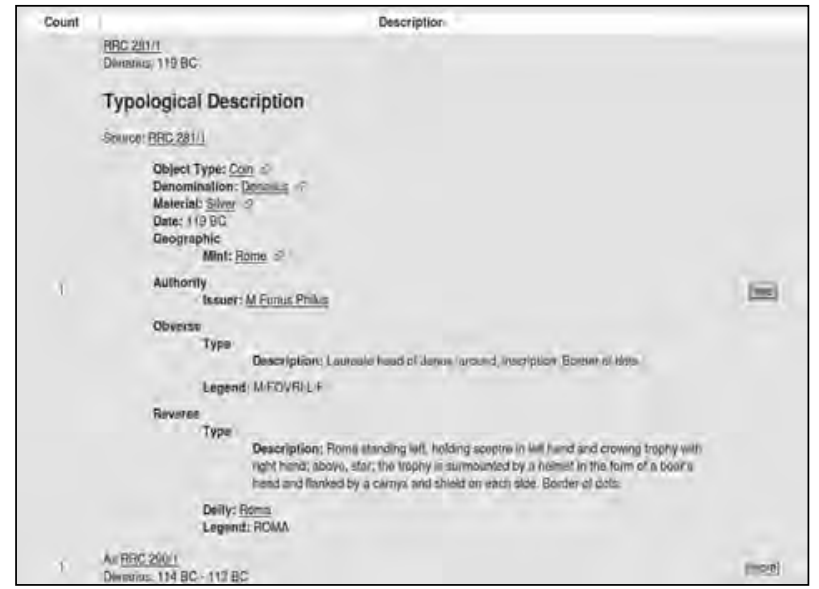

Figure 3. Screenshot of Hoard Record Page.

variable. By default, the script will look for a NUDS datastream by appending '.xml' to the URI. If the <ypeDesc> links to http://nomisma.org, '.nuds' is appended to extract the NUDS/XML model provided by Nomisma. A table row for each coin or coin group in the hoard contents is created. The denomination and date are displayed by default. For those coins or groups which link to coin types on Nomisma or OCRE, the <typeDesc > stored in the XSLT variable associated with that particular URI is passed through an XSLT template to generate a block of HTML which is hidden by default, but may be shown by Javascript with a mouse click. The XSLT template for rendering the Typological Description in hoard records is shared with XSLT for generating HTML views for coins and coin types, and therefore the HTML view of typologies in CHRR is identical to OCRE, complete with links to Nomisma or predefined search results (Fig. 3).

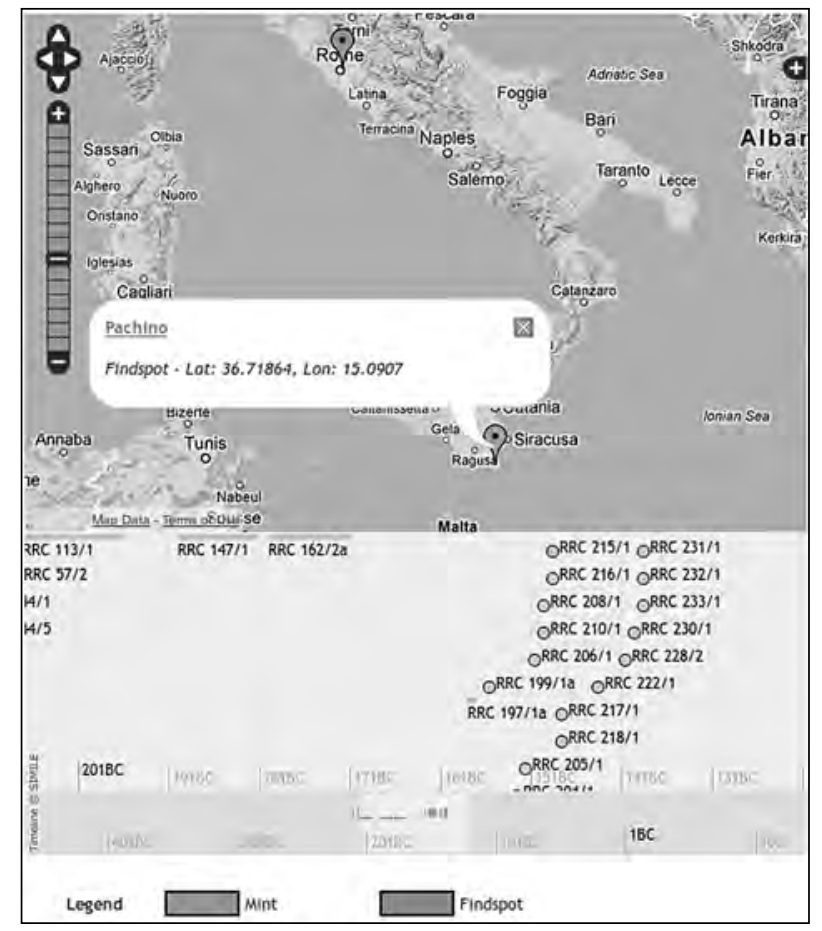

Figure 4. Temporal and geographic distribution of the Pachino hoard.

\section{Visualisation and Analysis}

CHRR's fundamental mode of visualization is geographic: the record page for a hoard displays a map combined with SIMILE Timeline through the intermediary J avascript library, Timemap. SIMILE Timeline is an open source chronological J avascript library developed by MIT (SIMILE 2014). Timemap was developed by Nick Rabinowitz and is a library

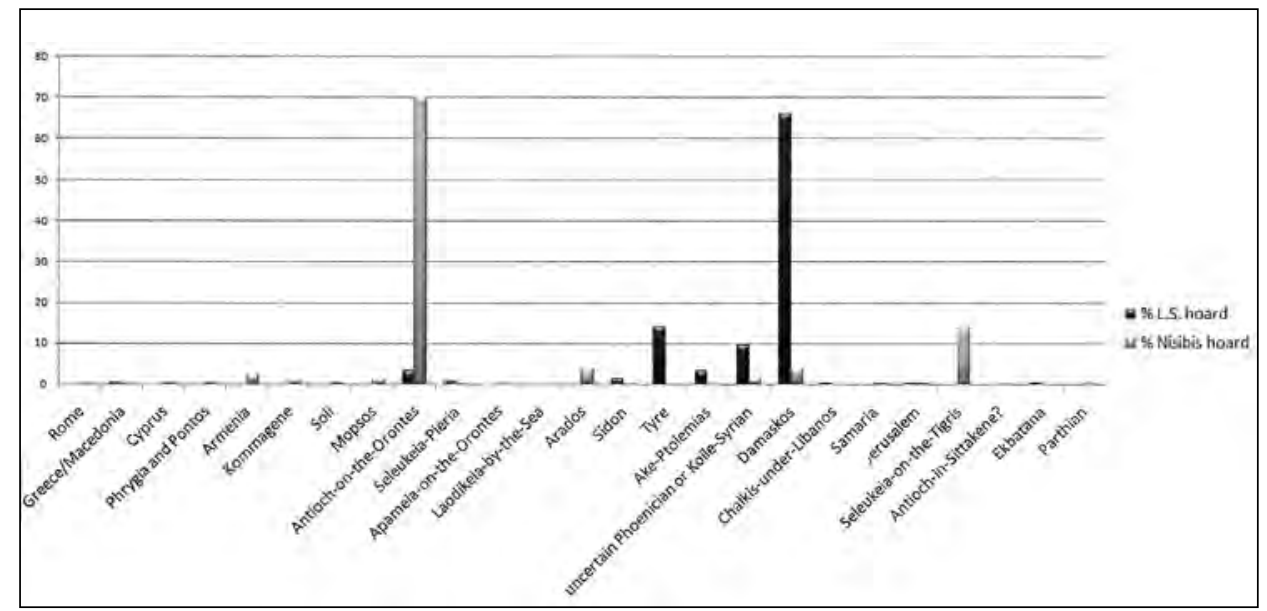

Figure 5. Comparison of mints between two hoards. From Wright 2010, Figure. 2. 


\begin{tabular}{|c|c|c|}
\hline Mlints represented in hoard & \%.L.S. hoard & $\% / n$ Nisibis hoard \\
\hline Rome & 0 & 0.19 \\
\hline Grecee//Mncedomin & 0.41 & 0.19 \\
\hline Cyprus & 0 & 0.39 \\
\hline Parygits and Pontos & 0 & 0.39 \\
\hline Arruenia & a) & 2.14 \\
\hline Kormusyene & 0 & 0.78 \\
\hline Kilikia & $n$ & 0.36 \\
\hline Antioch on the Orenies & 290 & 69.98 \\
\hline Seleuketa in Pieria & 0.4 & 0.19 \\
\hline Apaneata on the Oruntes & 0 & 0.19 \\
\hline Laodikeia by the Sea & n & 0.19 \\
\hline Arados & 0 & 3,51 \\
\hline Sidon & 1.24 & 0.19 \\
\hline Tyre & 14.05 & 0 \\
\hline Piolenails (Ake) & 372 & 0.19 \\
\hline Unertain mim in Phesenicta or Koile Byriy & 9.50 & 1.17 \\
\hline Damasceus & 66.51 & 3.70 \\
\hline Chalkis under Libunios & 0.41 & 0 \\
\hline Samaria & 0 & 039 \\
\hline Jetusilem & 0.41 & 0.39 \\
\hline Seleukeis on the Tygris & 0 & 14.04 \\
\hline Amioch in Sitrakene & 0 & 0.19 \\
\hline Ekbatana & 0.41 & 0 \\
\hline Parthía & 0 & 0.19 \\
\hline
\end{tabular}

Figure 6. Tabular results for mints in Figure. 5. From Wright 2010, Table 1.

that interlinks the timeline function with Google or OpenLayers maps. It is open source and available online (Timemap 2014). The map for a hoard in CHRR not only shows a point for the findspot and all of the mints associated with it, but the timeline shows every datable coin, which makes it easier for users to get a sense of the temporal, in addition to geographic, distribution of coins found within the hoard (Fig. 4).

One of the most important features of this project is its analytical functionality. Quantitative analysis of hoards provides insight to scholars on the social and economic conditions in the time and place where the hoard was buried. While IGCH (Thompson et al. 1973) is merely a catalogue of hoards containing very little consideration of their contexts, modern hoard statistics are quantified into charts. Further historical context can be ascertained about a particular hoard by comparing its contents to hoards in neighbouring geographic areas. A table in The Normanby Hoard shows a listing of the percentage of coins per mid-late third century emperor across fourteen different hoards (Bland and Burnett 1988a, 116). The format of the data in The Normanby Hoard is purely tabular, but more recent publications, such as Coin Hoards $X$ (Hoover, Meadows and Wartenberg 2010) include computer-generated graphs. Wright (2010) includes a column chart showing the percentages of coins in two hoards originating from various mints. The following page in Wright's article includes a representation of these data in a table. In an article about the Gaziantep Hoard in the same volume, Meadows and Houghton $(2010,147)$ include pie charts showing the geographic origins and general categories (Seleucid, Alexanders, etc.) ofits contents. According to Hoover, many charts published in this volume were generated in Microsoft Excel and submitted as images exported directly from that program or post-processed in Adobe Illustrator to improve the layout for publication (Fig. 5, which is based on the data reproduced in Fig. 6). Thus, each chart required manual entry into a spreadsheet the categories and values desired for visualisation. The scholar is limited by the time available to create new spreadsheets in the categories desired for statistical analysis. A comprehensive database solution like CHRR dramatically improves upon the spreadsheetbased method of chart generation used even in current hoard publications (Hoover, Meadows and Wartenberg 2010, 258-259. Fig. 6 shows the tabular format of the table represented graphically by Fig. 5).

With these charts and tables as a model for the arrangement and display of data to which scholars are accustomed, it was immediately apparent that Numishare should be adapted to replicate these statistical analyses and visualisations. With a broader set of typological fields available through Nomisma-defined coin types, it is possible to quantify hoards not only by ruler or denomination,

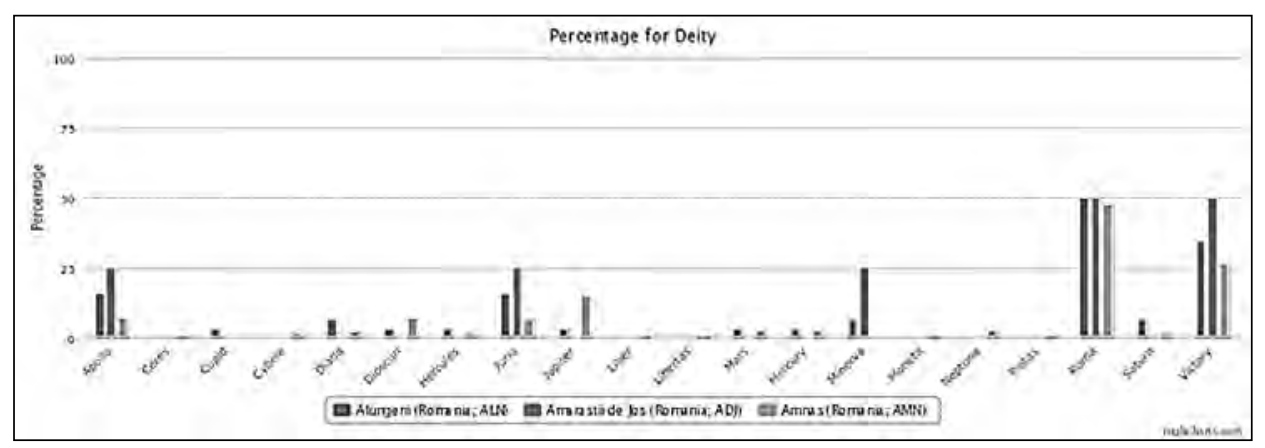

Figure 7. Visualisation of deities in a selection of Romanian hoards. 
From dBase III+ to the Semantic Web: Twenty-Five Years of the Coin Hoards of the Roman Republic Database Ethan Gruber and Kris Lockyear
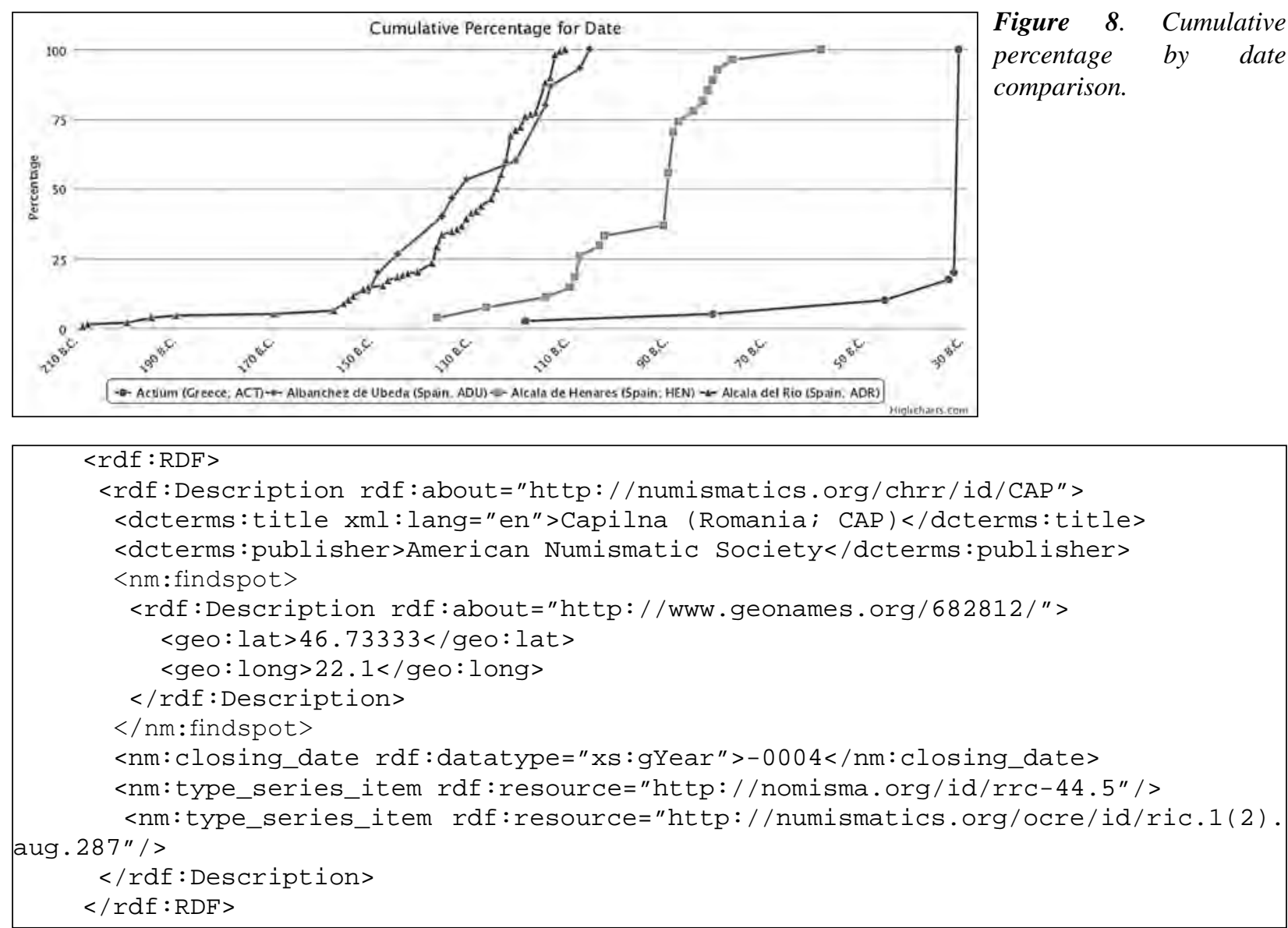

Code 3.

but by mint, region, material, dynasty, date, or even deity. The final category, deity, is rarely, if ever, analysed in printed hoard catalogues, which is striking considering the distribution of deities may lend insight into a hoard's possible religious context (e.g., votive deposits of coins within a sanctuary).

Hoard analyses are available through two avenues in CHRR: on the record page for a particular hoard, under the "Quantitative Analysis" tab, and through the "Analyse Hoards" page, which is accessible from the navigation menu. The user may select from a variety of options to generate results which may be visualised in the form of charts using the J avascript library, Highcharts (Fig. 7), or downloaded in a CSV file. For chart visualisations, the user may select the numeric response type between the options of count and percentage (of total coins in a hoard), as well as cumulative percentage when analysing dates. Next, the user selects the chart format: bar and column in most cases, but a variety of linear graph options are available for date visualisations. Next, the user may select one or more typological categories listed above, such as denomination or mint. Finally, the user may select hoards for comparison. When visualising data in chart form, the user may select up to 8 hoards for comparison or up to 30 for generating a CSV file. It may take up to 10 or 15 seconds to process 30 hoards for comparison, which is a significant improvement over manual methods employed before the availability of computers for calculating the data. The scholar is no longer restricted to the presentation of data provided by Bland and Burnett (1988b), for example, but now has greater control over setting the parameters of his or her own research questions.

With respect to CHRR, Numishare introduces an option to generate linear graphs based on the cumulative percentage of issue dates within a hoard. This type of graph shows the temporal extent of the 


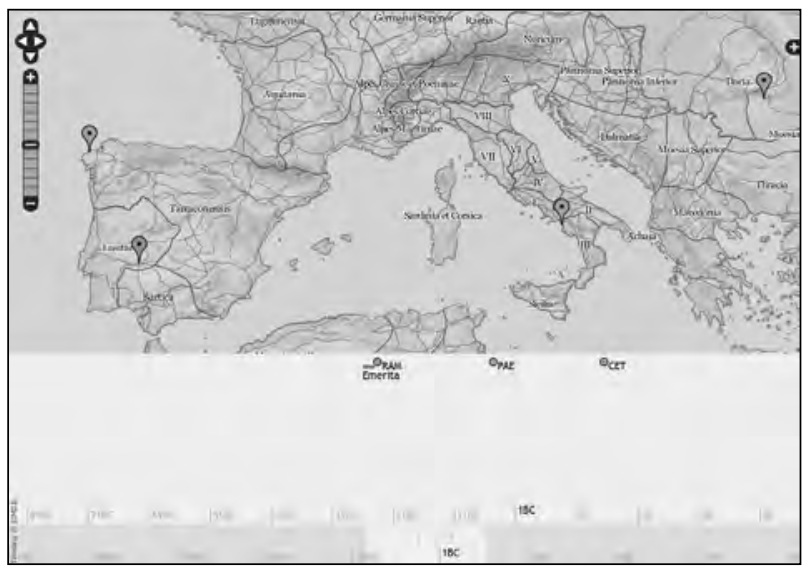

Figure 9. Distribution of RIC 1(2) Augustus $2 b$.

hoard, with particular focus on the most vigorous periods of hoarding activity. Perhaps no Republican hoard illustrates this more than the one found at Actium, where nearly $80 \%$ of its contents are denarii issued in 31B.C. by Mark Antony (all from uncertain mints) and buried shortly thereafter (Fig. 8).

\section{Integrating CHRR Data into OCRE}

Of the 694 hoards currently catalogued in CHRR, 72 contain references to Augustan types defined in RIC Volume I. These are 72 findspots which can be incorporated in to the maps of OCRE for perhaps one-quarter of all Augustan coin types. As part of its architecture, OCRE employs an Apache Fuseki-based RDF database and SPARQL endpoint for associating objects (whether physical coins or coin hoard records) with imperial coin types (Apache J ena 2014). The RDF describing a hoard associates its own URI to URIs of coin types by means of the Nomisma-defined nm:type_series_item. There may be many nm:type series item references in the $\mathrm{RDF}$ for each hoard. In the case of CHRR, most types will be be attributed to RRC numbers in Nomisma, but a significant minority link to types in OCRE. See Code 3, an abbreviated RDF fragment (numerous $\mathrm{RRC}$ type references have been omitted).

This RDF associates the Căpîlna (CAP; Each hoard is given a three-letter primary key which is hoped will become the standard identifier for Roman Republican coin hoards). hoard in CHRR with two coin types listed amongst its contents: RRC 44/5 and RIC Augustus 287. Additionally, the find spot is defined by the Geonames place (682812), which defines Căpâlna, Romania (CHRR, however, uses place names as given in the original publications. Romanian orthography was changed in the early 1990s leading to most instances of $\hat{i}$ being replaced by â). Once this RDF has been inserted into the triplestore, the OCRE record for Augustus 287 will immediately show a point on its map for this small Romanian town. The XSLT stylesheet which generates the KML file for this coin type (http:// numismatics.org/ ocre/id/ ric.1(2). aug.287.kml) uses SPARQL to query its findspots from the triplestore and process them into $\mathrm{KML}$ Placemarks. The closing date, defined by Nomisma as http:// nomisma.org/id/ closing_date and shown in the fragment above as $\mathrm{nm}$ :closing date, can be used to insert dates into the KML, making it possible to render the temporal extent of a coin type's circulation in OCRE using the TimeMap library (Fig. 9).

\section{Conclusions}

In general, numismatists have quickly embraced the benefits of the world wide web, and of online databases. The majority of these databases, however, are of collections, either personal or museum-based such as those of the ANS or the British Museum. Surprisingly, data about coin assemblages, be they hoards or site finds, are harder to find online despite the long history of the use of computer software to manipulate those data (e.g. Reece 1991; see also Lockyear 2007b). Exceptions include the Iron Age and Roman Coins from Wales data which can be downloaded from the ADS website (Guest and Wells 2007), and metal detected finds from the UK available from the Portable Antiquities Scheme website (Portable Antiquities Scheme 2014). Two new coin hoard projects, one looking at Romano-British finds and one looking at other Roman hoards, are due to begin in 2013. It is hoped that the work of the European Coin Find Network and the Nomisma project in defining numismatic concepts and creating stable digital representations of them, will enable the various projects to employ compatible terminology and allow the development of truly useful cross- database search and analysis tools.

\section{Acknowledgements}

The authors would like to thank Rick Witschonke for providing the initial impetus for the 
From dBase III + to the Semantic Web: Twenty-Five Years of the Coin Hoards of the Roman Republic Database Ethan Gruber and Kris Lockyear

project and for coordinating its development, and to Arianna Traviglia for organising the CHRR Online launch at CAA2013. The second author would also like to thank Michael Crawford for allowing access to his records now housed in the Department of Coins and Medals, and to the many members of the Department past and present for facilitating that access.

\section{Bibliography}

Apache Jena. 2014. "Fuseki: serving RDF data over HTTP.” Accessed January 15. http://jena.apache.org/ documentation/serving_data/.

Bland, R., and A. Burnett 1988a. "Normanby, Lincs: 47909 radiates to 289." In The Normanby Hoard and other Roman coin hoards. Coin Hoards from Roman Britain Vol VIII, edited by R. Bland and A. Burnett, 114215. London: British Museum Press.

Bland, R., and A. Burnett, eds. 1988b. The Normanby Hoard and other Roman coin hoards. Coin Hoards from Roman Britain Vol VIII. London: British Museum Press.

Crawford, M. H. 1969. Roman Republican Coin Hoards. London: Royal Numismatic Society.

Crawford, M. H. 1974. Roman Republican Coinage. Cambridge: Cambridge University Press.

Crawford, M. H. 1990. "From Borghesi to Mommsen: The creation of an exact science." In Medals and Coins from Budé to Mommsen, edited by M. H. Crawford, C. R. Ligota, and J. B. Trapp, 125- 132. London: The Warburg Institute, University of London.

Geonames. 2014. "About GeoNames." Accessed J anuary 15. http:// www.geonames.org/ about.html.

Gruber, E., G. Bransbourg, and A. Meadows. 2013. "Linking Roman Coins: Current Work at the American Numismatic Society." In Archaeology in the Digital Era. Papers from the 40th Annual Conference of Computer Applications and Quantitative Methods in Archaeology (CAA), Southampton, 26-29 March 2012, edited by G. Earl, T. Sly, A. Chrysanthi, P. Murrieta-Flores, C. Papadopoulos, I. Romanowska, and D. Wheatley, 249258. Amsterdam: Amsterdam University Press.

Gruber, E., S. Heath, A. Meadows, D. Pett, K. Tolle, and D. Wigg-Wolf. 2013. "Semantic Web Technologies Applied to Numismatic Collections." In Archaeology in the Digital Era. Papers from the 40th Annual Conference of Computer Applications and Quantitative Methods in Archaeology (CAA), Southampton, 26-29 March 2012, edited by G. Earl, T. Sly, A. Chrysanthi, P. Murrieta-Flores, C. Papadopoulos, I. Romanowska, and D. Wheatley, 262272. Amsterdam: Amsterdam University Press.

Guest, P., and N. Wells. 2007. Iron Age and Roman Coins from Wales [data-set]. York: Archaeology Data Service. Accessed J anuary 15, 2014. doi:10.5284/ 1000263.

Hoover, O., A, Meadows, and U. Wartenberg, eds. 2010. Coin Hoards X. Greek Hoards. New York: American Numismatic Society and the Royal Numismatic Society.

Lockyear, K. 1989. A Statistical Investigation of Roman Republican Coin Hoards. Master Thesis, University of Southampton.

Lockyear, K. 1991. "Simulating coin hoard formation." In CAA90. Computer Applications and Quantitative Methods in Archaeology 1990, edited by S. Rahtz and C. Lockyear, 195- 206. Oxford: Tempus Reparatum.

Lockyear, K. 1993. "Coin hoard formation revisited." In Computing the Past. Computer Applications and Quantitative Methods in Archaeology. CAA92, edited by J. Andresen, T. Madsen, and I. Scollar, 367- 376. Aarhus: Aarhus University Press.

Lockyear, K. 1995. "The supply of Roman Republican denarii to Romania." Studii și Cercetări de Numismatică 11:85- 102.

Lockyear, K. 1996a. "Dmax based cluster analysis and the supply of coinage to Iron Age Dacia." In Interfacing the past: Computer Applications and Quantitative Methods in Archaeology 1995, edited by H. Kamermans and K. Fennema, 165- 178. Leiden: University of Leiden.

Lockyear, K. 1996b. Multivariate Money. A statistical analysis of Roman Republican coin hoards with special reference to material from Romania. $\mathrm{PhD}$ diss., University College London.

Lockyear, K. 1999. "Hoard structure and coin production in antiquity - an empirical investigation." Numismatic Chronicle 159:215-243. 
Across Space and Time. Papers from the 41st Conference on

Computer Applications and Quantitative Methods in Archaeology. Perth, 25-28 March 2013

Lockyear, K. 2000. "Experiments with Detrended Correspondence Analysis." In CAA96. Computer Applications and Quantitative Methods in Archaeology, edited by K. Lockyear, T. Sly, and V. Mihailescu-Bîrliba, 9- 17. Oxford: Archaeopress.

Lockyear, K. 2007a. Patterns and Process in Late Roman Republican coin hoards 157-2 BC. Oxford: Archaeopress.

Lockyear, K. 2007b. "Where do we go from here? Recordingand analysing Roman coins from archaeological excavations." Britannia 38:211- 24.

Lockyear, K. in press. "The Coin Hoards of the Roman Republic database: the history, the data and the potential." American J ournal of Numismatics.

Meadows, A., and A. Houghton. 2010. "The Gaziantep Hoard, 1994 (CH 9.527; 10.308)," In Coin Hoards. Vol. X, edited by O. D Hoover, A. Meadows, and U. Wartenberg, 173- 223. New York: American Numismatic Society.

Nomisma. 2014. "Introduction." Accessed January 15. http://nomisma.org/ .

OCRE. 2014. "Online Coins of the Roman Empire." Accessed J anuary 15. http:// numismatics.org/ ocre/ .

Pleiades. 2014. "A community-built gazetteer and graph of ancient places." Accessed J anuary 15. http:// pleiades. stoa.org.

Portable Antiquities Scheme. 2014. "Portable Antiquities Scheme.” Accessed January 15. http://finds.org.uk/.

Reece, R. 1991. Roman Coins from 140 sites in Britain. Cirencester: Cotswold Press.

Ryan, N. S. 1988. Fourth Century Coin Finds in Roman Britain: a Computer Analysis. Oxford: Archaeopress.

SIMILE. 2014. "Timeline.” Accessed J anuary 15. http:// www.simile-widgets.org/timeline.

Thompson, M., O. Markhølm, and C. M. Kraay 1973. An Inventory of Greek Coin Hoards. New York: American Numismatic Society.

Timemap. 2014. "Project home.” Accessed January 15. https:// code.google.com/p/timemap/ .
UCL. 2000. "Celtic Inscribed Stones." Last modified September. http:// www.ucl.ac.uk/ archaeology/ cisp/ .

Wright, N. 2010. “A Late Seleukid Bronze Hoard, c. 1988 (CH 10, 349)." In Coin Hoards X. Greek Hoards, edited by O. Hoover, A. Meadows, and U. Wartenberg, 258- 259. New York: American Numismatic Society and the Royal Numismatic Society. 


\title{
Higeomes: Distributed Geodatabases in an Archaeological J oint Research Project
}

\author{
Frank Boochs, Kai-Christian Bruhn \\ Fachhochschule Mainz, Germany \\ Christophe Cruz \\ Université de Bourgogne, France
}

Ashish Karmacharya and Tobias Kohr

Fachhochschule Mainz, Germany

\begin{abstract}
:
The project 'HiGeoMes' seeks to connect knowledge about archaeological sites in the Near East with place names in ancient sources of the 2 nd millennium BCE. The paper describes the digital approach to integrate textual and geographical information by emphasising the impact of interfaces linking diverse datasets. Several OGC-based Web services provide reviewed archaeological information in a Web GIS with query capabilities. Place-related philological data are stored in an OWL-store to model the topological relations of unidentified sites. An interface integrates a graph-viewer with the Web GIS by invoking both WFS- and REST-services to spatially integrate the datasets. Furthermore, a full integration on the semantic level and emerging potentials are discussed.
\end{abstract}

\section{Keywords:}

Archaeological Data Infrastructure, Web GIS, Semantic Integration, Knowledge Management

\section{Introduction}

The integration of places mentioned in Babylonian and Assyrian texts with the location of known archaeological sites in the Near East is the focus of the three-year bilateral joint research project 'HiGeoMes - Die historische Geographie Obermesopotamiens im 2. Jt. v. Chr.: Interdisziplinäre Forschungen' funded by the French ANR and the German DFG since 2011. The project's main goal is to interconnect the documented settlement sites with place names in the written sources to better understand political, social and environmental developments in Upper Mesopotamia in the 2nd millennium BCE.

Current research in the historical geography of Ancient Mesopotamia in the 2nd millennium BCE is largely based on the "Répertoire Géographique des Textes Cunéiformes" (Groneberg et al. 1980; Nashef 1982), accompanied by the maps of the "Tübinger Atlas zum Vorderen Orient (TAVO)". However, since this research was documented, the number of old Babylonian texts has more than doubled, along

Corresponding author: boochs@geoinform.fh-mainz.de with a considerable increase in both quantity and quality of Middle-Assyrian sources. A prevailing compilation of current knowledgealso incorporating the archaeological record was published in 2009 (Cancik-Kirschbaum and Ziegler 2009).

Nevertheless, each of the scientific disciplines involved challenges complex methodological questions crucial for interpreting both the philological and the archaeological material. A thorough understanding of the historical geography relies on a combined interdisciplinary analysis of the record, each containing uncertainties for authoritative conclusions to be appropriately communicated between researchers affiliated at different institutions.

Considering this background, a digital information system is suitable for enabling this knowledge exchange only if it facilitates certain main specifications. It has to handle the philological and the archaeological record appropriately with a data-model that not only accounts for representing relevant knowledge of each research domain, but also allows for sharing and linking 
the available information. Two aspects inherent in the data of both domains could serve as nodes for this interconnection: space and time. As the Old Babylonian and Middle Assyrian texts already represent a chronological divide of the data sources, space remains as a viable candidate.

Archaeology comprises a vast amount of heterogeneous datasets with relevant absolute geographic references. Standards and technologies developed within international spatial data infrastructure (SDI) initiatives are available to achieve this objective. Although the European SDI initiative (INSPIRE) targets environmental data, previous research (Freire et al. 2012; McKeague et al. 2012) has demonstrated that the approach can also be applied for culturally protected sites.

In contrast, philological data derived from epigraphic sources commonly reference spatial features as toponyms, which precludes proper geographic modelling. At the same time, textual data contain complex interrelations among themselves. However, knowledge available in the context of this project is usually related to real objects and their environments. These descriptions are of interest to understand the interactions and interrelations of these objects. Consequently, ontologies provide an adequate tool to formally define this knowledge and to make it accessible to either people or to information systems (Grimm, Hitzler and Abecker 2007). This knowledge is modelled in a graph data structure which differs from a standard SDI data structure. Since the SDI approach is not adequate for textual data, theintegration of an SDI and textual knowledge is of special interest for the HiGeoMes project.

The objectives of the project are threefold. The first one aims at defining interoperable Web services on the archaeological HiGeoMes database. The second one consists of making available the knowledge from the epigraphic ArchiBab (Charpin 2013) database, which is currently not exploitable with a query language. The last one focuses on the ability of the system to integrate the archaeological database and the ArchiBab ontology into one interface. This integration allows us to give a higher degree of interpretation of data and to visualise integrated data.
This paper is composed of 5 sections. After the background of the key issues is illustrated, section 2 presents the Archaeological Data Infrastructure of HiGeoMes. Chapter 3 describes the semantic approach towards epigraphic data. In part 4, the integration of both approaches is discussed, before we conclude with a resume and outlook of the project.

\section{Background}

Corns and Shaw (2010) give a broad overview on the suitability of the SDI concept for the syntactically interoperable dissemination of archaeological data. The implementation of interoperability within an SDI, however, also presents several semantic challenges (Janowicz et al. 2010). Most semantic problems arise due to the lack of suitable content descriptions. To design an SDI with interoperability capabilities, it is necessary to add proper semantics to data, metadata and services.

Currently, most of the available information on the Web is provided as syntactic blocks, which require human experts to determine their semantics. Theneeded semantics can be provided by ontologies, allowing for reasoning by software inference mechanisms. In the Artificial Intelligence field, an ontology is an engineering mechanism, constituted by a vocabulary and a set of assumptions regarding this vocabulary. This information is specified using a first order logic theory. Using an ontology, it is possible to specify a concept, to define a number of restrictions that apply to a certain concept and create a hierarchy of concepts with subsumption relationships among them (Guarino 1998).

Knowledge formalisation and knowledge discovery have previously been used in archaeology. Forinstance, previous work has integrated heuristics with knowledge discovery tools within an intelligent search, and combined them with a genetic algorithm framework (Lazar 2002). Data was used to build models of the real world. Tools were tested on several large-scale archaeological data sets generated from an archaeological survey of the Valley of Oaxaca in Highland Mesoamerica. The "Archaeotools" project (Jaffrey et al. 2009) integrates huge sets of structured database records of archaeological sites with information extracted from literature reports 
and other unstructured sources. It advocates the benefits of well-defined ontologies and thesauri. In another project, researchers successfully integrated spatial inference through user defined spatial rules to classify unclassified excavated objects in industrial archaeology (Karmacharya et al. 2010).

\section{Archaeological Data Infrastructure}

The Archaeological Data Infrastructure (ADI) of HiGeoMes is built upon existent standards and technologies of an SDI. It leverages OGC Web services to facilitate the exchange of collected archaeological information among project partners and to ensure external researchers syntactically interoperable access to it.

\subsection{Technical architecture}

The architecture follows the principle of a Service Oriented Architecture (SOA). Components are loosely coupled, self-describing, stateless and standardised, ensuring a high degree of independence and reusability. Data dissemination is based on the "publish-find-bind" paradigm, in which a provider publishes resource metadata in a catalogue, a consumer finds this metadata, and then binds the resource in a final step.

Technically the architecture consists of three tiers: The data level stores vector-geometries of archaeological sites and raster images, Web services publish the data and a Web GIS client acts as an entry point for visualisation and simple analysis. An OGC-compliant Web Feature Service (WFS) enables direct access on data, while Web Map Services (WMS) perform visualisation tasks. Web Map Tile Services (WMTS) provide a standardised method to cache generated graphics for increased performance. The application harnesses a major asset of the SOA concept by integrating Web services from other providers. Google and OpenStreetMap serve cartographic layers and Geonames provides a Gazetteer. All components are implemented with open source products, and will be presented in more detail in this chapter.

\subsection{Archaeological data within HiGeoMes}

HiGeoMes examines the 2nd millennium BCE in Upper Mesopotamia. The archaeological

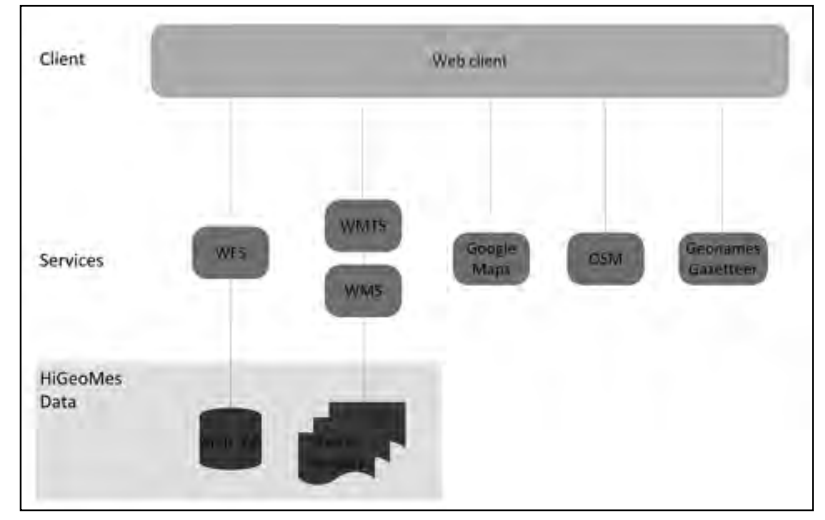

Figure 1. Architectural sketch of the Archaeological Data Infrastructure.

database that is maintained by the project partners at the Universität Mainz comprises of 706 sites. One quarter of the sites indicate a high confidence level based on the excavation reports. Information on other sites is based on around 30 surveys that are of lower certainty.

The project orientates the capture of archaeological data on three basic requirements: sites need to be locatable, datable and possess a bibliographic reference to facilitate review and further research. Both digital and analogue sources are investigated in this regard. Direct integration of digital sources has remained impossible with relevant sources, becauseinterfaces that would allow access to them are still widely missing. Even reuse of digital material is usually restricted to different thematic or technological constraints: some sources do not fit into the geographical, e.g. MEGA Jordan (Myers and Dagity 2012) or temporal scope, e.g. Pleiades (Simon, Barker and Isaksen 2012), and other sources only comprise of the most prominent sites. Technically, some sources do not provide better usability than analogue material (TAY Project 1998). Nevertheless, data needs to be derived from such sources because of their thematic quality. The most widely used digital source for locating sites is the ANE Placemarks (Pedersén 2012). The geometrically accurate locations are adopted for nearly half of the HiGeoMes sites, whereas no other information is included in the data.

Because of the restricted availability of useful digital material, conventional sources such as excavation reports, survey reports and compilations remain a major base for archaeological research 
within HiGeoMes. For instance, the "Atlas of PreClassical Upper Mesopotamia (APUM)" served as a starting point for the archaeological database with approximately 50 sites (Anastasio et al. 2004). Other important analogue sources include "Bibliographie der archäologischen Fundstellen und Surveys in Syrien und Libanon" (Lehmann 2002), "Tübinger Atlas des Vorderen Orients (TAVO)" (Hartmann 1980), "Répertoire Géographique Des Textes Cuneiformes", (Zadok and Röllig 1985), and "The Imperial Landscape of Ashu” (Altaweel 2008).

The archaeological data can be modelled geographically. This entails the capacity to visualise and analyse the information in a spatial context. In fact, correctlocalisation presents the mostimportant component of archaeological data. HiGeoMes keeps the geographic model and the archaeological data separately, linked through a common HiGeoMes ID; archaeological sites are stored in a geo-dataset with basic information, whereas comprehensive archaeological data are stored in an extensive database. This modular approach implies the advantage that the light geo-dataset can be used without the complex database involved. At the same time the data can be regarded in its entirety.

Currently, the geo-dataset forms part of the archaeological data infrastructure, where it is implemented in PostgreSQL 9.1(PostGIS 1.5.3). The locations are captured with the help of Quantum GIS and Google Earth. Capture of archaeological data is conducted through astandalonedesktop application. Based on the existing reference, an integration of the database within the ADI is possible in the future. The archaeologist can decide which data should be disseminated by the infrastructure and which data should not. Additionally, different access rights can be granted in the service layer (2.3).

The resulting HiGeoMes data presents a large collection of geo-referenced sites attached with detailed archaeological information. Collecting and investigating conventional sources, however, is a very time consuming task. Moreover, this work is done repeatedly, because many sources already consist of derived information. A large friction loss occurs in the simple process of reusing existing information. Digital information technologies possess the capacity to reduce this loss and invest more time to gain new knowledge. Nevertheless, the lessons learned in HiGeoMes show that an efficient use of digital technologies for the dissemination of archaeological data is still rare. The next chapter discusses the approach HiGeoMes takes towards this challenge.

\subsection{Dissemination via Geo Web services}

Web services present syntactically interoperable interfaces to provide data and functionality on the Web. The OGC explored this approach relatively early (1997) to develop such standards for spatial data (Zhao and Di 2011). During the next decade, SDI initiatives evolved on all administrative levels with the common aim to improve dissemination of spatial data. Based on the SOA concept, these initiatives act as a major driving force to further push OGC efforts. While the European initiative (INSPIRE) originally focuses on environmental data, today many other domains have recognised the capabilities of OGC Web services and adopted them (OGC 2014). In archaeology, the concept is not only convenient because archaeological data usually possess spatial references, but also for the particular capabilities the service abstraction layer implicates; metadata allow for the description of the data's complex characteristics and to increase their traceability. Likewise, it is possible to protect potentially sensitive data via control mechanisms or algorithms for intentional falsification. HiGeoMes demonstrates the advantages the approach contributes and discusses the shortcomings it still implies.

Archaeological sites collected at the University of Mainz are disseminated via a Web Feature Service (WFS), allowing standardised access to the data in Geography Markup Language (GML). This enables other components to consume the data and conduct analysis, such as search queries executed by the Web GIS client (2.4). While the WFS currently only exposes the geo-dataset with basic information, it can be extended to provide more specific data of the archaeological database.

Web Map Services (WMS) portray raster data sets of interest: Soviet ordnance maps (Wikipedia 2013) were processed to display relevantinformation such as water fountains, Corona satellite imagery (Fowler 2012; Scardozzi 2008) to show the region before human impact expanded to a broader scale 
(e.g. dam constructions), and a layer generated from SRTM data serves as a visual base map. As opposed to WFS, WMS do not serve the actual data, but only a visualisation of them (raster and vector). The restrained access makes WMS very popular among data providers who do not want to uncover their data entirely, but are able to serve a generated map in an interoperable way. WMS render Web capable image formats such as PNG or J PEG, which present lighter formats than the original raster data (often TIFF, etc.). The generating process takes time, however, potentially resulting in poor usability on the client side. This time can be eliminated by (pre-)caching the generated WMS output in form of rendered tiles that can be served directly upon request. While the approach might entail drawbacks for dynamic data, it is ideal to provide fast static map services (Weskamm 2011). The emerged standard of a Web Map Tile Service (WMTS) is used for all raster data within HiGeoMes.

Currently HiGeoMes offers four OGC-conform Web services that are implemented with MapServer (Vatsavai et al. 2006) and MapCache:

- WFS with archaeological sites,

- WMS/ WMTS with Russian maps,

- WMS/WMTS with Corona images,

- WMS/ WMTS with SRTM base map.

These Web services are invoked by the Web GIS client for data delivery, as they can be accessed by any GIS tool or Web application that supports OGC standards. HiGeoMes integrates the Google Maps API (Miller 2006), OpenStreetMap (Neis et al. 2010) and the Geonames gazetteer (Geonames 2013) from external interfaces. More specialised data like the Corona satellite images and Russian maps need to be downloaded, processed and set up in proper Web services before they can be used in a Web infrastructure. It should be obvious that the moreinitiatives providetheir data overinteroperable interfaces, the more information can be combined without additional processing efforts.

\subsection{Web GIS client}

The Web GIS serves as a first entry point into the ADI of HiGeoMes. While the data services can

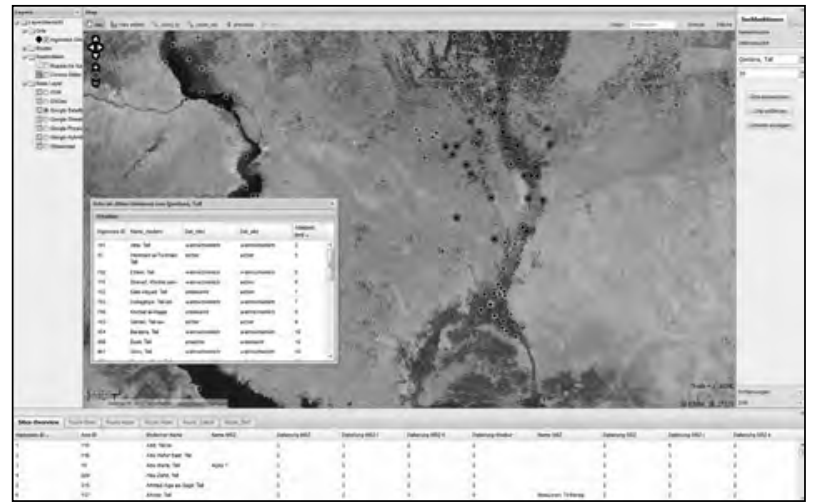

Figure 2. Buffer selection of archaeological sites in the Web GIS client.

be consumed by any OGC-compliant GIS client, the Web GIS creates a graphical user interface (GUI) to the infrastructure for a specific use case: it provides a research tool for archaeological researchers to explore, visualise and analyse HiGeoMes data. This use case requires the application to be directed towards domain experts, who are also technically untrained. A Web GIS is suitable to fulfil these needs, because functional access can be restricted. For future developments, this implies the possibility to identify further target groups with different use cases and provide diverse customised views on the data and capabilities.

The GUI is arranged into four regions, with the centre region displaying all data of the services within a map. A tool bar enables navigation, basic GIS functionality and querying for locations by their HiGeoMes ID or modern name. The latter tool invokes the Geonames gazetteer service (Geonames 2014). On the left, the data service layers can be (de-)activated in a tree structure. The bottom region supplies a sortable view on attribute data of the archaeological sites. A synchronised selection tool highlights rows in the table with corresponding locations on the map simultaneously. The right region offers further functionalities that can be applied on the archaeological sites. These tools can search locations by modern or prehistoric names, list and highlight sites within a specified perimeter of a selected site or measure and highlight direct distances between sites.

Technically the client is completely implemented in HTML, CSS and J avaScript, making it portable to PCs with a common browser. The 
ExtJ S library helps to build a GUI and arrange the different components within it (Orchard et al. 2009). OpenLayers brings geospatial capabilities to the application (Jansen and Adams 2010). Built upon these libraries, GeoExt facilitates the development effort offering capabilities such as measuring tools and a geonames search out of the box.

An internal survey among project partners showed that the majority perceive the Web GIS as easy to use and plan its regular use in the future. While searching and measuring capabilities were popular among participants, the combined geographic (map) and thematic (table) views were their favourite functionality. Besides the archaeological sites, the Google satellite imagery was very popular. Additionally, more specific layers, such as the Corona data, seemed useful.

\section{Semantic Approach Towards Epigraphic Sources}

The emergence of the Semantic Web in early 2000 has proposed inclusion of semantics for better machine-humans collaboration for handling huge amount of information that exists on the Web (Berners-Lee, Hendler and Lassila 2001). The intention was to give information a well-defined meaning in order to make it understandable to machines. In the Semantic Web, emphasis is given to the meanings of words rather than to words themselves so that theinformation provided by them could be used as knowledge formalised through semantic interpretations.

The Semantic Web provides a common framework that allows data to be shared and reused across applications, enterprises and community boundaries (Decker et al. 2000). At the core of the framework lies knowledge and knowledge representation tools such as ontologies. Conventionally, ontologies have been used as tools to represent knowledge and the Semantic Web framework maintains it. Web Ontology Language $(\mathrm{OWL})$ is that standard language recommended by W3C to model and represent knowledge in the Semantic Web framework.

The missing geographic link within epigraphic data is one of the key factors in achieving interoperability with other data. The vast amount of information in the dataset and the complexity in information patterns limits the dataset to be used through a conventional database system. Ontologies can express complex information through their axioms and theorems. In addition, expressing information logically through ontology helps machines understand information and thus can act upon it. This is vital for managing vast and complex datasets as in the epigraphic database.

\subsection{ArchiBab}

ArchiBab is an online service that allows users to query a database that contains information of Babylonian and Middle-Asyrian texts (Charpin 2014). It contains translations of clay tablets written in cuneiform. The textual ArchiBab database is regularly updated and it is close to be completed. Currently the database contains more than 31,000 texts corresponding to paleobabylonian archives. ArchiBab allows conventional queries using keywords. It also allows temporal queries, by using keywords referring to dates, for example "7/vii during the reign of Zimri-Lim". The database also contains a textual description for identified keywords in the Babylonian texts. Possible keywords are names of people, toponyms, kings, objects, etc. Thanks to ArchiBab, users can have access to textually modelled information. However, ArchiBab is unable to provide an overview of the knowledge contained in the texts. One of our main objectives is to extract the knowledge stored in the texts and develop tools that would link it to graphic representations of the Babylonian routes. An important limitation of ArchiBab is that because the information is stored as texts, it is not possible to use a standard query language to extract knowledge from it. We propose the use of constraints and rules to extract knowledge from ArchiBab texts, while focusing on toponyms and their environment. Some of the ancient toponyms have a modern equivalent in the archaeological database. Ancient routes used by caravans, merchants or troops are described in clay tablets. However, through using only textual information it is difficult to obtain a spatial representation of the routes. To accomplish this goal, we use the extracted knowledge referred to toponyms. Two processes were defined to visualise ArchiBab data. The first one consists of extracting all the knowledge that can be extracted from the ArchiBab database. Thus, an OWL file is generated 


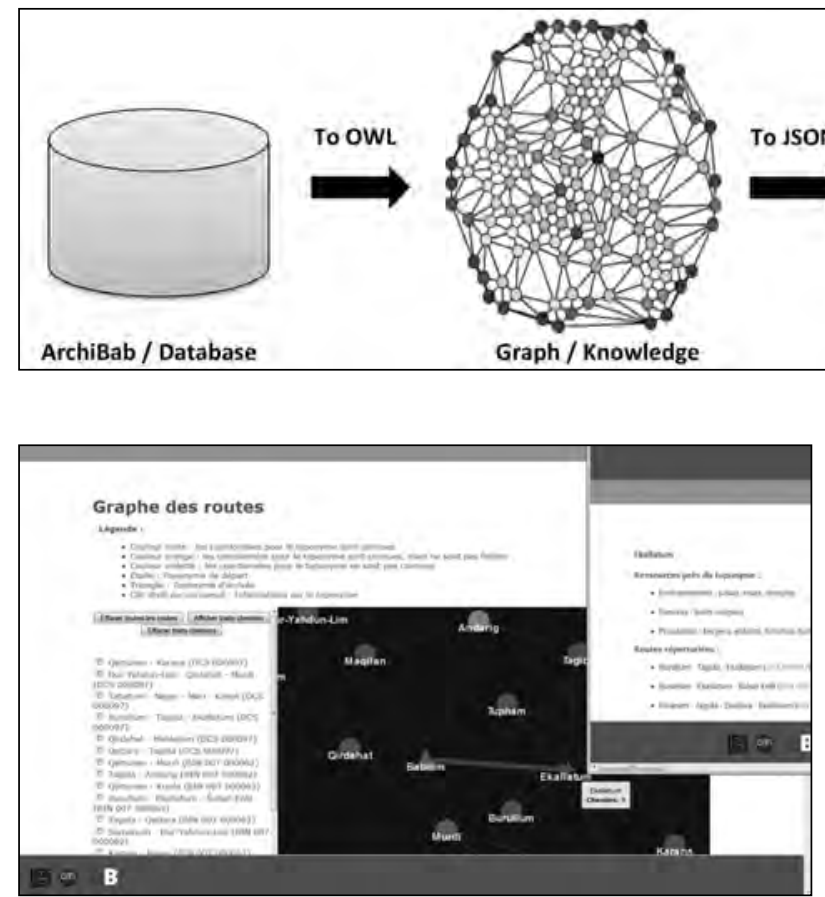

Figure 4. Graph visualisation of the routes.

from this process, which allows the computation of the ontology consistency, and to query the knowledge base using a standard query language such as SPARQL. Once the knowledge is queryable, the second process consists of generating data for its visualisation, and more specifically the route map. The result of this process can be a JSON file, which can be easily integrated to geospatial data

\subsection{Graph visualisation}

Visual Data Exploration eases the search of relevant data pieces in large volume datasets. It has always been important to include humans in the data exploration process (Keim 2002). Humans allow their perceptions to explore into the data to formulate hypotheses and conclusions when it could be explored visually. The Information seeking mantra (Shneiderman 1996) discusses three steps in "Visual Data Exploration": overview, zoom and filter. We implement this mantra for exploring data in the ArchiBab database.

ArchiBab is a large database with its own hidden graph to represent implicit relationships among data pieces. The graph consists of a set of objects extracted from the database which are called nodes. The connections or relationships

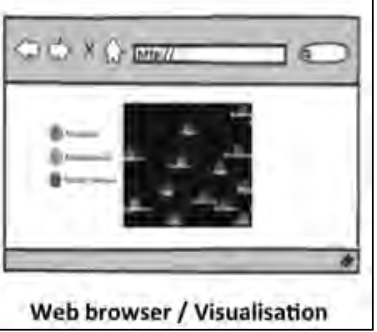

Figure 3. Presentation of the two main processes, extraction of knowledge to an OWL file, production of a Web interface to visualise the routes, and the toponyms and the environment.

between these objects are called edges. An example of such a graph can be a network defining the interrelation between toponyms and their routes. Such interrelations define domain knowledge. In this project, we use an OWL ontology and use graph visualisation to explore the interconnections and to define its associated semantics, which also model the knowledge. We use a J avascript Infovis Toolkit (Belmonte 2014) to generate the graph and the corresponding functionalities. Graphs are extracted from the ontology and rendered with the help of the J avascript Infovis Toolkit. Figure 4 shows the map of routes which are deduced from the relationships defined in the ontology. On the right of the figure, a file describes the environment of a selected station of the route. In addition, a route can be selected by a select box on the left of the graphical interface. The main intension is to provide broader picture of the semantic connections between different toponyms within the Archibab database.

\section{Linking Places and Sites}

Toponyms in epigraphic data are not geolocalised. This makes an SDI impossible for the distribution of such data, unless a mechanism is engineered to geo-localise the toponym sites. One of the most sought after mechanisms to provide spatial signatures to a spatial dataset is to couple it with equivalent spatial databases. Such heterogeneous data integration is a leading subject of research today (Cruz 2004; Cruz Sunna and Chaudhry 2004; Tanasescu et al. 2006). However, it is not straightforward in our case. Archaeological data in a relational database and epigraphic data in OWL each have their own structure. Hence, it seems unlikely that a syntactic integration would resolve the data integration issue. SDIs though designed for spatial data integration concentrate on syntactic integration. They have broad limitations when the data structures are this diverse. To have integration among such data structures, one data source should 


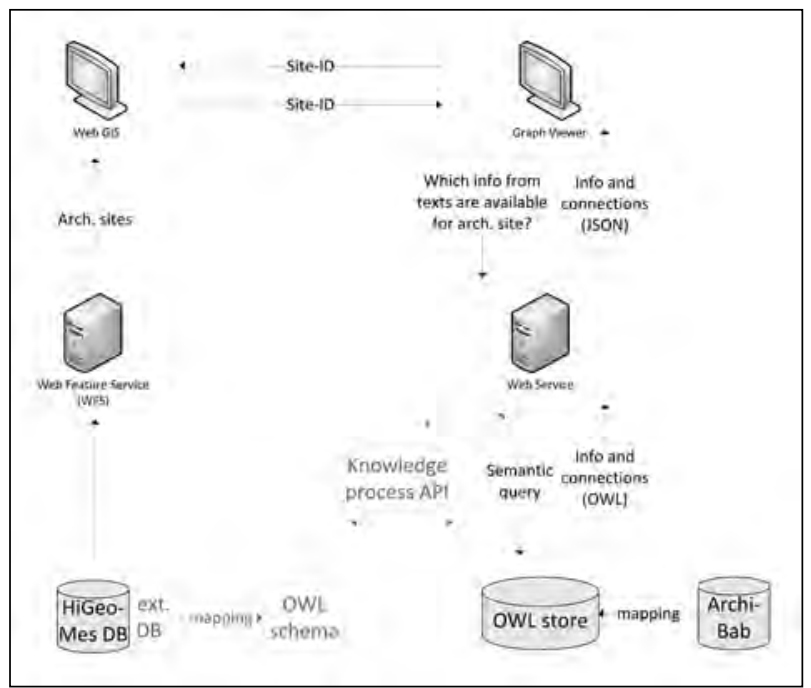

Figure 5. System Architecture.

understand the other data source. Semantics of the datasets thus play a major role in data integration. Syntactic approaches provided by standards, metadata and infrastructures such as an SDI are in need of semantic enablement or a semantic extension to accomplish this task (Janowicz et al. 2010). With this mantra, an architecture is designed to use semantics for data integration (Fig. 5).

The HiGeoMes architecture (Fig. 2) illustrates a mechanism that integrates the archaeological data shared through the SDI and epigraphic data present in the OWL ontology. HiGeoMes makes the resources of integrated data available via a Web service interface. The current approach establishes the connection to this additional information on a visual level. The WebGIS client hosting the spatial dataset from the archaeological data is capable of making smart queries to related toponyms in the epigraphic OWL ontology. These smart queries yield detailed knowledge on the queried sites. A graph visualisation to represent evoked knowledge about thequeried sites presents thesemantic relation of the site with respect to other places. This is independent to geolocalisation of the places. In parallel, the user can locate places from texts on the map that have been associated with archaeological sites. An integrated visual exploration of geographically and semantically modelled information is possible. However, to discover new knowledge, the different data sources need to be connected on the semantic level in the future (see section 5 and dotted features in Fig. 2).

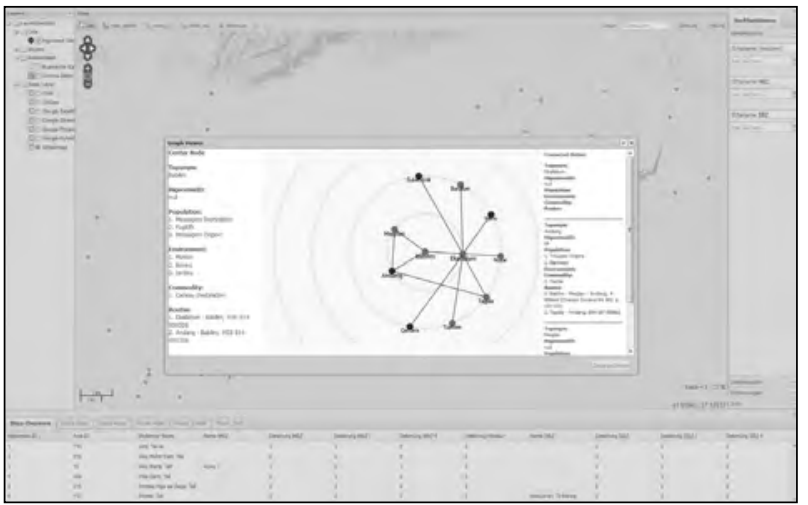

Figure 6. Graph Visualisation describing routes of the queried toponym within WebGIS client.

\section{Conclusions and Outlook}

The paper motivates the use of available SDI technologies for the dissemination of archaeological data and for providing digital research tools for scientists in the humanities. It presents the strengths of the concept for spatially referenced data and reflects on the drawbacks it still implies. A semantic approach is presented for modelling and querying epigraphic data without spatial reference. Motivated by the demand from humanities scholars, the work presents an integration of the two different approaches. The outcome has received high acceptance among archaeologists and philologists, who maintain two different views on their data and are able to explore them in a geographical and in a topological context respectively. The mode of information exchange within the research group is ready to be expanded to other scholars or for general public use, because the gateway and data interfaces follow standardised, mature and established protocols. At the end of the project the full list of sites will be openly available comprising a subset of the attributes via WFS and derivative file formats. The raster data will be moved into a more sustainable server environment and can be consumed in any GIS-environment capable of communicating with OGC-compliant WMS. Archaeological as well as philological research in the project area will have a common, citable and quality assured set of data on disposal on which further investigations with similar or different scope can rest upon.

From the information-technology perspective we regard the current solution as a proof of concept that indicates further potential. The integration 
implies several shortcomings, however, that will be addressed in the future. Currently the connection between the different sources is only established on a visual level. For the next step, we need to achieve integration on the semantic level (Fig. 5). Therefore, it will be important to further investigate semantic interfaces within the data sources. In this context, the involvement of OGC Web services such as the WFS will be of particular interest. Data generated during the HiGeoMes project is of value to the archaeologists and researchers working in Upper Mesopotamia and will be made available under a suitable free licensing scheme.

Such epigraphic and archaeological databases consist of numerous unanswered issues that need to be dealt with in future research. One issue is sharing a common name by multiple toponyms and multiple locations. Another issue are the missing links between toponyms in epigraphic datasets and modern day locations. This makes it impossible to geo-localise these toponyms. Every philologist and archaeologist has his or her own method to answer these unanswered issues. This expert knowledge needs to be documented and analysed in a future system. One must take into account that these unanswered issues are not possible to resolve independently through separate independent datasets. The issues within epigraphic data can only be solved if other datasets (like archaeological data in this case) are taken into account, for example. A ready to integrate prototype application will be developed for archaeologists and philologists to enter their expert knowledge through rules within the system. These rules combine different knowledge sources for reasoning. This way they will infer semantics within the archaeological dataset and ArchiBab dataset in order to provide answers to unanswered issues. The prototype application will use inference capabilities of the knowledge technology with the Semantic Web framework to infer expert knowledge through their hypothesis and facts for such answers.

The semantic enabled application for collaborative management of archaeological and philological datasets through expert knowledge possesses huge potential. Besides, integrating different datasets semantically to provide answers through knowledge discovery, the application has potential to automate the identifications of toponyms described with their relative geography by matching them to their corresponding absolute geography. This concept of geo-localising toponyms through spatial mapping with existing spatial dataset can be emulated on other similar projects (DFG-ANR-10FRAL-0003).

\section{Acknowledgements}

The authors would like to thank their partners from the humanities at the Collège de France, the Institute for Egyptology and Ancient Near Eastern Studies, JGU Mainz and the Institute for Ancient Near Eastern Languages and History, FU Berlin for the fruitful collaboration as well as the DFG and ANR for funding the HiGeoMes project.

\section{Bibliography}

Altaweel, M. 2008. The Imperial Landscape of Ashur: Settlement and Land Use in the Assyrian Heartland. Heidelberg: Heidelberger Orient Verlag.

Anastasio, S., M. Lebeau, and M. Sauvage. 2004. Atlas of Preclassical Upper Mesopotamia. Turnhout: Brepols.

Belmonte, N. G. 2014. “J avaScript InfoVis Toolkit." Accessed March 2. http:// philogb.github.io/jit/ .

Berners-Lee, T., J. Hendler, and O. Lassila. 2001. “The Semantic Web." Scientific American 284 (5):34- 43.

Cancik-Kirschbaum, E., and N. Ziegler. 2009. Entre Les Fleuves - I. Untersuchungen zur Historischen Geographie Obermesopotamiens im 2. Jahrtausend. Berlin: PeWe-Verlag.

Charpin, D. 2014. "Archibab. Archives Babyloniennes (XX-XVII siecles AV. J.-C." Accessed March 2. http:// www.archibab.fr/ en/ accueil.htm.

Corns, A. J ., and R. Shaw. 2010. "Cultural Heritage Spatial Data Infrastructures (SDI)-Unlocking the Potential of Our Cultural Landscape Data." In Proceedings of the 30th EARSeL symposium 2010: Remote Sensing for Science, Education, and Natural and Cultural Heritage, May 31 - June 3, edited by R. Reuter, 1-8. Paris: European Association of Remote Sensing Laboratories.

Cruz, I. 2004. "Geospatial Data Integration." Last modified December 3. http://ncgia.ucsb.edu/projects/ 
Across Space and Time. Papers from the 41st Conference on

Computer Applications and Quantitative Methods in Archaeology. Perth, 25-28 March 2013

nga/ docs/ pdf/ cruz.pdf.

Cruz, I. F., W. Sunna, and A. Chaudhry. 2004. "Semiautomatic Ontology Alignment for Geospatial Data Integration." In Geographic Information Science: Third International Conference, GI Science 2004 Adelphi, MD, USA, October 2004, Proceedings, edited by M. J. Egenhofer, C. Freksa, and H. J. Miller, 51-66. Berlin: Springer.

Decker, S., S. Melnik, F. Van Harmelen, D. Fensel, M. Klein, J . Broekstra, M. Erdmann, and I. Horrocks. 2000. "The Semantic Web: The Roles of XML and RDF." IEEE Internet Computing 4 (5):63- 73.

Fowler, M. J. F. 2012. "A Review of the CORONA Atlas of the Middle East (Beta)." Aerial Archaeology Research Group News 44:24- 29. Accessed March 14. http:// www. univie.ac.at/ aarg/ php/ cms/ file_download/ 51/ AARGNews-44.pdf.

Freire, F. C., E. P. Asensio, I. B. González, A. U. González, J. M. V. García, A. F. Bravo, C. Parcero-Oubiña, and P. Fábrega-Alvarez. 2012. "Proposal for a Cultural Heritage Application Schema within the INSPIRE Directive." In Multidisciplinary Research on Geographical Information in Europe and Beyond, Proceedings of the Association of Geographic Information Laboratories for Europe (AGILE 2012) International Conference on Geographic Information Science, 24-27 April 2012, edited by J. Gensel, D. Josselin, and D. Vandenbroucke, 339- 342. Avignon: Springer.

Geonames. 2014. “Geonames.” Accessed March 2. http:// www.geonames.org.

Grimm, S., P. Hitzler, and A. Abecker. 2007. "Logic, Ontologies and Semantic Web Languages." In Semantic Web Services: Concepts, Technologies, and Applications, edited by R. Studer, S. Grimm, and A. Abecker, 51- 106. New York: Springer.

Groneberg, B., J. R. Kupper, W. F. Leemans, and M. Stol. 1980. Die Orts- und Gewässernamen der altbabylonischen Zeit. Wiesbaden: Reichert.

Guarino, N. 1998. "Formal Ontology in Information Systems" In Formal Ontology in Information Systems: Proceedings of the First International Conference (FOIS'98) 6-8 June, Trento, Italy, edited by N. Guarino, 3- 15. Trento: IOS press.
Hartmann, K. P. 1980. Untersuchungen zur Sozialgeographie Christlicher Minderheiten im Vorderen Orient. Wiesbaden: Reichert.

Jeffrey, S., J. Richards, F. Ciravegna, S. Waller, S. Chapman, and Z. Zhang. 2009. "TheArchaeotools project, faceted classification and natural language processing in an archaeological context." Philosophical Transactions of the Royal Society A 367 (1897):2507- 2519.

Janowicz, K., S. Schade, A. Bröring, C. Keßler, P. Maué, and C. Stasch. 2010. "Semantic Enablement for Spatial Data Infrastructures." In Transactions in GIS 14 (2):111129.

Jansen, M., and T. Adams. 2010. OpenLayers: Webentwicklung mit dynamischen Karten und Geodaten. München: OpenSourcePress-Verlag.

Karmacharya, A., C. Cruz, F. Boochs, and F. Marzani. 2010. "Integration of Spatial Technologies and Semantic Web Technologies for Industrial Archaeology." In Proceedings of the 6th International Conference on Web Information Systems and Technology, 7-10 April, edited by J. Filipe and J . Cordeiro, 75- 80. Valencia: INSTICC Press.

Keim, D. A. 2002. "Information Visualization and Visual Data Mining." IEEE Transactions on Visualization and Computer Graphics 8 (1):1- 8.

Lazar, A. 2002. "Heuristic Knowledge Discovery for Archaeological Data Using Genetic Algorithms and Rough Sets." In Heuristic and Optimization for Knowledge Discovery, edited by R. A. Sarker, H. A. Abbass, and C. S. Newton, 263- 278. Hershey: Idea Group Publishing.

Lehmann, G. 2002. Bibliographie der archäologischen Fundstellen und Surveys in Syrien und Libanon. Rahden: Leidorf Pub.

McKeague, P., A. Corns, and R. Shaw. 2012. "Developing a Spatial Data Infrastructure for Archaeological and Built Heritage." International J ournal of Spatial Data Infrastructure Research 7:38- 65.

Miller, C. C. 2006. "A Beast in the Field: The Google Maps Mashup as GIS/2." Cartographica: The International Journal for Geographic Information and Geovisualization 41(3):187- 199.

Myers, D., and A. Dalgity. 2012. "The Middle Eastern 
Higeomes: Distributed Geodatabases in an Archaeological J oint Research Project Frank Boochs et al.

Geodatabase for Antiquities (MEGA): An Open Source GIS-Based Heritage Site Inventory and Management System." Change Over Time 2 (1):32- 57.

Nashef, K. 1982. Die Orts-und Gewässernamen der Mittelbabylonischen und Mittelassyrischen Zeit. Wiesbaden: Reichert.

Neis, P., D. Zielstra, A. Zipf, and A. Strunk. 2010. "Empirische Untersuchungen zur Datenqualität von OpenStreetMap-Erfahrungen aus zwei Jahren Betrieb mehrerer OSM-Online-Dienste." In Angewandte Geoinformatik 2010: Beiträge zum 22. AGIT-Symposium Salzburg, edited byJ . Strobl, 420-425. Berlin: Wichmann.

OGC. 2014. "Domains that use and develop OGC Standards." Accessed February 3. http://www. opengeospatial.org/ domain.

Orchard, L. M., A. Pehlivanian, S. Koon, and H. J ones. 2009. Professional J avaScript Frameworks: Prototype, YUI, Ext J S, Dojo and MooTools. Indianapolis: Wiley Publishing Inc.

Pedersén, O. 2012. "Ancient Near East on Google Earth: Problems, Preliminary Results, and Prospects." In Proceedings of the 7th International Congress on the Archaeology of the Ancient Near East: 12 April - 16 April 2010, vol. 3, 385- 393. Wiesbaden: Harrassowitz Verlag.

Scardozzi, G. 2008. “Old High Resolution Satellite Images for Landscape Archaeology: Case Studies from Turkey and Iraq." In Proceedings SPIE 7110, Remote Sensing for Environmental Monitoring, GIS Applications, and Geology VIII, edited by U. Michel, D. L. Civco, M. Ehlers, and H. J. Kaufmann, 14. Accessed March 13, 2014. doi:10.1117/ 12.799997.

Shneiderman, B. 1996. "The Eyes Have It: A Task by Data Type Taxonomy for Information Visualizations." In Proceedings. IEEE Symposium on Visual Languages. September 3 - 6, 1996 Boulder, Colorado, 336- 343. Los Alamitos: IEEE Computer Society Press.

Simon, R., E. Barker, and L. Isaksen. 2012. "Exploring Pelagios: A Visual Browser for Geo-Tagged Datasets." In International Workshop on Supporting User's Exploration on Digital Libraries collocated with International Conference on Theory and Practice of Digital Libraries (TPDL) Cyprus, September 27th, 2012, edited by E. Agirre, K. Fernie, A. Otegi, and M. Stevenson,
29- 34. Cyprus: PATHS. Accessed March 15, 2014. http:// ixa2.si.ehu.es/ suedl/ SUEDLproceedings.pdf.

Tanasescu, V., A. Gugliotta, J. Domingue, R. Davies, L. Gutiérrez-Villarías, M. Rowlatt, M. Richardson, and S. Stinčić. 2006. "A Semantic Web Services GIS Based Emergency Management Application." In The Semantic Web ISWC2006. 5th International Semantic Web Conference, ISWC 2006 Athens, GA, USA, November 2006, Proceedings, edited by I. Cruz, S. Decker, D. Allemang, C. Preist, S. Schwabe, P. Mika, M. Uschold, and L. Aroyo, 959-966. Heidelberg: Springer.

TAY Project.1998. "TAY: The Archaeological Settlements of Turkey." Accessed February 3. http:// tayproject.org/ enghome.html.

Vatsavai, R. R., T. E. Burk, S. Lime, M. Hugentobler, A. Neumann, and C. Strobl. 2012. Open-Source GIS. Springer Handbook of Geographic Information. Berlin, Heidelberg: Springer.

Weskamm,J . 2011. “Beschleunigungvon WebMapServices mit Hilfe verschiedener Proxies - wenn's mal wieder schnell gehen muss." Paper presented at FOSSGIS 2011 Conference, Heidelberg, Germany, April 5- 7.

Wikipedia. 2013. "Sowjetische Generalstabskarte." Last modified June 8. http://de.wikipedia.org/wiki/ Sowjetische_Generalstabskarte.

Zadok, R. 1985. Répertoire Géographique Des Textes Cunéiformes. Wiesbaden: Reichert.

Zhao, P., and L. Di. 2010. Geospatial Web Services: Advances in Information Interoperability. New York: IGI Global, Information Science Publishing. 


\title{
The Archaeological Resource Cataloging System (ARCS): A Better Way of Working with Digital Archives
}

\author{
Jon M. Frey \\ Michigan State University, USA \\ Timothy E. Gregory and Lita Tzortzopoulou-Gregory \\ Ohio State University, USA
}

\begin{abstract}
:
Researchers at the Ohio State University Excavations at Isthmia and Michigan State University present the Archaeological Resource Cataloging System (ARCS), an open-source software solution created with the support of an NEH Digital Humanities Startup Grant. ARCS is designed to provide low budget archaeological projects with the necessary tools to create an electronic repository of primary documents that have been digitised from legacy data. The software has been custom built with the goal of replicating in the digital realm many of the practices and procedures that have governed the organisation and use of primary archaeological documentation such as fieldbooks, photographs, and other hand written records. With ARCS, a community of users can mark digitised resources with keywords, sort search results into private or shared collections, and create hyperlinks between different types of archival data both within and between research institutions, all without affecting the unique properties of the actual source document.
\end{abstract}

\section{Keywords:}

Archaeology, Digitisation, Legacy Data, Virtual Research Environment

\section{Digitising Legacy Data}

It has been quite a while now since classical archaeologists "went digital" and to judge from our widespread use of electronic tools and media, it is safe to say that we are commonly agreed this is a good thing (Fulford et al. 2010). Today we can gather, analyse and share immense quantities of archaeological data at an unprecedented scale and speed. This is most apparent at surveys and excavations that were "born digital" over the past decade and are thus able to take full advantage of a growing number of "off the shelf" and custom built software solutions (Bobowski 2012; Porta Stabia 2011; Fee et al. 2013 and more generally Wallrodt's blog, "Paperless Archaeology" Wallrodt 2014). Yet for projects with a much longer history, moving from a traditional system of record keeping to a digital archive is much more complicated.

The advantages are clear enough. If they are properly maintained, digital archives serve as an excellent way to provide global access to

Corresponding author: freyjona@msu.edu archaeological records that are themselves becoming artefacts of an earlier era (Newman 2011). This is especially the case for the more traditional handwritten field notes, which are often the only account of an excavation and are therefore not permitted to leave a site's archive. A collection of electronic resources eases the burden not only on scholars who must otherwise travel to an excavation to carry out research but also on the projects themselves that can disseminate primary archaeological documentation without the logistic challenge of accommodating visitors throughout the season (Aldred 2005; Richards 2004; Xia 2011).

At the same time though, the push to digitise these older projects' legacy data' has brought with it a number of challenging developments (Allison 2008; Eiteljorg 2011). Of particular concern is the cost of digitisation. Even though a growing number of agencies now require a digital data storage and dissemination plan as part of any request for funding, there are very few organisations left that offer financial support for the mundane, timeconsuming and costly process of turning older 


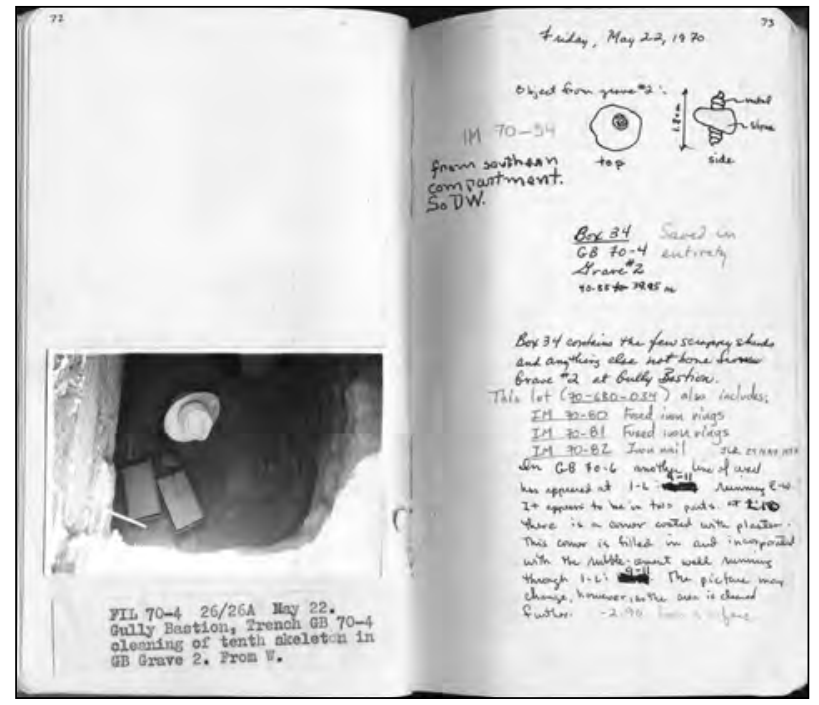

Figure 1. Pages from a field journal at Isthmia.

archaeological evidence into electronic files. As a result, only the most well-funded excavations have been able to engage in the type of large-scale, multiyear program that is required to digitise the tens of thousands of documents and images that makeup an archaeological collection (e.g. ASCSA 2014). Thus, instead of achieving the intended goal of increased access to a wider range of archaeological evidence, the trend toward electronic-based research has had the opposite effect of privileging the information and organisational structures of the 'big digs' over that of their less digitally visible peers.

Yet, even when they are able to afford a program of digitisation, projects face the difficult question of how best to turn a record keeping system that functioned efficiently on paper into an equally effective electronic system (Aldred 2005; Rabinowitz et al. 2012). A particularly clear example concerns the traditional field journal, which at any number of excavations is the most immediate and, arguably, most important form of primary documentation. Yet, field journals are also inherently 'messy' documents - in the pages of each volume one can find hand written notes, edits and revisions, pasted photographs and drawings, and even occasionally the traced outline of a small artefact. Most importantly, there are also frequent references to other field journals, maps and plans, and records of catalogued objects (Fig. 1). On the one hand, photographing or scanning this document faithfully reproduces its rich visual content, but a computer cannot easily search the resulting file. On the other hand, a simple transcription does not accurately represent the interrelated nature of the written and visual evidence, nor does it easily enable a reader to differentiate between original entries and later edits and additions.

More significantly, it is important to recognise that, in spite of their idiosyncrasies, all archaeological projects have developed systems of documentation that depend on several forms of evidence that must function together to recreate the fullest impression of the past (Eide et al. 2005; Prinke 2005). Within these systems and depending on the types of questions one is asking, certain forms of information are clearly more important than others. For example, a photograph of an artefact may not tell us as much as an archaeologist's account of that object's discovery. Thus, the transformation of a collection of physical records into separate electronic files runs the risk of creating a false sense of equivalencyamongall data. For thosefamiliarwith a project's recording system, this does not present an insurmountable problem - one simply gathers the electronic equivalents of the physical records they would normally consult. Yet, in the context of a digital repository for shared archaeological data, the important relationships and hierarchies of resource types are masked by the uniform appearance of information as it is typically displayed (e.g. IADB 2011 or Open Context 2014). This is not to say that records in a digital repository are lacking the proper documentation that helps to give them meaning. But in the increasingly open environment of shared data, it is more and more likely that a digital archaeologist will use information without firsthand knowledge of the underlying interpretive structure that gives it meaning. What is more, in the generally isolated environment of electronic research, there is typically no one present to provide the type of collective institutional knowledge that remains one of the strengths of being physically present at a site. In the field of classical archaeology where the unique details of each project's system of documentation is as much a point of pride as its artefacts, summary reports and robust metadata schemes are not an effective replacement for a conversation with a project director or on-site specialist. 


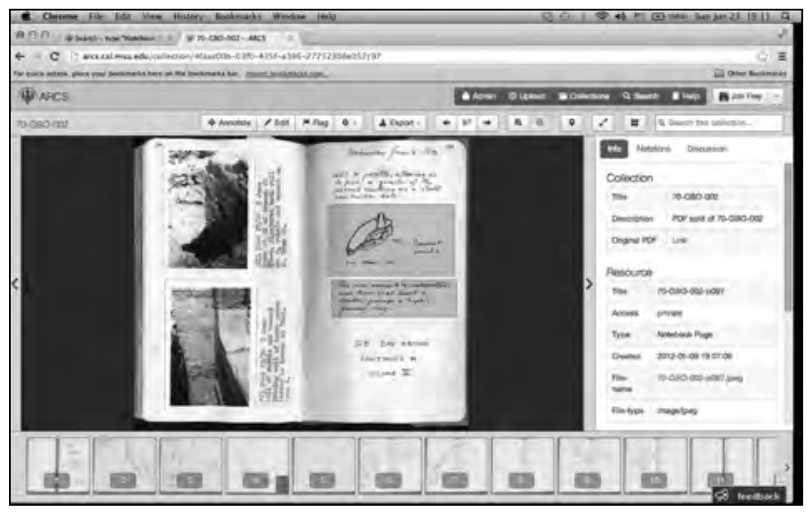

Figure 2. Screen capture of ARCS user interface showing digitised page of a field journal with metadata menu on right side.

\section{ARCS: The Archaeological Resource Cataloguing System}

Over the past few decades, archaeologists and archivists at the Ohio State University Excavations at Isthmia have faced such issues as part of the project's ongoing effort to digitise nearly fifty years' worth of archaeological documentation. This has led to our creation of ARCS: The Archaeological Resource Cataloguing System (ARCS 2014), an open source digital asset management solution developed with funding from the Michigan State University College of Arts and Letters and an $\mathrm{NEH}$ Digital Humanities Startup Grant. Instead of utilising existing software solutions, we have designed ARCS from the beginning in order to provide a low-cost alternative for projects like ours to manage and disseminate digitised archaeological documentation in a way that is responsive to their own budgetary constraints and research priorities. Most importantly, we have designed this web-based software in the belief that many of the problems currently facing archaeologists in the use of digital archives can be solved by retaining in the digital realm the same organisational principles and practices that were developed and refined over the past century at more traditional paper-based archaeological archives.

The ARCS code base, available on Github (Github 2014), is client-side J avaScript, written in CoffeeScript and built on open source libraries like Backbone.js, jQuery and jQueryUI. The overall look of ARCS was created starting with Twitter Bootstrap and further modified with custom components.
ARCS relies on modern browser technology to provide features like multi-file, asynchronous file uploads and in-page URL updates. On the serverside, a CakePHP application provides a RESTful J SON-based interface, renders HTML templates not rendered client-side, and handles image and document processing. Data is persisted in MySQL with optional Apache SOLR search integration. The end result is a dynamic web application that employs the sametypes of interactive clickand dragicons that are commonly found on most computer desktops. Aside from a faceted search utility that replaces many of the check boxes and form fields commonly used in complex databases, ARCS encourages users to interact with information just as one might scan through the pages of an actual book or a series of photographs.

ARCS displays any digital copy of a resource in a manner that replicates its original appearance but also allows it to be searched and linked to other resource types (Fig. 2). This is done in two different ways. For each unique resource, keywords can be entered through a consistently formatted user interface located in the "notations" menu to the right hand side of the page. Any word entered here becomes a search term as well as a possible link to other resources that have used the same expression. However, because many forms of evidence contain specific references to other types of information, ARCS also allows the creation of hyperlinks or "annotations" that connect specific areas of the displayed resource to other resources in ARCS, transcriptions, or URIs outside the system. All resources in ARCS are identified by a stable URI so there is no danger of broken or misdirected links. Annotations can be overlapped, and if a user finds them distracting, hidden from view. It is important to point out that all annotations are saved and displayed independently of the file that contains the digital resource. Thus, in its ability to augment, but not alter the appearance of the archaeological evidence it displays, ARCS successfully bridges the gap between the need for machine-readable digital data and the accurate recreation of an archived document.

Next, because the process of keywording and annotating tens of thousands of resources is an enormous task, ARCS relies on the input of the system's users to assist in the process of augmenting 


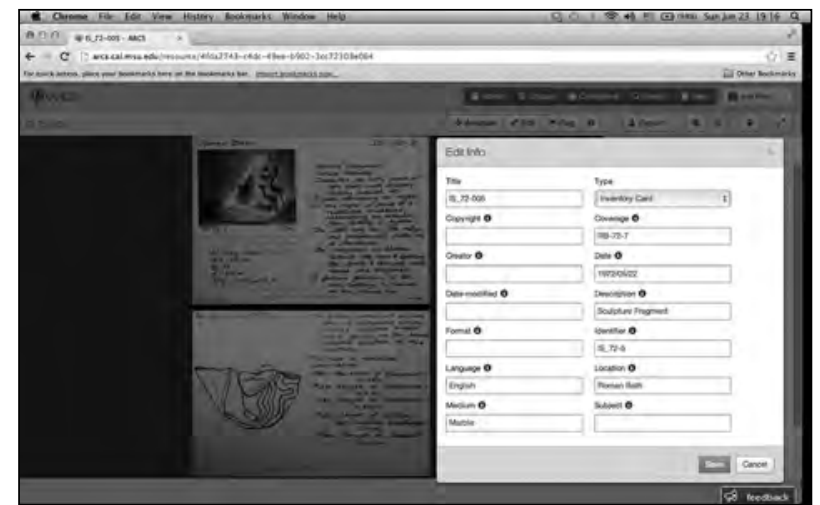

Figure 3. Screen capture of ARCS user interface for editing metadata.

the data it contains (Huvila 2008; Xia 2011). In essence, any concerned individual who has been given the appropriate digital permissions may annotate or keyword any resource in the ARCS database to which they have been given access. Because ARCS depends on a shared effort among interested users, the software is equipped with tools to ensure the reliability and accuracy of this information. First of all, users may flag any resource that appears to contain an error. Users with higherlevel permissions are alerted and can respond to the issue. In fact, it is not possible for anyone to correct an error in ARCS without first creating a flag that describes the nature of the problem. While this process may seem cumbersome, it is designed in order to generate a history of changes to each resource, so that those managing the system can determine what modifications were made and for what reasons. All user activity is also logged by the ARCS system so that those with a history of reliable activity on the site can be given greater responsibilities.

This "shared archiving" approach also applies to the creation of new resources and their associated metadata (Huvila 2008; Xia 2011). ARCS is equipped with an upload utility that allows users to create resources from single files or batches. Upon uploading, ARCS requests that user enter metadata for that resource, but only a unique identifier is initially required. Once a resource has been created, ARCS also relies on a collective effort to augment its metadata. Again, users with the appropriate permissions access the metadata menu by selecting a resource or group of resources, then clicking on the "edit" button near the top of the screen. The menu

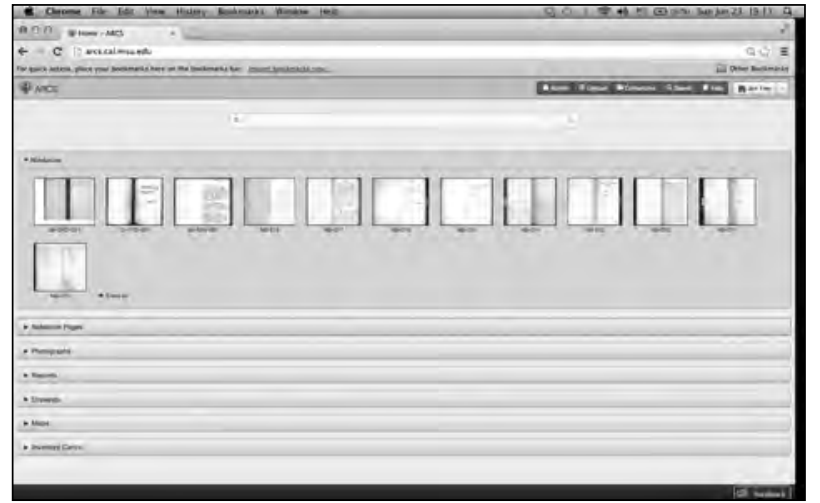

Figure 4. Screen capture of the ARCS opening page with information sorted thematically.

that appears displays all of the available metadata fields, each one of which is briefly described in an informative help text (Fig. 3).

Beyond the creation and augmentation of digitised archaeological resources, ARCSis equipped with a number of utilities that allow individual scholars to explore archaeological evidence in a web-based environment that more closely resembles the type of research that they would do if they had travelled to the actual material archive. Understanding that different research questions require different approaches to archaeological information, we have created an opening page that allows users to explore information thematically (Fig. 4). In this way, the user is encouraged to begin their investigation by consulting the maps, photographs or final reports for a specific year or location. Because the excavation notebooks form the central unifying element of the Isthmia system of record keeping, they have been listed first, but the order of this opening display can be modified to highlight any form of archaeological information that a project might want to emphasise.

Once they identified relevant resources, users can create collections in the same way that they might stack atop their desk the actual field journals, photographs and other documents they wish to consult. Thesecollections can besaved forlater useor shared with collaborators by means of a stable URI. Each individual resource is also associated with its own discussion tab. Here users can post comments or questions that become permanently associated with that resource. In this way, those who are more familiar with the history of a project or the specific 
details of a resource can participate in the creation of the type of institutional memory that is one of the benefits of work in person at archaeological project.

\section{Current Use of ARCS}

Although it is still in development, the ARCS system has already demonstrated its utility at Isthmia, a project withalonghistory ofarchaeological exploration, but with limited resources that can be dedicated solely to the process of digitisation. The shared archiving approach that lies at the core of the ARCS system allows projects like ours to digitise and upload data whenever it becomes possible to do so. As the amount of information grows, ARCS expands in size and complexity along with it. At Isthmia, where the digitisation of records has depended a great deal on the efforts of student volunteers, ARCS has also provided a way to ensure that archaeological evidence is being reliably and consistently created without the need for constant supervision. Moreover, ARCS holds a great deal of potential as a Virtual Research Environment (Rains 2011). In recreating many of the benefits of on-site study, ARCS enables year-round scholarly cooperation regardless of location. What is more, by acting as a central repository for a project's archaeological evidence, ARCS ensures that all participants in team research are making use of the same set of up-to-date information. At the same time, because ARCS can be easily modified to reflect the unique organisational structure of projects that began decades before the digital archaeological revolution, the system allows excavations and surveys to retain a great deal more control over the way that their evidence is interpreted by those who are less familiar with the project as a whole.

Finally, the ARCS system is already proving worthwhile as a tool for effective teaching and public outreach. As a recent test of the system in a classroom setting shows, ARCS can be used to educate students about the archaeological process as well. Over 150 students in online courses taught at Ohio State in both 2012 and 2013 were given the task of creating archaeological reports based on the primary documentation of a recent excavation made accessible through ARCS. A much smaller group of students at Michigan State have used the system to upload and annotate resources both in Greece and the United States. Inasmuch as the effort of student volunteers has always been a feature of work at archaeological sites, ARCS again reintroduces this mutually beneficial tradition into the digital realm. Moreover, as we come to recognise "the myth of the amateur" in crowdsourcing, it is perhaps worthwhile to consider the ways in which "student-sourcing" may offer a responsible alternative (Brabham 2012).

\section{Future Directions}

It should be noted that the ARCS system is still in an early stage of development and a number of issues remain to be solved. Foremost among them is the continual problem of implementing a metadata standard that is both responsive to the special needs of individual archaeological projects, but also is sufficiently universal to allow for effective communication and sharing of archaeological information (Rabinowitz et al. 2012; Wise and Miller 1997). We initially adopted the Dublincore 15 core attributes as our standard, but the number of modifications that we have made to the schema has resulted in a standard that is likely more idiosyncratic than the ontology that was already in use at the excavation (DCMI 2014). We are hopeful that one of two new schemata, CIDOC CRM-EH (University of South Wales 2014) and ArchaeoCore (Berenz et al. 2012) will better suit our unique needs.

J ust as importantly, it is essential to note that this software was designed to foster the process of digitising and augmenting primary archaeological documentation and to serve as a virtual research environment for scholarly collaboration, education and public outreach. However, its use as a permanent archival solution involves complexities that are far beyond the scope of the present project. As such, we have now turned to the development of an import/ export utility that will allow ARCS to work seamlessly with existing archival services such as ADS (University of York 2014) and tDAR (Digital Antiquity 2014) or data publication services such as OpenContext (OpenContext 2014).

Finally, it is clear that if we are to achieve the lofty goal of making archaeological data freely accessible between archaeological projects on a regional and global scale, while at the same time maintaining the unique identity of individual sites and projects, software solutions like ARCS much also include an ontology mapping and translation 
The Archaeological Resource Cataloging System (ARCS): A Better Way of Working with Digital Archives J on M. Frey, Timothy E. Gregory and Lita Tzortzopoulou-Gregory

tool. Such utilities are already a feature of tDAR and we are particularly interested in following recommendations for best practices from the Linked Ancient World Data Institute (Digital Classicist 2013)

Much remains to be done, but it is hoped that ARCS will provide a way for smaller archaeological projects with long histories, but limited budgets to participate on their own terms in the shift to digital archaeology. Moreover, we hope that ARCS will be seen as a clear demonstration of the ways in which an emulation in the digital realm of the processes and principles that have been in use at archaeological projects for over a century can provide effective solutions to many of the problems facing digital archaeologists today. After all, as classical archaeologists, we are particularly wellsuited to see the ways in which the lessons of the past remain relevant to this day.

\section{Bibliography}

Aldred, O. 2005. "Out with the old in with the new? Online presentation of excavation archives." Internet Archaeology 18. Accessed June 22, 2013. doi: 10.11141/ ia.18.2.

Allison, P. 2008. "Dealing with Legacy Data - An introduction." Internet Archaeology 24. Accessed June 22, 2013. doi: 10.11141/ia.24.8.

ARCS. 2014. "Create, relate, organize and search digitized primary evidence." Accessed March 15. http://arcs.cal. msu.edu/about.

ASCSA. 2014. "Digital resources.” Accessed March 15. http:// www.ascsa.edu.gr/ index.php/ digital-library/ .

Berenz, E., A. R. F. Burns, and L. Stylianopoulos. 2012. "Cataloging in the Cloud: Shared Shelf and ArchaeoCore." VRA Bulletin 39 (2):2. Accessed June 22, 2013. http:// online.vraweb.org/vrab/vol39/iss2/ 2 .

Bobowski, B. 2012. "Easy Recording System: Solutions Based on Web Free Apps Databases." In Revive the Past. Computer Applications and Quantitative Methods in Archaeology (CAA). Proceedings of the39th International Conference, Beijing, April 12-16, edited by M. Zhou, I. Romanowska, Z. Wu, P. Xu, and Philip Verhagen, 170176. Amsterdam: Pallas Publications.
Brabham, D. 2012. "The myth of amateur crowds: a critical discourse analysis of crowdsourcing coverage." Information, Communication \& Society 15(3):394- 410.

DCMI. 2014. "The Dublin Core Metadata Initiative." Accessed March 15. http:// dublincore.org/ .

Digital Antiquity. 2014. "tDAR Digital Archaeological Record." Accessed March 15. http:// www.tdar.org/ .

Digital Classicist. 2013. "Linked Ancient World Data Institute." Last modified May 23. http://wiki. digitalclassicist.org/Linked_Ancient_World_Data_ Institute.

Eide, Ø., J. Holmen, and A. Høy-Petersen. 2005. "Making the Resources Fit Together. Interconnection of Diverse Archaeological Document Collections." Internet Archaeology 18. Accessed June 22, 2013. doi: 10.11141/ ia.18.3.

Eiteljorg, H. 2011. "What Are Our Critical DataPreservation Needs?" In Archaeology 2.0, edited by E. Kansa, S. Kansa, and E. Watrall, 251-64. Los Angeles: Cotsen Institute of Archaeology.

Fee, S., D. Pettegrew, and W. Caraher. 2013. "aking Mobile Computing to the Field." Near Eastern Archaeology 76 (1):50- 55 .

Fulford, M., E. J. O'Riordan, A. Clarke, and M. Rains. 2010. "Silchester Roman Town: developing virtual research practice 1997-2008." In Digital Research in the Study of Classical Antiquity, edited by G. Bodard and S. Mahony, 15- 34. Farnham: Ashgate.

Github. 2014. "ARCS.” Accessed March 15. https:// github. $\mathrm{com} / \mathrm{calmsu} / \mathrm{arcs}$.

Huvila, I. 2008. "Participatory archive: towards decentralised curation, radical user orientation, and broader contextualisation of records management." Archival Science 8 (1):15- 36.

IADB. 2011. "Integrated Archaeological Database." Last modified May 20. http://www.iadb.org.uk/.

Newman, M. 2011. "The Database as Material Culture." Internet Archaeology 29. Accessed 22 June, 2013. doi: 10.11141/ia.29.8. 
Across Space and Time. Papers from the 41st Conference on

Computer Applications and Quantitative Methods in Archaeology. Perth, 25-28 March 2013

OpenContext. 2014. “Welcometo Open Context.”Accessed March 15. http:// opencontext.org/ .

Porta Stabia. 2011. "iPads at Pompeii." Last modified, April 12. http:// classics.uc.edu/ pompeii/index.php/ news/ 1-latest/ 142-ipads2010.html.

Prinke, A. 2005. "Digitising Historic Excavation Archives." Internet Archaeology 18. Accessed June 22, 2013. doi: 10.11141/ia.18.5.

Rabinowitz, A., M. Esteva, and J. Trelogan. 2013. "Ensuring a Future for the Past: Long-term Preservation Strategies for Digital Archaeological Data." In The Memory of the World in the Digital Age: Digitization and Preservation: An international conference on permanent access to digital documentary heritage, edited by L. Duranti and E. Shaffer, 941-954. Vancouver: UNESCO.

Rains, M. 2011. “Creating a Virtual Research Environment for Archaeology." In Archaeology 2.0, edited by E. Kansa, S. Kansa, and E. Watrall, 159-170. Los Angeles: Cotsen Institute of Archaeology.

Richards, J. D. 2004. “Online Archives." Internet Archaeology 15. Accessed J une 22, 2013. doi: 10.11141/ ia. 15.7

University of York. 2014. "Archaeology Data Service." Accessed March 15. http:/ / archaeologydataservice.ac.uk/ .

University of South Wales. 2014. "CIDOC CRM-EH Ontology." Accessed March 15. http://hypermedia. research.glam.ac.uk/kos/CRM/ .

Wallrodt, J. 2014. Paperless Archaeology Blog. Accessed March 15. http:// paperlessarchaeology.com/ .

Wise, A., and P. Miller. 1997. "Why metadata matters in archaeology." Internet Archaeology 2. Accessed J une 22, 2013. doi: 10.11141/ia.2.5.

Xia, J . 2011. "Open Access for Archaeological Literature: A Manager's Perspective." In Archaeology 2.0, edited by E. Kansa, S. Kansa, and E. Watrall, 233-49. Los Angeles: Cotsen Institute of Archaeology. 


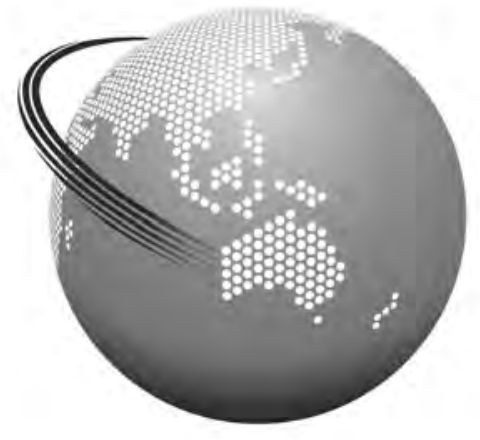

\section{DATA DISSEMINATION}

3D Modelling and Visualisation

Cultural Heritage Management \& Interpretation 



\title{
Reimagining Archaeological Publication for the 21st Century
}

\author{
Eric C. Kansa \\ Open Context and UC Berkeley, USA
}

\begin{abstract}
:
Scholarly communications stand at a crossroads. Long-established publication norms face disruption as researchers and their stakeholders shape and adapt to new dissemination models offered by the World Wide Web. Many researchers have seized the opportunity to experiment with ways to openly and collaboratively share a rich and more comprehensive picture of the archaeological past. Reform efforts to promote Open Access and Open Data have made impressive progress in recent years. However, communications in archaeology also face great challenges. Media interests continue to lobby for stronger and more punitive intellectual property laws. Such legislative efforts threaten to undermine much of the progress made by Open Access and Open Data advocates, since they would greatly increase the costs and legal risks in using the published archaeological record. Academic incentive and reward structures, coupled with deeply established notions of prestige, make many of our colleagues apathetic and sometimes overtly hostile toward new and more open forms of scholarship. Our current struggles in scholarly communications show how change can threaten existing institutional structures, funding models, modes of recognition and career advancement, and relationships between archaeology's stake-holding communities. In other words, publication has become political. Differing political visions help shape our expectations in issues like financial sustainability, the place of archaeological data in publishing, and which institutions should play a role in communicating and preserving the archaeological record. Recognising these various and often conflicting interests will make us better equipped to envision a more sustainable and equitable archaeology for the 21st century. Innovations in many areas, including Linked Open Data, Web services, and services for data citation and preservation, have enriched archaeology's information ecosystem. They also promise to make archaeology's knowledge contributions more broadly accessible and relevant to other disciplines and public communities. Optimistically, such innovations will take root in a changed landscape that better reflects and encourages the dynamism of our field.
\end{abstract}

\section{Introduction}

Current expectations in archaeological publishing are still largely oriented toward 20th century models. But that orientation does not reflect our current information context. The World Wide Web has radically transformed virtually every sphere of life, including our social lives, commerce, government, and of course, news, entertainment and other media.

The Web itself grew out of academia, as a means for researchers at CERN and other university laboratories to efficiently share documents (Heuer et al. 2008). However, while the Web emerged from an academic setting, academia has been remarkably reluctant to fully embrace the Web as Corresponding author: ekansa@berkeley.edu a medium for dissemination. The humanities and social sciences, including archaeology, still invest little social and intellectual capital in Web based forms of communication, at least in comparison to the biological and environmental sciences, where publication more regularly occurs in Web-centric venues such as the Public Library of Science and Peer-J.

How and why archaeologists publish deserves far greater discussion. Publication lies at the heart of academic archaeology, playing an integral role in our success in finding grants and employment and our identity as researchers. The economics, expectations, and constraints of publishing practices help shape what we know and communicate of the "archaeological record." As discussed below, the communication and preservation of primary field 
data and documentation fits poorly into normative publishing practices, leading to the hoarding, neglect, and loss of archaeological data.

Given that so many of us prioritise publication goals over virtually every other professional goal, it is remarkable how little we debate publication practices. Most academic archaeologists publish and often think strategically about publication without necessarily considering the institutional basis of publication practices. The costs, tradeoffs, economics and politics of publication remain largely unexamined. Nevertheless, the open access movement together with increasingly successful advocacy for "open data" has started to provoke more debate about publication practices (Lake 2012; Suber 2012). These scholarly communication reform movements have challenged largely tacit and unacknowledged assumptions about publication.

Though academia (including our discipline) has demonstrated reluctance to adapt to the new media environment, we ignore larger economic and policy changes at our peril. Archaeology is at a crossroads in how it situates itself within a changing legal, financial and political context. "Business as usual" publication is no longer tenable. But some of the very forces that make changing our publication practices so necessary are the same forces that make change so difficult. Thus, this paper explores some of the factors that shape archaeological publication in the 21st century, focusing on some of the ethical and political dimensions of publication.

\section{A Context of Neoliberalism}

Archaeologists, particularly those working in academicsettings, tend to avoid the Web as a primary communication medium. It may be tempting to cite academic "conservatism" as a rationale for this reluctance, but this has little explanatory power. Archaeologists are, if anything, selective in their "conservatism." Many archaeologists are highly engaged with new technologies. Photogrammetry, $\mathrm{XRF}$, GIS, remote sensing, various geophysical methods, 3D modelling, and even drones see rapid adoption in the discipline. Archaeologists also have professional incentives to distinguish themselves from their peers and do so through publishing innovative approaches in archaeological methods, theories, and interpretations. However, publication practices themselves remain highly resistant to change. To explore why, we need to look at the larger institutional and professional context in which academic archaeologists work.

In much of the wealthy, industrialised world, the past three decades have witnessed an accelerating consolidation of "neoliberalism," a loosely associated set of ideologies, economic policies, and institutional practices. As discussed below, neoliberalism provides a useful shorthand for describing the contemporary institutional milieu of academia. However, I need to acknowledge that neoliberalism has seen much deserved critique as an explanatory tool in social anthropology. As a theoretical framework, some ethnographers may over-useneoliberalismasan explanatorymechanism for virtually every observed accommodation or resistance to markets, government policies and NGOs (Elyachar 2012; Kingfisher and Maskovsky 2008).

While neoliberalism may have limited explanatory power in many ethnographic contexts, I believe it does have value to encapsulate changing institutional practices and ideologies in academia. Very broadly, neoliberalism refers to policies of economic liberalisation (deregulation), imposition of "market-based" dynamics (as opposed to central-planning or public support and financing), and corporate management methodologies, especially workplace monitoring (Lorenz 2012) and performance incentives. Broadly speaking, a set of largely unspoken and tacit "common sense" assumptions about how to motivate and reward scholarship underpin neoliberalism in academia.

What does neoliberalism have to do with publishing in archaeology? As it turns out, virtually everything about publishing in archaeology one way or another relates back to neoliberal policy making. Over the past few decades, consolidation in academia's commercial publishers has helped fuel dramatic price increases, averaging $7.6 \%$ per year for the past two decades and amounting to a 302\% cost increases between 1985 and 2005 (MoGuigan and Russell 2008). Subscription hikes are three to four times the overall rate of inflation, and have continued even after the Great Recession of 20082009 (Bosch and Henderson 2013). Ideologies and policies favouring market deregulation permit 
such commercial consolidation. At the same time, escalating subscription costs give commercial publishers consistently high profit margins $-35 \%$ in the case of Elsevier in 2011 (Mobbiot 2011). These price increases further exacerbate other outcomes of neoliberal policies. While publication costs have skyrocketed, academic libraries have witnessed declining budgets as higher education institutions struggle in a climate of fiscal austerity, at least in the United States (Bosch and Henderson 2013).

The escalating cost of higher education, or rather the increasing cooption of research and educational funding streams toward corporate interests, inevitably means that academic institutions pass the costs of neoliberal policies on to core constituents, namely lecturer/researchers and students. At least in the US, many researchers see stagnant or reduced salaries, smaller research budgets, and cut-throat competition for fewer faculty positions. For example, Curtis and Thornton (2014, Table A and C) note generally smaller faculty salaries at American universities, while top university administrative pay sees impressive gains. Currently, $70 \%$ of undergraduate courses at United States universities are taught by contingent junior lecturers. The pay and working conditions of this contingent class of scholars requires many of them to supplement their income with welfare assistance to pay for basic necessities such as food and shelter (Patton 2012). At the same time, students see an explosive growth in tuition, and in the United States, this has fed a mind-boggling \$1.2 trillion in student debt (Denhart 2013).

Neoliberal pressures on archaeological publication extend beyond cost increases and reduced public financing. Neoliberal ideologies also emphasise "instrumentalism" in research and education (Hamilakis 2004). In the United States, the United Kingdom, New Zealand, and Australia, in particular, but also in the European Union (see Olssen and Peters2005, 339), neoliberal perspectives have taken hold in education and research policy to promote competitiveness in the "Knowledge Economy". Policy makers increasingly expect direct and immediate financial returns for investment in education and research. Research, instructional, and other scholarly activities increasingly need to "pay for themselves." Instrumentalism creates obvious pressures for aligning scholarship toward easily commercialised ends. Students, under increasing pressure to service high levels of debt, especially feel pressure to focus on subjects thought to give high financial returns. Archaeologists often need to justify their course offerings in how they give students "transferable skills" that can be applied in more practical domains. University administrators also increasingly use instrumentalist rhetoric to argue against further erosion of public financial support. Since most public financing of research goes toward medical, engineering or scientific domains critical for economic competitiveness, university administrations prioritise these easily monetised domains in new hires, facilities, and other support.

Instrumentalist policies have little use for disciplines outside of the so-called STEM (science, technology, engineering, and mathematics) fields. As archaeological research, like many other disciplines, has very little chance at leading to a patentable scientific breakthrough or computational advance, it becomes increasingly marginalised in the contemporary neoliberal academic setting. This has exacerbated the bite of publication cost escalations. The worst publication cost escalations have focused on STEM journals, yet those are the journals prioritised in library budgets because of their strategic importance to universities. This leaves even less money for books and journals in the humanities and social sciences (Steele 2008).

\section{The Power of Publication in Archaeology}

One of the delicious ironies I found in doing background research for this paper centred on access. Scholarly treatments of "neoliberalism" and "archaeology" are plentiful, often authored by researchers on the avant-garde of archaeological and anthropological method and theory (Hamilakis 2004; Herzfeld 2010). Many such contributions offer scathing indictments of how archaeology, heritage conservation, and academia reinforce and reify growing economic and political inequality. However, most such contributions are only available via conventional closed access commercial or semi-commercial publishers, making the material unavailable to those who do not have institutional access. As will be discussed, surveillance and draconian legal enforcement give such pay-walls very sharp teeth. 
Why is it that even the researchers who are otherwise the most critical voices of archaeology as practiced tend to publish in conventional, closed access journals owned by massive corporations making yearly profits in the billions? Many researchers exploring scholarly communications have asked this question in various guises and domains. Diane Harley (Harley et al. 2010) led the largest and most comprehensive investigation of scholarly communications practices to date. Part of her study focused on archaeology. Unsurprisingly, Harley and her team noted how professional incentives and rewards deter many scholars from participating in digital publishing. Researchers often feel wary of committing effort toward digital projects when mainstream publication offers much more clear and certain rewards. Since even publications which critique archaeology tend to be authored by researchers wanting notice and recognition from their peers, established venues known for reaching the desired audience continue to see favour.

Moreover, publication is not just about communicating with one's peer community. Academic publication involves a selection of venues, choice of language and style, and other signals that communicate one's claims to a certain professional identity. Many of us who have taught undergraduates and graduate students have personally observed and mentored studentslearning how to communicate like one of us. It is a central aspect of the reproduction of academic culture. The mastery of publication practices can make or break a career, since publication is so heavily invested with prestige and social capital. J ournals can have very competitive review processes and rejection rates. A citation or a positive review from an elite scholar has implications for employment. The adage "publish or perish" captures these high stakes.

The rise of neoliberal policies compounds many of these publication pressures, making reform in scholarly communications all the more difficult to promote. As already discussed, neoliberal policies have made funding and academic job opportunities increasingly scarce over the past few decades. The competitive pressures involved in landing (or keeping) an academic job create more incentives to publish in recognised "name brand" journals. In terms of impact factor, a measure of how often a particular journal receives citations (see below), the top journals in archaeology are owned by Elsevier and Springer. The competitive nature of archaeological publishing helps reinforce the dominance of these established publishers.

\section{Publication Ethics}

Unfortunately, conventional publication practices perpetuate dysfunctions in a number of respects. The legal context of normative publication practices derives from and exacerbates the current institutional climate of neoliberalism. Normative publication practices and incentives also profoundly affect what we know of the "archaeological record." I argue that the kinds of content and the modes of communicating that content are shaped by how academia monitors and rewards publication performance.

The case of Aaron Swartz illustrates the high legal and ethical stakes involved in scholarly communications. Aaron Swartz, a prominent information activist, took his life after a failed plea bargain agreement with United States federal prosecutors. Hefaced 30-50 years in a federal prison for alleged mass-downloads from the subscriptionaccess J STOR repository. Though J STOR itself did not want to press charges against Swartz the US criminal justice system treated his alleged crimes more seriously than it treats human trafficking, which only carries a 20-year prison term (see Kansa, Whitcher Kansa and Goldstein 2013).

Swartz's case underscores how debates about scholarly publication are not merely "academic." Media industries have pressured legislative bodies and law enforcement agencies to enact stricter controls, more intrusive surveillance, and harsher punishments for copying (Samuelson 2003-2004). These laws apply not only to popular music and movies, but also to scholarly communications. Changing laws and media consolidation have led to several impediments to research across all domains, including archaeology:

- Legal controls, contractual restrictions, and technical locks inhibit the ability of libraries and archives to preserve the publications of the research community (J enkins 2014; Puckett 2010). 
- If copyright laws were enforced among the research community, routine academic research and instructional activities over the course of a single year would see a jaw-dropping $\$ 4.5$ billion in potential copyright liability (Tehranian 2007).

- The recent lawsuit filed against Georgia State University by Sage, Oxford University Press, and Cambridge University Press over "e-reserves" highlights clashing interests between researchers and publishers (Kansa, Whitcher Kansa and Goldstein 2013). The lawsuit, though dismissed, cost Georgia State University \$3 million in legal fees to defend. That $\$ 3$ million could have funded research, sustained a new faculty line, or (of course) sustained a fully open access publishing program.

The current legal context, together with massive industry consolidation, makes conventional research publishing today very different and much more costly and legally dangerous than in the preInternet era. Many researchers, particularly our colleagues in public and contract archaeology or thosestrugglingasadjuncts, early careerresearchers, and junior lecturers, either totally lack or regularly lose affiliations with institutions that subscribe to pay-wall resources such as JSTOR. Many of these people beg logins from friends and colleagues with access. Similarly, file-sharing of copyright-protected articles is routine. Email lists and other networks regularly see circulation of papers, all under legally dubious circumstances. Essentially, pay-walls create a criminalised underclass of researchers who bend and break rules to participate in their professional communities.

While access controls governed by such severe legal sanctions raise ethical concerns, they also complicate current and future research programs. For example, large-scale text-mining and automated entity identification techniques can be useful for building structured data and metadata from archaeological publications. If copyright owners (usually commercial publishers) withhold permission to apply these techniques, research insights gained from computational text analysis will be out of reach (Carroll 2013).

Thus, legal trends toward making copyright an absolute and perpetual property right shape how researcherscanuseavarietyofcomputationalanalysis methods. As Natural Language Processing (NLP) and Named Entity Recognition (NER) techniques mature, the legal disposition of archaeological publications will become an increasingly important policy concern for archaeology's professional societies and funders. While legal access to large corpora of archaeological texts will be an important precondition for such research techniques, so too will liberal permissions for reuse. A guiding policy principle toward reform centres on the notion that "free" needs to imply much more than just "free of charge." As first articulated in the open source software community, "free" also carries a much more important sense of "free as in speech" (Coleman 2012, 164-179). In order for scholarship to best promote freedom of expression, researchers need legal guarantees to access, critique, reuse, adapt and build upon the works of their colleagues without threat. Researchers also need such permissions applicable to large scale corpora, especially if they are to apply computational methods to large collections of texts. The current "default setting" of most conventional scholarly communication carries no such legal protection for researchers. This needs to change in order to permit advances in many areas of archaeological computing.

\section{Archaeological Data and Publication}

This description of the current legal context of academic publishing reflects how the debate over open access is a necessarily political one. After all, scholarly publishing involves more than the communication of knowledge, it also involves political questions about the allocation of prestige and financial resources. It is impossible to separate the political debate about reforming scholarly communications from research questions about how to best communicate archaeological research.

Similarly, the debate over how to best promote the research value of structured archaeological data involves political questions about prestige and money. Because data dissemination and archiving issues have grown in prominence relatively recently, there are perhaps fewer vested interests in managing structured data than conventional publications in archaeology. Thus, "reformist" intellectual property and access policies seem easier to enact with data than with moreconventional forms of archaeological 
publication. This reflects broader science policy directions in the US, the European Union, and elsewhere. Government sponsors of research increasingly encourage researchers to share "open" (free as in speech) data (see European Commission 2013; Holdren 2013).

The policy case for "open data" centres on the notion that public support for research should result in public goods, including data, which are free of restrictions on access and intellectual property, except in cases of overriding privacy or security concerns. Open licensing together with Linked Open Data, Web services, APIs (Application Program Interfaces) and other technical measures all work to promote the efficient interoperability and exchange of data. In archaeology, open data advocates highlight how open data can enable new research opportunities and make knowledge claims easier to evaluate and critique (see Kansa 2012; Lake 2012). Sharing data can give researchers more freedom to contest the interpretations of their peers or embark on new research programs synthesising data from multiple sources.

The availability of open research data in archaeology and elsewhere not only depends on high level government policies, but also other institutional factors, including professional norms and expectations. The archaeological record is not really a "record" until archaeologists create it through documentation and publication of field research. As discussed above, normative publishing practices shape who "owns" the past, based on who sets access and reuse conditions on the published archaeological record. Publication practices and professional incentive structures also help shape the availability of primary data, or in other words, "what constitutes the past." Current publication reward systems do not accommodate primary field data and documentation. This leads directly to the hoarding, neglect, and loss of archaeological data. Professional practices surrounding publication need to be adjusted if high-level government open data mandates will have any real effect.

My work with the archaeological data sharing system Open Context attempts to promote data sharing as a form of scholarly publishing. In working toward a model of "data sharing as publication," we are exploring different models for editorial evaluation and peer-review. We are also exploring how data sharing can be more than a mere "technical exercise" so that the communication of data can make demonstrableintellectual contributions. Open Context publishes a wide variety of archaeological data, ranging from archaeological survey datasets to excavation documentation, artefact analyses, chemical analyses of artefacts, and detailed descriptions of bones and other biological remains found in archaeological contexts. The datasets themselves often include rich media collections, including tens of thousands of drawings, plans and photos of artefacts, archaeological deposits, and ancient architectural features. The range, scale, and diversity of these data require dedicated expertise in data modelling and a sustained commitment to continual development and iterative problem solving. Most content in Open Context carries a Creative Commons Attribution License and can be retrieved in a variety of machine-readable formats (XML, CSV, J SON, RDF).

Open Context emphasises "data publishing" to help encapsulate and communicate the investment and skills needed for sharing reusable data, as well as raise the value of data sets as first-class research outputs. A publishing metaphor can help put that effort into a context that is readily recognised by the research community (i.e. data publishing implies efforts and outcomes similar to conventional publishing). We believe offering a more formalised approach to data sharing will help promote professional recognition (as noted by Harley et al. 2013), which will then motivate better data creation practices at the outset. The availability of well-documented, citable data sets also facilitates data reuse, thus enabling innovative research involving multiple data sets (Kansa and Whitcher Kansa 2013). Open Context uses the EZID system to mint persistent identifiers (DOIs and ARKs) and archives data with the University of California's California Digital Library, a unit that runs a major digital repository called Merritt. Archiving and persistent identifiers provide a stable foundation for the citation of data. Facilitating the citation of data can help situate data sharing within academia's conventions and traditions (see also Costello 2009).

At the same time, we recognise some of the limits of using "publishing" as a metaphor for data sharing. In our experience with publishing data, 
someproblems in data recording and documentation only became evident after researchers actually tried to reuse and analyse each other's datasets (Atici et al. 2013; Kansa, Whitcher Kansa, and Arbuckle 2014). In other words, problems in a dataset may go undetected, even after cycles of editorial review and revision, only to be discovered long after initial publication. Even using the term "publishing" with data can carry unfortunate baggage implying finality or fixity.

With Open Context, we often need to revise datasets periodically to fix errors or to annotate with new controlled vocabularies and ontologies through LinkedOpen Datamethods. Therecentedited volume "Thinking beyond the Tool" (Chrysanthi, Murrieta Flores and Papadopoulos 2012) helps highlight some of the fundamental and complex intellectual challenges inherent in data. Unfortunately, critical and theoretically informed perspectives on working with data do not receive enough attention in graduate training.As managing data carries so many challenges, we will probably always face the need to revise the semantic models and annotations applied to data published with Open Context. This implies a continual need for data curation to meet new needs and new theoretically informed models. This also implies that data dissemination and curation requires continual intellectual investment. Managing data is not merely a technical matter that can be overlooked in evaluating research.

The effort and expertise needed to review, clean, and annotate data parallels the coproduction and collaboration between editors and contributors in conventional publishing. However, Open Context diverges from conventional publishing in that it do not bring that collaborative improvement of data to a close. Open Context's datasets are not fixed as static products, despite our use of the word "publishing." In many respects, we treat datasets as software source code. Like source code, the data we publish are expressed as structured text. As is the case with source code (where new versions are "pushed" to the community), version control systems can improve the management, professionalism and documentation associated with ongoing and collaborative revision of datasets (see also Kratz and Strasser 2014). To help meet these needs, Open Context uses GitHub for dataset version control. A recent paper details a case study for how our editorial, annotation, publishing and version control practices assisted in the analysis and interpretation of multiple datasets submitted by 34 archaeologists studying early agriculture in Turkey. This exercise highlighted the need to improve data modeling practices. Recording inconsistencies made some data difficult to compare, even where created using common research protocols (Kansa et al. 2014). Nevertheless, the zooarchaeological interpretation of these aggregated data noted unexpected complexity in the dispersal of animal husbandry practices in Neolithic Anatolia (Arbuckle et al. 2014). With more examples of data publishing leading to significant research outcomes, we hope to encourage greater recognition for the intellectual investments inherent in meaningful data sharing.

Open Context now publishes key datasets in a number of specialisations covering topics as diverse as the development of early agricultural economies to the comprehensive settlement history of large portions of North America (Wells et al. 2014) Though data management and data publishing are seeing increasing recognition in the archaeological community, they are still not expected aspects of archaeological scholarship. Few archaeologists feel free to commit the effort required to improve data quality and documentation. This hesitation stems from relentless professional pressures that make deviation from established norms almost unthinkable to some archaeologists. In the case with Open Context, much of the effort to edit and annotate datasets falls upon Open Context's editors. After 10 years of advocacy, it is only recently that we sense greater willingness among some archaeologists to invest effort in documenting and annotating data for publication in Open Context. While we remain optimistic that the field increasingly recognises the need for professionalism in sharing data, our experiences with Open Context shows that changing a disciplinary culture requires years if not decades of concerted effort.

\section{Archaeological Publications as Data}

As we struggle to better situate data sharing and reuse with archaeology's publishing practices, we need to remember how publications themselves are evaluated with data. It is ironic that even though many archaeologists are reluctant to share data, most common publication incentive structures 
treat their papers as "data." That is, in many institutions, hires, promotion, and tenure all centre on "performance metrics," or numeric assessments of a researcher's publication record (Curry 2012; Garfield 2005). Some data sharing advocates focus on such reforming such metrics to reward data contributions.

The rise of performance metrics represents an important changein academic administration and is often seen as another manifestation of neoliberalism (see overview in Feller 2008). Performance metrics have assumed greater importance in administration and governance - sometimes described as 'audit culture' (Shore 2008) - because of their apparent rational objectivity. For many researchers in archaeology and other fields, metrics underlie the evaluation of a key aspect of their professional lives, namely publication.

One does not need to look hard to find examples of how performance metrics help shape academic practice. The United Kingdom and Australia have enacted two of the most prominent and ambitious programs of academic performance monitoring with, respectively, the Research Excellence Framework (REF) and the Excellence in Research for Australia (ERA). The United States has more decentralized university governance, and has no equivalent to the REF or ERA systems. Nevertheless, most US institutions also work with performance metrics both at the level of institutions and the level of individual researchers (Feller 2008). For example, in the US the "Impact Factor," which started as a numeric method to help libraries select journals for subscription, has now become a dominant publication performance metric (Curry 2012).

When metrics become significant factors in attracting or allocating financial resources, the choices involved in selecting metrics necessarily become political choices and subjects of debate. ImpactStory (ImpactStory 2014) recently launched (with major funding from the Alfred P. Sloan Foundation) an effort to provide alternative measurements of research outputs better aligned with Web-based modes of communication. Conventional citation metrics only count papers published in conventional peer-reviewed journals. Any form of scholarly contribution that falls outside of these venues, such as software, computational models, data, or even blog posts, literally do not "count." Researchers and institutions that value such alternative forms of scholarship often want their Web-native forms of contributions to count, provoking widespread enthusiasm among reform activists for the type of altmetrics ("alternative metrics") - being developed by ImpactStory.

\section{Counting on Open Archaeological Data?}

The availability of altmetrics that count contributions in data will not automatically lead to meaningful intellectual investment and engagement with data. It takes a great deal of time to convince university bureaucracies and granting foundations to adopt a new system of metrics. Entrenched constituencies inevitably have vested interests in already established means of assessment. Introducing new metrics that may disrupt an established status quo will be a slow and sometimes painful process.

Worse, using metrics implies that the objects being measured are commensurate. This can lead to problems in fields such as archaeology where notions of significance and value can only be understood by considering context. If data sharing metrics take hold in academic administration, archaeological data will be measured against data from other fields. For example, a certain dataset may uniquely and irreplaceably document a key epigraphic corpus of an ancient society whose written language is only understood by a dozen scholars worldwide. This dataset may count for next to nothing using conventional impact metrics or even altmetrics. Yet, it would be measured in the same way as a paper describing a new, readily commercialised nano-material or a dataset documenting social networks among corporate board members. All of these different forms of scholarly contribution have great value in their own right, but their significance is highly context-dependent. Ignoring context can mean any given metric will be as arbitrary and meaningless in a given situation as a measure of file size or a paper's alphabetical ranking by title.

The problems we encounter in encouraging more open, transparent and collaborative forms of research stem not merely from the reign of certain bad legacy metrics, but from institutional structures 
that promote profound power inequalities. Institutional hierarchies are partially defined by who measures and monitors whom according to which metrics. In other words, establishing and enforcing metrics can be political tools to discipline members of a community.

Many researchers now see relentless competition for diminishing public resources and employment prospects. Fierce competition makes it harder to motivate data sharing. Meaningful data sharing represents a collaborative activity that often requires a great deal of effort and commitment. Experience with efforts like Open Context shows that data do not naturally speak for themselves. Data often need extensive preparation, documentation, semantic annotation and review before they can be understood by a wider community. Moreover, a greater emphasis on data sharing means a greater emphasis on exposing the research process to scrutiny, whereas conventional publishing exposes only the final research products. Exposing the research process to a wider community requires collegiality and trust, neither of which is cultivated by today's hyper-competitive academic job market.

\section{Open Data Requires Institutional Reforms}

In short, academic archaeology's current institutional structures and reward systems make it very difficult to promote "free as in speech" forms of archaeological publication. The widespread use of standardised performance metrics to evaluate archaeological researchers and scholarship arguably promotes homogeneity in research products. Perversely, we seem to ask academic researchers to "distinguish" themselves by producing highly standardised and easily compared scholarly products.

One wonders if this cheapens both research outcomes and researchers themselves through commoditisation. In business theory, one can treat a class of goods as a commodity once consumers mainly differentiate between goods on the basis of price. When goods become "commoditised" they become more generic and interchangeable, setting a downward pressure on their price. It will be fascinating to explore if standardisation of research products and metrics promotes such commoditisation. If this is the case, it seems to go hand in hand with deflationary pressures in the academic job market.

This kind of question needs to be asked in building more sound policies governing research. There may be under appreciated costs associated with the widespread use of common metrics and uniform performance expectations. Issues of research autonomy, innovation, and measuring performance need to be better understood if we are to improve communications in archaeology. If we want to encourage more innovation and diversity in the conduct of research, we should encourage and reward more diversity in career paths and institutional structures. In other words, greater academic freedom and room for innovation in archaeological research may come with more institutional diversity. In certain institutional settings, data dissemination may be more valued than among university researchers. Archaeological career paths that emphasise and reward data sharing may be easier to promote in government offices, NGOs (not-for-profit organisations), and academic libraries. Archaeology's professional societies should encourage and recognise the contributions of archaeologists that move into these less traditional career settings.

Naturally, expanding institutional options and research career paths requires financing. Expecting archaeology's fiscal prospects to improve seems laughably naïve in the current context of fiscal austerity. However, archaeology is not alone in facing these challenges. Science, the humanities, and instruction more generally all suffer from underinvestment. It is time for our discipline to better understand, document, and communicate how neoliberal policies negatively impact research and academic freedom. Only through such understanding can we chart a course for reform and begin to change the political landscape that governs research and education.

\section{Conclusions}

An entire theoretical school of thought, postprocessualism, was heavily influenced by literary criticism. In his seminal work Reading the Past, Ian Hodder (1986) was explicit in considering the archaeological record as a kind of problematic 
Across Space and Time. Papers from the 41st Conference on

Computer Applications and Quantitative Methods in Archaeology. Perth, 25-28 March 2013

text that could be fruitfully subjected to multiple interpretations or readings. However, our theoretical perspectives urgently need updating. If the archaeological past is a text, it is now a digitised text, understood and evaluated in important ways through institutional performance metrics. And becauseof therapid growth of digital documentation, it is also now a much more structured text, managed in databases, organised with elaborate data models, and rich with many forms of media.

Our profession is very slow to come to grips with this transformation. Since archaeological theory is something of an elite preoccupation, the fact that theorists have not yet said too much about structured data probably stems in part from the fact that data is not on par with text in terms of status and prestige. Data and data management are still mainly fixations of technicians. However, if all these data that we now "manage" are to have meaning, we need to invest far more intellectual energy into understanding and communicating them.

\section{Bibliography}

Arbuckle, B. S., S. Whitcher Kansa, E. C. Kansa, D. Orton, D., C. Çakırlar, L. Gourichon, L. Atici, A. Galik, A. Marciniak, J. Mulville, H. Buitenhuis, D. Carruthers, B. De Cupere, A. Demirergi, S. Frame, D. Helmer, L. Martin, J. Peters, N. Pöllath, K. Pawłowska, N. Russell, K. Twiss, and D. Würtenberger. 2014. "Data Sharing Reveals Complexity in the Westward Spread of Domestic Animals across Neolithic Turkey." PLoS ONE 9(6):e99845. Accessed J une 30. doi:10.1371/journal.pone.0099845.

Atici, L., S. Whitcher Kansa, J. Lev-Tov, and E. Kansa. 2013. "Other People's Data: A Demonstration of the Imperative of Publishing Primary Data." Journal of Archaeological Method and Theory 20(4):663- 681.

Bosch, S., and K. Henderson 2013. "The Winds of Change | Periodicals Price Survey 2013." Library J ournal, April 25. Accessed June 30, 2014. http://lj.libraryjournal. $\mathrm{com} / 2013 / 04 /$ publishing/ the- winds- of-changeperiodicals-price-survey-2013/.

Carroll, M. W. 2013. "Creative Commons and the Openness of Open Access." New England Journal of Medicine 368(9):789- 791.

Chrysanthi, A., P. Murrieta Flores, and C. Papadopoulos, eds. 2012. Thinking beyond the Tool: Archaeological Computing and the Interpretive Process. Oxford: Archaeopress.

Coleman, E. G. 2012. Coding Freedom: The Ethics and Aesthetics of Hacking. Princeton: Princeton University Press.

Costello, P. 2009. “Motivating OnlinePublication of Data.” Bioscience 59:418-427. doi:10.1525/ bio.2009.59.5.9

Curry, S. 2012. "Sick of Impact Factors." Reciprocal Space, August 2013. Accessed April 7, 2014. http:// occamstypewriter.org/ scurry/ 2012/ 08/ 13/ sick-ofimpact-factors/ .

Curtis, J. W., and S. Thornton. 2014. "Losing Focus. The Annual Report on the Economic Status of the Profession, 2013-2014." American Association of University Professors, March-April. Accessed J une 30, 2014. http:// www.aaup.org/file/zreport.pdf.

Denhart, C. 2013. "How The \$1.2 Trillion College Debt Crisis Is Crippling Students, Parents And The Economy." Forbes, August 7. Accessed March 15, 2014. http:// www. forbes.com/ sites/ specialfeatures/ 2013/ 08/ 07/ howthe-college-debt-is-crippling-students-parents-and-theeconomy/.

Elyachar, J . 2012. "Before (and after) Neoliberalism: Tacit Knowledge, Secrets of the Trade, and the Public Sector in Egypt." Cultural Anthropology 27 (1):76- 96. doi:10.1111/ j.1548-1360.2012.01127.x.

European Commission. 2013. Guidelines on Open Access to Scientific Publications and Research Data in Horizon 2020. Version 1.0. 11 December 2013. Brussels: European Commission-Research and Innovation. Accessed J une 30, 2014. http:// ec.europa.eu/research/participants/ data/ ref/h2020/grants_manual/hi/oa_pilot/h2020-hi-oapilot-guide_en.pdf.

Feller, I. 2008. "Neoliberalism, Performance Measurement, and the Governance of American Academic Science." Center for Studies in Higher Education Research and Occasional Paper Series 13. Last modified October. http:// cshe.berkeley.edu/ neoliberalism-performancemeasurement-and-governance-american-academicscience.

Garfield, E. 2005. "The Agony and the Ecstasy - The 
History and Meaning of the J ournal Impact Factor." Paper presented at the International Congress on Peer Review and Biomedical Publication, Chicago, September 16. Accessed March 11, 2014. http://garfield.library.upenn. edu/papers/jifchicago2005.pdf.

Hamilakis, Y. 2004. "Archaeology and the Politics of Pedagogy.” World Archaeology 36 (2):287- 309.

Harley, D., S. Krzys Acord, S. Earl-Novell, S. Lawrence, and C. Judson King. Assessing the Future Landscape of Scholarly Communication: An Exploration of Faculty Values and Needs in Seven Disciplines. Center for Studies in Higher Education: Berkeley. Accessed J une 30, 2014. http:// escholarship.org/ uc/item/15x7385g.

Herzfeld, M. 2010. "Engagement, Gentrification, and the Neoliberal Hijacking of History." Current Anthropology 51(S2):S259- S267.

Heuer, R.-D., A. Holtkamp, and S. Mele. 2008. “Innovation in scholarly communication: Vision and projects from High-Energy Physics." Information Services and Use 28(2):83-96.

Hodder, I. 1986. Reading the Past: current approaches to interpretation in Archaeology. Cambridge: Cambridge University Press.

Holdren, J . P. 2013. "Increasing Access to the Results of Federally Funded Scientific Research.” Memorandum for the Heads of Executive Departments and Agencies, 22 February, 2013. Office of Science and Technology Policy (OSTP) Washington, D. C. Accessed J une 30, 2014. http:// www.whitehouse.gov/ sites/ default/ files/ microsites/ ostp/ostp_public_access_memo_2013.pdf.

ImpactStory. 2014. “About.” Accessed March 15. https:// impactstory.org/about.

J enkins, J . 2014. “Last Sale? Libraries’ Rights in the Digital Age.” College \& Research Libraries News 75 (2):69- 75.

Kansa, E. C., and S. Whitcher Kansa. 2013. “We All Know That 14 Is a Sheep: Data Publication and Professionalism in Archaeological Communication." J ournal of Eastern Mediterranean Archaeology and Heritage Studies 1 (1):88- 97.

Kansa, E. C., S. Whitcher Kansa, and B. Arbuckle. 2014. "Publishing and Pushing: Mixing Models for
Communicating Research Data in Archaeology." International Journal of Digital Curation 9 (1):57-70. Accessed J une 30. doi:10.2218/ijdc.v9i1.301.

Kansa, E. C., S. Whitcher Kansa, and L. Goldstein. 2013. "On Ethics, Sustainability, and Open Access in Archaeology." The SAA Archaeological Record 13 (4):1522.

Kingfisher, C., and J. Maskovsky. 2008. "Introduction The Limits of Neoliberalism." Critique of Anthropology 28 (2):115- 26.

Kratz,J ., andC. Strasser. 2014. "Datapublication consensus and controversies." F1000Research 3:94. Accessed J une 30, 2014. doi: 10.12688/f1000research.3979.2.

Lake, M. 2012. “Open archaeology.” World Archaeology 44(4):471- 478 .

Lorenz, C. 2012. "If You're So Smart, Why Are You under Surveillance? Universities, Neoliberalism, and New Public Management." Critical Inquiry 38 (3):599- 629.

McGuigan, G. S., and R. D. Russell. 2008. "The Business of Academic Publishing." Electronic J ournal of Academic and Special Librarianship 9 (3). Accessed March 15, 2015. http:// southernlibrarianship.icaap.org/ content/ v09n03/ mcguigan_g01.html.

Mobbiot, G. 2011. "Academic Publishers Make Murdoch Look like a Socialist." The Guardian, August 29. Accessed March 15, 2014. http://www.guardian.co.uk/ commentisfree/ 2011/ aug/ 29/ academic-publishersmurdoch-socialist.

Olssen, M., and M. A. Peters. 2005. "Neoliberalism, Higher Education and the Knowledge Economy: From the Free Market to Knowledge Capitalism." J ournal of Education Policy 20:313-345.

Patton, S. 2012. "The Ph.D. Now Comes With Food Stamps." The Chronicle of Higher Education, May 6. http:// chronicle.com/ article/ From-Graduate-Schoolto/ $131795 /$.

Puckett, J. 2010. "Digital Rights Management as Information Access Barrier." Progressive Librarian 34/35:11-24. Accessed March 15, 2014. http:// scholarworks.gsu.edu/univ_lib_facpub/ 50 . 
Across Space and Time. Papers from the 41st Conference on

Computer Applications and Quantitative Methods in Archaeology. Perth, 25-28 March 2013

Samuelson, P. 2003- 2004. "Should Economics Play a Role in Copyright Law and Policy?" University of Ottawa Law \& Technology J ournal, 1:1-21. Accessed June 30, 2014. http:// papers.ssrn.com/ abstract $=764704$

Shore, C. 2008. "Audit culture and Illiberal governance Universities and the politics of accountability." Anthropological Theory 8(3):278- 298.

Steele, C. 2008. "Scholarly monograph publishing in the 21st century: the future more than ever should be an open book." J ournal of Electronic Publishing 11 (2). Accessed March 15, 2014. doi:10.3998/3336451.0011.201.

Tehranian, J. 2007. "Infringement Nation: Copyright Reform and the Law/Norm Gap." Utah Law Review 2007:537; Loyola-LA Legal Studies 2007-46; University of Utah Legal Studies 08-20. Accessed March 15, 2014. http:/ / papers.ssrn.com/ abstract=1029151.

Wells, J. J., E. C. Kansa, S. W. Kansa, S. J. Yerka, D. G. Anderson, T. G. Bissett, K. N. Myers, and R. C. DeMuth. 2014. "Web-based discovery and integration of archaeological historic properties inventory data: The Digital Index of North American Archaeology (DINAA)." Literary and Linguist Computing. Accessed J une 30, 2014. doi:10.1093/llc/ fqu028. 


\title{
Playing Angkor: Exploring the Historical and Archaeological Themes of the Khmer Empire through Game Engine Technologies
}

\author{
Tom Chandler \\ Monash University, Australia
}

\begin{abstract}
:
The recent inclusion of the Khmer Empire as a study subject in the Australian national high school history curriculum signals opportunities and challenges in the wider scheme of how archaeological themes specific to Angkor can be investigated through computer game technology. This paper will canvas interactive visualisations developed by the author and suggest scenarios for how Angkor might be taught, researched and visualised through 3D modelling and computer game technologies.
\end{abstract}

Keywords:

Angkor, 3D Modelling, 3D Animation, Computer Games, Education

\section{Introduction}

In comparison to such well known historical themes as Rome, Greece and Egypt, the civilisation of Angkor has so far featured only fleetingly in computer game titles, making it opportune for virtual exploration. Still, the time and budgetary constraints that many educators face in developing game applications, and the high expectations that students may have of game technologies generally, mean that the endeavour of meaningfully representing medieval Angkor in a game format remains a challenging one.

One of the impediments to creating 3D (three dimensional) historical game worlds is the time taken to create accurate and culturally specific $3 \mathrm{D}$ models, not only of architecture and landscapes, but also of people and their tools, clothes and vehicles. While the careful creation of these many models can be an onerous task, it is also an essential one, for these models comprise the spatial lingua franca of a game world and the foundation upon which the dynamics of motion, interactivity and sound design are built.

My research has focused on the modelling and animating of 3D scenes of Angkor based upon arange of archaeological and historical data. In the process of repurposing these animations into interactive spaces that accord with educational themes, I have found myself faced with key questions. For example, how can 3D visualisations help to address the dearth

Corresponding author: tom.chandler@monash.edu of historical source material and the key subject topics of Angkor's development, achievements and decline? And, how might these visualisations be reformatted with game technologies to communicate primary source material and archaeological themes?

In lieu of trying to emulate ambitious, long form' narratives of historically themed and archaeologically informed multiplayer worlds such as 'World of Temasek' (set in the 14th century environs of modern day Singapore) some of the answers to these questions may lie in focusing the capabilities of game engine software to explore discrete locations in much more detail, trading breadth for depth

\section{Angkor in the Australian Year 8 History Curriculum}

In the Asia-Pacific World Depth Studies of the Australian Year 8 High school curriculum, students (or rather, their teachers) are given the choice of investigating one of three Asia-Pacific societies: Shogunate J apan, the Polynesian expansion across the Pacific, or Angkor and the Khmer Empire. The Year 8 depth study of Angkor and the Khmer Empire (c.802 - c.1431) comprises four main themes (ACARA 2013)which can be paraphrased as follows:

1. The way of life in the Khmer Empire, including, social, cultural, economic and political features. Key sources include 12th and 13th century CE stone bas-reliefs and the writings of the Chinese diplomat Zhou Daguan. 
2. Thereasonsfor Angkor'srisetoprominence, including wealth from trade and agriculture.

3. The cultural achievements of the Khmer civilisation, including its system of water management and the building of the temples of Angkor.

4. Theories of the decline of Angkor, suchas the overuse of water resources, neglect of public works as a result of ongoing war, and the effects of climate change. Elaborations include the development of an unstable climate, the rise of Theravada Buddhism and the breakdown of Angkor's water management system.

Once of the challenges teachers face in teaching Angkor is a paucity of source material: the primary sources being limited to a repertoire of temple inscriptions, bas-relief carvings and the only surviving account of Angkor by the 13th century Chinese diplomat Zhou Daguan (Cummins 2012). Can 3D visualisations of lifeat Angkor delve between these sources and bridge some of the gaps?

\section{Reappraising Time, Space and Interactivity in Historical Visualisations}

While the communication of Angkor as a city or civilisation must necessarily deal with large-scale maps that reconstruct road networks (Hendrickson 2007), irrigation systems (Evans et al. 2007) and the regional context of neighbouring kingdoms (Cowden 2009) there is much to be communicated in visualisations that approximate the space of daily experience. One example of such a scene is the reconstruction of a village shrine at Angkor in the 13th century researched and developed by the author and Martin Polkinghorne (Chandler and Polkinghorne 2012). Its format is a 20 second 3D animation. This animated scene was part of a series published online with National Geographic (National Geographic 2009).

Although the scene depicted in Fig. 1 was assembled several years before the Angkor depth study was published, as a visualisation it maintains several points of relevance to the educational themes listed above. Here the 'tower or pagoda'(Zhou and Harris 2007) described in the on screen excerpt from our key eye-witness informant on Angkor,

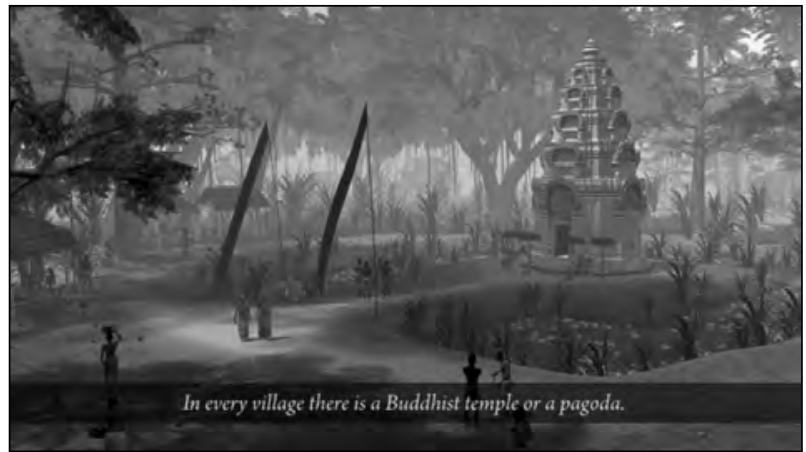

Figure 1. A scene of a village shrine at Angkor in the 1300 's. Near the centre of the image, a pair of Theravada monks walk past the causeway where a several figures converse, other figures can be seen sitting in the shade of the nearby wooden shelters or standing in the foreground of the image. The air here was 'thickened' with a tinge of yellow to mimic a humid air permeated with dust or smoke.

Zhou Daguan, is immediately apparent. However, the real emphasis of the scene corresponds with the first point of the depth study - the way of life in the Khmer Empire - because the emphasis of the scene is on the shrine's context in the cultural landscape of a village in the Khmer empire. Less directly, a scene centred around one of the multitude of smaller temples at Angkor and the complex network of endowments and tributes that underscored the Angkorian religious and political system offers an insight into the second and third themes of the depth study - Angkor's rise to prominence and the cultural achievements of the Khmer civilisation. Finally, the scene touches upon some of the theories of the decline of Angkor by showing a shift in the religion of the populace away from Brahmanism and Shivaism, as evidenced by the Theravada monks passing obliquely by a shrine of the older religion on their way elsewhere. Another option that is not presented here, but which could be possible with an extended animation, would be to journey forward in time and depict the shrine gradually falling into a state of neglect, disrepair and ruin. With the departure of the villagers and the encroachment of vines and stands of sapling dipterocarps, we would have a visual representation of the decline of Angkor and the neglect of public works in miniature.

But of course such non-interactive visualisations have their limits. As an animation, the space in the scene is enclosed in a predetermined 


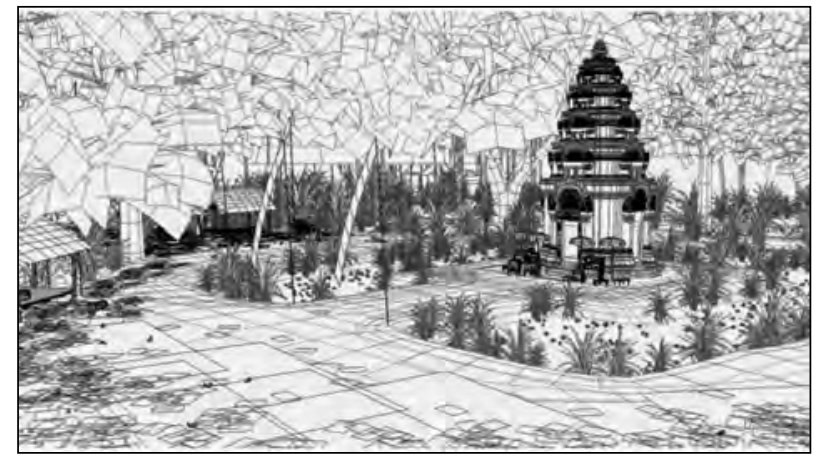

Figure 2. The $3 D$ model behind the colours and shadows in the preceding image. Much of the detail here is in the vegetation models.

sequence of images. We can rewind it if we like, but time stops when the animation ends - like a TV commercial, its fleeting format is soon forgotten.

If we could 'get inside' the animation and walk about we would neither beconstrained by the frames in the timeline or the animator's camera. To do so is nota complex matter; wecan import the3Dmodelled scene from which the animation derives (Fig. 2) into the Unity game engine, a popular cross-platform game engine developed by Unity Technologies that can be used to develop video games for web plugins, desktop platforms, consoles and mobile devices. Once inside, we can move about through a first person perspective and query any object or person in the scene through mouse clicks, key presses and rollovers (Fig. 3). For example, clicking on the Buddhist monks may reveal a paragraph of text on screen or a link out to an external website, paper or historical document about Theravada Buddhism in Cambodia. In querying the research sources and references upon which each digital model is based, we can address issues of methodology and rationale raised in the London Charter (Beacham, Denard and Niccolucci 2006). But as we move around we will soon realise that one thing is clearly different to the animation; the walking characters, the drifting cotton pennants flanking the earthen causeway to the shrine, and indeed the sounds that accompanied the animation, are all quiet and still. We are the only ones moving.

In this case, 'freezing' the scene is a deliberate decision. Certainly having everything fixed in place dispenses with (and defers deciding upon) many complexities, and programming a meaningful interactive game space is full of complications. For example, where would the characters go if they kept walking? Off the screen presumably, unless they were to stand in one spot and sway imperceptibly while they await your input (called an 'idle' animation in game design). As for the characters that were conversing with one another when you 'arrived' in the scene, what language would they be heard to be speaking when you approached them, and for how long? If you could talk to characters, what questions would you pose and how would they respond? How long would it be before the repetitive looping of background sounds and character gestures became predictableand irritating? It doesn't takelongbefore one is mired in decisions that demand a protracted game design document.

And stillness cuts out distractions. When you are the only thing that moves, every object in the scene becomes the subject of careful study. This hushed virtual museum space is also a library, because as well as viewing the exhibits and the labels that appear when items are approached, there are also links to online written, illustrated and photographic sources to illuminate the interrogation of the scene. But of courseroaming about a simulated historical environment and probing objects with a computer mouse and keyboard is hardly novel. While a contemplative and inaudibly hyperlinked
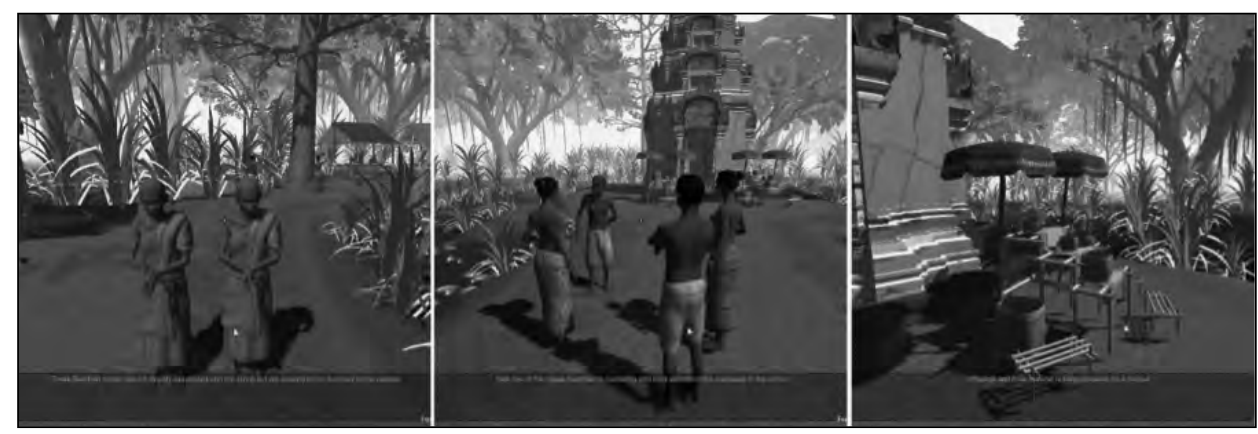

Figure 3. Above, three shots from the interactive interior of the animation space. 


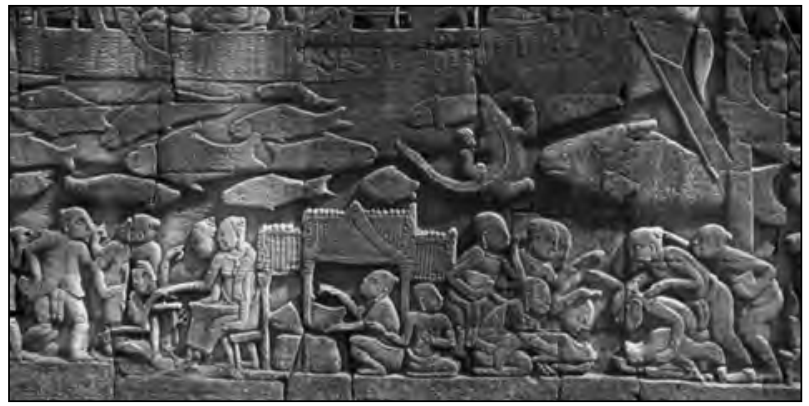

Figure 4. A scene from the Bayon bas reliefs showing townspeople going about domestic business while the profiles of gigantic fish fly incongruously above the roofs (the scene above the fish depicts a naval battle). On the lower left, a knelling man holds the hand of a seated woman while two merchants argue behind him. On the lower right, a crowd gathers around two roosters being goaded into a fight.

evocation of an Angkorian village may suit the history teachers running the class, there is always the danger that it may be dull for students. In future iterations of our research (our interactive is being developed in consultation with Nick Cummins, a history teacher at Suzanne Cory High School in Melbourne) there is much scope for renovating and rewiring the space that we have retrieved fresh from our animations. Certainly, just as there are manifold considerations for the meaningful design of an engaging game world, there are diverse practical and theoretical considerations in the effective design of virtual heritage learning environments (Champion 2008; Champion, Bishop and Dave 2012). Recent technologies such as connected dance pads for walking, gesture driven motion controllers or motion sensing input devices would go a long way towards innovating navigation and interaction in the prototype we have currently, but it must be kept in mind that access to the latest technologies is the exception, not the rule, in many schools across Australia.

\section{Behind the Bas Reliefs}

Thebas-reliefsfrom theBayon, BanteayChmar and Angkor Wat temples, chiselled in raised, semi$3 \mathrm{D}$ profile make readily interpretable modelling guides. The long galleries of action that the bas reliefs portray are like monochrome comic books carved in stone, but without the page breaks, thought balloons, speech bubbles and inset text boxes that guide the 21st century reader's understanding of sequential narrative. Still, these reliefs are primary source material in imagining life at Angkor (Roveda 2002; Roveda and Poncar 2002). The photograph of the 13th century bas-relief depicted in Fig. 4 for example, is a well-known illustration of daily life at Angkor. On the left, two bearded Chinese men in jackets appear to be haggling with a seated woman weighing goods in a market transaction, and to the right, a group of men huddle excitedly around a pair of roosters being goaded into a fight. It is unclear whether the events in the relief are occurring close together in time or space, but once this scene is modelled and imported into an interactive environment, the interrelations of activities and space can be more meaningfully explored (Fig. 5). As well as the practical examples of examining the merchandise in the market (for which Zhou's chapters provide a good deal of information, for example 'Products', 'Trade', 'Sought After Chinese Goods', 'Flora', 'Animals' and 'Vegetables'), if the scene were made editable then the rationale behind the reconstruction could become a subject of debate and discussion (Bonnet 2004; Staley 2003; Tosatto and Gribaudo 2009). But the topic of daily life depicted in the bas-relief in Fig. 4 is a rare diversion from the theme of warfare that dominates so many of most Angkorian bas-reliefs. In these carvings the order of events and action taking place is less ambiguous; most of the time thearmies are variously on campaign, preparing for battle, engaged in

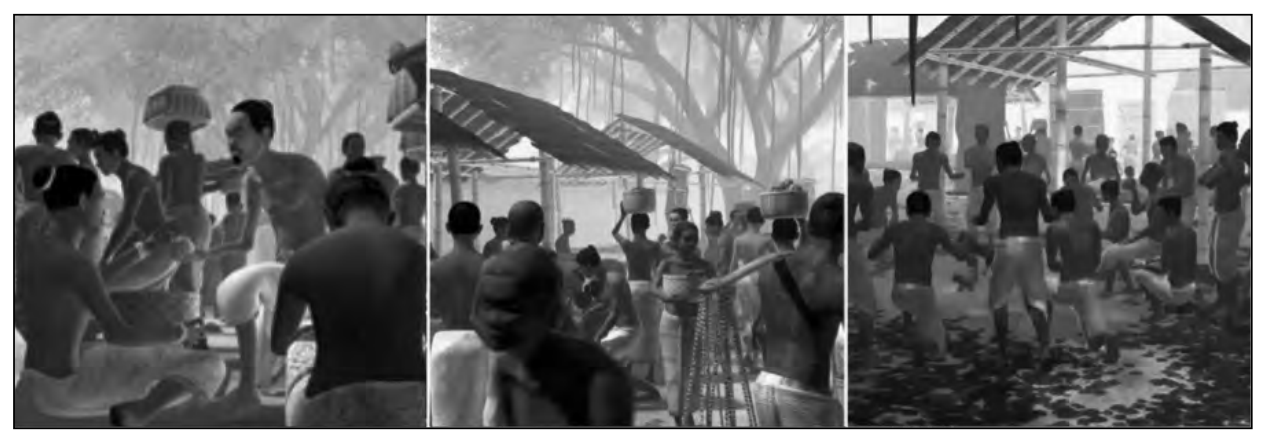

Figure 5. Above, three scenes modeled from the bas-relief in the preceding figure, they are occurring more or less simultaneously, though not near enough to each other to be perceived at the same time. 


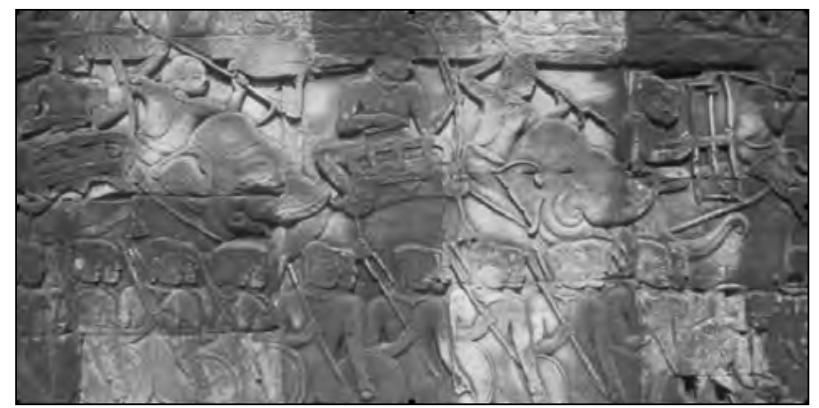

Figure 6. An advancing army on the Banteay Chmar basreliefs. Note the double bow ballista above at far right.

combat, fleeing their enemies or in pursuit of them (Fig. 6). The modelling of army on campaign (Fig. 7) demonstrates how the 3D space of the animation can bere-ordered to explore a perspective and depth that is suggested in the bas-reliefs but, because of the superimpositions rendered by its sculptors, often difficult to translate. Here again, a student can navigate among the statue-still models of soldiers and elephants and investigate, with text and external links, the insignia, apparel and weapons of the generals, officers and infantry (Jacq-Hergoualc'h and Smithies 2007).

\section{Lineages, Landscapes and Ancestor Spirits}

Though the detail in the interactive scenes can add a good deal to student's understanding of the Khmer personages, artefacts, animals and architecture evident in each scene, so far the viewer or player is assumed to be no more than a wandering and invisible eye, and the question of who we are when we visit this particular virtual world remains unanswered. For the teaching of Angkor through computer game technologies, this question is best remedied with the approximation of distinctively Khmer perspectives.

The concept of the 'avatar' is a well-known Sanskrit term popularly understood as the embodiment of a visitor to the virtual world. In a virtual Angkor, the notion of descending from an outside universe in an avatar has a range of parallels with Hindu epics depicted in the galleries of Angkor Wat. Certainly the inscriptions attest that the kings of Angkor were never shy of invoking allusions between themselves and the divine qualities of Indian gods, and, as playable historical characters,

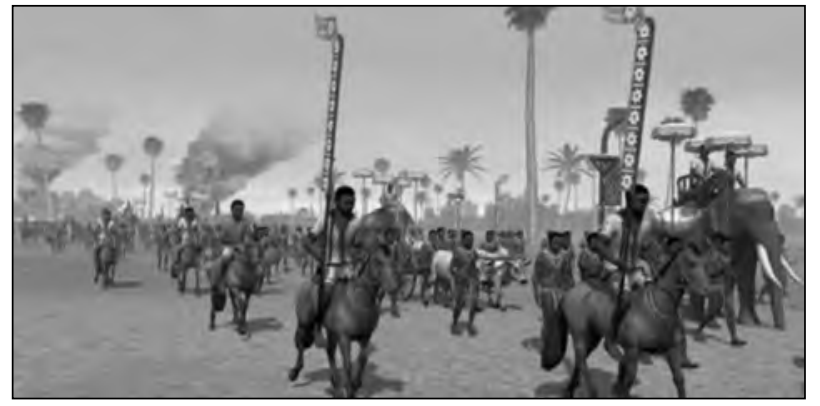

Figure 7. A scene of a Khmer army on campaign based upon the bas reliefs. The scene is too short to link to a wider narrative. The army, including women carrying infants, porters, captives and soldiers, could be marching from victory or retreating in defeat. Note the billowing smoke of burnt villages on the horizon at the far left.

there is an exhaustive list of Khmer kings to choose from. But instead of adopting the character of a historical persona, we could, as long as we account for some of the peculiar complexities of Angkorian royal succession, adopt the intergenerational continuity of a royal house or lineage. Such an abstract identity, if played judiciously, could endure for centuries, making it ideal for observing the passage of archaeological time.

However, for the communication of Angkor's archaeological themes through game technologies, how we physically modify our domain may be more important than our identity. For example, within the encoded rules of what we know of Angkorian treatises on kingship, royal works and temple foundations, we could gradually develop - with a nod to Will Wright's classic SimCity series - a novel urban layout across the Angkor plain. If we could 'play' through a span of almost a millennium, it would be interesting to test how closely our urban creation corresponds with the archaeological reality of Angkor. Using the settlement building blocks of the Angkorian landscape (temples, ponds, reservoirs, embankments, moats, enclosure walls, raised roads and canals), we might create something like sprawling and dispersed metropolis in the Greater Angkor Project map (Evans et al. 2007), with temples and major works in more or less the same configuration. What would be more likely though, and more instructive, is a very different conglomeration patterned against the same environmental template. Such a game would be a study not so much in the Angkor that was but the 


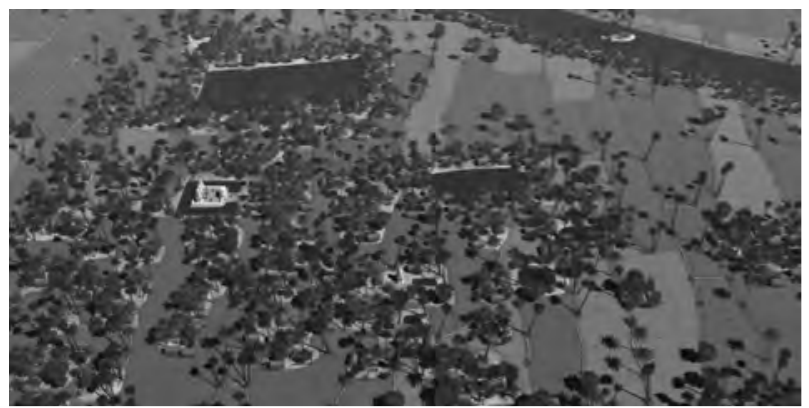

Figure 8. A modelling of the 12th century village of $\mathrm{He}$ Phka to the south of Angkor.

Angkor that could have been if another direction had been taken.

Then again, as with the scene of the village shrine, we should consider how much we could learn about Angkor if the virtual space in front of us was more limited. Here we could adopt a uniquely Cambodian identity that is neither a sovereign nor a lineage. We could instead become one of the localised spirits that Cambodians call the „ancestor people" or nak ta, described by the Khmer scholar Sok Keang as:

“...an ancestral local spiritual governor (administrator) who has power to judge for social justice, to bring peace, security, prosperity, health, and happiness to society as well as to the succeeding generations in a specific or limited territory." (Keang 2009)

As one of the local spirits historically identified with toponyms and topographical features throughout Cambodia (Chandler 1976) perhaps our domain might extend over an Angkorian village and its hinterland like the one modelled by the author in Fig. 8. In this microcosm of the Khmer empire where the faraway king and his court are known only through stories and songs, we could explore the fundamentals of Angkor's educational themes without ever laying eyes upon Angkor Wat.

\section{Bibliography}

ACARA. 2013. "History - Foundation to Year 10 Curriculum.Year 8: (2): The Asia-Pacific World.” Accessed July 3. http://www.australiancurriculum.edu.au/ humanitiesandsocialsciences/ history/ curriculum/f-10.
Beacham, R., H. Denard, and F. Niccolucci. 2006. "An Introduction to the London Charter." In The e-volution of Information Communication Technology in Cultural Heritage: where hi-tech touches the past: risks and challenges for the 21st century/ Short papers from the joint eventCIPA/VAST/EG/EuroMed, edited by M. Ioannides, D. Arnold, F. Niccolucci, and K. Mania. Budapest: Archaeolingua.

Bonnet, J. 2004. "Versando nuova linfa in una vecchia disciplina: impiego del 3D per insegnare e rappresentare il passato." [English Title: "Pouring New Wine into an Old Discipline: Using 3D to Teach and Represent the Past."]. Translated by F. Zaffe. Accessed March 15, 2014. http:// storicamente.org/bonnett_ital .

Champion, E. 2008. "Game-based historical learning." In Handbook of Research on Effective Electronic Gaming in Education, Information Science Reference, Florida USA, edited by R. Ferdig, 219-234. Hershey: Information Science Reference.

Champion, E., I. Bishop, and B. Dave. 2012. "The Palenque project: evaluating interaction in an online virtual archaeology site." Virtual reality 16 (2):121- 139.

Chandler, D. P. 1976. “Maps for the Ancestors: Sacralized Topography and Echoes of Angkor in Two Cambodian Texts." J ournal of the Siam Society 64 (2):170- 87.

Chandler, T., and Polkinghorne M. 2012. "Through the visualisation lens: temple models and simulated context in a virtual Angkor." In Old Myths and New Approaches - Advances in the Interpretation of Religious Sites in Ancient Southeast Asia, edited by A. Haendal, 218- 236. Melbourne: Monash University Press.

Cummins, N. 2012. "Teaching Asian Depth Studies." Agora 47 (4):34- 38.

Evans, D., C. Pottier, R. Fletcher, S. Hensley, I. Tapley, A. Milne, and M. Barbetti. 2007. "A comprehensive archaeological map of the world's largest preindustrial settlement complex at Angkor, Cambodia." Proceedings of the National Academy of Sciences of the United States of America 104 (36):14277- 14282.

Hendrickson, M. 2007. "Arteries of empire: an operational study of transport and communication in Angkorian Southeast Asia (9th to 15th centuries CE)." PhD diss., University of Sydney. 
Playing Angkor: Exploring the Historical and Archaeological Themes of the Khmer Empire Tom Chandler

J acq-Hergoualch, M., and M. Smithies. 2007. The armies of Angkor: military structure and weaponry of the Khmers. Bangkok: Orchid Press.

Keang, S. 2009. "Religious Practices and Political Life in Cambodia Today." In IIID.6 Relations between Religions and Cultures in Southeast Asia; Indonesian Philosophical Studies, I in Series IIID, South East Asia, Volume6, edited by G. Arivia and D. Gahral Adian, 85- 90. Washington DC: CRVP.

National Geographic. 2009. "The Khmer Empire." Accessed March 15. http://ngm.nationalgeographic. com/2009/ 07/ angkor/ angkor-animation.

Roveda, V. 2002. “Khmer Visual Narrative.” Museum 54 (1-2):44- 49.

Roveda, V., and J. Poncar. 2002. Sacred Angkor: the carved reliefs of Angkor Wat. Bangkok: River Books.

Staley, D. J . 2003. Computers, visualization, and history: How new technology will transform our understanding of the past. Armonk: M.E. Sharpe.

Tosatto, C., and M. Gribaudo. 2009. "A 3D History Class: A New Perspective for the Use of Computer Based Technology in History Classes." Lecture Notes in Computer Science 5794:719- 724.

Zhou, D., and P. Harris. 2007. A record of Cambodia: the land and its people. Chiang Mai: Silkworm Books. 


\title{
The Virtual Archaeology Project - Towards an Interactive Multi-scalar 3D Visualisation in Computer Game Engines
}

\author{
Arian Goren \\ Freie Universität Berlin, Germany \\ Kay Kohlmeyer, Thomas Bremer, Arie Kai-Browne \\ HTW University of Applied Sciences Berlin, Germany \\ Wiebke Bebermeier \\ Freie Universität Berlin, Germany \\ Dennis Öztürk, Stefan Öztürk and Tobias Müller \\ HTW University of Applied Sciences Berlin, Germany
}

\begin{abstract}
:
The Virtual Archaeology (VA) project seeks to accomplish an innovative virtual environment for researchers to test out (geo) archaeological hypotheses in a true interactive manner. Research of various academic interests, such as line of sight, network analysis, resources availability or site catchment might benefit from using gaming technology and the near-real world modelled environment which computer game engines are able to support. Linking virtual scenes to an underlying database will facilitate direct access to and visualisation of the data in realtime. First results from the project's test case on the temple of the Storm God in Aleppo have successfully maintained accurate, high-quality object geometry stored in universal file formats while substantially reducing file size to support quick rendering. These preliminary tests confirm that a true-to-detail multi-scalar 3D visualisation of the temple compound, interior reliefs and related research area is an achievable goal. Furthermore, storing data in universal formats and applying to engines for public use ensures the transparency of data and work procedures and the applicability to other research projects.
\end{abstract}

\section{Keywords:}

Virtual Archaeology, Game Engines, 3D Visualisation, Interactive Environments, Image Based Modelling

\section{Introduction to the Virtual Archaeology Project}

The archaeological tool-kit expanded dramatically in recent years with diverse research opportunities made available through new technologies. Researchers are encouraged to experiment with new forms of analysis and modelling of archaeological records, be it single artefacts, structures or sites. Shifting to digital recording methods, the amount and type of recorded data expands continuously (Forte in press;

Corresponding author: ariangor@zedat.fu-berlin.de
McPherron et al. 2009). Furthermore, increased precision of recorded data coupled with the variety of data storage types available (open-source and/ or proprietary) complicates integration of legacy data as well as newly acquired data with various formats into unified, comprehensive work environments (Bordes et al. 2006). 3D data recording and (semi)interactive data-repositories are already established practices in present day archaeology in both public institutions as well as the private sector, mainly related to cultural heritage work, conservation and restoration, archiving, or as educational tools for academia and the public (Beacham et al. 2006; 
Richards-Rissetto et al. 2013). Representative projects include ArchAtlas (2013), the Digital Archaeological Atlas of the Holy Land (2013), Amarna Virtual Museum (CAST UARK 2013), The Virtual Museum of Iraq (CNR-IT 2013), Digital Karnak (UCLA 2013), and Remixing Çatalhöyük (Çatalhöyük Research Project 2013).

Computer game engines and gaming technology are only beginning to attest their potential as powerful tools suited for academic research involving 3D modelling and visualisation of archaeological questions. The Berlin based Virtual Archaeology (VA) Project is currently one of the very few academic endeavours aiming to incorporate virtual environments generated by game engines in the interpretative archaeological tool-box. Coeval projects operating in this field include MayaArch3D (Agugiaro et al. 2011; University of New-Mexico 2012), Visualizing Angkor (Chandler 2013; Monash University 2013), Angkor Project Group (IWR University of Heidelberg 2013; Schäfer et al. 2013), project DAVID and Asehs2Art Program (Coastal Carolina University 2013; Garofalo 2013; Rudolph 2013), and the Modelling of the Mayan Mascarón from Chilonché (Merlo et al. 2012; 2013), the latter follows similar modelling methods discussed in this paper and has also reached, though only in certain aspects, similar results. The VA project focus is at providing scholars with an innovative platform for reconstruction and model-testing (Beacham et al. 2006). Primary goals are the compilation of workflows for handling data-sets from various sources and differing scales for realisation of trueto-detail 3D visualisations in a fully interactive virtual environment generated by game engines and linked to an underlying database. As work on the project still continues, first results outline prospects of integrating gaming technology in future evolution of archaeologically oriented 3D visualisation and modelling techniques.

\section{Project Goals}

When considering 3D visualisations as human-landscape interaction investigative tools a fundamental perspective arises, namely the benefits gained (or not) from incorporating new technologies into traditional work procedures (Bordes et al. 2006; Forte 2010). Should the archaeological toolbox be constantly expanded with new technologies and techniques simply because they are available? And if we choose to do so, how can new tools add to the existing methods rather than override them? The abundant use of 3D laser scanners in vast archaeological contexts provides a good example for the methodological concerns entailed with adaptation and application of technological novelties. 3D laser scanners can document various archaeological tangibles with extremely high resolution, easily generating enormous amounts of digital data. However, in many cases the data ends up as static digital representation of artefact(s) or reconstructed architecture relevant to a specific point in time (Allen at al. 2004; Moser et al. 2010). Furthermore, the spatial context tends to be underrepresented, leading to visual representations that might appear somewhat detached from their physical surroundings, popping up on blank backgrounds or modelled on a mocked-up landscape for illustrative purposes. This stresses out the importance of combining both functionality and accuracy in the visualisation rather than having to choose one over the other. Contemplating on these aspects, the VA project team believes that virtual environments can provide a suitable tool for attaining accurate scales and relations of modelled objects alongside high degree of functionality manifested through multiscalar scene display.

Game engine driven realistic representations based on archaeological and geographical data-sets is an exciting measure to generate an experimental platform for testing (geo)archaeological hypotheses, especially (but not only) those of spatio-temporal relevance. The prospects of reaching a virtual environment for analytical application in a true interactive manner is the core of the VA project. Inherent to this goal is the assumption that interactivity is a means able to facilitate comparative evaluation of temporal phases and spatial features comprising the visualised scene. The functionality of an interactive platform is closely related to the development of a database-linked modelling process involving dynamic data input within a real-time game engine. When achieved, the objective of establishing such a link will support the stepping-up of modelled 3D scenes from animated representations to scientifically applicable analytical tools. 


\section{Methodological Considerations}

Feasible applications of an interactive, analysis-viable platform range from straightforward ones such as cultural heritage management, conservation and restoration operations, and educational activities to more encompassing tasks such as view-shed analysis, network analysis, human-landscape dynamics and other areas of synchronic or diachronic interest. In accordance to the interdisciplinary nature of the project, the latter types of analysis emphasise the relevance in trying to incorporate broader environmental parameters into the modelling process rather than solely focusing on recording and archiving objects and/ or features confined to a site or a phase within a site (Forte in press). That is, the attempt made is to draw place for a platform which is flexible enough to offer next to traditional archaeological reconstruction also the possibility to test and simulate geospatial interactions, including those involving humanlandscape interaction.

For the creation of the preliminary geospatial layer information was derived from 3D laser scanners and GIS processed data-sets. Matching appropriate processing steps to certain data sources was dictated by the original type, content, capacity and function of the data-set. Consequentially, these format-oriented processing procedures produced characteristically different files (Bordes et al. 2006). Once stored in common formats, adaptation of the pre-processed data to designated 3D modelling software enriched the initial data with additional attributes. Considering the diverse nature of the data-sets involved, issues regarding the acquisition, storage, management and compatibility of information are imperative to the successful creation of a singleinclusive source. Complementing disparate information sources, for example paper maps and 3D point clouds, demanded agreement upon a common data exchange scheme. The efficient processing and rendering of high volumes of digitised information plays a key role in reaching simultaneous real-time visualisation of both single artefacts as well as entirelandscapes. Identifyingand resolving methodological and technical conflicts is a central objective linking the different components of the project. Data cross-compatibility is intensely addressed in this phase of the project, with emphasis on data exchange and digital processing power. The evaluation of relevant data exchange formats was commissioned while taking preliminary steps, such as data selection, data classification and converting between the different processing steps (Bordes et al. 2006; Merlo et al. 2012). Documentation of standardised processing procedures and software evaluation serve as stepping stones in developing reproducible working procedures for academic cooperations with similar interests (Beacham et al. 2006). Consequentially, potential pipelines, or guidelines, were developed. Those describe comprehensive modules for hosting information available in various formats (text coded, vector, raster, point-clouds), multiple scales (mm to $\mathrm{km}$ ) and different resolutions in a single source.

The proceeding step in later phases of the project will be to channel the processed files into a database. This should administrate type and quality of connectedness of attributes. The database in mind outlines physical entities comprising a virtual environment. Modelling entities for analytical purposes prompts adjustment of scales to meet specifications dictated by the architecture of the game engine, for example defining coordinates with double precision instead of float precision (Unigine Corporation 2013). Referring to the VA project methodological approach, maintaining the accuracy of the spatial resolution and the precision of geometric relations is regarded as key for complying with scientific standards. Furthermore, maintaining the accuracy of raw data-sets and addressing compatibility of data formats are vital to conform with principles of reproducibility (Merlo et al. 2012, 2013). Data should be accessible for renewed use and re-evaluation, similar to the field practice of leaving parts in archaeological sites unexposed for future researchers to return to.

The functionality of the platform is another central objectiveof theproject. Itshould besupported by linking a 3D scene to a database and enhanced through assigned interface(s). The executability and applicability of a comprehensive database is largely influenced by the correct definition of interfaces, those inherent to the schemed work-flows and those which are relevant to the end-user. Data querying capabilities are already being implemented in game design. However, they are currently very time consuming and involve direct engagement with asset editing in the game editor, hence requiring at least 


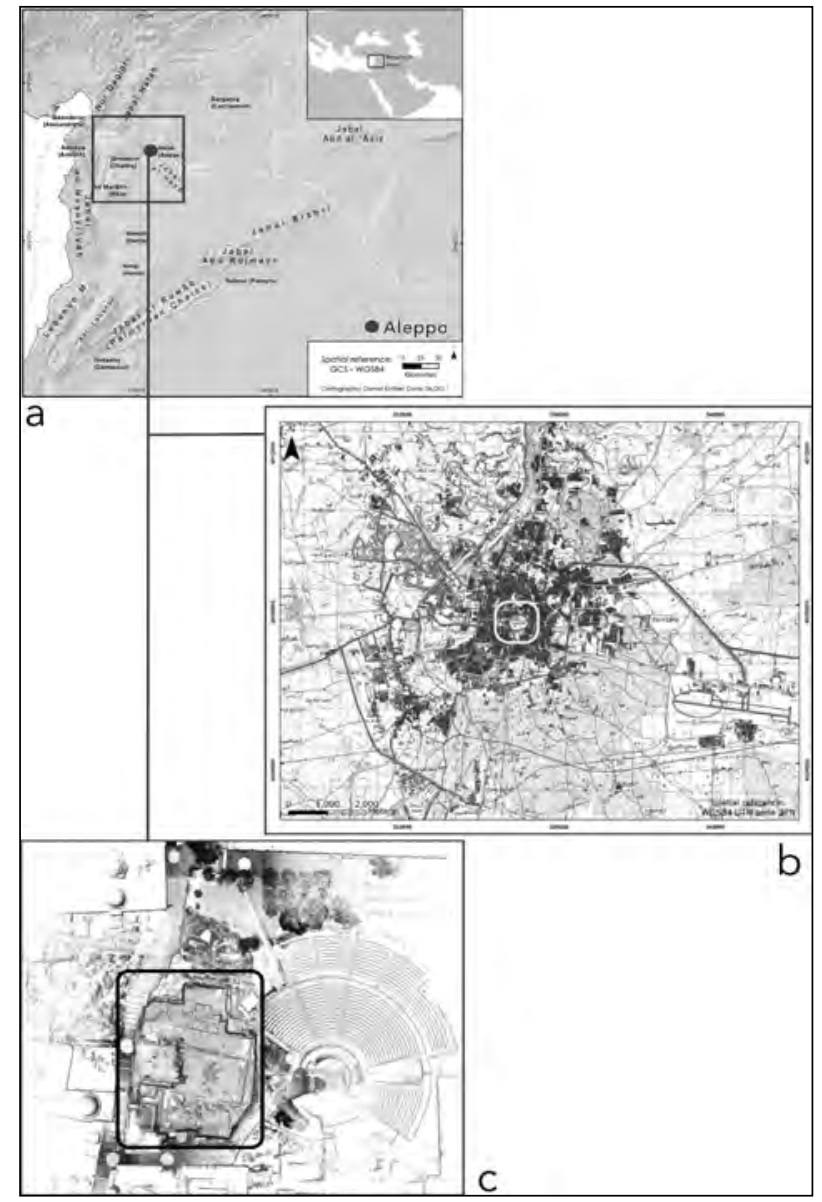

Figure 1. (a) Overview map, the research area marked red (courtesy of D. Knitter); (b) the city of Aleppo (detail) with the ancient Aleppo mound marked yellow; (c) the temple of the Storm god on top of the mound marked black. Colour version is available on-line.

some basic programming skills and acquaintance with specific object modelling formats (Gregory 2009, 49-55). Customising a targeted interface can provide non programming-savvy end-users not only with advanced data querying options but also with a powerful tool to perform simultaneous content editing and visual simulation.

\section{The Case of the Temple of the Storm God in Aleppo}

Thecasestudy chosen for testing theVA project viability is the temple of the Storm God on top of the ancient Aleppo mound and its surroundings (Fig. 1). The cultic function of the temple compound as the sitting place of the Storm God is attested to in cuneiform texts from the ruling house of Ebla, the influential power in the region in the later part of the Early Bronze Age (mid 3rd millennium BCE) (Kohlmeyer 2009, 2012). The temple has gained increasing importance in the religious pantheon of the Near Eastern world from the Middle Bronze Age onwards, maintaining this status until the Early Iron Age when the temple was destroyed for the last time in a devastating fire razing it almost to the ground and ultimately leaving it abandoned until well into the Hellenistic period.

The most prominent time in the existence of the temple was during the Hittite rule in the Late Bronze Age. Two major renovation phases took place in the 14th and 11th centuries BCE in which the temple reliefs and statues were changed or re-hewn in Hittite artistic style with hints of Mesopotamian influence and their position in the cella was altered (Kohlmeyer 2009, 2012, 2013). These decorative expressions indicate a much more fundamental alteration made to the temple's inner layout and spatial properties. In the Late Bronze Age renovation phase, the preceding Middle Bronze Age direct alignment of the cultic centre at the northern wall in front of the entrance was shifted to a typical Hittite right-angled bent-axis scheme, with the divine image located on the eastern facet hidden from direct view from the entrance. During the Early Iron Age and shortly before the temple was burnt down the direct-axis scheme was restored. Furthermore, a shift of $1.5^{\circ}$ in the alignment of the cultic axis was realised between that of the Early Bronze Age temple and that of the Middle Bronze Age temple. This shift might be correlated to changes in specific astronomical constellations (Kohlmeyer 2009; 2012; 2013) (Fig. 2).

The question of intentionality of these alterations is important to the research of the temple in both local and regional context. The temple was excavated by a joint Syro-German expedition operating at the site between 1996-2010, dedicating the last season to digitally document the temple compound and reliefs with 3D laser scanners. The evidence gathered during these extensive works raised interesting insights. The extraordinary importance of Aleppo's temple in supra-regional context, attested to by written sources and inferred from the unique relief decorations and the size of the temple, stands out respective to its location. The city is situated in present day northern Syria, 


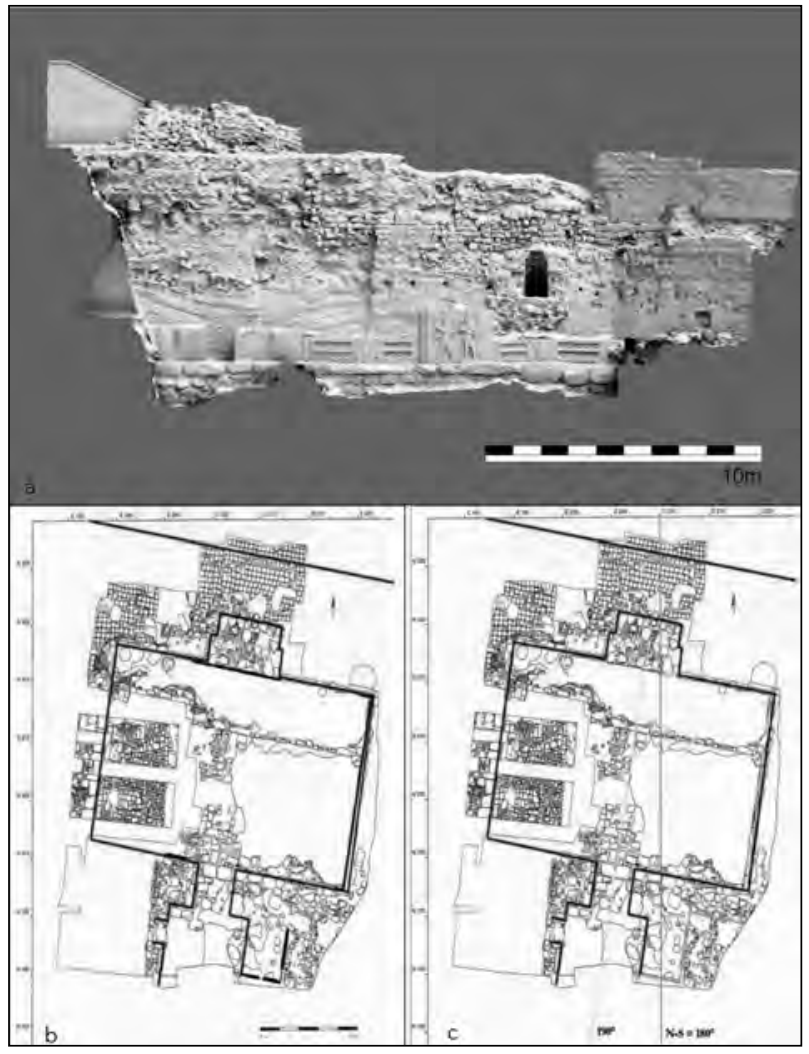

Figure 2. (a): High-polygon mesh of the eastern facet of the temple's cella after the 11th century BCE renovation phase. The image of the Storm God is placed centrally. To its right, the self-portrait of king Taita of Palistin with clear religious implications. (b) Schematic view of the temple's floor plan and cultic axis during the mid $3 \mathrm{rd}$ Millennium BCE and (c) the early 2nd millennium BCE.

an area of dry semi-arid BSk climate with an annual average precipitation of $330 \mathrm{~mm}$ and an annual average temperature of $17.3^{\circ} \mathrm{C}$ (Kottek et al. 2006; WMO 2013). Despite proximity to the Quwēq river running to the west of the city, the part of the Aleppo Plateau in which the city is located is a transitional region relatively close to the desert margin. Prior oscillations of the $200 \mathrm{~mm}$ rainfall isohypse northwards closer to or even past Aleppo cannot be ruled out, hence increasing the vulnerability of the city and its surroundings to available natural resources. Furthermore, at certain points in its history Aleppo was overshadowed by settlement clusters centred around neighbouring powerful political entities, such as Ebla to the South-West during the 3rd millennium BCE and Tell Refad to the North during the early 1st millennium BCE (Fig. 3) (Del Fabbro 2012; Kohlmeyer 2012).

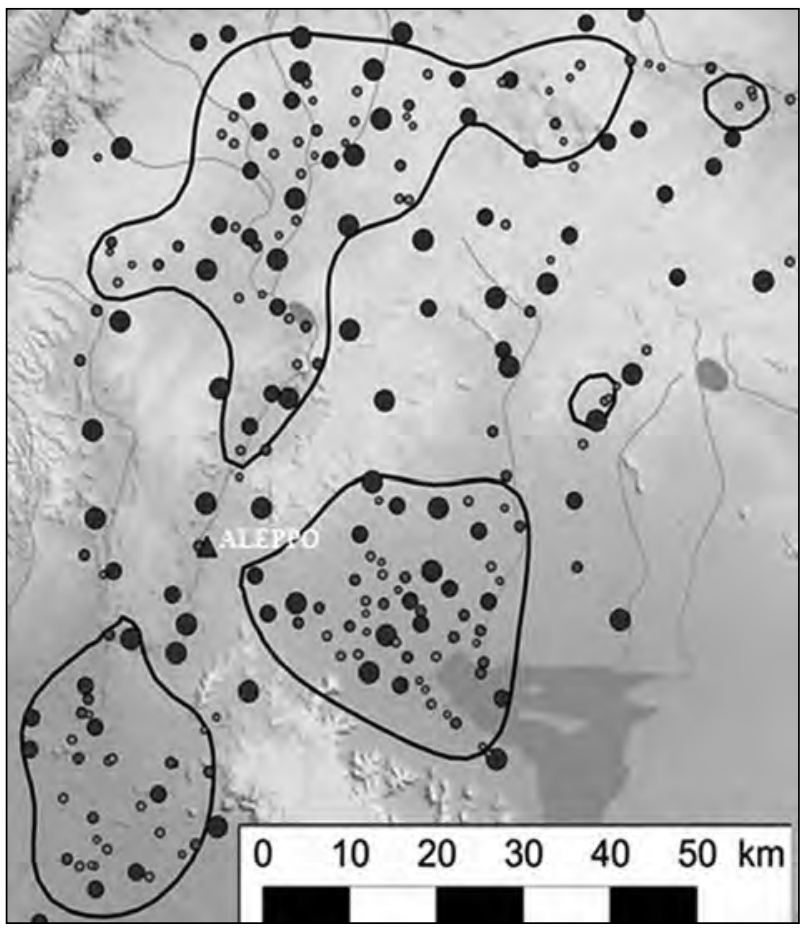

Figure 3. Description of the centrality of Aleppo using a betweenness index with four classes. Notice the outlined settlement clusters around Aleppo. Source: O. Nakoinz (in press). Colour version is available online.

Although important trade and transportation routes cross through Aleppo's jurisdiction the city still lacks sufficient environmental factors to convincingly support its geographical location as favourable for the regional meaningful entity it has developed to be. The influence of the $4.2 \mathrm{ka}$ BP Abrupt Climate Change (ACC) event and the subsequent increase in aridification, temperature rise and regional climatic degradation (Fiorentino et al. 2008; Kaniewski et al. 2010; Roberts et al. 2011; Weiss 2013) is a possible contributing factor among others to this inconsistency. Based on the archaeological knowledge acquired thus far, the opportunity to investigate different scenarios through virtual means holds promising potential to the understanding of Aleppo's place in a time of turmoil in the Levant in the Late Bronze AgeIron Age transitional period. Examining the extent to which changes in the temple's layout might correlate to shifts in astronomical constellations bear particular meaning in this respect, as well as possible concomitant changes in regional viewsheds from and to the temple. 


\section{Methods and Pipelines}

The data-sets used in theinitiation phase of the project were derived mostly from 3D laser scanners and GIS processed sources. The laser scans provide the basis for a high resolution documentation of the reliefs and architectural components of the temple in 3D point clouds and surface meshes. The geographical data-sets, processed in differing scales from various resources including digitised maps, earth observation systems, and CAD drawings, provide the basis for a detailed virtual landscape representation of the ancient Aleppo mound and its surroundings.

\subsection{Laser scanning}

Prior to the scanning field campaign in 2010 equipment performance was tested for different lighting conditions, object size, type of surface, image resolution, and file storage. The results of the technical evaluation were used to asses expected work load and overcoming possible technical difficulties. A protocol describing work procedures was summarised and later implemented on ground following three central chapters. The first chapter describes preparation steps. The temple compound was divided into sections in order to maintain reasonable scene size. The elements comprising the temple compound were classified as either structural component or relief and numbered with unique IDs (Fig. 4). Scan positions and scan sections were marked on a site map in order to gain flexibility both during field work as well as for digital post-processing. The second chapter in the protocol was applied during the actual scanning phase. Equipment and software were set up, reference points and scanned objects were marked and a field book was registered to insure anchor points for follow-up on work procedures. Resolution and settings of the individually scanned elements were regulated in order to achieve a uniform point spacing covering the entire site with high detail precision (Kai-Browne 2013). Consequentially, scan results were evaluated on-the-fly and re-scanning or correcting scan/ ambiance settings was commenced if needed.

The scanned elements were recorded from various positions in overlapping views as surfaces with complex geometry stored in 3D point clouds.

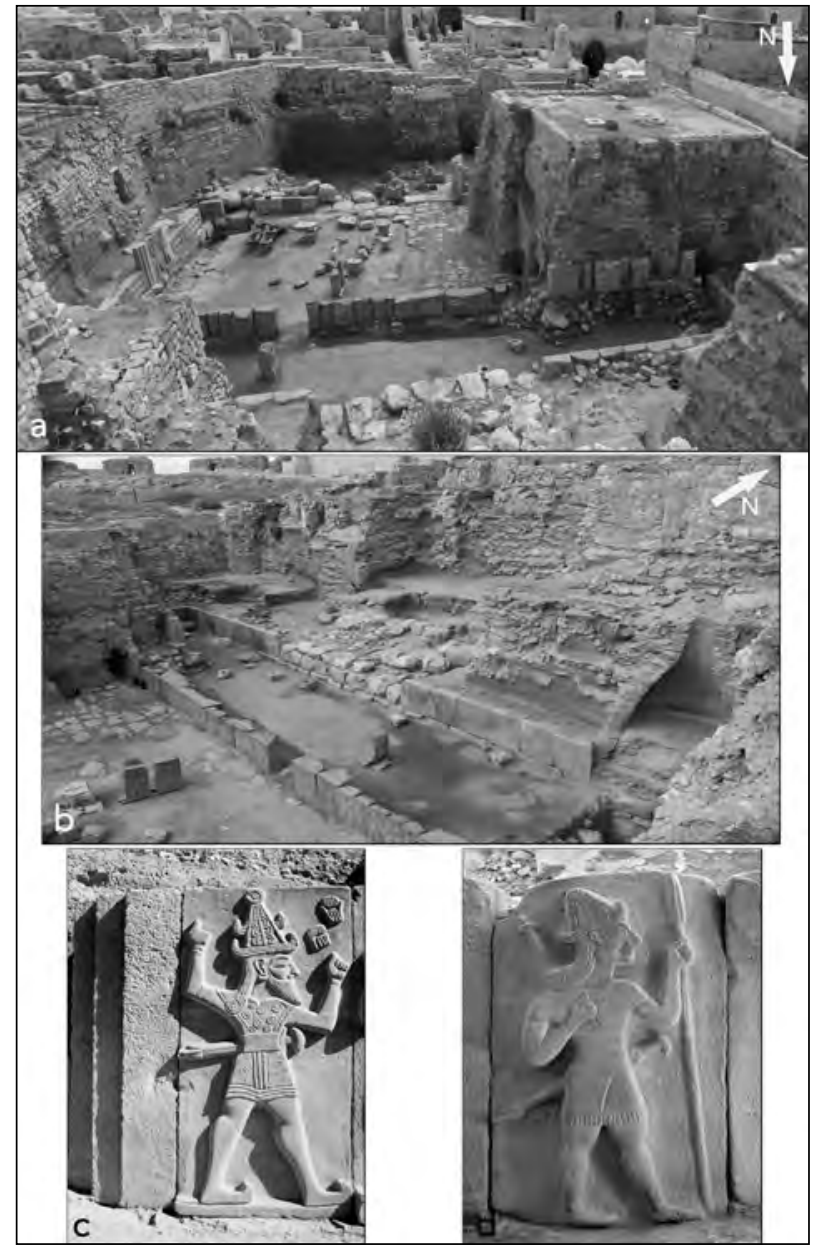

Figure 4. Overview of the Temple of the Storm God and the elements comprising it. ( $a$ and $b$ ): structural components; (c and d): exemplary relief type.

Structural components - walls, floors, wall bricks etc. - were captured using a Leica ScanStation2 panoramic device (operated with Cyclone 7.1 software) which is capable of scanning with 4-6 mm accuracy and less than $1 \mathrm{~mm}$ point spacing (Leica Geosystems 2013). Thus images were captured with accuracy sufficient to depict the architectural elements and their relations in detail (Kai-Browne 2013). The average point spacing used was $1 \mathrm{~cm} \mathrm{x}$ $1 \mathrm{~cm}$, adjusted to fit the distance between the scanner and the scanned element (effective spacing is slightly denser due to frequent scans-overlap). The reliefs required a much more sensitive device which is able to capture very fine details such as chisel marks, hieroglyphic carvings on the stone surface and relief curves. For this task the close range scanner Konica Minolta VI-9i was utilised, mounted with a normal 


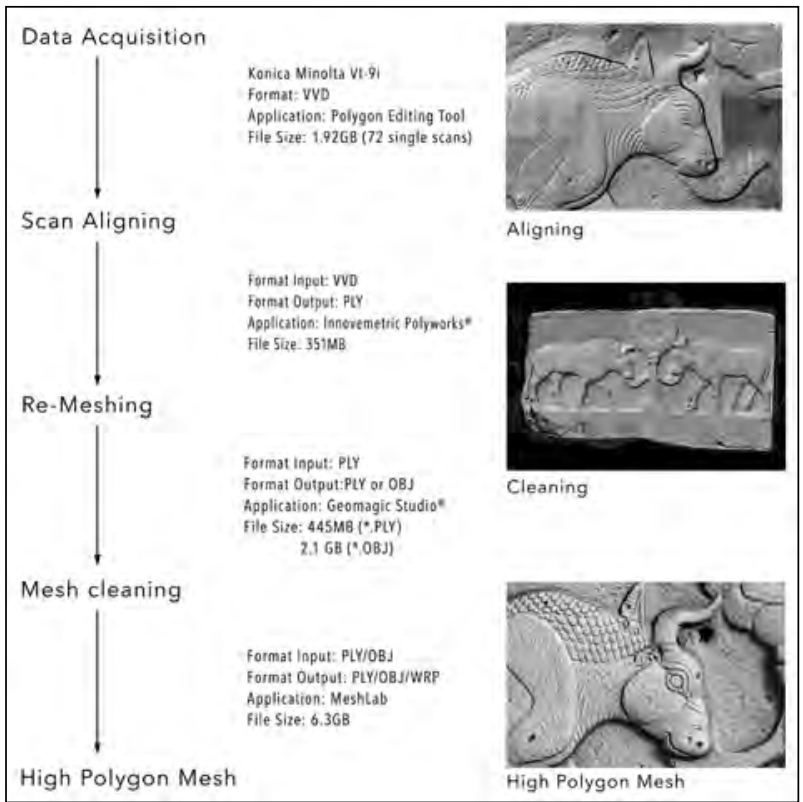

Figure 5. Exemplary pipeline for the 3D laser scans: capturing and pre-processing an oxen relief block (192 $\times 98 \mathrm{~cm}$ life size).

lens supporting an average acquisition distance of 0.8-1.2 $\mathrm{m}$ and providing an average lateral point spacing of 0.7-1.5 mm (Kai-Browne 2013; Konica Minolta Sensing Inc. 2006). For the relief block seen in figure 9, 72 single scans were taken, resulting in a total file size of 1.92 GB. Both scanners were equipped with internal digital cameras for capturing additional surface texture data. However, due to their relatively low-resolution additional images were taken with Nikon D80 and D40x external cameras. All scanning took place under regulated settings and were carefully documented in order to maintain consistency of records.

Thethird protocol chapterwas applied partially already during the field campaign and continued in lab (Fig. 5). It addresses initial scan handling and includes aligning scan elements in InnovMetric PolyWorks ${ }^{\circledR}$ and basic clean-up of the close range raw data in Geomagic Studio 12. Registering point cloud data from the Leica ScanStation2 within local excavation coordinate system was performed with the Leica Cyclone 7.1 software. The scans were subsequently exported as basic point clouds for meshing using the Poisson Surface Reconstruction algorithm. The raw format of all scans was saved as well to insure overall sustainability. As preparation for the 3D modelling, the scanned temple elements were adjusted and merged in Geomagic Studio 12, then meshed in MeshLab (version 1.31, Cignoni et al. 2008; Visual Computing Lab of CNR ISTI 2013) and exported to universal $3 \mathrm{D}$ modelling file formats (e.g. *.ply, *.obj). At the end of this process the highpolygon mesh of the temple compound contained 171,545,000 Polygons stored in a 6.3 GB large*.wrp file format.

\subsection{Geographical data-sets}

The geographical component involves producing Digital Terrain Models (DTM) from GIS processed data-sets, providing a reference terrain for the modelling of the site and the landscape in 3D. A research area encompassing $4800 \mathrm{~km}^{2}$ was outlined, representing the macro spatial scale. Incorporated are the city area of medieval Aleppo and the ancient mound, representing the mid scale and micro scale, respectively (Fig. 1).

Relevant geographical information was derived from topographic maps, earth observation systems, and CAD drawings. The data was processed with ArcGIS 9.3 and 10, Erdas Imagine 9.3 and QGIS versions 1.5 and 1.6 (OSGeo 2014). Evaluation of potential data sources took into consideration cartographic quality, resolution, and potential for meaningful extractable information (especially that of geomorphological nature). According to their original attributes and specifications, the selected data-sets underwent standard preparation and digital processing steps (Fig. 6). Key steps involved contour digitising, AOI selection, geocoding and rectifying, spatial adjustment, and attribute classification. Vector type data were discarded since they are incompatible with game engine systems respective generation of terrain. The processed files were interpolated in GIS environment using grid interpolation based on the ANUDEM algorithm (Hutchinson 1989; Nelson et al. 2009; Reuter et al. 2009), resulting in three DTMs depicting the three spatial scales of the research area in up to $10 \mathrm{MB}$ large GeoTIFF files holding resolutions ranging from $1 \mathrm{~m}$ to $50 \mathrm{~m} /$ pixel (Fig. 7).

The UTM WGS84 coordinate system was selected as the global reference system for all spatial records involved. Sources not originally assigned to this system were re-projected. The UTM coordinate system is based on metric units (Snyder 1987, 57-60) 


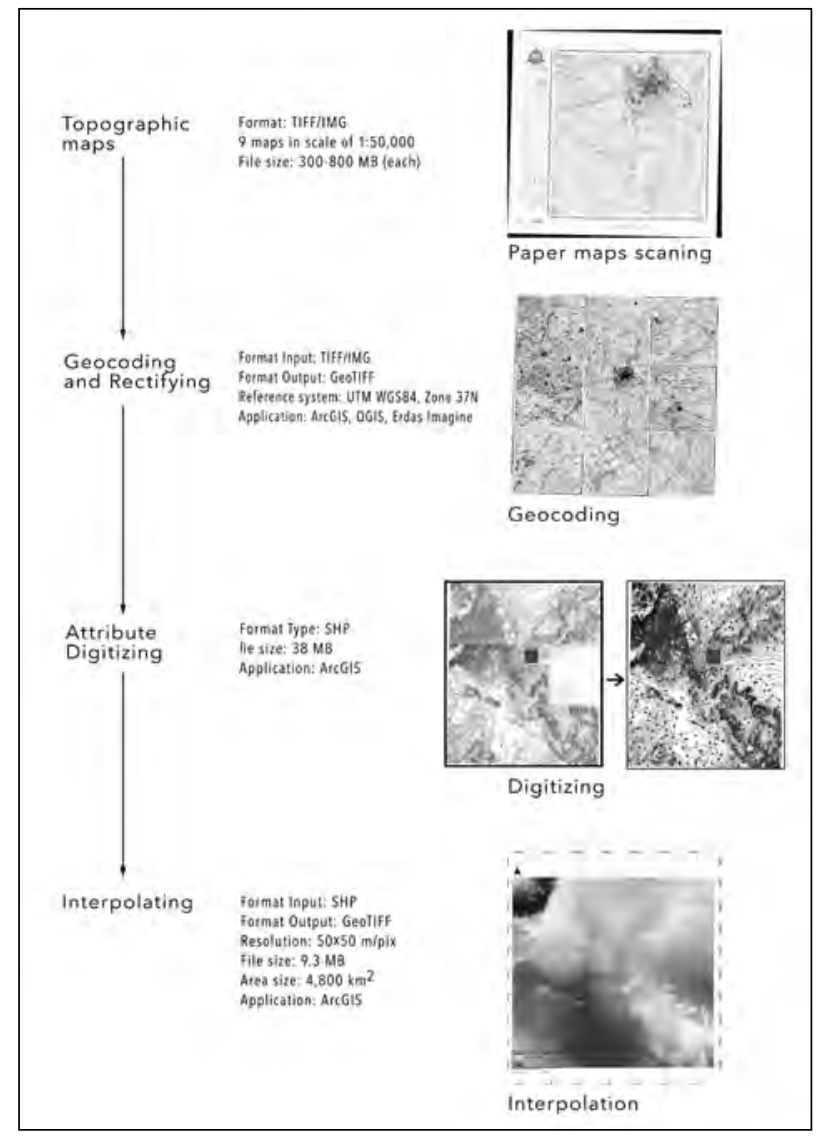

Figure 6. Exemplary pipeline for the geographic datasets: processing topographic maps (1:50,000).

which are easy to implement in game engines. This reduces the complexity of scaling the 3D models to terrain-levels and accurate spatial relations between objects can be better maintained. Furthermore, referring to real-world units can increase the engagement of end-users with the virtual scene and its accessibility. The walking distance from the temple mound to the Quwēq riverbank or how large the relief of the Storm God really is can be more intuitively perceived when scales and measures are metric rather than decimal degrees (McNamara 2001).

\subsection{D modelling and gaming technology}

Modelling and implementing the different components comprising the virtual scene is the most intricate part in the VA project. Efforts are focused on defining procedures to generate high resolution representation of an area thousands of kilometres large on the one hand and the fine

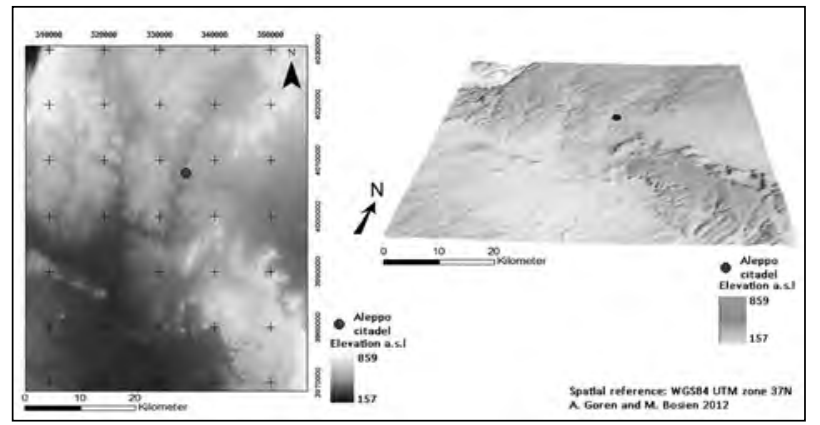

Figure 7. Digital Elevation Model of the research area in $2.5 \mathrm{D}$ (right). Colour version is available online.

carvings, decorations and hieroglyphic inscriptions of the reliefs on the other. In this respect, retention of details and the true positioning of elements in the virtual scene are essential. The initial phase of the project concentrated on realising solutions for combining products differing in their structure and file formats. Integration tests were performed using multiresolution and multiscale processed inputs. The key challenge is to create a merged multiscalar scene which can simultaneously and accurately visualise landscape and objects while maintaining high resolution in all viewing levels. Preferably, translating real-world coordinates and units into local engine units should undergo as little scaling as possible regardless of engine allocated Level of Details (LoD).

Based on the tests performed, two game design modelling pipelines were compiled thus far. The first pipeline regards modelling the temple compound and reliefs in 3D (Fig. 8). About 50 reliefs and statues comprise the temple interior, decorated with fine carvings of fine artistic detail with inscriptions in hieroglyphic Luwian on some of them. First, the laser scanner processed high-polygon relief blocks were manipulated into static low-polygon meshes using the Topogun software (version 2.00W64) to preserve as much geometric information as possible while reducing files to the smallest possible size (Alliez et al. 2008; Merlo et al. 2012; 2013). Using manual retopology techniques proved to be time consuming and provided variable results. Switching to decimation algorithms decreased the degree of variability and increased the reproducibility of the meshes since the process was influenced from the parameters applied rather than operator skills. Evaluation of different algorithms showed that the Quadric Edge Collapse Decimation algorithm in 


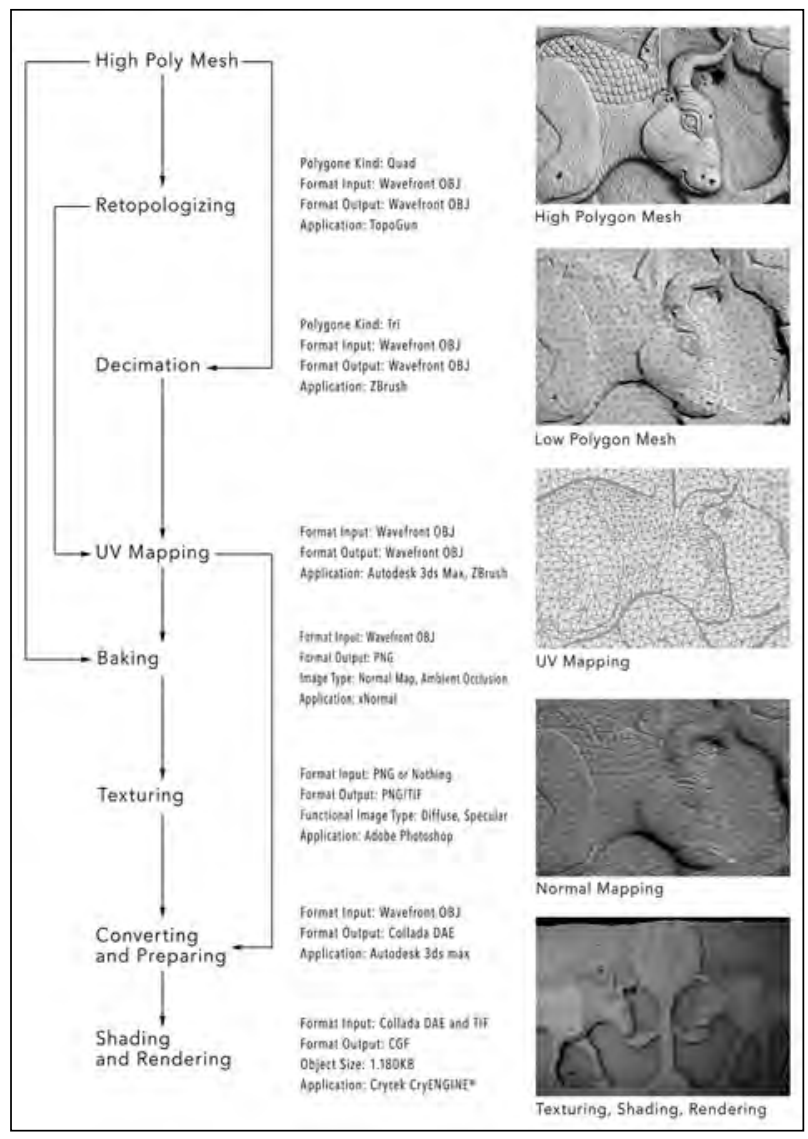

Figure 8. Exemplary pipeline for the game-design: modelling an oxen relief block.

Zbrush software (version $4 \mathrm{R} 4$ ) was sufficient to retain the basic shape of an object and was more time efficient compared to manual retopologisation (Alliez et al. 2008).

Fine surface details, such as carving marks or inscriptions, are lost during the decimation stage. Those were regained by applying UV and normal maps which enable mapping textures from a separate image file onto the decimated model. UV mapping describes the manner in which 3D objects are "unfolded" onto a 2D plane, thus allowing to track each point $(\mathrm{x}, \mathrm{y})$ from the two dimensional plane and represent it on the 3D object (Alliez et al. 2008; Glasbey and Mardia 1998; Heckbert 1986). A normal map contains the surface normals, which are found in the tangent space and are in accordance to the data stored in the UV map layout. The RGB values stored in the bitmap pixels correspond to the tangent normal of the surface. A surface normal is interpolated from adjacent normals, and thus virtual lighting effects are computed and surface irregularities are simulated (Blinn 1978; Mikkelsen 2008). These steps were performed with ZBrush, Autodesk 3ds Max (version 2011 and later), xNormal (version 3.17.13 and later, Santiago Orgaz \& Co. 2014) and Adobe Photoshop software. Shading and rendering was done in Crytek's CryENGINE ${ }^{\circledR} 3$ (with sandbox 3.4 and later). The final result retains high degree of fine surface detail while sufficiently minimising polygon count for a smooth interactive display (Cohen et al. 1998) (Fig. 9). The methods used here are widespread in gaming technology, however in their common use they are usually applied as a means to gain enhanced realism. In the general realm of game development it is not necessarily required to maintain high precision when modelling real objects as long as the final result is appealing. This might be sufficient and even desirable for showing 3D models in contexts related to popular culture and entertainment (Flaten 2011), however when scientific data is to be accurately represented good looks are not enough.

Different approaches were tested for modelling the DTMs. In this case, two fundamental aspects stemming directly from the current stand of gaming technology encouraged creative thinking on how to implement the landscape in the engines. Current game engines available for public use cannot properly process height-maps for a terrain as large as the project's study area. Another challenge addressed problematicformatcompatibilitybetween GIS software and gaming platforms, a friction point less evident when laser scanned material is involved (Gregory 2009, 49-55). Therefore, instead of trying to "stretch" these platforms beyond their intended capacity the team turned first to manipulate the engine-fed data itself before digging deeper into the architecture of the gaming platform.

The first pipeline, originally designed on the Unreal Engine 3 and later adjusted for the CryENGINE ® 3, attempted to decimate theareainto overlapping tiles subsequently merging them back together using Adobe Photoshop and ImageMagick (versions 6.6 and 6.7; ImageMagick Studio LLC 2013) to restore the initial scene. The geo-coded information in the DTM files is unreadable by game engines and the elevation heights were translated to grey values in Adobe Photoshop. The values were stretched to match the re-assembled scene 


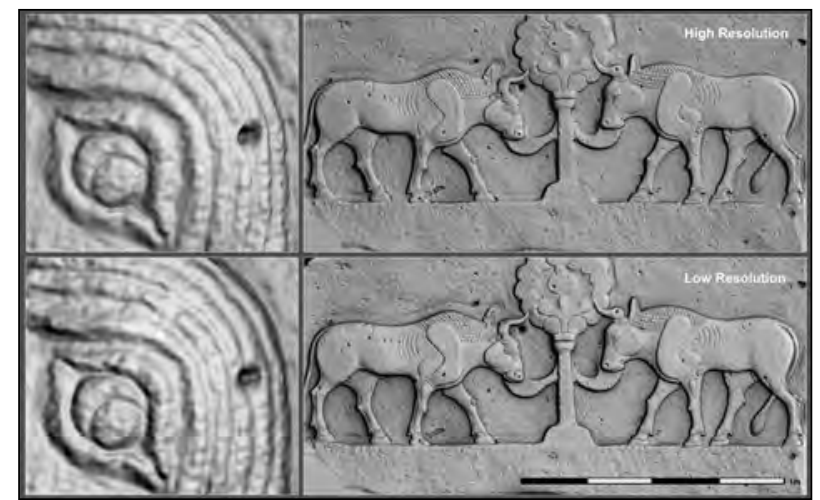

Figure 9. High-polygon and low-polygon meshes of an oxen relief compared. Top: pre-modelled high polygon mesh: 18,000,000 triangles, no textures, file size 1.55 GB. Bottom: processed low polygon 3D model: 40,000 triangles, two normal maps and two occlusion maps $(2048 \times 2048$ pixels each), final file size (in TIF format) 54.1 MB including texture maps.

and exported as *.bmp files through the g16convert tool in the Unreal Development Kit (UDK, version 2010 and later). Meeting engine terrain-level size specifications required adjusting and scaling-down the scene using conversion factors in the UDK. Object positioning was translated from the DTM GeoTIFF into adaptable engine units in a trial-anderror process to gain an appealing appearance while maintaining appropriate spatial resolution.

Despitesuccessful generation of representative test areas within the project's mid-spatial scale, severe display errors remained unsolved. Furthermore, the likelihood of accommodating propagating errors prompted by the multiple transformation and conversion steps involved led to evaluation of less complicated pipelines. Renewed evaluation of the landscape modelling is still taking place. It will incorporate steps similar to those outlined for the laser scanned material and will seek to produce curvature-based reduced mesh of the landscape. In parenthetical remark, many challenges still remain respective realistic data rendering. At the moment, overcoming Z-Buffering display artefacts is problematic in complex scenes due to high demand on processing power. Current solutions available for efficient display of object dynamics are still either partial and spatially limited or not offered for public use (as is the case, for example, with CryENGINE $\left.{ }^{\circledR}\right)$. Nonetheless, rapid developments in rendering algorithms are anticipated in the foreseeable future (already practised, for example, by Outerra (2013)). Methods for volumetric pixel rendering used by voxel engines (Kaufman et al. 1993) will be of high relevance in future modelling tools and large interactive environments (like the Geoverse software packages already in use by Euclideon Limited (2013)). Voxel engines are capable of minimising and even negating time-consuming steps such as retopologisation and meshing. However, demand on high computational power will probably remain a major obstacle in utilising these type of engines in the near future.

\section{First Results and Future Outlook}

Acentral aspectin theproject'svisionis tobring forth what M. Forte $(2010,9)$ refers to as 'Multiplicity of Affordance': “...the virtual link between object and environment: the code for re-interpreting the past in space and time". Accommodating "the archaeology of the third millennium" (Forte 2010) encompasses a constant negotiation between desired results, type and quality of principle data-sets, availability of computing power, format compatibility and information sustainability (Bordes et al. 2006). In the first phase of the VA project successful results were achieved in modelling the temple complex and reliefs and creating a detailed virtual scene of the temple and selected portions of landscape (however still as non-textured terrain). Applying rigorous decimation contributed tremendously in realising the better part of the project's modelling objectives thus far. Retaining accurate geometry, high quality textures and fine details in the close and mid-ranges was successful even when the number of polygons was dramatically reduced. For example, the processing of the relief block seen in figure 9 started with a 1.55 GB large file ( ${ }^{*}$.obj) of high-polygon mesh containing 18,000,000 polygons. After decimation and including texture maps, the low polygon relief has 40,000 polygons and measures only 54.1MB, a decrease of more than $95 \%$ in file size. The same applies for the temple compound, reduced from a $170,000,000$ polygons, $16 \mathrm{~GB}$ large file to a $520 \mathrm{MB}$ large file containing 80,000 polygons (Fig. 10). Modelling the entire research area remains an ongoingtask, butsimilarresultsshouldbeachievable. Testing possible work flows and evaluating work procedures led to compilation of comprehensive pipelines summarising the knowledge accumulated in the project thus far. This provides a basis for 


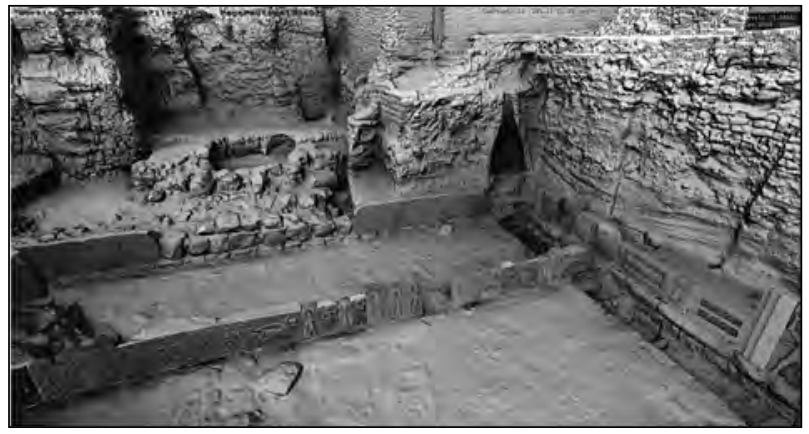

Figure 10. The temple compound and reliefs of the northern pedestal wall in the game engine (detail). High quality of details is still maintained despite reducing file sizes within the Gigabyte range. Colour version is available online.

future improvements in developing guidelines for fellow researchers engaged in the field of interactive visualisations (Beacham et al. 2006).

Though an open-source real-time gaming environment would be highly desirable, developing such a platform is not one of the project's goals. Nonetheless, even at the current state of technological development, the foreseen usability of the final product is not jeopardised since all the processed data is stored in universal formats such as ASCII, *.obj, *.ply or *.TIFF. In this respect, transparency of the scientific data is already practised by participating in the pilot phase of the German federal-funded project IANUS (2013) to ensure free access to the raw $3 \mathrm{D}$ data files used. Furthermore, as all the procedures described are based on software available for public use, the platform can run on any PC with an operating system that fulfils the hardware requirements of the software and game engines mentioned herein as described by their respective provider. One should bear in mind though that performance and quality of display can vary depending on hardware components, such as processor, RAM capacity and especially the graphic card.

Future work will concentrate on ways to support analytical capabilities. Facilitating a dynamic-link to an underlying database which holds the raw data is the first step to be taken. The data should be retained in open file formats, thus overcoming engine-specific concerns regarding restriction on proprietary file formats. The outcome wished for is establishing a database linked to interactive modelling processes. This goal concerns handling the definition of the interfaces within the pipeline and the different spatial scales involved. Preliminary evaluations currently carried out by the VA project team explore ways to facilitate querying functionality via a customised Graphical User Interface (GUI) accessible directly through the engine platform. Further steps will focus on exploring different means to facilitate dynamic data input within a real-time environment. This goal is intended to be exemplified by accessing information stored in star-catalogues, allowing an interactive evaluation of time-dependent alignments in the temple layout and cultic axes in relation to specific stellar constellations. Further intriguing analyses will turn to test regional interactions between the temple/city and other settlements at different points in history.

\section{Acknowledgements}

The VA project is directed by Kay Kohlmeyer and Thomas Bremer and initially funded by the IFAF Institute Berlin and the World Monuments Fund. The excavations of the Aleppo temple were directed by Wahid Khayyata, Hussein Zeineddin, Youssef Kanjou, and Kay Kohlmeyer. Fieldwork was funded by the German Research Foundation (DFG), Gerda Henkel Foundation, the World Monuments Fund, and TOPOI Cluster of Excellence, Free University of Berlin.

\section{Bibliography}

Agugiaro, G., F. Remondino, G. Girardi, J. von Schwerin, H. Richards-Rissetto, and R. De Amicis. 2011. "QueryArch3D: Querying and Visualizing 3D Models of a Maya Archaeological Site in a Web-Based Interface." Geoinformatics 6:10- 17.

Allen, P., S. Feiner, A. Troccoli, H. Benko, E. Ishak, and B. Smith. 2004. "Seeing into the Past: Creating a 3D Modeling Pipeline for Archaeological Visualization." In Proceedings of the 2nd International Symposium on 3D Data Processing, Visualization, and Transmission (3DPVT’04), 751- 758. Los Alamitos: IEEE.

Alliez, P., G. Ucelli, C. Gotsman, and M. Attene. 2008. "Recent Advances in Remeshing Surfaces." In Shape Analysis and Structuring, edited by L. De Floriani and M. Spangnulo, 53- 82. Heidelberg: Springer. 
The Virtual Archaeology Project - Towards an Interactive Multi-scalar 3D Visualisation in Computer Game Engines Arian Goren et al.

ArchAtlas. 2013. "ArchAtlas Version 4.1 home page." Accessed J une 15 2013. http:/ / www.archatlas.org/ Home. php.

Beacham, R., H. Denard, and F. Niccolucci. 2006. “An Introduction to the London Charter." In The e-volution of Information Communication and Technology in Cultural Heritage, Project papers from the joint event CIPA/ VAST/EG/EuroMed 2006, edited by M. Ioannides, D. Arnold, F. Niccolucci, and K. Mania, 263- 269. Budapest: Archaeolingua.

Blinn, J . F. 1978. "Simulation of wrinkled surfaces." In SIGGRAPH "78 Proceedings of the 5th annual conference on Computer graphics and interactive techniques, 286292. New York: ACM.

Bordes, N., S. Ulm, O. Pettersen, K. Murphy, D. Gwynne, W. Pagnon, S. Hungerford, P. Hiscock, J. Hall and B. Pailthorpe. 2006. "Data Grid for the Management, Reconstruction, Analysis and Visualization of Archaeological Data." In An Archaeological Life: papers in honour of J ay Hall, edited by S. Ulm and I. Lilley, 251- 264. Brisbane: Aboriginal and Torres Strait Islander Studies Unit, University of Queensland.

CAST UARK (Center for Advanced Spatial Technologies, University of Arkansas). 2013. "Amarna Virtual Museum home page." Accessed J une 15 2013. http:// amarna.cast. uark.edu/index.html.

ÇatalhöyükResearch Project. 2013. "Remixing Çatalhöyük About Page." Accessed June 15 2013. http://okapi. dreamhosters.com/ remixing/ mainpage.html.

Chandler, T. 2014. "Playing Angkor: Exploring the Archaeological Themes of the Khmer Empire through Game Engine Technologies." In Across Space and Time. Papers from the 41st Computer Applications and Quantitative Methods in Archaeology Conference (Perth, WA, 25-28 March 2013), edited by A. Traviglia, 379-385. Amsterdam: Amsterdam University Press.

Cignoni, P., M. Callieri, M. Corsini, M. Dellepiane, F. Ganovelli, and G. Ranzuglia. 2008. "Meshlab: an opensource mesh processing tool." In Sixth Eurographics Italian Chapter Conference, Salerno, Italy, J uly 2-4, edited by V. Scarano, R. De Chiara, and U. Erra, 129- 136. Aire-la-Ville: Eurographics Association.

CNR-IT (Italian National Research Council). 2013. “The
Virtual Museum of Iraq Overview." Accessed June 15 2013. http:// www.virtualmuseumiraq.cnr.it/prehome. htm.

Coastal Carolina University. 2013. "Welcome to Ashes2Art." Accessed J une 15. http:// www.coastal.edu/ ashes2art/index.html.

Cohen, J ., M. Olano, and D. Manocha. 1998. “AppearancePreserving Simplification.” In SIGGRAPH '98, Proceedings of the 25th Annual Conference on Computer Graphics, July 19-24, 1998, Orlando, FL, USA, edited by S. Cunningham, W. Bransford, and M. F. Cohen 115- 122. New York: ACM.

Digital Archaeological Atlas of the Holy Land. 2013. "Welcome to the Digital Archaeological Atlas of the Holy Land!" Accessed J une 15. http:// daahl.ucsd.edu/ DAAHL/ .

Del Fabbro, R. 2012. "The Roads from and to Aleppo: Some historical-geographical Considerations in Light of new archaeological data." In LEGGO! Studies presented to Prof. Frederick Mario Fales on the Occasion of his 65th Birthday, edited by G. B. Lanfranchi, D. Morandi Bonacossi, C. Pappi, and S. Ponchia, 201- 222. Wiesbaden: Harrassowitz Verlag.

Euclideon Limited. 2013. "Geoverse software Brochure." Accessed J une 15. http:/ / www.euclideon.com/ brochure/ .

Fiorentino, G., V. Caracuta, I. Calcagnile, M. D'Elia, P. Matthiae, F. Mavelli, and G. Quarta. 2008. "Third Millennium B.C. Climate Change in Syria highlighted by Carbon Stable Isotope Analysis of 14C-AMS dated Plant Remains from Ebla." Palaeogeography, Palaeoclimatology, Palaeoecology 266:51- 58.

Flaten, A. 2011. "Ashes2Art: A Pedagogical Case Study in Digital Humanities." In On the Road to Reconstructing the Past. Computer Applications and Quantitative Methods in Archaeology (CAA), Proceedings of the 36th International Conference. Budapest, April 2-6, 2008, edited by E. Jerem, F. Redő, and V. Szeverényi, 346-352. Budapest: Archeaeolingua.

Forte, M. 2010. "Introduction to Cyber Archaeology.” In Cyber Archaeology, edited by M. Forte, 9-13. Oxford: Archaeopress.

Forte, M. in press. "Cyberarchaeology: a Post-Virtual 
Across Space and Time. Papers from the 41st Conference on

Computer Applications and Quantitative Methods in Archaeology. Perth, 25-28 March 2013

Perspective." In Humanities and the Digital. A Visioning Statement, edited by D.T. Goldberg and P. Svensson. Boston: MTT Press.

Garofalo, M. 2013. "A Case Study: Architectural Accuracy, Virtual Modeling and Gesture-Based Learning at the Cyrene Treasury at Delphi." Paper presented at Across Space and Time 41st Computer Applications and Quantitative Methods in Archaeology Conference, Perth, Western Australia, March 25-28.

Glasbey, C. A., and K. V. Mardia. 1998. "A Review of Image Warping Methods." J ournal of Applied Statistics 25 (2):155- 171

Gregory, J . 2009. Game Engine Architecture. Wellesley: AK Peters/ CRC Press.

Heckbert, P. S. 1986. "Survey of texture mapping." Computer Graphics and Applications, Institute of Electrical and Electronics Engineers 6 (11):56- 67.

Hutchinson, M. F. 1989. "A new procedure for gridding elevation and stream line data with automatic removal of spurious pits." J ournal of Hydrology 106 (3-4):211- 232.

IANUS. 2013. "IANUS - Forschungsdatenzentrum Archäologie \& Altertumswissenschaften." Accessed J une 15 2013. http:// www.ianus-fdz.de/ .

ImageMagick Studio LLC. 2013. "ImageMagick software suite. Distributed under the Apache 2.0 license." Accessed October 10 2013. http:// www.imagemagick.org

IWR (Interdisciplinary Center for Scientific Computing) University of Heidelberg. 2013. "Angkor Project Group Homepage." Accessed June 15 2013. http://scotty.iwr. uni-heidelberg.de/ .

Kai-Browne, A. 2013. “Virtual Archaeology - Developing a Toolbox for the Interactive 3D Visualization of Archaeological Sites and Landscapes." Paper presented at the Sustainable Documentation in Archaeology: Technological Perspectives in Excavation and Processing conference, Xi'an, China, May 6-8.

Kaniewski, D., E. Paulissen, E. Van Campo, H. Weiss, T. Otto, J. Bretschneider, and K. Van Lerberghe. 2010. "Late Second-Early First Millennium BC Abrupt Climate Changes in Coastal Syria and Their Possible Significance for the History of the Eastern Mediterranean." Quaternary
Research 74:207- 215.

Kaufman, A., D. Cohen, and R. Yagel. 1993. "Volume graphics." Computer 26 (7):51- 64.

Kohlmeyer, K. 2009. "The Temple of the Storm God in Aleppo During the Late Bronze and Early Iron Ages." Near Eastern Archaeology 72 (4):190- 202.

Kohlmeyer, K. 2012. "Der Tempel des Wettergotes von Aleppo. Baugeschichte und Bautyp, räumliche Bezüge, Inventar und bildliche Ausstattung." In Temple Building and Temple Cult, edited by J . Kamlah, 55- 78. Wiesbaden: Harrassowitz Verlag.

Kohlmeyer, K. 2013. "Der Tempel des Wettergottes von Aleppo." In Tempel im Alten Orient. 7. Internationales Colloquium der Deutschen Orient-Gesellschaft, edited by K. Kaniuth, A. Löhnert, J. L. Miller, A. Otto, M. Roaf, and W. Sallaberger, 179-218. Wiesbaden: Harrassowitz Verlag.

Konica Minolta Sensing Inc. 2006. "Non Contact 3D Digitizer VIVID 9I/VI-9i Instruction Manual." http:// www.konicaminolta.com/instruments/ download/ instruction_manual/3d/pdf/vivid-9i_vi-9i_instruction eng.pdf.

Kottek, M., J. Grieser, C. Beck, B. Rudolf, and F. Rubel. 2006. "World Map of the Köppen-Geiger climate classification updated." Meteorologische Zeitschrift 15:259- 263.

Leica Geosystems. 2013. "Leica ScanStation2 product sheet." Accessed October 10 2013. http://hds.leicageosystems.com/ downloads123/ hds/ hds/ ScanStation/ brochures-datasheet/ Leica_ScanStation\%202 datasheet_us.pdf.

McNamara, A. 2001. "Visual Perception in Realistic Image Synthesis." Computer Graphics Forum 20 (4):211- 224.

McPherron, S. P., T. Gernat, and J. J. Hublin. 2009. "Structured Light Scanning for High-Resolution Documentation of in situ Archaeological Finds." J ournal of Archaeological Science 36:19- 24.

Merlo, A., L. Dalcò, and F. Fantini. 2012. "Game Engine for Cultural Heritage. New opportunities in the relation between simplified models and database." In 18th International Conference on Virtual Systems 
The Virtual Archaeology Project - Towards an Interactive Multi-scalar 3D Visualisation in Computer Game Engines Arian Goren et al.

and Multimedia (VSMM). Proceedings of the VSMM 2012 Virtual Systems in the Information Society 2-5 September 2012 Milan, Italy, edited by G. Guidi and A. C. Addison, 623- 628. Piscataway: Institute of Electrical and Electronics Engineers.

Merlo, A., C. Sánchez Belenguer, E. Vendrell Vidal, F. Fantini, and A. Alipetra. 2013. "3D Model Visualization Enhancements in Real-TimeGameEngines." In 3D-ARCH 2013 - 3D Virtual Reconstruction and Visualization of Complex Architectures, 25 - 26 February 2013, Trento, Italy, edited by J. Bohem, F. Remondino, T. Kersten, T. Fuse, and D. Gonzalez-Aguilera. Trento: ISPRS doi:10.5194/ isprsarchives-XL-5-W1-181-2013.

Mikkelsen, M. 2008. "Simulation of Wrinkled Surfaces Revisited." Master thesis, University of Copenhagen.

Monash University. 2013. "Visualizing Angkor." Last Modified October 23 2013. http://infotech.monash.edu/ research/groups/3dg/ projects/ visualising-angkor.html.

Moser, M., S. Hye, G. Goldenberg, K. Hanke, and K. Kovács. 2010. "Digital Documentation and Visualization of Archaeological Excavations and Finds Using 3D Scanning Technology." Virtual Archaeology Review 1 (2):143- 147.

Nakoinz. O. in press. "Zentralität - Theorie, Methoden und Fallbeispiele: Zur Analyse zentraler Orte." eTOPOI J ournal of Ancient Studies, Berlin.

Nelson, A., H. I. Reuter and P. Gessler. 2009. “DEM Production Methods and Sources." In Geomorphometry - Concepts, Software, Applications, edited by T. Hengl and H. I. Reuter, 66- 85. Amsterdam: Elsevier.

OSGeo (Open Source Geospatial Foundation). 2014. "QGIS A Free and Open Source Geographic Information System licensed under the GNU General Public License." Last modified March 12. http://qgis.osgeo.org.

Outerra. 2013. “About Outerra.” Accessed J une 15. http:// www.outerra.com/.

Reuter, H.I., T. Hengl, P. Gessler, and P. Sollie. 2009. "Preparation of DEMs for Geomorphometric Analysis." In Geomorphometry - Concepts, Software, Applications, edited by T. Hengl and H. I. Reuter, 87- 120. Amsterdam: Elsevier.
Richards-Rissetto, H., J . Robertsson, J . von Schwerin, G. Agugiaro, F. Remondino, and G. Girardi. 2013. "Geospatial Virtual Heritage: A Gesture-Based 3D GIS to Engage the Public with Ancient MayaArchaeology." In Archaeology in the Digital Era. Papers from the 40th Annual Conference of Computer Applications and Quantitative Methods in Archaeology (CAA), Southampton, 26-29 March 2012, edited by G. Earl, T. Sly, A. Chrysanthi, P. Murrieta-Flores, C. Papadopoulos, I. Romanowska, and D. Wheatley, 118130. Amsterdam: Amsterdam University Press.

Roberts, N., W. J. Eastwood, C. Kuzucuoğlu, G. Fiorentino, and V. Caracuta. 2011. "Climatic, Vegetation and Cultural Change in the Eastern Mediterranean during the MidHolocene Environmental Transition." The Holocene 21 (1):147- 162 .

Rudolph, B. 2013. "Kinecting Cultural Heritage Sites With ImmersiveAudio-GestureBased LearningEnvironments." Paper presented at Across Space and Time 41st Computer Applications and Quantitative Methods in Archaeology Conference, Perth, Western Australia, March 25-28.

Santiago Orgaz \& Co. 2014. "xNormal bakes your maps!" Accessed March 15, 2014. http:// www.xnormal.net/ .

Schäfer, A., H. Leitte, and H.G. Bock. 2013. "Ein automatisches und virtuelles 3D-Puzzle von KhmerTempeln im Angkorstil." Paper presented at the 4. Workshop der AG Computeranwendungen und quantitative Methoden in der Archäologie (CAA), Berlin, Germany, February 15-16.

Snyder, J .P. 1987. Map Projections - A Working Manual. USGS Professional Paper 1395. Washington: U.S. Government Printing Office.

UCLA (University of California, Los Angeles). 2013. "Welcome to Digital Karnak." Accessed J une 15. http:// dlib.etc.ucla.edu/projects/ Karnak/ .

Unigine Corporation. 2013. “Unigine Engine.” Accessed J une 15. http:// www.unigine.com/ products/ unigine/ .

University of New Mexico. 2012. "MayaArch3D: Digital Technologies for Research in Maya Archaeology Beta Version 1.o." Last modified October 1 2012. http:// mayaarch3d.unm.edu/ .

Visual Computing Lab of CNR ISTI. 2013. "Meshlab (developed at Visual Computing Lab of the Institute of 
Across Space and Time. Papers from the 41st Conference on

Computer Applications and Quantitative Methods in Archaeology. Perth, 25-28 March 2013

Science and Information Technology of the National Research Council of Italy (CNR ISTI) and with the support of the 3D-CoForm Project)." Accessed October 10. http:// meshlab.sourceforge.net/.

Weiss, H. 2013. "The Northern Levant during the Intermediate Bronze Age: Altered Trajectories." In Oxford Handbook of the Archaeology of the Levant, edited by M. Steiner and A. Killebrew, 367-387. Oxford: Oxford University Press.

WMO (World Meteorological Organization). 2013. “World Weather Information service: Weather Information for Aleppo." Accessed June 15. http:// www.worldweather. org/ 099/ c01261.htm. 


\title{
A Roman Street at the Time of Constantine: Interactive Visit with Access to Ancient Source Materials
}

\author{
Philippe Fleury, Sophie Madeleine and Nicolas Lefèvre \\ Équipe de recherche sur les littératures, les Imaginaires et les Sociétés (ERLIS) / Centre \\ Interdisciplinaire de Réalité Virtuelle (CIREVE), France
}

\begin{abstract}
:
The virtual model of ancient Rome created in Caen (France) is a digital model built from the available textual, archaeological and iconographic sources. It is also as realistic a model as possible. Finally, it is a model that makes available the sources used in its creation. Whereas the specialists see an hypothesis of justified reconstruction, the non-specialists find simply the display of a reality which they would otherwise have difficulty imagining. The objective of the team is to contribute to the scholarly knowledge of a city that marked the Western world in an indelible way by its architecture and its technology. This paper will focus on a particular example: the condition of a Roman street in the 4th century CE.
\end{abstract}

Keywords:

Virtual Reality, Ancient Rome, Streets

\section{Introduction}

Ancient Rome has always especially fascinated people in the western world. Reconstructions have been increasing since the Renaissance: literary reconstructions, drawings and watercolours, physical models (e.g. P. Bigot's and I. Gismondi's 20th century monumental models: Liberati 2003; Royo 2006). Today digital techniques offer new possibilities for reconstructing the past (among recent writings, see Frischer and Dakouri-Hild 2008; Vergnieux 2006; see also the international colloquiums of the Computer Applications and Quantitative Methods in Archaeology (CAA) in CAA 2014, and, since 2003, the biennial colloquium "Virtual Retrospect" organised in Bordeaux by R. Vergnieux). Many scholars around the world are working on ancient Rome (e.g. the project "Virtual Rome" in Italy: Pescarin 2008), but only two teams are rebuilding the entire city in its condition as of the 4th century CE: the team "Rome Reborn" at Indiana University (USA) (Frischer and Dakouri-Hild 2008) and the team "Plan de Rome" at the University of Caen, France (Fleury and Madeleine 2008). The two teams signed a joint venture agreement in 2008. The objective of the "Plan de Rome" research team is to reconstruct ancient Rome in the 4th century CE, not only with its main monuments but also with its hills, streets (Gruet and Pitte 2006), and houses. This

Corresponding author:philippe.fleury@unicaen.fr article will show two different aspects of the virtual model: the traditional reconstruction of public monuments and the reconstruction of the daily activities buildings, with the specific problematics of reconstructing streets with private dwellings and shops. The analysis of data is not the same in the two cases.

\section{Reconstructing Virtual Ancient Rome in Caen (France)}

\subsection{Paul Bigot's model}

The University of Caen owns the "Plan de Rome", an exceptional example of European cultural heritage (Fig. 1). It is a large plaster model of nearly 70 square metres which represents ancient Rome in the 4th century CE. It is the work of the architect P. Bigot (1870-1942), winner of the Grand Prix of Rome and professor at the Ecole des Beaux-Arts in Paris. Its only equivalents are its twin in Brussels (Belgium) and the model made by I. Gismondi in Rome (Pavia 2008).

Paul Bigot's model arrived in Caen by chance; Bigot had bequeathed his work to one of his pupils, Henry Bernard. Bernard was chosen as architect for the reconstruction of the University of Caen after the destruction of the Second World War and he gave the Bigot model to this institution. 


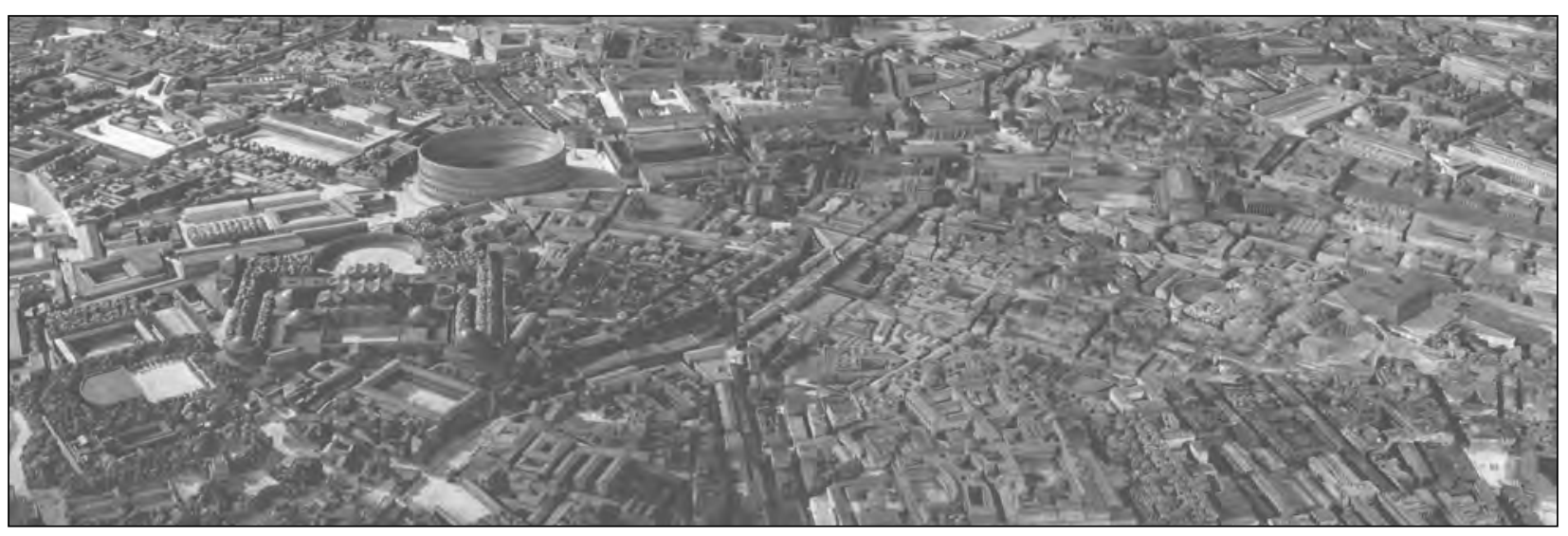

Figure 1. The physical model of Paul Bigot.

This physical model is a scientific and pedagogic object. It is used for research and for teaching, but it has its limits. The first limit is the date of its creation. Bigot's model was completed in 1913, with some corrections made between the two world wars. Since the 1950s, there have been new discoveries while earlier data have been reinterpreted. Updating cannot be carried out on the physical model because it is classified as a historic monument. The second limit is the way it can be used. A physical model on a scale of 1:400 can only be visited from an external viewpoint, making indoor spaces inaccessible and details not visible.

The creation of a new model using 3D technologies has proven successful. Nevertheless this model cannot be a duplicate of the physical model (a scan, for example). It had to be a new creation. Three main reasons explain why we preferred modelling Rome by hand. Firstly, the physical model scale was $1 / 400$ and if we had carried out a $3 \mathrm{D}$ scan, there would have been significant distortion of measurements. Second, as we have mentioned, Bigot's model cannot be updated. Third, we cannot use the terrain of the physical model, because it is a "Plan relief" where the elevations have been deliberately erased to make all buildings visible from the edge of the model.

We therefore sought to create the new model in a scientific environment to make it more suitable for research and educational purposes. The work we are presenting is being carried out by the research team "Littératures, Imaginaires et Sociétés" (ERLIS, groupe "Plan de Rome") (Université de Caen 2014a) with the support of the CIREVE at the University of
Caen Basse-Normandie. The aims of this technical platform is to promote the use of virtual reality in all the areas possible, in particular in the field of archaeological reconstitution.

\subsection{A new reconstruction of ancient Rome in Caen: for what and for whom?}

Our objective is to provide tools for a better understanding of ancient Rome. The work involves the development of a fully interactive model of ancient Rome that includes both its architecture and the machinery in use. The visitor of the virtual model is able to wander through a full-scale city and enter most of its large public monuments and a number of private residences. The expected project results are: firstly a digital $3 \mathrm{D}$ model of Rome as it was in the 4th century CE; secondly a digital 3D model of the principal machinery used in the Roman world; and thirdly links for each digital model to the body of sources (documentary, archaeological, and iconographic) used in their development. The body of source material is directly accessible via the interactive model (Fig. 5). The scientific objective is to provide a tool for researchers to test their architectural and topographical assumptions, to test the machines' functionalities, and to illustrate the assumptions developed regarding thereconstruction of the city. The virtual model is inseparable from research on the history of the real model, and furthermore, the updating of Bigot's work highlights the evolution of archaeological and historical knowledge of ancient Rome. The educational objective is to provide students and secondary school pupils, but also the public at large, with a vivid illustration of ancient Rome and an example of 
the ancient urban reality that is easily visualised on screen. Each year, three thousand school children visit the model in Caen and each month a hundred and fifty people attend "The Nocturnes du Plan de Rome", an interactive visit of a part of virtual Rome (Université de Caen 2014b).

\subsection{Selecting a time slice for the reconstruction}

The first step in our work was the choice of a particular date for the reconstruction because, in the realm of visual representation, only a synchronic approach has scientific value. The reconstruction of Rome is a snapshot of the city at a given point in time; in order to be scientifically credible, the reconstruction must not mix elements from different periods. The team chose the period of Constantine, more specifically the beginning of his reign, between 310 and 320 CE. Several factors account for this choice. Firstly, it seemed of interest for the visitor to be able to compare the virtual model with Bigot's physical model (he also chose this period) and the ruins that can still be seen in Rome (which are generally the most recent antique buildings, i.e. in their state as in the 4th or 5th century CE). Secondly, the reign of Constantine brought about an architectural climax when Rome seems to be at the height of its urban development. Thirdly, Late Antiquity is the best documented period from the archaeological point of view. Finally, since we plan to show different stages of urbanisation of ancient Rome, and, since in archaeology the last layer is the first layer excavated, it seemed normal to proceed in the same order.

\section{Reconstructing a Street: Specific Problems}

3.1 Reconstructing the town: the traditional approach

The work preliminary to the reconstruction itself involves the analysis of data sources, which is currently being performed by the members of the research team who have recourse to outside experts for help with specific issues (Fleury and Madeleine 2007). Before modelling a building, the team's researchers collect all the source materials (textual, iconographical, and archaeological data) which make it possible to understand its history and draw plans in $3 \mathrm{D}$. They first attempt to collect

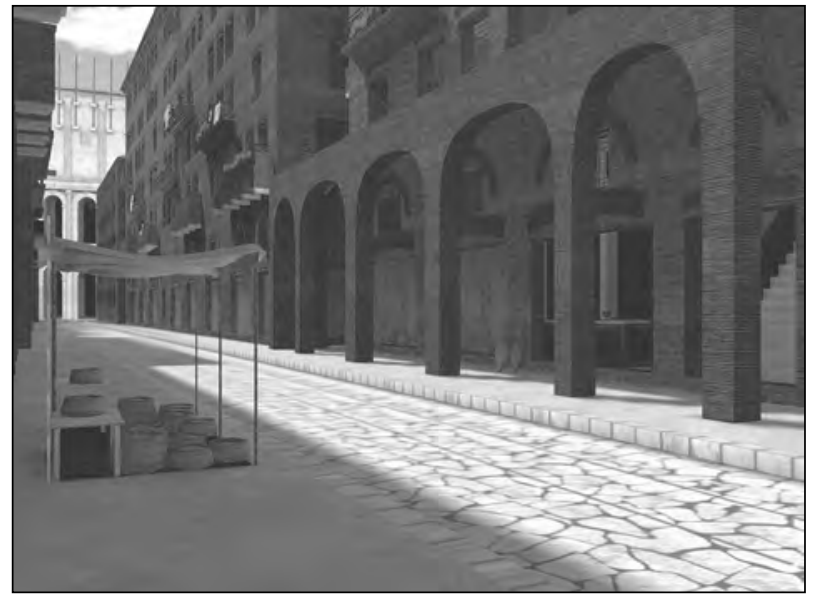

Figure 2. Streets of ancient Rome.

all the Latin and Greek texts on the subject. They are responsible for finding texts, translating them if needed, and extracting the data necessary for the virtual reconstruction. The analysis of the iconographic and archaeological sources comes next. The study of the archaeological reports must be conducted using a rigorous historical method; it is the conditions of the 4th century that are being reconstructed and these conditions must be isolated from all the available information. When all the data concerning a 4th century building have been collected and relevant information is still missing, we use what can be extracted from previous and subsequent periods or we work by analogy by further studying still standing buildings that have the same function as the one which is to be reconstructed. The virtual reconstruction is made only when all the data have been studied and synthesised by the team of researchers, but their work does not stop here. Daily collaboration with the modellers is necessary not only to answer questions concerning the creation of the model (measurements, materials used) but also to help them to understand the historical, functional and social context of the monument which is modelled.

\subsection{Reconstructing streets: particularities and difficulties}

Reconstructing a specific building is easier than reconstructing a street network with dwellings and shops that have not been so well documented. However, a digital reconstruction of Rome in the 4th century CE is not only a reconstruction of monumental Rome. It is also a reconstruction of 


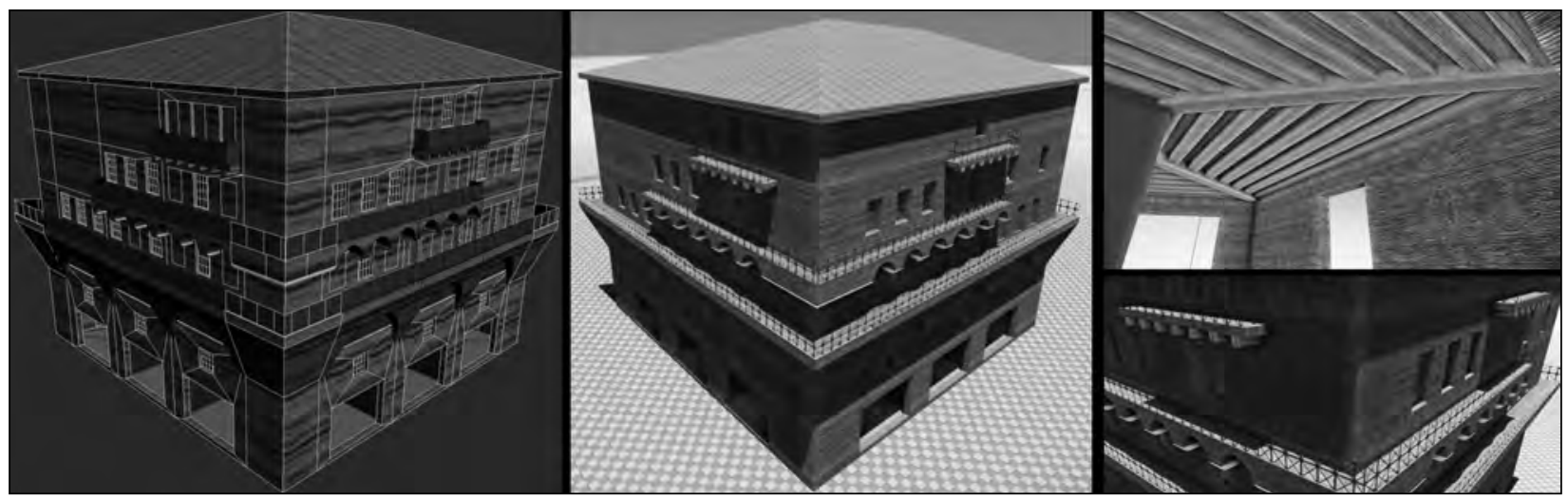

Figure 3. An insula created with the automatic process.

Rome in its daily life. The street network is necessary to give meaning to the public buildings (Fig. 2).

The first difficulty is the lack of the sources in a city which has been continuously inhabited and constantly rebuilt and reshaped, as Rome is. Therefore, in order to reconstruct houses and shops we had to work by analogy and used examples from Ostia, the port city of ancient Rome (Stöger 2011). This archaeological site is about $30 \mathrm{~km}$ west of Rome, and boasts well-preserved Roman urban architecture, in particular apartment buildings - insulae - which were typical of Rome, but were not present, for example, in the two well-preserved archaeological sites of Pompeii and Herculaneum (Monteix 2010). Apartment buildings housed most of the urban citizen population of ancient Rome, which could have numbered about one million people. The solution was thus to construct multistorey blocks of flats which were sometimes as high as seven storeys.

The second difficulty concerns the relief. A modern digital elevation model is used as a first step. But as the current terrain of Rome has changed drastically in places over the past 2000 years, the digital elevation model is manually corrected in a second step so as to createa model that approximates the historical terrain.

\section{Methodological Choices at the University of Caen}

\subsection{Interdisciplinary co-operation}

The virtual reconstruction of Rome in Caen involves interdisciplinary efforts across several fields of study. First there is philology. Ancient texts are the primary source for studying the topography of ancient Rome. How does one interpret the distinction between domus and insula? Texts have to be set against archaeological remains and iconographical data. The ruins of Ostia are essential for authentic representation of the form of the Roman streets. A precise study of some signs on the Forma Urbis Romae has been necessary for estimating the height of the buildings in Rome. Historians must locate the elements in a chronology and in a social and economic context. We also call upon urban geography and physical geography (the natural terrain of Rome). Of course, computer graphics (for representation) and computer science (for programming interactivity) are essential.

\subsection{Software}

The software used included: 3DS Max for modelling, texturing, rendering and motion; Daz Studio and MudBox for modelling sculptures; Photoshop for creating textures files; and CryEngine for real time navigation. We also used Flash for the graphical user interface and XML to store metadata.

The construction of street requires a particular workflow. We developed a shape-based modelling process to help us in the modelling, texturing, and exporting of data into CryEngine. Roman streets cannot be mapped quickly without an automatic process. Our process keeps each apartment building creation to under 1 minuteif done with theautomatic method, adopting optimum game development methods to keep real time cycles as fast as possible, and under 5 minutes with hand tweaking if needed (Fig. 3). 


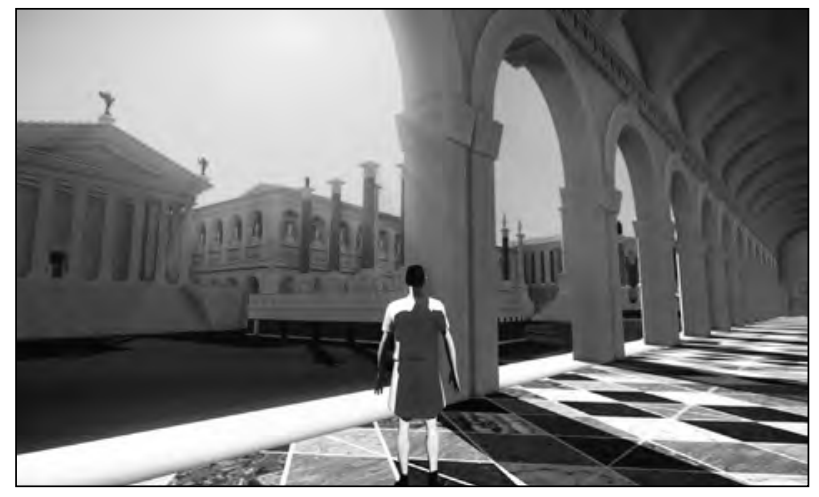

Figure 4. The interactive model of the Forum Romanum.

\subsection{Interactivity}

The "Plan de Rome" team is reconstructing ancient Rome in order to access the model in real time (Fig. 4). There are many advantages in undertaking an interactive tour. Foremost, people using the virtual model are no longer spectators, but actors. Whereas with a pre-calculated video, the visitor follows a precise script, the interactive world gives them the freedom to move where they want, when they want. The researcher can thus go precisely to the details which they want to verify and they can make a personal critique of the model. Since motion is calculated in real time, the exploration of the model can be an experiment on movement time in ancient Rome, which is an important issue for the understanding of daily life in Antiquity. How much time did it take to go from the Campus Martius to the Coliseum? How much time was necessary to reach the highest seat in the Theatre of Pompey? Understanding movement time is important for the understanding of events and ways of thinking. Visualisation in real time allows for a better appreciation of the effects of shadow

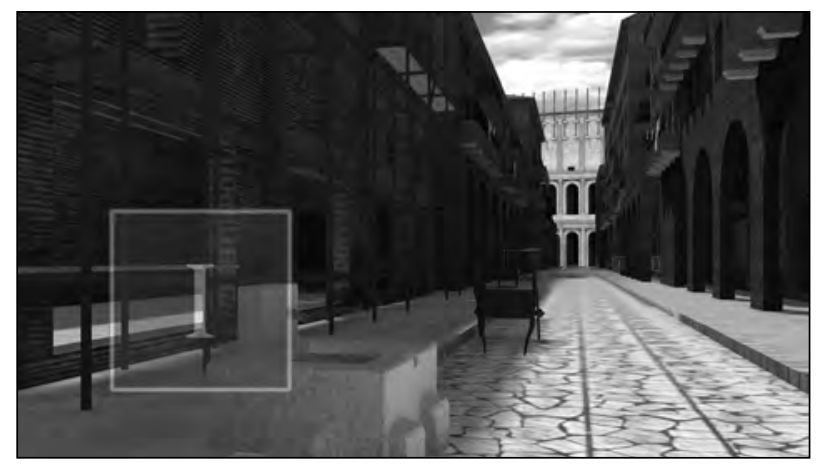

Figure 5. A relevant picture. and light, with respect to the period of the year or the time of the day, the height of the buildings, the distribution between dwellings and shops, traffic problems, and the necessary network for water supply and evacuation.

\section{$4.4 \mathrm{~A}$ relevant picture and a scientific model}

The methodology developed by the "Plan de Rome" team is inspired by the principles defined by J .-C. Golvin (Golvin 2003) with whom we have worked for a long time. Golvin is well known for his reconstructions of classical antiquity in watercolours (all these drawings are now exhibited in the Museum of Arles Antique, France), but many principles are common to reconstructions in watercolours and reconstructions in virtual reality, in particular the fundamental principle of pertinence. A relevant virtual picture is the most likely picture given the data we have. It means that the pictures must be complete. It is our belief that reconstructing only what is certain is a limited approach. We have found that pictures adopting different expedients to differentiate what is verified from what is not (transparency effects, different colours, models without texturing or with modern textures) are unsatisfactory. Nevertheless, the models must be based on valid data sources and it is important that the visitors of the interactive model know what is proven and what is not, with all the nuances between these two possibilities.

To solve this problem we worked with an interactive model in five dimensions (Golvin 2012). We have the three dimensions of all models: height, width, and depth. However a virtual model is more thorough than a physical model since we can walk inside it. Time is our fourth dimension. The fifth

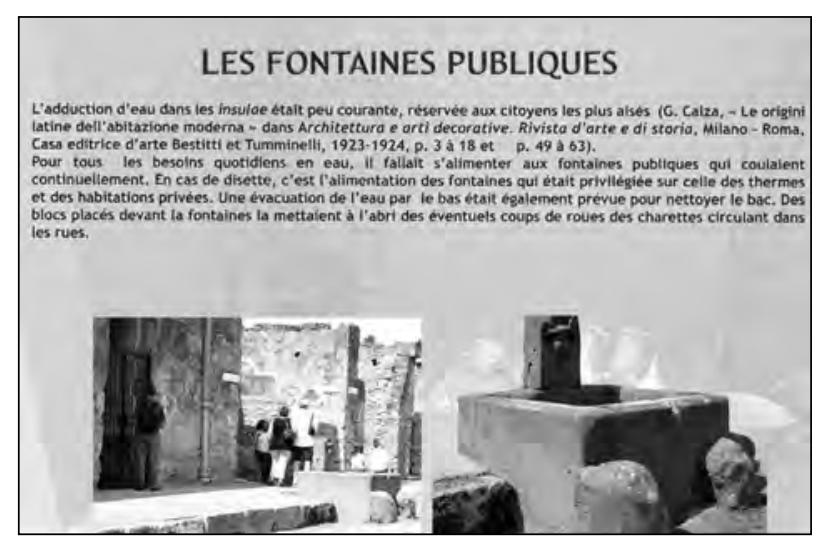




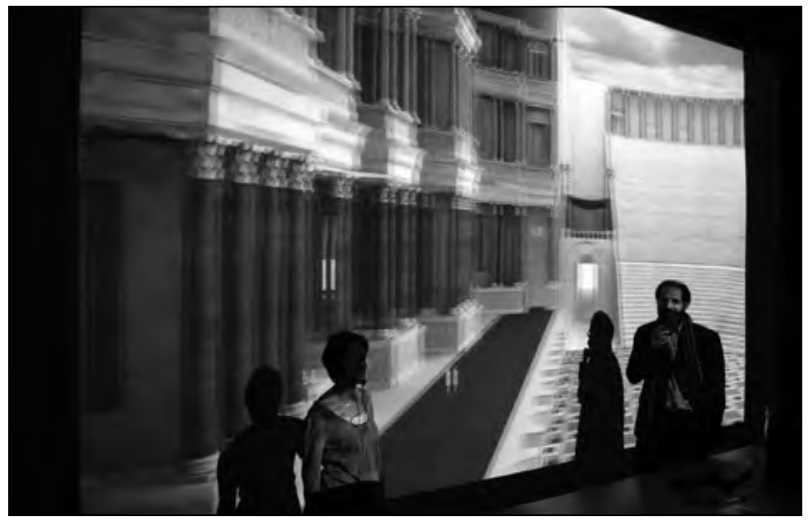

Figure 6. The stereoscopic display used for the interactive visits.

dimension is the interactive access to sources of data. Linked to the virtual model, there is a database with ancient texts, didactic, 2D pictures and a bibliography. With this documentation, we provide the visitor the possibility of consulting the research data. In reading the interactive documentation, visitors are able to obtain a good idea of the degree of reliability of the model (Fig. 5). When the visitor approaches a sign ("I" for Information), they can read the relevant documentation. They can see the amount of data we have, its nature and how the data have been used. Such thoroughness is an enormous undertaking, but it is the best means for demonstrating the degree of reliability of the reconstructions. Interactivity makes it possible, at the same time, to provide a complete picture and to educate the visitor about questions of authenticity.

\section{Conclusions}

The virtual model is a tool among others. It cannot exclude scientific commentary. The researcher must participate in the input stage and in the output stage of the model. The model needs a scientific mediator through written text or through oral presentation. Work produced by the project can also be accessed via scientific papers (e.g. Fleury and Madeleine 2007) or via presentations with a scientific mediator (Fig. 6). Our aim is to provide access to the recent research not only to scientists, but also to the public at large. Much more than a series of synoptic pictures, the interactive tour can be a good approach to understanding daily life in ancient Rome. The best way to understand a civilisation is through travel, but this is not always possible. The possibility of consulting an interactive visit can provide another way. The main difficulty is to separate scientific productions from imaginary ones because, when a picture of the past is produced, it is often perceived as the truth, even if it is only a hypothesis. Therefore B. Frischer has established Digital Applications in Archaeology and Cultural Heritage, the world's first on-line, peer-reviewed journal specifically dedicated to publication of 3D digital models of the world's cultural heritage sites, accompanied by related academic articles. As members of the editorial board of this journal, it is important to us to discuss our methods, our objectives, and our principles of research using all that is available to us in today's world of technology and science.

\section{Acknowledgements}

We are grateful to Catharine Mason and Bernard Frischer for editing and proofreading our English text.

\section{Bibliography}

CAA. 2014. "Computer Applications and Quantitative Methods in Archaeology." Accessed January 15. http:// www.caaconference.org/ .

Claridge, A., and A. Gallina, eds. 1996. Roman Ostia revisited: archaeological and historical papers in memory of Russel Meiggs. Rome: British School at Rome.

Fleury, P., and S. Madeleine. 2007. "Réalité virtuelle et restitution de la Rome antique du IV e siècle p.C." Histoire urbaine 18:157- 165.

Fleury, P., and S. Madeleine. 2008. "Problématique d'une restitution globale de la Rome antique. Une visite interactive avec accès dynamique aux sources anciennes." In Virtual Retrospect, edited by R. Vergnieux and C. Delevoie, 55- 60. Bordeaux: Ausonius.

Frischer, B. D,. and A. Dakouri-Hild, eds. 2008. Beyond illustration: $2 \mathrm{~d}$ and $3 \mathrm{~d}$ digital technologies as tools for discovery in archaeology. Oxford: Archaeopress.

Golvin, J.-C. 2003. "Modèle et maquette: quelques problèmes relatifs à l'image de restitution." Cahiers de la MRSH de Caen 33:179- 190.

Golvin, J .-C. 2012. “L'image de restitution et la restitution 
A Roman Street at the Time of Constantine Philippe Fleury, Sophie Madeleine and Nicolas Lefèvre

de l'image." Accessed April, 14, 2014. http://www. unicaen.fr/ cireve/ rome/ pdf/ COURS1.pdf.

Gruet, B., and J .-R. Pitte. 2006. La rue à Rome, miroir de la ville: entre l'émotion et la norme. Vol. 1. Paris: Presses del’Université Paris-Sorbonne.

Liberati, A. M. 2003. "La rappresentazione di Roma antica nel Plastico di Gismondi del Museo dellà civilità romana di Roma." Cahiers de la MRSH de Caen 33:243- 252.

Monteix, N. 2010. Les lieux de métier: boutiques et ateliers d’Herculanum. Rome: École française de Rome.

Pavia, C. 2008. "La ricostruzione dell'antica Roma. Breve storia del plasticismo romano." Forma Urbis, Itinerari nascoti di Roma antica 13 (5):30- 39.

Pescarin, S. 2008. "Back to II AD. A VR on-line experience with Virtual Rome Project." In The international Symposium on Virtual Reality, Archaeology and Cultural Heritage, edited by M. Ashley, S. Hermon, A. Proenca, and K. Rodriguez, 1-4. Aire-la-ville: Eurographics Association.

Royo, M. 2006. Rome et l'architecte: conception et esthétique du plan-relief de Paul Bigot. Caen: Presses universitaires de Caen.

Stöger, H. 2011. Rethinking Ostia: a spatial enquiry into the urban society of Rome's imperial port-town. Leiden: Leiden University Press.

Université de Caen. 2014a. "Scale Model of Rome." Accessed J anuary 15.http:/ / www.unicaen.fr/ rome/ .

Université de Caen. 2014b. "Les Nocturnes du Plan de Rome 2013-2014." Accessed January 15. http:// www.unicaen.fr/ cireve/ rome/pdr_renseignements. php?fichier=nocturne.

Vergnieux, R. 2006. “Réalité virtuelle et archéologie.” In Traité dela réalité virtuelle, edited by P. Fuchs, 229- 235. Paris: Ecole des Mines de Paris. 


\title{
Fortress City Saarlouis: Development of an Interactive 3D City Model Using Web Technologies
}

\author{
Kristian Sons \\ DFKI and Saarland University, Germany \\ Georg Demme, Wolfgang Herget \\ DFKI, Germany \\ Philipp Slusallek \\ DFKI, Saarland University and Intel VCI, Germany
}

\begin{abstract}
:
3D technology has become ubiquitous: any recent smartphone has hardware support to display graphics and with the advent of WebGL, $3 D$ technology has finally arrived in the majority of web browsers. This allows researchers to publish their results including synthetic or captured 3D data and to present them to a broad audience. However, creating interactive 3D applications remains a challenging task requiring expert knowledge. With XML3D there exists an extension to HTML5 that allows describing 3D scenes within the website. This enables web developers and designers to participate in the development of 3D applications. This paper illustrates how XML3D and related web technologies were used to develop a fully interactive kiosk application that allows to explore the $3 D$ city model of two different periods of the historic Saarlouis, a fortress city constructed by France's famous military engineer, Sébastien Le Prestre deVauban.
\end{abstract}

\section{Keywords:}

Virtual City, Web Visualisation, XML3D, WebGL, 3D Modelling

\section{Introduction}

The Web evolved from a simple hypertext medium to a full-fledged application platform featuring advanced 2D layouts, videos, and audio. With the advent of WebGL (Khronos 2011) in 2011, even hardware accelerated 3D graphics became available in the majority of browsers. However, WebGL provides a low-level graphics API which requires expertise knowledge. XML3D (Sons et al. 2010) extends HTML5 (W3C 2013) and thus makes $3 \mathrm{D}$ objects first citizen objects within the Web page. XML3D leverages Web technologies such as the Document Object Model (DOM), CSS and JavaScript. As a result, an interactive 3D scene can be developed just like any other Web application and 3D content seamlessly integrates with 2D content.

The "Fortified City of Saarlouis" kiosk project was realised in collaboration with the municipal museum of the city of Saarlouis. The objective of the project was to induce awareness of the eventful history of the city and to provide information about the French as well as Prussian periods of the city. Additionally, the kiosk provides an alternative to the existing diorama that shows the French era only, does not allow to include multimedia data, and is hard to maintain. Ultimately, the touch kiosk is more enjoyable, especially for younger visitors.

The Saarlouis kiosk was the first larger project for which an XML3D-capable Web browser was used - rather than a classical 3D real-time system. The main reasons for this decision were the easy integration of the additional material, the easy development of 2D and 3D GUI elements including their touch-based control, and - last but not least - the easy implementation of the application logic. TheXML3D browser met nearly all requirements for the project: only the stereoscopic rendering for the desired external screen was created in a VR system, which was synchronised to the main application.

Corresponding author: kristian.sons@dfki.de 
The following sections will explain the idea of XML3D in detail, outline the project - including former work on the city model and requirements that came from the museum - , and discuss some implementation details and the content pipeline. Finally, a comparison of the approach taken here to other common visualisation platforms will be presented and opportunities for future work will be discussed.

\section{XML3D}

If 3D graphics would be just as easy as creating web pages, millions of web developers would be able to write interactive 3D web applications, thus promoting the benefits of $3 \mathrm{D}$ applications to explore, examine and experience complex 3D data sets. To this end, the aim of XML3D is to bring 3D graphics to web developers by making it an integral part of the Web technology stack. XML3D is an extension to HTML5, leveraging CSS, DOM and other web technologies. It allows describing 3D objects such as meshes, groups, and lights in the web page. CSS can be used to assign material descriptions and transformations to these objects. Existing web elements and concepts are reused wherever applicable, e.g. images and video tags can be used for textures.

Web developers knowhow to create interactive web pages, listening to UI events and modifying the DOM during run-time. With XML3D, all these mechanisms work exactly the same for 3D content. Although the focus of XML3D is on the easy creation of 3D web applications, it has to meet the high user requirements for flexibility, performance and user experience. Therefore, XML3D is generic enough to map well to recent graphics APIs. For dynamic effects, XML3D includes a dataflow mechanism (Klein et al. 2012) that allows to map calculations required e.g. for skeletal animations, image processing and Augmented Reality to available hardware using WebGL or Intel's River Trail.

Two implementations of XML3D areavailable: the first one is a modified Chrome browser that is capable to render the scene using OpenGL 4.0 or a real-time ray tracer. The second one is a "polyfill" implementation that uses WebGL and J avaScript to emulate native XML3D support (Sons et al. 2013).

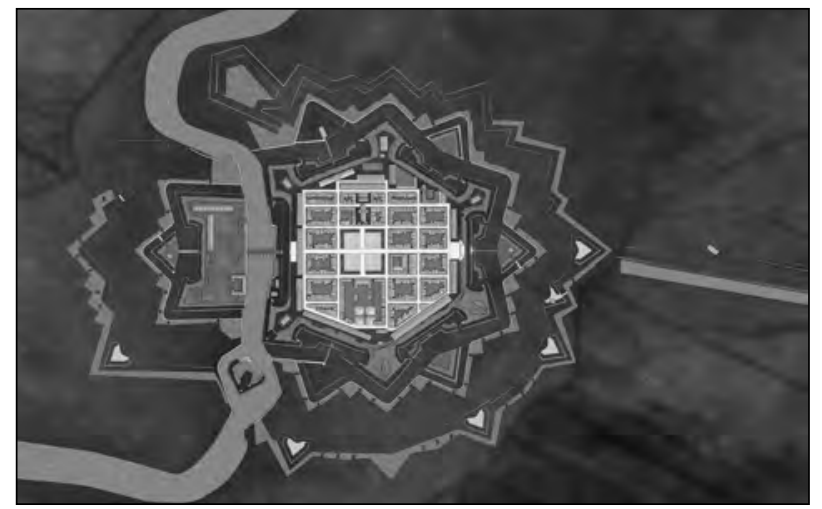

Figure 1. Top view of the digital fortress model.

\section{Project Outline}

In 1679, the French king Louis XIV was looking for a location for a fortress along the lower river Saar. He aimed at closing a gap in the chain of fortified cities that protected France's western border towards Prussia. Thomas de Choisy, later first governor of Saarlouis, was ordered to travel the river Saar and find a suitable place. He found it in a large bend of the river Saar which encloses a piece of low land. These conditions led to the idea to build an inundable fortress. Damming up the river Saar would flood the complete area north of the city making it hard to attack. In 1680, the foundation stone for the new city, then called "Saare-Louis", was laid. Only five years later in 1685 the Fortress was finished. After being operated by the French military for 130 years, the city was handed over to the Prussians in 1815 after the Treaty of Paris. The Prussians applied major changes to the fortress, adding more buildings and extending the defensive works. Finally, in 1889 the defortification of Saarlouis began. Saarlouis started growing rapidly after WWII. The city walls were torn down and the river Saar was regulated making the section of the river between the core fortress and the Hornwork a dead stream branch. Today only parts of the former fortress are present, but Vauban's hexagonal design still dominates the city's floor plan.

In order to convey the history of the fortress, works started with the development of two digital 3D models of the city for two points in time: one for the French period, shortly after the completion of the construction works in 1700, and one for the Prussian period in 1870. These models cover an area of roughly nine square kilometres. The area 


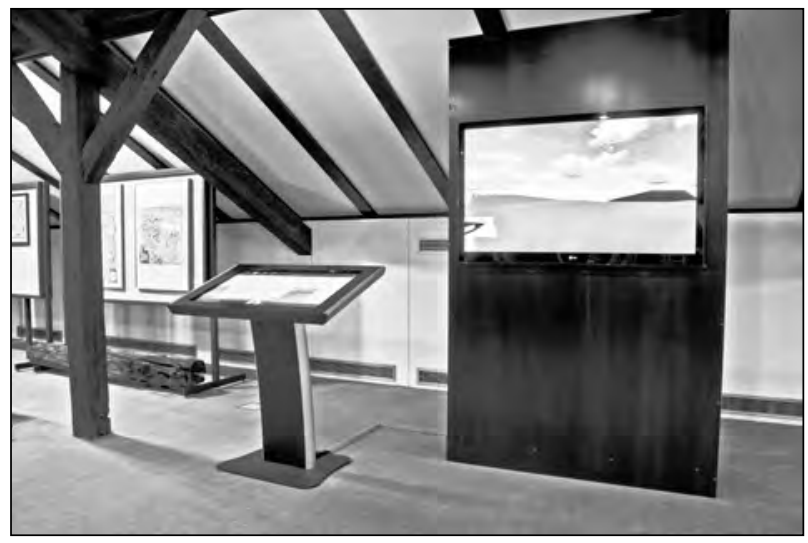

Figure 2. Setup of the Saarlouis kiosk showing the interaction console and the $3 D$ television.

within the city wall, which is most detailed, covers half a square kilometre and contains more than 250 individual constructions ranging from ecclesiastical, administrative and civil buildings to military installations, buildings and fortifications. Based on thesemodelsatwenty minuteinstructional video was created and several live interactive VR presentations were shown to the citizens of Saarlouis. Following the popular demand to havea permanent interactive 3D installation of the digital fortress model in the municipal museum of Saarlouis, a project for an interactive museum kiosk was set up.

The video and live presentations were designed to help museum staff to convey historical information more easily. However, the museum kiosk is intended to work on its own and therefore the 3D model had to be enriched with information otherwise conveyed by speakers. With common Web technologies it is very well possible to structure, link and integrate all kinds of information. Together with XML3D, which adds 3D capabilities to the list, the implementation of a standalone 3D visualisation application for Saarlouis was built on the widespread concepts and stable technology of the Web. Using these technologies it was possible to integrate 3D objects with explanatory texts of more than 100 pages in total, and present those along with several hundred images of old maps, drawings and photographs otherwise not accessible to the museum's visitors.

The two most common groups of visitors of the museum are either small groups of one to three people or larger groups of pupils. To accommodate for this, the kiosk was designed to be accessible using two different modes of operation. For the first mode, small groups can use a touch console to access the visualisation, navigate through the application and access the information. For the second mode, a large television screen is mounted right next to the interaction console that just shows the 3D view as either monoscopic or stereoscopic visualisation for larger groups. The television exactly mirrors the 3D viewpoint chosen at the touch console.

From the console visitors can choose to either view the virtual city model of the French or Prussian period. For each period the visitors have access to three modes of exploring the model: individual constructions, panoramic views at points of interest and virtual city tours. For individual constructions, over 200 individual objects were enriched with text andimages. Amapis presented to thevisitorsinorder to choose from sites grouped by topic, e.g. fortress works, military sites, and civil sites. Individual sites are marked on the map giving the impression of their distribution around the city and the structure of the fortress. For the panoramic views, visitors can choose from over 80 different spots in the city, on the defensive works and the surroundings of the city giving an in situ view of the specific sites. The virtual city tours take the visitors on a trip around the 3D model highlighting different aspects of the fortress such as bastions, barracks or common routes from and to the city. Visitors can pause the tour at any time, look around and continue the tour. Moreover the museum personnel can switch to free flight mode giving them the ability to freely move around for individual presentations. All interactions metaphors were chosen to be explicit, so no prior knowledge of interaction gestures is necessary.

\section{Implementation}

This section describes some implementation details and the content workflow that was developed in order to create the interactive kiosk application.

\subsection{Content}

The city model that is used in the kiosk application had been created in a previous collaboration with theSaarlouis citymuseum. Ateam of student assistants under professional supervision recreated buildings and historical sites from original 
plans that had been provided by the museum using the Cinema4D modelling software. The decision for Cinema4D was motivated by existing experience with the system; due to the declarative nature of XML3D, realisation of a similar content pipeline using other tools is possible. An exporter to XML3D also exists for the open-source Blender modelling system, and there are plans to makea converter from the COLLADA mesh transport format, which most modern 3D authoring systems support, available.

During that collaboration a previously existing plug-in for Cinema4D, which exports to XML3D, was extended. An option to add metadata, such as informational text, hyperlinks or images was added to the exporter, which leveraged Cinema's existing "tag" mechanics for attaching almost arbitrary information to an object in the 3D model. These tags were used to define anchor points for attaching contextual information, which would later be presented to the users of the kiosk.

\subsection{Design}

From the basic requirements that the 3D model should be interactively navigable by museum visitors, and that contextual information could be shown on request, the designer fashioned several mock-up images of how the application could look like. In several iterations with the Saarlouis city museum's director, these were refined and fleshed out into an interaction hierarchy, which detailed the sequence of steps a visitor could perform, and which views they would encounter when using the kiosk. In its final stage, the fake "screen shots" in this main design document already very closely resembled the final user interface.

Based on the interaction design document, the designer created isolated web pages for each of the views using HTML and CSS only. These intermediate results featured all the 2D interaction elements of the final application. Additionally, they inserted placeholders at appropriate places, which would later contain the 3D scenes. The Designer was provided with access to a license of the 3D modelling tool, such that where necessary, they could create single non-interactive renders of the city model, which were then used as representative elements for interaction purposes. Not rendering these live in the application has the advantage of leaving most

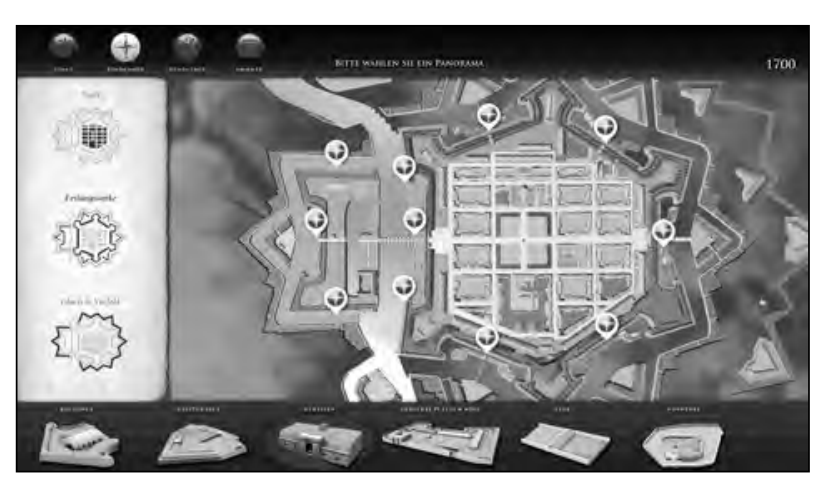

Figure 3. 2D Interface (top, bottom, left) and dynamic markers (white) overlaid on $3 D$ view.

of the rendering performance for the interactive city model.

These isolated web pages were then merged into a single document, where the different views could be shown and hidden as necessary by the interactions prescribed in the design document. The XML3D citymodel is shared amongall of theseviews, in order to conserve memory resources. Effectively, all the interaction elements are overlaid on top of the XML3D view, with a cut-out remaining to grant a view into the 3D scene. This single-page approach has the additional advantage that the application only needs to load everything once - onsite in the Saarlouis city museum this is typically done in the mornings when the kiosk is powered up. Visitors can then seamlessly use the kiosk throughout the day without any further delays that would be incurred by loading additional content.

Dynamic elements such as view-dependent links to additional information were fashioned such that they could be positioned according to the state of the scene. This meant making it such that these elements have a defined origin point which was also visually identifiable so the user would be able to make the connection between the overlaid 2D website element and the corresponding element of the scene geometry visible in the cut-out.

This scheme of single page design, merge and adoption was reiterated over several weeks, with each week adding one view or feature, on average. Of course, those features required not only the visual HTML and CSS components that were just described, but also needed to be connected functionally into a complete application. 


\subsection{Programming}

The main programminglanguage for the kiosk application was J avaScript, the lingua franca of the web. The programming required for the kiosk was mostly spent in managing the interaction of the 3D content with 2D interface elements. On top of the APIs provided by XML3D, it was necessary to compute the visible extents of elements from the 3D scene in the coordinate space of the website. This allowed the positioning of the dynamic interface elements as shown in the previous section in relation to the scene objects they refer to. The output from the XML3D rendering process is further used to determine whether a given object is visible at any given time, such that the screen is not cluttered by elements pertaining to invisible geometry.

When starting to develop the kiosk, thecamera controls offered by XML3D needed to be extended. This was necessary to integrate the pre-built tours that the kiosk should feature. Camera paths exported from Cinema4D were encoded in a suitable manner and can thus be played back on the kiosk. Meanwhile, such functionality has been integrated into XML3D and could be implemented with much less programming effort. Extending the existing camera API also had the advantage of presenting a yaw/ pitch/roll system to the application, further increasing ease of use. Having the camera controller support this system also allowed a simple transition of camera parameters to the VR system responsible for stereoscopic rendering of the model, which uses the same coordinate model. Here, too, the need for additional implementation effort has since been mitigated to some degree by the fact that XML3D now supports CSS3 3D Transforms (W3C 2011), which also feature yaw/ pitch/roll coordinates.

The last big part that comprises the code that drives the kiosk is the interaction management. That is, showing the right views at the right time, much the same as any other modern web application. The application makes heavy use of the jQuery framework here. The dynamic markers presented in the previous section have their website (DOM) elements generated on the fly using the PURE template engine, as does much of the page structure for the menu.

Agreat advantage of a web-based development approach as presented here is that modern browsers - the development process prominently relied on WebKit based browsers, such as Chromium - offer a very sophisticated debugging environment, just as it can be found in modern non-web development environments, allowing for example for live data inspection and in-place code replacement, as well as extensive profiling. These features allow for very rapid development cycles, and make it easy to find performance issues, the latter of which is essential on such an interactive application.

\section{Related Work}

Many projects spend efforts to accurately reconstruct ancient (Pescarin et al. 2009) or historic (Cabral et al. 2007) cities and their buildings. One common way to visualise the results is in a noninteractive way: the produced videos are easy to present to a broad audience using video portals such as YouTube or Vimeo.

The development of interactive applications that allow users to explore the reconstructions on their own involves expert knowledge in real-time rendering and after finishing the project, the results areharderto publish and to maintain. Recently, there has been a shift from using classical visualisation system such as OpenSG, OpenSceneGraph, Coin3D or Ogre3D, to the use of game engines such as Unity or Unreal Engine. This is mainly because game engines often come with powerful authoring systems and run-times for many platforms.

However, developing an interactive application with a game engine comes with some issues: firstly, if developers want to exploit the multiplatform capability, they have to develop the whole application in the game engines. This comes with the consequence that all non-3D elements of the application (e.g. menus, multi-media, application logicetc.) need to beimplemented in the gameengine environment. This in turn means that all the work has to be done by people that know how to handle the game engine environment. On the other hand as has been shown in thelast sections - by using web technologies the ability is gained to involve ordinary web designers and web developers in the creation process of the application. In standard setups, this implies that such a project can be achieved cheaper as well as faster. 
An additional drawback that comes with the use of game engines is the publishing of the data. The common game engines still need the installation of a plug-in and the penetration rate of these plug-ins is considerably small. Also, maintenance is difficult, because applications can break if the run-time plugin updates to a new version. Not at least longevity is a critical issue: The formats are proprietary and long time support is not guaranteed.

Recently, JavaScript 3D graphics libraries such as three.js and SpiderGL appeared that move the low-level WebGL functionality to a higher abstraction level. These frameworks have been used to present 3D models with associated textual contents, e.g. in (Callieri 2013). However, using these frameworks the authors need to learn the libraryspecific data structures and APIs and creating $3 \mathrm{D}$ web applications requires $3 \mathrm{D}$ specific know-how.

Only XML3D and Fraunhofer's X3DOM leverage the DOM, the central data structure for all web applications, for the structure of the 3D scene. This declarative approach helps web developers to create 3D web applications and all web libraries that work on the DOM can be used also for the 3D content of the application. In collaboration with Fraunhofer, we founded the W3C Community Group "Declarative 3D for the Web. Though implementations based on WebGL and J avaScript are already available today, standardisation will improve the support within browsers and give users the guarantee for a sustainable format.

\section{Conclusions}

With this work it was shown that XML3D enables non-graphics experts to develop a complex 3D application. There is still the need for experts in modelling such large scenes like Saarlouis, but the augmentation of the model with metadata like texts and anchor points for the code is pretty straightforward and does not require extensive prior knowledge.

Since the developed Cinema4D exporter does save all necessary data, especially the anchor points for specific objects, the model can be developed in parallel to the application development. This makes adding more and more objects to the model very easy and the model can be augmented with more information later without the need to change the application. Through the loose coupling between the model and the application the model can be exchanged easily. So the application's core framework can be reused for other projects.

The kiosk application has been running successfully since June 2012. The museum got positive feedback from visitors, but also some requests: visitors expressed theinterestin comparing both periods by switching the model at any time during navigation. This requires some additional work, because users could end up within buildings or wall that existed only in one of the periods, but could be added in a next version.

\section{Future Work}

Future plans include the transfer of the application to the WebGL-based implementation of XML3D. This will allow a presentation of the model on the Internet. Currently the structure and size of the model is too large to be transferred even over broadband connections to a casual viewer and to be rendered using J avaScript and WebGL. Reducing the complexity of the model could be done by modelling less detailed civil buildings and by exploiting instantiation of model elements.

\section{Acknowledgements}

The research presented in this paper has been generously supported by the Intel Visual Computing Institute as well as the EU project VERVE and FICONTENT, which is part of the Future Internet PPP program. Special thanks go to the staff of the municipal museum of Saarlouis.

\section{Bibliography}

Cabral, M., M. Zuffo, S. Ghirotti, O. Belloc, L. Nomura, M. Nagamura, F. Andrade, R. Faria, and L. Ferraz. 2007. “An experience using X3D for virtual cultural heritage." In Proceedings of the 12th International Conference on 3D Web Technology, 161- 164. New York: ACM.

Callieri, M., C. Leoni, M. Dellepiane, and R. Scopigno. 2013. "Artworks narrating a story: a modular framework for the integrated presentation of three-dimensional and textual contents." In Proceedings of the 18th Conference on 3D Web Technology, 167- 175. New York: ACM. 
Across Space and Time. Papers from the 41st Conference on

Computer Applications and Quantitative Methods in Archaeology. Perth, 25-28 March 2013

Khronos. 2011. "WebGL Specification." Last modified February 11. https:// www.khronos.org/ registry/ webgl/ specs/ 1.0.0/

Klein, F., K. Sons, D. Rubinstein, S. Byelozyorov, S. John, and P. Slusallek. 2012. "Xflow - Declarative Data Processing for the Web." In Proceedings of the 17th International Conference on 3D Web Technology, 37- 45. New York: ACM.

Pescarin, S., A. Palombini, V. Vassallo, L. Calori, C. Camporesi, B. Fanini, and M. Forte. 2009. 'Virtual Rome.” In Making History Interactive. Computer Applications and Quantitative Methods in Archaeology (CAA). Proceedings of the 37th Computer Applications and Quantitative Methods in Archaeology (CAA) Conference, edited by B. Frischer, J. Webb Crawford and D. Koller, 308-312. Oxford: Archaeopress.

Sons, K., F. Klein, D. Rubinstein, S. Byelozyorov, and P. Slusallek. 2010. "XML3D - Interactive 3D Graphics for the Web." In Proceedings of the 15th International Conference on Web 3D Technology, 175- 184. New York: ACM.

Sons, K., C. Schlinkmann, F. Klein, D. Rubinstein, and P. Slusallek. 2013. "Xml3d.js: Architecture of a Polyfill Implementation of XML3D." In 6th Workshop on Software Engineering and Architectures for Realtime Interactive Systems (SEARIS) Orlando, Florida, USA, 17 March 2013, 17 - 24. Orlando: IEEE.

W3C. 2012. “CSS 3D Transforms Module Level 3.” Last modified September 11. http://www.w3.org/TR/css3-3dtransforms/ .

W3C. 2013. "HTML5." Last modified August 6. http:// www.w3.org/TR/html5/ . 


\title{
An Interactive Virtual Roaming System for Beijing Hutong
}

\author{
Guoguang Du, Zhongke Wu, Mingquan Zhou, Kang Wang, Chongbin Xu \\ Beijing Normal University, China \\ Ziyang Li \\ Beijing City University, China
}

Pengfei Xu, Dongcan J iang and Xingce Wang

Beijing Normal University, China

\begin{abstract}
:
Beijing Hutongs, unique Chinese cultural heritage features, are an important part of Beijing traditional culture. Unfortunately, most of them are being damaged day by day. How to digitise these remaining relics, display them and disseminate them are now key issues. In this paper, we present a 3D interactive virtual roaming system based on Unity3d, which displays Beijing Hutongs in a realistic way. We used two technologies to build the 3D models of Beijing Hutongs. One consisted of manually generating 3D models by using 3D modelling software based on maps of Hutongs and the other consisted of using a multi-view stereo reconstruction technology. Then, we selected a $3 D$ game engine - Unity3d - to build a virtual environment and display the 3D models of Hutong. Furthermore, we added a variety of components to make the scene vivid. Finally, we achieved a $3 D$ stereo effect using Kinect to achieve natural interaction and simulate the four seasons.
\end{abstract}

\section{Keywords:}

Cultural Heritage, Multi-View Stereo, Unity3D, Kinect

\section{Introduction}

\subsection{Background of Beijing Hutongs}

Beijing Hutongs (Ding 2008) are the product of Beijing's long history. They are unique architectural feature and their appearance is shown in Fig. 1. Hutongs have a history of more than 800 years. The word "Hutong" first appeared during the reign of the Yuan Dynasty and is the transliteration of the Mongolian word "well". During the Qing Dynasty, the number of streets called "Hutong" in Beijing reached nearly 1000. In the 1980s, the number of streets was over 1300 . They were spread throughout the Imperial City. In recent years, with the advance of Beijing urban construction, the number of Hutongs has steadily reduced. How to digitise these relics, display them and disseminate them are now key issues.

The best way to preserve cultural heritage is to make peopleinterested in it. The means of spreading

Corresponding author: zwu@bnu.edu.cn and exchanging digital information are becoming manifold. Simple texts and images cannot vividly transfer information, as they do not convey dynamic processes and they cannot draw public attention. Virtual Reality Display Technology allows to build a computersimulated three-dimensional environment that integrates graphics, images, sound, animation, video, and other multi-dimensional information. The user can manipulate the virtual objects and feels immersed in an environment that combines the visual and audio experience.

In order to better preserve the Hutongs' legacy, we decide to use the existing virtual reality technology to build an interactive virtual roaming system for Beijing Hutongs.

\subsection{Related work}

Virtual Reality (VR) is a sophisticated system that utilises and synthesises different types of advanced technology to produce a virtual world allowing for multiple sensorial experiences. The 


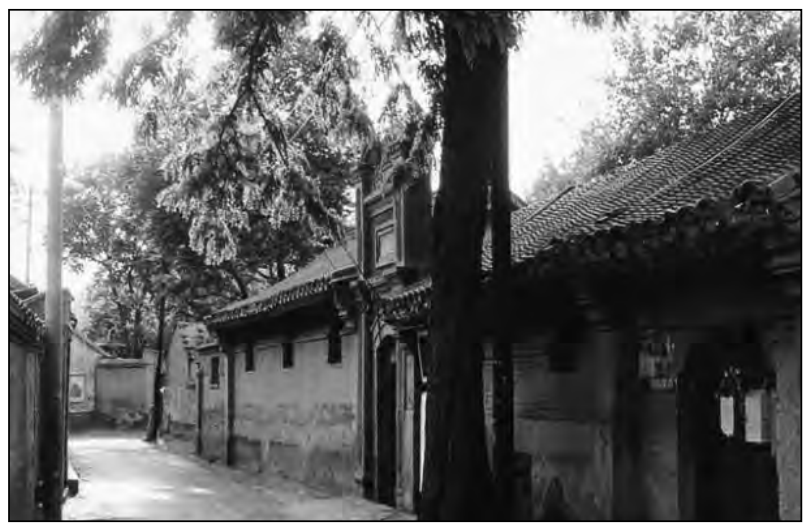

Figure 1. Beijing Hutong.

emergence of the three dimensional (3D) virtual technology has brought tremendous changes in the world. VR can immerse people in an environment that would normally be unavailable due to costs, safety issues or perception restrictions. A successful VR environment provides users with immersion, navigation, and manipulation opportunities (Heim 2000). Burdea and Coiffet (2003) described virtual reality as a simulation in which computer graphics were used to create a realistically-looking world that responded to user inputs. Applications to fields like entertainment, architecture, manufacturing art, medical, education and training have seen the effectiveness of this medium. The flexibility, reliability and adaptability of this environment are very much sought after, especially in education, training and the preservation of cultural relics.

In recent years, many significant progresses on virtual display research have been made by all countries in the world. Some important examples of this application are "Rome Reborn" project (Frischer Consulting 2013), China's “Dun Huang digital art protection and virtual tourism" project (Lu et al. 2002), and the "3D virtual exhibition of the Imperial Palace" project (James et al. 2008). These projects, which emphasise authenticity and immersion, were mostly developed based on high performance graphics workstations. Caves, domes and other special display equipment are needed to visualise the reconstructions and tourists must be in a particular place "to be personally on the scene". This not only requires high technology costs, but also creates inconvenience for tourists. Using digitisation technology will promote the preservation of major historical and cultural sites by recording geometry, colour, and texture information of the ancient buildings, creating virtual 3D model, deploying the results on work-group servers, and later making the virtual cultural sites available to the public through the Internet.

This paper presents the application of 3ds Max modelling technology and multi-view stereo technology to obtain the 3D models of Beijing Hutongs. These models were then moved into Unity3d game engine produced by Unity Technologies. Multiple functions were included to improve scene display. Additionally, Kinect was used to recreate a natural interaction and 3D stereo effect through stereo spectacles. At last, in order to display the gradual changes, we simulated the four seasons in the Hutong scene to make the scene more vivid.

\section{Key Issues of the Proposed System}

\subsection{How to obtain the 3D models of Beijing Hutong}

There are many limitations during the data acquisition process. For example, it is often difficult to acquire coherent and complete data of Hutong environments. Hutongs are often located in narrow streets surrounded by other buildings and other obstructions; consequently, photographs, videos or scans from certain positions might be impossible to obtain, either from the ground or from the air. Another common shortcoming is the problem of unwanted objects in front of the Hutongs, such as vegetation, street signs, vehicles and pedestrians. The difficulties of achieving the $3 \mathrm{D}$ data lead to the mixed use of several 3D reconstruction methods, such as combining 3ds Max manual models with multi-view stereo reconstruction technology. By using 3ds Max, we can obtain the models that are otherwise difficult to create, making up for the limitations of the multi-view stereo reconstruction technology.

\subsection{How to display the Hutong models in a good environment}

Hutong 3D models cannot provide themselves an immersive feeling, a good environment to display them is necessary. There are many robust game engines available that can be used and can provide excellent rendering, physics, music, and other sound effects. Among them, we chose Unity3d (Sa et al. 


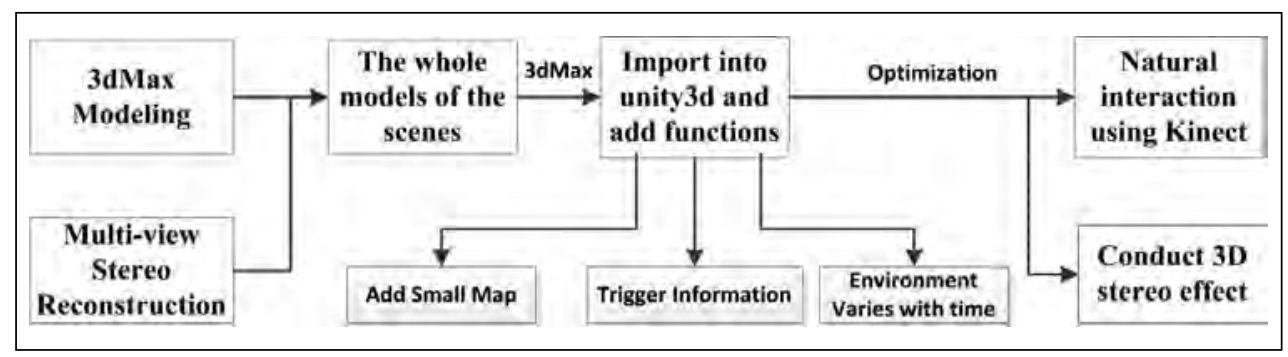

Figure 2. The entire design framework.

2010), which offers plenty of advantages. Unity3d supports many platforms including Windows, Linux, Mac, Android, and IOS. The Unity3d's builtin NVIDIA's PhysX Engine has an excellent physical effect. It also supports the JavaScript and C\# language, which makes its development easy.

\subsection{How to better experience the virtual Hutong environment}

It is assumed that one needs to roam in the scene in order to get a better experience. Thus, we decided to add a small map of the scene, a virtual character - the old Beijing voice - , and some other functions. To provide better interaction, we selected Kinect (Wikipedia 2013) as we believe it to be a valuable tool among those currently available on the market, such as the Wii Remote controller, data glove and other interactive devices. Kinect is the motion capture equipment proposed by Microsoft. Its biggest advantage is that it affords natural interaction. Microsoft Corporation launched Kinect forWindows SDK Beta, so that it can be conveniently developed in that environment to create natural interaction. Additionally, we also developed the $3 \mathrm{D}$ version of the virtual Hutong environment. The

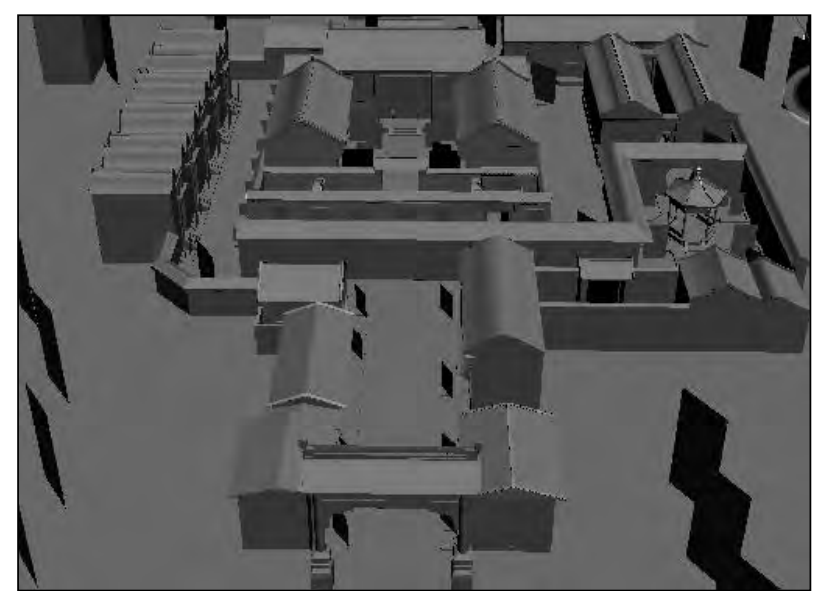

Figure 3. 3DS Max Model. public will have access to the $3 \mathrm{D}$ effect upon wearing a pair of anaglyph stereo spectacles.

\section{System Design and Implementation}

The full design framework is shown in Fig. 2.

\subsection{Obtaining the 3D models of the Hutongs}

The system contains two scenes from the Hutongs: one scene created with 3ds Max and one scene created with multi-view stereo reconstruction technology. The reason why we haven't use one scene is that it will affect the fluency of the system. Both the Hutong models constructed in 3ds Max and those constructed by multi-view stereo methods are in high resolution. If we had conflated these two models in one scene, we would have overloaded the system, thus affecting the rendering frequency. Therefore, it was decided to keep them separate

\section{3ds Max Modelling}

We used 3ds Max to construct the models of buildings, human figures, tables and chairs in the first scene. They constitute the overall scene

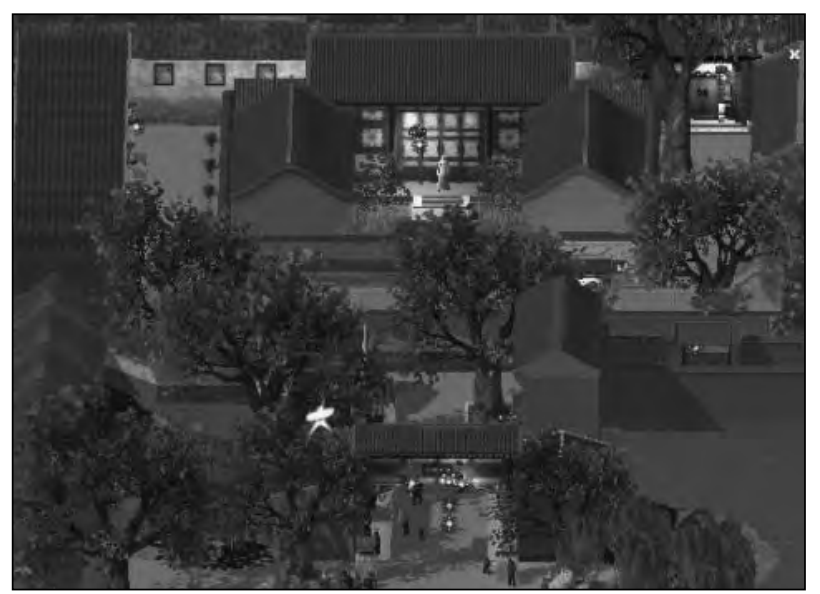

Figure 4. Effects in Unity3D. 


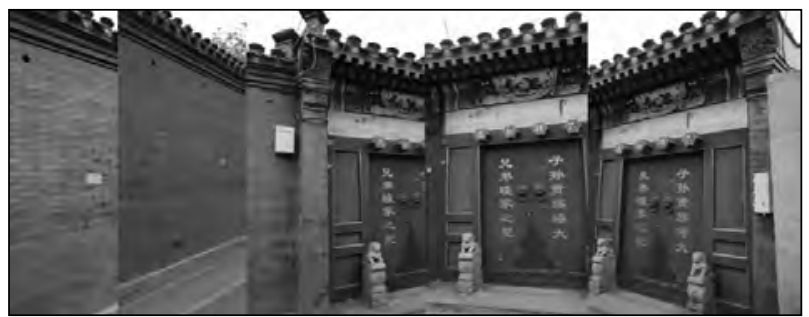

Figure 5. The photos taken for reconstruction.

contour, which can be seen in Fig. 3. We collected several texture images and combined them into the 3D models in order to render the 3D models as close to the real Hutongs as possible. Some textureimages were taken at Hutongs' locations. We also created several animated characters in order to make the scene more realistic. We then added trees and light to the scene in Unity3d, as shown in Fig. 4.

\section{Multi-view Stereo Reconstruction}

Among the numerous multi-view stereo reconstruction approaches, we adopted the approach presented by Furukawa and Ponce (Furukawa and Ponce 2010) - Patch-based Multiview Stereo Algorithm. Their method first need calibrated images, which provide the relationship between the image pixels and the 3D world. After that, the method uses matching technique based on small patches placed on the surface of the scene objects, which are subsequently back-projected onto the images. Initially, features like Harris corners (Harris and Stephens 1988) and DoG spots (Lowe 2004) were detected and matched across theimages, which were then projected on the object, defining the locations of the patches. These are defined in such a way that their re-projected footprints cover the actual images. They are then optimised so that any photometric discrepancy function across the reprojected patches is minimised. Later, the features were matched among images. By using the multiview geometry theory, we could obtain semi-dense clouds of small patches which served as a basis for denserstructuretriangulation. Finally, weperformed triangulation on these dense point clouds. The Poisson surface reconstruction algorithm (Kazhdan et al. 2006) as well as an iteratively refined visual hull method (Furukawa and Ponce 2008) were used at this end. This method provide outstanding performances in terms of reconstruction accuracy and completeness. On the evaluation site presented by Daniel Scharstein and Richard Szeliski (Daniel

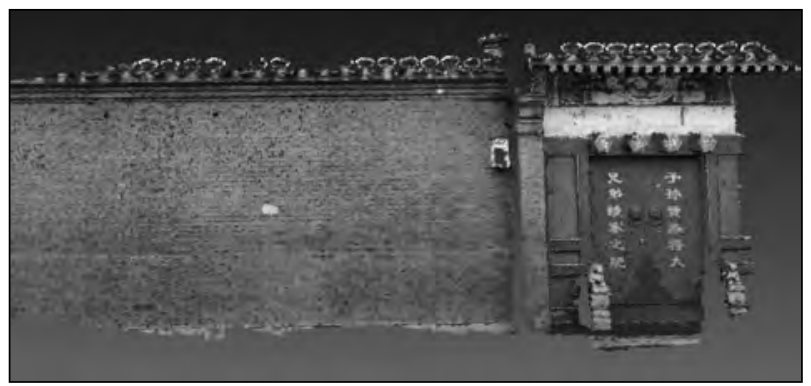

Figure 6. Point cloud reconstruction result of Beijing Hutong.

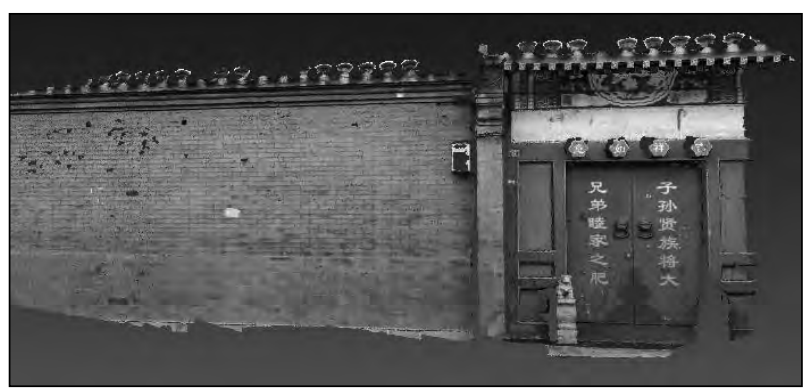

Figure 7. Mesh reconstruction result of Beijing Hutong.

Consulting 2013), its indicators are almost the highest. This algorithm does not require initial information such as bounding box, initial scene surface or the parallax range, and consequently it's very suitable for scene reconstruction, especially the reconstruction of outdoor scenes. It has been extended and successfully applied to 3D urban reconstruction (Furukawa et al. 2009; Furukawa et al. 2010) .

We initially took photos of one famous Beijing Hutong, the Zhanzi Hutong, which is located nearby Prince Gong Mansion. We took about 320 pictures that cover about thirty meters of the Hutong as show in Fig. 5.

Subsequently, we used the automated GUIbased end-to-end 3D reconstruction system from images, which integrates Furukawa's patch-based MVS algorithm developed by ChangChang $\mathrm{Wu}(\mathrm{Wu}$ 2013). It first calculates the camera parameters using the Structure from Motion tool - Bundler (Lourakis and Argyros 2004; Snavely et al. 2006; Snavely et al. 2008). Then it uses the patch-based Multi-view Stereo algorithm, which needs the camera parameters to obtain the 3D point cloud model of one Hutong, as shown in Fig.6. We then used Poisson reconstruction method to triangulate 


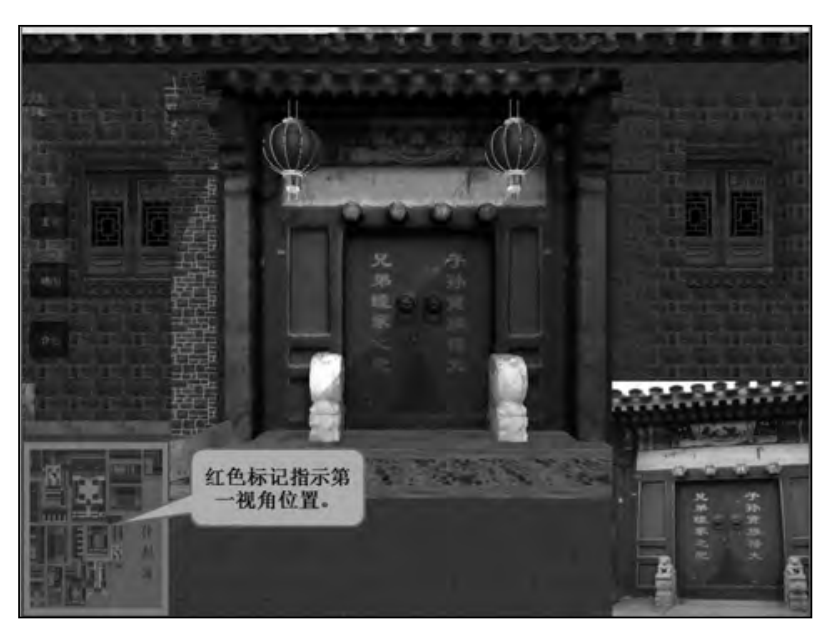

Figure 8. The small map of the scene.

the point cloud model shown in Fig. 7. The model was then processed in 3ds Max in order to get the file format supported by Unity3d (FBX file). The point cloud so obtained possessed the photo-quality colour, which was used in 3ds Max to generate a texture map. The resolution of the $3 \mathrm{D}$ models differs according to the input images, the more images and consequently more information, the higher the resolution. Since the project does not have access to expensive terrestrial laser scanners, we were unable to compare the quality obtained by models created by the MVS algorithm and models created by laser scanner. However, the obtained model resolution was relatively high and sufficient for display purposes.

3.2 Create virtual environment and add many functions

We used Unity3d software platform to createa friendly user interface, which allows for convenient and fast user operation. Users can employ the keyboard keys and the mouse to control the virtual character while roaming in the scene. The scenes provide a good sense of space, so viewers can truly experience and gain a 'feeling' for the environment.

We designed some specific features in order to show more vividly the environment, including the following:

a. Real-time viewing of the whole scene and independent navigation process, by providing a small map beacon that aids the navigation. We achieved this by mapping the 3D coordinates,

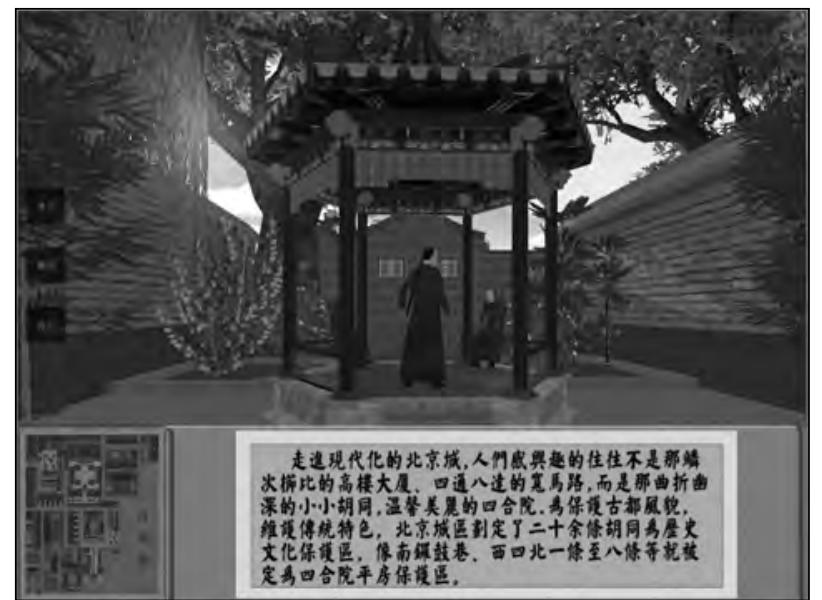

Figure 9. Triggered information.

the small map coordinates and the screen coordinates. The specific locations in the 3D scene were mapped into the 2D screen by extracting the $\mathrm{x}$ axis and the $\mathrm{z}$ axis. This $2 \mathrm{D}$ plane was then mapped with a quadrate small map image. The

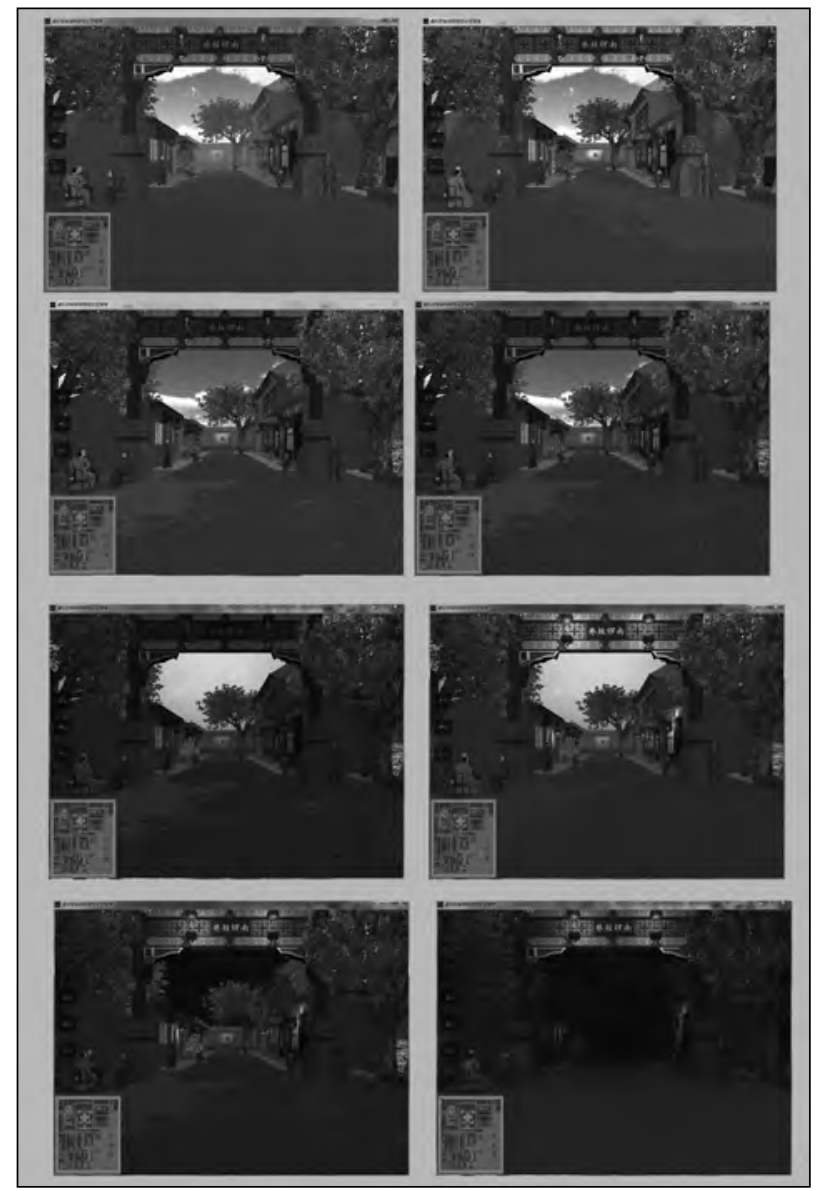

Figure 10. Different rendering effects. 


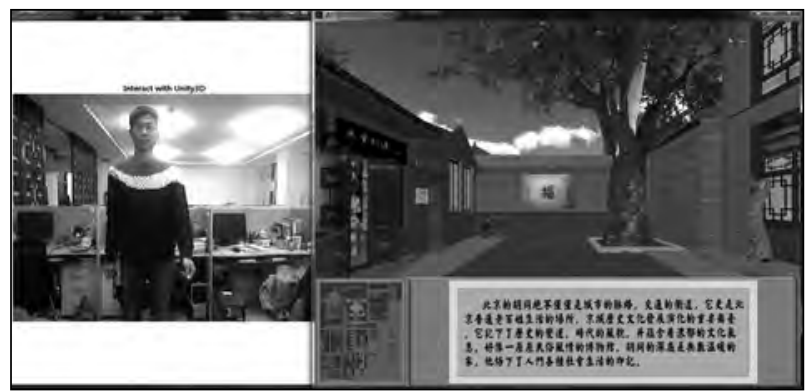

Figure 11. Using Kinect to control the virtual character.

red mark moves along with the virtual character. The effect picture is shown in Fig. 8.

b. Many parts of buildings or areas are marked: when users navigate to certain positions they can see relevant information, which includes texts, images and audio material. We achieved this by establishing limitations according to the character's position. If the position satisfies the trigger condition, the appropriate information appears. The results are shown in Fig. 9.

c. The environment changes with time: different light intensities are included, including fog densities, skies and angles of the sun in the morning, noon, afternoon and evening. We achieved this by using system's time to change different parameters. The results are shown in Fig. 10.

\section{Optimisation of the Virtual Hutong System}

\subsection{Natural interaction using Kinect}

We used Kinect to achieve natural interaction. Kinect can identify the human skeleton. In our case, the most widely used skeleton joints are the head joint, the left hand joint and the right hand joint. We obtain the position information of these three joints (Head. Position, RightHand. Position and LeftHand.Position) as the judgments. Kinect has its own coordinate which satisfies the right hand formula: on the right hand side of Kinect is the $\mathrm{x}$ axis, on the upside of Kinect is the y axis, and on the front side of Kinect is the negative $\mathrm{z}$ axis. We use the position information of three joints (Head.Position, RightHand.Position and LeftHand.Position) as the indicators of the position of the user. If you stretch

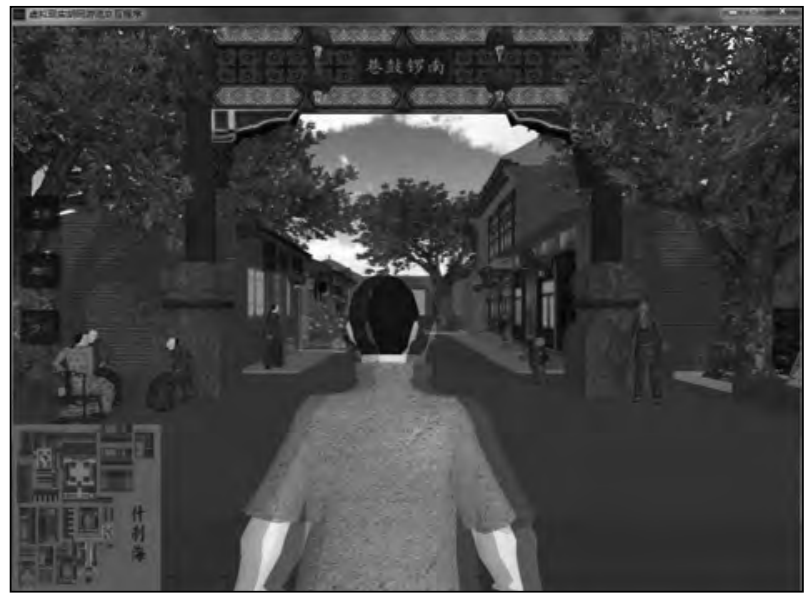

Figure 12. The $3 D$ effects of the scene.

out your right hand forward, the following command is used: RightHand.Position.z>Head.Position.z. We set this response to control the virtual character to moveforward. And if thefollowing command is used: LeftHand.Position.z>Head.Position.z, the virtual character goes back. We also used the distance between the head position and the hand position as another indicator to control perspective rotation. If RightHand.Position. $x>$ Head.Position. $x+0.45$ is used, which means you stretch out your right hand to the side, the virtual character rotates toward the right-hand side. Similarly, if the LeftHand. Position. $x<$ Head.Position. $x-0.45$ is used, which means you stretch out your left hand to the side, the virtual character rotates to the left. The results are shown in Fig. 11. By using Kinect, users do not need any external devices such as Wii Remote, data glove and other interactive devices.

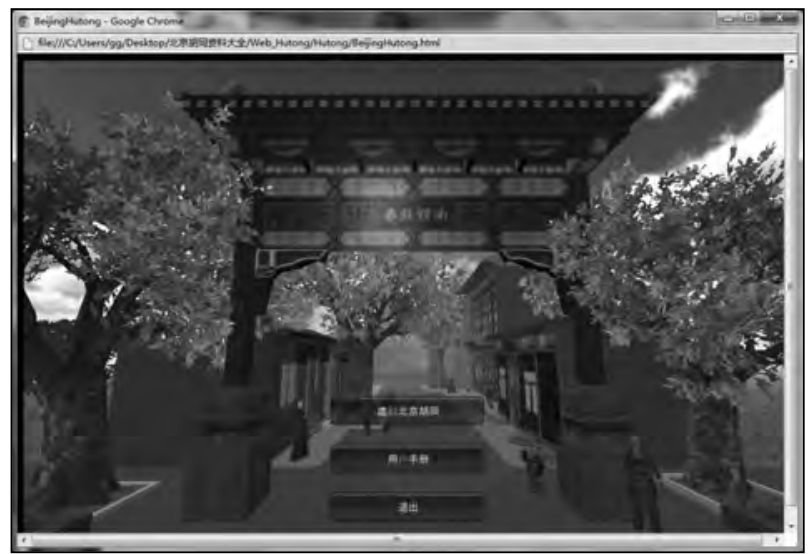

Figure 13. The Web Virtual Beijing Hutong. 


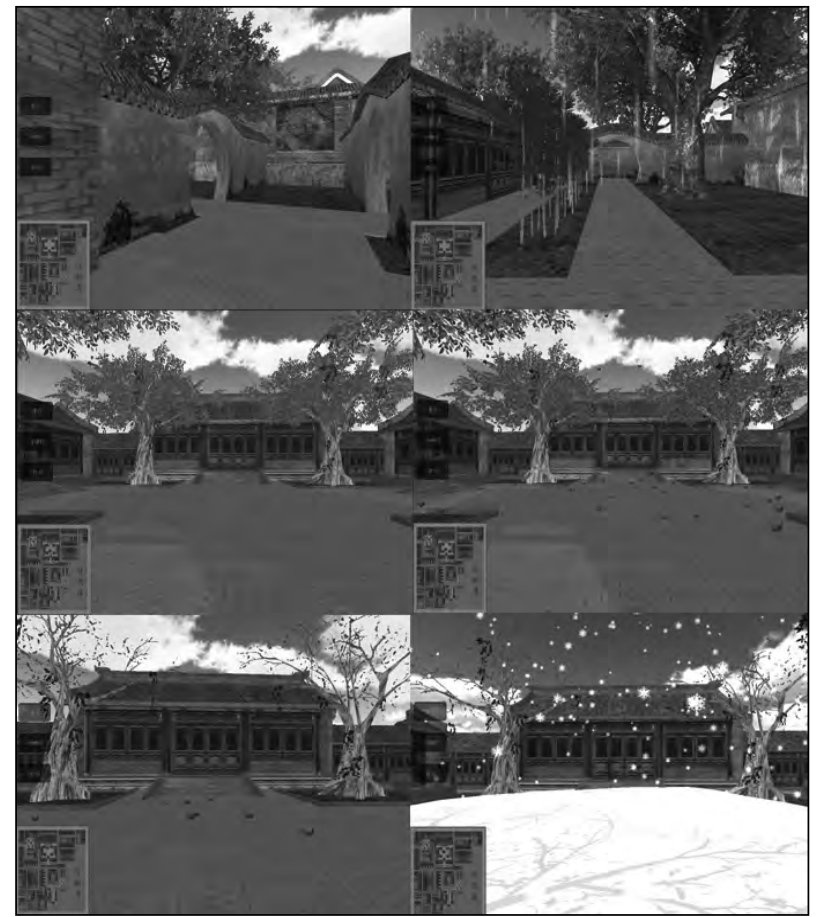

Figure 14. Seasons in the Virtual Scene.

\subsection{Conducting $3 D$ stereo effect}

We achieved $3 \mathrm{D}$ effect by the following workflow: initially, we obtained each frame image of the scene; secondly, we set two cameras, one of which was recording the Red light component while the other one was recording the blue and green components. Then, we merged the two cameras' views together. By controlling the distance of the two cameras, we can control the overlap part of the two cameras' views in order to achieve the best effect. 3D effect is then created by wearing a pair of anaglyph spectacles. The results are shown in Fig. 12.

\subsection{Putting the system on the website}

Since Unity3d supports many platforms, we generated directly the web file of Hutong so that it could be imported in a website. Developers can change the source html file to their own style and create a pop-up window on any website to run the system. The final effect is shown in Fig. 13. The only requirement is a web-player plug-in produced by Unity3d and we recommend using Google Chrome browser to get a better effect. We also created our own homepage to broadcast the Hutong culture.

\subsection{Season simulation in Beijing Hutong}

To enrich thecontent of thescene, wesimulated the four seasons in one courtyard of the Hutong scene. We set up four particle emitters to simulate spring rain, summer rain, autumn leaves and winter snowflakes. The spring rain particle emitter emits relatively small particles to represent spring; the summer rain particle emitter emits relatively larger and faster particles to represent summer rain; the fall is simulated by a release of leaves and the leaves were dynamically textured from green textures to yellow textures, to complete the transformation from summer to autumn. The snowflake particle emitter is used to emit snowflakes. The emitters are triggered according to the positions in the scene. The effect is shown in Fig. 14.

\section{Conclusions and Future Work}

Our multidisciplinary research spans information sciencetechnology and cultural heritage domains, and we have chosen Beijing Hutong as our research study-case. We built an interactive virtual roaming system for Beijing Hutong based on Unity3d, which allows for a valuable user experience. We used two methods to obtain the Hutong 3D models, displayed them on the Unity3d platform, added several components, provided a natural interactive method through Kinect to produce the $3 \mathrm{D}$ effect of the Hutong and to simulate the season transformation. The methods described in this paper are widespread and most of the used software is open source. What we proposed was an application example, which will possibly promote the development of virtual reality technology. Our work requires further development. Our future goals include the reconstruction of a larger number of Hutongs, the improvement of the resolution and the development of more realistic effects. Our work might not be able to fully reproduce the demolished Hutongs, but it is our hope that VR will be able to compensate for the loss of information on the Hutongs.

\section{Acknowledgements}

This work has benefited from the assistance and valuable input of many people. We would like to thank Dr. Y. Furukawa and J. Ponce for their Patchbased Multi-view stereo reconstruction algorithm; 
thanks to Dr. Wu ChangChang for his integrating work; thanks to N. Snavely, S. M. Seitz and colleagues for their bundler calibration algorithm; and thanks to M. Kazhdan and colleagues for their Poisson surface reconstruction method. We would like to thank also thank Unity Technologies for their wonderful Unity3d engine. This work was funded by the National Key Technology Research and Development Program of China No. 2012BAH33F04, Beijing Key Laboratory Program of China No.Z111101055311056 and the Fundamental Research Funds for the Central Universities No. 2009SD-11.

\section{Bibliography}

Burdea, G. C., and P. Coiffet. 2003. Virtual reality technology. New York: Wiley.

Daniel Consulting. 2013. "Multi-View Stereo Evaluation.” Last modified March 11. http://vision.middlebury.edu/ mview/ eval/ .

Ding, J . 2008 "The Images of Beijing Hutong In the Past 30 years." Social Science of Beijing (5):107- 112.

Frischer Consulting. 2013. "Rome Reborn.” Last modified August 1. http:// romereborn.frischerconsulting.com/ .

Furukawa, Y., B. Curless, S. M. Seitz, and R. Szeliski. 2009. "Manhattan-world stereo." In Proceedings of the IEEE Conference on Computer Vision and Pattern Recognition, 1422- 1429. Miami: IEEE.

Furukawa, Y., B. Curless, S. M. Seitz, and R. Szeliski. 2010. "Towards internet-scale multi-view stereo." In Proceedings of the IEEE Conference on Computer Vision and Pattern Recognition, 1434- 1441. San Francisco:IEEE

Furukawa, Y, and J. Ponce. 2008. "Carved visual hulls for image-based modeling." International Journal of Computer Vision 81(1):53-67.

Furukawa, Y., and J. Ponce. 2010. "Accurate, dense, and robust multi-view stereopsis." IEEE Transactions on Pattern Analysis and Machine Intelligence 32 (8):13621376.

Harris, C., and M. Stephens. 1988. "A Combined Corner and Edge Detector." In Proceedings of the 4th Alvey Vision Conference, 147- 151. IEEE.
Heim, M. 2000. Virtual Realism. Oxford: Oxford University Press.

Kazhdan, M., M. Bolitho, and H. Hoppe. 2006. "Poisson surface reconstruction." In Proceedings of the 4th Eurographics Symposium on Geometry Processing, 6170. Aire-la-Ville: Eurographics Association.

Lin, J. Q. P., and H. W. H. Din. 2008. "Using animation and interactive virtual technology to create interpretive materials for museum learning and promotion." In ACM SIGGRAPH ASIA 2008 Educators Programme article 16, 1- 10. Singapore: ACM.

Lourakis, M. I. A., and A. A. C. Argyros. 2004. "The Design and Implementation of a Generic Sparse Bundle Adjustment Software Package Based on the LevenbergMarquardt Algorithm." Technical report FORTH-ICS/ TR340. Heraklion: Institute of Computer Science.

Lowe, D. G. 2004. "Distinctive image features from scaleinvariant Keypoints." International J ournal of Computer Vision 60 (2):91- 110.

Lu, D., Y. Pan, and R. Chen. 2002. "Dunhuang Cave Virtual Rebuilding and Mural Restoration Simulating." Acta Geodaetica Et Cartographic Sinica 30 (1):12- 16.

Snavely, N, S. M. Seitz, and R. Szeliski. 2006. "Photo tourism: exploring photo collections in 3D." ACM Transactions on Graphics 25 (3):835- 846.

Snavely, N., S. M. Seitz, and R. Szeliski. 2008. “Modeling the World from Internet Photo Collections." International J ournal of Computer Vision 80 (2):189- 210.

Wang, S., Z. Mao, C. Zeng, H. Gong, S. Li, and B. Chen. 2010. "A new method of virtual reality based on Unity3D." In 2010 18th International Conference on Geoinformatics (Geoinformatics 2010), June 18th - 20th, 2010 Beijing, China, edited by Y. Liu and A. Chen, 1- 5. Beijing: IEEE.

Wu, C. 2013. "VisualSFM. A Visual Structure from Motion System." Accessed J une 10. http:// www.cs.washington. edu/homes/ccwu/vsfm/.

Wikipedia. 2013. "Kinect." Last modified October 9. http:// en.wikipedia.org/ wiki/ Kinect. 


\title{
A Documentation System for Digital Reconstructions with References to the Mausoleum of the Tang-Dynasty at Zhaoling, in Shaanxi Province, China
}

\author{
Mieke Pfarr-Harfst \\ Technische Universität Darmstadt, Germany
}

\begin{abstract}
:
The content of this paper includes a documentation system for digital reconstructions as a contribution to the preservation of knowledge within our digital cultural heritage. The idea for a comprehensive documentation of underlying sources and the process of reconstruction for digital reconstruction arose from nearly twenty years of experience in this area at the Technische Universität Darmstadt and the ongoing reconstruction project "The Imperial Tombs at Xi'an". Indeed, this project was based on research results, as yet unpublished, as well as on findings arising from the reconstruction process. The main goal of this documentation was the preservation of this knowledge for use in subsequent research projects. The initial comprehensive documentation of a digital reconstruction project was the result of three years of research, hitherto unparalleled in its depth. A system, the Four-Level-System, was developed specifically for digital reconstructions. The documentation preserves knowledge, essentially at the theoretical level. It is a first step in order to establish an adequate documentation system.
\end{abstract}

Keywords:

Digital Cultural Heritage, Digital Reconstruction, Virtual 3D Models

\section{Digital Reconstructions in the Context of the UNESCO Charta}

The "Charta for the Preservation of Digital Cultural Heritage" issued by UNESCO in 2003 was the starting point for researching into a documentation system for digital reconstruction as a contribution to the preservation of knowledge within our digital cultural heritage.

The UNESCO Charta defines digital cultural heritage as follows: Digital heritage consists of unique sources of human knowledge and human means of expression. It encompasses sources from all areas of daily life that are available in digital form (UNESCO 2003). Furthermore, in this Charta, UNESCO clearly warns against the loss of this knowledge and calls for the development of strategies and solutions for its preservation. According to this definition, digital reconstructions are regarded as part of digital cultural heritage. They are essential for the preservation of the knowledge contained therein. As an intersection of various scientific disciplines, especially architecture, history

Corresponding author: pfarr@ika.tu-darmstadt.de of architecture and archaeology, they consolidate knowledge and represent a scientific tool and a medium for cultural heritage. In effect, the definition of digital reconstructions and reflection upon their fundamental principles underscore their affiliation with cultural heritage.

Digital reconstruction is a digitally based reproduction of a no longer visible or no longer existent building, urban complex, structural environment or events influencing structural environment. It is based on scientific findings and other sources of human knowledge (Pfarr 2010, 9). The extensive interest in architectural structures that can be reconstructed, the fusion of sources as well as discussion among experts represents the content basis, while the technical system, consisting of hardware and software, represents the technical basis. Digital reconstruction is a synthesis of sources from the historical and cultural context, the project background and the process of reconstruction. All available information is collected, consolidated and assembled into a coherent picture. The result is a digital dataset that can be processed for research as well as for the transfer of knowledge. 


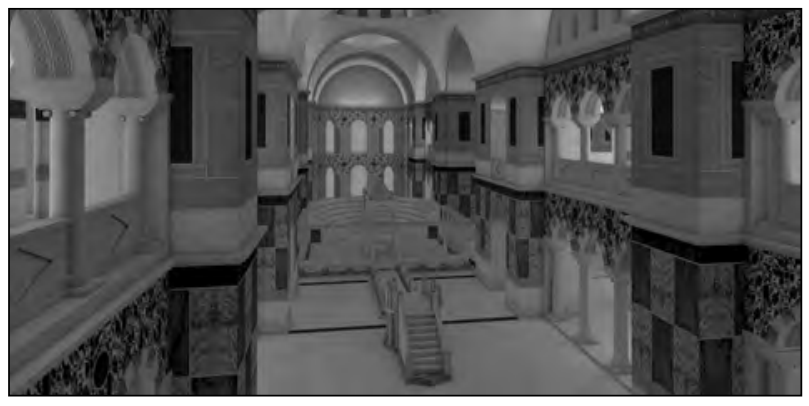

Figure 1. Digital reconstruction of St. John's Basilica in Ephesos. (C) Dept. IKA, TU Darmstadt, 2009.

A short cross-section of digital reconstructions from the Department of Information and Communication Technology in Architecture at Technische Universität Darmstadt will illustrate in terms of context, goals and project partners just how much expertise is available. The complexity of the following briefly described projects will underscore the role of digital reconstruction as a bearer of unique knowledge that can be lost due to a lack of documentation procedures. These digital reconstruction projects are especially dependent upon the people involved whose scholarly expertise is embedded into the work. If these people are missing, the knowledge is missing.

The first example is the project called "Ephesus during the Byzantine Period". The Austrian Archaeological Institute, the Austrian Academy of Sciences, the Romano-Germanic Central Museum Mainz, the Technical University Munich, and the Vienna University of Technology were involved as project partners.

The main goals of this project were to bring together all available information - such as text sources, archaeological findings, drawings, plans for the consolidation and visualisation of knowledge garnered in 100 years of excavations - and to substantiate the level of knowledge on the basis of digital models (Fig. 1). An incredible amount of findings was available for each building, district and for individual objects. The sources were digitised in the event that they had not been previously available in digital form. Moreover, 3D-models or 3D-scanning data of objects and building elements that had been prepared by other scientists as a basis for modelling were also worked into the model. The digital 3D model illustrates the complexity of the research results of the excavations at Ephesos.

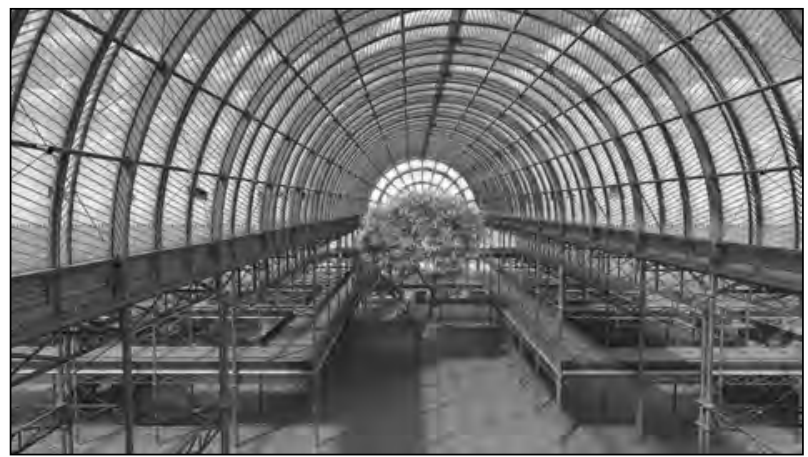

Figure 2. Digital Reconstruction of Crystal Palace in London. (C) Dept. IKA, TU Darmstadt, 2011.

The reconstruction process lasted two years and was characterised by a phase during which the digital 3D model was created at the computer and a phase during which this model was corrected and verified by the participating scholars. The $3 \mathrm{D}$ model for the first time brought all relevant sources together into three-dimensionality and initiated a sort of 'open research model' that has undergone several extensions since the completion of the original model.

The goal of the project "Digital Reconstruction of the Crystal Palacein London" was thevisualisation of a no longer extant building and the spatial perception of the time by means of a film using $3 \mathrm{D}$ technology. The Art and Exhibition Hall of Germany in Bonn was the main partner in this project.

The construction in a three dimensional space as a direct transfer of a building into reality can be well illustrated by the example of the reconstruction of the Crystal Palace. The working plans for all of the building components were available for this space. Until recent times the assembly methods of this modular construction could not be reassessed nor the construction methods be verified. The virtual 3D model makes the impression of space visible and explains the incredible engineering achievement (Fig. 2).

These two examples have shown the potential of digital reconstruction as a part of a research process. The knowledge generated and contained in digital reconstructions must be preserved by an appropriate system of documentation as per the UNESCO Charta. 


\begin{tabular}{|c|c|}
\hline Principles & Transfer: Digital Reconstruction \\
\hline \multirow[t]{3}{*}{ structured } & $\begin{array}{l}\text { structure of } 4 \text { levels - background, project } \\
\text { context, systematic, sources }\end{array}$ \\
\hline & $\begin{array}{l}\text { referencing the sources and the } \\
\text { reconstructions process }\end{array}$ \\
\hline & classification of objects and documents \\
\hline clearly arranged & See "structured" \\
\hline $\begin{array}{l}\text { transparent/ } \\
\text { comprehensible }\end{array}$ & $\begin{array}{l}\text { showing all sources, decisions, } \\
\text { misinterpretations and the workflow }\end{array}$ \\
\hline truthful & showing unknown parts of the research \\
\hline complete & showing all important backgrounds \\
\hline editable & open system \\
\hline
\end{tabular}

Table 1. The transfer of documentation principles to digital reconstructions.

\section{The Documentation System}

The lack of strategies for knowledge preservation in the context of the constantly increasing volume of digital models - especially in the Internet platform - uncovers a potential for the loss of knowledge at both content and technical level. Avoiding this it is necessary to find adequate strategies and solutions.

Our project provides a base structure for a new documentation system dedicated to the preservation of knowledge at content level. We must point out that this is a theoretical research project, which aims to create a universally valid documentation system that is applicable to most conceivable digital reconstructions. The emphasis is on content, not on technology.

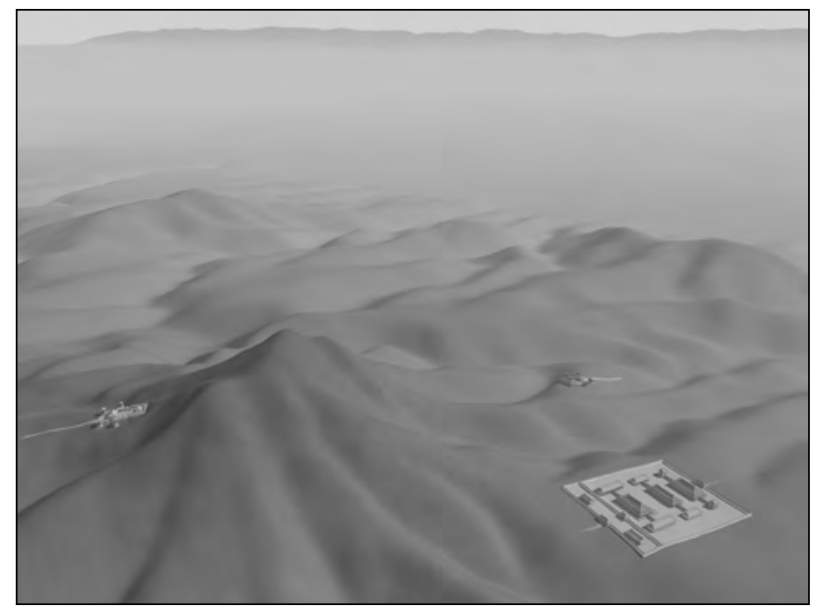

Figure 3. Digital Reconstruction of Imperial Tomb of Zhaoling, China - Area as a Whole. (C) Dept. IKA, TU Darmstadt, 2006.

The documentation system encompasses all components of digital reconstruction and is based on the fundamental principles of scientific documentation (Gaus 2005, 11-15), the London Charter (Denard 2012, 57-71) and known ontologies - for example CIDOC CRM (ICOM and CIDOC CRM 2013) - . These principles were transferred to the specific case of digital reconstruction. Table 1 shows the transfer of documentation principles to digital reconstructions. An example is the "transparent documentation" principle. In the case of digital reconstructions this means that all sources, decisions, workflow, possible misinterpretations and methodology must be comprehensibly presented (Pfarr 2010, 83).

Based on this transfer (Table 2) the so called 'Four-Level- System' as a new documentation

\begin{tabular}{|c|c|}
\hline Level of the Documentation System & Content \\
\hline level 1 - background & all informations about the project (partner, content, intention) \\
\cline { 2 - 2 } & results, perspectives \\
\cline { 2 - 2 } & structure of the 3D modell, technical basics \\
\cline { 2 - 2 } & common basics of the digital reconstruction \\
\hline level 2 - project context & the content of the project from th cultural, historical and architectural point of view \\
\hline level 3 - systematic & systematic of the documentation \\
\cline { 2 - 2 } & systematic of the reconstruction process, \\
\hline level 4 - objective evidence & all sources of the reconstructed building \\
\cline { 2 - 2 } & clear correlation of object - document \\
\cline { 2 - 2 } & clear correlation of process - document - object \\
\cline { 2 - 2 } &
\end{tabular}

Table 2. The Four-Level-System. 
system for digital reconstructions was developed. The first level, Level 1, is comprised of background with general information and parameters for the reconstruction project. Level 2 contains basic and important information about the project from the cultural, historical and architectural point of view. Level 3 involves methodology, specification of individual provisions such as nomenclature, classifications and structuring which must be coordinated with the question at hand. Level 4 involves objective evidence that constitutes the focal point and fulfils the requirement of scientific documentation - above all, the clear correlation between object and document - . In the case of digital reconstruction, the object is the building, complex or structure to be reconstructed and the document consists of the scientific sources. The focal point of the documentation system - the level of objective evidence - consists of three main sections. The starting point is the text-based building description, an overview of the most important parameters of the building with cross-references to the two other main parts, the sources' catalogues and the methods' catalogues.

In the sources' catalogue (Fig. 9) of each individual building the source is directly assigned to the object and in the methods' catalogue the object is assigned to the sources and the process (Fig. 10).

The level 'objective evidence' is based on a binding classification for all objects and sources. Thus, an appropriate nomenclature for all objects and documents, that is for all buildings, sources and the process itself must be developed and defined.

\section{The Reference Project}

The Four-Level-System was tested within a 'reference project' connected to the digital reconstruction of the mausoleum of the TangDynasty at Zhaoling, China (Fig. 3).

In this case, the Level 1 includes the project background and incorporates the subproject "Zhaoling Mausoleum" into the major project "The Digital Reconstruction of the Imperial Tombs of Xi'an". The goal of the major project was to visualise the immense spatial dimensions of the area and the archaeological sites in situ. The results were shown in an exhibition in the Federal Art and Exhibition

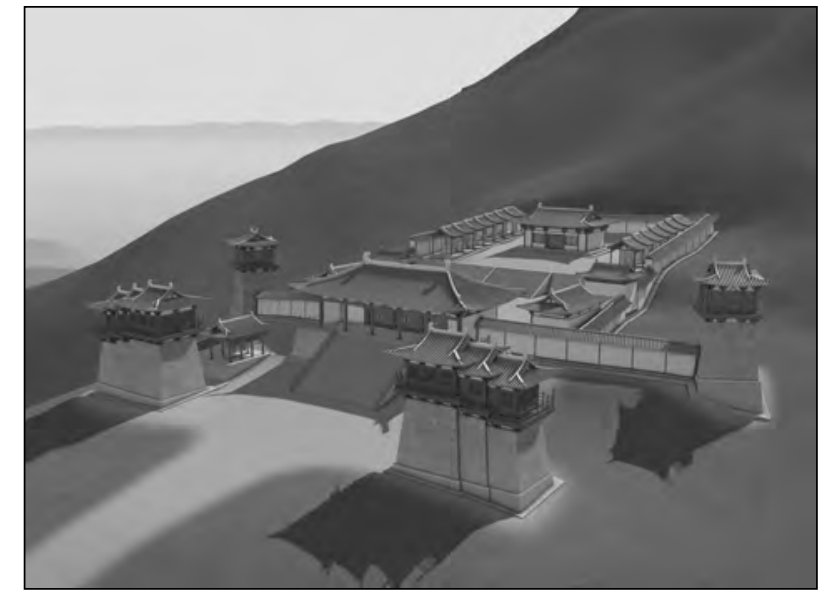

Figure 4. Digital Reconstruction of Imperial Tomb of Zhaoling, China - Northern Part. (C) Dept. IKA, TU Darmstadt, 2006.

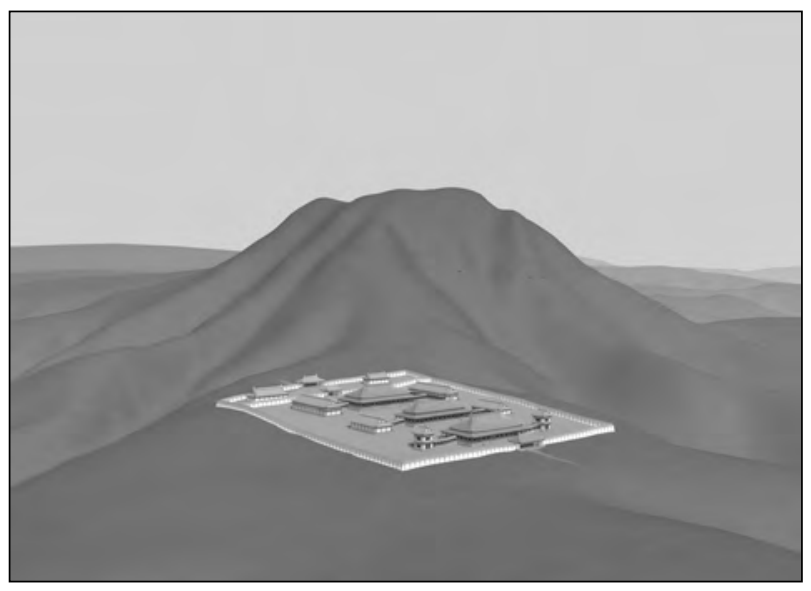

Figure 5. Digital Reconstruction of Imperial Tomb of Zhaoling, China-Southern Complex. (C) Dept. IKA, TU Darmstadt, 2006.

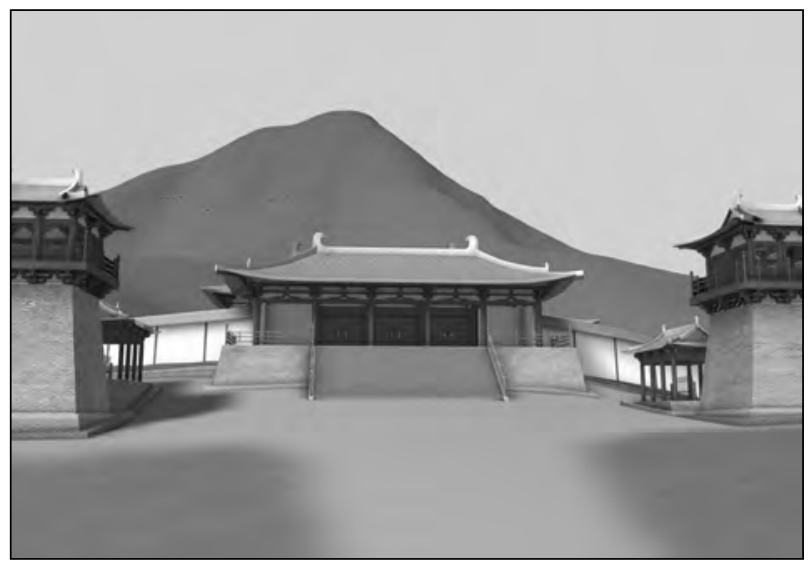

Figure 6. Digital Reconstruction of Imperial Tomb of Zhaoling, China - Southern Gate. (C) Dept. IKA, TU Darmstadt, 2006. 


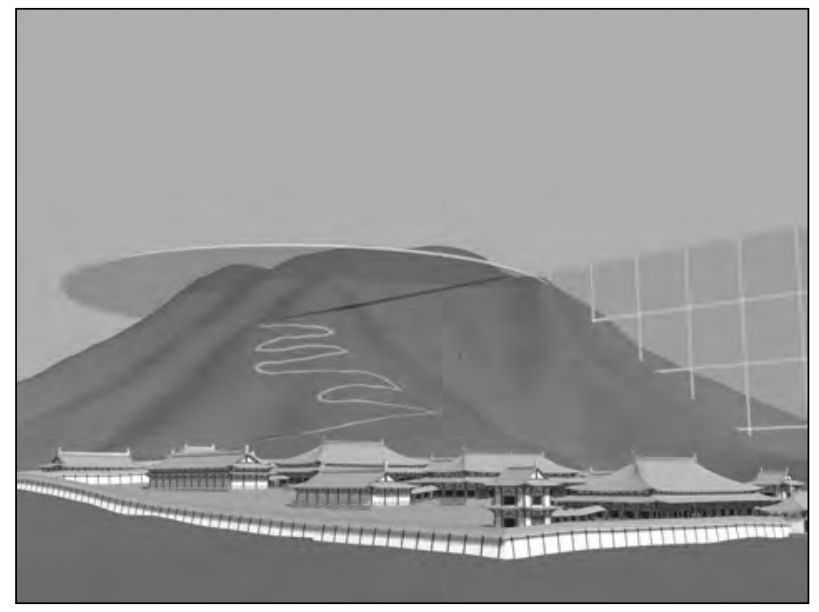

Figure 7. Digital Reconstruction of Imperial Tomb of Zhaoling, China - The Grave. (C) Dept. IKA, TU Darmstadt, 2006.

Hall in Bonn. As it is important to list the project partners, these too can be found at the first level of the documentation.

The second level - the project context includes a brief side trip into Chinese history, architecture and the prevailing conception of the hereafter. This second level is key to understand a digital reconstruction, especially the one of historical buildings and complexes. Architecture is always an expression of the prevailing society and the time during which it was constructed. This is also the case for the digital reconstruction of the imperial tombs at Xi'an. The rules of Chinese architecture in which the hierarchy of use is directly reflected in the arrangement of buildings shed light on complexes that no longer exist but are to be reconstructed. The same can be said of the Chinese conception of the afterlife. The duty of the emperor's subjects to take care of him after his death - as they did during his lifetime - legitimates and supports the hypothesis that there is a palace complex in the south.

For that reason the presentation of this context is necessary for a comprehensive documentation. The structure of the documentation, especially for the reference project, is established in Level 3 . The main structures of the 3D model and the scientific sources were transferred into appropriate classifications and nomenclature. The development of such a nomenclature was necessary in order to properly assign the underlying sources to individual reconstructed objects in form of buildings within the

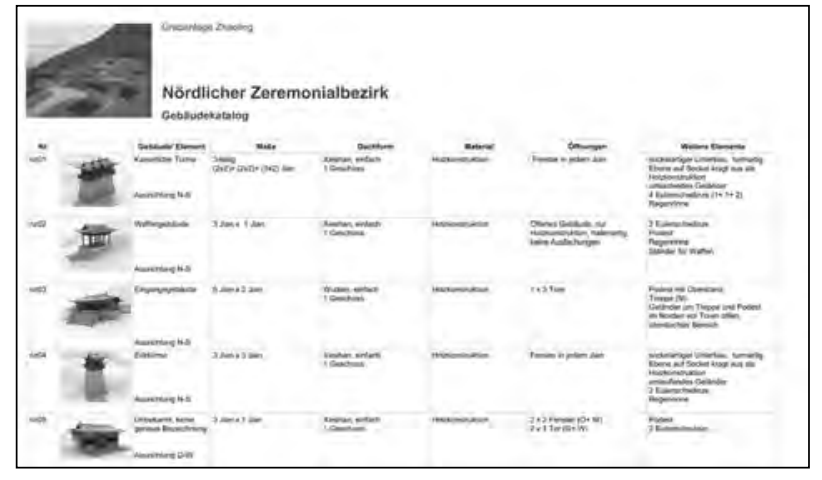

Figure 8. Documentation System for Digital Reconstructions - Building Catalogue. (C) Mieke PfarrHarfst, 2010.

imperial tombsatZhaoling. Theburial siteconsists of the complex with four major sectors and a total of 29 individual buildings. The entire complex including the 187 ancillary graves (Fig. 3) and the four main sectors, the North Ceremonial Complex with 11 buildings (Fig. 4), the South Palace with 12 buildings (Fig. 5), the South Gate with 6 buildings (Fig. 6), and the grave itself within the mountain (Fig. 7) were documented. These buildings and complexes were provided with appropriatenomenclature to facilitate a clear assignment of object to document. Thus, the nomenclature is composed of the first letters of the German notation for the given complexes and parts of complexes. After that, the number ID of the building is added. The buildings of each sector of the complex are brought together in a building catalogue, a sort of index. The catalogue provides an identity number for the building and gives further information (Fig. 8).

In addition to the objects, i.e. the buildings, the documents or sources were structured and divided into classifications and groupings of sources. In the case of the reference project, the most frequent source groupings are archaeological findings, drawings and comparable structures. The nomenclature follows the German version of the words. We classify the sources as 'hard' and 'soft' sources. Hard sources are the primary sources such as archaeological findings; soft sources, such as comparable structures, are subject to interpretation. This structuring of sources is transferred into an appropriate nomenclature that indicates the part of the complex, source classifications, source groupings and the amount of data. 
The focal point of the documentation, in the case of the reference project, is also the level of objective evidence, level 4 . As described above, at this level the following takes place: the definitive assignment of the underlying sources and the resulting virtual models as well as the documentation of the reconstruction process. Both parts of Level 4 are summarised in catalogues.

The definitive assignment of document to object takes place in the source catalogue (Fig. 9). The source with its nomenclature and designation can be found here, including information as to its significance and application, as well as its origin. Information concerning source classification and source grouping can be found here as well.

In the case of the reference project, a documentation of each of the 29 individual buildings of the entire complex was carried out as described in the section concerning level 3. Accordingly, each building has its own source catalogue for the documentation of the knowledge basis. From the catalogues it is also apparent for which building sections (foundation, roof, middle section) the sources have been drawn upon. Furthermore, the catalogues refer to the data repository in which all utilised sources are digitally available and are attached to the original documentation.

The results of digital reconstruction can be made comprehensible only through the disclosure of the reconstruction process. The reconstruction process itself must first be generalised with a binding glossary. The process consists of four phases: preparation, reconstruction, verification and finalisation. The preparation phase includes preliminary work relative to content, administration and technology. The reconstruction and verification phases are reiterated several times during the procedure and are in a process of constant change. The development of the finalisation phase is based on the goal of the project.

The four project phases were adopted for the reconstruction process of the reference project. An appropriate nomenclature has been defined, which demonstrates the relationship to the complex, process, project phase, as well as to the type of data. Altogether there were four reconstruction phases and four workshop phases in the reference project.

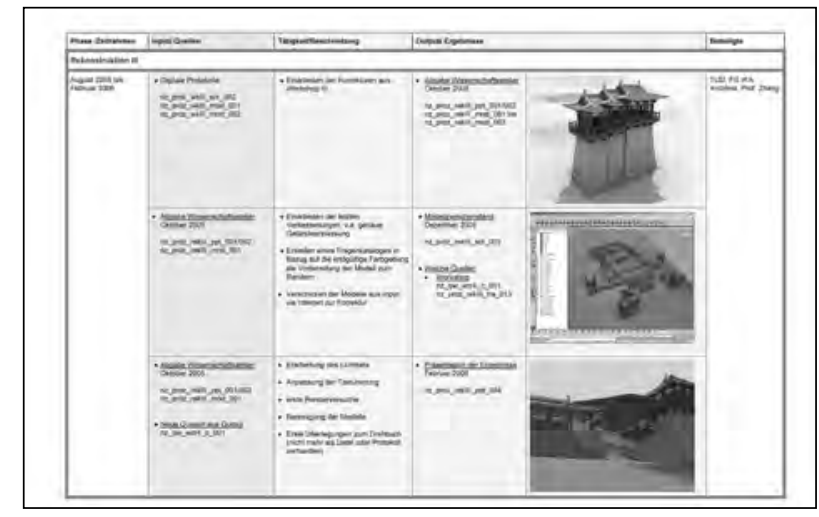

Figure 9. Documentation System for Digital Reconstructions - Source Catalogue. (C) Mieke PfarrHarfst, 2010.

The summary of the reconstruction process is provided in the methods catalogue (Fig.10). Sources, individual operations and their results are displayed in terms of input-output diagrams. The knowledge basis is given as input for each individual phase. It is available in the form of a plan, a survey, a comparable structure or as the results of a workshop. Output is the result of each individual phase, generally illustrated as the intermediate result of the 3D model.

We will use a specific example, the imperial towers of the North Ceremonial Complex, to clarify our point and we will point out how to find the way through the documentation system.

The identification number of the building can be found by means of the building catalogue for the North Ceremonial Complex. This building has three sections and a simple Xieshan roof (Fig. 8). The building description includes the function of the towers as a characteristic trait of an imperial complex as well as its position in the compound and includes further background information. There is also a reference to particular sources and milestones in the reconstruction process as well as to the source and methods catalogue.

The source catalogue for the building (Fig. 9) indicates the actual on-site situation. Only the plinth was verifiable through excavation. The wooden construction above it is based on comparable structures as well as outlines from the archaeologist in charge. The building methods' catalogue (Fig. 10) contains the various working phases, inputs 


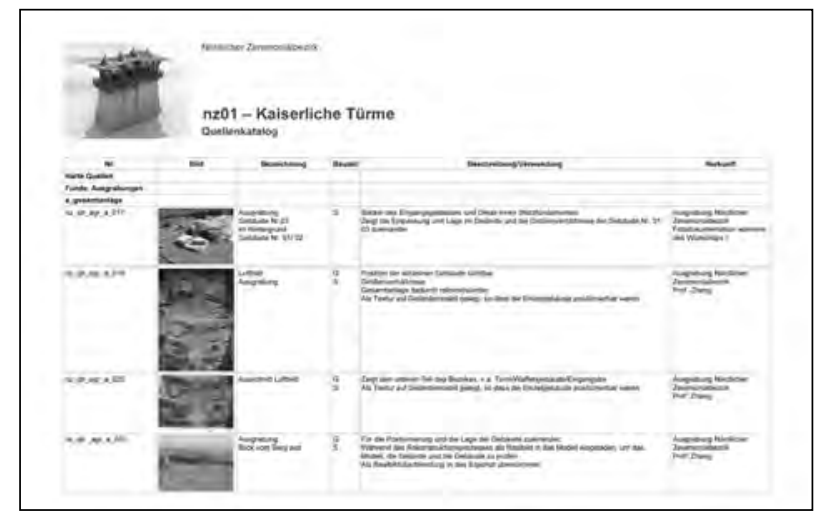

Figure 10. Documentation System for Digital Reconstructions - Methods Catalogue. (C) Mieke PfarrHarfst, 2010.

and results - the various stages of the model that become increasingly detailed.

The three sections of the documentation level, the building description, as well as the source and methods catalogues of all 29 individual buildings are available in a digital attachment - a sort of data repository - which includes all the digital datasets.

\section{Conclusions}

The documentation of our reference project should have - hopefully - clarified the complexity of a digital reconstruction and the knowledge contained therein. From a scholarly point of view, all of the described levels of documentation structure are important and indispensable. Equally essential are the demonstration of the reconstruction process as well as the clear interpretation of the underlying sources.

The described documentation system represents a basis for further research in the area of digital reconstruction. The next step of the research is to bring the documentation system to a usable size. The documentation system will be further developed in a large-scale research project that includes project partners from various academic disciplines and institutions and then transferred into a practicable methodology. "Practicable" in this case means easy to use without requiring additional staff and financial resources. In future, the problems of technical preservation of knowledge through archiving, administration and processing of data can only be solved with an interdisciplinary team.
However, unless there is a substantial change of awareness with regard to the potential loss of knowledge among all parties involved.

\section{Bibliography}

Denard, H. 2012. "A New Introduction to the London Charter." In Paradata and Transparency in Virtual Heritage, edited by A. Bentkowska-Kafel, D. Baker, and H. Denard, 57- 71. Farnham: Ashgate.

Gaus, W. 2005. Dokumentations- und Ordnungslehre: Theorie und Praxis des Information Retrieval. Berlin: Springer-Verlag.

ICOM and CIDOCCRM. 2013. "What is the CIDOCCRM." Last modified January 18. http://www.cidoc-crm.org/.

Pfarr, M. 2010. Dokumentationssystem für digitale Rekonstruktionen am Beispiel der Grabanlage Zhaoling, Provinz Shaanxi, China. PhD Diss., Technische Universität Darmstadt.

UNESCO. 2003. "Charter on the Preservation of the Digital Heritage." In Vol. 1 of Records of the General Conference. 32nd Session Paris, 29 September to 17 October 2003 edited by United Nations Educational Scientific and Cultural Organisation, 74-77. Paris: United Nations Educational Scientific and Cultural Organisation, 2004. Accessed J anuary 20, 2014. http:// unesdoc.unesco. org/ images/ 0013/ 001331/ 133171e.pdf\#page=80. 


\title{
3D Modelling Technologies in Humanities. A Literature-Based Survey about Reconstruction and Visualisation of Historic Objects
}

\author{
Sander Münster, Thomas Köhler \\ Technical University of Dresden, Germany \\ Stephan Hoppe \\ Ludwig Maximilian University of Munich, Germany
}

\begin{abstract}
:
3D modelling technologies have gained importance as tools for the reconstruction and visualisation of historical items during the last decades. The authors have completed the analysis of the content of 478 conference papers and articles related to $3 D$ reconstruction in the field of humanities in order to investigate current topics, technologies and involved institutions. The research showed that the analysed projects use a wide scope of technologies and are fast to adopt new technological developments as well as current socio-technological trends, while the implementation of 3D as 'everyday technology' is still in progress. Besides these findings, the authors identified an active scientific community, their protagonists, and current topics of research.
\end{abstract}

Keywords:

$3 D$ Reconstruction, Scientometrics, Survey, Scientific Community

\section{Introduction}

3D models and visualisation have always been an important medium for teaching, illustrating and researching historical facts and items. While historical picture sources usually provide elusive and fragmentary impressions, digital threedimensional reconstructions of historical objects and their depictions offer the chance to convey ideas in a more holistic and accessible way. Until 2000, virtual 3D modelling technologies and computer generated images of cultural heritage objects were used merely as a digital substitute of physical models (Novitski 1998). Nowadays, 3D models are widely used in presenting historic items and monuments to the general public (Greengrass and Hughes 2008) as well as in research (Favro 2006) and education (El Darwich 2005). In addition, 3D technologies serve a variety of cultural heritage management and conservation tasks. Recent case studies of 3D applications aim to present 3D models in a multipurpose way, due to the great effort involved in their creation. 3D modelling technologies offer the chance not only to digitise existing historic objects, but also to virtually reconstruct objects that are no longer 'physically' extant and are only

Corresponding author: sander.muenster@tu-dresden.de known from descriptions. A main element of both kinds of application is the creation of a virtual 3D model, which is a subjective, simplified image of an historic original (Stachowiak 1973). To make these models visually perceptible it is necessary to transfer them back into rendered images, i.e. as visualisations, animations or interactive content. Workflows for virtual reconstruction of existing objects can be technologically or logistically challenging, but a virtual reconstruction of a no longer existing object - or never realised parts or structures - is even more challenging, as it includes tasks such as interpretation or inclusion of information from historical sources. Usually, all reconstruction projects dealing with historic items consist of interpretation and digitisation stages. While interpretation tasks are primarily undertaken in humanities, cultural heritage, and sometimes geography and architectural studies, there are several scientific disciplines which, as we will analyse more closely in this investigation, are dealing with digitisation, modelling and visualisation aspects.

\section{Methods}

Recent investigations have tried to define the usage of $3 \mathrm{D}$ modelling for the humanities 
3D Modelling Technologies in Humanities

Sander Münster, Thomas Köhler and Stephan Hoppe

\begin{tabular}{|c|c|c|}
\hline Publication & Volume & Sample size \\
\hline 3DArch Conf. & $2005-2009$ & 112 \\
\hline CAA Conf. & 2007,2009 & 130 \\
\hline VAST Conf. & $2003-2007,2010$ & 105 \\
\hline J. Digital Heritage & from 2000 (keyword-based search) & 52 \\
\hline $\begin{array}{c}\text { Various project reports and publications } \\
\text { dealing with no longer existing objects }\end{array}$ & $1999-2011$ & 79 \\
\hline
\end{tabular}

Table 1. Sources of the data used for the analysis.

and cultural heritage studies as a field of research (Frischer 2008; Greengrass and Hughes 2008). One of the latest and most elaborate examples is the EC-funded project EPOCH, which ended in the year 2008 (Arnold and Geser 2008). The project included many leading European institutions and stakeholders, which analysed the state-of-the-art as well as future perspectives and challenges of the discipline. Anotherlongterm research project is VIA, which is surveying and supervising the workforce and cooperation in the field of archaeological illustration in Britain (Gibbons 2012).

\subsection{Research objectives}

While most of these investigations focus on specific aspects of the discipline, there is very little systematic research that is dedicated to 3D reconstruction based on empirical findings. The main objective of our project is to delineate the current state-of-the-arts based on empirical analysis of recent publications. What are our research questions? On the one hand, our research interest lies in the current use of that technology. This includes investigating use scenarios, workflows, collaborations and standards. On the other hand, we are interested in the scientific community and its discourses and the topics we aim to investigate are institutions, protagonists and current academic discourses.

\subsection{Methods}

We performed a two-stage analysis to address these challenges. The first stage included the analysis of the content of existing publications in order to examine current use scenarios, protagonists, and field of research (Mayring 2000; Münster and Köhler 2012). Experts were asked to examine the most respected conferences and publications. All the publications included had to be written in English and available online. The identification of relevant journal articles took place via keyword-based search.
A sample of 452 journal articles and conference proceedings was included in our analysis during this first stage (Table 1). Most of the projects described in the analysed publications dealt with data acquisition and model building for existing structures. Only a small number of the projects focused on no longer existingarchitectural structures. This kind of project seems to be particularly interesting for studying the links between digital technologies and traditional humanities.

To examine this link, the authors applied a Grounded Theory method on a sample of other 26 international publications dealing with reconstructions of no longer existing objects (Münster 2011). Grounded Theory as research paradigm originates in social sciences and provides a set of qualitative empirical research methods to uncover and determine complex phenomena (Bryant and Charmaz 2010). Social network analysis in conjunction with an underlying mathematical approach of the graph theory provides an array of tools for the analysis and visualisation of relational data, like - for instance - the connections between authors: this represents the core process for scientific analysis (Wellman 1988). We performed a social network analysis of common authorships to identify 'protagonists' or 'multipliers' meaning scholars or institutions that produce a large number of publications, or are vastly connected, or have important links within a scientific network.

How compelling are the results from such an empirical analysis? Firstly, potential deficiencies of this study could derive from the method of data collection, i.e. the size or range of the samplemay not be sufficiently representative of the field of research as a whole. Secondly, the publications analysed generally tend to represent the academic context rather then the situation of commercial institutions. 
Across Space and Time. Papers from the 41st Conference on

Computer Applications and Quantitative Methods in Archaeology. Perth, 25-28 March 2013

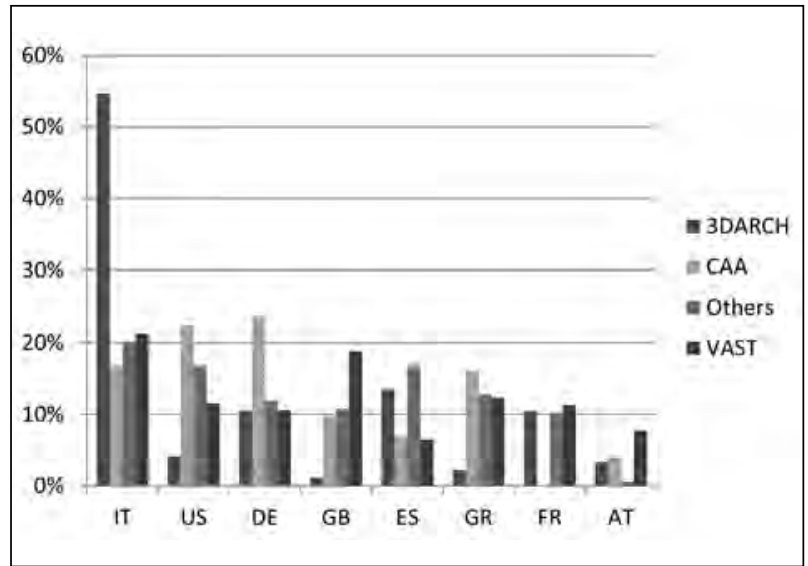

Figure 1. National affiliation of authors by employing institutions ( $n=1555$, Top 8).

\section{Findings}

\subsection{Authors and cooperation}

Authors' nationality was identified using the correspondence addresses noted in publications (Fig. 1). Authors in this sample belong to 38 nations, a large number of which are located in Europe. Overall, the most represented nation is Italy, with a percentage of Italian authors ranging between $15 \%$ and $60 \%$ across conferences. With regard to the disciplines they belong to (Fig. 2), most authors are affiliated to institutions dealing with computing. This quota is consistent across several conferences, i.e. approximately $60 \%$ of VAST presenters are affiliated to computing institutions. For $21 \%$ of authors it was not possible to identify the discipline they belong to.

Our analysis of a field of research is based on the assumption that collaborative publications require the transfer of knowledge between authors. The basic idea is that the development of a project and its publication is in most cases determined by existing personal connections and interactions between all the participating authors. Based on sociological role theory, such connection between people - whether weak or strong (Granovetter 1973) - could foster sharing and exchanging of ideas and information. From a structural point of view, connections between people across disciplinary and national borders play an important role in sharing and broadcasting information in social communities (for a discussion of scientific communities and inherent social interaction see Stützer et al. 2011).

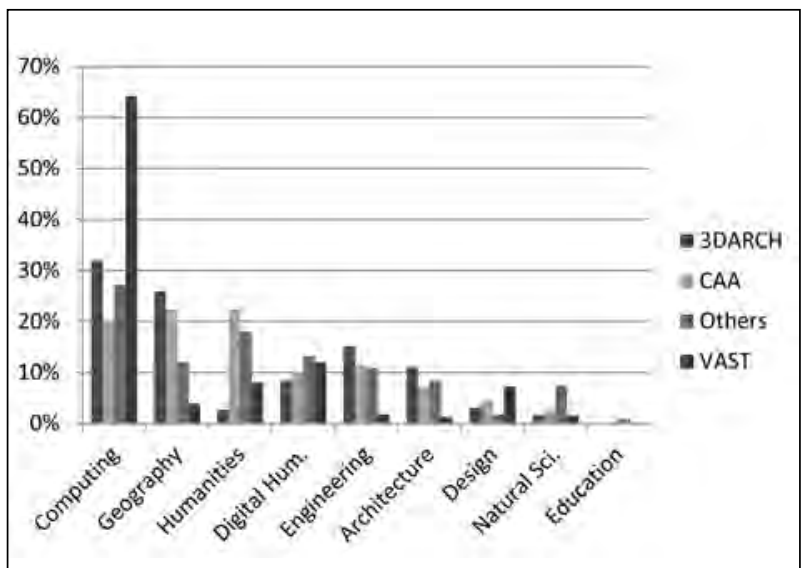

Figure 2. Disciplinary affiliation of authors by employing institutions $(n=1283)$.

Nevertheless, information transfer in the context of joint publications can only be assumed and it is not possible to determine its intensity or even the existence of information transfer between authors.

The publications analysed were written by 1500 scholars and contain over 3000 links between authors of co-authored articles (Fig. 3). Most of the publications have been written by authors belonging to institutes representing the same discipline and

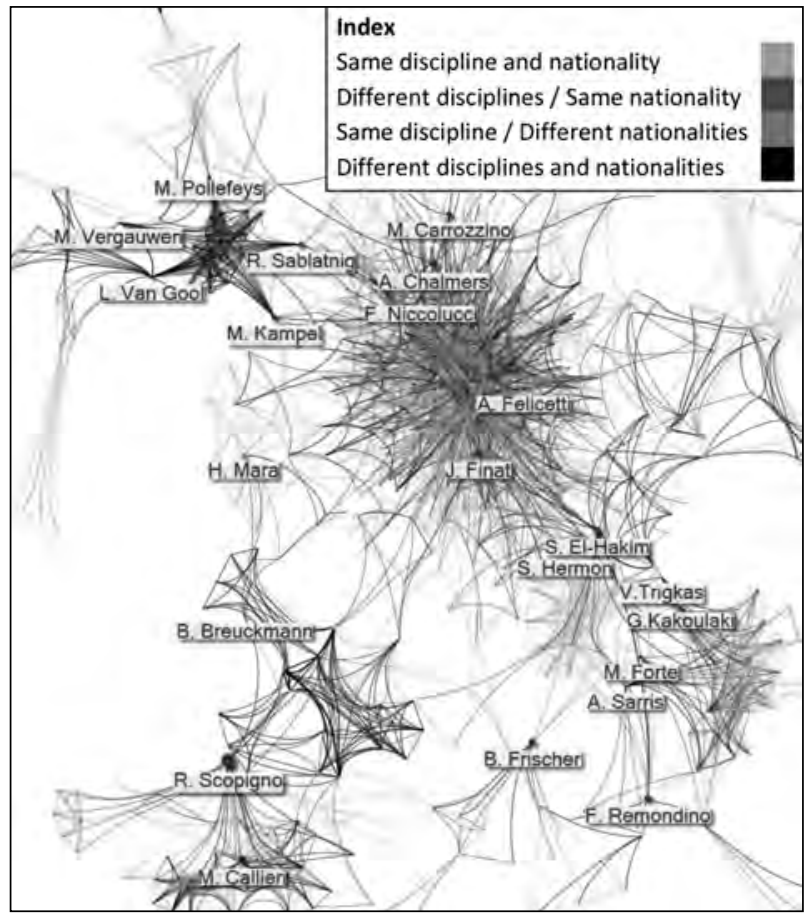

Figure 3. Author-Co-Author Relations - Persons (Multipliers highlighted). 
nationality. Protagonists of the field of research are researchers and institutions found in the topranking positions as regards, firstly, the number of connections to other authors ('Degree'), or, secondly, their structural relevance as connecting factors between author groups ('Betweenness Centrality'), or, thirdly, the number of publications (Wasserman and Faust 1994). These protagonists are highlighted in Figs. 3 and 4. But there are also several international or interdisciplinary networks visible, whose members have written more than just one joint publication. Some important multipliers, which connect groups of researchers to each other, could be identified.

If we introduce the institution linkage, a large number of interdisciplinary and international links (and consequently publications) can be observed (Fig. 4), particularly in reference to the collaboration between the University of Leuven and the Technical University of Vienna, as well as Zürich. Further, a smaller cluster includes mostly French and Italian institutions, encompassing authors from J apan as well as Germany. Hence, it is clearly evident that the scholars and institutions identified as protagonists are well connected both internationally and in terms of interdisciplinarity.

The preliminary results were discussed with experts in order to validate them. Generally, the identified 'multipliers' do not only actively publish, but often play key roles in the scientific community, for example as members of scientific committees, conference chairs, and project initiators or leaders.

\subsection{Topics and methods}

Another of our research goals was to identify current conference interests and content of contributions. In order to examine these aspects, we included in our analysis a sample of 339 articles from conference proceedings (Fig. 5).

We found out that over one third of the conference contributions (37\%) do not deal either with 3D modelling or historical objects. Nearly the same percentage of articles focus on single reconstruction projects. This means that they describe workflows to reconstruct certain historic items as 3D models. This means that they describe

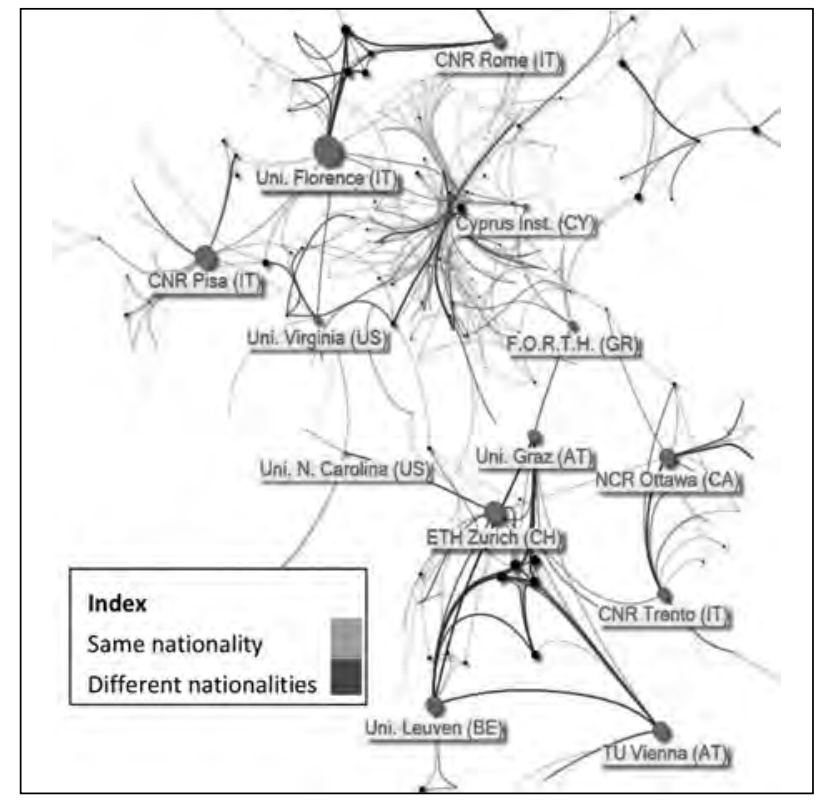

Figure 4. Author-Co-Author Relations - Institutions (Multipliers highlighted).

workflows for the reconstruction of certain historic items as 3D models. Another group of publications deals with specific aspects of $3 \mathrm{D}$ reconstruction for historical research purposes, like presentation and modelling strategies, data acquisition methods or handling and classification of $3 \mathrm{D}$ data. If we focus only on project reports (Fig. 6), we can identify two main strategies for the reconstruction of historical items, depending on whether the object to be reconstructed is still extant or not (DeFrancesco and D'Andrea 2008). In the first case, a reconstruction takes place via data acquisition and algorithmic model building. More than 2/3 of project reports deal with such a combination of data acquisition technologies and automated modelling for existing objects or artefact fragments.

A percentage of $16 \%$ of the publications deals with interpretative reconstruction of no

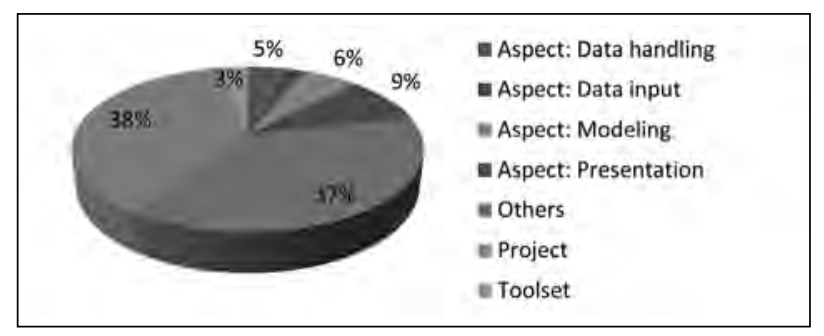

Figure 5. Proceeding topics $(n=339)$. 


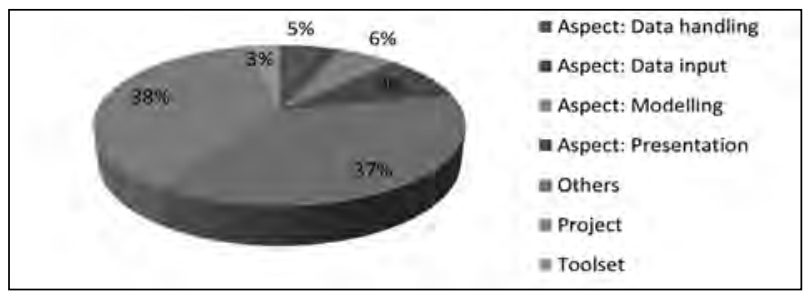

Figure 6. Project reports $(n=175)$.

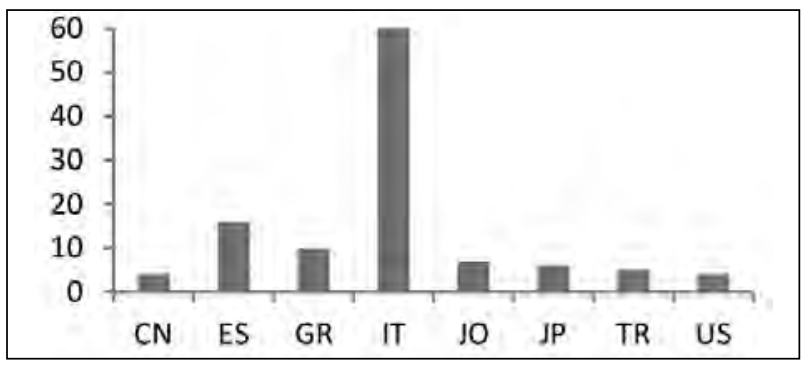

Figure 7. Location of Objects (Top 8).

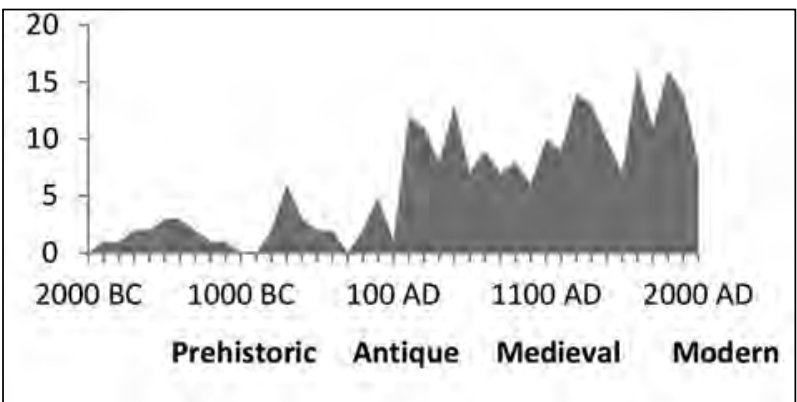

Figure 8. Time of origin of Objects.

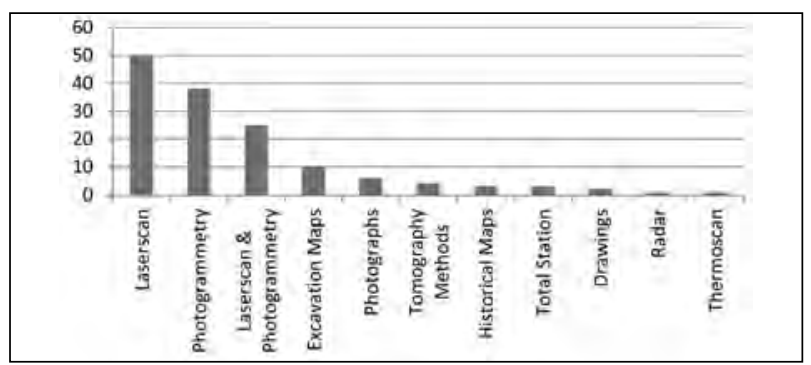

Figure 9. Types of Objects.

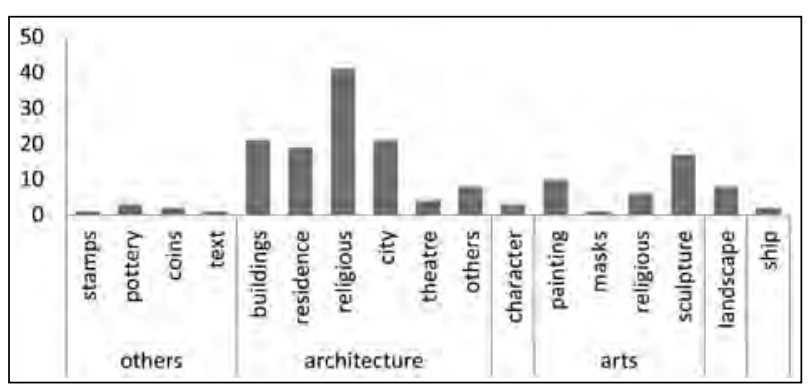

Figure 10. Data and sources included. longer existing objects undertaken using data from historical sources. In these cases, the creation of the 3D model usually takes place via VR or CAD modelling (Koller et al. 2006; Ioannides et al. 2013). Technical workflows for the creation of these models displayed minimal variations for more than a decade (Begand 2004; Masuch 1999), but output quality and tools have undergone rapid change. Most of these projects are undertaken by multidisciplinary teams using standardised 3D software for model building. While output quality and sources are broadly described in the publications, they do not provide any detailed information as to how the interdisciplinary collaboration was conducted. Besides these two main cases, there are several projects where data-driven automated modelling is used to reconstruct no longer extant objects.

Currently, 3D reconstructions mainly deal with artefacts and monuments or buildings. Objects reconstructed through 3D modelling are often architectural structures, mostly religious buildings like churches or temples (Fig. 9). Just recently a new trend has emerged of presenting real-life experiences, possibly by means of dynamic scene representations, relying on approaches used in the development of games (Feneley et al. 2008). Most items are located in or originate from Italy, Spain or Greece (Fig. 7). With regard to chronology of these objects, most projects deal with Roman, late Medieval or modern artefacts or monuments (Fig. 8).

\subsection{Workflows}

Data acquired by photogrammetric processes and laser-scanning were mostly used in the analysed projects as input for modelling (Fig. 10), and the technologies were often combined. Occasionally, other methods of data acquisition were deployed. Several historical and contemporary sources were also utilised in the reconstructions. Digitally recorded data provide scholars with the opportunity of building models in an automatic way using specific algorithms. Processes of data acquisition and modelling were addressed in a wide range of publications. Remondino et al. (2009) describe the combination of different methods to the modelling of buildings. Fassi (2007) compares and evaluates the application of photogrammetric processes and laserbased methods in the digitisation of interior spaces, 


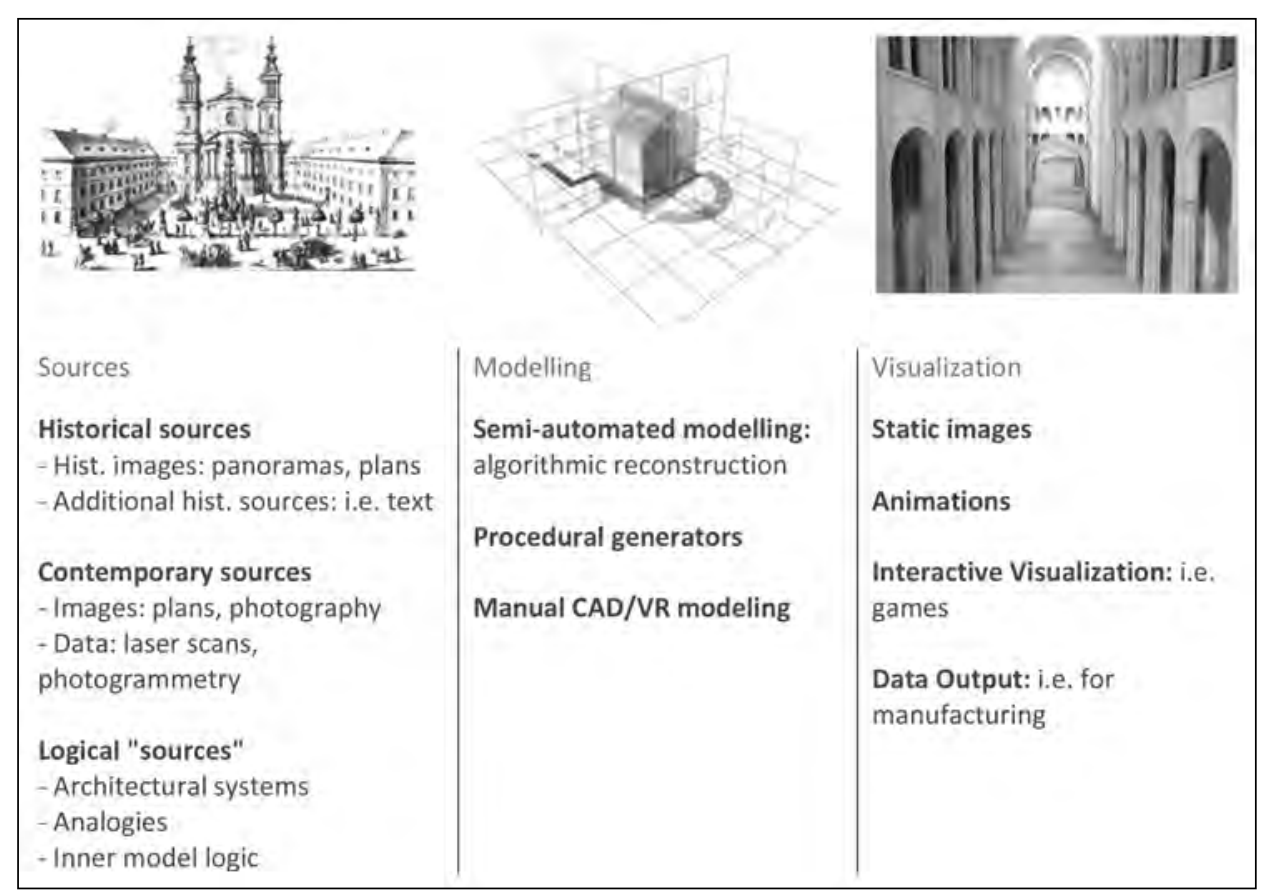

Figure 11. Classification schema: Sources, Modelling, Visualisation (Hermon 2008; Münster and Köhler in press).

whereas Grün (2008) presents a methodological overview of approaches and processes in the 3D reconstruction of complete landscapes. A number of publications deal in particular with the methods and technologies for small artefacts, for example statues, using 3D laser- scanning (Bruno et al. 2010). Currently there is plenty of research and development which aims to create fast, reliable and flexible algorithms for such modelling. Likewise, research and development are also in progress for modelling of non-extant objects, which is mostly donein a traditional manual modellingmanner, with some efforts to automate certain process aspects. For example, some projects deal with a parametric generation of architecture as well as libraries of preconstructed parts.

While the reconstruction of still existing objects is challenging on account of the technical aspects involved - like achieving a complete and accurate data acquisition, or creating an efficient and comprehensive algorithmic model - technical workflows for the reconstruction of these objects are widely established and similar to those adopted in other 3D modelling domains, like engineering and design. There are a number of specific challenges for such interpretative reconstructions, such as the need for interpreting historical sources and for an interdisciplinary creation process. The reconstruction of such objects is accomplished by acquiring information from historical sources such as plans or panorama images, as well as contemporary photographs (Fig. 11). For example, street grids or terrains would only slightly change over time, thus providing clues for reconstruction - even if buildings no longer exist. The quality of sources highly influences the validity of resulting models: historical sources rarely deliver all the information required for reconstructions. To attain a coherent model, decisions are made based on logical implications, like analogies to similar objects, requirements for an architectural system - such as for the Vitruvian system - , or simply on inner-model logic.

Another closely related issue is quality management during the modelling process (Hermon, Nikodem and Perlingieri 2006). One important strategy is to set up guidelines for workflows related to process or model quality. Workflow guidelines define the required level of accuracy needed to achieve a specific level of detail or criteria for the selection of objects to reconstruct. Process related guidelines define rules for workflow, i.e. for transparency, to conform to 'Good Scientific Practice'. Closely related to these are strategies for quality assurance. There are two main quality assurance strategies described in the analysed publications: on the one hand, employing an external committee, like boards of experts, to proof 
results, and on the other hand, involving a board of team members and ensuring quality during the creation process via periodic audits.

As described at the beginning of this article, the inherent purpose of a $3 \mathrm{D}$ model influences the type and quality of the outputs. The main outputs are depictions or 'renderings' of virtual models, either as static pictures or animated films and, increasingly, also as interactive applications. One important issue is that such outputs are mostly visually oriented while some projects focus on multisensorial outcomes, including, for example, aural impressions. In other cases, a 3D model is beingused as data input for other analytic steps, for example to perform FEM analysis or hydraulic simulations, or to create physical prototypes (Grellert and Haas in press).

\section{Current Trends and Discourses}

What are the current trends and discourses concerning 3D technologies for digital heritage purposes highlighted in current publications?

\subsection{On the way from prototypic to daily use}

Hitherto most 3D reconstruction projects have been prototypes and and the application of 3D modelling technologies is only gradually becoming a feature of the everyday work of archaeologists. During the past few years, large-scale funding schemes, like the EU ICT grants, have supported the development of cost-efficient tools, workflows and standards (3D-COFORM 2012) and the topic is widely debated at conferences. Nevertheless, currently most of the developed tools or workflows offer either highly automated workflows for very special uses, or still require IT-skilled operators and manual operations.

\subsection{Fast adoption of new technologies}

Huge technological developments have enhanced 3D modelling and visualisation during the recent years. Generally, developments and progress are rapidly transferred and adopted for cultural heritage purposes. There is a huge range of technologies described in current literature which are used - or sometimes 'abused' - for such purposes, i.e. medical computer tomography
(Granero et al. 2009) for data acquisition or CAVE-like environments for visualisation. Modern technological trends like Smartphone or Web 2.0 are also quickly adopted as well as current sociotechnological trends like crowd-sourcing (Gerth et al. 2005; Havemann and Wagener in press) or mobile computing.

\subsection{Standardisation, sustainability, sharing?}

Aspects like quality standards, compatibility, sustainability and requirements of target groups are often addressed in the literature, as are also prototypical workflows, guidelines and strategies for the creation of 3D models. The literature includes also guidelines for the use of historical reconstruction that are in line with, for example, the London Charter of 2006 (Beacham, Denard and Niccolucci 2006), which expanded into the Seville Charter (SEAV 2013) and provides parameters for the creation of 3D reconstructions. Although the London Charter is often addressed in publications related to the reconstruction of no longer existing objects, itsconventionsand guidelineshaveonlybeen thoroughly adopted in a few prototypical projects (Niccolucci et al. 2010). A similar phenomenon of limited practical application is also manifest in technical formats standardisation projects, as for example the Minerva Project (Fernie, Francesco and Dawson 2008, 44). Furthermore, a number of generic workflows for the digitisation of Cultural Heritage objects can be found in publications (Arnold and Geser 2008; Bruno et al. 2010; Dunn, Gold and Hughes 2007) together with conventions for presentation and visualisation (Frischer and Stinson 2007; Münster 2011).

A similar aspect is manifest in the documentation of 3D models. Whilst metadata appear to betheaccepted norm for describing virtual objects, with regard to an exact classification a variety of classification systems have been suggested, and currently no uniform metadata standard appears to be accepted as the norm. While documentation of the project results is often addressed in the literature, comprehensive documentation of the model building process is usually limited to the digitisation process. Most recently, approaches to the development of documentation methods for historical $3 \mathrm{D}$ modelling workflows have been proposed (Pfarr 2009). 
3D Modelling Technologies in Humanities

Sander Münster, Thomas Köhler and Stephan Hoppe

\subsection{Institutions: digital humanities and knowledge networks}

As outlined above, a great number of institutions and diverse disciplines are involved in the 3D visualisation of historical content. Thus, several different departments at universities and research institutions contribute to work in this field.

Research related to the 3D visualisation of historical subjects can be listed among the disciplines included in the broader subject of 'Digital Humanities' and in publications several Digital Humanities' institutions could be identified whose members combine knowledge of the subject and technical competence. Alongside these institutions, a number of networks have been created in recent years to foster collaboration. These include specialist associations such as Computer Applications and Quantitative Methods in Archaeology (CAA) and the International Committee for Documentation of Cultural Heritage (CIPA), as well as coordination networks such as the Carare program of Europeana, focused on standardisation and sustainability (Europeana 2013). Two relatively recent networks in this area are DC-NET (De Francesco 2010) focused on linking research and teaching activities in the area of Cultural Heritage - and the European Palatium network (Court Residence 2013) whose main purpose is the promotion of transnational research activities in the subject areas of history and archaeology. At the same time, there are a number of Communities of Practice, like for example the British Computer Vision Groups and the British 3D Visualisation in the Arts Network, founded in 2008 (3DVisA 2013).

\subsection{Presentation and publication}

An additional prominent subject in the literature is the presentation of models. Common (and controversial) discussions relate to whether a photorealistic or schematic representation should be aimed at. Moreover, with respect to the visualisation, the communication of complex and animate impressions of historical life is becoming increasingly deemed as desirable. This includes the reconstruction and representation of historical scenes from everyday life (Chandler 2014; Feneley et al. 2008) as well as the interactive representation of historical life (Ancona et al. 2010).
Additional trends evident in the literature relate to the presentation of content, where interactive web presentation environments - such as Google Earth - are being used (Erving, Rönnholm and Nuikka 2009; Remondino et al. 2009). A high level of immersion is also offered by augmented reality applications (Vlahakis et al. 2003; Zöllner, Becker and Keil 2010), while the next stages in multisensorial presentation of historical matter is already evident (Ch'ng 2009). Another significant trend can be identified in a (re-)materialisation of virtual $3 \mathrm{D}$ models using Rapid Prototyping processes.

\section{Conclusions}

Undoubtedly, 3D technologies are well established and widely used in many reconstruction projects of heritage objects. Monuments and buildings located in Mediterranean countries, dating from different periods, provide content for such reconstructions. A broad scientific community, including researchers from various disciplines and countries, has been established and Italy appears to be leading the way in this domain.

Scholars and institutions acting as 'multipliers' can be identified when one analyses the institutions and individuals involved in this field of research based on the authorship of publications. As a potential deficit of this study, the research methods and databases employed do not prove that persons occupying pivotal positions within the described author network are truly information exchange facilitators (Granovetter 1974; Newman 2001).

Although new technologies and trends are quickly spread and adopted, their implementation as every-day technology for cultural heritage purposes is still in progress. Future advances should focus on the development of cost-effective and easyto-use tools and workflows, as well as the definition of common standards and the improvement of collaboration and education. While these topics are prominent in academic discourse, their translation into research practice is still to come and further developments in interdisciplinary collaboration workflows, scientific reconstruction of dynamic systems or pedagogical models for traininghistorians and archaeologists on using 3D technologies, such as the ITN-DCH network (ITN-DCH 2014), are at the moment under development. 
Across Space and Time. Papers from the 41st Conference on

Computer Applications and Quantitative Methods in Archaeology. Perth, 25-28 March 2013

\section{Bibliography}

3D-COFORM. 2012. "Welcome to 3D-COFORM." Accessed April 2014. http://3dcoform.eu/index. php\#\&panel1-1.

3DVisA. 2013. "3D Visualisation in the Arts Network." Accessed J une 23. http:// 3dvisa.cch.kcl.ac.uk/ .

Ancona, M., V. Mascardi, G. Quercini, A. Bogdanovych, H. De Lumley, L. Papaleo, S. Simoff, and A. Traverso. 2010. 'Virtual Institutions for Preserving and Simulating the Culture of Mount Bego's Ancient People.” In The 11th International Symposium on Virtual Reality, Archaeology and Cultural Heritage VAST (2010), edited by A. Artusi, M. J oly-Parvex, G. Lucet, A. Ribes, and D. Pitzalis, 5- 8. Paris: Eurographics Association.

Arnold, D., and G. Geser. 2008. EPOCH Research Agenda for the Applications of ICT to Cultural Heritage. Budapest: Archaeolingua.

Beacham, R., H. Denard and F. Niccolucci. 2006. "An Introduction to the London Charter." In Project Papers from the Joint Event CIPA/VAST/EG/EuroMed Event (2006), edited by M. Ioannides, D. Arnold, F. Niccolucci, and K. Mania, 263- 269. Budapest: Archaeolingua.

Begand, C. 2004. Virtuelle 3D-Rekonstruktionen historischer Gebäude. Hamburg: Diplomica Verlag.

Bruno, F., S. Bruno, G. De Sensi, M. L. Luchi, S. Mancuso, and M. Muzzupappa. 2010. "From 3D reconstruction to virtual reality: A complete methodology for digital archaeological exhibition." J ournal of Cultural Heritage $11(1): 42-49$.

Bryant, A., and K. Charmaz. 2010. The SAGE Handbook of Grounded Theory. London: SAGE.

Chandler, T. 2014. "Playing Angkor: Exploring the Archaeological Themes of the Khmer Empire through Game Engine Technologies." In Across Space and Time. Papers from the 41st Computer Applications and Quantitative Methods in Archaeology Conference (Perth, WA, 25-28 March 2013), edited by A. Traviglia, 379-385. Amsterdam: Amsterdam University Press.

Ch'ng, E. 2009. "Experiential archaeology: Is virtual time travel possible?" J ournal of Cultural Heritage 10 (4):458-470.
Court Residence. 2013. "Welcome to PALATIUM." Accessed J une 23. http:// www.courtresidences.eu/index. php/home/ .

De Francesco, G. 2010. "DC-NET: The Establishment of the Digital Cultural Heritage Network." In The 11th International Symposium on Virtual Reality, Archaeology and Cultural Heritage VAST (2010), edited by A. Artusi, M. Joly-Parvex, G. Lucet, A. Ribes, and D. Pitzalis, 105- 110. Paris: Eurographics Association.

De Francesco, G., and A. D’Andrea. 2008. “Standards and Guidelines for Quality Digital Cultural Three-Dimensional Content Creation." In Digital Heritage - Proceedings of the 14th International Conference on Virtual Systems and Multimedia, edited by M. Ioannides, A. Addison, A. Georgopoulos, and L. Kalisperis, 229-233. Budapest: Archaeolingua.

Dunn, S., N. Gold, and L. Hughes. 2007. “CHIMERA: A Service Oriented Computing Approach for Archaeological Research." In Layers of Perception. Proceedings of the 35th International Conference on Computer Applications and Quantitative Methods in Archaeology (CAA), Berlin, Germany, April 2-6, 2007 (CD Edition), edited by A. Posluschny, K. Lambers and I. Herzog, 212-217. Bonn: Dr. Rudolf Habelt GmbH. Accessed May 1, 2014. http:// proceedings.caaconference.org/ files/ 2007/63_Dunn et_al_CAA2007.

El Darwich, R. 2005. “Modelle.” In Handbuch Medien im Geschichtsunterricht, edited by H.-J . Pandel and U. A. J . Becher, 580-591. Schwalbach: Wochenschau-Verlag.

Erving, A., P. Rönnholm, and M. Nuikka. 2009. "Data integration from different sources to create $3 \mathrm{D}$ virtual model." In 3D-ARCH 2009:3D Virtual Reconstruction and Visualization of Complex Architectures, 25-28 February 2009, Trento, Italy, edited by F. Remondino, S. El-Hakim, and L. Gonzo. Göttingen: Copernicus Publications. Accessed May 1, 2014. http://www.isprs. org/proceedings/ XXXVIII/5-W1/pdf/ erving_etal.pdf.

Europeana. 2013. "Carare project.” Accessed May 21. http:// www.carare.eu/ eng.

Fassi, F. 2007. "3D modeling of complex architecture integrating different techniques - a critical overview." In 3D-ARCH 2007:Virtual Reconstruction and Visualization of Complex Architectures,12-13 J uly 2007, ETH Zurich, Switzerland, edited by F. Remondino and S. 
3D Modelling Technologies in Humanities

Sander Münster, Thomas Köhler and Stephan Hoppe

El-Hakim. Göttingen: Copernicus Publications. Accessed May 1, 2014. http:// www.isprs.org/proceedings/ XXXVI/ 5-W47/ pdf/ fassi.pdf.

Favro, D. 2006. "In the eyes of the beholder: Virtual Reality re-creations and academia." In Imaging ancient Rome: documentation, visualization, imagination: Proceedings of the Third Williams Symposium on Classical Architecture, held at the American Academy in Rome, the British School at Rome, and the Deutsches Archäologisches Institut, Rome, on May 2O-23, 2004, edited by L. Haselberger, J. Humphrey, and D. Abernathy, 321- 334. Portsmouth: J ournal of Roman Archaeology.

Feneley, M., T. T. Chandler, N. H. Gleissenberger, and B. D. Alexander. 2008. "Reconstructing the West Mebon Vishnu: A marriage of traditional artefactual analysis with digital 3d visualization." In Virtual Systems and Multimedia, edited by T. G. Wyeld, S. Kenderdine, and M. Docherty, 73- 87. Berlin: Springer.

Fernie, K., G. De Francesco, and D. Dawson. 2008. "Technical Guidelines for Digital Cultural Content Creation Programmes. Version 2.0: September 2008." Last modified September 3o. http://www.minervaeurope. org/ publications/ MINERVA\%20TG\%202.0.pdf.

Frischer, B. 2008. Beyond illustration: 2D and 3D digital technologies as tools for discovery in archaeology. Oxford: Archaeopress.

Frischer, B., and P. Stinson 2007. "The Importance of Scientific Authentication and a Formal Visual Language in Virtual Models of Archeological Site: The Case of the House of Augustus and Villa of the Mysteries." In Interpreting The Past: Heritage, New Technologies and Local Development. Proceedings of the Conference on Authenticity, Intellectual Integrity and Sustainable Development of the Public Presentation of Archaeological and Historical Sites and Landscapes, Ghent, EastFlanders, 11.- 13. 9. 2002, edited by Flemish Heritage Institute, 49-83. Brussels: Ename Center for Public Archaeology and Heritage Presentation

Gerth, B., R. Berndt, S. Havemann, and D. W. Fellner. 2005. "3D Modeling for Non-Expert Users with the Castle Construction Kit v0.5.” In The 6th International Symposium on Virtual Reality, Archaeology and Cultural Heritage VAST (2005), edited by M. Mudge, N. Ryan and R. Scopigno, 49-57. Pisa: Eurographics Association.
Gibbons, G. 2012. Visualisation in Archaeology Project: Final Report. London: English Heritage.

Granero, L., F. Díaz, R. Domínguez, J . Hervás, S. Simón, E. Pérez, and M. Olcina. 2009. "Documentation of the Roman bronze hand found in the site of El Tossal in Lucentum." In ISPRS Archives Volume XXXVIII-5/W1 2009 WG V/4. 3D-ARCH 2009: 3D Virtual Reconstruction and Visualization of Complex Architectures. Accessed May 1, 2014. http:// www.isprs.org/proceedings/ XXXVIII/ 5-W1/pdf/granero_etal.pdf.

Granovetter, M. S. 1973. "Strange of the weak ties." American J ournal of Sociology 78 (6):1360- 1380.

Granovetter, M. S. 1974. Getting A Job. A Study of Contacts and Careers. Cambridge: Harvard University Press.

Greengrass, M., and L. M. Hughes (eds). 2008. Thevirtual representation of the past. London: Ashgate.

Grellert, M., and F. Haas. in press. "Between science and illusion. Filling gaps in "complete" virtual models." In Virtual Palaces II: Lost Palaces and Their Afterlife. Virtual Reconstruction Between Science and Media. Proceedings of the European Science Foundation Research Networking Programme PALATIUM meeting at Munich, 13-15 April 2012.

Grün, A. 2008. "Reality-based generation of virtual environments for digital earth." International J ournal of Digital Earth 1(1):88- 106.

Havemann, S., and O.Wagener. in press. "Castles and their Landscape - A case study towards parametric historic reconstruction." Virtual Palaces II: Lost Palaces and Their Afterlife. Virtual Reconstruction Between Science and Media. Proceedings of the European Science Foundation Research Networking Programme PALATIUM meeting at Munich, 13-15 April 2012.

Hermon, S. 2008. "Reasoning in 3D: A critical appraisal of the role of 3D modelling and virtual reconstructions in archaeology." In Beyond illustration: 2D and 3D digital technologies as tools for discovery in archaeology, edited by B. Frischer, 36-45. Oxford: Tempus Reparatum.

Hermon, S., J. Nikodem, and C. Perlingieri. 2006. "Deconstructing the VR - Data Transparency, Quantified Uncertainty and Reliability of $3 \mathrm{D}$ Models." 
Across Space and Time. Papers from the 41st Conference on

Computer Applications and Quantitative Methods in Archaeology. Perth, 25-28 March 2013

In The 7th International Symposium on Virtual Reality, Archaeology and Cultural Heritage VAST (2006), edited by D. Arnold, M. Ioannides, F. Niccolucci, and K. Mania, 123- 129. Nicosia: Eurographics Association.

Ioannides, M., A. Hadjiprocopis, N. Doulamis, A. Doulamis, E. Protopapadakis, K. Makantasis, P. Santos, D. Fellner, A. Stork, O. Balet, M. Julien, G. Weinlinger, P. S. Johnson, M. Klein, and D. Fritsch. 2013. "Online 4D Reconstruction using Multi-Images available under Open Access." In XXIV International CIPA Symposium, 2-6 September 2013, Strasbourg, France, edited by P. Grussenmeyer, 169-174. Göttingen: Copernicus.

ITN-DCH. 2014. “Home.” Accessed May 1, 2014. http:// www.itn-dch.org.

Koller, D., J. Trimble, T. Najbjerg, N. Gelfand, and M. Levoy. 2006. "Fragments of the city: Stanford's Digital Forma Urbis Romae Project." In Imaging ancient Rome: documentation, visualization, imagination: proceedings of the Third Williams Symposium on Classical Architecture, held at the American Academy in Rome, the British School at Rome, and the Deutsches Archäologisches Institut, Rome, on May 20-23, 2004, edited by L. Haselberger, J . Humphrey, and D. Abernathy, 237- 252. Portsmouth: J ournal of Roman Archaeology.

Masuch, M. 1999. "Virtual Reconstruction of Medieval Architecture." In Computer Animation and Simulation'99: Proceedings of the Eurographics Workshop in Milano, Italy, September 7-8, 1999, edited by N MagnenatThalmann and D. Thalmann, 87- 90. Wien: Eurographics Association.

Mayring, P. 2000. "Qualitative Content Analysis." Forum Qualitative Sozialforschung 1 (2):20. Accessed May 1, 2014. http://nbn-resolving.de/ urn:nbn:de:0114fqs0002204.

Münster, S.2011. "Entstehungs-undVerwendungskontexte von 3D-CAD-Modellen in den Geschichtswissenschaften." In Virtual Enterprises, Communities \& Social Networks, edited by K. Meissner and M. Engelien, 99- 108. Dresden: TUDpress.

Münster, S., and T. Köhler. 2012. "3D reconstruction of Cultural Heritage artifacts. A literature based survey." Paper presented at the 2nd International Symposium on Cultural Heritage Conservation and Digitization, CHCD2012 Beijing, China, October 17-18.
Münster, S., and T. Köhler. in press. "3D modeling as tool for the reconstruction and visualization of "lost" buildings in humanities. A literature-based survey of recent projects." In Virtual Palaces II: Lost Palaces and Their Afterlife. Virtual Reconstruction Between Science and Media. Proceedings of the European Science Foundation Research Networking Programme PALATIUM meeting at Munich, 13-15 April 2012.

Newman, M. E. J. 2001. "Scientific collaboration networks. II. Shortest paths, weighted networks, and centrality." Physical Review E 64 (1):016132-1-016132-7. Accessed February 28, 2014. doi: 10.1103/ PhysRevE.64.016132.

Niccolucci, F., D. Beacham, S. Hermon, and H. Denard. 2010. "Five years after: The London Charter revisited." In The 11th International Symposium on Virtual Reality, Archaeology and Cultural Heritage VAST (2010), edited by A. Artusi, M. Joly-Parvex, G. Lucet, A. Ribes, and D. Pitzalis, 101- 104. Paris: Eurographics Association.

Novitski, B. J. 1998. Rendering real and imagined buildings: the art of computer modeling from the Palace of Kublai Khan to Le Corbusier's villas. Gloucester: Rockport Pub.

Pfarr, M.. 2009. “Dokumentationssystem für Digitale Rekonstruktionen am Beispiel der Grabanlage Zhaoling, Provinz Shaanxi, China." PhD diss., University of Darmstadt.

Remondino, F., S. El-Hakim, S. Girardi, A. Rizzi, S. Benedetti, and L. Gonzo. 2009. "3D Virtual reconstruction and visualization of complex architectures - The 3D-ARCH project." In 3D-ARCH 2009:3D Virtual Reconstruction and Visualization of Complex Architectures, 25-28 February 2009, Trento, Italy, edited by F. Remondino, S. El-Hakim, and L. Gonzo. Göttingen: Copernicus Publications.

SEAV. 2013. "Principles of Seville. Final draft." Accessed October 2. http:// www.arqueologiavirtual.com/ carta/?page_id $=437$.

Stachowiak, H. 1973. Allgemeine Modelltheorie. Wien: Springer.

Stützer, C. M., K. M. Carley, T. Köhler, and G. Thiem. 2011. "The Impact of Brokers in Collaborative E-Learning Systems." Paper presented at the 8th conference on Applications of Social Network Analysis (ASNA 2011), 
3D Modelling Technologies in Humanities

Sander Münster, Thomas Köhler and Stephan Hoppe

Zürich, Switzerland, September 14-16.

Vlahakis, V., T. Pliakas, A. Demiris, and N. Ioannidis. 2003. "Design and Application of an Augmented Reality System for continuous, context-sensitive guided tours of indoor and outdoor cultural sites and museums." In The 4th International Symposium on Virtual Reality, Archaeology and Cultural Heritage VAST (2010), edited by D. Arnold, A. Chalmers, and F. Niccolucci, 155- 164. Brighton: Eurographics Association.

Wasserman, S., and K. Faust. 1994. Social Network Analysis. Cambridge: Cambridge University Press.

Wellman, B. 1988. "Structural Analysis: From Method and Metaphor to Theory and Substance." In Social Structures: A Network Approach, edited by B. Wellman and S. D. Berkowitz, 19- 61. Princeton: Princeton University Press.

Zöllner, M., M. Becker, and J. Keil. 2010. "Snapshot Augmented Reality - Augmented Photography." In The 11th International Symposium on Virtual Reality, Archaeology and Cultural Heritage VAST (2010), edited by A. Artusi, M. Joly-Parvex, G. Lucet, A. Ribes, and D. Pitzalis, 53- 56. Paris: Eurographics Association. 


\title{
A 3D Assessment Tool for Precise Recording of Ceramic Fragments Using Image Processing and Computational Geometry Tools
}

\author{
Fernando Zvietcovich, Benjamin Castaneda, Luis J aime Castillo and J ulio Saldana \\ Pontificia Universidad Catolica del Peru, Peru
}

\begin{abstract}
:
Recording ceramic fragments is essential for archaeological interpretation and conservation. When done manually, this task is very time consuming and greatly depends on the experience and skill of the archaeologist in charge. In this paper, we propose the implementation of a 3D acquisition and processing method to improve the accuracy and precision of the recording procedure. During the first step of the proposed process, 3D mesh models of ceramic fragments areobtained using a laser scanner. Subsequently, discrete 3D dynamic contour is utilised to extract points from thefragment's rim. Orientation and diameter of the complete vessel are then estimated using a non-linear least square approach. Experiments, using manual techniques, report precision errors (variability) less than $11.97 \%$ in the diameter and $3.75 \%$ in inclination, whereas the 3D method reports errors of $2.07 \%$ and $0.42 \%$ for the same measures. Moreover, accuracy experiments report accuracy errors of less than $4.78 \%$ in the diameter, and $4.30 \%$ in inclination. Theseresults suggest that the 3D method is accurate and more preciseand 13.3\% faster than the traditional methodology.
\end{abstract}

\section{Keywords:}

3D Mesh Modeling, Profile Extraction of Pottery, Laser Scanner, 3D Dynamic Contours

\section{Introduction}

Pottery analysis represents an important and unavoidable procedure that takes place after the collection of potsherds on most archaeological projects. Usually seen as one of the most common archaeological materials, these items provide archaeologist with vital information regarding many different aspects of the human past. They are a direct connection to ancient human civilisations and much information can be extracted from the careful examination and study of certain features of ceramic fragments. For instance, the determination, comparison, and classification of different types of ceramic fragments are fundamental to the construction of ceramic typologies, and the determination of a cultural affiliation can also provide important information (Orton, Tyers and Vince 1993). Technical drawing is the standard archaeological method utilised to record data from ceramic potsherds. In these drawings, the size, thickness, orientation, and shape of fragments are included and represented in a 2D diagram consisting on a profile contour of the potsherd around its axis

Corresponding author: castaneda.b@pucp.edu.pe of symmetry. In particular, ceramic potsherds from vessels that possess axial symmetry are completely characterised by its profile.

It is typical to find abundant ceramic potsherds collected in an archaeological project during an excavation season. Diagnostic fragments, that contain information of the rim of the vessel, are commonly utilised for the profile extraction in a 2D diagram in a traditional fashion. In this method, the profiles of fragments are manually drawn on a paper sheet helped by tools such as a profile gauge and a rim chart (Orton, Tyers and Vince 1993). This method heavily depends on the experience and the skill acquired by the archaeologist and, therefore, it suffers from high variability (low repeatability or precision) and it is time consuming as well as expensive; besides, sometimes more attention is paid to those devices than to the artefact itself. In addition to this issue, since the amount of material collected in an archaeological project could reach thousands of diagnostic fragments, the traditional recording method cannot handle such volume of information within reasonable time and cost (Mara and Sablatnig 2005). 
New methodologies for recording ceramic fragments capable of overcoming these difficulties are necessary. Several attempts were proposed in the past. During the last ten years, various research groups made important advances in developing computerised applications using 3D models of fragments (Kampel and Melero 2003; Karasik and Smilansky 2008; Yao and Shao 2003). They focused on increasing the accuracy of the recording; in particular, the extraction of the axis of symmetry which is not a trivial task and still remains an issue in 3D potsherd recording (Karasik and Smilansky 2008). On one hand, in the work by Karasik and Smilansky (2008), to estimate the axis of symmetry, it is assumed that the operator who scanned the fragment already positioned it in an approximately correct way (axis of symmetry parallel to the $\mathrm{z}$ axis). Similarly, in the work done by Yao and Shao (2003) the detection of corner points around the rim of the fragment for the plane fitting procedure and estimation of the orientation is completely dependent of the initial orientation of the fragment. In the work by Kampel and Melero (2003), a normal distribution is used for estimating the axis of symmetry. However, this leads to a non accurate estimation since normal vectors are sensitive to noise. In addition, a good compromise between accuracy and computational cost has not been properly achieved.

We propose here a novel methodology for recording ceramic fragments utilising a laser scanner to digitise the 3D models of fragments and applying 3D image processing and computational geometry tools for the profile estimation. We utilise a 3D discrete active contour for detecting the rim of the fragment which makes the procedure independent to the initial position of the model in the 3D space. Then, we utilise the detected rim for fitting the best plane and estimating the orientation of the fragment. Finally, we estimate the best circle that fits in the border of the rim for detecting the axis of symmetry, and therefore, the best profile of the fragment. This research measures the accuracy of the proposed techniques, includes a comparative study of the time utilised by the traditional method and the proposed 3D method, as well as the interand intra- variability (precision error) assessment of the same techniques.
This research only works with diagnostic ceramic fragments belonging to axial symmetric vessels affiliated to the Moche tradition from the North Coast of Peru. They were excavated in San J ose de Moro, Chepen, La Libertad, Peru by the San J osé de Moro Archaeological Program between J uly and August of 2012. The profiles were calculated using first the traditional method and, then, the $3 \mathrm{D}$ proposed technique. Then, bothresultsarecompared in terms of variability and time consumption.

This paper is organised as follows: in section 2 we describe the 3D scanning process using a laser scanner. In section 3, we explain the entire methodology and algorithms constructed for finding the orientation of the fragment, its diameter and the 2D profile around its axis of symmetry. In section 4, we describe the design of the experiments over the fragments using the traditional method and the 3D method. In section 5, the results of the experiments previously designed are explained and compared. The conclusions of the entire work are explained in section 5. At this point, some potential applications are suggested.

\section{3D Acquisition of Potsherds}

This study focuses on four fragments of large ceramic containers, locally known as "paicas", used for the production and storage of a fermented beverage based on corn called "chicha". These fragments werefound during the 20 years of research in the site of San J ose de Moro, in the J equetepeque Valley of northern Peru and they are illustrated in Fig. 1 - top. The 3D meshes of the ceramic potsherds were obtained from the commercial 3D laser scanner Next Engine HD (NextEngine Inc., CA, USA). This device projects a laser pattern over the target surface and estimates the 3D coordinate positions of each point around the pattern via 3D triangulation and image processing tools (Bernardini and Rushmeier 2002). The scanner sweeps the laser pattern around the entire fragment in a single view point. Then, a rotary wheel connected to the scanner rotates the fragment $360^{\circ}$ in order to acquire 3D models representing its various views. All views are displayed, registered and merged together in order to create a complete 3D mesh representation of the fragment utilising the software ScanStudio HD (NextEngine Inc., CA, USA). 


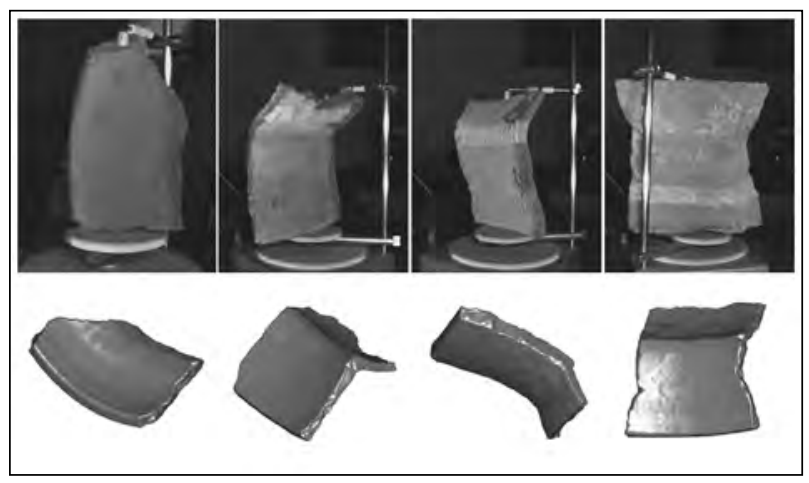

Figure 1. 3D mesh models of four ceramic fragments. Top: pictures of the fragments during the scanning process. Bottom: 3D meshes previously processed in Meslab.

The maximum accuracy of models obtained by NextEngine laser scanner is $0.13 \mathrm{~mm}$ while the maximum resolution is $50 \mathrm{k}$ points per inch squared and as reported in the technical specifications section of its user manual. In the industry, the accuracy of a system is defined as the degree of closeness of measurements of a quantity to that quantity's actual known value. The precision of a system measures the degree in which repeated measurements of a same quantity under the same conditions describes the same result. This is also called repeatability or reproducibility (the opposite of variability or precision error) and is strongly correlated to the standard deviation of the measurements. Both, accuracy and precision are defined in the work by Guidi et al. (2007) in the evaluation of the NextEngine Laser Scanner. Herein, they report a precision of $0.048 \mathrm{~mm}$. In order to verify the given value of accuracy, we scanned the width of three rectangular metal patterns of known dimensions $(1.1 \mathrm{~mm}, 1.2 \mathrm{~mm}$ and $1.7 \mathrm{~mm})$. We found and average accuracy error of $0.03 \mathrm{~mm}$, less than $0.13 \mathrm{~mm}$ reported by NextEngine specifications.

The 3D meshes of the fragments have an average amount of $42 \mathrm{k}$ points and took around 9 minutes per model. During the scanning procedure, the fragments were located $16.51 \mathrm{~cm}$ in front of the scanner. The spatial configuration of the scanner and fragments are illustrated in Fig. 2. The data was exported using object file format which contains information of the point coordinates representing the model, its 3D triangulation, and the texture colour attached to the mesh. Finally, the four 3D

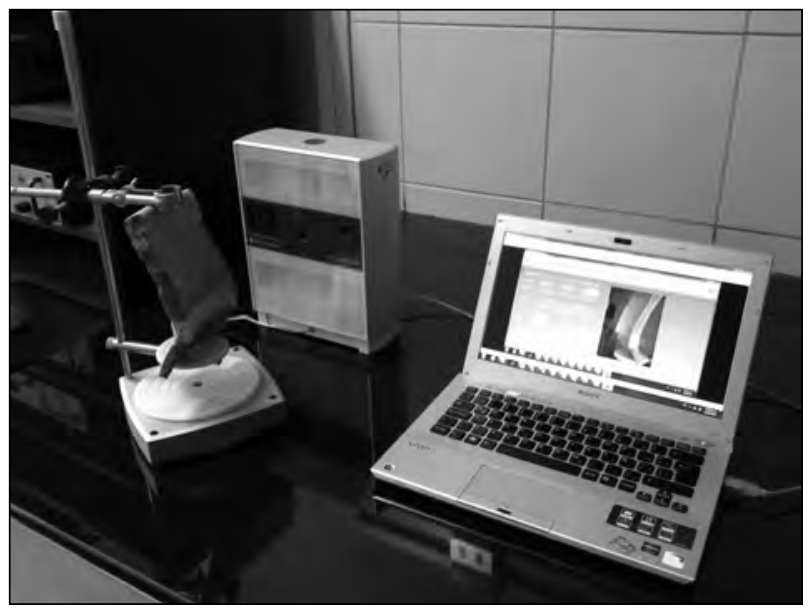

Figure 2. The scanning system: a NextEngine laser scanner connected to a computer and a rotatable support holding a ceramic fragment.

meshes corresponding to the ceramic fragments in study are loaded into Meshlab (Visual Computing Lab, ISTI - CNR, Italy) for a preprocessing step. Here, a hole-filling algorithm is utilised to fill the gaps around the models (Zhao, Gao and Lin 2007) whereas a Taubin $\lambda \mid \mu$ filtering procedure $(\lambda=0.5$, $\mu=-0.53$, and 10 iterations) is applied to the models in order to remove noise and preserve salient shape features (Taubin 1995). The resulting meshes are illustrated in Fig. 1 - bottom.

To assess the influence of the preprocessing step in the accuracy of the models we aligned both models before and after applying the noise and hole filters. Then, we computed the distance between models. We report $0.0011 \mathrm{~mm}$ as the mean distance with a sigma of $0.037 \mathrm{~mm}$. Since the mean distance is considerably less than the accuracy of models, we conclude that the preprocessing step does not alter the reliability of any measurement over preprocessed models.

\section{Algorithm}

The entire methodology consists in four steps: rim detection procedure, orientation estimation, estimation of axis of symmetry and the diameter of the rim, and 2D profile calculation. For the explanation of the sequence, a single ceramic fragment was utilised. Fig. 3 illustrates the flow chart of the entire procedure. 


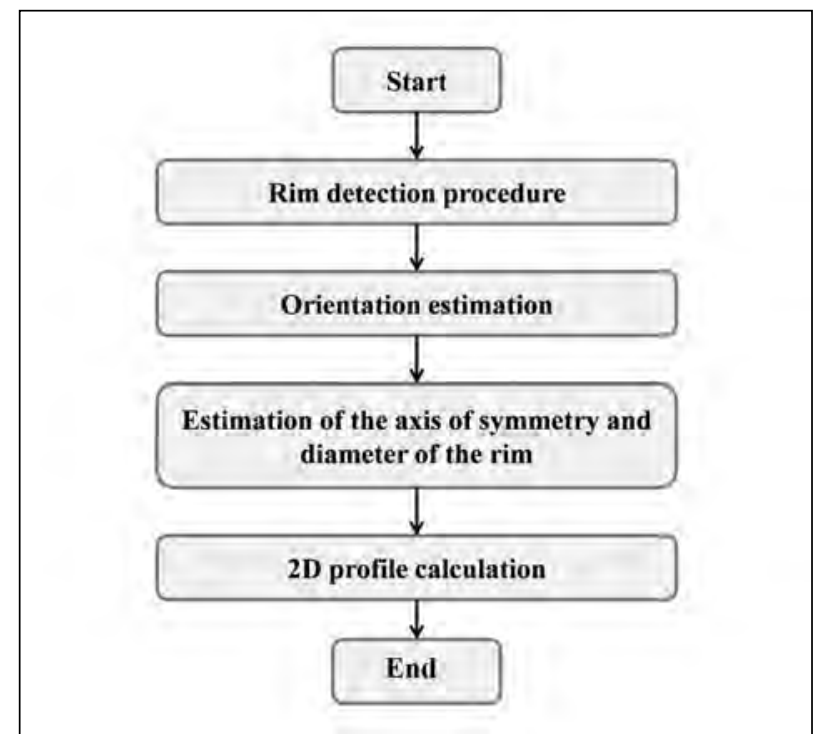

Figure 3. Flow chart of the algorithm proposed for the $2 D$ profile extraction of ceramic fragments.

\subsection{Rim detection procedure}

In this step, we attempt to find points belonging to the rim of the vessel. Since we are working with diagnostic fragments, part of the vessel rim is available. A mean curvature algorithm is applied on the 3D mesh of fragments in order to highlight sectors of high slope (Dong and Wang 2005). Typically, the corner points of the rim located in the top part of the vessel depicts high geometrical changes. Hence, these points will have high values of mean curvature, whereas, flat areas will have lower values as illustrated in Fig. 4a. Subsequently, a hysteresis thresholding algorithm is utilised in order to select important edges discriminating side effects produced by noise. The description of the algorithm is explained in Hubeli and Gross (2001) and the result is illustrated in Fig. $4 \mathrm{~b}$.

A 3D discrete active contour was designed and implemented for the mesh segmentation of the fragment. The algorithm allows the user to insert the first location of the contour over the $3 \mathrm{D}$ mesh. Then, the contour will be deformed until it reaches a stop condition dictated by the presence of edges. For more details about the description of the active contour, we refer to Lobregt and Viergever (1995) .The resultant deformed contours are depicted in Fig. 4c. Finally, the user manually selects the border representing the vessel rim on both sides, internal

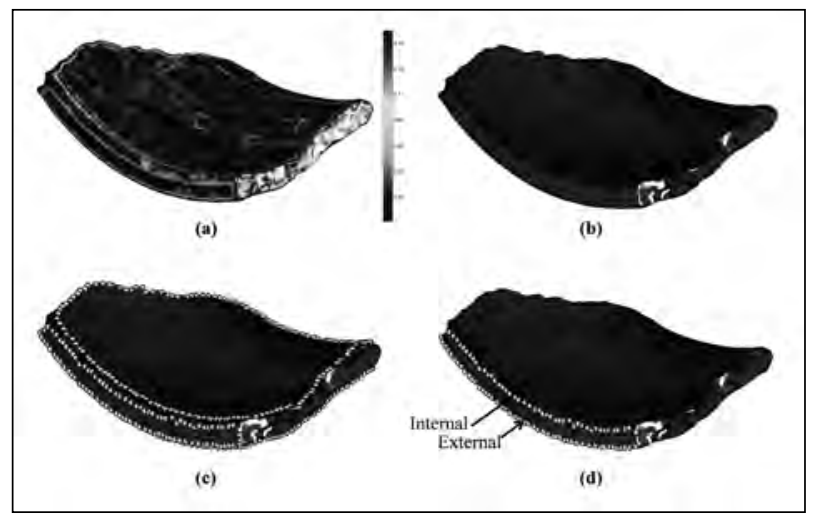

Figure 4. Rim detection procedure. (a) Colorised mean curvature of the fragment. (b) Edge discrimination procedure via hysteresis thresholding algorithm. (c) $3 D$ discrete active contour utilized for the borders segmentation. (d) Manual selection of the internal and external border of the rim.

and external. The result of the user selection is illustrated in Fig. 4d.

\subsection{Orientation estimation}

The orientation of a vessel is defined by the unitary vector; therefore all points belonging to the vessel rim are contained in a plane normal to this vector. In order to estimate that plane, a fitting procedure based in the least squares optimisation tool is applied over the points representing the vessel rim. We call the set of those Cartesian points representing the internal and external border $\mathrm{P}=\left\{\mathrm{P}_{\mathrm{n}}\right\}$ and $\mathrm{Q}=\left\{\mathrm{Q}_{\mathrm{n}}\right\}$ respectively, where $\left\{[]_{\mathrm{n}}\right\}=\left[\mathrm{x}_{\mathrm{n}}, \mathrm{y}_{\mathrm{n}}, \mathrm{z}_{\mathrm{n}}\right]^{\mathrm{T}}$ and $n=1, \ldots, N$, being $N$ the maximum number of points detected in the rim. The analytical description of a plane can be written as follows:

$$
\mathrm{z}=\mathrm{Ax}+\mathrm{By}+\mathrm{C}
$$

Subsequently, we define a cost function (Equation 2) consisting on the sum of the squared errors between $\mathrm{z}_{\mathrm{n}}$ and $\mathrm{Ax}_{\mathrm{n}}+\mathrm{By}_{\mathrm{n}}+\mathrm{C}$. The objective consists in estimating the parameters $\mathrm{A}, \mathrm{B}$ and $\mathrm{C}$ describing the best fitted plane in both borders internal and external.

$$
E(A, B, C)=\sum_{(\mathrm{i}=1)}^{\mathrm{N}}\left\|\mathrm{A}\left(\mathrm{x}_{\mathrm{i}}+\mathrm{By}_{\mathrm{i}}+\mathrm{C}\right)-\mathrm{z}_{\mathrm{i}}\right\|^{2}
$$

The unknown parameters $A_{P}, B_{P}, C_{P}$ and $A_{Q}$, $\mathrm{B}_{\mathrm{Q}}, \mathrm{C}_{\mathrm{Q}}$ corresponding to the sets $\mathrm{P}$ and $\mathrm{Q}$ respectively 


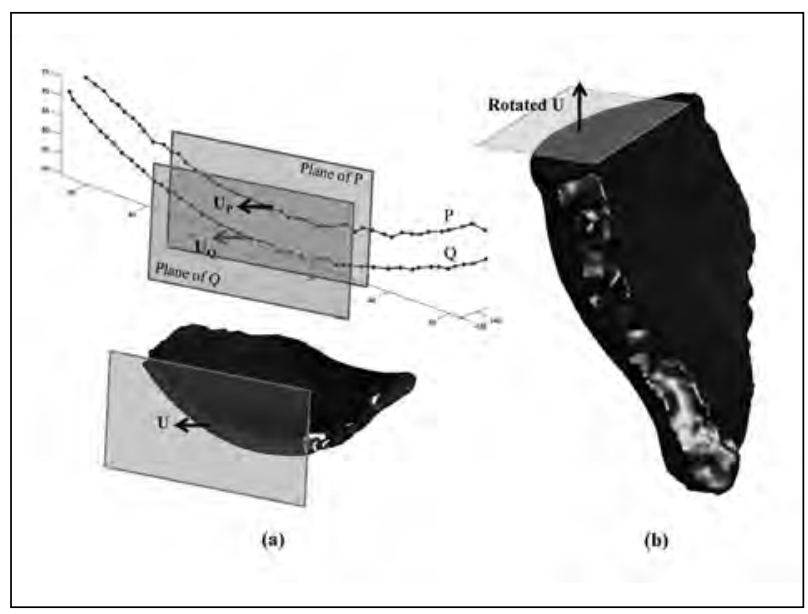

Figure 5. Orientation estimation and rigid transformation. (a)-top: Calculation of the normal vectors UP and UQ to the planes belonging to the borders $P$ and $Q$ respectively. (a)-bottom: The average vector $U$ (between UP and UQ). (b) Rigid transformation of the $3 D$ mesh of the fragment.

are calculated using a least squares procedure. Then, the normal vectors to these planes are given by

$$
\begin{aligned}
& \mathrm{U}_{\mathrm{P}}=\left[\mathrm{A}_{\mathrm{P}} / \mathrm{C}_{\mathrm{P}}, \mathrm{B}_{\mathrm{P}} / \mathrm{C}_{\mathrm{P}},-1 / \mathrm{C}_{\mathrm{P}}\right]^{\mathrm{T}} \\
& \mathrm{U}_{\mathrm{Q}}=\left[\mathrm{A}_{\mathrm{Q}} / \mathrm{C}_{\mathrm{Q}^{\prime}}, \mathrm{B}_{\mathrm{Q}} / \mathrm{C}_{\mathrm{Q}^{\prime}}-1 / \mathrm{C}_{\mathrm{Q}}\right]^{\mathrm{T}}
\end{aligned}
$$

and they are illustrated in Fig. 5a. Finally, the vector describing the orientation of the entire vessel is given by the unitary average among vectors $U_{P}$ and $\mathrm{U}_{\mathrm{O}}$ (Fig. 5b):

$$
U=\frac{\left(U_{P}+U_{Q}\right) / 2}{\left\|\left(U_{P}+U_{Q}\right) / 2\right\|}
$$

If the angle between $\mathrm{U}_{\mathrm{P}}$ and $\mathrm{U}_{\mathrm{Q}}$ are more than a threshold of $5^{\circ}$, a warning message indicates that something is incorrect in the rim detection procedure. Then, it is necessary to return to the previous step.

A rigid transformation is applied over the mesh model of the fragment; therefore the planes containing $\mathrm{P}$ and $\mathrm{Q}$ are parallel to the plane $\mathrm{z}=0$. We define the transformation matrix $\mathrm{R}$ as:

$$
R=I \cos \theta+\sin \theta[u]_{\mathrm{x}}+(1-\cos \theta) u \otimes \mathrm{u}
$$

$$
\text { where }\left[v_{\mathrm{x}} \mathrm{v}_{\mathrm{y}} \mathrm{v}_{\mathrm{z}}\right]^{\mathrm{T}}=\mathrm{U} \times\left[\begin{array}{lll}
0 & 0 & 1
\end{array}\right]^{\mathrm{T}} \text {, }
$$

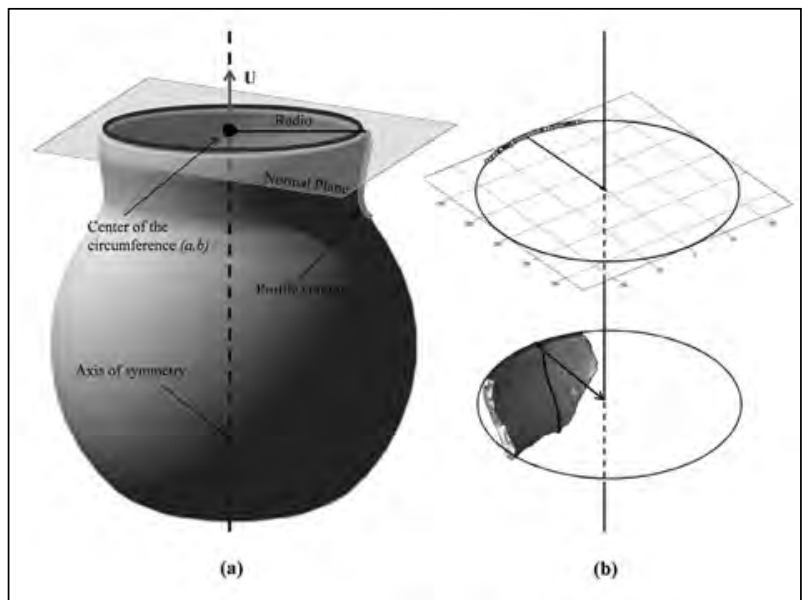

Figure 6. Estimation of the axis of symmetry and diameter of the rim. (a) Definition offeatures in a idealized complete vessel. (b) top: Fitting procedure of a circumference using the points of the rim. (b) bottom: Location of the fragment model around the axis of symmetry.

$$
\begin{aligned}
& u \otimes u=\left[\begin{array}{ccc}
v_{x}^{2} & v_{x} v_{y} & v_{x} v_{z} \\
v_{x} v_{y} & v_{y}^{2} & v_{y} v_{z} \\
v_{x} v_{z} & v_{y} v_{z} & v_{z}^{2}
\end{array}\right], \\
& {[u]_{x}=\left[\begin{array}{ccc}
0 & -v_{z} & v_{y} \\
v_{z} & 0 & -v_{x} \\
-v_{y} & v_{x} & 0
\end{array}\right]}
\end{aligned}
$$

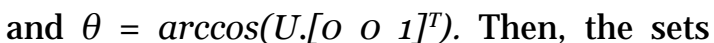
of points belonging to the internal and external rim are also transformed: $\mathrm{P}_{\mathrm{T}}=\left\{\mathrm{P}_{\mathrm{Tn}}\right\}=\left\{\mathrm{RP}_{\mathrm{n}}\right\}$ and $\mathrm{Q}_{\mathrm{T}}=\left\{\mathrm{Q}_{\mathrm{Tn}}\right\}=\left\{\mathrm{RQ}_{\mathrm{n}}\right\}$. The new Cartesian location of the fragment in the 3D space is depicted in Fig. 5c.

3.3 Estimation of the axis of symmetry and diameter of the rim

Since weare working with axial symmetric vessels, the projection of the rim over the plane $\mathrm{z}=0$ provides a perfect circumference. Then, the center of the circumference and the direction of the orientation vector define the axis of symmetry, whereas, the radio allows estimating the approximate rim's diameter of the vessel (Fig. 6a).

We project $\mathrm{P}_{\mathrm{T}}$ over the plane $\mathrm{z}=0$ in order to obtain a $2 \mathrm{D}$ representation of the points $\mathrm{P}_{\mathrm{T}}=\left\{\mathrm{P}_{\mathrm{Tn}}\right\}=\left[\mathrm{x}_{\mathrm{n}}, \mathrm{y}_{\mathrm{n}}\right]^{\mathrm{T}}, \mathrm{n}=1, \ldots, \mathrm{N}$. Hence, a non- 
linear least square fitting procedure is utilised over $\mathrm{P}_{\mathrm{T}}$ in order to find the equation of the circumference. The analytical description of a 2D circumference can be written as follows:

$$
L(a, b, r)=\sqrt{ }\left((x-a)^{2}+(\mathrm{y}-\mathrm{b})^{2}\right)-\mathrm{r}=0(7)
$$

It can be interpreted from equation 7 that for all coordinated points $(\mathrm{x}, \mathrm{y})$ which satisfy $\mathrm{L}(\mathrm{a}, \mathrm{b}, \mathrm{r})=0$, then, those points depict part of a circumference defined by the centre $(a, b)$ and radio $r$. We define a cost functional $F$ as the squared difference between $\mathrm{L}(\mathrm{a}, \mathrm{b}, \mathrm{r})$ and zero:

$$
F(a, b, r)=\sum_{(\mathrm{i}=1)}^{\mathrm{N}}\|\mathrm{L}(\mathrm{a}, \mathrm{b}, \mathrm{r})\|^{2}
$$

The unknown parameters $\mathrm{a}, \mathrm{b}$ and $\mathrm{r}$ are found by minimising $F$ using Simplex iterative procedure (Lagarias et al. 1998) until a desired convergence is reached. Initial values of the parameters are required by the algorithm. Subsequently, the axis of symmetry is defined with the following line equation:

$$
\zeta(t)=[a, b, o]^{\mathrm{T}}+\mathrm{t}[0,0,1]^{\mathrm{T}}
$$

where $t$, and the diameter is defined as:

$$
\mathrm{D}=2 \mathrm{r}
$$

Fig. $6 \mathrm{~b}$ illustrates the estimation of the 2D circumference around the axis of symmetry whereas Fig. 6.c depicts the location of the 3D mesh of the fragment around this same circumference.

\section{$3.42 D$ profile calculation}

In this step we attempt to extract the 2D profile of the fragment that contains more information of its shape utilising a cutting procedure. A vertical cut consists in the intersection of a plane and the triangulated mesh model of the fragment. The resultant points belong to the same plane and represent the profile of the fragment. The cutting plane must always contain the axis of symmetry and its normal vector must be always parallel to the plane $\mathrm{z}=0$. Then, there exist infinite planes that could cut the 3D mesh. A procedure consisting in the extraction of a finite number of vertical cuts is applied over the mesh model of the fragment. Then, an automatic selection procedure discriminates

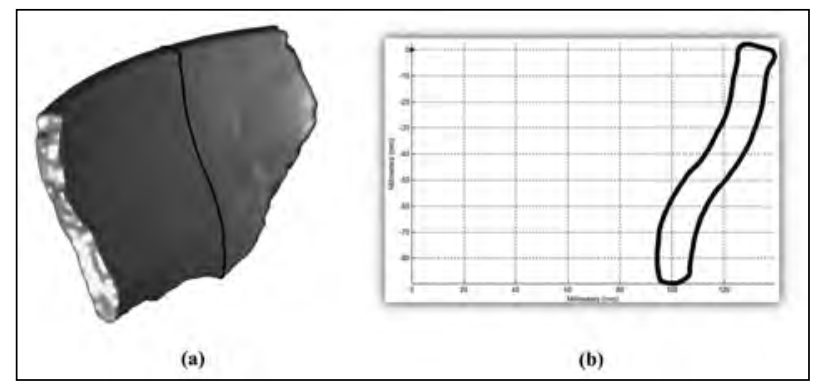

Figure 7. $2 D$ profile calculation. (a) Estimation of the profile with more information of the vessel shape. (b) Calculation of a $2 D$ diagram with the profile of the ceramic fragment. Here, the radio of the vessel rim and the location of the axis of symmetry can be deduced.

among cuts and selects the one with the largest perimeter (Fig. 7a).

A 2D diagram depicting the profile around its axis of symmetry is created. First, the cutting plane which contains the points belonging to the profile is rotated parallel to the plane $x=0$. Finally, the axis of symmetry is located on the left, whereas, the profile is located in the right of the gridded map (Fig. 7b). The resultant 2D diagram allows the user to identify the rim's diameter, thickness, inclination with respect to the horizontal lines and the shape of the fragment in an automatic fashion.

\section{Experiments}

In this step, we design four experiments in order to assess the precision, accuracy, and the depiction/processing time in both methods: the traditional and the 3D method.

4.1 Precision test (inter/intra variability) of the traditional method

The precision error is defined as the standard deviation of a series of measurements (Guidi et al. 2007). Then, the percentage precision error, also known as variability is defined as:

$$
E_{p \%}=\frac{\sqrt{\frac{1}{N} \sum_{i=1}^{N}\left(x_{i}-\bar{x}\right)^{2}}}{\bar{x}} 100 \%
$$

where $\mathrm{N}$ is maximum number of measurements, $x_{i}$ corresponds to the quantity of a single measurement, and $\bar{x}$ is the average of all the measurements. 
Three experienced archaeologists were trained to record four ceramic fragments using the following procedure:

- Tolocatea planarplateover therim of theceramic fragment; therefore the contact between the rim and plate is maximal. Then both the fragment and the plate are positioned perpendicular to a paper sheet, thus the plate is parallel to the horizontal. Then, the symmetry axis is perpendicular to that plate. This procedure is made for estimating the orientation of the fragment.

- To record the shape and thickness of the fragment's profile using a profile gauge. Both internal and external profiles are drawn by hand over the paper sheet taking into account the inclination registered in the previous step.

- To estimate the diameter of the vessel rim by manually positioning it over a rim chart. This chart contains concentric circumferences of several radios. The circumference that best fits with the rim of the fragment is selected. Finally, the axis of rotation is depicted as a vertical line separated from the rim by the radio selected in the previous description.

Inter-person variability assessment: three different archaeologists depicted the fragment profiles of four ceramic fragments using the traditional method. Intra-person variability assessment: each archaeologist depicted the same fragment profile three times. In summary, each fragment has nine manual depictions obtained from the traditional method.

4.2 Precision test (inter/intra variability) of the proposed 3D method

Three experienced archaeologists were trained to record ceramic fragments using the following procedure:

- To operate the 3D laser scanner to obtain 3D meshes of ceramic fragments. Then, the meshes are opened in Meshlab for a pre-processing step.

- To manage gradually the entire methodology proposed in this research until the 2D depictions of the fragment profiles are obtained. This procedure is performed using an interactive technique in Matlab (The MathWorks Inc., USA).

Inter-person variability assessment: three different archaeologists calculate the fragment profiles of four ceramic fragments using the $3 \mathrm{D}$ method. Intra-person variability assessment: each archaeologist calculates the same fragment profile three times. In summary, each fragment has nine profile depictions obtained by the proposed $3 \mathrm{D}$ method.

\subsection{Accuracy test of the proposed 3D method}

The accuracy error is defined as is in the work done by Guidi et al.:

$$
\mathrm{E}_{\mathrm{a}}=\left|\left[1 / N \sum_{(\mathrm{i}=1)}^{\mathrm{N}} \mathrm{x}_{\mathrm{i}}\right]-\mathrm{x}_{\text {true }}\right|
$$

where $\mathrm{N}$ is maximum number of measurements, $\mathrm{x}_{\mathrm{i}}$ corresponds to the quantity of a single measurement and $\mathrm{x}_{\text {true }}$ is the real value of the quantity. We define the percentage accuracy error as $\mathrm{E}_{\mathrm{a} \%}=\mathrm{E}_{\mathrm{a}} / \mathrm{x}_{\text {true }} * 100 \%$.

We select the manual depictions of the most experienced archaeologist as the real true measurements. Then, the average of quantities extracted from these $2 \mathrm{D}$ profiles is considered as $\mathrm{x}_{\text {true }}$. We use the nine calculations per fragment obtained by the 3D method as $\mathrm{x}_{\mathrm{i}}(\mathrm{N}=9)$.

\subsection{Assessment of the time utilised by thetraditional method and the 3D proposed method:}

The time utilised in recording the profile of each fragment utilising both methods is registered with a chronometer in order to assess and compare efficacy. The time utilised by the NextEngine laser scanner in digitising the fragments and for the preprocessing and manual steps was taken into account. However, since our approach is able to work with any other 3D acquisition methods, a faster laser device can be utilised for obtaining complex 3D models in few seconds (Center of Advance Spatial Technologies 2013).

\subsection{Definition of metrics}

We define three metrics which properly describe the profile representations obtained from 


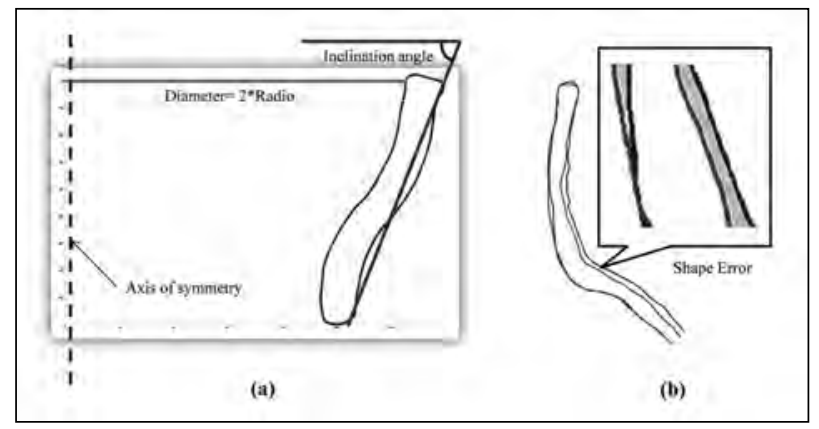

Figure 8. Definition of metrics. (a) The diameter and the angle of inclination of the fragment are extracted from the $2 D$ profile. (b) The shape error is defined as the average difference between two profile representations.

the ceramic fragments: diameter of the vessel rim, orientation angle of the fragment profile, and shape difference.

- Diameter: it consists of two times the radio of the circumference extracted from the rim of the ceramic fragments (Fig. 8a).

- Orientation angle: it is the angle formed by a horizontal line and the line that best fits the points corresponding to the external boundary of the profile (Fig. 8a).

- Shape difference: this metric measures the average error among the locations of points of various aligned profiles. It aims to estimate how similar is the shape of various profile depictions discriminating other error sources such as the diameter estimation or the orientation angle (Fig. 8b).

\section{Results}

5.1 Precision test (inter/intra variability) of the traditional method

This study reports the inter-person and intraperson variability of thethreeproposedmetrics using the traditional recording method. Table 1 reports inter-person variability less than $6.68 \%, 4.22 \%$ and $19.39 \mathrm{~mm}$ in orientation angle, diameter and shape difference respectively, whereas Table 2 reports intra-person variability less than $3.75 \%, 11.97 \%$ and $9.91 \mathrm{~mm}$ of the same metrics. Intra-person variability evaluates the degree of dissimilitude of metrics within a person. Since three persons

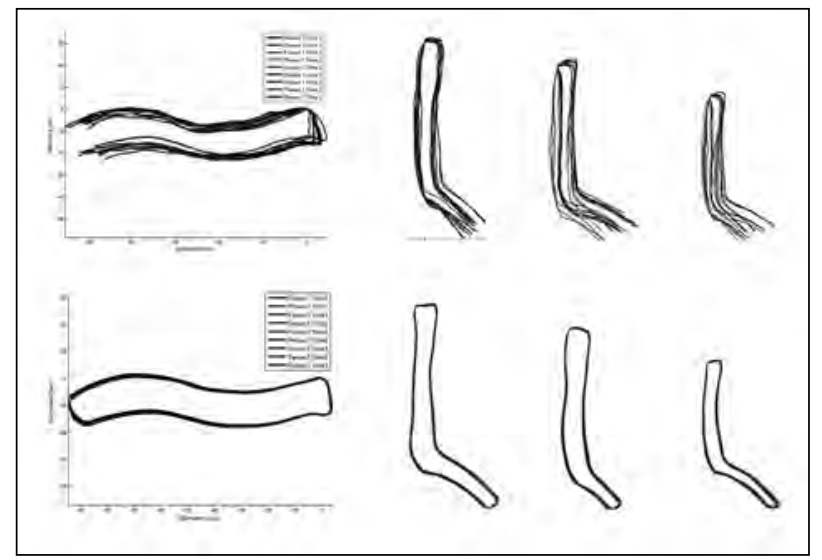

Figure 9. Inter/intra-person variability measurements of four ceramic fragments. Top row: profile depictions calculated using the traditional method. Bottom row: profiles depictions calculated by the $3 D$ system. It is possible to deduce that the proposed $3 D$ technique suffers of less variability compared with the manual technique.

performed the experiment, we have three values of intra-person variability. We show the minimum and the maximum of those three results. The $2 \mathrm{D}$ profiles obtained by this method are depicted in Fig. 9 - top.

\subsection{Precision test (inter/intra variability) of the proposed 3D method}

This study reports the inter-person and intraperson variability of the three proposed metrics using the 3D method. Table 3 reports inter-person variability less than $1.14 \%, 2.97 \%$ and $0.88 \mathrm{~mm}$ in orientation angle, diameter and shape difference respectively, whereas Table 4 reports intra-person variability less than $0.42 \%, 2.07 \%$ and $0.77 \mathrm{~mm}$ of the same metrics. In Table 4, as in the previous case, we show the minimum and the maximum of those three results. The obtained 2D profiles are depicted in Fig. 9 - bottom.

\subsection{Accuracy test of the proposed 3D method}

This study reports the percentage accuracy error of the first two proposed metrics using the $3 \mathrm{D}$ method. Table 5 reports accuracy errors less than $4.78 \%$, and $4.30 \%$ in orientation angle and diameter respectively. Since the shape difference metric is calculated using more than two depictions and we do not have a true pattern for the comparison, the accuracy error of that metric cannot be calculated. 
Across Space and Time. Papers from the 41st Conference on

Computer Applications and Quantitative Methods in Archaeology. Perth, 25-28 March 2013

\begin{tabular}{|c|c|c|c|c|}
\hline & Fragment 1 & Fragment 2 & Fragment 3 & Fragment 4 \\
\hline Angle & $2.16 \%$ & $3.75 \%$ & $2.68 \%$ & $1.72 \%$ \\
\hline Diameter & $5.57 \%$ & $11.97 \%$ & $3.47 \%$ & $3.16 \%$ \\
\hline Shape error (mm) & 5.14 & 9.51 & 9.91 & 7.41 \\
\hline
\end{tabular}

Table 1. A Inter-Person Variability Test using the traditional method for recording profiles of ceramic fragments. A total of 108 measurements were made over 4 ceramic fragments.

\begin{tabular}{|c|c|c|c|c|c|c|c|c|}
\hline & \multicolumn{2}{|c|}{ Fragment 1 } & \multicolumn{2}{c|}{ Fragment 2 } & \multicolumn{2}{c|}{ Fragment 3 } & \multicolumn{2}{c|}{ Fragment 4 } \\
\hline & Min & Max & Min & Max & Min & Max & Min & Max \\
\hline Angle & $2.57 \%$ & $6.68 \%$ & $1.29 \%$ & $5.46 \%$ & $0.94 \%$ & $4.74 \%$ & $1.41 \%$ & $3.61 \%$ \\
\hline Diameter & $0 \%$ & $2.1 \%$ & $0 \%$ & $4.22 \%$ & $1.54 \%$ & $3.43 \%$ & $1.12 \%$ & $2.11 \%$ \\
\hline Shape error (mm) & 4.25 & 6.49 & 4.15 & 18.60 & 7.31 & 19.39 & 4.80 & 14.66 \\
\hline
\end{tabular}

Table 2. Intra-Person Variability Test using the traditional method for recording profiles of ceramic fragments. A total of 108 meassurements were made over 4 ceramic fragments.

\begin{tabular}{|c|c|c|c|c|}
\hline & Fragment 1 & Fragment 2 & Fragment 3 & Fragment 4 \\
\hline Angle & $0.14 \%$ & $0.22 \%$ & $0.15 \%$ & $0.42 \%$ \\
\hline Diameter & $0.19 \%$ & $0.88 \%$ & $2.07 \%$ & $0.55 \%$ \\
\hline Shape error (mm) & 0.51 & 0.53 & 0.54 & 0.77 \\
\hline
\end{tabular}

Table 3. Inter-Person Variability Test using the proposed $3 D$ method for recording profiles of ceramic fragments. A total of 108 measurements were made over 4 ceramic fragments.

\begin{tabular}{|c|c|c|c|c|c|c|c|c|}
\hline & \multicolumn{2}{|c|}{ Fragment 1 } & \multicolumn{2}{c|}{ Fragment 2 } & \multicolumn{2}{c|}{ Fragment 3 } & \multicolumn{2}{c|}{ Fragment 4 } \\
\hline & Min & Max & Min & Max & Min & Max & Min & Max \\
\hline Angle & $0.21 \%$ & $0.94 \%$ & $0.29 \%$ & $1.14 \%$ & $0.14 \%$ & $0.53 \%$ & $0.05 \%$ & $1.01 \%$ \\
\hline Diameter & $0.58 \%$ & $2.07 \%$ & $1.03 \%$ & $2.12 \%$ & $2.36 \%$ & $2.97 \%$ & $1.15 \%$ & $3.23 \%$ \\
\hline Shape error (mm) & 0.41 & 0.57 & 0.48 & 0.56 & 0.37 & 0.65 & 0.65 & 0.88 \\
\hline
\end{tabular}

Table 4. Intra-Person Variability Test using the proposed 3D method for recording profiles of ceramic fragments. A total of 108 measurements were made over 4 ceramic fragments.

\begin{tabular}{|c|c|c|c|c|}
\hline & Fragment 1 & Fragment 2 & Fragment 3 & Fragment 4 \\
\hline Angle & $3.41 \%$ & $3.40 \%$ & $2.13 \%$ & $4.78 \%$ \\
\hline Diameter & $3.21 \%$ & $2.19 \%$ & $4.30 \%$ & $1.67 \%$ \\
\hline
\end{tabular}

Table 5. Accuracy Error Test of the proposed 3D method for recording profiles of ceramic fragments. A total of 72 measurements were made over 4 ceramic fragments.

\subsection{Assessment of the timeutilised by thetraditional method and the 3D proposed method}

The study reports that the traditional method takes an average of 15 minutes per fragment, whereas, the 3D method takes around 2 minutes without considering the acquisition time and the preprocessing step and manual interventions.
Considering 9 minutes for the acquisition time with NextEnginelaser scanner and 2 minutes for theother tasks, the whole procedure takes around 13 minutes. Then, $13.3 \%$ of reduction in the time utilised by the manual methods in recording the profile of the fragments is achieved by the 3D method proposed in this research. 


\section{Conclusions}

Theproposed 3D method can record and obtain profile representations of ceramic fragments with more precision (less variability) than the traditional method as reported in inter/intra variability and accuracy tests. Traditional methods show that no matter how well-trained the archaeologist is, it is pretty improbable for them to draw one fragment exactly the same as they repeat the experiment. This could get worst with large amount of fragments. The achieved accuracy of the proposed 3D method is acceptable (accuracy error less than 5\%) when the depictions of the most experienced archaeologist are taken as reference. Likewise, the 3D method reduces in $13.3 \%$ the time utilised by the manual methods in recording the profile of the fragments. This is fundamentally important since archaeology is an expensive discipline in which time is pretty valuable. The percentage of time reduction including the acquisition process with the NextEngine laser scanner is not considerably high. However, the recent development on 3D recording methods allows acquiring 3D models of objects in seconds and could reduces the time of the entire procedure in more than $50 \%$.

In addition, the field of applicability of this research allows implementing a large 3D data base of ceramic fragments in which the systematised information is based on the metrics calculated automatically. It would allow archaeologists to manage more information in less time for a low cost and will enable them to share and publish their information in an easier and better approachable fashion. Finally, this research opens the possibility of processing the 3D information of the fragments with other purposes such as the 3D reconstruction of the entire vessel based only on the information of the fragment, or the estimation of the amount of material utilised for its fabrication. A future research must be focused on the assessment of accuracy of the method in a higher amount of fragments.

\section{Acknowledgements}

The authors would like to thank the support of San José de Moro Archaeological Program (Perú) for providing access to all the material, technical information and professional assistance. In particular, we want to thank to Andrew Lorey for the revision and correction of this document. This research was partially supported by the Interdisciplinary Research Project DGI 2013-0113 from the Pontificia Universidad Católica del Perú.

\section{Bibliography}

Bernardini, F., and H. Rushmeier. 2002. "The 3D acquisition pipeline." Computer Graphics Forum 21:149172. Accessed February 07. doi: 10.1111/ 1467-8659.00574.

Center of Advance Spatial Technologies. 2013. "Minolta 91 Technical Specifications." Last Modified March 30. http:// cast.uark.edu/ home/ about/ resources/ researchinstruments/ scanners/ minolta/ minolta-9i-technicalspecifications.html.

Dong, C., and G. Wang. 2005. "Curvature estimation on triangular mesh." Journal of Zhejiang University SCIENCE 6:128-136. Accessed January 7, 2013. doi: 10.1631/jzus.2005.AS0128.

Guidi, G., F. Remondino, G. Morlando, A. Del Mastio, F. Uccheddu, and A. Pelagotti. 2007. "Performances evaluation of a low cost active sensor for cultural heritage documentation." In Proceedings of VII Conference on Optical 3D Measurement Techniques Volume 2, 59-69. Zurich: ETH.

Hubeli, A., and M. Gross. 2001. “Multiresolution Feature Extraction for Unstructured Meshes." In VIS '01. Proceedings of the conference on Visualization '01, 287294. Washington: IEEE.

Kampel, M., and F. J. Melero. 2003. "Virtual vessel reconstruction from fragment's profile." In Proceedings of the 4th International conference on Virtual Reality, Archaeology and Intelligent Cultural Heritage, edited by D. Arnold, A. Chalmers, and F. Niccolucci, 79-88. Brighton: Eurographics Association.

Karasik, A., and U. Smilansky. 2008. "3D scanning technology as a standard archaeological tool for pottery analysis: practice and theory." J ournal of Archaeological Science 35:1148- 1168.

Lagarias, J., J. Reeds, M. Wright, and P. Wright. 1998. "Convergence properties of the Nelder-Mead Simplex method in low dimensions." SIAM J ournal of Optimization 9:112- 147. 
Across Space and Time. Papers from the 41st Conference on

Computer Applications and Quantitative Methods in Archaeology. Perth, 25-28 March 2013

Lobregt, S., and M. Viergever. 1995. "A discrete dynamic contour model" IEEE Transactions in Medical Imaging 14:12- 24. Accessed November 14, 2012.

Mara, H., and R. Sablatnig. 2005. "A comparison of manual, semiautomatic and automatic profile generation for archaeological fragments." In Proceedings of the 10th Computer Vision Winter Workshop, edited by A. Hanbury and H. Bischof, 123-134. Zell an der Pram: Vienna University of Technology.

Orton, C., P. Tyers, and A. Vince. 1993. Pottery in Archaeology. Cambridge: Cambridge University Press.

Taubin, G. 1995. "Curve and surface smoothing without shrinkage." In Proceedings of the Fifth International Conference on Computer Vision, 852- 857. Cambridge, Massachusetts: IEEE.

Yao, F., and G. Shao. 2003. "Detection of 3D symmetry axis from fragments of broken pottery bowl." In 2003 IEEE International Conference on Acoustics, Speech, and Signal Processing, 2003. Proceedings. (ICASSP ‘03). Volume 3, 505- 508. Hong Kong: IEEE Signal Processing Society Press.

Zhao, W., S. Gao and H. Lin. 2007. "A robust Hole-filling algorithm for triangular mesh.” In Proceedings of 2007 10th IEEE International Conference on Computer Aided Design and Computer Graphics, edited by G. Wang, H. Li, H. Zha, and B. Zhou, 23 (12), 987- 997. Berlin: Springer. 


\title{
Eigen Paicas: A 3D Reconstruction of Entire Vessels Using Information of a Single Fragment and a Database
}

\author{
Fernando Zvietcovich, Benjamin Castaneda, Luis J aime Castillo and J ulio Saldana \\ Pontificia Universidad Catolica del Peru, Peru
}

\begin{abstract}
:
Traditionally, fragments of ceramic vessels are collected during an archaeological research project since they provide important pieces of evidence concerning cultural affiliation, dating, and other types of important information. However, complete vessels provide additional data such as food storage capacity and weight. A 3D reconstruction technique for reconstructing complete vessels based on fragments is proposed and applied to paicas, large ceramic containers from the Moche society of northern Peru. $A$ database of profile contours, derived from the $3 D$ models of 23 paicas, was established and used to reconstruct the shape of entire vessels from fragments using Principal Component Analysis (PCA) and the Simplex optimisation algorithm. Preliminary results from a group of four fragments provide good estimations with an average accuracy error of $14 \%$ and a precision error equal to $0 \%$.
\end{abstract}

\section{Keywords:}

3D Reconstruction, Moche Pottery, Principal Component Analysis, Pottery Clasification

\section{Introduction}

Fragments of ceramic vessels are customarily found and collected in archaeological contexts because they provide important archaeological information. Recording fragments and characterising aspects such as diameter, thickness, orientation, and shape allow the researcher to place the sherd in a ceramic typology, and to determine its cultural affiliation and age (Orton, Tyers and Vince 1993). On the other hand, complete vessels yield further information such as food storage capacity, physical dimensions (weight and height), and a sense of the amounts and types of materials used in their fabrication (Orton, Tyers and Vince 1993). Unfortunately, the number of ceramic fragments found during an archaeological excavation is usually much greater than the number of complete vessels recovered. For example, at the site of San J ose de Moro located in the J equetepeque Valley of northern Perú, the ratio between the number of complete ceramic containers, locally known as paicas, and fragments of such containers is roughly 1:600. Therefore, a methodology for estimating the geometry of complete vessels, using information extracted from a single ceramic fragment, is needed.

Corresponding author: castaneda.b@pucp.edu.pe
During the last ten years, the majority of the scientific research devoted to ceramic analysis has been focused on the accurate extraction of dimensional profiles from potsherds (Karasik and Smilansky 2008; Mara and Sablatnig 2005; Yao and Shao 2003). Only a few attempts have been made to propose a methodology for reconstructing complete vessels based on potsherds. For instance, Kampel and Melero (Kampel and Melero 2003) generated a reconstruction by a prolongation of theoriginal profile using a cubic spline that follows the shape indicated by $15 \%$ of the profile. This technique requires the assistance of an expert to edit the estimation previously described. Consequently, the estimation is highly dependent on the editor's expertise. Alternatively, the work of Liu, Pottman and Wang (2006) utilises the square distance minimisation (SDM) method for the surface reconstruction of archaeological pottery. Although the results are highly accurate, this type of predictive analysis requires almost all the geometrical information of the vessel. Therefore, a single small fragment cannot be used as a template for reconstruction using this approach. Marie and Qasrawi (2005) developed a third possible method of reconstruction by applying a matching and alignment procedure to fragments of the same pottery using moiré surface profile measurements. Using this method, the estimation of the pottery shape can be accurately obtained if there 


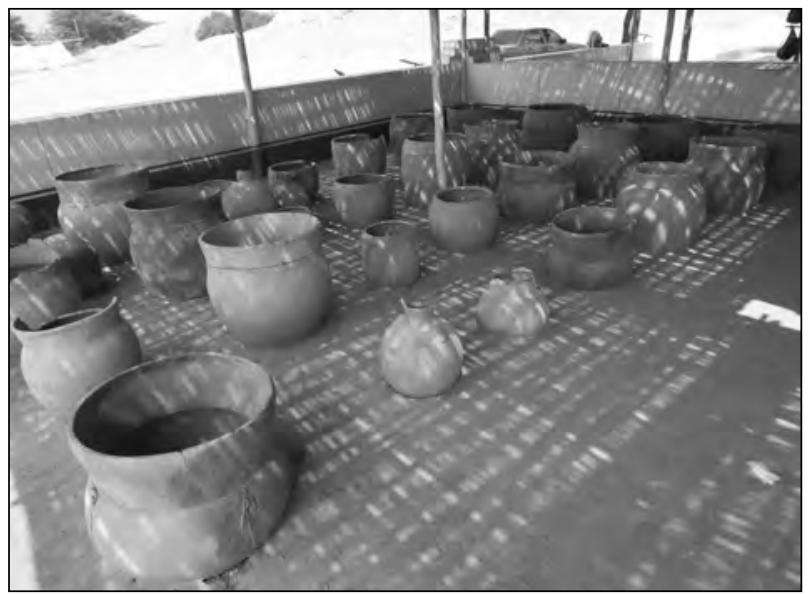

Figure 1. Store of paicas in the site of San Jose de Moro in the Jequetepeque Valley of northen Perú.

exists a large enough quantity of similar potsherds. However, this technique does not overcome the problem of attempting to extrapolate vessel shape from one single fragment.

Herein, we propose a novel methodology for pottery reconstruction based on the comparison of information exemplified by single potsherd against a database composed of several profiles of complete vessels. Within our approach, Principal Component Analysis (PCA) is first utilised to extract geometrical features from ceramic vessels in order to predict the most probable expanded shapeofa desired fragment. Then, a Simplex optimisation procedure is utilised to find the solution of a non-linear cost functional composed of 2 terms: (1) an underdetermined linear system formed from the information of the database using PCA and (2) a regularisation term which ranks solutions according to the similarity to the desired profile in the database. The case study presented here focuses on the reconstruction of fragments belonging to paicas. The database is comprised of the profiles of 23 paicas found during 20 years of research by the San Jose de Moro Archaeological Program.

The remainder of this paper is organised as follows. In Section 2, we describe the 3D acquisition process involving the use of a laser scanner, and we outline a photogrammetric approach for recording potsherds and paicas. Section 3 illustrates a methodology for the creation of a reference database devoted to ceramic classification. Section 4 provides a description of the entire algorithm for the profile

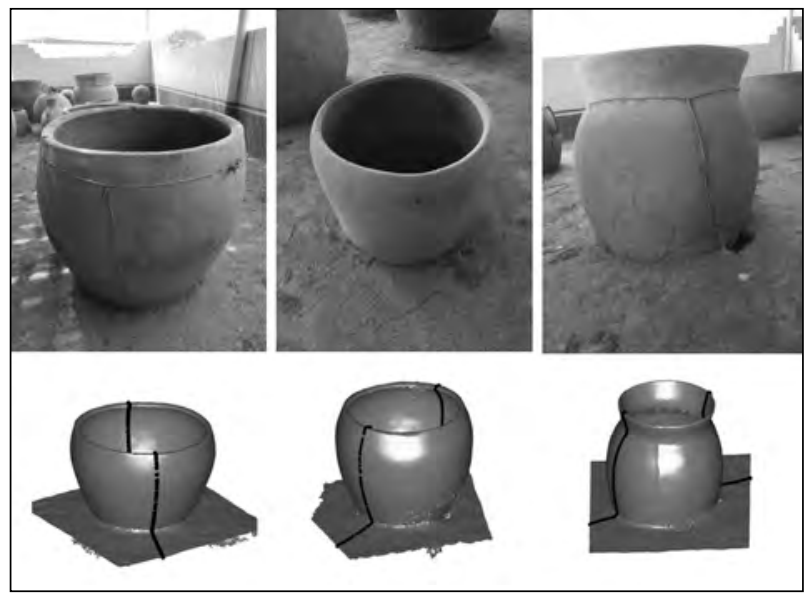

Figure 2. 3D mesh models of three paicas. Top: representative pictures of the vessels. Bottom: $3 D$ meshes of paicas obtained by Agisoft Phtoscan.

reconstruction of single potsherds using PCA and a Simplex optimisation procedure. In Section 5, we design two experiments in order to assess accuracy error and variability. Finally, we discuss the results of these experiments in Section 6 and suggest that a more accurate evaluation of the proposed technique in order to determine if our reconstructions provides the most probable estimation.

\section{3D Acquisition of Potsherds and Paicas}

The acquisition procedure is divided in two steps: 3D mesh modelling of paicas by a photogrammetric reconstruction tool and 3D recording of ceramic fragments using a laser scanner.

\subsection{Mesh modeling of paicas}

Twenty three paicas with average dimensions of about $80 \mathrm{~cm}$ high and $65 \mathrm{~cm}$ wide are available at the archaeological site. Examples of these vessels are illustrated in Fig. 1. 3D models of these paicas are generated by using Agisoft PhotoScan ${ }^{\circledR}$ (Agisoft LLC, St. Petersburg; Agisoft 2013) in a computer system equipped with an 4-core Intel i5 processor at $2.30 \mathrm{Ghz}, 8 \mathrm{~GB}$ of RAM and a ADM Radeon ${ }^{\mathrm{TM}}$ 6470M 512 MB RAM graphics card running Microsoft Windows 7 64-bit. This software utilises dense stereo reconstruction tools to produce a 3D mesh model from a set of unordered images with high overlap (at least 30\% shared between scenes is recommended). We record an average of 52 images 
per paica. Representative images of some of the paicas are illustrated in Fig. 2 - top.

Agisoft PhotoScan ${ }^{\circledR}$ performs the reconstruction in three stages: figure alignment, geometry building, and texture building. It requires the user to select the level of accuracy, quality and resolution in the reconstruction. For more information concerning the algorithms utilised in all the stages and the description of the parameters selected in Agisoft, we direct the reader to other works (Agisoft 2013; Scharstein and Szeliski 2002; Seits et al. 2006). The average total time required for the software to reconstruct each vessel is 2 hours while the average resolution is 1 million points per model. Some of the resultant 3D meshes are illustrated in Fig. 2 - bottom.

\subsection{D Recording of ceramic fragments}

Four indicative ceramic fragments belonging to paicas, which contain information about the rim of the vessel, were found in the same site of San J ose de Moro, Peru. These fragments are illustrated in Fig. 3 - top.

The 3D meshes of the ceramic potsherds were obtained with the commercial 3D laser scanner Next Engine HD (NextEngine Inc., CA, USA). This device projects a laser pattern over the target surface and estimates the 3D coordinate positions of each point around the pattern via 3D triangulation and image processing tools (Bernardini and Rushmeier 2002). The scanner sweeps the laser pattern around the entire fragment in a single view point. Then, a rotary wheel connected to the scanner rotates the fragment up to $360^{\circ}$ to acquire 3D models representing its various views. All views are displayed, registered and merged together in order to create a complete 3D mesh representation of the fragment utilising the software ScanStudio HD (NextEngine Inc., CA, USA).

The 3D meshes of the fragments have an average amount of $42 \mathrm{k}$ points, and $0.13 \mathrm{~mm}$ of accuracy. The acquisition lasted nine minutes per model on average. During the scanning procedure, the fragments were located $16.5 \mathrm{~cm}$ approximately in front of the scanner. The spatial configuration of the scanner and fragments is illustrated in Fig. 2. The data were exported using object file format (.obj)

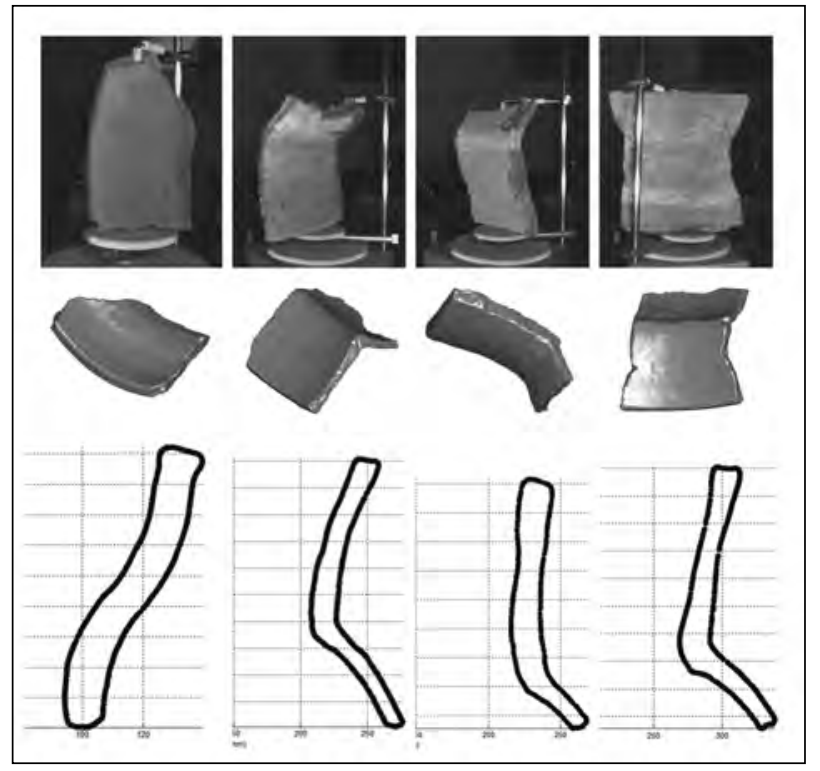

Figure 3. Recording procedure of four ceramic fragments. Top: pictures of the fragments during the scanning process. Center: 3D meshes obtained with a laser scanner. Bottom: $2 D$ profile representations of the fragments.

which contains information of the point coordinates representing the model, its 3D triangulation, and the texture color attached to the mesh.

Finally, the four 3D meshes corresponding to the ceramic fragments in study are loaded into Meshlab (Visual Computing Lab, ISTI - CNR, Italy) for a preprocessing step. Here, a hole-completion algorithm (Zhao, Gao and Lin 2007) is utilised to fill the gaps around the models while a Taubin $\lambda \mid \mu$ filtering procedure (Taubin 1995) is applied to the models in order to remove noise and preserve salient shape features. The resulting meshes are illustrated in Fig. 3 - center.

\section{Database Formation}

Archaeological evidence demonstrates that paicas possess a high percentage of axial symmetry. Therefore, a paica's complete geometry can be generated by rotating the profile contour of any such vessel around its axis of symmetry. The 23 paicas that were profiled using the photogrammetric reconstruction method are consistent with the majority of the evidence of entire preserved vessels found during 20 years of archaeological work. Thus, we consider them to represent a comprehensive 


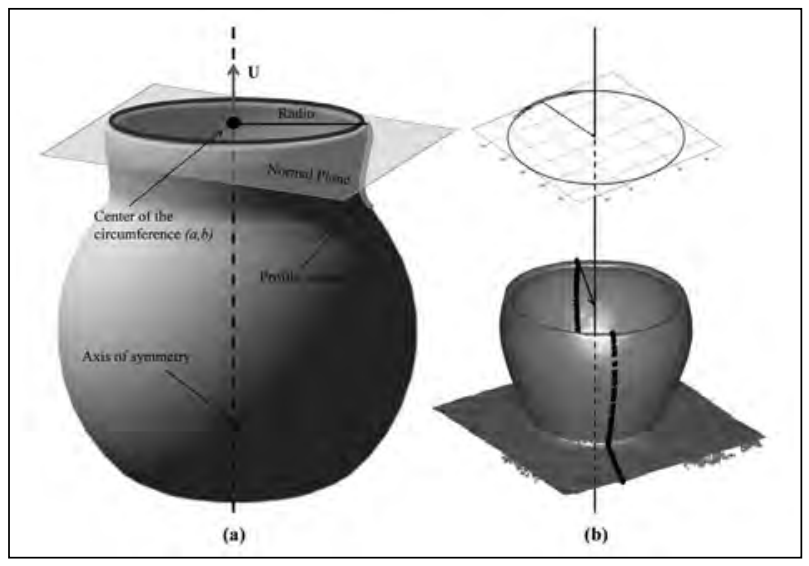

Figure 4. Estimation of the axis of symmetry and diameter of the rim. (a) Definition of features in an idealized vessel. (b)-top: Fitting procedure of a circumference using the points of the rim. (b)-bottom: Location of the fragment model around the axis of symmetry and calculation of its profile.

dataset of geometrical information pertaining to this type of container. It is this database that will be utilised for the reconstruction of potsherds. Although this model assumes that paica fragments found in the same archaeological area share some geometrical features with one or more profiles belonging to the database, this is not a controversial assumption to make.

The database formation consists of extracting and storing profile contours of the 23 mesh models of paicas and their alignment taking in account the diameter of their rims. Finally, a clustering procedure classifies the database in groups that share common geometrical features. The entire procedure is performed in six steps: orientation estimation, estimation of axial symmetry and the diameter of the rim, a profile calculation, profile segmentation, profile alignment and storage, and clustering procedure.

\subsection{Orientation estimation}

The orientation of a vessel is defined by the unitary vector such that all points belonging to the rim of the vessel are contained in a plane normal to this vector. In order to estimate that plane, a fitting procedure based on least squares optimisation is applied over the point set representing the vessel rim. Finally, a rigid transformation is applied over the mesh model of the vessel so that the plane

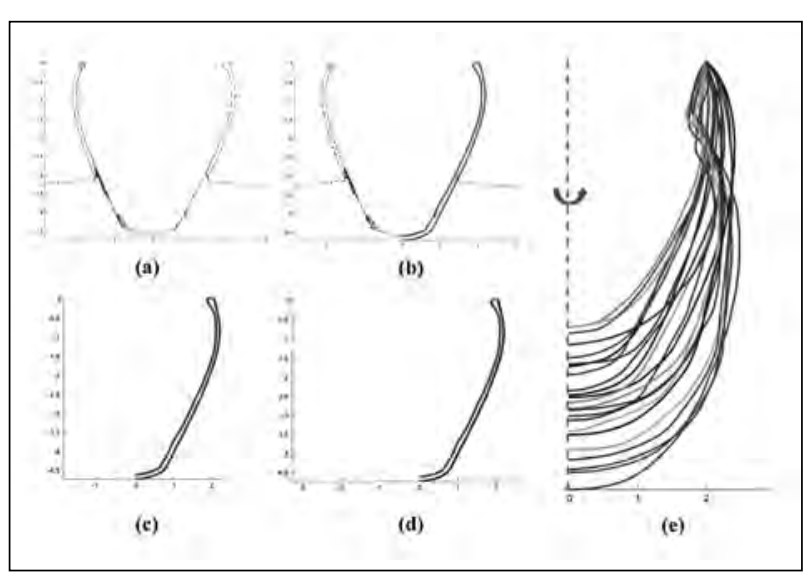

Figure 5. Segmentation and database formation. (a) A $2 D$ profile of a paica. (b) Manual segmentation of one side of the profile. (c) Segmented version of the profile. (d) Selection of the external border for the database formation. (e) Profile alignment around the same axis of symmetry and rim. Twenty three profiles constitute the entire database.

containing those points is parallel to the plane $\mathrm{z}=0$. This procedure is described in the work done by Karasik and Smilansky (2008) and the new Cartesian location of the vessel in the 3D space is depicted in Fig. 4a.

3.2 Estimation of the axis of symmetry and diameter of the rim

Since we are working with axial symmetric vessels, the projection of the rim over the plane $\mathrm{z}=0$ generates a circumference. Then, the center of the circumference and the direction of the orientation vector define the axis of symmetry, while the radius allows the estimation of the approximate diameter of the rim. The parameters of the circumference are found using a non-linear least square fitting procedure as explained by Karasik and Smilansky (2008). Fig. 4b illustrates the estimation of the 2D circumference around the axis of symmetry of one paica.

\section{$3.32 D$ profile calculation}

In this step we attempt to extract the $2 \mathrm{D}$ profile of the vessel utilising a cutting procedure. A vertical cut consists in the intersection of a plane and the triangulated mesh model of the paica. The resultant points belong to the same plane and represent the profile of the vessel. We use the approach made 


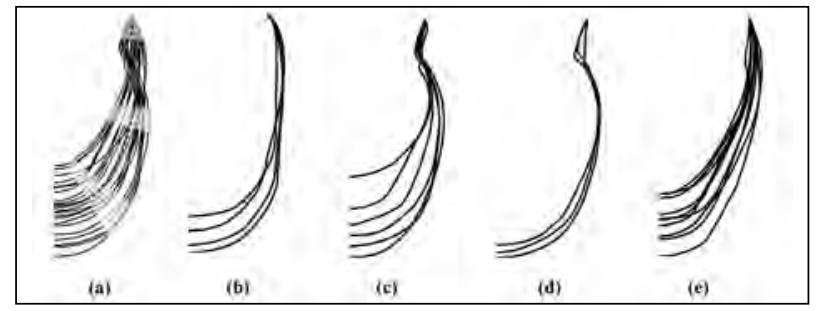

Figure 6. Database classification. (a) Entire database of profiles in which the discontinuous line depicts its average. (b)-(e): Determination of 4 clusters via K-Means clustering procedure and Principal Component Analysis (PCA). Each group shares geometric features.

of Karasik and Smilansky (2008) for the profile extraction and some results are illustrated in Fig. 5a.

\subsection{Profile segmentation}

Since the axis of symmetry cuts the profile in two equal parts, a manual segmentation procedure allows the user to select one side of the profile extracting the points that are relevant for its appropriate representation (see Fig. 5b). The resultant segmented profile of one paica depicting an internal and external border is illustrated in Figs 5c. Finally, we select the external border of the profile since both sides represents almost the same information due to the symmetry condition. This latter border is illustrated in Fig. 6d.

\subsection{Profile alignment and storage}

Twenty three external segmented profiles located around its axis of symmetry are obtained using the procedure previously described. At this point, all the profiles are not scaled to the real dimensions and they are located arbitrarily in the 2D space. The approach proposed in this paper requires that all the profiles of the database contain semantically the same features such as rim, neck, and body. Therefore, the profiles need to be aligned in such a manner that the location of their rims, necks, and bodies occupies approximately the same sector of the 2D map. Since each profile has different dimensions, we normalise them so that all of them have the same location and dimension of the radius of their rims, and share the same axis of symmetry. Finally, a cubic interpolation is applied over the profiles in order to make them contain the same amount of points (1000 points per profile) distributed uniformly around its longitude. The result of this procedure is illustrated Fig. 5e. After alignment of the profiles, they are storage in a single database.

\subsection{Clustering procedure}

Fig. 6a depicts a rich variety of geometrical features. A common practice in archaeology consists of classifying ceramic fragments by means of the shape of the neck in order to create a typology. The approach proposed in this paper takes advantage of this idea and classify the entire database in finite number of groups in which geometrical features are shared. Then, the reconstruction algorithm will utilise the cluster of profiles which posses the highest correlation to the ceramic potsherd being analysed.

The classification procedure is based on Principal Component Analysis (PCA) which transforms the 2D Cartesian representation of the profiles into vectors of uncorrelated weights that represent the same elements in another orthogonal space. The set of vectorised coordinates describing each profile of the database is represented by

$$
\mathrm{b}_{\mathrm{i}}=\left[\mathrm{x}_{1} \mathrm{y}_{1} \mathrm{z}_{1}, \mathrm{x}_{2} \mathrm{y}_{2} \mathrm{z}_{2}, \ldots, \mathrm{x}_{\mathrm{n}} \mathrm{y}_{\mathrm{n}} \mathrm{z}_{\mathrm{n}}\right]^{\mathrm{T}}
$$

where $\mathrm{i}=1,2, . ., \mathrm{m}$, and $\mathrm{m}=23$ and $\mathrm{n}=1000$ correspond to the maximum number of profiles and the maximum number of points of each profile, respectively. Subsequently, the database of 23 profiles is formed and represented by

$$
\mathrm{B}=\left[\mathrm{b}_{1}, \mathrm{~b}_{2}, \ldots, \mathrm{b}_{\mathrm{m}}\right]
$$

The mean of the database is calculated and subtracted from B in order to create the covariance matrix in which an eigen-decomposition is applied.

$$
\begin{aligned}
& \hat{B}^{T} \hat{B}=P \Lambda P^{\mathrm{T}}, \text { where } \\
& \hat{B}=\left[\mathrm{b}_{1}-\mu, b_{2}-\mu, \ldots, b_{\mathrm{m}}-\mu\right], \text { and } \\
& \mu=\frac{1}{m} \sum_{i=1}^{m} b_{i}
\end{aligned}
$$

The diagonal matrix contains the eigen-values of the database. We found that only four of these values are the most relevant (non-zero). Therefore, the database will be classified into four groups. The columns of the matrix $\mathrm{P}$ correspond to the eigen-vectors of the database. We only preserve the 
eigen-vectors with relevant corresponding eigenvalues $\left[\mathrm{P}^{\prime}\right]_{1000 \times 4}$ for the creation of the dictionary represented by

$$
\mathrm{D}=\hat{B} \mathrm{P}^{\prime}
$$

Then each profile of the database can be represented by a linear combination of the elements in $\mathrm{D}$ according to a desired vector of weights $\mathrm{w}_{\mathrm{i}}$ as explained in Eq. 5:

$$
\mathrm{b}_{\mathrm{i}}=\mathrm{Dw}_{\mathrm{i}}+\mu
$$

where $\mathrm{i}=1,2, . ., \mathrm{m}$, and $\mathrm{m}=23$. Then, each profile of paica is represented by $\mathrm{w}_{\mathrm{i}}$ in the eigen-space. Subsequently, we apply K-Means clustering over $\mathrm{w}_{\mathrm{i}}$ for its classification into four clusters as illustrated in Fig. 6 b-e. Here, it is evident that each profile within a cluster shares some geometric features; for instance, the shape of the neck of the vessels. We call the dictionaries belonging to each cluster $\mathrm{D}_{\mathrm{a}^{\prime}}, \mathrm{D}_{\mathrm{b}^{\prime}} \mathrm{D}_{c^{\prime}}$ and $D_{d}$.

\section{Reconstruction of Vessels}

We attempt to reconstruct indicative fragments which possess axial symmetry since they belong to paicas. The methodology reported by Karasik and Smilansky (2008) is utilised for the $2 \mathrm{D}$ profile extraction of the fragments. Fig. $3-$ bottom depicts the profile maps of four potsherds. The points belonging to their external border are represented by the vectorised set described in Eq. 6:

$$
\mathrm{q}_{\mathrm{j}}=\left[\mathrm{x}_{1} \mathrm{y}_{1} \mathrm{z}_{1}, \mathrm{x}_{2} \mathrm{y}_{2} \mathrm{z}_{2}, \ldots, \mathrm{x}_{\mathrm{s}} \mathrm{y}_{\mathrm{s}} \mathrm{z}_{\mathrm{s}}\right]^{\mathrm{T}}
$$

where $j=1,2,3,4$ and $s$ correspond to the maximum amount of points of each profile respectively. We must highlight that $\mathrm{s}<\mathrm{n}$.

The procedure is divided into two steps. The first step identifies the cluster of the database most similar to the fragment being analysed using the pattern recognition algorithm PCA. In the second part, we take the information of the selected group for the reconstruction of the entire vessel using PCA and a Simplex optimisation tool.

\subsection{Cluster selection}

This step attempts to find the paica profile

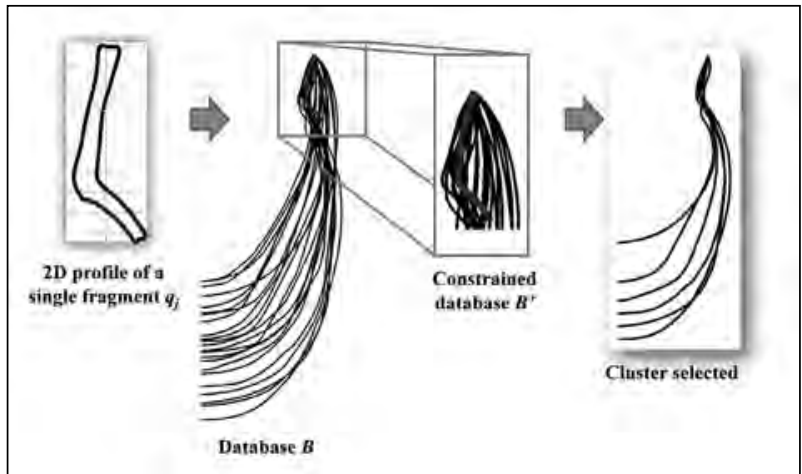

Figure 7. Cluster selection procedure. A new database B' is created accordingly to the size of the fragment being analyzed. After the application of PCA, a desired cluster is selected for the fragment.

most similar to the profile of the fragment being analysed. In (4), the dictionary is formed with information from entire vessels. Since we are working with a fragment that represents a portion of the vessel, the database B is constrained so that it only represents the same portion as in potsherds. We call this new database B' (Fig. 7).

Eqs 3 and 4 are recalculated using B' instead of B. Then, we obtain the dictionary D' and the database average, and they are introduced in Eq. 5 in order to find the set $\mathrm{w}_{\mathrm{i}}$ ' of vector of weights which represents the first portion of each profile in the database. Similarly, we find the set of vectors of weights $v_{j}$ representing each potsherd being analysed in terms of the same dictionary $\mathrm{D}^{\prime}$ as explained in Eq. 7:

$$
\mathrm{q}_{\mathrm{j}}=\mathrm{D}^{\prime} \mathrm{v}_{\mathrm{j}}+\mu^{6}
$$

Finally, we apply the Euclidean distance between $\mathrm{w}_{\mathrm{i}}{ }^{\prime}$ and $\mathrm{v}_{\mathrm{j}}$ in order to find which $\mathrm{w}_{\mathrm{i}}{ }^{\prime}$ is the nearest to a desired $v_{j}, j=c$ and $c \epsilon\{1,2,3,4\}$. The vector solution is called $\mathrm{w}_{\mathrm{i}}^{*}$ and its cluster (calculated in the previous section) is selected and assigned to the potsherd we want to reconstruct.

\subsection{Profile reconstruction}

Since we are working with a fragment, the selected dictionary $\mathrm{D}_{\mathrm{k}^{\prime}} \mathrm{k}=\{\mathrm{a}, \mathrm{b}, \mathrm{c}, \mathrm{d}\}$, needs to be constrained so that it only represents the portion of the fragment.

$$
D_{k}=\left[\begin{array}{l}
D_{1} \\
D_{2}
\end{array}\right]
$$




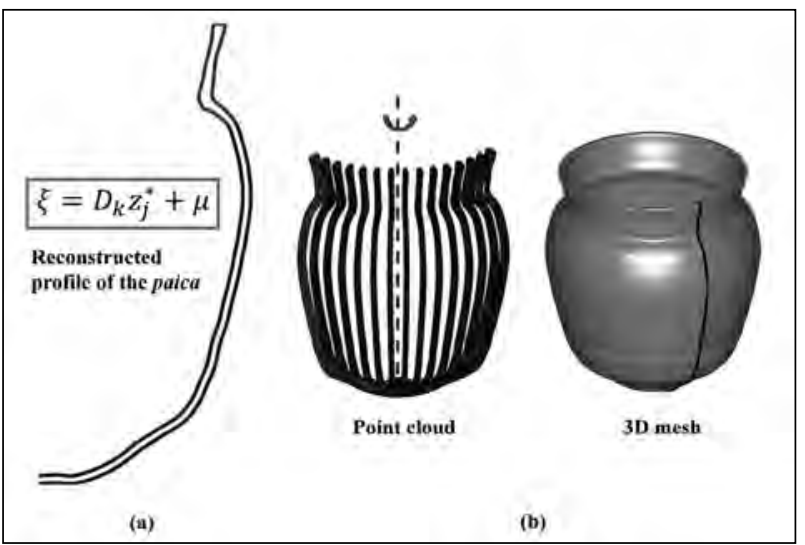

Figure 8. Profile reconstruction. (a) The $2 D$ profile is completely reconstructed according to Equation 11. (b) The reconstructed profile is rotated around its axis of rotation. The $3 D$ entire vessel is generated after a meshing procedure.

Eq. 8 describes $\mathrm{D}_{\mathrm{k}}$ as a composition of $\mathrm{D}_{1}$ and $\mathrm{D}_{2}$ where $\mathrm{D}_{1}$ represents the portion of the dictionary related to the information of the fragment in study, while $\mathrm{D}_{2}$ is related to the rest of the vessel. In the same way, is composed by $\mu_{1}$ and $\mu_{1}$.

We use $\mathrm{D}_{1}$ instead of $\mathrm{D}_{\mathrm{k}}$ in Eq. 5 in order to find the set of vector weights $\mathrm{z}_{\mathrm{j}}$ which generates a linear combination of the dictionary $\mathrm{D}_{1}$ in order to describe a desired potsherd as explained in Eq. 9:

$$
\mathrm{q}_{\mathrm{j}}=\mathrm{D}_{1} \mathrm{z}_{\mathrm{j}}+\mu_{1}
$$

Eq. 9 describes a linear system of the type $A x=b$ where $\mathrm{A} \leftarrow \mathrm{D}_{1}, \mathrm{~b} \leftarrow \mathrm{q}_{\mathrm{i}}-$ and $\mathrm{x} \leftarrow \mathrm{z}$. While $\mathrm{D}$ constitutes a non-singular matrix because it is formed of eigenvectors that are orthogonal between each other, $\mathrm{D}_{1}$ does not since it is a portion of D. Then, Eq. 9 is an underdetermined system that does not support a close solution of the type $x=A^{-1} b$. Therefore, it must be solved in an iterative fashion.

We propose a cost functional formed of two factors: a linear term and a regularisation term as described in Eq. 10:

$$
\psi\left(\mathrm{z}_{\mathrm{j}}\right)=\alpha\left\|\mathrm{D}_{1} \mathrm{z}_{\mathrm{j}}-\left(\mathrm{q}_{\mathrm{j}}-\mu_{\mathrm{i}}\right)\right\|^{2}+\beta\left\|\mathrm{D}_{1} \mathrm{z}_{\mathrm{j}}-\varphi\right\|^{2}
$$

where $\alpha$ and $\beta$ gives priority to the terms of the equation, and $\varphi=b_{i}{ }^{*}-\mu_{1}$. While the first term in Eq. 10 attempts to solve the system described in (7), the second term gives preference to a solution close to which is the most similar profile of a paica to the fragment being analysed.

We apply a Simplex optimisation procedure in order to minimise for desired values of and as described in Eq. 11.

$$
\mathrm{z}_{\mathrm{j}}^{*}=\min _{\mathrm{zj}_{\mathrm{j}}} \psi\left(\mathrm{z}_{\mathrm{j}}\right)
$$

Finally, the reconstructed profile is given by a linear combination of the elements belonging to the selected cluster $\mathrm{D}_{\mathrm{k}}$ according to the weights as described in Eq. 12.

$$
\xi=D_{\mathrm{k}} \mathrm{z}_{\mathrm{j}}^{*}+\mu
$$

Fig. 8a illustrates the reconstructed profile. Fig. $8 \mathrm{~b}$ describes the rotation of that profile around its axis of symmetry in order to create the entire 3D representation of the vessel.

\section{Experiments and Results}

\subsection{Experiments with artificial fragments}

In order to assess the accuracy and variability of the estimations performed by the present profile reconstruction algorithm, we propose the following experiment:

- Extraction of one complete profile of a paica from the database and, subsequently, extraction of a profile from a fragment containing the rim and the neck of the vessel.

- Application of the reconstruction algorithm in two cases: considering and not considering the profile of the paica as part of the database. This experiment aims to assess the accuracy of the estimation.

- Finally, we repeat this procedure 10 times by different users in order to assess inter-variability.

The procedure described is applied independently to the profiles of four different paicas. The resultant reconstructions are shown in Fig. 9. Here, the reconstructed profile is indicated using colour coding: the true profile (green), fragment profile (red), reconstructed profile (blue), the most similar profile in the database (black dashed). 


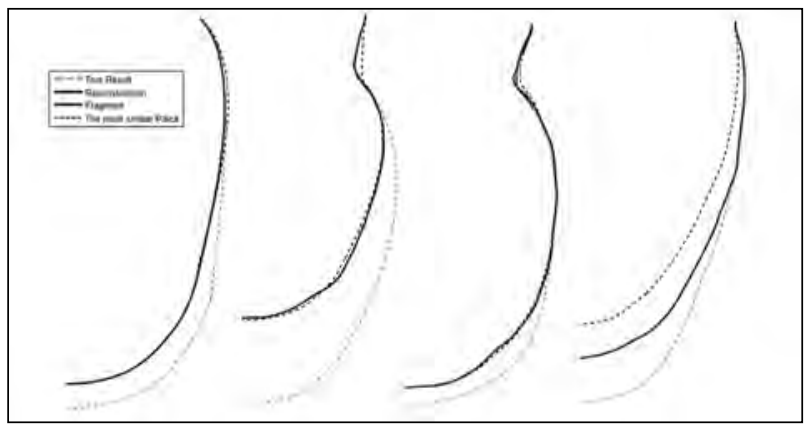

Figure 9. Profile reconstruction of four artificial fragments. Blue line depicts the reconstruction by the proposed method while green line corresponds to the true result.

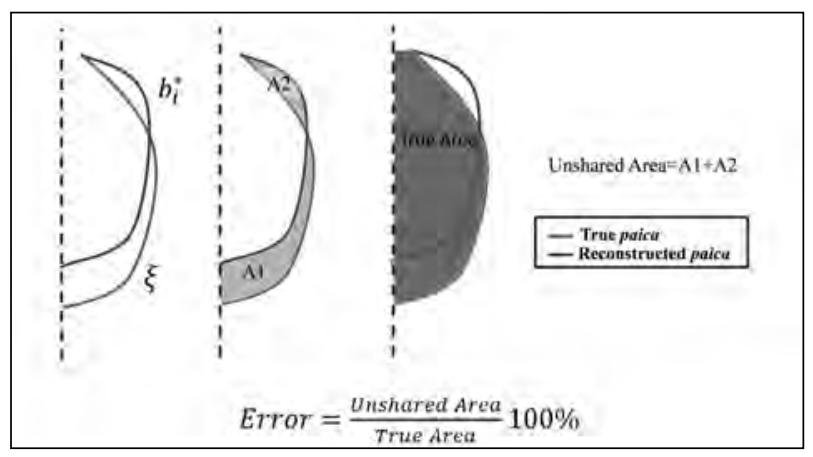

Figure 10. Definition of accuracy error. Both original and reconstructed profiles are assessed in terms of area with respect its axis of rotation. Then, the error corresponds to the percentage ratio between the unshared area and true area.

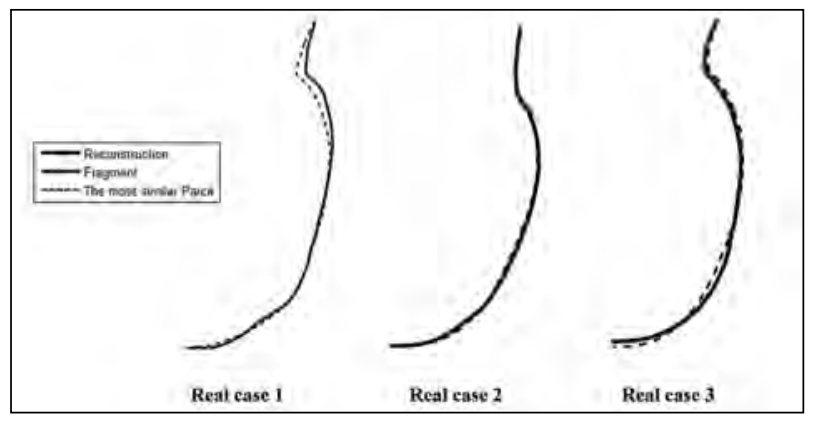

Figure 11. Profile reconstruction of three real fragments. The blue line depicts the reconstructed profile while the black discontinuous line depicts the most similar paica to the fragment being analysed.
The accuracy error for this experiment is defined as the percentual ratio between the unshared area and the true area formed by the profiles with respect to the axis of symmetry. A graphical explanation of these metrics is depicted in Fig. 10. Ideally, if both profiles, the reconstructed and the real one, are exactly the same, the accuracy error is equal to cero. Table 1 reports the accuracy assessment in both cases: considering and not considering the profile of the paica as part of the database.

On the other hand, the precision error is defined as the percentual ratio between the standard deviation of the areas surrounded by the profiles with respect to the axis of symmetry, and the average area for all of the measurements. Considering the reconstruction of four fragments in both cases described above, a total of 80 measurements was performed. The results report a $0 \%$ precision error for all cases.

\subsection{Experiments with real fragments}

Four real fragments belonging to paicas were reconstructed using the proposed approach. The acquisition procedure and the profile extraction of these potsherds are as explained in Section 2. Fig. 11 depicts the profile reconstruction of three of them while the 3D vessel reconstruction is shown in Fig. 12. The last fragment shows a pathological case in which the reconstruction is not satisfactory (Fig. 13a). This behavior is due to the fact that the fragment is not well supported by the database as is illustrated in Fig. 13b.

\section{Discussion and Conclusions}

The results shown in Table 1 report accuracy errors between $7.06 \%$ and $27.80 \%$ when the tested fragments came from paicas not contained within the reference database. On the other hand, accuracy errors between $0.26 \%$ and $0.66 \%$ were reported when the tested fragments were drawn directly from paicas in the database. Since this approach attempts

\begin{tabular}{|c|c|c|c|c|}
\hline Accuracy error & Fragment 1 & Fragment 2 & Fragment 3 & Fragment 4 \\
\hline $\begin{array}{c}\text { True paica not } \\
\text { considered }\end{array}$ & $10.38 \%$ & $27.08 \%$ & $7.06 \%$ & $11.49 \%$ \\
\hline $\begin{array}{c}\text { True paica } \\
\text { considered }\end{array}$ & $0.32 \%$ & $0.66 \%$ & $0.42 \%$ & $0.26 \%$ \\
\hline
\end{tabular}

Table 1. Accuracy error of the profile reconstruction of four fragments in both cases: including and not including the true paica in the database. 


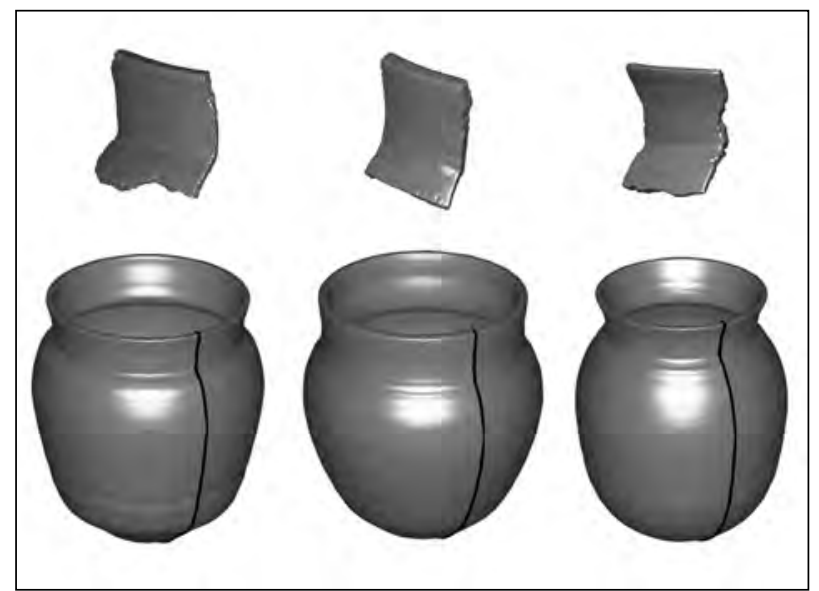

Figure 12. 3D reconstruction of entire vessels. Top: Fragments which have been reconstructed with the proposed approach. Bottom: Paicas generated by rotating reconstructed profiles around its axis of symmetry.

to estimate and reconstruct information which no longer exists, the results of the former case seem to be satisfactory. The results described by the latter case report drastically lower values of accuracy error because the fragments were indeed extracted from the reference samples themselves. Accordingly, we can affirm that this estimation procedure has zero bias. This means that, in the ideal case, one in which the database is large and represents all of the paica forms that ever existed, then, reconstruction of any given fragment will be highly accurate.

The opposite result of reconstruction is reported through the analysis of the last real fragment. As described in Fig. 10, if the database does not support the profile of the fragment, then the reconstruction will be inaccurate. Therefore, having a database containing a large variety of shapes is essential to the success of the proposed approach. We can summarise the ideal formation of the database by referring two parameters. Firstly, the number of profiles must be large enough to account for the enormous variety of fragments found in the archaeological site. Secondly, the classification scheme of the database needs to be properly and coherently defined. The classification procedure proposed in this paper is automatic and takes into account the geometric information of the vessels; however, it is possible that an expert archaeologist could propose another classification scheme based on a pre-defined paica typology. Moreover, our approach enables the progressive enlargement of

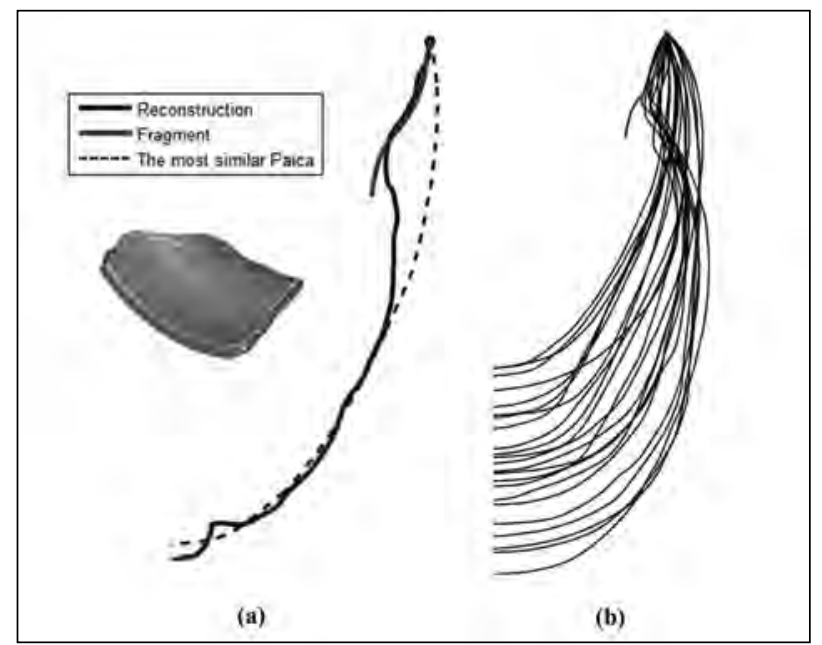

Figure 13. Pathological case of reconstruction. (a) Profile reconstruction of a real fragment shows a failure in the algorithm. (b) The failure is due to the fact that the fragment is not well supported by the database.

the database according to the digitisation of newly discovered paicas.

The variability experiment reports a $0 \%$ error in all the cases tested. This result was expected since the entire procedure is completely automatic and does not contain any source of user-dependent variation. This metric characterises a good result of our algorithm; however, the accuracy error is a more appropriate metric to evaluate the effectiveness of the reconstruction protocols.

In conclusion, the reconstruction algorithm linking singular fragments to the information contained within a comprehensivedatabaseprovides solid evidence that this methodology is appropriate for use in the archaeological interpretation of pottery and the related estimates of storage capacity and physical dimensions such as weight and height. Furthermore, the 3D digitisation process allows the replication of vessels and fragments in virtual and augmented reality. Finally, we would like to conclude by suggesting that a more comprehensive evaluation of this approach is required in order to determine the efficacy of our estimations.

\section{Acknowledgements}

The authors would like to thank the support of San José de Moro Archaeological Program (Perú) in providing access to all the material, 
Across Space and Time. Papers from the 41st Conference on

Computer Applications and Quantitative Methods in Archaeology. Perth, 25-28 March 2013

technical information and professional assistance. In particular, we want to thank to Andrew Lorey for the revision and correction of this document. This research was partially supported by the Research Project DGI 2013-0113 from the Pontificia Universidad Católica del Perú.

\section{Bibliography}

Agisoft 2013. "Agisoft Tutotial." Accessed March 25. http:// www.agisoft.ru/tutorials/ photoscan.

Bernardini, F., and H. Rushmeier. 2002. "The 3D acquisition pipeline." Computer Graphics Forum 21:149172. Accessed February 07, 2013. doi: 10.1111/14678659.00574 .

Kampel, M., and F. J. Melero. 2003. "Virtual vessel reconstruction from fragment's profile." In Proceedings of the 4th International conference on Virtual Reality, Archaeology and Intelligent Cultural Heritage, edited by D. Arnold, A. Chalmers, and F. Niccolucci, 79-88. Brighton: Eurographics Association.

Karasik, A., and U. Smilansky. 2008. "3D scanning technology as a standard archaeological tool for pottery analysis: practice and theory." J ournal of Archaeological Science 35:1148- 1168.

Liu, Y., H. Pottmann, and W. Wang. 2006. "Constrained 3D shape reconstruction using a combination of surface fitting and registration." Computer-Aided Design 38:572583.

Mara, H., and R. Sablatnig. 2005. "A comparison of manual, semiautomatic and automatic profile generation for archaeological fragments." In Proceedings of the 10th Computer Vision Winter Workshop, edited by A. Hanbury and H. Bischof, 123-134.Zell an der Pram: Vienna University of Technology.

Marie, I., and H. Qasrawi. 2005. "Virtual assembly of pottery fragments using moiré surface profile measurements." Journal of Archaeological Science 32:1527- 1533.

Orton, C., P. Tyers, and A. Vince 1993. Pottery in Archaeology. Cambridge: Cambridge University Press.

Scharstein, D., and R. Szeliski 2002. "A taxonomy and evaluation of dense two-frame stereo correspondence algorithms." International Journal of Computer Vision 47:7-42. Accessed March 10, 2013. doi: 10.1023/ A:1014573219977.

Seitz, S., B. Curless, J. Diebel, D. Scharstein, and R. Szeliski 2006. "A comparison and evaluation of multiview stereo reconstruction algorithms." In 2006 IEEE Computer Society Conference on Computer vision and pattern recognition Volume 1, edited by A. Fitzgibbon, C. Taylor and Y. LeCun, 519-528. New York: IEEE.

Taubin, G. 1995. "Curve and surface smoothing without shrinkage." In Fifth International Conference on Computer Vision, 1995. Proceedings, 852-857. Cambridge, Massachusetts: IEEE.

Yao, F., and G. Shao. 2003. "Detection of 3D symmetry axis from fragments of broken pottery bowl." In IEEE International Conference on Acoustics, Speech, and Signal Processing, 2003. Proceedings. (ICASSP '03). Volume 3, 505- 508. Hong Kong: IEEE Signal Processing Society Press.

Zhao, W., S. Gao, and H. Lin. 2007. "A robust Hole-filling algorithm for triangular mesh." The Visual Computer 23 (12):987-997. 


\title{
Towards the Automatic Classification of Pottery Sherds: Two Complementary Approaches
}

\author{
Chiara Piccoli \\ Leiden University, The Netherlands \\ Prashant Aparajeya \\ Goldsmiths, University of London, UK \\ Georgios Th. Papadopoulos \\ Centre for Research \& Technology - Hellas, Greece \\ John Bintliff \\ Leiden University, The Netherlands \\ Frederic Fol Leymarie \\ Goldsmiths, University of London, UK \\ Philip Bes \\ University of Leuven, Belgium \\ Mark van der Enden \\ University of Leicester, UK \\ J eroen Poblome \\ University of Leuven, Belgium \\ Petros Daras \\ Centre for Research \& Technology - Hellas, Greece
}

\begin{abstract}
:
This paper presents two complementary approaches to automatically classify pottery sherds: one that focuses on the sherd's profile and the other that examines visual features of the sherd's surface. The methods are validated using a set of pottery sherds that were collected during surveys at the ancient site of Koroneia (Greece), which were carried out by the 'Ancient Cities of Boeotia' team (under the directorship of Professor J. Bintliff). Both automatic classification techniques produce good results using different sherd classification criteria, such as shape, production technique and chronology.
\end{abstract}

\section{Keywords:}

Sherd Classification, Profile Matching, Visual Feature Extraction

\section{Introduction}

The automatic classification of pottery sherds has stimulated great interest among archaeologists and computer scientists in recent years (e.g. Karasik 2011; Makridis and Daras 2012; Martinez-Carrillo 2011). Pottery is the most common archaeological evidence that is found during fieldwork and pottery specialists are confronted with the time consuming

Corresponding author: c.b.m.piccoli@arch.leidenuniv.nl task of processing tens of thousands of sherds to be able to make hypotheses on the chronology, the functional zoning and trade exchanges of the site under study. Comparisons between different archaeological sites and regions are then made possible, thus highlighting differences and commonalities in the economy of the ancient world (Poblome et al. 2012; Reynolds 2010). This paper presents two automated complementary approaches that compensateand complement one another in the 
difficult task of pottery classification: one is based on the matching of the sherd's profile and the other one exploits the extraction of visual features (such as colour and texture information) from the pottery sherds. The final goals that we aim to achieve are to (1) reduce the time of pottery classification and (2) improve the consistency of the results. Besides being an aid for the pottery specialists, these two approaches can also be used as a training tool for archaeology students in the process of learning how to classify pottery, since these methods are based on the same procedure that archaeologists follow to process sherds.

\section{The Archaeological Context}

The pottery dataset that was used for the development of the matching algorithms and techniques that we present in this paper comes from the survey of the ancient city of Koroneia in Boeotia, situated on a hill surrounded by the ridges of Mount Helicon in Central Greece. The study of this site started in 2006 as part of a regional survey, which is carried out since the late 1970s on the whole Boeotia region, under the directorship of Professor John Bintliff. The archaeological traces on the hill suggest occupation phases from Prehistory up to the 14th century when the site was abandoned (Bintliff 2011). The aims of the survey of Koroneia are to (1) map the extent of the ancient city and to identify spatial changes in the settlement over time, and (2) recognise different functional zones in the city, such as domestic, public, and production units. A variety of non-destructive methods are being applied to study Koroneia, such as geophysical analysis, recording of architectural remains and surface collection of pottery sherds (Bintliff et al. 2011).

Pottery, as is the case for other GraecoRoman sites, is the most abundant source for reconstructing the nature and history of ancient Koroneia. The amount of sherds that is present on the hill is estimated at about 2 million, of which around 100.000 were systematically collected by the end of the survey. The majority of the material that comes from Koroneia is made of fragments of pottery, whose edges have been worn by exposure on the surface and agricultural damage. The problems related with collection and identification of survey pottery have been already discussed elsewhere (Rutter 1983; Schon 2011), and this material constitutes a particularly interesting and challenging dataset to train the matching algorithms presented in this work.

In order to develop the classification algorithms, we selected 203 sherds that had been classified by the pottery specialists. In detail, the distribution of the sherds in the classes assigned by the experts was as follows: regarding shape types, $24,6 \%$ were bases, $17,7 \%$ were body sherds, $3,5 \%$ were handles 53,7\% were rims and $0,05 \%$ were unclassified; regarding the production technique used, 95,1\% were wheel made and 4,9\% were handmade; finally, regarding chronology, the sherds have been grouped into Classical-Hellenistic (1,5\%), Hellenistic (36,9\%), Roman (36,5\%), HellenisticRoman (7,4\%) and unclassified (17,3\%). Pictures of the sherds were taken from the front and back side, and from the profile view with an HD camera. The following sections present the two approaches, along with the results of the pilot stage and suggestions for future improvements.

\section{Profile Matching Approach}

Our first approach tackles the pottery classification task by taking into consideration the sherd's profile, on the classical assumption that two pots can be differentiated from each other on the basis of their profile structures. This approach uses as ground truth archaeological taxonomic books, in which the profiles of the various pottery shapes are published along with their description. In our case, we used the publications by Susan Rotroff (1997; 2006) on the pottery from the Athenian Agora for the Hellenistic period, and the publication by J ohn Hayes (1972) for the Roman period.

The algorithm aims to match the profile of a newly collected sherd to the profiles that are published in the pottery catalogues. To develop the method, we selected 9 sherds that the pottery specialists had classified by indicating exact matches in the reference books. By matching these sherds from Koroneia with corresponding profiles that are published in the chosen reference books, we hypothesise that it is possible to highlight interesting similarities and differences among pottery productions that can be quantified in a mathematical way. 
Recent works propose automatic ways to classify artefacts based on their profile. For example, Durham et al. (1995) used the generalised Hough transform to perform artefact retrieval and matching by edge detection and thresholding. A reference point at the top left corner of an image is chosen to create the feature vectors. The matching process is done in two different ways: the whole shape and part of it is matched, in the latter case with a manual intervention. In a similar fashion, Mara et al. (2002) and Mara and Kampel (2003) developed a system for sherd classification based on a Houghinspired method where the curvature properties of the object were used. Mom (2005) and Mom and Paijmans (2008) designed a tool named SECANTO that considers the sum of squared distances between the contour of vessels to perform the comparison by measuring dissimilarities and finding "look-alikes". Gilboa et al. (2004) developed a mathematical and computational tool for morphological description, classification and analysis of archaeological artefacts. In their approach, first a curvature function is defined for each fragment and then compared by measuring their relative distance. Hristov and Agre (2013), Kampel and Sablatnig (2007), Karasik (2010), and Maiza and Gaildrat (2005) present other recent profile-based automated pottery classification approaches. Our new method is designed to be applicable to large datasets and be robust to noise, deformations and even deal with partial shape matching, all topics which prove very challenging for these other previous works.

The strategy we adopted is inspired by the Scale Invariant Feature Transform (SIFT) method of Lowe (1999; 2004) and is based on the development of a shape matching algorithm that is invariant to translation, scale and rotation. Importantly, we are not directly using the SIFT method but, instead, apply our method to the shape of $2 \mathrm{D}$ objects rather than to the intensity fields of images as is traditionally done with SIFT. In addition, our shape representation is derived from the region based medial point description of shapes, proposed by Kovács, Fehér, and Julesz (1998). This model is based on human visual perception and how human attention is driven to certain shape characteristics such as corners and salient symmetries. In this paper we propose a possible implementation of Kovács' model, by developing a method that performs shape matching to pottery sherds' profiles, but that can

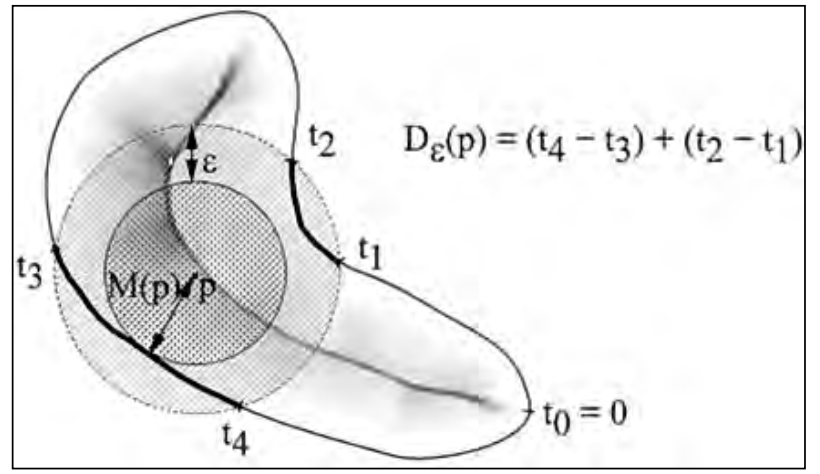

Figure 1. The $D_{\text {eps }}$ function for a simple shape (after Kovács, Fehér and Julesz 1998, 2325).

be generalised to all kinds of 2D objects and their contours. In order to match the sherd's profile with the profiles in the reference books, the algorithm exploits feature extraction through a top-hat filter (Vincent 1993) (from mathematical morphology applied to 2D images) and dominant feature points analysis.

\subsection{Feature extraction and matching}

\section{Medialness measurement}

Our feature extraction process is based on the medialness measurement of the pottery sherds' profile. The purpose of performing the medialness measurement of the object is to provide an effective description of the image which is local and compact and can be easily applied at different spatial scales (Kovács, Fehér and Julesz 1998). The goal is to extract themostinformative description of the object (or shape), cumulatively, in order to have sufficient information on the object with which to classify it. A medial point is well defined by computing the $D_{e p s}$ function, which is based on equidistance. The $D_{e p s}$ value at any point in space represents the degree to which this point is associated with a percentage of bounding contour pixels of the object within a tolerance of value eps (Kovács, Fehér and Julesz 1998) (see Fig. 1).

The $D_{e p s}$ function is defined as the sum of the curve segments falling inside the eps neighbourhood (represented as the thick boundary segments within the grey ring) of the $\mathrm{M}(\mathrm{p})$ radius circle around $\mathrm{p}$ (Kovács, Fehér and J ulesz 1998). The mathematical definition of $D_{e p s}$ is: 


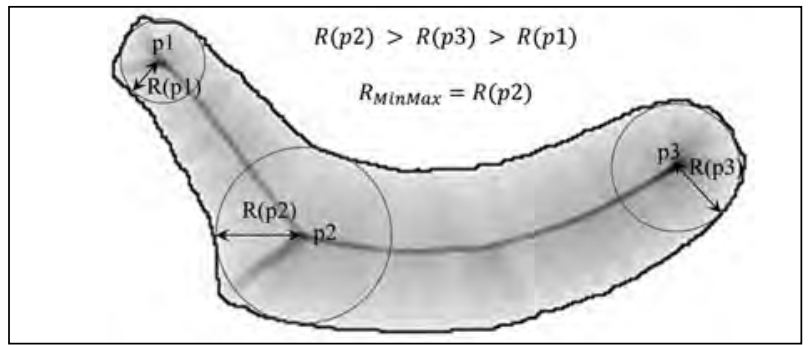

Figure 2. Illustration of maximum of the minimum radial distance $\left(R_{\text {MaxMin }}\right)$.

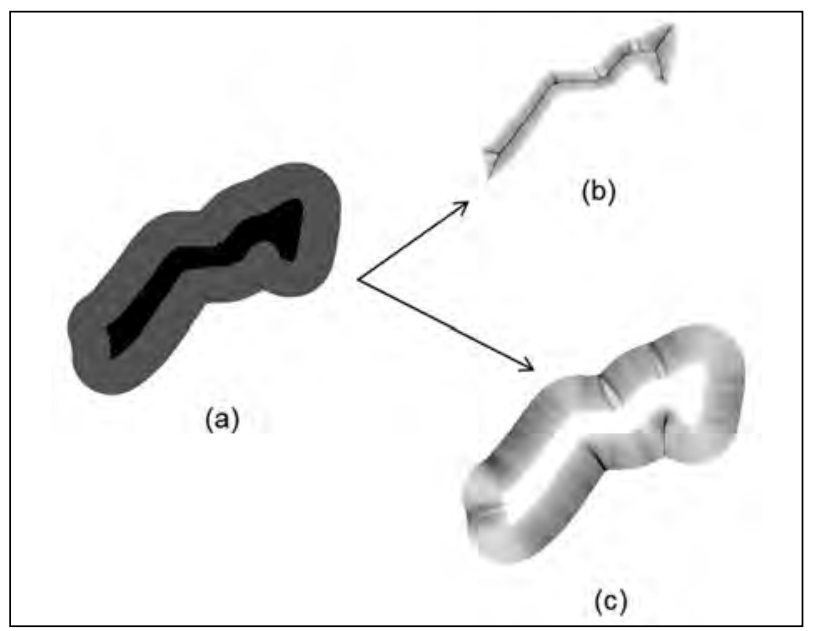

Figure 3. The black region of (a) indicates where the internal medialness will be performed, while the grey region is the restricted region for the exterior medialness measurement. (b) represents the internal medialness and (c) the exterior medialness of the sherd.

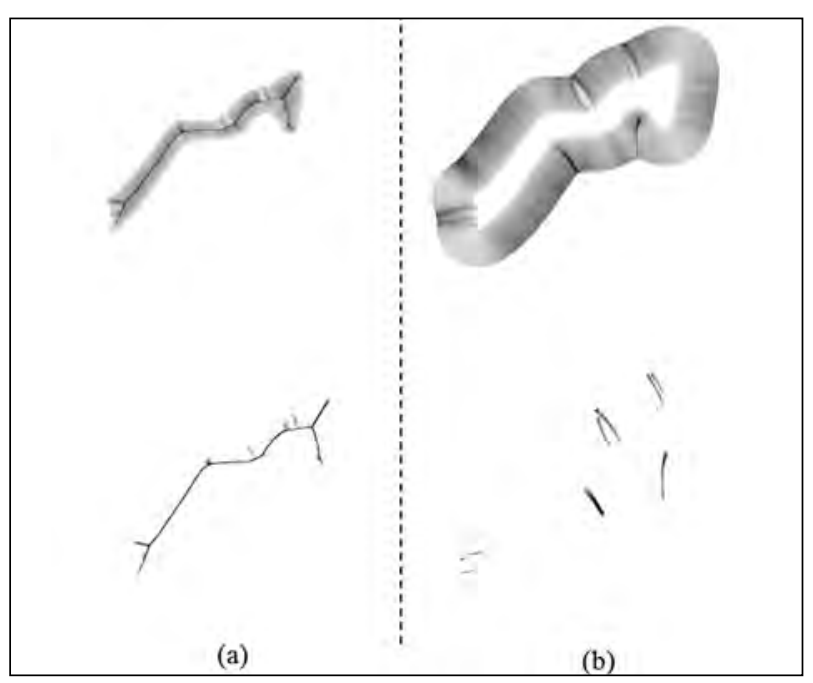

Figure 4. Top-hat transform on the image showing (a) internal medialness and (b) external medialness. The images at the bottom display the candidate feature points.

$$
D_{e p s}=\frac{1}{T} \int_{(p-b \mid<M(p)+e p x} d b
$$

where $p=\left[x_{p}, y_{p}\right]$, i.e. a point in the image space; $\mathrm{b}(\mathrm{t})=|\mathrm{x}(\mathrm{t}), \mathrm{y}(\mathrm{t})|$ is a vector in the $2 \mathrm{D}$ space of the image describing the bounding contour $\mathrm{B}$ of the object; $M(p)$ is the smallest distance between pixel $p$ and the bounding contour. Mathematically:

$$
M(p)=\min _{[|\leqslant \leqslant \leqslant|}|p-b(t)|
$$

and $\mathrm{T}$ is defined as:

$$
T=\int_{h \in B} d b
$$

which gives the total measure of the set. The medialness measurement is performed for both the internal and external regions of the object. For the exterior medialness measurement, a region restriction has been applied which depends on the parameter $\mathrm{R}_{\text {MaxMin }}$ (see Fig. 2).

The interior medialness reflects in fact the sherd's medial description, while the exterior medialness shows the nature of the concavities that are present on the sherds. Fig. 3 shows the internal and external medialness of a sherd.

\section{Dominant point extraction}

The dominant point extraction is a process for identifying the most informative feature points from the medialness image. Dominancy is decided by how many boundary pixels are in the vicinity of a medial point. If a point (p) represents a large amount of edge information (under the tolerance eps), then it will be considered as a candidate dominant point. To extract automatically such dominant points, a top-hat transform is used.

The top-hat transform is a well-known morphological processes in the field of image processing. Between the two types of top-hat transform (black and white), here (as shown in Fig. 4) we chose to use the black top-hat transform to extract the most informative feature points from the medialness image. In order to correctly detect the sherd's profile, the image of its medialness measurement is first filtered by using 'image closing', a morphological transformation that fills the gaps in the image's contours. The top-hat transform is then applied, as the difference of image closing and the original image (of medialness) itself, followed by thresholding the peak values (i.e. discarding the 
lower peaks considered as noise). Upon application of the top-hat transform, sequences of peaks are generated, which are called dominant points.

\section{Matching process}

The matching process uses the dominant points to match the external and internal features of the test case, respectively, to pre-computed external and internal dominant points of the target image. In order to make the matching invariant to scale and rotation, first it is required to find the scale and rotation of the test image with respect to the target image. Scale $(\beta)$ is defined as the ratio of the minimum radial distance (as defined in medialness measurement) and rotation is the difference of orientations (response direction) of two matching feature points with respect to the positive x-axis. A rotation invariant feature spread has been used to perform the matching task efficiently. If the feature points $\left(\mathrm{p}_{1}, \mathrm{p}_{2}\right)$ of the test image match to $\left(\mathrm{q}_{1}, \mathrm{q}_{2}\right)$ of the target image, respectively, then the scale and rotation of the image are defined as:

$$
\begin{gathered}
\beta=\frac{R \min _{p}}{R \min _{q}} \\
\theta=\text { Orientation }_{\left(p_{3}, p_{2}\right)}-\text { - }_{\text {rientation }}^{\left(q_{i} \cdot z_{2}\right)}
\end{gathered}
$$

The total matching performance is evaluated as the ratio of the total number of dominant points matched (both internal and external) to the total number of dominant points in the test case.

\section{Visual Features Extraction Approach}

Recently, several approaches for the automatic classification of archaeological sherds have been presented that consider colour and texture information from pictures. In Kampel and Sablatnig (2000), the sherd colour is used, while Smith et al. (2010) employ both colour and texture characteristics. Additionally, texture-based features are used and a profile morphological analysis is performed by Li-Ying Qi and Wang Ke-Gang (2010) and Karasik and Smilansky (2011), respectively. A common characteristic of the above methods is that they are designed to take into account the particular characteristics that are present in the sherd databases that are used for experimentation.
In this section, a novel technique for automatic archaeological sherd classification is presented, which is based on the extraction of colour and textural local features from the sherd surface and the subsequent estimation of a global sherd descriptor vector, using a new 'Bag-of-Words' technique. The method takes intoaccount information from both the front and the back view of the sherd for computing a more complete description. Additionally, a feature selection algorithm is applied in order to maintain the most discriminating features.

Regarding the feature extraction procedure, a combination of relatively simple low-level visual features focusing mainly on the colour properties of the sherds, is used. These were selected after extensive experimentation and aim at handling also low-textured sherds or fragments that present extensivedeterioration on their surface. Thefeatures employed are:

- Colour components RGB, HSV and YIQ, which are typically present in most visual classification frameworks and also exhibit low computational complexity;

- Standard deviation (Guo et al. 2010), whose histogram is proven to be very efficient in a variety of classification tasks;

- Michelson contrast (Michelson 1927), which is appropriate for modelling faint areas on the sherd surface that are due to deterioration caused by subsoil substances and time;

- Kirsch edge map (Kirsch 1971), whose statistical analysis is used to reveal the degradation degree or rills on the sherd surface;

- Local binary patterns (Ojala, Pietikainen and Maenpaa 2002) are efficient descriptors designed for texture classification and have been widely used due to their simplicity and rotationinvariance characteristic.

All the above features were selected after extensive experimentation, as they have been shown to outperform typical well performing descriptors that have been proposed in the literature for the analysis of general purpose images, e.g. Scale Invariant Feature Transform (SIFT). To produce a 
global descriptor vector for every examined sherd image, the 'Bag-of-Words' (BoW) (Csurka et al. 2004) methodology is followed. In more detail, this methodology initially requires a clustering of the computed descriptors, where the estimated clusters include a fixed-size vocabulary of so-called visual words. Subsequently, histograms of the estimated words, that are computed using the constructed vocabulary of visual words and the original descriptors, are used for representing the image content. Typical techniques of this category employ the K-means algorithm for clustering (Chimlek et al. 2010; Hotta 2009; Kandasamy and Rodrigo 2010; Sheng et al. 2010), mainly due to its ease of implementation. However, K-means has increased sensitivity to its initialisation and local search strategy. In order to overcome the aforementioned problems, a new technique for creating 'Bag-ofWords' is proposed, using the Reddi, Rudin and Keshavan multi-thresholding concept (Reddi, Rudin and Keshavan 1984). In particular, visual 'words' are created by applying multiple thresholding on each local feature's histogram of values. The adopted method of Reddi has the advantage of maximising the interclass variance between histogram peaks and locating thresholds on histogram valleys. By locating thresholds on histogram valleys, the possible loss of information due to histogram clustering is minimised. More specifically, if we create an image I of dimensions $\mathrm{KxL}$ and that each pixel's value belongs in the interval $[0,255]$, where 0 corresponds to black and 255 to white colour (i.e. greyscale values). The proposed $\mathrm{BoW}$ model can then be described by the following steps: initially, histogram extraction for each local feature $f_{s}$ takes place according to the following equation:

$$
h_{f}(x)=\sum_{i=0}^{K} \sum_{j=0}^{L} d\left(f_{x}(i, j)\right), x=0,1,2, \ldots .255
$$

where $f(i, j)$ is the feature valueat pixel $(i, j)$ and $d$ is the delta function, which is defined as follows:

$$
d\left(f_{s}(i, j)\right)=\left\{\begin{array}{c}
1, i f f_{s}(i, j)=x \\
0, \text { otherwise }
\end{array}\right.
$$

Then, the accumulated histogram $\mathrm{AH}_{\mathrm{f}}$ is estimated for every feature, taking into account all sherds in the used dataset according to the following equation:

$$
A H_{f,}=\sum_{i=0}^{N} h_{i J_{r}}(x)
$$

where $\mathrm{N}$ is the total number of sherd's images. Finally, Reddi, Rudin and Keshavan (1984) multi-thresholding is applied to each feature's accumulated histogram $\mathrm{AH}_{\mathrm{f}}$. Visual "words" are created according to the features' values and the estimated thresholds, as described above. Using this transformation, the dimensionality of the final global feature vector is efficiently decreased from its original value (i.e. the number of histogram bins) to the number of the utilised thresholds. After creating the BoW, all local features are concatenated forming a global descriptor vector that describes the whole sherd image.

Having computed the low-level visual description of a given sherd image, a feature selection step is applied for maintaining the most distinctive features and improving the time performance of the overall classification framework. The feature selection techniques that were comparatively evaluated are: a) Correlation-based Feature Selection (CFS) (Hall 2000), b) Chi-Square attribute selection (J onhson, Kotz and Balakrishnan 1994), c) Consistency-based (Liu and Setiono 1996), d) Principal Component Analysis (PCA) (Jolliffe 1986), e) Relief Attribute Selection (Robnik-Sikonja and Kononenko 1997) and e) Support Vector Machines (SVM)-based (Guyon et al. 2002). From the above mentioned methods, the PCA technique led to the best classification performance. To this end, the reported experimental results are computed using PCA for realising feature selection.

At the final stage of the proposed algorithm, every examined sherd is associated with one of a set of predefined classes/types. To perform this task, a series of different classification techniques were experimentally evaluated. The latter included the application of the following classifiers: a) K-Nearest Neighborhood (KNN) (Aha and Kibler 1991), b) SVM (Burges 1998), c) Naïve Bayes (John and Langley 1995), d) Sequential Minimal Optimisation (SMO) (Platt 1999) and e) Simple Logic (Sumner, Frank and Hall 2005). From the aforementioned classification schemes, the KNN algorithm led to the best overall classification results.

\subsection{Reddi multi-thresholding}

In this section, the multi-thresholding technique which is used in the 'Bag-of-Words' 
creation is described in more detail In the literature, there are several histogram-based multithresholding techniques which are used mainly for image segmentation or image binarisation (single threshold). The method of Reddi, Rudin, and Keshavan (1984) extends the global (binary) threshold method of Otsu (1979), which is one of the most efficient methods for global thresholding, to the multi-thresholding case. The considered criterion consists of the selection of the thresholds so that the interclass variance between dark and bright regions is maximised. The Reddi multi-thresholding technique, which is applied to all selected visual features, except for LPB (LBP histogram has only 24 bins), can be summarised in the following steps: Initially, the number of thresholds $\mathrm{N}$ is defined. Then, the threshold values are initialised according to the following equation:

$$
k_{f}=\frac{256}{N+1}
$$

where 256 is the range of possible pixel values in a gray scale image. When this algorithm is applied to normalised features, the range of possible values can change from $[0,255]$ to $[0,1]$. Subsequently, the following error values are calculated for each threshold $\mathrm{k}_{1}$ :

$$
\begin{gathered}
e_{1}\left(0, k_{1}\right)=\frac{\left[m\left(0, k_{1}\right)+m\left(k_{1}, k_{2}\right)\right]}{2}-k_{1} \\
e_{2}\left(k_{1}, k_{2}\right)=\frac{\left[m\left(k_{1}, k_{2}\right)+m\left(k_{2}, k_{3}\right)\right]}{2}-k_{2} \\
\ldots \\
e_{n}\left(k_{n-1}, k_{n}\right)=\frac{\left[m\left(k_{n-1}, k_{n}\right)+m\left(k_{n}, 255\right)\right]}{2}-k_{n}
\end{gathered}
$$

where

$$
m\left(k_{i}, k_{j}\right)=\frac{\sum_{k_{i}}^{k_{j}} x p_{k}}{\sum_{k}^{k_{j}} p_{\varepsilon}}
$$

$\mathrm{k}_{1}$ and $\mathrm{k}_{\mathrm{j}}$ are neighbouring thresholds, $\mathrm{x}$ is the position in the histogram and $p_{x}$ is the value in this position. Then, new threshold values are calculated according to the following equation:

$$
k_{i}+\operatorname{round}\left(e_{i}\right), i=1,2, \ldots n
$$

The overall procedure is repeated until

$$
\max \left(\left|e_{1}\right|,\left|e_{2}\right|, \ldots,\left|e_{n}\right|\right) \leq 0.5
$$

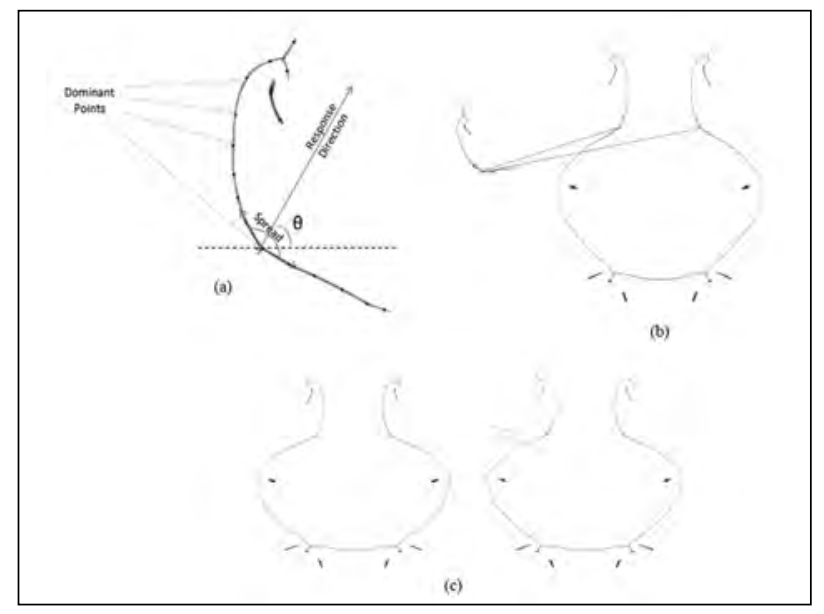

Figure 5. (a) displays the description of features that are extracted using the medialness measurement. The algorithm relies on recognising the dominant points that describe the geometry of the profile. For this reason, there can be two locations in the target image where a dominant point in the test case finds a match, as shown in (b). A following step must be performed that finds the correct rotation, scale and orientation of the test image, in order to find the best matching location, as shown in (c).

A more detailed description of the presented approach can be found in Makridis and Daras (2012), where extensive experiments as well as a comparative evaluation are also given.

\section{Results}

The profile matching approach based on medialness measurement performs well when the sherd has reasonably recognisable features such as ridges, concavities, and variations of the object's thickness. Fig. 5 shows the matching of an actual sherd profile with the profiles labelled in the reference books. If the sherd has less revealing medialness or it is flattened (e.g. body sherds), then the algorithm gives multiple matching locations with a similar matching percentage as shown in Fig. 6. Although the results shown in Fig. 6 are promising and demonstrate that in principle it is possible to find good matches between sherds and reference profiles, at this stage manual inspection of the results is essential to verify the archaeological meaningfulness of the matches.

The visual features extraction approach was experimentally evaluated using the already 


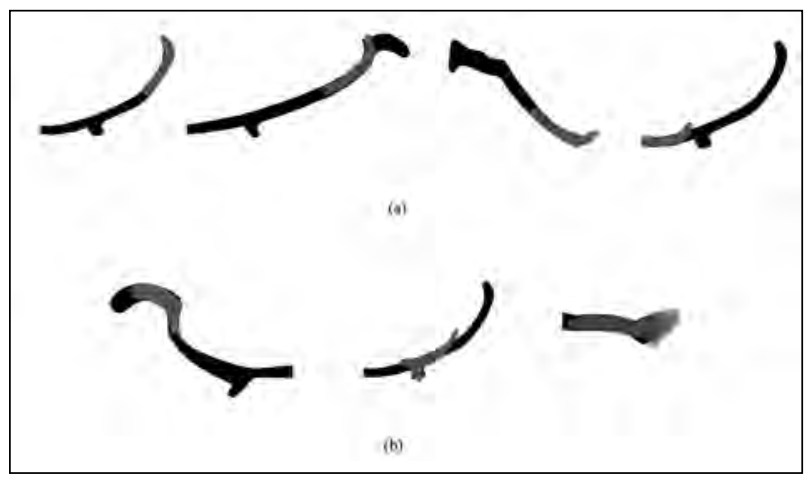

Figure 6. This image shows the matching between the profiles of a number of sherds as they are found in the reference books (in black) and those that were found during the survey at Koroneia (in grey). The first match to the left shows a good correspondence obtained between the sherd and the reference profiles. However, since the sherd has a high degree of flatness, multiple matches are found (a). In contrast, when the sherd has more prominent morphological features, only a single match per sherd is found.

described Koroneia pottery dataset that contains images of approximately 200 sherds, where $25 \%$ of the sherds were used for training and the remaining $75 \%$ were used for evaluation. Detailed experimental results are given in Tables 1-3 for three different classification criteria, namely sherd type, production technique and chronology. The obtained classification results are given in the form of the calculated confusion matrices, while the overall classification accuracy (i.e. the percentage of the sherds that were classified correctly) is also given for every case.

\section{Discussion and Future Work}

The aim of this study was to assist in the manual classification of sherds that is carried out by pottery specialists, by providing an automatised, computer-based classification approach that allows users to obtain consistent results. This paper presents the preliminary results of the two complementary approaches we have developed that take into consideration different characteristics of the sherds, namely, their profile and texture. The approaches were tested using a challenging dataset, i.e. sherds that were collected during surface survey and have therefore deteriorated due to surface exposure and ploughing.

\begin{tabular}{|c|c|c|c|l|l|}
\hline \multicolumn{5}{|c|}{ Confusion matrix } \\
\hline & \multicolumn{5}{|c|}{ Associated class } \\
\hline \multirow{3}{*}{$\begin{array}{c}\text { Actual } \\
\text { class }\end{array}$} & & body & base & handle & rim \\
\cline { 2 - 6 } & body & $63,89 \%$ & $13,89 \%$ & $0,00 \%$ & $22,22 \%$ \\
\cline { 2 - 6 } & base & $44,44 \%$ & $11,11 \%$ & $3,70 \%$ & $40,74 \%$ \\
\cline { 2 - 6 } & handle & $0,00 \%$ & $0,00 \%$ & $66,67 \%$ & $33,33 \%$ \\
\cline { 2 - 6 } & rim & $9,88 \%$ & $2,47 \%$ & $0,00 \%$ & $87,65 \%$ \\
\hline \multicolumn{6}{|c|}{ Overall classification accuracy: $65,99 \%$} \\
\hline
\end{tabular}

Table 1. Experimental results for 'Sherd type' criterion.

\begin{tabular}{|c|c|c|c|}
\hline \multicolumn{3}{|c|}{ Confusion matrix } \\
\hline & \multicolumn{3}{|c|}{ Associated class } \\
\hline \multirow{3}{*}{ Actual class } & & hand & wheel \\
\cline { 2 - 4 } & hand & $80,00 \%$ & $20,00 \%$ \\
\cline { 2 - 4 } & wheel & $2,78 \%$ & $97,22 \%$ \\
\hline \multicolumn{3}{|c|}{ Overall classification accuracy: 93,96\% } \\
\hline
\end{tabular}

Table 2. Experimental results for 'Production technique' criterion.

\begin{tabular}{|c|c|c|c|l|l|}
\hline \multicolumn{5}{|c|}{ Confusion matrix } \\
\hline & \multicolumn{5}{|c|}{ Associated class } \\
\hline \multirow{3}{*}{$\begin{array}{c}\text { Actual } \\
\text { class }\end{array}$} & & $\mathrm{CH}$ & $\mathrm{H}$ & $\mathrm{HR}$ & rim \\
\cline { 2 - 6 } & $\mathrm{CH}$ & $50,00 \%$ & $0,00 \%$ & $0,00 \%$ & $22,22 \%$ \\
\cline { 2 - 6 } & $\mathrm{H}$ & $3,57 \%$ & $64,29 \%$ & $3,57 \%$ & $40,74 \%$ \\
\cline { 2 - 6 } & $\mathrm{HR}$ & $0,00 \%$ & $75,00 \%$ & $16,67 \%$ & $33,33 \%$ \\
\cline { 2 - 6 } & $\mathrm{R}$ & $0,00 \%$ & $38,89 \%$ & $1,85 \%$ & $87,65 \%$ \\
\hline \multicolumn{6}{|c|}{ Overall classification accuracy: $55,65 \%$} \\
\hline
\end{tabular}

Table 3. Experimental results for 'Chronology' criterion (CH: Classical-Hellenistic, $H$ : Hellenistic, HR: Hellenistic-Roman, R: Roman) .

The profile-based approach proposes to tackle the automated classification of pottery sherds by adapting Kovács' method on shape representation (1998) to the shape matching problem. Our implementation of Kovács' method uses as ground truth the images of classified pottery shapes from the books of Rotroff (1997; 2006) and Hayes (1972) that are used by the pottery specialists as reference to create the classification of imported pottery wares at Koroneia. For the moment only a small selection of sherds from Koroneia was used to develop the method. In the future a larger set of sherds will be considered and the results will be used to provide a quantified reference of pottery variations by overlapping the profiles of the sherds that were 
found at Koroneia with published material, thus offering further insight into Koroneia's pottery assemblages.

The visual features extraction approach exploits a new 'Bag-of-Words' technique that overcomes the limitations of traditional $\mathrm{BoW}$ methods. This approach exhibits promising classification results for all supported criteria and most defined classes. However, there are also classes that present low recognition rates, i.e. 'base' and 'Hellenistic-Roman'. The 'base' class was confused with 'body' and 'rim', which can be related to the use of pictures as input data for the classification. In fact, in the case of pottery fragments, where only a small fraction of the original complete shape is preserved, the algorithm may not be able to detect the features from the pictures that are relevant to distinguish between e.g., a fragment of a base and a rim. For this reason, attention must be paid to how the pictures are taken; also, the combination of the visual features approach with the profile-based approach that we described could increase the accuracy of the classification. Regarding the 'Hellenistic-Roman' class, this was mainly confused with the 'Hellenistic' class. The sherds for which the computer-based and the manual classification have returned different classes are currently under scrutiny by the pottery specialists to establish whether this mismatch could provide further insight into the classification of Hellenistic and Roman sherds. We envision that the visual extraction approach could be used to highlight the sherds for which conflicting classifications exist, and that therefore need to be reconsidered by the pottery specialists.

As future work, the two approaches will be combined in order to fully exploit their complementarity in the classification of sherds. Also, we propose to include pictures of clay fabric to be classified using the visual features extraction approach. In this way, the automatic classification of the sherds will be integrated with crucial information for the identification of local production of pottery and trade exchanges (see Moody et al. 2003). In addition, we will investigate the potential of unsupervised machine learning techniques to cluster the sherds in order to compare the groupings that the algorithm creates with those created by manual classification. The unsupervised machine learning could help in highlighting new groups or in combining previously separated categories. In this way, a more objective classification could be obtained, by limiting the bias inherently connected with manual classifications (e.g. the so-called "Wallcott's shoehorn" as defined by Gould 1989).

\section{Acknowledgements}

Theworkpresentedinthispaperwassupported by the European Commission under contract FP7258749 CEEDs and by the CORES network of the Belgian Programme on Interuniversity Poles of Attraction (http:/ / iap-cores.be/).

\section{Bibliography}

Aha, D. W., D. Kibler, and M. K. Albert. 1991. "Instancebased Learning Algorithms." Machine Learning 6:37-66.

Bintliff, J. 2011. "Coronea (Antiquity).” In Encyclopedia of the Hellenic World, Boeotia. Accessed March 15, 2013. http:// www.ehw.gr/l.aspx?id=12891.

Bintliff, J., B. Slapšak, B. Noordervliet, J. Van Zwienen, I. Uytterhoeven, K. Sarri, M. Van der Enden, R. Shield, and C. Piccoli. 2011. "The Leiden-Ljubljana Ancient Cities of Boeotia Project 2009 Season." Pharos 17 (2):1- 63.

Burges, C. J. C. 1998. "A Tutorial on Support Vector Machines for Pattern Recognition." Data Mining and Knowledge Discovery 2:121- 167.

Chimlek, S., K. Kesorn, P. Piamsa-Nga, and S. Poslad. 2010. "Semantically Similar Visual Words Discovery to Facilitate Visual Invariance." In Proceedings of the 2010 IEEE International Conference on Multimedia and Expo, ICME 2010, 19-23 July 2010, Singapore, 1242- 1247. Singapore: IEEE.

Csurka, G., C. Dance, L. Fan, J. Willamowski, and C. Bray. 2004. "Visual Categorization With Bags of Keypoints." Paper presented at the ECCV International Workshop on Statistical Learning in Computer Vision, Prague, May 1016. http://cmp.felk.cvut.cz/eccv2004/files/ECCV-2004final-programme.pdf.

Durham, P., P. H. Lewis, and S. J. Shennan. 1995. "Artefact Matching and Retrieval Using the Generalised Hough Transform." In Proceedings of the 21st Computer Application and Quantitative Methods in Archaeology Conference, Staffordshire University, Stoke-on-Trent, 
Across Space and Time. Papers from the 41st Conference on

Computer Applications and Quantitative Methods in Archaeology. Perth, 25-28 March 2013

3-8th April 1993, edited by J. Wilcock and K. Lockyear, 25- 30. Oxford: Tempus Reparatum.

Gilboa A., A. Karasik, I. Sharon, and U. Smilansky. 2004. "Towards Computerized Typology and Classification of Ceramics." J ournal of Archaeological Science 31 (6):681694.

Gould, S. J. 1989. Wonderful Life. New York: W. W. Norton \& Co.

Guo, Z., L. Zhang, and D. Zhang. 2010. "Rotation Invariant Texture Classification Using LBP Variance (LBPV) with Global Matching.” Pattern Recognition 43 (3):706- 719.

Guyon, I., J. Weston, S. Barnhill, and V. Vapnik. 2002. "Gene Selection for Cancer Classification using Support Vector Machines.” Machine Learning 46:389- 422.

Hall, M. A. 2000. "Correlation-based Feature Selection for Discrete and Numeric Class Machine Learning." In Proceedings of the Seventeenth International Conference on Machine Learning (ICML 2000), edited by P. Langley, 359- 366. San Francisco: Morgan Kaufmann Publishers.

Hayes, J. W. 1972. Late Roman Pottery. London: The British School at Rome.

Hotta, K. 2009. "Scene Classification Based on Local Autocorrelation of Similarities with Subspaces." In Proceedings of the 2009 IEEE International Conference on Image Processing (ICIP 2009), edited by L. Karam and T. Pappas, 2053- 2056. Cairo: IEEE.

Hristov, V., and G. Agre. 2013. "A Software System for Classification of Archaeological Artefacts Represented by 2D Plans." Cybernetics and Information Technologies 13 (2):82-96.

J ohn, G. H., and P. Langley. 1995. "Estimating Continuous Distributions in Bayesian Classifiers." In Proceedings of the Eleventh Conference on Uncertainty in Artificial Intelligence, edited by P. Besnard and S. Hanks, 338- 345. San Francisco: Morgan Kaufmann Publishers.

Jolliffe, I. T. 1986. Principal Component Analysis. New York: Springer.

Jonhson, N. L., S. Kotz, and N. Balakrishnan. 1994. Continuous Univariate Distributions. New York: John Willey.
Kampel, M., and R. Sablatnig. 2000. "Color Classification of Archaeological Fragments." In Proceedings of the Fifteenth IEEE International Conference on Pattern Recognition (ICPR 2000), edited by A. Sanfeliu, J. J. Villanueva, M. Vanrell, R. Alquézar, J. Crowley, and Y. Shirai, 4:4771- 4774. Barcelona: IEEE.

Kampel, M., and R. Sablatnig. 2007. "Rule Based System for Archaeological Pottery Classification." Pattern Recognition Letters 28 (6):740- 747.

Kandasamy, K., and R. Rodrigo. 2010. "Use of a Visual Word Dictionary for Topic Discovery in Images." In Proceedings of the Fifth International Conference on Information and Automation for Sustainability (ICIAfS 2010), edited by M. N. Halgamuge, 510-515. Colombo: IEEE.

Karasik, A. 2010. "A Complete, Automatic Procedure for Pottery Documentation and Analysis." In IEEE Computer Society Conference on Computer Vision and Pattern Recognition Workshops (CVPRW 2010). San Francisco, California, USA, 13-18 J une 2010, 29- 34. San Francisco: IEEE.

Karasik, A., and U. Smilansky. 2011. "Computerized Morphological Classification of Ceramics." Journal of Archaeological Science 38 (10):2644- 2657.

Kirsch, R. 1971. "Computer Determination of the Constituent Structure of Biological Images." Computers and Biomedical Research 4:315- 328.

Kovács, I., Á. Fehér, and B. Julesz. 1998. “Medial-point Description of Shape: A Representation for Action Coding and its Psychophysical Correlates." Vision Research 38 (15):2323-2333.

Li-Ying Q., and W. Ke-Gang. 2010. "Kernel Fuzzy Clustering Based Classification of Ancient-Ceramic Fragments." In The 2nd IEEE International Conference on Information Management and Engineering (ICIME), 348- 350. IEEE: Chengdu.

Liu, H., and R. Setiono. 1996. "A Probabilistic Approach to Feature Selection - a Filter Solution." In Proceedings of the Thirteenth International Conference on Machine Learning (ICML '96), edited by L. Saitta, 319- 327. San Francisco: Morgan Kaufmann Publishers.

Lowe, D. G. 1999. “Object Recognition from Local Scale- 
invariant Features." In Proceedings of the Seventh IEEE International Conference on Computer Vision, 1999. Volume 2, 1150-1157. Washington: IEEE Computer Society.

Lowe, D. G. 2004. “Distinctive Image Features from Scaleinvariant Keypoints." International J ournal of Computer Vision 60 (2):91- 110.

Maiza, C., and V. Gaildrat. 2005. "Automatic Classification of Archaeological Potsherds." In 8th International Conference Computer graphics and artificial intelligence (3IA'2005), Limoges, France, edited by D. Plemenos, 135- 147. Limoges.

Makridis, M., and P. Daras. 2012. "Automatic Classification of Archaeological Pottery Sherds." ACM Journal on Computing and Cultural Heritage 5 (4):1- 21.

Mara, H., and M. Kampel. 2003. "Profile Extraction of Archaeological Fragments for Classification.” In Proceedings of Eighth Computer Vision Winter Workshop (CVWW'03), edited by O. Drbohlav, 62- 72. Valtice: Czech Pattern Recognition Society.

Mara, H., M. Kampel, and R. Sablatnig. 2002. "Preprocessing of 3D-Data for Classification of Archaeological Fragments in an Automated System." In Vision with Non-Traditional Sensors. 26th Workshop of the Austrian Association for Pattern Recognition (ÖAGM), edited by F. Leberl and F. Fraundorfer, 257264. Graz: Österreichische Computer Gesellschaft.

Martinez-Carrillo, A. L. 2011. "Computer Applications in Archaeological Pottery: a Review and New Perspectives." In On the Road to Reconstructing the Past. Proceedings of the 36th Computer Applications and Quantitative Methods in Archaeology Conference. Budapest, April 2-6, 2008, edited by E. Jerem, F. Redő, and V. Szeverényi, 397-401. Budapest: Archaeolingua.

Michelson, A. 1927. Studies in Optics. Chicago: University of Chicago Press.

Mom, V. 2005. "SECANTO- The Section Analysis Tool." In The World is in your Eyes. Proceedings of the 33rd Computer Applications and Quantitative Methods in Archaeology Conference. Tomar, March 2005, edited by A. Figueiredo and G. Leite Velho, 95- 102. Tomar: CAA Portugal.
Mom, V., and J. J. Paijmans. 2008. "SECANTO: A Retrieval System and Classification Tool for Simple Artifacts." In Layers of Perception: Proceedings of the 35th Computer Applications and Quantitative Methods in Archaeology Conference. Berlin, Germany, April 2-6, 2007, edited by A. Posluschny, K. Lambers, and I. Herzog, 164- 170. Bonn: Dr. Rudolf Habelt GmbH.

Moody, J., H. Lewis Robinson, J. Francis, L. Nixon, and L. Wilson. 2003. "Ceramic Fabric Analysis and Survey Archaeology. The Sphakia Survey.” ABSA 98:37- 105.

Ojala, T., M. Pietikainen, and T. Maenpaa. 2002. "Multiresolution Gray-scale and Rotation Invariant Texture Classification with Local Binary Patterns." IEEE Transactions on Pattern Analysis and Machine Intelligence 24 (7):971- 987.

Otsu, N. 1979. "A Threshold Selection Method from Graylevel Histograms." IEEE Transactions on Systems, Man, and Cybernetics 9 (1):62- 66.

Platt, J . 1999. "Fast Training of Support Vector Machines using Sequential Minimal Optimization." In Advances in Kernel Methods - Support Vector Learning, edited by B. Schölkopf, C. Burges, and A. Smola, 185- 208. Cambridge: MIT Press.

Poblome, J., P. Bes, and R. Willet. 2012. "Thoughts on the Archaeological Residue of Networks. A View from the East." In Rome, Portus and the Mediterranean, Archaeological Monographs of the British School at Rome, edited by S. Keay, 393-401. London: The British School at Rome.

Reddi, S. S., S. F. Rudin, and H. R. Keshavan. 1984. "An Optimal Multiple Threshold Scheme for Image Segmentation." IEEE Transactions on Systems, Man, and Cybernetics 14 (4):661- 665.

Reynolds, P. 2010. "Trade Networks of the East, 3rd to 7th Centuries: The View from Beirut (Lebanon) and Butrint (Albania) (Fine Wares, Amphorae and Kitchen Wares)." In LRCW3 Late Roman Coarse Wares, Cooking Wares and Amphorae in the Mediterranean Archaeology and archaeometry. Comparison between western and eastern Mediterranean, edited by S. Menchelli, S. Santoro, M. Pasquinucci, and G. Guiducci, 89-114. Oxford: Archaeopress.

Robnik-Sikonja, M., and I. Kononenko. 1997. “An 
Across Space and Time. Papers from the 41st Conference on

Computer Applications and Quantitative Methods in Archaeology. Perth, 25-28 March 2013

Adaptation of Relief for Attribute Estimation in Regression." In Proceedings of the Fourteenth International Conference on Machine Learning, edited by D. H. Fisher, 296- 304. San Francisco: Morgan Kaufmann Publishers.

Rotroff, S. I. 1997. The Athenian Agora Volume XXIX. Hellenistic Pottery, Athenian and Imported Wheelmade Table Ware and Related Material. Princeton: ASCSA.

Rotroff, S. I. 2006. The Athenian Agora Volume XXXIII. Hellenistic Pottery: The Plain Wares. Princeton: ASCSA.

Rutter, J. B. 1983. "Some Thoughts on the Analysis of Ceramics Data Generated by Site Survey." In Archaeological Survey in the Mediterranean Area, edited by D. R. Keller and D. W. Rupp, 137-142, Oxford: Archeopress.

Schon, R. 2011. "Vox Clamantis in Campo: Further Thoughts on Ceramics and Site Survey." In Our Cups are Full: Pottery and Society in the Aegean Bronze Age, edited by W. Gauss, M. Lindblom, R. A. K. Smith, and J. C. Wright, 231-241. Oxford: ArchaeoPress.

Sheng, X., F. Tao, Li Deren, and W. Shiwei. 2010. “Object Classification of Aerial Images With Bag-of-Visual Words." IEEE Geoscience and Remote Sensing Letters 7 (2):366- 370

Smith, P., D. Bespalov, A. Shokoufandeh, and P. J eppson. 2010. "Classification of Archaeological Ceramic Fragments Using Texture and Color Descriptors.” In IEEE Computer Society Conference on Computer Vision and Pattern Recognition Workshops (CVPRW 2010). San Francisco, California, USA 13-18 J une 2010, 49- 54. San Francisco: IEEE.

Sumner, M., E. Frank, and M. Hall. 2005. "Speeding up Logistic Model Tree Induction.” In Knowledge Discovery in Database: PKDD 2005. Proceedings of the Ninth European Conference on Principles and Practice of Knowledge Discovery in Databases, edited by A. J orge, L. Torgo, P. Brazdil, R. Camacho, and J . Gama, 675- 683. Berlin: Springer.

Vincent, L. 1993. "Morphological GrayscaleReconstruction in Image Analysis: Applications and Efficient Algorithms." In IEEE Transactions on Image Processing 2 (2):176201. 


\title{
Shape and Technological Organisation of Lithic Solutrean Points from Iberia: a Computational Approach for Exploring the Diversity of Shapes
}

\author{
Isabell Schmidt \\ University of Cologne and Neanderthal Museum, Germany \\ Vincent Mom \\ Digital Preservation Projects (DPP) Foundation, The Netherlands
}

\begin{abstract}
:
This paper presents results of a shape analysis conducted on lithic Solutrean points from the Iberian Peninsula. By using SECANTO, a computer application especially designed for this purpose, thevariability of shapes between and within selected Solutrean point types is explored and discussed. Shape has always been considered an important variable in the analysis of prehistoric lithic Solutrean points, namely in typological approaches. However, besides being rarely objectified and quantifiably measured, little effort has been made to understand interrelation between morphology and techniques applied during production processes, or the effects of use-life on the artefacts' shape. The study investigates these interrelations and demonstrates the potential of an objectified computational approach of shape analysis. The analysis can be used to identify and explore methodological problems in existing typologies as well as to set up new models on shape variability in lithic tools.
\end{abstract}

Keywords:

Computer Applications, Shape Analysis, Solutrean Points, Typologies, Lithic Technology

\section{Introduction}

The study of archaeological objects relies at its verybase(and though at anyhigher level ofinference) on criteria and variables chosen to systematise and categorise the record. Typologies have frequently been used in Paleolithic research on stone tools (Bordes 1961; 1967; Laplace 1962; 1972; SonnevilleBordes and Perrot 1954). Notwithstanding their success, they were frequently questioned and discussed (e.g. Semonov 1970). Two methodological problems became apparent almost from their initial introduction into Palaeolithic research: firstly, the inconsistent selection of defining variables, and secondly their vulnerability to subjectivity during analysis. These aspects still play an important role in current discussions (see for example Aubry et al. 2008 and contributions therein; Schmidt and Mom 2012; Shott 2003) and shall be addressed in the following by two case studies conducted on lithic tools deriving from the Solutrean technocomplex of the Iberian Peninsula.

Corresponding author: schmidt@neanderthal.de

\section{Solutrean Points and Typological Classification}

The Solutrean technocomplex occurs in southwestern France and Iberia and lasts from about 25 to $19 \mathrm{ky}$ cal BP (calibrated before present). It was originally defined by the presence of invasively shaped artefacts, summarised as 'Solutrean points', which were produced using pressure retouch or soft-hammer direct percussion to shape one or both surfaces. Being distinct from artefacts occurring in the earlier (Gravettian) and subsequent (Badegoulian, Magdalenian) technocomplexes, Solutrean points were used as index fossils to define and internally subdivide the cultural succession of the Solutrean (Smith 1966). Spatially and temporally restricted occurrences of several Solutrean point types are recorded during the Upper Solutrean (Banks 2009; J ordá Cerdá 1955; Soler 1986; Straus 1983; Zilhao 1997).

Some of these well-established point types are of similar or equal shape, but are conventionally 
Figure 1. Comparing the shape of two Solutrean points: a. measuring the differences (tanged and winged points) and $b$. finding the lowest distance value (shouldered points).

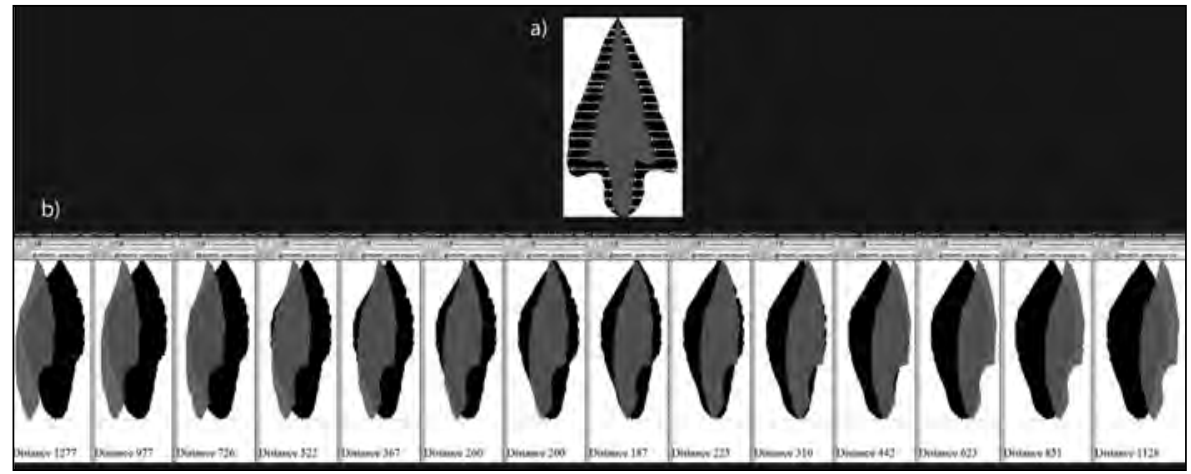

distinguished because of different technological strategies applied during production. In the following case studies, we concentrate on these specific types. They directly allow investigating relations between shape and technological organisation of tool production and use, as well as spatial distribution. Morphometric studies often ignore effects of technological choices during production and use-life of tools, but we argue that this interplay must be considered a key concern in morphometric analysis in general (Schmidt and Mom 2012). Morphometric studies which do not consider the processes of production, function, and use will hardly be able to pose and answer relevant questions to the prehistoric records.

\section{Materials and Methods}

\subsection{Studied material}

Data presented in this study were obtained within the framework of a techno-functional analysis of almost 1500 Solutrean points - including preforms and fragments - deriving from 63 Spanish and Portuguese sites. The sample comprises about 400 well-preserved and (nearly) finished specimens, attributed to Upper Solutrean contexts. Out of this database, four point types were selected for the present study. Classically they are referred to as unifacial points, Laurel Leaf points, FrancoCantabrian shouldered points' and 'Mediterranean' shouldered points. In total, the subsamplecomprises 231 specimens.

The common distinction between 'unifacial points' and bifacial 'Laurel Leaf' points (cf. Sonneville-Bordes and Perrot 1954) proved to be of chronological significance for the Early to Middle Solutrean context in France and Iberia (Smith 1966;
Zilhao 1997). However, within the Iberian Upper Solutrean context, this technological dichotomy already proved to be irrelevant for several point types (e.g. tanged and winged points, Tiffagom 2006; concave based points, Schmidt 2013), but remained uncontested so far in the case of leafshaped points.

Shouldered points from the Iberian Solutrean are generally distinguished into two types, the Franco-Cantabrian and the Mediterranean shouldered points (Fortea Pérez and J ordá Cerdá 1976; Jordá Cerdá 1955), which, as the names suggest, did show distinct spatial distributions (see below). To avoid these geographical names, they will be referred to as shaped shouldered points ('Franco-cantabrian shouldered points') and abrupt retouched shouldered points ('Mediterranean shouldered points').

\subsection{Comparing shapes using SECANTO}

The use of computer programs improves objectivity, efficiency and reproducibility in the area of shape analysis considerably. We used the computer program SECANTO (Mom 2005; Schmidt and Mom 2012) to objectify and quantify the differences in shape between each analysed specimen. Fig. 1 shows how the 'shape distance' between two points is measured.

The two points are scaled along the vertical axis to equal height. Subsequently, the differences (distances) between the outer boundaries of the two projected shapes are measured. Both the left side and the right side of the shapes contribute 150 values. The differences are squared and summed, after which the square root of the sum is taken. The value of the resulting quantifier is a measure for 


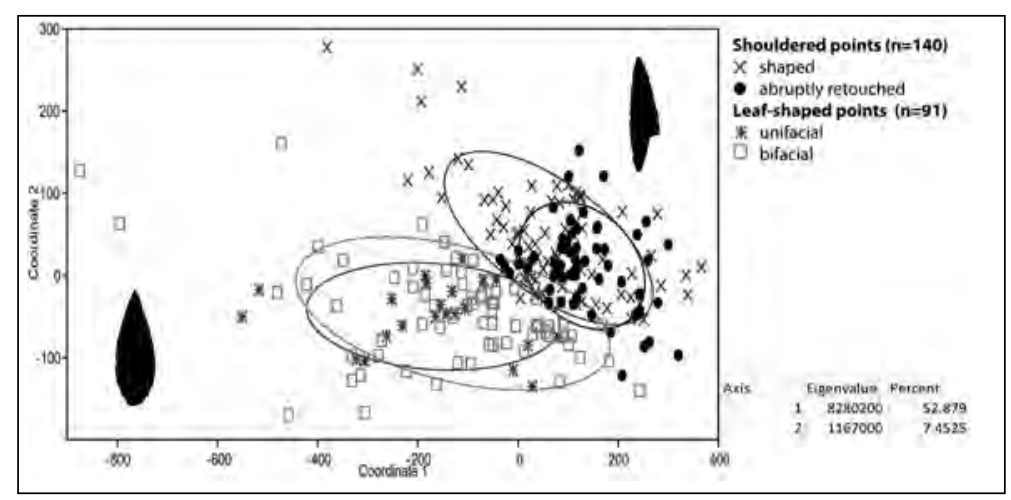

Figure 2. Principal Coordinate Analysis (PCoA) scatter plot (1st and 2nd axis) for selected Solutrean point types (see legend). Distance matrix calculated using SECANTO (Schmidt and Mom 2012), PCoA using PAST (Hammer, Harper and Ryan 2001). Transformation exponent $c=2$; similarity index: user distance; eigenvalue scale. Concentration ellipses set to $68 \%$.

the difference in shape between the two points (cf. Schmidt and Mom 2012).

Repeating this calculation for all pairs of points in the data set, results in a symmetric distance matrix with values of zeros along the diagonal axis. This distance matrix is the basis for subsequent statistical analyses of the data set.

\subsection{Explorative statistics}

Different statistical methods can be used for the exploratory analysis of the distance matrix. For our purpose, we use the Principal Coordinate Analysis (PCoA), also known as metric multidimensional scaling (MDS). The calculations were done with the free statistical package PAST (Hammer, Harper and Ryan 2001).

The PCoA positions the objects within a space of reduced dimensionality, based on the SECANTO distance values. The eigenvalues ("importance of a given dimension in accounting for variation in inter-point distances", Shennan 2004, 347) and percentages ("percentage of the inter-point distance in the data accounted for by that dimension", ibid.) are provided for the 1st and 2nd principal coordinate. For interpretation of the two-dimensional scatter plot, it is necessary to re-examine the structuring factors of the distribution, as calculation in this case starts from a single distance value, not from several variables defining each specimen. To do so, the distribution has to bechecked against morphological characteristics of the individual points.

\section{Case Studies}

To test and evaluate the exploratory potential of shape analysis using SECANTO, we performed two case-studies on lithic Solutrean points. These analyses demonstrate the ability and potential that lies in an objectified, computational approach. It enables a working hypothesis about the reasons for different ranges and patterns of variability in shape.

\subsection{First case study: shapes and technological strategies}

The first case study explores the variability of shapes between all four classical Solutrean point types of the Iberian Peninsula introduced above: the shaped and the abrupt retouched shouldered point types, the unifacial points, and the bifacially shaped (Laurel Leaf) points, the latter two summarised subsequently as leaf-shaped points. The total sample consists of 231 specimens.

Examining the output of the PCoA analysis of the SECANTO distance matrix (Fig. 2) shows that the 1st coordinate captures variability of the lengthwidth proportions, with broad and short specimens in the negative range (to the left) and elongated ones in the positive range (to the right). The 2 nd coordinate displays variability of morphology and ratio between stem (shoulder) and point, and basal and terminal end, respectively. The main observations are:

- SECANTO discriminates between the two morphological groups of shouldered points and leaf-shaped points, although morphological differences within these groups are greater than between them.

- Overlap on the first two axes exists for specimens with extremely short stems (shouldered points) or elongated and asymmetric shapes (leafshaped points). 


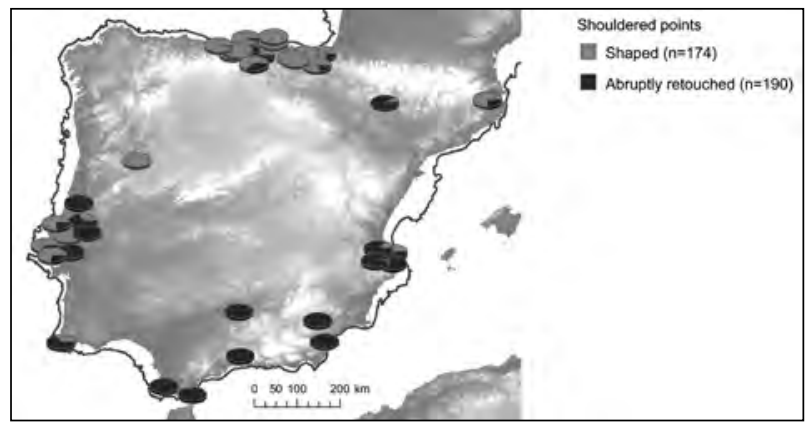

Figure 3. Spatial distribution of shaped and abrupt retouched shouldered points $(n=369)$ taken from a database comprising specimen which are excluded from the present analysis of shapes (i.e. fragmented points). Pie-charts reflect ratio between the two types for each single site ( $n=41$, not divided by single assemblages).

- Based on shape alone, no differentiation can be made between the unifacial points and Laurel Leaf points.

- Based on shape alone, no differentiation can be made between the two technologically distinct types of shouldered points (shaped and abruptly retouched).

- A difference in morphological variation exists between shouldered and leaf-shaped points: the latter cover almost the same variability of shapes, while there is a distinct pattern among shouldered points.

- For leaf-shaped points, the results suggest that the distinction between unifacial points and Laurel Leaf points - which involves distinct technological strategies of blank production and modification - has little effect on the final shape in the Iberian Upper Solutrean context. It also indicates that possible resharpening processes similarly affected the morphology of both types, although short and broad specimen with short terminal ends (most likely affected by resharpening) tend to be bifacially shaped points (Fig. 2, upper left area). Our working hypothesis based on the SECANTO analysis is that the two technological strategies were applied interchangeably to obtain identical morphological tools.

Contrarily, abrupt retouched and shaped shouldered points show distinct patterns: the spectrum of shapes is much more defined among abrupt retouched than among shaped shouldered points (Fig. 2). The former are in general more elongated and thin, with a tendency towards specimen with very short stems (shoulders) compared to the terminal (pointed) part. The latter show a greater heterogeneity which includes a number of points with very short pointed ends in relation to the size of their stems. Two hypotheses can be proposed based on the observations made on shouldered points. Firstly, technological strategies chosen during production do have an influence on the extent of shape variability of the tools. Secondly, shaped shouldered points were probably more intensely resharpened than abrupt retouched ones.

However, other than in leaf-shaped points, the two technological types show regionally distinct distributions across the Iberian Peninsula. This leads us to the second case study that looks at the geographical variability of their shapes.

4.2 Second case study: shape, technology, and geographical distribution

For shouldered points, we would like to test whether the differences in shape variability represent geographical phenomena related to the technological strategy used during production.

The distribution of shaped shouldered points is mainly restricted to northern and western parts of the Iberian Peninsula, while abrupt retouched points occur dominantly in south-eastern and western Iberia, and are very rare in northern Iberia (Fig. 3). The area of overlap, where both types occur in comparable numbers (although generally few) is the western region, i.e. in Portugal (Aubry 2001; Bicho et al. 2003; Cascalheira 2010; Zilhao 1997).

In the first step, the sample was again discriminated by the technology of modifications, that is between shaped/ partially shaped $(n=79)$ and abruptly retouched $(\mathrm{n}=61)$ shouldered points (Fig. 4). In a second step, the sample is divided by three main regions; northern, south-eastern and western Iberia (Fig. 5).

Taking a closer look at the variability of shape for these two technological point types, the first two principal coordinates of the PCoA (Fig. 4) capture 


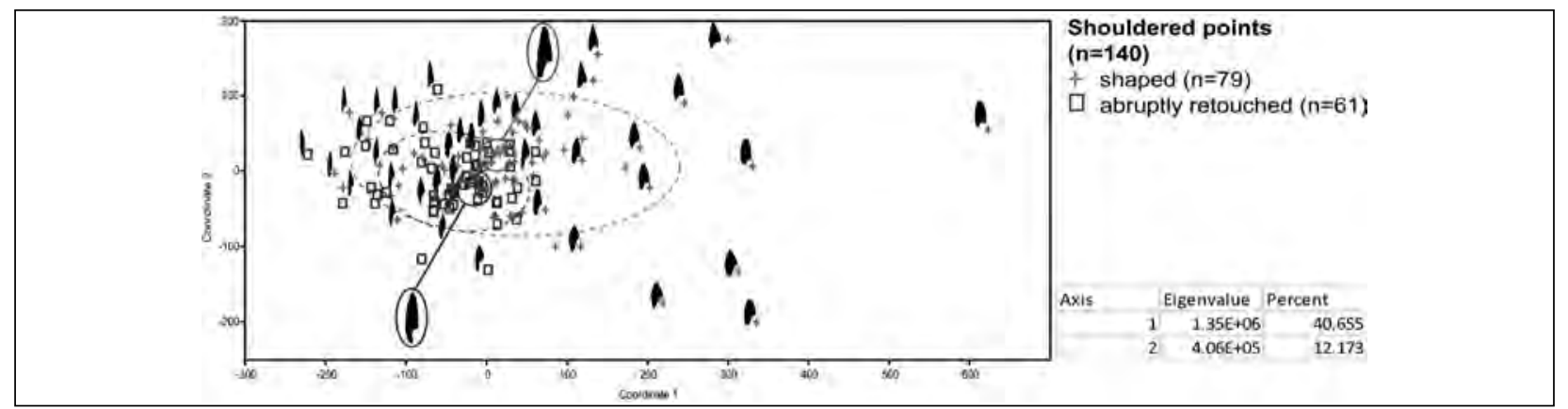

Figure 4. Principal Coordinate Analysis (PCOA) scatter plot (1st and 2nd coordinate) of SECANTO distances calculated for shouldered points, divided by technique (see legend). Distance matrix calculated using SECANTO, PCoA using PAST, (Hammer, Harper and Ryan 2001). Transformation exponent $c=2$; similarity index: user distance; eigenvalue scale. Concentration ellipses set to $68 \%$. Images of points are not to scale.

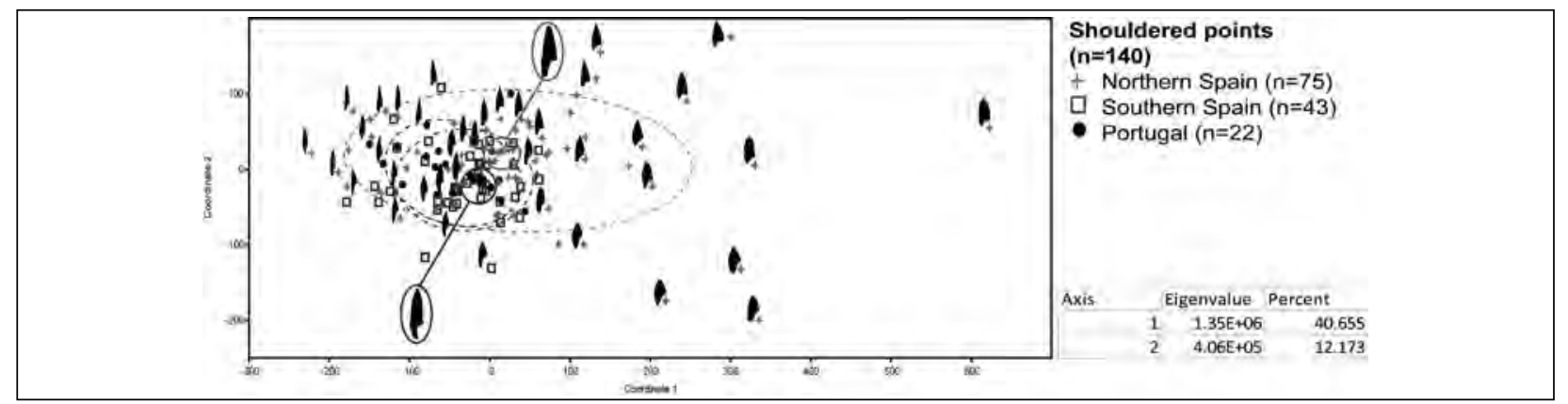

Figure 5. Principal Coordinate Analysis (PCoA) scatter plot (1st and 2nd coordinate) of SECANTO distances calculated for shouldered points, divided by region (see legend). Distance matrix calculated using SECANTO, PCoA using PAST, (Hammer, Harper and Ryan 2001). Transformation exponent c=2; similarity index: user distance; eigenvalue scale. Concentration ellipses set to 68\%. Images of points are not to scale.

the following morphological characteristics: the 1st coordinate accounts again for the length/ width ratio of the points, the ratio being in this visual output higher (elongated points) on the left (negative values) and lower (short and broad) at the right (positive values). The 2nd coordinate captures the ratio between length of stem and length of point (negative values = longer stems; positive values = longer points).

As stated above, the SECANTO analysis indicates that shapes are significantly less variable among abrupt retouched shouldered points. Moreover, they tend to dominate the thin and elongated point morphologies. Shaped and partially shaped shouldered points of southern Spain and Portugal obviously undergo different processes.

Resharpening most likely affects the terminal part of these tools and therefore reduces the point/ stem as well as the overall length/ width ratio. It can be expected that such specimens are sorted to the right of the scatter diagram (Fig. 4). Only shaped shouldered points occur here, indicating that they repeatedly underwent resharpening processes, contrary to abruptly retouched points.

Comparing this output to a now spatially coded PCoA of the same sample (Fig. 5), shouldered points in northern Iberia do cover even both, the left and right extreme of shape-variability on the 1st coordinate. Contrarily, variability is much less pronounced in western as well as in south-eastern Iberia. It appears that the shaped shouldered points of western Iberia are as standardised as the abruptly retouched ones in these areas, while morphologies of abrupt retouched shouldered points in northern Iberia are extremely heterogeneous.

Several hypotheses can be set up based on these observations to explain the different patterns, requiring analysis of raw material, blank selection, 
point production, and use-life. Variability could emerge from different availability of good quality raw material in the areas. Technologically, the material suggest that the selection of more standardised blanks during the process of manufacture of shouldered points in western and southern Iberia be they shaped (west) or abruptly retouched (west and south-eastern) - led to more standardised morphologies. Also, points from northern Iberia underwent resharpening processes more frequently than those in other areas. Such longer use-life cycles could also account for the overall less frequent occurrence of shouldered points in northern Iberian sites.

\section{Final Remarks}

Our study demonstrates the potential for objectified, computational approaches to the analysis of shapes. It shows that such data can be used to identify and subsequently explore problematic methodological issues in existing typological systems. Moreover, we hope we showed its usefulness as a tool to develop hypothesis on shape variability of lithic points. It stimulates research questions on technological organisation of prehistoric hunter gatherers, and provides insights into regional and temporal variability.

\section{Acknowledgements}

We sincerely thank G. Koert for processing images. Thework on Solutrean points of I.S. is part of her $\mathrm{PhD}$ thesis written at the Institute of Prehistoric Archaeology, University of Cologne, financially supported by the German National Academic Foundation (Studienstiftung des Deutschen Volkes), the German Research Foundation (DFG) within the CRC 806 "Our Way to Europe" and the Neandthal Museum, Mettmann, Germany. Many institutions and excavators in Spain and Portugal provided access to collections; we owe our sincere thanks to: Museu Arqueológic Comarcal de Banyoles, Museo Arqueologico de Santander, Arkeologi Museoa Bilbao, Museo Altamira (Santillana del Mar), Centro de custodia y gestión de materiales arqueológicos y paleontológicos de Gipuzkoa (San Sebastian), Museo Nacional de Ciencias Naturales (Madrid), Universidad de Salamanca, Museo Nacional de Arqueologia Lisboa, Universidade do Algarve (Faro), Museo de Cádiz, Universidad de Cádiz,
Museo Arqueologico Almeria, Museu de Prehistória de Valéncia, and Museo Arqueologico de Oviedo.

\section{Bibliography}

Aubry, T. 2001. “L'occupation de la basse vallée du Côa pendant le Paléolithique supérieur." In Les premiers hommes modernes de la Péninsule Ibérique. Actes du Colloque de la Commission VIII de l'UISPP (Vila Nova de Foz Côa, 22-24 Octobre 1998), edited by J. Zilhão, T. Aubry, and A. Faustino Carvalho, 253-273. Lisboa: Instituto Português de Arqueologia.

Aubry, A. T., F. Almeida, A. C. Araújo, and M. Tiffagom, eds. 2008. Space and time: which diachronies, which synchronies, which scales? Typology vs. Technology. Oxford: Archaeopress.

Banks, W. E., J . Zilhão, F. d’Errico, M. Kageyama, A. Sima, and A. Ronchitelli. 2009. "Investigating links between ecology and bifacial tool types in Western Europe during the Last Glacial Maximum." Journal of Archaeological Science 36:2853-2867.

Bicho, N., M. Stiner, J Lindly, C. Ferring, and J . Correia 2003. "Preliminary results from the Upper Paleolithic Site of Vale Boi, southwestern Portugal." J ournal of Iberian Archeology 5:51- 65.

Bordes, F. 1961. Typologie du Paléolithique ancien et moyen. Paris: CNRS Editions. Originally published as Typologie du Paléolithique ancien et moyen. Bordeaux: Publications del'Institute de Préhistoire del'Université de Bordeaux.

Bordes, F. 1967. "Considérations sur la typologie et les techniques dans le Paléolithique." Quartär 18:25- 55.

Cascalheira, J . M. M. 2010. Tecnologia Líthica Solutrense do Abrigo de Vale Boi (Vale do Bispo). Faro: UNIARQ.

Fortea Pérez, F. J ., and F. J ordá Cerdá 1976. “La Cueva de Les Mallaetes y los problemas del Paleolítico superior del Mediterráneo español." Zephyrus 26-27:129- 166.

Hammer, Ø., D. A. T. Harper, and P. D. Ryan. 2001. "PAST: Paleontological Statistics Software Package for Education and Data Analysis." Palaeontologia Electronica 4 (1):37- 66. Accessed September 26, 2012. http:/ / palaeoelectronica.org/2001_1/past/issue1_01.htm. 
Jordá Cerdá, F. 1955. El Solutrense en España y sus problemas. Oviedo: Servicio de Investigación Arqueológica de la Diputación Provincial de Asturias.

Laplace, G. 1962. "Solutréen et foyers solutréens. Essai de typologie analytique sur le phénomène de Solutréanisation." Munibe 14:414- 455.

Laplace, G. 1972. “La Typologie analytique et structurale: Base rationnelle d'étude des industries lithiques et osseuses. Banques de données archéologiques." Colloques Nationaux 932:92- 143. Paris: CNRS Editions.

Mom, V. 2005. "SECANTO, the SECtion ANalysis TOol." In The world is in your eyes. CAA2005. Computer Applications and Quantitative Methods in Archaeology. Proceedings of the 33rd Conference, Tomar, March 2005, edited by A. Figueiredo and Gonçalo Velho, 95- 101. Tomar: CAA Portugal.

Schmidt, I. 2013. "The Solutrean Concave Based Points from northern Spain: Analysis of Production, Hafting, Maintenance, and Recycling." In Pleistocene foragers: Their culture and environment. Festschrift in honour of Gerd-Christian Weniger, edited by A. Pastoors and B. Auffermann, 71-83. Mettmann: Neanderthal Museum.

Schmidt, I., and V. Mom 2012. "Computer-aided classification of archaeological objects - methodological issues in comparing shapes of Solutrean points." In Proceedings of the IV Conference of Jovens em Investigação Arqueológica, Universidade do Algarve, Faro (Portugal) from 11th to 14th May 2011, edited by J. Cascalheira and C. Gonçalves, 39-46. Faro: Núcleo de Arqueologia e Paleoecologia.

Semonov, S. 1970. "The form and functions of the oldest tools. (A reply to Prof. F. Bordes)." Quartär 21:1- 20.

Shennan, S. 2004. Quantifying archaeology. Edinburgh: University Press.

Shott, M. 2003. "Time as sequence, Type as Ideal: Whole-Object Measurements of Biface Size and Form in Midwestern North America." In Multiple Approaches to the Study of Bifacial Technologies, edited by M. Soressi and H. Dibble, 251-271. Pennsylvania: Museum of Archaeology and Anthropology.

Smith, P. E. 1966. Le Solutréen en France. Bordeaux: Imprimeries Delmas.
Soler, N. 1986. “Les indústries del Paleolitic Superior en el nord de Catalunya." PhD diss., Universitat de Barcelona.

Sonneville-Bordes, D., and J. Perrot 1954. "Lexique typologique du Paléolithique supérieur. Outillage lithique: I Grattoirs - II Outils solutréens." Société Préhistorique Française 51:327- 335.

Straus, L. G. 1983. El Solutrense Vasco-Cantábrico: una Nueva Perspectiva. Altamira: Centro de Investigación y Museo de Altamira.

Tiffagom, M. 2006. Dela Pierre à l'homme. Essai sur une Paléoanthropologie Solutréenne. Liège: ERAUL.

Zilhão, J. 1997. O Paleolítico Superior da Estremadura Portuguesa. Lisbon: Edições Colibri. 


\title{
Is the use of GIS in Cultural Heritage Outdated?
}

\author{
Claire Reeler \\ University of Sydney, Australia
}

\begin{abstract}
:
This paper opened the session "GIS in Cultural Heritage consultancy work (S18)" at the 41th Computer Applications and Quantitative Methods in Archaeology Across Space and Time conference. The objective of this paper was to promote discussion of the topic of Geographic Information Systems (GIS) in consulting archaeology within a "focus session". Short presentations by each speaker were followed by an open discussion of the topics raised. A synopsis of the ensuing discussion is provided at the end of the paper. The rather controversial title of the session was intended to open debate into the continued relevance of GIS in consulting archaeology, as well as introduce a discussion of the new technologies available in the field.
\end{abstract}

\section{Keywords:}

GIS, Heurist, FAIMS, Fieldwork, Data Management

\section{Introduction}

The use of Geographic Information Systems is long-established in archaeology. Bibliographies on the subject are exhaustive (see discussion below), courses are taught on GIS and Archaeology at several respected universities around the world, including at MSc level. On a popular level, the subject even has its own Wikipedia entry, cross-referenced to "computational archaeology" (Wikipedia 2013a). The software companies that produce GIS products, most notably ESRI with AroGIS software, have recognised the market share of archaeologists and offer information and even toolkits specifically targeted at archaeologists. It almost seems axiomatic that where there's an archaeologist and a computer, there will be GIS.

It has been suggested in the past that the cost of GIS software is a major limiting factor, especially for smaller cultural heritage consultancies, however, this is increasingly less of an issue, with open source options, such as Quantum GIS, available for a range of platforms, as well as relatively cheap commercial options, such as Manifold. The availability of open source software allows those with the skill and ability to learn to access GIS software. A basiclevel of technical know-how and the ability to learn through experimentation means that GIS software is no longer available only to large organisations that can afford the license fees for commercial products. In fact, many organisations are moving to open source options as they are demonstrated to be superior products for many purposes. Certainly the software

Corresponding author: claire@lentz.com.au is easily available to most archaeologists these days, and cost can no longer be convincingly argued to be a limiting factor.

It should be emphasised that there is a distinction between GIS software and the ability to perform GIS functions. As will be elaborated below, GIS software is only one aspect of the range of tools available to archaeologists who use GIS. Many archaeologists "do GIS" using the GPS and camera built into their phone, in conjunction with Google Earth or similar software, rather than using commercial GIS software. By recognising this distinction it is possible to recognise the truly ubiquitous nature of GIS in archaeology. Different members of the archaeological community have different requirements and for those whose requirements concern primarily basic mapping functions, which is often the majority, particularly of field archaeologists, a range of simpler tools is often all that is required. More complex, analytical functions, for which GIS softwareis often required, is often seen as the purview of specialists either within or even external to the ranks of archaeologists. Increasingly, however, even this distinction is blurring and as tools like FAIMS (FAIMS2014a) and Heurist (Wikipedia 2013b) become more developed, more and more functions can be done using these alternatives.

The reasons for the symbiosis between archaeologists and GIS are legion and quite beyond the scope of this paper. Most archaeologists with any interest in the subject are aware of the wealth of literature examining in depth the happy interactions 
between people primarily searching for patterns in spatially-located data and a computational tool designed to analyse spatial datasets. Ever sinceAllen, Green and Zubrow's (1990) seminal Interpreting Space: GIS and Archaeology led the discussion, right through to recent examples such as Connolly and Lake's (2006) Geographical Information Systems in Archaeology, there have been many publications, some concentrating on specific, project examples and others examining the issues attendant with the overall application of GIS in the usual selfreflective manner employed by disciplines within the Humanities disciplines. Entire bibliographies are available online for those who wish to pursue the literature. One need refer only to the Proceedings of any CAA conference, at least since the 1990s, to read many examples of exemplary work in this field.

With such an established presence in the discipline, is there any argument for questioning the place of GIS? Even this questioning is not unique. Allen (1990) included a chapter entitled "Manipulating Space: A commentary on GIS applications". Other examples include Barcelò and Pollares (1996); Beex (2003); Church, Brandon and Burgett (2000); Pickles (1997); and Wright, Goodchild and Procter (1997) to mention just a few. However, it may be worth re-examining the argument within a further context. Recentyears have seen an upsurge in the availability of applications for tablets and other relatively small devices, including mobile phones. These applications include GPS tools, database tools and of course, the ever-present availability of a camera built-in within most devices used in the field. Furthermore, advances in database systems, most notably, Heurist, developed at the University of Sydney, have altered the way that data is managed.

This paper examines the role of GIS software versus other types of software that can beused for GIS functions to varying degrees. Thecurrent state of GIS in archaeology is examined, allowing conclusions to be drawn about possible future directions and a short account is given of the discussions during the open forum part of the session.

\section{Data Management Systems}

It is now possible to record the location of an item in the field, photograph it and enter the information into a database literally on one's phone in the field. In NSW there is an iPhone application available to register archaeological sites into the State Database (AHIMS) from an iPhone in the field (as long as one is within range of mobile phone signals). Those interested can examine it at NSW Government 2014. It is not the intent of this paper to provide a detailed critique of this or any other particular application.

A national project funded through the Australian National eResearch Collaboration Tools and Researches (NeCTAR) program, and based at the University of New South Wales, in collaboration with 40 Australian and international organisations, has been developed in order to develop, a "new digital infrastructure for archaeology" (FAIMS 2014a). The project is called the Federated Archaeological Information Management System (FAIMS) and currently has a mobile application for archaeological fieldwork under development (FAIMS 2014b). FAIMS aims at capturing and providing an archaeological dataset which can then be exported to and managed within a database. One database which incorporates the ability to import a FAIMS dataset is Heurist, developed at the University of Sydney (J ohnson 2013; J ohnson et al. 2012a; J ohnson et al. 2012b).

Heurist (Heurist 2014) is designed as a research tool and enablesthestoring andinterlinking of many forms of research data. Heurist includes a basic mapping application, linked to the database information and can also generate timelines. Heurist describes itself as an "Academic Knowledge Management System".

Faced by these advances in technology, the obvious questions are - "if I can use my phone to record all I need in the field, do I need to invest in a GIS for fieldwork?" and "if my database can store geographic data and generate maps do I still need GIS at all?". It can be argued that it is even more essential to ask these questions in the cultural heritage consultancy world, where the old cliché "Time is Money" applies. Fast, efficient and appropriate technology is essential to stay competitive. Partly because of these constraints, cost is also an important factor. Although it has been demonstrated that the cost of the software is no longer an issue, there are still costs attendant 
on training and finding skilled personnel, not to mention the time needed to process, manipulate and analyse data.

It is not the intention of this paper to perform an in-depth analysis of the value of mobile applications in archaeological fieldwork. There is an entire session at this conference devoted to the topic of these applications and the papers demonstrate the excitement that the topic is generating, as well as the practical advantages of these systems. Neither is it the intent of this paper to evaluate the role of systems such as Heurist, the application and advantages of which have been amply demonstrated in other papers at this and previous conferences. Rather this paper aims to look critically at the roles that GIS plays in archaeology and cultural heritage management and to open a discussion about whether or not it is still the best tool for the job in a range of contexts.

\section{GIS in Archaeology}

The task of examining the roles of GIS in archaeology has been well covered by the huge range of literature on the subject, described earlier. In order to simplify the process, a somewhat mundane entry point is to examine the actual entry for "GIS in Archaeology" in Wikipedia and to use that as a discussion point for the baseline perspective of the subject. The intent is not to attain an academically rigorous definition, merely to stimulate discussion, and thus Wikipedia can be said to suit this purpose.

Rather tellingly, perhaps, the Wikipedia entry is divided into three sections, which are an introduction to the subject, and then "GISin Survey" and "GIS in Analysis". One expects the "GIS in Survey" section to cover fieldwork applications, and it does, but interestingly enough it also discusses predictive modelling. Whilst at first glance, one might think thatpredictivemodellingwould bebetter placed in the "analysis" section; within the cultural heritage consultancy world, the use of predictive modelling to inform field survey methodologies is often regarded as critical. Predictive modelling can be a very useful tool in order to avoid wasting time surveying large tracts of empty land and instead focussing efforts (constrained by limited budgets and/ or time) on those areas most likely to produce results. An example of using predictive modelling to inform field surveys in north-eastern South Australia is provided by Marwick et al. (2013).

The 'creep' of an analytical tool into a discussion of field techniques further indicates how artificial the divide between fieldwork and analysis is in archaeology. Any experienced archaeologist knows that the two are deeply interconnected and constantly inform one another, even in the commercial world. However, there are slightly different applications of GIS in each of the two aspects of archaeology, sufficient to justify the two headings.

The case for GIS in fieldwork is one that seemed self-evident just a few years ago. However, recently the portability of smaller devices has had a subtle and somewhat unforeseen effect. It was expected that such technology would allow users to carry portable versions of GIS software into the field, thus increasing the efficacy of GIS in the field. The releases of mobile versions of even such relatively resource-heavy systems as ESRI's ArcGIS were aimed at this potential market. However, to a certain extent, the use of mobile devices may be said to have usurped the need for relatively complex systems such as GIS in the field. Some field archaeologists prefer to save time and battery life by running very simple systems, perhaps integrating GPS positioning with photos and saving sufficient raw data to import into the GIS once back at the field station, or even sending the data back to the main office to be processed.

Similarly, the increased use of Google Earth generally, means that some archaeologists bypass GIS altogether for fieldwork and instead use a combination of Google Earth, GPS and the mobile device cameras, operating at capabilities close to those achieved by field archaeologists using GIS 10 years ago. Of course, further advances such as the use of FAIMS (Sobotkova et al., 2014), ODK and Heurist impact on the use of 'traditional' GIS in the field, bypassing the use of software such as ArcGIS altogether.

GIS for analysis is the fundamental role of GIS in archaeology, in fact it is the analysis tools that have been used to justify the use of GIS as a tool in archaeology. Many of the discussions in the literature centre on using GIS for analysis and 
sessions at conferences such as CAA demonstrate many varied analyses, which can be applied in multifarious research conditions. The power of GIS lies in the tools which allow complex manipulation of the data at many levels, both visually and through queries from the database.

In the academic context, research is the primary activity and use of GIS is fundamental to many avenues of research, particularly in spatial archaeology. The language used at conferences such as CAA demonstrates that many researchers are familiar with GIS as tools and use these tools to further their research aims. GIS is an undisputed part of the toolkit of many archaeologists, particularly those involved in spatial analysis. In the consulting environment, research often has to be fitted in where funding and time is available. Few archaeologists and cultural heritage consultants avoid research altogether, however many do less than they would like because of the realities of the consulting environment. Use of GIS in this environment is mainly tailored towards achieving the immediate goals of the particular project. Many consultants have elementary skills in GIS. However, it is an important point that many other consultants also have very little familiarity with GIS and similar skills and we are all familiar with scenarios where one is given "GIS files" in formats such as AutoCAD or even PDF, and people say "we need a database, let's use Excel".

Given this level of knowledge and the fact that to a certain extent staying current with useful advances in the mapping/ database realm will always remain a somewhat specialised sideline, one can make an argument that use of full GIS suites is perhaps not necessary for a majority of mapping and simple data management tasks in the consulting environment. A certain range of simple tasks are needed, often including import of data from clients, the ability to do basic level mapping and simple data management.

\section{The Current Situation}

Some consultants manage adequately using a suite of tools (often available online), such as Google Earth, OziExplorer or Basecamp. One can even argue that software such as FAIMS and Heurist can be utilised to perform many of the tasks that archaeologists require, particularly in the consulting environment, without need for traditional GIS software at all. Indeed, as tools such as these begin to incorporate many functions formerly only possible within complex GIS systems, the definition of what constitutes a GIS begins to blur.

As a snapshot of the current situation, we can state that at the moment we can identify a convergence as powerful GIS tools, capable of performing complex analysis becomemoreand more readily available, particularly in the open source environment. At the same time, mobile devices become more powerful and capable of integrating a range of functions useful to archaeologists. Data management systems, in turn, are able to perform an increasing number of complex spatial tasks, whilst integrating data from a range of sources.

However, technical skills and the interest and time required to set up and maintain the appropriate systems to manage data within any particular organisation are not universal and on a cost-benefit level it is often more appropriate to outsource the technical aspects, or train certain individuals with a particular interest within the organisation to handle these aspects, rather than to expect every archaeologist to become a system administrator (sys admin) or database administrator (DBA).

\section{Conclusions}

In summary, it is likely that GIS will continue to play an important role in archaeology, including within the consulting world, however the nature of that interaction with GIS may not take the form of traditional analyses using large, resource-heavy, expensive, bespoke systems. It may instead involve a relatively customised simple mapping interface on a mobile device in the field, for example. One may therefore argue that in order to remain competitive within the market, consultancies need to track technological changes in the field and either outsource their data management needs or train someone in-house to manage the data. Data management is increasingly a requirement in many areas. In the research realm, Australian Research Council (ARC) grants now require a data management component in order to secure funding. Clients in the commercial world may soon insist on similar requirements. 


\section{Discussion Synopsis}

At the conclusion of the three papers offered in this session, an interesting discussion took place between many participants in the session. This discussion covered aspects of the use of GIS in field recording in consulting environments; the expectations of clients in terms of both GIS capability and data management and the value of large, commercial, bespoke systems versus tools that enable archaeologists to essentially build their own system and environment. The value of tools such as FAIMS formed a lively part of that aspect of the discussion. The discussion topics generated a lot of interest in the room, engaged most of the people present and led to time being over-run all the way through the tea-break. Many present expressed the opinion that they found the opportunity for extensive discussions offered by such a focus session extremely valuable and the organisers of the conference were to be complemented on providing such a forum.

\section{Bibliography}

Allen, K. M. S. 1990. "Manipulating Space: A commentary on GIS applications." In Interpreting Space: GIS and Archaeology, edited by K. M. S. Allen, S. W. Green, and E. B. W. Zubrow, 197- 200. NewYork: Taylor and Francis.

Allen, K. M. S., S. W. Green, and E. B. W. Zubrow, eds. 1990. Interpreting Space: GIS and Archaeology. New York: Taylor and Francis.

Barcelò, J . A., and M. Pollares. 1996. "A critique of GIS in Archaeology. From visual seduction to spatial analysis." Archeologia e Calcolatori 7:313- 326.

Beex, W. 2003. “Use and abuse of digital terrain/ elevation models." In Enter the Past. The E-way into the four Dimensions of Cultural Heritage. CAA 2003. Computer Applications and Quantitative Methods in Archaeology, edited by K. Fischer-Ausserer, W. Borner, M. Goriany, and L. Karlhuber-Vockl, 240-242. Oxford: Archaeopress.

Church, T., J. Brandon, and G. Burgett. 2000. "GIS applications in archaeology: method in search of theory." In Practical applications of GIS for archaeologists: a predictive modeling kit, edited by K. Wescott and R. Brandon, 135- 155. New York: Taylor and Francis.
Connolly, J., and M. Lake. 2006. Geographical Information Systems in Archaeology. Cambridge: Cambridge University Press.

FAIMS. 2014a. "Welcome."Accessed March 15. http:// www.fedarch.org/wordpress/welcome-message/ .

FAIMS 2014b. “ Mobile Applications.” Accessed March 15. http:// www.fedarch.org/ wordpress/ mobile-application/.

Heurist. 2014. "Humanities eResearch applications, University of Sydney." Accessed March 15. http:// heuristscholar.org.

J ohnson, I. 2013. "Integrating Heurist with ODK: a generic solution for field and laboratory data collection." Paper presented at the Across Space and Time. 41st Computer Applications and Quantitative Methods in Archaeology Conference, Perth, Western Australia, March 25-28.

Johnson, I., S. Hayes, B. McLoughlin, and M. McCallum. 2012a. "Joining the pots: linking and publishing excavation data using Heurist." Paper presented at the 40th Computer Applications and Quantitative Methods in Archaeology conference, Southampton, UK, March 26- 29.

Johnson, I., B. McLoughlin, M. McCallum, A. Wilson, and S. Hayes. 2012b. "Linking with legacy: Modelling spatiotemporal distribution patterns of 40 year old excavation data from the settlement site of Zagora." Paper presented at the 40th Computer Applications and Quantitative Methods in Archaeology conference, Southampton, UK, March 26- 29.

Marwick, B., P. Hiscock, P. Hughes, and S. Sullivan. 2013. "The use of mobile Geographc Information Systems for intensive archaeological survey in arid northeastern South Australia." Paper presented at the Across Space and Time. 41st Computer Applications and Quantitative Methods in Archaeology Conference, Perth, Western Australia, March 25-28.

NSW Government. 2014. "AHIMS site recording." Accessed March 15. http://www.environment.nsw.gov. au/licences/DECCAHIMSSiteRecordingForm.htm.

Pickles, J. 1997. "Tool or science? GIS, technoscience, and the theoretical turn." Annals of the Association of American Geographers 87 (2):363- 372. 
Sobotkova, A., B. Ballsun-Stanton, S. Ross, and P. Adela Sobotkova, A., B. Ballsun-Stanton, S. Ross, P. Crook. 2014. "Arbitrary Offline Data Capture on all of your Androids: The FAIMS Mobile Platform.” In Across Space and Time. Papers from the 41st Computer Applications and Quantitative Methods in Archaeology Conference (Perth, WA, 25-28 March 2013), edited by A. Traviglia, 80-88. Amsterdam: Amsterdam University Press.

Wikipedia. 2013a. "GIS in Archaeology.” Accessed March 16. http:// en.wikipedia.org/ wiki/GIS_in_archaeology.

Wikipedia. 2013b. "Heurist.” Accessed March 16. http:// en.wikipedia.org/ wiki/ Heurist.

Wright, D. J., M. F. Goodchild, and J . D. Proctor. 1997. "Demystifying the persistent ambiguity of GIS as 'tool' versus 'science'." Annals of the Association of American Geographers 87 (2):346- 362. 


\title{
The End Game: As Scotland's Historic Land-Use Assessment Project Reaches Completion What Have We Learned?
}

\author{
Kirsty Millican and Mike Middleton \\ The Royal Commission on the Ancient and Historical Monuments of Scotland, UK
}

\begin{abstract}
:
For over a decade the Historic Land-Use Assessment Project, a partnership between Historic Scotland and the Royal Commission on the Ancient and Historical Monuments of Scotland, has undertaken thechallenge of mapping the character of Scotland's historic landscape. By 2015 the Project will have delivered 100\% coverage and, for the first time, Scotland will have a map providing time-depth within the landscape; a map showing both current and relict landscape use. The final stages of this project provide a valuable opportunity for review and reflection. This paper will review where we have reached and will consider some possibilities for the future.
\end{abstract}

\section{Keywords:}

Historic Land-Use Assessment, Landscape, Characterisation

\section{Introduction}

The Historic Land-Use Assessment (HLA) Project (HLAmap 2014) is a partnership between Historic Scotland and the Royal Commission on the Ancient and Historical Monuments of Scotland (RCAHMS), and has been mapping Scotland's historic landscape character for over a decade. With completion due in 2015, Scotland will soon have a country-wide map illustrating time-depth within the landscape and giving users a powerful tool to help understand the way in which the landscape has been changed by people through time. With the completion of the map drawing near, this provides a valuable opportunity for review and reflection and to consider where the project has got to and opportunities for the future.

\section{The Historic Land-Use Assessment: Theory and Method}

HLA began with a pilot project in 1996 which led to the establishment of the HLA project proper a couple of years later (Dyson Bruce et al. 1999). Conceived in reaction to the inability of Landscape Character Assessments to deal adequately with the historic dimensions of landscapes, HLA was seen as a way of contributing to future discussions about the management of the landscape and was established with the aim of producing a digital map depicting

Corresponding author: kirsty.millican@rcahms.gov.uk the historical complexity of the Scottish landscape (Dixon et al. 1999). Central to the concept behind HLA is the European Landscape Convention's definition of landscape as '....an area, as perceived by people, whose character is the result of the action and interaction of natural and/ or human factors' Article 1, European Landscape Convention (Council of Europe 2000). In essence, the HLA project views the modern landscape as a historical resource that can be understood and evaluated, as something with inherent time-depth, the identification of which adds value to our understanding of the landscape. This time-depth can be assessed, interpreted and ultimately presented in a digital map.

HLA, therefore, essentially analyses the character and time-depth of the whole landscape and records any land-use that has left a mark on the landscape, whether that land-use is current or relict. It is compiled at a scale of 1:25000, which in practice means that the smallest recorded unit is 1 hectare. A wide range of sources are employed to assess the landscape, including maps, aerial photographs and existing historic environment databases (RCAHMS 2012). The current Ordnance Survey map and recent vertical aerial photography provide the starting point, and sources such as historic maps and historic vertical aerial photography provide information about the impact of changes since the maps were produced or photographs taken. RCAHMS' own database (RCAHMS 2014) and 


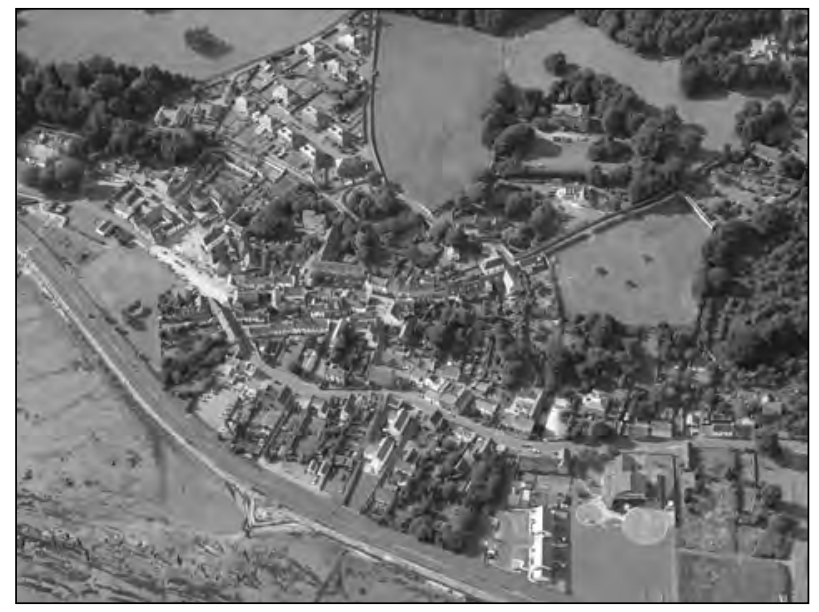

Figure 1. Aerial view of the medieval town of Culross, Fife, showing the medieval layout preserved in the current village. Crown copyright RCAHMS DP014181.

resources as well as available Historic Environment Record (HER) datasets provide information about recorded archaeological sites, and finally, a variety of documentary sources are consulted to provide background information. Based upon the physical remains of land-use identified and interpreted from these sources, the whole of the landscape is divided up into a series of generic types (RCAHMS 2013). These types characterise landscape features by form and function, as well as period of origin. All areas are assigned a historicland-use type - this is the current land-use in that location and essentially records the origins of the current landscape, which could be a medieval town (Fig. 1), or 20th forestry plantation, for example. If any traces of past activity are still visible in that part of the landscape, that same area is assigned a relict land-use type, or if there is extant evidencefor more pastland-uses, up to three in total. Relict landscapes are essentially landscapes that are not now active, but enough remains to identify them. They can consist of landscape features such as fields or crofts, or archaeological landscapes like medieval or post medieval rigand furrow cultivation (Fig. 2) or prehistoric settlement.

This information is transcribed into a GIS, at a scale of 1:25,000, thereby creating a digital map of the origins of the landscape. As a digital map, the data can be manipulated and analysed at a variety of scales and in many different ways. It can be broken down into discrete units, for example, or studied by particular attribute classes, such as period or type of land-use. It is therefore a flexible tool, with

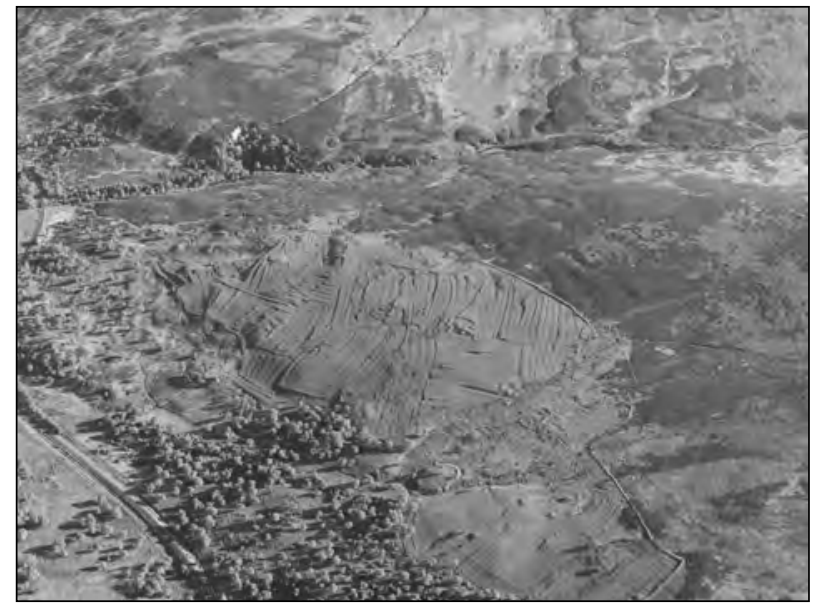

Figure 2. Aerial view of the township, field system and rig system at Learable, Sutherland, a relict landscape preserved in current moorland. Crown copyright RCAHMS DP080123.

potential uses in many different contexts. The map scale of 1:25000 was selected as the smallest scale that showed field boundaries, and places HLA between the broader brush Landscape Character Assessment (1:50,000) and the finer grained Historic Environment Record. From the outset HLA was recognised as an important addition to the suite of landscape-scale data, offering specialists a landscape-wide framework for site-specific data and giving non-specialists a fuller appreciation of timedepth than had previously been possible. As such, HLA data are potentially of greatest use when used in combination with other sources of landscape data (Dixon et al. 1999, 165).

HLA, therefore, is a powerful tool that can help us to understand how Scotland's landscape has been changed by people through time. It can help unravel the processes that have shaped the modern landscape and can demonstrate how past events and decisions continue to resonate in the present. This is clearly illustrated at an area called Bauds of Cullen in Aberdeenshire, in north-east Scotland (Fig. 3), where HLA analysis of the area identified an earlier landscape of crofting smallholdings, which had recently been converted to woodland. Rather than woodland planting removing any trace of the earlier land-use, the buildings and layout of the earlier landscape have been preserved within the woodland, the earlier land-use shaping the current use of the landscape. 


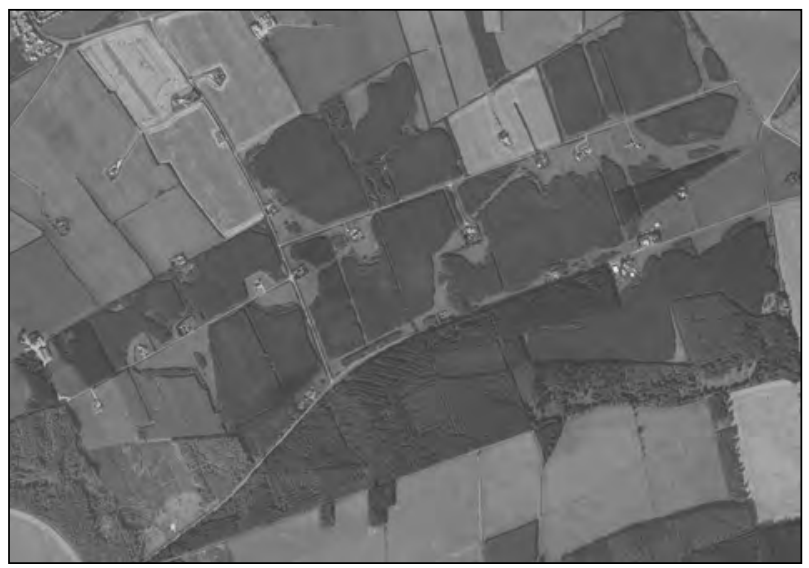

Figure 3. Vertical aerial image of Bauds of Cullen, Aberdeenshire, showing the regular layout of crofting smallholdings preserved in a current forestry plantation. (C)NextPerspectives 2013: Licensed to Royal Commission on the Ancient and Historical Monuments of Scotland for PGA, through NextPerspectives.

\section{The Historic Land-Use Assessment: Applications}

From the very beginning, HLA was envisaged as an important new tool in the understanding and management of the historic landscape, thereby ensuring that the inherited character of the Scottish landscape could be taken into account within decisions affecting its future. As the map nears completion, how far have we achieved this aim and what of the future?

There is no doubt that HLA provides a comprehensive overview of the historic landscape. By supplying information about the time-depth in the landscape, it provides a framework from which decisions can be made, and a starting point from which to consider issues and proposals. It does not make judgements on which areas or polygons are 'better' or more significant than others. Instead it provides the information base from which such judgements can be made. It cannot answer every question about the landscape, but rather focuses upon the assessment of the surviving time-depth within the present landscape, affording a landscape framework for site-specific information and a human dimension to other forms of environmental data. As a result, it is complementary to existing datasets, rather than simply a stand-alone resource. This can be clearly illustrated when HLA data are

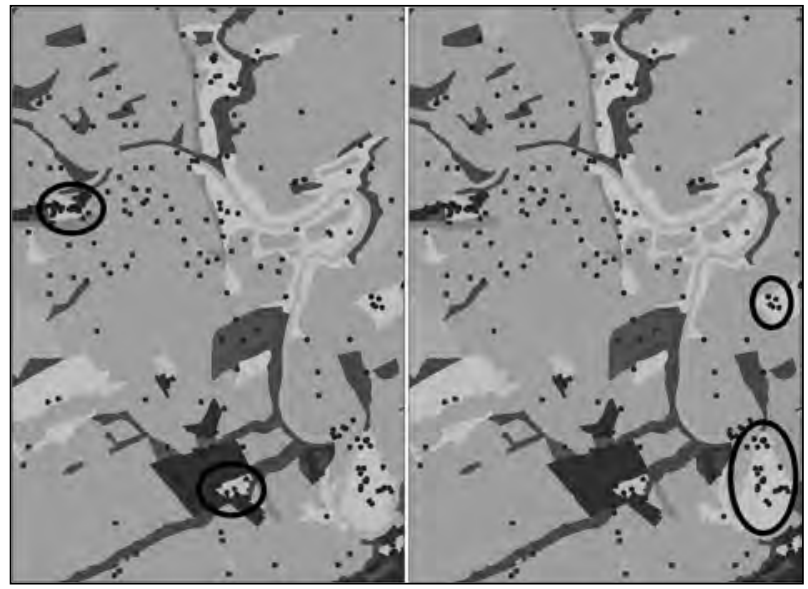

Figure 4. HLA data provides contextual information in relation to the much finer-grained historic environment data. Here archaeological records can be seen to cluster within two particular landscape types: medieval villages (left) and designed landscapes (right). Crown copyright RCAHMS.

viewed alongside the Historic Environment Record (Fig. 4). Here, the HLA data provide the landscape context in relation to the much finer-grained Historic Environment Record data and also helps to explain why the archaeological records cluster in the way that they do; in this case reflecting the presence of medieval villages and designed landscapes.

Overall, HLA demonstrates very clearly the complexity of the Scottish landscape and the varied processes and events that have influenced it and continue to shape it today. The map presents a tapestry of change and process in the landscape, showing both present land-use and archaeological landscapes in a single map, and clearly demonstrates the importance of considering the whole landscape, rather than just individual sites.

With more than $80 \%$ of Scotland now mapped by HLA, an increasing proportion of the country now has available data dealing with the historic landscape. At its inception, it was envisaged that HLA would contribute to the planning process by providing a better understanding of the impact of loss or change to the historic dimension of the landscape, but also more widely as a basis for land management decisions (Dyson Bruce et al. 1999, 1920). Some progress has been made here. The data have been provided to Local Authority archaeologists and other users as it became available. As more 
Local Authority areas are completed, HLA data are becoming more widely available for incorporation in the planningprocess. Examples include: Stirling and Aberdeenshire councils, who have created standard policies for developments in areas where particular HLA types exist (Dixon 2007, 79); the use of HLA to inform management strategies for National Scenic Areas (RCAHMS and Historic Scotland 2002; 2003); and the adoption of HLA by the Forestry Commission Scotland to inform forestry planting and design (Ritchie and Wordsworth 2010). Clearly these are very positive steps, yet this is by no means a universal pattern and in some areas take-up of the data have been slow. For some the data are seen as too complex and difficult to use, or too general to be of any specific use. In many cases, this is due to a lack of GIS knowledge. While some training and guidance can be supplied through the HLA project, it is difficult to see how to overcome this latter barrier, though ongoing developments in the online map and guidance provision are likely to go some way towards alleviating this.

There are also examples of use of the data out-with the historic environment field. Perhaps most significant in this regard is the use of the data to help define the special qualities of the landscape within the Loch Lomond and the Trossachs National Park (Scottish Natural Heritage and Loch Lomond and The Trossachs National Park Authority 2010) and the landscape character assessment of the Cairngorms National Park, as part of its landscape framework (Cairngorms National Park 2014; Grant 2009; Scottish Natural Heritage and Cairngorms National Park Authority 2010). Both evaluations involved combining information on landscape character, historic land-use, biodiversity and the built environment to identify landscape qualities, character and sensitivities. These went beyond the description of the historic dimension of the landscape and began to look at the relative importance and sensitivity of these special landscapes to change. However, most significantly, HLA data were combined with quantitative and qualitative data concerned with other aspects of landscape, buildingamoreholisticviewoflandscape, landscape character, change and the pressures and trends affecting the landscape. These combined data are being used to inform planners and decision makers, but it also has applications beyond this in terms of understanding the relationship of the historic landscape to other aspects of the natural environment, and the values people place upon their landscapes and environment.

This begins to point to exciting future directions for the use of HLA data, notably within interdisciplinary studies. For example, it has been noted that the protection of historic landscapes may have positive impacts upon biodiversity and ecosystems (Loch Lomond and Trossachs National Park 2012, 36) and that an understanding of past landscapes can have significant environmental as well as cultural value (Clark et al. 2004, 42). Indeed there may be a link between areas rich in archaeological heritage and biodiversity (Fry 2003, 244). The benefits to people of engaging with the natural environment are well known, and indeed the Millennium Ecosystem Assessment defines cultural services, of which cultural heritage is one part, as one of the things in the 'natural' environment that benefit people (Millennium Ecosystem Assessment 2005, 120). Therefore, the HLA data and an understanding of the time-depth of the landscape can surely contribute to studies dealing with wellbeing and landscape engagement. Undoubtedly there are other interdisciplinary applications of which HLA has the potential to be a part; the historic environment is, of course, only one part of the landscape and environment (Clark et al. 2004; Porter 2004, 103-5). HLA, therefore, is strongly placed to contribute to such studies, particularly as the GIS structure of the data provides the flexibility to combine it with multiple sources of data.

Such interdisciplinary applications will help realise the original purpose of the HLA project, namely to inform landscape management about the extent and complexity of its historical dimension. This is easier than it was at the beginning of the project due to the wider availability of differing GIS datasets, providing more opportunities for more people to combine and analyse data, and possibly also due to a wider recognition of the intertwined nature of history, culture, landscape and the environment. Scotland's Environment Web (Scotland's Environment 2014), which aims to draw together all datasets related to the natural and cultural environment in Scotland, provides one such opportunity. Clearly, then, the potential of HLA to inform wider landscape applications may be more fully realised in the future. Allied fields include 
geology, biodiversity, water management and landscape character, but are likely to also include other, as yet unrealised, applications. The challenge for us lies in promoting the availability and value of the HLA data to groups who have perhaps not considered it before or are unaware of its existence, and of demonstrating to them that a map showing landscape time-depth has much to add to the understanding and management of landscape.

\section{Conclusions}

The Historic Land-Use Assessment Project has been a massive undertaking, over a decade in the making, and is something that is unlikely to be undertaken again. The rapidly approaching end of the project presents interesting and exciting challenges for the use and application of the data. These include applications considered at the start of the project, predominantly those relating to planning and land management in Scotland, but there will be others that were not considered in 1996. In particular, HLA has the potential to inform multidisciplinary approaches to landscape, where a map of time-depth in the landscape can add value and insight to data dealing with other aspects of the landscape and environment. It has great potential for landscape monitoring, assessing changes against the data recorded between 1996 and 2015, complementing existing landscape monitoring indicators. These remain to be fully developed, yet the potential is there. The existence in the near future of a map displaying time-depth across the whole of the landscape of Scotland is set to bring an exciting new dimension to landscape studies and management.

\section{Bibliography}

Cairngorms National Park. 2014. "Introduction.” Accessed J anuary, 15. http:// cairngorms.co.uk/ landscape-toolkit.

Clark, J ., J . Darlington, and G. Fairclough. 2004. Using Historic Landscape Characterisation. Swindon: English Heritage and Lancashire County Council.

Council of Europe. 2000. European Landscape Convention. Florence: Council of Europe.

Dixon, P. 2007. “Conservation not Reconstruction: Historic Land-Use Assessment (HLA), or Characterising the Historic Landscape in Scotland." Landscapes 8 (2): $72-83$.

Dixon, P., L. Dyson Bruce, R. Hingley, and J . Stevenson. 1999. "Historic Land Use Assessment Project." In Landscape Character: Perspectives on Management and Change, edited by M. B. Usher, 162-9. Edinburgh: The Stationary Office.

Dyson Bruce, L., P. Dixon, R. Hingley, and J . Stevenson. 1999. Historic Landuse Assessment (HLA): Development and Potential of a Technique for Assessing Historic Landuse Patterns, Report of the Pilot Project 1996-1998. Edinburgh: Historic Scotland and the Royal Commission on the Ancient and Historical Monuments of Scotland.

Fry, G. 2003. "From Object to Landscapes in Natural and Cultural Heritage Management: A Role for Landscape Interfaces." In Landscape Interfaces: Cultural Heritage in Changing Landscapes, edited by H. Palang and G. Fry, 237- 54. Dordrecht: Kluwer Academic Publishers.

Grant, A. 2009. Cairngorms National Park Landscape Character Assessment: Final Report. Grantown on Spey: Cairngorms National Park Authority.

HLAmap. 2014. "The Historic Land-use Assessment Data for Scotland.” Accessed J anuary, 15. http:// hla.rcahms. gov.uk/.

Loch, L., and The Trossachs National Park. 2012. National Park Partnership Plan 2012-2017: Strategic Environmental Assessment. Balloch: Loch Lomond and The Trossachs National Park Authority.

Millennium Ecosystem Assessment. 2005. Ecosystems and Human Well-being: Synthesis. Washington DC: Island Press.

Porter, K. 2004. "The Natural Area Experience." In Countryside Planning: New Approaches to Management and Conservation, edited by K. Bishop and A. Phillips, 91- 108. London: Earthscan.

RCAHMS 2012. "Historic Land-useAssessment: Sources." Accessed April 29, 2014. http:// hla.rcahms.gov.uk/ sites/ default/files/HLA\%20Sources.pdf.

RCAHMS. 2013. "Historic Land-use Assessment: Types.” Accessed April 29, 2014. http:// hla.rcahms.gov.uk/ sites/ default/files/TypeDefinitions.pdf. 
The End Game: As Scotland's Historic Land-Use Assessment Project Reaches Completion What Have We Learned Kirsty Millican and Mike Middleton

RCAHMS. 2014. “Canmore.” Accessed J anuary 15. http:// canmore.rcahms.gov.uk/ .

RCAHMS and Historic Scotland. 2002. The Historic Land-use Assessment of the Solway Coast National Scenic Area. Edinburgh: Historic Scotland and the Royal Commission on the Ancient and Historical Monuments of Scotland.

RCAHMSand Historic Scotland. 2003. TheHistoric Landuse Assessment of the Wester Ross National Scenic Area. Edinburgh: Historic Scotland and the Royal Commission on the Ancient and Historical Monuments of Scotland.

Ritchie, M., and J. Wordsworth. 2010. Identifying the Historic Environment in Scotland's Forests and Woodlands. Edinburgh: Forestry Commission Scotland.

Scotland's Environment. 2014. "Welcome to Scotland's Environment." Accessed January 15. http://www. environment.scotland.gov.uk/ .

Scottish Natural Heritage and Cairngorms National Park Authority. 2010. The Special Landscape Qualities of the Cairngorms National Park. Scottish Natural Heritage Commissioned report. Inverness: Scottish Natural Heritage.

Scottish Natural Heritage and Loch Lomond and The Trossachs National Park Authority. 2010. The Special Landscape Qualities of the Loch Lomond and The Trossachs National Park. Scottish Natural Heritage Commissioned report. Inverness: Scottish Natural Heritage. 


\title{
A 21st Century Record: Maintaining a Modern Monuments Record
}

\author{
Susan Hamilton \\ The Royal Commission on the Ancient and Historical Monuments of Scotland, UK
}

\begin{abstract}
:
The Royal Commission on the Ancient and Historical Monuments of Scotland (RCAHMS) holds Scotland's national monument record, which is accessiblethrough the online databaseCanmore. This paper considers how the records held by RCAHMS have developed over time, mirroring wider changes in attitudes to conservation and cultural heritage. The information within the Canmore database comes from a wide range of sources, and places are not only recorded because they embody traditional heritage values - such as architectural form - but also because they are given a value by a community. This can include values related to intangible cultural heritage. In creating a 21st century record, it is important that there are no barriers to accessing the information held within Canmore. The paper considers a number of barriers to comprehension and suggests ways that these may be countered.
\end{abstract}

\section{Keywords:}

National Inventory, Information Management, Cultural Heritage, Historic Environment

\section{Introduction}

This paper identifies an almost imperceptible shift which has transformed monument records from a pedagogic tool of the authorised heritage discourse to an agile repository covering 'cultural heritage' in the widest possible sense, and questions the extent to which this is a response to changing technology.

The record held by RCAHMS is used as a case study. It is shown that although the changing technology has underpinned this, in most cases drivers come from elsewhere, and the long term impact of global heritage charters is highlighted.

This discussion is followed by considering how to continue to make cultural heritage data available, and as free as possible from barriers to understanding. This is fundamental to ensuring that the shift in monument records is maintained, ensuring their continuation and development as widely shared resources. Examples are used to illustrateexistingbarriersanditcanbedemonstrated that a willingness to embrace new technology can inadvertently create obstacles, unless a strategic approach is taken to identify and manage these.

By embracing a new, wide-ranging monument record and working to reduce and prevent barriers Corresponding author: susan.hamilton@rcahms.gov.uk to engagement, there will be significant benefits to Scotland; benefits that could go far beyond traditionally defined notions of 'heritage' and which signal the increasing adoption of an inclusive, participatory approach to cultural heritage.

This paper continues a series reflecting on the work of RCAHMS to make information on Scotland's historic environment available, the most recent summary of which is by Peter McKeague and Rebecca J ones (McKeague and J ones 2008).

\section{The RCAHMS Inventory}

When RCAHMS was founded in 1908, the inventory' was envisaged as a publication which listed ancient monuments and historic buildings. Once listed, the features recorded in the inventory could then be considered for some form of state protection. At this time, interest in heritage was considered a minority one; a 2008 publication celebrating the centenary of RCAHMS noted that the first Commissioners "could not have imagined the developments that would unfold through the century, together with the evolution of the public's enthusiasm and engagement with their historic environment,' and that their 'minority interest would one day become so universally accepted as part of our national psyche' (Ferguson 2008, 11). Not only has the historic environment become a popular interest, our understanding of it has also developed. The 
draft Historic Environment Strategy for Scotland (Scottish Government 2013) includes the following definition: 'Scotland's historic environment is the evidence for human activity that connects people with place, and includes the associations we can see, feel and understand.' This wide-ranging definition allows for an inclusive approach to data gathering, as explored below.

The earliest published RCAHMS inventories are examples of an Authorised Heritage Discourse (AHD) (Otero-Pailos and West 2010, 57); being produced by specialists for a specialist purpose. The monument descriptions contain what would now be described as technical jargon - understandable as the documents were being written for fellow experts. Each monument or building that was recorded had to be worthy of inclusion according to implicit and explicit considerations, including architectural merit - but often relating to aesthetic judgements, and as such were places that had a value according to the AHD. The inventories were not intended to be widely circulated, and had relatively small print runs, reflecting the place of the historic environment as a minority interest.

A century later, an enormous shift has occurred; the national inventory is now the online Canmore database, and inventory volumes are no longer published. The information held within the inventory reaches a worldwide audience. This result of the digital revolution has perhaps overshadowed a change of equal magnitude: exactly what it is that the national inventory records. It is now an inclusive compilation of data from a variety of sources perhaps only some of which (designations and RCAHMS survey) could be seen as being created as part of the traditional AHD.

This acceptance of a wide range of data has had a long genesis and is not a result of computerisation or driven by technology. The RCAHMS collection - now comprising some 15 million drawings, photographs, manuscripts and objects - was founded to supplement the work of inventorisation, providing illustrative material (Ferguson 2008, 5). Once begun, collecting continued and began to form part of the evidence base itself. Two significant examples came to RCAHMS in the 1980s: the Ordnance Survey archaeology card index, and the records of the Scottish Industrial Archaeology
Survey (SIAS). These survey programmes recorded sites and monuments which, in many cases, would not have met the original inventory's purpose. The OS Archaeology Survey recorded upstanding monuments for mapping (a role which RCAHMS continues to this day) and SIASrecorded monuments of Scotland's industrial past at a time when their numbers were in decline but before industrial archaeology had the prominence or support it does today.

The Canmore database now also includes reports of work undertaken by historic environment professionals outside RCAHMS, including commercial archaeological units, architectural historians and academics. Most of these reports are catalogued and reported without validation by RCAHMS staff, and the record makes clear what the origin of the data is. This is a significant difference to the original inventory, when each monument was visited by RCAHMS. The increase in archaeological activities undertaken as a result of developer-funded archaeology and an inclusive collecting policy arethe primary reasons for this, but the result is a national inventory that is the product of many organisations and individuals. This inventory is now compiled and curated by RCAHMS - not authored in its entirety.

The inventory also records the activities of communities of interest, such as amateur archaeologists and local heritage societies. Groups across Scotland can submitinformation viaan online form with an inbuilt validation stage. Perhaps most significantly, RCAHMS encourages the submission of user-generated content from individuals as text and photographic contributions to Canmore. At the time of development, the ability for users to add content was considered to be RCAHMS responding to 'Web 2.0' and taking advantage of the latest technology, whereas it is in fact the result of many years of learning to let go' of the national inventory and the shift from author to compiler - an extension of the contributions made by the professional elements of the sector (Hamilton, Jones and McKeague 2014) (Fig. 1).

The development of Canmore as national inventory has been an organic process, the record growing and changing with theinclusion of each new dataset and reflecting an increasingly open-minded approach to inventorisation. It is now possible to 


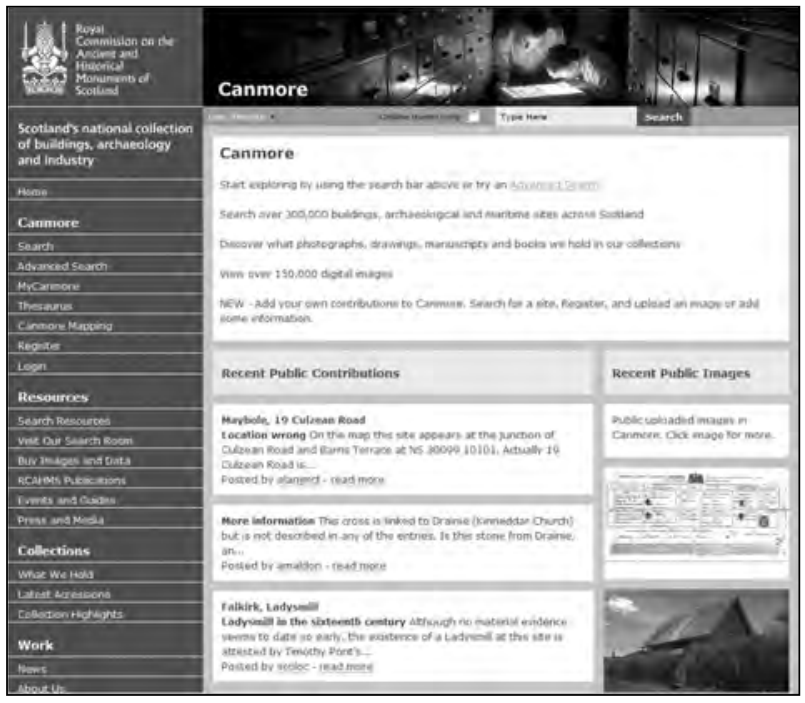

Figure 1. User-Generated Content on Canmore. Crown Copyright RCAHMS, 2013.

recognise that this mirrors the development of cultural heritage and conservation theory and is not necessarily a side-effect of the increasingly participative nature of the internet. A case study of the Nara Document (ICOMOS 1994) illustrates this and outlines the way in which a 21st century national monument record can be understood and provides a theoretical background for this discussion

In 2013, Canmorecontainsmanyrecordswhich recognise community values; both communities of interest and communities of place. Examples of this include the early recording of industrial monuments or the gathering of information by a local heritage society. This reflects the principles debated at a forum held in Nara, J apan, which discussed modern conservation practices and in particular looked at the meaning of the concept of 'authenticity' as applied to conservation.

The Nara Document on Authenticity was produced by the International Council on Monuments and Sites (ICOMOS) and builds on the Charter of Venice (ICOMOS 1964). The Document recognises that responsibility for the cultural heritage belongs in the first place to the culture which created it. The Document covers the values attributed to the heritage' and notes that 'Our ability to understand these values may be understood as credible or truthful. Knowledge and understanding of these sources of information, in relation to original and subsequent characteristics of the cultural heritage, and their meaning, is a requisite basis for assessing all aspects of authenticity' There are clear implications for the maintenance of monument records within the Nara Document; they are a source of authenticinformation aboutcultural heritage. The Document makes clear that this information can be tangible or intangible, and states that 'authenticity judgements' may come from a range of information sources including 'form and design' (a traditional value of the AHD) as well as 'spirit and feeling'. This links to concepts of intangible cultural heritage, work on which is gathering pacein Scotland through development of a database (UNESCO 2014). The Scottish Culture Secretary, Fiona Hyslop, made a speech in June 2013 in which she noted that it was the role of Government to work with partners to ensure that 'our tangible and intangible culture and heritage can thrive' (Hyslop 2013); signalling the increased prominence that intangible cultural heritage is enjoying as part of culture.

While the development of the RCAHMS database has been incremental, the Nara Document allows us to demonstrate what thenational inventory now represents. Particularly important within this is the ability for communities to record information about 'their' heritage. This shared ownership of the inventory may go some way to mitigate against the tensions which can arise when there are different views on how to 'manage' a heritage asset - a topic which has been explored by Emma Waterton (2005).

\section{Canmore and Community Values}

The Canmore database can be described as an inventory of places, each of which has one or more 'values' attached to them. Looked at in this way, the database represents an opportunity to embrace all spatial aspects of Scotland's rich cultural heritage and, as the following examples demonstrate, can continue to create a multi-layered, rich, record of the nation. Being aware of the changes that have occurred within the national inventory allows RCAHMS to continue to develop a flexible approach to holding a national monument record, successfully serving all communities and users.

The opportunities to record places and link them to a range of 'values', does not preclude the maintenance of an authoritative record of archaeology, architecture, form and design. An 
example of this is the record in Canmore for the Bernat Klein studio in theScottish Borders, designed in 1970. It is a highly-regarded building with an important place in the history of modern Scottish architecture, and the Canmore record demonstrates why, listing the awards the architect received in addition to other structural details (RCAHMS 2014a).

Other values attached to a record can be of a very different nature. Intangible cultural heritage is an obvious example of this. The RCAHMS record for Hallaig, on the island or Raasay off the Isle of Skye provides a good example of a descriptive account of the structural composition of an abandoned township alongside a translation of a Gaelic poem which describes the emotional impact of the Clearances (RCAHMS 2014b).

A further recent example is that of the Tinker's Heart, a place of continuing importance to Scotland's travelling community (RCAHMS 2014c) (Fig. 2). The inclusion of sites such as this can only help to create a genuinely representative national record, free of restrictive preconceptions of what is important or should be valued, and absolutely in keeping with the principles of the Nara Document.

There is of course a pragmatic aspect to everything discussed above. As a publicly-funded body, RCAHMS needs to be able to demonstrate that its websites and collections are being used. This can be in the financial sense - measured through revenue generated by image sales - and through the now traditional recording of numbers of page hits and time spent on pages. There is also a growing trend towards measuring impact (Tanner 2012) and it is logical that in order to have the greatest possible impact upon users, Canmore must appeal to the greatest number of users, who should be engaged, not excluded, by the tone or character of the database.

\section{Managing the 'New' National Inventory}

Having established that the Canmore database is now a product of a variety of diverse authors, there are many considerations which should be taken into account when managing it, in order that no user should be excluded as a result of a 'comprehension barrier' - a term adopted by Newman (Newman

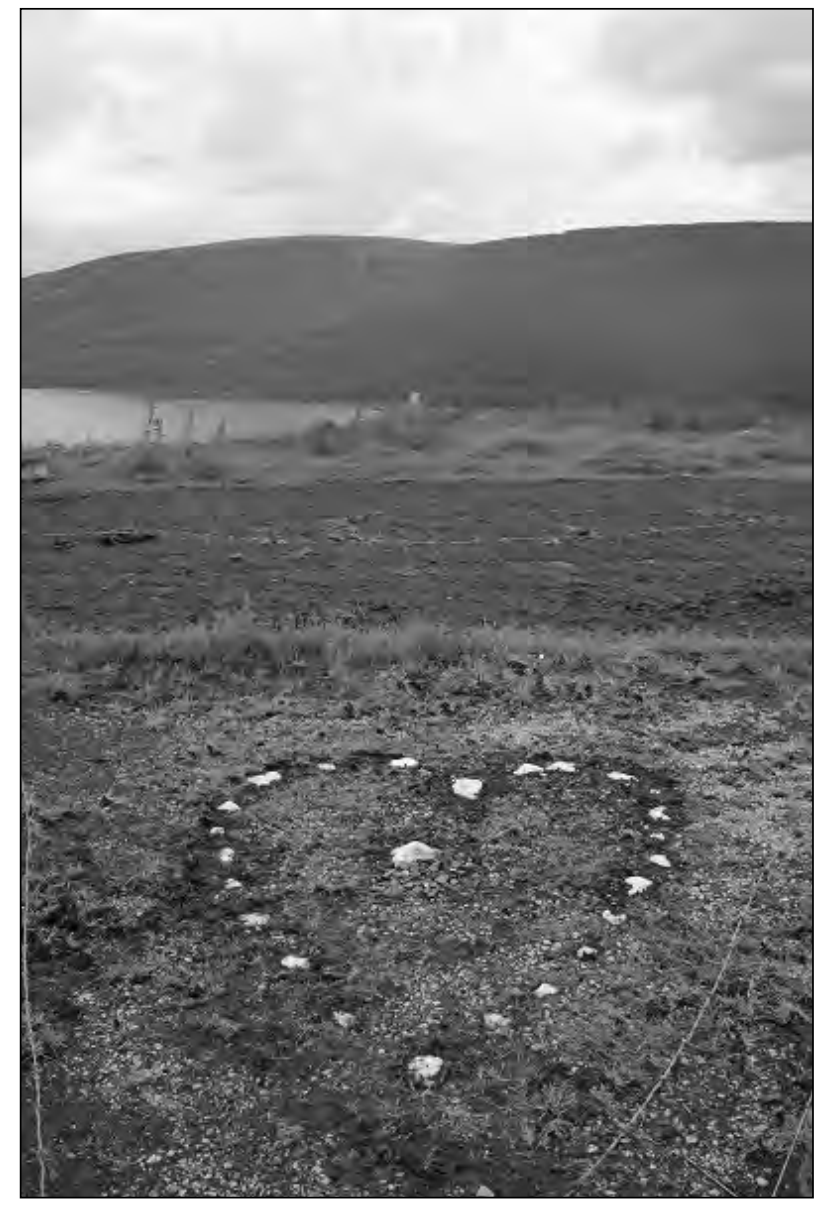

Figure 2. The Tinker's Heart. Crown Copyright RCAHMS, 2013 DP146853.

$2007,68)$. A number of case studies are given below to consider this concept.

Members of a 'community of interest', the UK Pillbox Studies Group (UKPSG) got in touch with RCAHMS because they were recording information on 20th century defensive structures in Scotland and offered to help update and enhance the information in the Canmore database. A member - based in England - was given access to an online recording form, developed as part of the Scotland's Rural Past Project (Scotland's Rural Past 2014), which allows users to submit information to Canmore via an inbuilt validation stage.

Until UKPSG activity began, only groups trained by RCAHMS - usually in small numbers and all within Scotland - had used this form. An issuewas encountered almost immediately; the submission 
of new data required input of the Scottish parish. It is very difficult to find an interactive parish map for Scotland, creating a problem for this group of remote users. Within RCAHMS, staff were so used to working with the parish system - a layer which is automatically loaded on all desk-top GIS applications - it did not register that this could be a barrier. It is important that when working with new audiences, this assumption that everyone has access to the technology does not become widespread.

This is a useful example of a comprehension barrier obstructing interaction. In order to overcomethis, the inclusion of a 'Parish' layer on the PastMap website (PastMap 2014) is currently being considered.

A comprehension barrier can also occur when a record contains technical jargon. Although the use of archaeological and architectural terms is inevitable and should not be avoided - for example the building description given of the Bernat Klein studio - it can be mitigated when necessary. The Canmore record for the complex multi-period site of J arlshof, Shetland Islands, is a good example of this, where a jargon-free summary sits above the more detailed excavation reports: (RCAHMS 2014d). This can stand as an example of developments driven by technology; when the database was launched online, it contained much industry-specific jargon and not every record has a summary. The wider audience to which the data is now exposed may have to still negotiate this jargon, which can act as a barrier to comprehension.

In addition to recognising that the database is a collection of records of places holding a multiplicity of values, it should also be presented as a dynamic snapshot, not a static record. This is not just a case of ensuring data currency, but is also a key part of not excluding users and of engaging new users. As an example, there are a number of mosques in Scottish cities which are housed in former churches (RCAHMS 2014e), but this significant change in use has often not been recorded, creating the risk of giving the impression that it is only the use of the structureas a Christian place of worship that is worth recording, and potentially excluding engagement in the record by the Muslim community. At the simplest level, a search for a mosque's name would not return any results.
An upcoming project, currently (May 2013) in the development phase, is aiming to engage communities with their urban environments in new ways and may provide working examples of how to reduce the risk of excluding both communities of interest and communities of place. Scotland's Urban Past will seek to engage people in their urban environments by carrying out a range of recording, knowledge exchange and training activities. These will not be limited to passing on knowledge of architectural history but will also include telling the stories of buildings by relating their social history, or by developing themed tours (in real life or virtually) which may for example focus on places of note in Glasgow's gay community or Inverness's Polish community. The central point of this project is that it will be 'community up', not 'expert down'. The role of RCAHMS will be as facilitator, rather than teacher - this mirrors the shift from author to compiler.

\section{Benefits of the 21st Century Record}

There are many benefits which could arise from the further promotion of the inclusive monuments record described above. All work undertaken by public bodies in Scotland must contribute towards the National Performance Framework (Scottish Government 2011), and the most relevant national outcome for heritage is that 'we value and enjoy our built and natural environment and enhance it for future generations'. Within this are relevant indicators, including 'improve peoples' perceptions of their neighbourhoods' and 'improve the state of Scotland's historic sites'. It is immediately obvious that a good understanding of the historic environment is essential in order to contribute to these indicators, and that an accessible monument record is a step towards this. The open approach to ingest of data also provides a good example of a Government body actively engaging with and empowering citizens.

Beyond heritage, widening use of the internet is an indicator which cuts across two other national outcomes (that Scotland be 'wealthier and fairer' and 'smarter') and projects such as Scotland's Urban Past will actively seek to engage with groups who perhaps do not currently have the knowledge to interact with heritage online. This may be a growing opportunity for the heritage sector, which has traditionally been 
quick to embrace computing applications.

Each additional community value placed upon a record will help to create a multi-layered monument record. It will also allow a form of browsing, encouraging users to spend longer online by jumping from record to record linked by tags or themes. The addition of user-generated classifications would provide an additional way into the record for new users, especially those outside Scotland and less familiar with domestic geographies.

Promoting browsing and serendipitous discovery would also serve the pragmatic requirement to keep users on record pages for longer and may also encourage image sales; both would provide a clear benefit for RCAHMS.

\section{Conclusions}

In keeping with the principles of the Nara Document, no-one should feel that their own experience of their historic environment is not worthy of inclusion in Scotland's national monument record. Although more than a century has passed since the process of inventorisation was begun, the modern Canmore database also embodies the spirit of the RCAHMS Royal Warrant of 1992, which charged RCAHMS with making a "an inventory of all ancient and historical monuments and constructions connected with, or illustrative of, the contemporary culture, civilisation and conditions of the life of the people in Scotland from the earliest times" (RCAHMS 1992). The wideranging nature of the recent Historic Environment Strategy for Scotland, and the inclusive approach suggested by the Scottish Government should ensure that the national inventory should continue to grow. It should continue to flourish and be a living, growing document, recording the nation, which any interested party can contribute to and take shared ownership of. It should also be ensure that it continues to be driven by the sector, rather than the technology.

\section{Acknowledgements}

The author is grateful to the Royal Society of Edinburgh for a generous grant to present this paper and to Kirsty Lingstadt, Mike Middleton and Robin Turner (all RCAHMS) for comments on earlier drafts of this paper. Views expressed in this paper are personal opinions of the author and do not necessarily reflect those of RCAHMS.

\section{Bibliography}

Ferguson, L. 2008. Treasured Places: A Centenary. Edinburgh: RCAHMS. Accessed June 7, 2013. http:// www.rcahms.gov.uk/ treasured-places-a-centenary.html.

Hamilton, S., R. Jones, and P. McKeague. 2014. "Old Places, New Ideas: New Routes into Canmore, the National Inventory of Scotland." In Archaeology in the Digital Era. Papers from the 40th Annual Conference of Computer Applications and Quantitative Methods in Archaeology (CAA), Southampton, 26-29 March 2012, edited by G. Earl, T. Sly, A. Chrysanthi, P. Murrieta-Flores, C. Papadopoulos, I. Romanowska, and D. Wheatley, 291298. Amsterdam: Amsterdam University Press.

Hyslop, F. 2013. "Past, Present and Future: Culture and Heritage in an Independent Scotland." Accessed $12 \mathrm{~J}$ une. http:// www.scotland.gov.uk/ News/ Speeches/CultureHeritage05062013.

ICOMOS. 1964. "International Charter for the Conservation and Restoration of Monuments and Sites. Charter of Venice." Accessed J une 11, 2013. http:// www. icomos.org/ charters/venice_e.pdf.

ICOMOS. 1994. "The Nara Document on Authenticity." Accessed J une 7, 2013. http:/ / www.icomos.org/ charters/ nara-e.pdf.

McKeague, P., and R. H. Jones, 2008 "The national database for Scotland: evolution of the digital resource." In Layers of Perception. Proceedings of the 35th International Conference on Computer Applications and Quantitative Methods in Archaeology (CAA) Berlin, April 2-6 2007, edited by A. Posluschny, K. Lambers, and I. Herzog, 186-193. Bonn: Koll. Vor- und Frühgeschichte.

Newman, M. 2007. "Not surfing but drowning: Historic environment data on the Internet, addressing intellectual barriers to access." In Contemporary and historical archaeology in theory: papers from the 2003 and 2004 CHAT Conferences, edited by L. McAackney, M. Palus, and A. Piccini, 67- 74. Oxford: Archaeopress.

Otero-Pailos, J . G., and S. West. 2010. “Heritage values.” 
Across Space and Time. Papers from the 41st Conference on

Computer Applications and Quantitative Methods in Archaeology. Perth, 25-28 March 2013

in Understanding Heritage in Practice edited by S. West, 47- 87. Manchester: Manchester University Press.

PastMap. 2014. “PastMap.” Accessed March 15. http:// pastmap.org.uk/ .

RCAHMS. 1992. "Royal Warrant." Accessed 7J une 2013. http://www.rcahms.gov.uk/ our-history.html.

RCAHMS. 2014a. "Bernat Klein studio.” Accessed March 15. http:// canmore.rcahms.gov.uk/ en/ site/217202/ .

RCAHMS. 2014b. "Raasay, Hallaig." Accessed March 15. http:/ / canmore.rcahms.gov.uk/ en/ site/ 11460/ details/ raasay+hallaig/ .

RCAHMS. 2014c. “Tinker's Heart.” Accessed March 15. http:// canmore.rcahms.gov.uk/ en/ site/ 320140/ details/ tinker+s+heart/ .

RCAHMS. 2014d. "J arlshof." Accessed March 15. http:// canmore.rcahms.gov.uk/ en/ site/513/ .

RCAHMS. 2014e. "Carfin, 2 Cleland Road, Carfin Parish Church." Accessed March 15. http://canmore.rcahms. gov.uk/en/site/313794/ .

Scotland's Rural Past. 2014. "Scotland's Rural Past." Accessed March 15. http://www.scotlandsruralpast.org. $\mathrm{uk} /$.

Scottish Government. 2013. "The Historic Environment Strategy for Scotland." Accessed 12 June. http:// www. scotland.gov.uk/Publications/ 2013/ 05/ 1373/ downloads.

Tanner, S. 2012. "Measuring the Impact of Digital Resources: The Balanced Value Impact Model." Accessed June 7, 2013. http://www.kdcs.kcl.ac.uk/innovation/ impact.html.

Waterton, E. 2005. “Whose Sense of Place? Reconciling Archaeological Perspectives with Community Values: Cultural Landscapes in England." International J ournal of Heritage Studies 11:309- 326.

UNESCO. 2014. "Living culture in Scotland." Last modified March 27. http://www.ichscotlandwiki.org. 


\title{
Preserving Lost Industrial Heritage: Newcastle Australia
}

\author{
Tessa Morrison, Helen Giggins and Nicholas Foulcher \\ University of Newcastle, Australia
}

\begin{abstract}
:
This paper considers an alternative method of preserving cultural heritage of industrial sites, which is a retrospective and holistic approach and encapsulates the evolution and development of industrial sites through history. It adopts existing virtual technologies such as augmented reality and mobile technologies making it possible to reconstruct the lost and invisible city, which is then also accessible through a mobile application. The mobile application detects the location of the user, which enables the user to view relevant digital models about the industrial past, through a mobile device such as a smartphone or tablet device. The industrial city Newcastle, Australia is the case study being used by the authors and three eras of industrial growth, the 1880s, 1930s and 1950s are being reconstructed. The paper will outline this alternative method, how it is being implemented and the future of this method's application.
\end{abstract}

\section{Keywords:}

Lost Cultural Heritage, Industrial City, Newcastle Australia, Augmented Reality, Mobile Technologies

\section{Background}

In September 1797, first lieutenant John Shortland while on his way to Port Stephens, (150 kilometres north of Sydney, Australia), entered an estuary of a river. In a letter to his father he claimed that it was a 'very fine coal river' in which vessels from 60 to 250 tons would be able to load with great ease (Shortland 1915). However, it was another four years and a change of Governor before Governor Philip King sent Lieutenant-Colonel William Paterson to report on the prospects of the coal deposits, the river and the surrounding land. Paterson arrived at the estuary of the River, which he renamed Coal River, on J une 14, 1801. He was overwhelmed by the volume of visible coal deposits, the estuary became known as Coal Harbour. After a settlement was established Newcastleproduced coal, salt, lime and cedar, from the surrounding forests, which was shipped to Sydney and was not needed for the Colony's own consumption was exported. Governor King reported to the Duke of Portland in London "This being the first natural produce of the Colony that has tended to any advantage (King $1898,477)$." The city of Newcastle was becoming the major industrial city in New South Wales.

Many of the industries are clustered on the north-west side of the Port of Newcastle including

Corresponding author:

Tessa.morrison@newcastle.edu.au the coal loaders that operate24-hours per day. There is a constant change in the industrial landscape with either modernisation of some industries and the demise of other industries. Other areas where coal pits dominated the landscape have become suburbs where industry no longer exists. Not all the important industries that have shaped Newcastle have survived. The State Dockyard opened in 1942 and closed in 1987 and the BHP steelworks opened in Newcastle in 1911 and closed in 1999. Both employed large workforces (the steelworks employed up to 13,000 workers).The industrial port of Newcastle has gone through phases of change and redevelopment and this makes any preservation of industrial sites problematic as new industries and structures replace the old, or industrial sites are transformed into recreation or housing sites.

\section{Current Preservation of the Industrial Heritage of Newcastle}

In inner Newcastle, the transformation from an industrial to post-industrial landscape has threatened the retention of many historic buildings resulting in the loss of much of the city's industrial built heritage. Within Newcastle, the impact of economic and political issues on built heritage can be seen in the current uncertainty surrounding uses for both the Carrington Hydraulic Engine Station (1875) and Nobby's Lighthouse Headland (1854), which are being run by the Port authority. At the 
Carrington Hydraulic Engine Station there has been considerable financial investment in conservation works with the ambition that the building can eventually be adaptively reused (Butson 2010, 4); however, this investment has not continued and the building is in poor condition and declining but there appears to be no political will to do anything about it.

Attempts to preserve industrial cultural heritage have been partial and not altogether successful. The Newcastle Museum has an exhibition gallery on the 'Newcastle Story' which concentrates on the natural environment, early Aboriginal life, a brief summary of Newcastle's history, and its people. However, although the exhibition mentions the industry of Newcastle its main display is separate from the 'Newcastle Story' gallery. One exhibition gallery is dedicated to BHP Steelworks, which is a small part of Newcastle's industrial history. The exhibition contains objects, interactive exhibits, images, videos, and sound clips while the exhibition is an informative and interesting part of Newcastle's industrial heritage, it is disconnected and completely out of context. Outside of the museum is a piece of industrial machinery which has been restored and is now used as a signpost for the museum. Whilst this is an interesting architectural use of this piece of machinery it does little to preserve the heritage that surrounds it. From the exhibits the visitor to the museum would have very little idea of the importance of industry to Newcastle's development and planning.

There have been some very successful international examples for preservation of industrial sites. Zollverein industrial complex in Land Nordrhein-Westfalen, Essen, Germany consists of the complete infrastructure of a historical coalmining site, it has some industrial buildings of outstanding architectural merit. The mines were closed in 1993 after 150 years of production. It is now open to the public and is a UNESCO World Heritage site. The visitor can take a tour of the old industrial buildings, there is a museum which explains the history and workings of the mine and the surrounding land has been transformed into a park where concerts are held. It is an extremely successful preservation which preserves both the building and its history, and captures the public's imagination. Some preservations have preserved

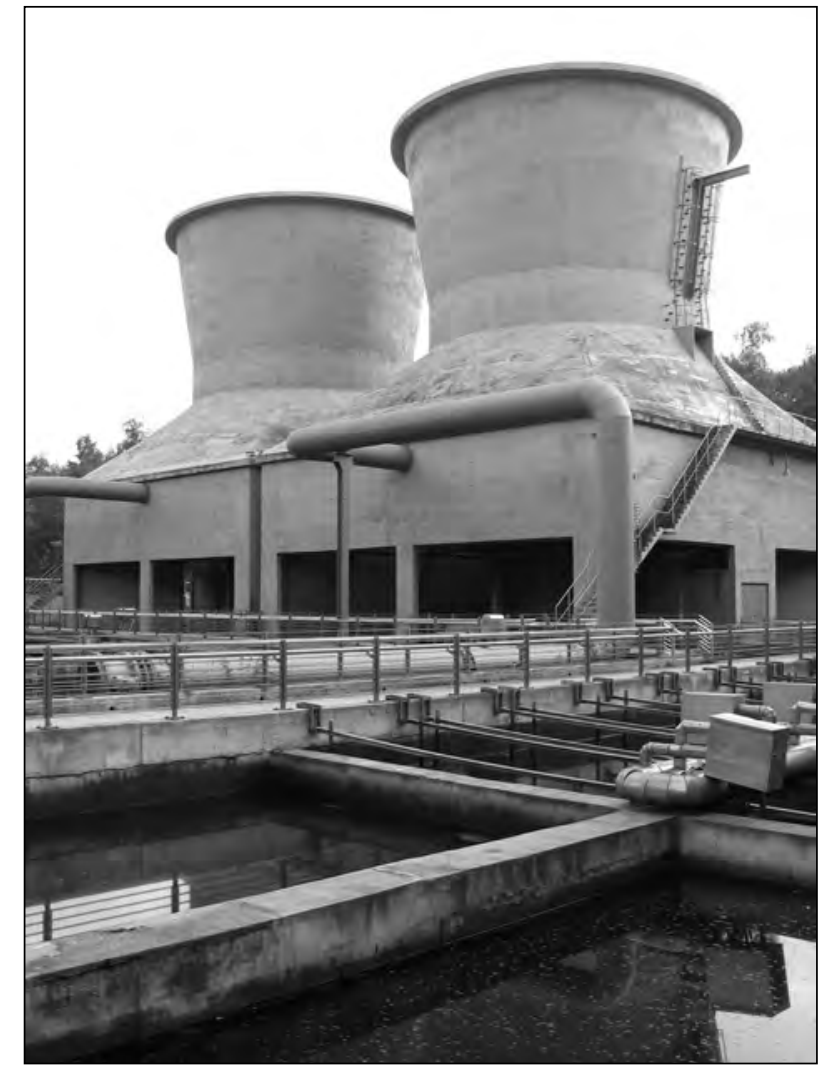

Figure 1. The Jahrhunderthalle (Century Hall) (Photograph by Tessa Morrison).

the building and surrounds but the building's function has been changed to get greater utility from these massive buildings. The J ahrhunderthalle (Century Hall) at Bochum, Germany was built in 1902, formerly the gas power station of the Bochum Company, it has now become an extraordinary festival hall. Not far from the city centre it has become a vital part of the city's cultural events. Tate Modern, formally Bankside Power Station in central London, originally designed by the architect Sir Giles Gilbert Scott and built in two stages in the midtwentieth century, is now an important landmark of London and a significant international gallery of Modern art. As impressive as these restorations are they are very rare and often require significant input from governments with the reinforcement of specific urban and economic policies.

The preservation of these sites is only possible because its mines or the industry had out lived their usefulness and were no longer commercially viable. However, many industrial sites remain viable and productive, like Newcastle and many others around 
the world, and a physical restoration in situ is impossible.

\section{The Newcastle Project}

Industrial cities are continually losing their industrial heritage due to the constant need of modernisation and increases in productivity. The question of how do we preserve the cultural heritage of industrial sites?' has become an increasingly important issue in Australia and throughout the world. The industrial landscape is either rapidly changing or disappearing and only a small fraction of it is being preserved. Whilst the industry remains viable and profitable, preservation is not always considered. It is the scale of the sites that makes it difficult to preserve them even partially. The main aim of this project is to develop a formal framework for an alternative way of conserving cultural heritage of industrial sites, through virtual technologies such as augmented reality (AR) and mobile technologies.

As developments in digital technology exponentially increase, so do the opportunities for exploring the application of the ecology of digital mediums. The current technological climate, driven by a thriving social networking movement, makes it possible for both users and researchers to be directly involved in contributing layers of meta-data to a constantly evolving virtual urban topography. Through the lens of the current entrylevel smart phone, a user is exposed to an extra dimension of information, which runs in parallel to the physical world. If this extra dimension is applied to applications of preserving the cultural heritage of a place, the historical value and identity can be virtually reborn and conserved for future generations. This is made possible by the continuing advances in augmented reality applications (Morrison and $\mathrm{Gu}$ 2011); this process of exploration in a city is linked with a ubiquitous platform of multimedia content that has the potential to spark a rebirth of an architecture of the past, for the future.

The project builds on existing AR and mobile technologies (Portales, Lerma and Navarro 2009). This research is presented in two different forms: 1. Through a typical AR interface enhanced with additional data capture and analysis applications to present the research and professional communities the detailed and analysed virtual preservation of the cultural heritage of Newcastle industrial sites; 2. Through the increasingly accessible and popular mobile devices such as an iPhone/iPad to engage the general public enabling their immediate access to key facets of this preservation.

Newcastle has had some significant periods in its development and its extensive photographic documentation goes back to the 1860s. The project is currently reconstructing three eras of industrial grouth: the 1880s, 1930s and 1950s. The viewer will be able to switch from one era to another viewing the old photographs from each era in situ.

\section{Pilot Grant and the First Stage of the Project}

To begin this project the authors applied and received a pilot grant of AU\$15,000 which was awarded by the Faculty of Engineering and Built Environment, the University of Newcastle. Because of the relatively limited size of the grant we were unable to do anything on a large scale and our options were limited as far as developing any new technology. To take advantage of this grant it was decided to centre the pilot around an exhibition at the Newcastle Regional Museum. This ensured public interaction and engagement in the project which is important to the success of the project and to the collection of extra data, such as photographs of the city when expanding the project beyond the Victorian era. The grant was to pay for equipment, a research assistant, the exhibition and the associated websites. Since we did not have enough funds to create a new mobile application our first aim of the project was to adapt existing mobile technologies.

The first stage of this project is now completed. In December 2012 an exhibition was staged at the Newcastle Regional Museum. The exhibition consisted of 30 large panels, approximately 90 $\mathrm{x} 120 \mathrm{~cm}$ each, three information panels and 27 'then and now' images of sites around Newcastle. These sites were selected on the theme of Victorian Newcastle; the selection was to take advantage of the large photographic collection from the late 19th century, the Snowball Collection, from the University's Cultural Collection, which is of outstanding quality. The importance of the Snowball collection is that it captured Newcastle at a significant time in its development, between the 


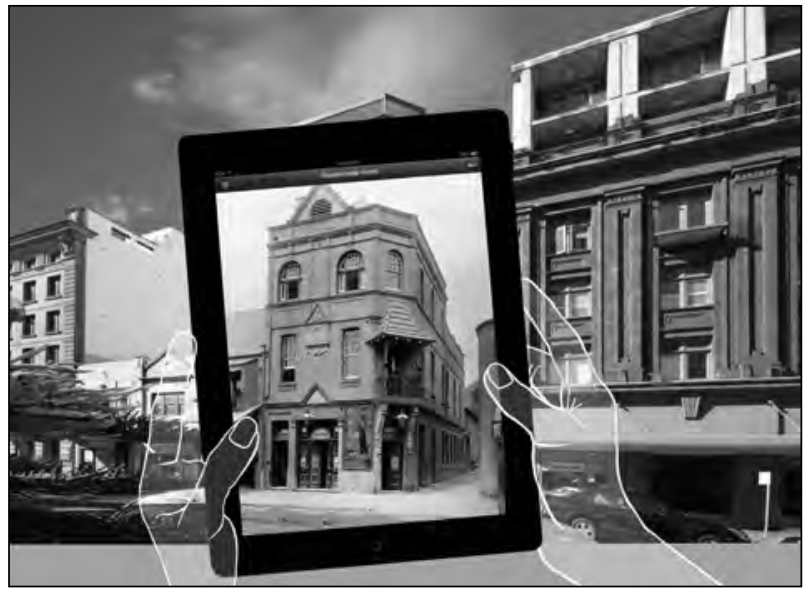

Figure 2. One of the 'then and now' images displayed at the museum (Photographs by Tessa Morrison and Ralph Snowball).

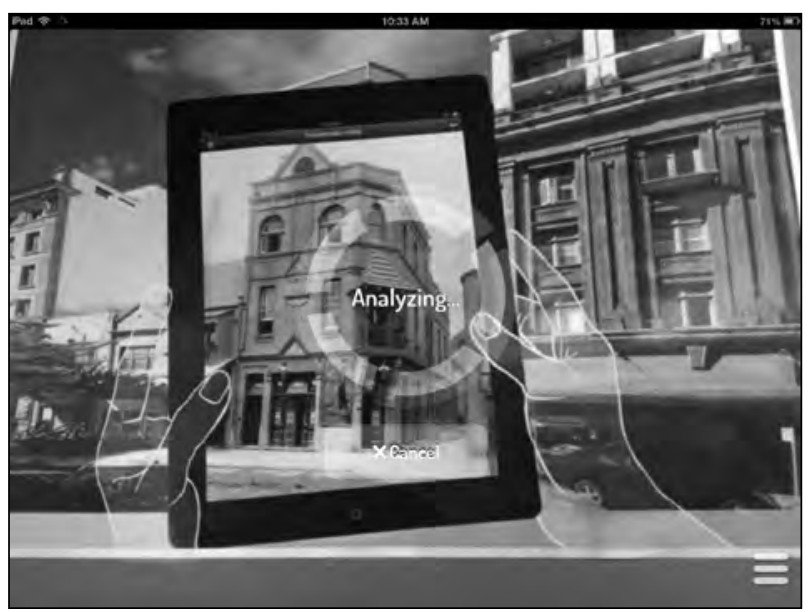

Figure 3. Scanning the Museum images on an iPad.

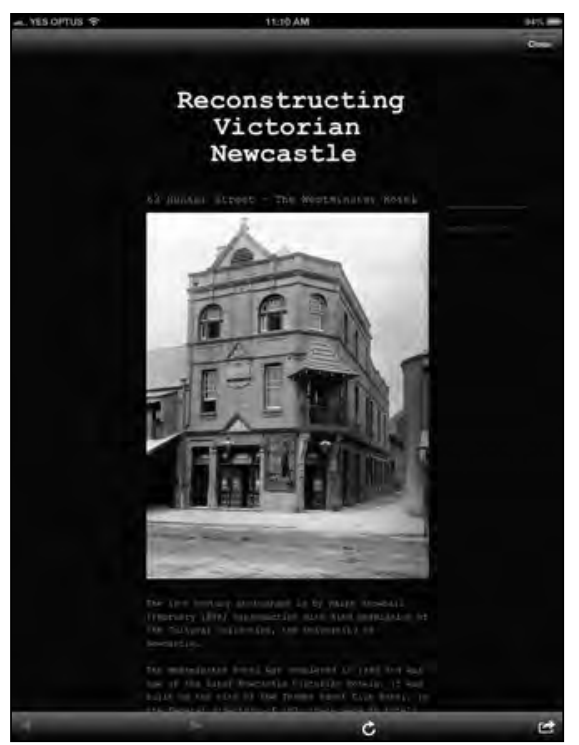

1880s and 1915, and the coal industry dominated the city.

ThevisitorstotheMuseumobtainsinformation about a route around the city which would enable the user to walk around with their smart phone or tablet and view the 19th century photographs which have been digitally overlaid onto the 25 modern sites - bringing the Victorian city to life.

Because the amount of the pilot grant did not allow for the development of a new mobile application, we first needed to investigate what existing technology was available to be adapted for our specific needs. A literature review was carried out to provide an overview of what existing applications and technology was available for implementation in the project. One notable and inspirational project found was "Streetmuseum", an application developed by the Museum of London (Museum of London 2014). Streetmuseum uses augmented reality to overlay historical images onto real life areas of interest in London via the camera of a smart phone. However, while this application presented a very interesting precedent, limitations were noted concerning the reduced budget and resources available for the project.

In initial stages of the project the authors considered using three-dimensional CAD models to present the historical documentation in more interactive way. A notable precedent reviewed was AR Player (Inglobe Technologies 2012), a standalone application which uses AR to project three-dimensional models from 'scanning' a markerbased image. Challenges were met once again in relation to the allocated budget of the project, but more so surrounding the existing external infrastructure available in Newcastle (GPS range, available WiFi networks etc.).

From this review of existing application and technology, an initial prototype was implemented usinga combination of existingopen sourcesoftware. This first prototype used Hoppala (Hoppala Agency 2014) an open-source platform for building mobile augmented reality (AR) content in conjunction with Layar (Layar 2014), one of the industry pioneers in mobile AR development and browsing tools. Using the Hoppala platform provided an excellent starting point for understanding what information 


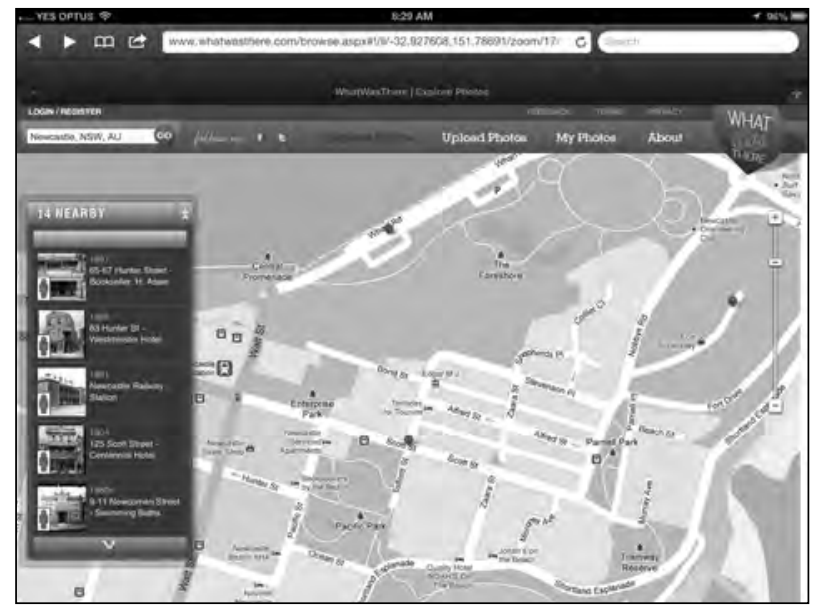

Figure 5. Google Maps indicating the position of the sites.

we needed to display via geo-coding and GPS tracking. However, this proved to be difficult in later stages of our development due to the high resolution, or quality, historical imagery we wanted to display for the user. There was also a downfall in the GPS location technology that was required for the prototype. As most consumer-end smart devices possess similar capabilities, it became evident that the lack of adequate cellular, 3G and 4G coverage was the main contributing factor. The application makes use of Points of Interest (POIs), which as a minimum specify an exact location, via a longitude and latitude, and name and descriptive data. As the host application, Layar, requires a steady stream of GPS location data with relevant POI's, this open source platform was insufficient and at times unreliable due to patchy cellular coverage. Ultimately, this resulted in a poor user experience and it was decided that another approach was required.

The prototype that was eventually decided upon and featured at the Newcastle Regional Museum exhibition employed two separate 'experiences' for the user to interact with the POI's. These could be defined as an 'exhibition experience' and a 'walking-tour experience'. The 'exhibition experience' used a series of large high resolution, physical photographic panels that were individual stored as 'reference' images within the 'Layar Creator' platform. When scanned with Layar by the user within the exhibition space, using augmented reality technology, a unique set of meta-data would be displayed to the user. In the exhibition, this

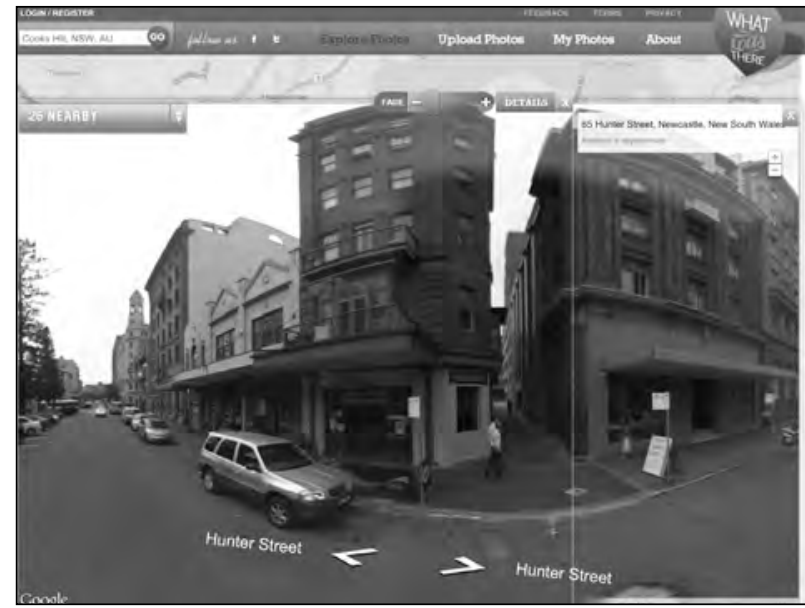

Figure 6. Streetscape, through Google Maps of Westminster Hotel. The body of the building still exists. Some of the Victorian detail has been stripped away with the modernisation of the building over the years and a further three floors added.

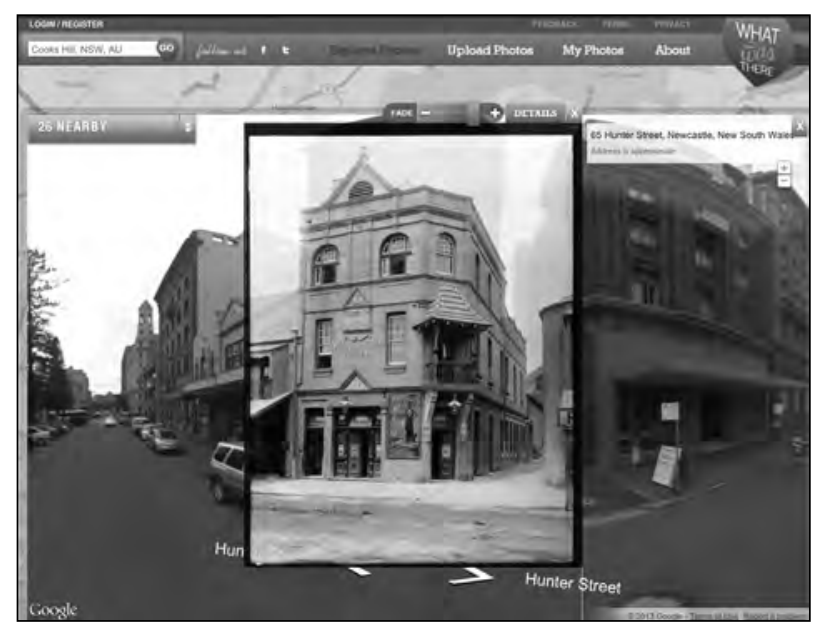

Figure 7. The fade function in WhatWasThere mades possible to see the 'then and now'images together.

consisted of two images, one the historic photo or the location, and secondly an icon linking to further information online. This resulted in the user being presented with two ways of interacting via AR. First by tapping the high resolution image of a pop-up historical photo (Fig. 3) - this allowed the user to be linked with further information and alternate photos of the site via a free blogging platform (setup using Tumblr). This additional information might for instance include facts about the location at the time the historical photo was taken. Second, by tapping the "WhatWasThere" (Enlighten Ventures 


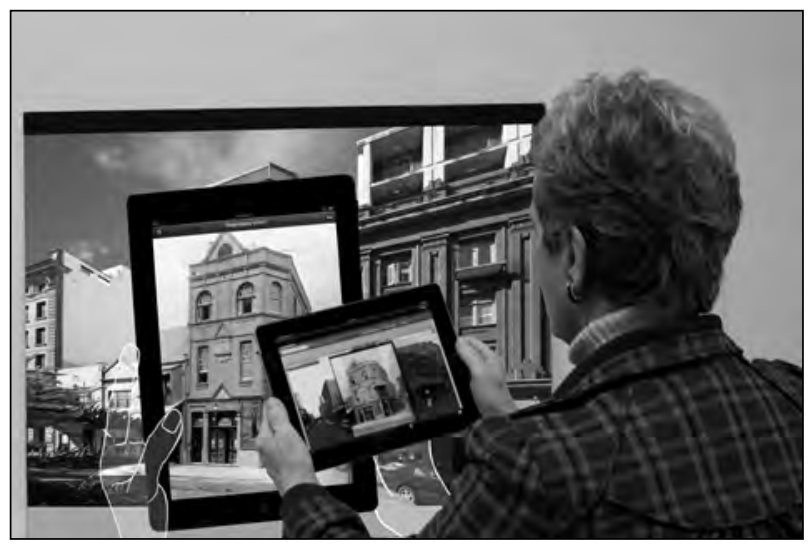

Figure 8. The image of the Westminster Hotel superimposed over the modern building which is currently being converted into residential apartments.

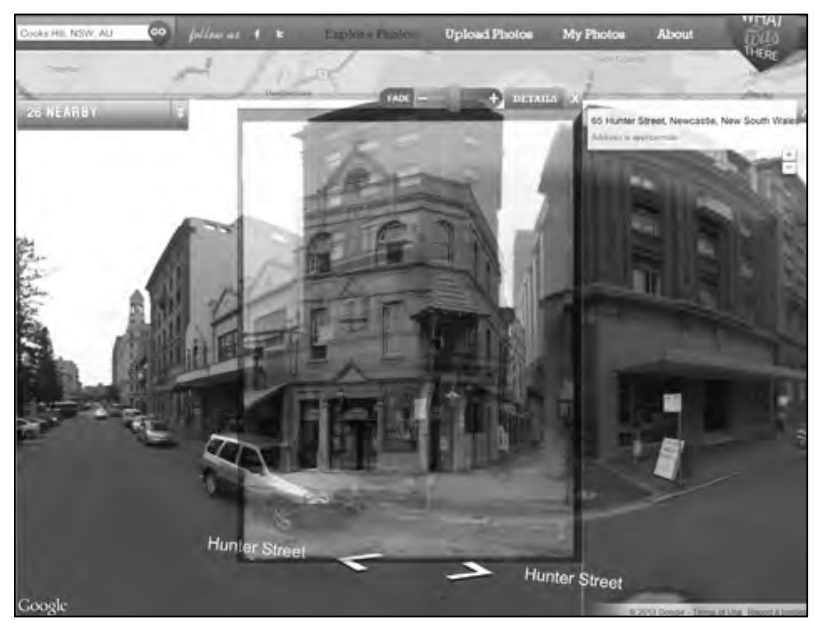

Figure 9. A visitor at the Museum interacting with the exhibition panels (Photograph by Tessa Morrison).

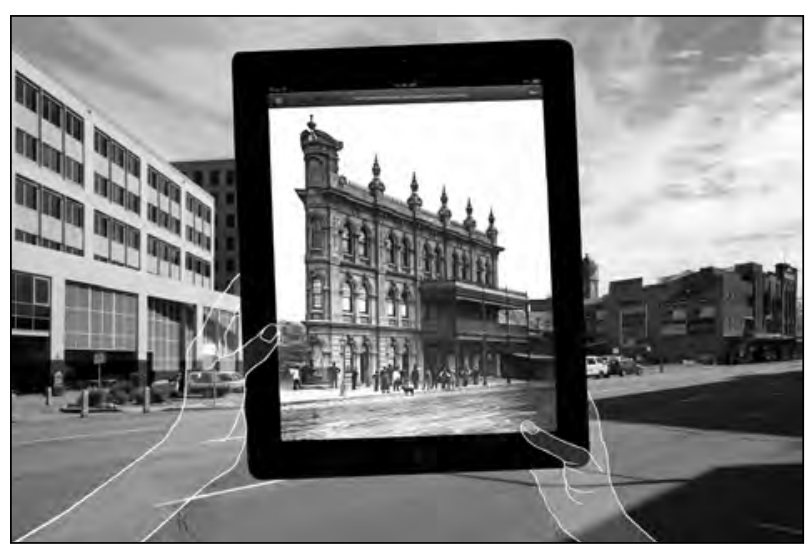

Figure 10. Hunter Street, the main street in Newcastle, 1896 and 2012 (Photographs by Tessa Morrison and Ralph Snowball).
2014) icon - this allowed the user to be linked with a web and mobile based application/ website called WhatWasThere revealing the historical images overlayed in-situ. The site allows the user to place the location in the context of a local map.

The second part of the exhibition experience is the so-called 'walking-tour experience', which makes use of a printed handout to encourage exhibition attendees to visit 25 in-situ locations around the CBD of Newcastle. When the user arrives at the location, they can use information on the handout to be able to access the "WhatWasThere" information about each location. The user can load the historic image onto their mobile device, and then fade this image in and out to experience how it would overlay on the current location. The site also shows users other historical sites nearby the current location. This allows the user to experience the cultural heritage of the locations in-situ.

Next stage of the project will begin later this year; another exhibition is in planning, i.e. getting funding, on looking at industrial Newcastle, using similar technology to what we used in last year's exhibition. This exhibition will also be extended to include oral histories and instead of concentrating on the one era it will be extended to three eras of industrial growth: the 1880s, 1930s and 1950s, and will include the steel industry's demise in the 1990s.

\section{Conclusions}

The project has provided both public and academic outcomes. Newcastle has a significant tourist industry. Its magnificent beaches and the vineyards of the Hunter Valley are out of sight of the industrial sites yet they were originally industrial sites themselves. For an interested tourist visiting the Newcastlearea this interactive AR application would give an insight into the history and development of Newcastle that they would not be able to get with any other media. Even if the same images were in the Museum they would not give the visitor the same depth of understanding as experiencing theimage in situ and see the changes through the different eras.

However, the main propose and benefit is for the academic community. This proposal presents an important application of an existing technology through an AR interface enhanced with 
Preserving Lost Industrial Heritage: Newcastle Australia

Tessa Morrison, Helen Giggins and Nicholas Foulcher

additional data capture and analysis applications it can be utilised to preserve, analyse and present cultural heritage which would otherwise be lost. The project will be mapping large sections of the city, where the industry no longer exists, and the current industrial area, where industry has existed very early in Newcastle's history. Many areas can be mapped sequentially; which will build a truer perception of the industrial landscape of the era. The embedded data such as data analysis that affect an industrial city, such as the distribution and changes of population, ethnicity, professions, family incomes, political party preferences, urban and transportation patterns, infrastructure building etc., will further understanding of the cultural and societal aspect of the industrial past of the city. These detailed analyses are particular useful for user groups such as heritage conservationists, architects and urban designers, policy makers, economy and sociology researchers. It will present a holistic and new view of the cultural and societal heritage for industrial sites.

Both this project and AR technologies are in their infancy. This technology has great potential to assist as a tool for architectural historians. It brings in a further aspect to the virtual model that promotes understanding in the relationship of the building and the natural or built topologies. Newcastle is an idea city for a case study to test the effectiveness of these technologies to preserve the cultural heritage of industrial sites and of the industrial city. It has a long history of industrialisation which had been documented since European settlement: 1) the origins of the city are in industry; 2) it is an evolving industrial city; 3) thereare copious historic materials available. Newcastle has a rich industrial past worth persevering and the study in this research would make an excellent prototype for the preservation of other industrial sites.

The Newcastle project explores and demonstrates an alternative method for conserving and enhancing industrial heritage through applying $\mathrm{AR}$ and mobile technologies. Furthermore, it enhances the traditional preservation method to enable the superimposition of heritage across different eras, as well as preserving the lost heritage through virtual technologies and contextualising them by embedding them in the current physical environment. The significance of the alternative method being proposed, of preserving cultural heritage of these industrial sites, is a retrospective and holistic approach, which will encapsulate the evolution and development of these industrial sites through history.

\section{Bibliography}

Butson, T. 2010. "Historic building's return to elegance." The Newcastle Herald, 17J une.

Enlighten Ventures. 2014. "WhatWasThere." Accessed March 15. http:// www.whatwasthere.com/.

InglobeTechnologies.2012. "AR-media ${ }^{\mathrm{TM}}$ Player."Accessed March 15, 2014. http://www.inglobetechnologies.com/ en/new_products/arplayer/info.php.

Hoppala Agency. 2014. "Hoppala Augmentation." Accessed March 15. http:// augmentation.hoppala.eu/ .

King, P. 1898. "Letter the Duke of Portland dated 21 August 1801." In Historical Records of New South Wales: Volume IV Hunter and King, 477. Sydney: William Applegate Gullick, Government Printer.

Layar 2014. "Layar." Accessed March 15. http://www. layar.com/.

Morrison, T, and N. Gu. 2011. "What Architectural Historians Can Learn from Augmented Reality Technologies?" In Proceedings of Electronic Visualisation and the Arts (EVA London 2011), edited by S. Dunn, J. Bowen, and K. Ng, 191- 196. London: British Computer Society

Musuem of London. 2014. "Streetmusuem." Accessed March 15. http://www.museumoflondon.org.uk/ Resources/app/you-are-here-app/home.html.

Portales, C., J. L. Lerma, and S. Navarro. 2009. "Augmented Reality and Photogrammetry: A Synergy to Visualize Physical and Virtual City Environments." ISPRS Journal of Photogrammetry and Remote Sensing 65 (1):34- 42 .

Shortland, J. 1915. "Letter to his Father." In Historical Records of Australia: Volume V, July, 1804 - August, 1806, 481. Sydney: The Library Committee of the Commonwealth Parliament, Government Printers. 


\title{
Uncovering the Missing Routes: an Algorithmic Study on the Illicit Antiquities Trade Network
}

\author{
Christos Tsirogiannis \\ Cambridge University, UK \\ Constantinos Tsirogiannis \\ Aarhus University, Denmark
}

\begin{abstract}
:
In the present work we provide a quantitative study on the trade network of Italian and Greek illicit antiquities. In the first part of this study, we analyse thoroughly the structure of this network using standard tools from the field of social network analysis. In the second part, we examine different algorithms that use the known instance of the network to infer information that is missing from the police records. The specific problem that we consider is that for certain artefacts it is not known exactly what was the sequence of people that traded these items through the network. For this reason, we examine three different algorithms that estimate potential sequences of transactions within the network. We have conducted experiments using these algorithms, and we have evaluated their performance in practice.
\end{abstract}

\section{Keywords:}

Illicit Antiquities, Network Analysis, Algorithms on Imprecise Data

\section{Introduction}

The trade of illicit antiquities holds a prominent position in present day art crime. Two of the countries that have been affected by this trade are Italy and Greece (Godart, De Caro and Gavrili 2008; Watson and Todeshini 2007). During the last decades, thousands of antiquities were illegally excavated within these countries and exchanged worldwide via a global trade network. This network consisted of looters, art dealers, private collectors, but also respectable museums and auction houses. Until recently, a closed group of art dealers had the main role in this network; these include art-gallery owner Giacomo Medici, the American dealer Robert Hecht, and the associates Robin Symes and Christos Michaelides.

The combined efforts of forensic archaeologists and police investigators have uncovered a considerable part of the trade network that handled Italian and Greek illicit antiquities. Due to these efforts, the authorities were able to put an end to the illegal activities of the main dealers (Gill and Chippindale 2006; Gill and Tsirogiannis 2011). Thus, during the late 90's and the 00's, hundreds of illegally traded artefacts were seized and returned to the countries from which they have been originally

Corresponding author: ct363@cam.ac.uk excavated (Gill and Chippindale 2006). Among the repatriated antiquities there are some of the finest artefacts that have been excavated during the last century. Such is the case of the Euphronius Krater that was returned to the Italian authorities (Watson and Todeshini 2007), but also the golden Macedonian wreath that was repatriated to Greece in 2007 (Godart, De Caro and Gavrili 2008).

However, a large part of the activities that took place within this illegal trade network remains unknown. There are some transactions that the police investigations could not trace. Therefore, there are several artefacts for which the authorities know that they were illegally traded, yet it is unknown who were the specific people involved in these transactions. For most of those cases the authorities know that, at some point in time, an artefact was in the possession of a person $\mathrm{A}$, and that afterwards the same artefact somehow came into the possession of a person $B$. Yet, it remains unclear what was the exact sequence of people through which this item was traded between individuals A and $\mathrm{B}$. We call this sequence the 'transaction path' between A and B for this artefact.

The goal of the present work is twofold. First, we analyse the structure of this trade network 


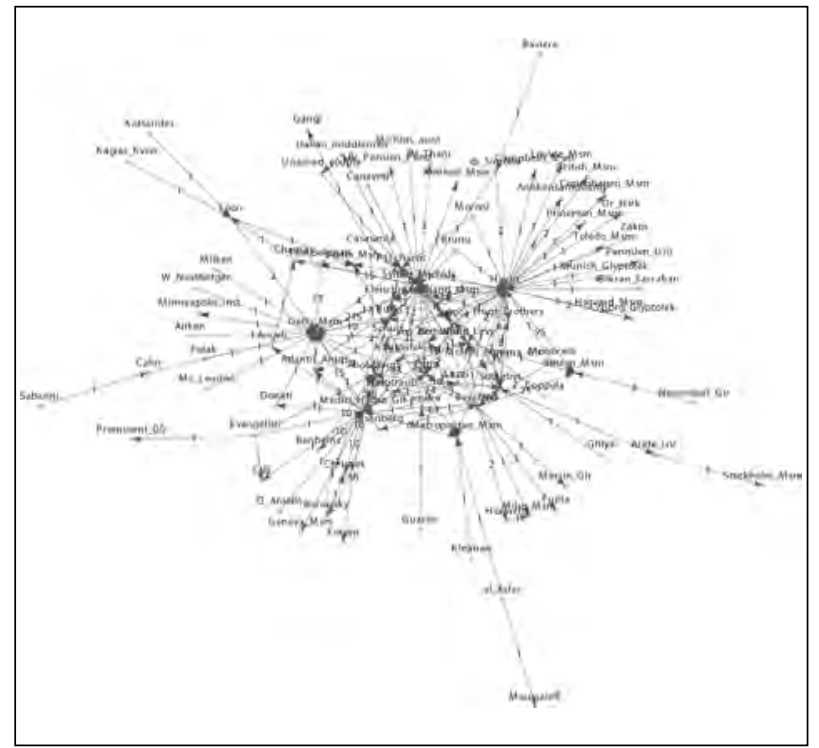

Figure 1. The directed version of the modelled network.

using standard tools from the field of social network analysis. To do this, we constructed an instance of the recent trade network of Italian and Greek illicit antiquities. We created this instance of the network based on the book of Watson and Todeschini 'The Medici Conspiracy' (2007) which provides a good description of the modern trade network that handled Italian (mostly) and Greek illicit antiquities. In our analysis, we measure the connectivity between the members of this network, showing how it compares to well-defined families of networks, and we also compute which are the most central members of the network.

The second goal of the present work is to try to tackle the problem of finding transaction paths in the network by using an algorithmic approach. More specifically, we study three different algorithms that estimate possible transaction paths on a model of the examined network. To assess the performance of the studied methods we used the concise instance of the network that we extracted from the book of Watson and Todeschini. One of the methods that we used for estimating transaction paths produced promising results. Yet, the performance of the examined methods seems to be affected by the amount of data that we have from past transactions in the network.

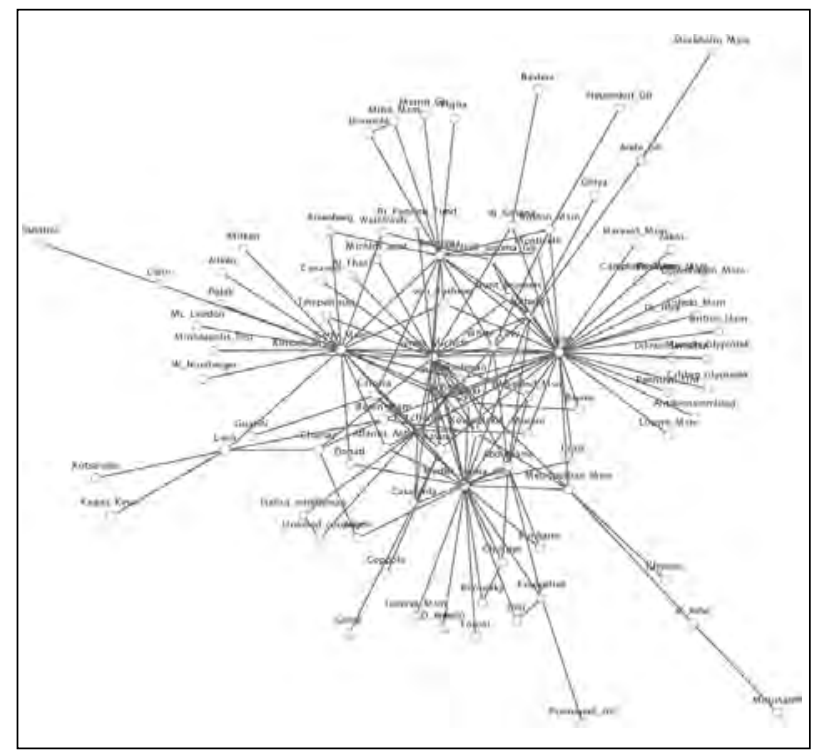

Figure 2. The undirected version of the modelled network.

\section{Modelling the Network}

\subsection{Preliminaries and mathematical definitions}

To model the network of the illicit trade of antiquities we consider two different representations. For both of the representations, the nodes of the network correspond to people or foundations that have participated in at least one exchange of an illicit antiquity. For each of these representations, the links in the network connect pairs of nodes who exchanged at least one artefact directly, that is without the intervention of other people. In the first representation, links are directed to indicate the direction of transactions: who sold artefacts to whom. In this version of the network, each directed link from a node $x$ to a node $y$ is assigned a positive weight; this weight is equal to the number of artefacts that are known to have been sold from node $x$ to node $y$. Note that it is possible that the same pair of nodes $x$ and $y$ can be connected with two links of opposite directions; this is the case if $x$ has sold items to $y$, and also $y$ has sold items to $x$. This representation allows us to track the transaction paths of artefacts in the network and also to highlight which links were used to carry out many transactions. We call this version of the network the directed network.

In the second representation of the network, links between pairs of nodes are undirected; that is, 
if there was any direct transaction between a pair of nodes then we connect these nodes with a unique undirected link. Therefore, in this representation of the network there can exist at most one link that connects the same pair of nodes. Also, we consider that each link in this representation is not assigned with any weight. This representation is more appropriate for examining the structure of acquaintances in the network. We call this version of the network the undirected network.

In the present work, we use $\mathrm{V}$ to denote the set of nodes in the network. For a pair of nodes $x$ and $y$ such that there exists a link from $x$ to $y$ in the directed version of the network, we use $w(x, y)$ to denote the weight of this link. We define a path between two nodes $x$ and $y$ of an undirected network as a chain of links that connects these two nodes. Of course, there can be many paths that connect the same pair of nodes. Among those paths, the shortest path is the one that consists of the minimum number of links. We call the number of links in the shortest path from $x$ to $y$ the distance between $x$ and $y$. Note that the shortest path may not always be unique, there can be more than one shortest paths between the same pair of nodes $x, y$.

\subsection{Building the network}

In order to analyse the trade network of illicit antiquities, we want to build an instance of this network based on the knowledge that we have from the criminological literature. Wealso want to use the sameinstance of thenetwork to test the performance of algorithms that indicate paths in this network. For this reason, we have to build a 'restricted' instance; that means we have to construct an instance of the network that does not reflect the entire knowledge that we have today on the studied trade network of illicit antiquities. Hence, we can split the set of all known transactions of illicit antiquities into two subsets: a 'base' subset, and a 'test' subset. We use the transactions of only the 'base' subset to create the nodes and the links of the restricted network; in this way, we construct both the directed and the undirected version of this network. Then, we apply our algorithms on the created network to evaluate how well they can estimate the transaction paths that appear on the 'test' subset of transactions.
In our study, we constructed an instance of the network using a small but representative subset of the related literature; that is the network that is described in the book of Watson and Todeschini The Medici Conspiracy'. This book is a highly acclaimed resource that presents a major part of the trade network of Italian and Greek illicit antiquities during the period from 1972 to 2001. Of course, this book does not cover the entire set of recorded transactions of illicit antiquities during this period. Hence, we consider that this resource provides a nice general picture of the network, while on the same time it is far from being complete. For the remaining part of this paper we refer to the instance of the network that we extracted from the book of Watson and Todeschini as the modelled or base network. In this way, we want to distinguish this instance from the actual network that existed in the real world.

\subsection{Analysis of the network}

The network that is described in the book of Watson and Todeschini has ninety-seven nodes; the directed version of the network has 181 directed links, while the undirected version has 171 links. The maximum number of links that an undirected network of $n$ nodes can have is $n(n-1) / 2$, that is 4656 links when $n=97$. Therefore, our modelled network is relatively sparse. The network consists of two connected components, one large component that consists of ninety-two nodes and 177 directed links (167 undirected), and a very small component that consists of only five nodes and four links (both in the directed and the undirected version). The small component represents the transaction of a single artefact among actors that seem unrelated to the main core of the network. For this reason, we have decided to focus on the main component of the ninety-two nodes; for the rest of this paper we will refer to this component as if it was the entire network described in Watson's book.

The ninety-two nodes of the network correspond to individuals, but also to organisations that were involved in the trade of illicit antiquities. Most of the individuals that appear in the network can be distinguished into the following groups; looters, art dealers, middlemen employed by dealers, private collectors, and employees of museums. As for the nodes that represent organisations, almost all of them correspond either to museums and 
galleries, or to auction houses such as Christie's and Sotheby's.

A simple way to understand the structure of the network is to measure the degrees of thenetwork nodes. The degree of a node is the number of links in the network that are incident to this node. In our modelled network, seventy-nine out of the ninetytwo nodes have a degree from one to five links. For the rest of the nodes, we have only five nodes that have a degree which is larger than or equal to fifteen; these are the nodes that correspond to art dealer Robert Hecht (degree 38), art-gallery owner Giacomo Medici (degree 29), associate art dealers Robin Symes and Christos Michaelides (degree 26), the prominent Getty Museum at Los Angeles (degree 22), and dealer Gianfranco Becchina (degree 15). Hence, we can see that these five nodes play a major role in the network: 121 out of 167 links of the undirected network are adjacent to these nodes. This corresponds to approximately $72 \%$ of the total number of links in the network.

This interesting distribution of degrees in the network (many nodes of small degree and very few nodes of large degree) is not uncommon for real world networks. This is one of the main features of a special category of networks which are called scale-free networks (Barabási and Réka 1999). Although our modelled network seems to fulfil known properties of scale-free networks we should hold back from calling it a scale-free network itself. This is mainly because the size of our network is very small: it is generally considered that scale-free networks should consist of at least a few thousands of nodes.

In the field of social network analysis there has been ample attention for another category of networks, which are known as small-world networks
(Watts and Strogatz 1998). This category includes a large number of social networks, but also networks that have been observed in natural sciences (Del Sol and O'Meara 2005; Del Sol, Fujihashi and O'Meara 2005; Fell and Wagner 2000). Informally, we could describe a small-world network as a network whose structure satisfies two conditions; the first condition is that the average distance among all pairs of nodes in the network is quite small. The second condition that defines a small-world network is that the nodes of the network should be tightly clustered in a local scale. This means that if two nodes have a common neighbour then usually there is also a link that connects these two nodes directly. To avoid getting into technical details, we choose not to provide the formal mathematical definitions of these properties in the present work. However, we state here that we verified that the undirected version of our modelled network fulfils these properties, proving that it is a small-world network as well.

\subsection{Identifying the most central nodes}

Next we examine different ways of determining which are the most important nodes in our modelled network. So, how do we decide if a node in the network is 'important'? One way to do this is to calculate its centrality, that is how central is this node with respect to the rest of the network. There are many different concepts of centrality that are used in social network analysis. One of them is the so-called degree centrality; the higher the degree of a node, the more central this node is. Earlier in this section, we indicated the five nodes that have the highest degree centrality in our modelled network (Table 1). We have also considered two more measures of centrality: the closeness centrality and the betwenness centrality. These two measures reflect the structure of shortest paths within the network.

\begin{tabular}{|c|c|c|c|}
\hline Name & Degree Centr. & Closeness Centr. & Betweeness Centr. \\
\hline Robert Hecht & 38 & 0.59 & 1789.5 \\
\hline Giacomo Medici & 29 & 0.52 & 997.2 \\
\hline Symes and Michaelides & 26 & 0.54 & 875.9 \\
\hline Getty Museum & 22 & 0.52 & 1083.5 \\
\hline Gianfranco Becchina & 15 & 0.57 & 492.41 \\
\hline
\end{tabular}

Table 1. The five most central nodes in the network together with the respective values for three different centrality measures. 


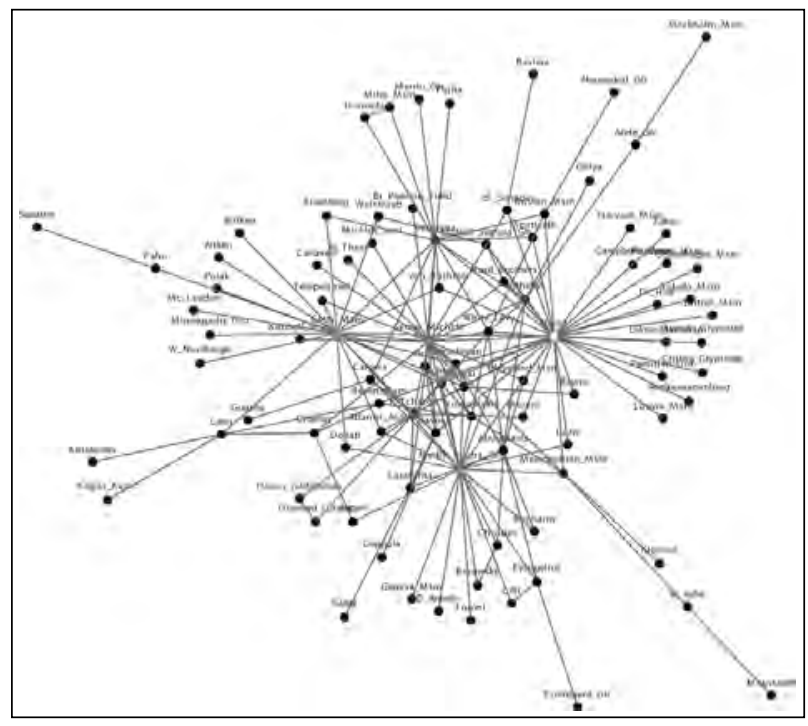

Figure 3. The undirected version of the studied network with nodes shaded according to their betweeness centrality values; nodes with low centrality values are indicated with a darker shade, while the nodes of lighter shades have high centrality values.

Intuitively speaking, ifanode $x$ hasarelatively large value of closeness centrality then we can reach $x$ more easily from most of the other nodes in the network. On the other hand, betwenness centrality measures how probable it is to cross a certain node $x$ if we want to choose a shortest route between any other two nodes. For a formal definition of these centrality measures the reader may refer to the work of Freeman (1979). For the undirected version of our modelled network, the five nodes with the largest degree centrality values are exactly the ones that have highest values for closeness centrality and betwenness centrality, yet in slightly different order for each of these measures (Table 1).

\section{Estimating Transaction Paths in the Network}

One of our main goals in this paper is to design algorithms that can estimate the path that an artefact traversed in the network. Due to incomplete data that come from police investigations, there are many cases where we know that an artefact was in the possession of one person and eventually ended up in the hands of another person, but we don't know who took hold of this item in between. Going back to the directed representation of the network, this translates to the following problem: given a start node $x$ and an end node $y$ in the network, we want to find the most 'reasonable' path through which an item could have been dispatched from $x$ to $y$. Here we consider a path from $x$ to $y$ to be a sequence of directed links, that starts at $x$ and ends at $y$. Of course, there can be many ways to define what is a 'reasonable' path between two nodes in the network, if such a path exists. In our approach, we try to extract a path based on the structure of the directed network and the weights of its links. In this way we consider that the extracted path was produced according to the knowledge that we have on past transactions that took place in the network.

Next we describe in detail three different algorithms that we used for estimating transaction paths between given pairs of nodes. We also present experiments that we conducted using these algorithms and we evaluate their performance.

\subsection{Description of the algorithms}

For all three algorithms that we consider in this section, theinput of thealgorithm is the directed representation of the network, and two network nodes: a start node $x$ and an end node $y$. The output is a directed transaction path that connects $x$ to $y$. Two of the algorithms that we examine are novel methods that we designed for the purpose of this work, and the third algorithm is the standard method of computing the shortest path between two network nodes.

\section{The Local Expansion Method}

\section{- Technical description}

In this method we expand a transaction path by adding each time a link of the largest possible weight, while maintaining that the path does not contain a cycle. More specifically, we begin from the start node $X$, and we look for all neighbour nodes of $x$. In this context, a neighbour of $x$ is a node which is connected to $X$ with a directed link whose source is $x$. From all the neighbours of $x$, we pick the node $v_{1}$ that satisfies the following properties: a) there exists a simple path from $x$ to $y$ that contains the directed link $\left(x, v_{1}\right)$, and b) this link from $x$ to $v_{1}$ has the maximum possible weight. After we select $v_{1}$ in this manner, we add this node and the link $(x$, $v_{1}$ ) to the transaction path that we expand. If $v_{1}$ is 
the same node as $y$, the end node of the queried path, then we stop and we return the computed transaction path. Otherwise, we continue expanding the path from $v_{1}$ in a similar manner; looking at the neighbours of $v_{1}$, we pick the node $v_{2}$ such that there exists a simple path from $x$ to $y$ that includes links $\left(x, v_{1}\right)$ and $\left(v_{1}, v_{2}\right)$, and the value $w\left(v_{1}, v_{2}\right)$ is the largest possible. We continue this process until the last node that was added to the path is $y$.

- Intuition

The intuition behind this method is that the transaction path of an artefact is expanded by adding each time the most 'probable' connection; when a member $x$ of the network acquires the artefact, this artefact is then forwarded to the member $y$ with whom $x$ has had the most transactions so far. Since we know that eventually the artefact came to the possession of member $y$, we also make sure that $x$ always hands in the artefact to a member $y$ such that it is still possible for this item to end up from $y$ to $y$.

The Maximum-Weight Arborescence Method

\section{- Technical description}

This method constructs a transaction path between $x$ and $y$ that maximises the minimum weight that any link of the path may have. In more detail, starting from $x$ this method constructs a maximum weight arborescence in the network rooted at $x$. In graph theory terminology, an arborescence is a directed network that has a tree structure and which fulfils the following property; amongits nodes there exists a special root node such that there exists a unique directed path between the root and any other node in the network (Georgiadis 2003). This implies that an arborescence does not contain cycles: all directed paths from the root to the rest of the nodes are simple paths.

The presented method computes first the maximum weight arborescence that has $x$ as root, and then extracts the unique path that connects $x$ with $y$ in this arborescence. This path is known to have a special property; from all paths that lead from $x$ to $y$ in the network, this path maximises the weight of the minimum-weight link in the path.

\section{- Intuition}

The maximum-weight arborescence method constructs a transaction path whose connections are all 'fat'; that means each connection in this path has carried out at least a relatively good number of transactions.

\section{The Shortest Path Method}

\section{- Technical Description}

This method simply computes a shortest path between the given nodes $x$ and $y$. Recall that this is a path from $x$ to $y$ that consists of the minimum number of links. This is a standard method that is used for a wide range of network applications such as transportation and social network analysis (Fu, Sun and Rilett 2006).

\section{- Intuition}

We use this method as a point of reference for the other two algorithms. In particular, we want to test a simple method that does not primarily depend on the number of past transactions that took place through the connections of the network.

\subsection{Experimental Evaluation}

We implemented all three algorithms that we describe in this section, and we conducted experiments in order to evaluate their performance. The implementation of the algorithms was done in the $\mathrm{C}++$ programming language. The experiments were carried out using the directed version of our modelled network and two different sets of queries. Each query is a pair of nodes; a start node and an end node of a transaction path of a real artefact that was illegally traded in the past. For each query pair we know in advance what is the exact transaction path that corresponds to this pair.

The set of queries that we used contains thirteen pairs. These pairs correspond to transaction paths of actual artefacts: we retrieved these paths from several criminological sources that refer to the illicit trade network that we study. We intentionally chose paths that contain exclusively nodes that appear in our modelled network. However, most of these query paths contain at least one link that does 


\begin{tabular}{|c|c|c|}
\hline Method & Set A & Set B \\
\hline Local Expansion & $3 / 5(60 \%)$ & $3 / 8(37.5 \%)$ \\
\hline $\begin{array}{c}\text { Maximum-Weight } \\
\text { Arborescence }\end{array}$ & $2 / 5(40 \%)$ & $3 / 8(37.5 \%)$ \\
\hline Shortest Path & $1 / 5(20 \%)$ & $3 / 8(37.5 \%)$ \\
\hline
\end{tabular}

Table 2. The performance of the three algorithms that estimate transaction paths, given the set of thirteen queried paths. The column indicated as 'Set A' refers to the set of the five transaction paths that exist in our modelled network. In this column, the performance of each algorithm appears as the percentage of the paths that the algorithm computed and which are identical to the original query paths. The last column corresponds to the set of the eight query paths that contain at least one link that is missing from the modelled network. In that column, the performance of each algorithm appears as the percentage of the paths that were computed by the algorithm and have an edit distance one from the original query path.

not appear in the modelled network: this is the case for eight out of thirteen of the paths. If a node or a link of a path is not present in the modelled network then this path cannot be retrieved from any of the algorithms that we examine.

To measure how much a computed path deviates from the original path, we calculated a version of the Levenshtein distance between the two paths (Wagner and Fischer 1974). In the most usual setting, the Levenshtein distance is a measure that describes how different two words are. In short, this distance is defined as the minimum number of letters that we have to add, subtract, or substitute in the first word so that it becomes identical to the other word. For example, the words 'stalker' and 'snake' have a Levenshtein distance equal to three because we have to subtract two letters from the first word ( $\mathrm{I}$ ' and ' $r$ '), and substitute one more (use ' $n$ ' in the place of ' $t$ ') in order to change it into the second word.

In our application, we use a slightly different definition of this distance. Given the two paths, we define the Levenshtein distance between them to be the minimum number of nodes that we have to add, subtract, or substitute in order to turn one path identical to the other. Hence, the transaction paths ' Becchina $\rightarrow$ Sotheby's $\rightarrow$ Shelby White' and Medici $\rightarrow$ Hecht $\rightarrow$ Sotheby's $\rightarrow$ Shelby White' have a Levenshtein distance equal to two, because we have to add one node in the first path ('Medici'), and substitute one more (put 'Hecht' instead of 'Becchina') in order to make it identical with the second path.

To evaluate the performance of each of the examined algorithms, we distinguished the thirteen query paths into two sets: in Set A we have the five paths that do appear in our modelled network; on the other hand, Set B contains the eight query paths for which there exists at least one link in each path that does not appear in our modelled network. For every algorithm that we examine, we feed each query pair as input to the algorithm, together with the directed version of our modelled network; then we compare the path returned by the algorithm with the actual transaction path for this pair. For the first set of queried paths, we measured how many of the paths were computed exactly by each algorithm. For the second set of query paths, we measured the Levenshtein distance between the computed path and the actual path, and we calculated for how many cases the computed path has only distance one from the actual path; that means that the returned path is almost identical to the actual one. For the results of the experiments, see Table 2.

\subsection{Discussion}

From the results of our experiments, we see that for the first set of queries the local expansion method yielded better results than the two other methods; this method guessed correctly most of the paths, achieving a performance of $60 \%$. For the second set of queries, all of the algorithms had the same performance: all three algorithms returned paths that are almost identical to the correct ones in three out of eight cases. Recall that for this set of queries it is impossible for the given algorithms to compute the correct path exactly. From these results we can see that the local expansion method has a quite good performance, when the queried path exists in the modelled network. Note that the local expansion method expands a path by taking decisions on a local scale; the path is expanded by one node at a time, and each time the last nodein the path is the one that 'defines' who is the next one to be added. Given that this method performs better than the two other algorithms, we could consider this as an indication that, to some extent, the structure of a 
Uncovering the Missing Routes: an Algorithmic Study on the Illicit Antiquities Trade Network Christos Tsirogiannis and Constantinos Tsirogiannis

path is influenced more by the neighbourhood of the network nodes, rather than by some global property of the network.

Moreover, the experiments showed that the three methods that we examine have an average performance when the queried paths do not exist in the modelled network. This probably indicates the limitations of using an incomplete modelled network; if there is a lot of data missing from the network that we use for our computations, then there will be many cases where it is impossible to produce a correct estimation of a transaction path.

\section{Conclusions and Future Work}

In the present work we analysed the structure of the recent trade network of Italian and Greek illicit antiquities. We built a concise instance of this network and we measured several structural properties of this instance. More than that, we described an algorithmic approach for tracking transactions paths in the modelled instance of this network. We evaluated three different algorithms that estimate transaction paths in the network based exclusively on the available data on past illegal transactions. One of the algorithms that we examined produced promising results. However, there seem to be limitations in the performance of these algorithms. These limitations possibly have to do with the amount of data that might be missing from the instance of the network that we use for our predictions.

A possible direction for future research would be to examine if we can improve the performance of methods that construct transaction paths by incorporating extra restrictions in the network. For example, we could forbid that any path may have more than two major dealers, since this would increase unreasonably the price of the artefact.

\section{Bibliography}

Barabási, A. L., and A. Réka. 1999. "Emergence of scaling in random networks." Science 286 (5439):509- 512.

Fell, D. A., and A. Wagner. 2000. "The Small World of Metabolism." Nature Biotechnology 18 (11):1121-1122.

Freeman, L. C. 1979. "Centrality in Social Networks,
Conceptual Clarification.” Social Networks 1:215-239.

Fu, L., Sun, D., and L. R. Rilett. 2006. "Heuristic Shortest Path Algorithms for Transportation Applications: State of the Art." Computers \& Operations Research 33 (11):3324-3343.

Georgiadis, L. 2003. "Arborescence Optimization Problems Solvable by Edmonds ` Algorithm." Theoretical Computer Science 301 (1):427-437.

Gill, D. W. J., and C. Chippindale. 2006. "From Boston to Rome: Reflections on Returning Antiquities." International J ournal of Cultural Property 13:311-331.

Gill, D. W. J., and C. Tsirogiannis. 2011. "Polaroids from the Medici Dossier: Continued Sightings on the Market." The J ournal of Art Crime 5:27-33.

Godart, L., De Caro, S., and M. Gavrili. 2008. Nostoi. Repatriated Masterpieces. Athens: Greek Ministry of Culture.

Del Sol, A., Fujihashi, H., and P. O’Meara. 2005. “Topology of small-world networks of protein-protein complex structures." Bioinformatics 21 (8):1311-1315.

Del Sol, A., and P. O'Meara. 2005. "Small-World Network Approach to Identify Key Residues in ProteinProtein Interaction." Proteins: Structure, Function, and Bioinformatics 58 (3):672-682.

Wagner, R. A., and M. J. Fischer. 1974. "The Stringto-String Correction Problem." Journal of the ACM 21 (1):168-173

Watson, P., and C. Todeschini. 2007. The Medici Conspiracy. New York: Public Affairs.

Watts, D. J ., and S. H. Strogatz. 1998. "Collectivedynamics of 'small-world' networks." Nature 393:440-442. 
